Hausmanninger $\cdot$ Kritik 



\section{Thomas Hausmanninger}

\section{KRITIK \\ DER MEDIENETHISCHEN VERNUNFT}

Die ethische Diskussion über den Film in Deutschland im 20. Jahrhundert 
Gedruckt mit Unterstützung des Förderungs- und Beihilfefonds Wissenschaft der VG Wort

Die Deutsche Bibliothek - CIP-Einheitsaufnahme

\section{Hausmanninger, Thomas:}

Kritik der medienethischen Vernunft: die ethische Diskussion über den Film in Deutschland im 20. Jahrhundert / Thomas Hausmanninger. - München: Fink, 1992

Zugl.: München, Univ., Diss., 1991 u.d.T.: Hausmanninger, Thomas: Der medienethische Diskurs über den Film in Deutschland im 20. Jahrhundert

ISBN 3-7705-2805-0

ISBN 3-7705-2805-0

(C) 1993 Wilhelm Fink Verlag, München

Herstellung: Ferdinand Schöningh GmbH, Paderborn 
Meinen Eltern, Margit und Robert Hausmanninger 



\section{VORWORT}

Das vorliegende Buch stellt eine etwas bearbeitete und erweiterte Fassung meiner Dissertation dar, die unter dem Titel „Der medienethische Diskurs über den Film in Deutschland im 20. Jahrhundert. Epochentypologische Rekonstruktion“ im Sommersemester 1991 von der Katholisch-Theologischen Fakultät der Ludwig-MaximiliansUniversität München angenommen wurde. Der Text entstand in dem Jahren 1988-91 und im Sommer 1992; für den Druck ergänzt wurden insbesondere der Punkt 4.7 und erhebliche Teile in 6.2. Dafür, daß ich dieses Buch in dieser Form und diesem Umfang schreiben konnte, schulde ich einigen Menschen aus meiner Umgebung nicht geringen Dank.

Allen voran möchte ich dabei an dieser Stelle meinem Lehrer und Chef Prof. Dr. Wilhelm Korff herzlich danken. Er hat nicht nur die Entstehung der Dissertation gefördert und begleitet, sondern mir auch in der unter dem Druck eines Zeitvertrags stehenden Schlußphase seine ,personale' Unterstützung gegeben, ohne die die Arbeit wohl kaum rechtzeitig zum Abschluß gekommen wäre. Gleichzeitig möchte ich die Gelegenheit nützen, um ihm für die bisherigen Jahre meinen Dank auszusprechen, in denen ich bei ihm als wissenschaftlicher Mitarbeiter/Assistent am Lehrstuhl für Christliche Sozialethik tätig sein konnte. Vieles, das ich in den letzten Jahren gelernt habe und das auch in dieses Buch eingeflossen ist, ist die Frucht der hierdurch ermöglichten Zusammenarbeit.

Danken möchte ich auch Heinrich Schilling für seine Einführung in einige Bereiche des Films, die mir bis dato noch wenig vertraut waren. Insbesondere für die vorsichtige Bekanntmachung mit dem mir nicht ganz geheueren Genre des Horrorfilms - das zumindest ansatzhaft zu kennen sich bei einer Arbeit wie der vorliegenden kaum vermeiden läßt - bin ich ihm sehr verbunden. Nicht zuletzt meine Auseinandersetzung mit der Gewaltproblematik hat davon profitiert. In diesem Zusammenhang danke ich auch Michael Schaudig, der mich zu Beginn der Arbeit auf die Kinoreformer gestoßen und mir einige wertvolle Hinweise bezüglich der Fundorte alter Literatur gegeben hat.

Weiter gilt mein Dank auch Dr. Ludger Müller für seine umsichtige Lektorierung des Texts und die Korrektur meines recht erratischen Umgangs mit Kommata sowie für die Vorbereitung der Druckvorlage. Die ,printmediale Ästhetik' des Buchs wäre ohne ihn in dieser Weise nicht leistbar gewesen.

SchlieBlich danke ich dem Wilhelm-Fink-Verlag für seine freundliche Bereitschaft, mich an dem ohnehin schon sehr umfangreichen Text noch weiterarbeiten zu lassen. Aktualität und Praxisrelevanz, die mir sehr am Herzen liegen, konnten dadurch nochmals erheblich gefördert werden. In diesem Zusammenhang danke ich auch der VG Wort für die Gewährung eines Druckkostenzuschusses. 



\section{INHALT}

1. DER FILM IN DER MODERNE: DAS MEDIUM UND SEINE GESCHICHTE

1.1. Zwischen Urgeschichte und Moderne: Zur Relevanz der Film-Vorgeschichtsschreibung für einen Begriff vom Film

1.2. Das Werden der Kinematographie: Die technische Vorgeschichte des Films

1.3. Die Existenz des Films als Ware und Industrieprodukt

1.4. Kommunikation und Öffentlichkeit in der Moderne: Film im Rahmen der gewandelten Kommunikationssituation in der Industriegesellschaft

1.5. Binnenorientierung: Notizen zu Stilgeschichte und Genreentwicklung

1.6. Das Medium Film: Systematische Orientierung

2. DIE ERÖFFNUNG UND SYSTEMATISIERUNG DER MEDIENETHISCHEN FRAGESTELLUNG DURCH DIE KINOREFORMBEWEGUNG ZU BEGINN DES 20. JAHRHUNDERTS

2.1. Kinoreform und Bildungsbewegungen der Jahrhundertwende: Kontext, Struktur und Wirkung der Kinoreformbewegung

Der kulturreformerische Kontext der Kinoreformbewegung

Strukturelle Organisation und Einflußnahme der Kinoreformer

2.2. Kunst und Massenkultur: Ästhetik als Wurzel einer kulturpessimistischen Bewahrethik

Der reformerische Kunstbegriff als idealisierter Kontrastbegriff zur Massenkultur

Der Rezeptionsidealismus Konrad Langes: Die ethisch-ästhetische Doppelperspektive

Abbildrealismus und Ausschluß gesellschaftlicher Bezüge: Kunst als Stabilisator

Prinzipielle ethisch-ästhetische Verortung und Normierung des Films

2.3. Devianzvorwürfe I: Moralische Primitivierung und zivilisatorischer Kulturverfall. Anthropologischer Pessimismus und reformerisches Kulturkonzept

Ethoskorruption und Latenz: Die negative Anthropologie der Reformer

Kultur als Disziplinierung: Das Kulturkonzept der Reformer 
$\begin{array}{ll}\text { Negative Anthropologie und Modernitätskritik } & 113\end{array}$

Versuchte Rückgewinnung der Natur über Tradition und Volkskuitur 115

$\begin{array}{ll}\text { Die Dichotomien der Reformer } & 118\end{array}$

2.4. Devianzvorwürfe II: Kriminalisierung und Sexualisierung. Mimetisches Wirkungskonzept und kontramoderner Antiautonomismus

Die drei Formen der Kriminalisierungsthese

Die reformerische Wirkungsthetik

$\begin{array}{ll}\text { Der ideologische Charakter der Wirkungsthesen } & 130\end{array}$

Die Sexualisierungsthese der Reformer

Zeitgenössischer Ethoswandel als phänomenale Basis des Sexualisierungsvorwurfs

Autonomisierung als eigentliches Skandalon der Sexualisierungsthese

2.5. Devianzvorwürfe III: Soziale Destabilisierung. Bewahrethische Hegemonie und strukturautoritäres Gesellschaftskonzept

Der Destabilisierungsvorwurf der Reformer

Kontrast: Die zeitgenössische filmgeschichtliche Situation

Die Realitätsferne des Destabilisierungsvorwurfs

Die Kritikfeindlichkeit der Reformer

Zur zeitgenössischen Interaktionssituation von Publikum und Film

Demokratisierung und kommunikative Öffentlichkeit als eigentliches Skandalon im Destabilisierungsvorwurf

2.6. Das Gesicht der Reform: Strukturautoritäre Lösungsvorschläge und totalitäre Konsequenzen

Umfassende Ermächtigung und Flexibilisierung der Zensur durch Gesetze

Der protototalitäre Charakter des reformerischen Zensurkonzepts

Faktisch-historische Konkretion: Zur Wirkung der Kinoreform

Besteuerung, Konzessionspflicht und schulisches Monopol als flankierende Maßnahmen

Kommunalisierung als antidemokratische prozessuale Realisierungsform der Reform

Verstaatlichung als Zielkonsequenz der Kinoreform

Das strukturautoritäre Lösungskonzept der Reformer: Film als Instrument eines staatlich gesicherten Social engineering durch die ,Gebildeten“

3. TOTALITÄRE MEDIENETHIK: TRANSFORMATION UND FLEXIBILISIERUNG DER REFORMERISCHEN STRUKTURAUTORITÄT IM KULTURFUNKTIONALISMUS DER NATIONALSOZIALISTEN

Methodologische Vorüberlegung $\quad 202$

Generelle These und Vorgehensweise $\quad 203$

3.1. Führerprinzip und Gemeinschaftsprinzip als generelle organisatorisch-ethische Ordnungsprinzipien des Nationalsozialismus

Das Führerprinzip als oberstes Ordnungsprinzip des Nationalsozialismus $\quad 205$

Das Gemeinschaftsprinzip als Integrationsprinzip 206

Die Zuordnung von Führer- und Gemeinschaftsprinzip 209 
3.2. Partielle Assimilation an moderne Dynamisierungsprozesse und kontramoderne Gesamtstrategie

Versuchte Integration von technisch-instrumentellen Errungenschaften der Moderne durch anthropologischen Rassismus

Destruktion der Autonomisierung und Subjektivierung bei Assimilation an soziale Mobilität und organisatorischer Flexibilisierung der kontramodernen Gesamtkonzeption

3.3. Das nationalsozialistische Staats- und Gesellschaftskonzept als totalitäre, dichotomisch-führungsfunktionale und regressiv-statische Konzeption

Die nationalsozialistische Gesellschaft als totalitäre Struktur

Die dichotomisch-führungsfunktionale Einrichtung der nationalsozialistischen Gesellschaft

Der regressiv-statische Charakter der nationalsozialistischen Gesellschaftskonzeption und dessen Verhältnis zu dem der reformerischen

3.4. Das Kunst- und Kulturkonzept des Nationalsozialismus und seine gesellschaftlich-politische Funktion

Der nationalsozialistische Kunst- und Kulturbegriff unter dem Gemeinschaftsprinzip und das nationalsozialistische Natur-Kultur-Verhältnis

Kontramoderne Normierung von Kunst, Kultur und ihrer Aufgabe als Konsequenz der Rassenontologie

Die politische Funktion von Kunst und Kultur unter dem Führerprinzip

3.5. Nationalsozialistische Filmpolitik und Social engineering unter dem Propagandaprinzip

Die Fixierung des Propagandaprinzips als oberstes Prinzip der Medien-

funktion im Nationalsozialismus durch Goebbels

Die filmtheoretische Ausarbeitung der Goebbels'schen Vorgaben bei Hippler

Zur scheinbaren Dissonanz von Filmtheorie und faktischem Filmschaffen im Nationalsozialismus

Die prinzipienkohärente Struktur der nationalsozialistischen Filmpolitik

3.6. Nationalsozialistische Filmorganisation unter dem Führerprinzip

Die Einrichtung des Propagandaministeriums und der Reichskulturkammer

Die Übernahme und Modifikation des Reichslichtspielgesetzes

Zentralistisch-flexible Organisation der Zensur

Ausschaltung der Kunstinterpretation und Einrichtung der Prädikatisierung

Sukzessive Verstaatlichung

Die nationalsozialistische Filmorganisation als strukturelle Realisierung der generellen Ordnungsprinzipien

3.7. Nationalsozialistische ,Medienethik' und reformerisches Erbe 251

Die Ebene der rassistisch-deontologischen Prinzipienethik 252

Die Ebene des totalitären Utilitarismus

Die kontramoderne Position des Nationalsozialismus als Wurzel der Aufspaltung der beiden Ebenen

Nationalsozialistische und reformerische Medienethik 
4. REDUNDANZ UND METAPHYSISCHE KEHRE: DIE PSEUDOAUTONOME EIGENTLICHKEITS- UND BEFÄHIGUNGSETHIK DER FILMERZIEHUNG IN DEN S0ER UND 60ER JAHREN

4.1. Kulturtheoretische Grundfigur: Modernitätskritik als ,Wertkritik'

Technik als Initiatorin von Fremdbestimmung und Werteverfall

Zerstörung der Wertorientierung durch die naturwissenschaftliche Rationalisierung

Nivellierung, Kommerzialisierung und Fremdbestimmung durch Ökonomie

Entwertung von Metaphysik und Religion durch Globalisierung

Die Keilhackersche Modernitätskritik

4.2. Gesellschaftskritische Fortschreibung: Dynamisierungskritik und Verlust der ,Eigentlichkeit ${ }^{\circ}$

Dynamisierungs- und Diversifizierungskritik: Pessimistische Bewertung der Entwurfsautonomie

Kritik am Verfall der ,Eigentlichkeit' durch Manipulation und Uniformierung

4.3. Metaphysische Kehre, Wertethik und Askese: Versuchte Wiedergewinnung von Selbstbestimmung, Moralität und Eigentlichkeit durch Etablierung einer ,Kontramoderne'

Ansatz: Versuchte Rückgewinnung der Moralität durch Etablierung zweier Welten

Individuelle Vermittlung und gesellschaftliche Verankerung der Wertewelt durch kontramoderne Orientierungsformen und soziale Repräsentanz

Versuchte Stützung der Kontramoderne durch Metaphysik und Religion

Versuchte Rückgewinnung der ,Eigentlichkeit' durch handwerkliche Kreativität

Versuchte Rückgewinnung begrenzter Autonomie durch Askese und Verzicht

Die kontramoderne Kritik- und Lösungskonzeption Keilhackers

4.4. Redundanz I: Wiederaufgriff der reformerischen Devianzvorwürfe und ihrer Pessimismen durch die Filmerziehung

Wiederanknüpfung an die Kinoreform

,Moralische Primitivierung؛: Anthropologie und Natur-Kultur-Verhältnis

Die bewahrethische Inklination der Filmerziehung

,Sexualisierung: Konkretion der negativen Anthropologie und Stellungnahme gegen einen Ethoswandel

,Kriminalisierung: Sozialontologische Konkretion des anthropologischen Pessimismus

,Soziale Destabilisierung': Zeitentsprechende Modifikation des reformerischen Vorwurfs und Verbindung mit der Keilhackerschen Wertkritik

Filmerziehung und Kinoreform: Redundanz der Vorwürfe und Kongenialität der Konzepte

4.5. Redundanz II: Fortschreibung der Keilhackerschen Modernitätsund Zivilisationskritik

Materialismus und Werteverfall als generelle Zeitsignatur

Moralischer und letztbezüglicher Nihilismus als Frucht von Werteverfall und Sinnverdrängung 
Letztbezüglicher Nihilismus als Folge der Globalisierung und der modernen Pluralität

Manipulation und Zerstörung der ,Eigentlichkeit‘: Extraversion, sekundäre Welten, Uniformierung

Die Devianzkritik der Filmerziehung und das Erbe des Schulgründers

4.6. Die pseudoautonome Eigentlichkeits- und Befähigungsethik der Filmerziehung

Prinzipienethischer Ansatz: ,Gültiges Menschsein` als oberste Zielmaxime

Die Grundfigur: Pseudoautonome Befähigungsethik

Der Ansatz der Rückgewinnung von Moralität: Erkenntnistheoretische Einführung des Zwei-Welten-Konzepts

Die Formalstruktur der ,moralischen Sphäre‘

Der kontramoderne Charakter der ,moralischen Sphäre‘

Transformation des filmerzieherischen Ethikansatzes in eine medienethische Grundkonzeption

Versuchte Rückgewinnung von Sinnhaftigkeit und Orientierungskonsistenz unter partieller Nutzung des Films

Versuchte Rückgewinnung von ,Eigentlichkeit' durch Restitution der vita contemplativa

Versuchte Rückgewinnung von ,Eigentlichkeit" durch handwerkliche Kreativität und unmittelbare Weltbegegnung

Versuchte Rückgewinnung von Selbstbestimmung durch Askese und Verzicht

4.7. Exkurs: Partielle Repetition und Transformation reformerisch-filmerzieherischer Axiome und Theoreme in den 80er und 90er Jahren

Die ,Aktualität' der ,Tradition': Fortwirken reformerisch-filmerzieherischer Optionen im Bereich der Medienpädagogik

Transformative Revitalisierung des reformerisch-filmerzieherischen Pessimismus mit lerntheoretischen Mitteln

\section{STANDPUNKTSWECHSEL: DIE NEGATIONSETHIK DER} MEDIENTHEORIE DER KRITISCHEN THEORIE

5.1. Ansatz: Die determinative Bedeutung der zeitgenössischen Situation für den Entwurf der Kritischen Theorie

Methodologischer AufriB

Die Verkehrung der emanzipativen Intentionen der Aufklärung in Totalitarismus: Die geschichtsphilosophische Fragestellung der Kritischen Theorie

5.2. Die Herrschaft der instrumentellen Vernunft: Der rationalitätstheoretische Kern der Kritischen Theorie

Das subjektphilosophische Paradigma: Subjekt-Objekt-Differenzierung

Die Genese der instrumentellen Vernunft: Funktionalisierung, Herrschaft und Repression unter dem Selbsterhaltungsprinzip

Die Auflösung der Subjektivität im instrumentellen Gemächte: Das endgültige Scheitern des Emanzipationsversuchs der Menschheitsgeschichte Der Bogen der Vernunftkritik: Realisierung der geschichtsphilosophischen Prämissen und Verankerung des Verfalls durch Begriffsidentifikationen 
5.3. Konkretion I: Die Aufklärungs- und Modernitätskritik der Kritischen Theorie

Aufklärung und Moderne als Kristallisation der instrumentellen Vernunft 423

,Kritische' und ,konservative‘ Modernitätskritik 428

5.4. Konkretion II: Das Gesellschaftskonzept der Kritischen Theorie

,Herrschende` und ,Beherrschte‘: Das dichotomische Basisparadigma der kritischen Gesellschaftstheorie

Arbeitsteilung und Institutionalisierung: Die Fixierung der quasi-ontologischen Grundkonstellation der Gesellschaft

Kapitalismus als Strukturgestalt instrumenteller Vernunft

Faschismus und Stalinismus als Strukturgestalten der instrumentellen Vernunft

Gesellschaftstheorie als Totalitarismustheorie: Der Bogen der geschichtsphilosophischen Fragestellung

5.5. Kultur und Medien im totalitär-instrumentellen System: Das Kulturindustrietheorem der Kritischen Theorie

Konvertibilität und Profitabilität als Determinanten der Kulturindustrie

Kulturindustrie als Herrschaftsinstrument

Appendix: ,Kritische' und ,konservative' Medienkritik

5.6. Ethik der Negation: Die Untauglichkeit der Medien für eine Lösung und die Aufbewahrung des Humanum in der Kunst

Die Negationsethik der Kritischen Theorie

Ästhetische Erlösung: Kunst als Hort ,wahrer Humanität‘

\section{BAUSTEINE FÜR EINE MODERNITÄTSGERECHTE MEDIEN-} ETHIK IN BEZUG AUF DEN FILM

6.1. Generelle Grundlinien einer modernitätsgerechten Ethik im theologischen Kontext

Der Mensch als Person und Bild Gottes: Die theologisch-anthropologische Verankerung des autonomen Subjekts und seiner Würde

Das ,nichtfestgestellte Wesen': Die anthropologische Bestimmung der Autonomie im Kontext des Natur-Kultur-Verhältnisses

Dynamik und Konsistenz: Der Mensch im Spannungsfeld von Entwurf und Entlastung

Das ethische Basisparadigma: Autonome Moral im Kontext eines universalisierbaren und konsensfähigen Rahmenethos

Strukturelle Konkretion: Repräsentativ-demokratische Gesellschaft und Trennung der Kultursachbereiche

6.2. Bausteine einer modernitätsgerechten Medienethik

Strukturethischer Baustein: Aufgabenstellung der Medien, grundsätzliche Gebotenheit einer offenen Kommunikationsstruktur und der Trennung der Kultursachbereiche

Unterhaltungsethischer Baustein: Struktur und Legitimität entlasteten Verhaltens im Kontrast zur Kunstrezeption 
Inhaltsethischer Baustein: Material-ethische Grundlinien zu Legitimität und Grenzen medialer Inhaltsformen

Institutionsethischer Baustein: Überlegungen zu Aufgaben und Grenzen institutionalisierter Kommunikationskontrolle im Filmbereich am Beispiel von FSK und BPS 



\section{EINLEITUNG}

Die Medien stellen den bislang letzten durch gesellschaftliche Diversifizierung entstandenen Kultursachbereich in den Zivilisationen der Moderne vor. Sie bilden neben Politik, Religion, Wissenschaft, Technik, Kunst und Ökonomie spätestens ab der Mitte des 19. Jahrhunderts eine relativ autonome, mit ihren eigenen, nicht unmittelbar auf andere Bereiche rückführbaren Sachgesetzlichkeiten ausgestattete Sphäre, die mit den anderen Bereichen zwar wohl interagiert, mit ihnen jedoch nicht koinzident ist. Ihre Ausdifferenzierung und Selbstetablierung geschieht einmal über die neuen Reproduktionsmittel des Drucks sowie der Fotografie und des Films und wird zum anderen durch die ab dieser Zeit breitenwirksam durchgesetzte Alphabetisierung begünstigt. Gleichzeitig aber ist die Herausbildung der medialen Sphäre untrennbar mit der Ideengeschichte der Neuzeit verbunden, welche jene auf Rationalisierung, Autonomisierung, Subjektivierung und Demokratisierung gerichtete Dynamik in Gang setzt, die heute unter dem Stichwort des ,Projekts der Moderne' kontrovers diskutiert wird. Diese Dynamik ist es, die sich in den sozial-strukturellen Prozessen einer mit Industrialisierung und Verstädterung einhergehenden Verbreiterung der Öffentlichkeit und darin angemeldeter Mitspracherechte aller Gesellschaftsmitglieder realisiert und welche die Etablierung der Medien sowohl mit ermöglicht als auch von diesen wiederum befördert wird. So sorgen die Medien, nachdem sie von den sich als autonom und mitspracheberechtigt begreifenden Subjekten geschaffen worden sind, für deren interaktive Vernetzung in Form einer gesellschaftlichen oder sozialen Kommunikation und lassen sie aus dem Publikum der Salons und literarischen Zirkel ein umfassend mediales, d.h. aber: aus dem internen ein öffentliches Publikum werden, das nun seine diskursive Kompetenz zunehmend in den Gesellschaftsprozeß einzubringen sucht und entsprechende Rechte auch politisch einfordert. Die Struktur und die Bedeutung der Medien sind derart mit dem Projekt der Moderne und seiner gesellschaftlichen Realisierung aufs engste verbunden.

Gleichzeitig stellen die Medien ein Phänomen vor, das dieser Realisierung eine zusätzliche Qualität verleiht und einer entsprechenden Reflexion bedarf: Die Medien schaffen einen Kommunikationsbereich, der die Kontaktnahme der Subjekte weitgehend anonymisiert und kollektiviert und der so eine neuartige Realität in der Gesellschaft etabliert. Neben der informationellen Sphäre erhält dabei auch die imaginative eine neue Qualität; Bilder, Chiffren und symbolhafte Interpretamente stehen jetzt in nie gekanntem Maß zur Verfügung. Das aber fordert ein theoretisches Bedenken des Medienbereichs, welches weder in der Erforschung ökonomischer, politischer und kunstbezogener Sachgesetzlichkeiten, noch überhaupt in nur einer deskriptiv-empirischen Analyse sich erschöpfen kann. An die Seite einer solchen Analyse muß vielmehr eine normative, näherhin eine ethische Auseinandersetzung mit dem Kultursachbereich der Medien treten, die dann in Analogie zu den diesbezüglichen Konstruktionen einer politischen Ethik und einer Wirtschaftsethik als $\mathbf{M e}$ - 
dienethik bezeichnet werden kann und wird. Aufgabe dieser Medienethik ist es, unter Wahrung der relativen Autonomie des Medienbereichs dessen Struktur und Funktion auf seine ethischen Prinzipien und Prämissen hin zu reflektieren sowie solche Prinzipien und Prämissen argumentativ zu entwerfen. Um die Einlösung des mit dieser Aufgabe umrissenen Desiderats nun bemüht sich seit kurzem explizit die theologische Ethik und hierin wieder besonders die Sozialethik. So haben auf katholischer Seite Autoren wie Alfons Auer, Gerfried Hunold, Günter Virt und Alois Huter vorwiegend in Aufsätzen - versucht, Schritte in Richtung einer medienethischen Konstruktion zu unternehmen und einen medienethischen Diskurs in Gang zu setzen. Auf evangelischer Seite sind etwa Theodor Strohm und Anne van der Meiden in diesen Diskurs eingetreten und hat neben einer Studie der EKD sich auch die „Zeitschrift für evangelische Ethik" der Thematik angenommen. In der Tat stellt sich die medienethische Reflexion auch, im Sinn gewissermaßen einer bereichsspezifischen Anstrengung der theologischen Ethikkonstruktion, als Anforderung dar, die spezifisch von der christlichen Sozialethik eingelöst werden kann. Diese begreift als „Sozialstrukturenethik" (A. Rich) im Unterschied zur Moraltheologie ja gerade die ethische Reflexion struktureller Gegebenheiten als ihre besondere Aufgabe und ist derart auch für den Strukturbereich der Medien zuständig.

Gleichwohl steht das Unterfangen einer expliziten medienethischen Konstruktion noch an seinem Beginn. Trotz der Bemühungen der genannten (und anderer) Autoren sowie einiger Versuche zu einer Journalismusethik liegt noch keine umfassende ethische Systematik für den Medienbereich vor und befindet sich das Projekt einer solchen Systematik noch in einem Stand, in dem weder seine Prinzipien noch die Grundoptionen schon allgemein konsensfähig geklärt sind. $\mathrm{Zu}$ dieser Klärung nun will ich mit dem vorliegenden Text einen Beitrag leisten, indem ich eine epochentypologische Rekonstruktion der implizit betriebenen Medienethik in der Auseinandersetzung um den Film vorlege, wie sie in Deutschland in diesem Jahrhundert geführt wurde und wird. Obschon nämlich das Desiderat einer Medienethik unter diesem Titel erst in den letzten Jahren vorgetragen worden ist, finden sich Bemühungen um eine ethische Reflexion des medialen Bereichs - meist freilich nicht explizit als solche deutlich gemacht - schon seit geraumer Zeit. Genau besehen setzen sie in systematischer und bereichsspezifischer Form bereits mit der ,Schmutz- und SchundDebatte' um die Trivialliteratur Ende des 19. Jahrhunderts ein, welcher noch die Diskussion um die Zuständigkeitsbereiche der literarischen Öffentlichkeit vorausgeht, wie sie vor allem im 18. Jahrhundert geführt wird. Während die Zuständigkeitsdebatte jedoch eher in den Bereich der politischen Ethik fällt, werden mit der Trivialliteraturdebatte erstmals spezifisch medienbezogene Fragen gestellt und grundlegende Optionen getroffen. Dabei macht diese Debatte vor allem deutlich, daß die Medien in dem Moment, wo sie den Stand technisch-industrieller Verbreitung erreichen, sofort ins Kreuzfeuer einer normativen Auseinandersetzung geraten, die zumeist Beschränkungen und Beschneidungen ihrer Abundanz fordert und bis heute anhält. Alsbald verschiebt sich dann aber der Gegenstandsbereich der Auseinandersetzung von den Printmedien zum Film. Dieser scheint bis zur Stunde geradezu das zentrale Skandalon in jeder normativen Reflexion über die Medien zu sein. In der Tat stellt er auch gegenüber den Printmedien eine neue Qualität medialer Vermittlung dar. So umfaßt er mit seiner synästhetischen Struktur beinahe die ganze Band- 
breite kommunikativer Äußerungsmöglichkeiten und eignet ihm in seiner schichtübergreifenden Breitenwirkung, die letzthin von Fernsehen und Video nochmals verstärkt worden ist, beinahe eine lebensweltliche Allgegenwart. Bereits früh und nachhaltig ruft er deshalb Ängste und Pessimismen auf den Plan, die normative Regelungen fordern. Hierbei finden sich die Argumente insbesondere der ,Schmutz- und Schund-Debatte bruchlos auf die Auseinandersetzung um den Film übertragen und hebt in Deutschland ab etwa 1910 die bislang konsistenteste und umfassendste Mediendebatte an, die bisher geführt worden ist. Ihre Argumente kehren später, angewandt auf Comics, TV und Video, kaum verändert wieder. In der normativen Auseinandersetzung um den Film lassen sich mithin alle zentralen bislang getroffenen Optionen und Basisparadigmen sowie die wichtigsten Argumentationsformen auffinden, deren sich das implizite medienethische Bemühen dieses Jahrhunderts in Deutschland bislang bedient hat. Für das gegenwärtige Desiderat einer expliziten Konstruktion einer Medienethik scheint mir daher die Kenntnis und Reflexion dieser fast ein Jahrhundert umfassenden Bemühungen wichtig und hilfreich zu sein. Solche Kenntnis erlaubt es dann auch, die gegenwärtigen kontroversen theoretischen und praktischen Optionen der Debatten um Video und Fernsehen besser verstehen und einordnen zu können. Erst auf dem Hintergrund einer, durchleuchteten' Tradition wird das Fortschreiten zu neuen Entwürfen möglich sein.

Ich werde im folgenden daher die bisherigen Versuche medienethischer Kriterienbildung in den normativen Diskursen zum Film einer Kritik unterziehen - und dies durchaus im kantischen Sinn des Begriffs: Zum einen nämlich wird diese Kritik ein rekonstruktives Unterfangen sein, das die ethischen und ethikrelevanten Grundoptionen - also den , letztbezüglichen' Horizont - der normativen Aussagen in diesen Diskursen erarbeitet. Zum anderen werde ich diese Grundoptionen und die darauf aufruhenden medienethischen Vorschriften an den Reflexionsbeständen der modernen theologischen Ethik kritisch auf ihre Tragfähigkeit hin prüfen. In diesem Sinn werde ich eine rekonstruktive Kritik von vier epochalen Typen des normativen Diskurses zum Film aus ethischer Perspektive vornehmen. Im Zentrum der Rekonstruktion stehen neben den spezifisch ethischen Aussagen und ihrer argumentativen Formalkonstruktion einmal die jeweiligen anthropologischen Vorgaben und Axiome. Erst auf der Basis eines ,Menschenbilds' lassen sich ja ethische Präskriptionen im Hinblick auf diesen Menschen und seine Weltkonstruktion machen, und erst aus der Rekonstruktion dieser jeweils zu Grund gelegten Basis werden umgekehrt die ethischen Aussagen und Optionen verständlich. In diesem Zusammenhang will ich auch die jeweilige spezifische Verhältnisbestimmung von Natur und Kultur eruieren. Aus dieser nämlich leitet sich in der Regel die Verhältnisbestimmung von Sein und Sollen ab und entwirft sich das ethische Grundparadigma als deontologisches oder teleologisches. Weiter werde ich auf die jeweils in den Epochentypen mit enthaltene Gesellschaftstheorie eingehen, da in deren Kontext erst die strukturethische Verortung der Medien, die ihnen verordnete Funktion und Rolle transparent und begreifbar werden. Erst die Bestimmung des Gesellschaftskonzepts der jeweiligen Theorien läßt die Stellung der letztgenannten zur gesellschaftlichen Kommunikationsfunktion der Medien deutlich vor Augen treten. Außerdem scheint es mir notwendig, die theoretische Bestimmung der Rolle der Kunst, ihrer Wesensbestimmung und Aufgabenaskription zu beleuchten. In vielen Fällen nämlich werden Funktion und Spezifika der Medien 
mit denen der Kunst vermengt, um nicht zu sagen: verwechselt, und Kunst und Medien gegeneinander ausgespielt. Schließlich wird in der Rekonstruktion die Haltung der jeweiligen Theorien zum Projekt der Moderne deutlich werden und sich die Auseinandersetzung um den Film als mit der Auseinandersetzung um dieses Projekt verknüpft erweisen. Entsprechend der oben skizzierten Konnotation der Herausbildung des Medienbereichs als eigenständigen Kultursachbereichs mit der Ideengeschichte der Neuzeit und Moderne kann denn auch die Mediendebatte nicht schlechthin unabhängig von der Debatte um diese Ideengeschichte gedacht und realisiert sein, ja es wird sich sogar zeigen, da $\beta$ die Einbettung der medienethischen Reflexion in eine umfassendere Reflexion des Projekts der Moderne und seiner gesellschaftlichen Realisierung zunehmend bestimmend für die getroffenen medienethischen Optionen wird und gleichzeitig an Explizitheit und beanspruchtem Raum gewinnt. Von Epoche zu Epoche wird deshalb einerseits eine komplexere und differenziertere Theoriestruktur vor Augen treten und andererseits die Stellung zu den Medien sich zunehmend als eine systematische Stellung zur Moderne erweisen.

Die so perspektivierte Rekonstruktion konzentriert sich dabei auf bereits abgeschlossene Diskurse, die schon eine epochale Diagnose zulassen. Außerdem suche ich auch dort nur die exemplarisch wichtigsten auf, deren Optionen entweder eine bis heute anhaltende Prägewirkung für die medienethische Reflexion haben oder eine wegen ihres zeitlichen Umfangs nicht neglegierbare Wirkung hatten. Als solche exemplarische Diskursepochen sind zu betrachten: die Phase der Kinoreformbewegung der 10er und 20er Jahre, die Zeit des Nationalsozialismus, die Tätigkeit der Filmerziehung in den 50er und 60er Jahren und die Zeit der Kritischen Theorie. Durch die Kinoreformer nämlich, welche die filmbezogene Mediendebatte eröffnen, werden sowohl jene zentralen Vorwürfe gegen Film eingeführt und grundlegend theoretisch verankert, die bis heute diskursbestimmend sind und neuerdings auch Fernsehen und Video treffen. Sie kehren explizit bei den Filmerziehern wieder und tradieren sich über diese bis in die medienkritischen Diskurse der 80er und 90er Jahre vor allem zur Problematik der Gewaltdarstellung in Medien. Die Epoche des Nationalsozialismus wiederum kann schon aus Gründen ihres Umfangs nicht ausgeblendet werden. Außerdem aber liefert der Nationalsozialismus das Beispiel eines durchaus theoretisch reflektierten Versuchs, die Medien für ein umfassendes Social engineering einzusetzen, und erlaubt entsprechend in besonders krasser Weise die Erkenntnis prekärer und zu verwerfender Optionen. Pointiert zudem gegen eine Forschungsrichtung, die diese Phase der deutschen Geschichte als eine Art Schicksalsschlag betrachten will, scheint mir die Prüfung (vordringlich rückwärtiger) Traditionslinien wichtig. Über ihre Relevanz als Transmissionsriemen für eine Tradierung der reformerischen Optionen in die Auseinandersetzungen der Gegenwart hinaus stellt dann die Filmerziehung außerdem eine medienethische Reflexion vor, die sich unmittelbar und systematisch weiter ausgreifend als Reformer und Nationalsozialisten gegen die Moderne stellt. Sie ordnet sich derart in die zeitgenössischen ,konservativen' Kulturtheorien ein und liefert ein paradigmatisches Beispiel für eine kontramoderne Medienethik. Die Kritische Theorie schließlich versucht, auf einer emanzipativen Grundoption ebenfalls eine modernitätskritische Medienethik zu entfalten und erlaubt in kontrastiver Rekonstruktion zur Filmerziehung die Vervollständigung der Prüfung der Tragfähigkeit eines jeden solchen Versuchs. 
In diesen Epochen, die mit der epigonalen Rezeption der Kritischen Theorie durch Medientheoretiker sich bis gegen 1985 erstreckt, ist zugleich das 20. Jahrhundert weitgehend umspannt und kann die Rekonstruktion als aus systematischem Gesichtswinkel vollständig betrachtet werden. Ausgeklammert werden können hierbei die verstreuten Unternehmungen der deutschen Kommunisten in den 20er Jahren, die sich mit Reden und kleineren Aufsätzen um einen ,Arbeiterfilm bemühten. Ihre Optionen haben kaum Wirkung entfaltet. Sie sind zudem in den zentralen Punkten auch in der Kritischen Theorie aufgehoben, so daß sie durch die historiographische Aussparung dieser Phase dennoch der Systematik nicht verloren gehen. Ähnliches gilt für den Versuch vorwiegend Kreimeiers, in den 70er Jahren aus der Position eines orthodoxen Marxismus-Leninismus den Film zu reflektieren. Historiographisch ist auch sein Unterfangen eher marginal, und systematisch lassen die zentralen marxistischen Optionen ebenfalls in Auseinandersetzung mit den Autoren der Kritischen Theorie mitreflektieren. Schließlich werde ich auch auf einen Aufgriff der in neuerer Zeit erst anhebenden Versuche einer Medienpädagogik verzichten, die sich um die Umsetzung der Theorie des kommunikativen Handelns von Habermas in die Pädagogik bemüht. Zum einen ist dieser Diskurstyp noch kaum entfaltet und zum anderen liefern die dort getroffenen pädagogischen Optionen auch implizit bislang noch keinen weiter reichenden ethischen Entwurf. Eine epochentypologische Reflexion dieses Diskurstyps kann daher erst zu einem späteren Zeitpunkt stattfinden.

Entsprechend den bereits angedeuteten Schwierigkeiten des normativen Diskurses zu Film, sich in einer freundlich gesinnten Weise mit diesem Medium einzurichten, und der meist kontramodernen Stellungnahmen in den einzelnen Epochen wird die Rekonstruktion der vier Ethiktypen vordringlich Irrwege, kaum aber in diesen Typen ein tragfähiges Gerüst für die Konstruktion einer realitätsgerechten Medienethik erweisen können. Daher kommt auch das gegenwärtige Desiderat, eine $\mathbf{M e}$ dienethik erst zu schaffen, nicht von ungefähr; trotz des implizit längst begonnenen und nachhaltigen Diskurses hat dieser eine konstruktive Medienethik noch nicht hervorgebracht. Gleichwohl halte ich gerade in der gegenwärtigen Situation des Anfangens und Entwerfens die Kenntnis der bislang begangenen Irrwege für unverzichtbar. Nicht zuletzt eine partiell wahrnehmbare Fortführung dieser Wege in den Diskussionen der Gegenwart zeigt, daß die Verfaßtheit der Fundamente des bisherigen medienethischen Diskurses noch nicht in ausreichender Weise ausgelotet und bewertet ist. Auch das Unterfangen einer Neukonstruktion aber kann von der Kenntnis der Fehldispositionen profitieren. Es kann im Wissen um die Unwegsamkeiten und Mängelformen im Gelände ethischer Theoriebildung seine eigenen Schienen umsichtiger und damit tragfähig legen. Einen ersten Versuch solcher Schienenlegung will ich daher im Anschluß an die Rekonstruktionen selbst unternehmen und einige Linien zu einer Medienethik für den Film ausziehen. Angesichts der desolaten Situation der rekonstruierten Mediendiskussion freilich kann dieser Versuch nur einen Diskussionsbeitrag zu den gegenwärtigen Konstruktionsbemühungen darstellen. Gleichwohl versuche ich mit ihm, entgegen Ingeborg Bachmanns Diktum, daB die Geschichte stets lehre, aber keine Schüler finde, die Rekonstruktion der Defizienzen auf eine Konstruktion hinzuleiten. Hierbei wiederum scheint $\mathrm{mir}$ insbesondere die Grundlegung einer modernitätsgerechten Ethik, wie sie von der theologischen Ethik der Gegenwart geleistet worden ist, das nötige Fundament bereitstellen zu können. 
Einführen aber will ich das gesamte Projekt der Rekonstruktion des medienethischen Diskurses über den Film mit einer Skizze des in Frage stehenden Mediums und seiner Geschichte. Diese Einführung soll es erlauben, zum einen auch ohne filmspezifische Kenntnisse den Rekonstruktionen zu folgen und zum anderen eine empirisch-systematische Basis für die rekonstruktive Auseinandersetzung zu gewinnen. 


\section{DER FILM IN DER MODERNE: DAS MEDIUM UND SEINE GESCHICHTE}

Das Wort ,Film' umfaßt heute im deutschen alltäglichen Sprachgebrauch eine gewisse Variationsbreite an Bedeutungen. Etymologisch geht es - nach Kluge ${ }^{1}$ - zurück auf die Bedeutung ,Fell' und ,Haut' im westgermanischen, woraus sich über diverse Ableitungen das englische ,film' in der Bedeutung ,Membran' entwickelt hat. 1891 gelangt das englische Wort ins Neuhochdeutsche mit der Bedeutung „lichtempfindlicher Zellhornstreifen für Lichtbilder“2. Im 20. Jahrhundert wandelt sich Kluge zufolge die Bedeutung zu „Bildstreifen im Lichtspiel“3. nach der Bezeichnung für das lichtempfindliche Zelluloid, mit welchem fotografische Phasenaufnahmen von Bewegungen gemacht werden. ,Film' steht gleichwohl auch für die Projektion dieser Aufnahmen im ,Kino', welches wiederum den Ort bezeichnet, den man aufsucht, um, sich einen Film anzusehen'. ,Film' zielt damit über die Materialbezeichnung hinaus auch auf das ,Werk', nämlich die von einem Team erstellten und zu einem Gesamt komponierten, heute mit Ton unterlegten Phasenaufnahmen. ,Film' kann jedoch im Alltagssprachgebrauch auch mit einer Spezifikation inhaltlicher Natur belegt sein, die gleichwohl nicht ausgesprochen wird: ,Film‘ meint häufig ,Spielfilm‘ im Gegensatz zum Dokumentar-, Lehr- oder sonstigen -film. „Ich habe mir einen Film im Fernsehen angesehen" will entsprechend oft sagen: einen Spielfilm - und nicht die Nachrichten- oder eine Wissenschaftssendung. Das Wort ,Film' bleibt im Deutschen daher etwas unscharf, während ,Kino' auch in dem Satz: „Ich war gestern im Kino“, der ebenfalls sagen will: „Ich habe mir dort einen Film angesehen", immerhin noch auf den Ort der Vorführung mitzielt und damit spezifischer begrenzt ist. Gleichwohl konnotieren manche Autoren mit ,Kino' auch den Aspekt der Ware, den Warencharakter des Films, da mit dem Ort der Vorführung zugleich ja ein Ort der ökonomischen Verwertung des ,Films' (jetzt als, Werk' gebraucht) mitbenannt ist ${ }^{4}$.

Gemäß diesen Unschärfen variieren die Definitionsversuche in der Filmwissenschaft. Das Bild wird noch angereichert durch international unterschiedliche Begriffsverwendungen und entsprechende Literaturübersetzungen. So hat das Französische etwa als Materialbezeichnung ein eigenes Wort: ,la pellicule'. Der Neologismus ,cinéma' dient häufig der Bezeichnung für das ,Kunstkino', bzw. der Ventilierung ästhetischer Problemkreise; ,film' kann ein spezielles Werk bezeichnen, jedoch auch

\footnotetext{
${ }^{1}$ Kluge, Etymologisches, 197

${ }^{2}$ Kluge, Etymologisches, 197

3 Kluge, Etymologisches, 197; diese Bedeutungsangabe ist, gemessen am tatsächlichen Sprachgebrauch, etwas verkürzend.

${ }^{4}$ So etwa Karsten Witte, der seine Textsammlung daher auch „Theorie des Kinos“ nennt, micht zuletzt, um Kracauers „Theorie des Films" Material zur theoretischen Durchdringung der Punktionalität des Films über seine „pure Materialität hinaus“ (Witte, Theorie, 7) an die Seite au stellen. Vgl. Witte, Theorie; Kracauer, Theorie
} 
den ökonomischen Aspekt anzielen. Im Englischen trifft man auf die Hochbezeichnung ,motion pictures', die vom ,distinguierteren' Publikum verwendet wird, gleichzeitig jedoch der Abgrenzung von anderen ,pictorial arts' dient. ,Movies' als Kurzform dazu findet sich meist im Alltagsgebrauch, vermag aber auch den ökonomischen Aspekt zu beinhalten. ,Talkies' wird benützt, um den Tonfilm vom ,silent screen` abzuheben. ,Film‘ wiederum enthält im Englischen eine ähnliche Begriffsunschärfe wie im Deutschen.

Einen Begriff von ,Film' als Medium sich zu erarbeiten, ist jedoch für das Unternehmen einer Rekonstruktion der zentralen normativen Diskurse zu diesem Medium unerläßlich. Der Gegenstand dieser Diskurse muß in seinen Grundcharakteristika, seinen Bedingungsstrukturen und Wesenszügen bekannt sein, um die Auseinandersetzung um ihn verstehen und kritisch nachvollziehen zu können. Diese Grundcharakteristika wiederum sind nicht nur formalästhetisch zu fassen: Der Film nämlich ist ein spezifisch technisch zustandegebrachtes Medium, das erst auf der Basis einer bestimmten technischen Reflexionsform und durch spezifisch technische Erfindungen entsteht. Die Technizität prägt ihn dabei bis in die Ästhetik hinein. Weiter ist seine Existenz und Verbreitung prinzipiell ökonomisch vermittelt. Schon seine Herstellung, sein ProduktionsprozeB ist ein Unternehmen, ein ,joint venture von Geldgebern, Autoren, Regisseuren, Technikern (bzw. technischen Betrieben) und Schauspielern, und erst durch seine mehr oder weniger profitable Auswertung im Kino (sowie heute auch auf Video bzw. im TV) findet er sein Publikum. Schließlich zielt er dabei von vorneherein auf ein großes, ein ,massenhaftes' Publikum ab, d.h. er richtet sich auf Öffentlichkeit und öffentliche Kommunikation. Diese Momente also sind es, die ihn in seinem Wesen (mit-)determinieren und die es daher bei einem Definitions- oder Deskriptionsversuch zusätzlich zur Formalästhetik und Historie des Films in Blick zu nehmen gilt. Nur dann ist der Film zureichend begriffen. Nur dann können auch die mit seiner so bestimmten Medialität gegebenen ethischen Fragestellungen richtig eingeordnet werden und erschließen sich die normativen Diskurse über den Film, ihre spezifischen Befürchtungen, Wertungen und Regelvorschläge in hinreichender Weise.

So tut es zwar durchaus not, in groben Zügen zumindest die Hauptströmungen der Filmgeschichte auch in ästhetischer Hinsicht vor Augen zu haben, wenn beispielsweise die Schriften der Reformer auf ihren ethischen Gehalt hin untersucht werden. Die spezifisch formalästhetisch perspektivierte Filmhistorie muB deshalb durchaus ausgeleuchtet werden. Doch bedarf es zugleich einer Skizze der Entwicklung der Kommunikations- und Öffentlichkeitsstruktur, um die reformerischen Befürchtungen diesbezüglicher pernizioser Wirkungen verorten zu können. Ebenso ist es nötig, die ökonomischen Bedingtheiten der Filmproduktion zu kennen, um etwa die diesbezüglichen Anwürfe des Kulturindustrietheorems der Kritischen Theorie einzuordnen. Ich will daher im folgenden neben dem filmhistorisch-ästhetischen auch den technikgeschichtlichen Aspekt des Films beleuchten, die ökonomische Verfaßtheit dieses Mediums in den Blick nehmen und den kommunikativ-öffentlichkeitsstrukturellen Bedingungen und Veränderungen im Verlauf seiner bisherigen Geschichte nachgehen. Auf diese Weise soll ein detaillierter, realitätsbezogener $\mathrm{Zu}$ gang zu diesem Medium und ein möglichst weiter Horizont für sein Verständnis geschaffen werden. 
Insbesondere die Veränderungen in der Struktur der Öffentlichkeit sind dabei als epochenspezifische zu fassen, näherhin als Veränderungen, die im Kontext des Projekts der Moderne stehen und aus diesem Projekt heraus begriffen werden können. Auch die ökonomische und technische Determination des Films jedoch läßt sich in diesen Kontext stellen und kann als spezifisch für die Moderne gelten. Der Film erweist sich dann aus den vorgängig benannten Kondeterminationen heraus als ein spezifisch modernes Medium, das mit den Struktureigenschaften der Moderne in enger Beziehung steht und seinerseits - zusammen mit den anderen Medien - diesen Struktureigenschaften mit zur Realisation verhilft. Diese Zugehörigkeit des Films zur Moderne halte ich für zentral - ihre Berücksichtigung verschafft der Rekonstruktion der Auseinandersetzung um den Film erst den systematischen Horizont, in dem ein Verständnis des Films und seiner (gesellschaftlichen) Funktion entstehen bzw. entsprechenden Fehldeutungen dieser Funktion entgegengetreten werden kann. Der Situierung des Films im Kontext der Moderne will ich mich daher in besonderer Weise widmen.

Gleichwohl gibt es im Bereich der Filmhistorie namhafte Bemühungen, die einer solchen epochentypologischen Zuordnung entgegenstehen und stattdessen versuchen, die Historie des Films durch Analogiebildung weit in die Vergangenheit zurückzuverfolgen. Zur Verdeutlichung meiner Position will ich deshalb zunächst einen solchen generalhistorischen Ausgriff an zwei Beispielen überprüfen, um dann eine knappe systematische Skizze der prinzipiellen Strukturmomente der Moderne zu geben. Im Anschluß daran werde ich die Linien der damit in Zusammenhang stehenden technischen, ökonomischen und ästhetischen Verfaßtheit des Films ausziehen sowie seine Verbindung mit dem Wandel der Öffentlichkeitsstruktur vor Augen stellen. Mit diesem Ansatz und den vier ausgezogenen Linien scheint mir dann eine systematische und konkrete Orientierung zugleich geleistet, die den nachfolgenden Rekonstruktionen hilfreich ist.

\subsection{Zwischen Urgeschichte und Moderne: \\ Zur Relevanz der Film-Vorgeschichtsschreibung für einen Begriff vom Film}

Wie bei allen pictorialen Künsten und pictorial arbeitenden Medien stellt sich dem historisch Fragenden das Problem des Anfangs der Geschichte seines Untersuchungsgegenstands. Und wie bei allen pictorialen Künsten und Medien zeigt sich unter ihren Historikern die Neigung, mit Hilfe von Analogiebildung weitreichende Ahnenreihen nach rückwärts zu erstellen. Ähnlich der (behaupteten) Historie von Karikatur oder Comics ${ }^{5}$ scheint so auch die Filmgeschichte ihren Anfang in der Ur-

${ }^{5}$ Für den Bereich der Karikatur sei hier angeführt: Fuchs, Karikatur, der in seinem nach wie vor gïltigen Standardwerk zur Karikatur Traditionsreihen bis in die Vorgeschichte erstellt. Fuchs freilich kann bei der Karikatur noch mit Recht darauf verweisen, daß zumindest die alten Völker bildliche Satire schon gekannt haben. - Anders verhält es sich bei den Comics. Sterankos paradigmatisch-typischer Versuch der Begründung einer Geschichte der Comics greift ebenfalls bis in die Vorgeschichte zurück und sieht in den Höhlenmalereien eine Art visueller Kurzschrift, die er unter dem Etikett graphisch-narrativer Kommunikation zu Vorläufern der Comics erklärt (vgl. Steranko, History I, 5). Das genannte Etikett erlaubt ihm unter Abstraktion des kulturgeschichtlichen Kontexts die Annexion beinahe der gesamten Kunstgeschichte für die Geschichte der Comics. Ähnlich verfahren andere Autoren, etwa: Metken, Comics. Die World 
geschichte des Menschen zu nehmen. Es stellt sich die Frage, ob ein so weitreichender Ausgriff klärend oder verunklärend wirkt. Die zugrundeliegende Begriffsstrategie sei daher an zwei repräsentativen Beispielen untersucht:

Friedrich von Zglinicki bemüht sich mit seinem 1956 erschienen „Weg des Films“ primär um eine Zusammenstellung der „historischen Tatsachen"6. Gegen eine "geistsprühende und sensationelle Behandlung des Themas ${ }^{\text {"7 }}$ setzt er sich pointiert ab, wobei seine Distanzierung hauptsächlich auf zeitgenössische, feuilletonistische bzw. „novellistische ${ }^{\text {“8 }}$ Filmgeschichten zielt. Ihnen gegenüber legt Zglinicki Wert auf Wissenschaftlichkeit, die er verbürgt sieht in einer strengen Orientierung an ,Daten'. Trotz dieser Ausrichtung auf historische Faktizität erhebt sein Werk einen systematischen Anspruch. Es versucht, unter dem Motto: „Historia est magistra vitae“ ${ }^{\text {“9 }}$ den Film aus seinen geschichtlichen Wurzeln zu erklären, da „die Auseinandersetzung mit den historischen Begebenheiten des Films und seiner Vorläufer überhaupt erst die Basis darstellt, um zu allen anderen filmischen Problemen Stellung nehmen zu können" ${ }^{10}$. Seine Absicht ist es, auf diese Weise zu ,einer höheren Auffassung von dem Wesen dieser künstlerisch-technischen Ausdrucksform (d.i. der Film, T.H.) zu gelangen"11.

Die hermeneutische Perspektive ist gleichwohl etwas schillernd. Zwar nennt Zglinicki den Film schon hier eine „künstlerisch-technische Ausdrucksform“ (s.o.), macht unter Zitation Panofskys ${ }^{12}$ auf die näheren gesellschaftlich-ökonomischen und technologischen Umstände der Entstehung des Films aufmerksam und zieht damit einen recht präzisen Kreis auch für die Vorgeschichtsschreibung. Die Wurzeln des Films könnten auf dieser Basis als spezifisch moderne angesetzt, d.h. näherhin: in den spezifischen technisch-ökonomischen und gesellschaftlichen Entwicklungen der Moderne - oder zumindest des 18./19. Jahrhunderts - aufgesucht werden. Doch Zglinicki greift weiter zurück und setzt die ersten Vorläufer des Films schon bei den

Encyclopedia of Comics ist demgegenüber vorsichtiger und betont gerade den kulturgeschichtlichen Unterschied. Sie erwähnt dabei auch den Film: „As cannot be sufficiently reiterated, the comic strip is emphatically not a medium of graphic narration. (...) there is as much a generic distance between the comics and the Trajan Column or Queen Mathilde's tapestry as exists between the cinema and shadow theater." (Horn, Encyclopedia, 9) Das Bewußtsein, das hier Historiker des Comic dem Film gegenüber an den Tag legen, fehlt manchen Historikern des Films.

${ }^{6}$ Zglinicki, Weg 1, 7; Zglinickis Werk stellte bei seinem Erscheinen 1956 die erste umfassende deutsche Filmgeschichte von wissenschaftlichem Rang dar und ist mit seinen vom Autor verarbeiteten über 800 Titeln internationaler Sekundärliteratur noch heute eine der am weitesten ausgreifenden Datensammlungen zur Vor- und Entstehungsgeschichte des Films. 1986 hat der Autor nochmals eine Kurzfassung seiner Arbeit publiziert: Zglinicki, Wiege. Letztere Veröffentlichung revidiert einen Teil der Position Zglinickis von 1956, die gleichwohl als paradigmatisch für ein entsprechendes Vorgehen hier diskutiert werden soll. Die veränderte Stellung des Autors wird an entsprechender Stelle in der Fußnote benannt werden.

${ }_{8}^{7}$ Zglinicki, Weg 1, 7

8 Zglinicki, Weg 1, 6

9 Zglinicki, Weg 1, XI

${ }_{10}$ Zglinicki, Weg 1, 7

11 Zglinicki, Weg 1, 6

12 Panofsky, Geburt; Panofsky sieht die Entstehung des Films gebunden an die das ,Zeitalter der Massen' bedingenden technischen und ökonomischen Entwicklungen des 19. Jahrhunderts und lehnt einen Ansatz wie den Zglinickis explizit ab (vgl. Panofsky, Geburt, 2-3, 5-10; Zglinicki, Weg 1, 20). 
Höhlenmalereien an. Er ist sich der Bedenken bewußt, die gegen einen so weit zurückreichenden Ausgriff in die Geschichte der Menschheit vorgebracht werden können ${ }^{13}$. Gleichwohl betrachtet er den Film als eine notwendig entstandene Kunstform, die er als das Ergebnis einer mehr oder weniger linearen Entwicklung sieht:

„Aber bedenken wir, daß solche Schöpfungen wie die Kinematographie nicht von einem Einzelnen, auch nicht vom Zufall erzeugt werden, sondern von der Zeit selbst. So hat auch der Film eine recht lange Entwicklungsgeschichte hinter sich. Aus dem Streben der Jahrtausende entstand hier eine neue Ausdrucksform $(. . .)^{\text {«14. }}$.

Das ,Streben der Jahrtausende' ging nach Zglinicki dahin, Bewegung zur Darstellung zu bringen: „Film ist Bewegungskunst und diese Bewegungskunst beschäftigte bereits den Urzeitmenschen" ${ }^{15}$. Die Sehnsucht nach Bewegungsdarstellung erscheint Zglinicki folglich so alt und so grundlegend, daß er sie in einem „Urtrieb des Menschen, Bewegungserlebnisse auf einer künstlerischen Ebene festzuhalten “16 verankert. Den Grund für den Wunsch nach künstlerischer Fixierung überhaupt wiederum sieht er in dem Bedürfnis, das eigene Leben und die eigene Umgebung „,der Nachwelt zu überliefern" ${ }^{\text {"17 }}$, also im Bedürfnis der Selbstmitteilung an künftige Generationen. $\mathrm{DaB}$ dies zunächst in bildlicher Form geschieht, führt er unter Zitation Schopenhauers (,Alles Urdenken geschieht in Bildern“18) auf die ,Nähe des Bilds zur Wirklichkeit' zurück. „Das Bild ist durch die optisch erfaBbare Wiedergabe eines Seins oder eines Vorgangs (...) die klarste, einfachste und allgemein verständlichste Form einer Erlebnisübermittlung “19 , es ist „nächstliegendes Hilfsmittel, um Geschehenes, Nachrichten oder Wünsche an ferne Personen oder auch an die Nachwelt gelangen zu lassen“20. Die Nähe zur Wirklichkeit (besser: die optische Nähe zur optisch erfaßbaren Wirklichkeit) freilich ist dort noch unvollkommen, wo das Abzubildende bewegt ist, das Abbild aber in Erstarrung gebannt bleibt. Zglinicki spricht daher vom „alte(n) Menschheitstraum, das Bild beweglich zu machen und damit noch mehr der Wirklichkeit anzugleichen“21. Dieser ,Menschheitstraum" scheint mit dem Film zur Erfüllung und zu einem gewissen Abschluß gekommen zu sein ${ }^{22}$.

${ }^{13}$ „Es mag vielen widersinnig vorkommen, in diesem Buch Jahrtausende zurückzugehen, da es sich doch um ein Werk handelt, das einzig und allein die Aufgabe hat, den ,Weg des Films' zu beschreiben." (Zglinicki, Weg 1,9)

14 Zglinicki, Weg 1, 9

15 Zglinicki, Weg 1, 14

16 Zglinicki, Weg 1, 14; Hervorhebung von mir.

17 Zglinicki, Weg 1, 16

18 Zglinicki, Weg 1, 9, 12

${ }^{19}$ Zglinicki, Weg 1, 10

${ }^{20}$ Zglinicki, Weg 1,11

21 Zglinicki, Weg 1, 12

2 Der Vorstellung eines Abschlusses entsprechend verhält sich Zglinicki zu anderen zeitgenössischen Formen der Bewegungsfixierung etwas verständnislos. So schreibt er etwa zu den Comies und Fotoromanen: „Man sollte meinen, daß diese Form des kinematographischen,Vorläufers' ihre Aufgabe erfüllt hätte, nachdem der ,Film‘ einmal erfunden und überall gebräuchlich ist. Merkwürdigerweise ist dem nicht so: Aus unerklärlichen Gründen scheint die Menschheit auf den Stand des Mittelalters zurückgekehrt zu sein - das beweisen die ungeheuere, geradem beispiellose Beliebtheit und Verbreitung der sog. strips in der Tagespresse, den Zeitschriften, den Bilderbüchern und ,Schmökern', strips, die in geradezu märchenhaft hohen Auflagen 
Aus dieser Perspektive unternimmt Zglinicki dann einen Durchgang durch die (frühe) Kunstgeschichte der Menschheit. Er gibt diesem Durchgang den Charakter eines historischen Belegs der These, daß hinter allen zitierten Erscheinungen letztlich der Drang nach Bewegungsdarstellung zu finden sei (vom Bedürfnis nach traditionsbildender Kommunikation wird dabei wieder abstrahiert). So schreibt er bereits den Höhlenzeichnungen, wie oben angedeutet, eine solche Absicht als primäre Absicht zu: „Das Einfangen des bewegten Lebens durch ein farbiges Sichtbarmachen auf den Höhlenwänden scheint die hauptsächliche Sorge derer gewesen zu sein, denen wir dieses Vermächtnis voll packendem Realismus verdanken. ${ }^{\text {23 } 3}$ Aus demselben Impetus heraus deutet er die Vielgliedrigkeit diverser Tier- und Menschenkörperdarstellungen als "übereinandergezeichnete Bewegungsphasen“" ${ }^{24}$, sieht er mit Gregor in den schwedischen Felsenbildern der Bronzezeit und den Steinplatten des Kiwikmonuments die „erkenntnistheoretische Urzelle des Films ${ }^{\text {“25 }}$ und verweist er auf Reihendarstellungen (hintereinandergestellte Figuren oder Prozessionen) der altägyptischen Reliefs, wobei er auch der Wiederholung derselben „Zustands- oder Bewegungsphasen“ die Intention attestiert, einen „Eindruck der Bewegung“ erzeugen zu wollen ${ }^{26}$. Später führt er dann Rollsiegel, Friese, bebilderte Säulen und dergleichen mehr, an, um die Linearität einer durch den Wunsch nach Bewegungsfixierung entstandenen Entwicklung zu erweisen. Eine Beziehung zum Film legt er immer wieder nahe: „Würde man die einzelnen gezeichneten Figuren an den Wänden so mancher Tempelbauten und Grabkammern auf einem Filmstreifen aufnehmen und später abrollen lassen, so müßte der Eindruck einer Bewegung entstehen und wir

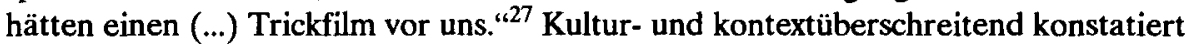
er in dieser Weise Analogerscheinungen in der Kunstgeschichte der Menschheit ${ }^{28}$. Dieselbe wird - pointiert formuliert - zur ,jahrtausende lange(n) Vorbereitung ${ }^{429}$ auf den Film.

Systematisiert man den Gedankengang Zglinickis zur Vorgeschichtsschreibung, so ergeben sich folgende Bestimmungsstücke der Entstehung des Films aus einer ,menschheitsalten Sehnsucht': einmal der ,Urtrieb' künstlerischer Bewegungsfixierung, zum anderen der Wunsch nach generationsübergreifender Mitteilung, d.h. nach traditionsbildender Kommunikation. Beide Bestimmungsstücke können als anthro-

erscheinen und deren Zeichner Fortsetzungen über Fortsetzungen ersinnen, um sich diesen so leicht in den Schoß fallenden Verdienst nicht entgehen zu lassen." (Zglinicki, Weg 1, 22)

${ }^{23}$ Zglinicki, Weg 1, 16

24 Zglinicki, Weg 1, 14

25 Zglinicki, Weg 1, 18; Vgl. auch: Gregor, Zeitalter

${ }^{26}$ Zglinicki, Weg 1, 19

27 Zglinicki, Weg 1, 20

28 vgl. zur Verankerung des hier diskutierten Anfangs der Filmgeschichte in der frühen Kunstgeschichte besonders: Zglinicki, Weg 1, 14-22. Die genannte Theorieperspektive kehrt freilich im ganzen Buch wieder.

${ }^{29}$ Zglinicki, Weg 1, 13; wie erwähnt, revidiert Zglinicki 1986 diese seine Position bis zu einem gewissen Grad. Gregors Rede von der „erkenntnistheoretischen Urzelle“ des Films in den schwedischen Felsenbildern bezeichnet er nun als "schon sehr optimistisch“ (Zglinicki, Wiege, 25), die Beiziehung der altägyptischen Reliefs als "allzu gewagt“ (ebd.) und den Verweis auf die ,trickfilmähnliche' Struktur diverser Rouleaus als "übertrieben“" (ebd. 26). Schattenspiele u.ä. aber nennt er noch, denn das Kriterium ist ihm noch immer nicht der kulturhistorische Kontext, sondern eine äußerst formal-abstrakte Bestimmung: die 1956 zitierten Vorläufer seien noch keine „echte kinetische Schaukunst“ gewesen, da nicht bewegt (vgl. ebd. 26). 
pologische Wurzeln betrachtet werden. Ein drittes Bestimmungsstück stellt der Verweis der Nähe des Bilds zur (optisch faßbaren) Wirklichkeit dar. Es kann als erkenntnistheoretische Wurzel apostrophiert werden.

Einen analogen Gedankengang führt Terry Ramsaye in seiner erstmals $1926 \mathrm{er}$ schienenen Filmgeschichte durch ${ }^{30}$. Auch er beginnt seine Geschichte mit einer „Prehistory of the Screen" ${ }^{\text {"31 }}$ und setzt dabei anthropologisch an. Zeittypisch ist dieser Ansatz einerseits geprägt von evolutionstheoretischen und andererseits von der frühen Psychoanalyse verpflichteten triebtheoretischen Vorstellungen. Die evolutionstheoretische Perspektive ist es, die ihn zu einer Durchführung seiner anthropologischen These im Rückgang auf die Urgeschichte führt; die triebtheoretische Perspektive läßt ihn dabei nach Grundantrieben forschen.

Auf der Suche nach dem Beginn der menschlichen Evolution, nach ihrem GrundImpetus, definiert Ramsaye den Menschen als ein ,Wesen des Wunschs', insbesondere des Wunschs nach der Wiederholung des Angenehmen. In diesem Wunsch sieht er den Antrieb zur Tat ${ }^{32}$. Als Voraussetzung der Möglichkeit von Wiederholung konstatiert er Erinnerung, welche im Verbund mit dem Wunsch dann zu einer Reproduktion des das Angenehme schaffenden Ereignisses führe ${ }^{33}$. Schritt für Schritt lerne der Mensch solcherart Verhalten. Im Wiederholen des Angenehmen und der Memorierung angenehmer Erlebnisse entstehe das erste Wissen ${ }^{34}$. Der Anfang der Evolution scheint damit gefunden.

Die Forschung nach (inhaltlich bestimmten) Grundantrieben führt Ramsaye dann einerseits zu „,sex and combat“ als den ,chief instincts“35, andererseits zu den ,basic desires' der biologischen und emotionalen Selbstreproduktion und der Kommunikation $^{36}$. In der Nacherfindung einer Evolutionsleiter der Kommunikation stellt er im Unterschied zu Zglinicki neben das Kriterium der Nähe des informationsübermittelnden Zeichens zur zu übermittelnden Wirklichkeit das Kriterium der Geschwindigkeit und der durch sie ermöglichten Quantifizierbarkeit: Der Versuch der Mit-

${ }^{30}$ Ramsaye, Million; Ramsaye's Filmgeschichte, die sich noch auf den Stummfilm bezieht, gilt nach wie vor als Klassiker, der eine Fülle von fein säuberlich zusammengetragenen Daten enthält und zudem durch die Zeitgenossenschaft und in einigen Fällen persönliche Bekanntschaft des Autors mit den Vätern des Films, darunter Edison und die Gebrüder Lumière, Porter, Selznick und Zukor, einen besonderen Wert und Reiz erhält.

${ }_{31}$ Ramsaye, Million, xxxvii

32 vgl. Ramsaye, Million, xxxviii-xxxix: „Man is the most wishful thing on the face of the earth. (...) Out of the power and the experience of the Wish man early found that some things were highly pleasurable. (...) Then, impatient of waiting for these pleasant things to happen of their own accord, came the impulse to push ahead and make them happen. Man sought to repeat the pleasant event."

${ }^{33}$ vgl. Ramsaye, Million, xxxix: „It took memory to know that the repetition of the event would bring a repetition of pleasure. Memory thus came to seek the repetition of the pleasure by the re-creation of the event."

34 vgl. Ramsaye, Million, xxxix: „That dawning ability to reenjoy by re-creation of the event of pleasurable memory was the beginning of knowledge."

${ }_{36}$ Ramsaye, Million, xi

${ }^{36}$ vgl. Ramsaye, Million, xl: „Out of the Wish, his blazing and gnawing desires, man evolved expression, communication and all of his arts. (...) The chief of his desires, the keenest of his Wishes, the greatest of his re-creations is the business of re-creating himself biologically and his cmotional adventures in memory and art forms." 
teilung beginnt der Kommunikationsleiter zufolge mimetisch - mit einer möglichst ,wirklichkeitsgetreuen' Wiedergabe des zu übermittelnden Inhalts. Pantomime steht entsprechend an ihrem Beginn ${ }^{37}$. Ihre weiteren Stufen sind jedoch gezeichnet von zunehmender Abstraktion. Bildliche Fixierung, anfangs in Form der Skulptur, dann durch Zeichnung, wird durch symbolische Reproduktion und schließlich durch Sprache und Schrift abgelöst ${ }^{38}$. Die zunehmende Abstraktion sieht Ramsaye bedingt durch die Notwendigkeit einer Beschleunigung der Kommunikationsprozesse und einer Häufung der zu übermittelnden Inhalte ${ }^{39}$. Bewegung spielt dabei überall eine Rolle - sie diene einer körpernahen Memorierung: „Memory lives in motion.“40. Rhythmus und Bewegung seien es, die in Pantomime und Tanz das memorative Element darstellten und die letztlich auch die Sprache trügen ${ }^{41}$. Bewegung wird zudem als integrales Moment des Denkens apostrophiert ${ }^{42}$.

Das mimetische Moment als die treibende Kraft aller Entwicklungen innerhalb der Kommunikationsleiter aber kristallisiert sich für Ramsaye in der Bildlichkeit. Sie kann ihm als die bleibende Unterströmung der Kommunikation faßbar gemacht werden. Die unter dem Druck der Fixier- und Quantifizierbarkeit entstandenen, abstrahierenden Abkürzungsverfahren, die in Sprache und Schrift gipfeln, nämlich dienen der ,picture-transmission“43. Das einerseits zum abstrakten Schriftzeichen geronnene Bild, drängt auch für Ramsaye daher - um die Mimesis zu vollenden - in seiner anderen, künstlerischen Existenzform zur Bewegung. Bewegung steht für Leben $^{44}$, Leben sollte einst in bildlicher Fixierung wiederholt und kommuniziert werden. Vollendet ist der Gang dieser evolutiven Geschichte so erst, wenn das Bild selbst zur Bewegung gelangt ist. Schon in der pantomimischen Visualisierung eines Ereignisses erblickte Ramsaye ja ein ,motion picture“ - ein ,Bewegungsbild“, das gleichzeitig die englische Bezeichnung für Film ist. Der Film ist darum für ihn, wie

${ }^{37}$ vgl. Ramsaye, Million, xli: „This (pantomime, T.H.) is the simplest form of telling. (...) It is, note this, an effort to make a living picture, a motion picture, the medium of making the appearance of the event occur again."

${ }_{38}^{38}$ vgl. Ramsaye, Million, xli, xliv-xlv, xlix-xlvi

39 vgl. Ramsaye, Million, xlii: „Communication became impatient of the pace of the cave artists. (...) Continuing consideration of Things and Places and developing recognition of Time and Space brought a complexity of emotions and ideas. Mud images and wall pictures could not keep up with the flow of thought and things to be said."

${ }_{41}$ Ramsaye, Million, xly

41 vgl. Ramsaye, Million, xliv-xlvii

42 vgl. Ramsaye, Million, xlv-xlvii; ,(...) motion is an integral part of thinking, and not a mere aid to it." (ebd. xlvii) Ramsaye bezieht sich dabei auf psychologische Untersuchungen seiner Zeit, die auf Muskelkontraktionen und kleine Bewegungen während der Denkvorgänge hinweisen. Am Beispiel der ,one-woman-actress' Gay MacLaren, die in der Lage war, 18 Theaterstücke, darunter auch Shakespeares personen- und zeitintensive Stücke, allein zu spielen, zieht Ramsaye die Linie weiter aus zur bildlichen Abfolge als Memorierungsstütze des menschlichen Gedächtnisses: MacLaren habe durch Bild- und Bewegungsassoziation diese Stücke gelernt. (vgl. Ramsaye, Million, xlv-xlvii)

${ }^{43}$ Ramsaye, Million, xlix

44 auch für Ramsaye: „We are going and going, where or nowhere makes no matter if we but go. All this movement may seem no more than the dance of the midges where the sunbeam shafts through the birches over the trout pool, but it seems that much - life. (...) Motion is the be all and end all. The going is life." (ebd. xlviii-xlix) 
für Zglinicki, die Erfüllung eines menschheitsalten Traums: „The motion picture is the realization of the age-old Wish of the world. “45

Ramsayes triebtheoretischer Ansatz sieht daraus auch ein inhaltliches Moment entspringen. Der Weg des Bilds zum Schriftzeichen und zur Sprache erscheint ihm ein Stück weit zu abstrakt geworden zu sein: „The process by which the cave picture became written language tended to carry the business of expression off into the heights of abstraction a good deal beyond the original intent ${ }^{\prime 46}$. Mit dem Film ist daher nicht nur der Drang des Bilds zur Bewegung erfüllt, es ist zugleich das ursprüngliche, trieborientierte Bedürfnis des Selbstausdrucks und der Kommunikation durch die stark emotionalisierenden Filminhalte wieder zu seinen Wurzeln zurückgeführt. Denn in ,desire lag aller Anfang von Selbstausdruck, Kunst und Kommunikation: „Nothing but desire has ever forced expression, and all of the expressions of art (...) are efforts, partially successful, to attain the objects of the Wish. ${ }^{\triangleleft 47}$ Die ,desires', insbesondere die ,chief desires' biologischer und emotionaler Selbstreproduktion, stellen für Ramsaye die anthropologischen Wurzeln der inhaltlichen Füllung aller Expression und Kommunikation dar. Sie erklären darum ,the inexorable persistence and dominance of the love story in the fiction of stage and screen and printed word. (...) Beauty and art, for the majority, are inseparable from sex. ${ }^{448}$ Der Film, der insbesondere in seinen frühen Formen trieborientierten Themen Rechnung trug und zudem zu einer die Pantomime übertreffenden Mimesis visueller Wirklichkeit fähig ist, trifft Ramsaye zufolge daher genau die ältesten Wunschvorstellungen der Menschheit:

"The film is the primeordial art, freed and empowered. For eons the picture on the wall could only say ,bear' and, woman'. Now endowed with motion it can say, There goes the bear' and more joyously still ,Here comes the woman'.“49

Der Kreis ist damit geschlossen: Was am Beginn der Menschheitsgeschichte die Leiter der Kommunikation initiierte, nämlich das Bedürfnis nach ,recreation' des angenehmen Erlebnisses durch mimetische Reproduktion des zugehörigen Ereignisses, ist mit dem Film auch für Ramsaye zu einem zumindest vorläufigen Abschluß und einer Erfüllung gelangt. Dem Film eignet eine gewaltige mimetische Potenz und er führt diese in einer großen Nähe zu den die Kommunikation schon am Beginn der Menschheitsgeschichte bedingenden ,desires‘ zu inhaltlicher Aktualisierung.

Ramsaye und Zglinicki greifen also in ihrer Vorgeschichtsschreibung des Films beide bis in die Urgeschichte der Menschheit zurück. Sie bedienen sich in der Festlegung ihrer Theorieperspektiven ähnlicher Bestimmungsstücke: Ein Verlangen nach Bewegungsdarstellung, der Wunsch traditionsbildender Kommunikation und die mimetische Nähe des Bilds zur ,Wirklichkeit' werden von ihnen konstatiert. Zglinicki bemüht sich dann um einen historischen Beleg seiner These, indem er Analogate der Bewegungsdarstellung in der frühen Kunstgeschichte sucht. Ramsaye greift auf historische Argumente, etwa die der Schrift zugrundeliegenden bildlichen Formen, zurück,

\footnotetext{
${ }^{45}$ Ramsaye, Million, xxxviii

${ }^{46}$ Ramsaye, Million, lxiv

${ }^{47}$ Ramsaye, Million, xxxviii

48 Ramsaye, Million, xl

${ }^{49}$ Ramsaye, Million, lxx
} 
argumentiert jedoch - evolutionistisch-triebtheoretisch geleitet - stärker auf einer anthropologischen Ebene. Die Frage stellt sich, ob ihre Ausgriffe an den Anfang der Menschheitsgeschichte zum Zweck der Film-(vor-)geschichtsschreibung überzeugen und was beider Ansätze für eine Begriffsbestimmung des Films austragen.

Zglinickis Beobachtungen, daß sich in der Kunstgeschichte der Menschheit auch schon sehr früh zumindest Analogate zur Bewegungsdarstellung finden, kann zweifellos nicht bestritten werden. Ob in allen von ihm beigezogenen Bildern das Bemühen um Bewegungsfixierung vorliegt, sei dahingestellt; ein gut Teil seines Materials läßt es zumindest vermuten. Auch die Beobachtung der mimetischen Bedeutsamkeit des Bilds trifft Realität. Denkt man etwa an barockes Bemühen um Bewegtheit der Darstellung oder an Leonardos beinahe besessenes Verlangen nach größtmöglicher Wirklichkeitsannäherung bis hin zur Täuschung (die ihm als täuschende Ähnlichkeit fast zum Qualitätskriterium wird), so wird deutlich, daß mimetische Bestrebungen auch im Sinne der Bewegung - immer wieder dingfest gemacht werden können.

Problematisch aber ist die Ausschließlichkeit der Perspektive, unter der Zglinicki kunstgeschichtliches Material betrachtet: Sein Blickwinkel ist einzig und allein durch die Frage bestimmt, ob in einer bildlichen Darstellung das genannte Bemühen erkennbar sei. So bemerkt er, da $B$ unter der Voraussetzung der Anerkenntnis des „Traum(s) von der Wiedergabe des Bewegten ${ }^{\text {c50 }}$ es freilich ,nicht schwer falle, in der Entwicklung künstlerischer Gestaltung bei fast allen Völkern Motive der Bewegungsdarstellung aufzufinden ${ }^{51}$. Der daneben nicht unwichtige kulturelle, etwa soziale, politische oder religiös-kultische Kontext dieser Motive bleibt jedoch unberücksichtigt, obgleich Zglinicki seine Untersuchung als kulturhistorische apostrophiert ${ }^{52}$. Zglinicki führt zwar in einzelnen Fällen kulturhistorische Kontexte an etwa, daß die Höhlenzeichnungen wohl religiös-kultische Funktion ${ }^{53}$ besessen haben -, doch sind sie ihm nebensächlich im Vergleich zu seinem primären Unterfangen, Bewegung darin zu entdecken. Mit einer gewissen ,Großherzigkeit ${ }^{54}$ vermag er daher Höhlen- und Grabzeichnungen, die Trajanssäule, barocke Rouleaus der Krönungszüge, den Parthenonfries, Moritatenplakate, die laterna magica, Guckkästen, Kaiserpanoramen und Pleoramen in einem Satz als „Vorläufer des Films“ zu nen$n^{55}{ }^{55}$. Von der Kommunikationsabsicht und dem Kommunikationskontext wird mit dieser großen Geste abstrahiert. (Die Kommunikationsabsicht ist mit dem Titel ,Mitteilung des eigenen Lebens und der eigenen Umgebung an die Nachwelt ${ }^{56}$ unter kulturhistorischem Anspruch ohnehin etwas vage benannt.) Abstrahiert wird auch von den Brüchen des mimetischen Bemühens in der Kunstgeschichte. So ist etwa die mit-

${ }_{51}^{50}$ Zglinicki, Weg 1, 20

51 vgl. Zglinicki, Weg 1, 20: „Wenn wir das tun (eben die Perspektive der Bewegungsdarstellung als einzige Untersuchungsperspektive akzeptieren, T.H.), fällt es uns nicht schwer, in der Entwicklung künstlerischer Gestaltung bei fast allen Völkern solche und ähnliche Motive aufzufinden".

${ }_{53}$ vgl. Zglinicki, Weg 1,9

53 vgl. Zglinicki, Weg 1, 14-15

54 vgl. Zglinicki, Weg 1, 23: ,... die soeben beschriebenen frühen Erzeugnisse der bildenden Kunst in großherziger Weise als ,kinematographische Vorläufer" bezeichnen ..." (Hervorhebung von $\mathrm{mir}$ )

${ }_{56}^{5}$ vgl. Zglinicki, Weg 1, 20

56 vgl. Zglinicki, Weg 1, 16 
telalterliche Buchmalerei an größtmöglicher Wirklichkeitsannäherung durch täuschend perspektivische Darstellung nicht interessiert. Perspektive wird erst später (wieder) entdeckt und dann geradezu als neue Errungenschaft gefeiert. Verständlich werden solche, die von Zglinicki insinuierte Linearität des ,Strebens der Jahrtausende' störende Entwicklungen nur unter Einbezug des jeweiligen kulturhistorischen Kontexts und die damit erfolgende Einordnung in die systematisch rekonstruierte Strukturgestalt einer Epoche.

Bezieht man jedoch diesen epochalen Kontext und die jeweilige Kommunikationsabsicht in die Reflexion der zitierten Analogate in der Kunstgeschichte mit ein, so läßt sich die aufgestellte Ahnenreihe nicht mehr unproblematisch erhalten. Es ist ein anderes, ob mit einer Höhlenzeichnung eine kultische Handlung in einem mythischanimistischen Kontext vollzogen, mit der Trajanssäule oder dem Teppich von Bayeux ein politisch-propagandistisches Ziel im Kontext größerer etablierter politischer Strukturgebilde verfolgt, mit den Buchmalereien Katechese im Kontext des mittelalterlichen Ordo betrieben oder mit einem Moritatenplakat Jahrmarktsunterhaltung mit moralischer Quintessenz für die proletarisierten Massen der bürgerlichen Epoche geboten wird. Dieses ,Andere“ wirkt sich auf die Gestalt des jeweiligen künstlerischen Unterfangens mit wesensverändernder Bedeutsamkeit aus. So ist auch der Film nicht zureichend begriffen, will man ihn nur unter dem Aspekt der Bewegungsfixierung verstanden wissen. Eine so perspektivierte Ahnenreihe, die sich zur Aufgabe nimmt, den Film aus seinen historischen Wurzeln zu erklären ${ }^{57}$, steht daher in der Gefahr, nicht nur zu unpräzise angesetzt zu bleiben, sondern auch verunklärend zu wirken. Sie wirkt sich auf die Bestimmung des Begriffs ,Film inflationär aus und läßt die Funktion dieses Mediums über die Erfüllung des Drangs nach Bewegungsfixierung hinaus ein Rätsel bleiben.

Ähnlich verhält es sich mit dem Ansatz Ramsayes. Hier ist es die (evolutionistisch-triebtheoretisch durchgeführte) anthropologische Perspektive, die den Begriff ,Film' durch Vorgeschichtsschreibung eher entgrenzt als definiert. Unter anthropologisch-systematischem Gesichtspunkt gibt sein Gedankengang - abstrahiert man von dem Versuch, die anthropologischen Grundlinien etwas populär evolutionstheoretisch zu verankern ${ }^{58}$ - zwar einige interessante Denkanstöße. Zweifelsohne sind mit dem Verweis auf die Kommunikationsbedürftigkeit des Menschen, seinen Wunsch nach Traditionsbildung und seine Triebbestimmtheit einige anthropologische Daten benannt, die im Kontext einer (ethischen) Reflexion des Films bedacht werden müssen. Auch die Lust an der Bewegung und die Konnotation von ,bewegt' mit ,Leben' wären hierher zu rechnen. Die Verknüpfung des weiteren mit der erkenntnistheoretischen Beobachtung der mimetischen Kraft des Bilds vermag zur Erhellung der Anziehungskraft des Films unter Umständen und bei näherer (etwa psychologischer) Spezifizierung etwas beizutragen. So gelingt es Ramsaye beispielsweise, der, wie auch Zglinicki, unsere Kultur mehr als eine ,idolozentrische' denn als eine logozen-

${ }^{57}$ vgl. Zglinicki, Weg 1, XI, 6-7

58 Dem heutigen Leser wird es nicht mehr möglich sein, die etwas zu fantasiereiche Narration der Evolution der menschlichen Kommunikation bei Ramsaye unkommentiert nachzuvollziehen; allein, man wird dem Werk von 1926 nicht mehr an Tiefe zu etwa der Sprachentstehung abverlangen dürfen, als der damaligen zeitgenössischen Spekulation zu Gebote stand. 
trische betrachtet ${ }^{59}$, bereits aus dem triebtheoretischen Blickwinkel seines Ansatzes ein weitaus unverkrampfteres Verhältnis zur Bildlichkeit und zu den Inhalten des frühen Films zu gewinnen, als das bei Zglinicki der Fall ist ${ }^{60}$. Doch bleiben Ramsayes Denkanstöße auf der Ebene des Anstoßens. Seine anthropologische Verankerung des Films in der Vorgeschichte der Entstehung von Kommunikation überhaupt ist zu unspezifisch angesetzt. Dies zeigt sich nicht zuletzt darin, daß ihm die Entstehung des Films gewaltig verzögert scheint ${ }^{61}$. Da Ramsaye Kommunikation in ihrem ,mainstream' bildlich unterfuttert und mimetisch begründet sieht, und er diese Mimesis als möglichst realistische Rekreation der zu übermittelnden (optischen) Wirklichkeit charakterisiert, muß sich ihm dieser Gedanke aufdrängen: Erst der Film stellt dann die Erfüllung des Drangs nach Perfektionierung der visuellen Mimesis dar. Die konstatierte Verspätung ist umso verblüffender, wenn der genannte Drang wiederum als die einzig treibende Kraft in der Kommunikationsgeschichte angesehen wird. Auch bei Ramsaye ist es so die Neigung zu einer monokausalen Engführung der Vorgeschichtsschreibung, welche seine Evolutionslinie des Films problematisch werden läßt.

Der Mimesis-Begriff selbst ist darüber hinaus zu ungenau gefaßt. Wie mit Zglinickis so sind auch mit Ramsayes Ansatz Brüche in der Linearität einer Kunstge-

${ }^{59}$ Zglinicki spricht etwa von der „Herrschaft des Bilds, die von unserem ganzen Leben Besitz ergriffen hat" (Zglinicki, Weg 1, 12), Ramsaye gar von der „eye-mindedness" unserer Welt (Ramsaye, Million, lvii).

${ }^{60}$ Zglinicki bewertet die ,Herrschaft des Bilds' kulturpessimistisch: Er betrachtet das Bild gewissermaßen als kommunikationstechnisches Abkürzungsverfahren, das zwar dem ,Tempo unserer Zeit' angemessen sei, jedoch ,Besinnlichkeit' und ,Geistigkeit' (bzw. Abstraktionsfähigkeit) verlorengehen lasse (vgl. Zglinicki, Weg 1, 12: „Die Ursachen [der ,Herrschaft des Bilds', T.H.] liegen ganz einfach in dem wachsenden Materialismus, eng verbunden mit dem Fortschritt der Zivilisation, bzw. mit dem, was wir Zivilisation nennen: der Jagd nach dem Glück, dem Tanz ums Goldene Kalb, der Sucht des Verdienens um jeden Preis, der Geldgier des Großstadtroboters. Der Erfolg des Bilds ist im ,Tempo unserer Zeit begründet ${ }^{\prime}$ [...]. Wer kann sich heute noch den Luxus besinnlicher Stunden erlauben? [...] Das mit kurzem Text versehene Bild hat spaltenlange Artikel zu ersetzen; die Bilderfolge [...] tritt an die Stelle ganzer Romane; [...] Die täglichen Eindrücke überstürzen sich ohnehin so, daß eine Verarbeitung im tieferen Sinne kaum mehr möglich ist."). Ramsaye hingegen kommt aus seiner Triebtheorie heraus zu einem positiveren Urteil. Auch er beobachtet, daß die Mehrheit ,did not jump off the concret bank of pictures into the abstract river of words." (Ramsaye, Million, lxiii) Er sieht, daß die Meisten "are still sitting by the river, making small use of the alphabet and looking at pictures of Things, mostly bears and women." (Ramsaye, Million, lxiii) Doch beunruhigt ihn dies nicht weiter - sein evolutionistisch-triebtheoretischer Ansatz erlaubt, dies feststellen zu können, ohne es abwerten zu müssen. Kommunikation begann für ihn körpernah, wurde durch die nötig gewordenen Abkürzungsverfahren von Sprache und Schrift ohnehin „, a good deal beyond the original intent" (vgl Ramsaye, Million, lxiv) in die ,Höhen der Abstraktion' getragen und findet mit dem Film wiedeı zum Grund zurück: „The motion picture is close to the soil. A silly sanctity surrounds the standard, accepted, classic and traditional views of art." (Ramsaye, Million, xiii) Entgegen dieser „sanctity" identifiziert Ramsaye schon im Vorwort seines Buchs die Wurzeln der Künste in den Trieben: „Like all the great arts its (the motion picture's, T.H.) appeal is based on a few primitive, and therefore universal, instincts and mechanisms in man." (Ramsaye, Million, xi) Das triebtheoretische Moment seines Ansatzes ermöglicht ihm so, den Film mit einem positiven Unterton ,specific, primitive, actual, faster than life and twice as natural“ (Ramsaye, Million, lxix) zu nennen.

61 ,To the investigator who will pursue the facts through a maze of obscurities, one of the most interesting aspects of the screen is its belated arrival. The motion picture was a great deal overdue many, many centuries ago." (Ramsaye, Million, xxxvii) 
schichte als Mimesis-Geschichte unerklärlich. Wäre Mimesis, wie Ramsaye sie versteht, die einzig treibende Kraft hinter allen künstlerischen Schöpfungen, so müßte Kunstgeschichte letztendlich Realismusgeschichte sein. Um das historische Kontrafaktum zu verstehen, hätte man den Mimesis-Begriff als Erklärungsinstrument für das Werden der Kunstgeschichte entweder aufzugeben oder durch Hinzuziehung weiterer Erklärungsinstrumente zu modifizieren. Der Rekurs auf die Psychologie zum Beispiel würde es erlauben, abstrakte Bildschöpfungen etwa als Mimesis einer inneren Gestimmtheit faßbar zu machen. Gleichwohl sind auch die Vorbehalte gegen eine psychologische Engführung der Kunsttheorie bekannt und nicht ohne weiteres von der Hand zu weisen. Für ein Verständnis des Films und seiner Vorgeschichte (sowie seine ,verzögerte' Entstehung) wäre damit ohnehin noch nicht genug geleistet.

Will man den Film in seiner Besonderheit verstehen, so gilt es daher konkreter, d.h. geschichtlich zu spezifizieren. Anthropologische und erkenntnistheoretische Grundlinien nämlich sind Grundlinien. Sie können einen Rahmen bereitstellen, innerhalb dessen sich ein Verständnis zu entwickeln vermag. Zur Präzisierung dieses Verständnisses aber tut es not, auf die Entwurfsleistungen des Subjekts und Gegenstands der Anthropologie, des Menschen, zu blicken, d.h. also gerade jene bei Zglinicki und Ramsaye weitgehend ausgeblendeten kulturellen, sozioökonomischen und technologischen Kontexte in die Reflexion einzubeziehen, von denen der eigentliche historische Entstehungsort des Films geprägt ist. Erst wenn man die besonderen historischen, d.h. auch: unterscheidenden Eigenschaften und Strukturmerkmale in den Blick nimmt, durch die sich die Entstehungszeit des Films faktisch auszeichnet, besteht wirklich die Chance, dieses Medium in seiner Spezifität, seinen typischen Eigenarten erfassen zu können. Erst aus dem ,epochalen' Kontext erhellt sich dann auch, weshalb der Film zu diesem und keinem anderen Zeitpunkt, in die Welt kommt'.

Die Epoche aber, in der der Film entsteht, ist die Moderne, d.h. jener Zeitabschnitt, der im 19. Jahrhundert - etwa 1850 - einsetzt und um dessen Bestand oder Verabschiedung heute eine heftige Diskussion geführt wird. ${ }^{62}$ Die systematische

${ }^{62}$ Gegenüber stehen sich bekanntlich Verfechter des Projekts der Moderne, wie Jürgen Habermas, und die Kritiker dieses Projekts, die einmal zu seiner Verwerfung neigen, wie Hartmut und Gernot Böhme, einmal seine Transformation zur ,Postmoderne' konstatieren oder fordern, wie Francois Lyotard oder Wolfgang Welsch. Neuerdings gesellt sich zur Auseinandersetzung auch eine bewußtseinspsychologische Autonomiekritik und eine phänomenologische Analyse ,postmoderner' zeitgenössischer Phänomene der Alltagskultur. (vgl. zum letzten: Meyer-Drawe, Illusionen; Schönhammer, ,Walkman') - Die genaue Datierung des Projekts der Moderne bereitet dabei ähnliche Schwierigkeiten wie jene einer sich als Epochenbegriff verstehenden Postmoderne. Aus der Literaturwissenschaft und Kunstgeschichte in die Kulturphilosophie importiert würde der Begriff nur die seinem Herkunftsbereich entsprechende Zeitspanne nach der Mitte des 19. Jahrhunderts bezeichnen dürfen. Schon Habermas aber hintersteigt diese temporale Marke, wenn er das Projekt der Moderne mit den von Weber skizzierten Rationalisierungsprozessen und den Ideen der Aufklärung in Konnex bringt. Genau besehen müßte man daher mindestens vom ,Projekt von Neuzeit und Moderne‘ sprechen, obschon auch damit noch kein völlig zureichender, präziser Epochenumkreis gezogen wäre; mindestens die Rationalisierungsprozesse dringen mit ihren Wurzeln in noch tiefer gelegenes historisches Erdreich. Obschon ich dem Datierungsproblem nun nicht - gewissermaßen in einer Parallelisierung des Welsch'schen Umgangs mit diesem Problem in der Postmodernediskussion - vollständig in die Behauptung ausweichen will, durch den Begriff sei nur ein strukturell-systematischer Schwerpunkt von Entwicklungen bezeichnet, auf deren Prägekraft man heute zunchmend aufmerksam 
Struktur dieses Zeitabschnitts, seine ideengeschichtliche Bestimmtheit und seine kulturelle und sozioprozessuale Strukturiertheit nun hat Jürgen Habermas mit dem Schlagwort vom ,Projekt der Moderne zu fassen gesucht, das ich bereits verwendet habe und nun terminologisch genauer einführen will. Eben dieses Projekt nämlich umschreibt die epochalen Eigentümlichkeiten, die grundsätzliche Rahmenstruktur, in die die ökonomischen, technologischen und sozialen Entwicklungen einverwoben sind, von denen die Heraufkunft und die Geschichte des Films mitbedingt sind. Eine prinzipielle Strukturskizze des Projekts der Moderne tut daher not. - Habermas selbst versucht, mit diesem Titel unter Rekurs auf Max Weber die Ausdifferenzierung der ,Wertsphären' Wissenschaft, Moral und Kunst als jeweils autonomer kultureller Sektoren mit eigener Entwicklungslogik und Rationalität sowie den damit einhergehenden Zerfall der (geschlossenen und übergreifenden) Weltbilder als Kernmomente der Moderne dingfest zu machen. ${ }^{63}$ Diese Momente stellt er zudem in einen Zusammenhang mit den Ideen der Aufklärung, insbesondere mit dem Gedanken der Autonomie des vernünftigen Subjekts, dem aufgrund seiner Vernünftigkeit auch Kompetenz und Recht zur Selbstbestimmung und freiheitlichen Existenz zugesprochen werden kann, und dem Bestreben, auf dieser Basis eine Lebens- und Gesellschaftsorganisation vorzunehmen, die den Subjekten eine ihnen zugepaßte und fortschrittsfähige Struktur kollektiver Existenz bereitstellen soll. Als Strukturmomente des Projekts der Moderne lassen sich mithin die Subjektivierung und Autonomisierung des Menschen und die Rationalisierung der Weltbilder sowie der Lebensund Gesellschaftsverhältnisse fassen. In ihrer gesellschaftlichen Realisierung bedingen diese Momente zudem eine Tendenz zur Demokratisierung. Im folgenden will ich diese Momente nun etwas genauer explizieren. Dabei gehe ich an manchen Stellen etwas über Habermas hinaus.

Als erste Wurzel des Projekts der Moderne läßt sich zweifellos die Rationalisierung apostrophieren, die mit der Wandlung - bzw. umfassenden Durchsetzung des wissenschaftlichen Paradigmas in der Neuzeit sich auf alle Lebens- und Gesellschaftsbereiche auszudehnen beginnt, und die, wie Weber und Habermas beschreiben, auf die Weltbildkonstitution zurückwirkt und geschlossene Weltbilder aufsprengt. Der Ursprung dieser Rationalisierung kann nun zwar bereits in der frühen

werde, werde ich mit dem Label ,Projekt der Moderne im folgenden Prozesse bezeichnen, die partiell auch schon vor 1850 greifbar sind. Ich verstehe damit den Begriff ,Projekt der Moderne' als präzisierende Struktursammlung von ideengeschichtlichen und kulturell-sozialen Entwicklungen und Einsichten, die vordringlich in der Neuzeit wurzeln, für die (endgültige) Ablösung zentraler Strukturmerkmale der vorneuzeitlichen Epochen sorgen und im 19. Jahrhundert eine bis heute anhaltende, alle lebensweltlichen und gesellschaftlichen Strukturen prägende und auf Internationalisierung drängende Dynamik entfalten. Das Label ,Projekt der Moderne' behalte ich dabei bei, ohne es um die Neuzeit zu ergänzen oder durch eine andere Formulierung ersetzen zu wollen, da einmal der Begriff inzwischen diskursiv eingeführt ist und zum anderen die in Frage stehenden Entwicklungen erst mit der Moderne (bzw. etwas weiter angesetzt: mit dem 19. Jahrhundert) zu ihrer eigentlichen Gestalt und ihrem endgültigen Austrag gelangen. Die Postmodernediskussion zeigt zudem, daß die Moderne nicht beliebig um neue Strukturmerkmale erweiterbar ist und eine relativ deutliche historisch-systematische Gestalt besitzt, d.h. mithin

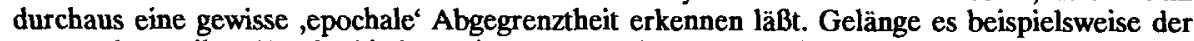
Postmoderne, ihre Verabschiedung eines systematischen Einheitspostulats (etwa der Vernunft oder des Subjektgedankens) durchzusetzen, so wäre die Moderne in der Tat verlassen und ein neuer Zeitabschnitt eröffnet.

63 vgl. Habermas, Moderne 
Erfindung der Werkzeugtechnik, d.h. mit einem fast Zglinicki'schen Ausgriff zu Beginn der Morgendämmerung der Menschheit, gesehen werden. So ermöglicht die Entwicklung dieser Frühform von Technik die Freisetzung vom Naturzwang und die Verbesserung der Existenzchancen sowie die Konstitution eines zugehörigen objektivierend-instrumentellen Rationalitätstyps. Werkzeuge helfen dem Menschen zu seinem Überleben, zu gesteigerter Produktivität bei gleichzeitiger Verminderung des hierfür aufgewendeten Arbeitseinsatzes und damit zur Verbesserung seines ,Lebensstandards'. Außerdem regt die Erfindung von Werkzeugen die Ausbildung einer spezifischen ,Werkzeugintelligenz' an, die einmal die Welt unter funktionalem Aspekt aufzufassen lernt, zum anderen aber auch Rationalität selbst als Werkzeug für die Erreichung bestimmter funktionaler Ziele zu verstehen und einzusetzen beginnt. Ihre eigentlich prägende Gestalt jedoch erhält die Rationalisierung erst mit der Heraufkunft der Naturwissenschaften, der empirisch-methodischen Zuwendung zur Welt als einer Gesamtheit objektivierbarer Tatsachen und der quantifizierend-abstraktiven, mathematisch-logischen Fixierung ihrer Erkenntnisse. An die Stelle einer spekulativen Theoriebildung bezüglich der umgebenden Welt tritt nun die experimentelle und methodische Erforschung derselben sowie eine den jeweiligen Gegenstandsbereichen zugepaßte abstraktive Fixierung des Erkannten in ,positiven Gesetzen'. Im Übergang zur Neuzeit wandert der Reflexionstyp der naturwissenschaftlich initiierten Rationalisierung in andere Wissenschaftsbereiche ein; gleichzeitig beginnt die Rationalisierung, sich auf die Gesamtheit der individuellen und gesellschaftlichen Lebensverhältnisse auszudehnen. Sie führt zunächst - mit Weber gesprochen - zu einer ,Entzauberung', d.h. zu einer Auflösung numinos-metaphysischer Weltbilder, und zu einer Diversifizierung, die ,ganzheitliche‘ Weltvorstellungen (wie etwa den mittelalterlichen Ordo) durch bereichsspezifische Paradigmen ablöst. Eine Art ,säkularisierter' Sachorientierung und der Entwurf ,sachlogischer', d.h. segmentärer, voneinander unterschiedener und in sich relativ autonomer gegenstandsorientierter Reflexionstypen werden möglich. Dieser Rationalisierung findet sich auch die Ökonomie unterworfen, die zugleich wiederum eine der zentralen Förderinnen der Rationalisierung selbst ist. So beginnt diese Förderung bereits mit der Erfindung des Geldes, dessen Tauschabstraktion den rationalen Vergleich von Ungleichem mit Ungleichem ermöglicht. Eine bedeutende Fortsetzung findet diese Rationalisierung mit der Entwicklung des Handels und insbesondere der Erfindung der Buchführung, die rationale Kalkulation methodisch perfektioniert. Über die Erfindung des Bankwesens, die Ergänzung der Warenwirtschaft durch die Geldwirtschaft und schließlich die spezifisch moderne Rationalisierung im Produktionsbereich führt die ökonomische Rationalisierung in eine exponentielle Entwicklung. In Kombination mit Wissenschaft und Technik entwickelt sie in der Moderne eine zunehmende instrumentelle Dynamik, die zu enormen Fortschritten und einer erstaunlichen Verbesserung der materiellen Lebensqualität führt. Dabei sind es sowohl die mit jeweils relativer Autonomie ablaufenden ,sachlogischen', diversifizierten und spezialisierten Reflexionen in den einzelnen Bereichen, als auch ihre partielle und fallweise Kombination, die diese Fortschritte aus sich hervortreiben, und es ist die Moderne, in der diese Form der Rationalisierung zu ihrer (vorläufigen) Vollgestalt kommt und beherrschend wird. Die Moderne ist es auch, in der die Strukturierung und Einrichtung der gesellschaftlichen Verhältnisse zunehmend ,rationalisiert' wird und sich diese Rationalisierung 
auf den individuellen Lebensvollzug ausdehnt. Die rationalisierte Gesellschaft verlangt von ihren Mitgliedern eine ,methodische Lebensführung', d.h. eine zielgerichtete, partiell selbstinstrumentelle Einrichtung der individuellen Lebensvollzüge.

Im Zug der Ausbildung dieser Rationalisierung und einer neuen, rational-wissenschaftlichen Weltbewältigungskompetenz verändert sich auch das Selbstverständnis des Menschen. Dieser beginnt sich nun vordringlich als Vernunft- und Freiheitswesen zu begreifen, als Wesen, dem in seiner Vernunft die Kompetenz zur Realisierung seiner Freiheit gegeben ist. Der Mensch erscheint sich fortan als Subjekt und bestimmt seinen Status als den der Autonomie: Fähig zu vernünftiger Erforschung der Wirklichkeit und zur vernünftigen Einrichtung seiner Lebensverhältnisse sieht sich der Mensch sowohl in individueller als auch in sozialer Hinsicht als Herr seiner und der kollektiven Geschichte. Er fühlt sich in der Lage, die Gestaltung seines Geschicks und der Gesellschaftsverhältnisse in seine eigenen Hände zu nehmen, und er versteht Geschick und Gesellschaft dabei zugleich als solche von ihm entworfene Gestaltungen. Damit verspricht die rationale Durchdringung der Welt, rückangewendet auf sein eigenes Wesen und seine geschichtlich-gesellschaftliche Existenz, die endgültige Lösung aus heteronomen Zwängen, denen der Natur ebenso wie denen metaphysischer ,Hinterwelten'. Die Welt wird zum Entwurf und die Begründungslogik hierfür wird vordringlich sachspezifischen Strukturen entnommen. Im Vernunftpathos der Aufklärung findet dieses neue Selbstverständnis seinen emphatischen Ausdruck.

Die Rationalisierungsprozesse des neuzeitlich-modernen Subjekts, des Menschen, der den ,Ausgang aus seiner selbstverschuldeten Unmündigkeit' (Kant) genommen hat, münden durch die Autonomisierung hindurch dann zugleich in Individualisierungs- und Dynamisierungsprozesse, die soziale Mobilität an die Stelle statischer Gesellschaftsverhältnisse setzen. Mit dem Gedanken des autonomen Subjekts ist ideengeschichtlich ein Prozeß eingeleitet, der in seiner sozialen Realisierung zur Auflösung aller geschlossenen Formen von Gesellschaft führt und insbesondere die Ständegesellschaft unterhöhlt. Als autonome, durch ihre Vernunftbegabtheit in Sachen Weltbewältigung und gesellschaftlichen Belangen kompetente Wesen nämlich drängen die neuzeitlichen Subjekte letztlich auf Beteiligung an den politischen Prozessen, auf Mitspracherechte bei der Organisation des Gemeinwesens und - in the long run - schließlich zunehmend auf Demokratisierung. Eine zirkelinterne, schicht- oder gruppenspezifische Requirierung des Subjektgedankens ist nicht (mehr) möglich; der Gedanke selbst zielt in seiner grundsätzlichen Allgemeinheit und Prinzipialität auf auch soziale Universalisierung. Nachdem die Idee des kraft seiner Vernunft autonomen Subjekts einmal in der Welt ist, beanspruchen diesen Status mehr und mehr alle vernunftbegabten Wesen, d.h. auch jene, die weder durch Standeszugehörigkeit noch durch Bildung material für eine Ausübung ihrer vernünftigen Potenz ausgestattet worden sind. Die Grundideen des Projekts der Moderne, die im Subjektgedanken ihren anthropologischen Kulminationspunkt gewinnen, finden eben wegen dieses Kulminationspunkts universelle Ausbreitung und führen damit zu einer Verwandlung der gesellschaftlichen Strukturen. Sie bedingen auf diese Weise eine Veränderung der Öffentlichkeit und die Heraufkunft demokratischer Gesellschaftsformen mit.

Diese Strukturbedingungen der Moderne nun sind es, unter denen die Medien und besonders der Film - erst entstehen können und unter deren kontextueller Berücksichtigung die konkret-faktischen Eigentümlichkeiten derselben erst in ihrer sy- 
stematischen Bedeutung verständlich werden. So ist gerade der Film, bei dem es sich um ein dezidiert technisch ermöglichtes Medium handelt, beispielsweise eine Frucht spezifisch moderner technischer Reflexion und steht er so in enger Verbindung mit der modernen Rationalisierung. Außerdem ist er ein durch und durch ökonomisch vermitteltes Medium, das von vorneherein unter ökonomischen Gesichtspunkten entworfen wird. Auch das verklammert ihn mit der modernen Rationalisierung und bringt ihn in unmittelbaren Konnex mit dem Projekt der Moderne. Gleichzeitig läßt sich daraus erhellen, weshalb er ,so spät' entsteht: Die Strukturbedingungen der Moderne, die technische und ökonomische Rationalisierung, erst schaffen (wie zu sehen sein wird) kontextuelle und materiale Bedingungen - technische Vorerfindungen und wirtschaftliche Nutzungsinteressen - die ihm zur Existenz verhelfen. Erst sie stellen auch eine veränderte Öffentlichkeit bereit, ein schichtübergreifendes Publikum, das ihn im erforderlichen Ma $\beta$ an sich ziehen, nutzen und profitabel machen kann. Umgekehrt sind es dann auch die Medien, die die Durchsetzung der Struktureigenschaften der Moderne fördern, ja das Projekt der Moderne beschleunigt vorantreiben. Hier wiederum ist es besonders die Veränderung der Struktur der Öffentlichkeit, die von den Medien mitbedingt wird und an der sie, darunter auch der Film, einen gewichtigen Anteil haben. So sind sie es, die die autonomen Subjekte zu einer neuen Öffentlichkeit versammeln und damit diese Öffentlichkeit sich zugleich als eine solche von Subjekten bewußt werden lassen. Ohne die Medien wären der in der Axiomatik des Projekts der Moderne angelegte gesellschaftliche Wandel und der zunehmende Demokratisierungsprozeß nicht - oder zumindest nicht so relativ rasch zur Durchsetzung gekommen. Der Film ist so meines Erachtens nur zureichend begriffen, wenn man ihn im Kontext des Projekts der Moderne betrachtet. Beim Auszug der Linien seiner konkreten historischen Entstehung und Situierung, d.h. näherhin vor allem bei der Deskription der technischen, ökonomischen und gesellschaftlich-kommunikativen Bedingtheit will ich dies im folgenden deutlicher werden lassen. Gleichzeitig soll diese Deskription einen den Phänomenen nahen, realitätsgerechten Begriff von Film ermöglichen, der für die Beschäftigung mit den Auseinandersetzungen um dieses Medium eine auch informationelle Basis schafft.

\subsection{Das Werden der Kinematographie: Die technische Vorgeschichte des Films}

Zglinicki und Ramsaye ist grundsätzlich zuzustimmen, wenn sie als Wesenseigenschaften des Films die Bewegungsaufzeichnung und -wiedergabe nennen. Schon der ältere Name des Films: ,Kinematographie', verweist darauf. Obgleich die Genannten zu undifferenziert bleiben, wenn sie diese fundamentalsten Eigenschaften des Films zum mehr oder minder monokausalen Angelpunkt ihrer Vorgeschichtskonstruktion machen, so muß die Untersuchung der Vorgeschichte doch von diesem Fundament ausgehen, um dann zusätzliche Bestimmungsstücke aufzuweisen. Die Vorgeschichte des Films nämlich beginnt mit der technischen Verfügbarmachung eben der Möglichkeiten, Bewegung festzuhalten und zu reproduzieren, wenngleich sich der Film keineswegs darin erschöpft. Wichtig dabei ist, daß es sich um eine technische Verfügbarmachung handelt; ,Film' ist das Resultat einiger deutlich benennbarer, historisch faßbarer technischer Umsetzungen von technologischer Reflexion, wie sie akzeleriert vor allem im 19. Jahrhundert auftreten. In diesem Jahrhundert nämlich entsteht 
eigentlich erst Technik als dynamisiertes Phänomen ${ }^{64}$, und findet diese so zu ihrer spezifisch modernen Gestalt. An der Wende vom 18. zum 19. Jahrhundert geraten Naturwissenschaft, Technik und Industriewirtschaft als zunächst relativ eigenständige Reflexionsbereiche in eine Wechselbeziehung zueinander, die eine neue Struktur schafft ${ }^{65}$. Folge der Wechselbeziehung ist einerseits eine Theoretisierung der häufig aus rein praktisch-experimentellem Handeln entsprungenen technischen Machinationen, d.h. deren zunehmende Rationalisierung. Andererseits führt die Beziehung zu einer technikkooperativen Praktifizierung der im Ursinn von,$v \varepsilon \omega \rho i \alpha^{*}$ auf ,reine Erkenntnis‘ ausgerichteten (Natur-)Wissenschaften, die derart (zumindest partiell) einem instrumentellen Rationalitätstyp unterworfen werden. Schließlich hat die Beziehung eine Implantation ökonomischer Zwecksetzungen in beide zur Konsequenz ${ }^{66}$. Der werkzeughafte Charakter der vorindustriellen und vormodernen Technik wird dabei verlassen; die neue Struktur entfaltet eine bislang ungekannte, auf globale Transformationen zielende Dynamik ${ }^{67}$. Technik erhält in der Moderne eine veränderte, weltkonstitutive Qualität. Sie hilft nicht mehr nur dem Menschen, in seiner Welt etwas zu bearbeiten, sondern sie prägt seine Welt als ganze ${ }^{68}$. Die Vorgeschichte des Films (und auch ein gut Teil seiner Geschichte selbst) ist auch ein Stück Technikgeschichte. Begreift man sie als solche, so läßt sich (wie angedeutet) daraus zugleich erhellen, weshalb der Film erst ,so spät‘ entsteht: Die Dynamisierung

${ }^{64}$ vgl. zu diesem Gedanken auch: Ceram, Archäologie, 13-14: „Kinematographie ist als technische Apparatur Summe von Entdeckungen und Erfindungen, die vor allem im 19. Jahrhundert gemacht wurden. Nur in diesem Jahrhundert wurde überhaupt ,Technik' entwickelt; und nur im abendländischen Raum. Die Antike kannte zwar Mathematik, Physik, (Al-)Chemie. Das ergab in der Praktifizierung Mechanik, aber nicht Technik. Mechanik ist Statik, Technik ist Dynamik (...)" - Cerams von Spengler (Spengler, Technik, 67) übernommener Technikbegriff bedürfte freilich der Diskussion, nicht zuletzt, da Spengler schwerlich als besonders reflektierter Zeuge hierzu zu werten ist. Dennoch ist die Zielrichtung seines Hinweises und seiner Begriffsdifferenzierung Technik/Mechanik hilfreich zur Erfassung der hier angegangenen Problemlage. Mit Gehlen läßt sie sich stützen (vgl. unten).

65 Arnold Gehlen, der die Etablierung der genannten Wechselbeziehung zu dieser Zeit als den zweiten großen Einschnitt in der Menschheitsgeschichte begreift, spricht hier von der Entstehung einer „Superstruktur“, die eine geschichtsmächtige Eigendynamik entwickelt und kulturtransformatorische Wirkung entfaltet. (vgl. dazu: Gehlen, Seele; Gehlen, Technik; Gehlen, Studien)

${ }^{66}$ vgl. hierzu über Gehlen, Technik, 98 hinaus: Stork, 41-46; Stork verweist auf die Technisierung der Naturwissenschaften durch Untersuchungsinstrumente, Laboratorien etc. Demgegenüber sieht er im Bereich der Technik das handwerklich-praktische Element schwinden und den Theorieanteil wachsen.

67 vgl. Gehlen, Technik, 97-103; Gehlen faßt dabei das Unbehagen an der Technik als Symptom der durch dieselbe mit inaugurierten weltweiten Kulturtransformation auf. (vgl. zu diesem Gedanken auch: Korff, Leitideen)

${ }^{68} \mathrm{Um}$ diese Tatsache in der hier gebotenen Kürze zu illustrieren, sei nur an den großen Blackout in den 70er Jahren in New York erinnert. - Die weltkonstitutive Kraft der Technik, wie sie sich gerade im 19. Jahrhundert,entbirgt', wird denn auch rasch Gegenstand der philosophischen Reflexion und Auseinandersetzung. Dessauer macht den ersten das Wort „Technik“ als „Gesamtbezeichnung eines Einheitsgebietes“ gebrauchenden Vortrag 1884 und den ersten Buchtitel 1887 aus (vgl. Dessauer, Streit, 19-20). Lenk setzt dem noch Veröffentlichungen des Ökonomen Johann Beckmann 1777 und (vom selben Autor) 1806 als früheste technikphilosophische Abhandlungen voraus (vgl. Lenk, Technik, 14-15). Die umfassendste Auseinandersetzung mit dem weltkonstitutiven Charaker der Technik findet sich in unserem Jahrhundert dann bekanntlich bei Martin Heidegger, aber auch bei Arnold Gehlen und - als Rationalitätsanalyse - bei Max Weber. 
der Technik in der Moderne ist die Voraussetzung für die Geburt des infrage stehenden dynamischen Mediums aus der Kombination mehrerer Einzelerfindungen dieser Zeit. Diesen Entwicklungsgang möchte ich im folgenden genauer skizzieren.

Die Möglichkeit der Bewegungswiedergabe basiert nun freilich zunächst auf zwei nichttechnischen Voraussetzungen, einer physiologischen und einer psychologischen Eigentümlichkeit der menschlichen Wahrnehmung, die (zumindest im ersteren Fall) schon bekannt waren, lange bevor der Gedanke an ihre Nutzung entstehen konnte. Es sind dies die Nachbildwirkung und der stroboskopische Effekt. Die Nachbildwirkung beruht auf der Trägheit der Netzhaut und läßt schnell aufeinanderfolgende Bewegungszustände als zusammenhängende Kette erscheinen (etwa eine in der Dunkelheit geschwungene Lichtquelle, die dann nicht als kreisender Punkt, sondern als leuchtender Kreis erscheint). Der stroboskopische Effekt wiederum besteht in der psychisch begründeten Neigung, stehende Einzelphasen von Bewegungszuständen zum Bewegungseindruck zu verknüpfen. Die Nachbildwirkung ist bereits seit der Antike bekannt ${ }^{69}$ und wird später dann, um $150 \mathrm{n}$. Chr., von Ibn al Haitam beschrieben $^{70}$. Die Entdeckung des stroboskopischen Effekts unterliegt dem Streit: Einige Autoren wollen sie in den recht unklaren Zeilen des Lucretius Carus entdecken ${ }^{71}$, andere erst in den expliziten Versuchen Plateaus und Stampfers hierzu ${ }^{72}$.

Wie immer dieser Streit auch zu entscheiden wäre - es bleibt unhintergehbar, daß erst im 19. Jahrhundert mit Plateau und Stampfer ein Stadium erreicht ist, das eine Nutzung beider Effekte ermöglicht. Plateau wie auch Stampfer nämlich setzen ihre physiologisch-psychologischen Erkenntnisse technisch in Apparaturen um. Plateau konstruiert 1832 einen Apparat, der Bewegungsillusion erzeugt, und legt 1836 das ,Gesetz' des stroboskopischen Effekts fest; Stampfer konstruiert ebenfalls 1832 einen Apparat, den er denn auch „Stroboskop" nennt. Vorstudien dazu hatten Faraday und Roget angestellt, die Plateau und Stampfer bekannt waren ${ }^{73}$. Bei ihren (und ihres Zeitgenossen William Horner) Apparaten handelt es sich um geschlitzte Scheiben (bei Horner: Trommeln), die, in Rotation versetzt, mit Hilfe von Phasenbildern den Eindruck eines Bewegungsablaufs bewirken ${ }^{74}$. Im Gegensatz zu Schiebebildern und Nebelbildern, welche auf mechanischem Wege Bewegung erzeugten, wird hier eine Illusion echter Bewegung hervorgerufen ${ }^{75}$. Die Entwicklung einer Möglichkeit

${ }_{70}^{69}$ vgl. dazu: Ramsaye, Million, 2

70 vgl. Ceram, Archäologie, 13, 20; Zglinicki, Weg 1, 108-112

71 so etwa Zglinicki, Weg 1, 34

72 so etwa bei: Traub, Als man anfing, $12-13$

${ }^{73}$ vgl. Traub, Als man anfing, 12-13; Ceram, Archäologie, 16-17; zu Roget auch: Ramsaye, Million, 10-11

${ }^{74}$ Plateau nannte seine Erfindung Phenakistiskop, Stampfer, wie erwähnt, Stroboskop. Horner erfand 1833 das ,Lebensrad'. (vgl. Zglinicki, Weg 1, 116-119) Zglinicki erwähnt in diesem Zusammenhang beständig auch das Thaumatrop (Zglinicki, Weg 1, 109-111; ders. Wiege, 42), eine rotierende Scheibe, die auf einer Seite etwa einen Vogel, auf der anderen einen Käfig zeigt und durch Drehung den Eindruck erzeugt, der Vogel befinde sich im Käfig. Da das Thaumatrop jedoch nur die Nachbildwirkung, nicht jedoch den stroboskopischen Effekt nutzt, d.h. nicht auf Bewegungsillusion abstellt, ist es für die infrage stehende Entwicklungsreihe irrelevant.

${ }^{75}$ Schiebebilder in der laterna magica, wie sie schon früh bekannt waren, konnten zwar mit Hilfe von Glasdiapositiven einen Wagen vor einer Landschaft vorbeifahren lassen, doch drehten sich dessen Räder nicht. Die Nebelbilder erzeugten Bewegung durch Projektion auf Rauch, konnten jedoch keinen Bewegungsablauf zeigen. (Vgl. dazu: Zglinicki, Weg 1, 63-75; Zglinicki, Wiege, 39-40) 
der Bewegungswiedergabe steht so zeitlich vor der der Bewegungsaufzeichnung. Die bewegten Figuren Plateaus und Stampfers sind daher noch gezeichnet. Trotzdem kann festgestellt werden, daß mit der Nutzbarmachung der Nachbildwirkung und des stroboskopischen Effekts durch Plateau, Stampfer und Horner zu Beginn des 19. Jahrhunderts die technische Entstehungsgeschichte des Films einsetzt.

Dem voraus gehen freilich die Entdeckungen der beiden Projektionsmöglichkeiten: durch die camera obscura auf einen potentiellen Bildträger und durch die laterna magica auf eine reflektierende Fläche, etwa eine weiße Wand. Eine erste, noch rudimentäre Beschreibung der camera obscura findet sich bereits bei Ibn al Haitam (1038), präziser dann bei seinem späteren Kommentator Kamal al Din (zu Beginn des 14. Jahrhunderts ${ }^{76}$. Obgleich Roger Bacon im 13. Jahrhundert die eigentliche ,Erfindung' (im Sinne der Konstruktion) der camera zugeschrieben wird, kann erst von Leonardo da Vinci mit Sicherheit gesagt werden, daß er sie verwendet hat ${ }^{7}$. Durch Johann Baptist Porta findet sie im 16. Jahrhundert größere Verbreitung ${ }^{78}$. Die camera obscura steht noch auf der Ebene einer prinzipiellen Entdeckung, d.h. mit ihr ist ein wichtiges Prinzip, die Projektionsmöglichkeit, gefunden. Die technische Perfektionierung durch Linsen, und insbesondere die Erfindung eines geeigneten Bildträgers wie der fotografischen Platte, fehlen ihr jedoch bis ins 19. Jahrhundert hinein, so daß sie zunächst nur die Qualität eines Hilfsmittels hat. Sie ist in diesem Stadium den gerasterten Glasplatten ähnlich, die den Zeichnern zur Erfassung und zum Studium perspektivischer Verkürzung und der Proportionen dienten. Entsprechend bedarf die camera zu Leonardos Zeiten des Zeichners, wenn das von ihr projizierte Bild fixiert werden soll; es sind hier noch dessen individuelle Linienführung und das künstlerische Geschick, welche das Bild prägen. Der Charakter der camera ist bis zur Erfindung der Fotografie ein rein instrumenteller; sie ist noch frühe Technik im Sinne einer (mit einer Paraphrase Gehlen'scher Begrifflichkeit gesagt) Organergänzung ${ }^{79}$.

Etwas anders liegt der Fall bei der laterna magica. Eine erste Beschreibung dieser Projektionsvorrichtung liefert Athanasius Kircher in seiner „Ars magna lucis et umbrae", jedoch noch nicht in der ersten Auflage seines Werks 1646, sondern in dessen zweiter 1671. Die eigentliche Erfindung der laterna soll daher Zglinicki zufolge dem Physiker Christian Huygens zu verdanken $\operatorname{sein}^{80}$. Die laterna magica wird nun nicht von Zeichnern zur Herstellung andersartiger künstlerischer Medien (etwa Tafelbilder) benutzt, sondern von Projektionskünstlern verschiedenster Couleur zu ganz anderen Zwecken. Ihr Name: Zauberlaterne, gibt dabei treffend viele dieser Zwecke

76

77 vgl. Zglinicki, Weg 1, 45-46

77 so Zglinicki, Weg 1, 47

78 vgl. Zglinicki, Weg 1, 47-49

79 Gehlen versucht bekanntlich, das Werden der Technik anthropologisch zu reflektieren und spricht Technik als eine kompensatorische Veranstaltung des „Mängelwesens Mensch“ an, die dessen Instinktunsicherheit und Umweltunangepaßtheit ausgleichen soll. Frühe, vorindustrielle Technik versteht er so als Organersatz und Organentlastung. Mit dem Begriff der Organüberbietung deutet sich bei ihm dann jener qualitative Sprung an, der in der industriellen Technik vollzogen ist: der werkzeughafte Charakter wird zunehmend überstiegen und schlägt in eine exponentiell weltverändernde Eigendynamik um. (vgl. Gehlen, Technik, 93-94; auch: Gehlen, Der Mensch, 33-42, 60-64, 385-399)

${ }^{80}$ vgl. Zglinicki, Weg $1,55-56$ 
wieder. Athanasius Kircher etwa benützte die laterna (neben Versuchen mit Schriftprojektionen), um damit seine Freunde im gegenüberliegenden Haus zu erschrekken, indem er nachts Bilder auf dessen Papierfenster projizierte ${ }^{81}$. Andere Zeitgenossen und Nachfahren Kirchers, wie etwa Schröpfer, erzeugten damit Geistererscheinungen, eine Kunst, die sich bis zu Robertsons Phantasmagorien im 17./18. $\mathrm{J}$ ahrhundert hielt ${ }^{82}$. In all diesen Fällen wird deutlich, daß sich mit der laterna eine neue, nämlich technisch-mediale Qualität ankündigt ${ }^{83}$. Die Gespenstervorführungen sind ebenso wie spätere pädagogische Verzweckungen der laterna in ihrer Wesensstruktur geprägt durch technisch ermöglichte Projektion. Was auf der Wand oder dem aus der Räucherpfanne aufsteigenden Nebel erscheint, ist nicht mehr die Zeichnung auf Glas, sondern ihre projizierte Gestalt, die ihr eine andere Eigenart und damit eine veränderte Wirkung verleiht. Mit der laterna deutet sich erstmals an, was im 19. Jahrhundert auf dem Weg zum Film dann durchgeführt wird: daß der Einfluß der Technik auf die darstellenden Künste die künstlerische Darstellung in ihrem Wesen umzuformen beginnt. Der Einfluß der Technik ist hier nicht mehr nur instrumentell im Sinne des Hilfsmittels, bei dem das dieses Mittel benützende Subjekt die einzig wesensprägende Leistung vollbringt, sondern konstitutiv für das Wesen des künstlerischen Produkts. Nicht mehr der das Instrument führende ,Handwerker' allein schafft hier die eigentliche Qualität, sondern das neuartige Zauberding, das bereits ein $\mathrm{Me}$ dium ist, konstituiert diese Qualität entscheidend mit und ist als solches eine Botschaft. ${ }^{84}$ Dieser Einfluß des technischen Instrumentariums auf die Kunstproduktion und die darin tätige Kreativität des Subjekts, die den handwerklichen Kunstbegriff aufzulösen beginnt, wird später bei Fotografie und Film besonders deutlich und treibt spezifische Ressentiments gegen diese Medien aus sich hervor. Die Produkte von Fotografie und Film nämlich gelten aufgrund ihrer technischen Herstellungsform nicht mehr als, eigentliche' Kunstrealisationen, sondern als minder zu bewertende Erzeugnisse, denen die Produkte einer noch handwerklichen Kreativität kontrastiv und korrektiv gegenübergestellt werden (vgl. dazu auch 4.3. und 4.6.). Schon mit der laterna nun scheint die technisch bedingte Veränderung, die in der angedeuteten Weise später moniert werden wird, historisch auf.

81 vgl. Zglinicki, Weg 1, 59

82 vgl. Zglinicki, Wiege, 38-39

${ }^{83}$ Der Verweis darauf, daß Vorläufer der hier genannten magischen Darbietungen auch schon mit der camera obscura vollzogen wurden - in einem verdunkelten Zimmer wurden Szenen von draußen auf die Wand projiziert - fällt hier nicht wesentlich ins Gewicht. Erst mit der laterna nämlich ist ein technischer Stand erreicht, der diese Projektionskunst flexibel verfügbar, d.h. unabhängig von Wetterlage, Ort und parallel agierenden Darstellern macht. (vgl. dazu auch: Zglinicki, Weg 1, 50-51) Zglinicki sieht die genannte Verwendungsweise der camera denn auch erst mit der laterna zu ihrer eigentlichen Praktikabilität gelangt.

${ }^{84}$ Mit diesem Verweis sei Ceram widersprochen, der die laterna magica noch in den Bereich der Mechanik einordnet und ihren technischen, medialen Charakter nicht anerkennen will (vgl. Ceram, Archäologie, 16). - Auch McLuhans Formulierung, daß das Medium die Botschaft sei, stimme ich jedoch nicht zu; sie ist zu absolut. Die Form einer Aussage prägt wohl das ,Wesen des Gehalts, ist aber nicht dessen ,Wesen'. So nimmt sich etwa der ,Zauberberg' von Thomas Mann als Roman anders aus denn als Film. Sein Gehalt aber läßt sich in beiden Formen finden; keineswegs liegen zwei völlig verschiedene Gehalte und Aussagen vor. Daher spreche ich davon, $\mathrm{da} B$ das Medium eine Botschaft, nicht aber die einzige sei. 
Im 19. Jahrhundert aber erst setzen die eigentlichen Entwicklungen ein, die dann den Film hervorbringen. Nachdem Plateau, Stampfer und Horner begonnen haben, Apparate für die technische Erzeugung von Bewegungsillusion zu bauen, folgt eine Fülle von Parallelexperimenten, Nebenentwicklungen und Erfindungen, die den Eindruck einer sich überschlagenden Suche nach der richtigen Lösung eines noch etwas diffusen Desiderats erweckt. Dieses Desiderat besteht darin, in irgendeiner Weise die Nachbildwirkung und den stroboskopischen Effekt technisch zu nutzen; in welcher Weise das jedoch geschehen soll - ob mit Phasenzeichnungen auf Papier oder auf Glas, ob durch Reihung solcher Bilder auf Scheiben, Bändern oder Abblätterstapeln, ob in Geräten zum Hineinsehen oder durch Projektion - ist nicht so schnell geklärt. Vielfältigste Formen und Möglichkeiten werden durchprobiert und wieder verlassen; die Geschwindigkeit, mit der Patente angemeldet werden und patentierte Geräte als veraltet, überholt und uninteressant gelten, läßt sich bereits vergleichen mit der gegenwärtigen, sich überstürzenden Entwicklung im Bereich der Computertechnologie. Versucht man rückblickend eine Generallinie herauszupräparieren, so kann diese in der (Weiter)entwicklung der camera obscura durch insbesondere geeignete Bildträger und Objektive zur fotografischen Kamera einerseits, und der laterna magica zum Filmprojektor andererseits gesehen werden.

Der Weg zur Fotografie beginnt, wenn man so will, 1727 mit der Entdeckung Johann Heinrich Schulzes, daß Gegenstände sich auf einer Mischung aus Kreideschlamm und Silbernitrat selber zur Abbildung bringen ${ }^{85}$. Diese Abbildung ist freilich noch unbeständig; ebenso sind dies Thomas Wedgewoods Papierbilder von 1802. Gemeinhin nennt man daher Daguerres ,Daguerrotypien' als den eigentlichen Beginn der Fotografie und verweist auf die Vorleistungen Niépces, der 1822 den ersten "Bildeindruck" auf lichtempfindlichen Schichten in der camera obscura erhalten haben soll ${ }^{86}$. Daguerre gelingt es 1839 , seine Erfindung für eine bescheidene Pension an den französischen Staat zu verkaufen und damit seine Wirkung zu sichern. Die fotografischen Abbildungen, die er herstellt, sind noch einmalig, nicht reproduzierbar und keine Fotos im heutigen Sinn. Genau besehen ist sein Verfahren bereits veraltet, als der Staat es kauft. Zur selben Zeit nämlich fertigt Hippolyte Bayard bereits Papierabzüge an und macht einen bedeutenden Schritt über Daguerres Metallplatten hinaus. Daguerres Liaision mit dem Staat aber verhindert zunächst, daß Bayards Erfindung zur Wirkung gelangt ${ }^{87}$. Erst über Henry Fox Talbots Analogerfindung eines Verfahrens, das nun beliebig viele Papierabzüge ermöglicht, wird die Reproduktion auf Papier ab 1841 gebräuchlich. Das Negativ wird bei Talbot noch auf transparentem Papier fixiert; kurze Zeit später verwendet man dafür Glasplatten ${ }^{88}$. Die Ent-

${ }^{85}$ Auf Schulze verweist etwa: Ceram, Archäologie, 73; wichtig nimmt ihn auch Zglinicki, Weg 1, 143. Die Versuche Schulzes können freilich nur als allergrundsätzlichste Wurzel der Fotografie gelten; er arbeitet ja noch ohne Kamera und entdeckt im Grunde nicht mehr als die Lichtempfindlichkeit seiner Kreideschlamm-Silbernitrat-Mischung.

${ }_{86}$ vgl. Zglinicki, Weg 1, 147

87 vgl. Ceram, Archäologie, 75; mit Bayards Namen verbindet sich eines der vielen tragischen Erfinderschicksale. Seine Erfindung wurde zu seinen Lebzeiten nie gewürdigt - die einzige Auszeichnung, die er erhielt, wurde ihm für treue Dienste als Bürovorsteher im Finanzministerium zuteil.

88 vgl. Zglinicki, Weg 1, 150 
wicklung eines Glasdiapositivs weist in diesem Zusammenhang auf die Idee der Projektion ${ }^{89}$.

Etwa zwischen 1840 und 1870 liegen dann die Jahre der ,Reifung,, d.h. der Ausweitung, Verbesserung und Präzisierung der fotografischen Möglichkeiten. Auf dem Sektor der Kamera werden insbesondere leistungsstärkere Objektive geschaffen; deren wichtigstes ist das nach seinem Erfinder benannte Petzval-Objektiv, das nicht nur für Aufnahmen, sondern auch für die Projektion verwendbar ist ${ }^{90}$. Der Übergang vom nassen Kollodiumverfahren, bei welchem die nasse Platte sofort nach der Herstellung belichtet werden mußte, zum Trockenschichtverfahren ${ }^{91}$ bedeutet einen ersten Schritt zur Abkehr von der Beschränkung der Fotografie auf Experten. Trokkenschicht-Bildträger können vorproduziert und an Konsumenten verkauft werden, die das Herstellungsverfahren nicht mehr zu kennen brauchen, um mit den Bildträgern arbeiten zu können. Um etwa 1871 wird die Trockenschichtplatte zum fertigen Handelsartikel. Die ,Erfindung' des Rollfilms, dessen Frühformen schon 1854/55 mit gerollten Papiernegativen angesetzt werden können ${ }^{92}$, wird auf der Basis der Entdeckung des Zelluloids als Schichtträger für lichtempfindliche Emulsionen von Goodwin im Prinzip zuende gebracht; George Eastman sorgt dann durch ,Nacherfindung" (Ceram) für die Verbreitung dieser Form ${ }^{93}$. Gerade letzterer ist es, der die Bewegung in Richtung einer breitenwirksamen Popularisierung der Fotografie vorantreibt. Eastmans relativ unproblematisch zu handhabende Kamera, die lange Zeit als die perfekteste gilt ${ }^{44}$, gibt im Prinzip jedem die Möglichkeit, Fotograf zu werden. Eastmans Kodak-Company wirbt entsprechend mit der Simplizität des Vorgangs: „You press the button - we do the rest.“" ${ }^{\text {95 }}$

Zwei Momente sind im Zusammenhang dieser Entwicklung besonders festzuhalten: Die Veränderung künstlerischer (Re-)Produktion von Wirklichkeit durch technische (Re-)Produktionsmittel und die Massenwirksamkeit derselben durch Vereinfachung des Verfahrens mit Hilfe technischer Perfektionierung. Hatte die darstellende Kunst seit der frühen Renaissance in vielen ihrer Bereiche großen Wert auf ,Wirklichkeitsnähe' gelegt und war die möglichst treue Reproduktion immer wieder eines der Zentralthemen künstlerischen Forschens gewesen, so beginnt die werdende Fotografie diese Aufgabe zwischen 1840 und 1870 rasch für sich zu requirieren. Schon zu Daguerres Zeit wird beispielweise die Portraitfotografie ein hervorragendes Aufgabengebiet der neuen, freilich noch nicht als solche anerkannten Kunst. Die bildende Kunst muß sich mit dem entstandenen Potential auseinandersetzen, und gerade die genannten Jahre lassen eine Abgrenzung von der Fotografie (oft explizit, wie bei Turners ,antifotografischen' Landschaften) und bewußte Eroberung nicht(abbildungs-)realistischer Regionen erkennen ${ }^{96}$. Mit der Fotografie wiederum sind

${ }^{89}$ vgl. Zglinicki, Weg 1, 150-151

90 vgl. Zglinicki, Weg 1, 150

91 vgl. Zglinicki, Weg 1, 151-153

92 vgl. Zglinicki, Weg 1, 154

93 vgl. Ceram, Archäologie, 83; Zglinicki, Weg 1, 156-158

${ }^{94} \mathrm{vgl}$. Zglinicki, Weg 1, 160-161

95 Ceram, Archäologie, 79, 88

${ }^{96}$ Auf die Auseinandersetzung des Impressionismus mit der Fotografie sei hier ebenso verwiesen wie auf Kubismus und Futurismus. Das Spiel der Impressionisten mit Licht und Wahrnehmungsweisen ist bekannt; Monets Experimente mit gemalten Abblätterbüchlein liegen auf 
Möglichkeiten einer zunehmend exzessiven Fixierung und Vervielfältigung des Sichtbaren geschaffen. Größere Lichtempfindlichkeit der Bildträger erlaubt es, gestellte Aufnahmen mit Belichtungszeiten bis zu 30 Minuten $^{97}$ zunehmend durch Schnappschüsse und deren betontere Dynamik zu ersetzen. Die so entstehende Momentfotografie ermöglicht nicht nur das Studium in actu erhaschter Bewegtheit, sondern auch die ,Dokumentation' kleinster Zeiteinheiten. Dokumentaristische Bildbände entstehen daher schnell; der ,Schnappschuß" verhilft zum Einfangen auch all jener Momente, die sich unbeobachtet glaubten (und gilt daher als besonders wirklichkeitsecht ${ }^{98}$ ). Die Reproduktion auf Papier schreibt fort, was schon mit den Druckgraphiken und den englischen Print shops begonnen hatte: eine Bebilderung der Welt mit Hilfe technischer Mittel. - Die Verfügbarkeit für jedermann durch tragbare, leicht zu handhabende Kameras und ,trockene' Filme sorgt für eine explosionsartige Verbreitung der neuen Kunst - und damit in gewisser Weise auch für deren ,Demokratisierung (Monaco) ${ }^{99}$. Obgleich sie jedem „Kretin“ eine „indiskrete Durchleuchtung der Natur, der Gesellschaft und aller privaten Beziehungen“ ${ }^{100}$ erlaubt, verringert sie wie bei keiner anderen Kunst die Distanz zwischen dem Experten und dem Laien (bzw. dem Künstler und dem Dilettanten).

Die skizzierte Entwicklung verhilft nun zwar dazu, die sichtbare Welt auf einem Bildträger einzufangen, und dies mit immer weniger Gerätschaften und Umständen zu tun, liefert aber nur ein starres Abbild. Das Problem, der Bewegung auf den Grund zu gehen, bleibt eine Herausforderung, der sich auf fotografischem Gebiet besonders Eadweard Muybridge und Etienne Marey stellen. Muybridge gelingt es, nach langen Versuchen, Phasenaufnahmen galoppierender Pferde zu machen, wobei die Phasen noch so weit auseinanderliegen, da $B$ gemeinhin von Reihenfotografie gesprochen wird. Die Reihenfotografie bringt Muybridge zu Ruhm, obgleich er lediglich der Ausführende, nicht aber der Erfinder war ${ }^{101}$. Hatte Muybridge noch mit

dieser Linie. Duchamps „Nu descendant un escalier“ wirkt bereits wie eine malerisch-strukturelle Umsetzung der Reihenfotografie (dazu mehr unten). Der Futurismus schließlich kennt Bewegungsdarstellungen, die mit eben den Verwaschungen operieren, die allzu rasche Bewegung auf einem Foto hinterläßt. (vgl. dazu auch: Monaco, Film verstehen, 30-37)

vgl. Eder, Fotografie, 611. Die angegebene Zeit gilt für Daguerrotypien. Talbots Verfahren hatte die Zeit schon auf 3 Minuten gesenkt; beim nassen Kollodiumverfahren betrug die Belichtungszeit nur noch 10 Sekunden; Bromsilbergelatine von 1878 drückte die Zeit nochmals auf 1 bis $1 / 200$ Sekunde.

98 Echtheit scheint gerade in der frühen, noch stark an künstlerischem Realismus orientierten Phase der Fotografie jenes Kriterium abzugeben, das in der bildenden Kunst einst Originalität war. - Der Dokumentarismus setzt sich schon sehr bald fest; als einer der ersten Dokumentaristen kann Matthew Brady genannt werden, der Fotos des amerikanischen Bürgerkriegs machte. Auf die Neigung der Dokumentaristen, ,Realität' vorzüglich im Erschreckenden und Elenden zu suchen, verweist nicht ohne treffende Ironie Ceram, Archäologie, 79.

${ }_{100}$ vgl. dazu: Monaco, Film verstehen, 29, 32

100 Ceram, Archäologie, 79

101 Ausgangspunkt des Unterfangens war eine Wette des Governors Leland Stanford mit James Keene und Frederick MacCrellish darum, ob ein galoppierendes Pferd zu irgendeinem Zeitpunkt alle vier Beine in der Luft habe oder nicht. Stanford wollte die Frage durch Muybridges Fotografie beantworten lassen. Schon die Idee zur Kamerareihe aber hatte Stanford, nicht Muybridge. Die elektrischen Mechanismen zur intervallweisen Auslösung der Kameras entwikkelte John Isaacs, ein Ingenieur, der, wie Ramsaye feststellt, Muybridges Ruhm begründete, ohne selbst je im Zusammenhang mit der Reihenfotografie genannt zu werden. (vgl. hierzu: Ramsaye, Million, 22, 34, 35-36) 
Kamerareihen gearbeitet, so versucht Marey, seine Bildfolgen mit Hilfe eines entsprechenden Mechanismus in einer Kamera zu bekommen. Er konstruiert mit einem sogenannten fotografischen Revolver und einer fotografischen Flinte Kameras, die einmal mit beweglichen Negativplatten, einmal mit einer Platte, auf welcher die Phasen nebeneinander aufgezeichnet werden, arbeiten ${ }^{102}$. Auch ein erster Mechanismus für den Filmtransport in einer Kamera stammt von ihm ${ }^{103}$.

Damit - mit Momentfotografie und Reihenfotografie - ist die Möglichkeit geschaffen, zur Erzeugung von Bewegungsillusion statt gezeichneten Phasenbildern fotografische Phasenaufnahmen zu verwenden. Deren Fixierung geschieht lange Zeit auf Glas. Experimente mit der Projektion von gezeichneten Phasenbildern hat bereits 1853 Franz von Uchatius durchgeführt. Ihm schreibt man daher die erste bedeutsame Weiterentwicklung der laterna magica zum Projektor für bewegte Bilder zu. Sein Gedanke war einfach: Er kombinierte die rotierende Scheibe des Zoeotrops von Horner mit der laterna ${ }^{104}$. Plateau äußert dann 1849 den Einfall, die Zeichnungen durch Fotografien zu ersetzen ${ }^{105}$. Henry Heyl macht die Idee 1870 zur Tat und projiziert (noch gestellte) Phasenaufnahmen, ohne freilich zu sehr überzeugenden Ergebnissen zu kommen. Auf zufriedenstellendere Weise gelingt dies 1879 Muybridge, der mit seiner Reihenfotografie über enger beieinanderliegende Phasen und damit über eine günstigere Ausgangsposition verfügt. Er projiziert seine Bilder von Glasdiapositiven, die auf eine rotierende Scheibe montiert sind ${ }^{106}$. Anschütz führt dieses Grundprinzip dann $1887 \mathrm{zu}$ einem kommerziell nutzbaren Gerät weiter: dem Elektrotachyskop, einer Art Guckkasten, in welchem gegen Entgelt kurze bewegte Szenen zu sehen sind. Seine Schöpfung wird auf der Weltausstellung 1893 in Chicago gezeigt $^{107}$. Mit der Verwirklichung in Muybridges Version des Zoopraxiskops und in Anschütz' Elektrotachyskop sind die beiden Möglichkeiten der bewegten Rezeption von Phasenaufnahmen auf Glasdiapositiven ausgeschöpft. Die entscheidende Weiterentwicklung geschieht dann andernorts durch den Einsatz von Zelluloidfilmen, wobei die grundsätzlichen Alternativen von Projektion und Guckkastensystem erhalten bleiben.

Eine Projektionsvorrichtung für Filme - das Praxinoskop - erfindet zunächst Emile Reynaud, der anfangs mit gezeichneten Bildern auf Papierfilmen, ab 1888 dann auf Zelluloid, arbeitet ${ }^{108}$. Um die Zeichnungen jedoch durch Fotografien ersetzen zu können, muß erst eine entsprechende Kamera für Phasenaufnahmen auf Filmen geschaffen werden. Das technische Problem, das sich dabei stellt, ist dasselbe, das später bei der Projektion solcher Filme auftaucht: will man ein präzises Abbild erhalten, so ist es unerläßlich, den Film während der Belichtung kurz anzuhalten.

102 vgl. Zglinicki, Weg 1,180

103 vgl. Zglinicki, Weg 1, 183; Marey verwendete dabei noch unperforierte Papierfilme. Er soll jedoch bereits 1889 auf Zelluloid umgestellt und 1892 bereits eine Projektionsvorrichtung für solcherart aufgenommene Filme konstruiert haben. (Zglinicki, Weg 1, 184-185)

104 vgl. Zglinicki, Weg 1, 131- 134

105 vgl. Ceram, Archäologie, 80

106 vgl. Ceram, Archäologie, 81; Ramsaye zufolge stammt auch dieser Gedanke nicht von Muybridge selbst, sondern von dem französichen Maler Meissonier, der Muybridge während eines Frankreichaufenthalts dazu angeregt haben soll. (vgl. Ramsaye, Million, 39-41)

107 vgl. Zglinicki, Weg 1, 189

108 vgl. Zglinicki, Weg 1, 135-139 
Kameras hierzu werden, neben derjenigen Mareys, in rascher Folge von verschiedensten Personen gebaut. Das Labor Edisons soll eine entsprechende Kamera 1888 fertiggestellt haben ${ }^{109}$. $\mathrm{Zu}$ den ersten, die in der Bewältigung des gesamten Problembereichs am weitesten waren, zählt jedoch Louis Le Prince. In einer Patentschrift beschreibt er eine getrennte Aufnahme- und Wiedergabevorrichtung mit mehreren Objektiven. 1889 experimentiert er mit einer Kamera mit nur einem Objektiv und mit Zelluloidfilm. Zur selben Zeit beginnt er eine Konstruktion, die Perforation und Malteserkreuzschaltung vorsieht. 1890 stellt er erfolgreich einen Film her und führt ihn einigen Herren in der Pariser Oper vor. Dann verschwindet Le Prince auf rätselhafte Weise ${ }^{110}$.

Zur selben Zeit baut Laurie Dickson bei Edison eine Kamera für perforierten Film. 1889 soll Dickson auch Filme projiziert haben, doch ist diese Nachricht umstritten. Ein Zeitungsausschnitt von 1890 allerdings belegt eine Projektion für dieses $\mathrm{Jahr}^{111}$. Die Konstruktion des Kinetoskops, eines Guckkastens, in welchem ein zu einer Endlosschleife geklebter Film vorgeführt wird, verzögert bei Edison ab 1891 dann die Fortentwicklung der Projektionsmöglichkeiten ${ }^{112}$. Stattdessen arbeiten Otway und Gray Latham, die ins Kinetoskop-Geschäft einsteigen und ein KinetoskopTheater eröffnen, mit Eugene Lauste erfolgreich an der Entwicklung eines Projektors und einer Kamera. Am 21. April 1895 veranstalten sie eine öffentliche Projektion. Sie sind freilich nicht die Einzigen: in den beiden Jahren 1894/95 überschlagen sich die Bemühungen, Filme zu projizieren und werden parallel an mehreren Orten der Welt Projektoren und Kameras entwickelt. Le Roy soll schon im Februar 1894, allerdings nicht öffentlich, projiziert haben ${ }^{113}$; am 22. März 1895 findet die erste Vorführung der Gebrüder Lumière (noch als geschlossene Veranstaltung) statt; im September des Jahres stellt Armat seinen ,stop-motion-mechanism' in einem fremden Projektor vor und gibt so eine Lösung des Problems, jedes Bild bei der Projektion kurz anzuhalten ${ }^{114}$; am 1. November treten die Skladanowkys mit ihrem Doppelprojektor an die Öffentlichkeit ${ }^{115}$; am 1 . Dezember schließlich findet die heute als ent-

109 vgl. Ceram, Archäologie, 84

110 vgl. Zglinicki, Weg 1, 194-196; Le Prince unternimmt im August 1890 eine geschäftliche Reise nach Frankreich, auf der er seine gesamten Apparate und Zeichnungen mit sich führt. Als er im Dezember von Dijon mit dem Zug abreist, verschwindet er, ohne daß polizeiliche Nachforschungen je den Grund dafür zu erheben vermögen.

111 vgl. Fulton, Motion, 6; dort findet sich auch ein Abdruck dieses Zeitungsausschnitts. Im selben Jahr 1889 baut auch Friese-Greene eine Filmkamera; ob er projiziert hat, ist unklar. (vgl. Fulton, Motion, 10)

${ }^{112}$ Die Erwägungen, die Edisons Engagement in der Projektorentwicklung verzögert haben, sollen ökonomischer Natur gewesen sein: Kinetoskope brauche man eine ganze Reihe, um genug Möglichkeiten für mehrere Betrachter zu schaffen, Projektoren hingegen erlaubten das Zusehen sehr vieler Menschen, so daß aus der Perspektive des Apparatebaus das Kinetoskop profitabler erscheine (vgl. Ramsaye, Million, 119). Interessant dabei ist, daß für Edison weder der Gesichtspunkt der Filmproduktion - obwohl er Filme produziert und sogar exportiert hat - , noch derjenige des Vorführgeschäfts - in das die Lathams einstiegen - relevant schien.

113 So Ceram, Archäologie, 145

$114 \mathrm{vgl}$. Fulton, Motion, 11

115 Um Skladanowsky und Skladanowsky wurde - nicht nur zur Zeit des Nationalsozialismus - gerne Aufhebens gemacht: bot doch ihre Vorführung vor den Lumières scheinbar die Chance, die Priorität der Filmentwicklung für Deutschland zu requirieren. Nicht nur angesichts der amerikanischen Entwicklungen wirkt dieses Unterfangen etwas lächerlich - tatsächlich 
scheidend betrachtete Projektion der Lumières im Grand Café am Boulevard des Capucines gegen Eintrittsgeld statt ${ }^{116} ; 1896$ baut Robert Paul in England einen Projektor und führt ihn im Februar am Finsbury Technical College vor ${ }^{117}$. Lumières Gerät aber setzt sich durch; nicht zuletzt aufgrund der Einfachheit seiner Konstruktion: Ihr Handkurbelapparat ist unabhängig von Elektrizität, sowohl bei der Aufnahme, als auch bei der Wiedergabe; er ist leicht tragbar und als Kamera wie auch als Projektor zu gebrauchen ${ }^{118}$.

Das neue Medium ist damit geworden. Der skizzierte Entwicklungsgang dokumentiert, daß es ein spezifisch technisches und dynamisches Medium ist. Die Geburt des Films läuft ausschließlich über die Erfindung und Perfektionierung der Apparate sowie der Bildträger; er selbst ist ohne Technik nicht denkbar. Der zugehörige Diskurs ist dementsprechend ein instrumentell-,praktikbezogener', nicht aber ein ästhetischer. Die zu lösenden Probleme sind technischer Natur und die Erfinder des Films sind zunächst auch nur an dieser technischen Seite interessiert. Aus der hohen Geschwindigkeit der gezeigten Entwicklung, aus den Mehrfach- und Parallelerfindungen sowie aus der kombinatorischen Schaffung des Films daraus erhellt zugleich die Wandlung der Erfindungsprozesse unter den Bedingungen der modernen, industriellen Technik, die eben auch die Entstehung des Films nicht unbeeinflußt läßt. An die Stelle der Pioniererfindung, die noch die paradigmenstürzende Tat eines genialen Einzelnen ist und sich daher durch eine besonders hohe „Sprungweite“ (Stork) auszeichnet, treten allmählich die Entwicklungserfindung und die Gruppenerfindung, die Bestehendes weiterformen bzw. aus gegebenem Stand etwas Variiert-Neues schaffen $^{119}$. Häufig geschieht das dann auch nicht mehr durch einen Einzelnen, sondern in arbeitsteiligen - und damit rationalisierten - Verfahren durch einen Stab. Aus dem ,Tinkerer', dem einfallsreichen Bastler, wird der Laborleiter, der in geregelter Arbeitszeit mit anderen zusammen, die von ihm oder dem Träger des Labors ein festes Gehalt beziehen, etwas erarbeitet. An Werk und Biographie Edisons läßt sich dieser

wurden Kameras und Projektoren in den genannten Jahren an mehreren Orten der Welt parallel und unabhängig voneinander entwickelt. (vgl. zum Prioritätenstreit in der Filmgeschichte stellvertretend für andere: Niessen, Der „Film“, dagegen: Traub, Als man anfing, 38-41, Ceram, Archäologie, 146-148)

116 In einer rückwärtigen Extrapolation betrachtet man Kommerzialität und Öffentlichkeitsbezogenheit als entscheidende Ingredienzien einer Definition von Film. (vgl. dazu auch: Gregor/Patalas, Geschichte 1, 11)

117 vgl. Fulton, Motion, 9

118 So Wright, der anstelle jedes Prioritätenstreits pragmatisch nach den Gründen der praktischen Wirksamkeit einer Erfindung fragt. (vgl. Wright, View, 6)

119 vgl. zur Veränderung der Erfindungsprozesse: Dessauer, Streit, bes. 168-169; Stork, Einführung, 5-9, 29; Dessauer weist der Pioniererfindung den Zug der genialischen Einzeltat zu, die mit dem Signum des Persönlichen ausgestattet und ,ihrer Zeit meist voraus' ist. Er unterscheidet davon jedoch dann nicht die Gruppenerfindung, sondern die „Entwicklungserfindung“, die er in der Nähe zur "Konstruktion“ ansiedelt und deren Signifikanz darin liegt, daß sie aus Gegebenem fast organisch hervorwächst. Sie entsteht Dessauer zufolge aus der ,Reife der Zeit', d.h. sie wird notwendig gemacht; wer sie macht, ist zufällig. Diese Unterscheidung liegt begründet in Dessauers platonisierender Vorstellung der Vorgebildetheit einer Erfindung im Naturzusammenhang: „Der Kosmos enthält außer den fertig gestalteten (...) ,wirklichen“ Dingen einen unabsehbar großen Vorrat in ihrer Beschaffenheit bestimmter, aber (noch) nicht existierender Objekte (...) Wir nennen sie ,prästabilierte‘ Objekte. Es ist zu zeigen, daß erstmaliges technisches Gestalten, ,Erfinden', die gedankliche Gewinnung und manuell-werkzeugliche Ausarbeitung von Lösungsformen ist, die ,prästabiliert' sind.“ 
Übergang beinahe idealtypisch ablesen. Obwohl sein Name immer noch die Konnotation des Großen Erfinders bei sich führt, gründet Edison schon frühzeitig ein Labor und arbeitet mit einem fest angestellten Team. Während der Entwicklung einiger ,Erfindungen' ist er häufig gar nicht anwesend; er delegiert Aufgaben an seine Mitarbeiter. Dickson etwa wird von ihm regelrecht für die Erarbeitung der Apparate für den Film abgestellt. Am Beispiel der Reaktion Edisons auf Dicksons Experimente zur Projektion läßt sich auch zeigen, wie ,Erfindungen' nicht mehr quasi aus, genialer Stunde' entstehen, sondern wie sie rational geplant - oder eben auch gemäß rationaler Planung verzögert werden: Die ökonomischen Erwägungen zum Kinetoskop ließen es ungünstig erscheinen, allzurasch mit einem Projektor auf den Markt zu kommen. Gleichzeitig aber machen die Mehrfach- und Parallelerfindungen deutlich, $\mathrm{da} B$ hier eine Eigendynamik entsteht, die Prozesse gewissermaßen aus sich heraus vorantreibt ${ }^{120}$. Statt von der ,Erfindung' des Films in der Moderne wäre daher besser von seiner ,Entwicklung' zu sprechen.

Der geschilderte Entwicklungsgang nun zeigt, daß der Film in der Tat die Folge spezifischer Erfindungsprozesse und technischer Reflexionen der Moderne ist. Zwar gehen den bedeutsamen Vorerfindungen des 19. Jahrhunderts noch einzelne Apparaturen und Ideen voraus, doch läßt sich erst in diesem Jahrhundert die eigentliche, von zunehmender Beschleunigung gekennzeichnete Entwicklung erkennen, die nach 1840 überbordet. Erst die industrielle Technologie, die rational-methodische Weiterentwicklung vorhandener Apparate bzw. ihre Kombination und die im Hintergrund wirksame Veränderung der Erfindungsprozesse bringen am Ende des Jahrhunderts den Film hervor. Das technische Moment bestimmt dabei die Qualität des neuen Mediums in ganz grundsätzlicher Weise: Es macht sein Wesen aus. Kamera und Projektor sind nicht mehr nur einfach Werkzeuge. Sie bestimmen in entscheiciendem Maße mit, was mit ihrer Hilfe produziert wird. Eine gezielte Veränderung ihres Produkts läuft daher in der Regel über eine gezielte Veränderung der Aufnahme-, seltener der Wiedergabetechnik ${ }^{121}$. Der Film zeigt eine Realität, die sich nur technisch herstellen und vermitteln läßt; er ist - mehr noch als die laterna magica - technisches Medium. Zusammen mit der Fotografie verändert er die Welt der Bilder und damit das Bild der Welt.

Zum Wesen der industriellen Technik der Moderne aber gehört es, daß sie mit Ökonomie verklammert ist. Auch dies macht einen Teil ihrer Evolution, zumindest ein gut Teil des Tempos dieser Evolution aus. Entwickelt wird nicht nur, was rationale technologische Reflexion als möglich entdeckt, sondern auch und gerade, was sich zu profitabler ökonomischer Exploitation eignet. Film ist daher von Anbeginn an Ware - ebenso wie es die Apparate seiner Herstellung und Vermittlung sind. Diesem Aspekt soll im folgenden nachgegangen werden.

${ }^{120}$ Diese Eigendynamik scheint mir nicht notwendig im Sinne von Dessauers, prästabilierter Objektharmonie gesehen werden zu müssen. Statt seiner platonisierenden Vorstellung läßt sich die Frage auch durch Erhellung der Kommunikationsprozesse klären; selbst dort, wo die Lösung eines technischen Problems nicht mitgeteilt wurde, könnte doch die Zielrichtung bisheriger Entwicklungen auf dieses Problem hin kommuniziert worden sein.

${ }^{121}$ So war etwa die berühmte Szene bei Kerzenlicht in Kubricks „Barry Lyndon“, die ohne weitere Beleuchtung gedreht werden sollte, nur mit Hilfe eines Spezialobjektivs möglich, das die Zeiss-Werke ursprünglich für die NASA gebaut hatten. (vgl. dazu: Monaco, Film verstehen, 76) Technik determiniert hier die Ästhetik - bzw.: veränderte Ästhetik bedarf veränderter Technik. 


\subsection{Die Existenz des Films als Ware und Industrieprodukt}

Der Film entsteht unter den Bedingungen der Industriekultur und der Industriewirtschaft der Moderne. Es verwundert daher nicht, daß ihm der Warencharakter von seiner Entstehung an eigen ist. Filme als Werke wie auch sämtliche zu ihrer Herstellung nötigen Apparate sind Verkaufsprodukte; in nicht unbeträchtlichem Maße gilt das sogar für die an der Produktion von Filmen beteiligten Menschen (vgl. unten etwa zum Starsystem). Selbst die ganze Vorgeschichte des Films ist begleitet und bestimmt von ökonomischen Zwecksetzungen. Auch darin liegt ein Spezifikum der Moderne, in der der Film entsteht: Oft läßt erst ökonomische Rationabilität das, was die Kreativität des Menschen hervorzubringen in der Lage ist, ,rational', d.h. vernünftig, erscheinen und sorgt so für seine Realisierung. Dabei richtet sich die ökonomische Rationalität der Moderne vordringlich auf Innovation: Moderne Wirtschaft ist wesentlich ,Innovativwirtschaft' (W. Korff) und damit auf nicht nur quantitative Steigerung, sondern auch auf qualitativen Überstieg gerichtet. Die Produktion, die unter dem Profitprinzip zwar zu einer gewissen Beharrung auf Bewährtem (dessen Absatz gesichert ist) tendiert, wird derart zugleich einer Orientierung auf Neues, einem Wandel unterworfen. Sie findet sich rational zielgerichtet dynamisiert und bringt zusammen mit der Suche nach neuen Märkten ständig neue Waren hervor. Ein gut Teil der bei ihrer Verfügbarmachung ökonomisch betreuten Erzeugnisse des Menschen erwachsen dadurch oftmals einzig aus ökonomischem Kalkül und sind deshalb prinzipiell ökonomisch determiniert. Die spezifisch moderne Vereinnahmung profitabler Erfindungen und Erzeugnisse durch eine auf quantitatives und qualitatives Wachstum gerichtete, dynamisch-rationalisierte Ökonomie läßt sich nun ebenfalls im Bereich des Films und seiner Vorerfindungen entdecken. Die ökonomische Rationalisierung und Dynamisierung ist ein wesentliches Movens für die Entstehung und Entwicklung dieses Bereichs und bedingt einen raschen Wechsel der ,Produktpalette'.

Im Bereich der Fotografie setzt die ökonomische Verzweckung bereits mit der Daguerrotypie ein. Sie initiiert die Verwertung der neuen, Malerei mit Licht' im Portraitgeschäft und erlaubt „Tausenden von Durchschnittsbürgern die Art von Unsterblichkeit, die bislang einer Elite vorbehalten “122 ist. Trotz des Kunstanspruchs der frühen Fotografen, die häufig Maler waren, und trotz des Versuchs der Nobilitierung der Fotografie durch Betonung ihrer wissenschaftlichen Bedeutung ${ }^{123}$ ist der Siegeszug ihrer pekuniär profitablen Nutzung nicht aufzuhalten. Die Reproduktion auf Papier stellt auch unter diesem Aspekt einen bedeutungsvollen Schritt dar. Bleibt die ökonomische Auswertung der Fotografie zunächst zwar (mit Ausnahme der staatlichen Unternehmungen in Sachen Daguerre) Einzelinitiative, so nimmt sie, nach mehreren halbwegs erfolgreichen Firmengründungen anderer, mit George

${ }_{122}^{12}$ Monaco, Film verstehen, 32

${ }^{123}$ Die Insistenz auf der wissenschaftlichen Bedeutsamkeit ist besonders deutlich bei der Reihenfotografie Muybridges; sie diente auch der Legitimation erster Aktaufnahmen. Beim Film kehrt diese Insistenz wieder und hält sich bis in die 30er Jahre als wesentlicher Aspekt der Bewertung des neuen Mediums. Die Vorliebe der filmfreundlichen Autoren der ersten vier Jahrzehnte für den ,Kulturfilm' kann dabei als deutlich durch eine Nobilitierungsabsicht mitmotiviert gelten. 
Eastman unmißverständlich industrielle Dimensionen an. Eastman, der seine Karriere als Bürobote und Hobbyfotograf beginnt, steigt mit der Entwicklung neuer Bildträger (zunächst Platten, dann Papierfilme) in dieses Geschäft ein und macht sich mit Unterstützung Oberst Henry Strongs selbständig ${ }^{124}$. Die Konstruktion einer Kamera und die (Nach-)Erfindung des Zelluloidrollfilms bringt ihm den Durchbruch; durch Aufkauf möglichst vieler fremder Patente versucht er, eine Monopolstellung auf dem Markt zu erreichen, was ihm auch bis zu einem gewissen Grad gelingt. Die Industrialisienung der Fotografie etabliert sich auf der Basis und im Verbund mit ihrer Popularisierung (vgl. oben). Eastman ist dabei sowohl im Bereich des Apparatebaus als auch der Herstellung von Bildträgern und schließlich des Einzelhandels (Ladenketten) tätig ${ }^{125}$.

Die Schaffung bewegter Bilder in Guckkästen und durch Projektion hat gleichfalls rasche kommerzielle Verwertung zur Folge. Schon Anschütz' Elektrotachyskop gilt nicht nur als technisch interessantes Objekt auf der Weltausstellug, sondern wird von der Firma Siemens in 78 Exemplaren zu Verkaufszwecken gebaut ${ }^{126}$. Besonders deutlich ist die Verklammerung von technischer Innovation bzw. Erfindergeist und ökonomischer Rationalisierung dann bei Edison und seinem Labor. Kaum etwas wird dort entwickelt, das nicht Profitabilität verspricht. Nicht profitabel erscheinende Experimente werden meist rasch abgebrochen. Der ,Zauberer vom Menlo Park ${ }^{\mathbf{1 2 7}}$, der sich gerne als Pioniererfinder inszeniert, ist bereits ein Industrieller, der projektbezogene Arbeit leistet bzw. leisten läßt. Die erste Lösung des Projekts, bewegte Bilder zu zeigen, ist, wie geschildert, das Kinetoskop. Edison vereint dabei Herstellung und Vertrieb der Apparate mit der Herstellung zugehöriger Filme in seiner Hand. Zum Zweck der Filmproduktion läßt er eine Kamera entwickeln und ein Studio bauen. Ziel des ganzen Unterfangens ist der Verkauf.

Die ersten Filme Edisons enthalten schon rudimentäre Sujets ${ }^{128}$. Die Gebrüder Latham aber sind es, die dann eine publikumsorientierte Ausdehnung der Variationsbreite der Filmszenen fordern, um einer Erschöpfung des Kinetoskop-Geschäfts entgegenzuwirken. Sie richten zunächst mit Geräten, die sie von Edison kaufen, ein Kinetoskop-Theater ein und leisten einen ersten Schritt zu einer Differenzierung von Produktion, Vertrieb und Vorführung als eigenständigen Wirtschaftszweigen. Angeregt von den enormen Erfolgen der zeitgenössischen Preisboxkämpfe inaugurieren sie die filmische Wiedergabe derselben und einen Programmwechsel in bestimmten Abständen. Da Edisons filmische Ausrüstung für die Aufnahme noch des Studios be-

${ }^{124}$ vgl. Zglinicki, Weg 1, 158-161

125 Das Anti-Trust-Gesetz zwingt Eastman dann jedoch, seine Ladenketten wieder aufzugeben. (vgl. Zglinicki, Weg 1, 161)

126 vgl. Ceram, Archäologie, 82

127 Der Name wurde Edison in Orientierung am Standort seines Labors zuteil; er spiegelt zugleich die mythische Qualität, die diesem Mann bereits zu Lebzeiten zugeschrieben wurde. Auf die Neigung zur Mythologisierung verweist auch: Ramsaye, Million, 51: „The people call him Wizard because they love magic and mystery, hoping against hope, that there is a royal road to All Desire."

${ }_{128}$ Der Streifen mit Fred Otts Niesen enthält bereits ein solches, rudimentäres Sujet: gezeigt wird, wie ein Junge sich hinter Ott schleicht und eine Pfefferbüchse schüttelt - daraufhin niest Ott. Das Ganze ist schon eine komische Szene, wie sie in diversen Analogaten in späteren Filmen nicht unbekannt ist. (vgl. Ramsaye, Million, 83) 
darf, werden Kontrakte mit Boxern geschlossen und die Kämpfe vor der Kamera nachgestellt ${ }^{129}$. Lathams Innovation besteht so in der Erkenntnis der Notwendigkeit einer kommerziell orientierten Produktion, die sich auf breiterer Basis an die Wünsche und Bedürfnisse des Publikums zurückbindet. Auch darin läßt sich die spezifisch ökonomische Rationalisierung der Moderne und die Zugehörigkeit des Films zu dieser Epoche erkennen: Die ökonomisierenden Subjekte suchen nach neuen profitablen Möglichkeiten und erweisen sich dabei als innovativ. Eben dieses innovativexpansive, fortschrittsorientierte Moment aber gehört mit zu den Momenten, die die moderne von der vormodernen Wirtschaft unterscheiden.

Auguste und Louis Lumière schließlich, die dem neuen Medium endgültig (das heißt: mit entscheidender Wirksamkeit) zur Geburt verhelfen, beginnen ihr Unterfangen bereits als Industrielle. Zusammen mit ihrem Vater leiten sie eine Fabrik für fotografische Produkte aller Art. Sie sind zunächst durchaus technisch orientiert: Profitabilität erwarten sie sich von der Vorführung ihrer Kamera-Projektor-Kombination, nicht von den Inhalten der gezeigten Filme. Das Plakat zu ihrer ersten Vorstellung kündigt dementsprechend den Apparat, nicht aber Filme $a n^{130}$. Gleichwohl beginnen die Lumières sofort mit der Produktion von Filmen für die Vorführungen. Der Erfolg der Vorstellungen im Grand Café - innerhalb weniger Wochen steigen die Einnahmen auf zweitausend Francs täglich an ${ }^{131}$ - veranlaßt sie, bald weitere Kinematographentheater einzurichten. 1896 entstehen schon erste Theater im Ausland: in London, Brüssel, Bordeaux, Berlin und New York ${ }^{132}$. Gleichzeitig steigen die Lumières ins Lizenzgeschäft ein und vergeben eine jeweils kostenpflichtige Vorführerlaubnis an Freunde und Mitarbeiter ${ }^{133}$. Die Lumières sind wohl auch die ersten, die Kameraleute ausbilden und mit dem Auftrag, Aktualitäten, Kuriositäten und andere verwertbare Filme zu , schießen ${ }^{134}$, ins In- und Ausland entsenden ${ }^{135}$. Die Gründung einer Gesellschaft für den Export in die USA allerdings scheitert dann an Edisons Vorherrschaft dort ${ }^{136}$. Trotzdem läßt die Tätigkeit der Lumiéres damit zunächst schon erkennen, daß die ökonomische Orientierung auch die zunehmend internationale Kommunikation befördert. So legt die von ihnen eingeführte Ausbildung und Entsendung von Kameraleuten den Grund für einen allmählich entstehenden filmischen Journalismus, der später über Wochenschau und schließlich über das Fernsehen die innergesellschaftliche und globale Auseinandersetzung mit Tagesaktualitäten sowie politischen und kulturellen Ereignissen vorantreibt und zudem die Bevölkerung der einzelnen Staaten mit der Weltbevölkerung tendenziell vernetzt. Weiter zeigt sich bei den Lumiéres, daß ihre ökonomische Tätigkeit von der Herstellung des Rohmaterials bzw. der Apparate über die Produktion von Filmen bis zum Export und zur Vorführung alle Bereiche des Film-business umfaßt. Mit Recht kann man daher sagen, daB mit den Gebrüdern Lumière sich endgültig eine Filmindu-

\footnotetext{
${ }^{129}$ vgl. Ramsaye, Million, $108-110$

130 vgl. Fulton, Motion, 13

131 vgl. Gregor/Patalas, Geschichte I, 11

132 vgl. Ceram, Archäologie, 152

133 vgl. Ceram, Archäologie, 152

134 Von,drehen' kann man vorerst nur bedingt sprechen - der größte Teil des Materials der Lumières entspricht noch dem Schnappschuß im Bereich der Fotografie.

${ }_{135}$ vgl. Gregor/Patalas, Geschichte I, 11

136 vgl. Gregor/Patalas, Geschichte I, 11
} 
strie etabliert ${ }^{137}$, und daB diese Industrie bereits eine kommunikationsfördernde Bedeutung besitzt. Die Filmproduktion der beiden Brüder zudem ist rege; ein erster, großer Katalog des Jahrs 1897 bietet bereits 385 Streifen an. Bis 1898 erscheinen sechs weitere Kataloge, die insgesamt etwa tausend Filme enthalten ${ }^{138}$. Dabei bilden sich schon anfängliche Formen von Genres heraus: Der erste Katalog unterscheidet in den Überschriften Vues générales von Vues comiques und verschiedenen ,Auslandsberichten ${ }^{\mathbf{1 3 9}}$. In den weiteren Katalogen sind gar Frühformen von Historiendramen enthalten: „Faust“ in zwei Teilen, „Leben und Passion Christi“, Filme über Napoleon und $\mathrm{Nero}^{140}$.

In den ersten Jahren des zwanzigsten Jahrhunderts festigt sich die Binnenstruktur der neuen Industrie. Um 1905 kann das Konzept der ausschließlich zur Vorführung von Filmen beutzten Filmtheater als durchgesetzt gelten. Um 1908 gibt es in den USA mehr als fünftausend ,Nickelodeons' (wie die kleinen Theater wegen ihres Eintrittspreises von fünf Cent, also einem ,nickel', genannt werden). Die Bereichsspezifizierung von Herstellung (Rohfilm, Apparatebau), Produktion (Filmwerke), Verleih und Vorführung ist zu dieser Zeit abgeschlossen. Mit der Bereichsspezifizierung sind die bis heute existenten Zweige der Filmindustrie entstanden.

Kämpfe, Auseinandersetzungen und monopolistische Tendenzen innerhalb der Zweige sowie durch neuerliche Zusammenschlüsse der ausdifferenzierten Bereiche untereinander sind damit freilich nicht beendet. Die Etablierung einer Filmindustrie hat sofort auch das Ringen um die ökonomische Vorherrschaft zur Konsequenz. Ab 1897 beginnt Edison in den USA eine lang anhaltende Serie von gerichtlichen Verfahren um Patente; andere, neu gegründete Filmgesellschaften antworten mit Gegenklagen, so da $B$,im ersten Jahrzehnt der Geschichte der Filmindustrie mehr als fünfhundert Prozesse angestrengt ${ }^{* 141}$ werden. Nach einer kurzen Phase der Befriedung durch die Motion Pictures Patents Company (MPPC) 1909 setzt eine neue Runde von Verfahren ein, in der Trustprozesse die Patentprozesse ablösen ${ }^{142}$. Zur gleichen Zeit gelingt es in Frankreich Charles Pathe, das erste Filmimperium internationalen Ausmaßes aufzubauen. Pathé, gelernter Schlachtermeister, beginnt seine Karriere als Schausteller mit einem Kinetoskop Edisons. Der finanzielle Erfolg gibt ihm die Basis, zusammen mit einem Erfinder eigene Apparate zu konstruieren und mit seinen Brüdern die Pathé Frères zu gründen ${ }^{143}$. Zunächst lediglich im Apparatebau tätig, beginnt die neue Gesellschaft 1897/98 auch mit der Filmproduktion. Rasch verleibt sie sich jedoch andere Zweige der neuen Industrie ein: Zu Rohfilmfabriken

137 In diesem Sinne Ceram, Archäologie, 153

138 vgl. Ceram, Archäologie, 151

139 vgl. Ceram, Archäologie, 151; Ob man allerdings, wie Ceram, dabei schon von „Kurze(n) Spielfilme(n), Dokumentarfilme(n), Kulturfilme(n) und sogar Trickfilme(n)“ (ebd.) sprechen sollte, sei in Zweifel gezogen. Für günstiger halte ich es, die genannte Differenzierung als Vorform einer Genredifferenzierung zu betrachten. Den Rückwärtslauf beim Projektor schon als Trickfilm anzusprechen, wie Ceram dies tut, scheint mir ohnehin zu weit gegriffen. Zweifelsohne aber finden sich in den frühen Streifen schon gewisse szenische Grundformen und Grundsituationen, die später in ausgearbeiteten Spielfilmen wiederkehren.

140 vgl. Ceram, Archäologie, 151

141 Monaco, Film verstehen, 220

142 vgl. Monaco, Film verstehen, 221

143 vgl. Ceram, Archäologie, 246-248 
gesellen sich Verleihfirmen und Theaterketten sowie Exportfirmen ${ }^{144}$. Pathés ,vertikal gegliederte, nahezu monopolistische Position “ ${ }^{445}$ dominiert große Teile des europäischen und sogar des amerikanischen Markts. Vor 1914 vertreibt Pathé in den USA doppelt soviele Filme wie die ganze amerikanische Filmindustrie ${ }^{146}$; insgesamt sind in dieser Zeit $90 \%$ aller in der Welt vorgeführten Filme französischer Herkunft. Ab 1914 jedoch kehrt sich dies mehr und mehr zugunsten der USA um, ${ }^{147}$ die ab 1928/29 mit bis heute wirksamer Nachhaltigkeit eine Dominanz auf dem internationalen Markt anstreben und partiell erreichen.

Die ökonomische Entwicklung in den USA läßt sich mit Prokop ${ }^{148}$ zu Phasen systematisieren. Von 1896 bis 1908 kann von einem Polypol gesprochen werden. Viele kleine Gesellschaften stehen relativ selbständig und unabhängig nebeneinander. $\mathrm{Zu}$ den wichtigsten zählen dabei Dicksons American Mutoscope and Biograph Company, Blacktons Vitagraph Company und Edisons Company. Ab 1902 gesellen sich Lubin, Kalem, Selig und Essanay als erfolgreiche Konkurrenten hinzu, nach 1905 erscheinen Loew, Warner, Zukor, Fox, Goldwyn und Laemmle. Doch bleibt der Markt offen genug, um die Existenz aller - trotz der Hegemonialstellung des Pathé Trusts - zu sichern ${ }^{149}$.

Die Auswirkungen des Patentstreits sind es, die dann zu einer zweiten Phase, der des Oligopols von 1909 bis 1929 führen. Das Scheitern der MPPC nämlich sorgt ab 1910 für eine neuerlich unübersichtliche Konkurrenzsituation und die Einleitung horizontaler und vertikaler (bereichsübergreifender) Konzentrationen ${ }^{150}$. Erstmals gewinnen nun auch ,fachfremde' Geldgeber, die Großbanken, Einfluß auf die bis dahin unternehmerisch unabhängigen Filmgesellschaften; ,Producersupervisors ${ }^{\star}$ werden eingesetzt, die die Produktion auf Effizienz und Rentabilität hin überwachen. Gleichzeitig findet eine hierarchische Gliederung des mehr und mehr arbeitsteiligen Film-business statt. Eine Marktstrategie zur Gewinnung eines größeren Publikums wird in dieser Zeit mit dem Ausstattungsfilm und dem Starsystem gefunden: Kostenintensive Ausstattung und Einsatz gefeierter und mit glamouröser ,Aura' umgebener Stars sollen den Erfolg garantieren ${ }^{151}$. Die parallel dazu liegende Errichtung teuerer Erstaufführungskinos soll einerseits den Glamour der Filme im Publikumsbereich

144 vgl. Gregor/Patalas, Geschichte I, 11

145 vgl. Monaco, Film verstehen, 220

146 vgl. Monaco, Film verstehen, 220

147 vgl. Gregor/Patalas, Geschichte I, 12

148 Prokop, Soziologie - Prokops Untersuchung ist aufgrund ihrer Materialfülle und Systematik hilfreich. In einigen Punkten jedoch werde ich von Prokops Darstellung abweichen und ihm sogar widersprechen: Keineswegs scheint mir die von ihm im Sinn der Kritischen Theorie konstatierte Standardisierung und ,Entspezifizierung' der Filminhalte derart umfassend zu sein, wie er glauben machen möchte. Auch vermag ich die Annahme einer nur formalen Innovation durch die Industrie zum Zweck der Publikumsbindung nicht zu teilen. Hier scheint mir Prokop den theoretischen Vorgaben des Paradigmas der Kulturindustriehypothese gegen die empirische Situation erlegen zu sein. (Zur genaueren Ausführung dieser Hypothese und der genannten Phänomene von Standardisierung und ,Entspezifizierung“ vgl. 5.5.)

149 vgl. Prokop, Soziologie, 25-46

150 vgl. Prokop, Soziologie, 49

151 vgl. Monaco, Film verstehen, 221; Prokop, Soziologie, 50-52 
fortsetzen, andererseits, gehobenere Schichten' zum Kino führen ${ }^{152}$. Insbesondere mit Blick auf die letzteren entstehen Film-Codes ${ }^{153}$.

Auffällig ist dabei, da $B$ die genannten Codes nicht selten unter aktiver Beteiligung des Publikums bzw. auf Druck sich organisierender Teile desselben hin entstehen. Ähnlich dem in den 50er Jahren für die kommerziellen Comics etablierten Code nämlich führen sich die inhaltsnormativen Vorschriften für den Film meist auf die Tätigkeit von in Vereinen organisierten, der gehobenen Mittelschicht angehörigen Gesellschaftsmitgliedern zurück, die ihre Weltauslegung, insbesondere mittelschichtsspezifische Moralvorstellungen, filmisch repräsentiert und konkurrierende Interpretamente ausgeschlossen sehen wollen. Die Codes zeigen sich so weniger als publikumspädagogische Veranstaltungen der Produzenten und Geldgeber, sondern mehr als Folge einer ,Basisaktivität', in der sich ein gesellschaftlicher Entwicklungstrend zur Selbstdurchsetzung der Mittelschicht realisiert. Diesem Trend, wie er soziologisch als typisch für die modernen Industriegesellschaften gelten kann, scheinen mir auch die moralkodifikativen Invektiven diverser Banken und anderer Geldgeber gegenüber der Filmindustrie zuzurechnen zu sein. Im Unterschied zu einer Interpretation des Phänomens der Codebildung, die (wie tendenziell die Kritische Theorie) darin eine ,erzieherische', ja manipulative Aktivität der Produzenten und ihrer Finanziers am Werk sehen will (vgl. 5.5.), scheint mir daher eher eine ,Erziehung der Produktion' durch das Mittelschichtspublikum wahrnehmbar zu sein, die sich auch über die dieser Schicht zugehörigen Finanziers ausdrückt bzw. unter diesen eine entsprechende Reaktion auf eine mittelschichtsspezifische Marktsituation provoziert. Umgekehrt freilich sorgt dann gerade die ökonomische Verfaßtheit der Filmproduktion wieder dafür, daß sich Codes selbst unter oligopolistischen Bedingungen selten sehr lange halten können: Da der Film sich soziologisch als zunehmend schichtübergreifendes Medium darstellt, bleiben auch die Bedürfnisse anderer Schichten ökonomisch relevant und wollen sie berücksichtigt sein. Mit einer konstanten Publikumsgunst auf breiter Basis kann daher nie unter durchgängig auf eine Schicht hin statifizierten Bedingungen gerechnet werden. Außerdem schlagen sich der soziale Wandel, den es in industrialisierten Gesellschaften stets gibt, und die diskursive Prozessualität der lebensweltlichen Meinungs- und Überzeugungsbestände im Bereich der Publikumswünsche nieder. Selbst die ,Mittelschichtsspezifität' ist so einer Veränderung unterworfen, und die auf sie orientierte Gehalteproduktion muß sich letztlich in den Prozeß der Gesamtgesellschaft eingliedern. All dies bedingt neben der von den Codes indizierten Statifizierungstendenz der Ökonomie auch einen Zwang zur innovativen Reaktion auf eine starke Veränderlichkeit der Marktsituation, die kaum durch eine kodifizierte Repetition identischer Sujets und Gehalte allein in den Griff zu bekommen ist.

Der letztgenannten Notwendigkeit entspricht es weiter, daß gegen Ende der 20er Jahre eine übergroße Standardisierung der unter den Direktiven des Oligopols pro-

152 vgl. Prokop, Soziologie, 52-54; Prokop verweist auf den vielsagenden Slogan dieser Zeit: „Selected pictures for selected audiences“. Kracauer hat 1926 für die Parallelentwicklung der Kino-Paläste Berlins entsprechende Kritik bereit: Lediglich der Bildungs-Hochmut der Mittelschichten äußere sich in dem Versuch, aus den Kinos Theaterräume zu machen. Vgl. Kracauer, Kult

${ }^{53}$ vgl. Prokop, Soziologie, 57-63 
duzierten Filme einen Publikumsrückgang erzeugt, dem durch umfassende Innovationen begegnet werden muß. Hierbei erweist sich nicht zuletzt die Einführung des Tonfilms als profitabel, der neben einer veränderten Formalästhetik und ihren Möglichkeiten, die sich etwa im neuen Genre des Musicals niederschlagen, auch inhaltliche Innovationen bedingt. Solche inhaltliche Innovationen führen beispielsweise zur ,Schwarzen Serie', die sich sozialkritischen Themen widmet (vgl. 1.5.) und für welche der Ton die Möglichkeit einer gewissen, da sprachlich vermittelten, Theoriebildung eröffnet. Statt ,stummen', auf Aktion angewiesenen Handlungsgängen mit wenig Text in ,Zwischentiteln' nämlich läßt der Ton nun die Reflexion der Protagonisten und theoretische Dialoge zu, mit denen zeitgenössische Themen ausführlicher behandelt werden können. Gerade in der ,Schwarzen Serie‘ gerät der Film hierbei zum Ort und Instrument der sozialen Kommunikation, die nun auch in den populärunterhaltenden Medien die gesellschaftliche Situation und aktuelle Thematiken verhandelt. Allerdings führen die mit dieser Innovation verbundene neuerliche Kostensteigerung und die mangelnde Effizienz der Kartellgesetzgebung zugleich in die dritte Phase der ökonomischen Filmhistorie: die eines Quasi-Monopols ${ }^{154}$ von 1930 bis 1946. Fünf Großkonzerne und drei kleinere Firmen dominieren weitgehend Produktion, Verleih und Vorführung; obgleich die Gesetzgebung ein ,offenes' Monopol verhindert, sorgen ein Vertragsnetz zwischen ihnen und ihr Zusammenschluß in der Motion Picture Association of America (MPAA) für eine monopolähnliche Stellung der Firmen ${ }^{155}$. Die Kostenintensität der Produktion hat weiter zur Folge, daß die Amortisationsbasis in internationalem Rahmen erweitert werden muß. Durch Warenexport (Export der Filme) und Kapitalexport (Aufkauf von Lizenzen, Verleihfirmen, Stars und Regisseuren) versucht sich die amerikanische Filmindustrie die Vorherrschaft auf dem internationalen Markt zu sichern und erringt sie in der Tat eine Dominanzstellung bis etwa $1940 .{ }^{156}$ Der erforderliche Planungsumfang leitet eine neuerliche Tendenz zu bürokratischer Verwaltung und Standardisierung ein, die wieder von Konflikten mit den Publikumswünschen begleitet wird. ${ }^{157}$ In der Tat nämlich zeigt das ,nationale' Publikum wiederholt eine Neigung, sich auf längere Sicht einer ausschließlich international orientierten und entsprechend auf nationenübergreifende Rezipierbarkeit abgestellten Produktion zu widersetzen und daneben auch ,spezifische', auf die Belange und Typika der eigenen Kultur und Gesellschaft ausgerichtete Themen und Formen zu fordern. Neben der internationalisierten und hierdurch ,entspezifizierten' Produktion verlangt der Binnenmarkt daher auch immer wieder nach ,spezifischen', ,eigenen' Produkten. Die Notwendigkeit internationaler Amortisation und die Existenz ,nationaler' Bedürfnisse kollidieren daher nicht selten und führen die Ökonomie in Konflikte, die durch Flexibilisierung und wechselhafte, oft widersprüchliche Strategien beantwortet werden. Der Zweite Weltkrieg unterbricht

${ }^{154}$ Prokop spricht hier unvermittelt von einem Monopol. Dies aber erscheint mir zu ungenau: Wie nachfolgend bemerkt, handelt es sich um vertragliche Verflechtungen zwischen den Firmen, die deren ökonomische Dominanz sichern sollen, gleichwohl keine umfassende Herrschaft garantieren und auch keinen geschlossenen Verbund im Sinn eines Konzerns mit einem einzigen Katalog von Direktiven darstellt.

155 vgl. Prokop, Soziologie, 73-83

156 vgl. Prokop, Soziologie, $84-87$

157 vgl. Prokop, Soziologie, 91-97; im Unterschied zu Prokop ziehe ich es hier vor, von einer Tendenz zu sprechen. Prokop sieht eine Determination vorliegen. 
diese Entwicklung und ihre Konflikte und erlaubt aufgrund der Abschottung der Grenzen eine weitgehend isolierte Binnenentwicklung der nationalen Filmindustrien.

Die nach dem Krieg wieder zugänglich gewordenen europäischen Märkte und die derangierte Situation der europäischen Filmindustrie bieten dann ab 1946 Möglichkeiten, die Internationalisierung der Amortisationsbasis weiter zu verfolgen und partiell erfolgreich die Errichtung einer monopolähnlichen Stellung in internationalem Rahmen anzugehen, die gleichwohl ständig durch unabhängige Initiativen gefährdet wird und zu einer großen Flexibilität gegenüber den internationalen Märkten nötigt. ${ }^{158}$ Am Beginn dieser Situation steht ein Rückgang der Besucherzahlen in den USA, der neben einer gewissen Frustration des Publikums durch repetitive Marktstrategien auch durch die zunehmende Motorisierung und schließlich die Einführung des Fernsehens verursacht ist. Das Entflechtungsurteil von 1946 führt dazu, daß die Monopolstellung im eigenen Land zunächst einmal zerschlagen wird. Wiederum läuft der Kurs zur Stabilisierung über Innovation und Arrangement: Innoviert wird sowohl inhaltlich als auch formal. So sorgt die Einführung neuer Aufnahme- und Projektionsverfahren, d.h. hauptsächlich die Erfindung des Farbfilms und des Cinema-Scope-Formats für neue ästhetische Möglichkeiten, die von inhaltlichen Veränderungen begleitet werden. Daneben kann nach einer Phase erbitterten Kampfs ein Arrangement mit dem Fernsehen statt aufreibender Konkurrenz erreicht werden. Zunächst verkaufen die Filmgesellschaften ihre alten Schwarz-Weiß-Filme an TV-Networks, dann leiten sich Verflechtungen auf Kapital- und Produktionsebene ein. ${ }^{159}$ Die Verbreiterung des Zugangs zum Publikum durch das Fernsehen trägt wiederum zu einer Differenzierung des Angebots auf Zielgruppen (und damit konnotierte Sendezeiten) bei, das erneut einen ökonomischen Aufschwung einleitet. Internationale Expansion und eine flexible Ausrichtung auf ,extraterritoriale‘ Märkte aber ist zusätzlich notwendig, um einen profitablen Stand zu erhalten; ein diesbezüglicher neuerlicher Zugriff auf v.a. den europäischen Marktbereich inszeniert sich anfangs, nach 1946, als überschwemmungsähnlicher Export alter Filme. Mit Hilfe einer Exportabteilung der MPAA, deren Aufgabe darin besteht, ,amerikanischen Filmen gleiche Rechte auf den nationalen Märkten zu sichern" ${ }^{160}$, wird auf gewissermaßen ,diplomatischem' Wege die allmähliche Reetablierung einer amerikanischen Dominanz projektiert. Das im Ausland eingespielte Kapital, das häufig nur zu Teilen in die USA transferiert werden darf, stellt die Basis für die Beteiligung an europäischen Produktionen auf Kapitalebene dar ${ }^{161}$; die Krisensituation Ende der 50er Jahre, die mit der üblichen zeitlichen Versetzung nun auch hier die Konsequenzen einer Verlagerung der Freizeitaktivitäten spürbar werden lassen, erlauben dann zusätzliche Aufkäufe von Produktions- und Verleihfirmen ${ }^{162}$. Mit ihrer zunehmenden Dominanzstellung erhalten die Großfirmen eine Art Torhüterfunktion an den Zugängen

158 Prokop spricht von einem „internationalen Monopol“, doch scheint mir das zu massiv. Zweifelsohne aber ist die Stellung der amerikanischen Filmindustrie insbesondere in Europa so übergewichtig, daß von einer monopolähnlichen Situation gesprochen werden kann. (vgl. auch: Prokop, Soziologie, 139-239)

150 vgl. Prokop, Soziologie, 141-142, 144- 145

160 Prokop, Soziologie, 146

161 vgl. Prokop, Soziologie, 147

162 vgl. Prokop, Soziologie, 148 
zum Weltmarkt, so daß kostenintensive europäische Produktionen, die zur Amortisation ebenfalls auf Export angewiesen sind, sich häufig schon vom Drehbuch an zur Kooperation mit amerikanischen Firmen genötigt sehen ${ }^{163}$ und Kollisionen mit spezifisch europäischen oder landesbedingten Publikumswünschen entstehen (können).

In den USA selbst gibt es nach 1970 weitere Verflechtungen. Einerseits streben Filmgesellschaften nach wie vor den Besitz bzw. das Arrangement mit TV-Networks an - besonders wichtig dabei: Pay-TV-Stationen, die sich auf Spielfilme spezialisiert haben. Andererseits werden Produktionen nicht mehr nur für die Vorführung im Kino, sondern auch für den Video-Markt gemacht ${ }^{164}$. Daneben steht das Engagement im Werbefilm-Bereich. Diversifikation sorgt über die Kapitalebene schließlich für Konglomerierung mehrerer, einander durchaus fremder Industriezweige, so daß die Filmproduktion häufig nur noch ein Tätigkeitsfeld großer Konzerne neben anderen ist ${ }^{165}$. Zugleich aber entwickelt sich seit Mitte der 70er Jahre eine starke Bewegung neuer Independents, d.h. unabhängiger Filmemacher und Produzenten, und kleinerer Firmen ${ }^{166}$. Hierbei zeigen sich Zusammenschlüsse, wie etwa die aus einer Kooperation von Independents entstandene Firma ,Orion Pictures', als mitunter durchaus konkurrenzfähig und erfolgreich. Auch die gegenwärtige Situation wird so trotz ihrer monopolistischen Tendenz immer wieder von Innovationen unabhängigen Unternehmertums durchbrochen, und kann nicht als vollständig geschlossen beurteilt werden. Die Diversifikation ermöglicht zudem die Produktion eines gewissen Kontingents an weniger breitenwirksamen und profitablen Filmen, d.h. damit auch eine experimentelle Innovation, die von Profiten anderer Firmenzweige mitgetragen wird. - Insgesamt bietet sich damit ein heterogenes Bild: So kann man sagen, daß der Film aus ökonomischen Gründen einerseits auf seine Internationalisierung, andererseits auf Verflechtung mit neuen Kommunikationstechnologien und -netzen drängt. Spürbar wird die Internationalisierungstendenz bereits in der Phase des QuasiMonopols ${ }^{167}$, mit endgültiger Konsequenz durchgeführt aber wird sie, nun zusammen mit der Verflechtung mit neuen Kommunikationstechnologien, erst nach dem Zweiten Weltkrieg. Dabei zeigt sich zum einen, daß vor allem die amerikanische Filmindustrie auf eine monopolähnliche Dominanz in internationalem Rahmen abzielt. Zum anderen aber ist auch erkennbar, daß eine haltbare Statifizierung dieser Dominanzstellung und ihrer Produktionsstrategien zu dauernder Anpassung an veränderte Bedingungen nötigt, die diese Statifizierung der ökonomischen Stellung letztlich zu einer dynamischen Innovativität der Produktion zwingen. Außerdem wird die mono-

163 vgl. Prokop, Soziologie, 147

164 vgl. Prokop, Soziologie, 243-245

165 vgl. Prokop, Soziologie, 247-249

166 vgl. Monaco, Film verstehen, 234; viele dieser Produzenten sind gleichzeitig Regisseure oder Stars. Ihre Tätigkeit zeitigt, wie etwa bei Barbara Streisand, oder auch Robert Redford, interessante Ergebnisse. Redford hat einige Jahre in der Mitte der 80er ganz bewußt auch der Heranbildung und Förderung neuer, nicht gebundener Talente gewidmet.

${ }^{167}$ Pathés Trust ist in diesem Zusammenhang noch als Pioniertat zu verstehen. In dieser frühen Zeit ist expansives Verhalten noch eine zwar profitable Möglichkeit, jedoch kein Gebot um des Überlebens willen, da die Produktionskosten noch unglaublich niedrig sind. Während der Zeit des Monopols hingegen verursachen der erreichte Standard und die sehr eng gewordene Konkurrenzsituation neue Notwendigkeiten (teuere Ausstattung, Stars) und damit Kosten, die nur durch internationale Auswertung wieder eingespielt werden können. 
polistische Tendenz der Gesamtsituation von unabhängigen Initiativen flankiert und flexibilisiert, so daß sich das Bild eines anhaltenden Ringens um den jeweiligen ökonomischen Standort ergibt. Ein gewisser, nicht unbeträchtlicher Erfolg bei der Errichtung einer Hegemonialstellung der amerikanischen Filmindustrie auf dem internationalen Markt bleibt dabei freilich dennoch zu konstatieren.

Die Entwicklung der nationalen Filmindustrien außerhalb der USA ist, wie die vorstehende Skizze schon verdeutlicht, durchaus nicht völlig unabhängig von dieser Phasengliederung. Eine vollständige Freisetzung von Auseinandersetzungen und Interaktionen mit der amerikanischen Filmindustrie erfährt insbesondere die europäische Filmindustrie nur in den Phasen des Poly- und Oligopols und in den Zeiten der Kriege. Davon wiederum ist die Zeit bis zum Ersten Weltkrieg von Pathé dominiert. Gleichwohl hindert dies die Kreativität der nationalen europäischen Produktion nicht. Sowohl in den vollständigen Freisetzungsphasen als aber auch in den Phasen der amerikanischen oder französischen Dominanz bilden sich nationale Spezifika heraus, die mitunter sogar eine globale Prägekraft entfalten. Während des Ersten Weltkriegs etwa erhält der dänische Film Gelegenheit, zu Einfluß zu gelangen. Die Erzeugnisse der italienischen Filmindustrie werden schon früh stilbildend wirksam und liefern mit dem Divenkult ein Vorbild des amerikanischen Starsystems. Die russische Filmindustrie macht mit den Regisseuren Eisenstein, Pudowkin und Vertow ästhetische Geschichte, bevor sie 1919 verstaatlicht wird. Jedoch auch dort kann sie sich noch zumindest zur Zeit des recht liberalen zuständigen Kommissars Lunatscharski ziemlich frei entwickeln ${ }^{168}$. Später freilich bedeutet das kontramoderne ökonomische Programm des Kommunismus eine beständige Obstruktion für die Entwicklung des russischen Films. In Deutschland versucht zur Zeit der Pathe'schen Hegemonie Oskar Messter zu wirtschaftlicher Geltung zu kommen. Er wird im Bereich des Apparatebaus tätig, nimmt jedoch auch die Filmproduktion auf und wird insbesondere wichtig durch die Schaffung einer Wochenschau (der ,MessterWoche $)^{169}$. Freilich erlangt er "niemals eine Stellung, die derjenigen der großen französischen, dänischen oder italienischen Unternehmer vergleichbar" ${ }^{\text {"170 }}$ wäre, doch gelingt es ihm immerhin, in Deutschland einen nicht unbedeutenden Konzern aufzubauen. Messters Verhältnis zu den Mächtigen befördert seine Unternehmungen; 1898 bereits erhält er die Erlaubnis des Kaisers, diesen auf seinen Reisen mit der Kamera zu begleiten ${ }^{171}$. Er verbindet wirtschaftliche mit pädagogischen Bestrebungen, die nicht nur in seinen Werbefilmen („Bade zuhause!“) zutage treten, sondern auch in den Kriegswochenschauen des Ersten Weltkriegs, die er propagandistisch ,ergänzt ${ }^{172}$.

Gerade in Deutschland mischen sich Politik und Ökonomie beträchtlich in der Gestaltwerdung der nationalen Filmindustrie und führen schließlich in eine verderbli-

${ }_{169}^{168}$ vgl. Gregor/Patalas, Geschichte I, 79

169 vgl. Traub, Als man anfing, 54-59; Ceram, Archäologie, 248-251

170 Gregor/Patalas, Geschichte I, 13

171 vgl. Zglinicki, Wiege, 78

172 vgl. Zglinicki, Wiege, 79, 82; Kracauer, Caligari, 21-22, 29; Kracauer verweist auf gestellte Kriegsszenen, in denen sich feindliche Soldaten den deutschen Truppen ergeben. Die propagandistische Verzweckung des Films allerdings war im Ersten Weltkrieg - wie auch im Nationalsozialismus - durchaus Allgemeingut. 
che Entwicklung. Das politische Engagement der deutschen Hochfinanz begleitet ab 1917 deren Tätigkeit im Filmbereich, die die Gründung der Ufa zur Folge hat. Unter maßgeblicher Beteiligung Hugenbergs entsteht 1916 bereits die Deutsche LichtbildGesellschaft (DLG, auch: Deulig), die eine ,bessere zentrale Nachrichten- und Propagandavermittlung“"173 garantieren soll. 1917 veranlaßt Ludendorffs Kriegsministerium die Gründung des Bild- und Film-Amts (Bufa), das er als eine Maßnahme zur „Vereinheitlichung der deutschen Fümindustrie“ versteht, die nach „großen Gesichtspunkten eine planmäßige und nachdrückliche Beeinflussung der (...) Massen im staatlichen Interesse ${ }^{\text {(174 }}$ sicherstellen soll. Gleichzeitig bewirkt das ,staatliche Interesse jedoch den Einfuhrstopp ausländischer Filme ab dem 17.2.1916 und damit die Schaffung eines ersten wirtschaftlichen Freiraums für die Entwicklung der Filmindustrie. In Kooperation mit der Deutschen Bank wird noch im gleichen Jahr 1917 die Gründung der Universum Film AG (Ufa) vorgenommen, die nach einer Phase freierer Produktion, aber unveränderter wirtschaftlicher Machtverteilung in der Weimarer Republik als allzu probates Instrument den Nationalsozialisten in die Hände gelegt wird. Die staatliche Einfuhrkontrolle ermöglicht auch hier der deutschen Filmindustrie eine wirtschaftliche Chance, die sie jedoch nur zu Teilen aus ihrer Krisensituation befreit, wie die beständigen Umstrukturierungen unter staatlicher Beteiligung beweisen, die schließlich im Ufi-Trust gipfeln. ${ }^{175}$ An die Stelle der ökonomisch krisengeschüttelten, ästhetisch jedoch hoch kreativen und - ein einziges Mal einen Stand der Weltgeltung erlangenden Filmproduktion der 20er Jahre ${ }^{176}$ tritt der Verfall an die Gängelung durch die Reichskulturkammer. Vom Drehbuch über den Finanzierungsplan bis zum fertig geschnittenen Produkt muß alles dort eingereicht und genehmigt werden. Die zeitweiligen wirtschaftlichen Scheinblüten der deutschen Filmindustrie zwischen 1933 und 1945 sind mit weitgehendem Verlust ihrer ästhetischen Potenz und inhaltlichen Freiheit erkauft. Auch hier hindert ein kontramodernes Programm, der Nationalsozialismus, die Entwicklung des Films empfindlich (vgl. dazu 3.).

Nach 1945 tritt wieder das genannte Hegemoniestreben der amerikanischen Filmindustrie auf den Plan. Gleichzeitig verringert der deutsche Film in weiten Teilen seiner Gebiete seine ästhetische und inhaltliche Qualität so sehr, daß seine Produkte in den 50er Jahren beinahe schon zum Synonym für ,künstlerische Belanglosigkeit und Antiquiertheit" werden ${ }^{177}$. Der wirtschaftliche Niedergang des deutschen Films verdankt sich allerdings weniger diesem Qualitätschwund - 1956 und

${ }^{173}$ Zglinicki, Wiege, 95

174 Schreiben Ludendorffs an das Kgl. Kriegsministerium vom 4.7.1917, in: Bredow/Zurek, Film und Gesellschaft, 102-104, 102

175 vgl. hierzu auch: Spiker, Kapital und 3.8.

176 Es ist dies die Zeit des expressionistischen Films, sowie der Filme Fritz Langs, welche internationale Beachtung finden. Lediglich dem Neuen Deutschen Film der späten 60er und frühen 70er Jahre ist es wieder gelungen, etwas Aufmerksamkeit außerhalb deutscher Grenzen zu erregen; doch ist diese Beachtung keineswegs mit der stilbildenden Kraft der 20er Jahre vergleichbar, deren Ausläufer noch 30 und mehr Jahre später etwa in den Filmen Hitchcocks zu spüren sind.

177 Gregor/Patalas, Geschichte II, 419-421; vgl. auch: Seidl, Der deutsche Film; Seidl spricht sich, nicht ganz zu Unrecht, für ein genaueres Zusehen aus. Trotzdem bleibt Gregor/Patalas' Urteil verständlich - neue Kräfte sind in den 50er Jahren noch nicht nachgewachsen und die alten durch den Nationalsozialismus entweder isoliert oder korrumpiert worden. 
1958 gelten heute als danach nicht mehr erreichte Erfolgsjahre ${ }^{178}$-, sondern mehr der Demontage des Ufi-Trusts als einer ,vertikale(n) Organisationsform des deutschen Kinos “179 durch die Westaliierten, dessen wirtschaftliche Stärke die Neugründungen der späten 40er Jahre nicht mehr zu erreichen vermögen, sowie durch den GATT-Beitritt der BRD 1951, bei welchem auf Importrestriktionen für den Film verzichtet wird. Das „Oberhausener Manifest“ ${ }^{\star 180}$ ebenso wie die Filmgesetzgebung bemüht sich dann um Bedingungen, die sowohl der qualitativen Abwärtsbewegung als auch der wirtschaftlichen Abhängigkeit entgegenwirken sollen. Wenngleich die Gruppe der jungen Filmer, die 1962 das genannte Manifest unter dem Anspruch verkündet, ,den neuen, deutschen Spielfilm zu schaffen“"181, damals eine Außenseiterrolle spielt, so können sich ihre Vorstellungen doch im Laufe der Jahre durchsetzen und über die Filmförderungsrichtlinien strukturell wirksam werden. Absicht der ,Oberhausener' nämlich ist es, „Freiheit von der Beeinflussung durch kommerzielle Partner (...) (und) von der Bevormundung durch Interessengruppen “182 zu gewinnen. In die gleiche Richtung zielt die Filmförderung, die - nach Vorformen ab 1950 1965 mit dem ,Kuratorium Junger Deutscher Film' und 1968 mit dem Filmförderungsgesetz (FFG) erste Gestalt annimmt. Unter der Zielsetzung, „die Qualität des deutschen Films auf breiter Grundlage zu steigern und die Struktur der Filmwirtschaft zu verbessern“"183, entsteht bis heute ein System verschiedener Förderungsmaßnahmen, die in wechselseitiger Ergänzung die deutsche Filmproduktion voranbringen sollen: Für die Durchführung des FFG ist die öffentlich-rechtlich strukturierte Filmförderungsanstalt (FFA) zuständig. Ihre Arbeit wird von der Förderung des Bundesinnenministeriums (Bundesfilmpreis, Produktions- und Abspielförderung, Stipendien) ergänzt; während die FFA das Hauptgewicht auf wirtschaftliche Rentabilität legen soll, zielt die Förderung des Bundesinnenministeriums stärker einen qualitativen Standard an. Flankiert wird beider Arbeit durch das ,Kuratorium' sowie durch regionale Förderungen der Länder, die, wie die Förderung durch das BMI, primär kulturell-qualitativ perspektiviert sind. Das Film/Fernsehabkommen bemüht sich seit 1974, an die Stelle zermürbender Konkurrenz beiderseitig fruchtbare $\mathrm{Zu}$ sammenarbeit zu setzen. - Obgleich Mitte der 70er Jahre der hauptsächlich durch die Förderung entstandene ,Neue Deutsche Film' beginnt, international Aufmerksamkeit zu erregen - 1976 wird er Newsweek-Titel ${ }^{184}$-, und obgleich das Jahr 1979 großen wirtschaftlichen Erfolg bringt, gerät er in den 80er Jahren wieder aus dem Blick und in die roten Zahlen. Mit Hilfe der Förderung ist es zwar gelungen, zumindest kurzzeitig so etwas wie ein deutsches Kunst-Kino zu etablieren, nicht jedoch,

178 vgl. Neumann, Film heute, 38

179 Neumann, Film heute, 12

180 Das Manifest wird 1962 auf den Westdeutschen Kurzfilmtagen in Oberhausen von 26 damals noch unbekannten, jungen Regisseuren verfaßt, unter denen sich auch Alexander Kluge und Edgar Reitz befinden. Von diesen und Peter Schamoni abgesehen, können sich jedoch nur wenige später durchsetzen. Gleichwohl bleibt das Manifest richtungsweisend für die Folgezeit. Im Auftrag der Manifestanten gründen Kluge und Reitz zudem das ,Institut für Filmgestaltung Ulm' an der Hochschule für Gestaltung.

181 Oberhausener Manifest, zit. nach: Pflaum/Prinzler, Bundesrepublik, 9

182 Oberhausener Manifest, zit. nach: Pflaum/Prinzler, Bundesrepublik, 9

183 Einleitungstext des Gesetzes, zit. nach: Neumann, Film heute, 69

184 vgl. Pflaum/Prinzler, Bundesrepublik, 32 
gegen den Konkurrenzdruck v.a. der amerikanischen Anbieter einen vergleichbaren wirtschaftlichen Erfolg zu setzen ${ }^{185}$. Der weitgehend offene Markt Bundesrepublik bleibt von außen bedrängt. Durchaus logische Konsequenz ist die internationale Orientierung namhafter deutscher Regisseure, die einer Produktion im Ausland, nicht zuletzt in den Vereinigten Staaten, keineswegs abgeneigt sind.

Die vorstehende Skizze der ökonomischen Entwicklung des Films nun verdeutlicht, da $B$ dieser in der Tat ein ökonomisch (mit-)determiniertes Phänomen ist. Er wird rasch von der modernen Ökonomie an sich gezogen und nachhaltig geformt und weiterentwickelt. Zunächst ist erkennbar, daß schon die Vorgeschichte des Films unter den Bedingungen der modernen Industriekultur stattfindet, wie etwa an der rationalen Industrialisierung der Fotografie oder den rationalisierten Bedingungen der Arbeit im Labor Edisons deutlich wird. Alle Schritte zum Film sind jeweils bereits für sich von ökonomischen Verwertungsabsichten begleitet. Der Film selbst wird dann unter industriellen Bedingungen und Zwecksetzungen entwickelt und das einzelne Filmwerk ist von vorneherein Ware. So sorgt die ökonomische Rationalisierung schon bald für eine rationale, d.h. arbeitsteilige Produktion und eine publikumsorientierte Produktionsplanung. Ohne profitable Auswertung im Kino (später auch im TV und durch Video) ist der Film gar nicht denkbar. Dabei macht sich besonders in der Frühzeit das innovative Moment moderner ökonomischer Rationalität bemerkbar, das für unternehmerische ,Pionierleistungen' bei der Entdeckung neuer Exploitationsmöglichkeiten des Mediums und neuer Märkte sorgt und sich zugleich inhaltlich auf den Film auszuwirken beginnt. Das tritt schon in der Erkenntnis der Lathams zu Tage, daß eine kommerziell, d.h. am Zielpublikum und den Zeitumständen bzw. deren Moden orientierte Produktion not tut. Auch die Entstehung von Sujets und Genres kann auf diesem Hintergrund gesehen werden. Divenkult, Starsystem und Blockbuster-System (eine Marktstrategie, die durch gigantischen Produktionsaufwand kommerziellen Erfolg sichern will) sind Konkretionen dieser Tatsache. Die moderne dynamisch-rationalisierte Ökonomie erscheint so als wesentlicher Motor für die Etablierung einer Vielfalt von Filmformen und Inhalten, so daß die ökonomische Rationalisierung als wesentliches Konstitutivum des Films gelten kann. (Lediglich die kontramodernen Einbrüche des Nationalsozialismus und Kommunismus obstruieren den Gang der modernen ökonomischen Rationalisierung zeitweilig.) Monopolistische Tendenzen im nationalen wie internationalen Rahmen ebenso wie diversifikative Eingliederung des Films in eine heterogene Produktpalette lassen sich schließlich in neuerer Zeit als Eigentümlichkeiten der ökonomischen Betreuung und

${ }^{185}$ Worin nun genau die Gründe zu suchen sind, daß das Unterfangen Neuer Deutscher Film mehr oder weniger gescheitert ist, bedürfte einer eigenen Untersuchung. Zweifellos hat Neumann recht, wenn er auf die ,Schwerverdaulichkeit' mancher der hierbei entstandenen Produktionen verweist; auch eine Veränderung der Publikumspräferenzen und eine gewisse Unbeweglichkeit der ,Filmemacher" mag hier eine Rolle spielen. (vgl. Neumann, Film heute, 17, 20-23) Trotzdem scheint mir das nur ein Teil der Antwort zu sein. Das Fehlen von Importbeschränkungen für den bundesrepublikanischen Markt macht es sowohl schwer, selbst publikumsträchtige Produktionen zu lancieren, als auch, ein Publikum erst zu erziehen und heranzubilden. Darüber hinaus mag die Tatsache, daß durch v.a. amerikanische Produktionen der sogenannte ,Unterhaltungsfilm-Sektor' durchaus ökonomisch zufriedenstellend abgedeckt werden kann, die Entwicklung gerade eines deutschen Kunstkinos in der Nische der Förderung begünstigt - um nicht zu sagen: gefordert - haben. 
Bestimmung des Films erkennen. All diese Momente ordnen den Film deutlich der Moderne und ihren Strukturen ein. Sie zeigen erneut, da $B$ der Film als Medium erst unter diesen Bedingungen in seiner Spezifität entstehen konnte.

Zugleich aber stellen diese Bedingungen und Determinationen in anderer Hinsicht ein recht heterogenes und in sich widersprüchliches Strukturbild vor. So ließ die ökonomische Determination zusammen mit einer prekären, der Differenziertheit der Inhalte und der Vielfalt der Filmformen hinderlichen Monopolisierung - v.a. im internationalen Rahmen - auch eine Tendenz zur Beharrung auf bereits erfolgreichen Marktstrategien erkennen, die dem innovativen Strukturmoment moderner Wirtschaft ebenso wie der lebendigen, kreativen Weiterentwicklung des Films entgegenstehen. Diese Tendenz wird erstmals schon am Beispiel Pathés sichtbar, wobei Pathés Unternehmung noch als eine Expansion gewertet werden kann, die primär auf unternehmerische Pionierleistungen zurückgeht. Die Expansionen der amerikanischen Filmindustrie und die Internationalisierung des Films heute stellen dagegen weitaus mehr eine strukturelle (und damit triebkräftigere) Notwendigkeit im Kontext der generell greifbaren, internationalen ökonomischen Verflechtungen dar, der sich auch ,binnenorientierte' Filmindustrien oft nur schwer entziehen können. In der Folge geraten dann mitunter Binnenmärkte und ihre spezifischen Forderungen zu ökonomisch angesichts des Produktionsaufwands uninteressanten Absatzbereichen, die es geraten sein lassen, einen Verlust von Publikumsteilen auf dem Binnenmarkt zugunsten internationaler Auswertung einer Produktion in Kauf zu nehmen. Nationale Spezifika, binnenbezogene Thematiken und aktuelle Fragestellungen als potentielle Filminhalte drohen hierdurch in der Produktion zurückgedrängt zu werden, und eine nicht sofort auf eine globale Skala gerichtete gesellschaftliche Kommunikation wird in ihrer filmischen Vermittlung behindert. Sehr fruchtbare Projekte, wie etwa die Auseinandersetzung R. W. Fassbinders mit der bundesdeutschen Geschichte in der Trilogie seiner Frauenfilme stellen sich unter dieser Perspektive als ökonomisches Risiko dar, das entweder durch Filmförderung getragen oder in der von einer industriellen Diversifizierung ermöglichten, ökonomischen Nischenstruktur eingerichtet werden muß. Die Steigerung des technischen Produktionsstandards und die damit verbundene Kapitalintensität, die oft eine vorrangig internationale Amortisationsbasis fordern, können zusätzlich solche Nischen unerfreulich beschränken.

Gleichwohl war andererseits zu sehen, daß aus der ökonomischen Kondetermination von Form und Inhalt des Films noch nicht unmittelbar auf etwa eine dauerhafte Standardisierung oder einen nachhaltigen Ausschluß von kreativer Innovation geschlossen werden kann. Aufgrund ihrer notwendigen Publikumsverwiesenheit zeigt die Ökonomie des Films vielmehr, daß sie, obschon sie Tendenzen zu Statifizierung durch monopolistisches Hegemoniestreben, Codes und Orientierung auf international profitable Rezipierbarkeit erkennen läßt, solche Statifizierungsunternehmungen immer wieder aus ebenfalls ökonomischen Gründen durchbrechen muß. Angesichts eines binnenmarktbezogen zunehmend schichtübergreifenden und heterogenen Publikums, das sich nicht allein mit serialisierten und internationalisierten Produktionen dauerhaft interessieren läßt, sowie der gesellschaftlich-diskursiven Prozessualität, die eine ständige Veränderung auch der filmbezogenen Erwartungshaltung bedingt, erfordert der Erhalt einer profitablen Stellung auf dem Markt große Flexibilität, Diffe- 
renzierungsbereitschaft und stetige Innovation. Diese Binnenmarktsituation flexibilisiert auch den internationalen Markt und macht ihn - entgegen einer Profitsicherung durch schablonisierende Produktionsstrategien - schwer kalkulierbar. Darüber hinaus erweisen sich die Konnexion mit Fernsehen und Video sowie die industrielle Diversifizierung der Gegenwart als für kreative Inputs hilfreich: Die Publikumsstreuung und -fülle des Fernsehens und dessen tagesübergreifende Präsenz ermöglichen eine Differenzierung des Angebots auf Zielgruppen hin, die einer um breiter Rezipierbarkeit willen vorgenommenen Nivellierung der Gehalte entgegenwirken kann. Ebenso erlaubt die Diversifizierung das ,Mittragen' von wenig publikumsträchtigen Experimenten und Innovationen. Ähnlich dem Buchmarkt, der gleichfalls Profite aus breitenwirksamen Produktionen für als kulturell wichtig erachtete, jedoch wenig profitable Produkte ,abzweigt', eröffnet so auch die Diversifizierung Nischenstrukturen und Räume für ,unpopuläre‘ Kreativität. Selbst unter einer monopolistischen Tendenz bleiben derart über den Marktmechanismus, der zur Orientierung am Publikum zwingt, und durch die genannte Profitumleitung kreativitäts- und pluralitätsfördernde Strukturmomente erkennbar, die einer einlinigen Interpretation ständiger ökonomistischer Verhinderung von Differenzierung und innovativer Initiative widersprechen.

Die industrielle Geschichte des Films zeigt sich also als eine Geschichte sehr heterogener und in sich auch widersprüchlicher Entwicklungen, Tendenzen und Strukturen, die die Determination des Films durch die moderne rationalisierte und dynamisierte Ökonomie als eine konfliktuöse erscheinen lassen. Eine einlinige, inhaltsspezifische Auslegung dieser Determination, die die Konstitution der inhaltlichen Entwicklung des Films einzig auf publikumsstrukturelle Einflüsse oder auf die Produktplanung der Kapitalgeber zurückführt, untersagt sich deshalb. Der Einfluß der modernen ,Innovativwirtschaft' scheint sich vielmehr zwischen den beiden Polen Monopolisierung/Standardisierung und unabhängige Innovation/Diversifizierung/ Vielfalt anzusiedeln und mehr ein ständiges Hin und Her zu evozieren, als auf einem ,monopolkapitalistischen' oder ,pionierökonomischen' Strukturgesetz zu beruhen. Die in diesem Zusammenhang wiederholt erwähnte Publikumssituation, die hier zunächst als Situation der Nachfrage und damit des Absatzmarkts im Blick stand, verweist jedoch zugleich auf eine weitere Determinante des Mediums Film: Zusammen mit den Umschichtungen der bürgerlichen Gesellschaft zur Industriegesellschaft nämlich wandeln sich die Kommunikationsstrukturen und entsteht ein neues Publikum der bürgerlichen Publizität. Nach den technischen und ökonomischen Determinanten soll dieser kommunikativen, publikumsstrukturellen Determinante im folgenden nachgegangen werden.

\subsection{Kommunikation und Öffentlichkeit in der Moderne: Film im Rahmen der gewandelten Kommunikationssituation in der Industriegesellschaft}

Film entsteht als neues Medium neben den Printmedien zu einem Zeitpunkt, als die mediale Kommunikation bereits aus der Beschränkung auf kleine Kreise, die zumeist als gesellschaftliche Schichten erfaßbar sind, herausgelöst und zur Massenkommunikation geworden ist. Er steht in einem gewandelten Kommunikationszusammenhang, in dem nicht mehr nur die Mitglieder eingegrenzter Zirkel miteinan- 
der in Kontakt treten und Austausch pflegen, sondern potentiell alle Gesellschaftsmitglieder sich als Subjekte solcher Kontaktnahme verstehen und entsprechende Möglichkeiten hierfür zu requirieren beginnen. Der Film ist eine dieser requirierten Möglichkeiten - und er kommt den Erfordernissen der neuen Kommunikationssituation hervorragend entgegen: Von Beginn an ist er Medium für ,die Massen', d.h. eine zahlenmäßig möglichst umfangreiche Rezipientenschaft. Schon seine Rezeptionsform in öffentlichen Räumen wie Cafes, Schaubühnen, Wirtshäusern und - im Verlauf seiner Geschichte rasch zunehmend - Kinos verweist darauf; auch die gegenwärtige Form reprivatisierter Rezeption über TV und Video legt es auf ein ,Millionenpublikum' an. Damit fördert der Film zugleich die in der neuen kommunikativen Situation gegebene Tendenz zur Aufsprengung von Schichtgrenzen. Weil er auf das ,große Publikum' zielt, will er von vorneherein potentiell alle Mitglieder einer Gesellschaft als Rezipienten. Seine Zuschauer können nicht mehr nur von einer Schicht oder einer Zielgruppe gestellt werden. Das neue, pictoriale Medium, das Ende des 19. Jahrhunderts entsteht, richtet sich endgültig für jene zunehmend schichtübergreifenden Publikumskonglomerate ein, die sich im Zuge der Industrialisierung vor allem in den großen Städten bilden und deren kulturelles Bedürfnis eine andere Form von Kultur fordert: eine Massenkultur. Es ist damit in besonderer Weise bedingt durch und verklammert mit einer sozialstrukturellen Entwicklung, die als Verbreiterung der Öffentlichkeit und Errichtung eines gesamtgesellschaftlichen Kommunikationszusammenhangs beschrieben werden kann.

In dieser sozialstrukturellen Entwicklung wiederum, in der Entstehung dieses Kommunikationszusammenhangs und seines Publikums, wird nun die Verklammerung der Medien und des Films mit dem Projekt der Moderne in seiner eigentlichen Bedeutung wirksam. War unter technikgeschichtlichem und ökonomischem Aspekt vordringlich die Determination des Films durch die moderne Form von Technik und Ökonomie im Blick, so läßt sich nun eine Wechselwirkung erkennen: Die Medien und der Film nehmen an diesem Strukturmoment des Projekts der Moderne, an der Veränderung der Öffentlichkeit und der Heraufkunft einer demokratischen Gesellschaftsstruktur nun konstitutiven Anteil. Sie bedingen die Realisierung der ideengeschichtlichen Axiomatik des Projekts der Moderne in diesem Bereich mit. Wie sich nämlich zeigen läßt, erweisen sich die Medien als Beförderer der Entstehung eines seiner selbst bewußten Massenpublikums im Sinn einer auf gesellschaftliche Mitsprache abstellenden Öffentlichkeit und damit geradezu als Durchsetzungsinstrumente der vom Projekt der Moderne gesetzten Vorstellung des autonomen, vernunftbegabten Subjekts, das aufgrund seines Subjektstatus in allen öfentlichen Belangen mitspracheberechtigt ist. Verstärkt wird dieser grundsätzliche Durchsetzungsprozeß noch durch das Zusammentreffen der von den Medien eingerichteten Kommunikationsstruktur mit der im 19. Jahrhundert gegebenen Ansammlung der Massen in den Städten. Auch diese Massen treten in den medial vermittelten Kommunikationsproze $B$ ein und requirieren dadurch zunehmend Mitspracherechte sowie den diesen Rechten zugrundeliegenden Subjektstatus. Damit sorgen die Medien für eine Verbreiterung der Öffentlichkeit und eine ,soziale Universalisierung der begriffslogisch bereits universell angelegten Bestimmung des Menschen als vernünftigen Subjekts. Im folgenden will ich daher die medial veränderte Kommunikationsstruktur der Moderne und ihre interaktive Bedeutung für eine Verbreiterung der 
Öffentlichkeit und eine zunehmende soziale Einforderung der Axiomatik des Projekts der Moderne skizzieren. Dabei werde ich auch den Film in diesem Kontext situieren und seine Relevanz für den genannten Prozeß verdeutlichen.

Eine erste spezifisch medial vermittelte Konstitution von Öffentlichkeit läßt sich dabei nun bereits vorneuzeitlich in der Reformation ausmachen, deren Kampf massenwirksam publizistisch begleitet wird: So regt Martin Luther selbst dazu an, die Möglichkeiten des Buchdrucks und insbesondere der Druckgrafik zur Aktivierung der Stände und des Volks zu nutzen; vor allem die Karikatur wird auf diese Weise als öffentlichkeitswirksames Agitations- und Kommunikationsmittel eingesetzt ${ }^{186}$. Gleichwohl läßt sich darin nur eine gewisse Vorform der nach dem bisher Gesagten in Frage stehenden Entwicklungen ausmachen. So kann von Massenkommunikation hier nur sehr eingeschränkt, von einer Massenkultur und entsprechenden Auswirkungen auf ein zunehmend politisiertes Publikum noch kaum gesprochen werden. Zwar ergibt sich eine Vermittlung zwischen voneinander räumlich und personell getrennten Gruppen miteinander, die nur durch die Printmedien in Kontakt kommen, und zieht der Religionsstreit politische Veränderungen nach sich. Doch geht es hierbei noch nicht um genuin politische Mitspracherechte und bleiben die gesellschaftlichen Strukturen, die bestehenden politischen Kompetenz- und Machtzuteilungen weitgehend anerkannt. Eine politisch virulente Öffentlichkeit, die auf Umgestaltung der gesellschaftlichen Strukturen als solchen zielt, entsteht erst im Zusammenhang mit der Herausbildung eines spezifischen Publikums für Kultur und mit der Einrìichtung einer bürgerlichen Öffentlichkeit. Vor dieser Herausbildung ist Kultur - Musik, Theater, Malerei - zunächst weitgehend höfisch gebunden, nicht zuletzt, weil ökonomisch vom Hofe abhängig, und ist Öffentlichkeit eine repräsentative Öffentlichkeit der Fürsten und am Hofe. Sie ist im Sinne eines Status mit kodifizierten Verhaltensmerkmalen zu verstehen und stellt die Zelebration einer Standesidentität vor, nicht aber eine kommunikative, gesellschaftliche Sphäre ${ }^{187}$.

Eine solche entsteht vielmehr im späten 17. und im 18. Jahrhundert. Dort findet der entscheidende erste Schritt statt, wenn sich das zunehmend florierende Zeitungswesen und die allmählich etablierten Unternehmungen der Salons, der Kaffeehausgesellschaften und politischen Clubs zu verbinden beginnen und eine Art ,literarische Öffentlichkeit' entstehen lassen. Die Wurzeln des Zeitungswesens reichen dabei bis ins 13. Jahrhundert zurück, wo aus den Notwendigkeiten des Fernhandels heraus bereits ein Kommunikationsnetz geschaffen wird. Dieses Netz kann und will jedoch noch nicht Öffentlichkeitscharaker beanspruchen. Der Nachrichtenverkehr dient daselbst noch den wirtschaftlichen Privatinteressen und wird daher privativ, d.h. unter bewußtem Ausschluß fremder Zugänge, gehandhabt. Gegen Ende des 17. Jahrhunderts aber, als Zeitungen beginnen, regelmäßig Nachrichten in allgemeiner Zugänglichkeit zu verbreiten, entsteht eine „publizistisch bestimmte Öffentlichkeit“"188, die sich der repräsentativen entgegenzusetzen beginnt. Nicht nur über den

186 Luther fordert etwa dazu auf, ,das edle Götzengeschlecht des Antichrist mit Malen anzugreifen" (vgl. Fuchs, Karikatur I, 71) und wird so zum Vorreiter einer kirchenpolitisch-agitatorischen Nutzung nicht nur des Flugblatts und der Streitschrift, sondern eben auch der Karikatur, deren Bildlichkeit für die leseunkundigen Massen rezipierbar ist.

187 vgl. Habermas, Strukturwandel, 20-21, 24-25

188 Habermas, Strukturwandel, 30 
Warenverkehr, sondern auch über den Nachrichtenverkehr konstituiert sich so eine neue Sphäre der Gesellschaft. Ihre Träger sind die ,Bürgerlichen', die sich aus Handelskaufleuten, Bankiers, Verlegern und Manufakturisten rekrutieren. Sie stellen das eigentliche Publikum dar, ,das von Anfang an ein Lesepublikum ist “"189. Zeitschriften ergänzen im letzten Drittel des 17. Jahrhunderts dann die Zeitungen ${ }_{2}$ und neben reinen Nachrichtenaustausch treten pädagogische Belehrungen, Kritikén und Rezensionen $^{190}$; das Publikum beginnt sich zu einem gebildeten zu entwickeln und findet seinen internen Kontakt und sein Selbstbewußtsein durch die printmediale Vermittlung.

Andererseits breiten sich im 18. Jahrhundert zunehmend die Diskutierklubs der Kaffeehäuser und Salons aus; sie befleißigen sich, wie die Zeitschriften, eines breiten Themenspektrums und institutionalisieren unmittelbar einen Diskurs. In der Verbindung mit den Unternehmungen des Zeitungs- und Zeitschriftenwesens - periodische Druckschriften kursieren in den Salons und Kaffeehäusern und werden mitunter sogar vom dortigen Publikum herausgebracht - weitet sich die kommunikative Sphäre bereits über den eigenen Zirkel hinaus aus und beginnt andere ,Gesellschaften' in den ,gebildeten Discours' mit einzubeziehen. Überregionale Kontakte und Diskussionen entstehen, die bald die ,rein kulturellen' Themen durch politische ergänzen. Unvermeidliche Auseinandersetzungen mit der ,Obrigkeit' lassen dann dieses kommunikativ konstituierte Publikum sich zunehmend als einer bürgerlichen Öffentlichkeit bewußt werden ${ }^{191}$, das auf seine eigenen diskursiven Kompetenzen pocht und sich ein Recht zu deren Ausübung reserviert. Bürgerliche Öffentlichkeit also ist die Öffentlichkeit eines Kommunikationszusammenhangs und einer abgegrenzten gesellschaftlichen Schicht. Gleichzeitig liegt darin bereits eine erste Requirierung von Mitspracherechten und eine erste Realisierung aufgeklärten Subjektbewußtseins: Das Publikum wird ein räsonnierendes und setzt sich aus jenen aufgeklärten Subjekten zusammen, die ihre Mündigkeit im Mut verkörpert sehen, „sich [ihres] Verstandes ohne Leitung eines anderen zu bedienen". ${ }^{12}$ Im 18. Jahrhundert verfestigt sich auf diese Weise eine Art Gegenöffentlichkeit, die schon eine - freilich noch schichtspezifische - Gleichrangigkeit der Diskurspartner kennt. Damit ist zugleich Macht in Blick genommen; das Räsonnement greift in die Herrschaftsstrukturen ein und will an deren Gestaltung Anteil haben. ${ }^{193}$ Eine erste, freilich noch zirkelinterne,

$189 \mathrm{vgl}$. Habermas, Strukturwandel, $37-38$

190 vgl. Habermas, Strukturwandel, 39

191 vgl. Habermas, Strukturwandel, 38

192 Kant, Aufklärung, 53

193 Habermas verweist in diesem Zusammenhang darauf, daß die Neigung dieser Zeit zu Geheimbünden und Vereinigungen mit Arkandisziplin als notwendige Reaktion auf die Ungleichzeitigkeit dieser ,avantgardistischen' Entwicklung mit den Machtstrukturen des Absolutismus zu lesen seien: „Die Vernunft, die sich in der rationalen Kommunikation eines Publikums gebildeter Menschen im öffentlichen Gebrauch des Verstandes verwirklichen soll, bedarf, weil sie jedes Herrschaftsverhältnis bedroht, selber des Schutzes vor einer Veröffentlichung. Solange die Publizität ihren Sitz in der fürstlichen Geheimkanzlei hat, kann sich Vernunft nicht unvermittelt offenbaren. Ihre Öffentlichkeit ist noch auf Geheimhaltung angewiesen, ihr Publikum bleibt, selbst als Publikum, intern." (Habermas, Strukturwandel, 51) - Das kritische Moment der neuen Publizität zeigt sich publizistisch auch im Aufkommen der satirischen Zeitschriften, die nicht zuletzt die genuin politische Karikatur als kontinuierlichen (aufgrund periodischer Erscheinungsweise) Zeitkommentar entwickeln. Die Kontinuität bedeutet einen wirkmächtigen Schritt über die Print-shops in England hinaus, die ebenfalls Karikaturen vertreiben. 
Einforderung der Axiomatik, der aufklärerisch-ideellen Grundmomente des Projekts der Moderne findet statt und wird durch die Medien vermittelt und befördert.

In Konnex mit der Selbstkonstitution der bürgerlichen Öffentlichkeit steht auch die Herausbildung eines veränderten Kunst- bzw. Kulturpublikums ${ }^{194}$. Sie ist schon in der Öffnung der Hof- und Residenztheater für das ,Volk‘ angelegt, die das ,Parterre allmählich zum Raum der ,gebildeten Stände' macht. Jene beginnen nach und nach das gemeine Volk in den obersten Rang zu verdrängen und selbst „,mit der höfischen Elite zu einer großstädtischen Gesellschaft ${ }^{\star 195} \mathrm{zu}$ verschmelzen, die gegen Ende des 17. Jahrhunderts ,in literarisch-publizistischen Zusammenhängen schlechthin ,le public genannt ${ }^{\star 196}$ wird. Die Entwicklung findet eine Parallele in der Etablierung von privaten Konzertgesellschaften, welche schließlich die Kommerzialisierung von Musik, damit jedoch auch ihre Zugänglichkeit für jedermann und die Rezeption um ihrer selbst willen zur Folge hat. Das neuartige ,öffentliche Konzert' verbreitet sich von Italien her rasch über ganz Europa; in Deutschland wird es zuerst in reichen Handelsstädten zu einer ständigen Institution ${ }^{197}$. Als weitere Parallele kann noch der Weg der Malerei aus höfischer Bindung heraus in die ersten Ausstellungen der Salons und schließlich die sich institutionalisierenden Museen bezeichnet werden. Mit einem Konzert-, Theater- und Museumspublikum richtet sich ein neuer Diskurs ein: das Laienurteil über Kunst. Zuständig ist nun jeder; die Kunstfrage wird zur diskutablen und diskutierten Geschmacksfrage. Diese bringt denn auch eine neue Profession hervor, den Kunstrichter. Letzterer übernimmt eine „eigentümlich dialektische Aufgabe“, da er sich als „Mandatar des Publikums“ ebenso wie als „dessen Pädagoge" versteht ${ }^{198}$. - Auch das ,breite‘ Publikum der Kultur ist, wie das der Salons und der Publizistik, zunächst ein eingegrenzter Zirkel. Obgleich emanzipativ nach oben - nicht sofort aus der großbürgerlichen Oberschicht der Salons etwa kommt das Theaterpublikum des Parterre, sondern aus dem Bereich der Kaufleute, doch setzt es sich als gesellschaftlich achtenswert durch ${ }^{199}$ - bleibt es ,unter sich'. Eine breite Masse ist es nicht und will es auch nicht sein. Im 19. Jahrhundert erst verändert sich dies; nun entstehen die erwähnten ,Massen' und findet eine universelle Requirierung der Ideen des Projekts der Moderne, gewissermaßen deren ,Sozialisierung statt.

Vor allem aus dem Agrarbereich strömt jetzt die seit dem 14. Jahrhundert anwachsende, verarmende Bevölkerung in die Städte, um dort Arbeit zu finden. Sie ist illiterat und pauperisiert; die Pauperisierung weitet sich bis zur Mitte des 19. Jahrhunderts in einem Maße aus, das über die Industriearbeiter hinaus auch weite Kreise der Handwerkerschaft, der Kleinbauern und Tagelöhner sowie der unteren Beamtenschaft ergreift ${ }^{200}$. Es entstehen proletarisierte Bevölkerungskreise, die allein

Eine erste satirische Zeitschrift mit Karikaturen erscheint bereits 1701/1702 in Amsterdam unter dem Titel ,Äsop in Europa“ (vgl. dazu: Fuchs, Karikatur I, 21).

194 vgl. zum folgenden: Habermas, Strukturwandel, 54-60

195 Hölscher, Öfentlichkeit, 432

196 Hölscher, Öffentlichkeit, 432

197 vgl. Schwab, Konzert, 6, 197- 199

198 Habermas, Strukturwandel, 57

199 vgl. Habermas, Strukturwandel, 55

200 vgl. zur Entwicklung des Pauperismus: Abel, Massenarmut; Abel stellt sich mit seinem Buch der vulgärmarxistischen These, daß der Pauperismus erst mit der Industrialisierung entstanden sei, fundiert entgegen. 
schon durch ihre unübersehbare Anwesenheit zum Problem werden. Jenseits der ökonomischen Problematik rufen die nun zu wesentlichen Teilen in Städten versammelten Massen, die dadurch erst zu solchen werden, eine radikale Veränderung der Kommunikationssituation hervor. Sie bringen - trotz Verarmung - ein Bedürfnis nach kultureller Ablenkung und Unterhaltung mit, das aus rein numerischen Gründen nur mehr durch entsprechende Massenkommunikationsmittel befriedigt werden kann. Die Alphabetisierung, die sich ab der Mitte des 19. Jahrhunderts zunehmend durchsetzt, verschärft einerseits die Dringlichkeit des Kulturbedürfnisses, erlaubt aber andererseits auch eine erste wirksame Befriedigung desselben: Eine massenhafte Herstellung von Druckschriften wird möglich, die der Kulturverbreitung - mit welchem Niveau auch immer - dienen kann. Gleichzeitig entsteht auf diese Weise ein neues Lesepublikum, das an die Seite des etablierten bürgerlichen tritt. Je mehr die Industrialisierung ,greift', desto mehr erwirbt sich dieses neue Publikum auch die ökonomische Basis für eine entsprechende Teilhabe an Gebrauchskulturgütern, die prompt geliefert werden. Als entscheidendes Datum kann dabei der Übergang im Zeitungswesen der USA vom Abbonnementvertrieb zum Straßenverkauf 1894/96 gelten, der zeigt, daß das öffentlichkeitsbildende Publikum über den Kreis der Aristokraten, wohlhabenden Bürger und Akademiker hinausgewachsen ist und als entsprechende (ökonomische) Basis für die Fortentwicklung des Zeitungswesens gilt. Ein neuer Berufsstand, der der ,Schnellschreiber', hilft zudem, die expansiv anwachsende Nachfrage nach erzählerischen Druckwerken zu decken; billige Buchreihen und serielle Romanhefte (wie beispielsweise die ,Dime-Library' und die Pulps in den USA) sorgen nicht zuletzt für eine entsprechende Preisgestaltung für die konsumierenden ,unteren Schichten'.

Neben den Druckschriften spielt für die mediale Konstitution dieses Publikums nun auch der Film eine nicht zu unterschätzende Rolle: Die proletarisierten Bevölkerungskreise (darunter die gesamte Arbeiterschaft) nämlich sind es, die in der Frühzeit des Films dessen erste Rezipienten stellt. Ihr Kulturbedürfnis greift das neue Medium sofort bereitwillig und vorurteilslos auf. Der Film kommt ihrem Rezeptionsbereich dadurch entgegen, daß er in früher Zeit jene Orte wählt, die ohnehin schon die kulturellen Vergnügungsstätten der, unteren Schichten' darstellen: Film gibt es als Kneipen- und Kaffeehausspektakel sowie in Wanderkinos, die von Schaustellern betrieben werden (der Betrieb eines Kinos gilt dementsprechend längere Zeit als Schaustellergewerbe ${ }^{201}$ ). Neben den Zirkus und das Kneipentheater tritt er mit solchem Erfolg, daß diesen mehr und mehr das Publikum entzogen wird ${ }^{202}$. Gezeigt wird er in Vororten der großen Industriestädte und auf Jahrmärkten. Auch die Variétes nehmen ihn in ihr Programm - als Pausenfüller; mit der Zeit kehrt sich das Verhältnis hier dann um, und die Akrobaten- und Zirkusnummern werden zu Pausenfüllern zwischen den immer begehrteren Filmen. Der Film ist dem neu entstehenden - proletarischen - Publikum, was dem bürgerlichen Theater und Konzert sind - in der Bezeichnung ,Nickelodeon' für die frühen amerikanischen Kinos äußern sich daher trefflich sowohl der soziale Standort des frühen Films und seiner Rezipienten, als auch das Wesen des Rezeptionsbedürfnisses als eines kulturellen.

201 vgl. Brauneck, Frühgeschichte, 8

202 vgl. Kracauer, Caligari, 22 
Wie die Schranke zwischen den Schichten kontrafaktisch zunächst noch festgehalten wird, so liegt anfangs auch die Schranke zwischen den Kulturgütern fest. Der frühe Film mit den Zügen „eines Gassenjungen“, der „Attraktion für junge Arbeiter, Ladenmädchen, Arbeitslose, Bummelanten “ ${ }^{\prime 203}$ ist, steht dem bürgerlichen Publikum in üblem Geruch. Nicht zuletzt wohl, weil dieses spürt, daß die Publizität, der Öffentlichkeitsbereich, gewachsen ist und der Dynamik einer Verbreiterung der Sphäre der Öffentlichkeit nicht zu entkommen sein wird. Schon mit der Literarisierung der ,Massen' vergrößert sich auch das literarische Publikum. Dessen Exklusivität - hier durchaus doppeldeutig im Sinne des Ausschlusses wie auch einer standesbewußten Werthaftigkeit (,Distinguiertheit') gebraucht - erfährt sogleich unliebsame Einbußen. Die Rezeption des Kinos in den niederen Schichten erlaubt dann vorerst noch die Ausgliederung der sich unerfreulich ins Licht der Öffentlichkeit Drängenden zumindest aus dem (behaupteten) Bereich der Kultur durch Neglegierung des neuen Mediums. Gleichwohl deutet sich schon an, daß dem gesellschaftlichen Wandel insgesamt nicht mehr zu wehren sein wird. Die generellen Grundmerkmale von Öffentlichkeit und Publikum werden im ausgehenden 19. Jahrhundert unübersehbar relevant: Die gegen das Zeremoniell der Ränge durchgesetzte Ebenbürtigkeit ${ }^{204}$ wird nun auch von jenen eingefordert, deren ,Niveau' eine solche Forderung bislang nicht einmal in Erwägung ziehen ließ; die diskursive Zuständigkeit für alle gesellschaftlichen Gegenstände ${ }^{205}$ wird als Zuständigkeit aller insistiert; die durch Warenform der Kulturgüter ermöglichte Zugänglichkeit derselben für jedermann, die eine „prinzipielle Unabgeschlossenheit des Publikums“206 ${ }^{40 u r ~ K o n s e q u e n z ~}$ hat, macht die Öffnung der ,Öffentlichkeit' für die Massen zur einfachen, wenngleich als bedrohlich empfundenen Tatsache.

Dabei sind es gerade die Medien, durch deren Ausbreitung dieser Prozeß fühlbar vorangetrieben und den generellen Publikumsmerkmalen zur Durchsetzung verholfen wird. Im 19. Jahrhundert ist offensichtlich, daß mit Zunahme der Medienrezeption eine Verbreiterung des Publikums unausweichlich ist. Zusammen mit der Ausbreitung der Druckschriften in dem nun lesekundigen, jedoch noch keineswegs ,gebildeten` Publikum und mit der Nutzung des Films zur Verständigung über die ,Lage der Welt' und die eigene Position darin wächst auch das Bewußtsein der ,unteren Schichten', Teil der gesamten Öffentlichkeit zu sein. Die von der Industrialisierung auch ökonomisch allmählich über das bloße Existenzminimum hinausgehobenen Massen beginnen, zusammen mit ihrer neuen Fertigkeit auch neue, nicht bloß kulturelle, sondern gesellschaftliche und politische Bedürfnisse und Interessen zu entwickeln. Mit dem Anwachsen ihres Konsums von Medien wächst auch ihre gesellschaftliche Selbstverständigung und beginnen sie, den theoretisch schon im 18. Jahrhundert für alle Menschen behaupteten Subjektstatus mit all seinen Mitspracherechten konkret und praktisch einzufordern. Die Zirkelinternität der bürgerlichen Öffentlichkeit läßt sich nicht länger aufrechterhalten und das Projekt der Moderne wird gewissermaßen ,sozialisiert'. Die sozialstrukturelle Gesamtentwicklung kann bis zu diesem Zeitpunkt daher als Weg vom aristokratisch-bürgerlichen Publikum der

${ }^{203}$ Kracauer, Caligari, 22

${ }^{204}$ vgl. Habermas, Strukturwandel, 52

205 vgl. Habermas, Strukturwandel, 52

206 Habermas, Strukturwandel, 53 
Salons und dem bürgerlichen der Kultur, als einer gebildeten, aufgeklärten Schicht mit einer Tendenz zur Demokratisierung nach oben (innerhalb des Publikums und im Verhältnis zu den Ständen darüber gelten alle als egalitär), zu einem Medienpublikum mit einer Tendenz zur Aufsprengung schichtspezifischer Begrenzungen schlechthin beschrieben werden. Als ideengeschichtliche Triebkraft läßt sich unter den sozialen Prozessen dabei die Axiomatik des Projekts der Moderne spüren, zu deren Durchsetzung und Realisierung die Medien beitragen.

Für den Film hat jene ,prinzipielle Unabgeschlossenheit' der Öffentlichkeit dann freilich auch in der umgekehrten Richtung - von oben nach unten - Konsequenzen. Zunächst nämlich findet ein Versuch einer erneuten Etablierung schichtspezifischer Barrieren, jetzt in Bezug auf die Nutzung der Gebrauchskultur, statt, indem der Film in den Bereich der bürgerlichen Oberschichten gezogen werden soll, bevor dann nicht zuletzt durch dieses Unterfangen, das immerhin breite Kreise des, gebildeten ${ }^{6}$ Publikums an den Film heranführt, eine endgültige schichtübergreifende Filmnutzung bewirkt wird. Die eingangs erwähnte Tendenz des spezifisch massenmedial verfaßten Phänomens Film, universelle Rezeption zu erreichen, die keine Schichtspezifität mehr duldet, setzt sich also zunehmend durch und parallelisiert so den Prozeß der Verbreiterung der Öffentlichkeit und der Universalisierung von Teilhaberechten an dieser. - Zunächst aber beginnt das bürgerliche Publikum nach 1908 -, obgleich die Dominanz der Arbeiter und anderer, unterer Schichten' im Kino noch bis in die 20er Jahre bestehen bleibt - den Film in seinen eigenen Kulturbereich zu ziehen. Konsequenzen für Form und Inhalt der Filme bleiben nicht aus: In Frankreich findet der Wandel seinen Ausdruck in der formal sehr steifen,Film d'Art'-Bewegung, die durch Adaption von Hochliteratur und Bühnenstücken eine Art filmische Imitation des Theaters versucht und mit dem Auftritt berühmter Theaterakteure wirbt ${ }^{207}$. Auch in Deutschland beginnen Bühnenschauspieler, für den Film zu arbeiten; auf Seiten der Regisseure versucht sich Max Reinhardt in Literaturverfilmungen. Renommierte Autoren tun es ihnen bald gleich. 1914 gibt etwa Pinthus ein "Kinobuch“ heraus, in welchem Autoren wie Hasenclever, Lasker-Schüler, Brod, Rubiner, Zech, Ehrenstein und Pinthus selbst Scripts für Kinodramen wiedergeben, mit welchen sie die Sehweise des Films (auch literarisch) umzusetzen trachten ${ }^{208}$. Umgekehrt schreibt Hoffmannsthal 1913 ein Script für ein ,Kinodrama ${ }^{209}$. Die deutschen Expressionisten bemühen sich mit nicht geringem Erfolg um die Entdeckung ,spezifisch filmischer' Ausdrucksformen und um neue Gestaltungsweisen - hier entstehen dann erste Formen echter Filmkunst, die nicht mehr durch Übertragungen von Formen und Inhalten tradierter Künste einen entsprechenden Anspruch zu stellen versuchen, sondern Neues schaffen. - Zum anderen äußert sich das Eindringen des Bürgertums in den Kino-Bereich durch den zunehmenden Bau von Kinotheatern in den Innenstädten, deren Räumlichkeit bereits den Kinobesuch „formal dem Theaterbesuch ähnlich““210 werden läßt; sie sind häufig große, repräsentative Bauten mit entspre-

207 vgl. Gregor/Patalas, Geschichte I, 16

208 vgl. Brauneck, Frühgeschichte, 13-14

209 vgl. Kracauer, Caligari, 24; ,Kinodrama' ist in jenen Jahren auch eine Genrebezeichnung und meint jene (meist melo-)dramatischen Filme, die neben komischen und abenteuerlichen Geschichten solche mit ,Bedeutsamkeit' zu erzählen versuchen.

${ }^{210}$ Brauneck, Frühgeschichte, 8; vgl. auch: Kracauer, Kult 
chender Sitzplatzzahl und Ausstattung. Die Programmlänge wächst auf bis zu vier Stunden an, und die Teilnahme daran von Anfang bis Ende wird allgemeiner Usus ${ }^{211}$. So, wie sich das Verhalten der bürgerlichen Kinobesucher, die vorwiegend der Mittelschicht entstammen ${ }^{212}$, dem des Theaterpublikums angleicht, so verändert sich auch die Preisgestaltung: Die Eintrittpreise steigen fast auf die Höhe derjenigen für das Theater ${ }^{213}$. Das Engagement von Musikern, die auf dem Piano zu den Filmen improvisieren, liegt auf derselben Linie einer ,Verfeinerung' des äußeren Rahmens gemäß den überkommenen, bürgerlichen Kunstvorstellungen ${ }^{214}$. Die Rede vom ,Lichtspieltheater' illustriert die Entwicklung auf sprachlicher Ebene.

Gleichwohl treiben diese Versuche einer Requirierung des Films duch die ,Gebildeten' letztlich nicht die erneute Ausgliederung der ,unteren Schichten' aus dem Kulturbereich Film aus sich hervor, sondern sorgen sie nur für eine Durchmischung der Rezeptionskreise und damit für eine zunehmende Auflösung von Schichtgrenzen auch in diesem Bereich. Ab 1910/1917 kann man sowohl in Europa als auch in den USA weitgehend von einer solchen Durchmischung sprechen; zwar zeichnen sich unterschiedliche Präferenzen im Bereich der Genres, wie auch oft räumliche Trennung der Rezipienten (durch Entstehung gewissermaßen schichtspezifischer Kinos) ab, doch wird das Medium von allen Schichten genutzt und werden die Grenzen damit durchlässig. In den 20er Jahren findet sich in Deutschland kurzzeitig eine Phase, in der versucht wird, den Film als Instrument revolutionärer Pädagogik für die Arbeiterbewegung fruchtbar zu machen, sozialen Realismus ins Kino zu bringen und die Schichterweiterung gewissermaßen von unten her umzukehren. Die angezielte ,Abkehr vom bürgerlichen Film' vermag jedoch diesen nicht mehr zu verdrängen, ebensowenig wie das Bürgertum v.a. der in dieser Zeit teilweise proletarisierten, jedoch aufstrebenden Mittelschichten ${ }^{215}$ aus den Lichtspielhäusern zu vertreiben ist. Trotzdem bringt der Versuch eine gewisse Innovation mit sich; einerseits entsteht eine naturalistische Schule ,Neuer Sachlichkeit', deren hervorragendster Vertreter in Deutschland G.W. Pabst wird, andererseits versucht insbesondere die kommunistische Szene, so etwas wie einen Diskurs zum Film speziell im Bereich der Arbeiterschaft in Gang zu setzen ${ }^{216}$. Filmkritiken werden auch in der Arbeiterpresse gebräuchlich. In der Sowjetunion bemüht der Film sich in diesen Jahren explizit um

211 vgl. Brauneck, Frühgeschichte, 8; in den Kneipenkinos war ein reges Kommen und Gehen die Regel.

${ }^{212}$ Eine Schichtveränderung, die sich allenthalben zeigt: in Frankreich im Zusammenhang mit der erwähnten Film d'Art-Bewegung, in den USA zur Zeit des Oligopols, und in Deutschland um 1910/1914. (vgl. Prokop, Soziologie, 64-66; Altenloh, Soziologie)

$213 \mathrm{vgl}$. Altenloh, Soziologie, 19; Altenloh verweist auch auf die Veränderung der Konventionen im Bereich der Kleidung: „Man sieht heute in den Logen elegante Toiletten, besonders bei Premieren - vor zwei Jahren noch ein Ding der Unmöglichkeit." (ebd. 19) - Die Nickelodeons hatte man noch in ,Alltagskluft" aufgesucht; nicht zuletzt, da Arbeiter häufig direkt von der Arbeitsstätte ins Kino gingen.

214 vgl. Altenloh, Soziologie, 20

215 Die Verarmung der Mittelschichten in den 20er Jahren stellt diese weitgehend der, Arbeiterklasse' gleich, doch werden die Schichtgrenzen nach unten auf der Ebene einer Art Standesbewußtsein peinlichst gewahrt. Kracauer weist darauf hin, daß der Versuch der Identifizierung nach oben hier eine Solidarisierung mit den unteren, ebenso proletarisierten Bevölkerungskreisen verhindert. (vgl. Kracauer, Caligari, 141-142)

${ }^{216}$ vgl. dazu die reichhaltige Dokumenation von Kühn, Tümmler und Wimmer: Kühn, Arbeiterbewegung 
eine revolutionäre Pädagogik und wird als ,Revolutionsfilm' auch in Westeuropa stilbildend wirksam. In den USA gelingt es den Filmen Chaplins, ein Unterschichtspublikum, das sich in seinen Sujets trefflich wiederzuerkennen vermag, gleichermaBen wie ein mittelständisches zu interessieren. Die Sondersituation als Einwandererland weist dem noch ,stummen' Film dort ohnehin eine verbindende Funktion zu. Mit den Monumentalfilmen Griffiths (noch aus den Jahren um 1916/17), den Melodramen Sternbergs und Stroheims sowie den Komödien und Historienfilmen Lubitschs gewinnt das Kino in den USA gleichzeitig ein spezifisch bürgerliches Publikum. - Jenseits aller didaktischen Versuche etabliert sich der Film in den 20er Jahren allenthalben für eine breite Rezipientenschaft; er wird ,salonfähig' für das Bürgertum und Diskursgegenstand auch in oberen Kreisen.

Die Differenzierung des Nutzungsumfangs nach Schichten ab den 30er Jahren läßt sich dann wie folgt skizzieren: Der Übergang vom Unterschichts- zum Mittelschichtspublikum während des amerikanischen Oligopols hat sich bis zu den 30er Jahren allenthalben durchgesetzt, ohne daß die Unterschicht die Kinos völlig verlassen hätte. In den Jahren bis 1946 in den USA und bis ca. 1956 in Europa stellt das Kino eine der bedeutendsten Attraktionen für die Freizeitgestaltung in den Industriegesellschaften dar und hat es quer durch die Schichten Konjunktur. Legt man die in der amerikanischen Soziologie gebräuchliche (Grob-)Unterscheidung von vier Schichten: Unter-, untere Mittel-, obere Mittel-, und Oberschicht, zugrunde, so zeigt sich, $\mathrm{da} B$ in den genannten Jahren die untere Mittelschicht das Hauptkontingent an Filmrezipienten stellt ${ }^{217}$. Zugleich läßt sich ein Trend zum Kinobesuch bei Personen mit mittlerer und höherer Schulbildung - zumindest in den USA - beobachten ${ }^{218}$. In den USA wie in Europa stellen dabei die Altersgruppen zwischen 17 und 20 bzw. unter 25 Jahren den größten Anteil des Filmpublikums ${ }^{219}$.

Mit der Veränderung der Freizeitmöglichkeiten durch insbesondere die Motorisierung und das Fernsehen nach 1946 (in Europa nach 1956) wandelt sich das Bild ein wenig. Die untere Mittelschicht zieht sich in den USA aus dem Kino etwas zurück ${ }^{220}$, nicht jedoch vom Filmkonsum, der nun vorwiegend über TV geschieht ${ }^{221}$. Die Häufigkeit des Kinobesuchs in der Unterschicht wächst hingegen, je näher diese an die untere Mittelschicht heranreicht ${ }^{222}$. Analysen der deutschen Situation haben ergeben, daB hier die untere Mittelschicht und ebenfalls die nahe an sie heranreichenden Teile der Unterschicht große Kontingente der Kinobesucher stellen ${ }^{223}$. Besonders selten besuchen Angehörige der Oberschicht in den USA und in Europa das Kino $^{224}$. Die Altersverteilung erhält sich; im Alter von 16 bis 24 Jahren zählt der Film zu den häufigst genutzen Medien ${ }^{225}$. Insgesamt kann man sagen, daß keine Schicht

217 vgl. Prokop, Soziologie, 123-127

218 vgl. Prokop, Soziologie, 127; Prokop, Soziologie, 262 zeigt, daß dies gegenwärtig auch für die Situation in Deutschland zutreffend ist.

219 vgl. Prokop, Soziologie, 127

220 vgl. Prokop, Soziologie, 183-184

221 vgl. dazu auch: Prokop, Soziologie, 263-264; Prokop nimmt dort eine Differenzierung nach Filmarten vor.

222 vgl. Prokop, Soziologie, 186

223 vgl. Prokop, Soziologie, 186

224 vgl. Prokop, Soziologie, 185

225 vgl. Prokop, Soziologie, 184 
vom Kinobesuch völlig Abstand nimmt; durch die Verbreitung des Fernsehens wird die Rezeption von Film in allen Schichten noch gefördert.

Präferenzen nach Genres können innerhalb der einzelnen Schichten festgestellt werden; sie haben nicht zuletzt, wie schon aus der Film d'Art-Bewegung erhellt, Anteil auch an deren Entwicklung. Grobstrukturell zeigt sich eine Präferenz des ,Unterhaltungsfilms' in allen Schichten. Die oberen Schichten bevorzugen dabei Unterhaltung mit kulturellem Anstrich oder ,Kunstvalenz' (,gehobene Unterhaltung"), d.h. die Genres des biographischen oder historischen Films sowie Literaturverfilmungen $^{226}$. Die unteren Schichten neigen zur ,unproblematischen', leichten Unterhaltung, d.h. zu den Genres der Komödie, des Lustspiels etc ${ }^{227}$. Quer durch alle Schichten besteht eine Vorliebe für Abenteuer im weitesten Sinne ${ }^{228}$. Daneben entstehen Präferenzwellen, wie etwa die Konjunktur der sozialkritisch getönten Kriminalfilme der ,Schwarzen Serie' in den 40er Jahren, des Western in den 50er/60ern, der Sciencefiction in den 70ern oder des (genrekombinatorischen) Actionfilms in den 80ern deren Genese jeweils multifaktoriell angesetzt werden muß. Zeitereignisse, historische Umstände und gesellschaftliche Aktualitäten wären hier zu berücksichtigen; so hat etwa zweifelsohne die Erfahrung der Depression und des Zweiten Weltkriegs die Entstehung der ,Schwarzen Serie' ebenso mit bedingt wie die hohe Rezeptionsbereitschaft für diese Filme zu dieser Zeit ${ }^{229}$.

Die Entstehung und Weiterentwicklung des Films geschieht - so kann nun festgestellt werden - unter den Bedingungen einer veränderten Publikums- und Öffentlichkeitsstruktur und ist in den weiteren Kontext der allmählichen Realisierung der Ideen des Projekts der Moderne zu stellen. Aus diesem Kontext nämlich wird die sozialstrukturelle Veränderung der Öffentlichkeitssphäre erst auf ihre ideengeschichtliche Dynamik hin durchsichtig. So ist sie im Innersten getragen von der Idee des autonomen Subjekts, das durch seine Vernunftbegabtheit zur Gestaltung seiner Lebens- und Gesellschaftsverhältnisse sowohl befähigt als auch berechtigt ist und entsprechend auf zunehmende sozialstrukturelle Garanz und Einlösung entsprechender Mitsprachemöglichkeiten drängt. Die Durchsetzung des damit gesetzten Anspruchs wird angestoßen durch die privaten Zirkel des 18. und 19. Jahrhunderts, jedoch erst unter maßgeblicher Beteiligung der Medien realisiert, die dann auch den Einzug der Massen in den Raum der Öffentlichkeit befördern und vermitteln. Als sozialhistorische Voraussetzung dieser Verbreiterung der Öffentlichkeit erscheint dabei die Versammlung großer Bevölkerungskreise in den Städten zu ,Massen', deren Kulturbedürfnis durch die Alphabetisierung sowohl verstärkt als auch mit Hilfe von Druckerzeugnissen erstmals beantwortbar wird. Das Massenpublikum wird zum Medienpublikum (und damit eigentlich erst ein solches), wie zuvor bereits das bürgerliche selbst eigentlich ein Medienpublikum oder zumindest ein medial vermittel-

226 vgl. Prokop. Soziologie, 112- 114, 214

227 vgl. Prokop. Soziologie, 112, 214

228 vgl. Prokop, Soziologie, 112

${ }^{229}$ Die Bedeutung des Films für die soziale Kommunikation, seine Rolle als Zeitkommentator und gesellschaftliche Reflexionszone treten hier in den Blick. Darauf ist später noch genauer zurückzukommen. 
tes gewesen ist ${ }^{230}$. Die prinzipielle Zugänglichkeit der Medien(-produkte), die durch ihren Warencharakter gegeben ist, und die durch Alphabetisierung und Schulgesetzgebung erreichte Anhebung des Bildungsniveaus sorgen für eine zunächst unliebsame Ausweitung des Publikums, für eine Öffnung des abgegrenzten Zirkels der bürgerlichen ,Gelehrtenrepublik' zur Gestalt allmählicher, demokratischer Öffentlichkeit. Was sich im Bereich der literarischen Publizität schon ab der Mitte des 19. Jahrhunderts abzeichnet, wird im Bereich des Films ab 1910 spürbar: Aufgriff, Bearbeitung und Rezeption des neuen Mediums in allen Schichten. Film ist sofort Massenmedium - zunächst für die proletarisierten Bevölkerungskreise; der Umfang der ,Massen` erweitert sich dann rasch quer durch die Sozialstruktur der bürgerlichen Gesellschaft. Damit wird der Film Teil der im 19. Jahrhundert zunehmend etablierten Kulturgestaltung und -verteilung mit Hilfe technischer Mittel, über ökonomisch eröffnete Kanäle und durch solcherart entstehende Medien. Er trägt in dieser Funktion zur ,Sozialisierung‘, zur Durchsetzung des Projekts der Moderne auf breiter Basis bei.

Das in dieser neuartigen Kommunikationssituation einer verbreiterten Öffentlichkeit und eines veränderten Kulturpublikums entstehende Medium Film entwikkelt sich schnell formal und inhaltlich weiter. Es differenziert Genres und Darstellungstechniken aus und entfaltet eine Stilgeschichte. Seiner Binnendifferenzierung soll in einem letzten Punkt noch nachgegangen werden.

\subsection{Binnenorientierung: Notizen zu Stilgeschichte und Genreentwicklung}

Filmgeschichte als Stilgeschichte auch nur annähernd erschöpfend zu schreiben, erforderte ein Buch. Das Unterfangen wurde zudem - insbesondere unter kunstgeschichtlichem Aspekt ${ }^{231}$ - bereits mehrfach geleistet, so daß hier darauf verzichtet werden kann, es wiederholen zu wollen. Eine diesbezügliche Lücke muß nicht mehr geschlossen werden. So soll es im folgenden lediglich darum gehen, durch Deskription einiger zentraler formalästhetischer und inhaltlicher Entwicklungen eine Binnenorientierung zu ermöglichen, die den Film als ästhetisches Phänomen deutlicher vor Augen stellt. Technische und ökonomische Determinanten spielen freilich in diese Perspektive hinein.

Film ist ein äußerst flexibles, anpassungsbereites und inklusionsfreudiges Medium. Er neigt von Beginn an dazu, Darstellungsformen der traditionellen Künste für sich fruchtbar zu machen, Inhalte aus deren Bereichen zu übernehmen und mit spielerischer Neugier sich alles anzueignen, was ihm umsetzbar erscheint. Bereits bei den Lumiéres zeigt er daher ein vielgestaltiges Gesicht. Zwar steht bei ihren ersten Filmen die Faszination der Bewegungsaufzeichnung und -wiedergabe derart im Mittelpunkt, da $B$ man gemeinhin konstatiert, der frühe Film habe den „Naturalismus“ im Sinn einer dokumentarischen Spiegelung der ,Realität, wie sie ist,' wieder zum

${ }^{230}$ Das gilt wiederum besonders für Deutschland, wo durch das Fehlen einer großen Hauptstadt mit zentrierender Funktion (wie etwa Paris in Frankreich) die kommunikative Vermittlung eines Publikums immer schon auf publizistische Mittel - Medien - angewiesen ist. (vgl. dazu: Hölscher, Öfentlichkeit, 433)

${ }^{231}$ So etwa Gregor und Patalas, die ihr Unterfangen einer Filmgeschichte von vorneherein als ,Einführung in die Geschichte der Filmkunst“ (Gregor/Patalas, Geschichte I, 7) ansetzen. 
Leben erweckt ${ }^{232}$, das Einfangen des Bewegten an sich sei erregend genug gewe$\operatorname{sen}^{233}$ und am Anfang der Filmgeschichte habe so die simple Faszination des Abbildrealismus gestanden. Fiktionalität ${ }^{234}$, bzw. Narrativität ${ }^{235}$ sei dann erst bei Mélies und Porter auffindbar. Doch gibt es schon in den frühen Filmen der Lumiéres narrativ-fiktionale Elemente. Der Streifen „L'arroseur arrose“ (1895) etwa, der einen Gärtner beim Gießen zeigt, stellt eine Art „Urform der Filmburleske“ ${ }^{\text {236 }}$ dar - hinter dem Gärtner nämlich erscheint ein Junge, der den Wasserfluß stoppt, indem er auf den Schlauch tritt; als der Gärtner verblüfft das Schlauchende betrachtet, gibt der Junge den Schlauch wieder frei und zum Vergnügen des Publikums spritzt sich der Gärtner nun selbst naß. Das Vergnügen an diesem Film ist sogar auf einem Werbeplakat für Lumiéres Cinématographe eingefangen (Zuschauer im Vordergrund erheitern sich und applaudieren, während im Hintergrund die Szene aus „L'Arroseur arrosé" zu sehen ist) ${ }^{237}$; gerade auch dieses Plakat dokumentiert, daß es hier nicht nur um die Faszination des Abbildrealismus geht, sondern um die Ergötzlichkeit einer ,Story oder, um präzise zu sein: einer narrativen Szene. Schon bei den Lumiéres tendiert der Film also dazu, über bloße Bewegungsaufzeichnung hinauszugehen. In ihren Katalogen finden sich zudem erste Genreeinteilungen (vgl. 1.3.); ab 1897/98 kennen sie drei Sparten, die neben Humoristischem und den ,Historiendramen“ dokumentarischen Realismus bieten. Die beiden Grundrichtungen des Films: die narrativ-fiktionale und die dokumentarisch-informationelle, sind von Beginn an vorhanden. In den Historiendramen zeigt sich die genannte Bereitschaft, Inhalte anderer Künste, in diesem Fall der Literatur, aufzunehmen. Die Szenen sind nicht selten ,arrangiert', d.h. das Geschehen wird nicht nur ,auf der Straße' gesucht und abgefilmt, sondern in Szene gesetzt; ,arranged scenes“238 finden sich genaugenommen schon bei Edison (Fred Otts Niesen, vgl. 1.3.) und den Lathams (nachgestellte Preisboxkämpfe, vgl. 1.3.).

Bei Mélies freilich gewinnen die genannten Momente an Explizitheit und Reflexion. Mélies, der aus der Tradition des Illusionstheaters kommt, beginnt, seine Filme bewußt zu inszenieren. Er legt ihnen zuvor ersonnene Geschichten zugrunde und führt Regie in einer Weise, die mit heutigen Regisseuren vergleichbar ist. Sein bewußt gestalterischer Einfluß auf die Filme erlaubt es, bei ihm von Autorenschaft zu sprechen $^{239}$. Zugleich läßt sich wieder die flexible Aufnahme- und Kombinationsbereitschaft des Films erkennen: Die Bühnentricks des Illusionismus, wie auch die Inhalte des Varieté und des Schaustellergewerbes erweisen sich als kompatibel mit dem Film und helfen, sein Repertoire zu erweitern. Mélies dreht fantastische Filme,

${ }^{232}$ So etwa: Gregor/Patalas, Geschichte I, 13

233 vgl. Ellis, History, 34: „The novelty of captured motion was intriguing enough at first.“

234 vgl. Gregor/Patalas, Geschichte I, 14

235 vgl. Knight, Art, 15

${ }^{236}$ So Gregor/Patalas, Geschichte I, 13 trotz ihrer Zuweisung der Fiktionalität an Mélies.

237 vgl. Nachdruck bei: Ellis, History, 28

238 vgl. Fulton, Motion, 14, der die Schaffung der "machine“ - nämlich des Projektors und der Kamera - von der ästhetischen Entwicklung unterscheidet und innerhalb dieser zu Beginn wiederum ,arranged scenes“ (eine durchgängige Einstellung) von ,arranged shots“ (Kombination verschiedener Szenen nacheinander) differenziert.

239 vgl. dazu auch Gregor/Patalas, Geschichte I, 15: „Mélies (...) unterwarf das neue Medium zum erstenmal der Subjektivität eines Gestalters." 
kreiert mit einer Verfilmung von Jules Vernes "Reise zum Mond“ (1902) den Science-fiction-Film und experimentiert mit Tricks. Er entdeckt die Doppelbelichtung, arbeitet mit Zeitraffer und Blendeneinstellungen. Was später die Surrealisten am Film faszinieren wird: Realität nicht nur wiederzugeben, sondern mit Hilfe spezifischer Techniken erst zu schaffen, ist bei Mélies schon verwirklicht. Daneben findet bei ihm zeitgenössische Satire ebenso ihren Weg in den Film - er attackiert etwa die Pläne der Untertunnelung des Ärmelkanals ${ }^{240}$-, wie politisches Engagement - 1899 bezieht er mit „L'Affaire Dreyfus“ Stellung gegen das diesbezügliche Urteil und fordert, wie Zola und Jaurès, dessen Revision ${ }^{241}$. Dokumentarberichte und semidokumentarische Filme ergänzen sein Programm. Bereits zu Mélies' Zeit erreicht der Film also eine beträchtliche inhaltliche und formale Bandbreite.

Sehr experimentierfreudig sind auch die Anfänge des Films in den USA. Formalästhetisch bedeutsam ist dabei Porters Arbeit mit ersten Formen der Montage, die dann von Griffith weitergeführt (und später von den russischen Revolutionsfilmern grundsätzlich theoretisch reflektiert) werden. Porter arbeitet mit Schauplatzwechseln während einer Szene, blendet durch Schnitte während einer Szene zu einer Parallelhandlung an einem anderen Ort um und wieder zurück oder zerlegt eine Szene schon rudimentär in verschiedene Einstellungen ${ }^{242}$. Er erzielt damit etwas, spezifisch Filmisches': die Aufspaltung der zeitlichen und räumlichen Kontinuität, wie sie im Theater unausweichlich - und sogar ein Gebot - ist, und ihre Ersetzung durch ,gedankliche Kontinuität“243. Ähnlich arbeitet auch Griffith, der mit seinem Monumentalfilm „Intolerance“ (1916) eine paradigmatische Illustration des Kampfs von Gut und Böse versucht, die nur noch einen geistigen Zusammenhang besitzt. Griffiths ,gigantische Metapher" (Ramsaye) allerdings überschreitet ein wenig die intellektuelle Kapazität seines Publikums und bleibt weitgehend unverstanden ${ }^{244}$. - Als eine der zentralsten Wesenseigenschaften des Films mußte freilich früher oder später die kombinatorische Arbeit mit Montage gefunden werden, sei es durch Porter und Griffith oder durch andere ${ }^{245}$. Sie erweitert die Darstellungsmöglichkeiten des Films beträchtlich und bedeutet einen der wichtigsten Schritte über eine theaterbezogene Ästhetik hinaus ${ }^{246}$.

${ }^{240}$ Gregor/Patalas, Geschichte I, 15

241 vgl. Gregor/Patalas, Geschichte I, 15

242 vgl. hierzu: Fulton, Motion 35-42; Fulton gibt die Beschreibung des Edison-Katalogs zu Porters „Life of an American Fireman" (1902) wieder und verweist auf eine Art Montage von Einstellungen: „It is easy to imagine how the incident (...) would be presented in a film today. The film would crosscut (cut back and forth between scenes to represent simultaneous action in seperate locales) (...) Porters film does in part anticipate this type of treatment. There is even a close shot - of a fire-alarm box as a hand reaches up to turn in alarm." (Fulton, Motion, 36)

${ }_{243}$ Gregor/Patalas, Geschichte I, 28

244 vgl. Ramsaye, Million, $\mathrm{Ix}-\mathrm{lxi}$

245 Darauf verweist etwa: Monaco, Film verstehen, 257-258

${ }^{246}$ Auch heute noch kann die Montage neben des Misé en Scène als zentrales formalästhetisches Mittel des Films genannt werden, wenngleich freilich durch Schwenk und Kamerafahrt ähnliche Ergebnisse erzielt werden. Auf das Verhältnis von Misé en Scène und Montage als demjenigen einer wechselseitigen Verklammerung und Angewiesenheit verweist insbesondere Godard: Godard, Montage. - Hier aber soll es nicht so sehr um eine detaillierte formalästhetische Theorie gehen, sondern um eine Groborientierung in den grundsätzlichsten Stilmitteln. 
Ebenfalls einen Bruch mit der Theaterästhetik stellt zu dieser Zeit die Entstehung der Slapstick-Comedy in den USA bei Sennet und ihre melodramatische Weiterführung bei Chaplin dar. Die Große Verfolgungsjagd, in welche sie meist mündet, ist geradezu als Auflösung jeglichen Handlungszusammenhangs zu interpretieren ${ }^{247}$; inhaltlich setzt sich in ihr eine anarchische Lust fest, die wohl auch als Replik des amerikanischen Individualismusprogramms auf die Industriegesellschaft und ihr kollektiv-urbanes Regelwerk betrachtet werden darf ${ }^{248}$.

Zwischen 1910 und 1930 liegt jene virulente Phase des Films, in welcher er als Kunstform erste Anerkennung findet, die ersten wichtigen Theorien geschrieben werden und die Niveaus zusammen mit den Publikumsschichten auseinanderzufallen beginnen. Wo der Film d'Art in Frankreich ein ästhetisch äußerst schwerfälliger Versuch der Nobilitierung des neuen Mediums zur Kunstgattung geblieben ist, gelingt es ab 1913 dem deutschen Film, sich über die Verbindung mit dem Expressionismus als solche zu etablieren und gar Weltgeltung mit stilbildender Relevanz zu erreichen. Neben formal genuin expressionistischen Filmen, wie Robert Wienes „Kabinett des Dr. Caligari“ (1920), die stark auch über das (theaterhafte) Dekor Wirkung erzielen, stehen in dieser Zeit vor allem inhaltliche Verbindungen mit dem (literarischen) Genre der Gothic Novel Mary Shelleys und Bram Stokers oder dem psychologisierenden Schauerroman E.T.A. Hoffmanns. Sowohl Wegeners („Der Student von Prag“ [erste Fassung 1913], „Golem“ [erste Fassung 1915]), als auch Murnaus Filme („Nosferatu“ [1922], „Schloß Vogelöd“ [1921]) bemühen sich um bedeutungsschwangere Tiefe und provozieren eine individualpsychologisch-symbolorientierte Rezeption. Das Genre des Horrorfilms nimmt hier seinen Ursprung; zugleich gelingt es diesem deutschen Kunstfilm durch seine Genrezugehörigkeit auch, ein breites Publikum zu finden.

Bis zu einem gewissen Grad vermögen das auch die französischen Impressionisten und Surrealisten dieser Periode, die jedoch einen streng formalen Weg gehen und dabei ein wenig in Gefahr geraten, allzu esoterisch zu werden. Oftmals kommen sie aus dem Bereich der bildenden Kunst und der Literatur; nicht nur Canudos Manifest, das den Film zur „siebten Kunst“ ${ }^{\star 249}$ erklärt, zeigt so, wie das neue Medium auf den herkömmlichen Kunstbetrieb zurückzuwirken beginnt. René Clairs Versuche etablieren dann auch für den Film jene ,Experimentalität', die in der Literatur als binnenbezogenes, rein formorientiertes Spiel mit der eigenen Tradition (und den Möglichkeiten einer Transformierung der Gestaltungsweisen anderer Künste in den eigenen Bereich) bereits üblich wird. Das ,cinéma pur' sagt schon im Namen, daß es ihm um „Filmrhythmus (...) jenseits von Tatsachenlogik und Realität“ geht, der ,von allen dokumentarischen und dramatischen Elementen ${ }^{، 250}$ befreit ist.

\footnotetext{
${ }_{247}^{24 g l . ~ M o n a c o, ~ F i l m ~ v e r s t e h e n, ~} 260$

${ }^{248}$ vgl. dazu auch: Gregor/Patalas, Geschichte I, 34, die freilich mehr auf Technik und Zivilisation allgemein abheben.

${ }^{249}$ vgl. Gregor/Patalas, Geschichte I, 68

250 So Henri Chomette, der Bruder Clairs; Zitat nach: Clair, Tonfilm, 64; in Deutschland wird bei Ruttmann und den Experimentellen der 60er und 70er Jahre die Struktur dann häufig völlig abstrakt. Ruttmann arbeitet mit rein graphischen Rhythmen; Werner Nekes etwa verarbeitet rotes und grünes Vorspannmaterial in raschem Wechsel („Schnitte für ABABA“ [1967)). - Im Unterschied zum Erzählkino freilich ist hier die Methode mit ihrer einmaligen Anwendung auch schon verbraucht. Selbst wenn man mit Blick auf die Methoden des Erzählens zu der
} 
Nicht so esoterisch, sondern didaktisch orientiert ist um 1919 das russische Revolutionskino. In seinem Rahmen schaffen die Regisseure Kuleschow, Eisenstein und Pudowkin die Theorie der Montage und fixieren nun auch theoretisch, was Porter, Griffith und andere praktisch erproben, nämlich die Möglichkeit, durch Aneinanderfügen verschiedener Szenen und Einstellungen neue Bedeutungsgehalte derselben zu erzeugen. Kuleschow führt die Grundidee 1922 experimentell in einem Film durch, indem er Aufnahmen zweier Darsteller an verschiedenen Orten in Moskau mit einer Aufnahme des Weißen Hauses kombiniert und auf diese Weise den Eindruck erzeugt, daß sich die Darsteller vor dem Weißen Haus begegnen, das nun seinen Platz gegenüber dem Moskauer Puschkin-Denkmal hat ${ }^{251}$. Eisenstein und Pudowkin wollen die interaktiv entstehende Uminterpretation der Abbildgehalte durch Montage nun auch für abstrakte, im Sinne der russischen Revolution bewußtseinsbildende Aussagen nutzen. Pudowkin definiert daher Montage „als ein allseitiges, mit allen möglichen Kunstmitteln zu verwirklichendes Aufdecken und Aufklären von Zusammenhängen zwischen Erscheinungen des realen Lebens in Filmkunstwerken." ${ }^{\prime 252}$ Zusammen mit den Filmen der russischen Regisseure gewinnen ihre Theorien bald internationalen Einfluß; das Wesen der Montage wird von ihnen sehr präzise auf den Punkt gebracht.

Neben dem ausgesprochenen Kunstkino stehen in diesen Jahren freilich auch wesentlich ,trivialere‘ Filme und Filmformen. Eine große Zahl expressionistisch dekorierter ,Kammmerspielfilme (Gregor/Patalas) etwa erzählt „naturalistische Kleinbürger- und Dienstbotendramen mit tristem Ausgang ${ }^{\prime 253}$ und gewinnt ein entsprechend spezifisches Publikum. Gleichzeitig entsteht der Serienfilm, der über mehrere Folgen hinweg ein Thema ausbreitet und so für ein kontinuierliches Publikumsaufkommen sorgen soll. In Deutschland findet sich eine erste Verwirklichung dieses Konzepts mit der „Homunculus"-Reihe (1916), die, ebenso wie „Fantomas“ $(1913 / 14)$ in Frankreich, quer durch alle Schichten hindurch begeistert rezipiert wird $^{254}$. Detektivserien verbuchen dann allenthalben großen Erfolg und schaffen ein wirkmächtiges Pendant zu den Nick-Carter- und Pinkerton-Romanheftserien; tatsächlich entspringt die Figur des ,Empereur du Crime', Fantomas, dem printmedialen Bereich, nämlich den gleichnamigen Fortsetzungsromanen zweier junger Feuilletonisten $^{255}$, und entsteht in Deutschland eine Nick-Carter-Filmserie. Auch in

Überzeugung kommt, daß „ein Modell der Darstellung, ein zweites Mal angewendet, (...) keine Neuigkeit mehr (ergibt), höchstens eine Variation" (Handke, Ich bin ein Bewohner, 20), so vermag die Variation des Darstellungsmodells dort doch noch mehr neuen Inhalt zu ergeben als bei jenem Experiment, das das Darstellungsmodell selbst zum Inhalt macht.

251 vgl. Gregor/Patalas, Geschichte I, 101

252 Pudowkin, Montage, 80; daß der Enthüllungscharakter geradezu als Wesensmerkmal der Montage insistiert wird, zeigt auch folgendes Zitat: „Wenn auf der Leinwand neben Bergen von aus kommerziellen Erwägungen aufgenommenem Weizen vom Hunger ausgemergelte Kinder ruinierter Farmer erscheinen, so ist das Montage. Der mit dem Verstand zutage geförderte $\mathrm{Zu}$ sammenhang frappiert durch das unmittelbare Schauspiel eines empörenden Widerspruchs.“ (Pudowkin, Montage, 81)

253 Gregor/Patalas, Geschichte I, 52

254 vgl. Gregor/Patalas, Geschichte I, 18; der schichtübergreifende Erfolg der FantomasReihe illustriert sich auch darin, daß die Gebrüder Apollinaire gar eine Société des amis de Fantomas gründen und Gedichte über die Figur schreiben.

${ }^{255}$ vgl. dazu: Gregor/Patalas, Geschichte I, 18 
den USA wird das Serienkonzept verwirklicht. Der Film ist so noch immer Teil der Populärkultur, wenngleich er jetzt sich als spezifisch künstlerisch verstehende Blüten hervorbringt und das Publikum sich allmählich zu spalten beginnt. - Ab 1917/18 gibt es dann in Deutschland eine große Zahl von ,Aufklärungsfilmen', die ein neues Genre etablieren, nämlich den Sexfilm bzw. die Pornografie. Bereits die Erfindung der Fotografie hatte rasch eine entsprechende Nutzung der neuen abbildrealistischen Möglichkeiten - in kleinen Zirkeln herumgereichte oder unter dem Tisch gehandelte erotische und pornografische Bilder - zur Folge, so da $B$ es nicht verwundert, da $B$ auch der Film bald diesen Reizen dienstbar gemacht wird. In Deutschland ist es die Zensurfreiheit, die ab 1917/18 das Unterfangen auch öfentlich erlaubt; andere Länder stehen freilich keineswegs zurück. Dabei gibt es zwei Formen erotischer Thematisierungen, die voneinander zu unterscheiden sind: So sind etwa in Deutschland die Filme Richard Oswalds von einem sexualpolitischen Impetus getragen - er dreht u.a. Filme über Geschlechtskrankheiten, um anstelle schlichten Sexualverbots über Vorbeugungsmaßnahmen zu informieren -, die alsbald zu Unrecht als Pornographie gegeißelt werden und aus heutiger Sicht eher Spiegelungen eines Ethoswandels denn blanke Exhibition von Sexualität sind (vgl. dazu auch 2.4.). Andere Produkte hingegen zielen einzig auf profitable Lust und verschleiern ihre diesbezügliche Absicht auch kaum. Titel wie: „Am Rande des Sumpfes“, „Frauen, die der Abgrund verschlingt“ oder „Hyänen der Lust“ ${ }^{\star 256}$ entsprechen schon in der Formulierung heutiger Pornografie. Die Auseinandersetzung um diese Filme ist heftig ${ }^{257}$, nicht zuletzt wohl, da ihre Ausgliederung aus dem herkömmlichen Filmbetrieb und ihre Einweisung in gesellschaftliche Reservate - eigene, kontrollierte Kinos, die einen entsprechenden Status auch im allgemeinen Bewußtsein haben - noch nicht gelungen ist. Verdrängen freilich läßt sich das neue Genre sowohl im einen, sexualpolitischen, als auch im anderen, pornographischen, Fall nicht mehr.

Die Phase zwischen 1930 und 1945 bringt, wie bereits erwähnt, weltweit dann die Innovation des Tonfilms. In den USA hat sich das Film-business inzwischen industrialisiert; wie schon erwähnt, setzt mit den 30er Jahren auch die internationale Hegemonialstellung des amerikanischen Films ein. In Deutschland sorgt der Nationalsozialismus für eine kurze Scheinblüte des deutschen Films; amerikanische Filme aber sind auch in dieser Periode immer noch dort zu sehen. - Zu Beginn der 30er Jahre gelingt es kurzzeitig dem britischen Film, eine wichtige Rolle zu spielen. Es etabliert sich eine Schule des Dokumentarfilms, deren herausragende Figur, John Grierson, nicht zuletzt von den Russen gelernt hat, und die ähnliche Ziele der ,Dra-

${ }^{256}$ vgl. Kracauer, Caligari, 50-51; auch Oswalds Filme freilich benützen die Informationsvermittlung zum Zwecke der Präsentation erotischer und sexueller Szenen. Ähnlich den (Schulmädchen-, Hausfrauen- etc.) ,Report'-Serien unserer Zeit dreht Oswald auch Fortsetzungen seiner Filme und macht so Serien daraus.

${ }^{257}$ Die Heftigkeit der Entrüstung wie auch die verdeckte Lust der Entrüsteten illustriert etwa Moreck, der dem Thema in seiner "Sittengeschichte des Kinos" immerhin 64 Seiten widmet: „In der Photographie ist sie (die Nacktheit, T.H.) gleichsam stumm, in der Kinematograpie wird sie beredt, und sie beherrscht die ganze Skala vom sinnenverwirrenden Geflüster bis zum tollen, aufpeitschenden Brunstschrei.“ (Moreck, Sittengeschichte, 146) - Morecks Faszination durch die ,Sinnenverwirrung' zeigt sich nicht zuletzt auch darin, daß er trotz aller Entrüstung eine genußreiche Bebilderung dieser Kapitel vornimmt. - In der Beschäftigung mit der Kinoreformbewegung wird auf das Thema zurückzukommen sein. 
matisierung des Alltäglichen ${ }^{258}$ verfolgt. Auch der englische Spielfilm aber hat Bedeutung; Alfred Hitchcock beginnt seine Karriere hier und dreht immerhin 25 Filme, bevor er 1939 in die USA geht. - Experimente mit dem Tonfilm nun sind bereits vor den 30er Jahren gemacht worden. Schon Dicksons erster Versuch der Projektion, mit der er den heimkehrenden Edison überraschen wollte, war ein Versuch, durch Koppelung mit dem Phonographen ,Talkies' zu kreieren ${ }^{259}$. Analoge Kombinationsversuche folgen auch andernorts; das jedoch jeweils unbewältigte Problem besteht in der Synchronizität von Ton und Bild. Am Ende einer akribischen Forschungsreihe, deren erste Untersuchungen bereits in den 60er Jahren des 19. Jahrhunderts, also vor dem Film, angesetzt werden können ${ }^{260}$, steht der Lichtton, dessen Spur auf der Filmrolle selbst abgebildet werden kann, und der so durch synchronen Transport mit den Bildern auch zu einem synchronen audio-visuellen Eindruck führt. Die ersten Patente zum Lichtton werden schon früh angemeldet; zwischen 1918 und 1925 jedoch erst liegen die Jahre seiner Vollendung ${ }^{261}$. Seine Durchsetzung beginnt ab 1926 gegen lang anhaltende Widerstände von Kinobesitzern, die die Anschaffung neuer Projektionsapparate scheuen ${ }^{262}$, Kinomusikern, die von Arbeitslosigkeit bedroht sind ${ }^{263}$, Schauspielern, die entweder die gewünschte Sprache nicht sprechen ${ }^{264}$ oder ihre Darstellungsform pantomimischer Übertreibung nicht der moderateren Spielweise, die der Tonfilm erfordert, anpassen können ${ }^{265}$. Argumentiert wird dabei häufig auf ästhetischer Ebene: durch die Kombination mit Ton, so heißt es, verliere der Film sein grundlegendes Wesensmerkmal, eine visuelle Kunst zu sein; die Reinheit des pictorialen Ausdrucks gehe mit der Einführung des Tons verloren. Tatsächlich wandelt sich die ästhetische Form durch den Ton ${ }^{266}$, jedoch läßt sich dies auch als Bereicherung lesen: Die Hinzufügung einer weiteren Darstellungsebene ermöglicht mehr noch als die musikalischen Begleitinterpretationen neue formale Interaktionsmöglichkeiten. Zugleich entsteht ein neues Genre: der Musikfilm, und in der Tat ist auch der erste erfolgreiche Tonfilm ein solcher. 1927 erscheint die Verfilmung des melodramatischen Bühnenstücks „The Jazz Singer“ und leitet eine Welle von Musik- und Revuefilmen ein, deren Erfolg unvermittelt bis in die 50er Jahre anhält ${ }^{267}$. Das nar-

258 vgl. hierzu: Gregor/Patalas, Geschichte I, 184

259 vgl. Dickson/Dickson, History, 12; Dickson erzählt, er sei in der Projektion auf der Leinwand erschienen und habe Edison mit den Worten begrüßt: „Good morning, Mr. Edison, glad to see you back. I hope you are satisfied with the kinetophonograph." (vgl. auch: Ramsaye, Million $_{260}$;6; nach Ramsaye stützt Edisons Aussage Dicksons Erzählung.)

260 vgl. Jossé, Tonfilm, 36

261 vgl. Jossé, Tonfilm, 127-202

262 vgl. Jossé, Tonfilm, 283

263 vgl. Jossé, Tonfilm, 284-287

264 vgl. Josse, Tonfilm, 288: Betroffen sind vor allem die in die USA ausgewanderten Stars, die freilich häufig, wie etwa Emil Jannings, durch Rückkehr in ihr Heimatland dem Problem entkommen können.

${ }^{265}$ vgl. Jossé, Tonfilm, 288-289

${ }^{266} \mathrm{Zu}$ jenen, die das schnell sehen und positiv beurteilen, zählt etwa Kurt Weill, der 1930 in einer Antwort auf eine Umfrage Kracauers, welcher damals Filmredakteur der ,Frankfurter Zeitung“ ist, schreibt, daß „der Tonfilm (...) seine eigenen, selbständigen Ausdrucksformen finden" müsse, weder aber Vertonung von Stummfilmen, noch „bloße Fotografie von Theatervorstellungen" sein dürfe. (vgl. Weill, Tonfilm, 188) Auf die veränderte Rolle der Musik macht er dabei besonders aufmerksam (vgl. ebd.).

267 vgl. Toeplitz, Geschichte 1, 566-577 
rative Element tritt in diesem Genre häufig hinter der Musik und den Tanzeinlagen zurück; das ornamentale Moment tritt demgegenüber in Vordergrund ${ }^{268}$. - Wichtigstes Genre der 30er Jahre jedoch ist der Gangsterfilm, der in den 40er Jahren andere Genres zu beeinflussen beginnt und als ,Film Noir (oder: Schwarze Serie) eine ganze Epoche formt. Diese beginnt exakt 1930 mit Mervyn LeRoys „Little Cesar“, der Geschichte eines skrupellosen Gangsters, der durch allerlei Tricks öffentliches Ansehen erlangt. Zweifelsohne spiegeln sich die Erfahrungen mit der Depression einerseits und mit dem organisierten Verbrechen andererseits in diesen Filmen wider. Filme wie: „Public Enemy“ (1931) und „I'm a Fugitive From a Chain Gang“ (1932) führen das, was mit „Little Cesar“ begonnen ist, zu direkter (Sozial-)Kritik weiter; sie zeitigen nicht selten Wirkungen, die zu strukturellen Veränderungen in den kritisierten Verhältnissen führen ${ }^{269}$. Die Schwarze Serie dann, die ihre Bezeichnung sowohl aus ihrer Beleuchtungstechnik und einer Vorliebe für Nachtsszenen, als auch ihrem resignativen Zynismus zieht, thematisiert über Kriminalität hinaus auch die Kälte und Richtungslosigkeit der verstädterten Zivilisation, sowie die Verlorenheit des Einzelnen darin. „Detour“ (1936), die Geschichte eines Mannes, der quer durch die Staaten zu seiner Verlobten unterwegs ist, dabei unschuldig in Mordverdacht gerät und per accident tatsächlich jemanden tötet, kann, obgleich selten genannt, als Paradestück dieser Epoche gelten. - Andere Genres freilich behaupten sich auch; so etwa der Western, der mit John Ford schon in dieser Zeit den herausragendsten Regisseur gefunden hat, die Screwballcomedy, der Horrorfilm und die (historische) Romanze. Bedeutend noch ist die Entwicklung des Animationsfilms, der durch Disneys Studio zu Weltgeltung (und bislang kaum wiederholtem Standard) gebracht wird.

Nach 1945/46 setzt eine Periode des Filmschaffens ein, die durch sehr divergente Entwicklungen gekennzeichnet ist. Einerseits wird in den 50er Jahren die Auseinandersetzung mit dem Fernsehen auch ästhetisch bedeutsam - sie führt zur Einführung neuer Techniken, deren nachhaltigste die des Farbfilms ist. Andererseits hat eine relativ unabhängige Entwicklung v.a. in Europa die Entgegensetzung von Autoren- und Genrekino zur Folge. Zum Dritten beginnt sich die Internationalisierung (trotz amerikanischer Hegemonie) auch auf den asiatischen Bereich und die Dritte Welt zu erstrecken. - Experimente mit dem Farbfilm werden schon in den 30er Jahren unternommen. Genaugenommen war auch der Stummfilm nicht immer Schwarzweiß; mit Hilfe von viragiertem (einfarbig getöntem) Material wurde dort die Stimmung unterstrichen. So verwendete man beispielsweise bei Nachtszenen Blau, bei Tagszenen ein gelbliches Braun; Eisensteins „Panzerkreuzer Potemkin“ (1925) läßt eine rote Fahne in dem sonst, farblosen' Film flattern. 1935 wird dann durch das Technicolor-Drei-Streifen-Verfahren die Möglichkeit, in Farbe zu drehen, zugänglich. Das noch aufwendige Verfahren erhält 1952 durch Eastman-Kodaks

${ }^{268}$ Toeplitz bemerkt dazu, daß diese Art Film leichter zu produzieren sei, weil kein Dialog inszeniert werden müsse. Das Argument scheint mir etwas kurzatmig; bedeutsamer ist schon sein Hinweis, daß Musikfilme keiner Synchronisation bedürften und leichter exportierbar seien. (vgl. Toeplitz, Geschichte 1, 589) Allerdings scheint mir die Erklärung des Erfolgs dieses Genres auch einer Reflexion der zeittypischen Präferenzen, mithin einer gesellschaftshistorischen Reflexion zu bedürfen.

${ }^{269}$ vgl. dazu: Gregor/Patalas, Geschichte I, 208 
Farb-Negativ-Material Konkurrenz ${ }^{270}$. Während vor 1952 Schwarzweiß Standard ist, nimmt zwischen 1955 und 1968 das Angebot an Farbfilmen zu und macht ab 1968 begünstigt durch neuerliche Innovationen beim Filmmaterial - den Farbfilm zur Norm $^{271}$. Seine Durchsetzung verdankt sich jedoch zum größten Teil der Konkurrenz mit dem Fernsehen; seine Beibehaitung heute auch der Zusammenarbeit mit diesem Medium (die Sekundärverwertung durch das Farbfernsehen setzt den Farbfilm voraus). Die Farbe eröffnet neue ästhetische Möglichkeiten, sowohl etwa einer größeren Realistik (von der insbesondere der Western in den 50er Jahren zehrt), als auch der Verfremdung (etwa in der Kombination von Schwarzweiß und Farbe in Marianne Rosenbaums „Peppermint Frieden“ [1983], wo die Realszenen Schwarzweiß und die Traumsequenzen farbig sind; oder durch die unnatürlich-stechenden Leuchtfarben in Jean-Jaques Beineix' „Mond in der Gosse“ [1984], welche die opernhafte Irrealität des Geschehens unterstreichen). Auseinandersetzung mit der Konkurrenz des Fernsehens leitet schlieBlich Experimente mit einem nicht TV-kompatiblen Format - Cinema Scope - und Erweiterungen der Wahrnehmungsweisen durch 3D-Verfahren, Cinerama und Stereo- oder Sensoround-Ton ein. Während sich schon nach kurzer Zeit erweist, daß das 3-D-Verfahren nicht auf ausreichende Akzeptanz beim Publikum stößt und daß Zusammenarbeit mit dem Fernsehen profitabler ist als Konkurrenz, bleiben die neuen Tontechniken in Gebrauch. Wo sie auf ein geeignetes Equipment in den Kinos stoßen, bieten sie dem Zuschauer ein zumindest auditives Raumerlebnis.

Hat sich in den USA in den Dreißigern und Vierzigern das Filmschaffen soweit industrialisiert, daß Konfektionierung allmählich zu Publikumsrückgängen führt (vgl. 1.3), so entstehen nach 1945/46 Innovationen durch die Neukonstitution eines Autorenkinos. Insbesondere in Europa bilden sich deutlich von der Hollywood-Ästhetik abgegrenzte Stilistiken heraus, welche auch weiterwirken, als es dem amerikanischen Film wieder gelingt, seine Monopolstellung zu reetablieren. - In Italien entsteht eine Schule des Neorealismus, die die Erfahrungen des Alltags und der aktuellen historischen Situation umzusetzen sucht. Eine gewisse Sprödigkeit setzt sich in diesen, häufig mit einfachen technischen Mitteln, weniger Kapitalaufwand und unter Einbezug von Laiendarstellern gedrehten Filmen fest. Der ,Glanz der Oberfläche‘, den das auf Perfektion bedachte Hollywood-Kino besonders entwickelt hat, wird hier durch Kratzer und rauhe Flächen zerstört. Politisches Engagement, Stellungnahme, Realbezug sind Zentralbegriffe dieses ästhetischen Konzepts, das sich auch theoretisch formuliert. Schriftliche Reflexion und Filmschaffen gehen Hand in Hand; mit der Zeitschrift ,Cinema' entsteht ein Forum für programmatischen Austausch ${ }^{272}$. Obgleich das Publikum zögernd und etwas widerstrebend reagiert und obgleich die Auseinandersetzung mit der Zensur hart ist, setzen die Regisseure des Neorealismus - De Sica, Visconti, Rosselini - Standards, die bis in die 70er Jahre prägend blei-

270 vgl. Monaco, Film verstehen, 105

271 vgl. Monaco, Film verstehen, 106-107

272 vgl. Gregor/Patalas, Geschichte II, 270; die Zeitschrift bringt bereits 1943 eine Art Manifest, das eine Trennung von der „naiven und manierierten Konventionalität“, den „phantastischen oder grotesken Verfertigungen, die menschliche Probleme ausschließen", und Historiengemälden fordert, die „nicht von politischer Notwendigkeit bedingt“ sind. (vgl. Zitat bei Gregor/Patalas, Geschichte II, 270) 
ben. Tatsächlich formt der Neorealismus auch den Unterhaltungsfilm der Folgezeit mit und wird so quer durch die Niveaus stilbildend wirksam. Fellini und Antonioni greifen seine Elemente auf und tradieren sie in ihren sehr persönlichen Formen des Autorenfilms.

In Frankreich, das ab Ende der 50er Jahre entscheidende Anstöße der Innovation liefert, hat sich zunächst die Stilistik der amerikanischen Schwarzen Serie der 40er Jahre so sehr festgesetzt, daß diese Richtung aus der regen französischen Produktion heraus einen französischen Begriff - Film Noir - erhält. Nach 1945 nimmt der französische Film diese Richtung wieder auf und konfrontiert noch in den 50er Jahren während der Phase expliziter Bürgerlichkeit, die in den USA und im übrigen Europa den Film in Breite erfaßt, das Publikum mit pessimistisch-düsteren Versionen der Zynik des Lebens. In der populären, um diese Zeit einsetzenden Verwechslung dieser etwas klischeehaften ${ }^{273}$ Gestimmtheit mit existentialistischen Positionen ${ }^{274}$ beginnt sich eine Typik auszubilden, die Teile des französischen Films bis heute bestimmt und besonders im ,unterhaltenden' Bereich Wirkung entfaltet. Paradigmatisch für das Revival des Film Noir sind die Produkte Yves Allégrets; Jaques Derays „Mörderischer Engel“ (1987) kann als Beispiel der Gegenwart für den pessimistisch,existentialistischen' Unterhaltungsfilm genannt werden.

Ein neues Kunstkino und ästhetische Innovation aber findet sich dann wieder mit der ,Nouvelle Vague', einer vielgestaltigen Richtung, die auf eine programmatische Festlegung ihres Stils verzichtet. Gleichwohl entfaltet sie sich in Zusammenarbeit mit der Theoriearbeit der Zeitschrift ,Cahiers du Cinéma', deren Chefredakteur, André Bazin, geradezu als „Nestor der neueren französischen Filmkritik“275 gilt und eine filmtheoretisch wichtige Stellung besitzt. In der Zeitschrift attackiert 1954 Truffaut den ,traditionellen' französischen Film als in Genres festgefahren und fordert stattdessen Autorenschaft und individuelle Innovation ${ }^{276}$. Zusammen mit anderen Cineasten, die sich um die Zeitschrift gruppieren, setzt er diese Forderung dann in die Tat um; der Filmkritiker und Cineast wird zum Regisseur und Autor. So ergibt sich mit der Nouvelle Vague der Fall, daB ihre Hauptvertreter aus der theoretischen journalistischen - und rezeptiven - sie alle lernten in der Pariser Cinemathek aus der Rezeption und Diskussion der internationalen Filmgeschichte - Beschäftigung mit dem Film selbst zum Filmschaffen kommen ${ }^{27}$. Trotz der starken Intellektualität, die vor allem in den Filmen Resnais' und Godards zum Tragen kommt, bringt diese Bewegung auch Filme des Genrekinos hervor, die meist zugleich eine Auseinandersetzung mit demselben darstellen, jedoch für ein breiteres Publikum zuträglich sind.

${ }^{273}$ Gregor/Patalas sprechen bei dem Versuch einer Generalcharakteristik dieser Epoche von „klischeehaftem Pessimismus“ und einer ,Koketterie mit der Abgründigkeit"; zweifelsohne treffen sie ein gut Teil der Entwicklung damit. (vgl. Gregor/Patalas, Geschichte II, 294)

${ }^{274}$ Jean-Paul Sartre verweist selbst schon 1946 auf eine gewisse Vulgarisierung des Existentialismus durch seine Popularisierung, die „die skandal- und bewegungssüchtigen Leute“ dazu verführe, sich einer modischen Etikette zu bedienen, ohne dieses inhaltlich „,rechtfertigen“ zu können. (vgl. Sartre, Existentialismus, 9)

275 Gregor/Patalas, Geschichte II, 475

276 vgl. Truffaut, Tendenz

277 Truffaut verweist in einem Interview 1962 daher auch darauf, daß er und seine Kollegen „im Vergleich zu den amerikanischen Cineasten (...) alle Intellektuelle“ seien. (Vgl. Truffaut, nouvelle vague, 187 
Damit ist die Nouvelle Vague durchaus eine mit Wirksamkeit ausgestattete ästhetische Schule für das Publikum; in den 50er Jahren als Desiderat geäußert, in den 60er Jahren mit Nachhaltigkeit durchgeführt, bleibt sie bis heute, gerade durch ihre Vielschichtigkeit, stilistisch bedeutsam. Sie ist zudem nicht nur symptomatisch, sondern auch entscheidend initial für die Etablierung eines Autorenfilms neben (und teilweise auch in) dem ,Kommerzkino' in Frankreich, in anderen europäischen Ländern - etwa in Italien durch Fellini, Antonioni, Pasolini; in Schweden durch Bergman.

Auch der Neue Deutsche Film (vgl. 1.3) ist wesentlich Autorenfilm. Bei Wim Wenders sowie bei Fassbinder muß er zudem als Reflexion der Amerikanisierung der deutschen Gesellschaft und des deutschen Kinos betrachtet werden. Insbesondere Fassbinder nützt die Darstellungs- und Sehgewohnheiten des amerikanischen Films für seine Projekte und erreicht so auch mit seinen sehr persönlichen und problematisierenden Themen auf dem deutschen Binnenmarkt breiteres Publikum. Wie die Franzosen der Nouvelle Vague haben die Autoren des Neuen Deutschen Films sich vornehmlich filmgeschichtlich und filmtheoretisch gebildet; die Formen des Autorenfilms sind daher nicht zuletzt als Auseinandersetzung des Mediums mit sich selbst und seinen eigenen Traditionen zu interpretieren. Analog der Nouvelle Vague findet der deutsche Autorenfilm internationale Beachtung. - Das Genrekino freilich ist in Deutschland nicht abwesend. Vor dem Oberhausener Manifest feiert es, bis etwa 1959 (als dem ,Spitzenjahr' der deutschen Filmproduktion), Erfolge insbesondere mit Filmserien: den Paukerfilmen und den Edgar-Wallace-Krimis. Obgleich meist als extrem ,verbürgerlicht' charakterisiert, bringt auch schon das deutsche ,Fünfziger-Jahre-Kino' kritische Töne hervor, leidet aber noch etwas unter der Abwesenheit jungen Nachwuchses. Gegenwärtig stellt sich dem seit 1979 im Rückgang begriffenen Autorenfilm ein neues Genrekino entgegen, das sich vor allem am amerikanischen Standard orientiert und durch aufwendige Produktion internationale Verbreitung anstrebt. Paradigmatisch sind hier der Ausstattungsfilm („Name der Rose“ [1986]), die Science-fiction („Enemy Mine“ [1985]) und Fantasy („Unendliche Geschichte“ [1984]). Mit „Otto“ und den „Supernasen“ überträgt sich die spezifisch deutsche Fernsehkomödie und der Klamauk in den Filmbereich; die Interaktion der beiden Medien verdeutlicht sich darin.

Die Rezeption des Autorenkinos in den USA provoziert dort eine ähnliche Entwicklung. Ausgelöst durch Truffaut und die Gruppe um ,Cahiers du Cinéma' setzt eine lebhafte Diskussion über Autorenschaft und Genre ein. Forum ist auch hier eine Zeitschrift: ,Film Culture'; dort initiiert Sarris die Debatte 1962/63 mit „Notes on the Auteur Theory in $1962^{\prime 2278}$. Neben dem sich etablierenden Autorenkino bleibt freilich das Genrekino in den USA tragend; schon vor der Debatte ist an Regisseuren wie Hitchcock und Ford deutlich geworden, daß sich beides nicht auszuschließen braucht.

Diese Konvergenz von Genre- und Autorenproduktion bildet sich auch gegenwärtig in zeitgenössischen Filmen ab. Formalästhetisch kennzeichnend für die diesbezügliche Entwicklung in den USA ist einerseits die Tendenz zur Genrekombination und andererseits zur Verarbeitung der Video- und Werbefilmästhetik. Alan Parker

${ }^{278}$ vgl. Sarris, Auteur Theory; Die Verwendung des französischen Begriffs verweist nochmals auf die Initiierung der Thematik durch die Nouvelle Vague. 
und Adrian Lyne können als symptomatisch für diese Tendenz stehen. Parkers „Angel Heart" (1987) beispielsweise stellt eine Genrekombination aus Horrorfilm und Detective-story der Schwarzen Serie dar und arbeitet hauptsächlich mit einem visuellen und auditiven Rhythmus. Obschon derart die Formalästhetik an die Musikvideos erinnert, gelingt es Parker, sie zugleich narrativ zu nutzen und eine neue Verbindung zeittypischer Sehgewohnheiten mit einer intensiven Erzählung zu erzeugen. Analog konstruiert ist Lynes „9 1/2 Wochen“ (1985), ein Film, der die Geschichte einer klaustrophobischen erotischen Verstrickung erzählen möchte, jedoch statt einer psychologischen Anlage im Stil Bergmanns eine distanzierte episodische Reihung vorwiegend visuell ästhetischer Sequenzen benutzt, um die in der Verstrickung anwesende Bezugslosigkeit der handelnden Personen, die letztlich in sich selbst verstrickt sind, deutlich zu machen. Die starke Insistenz auf Dekor, Interieurs, Textilien und Lebensmitteln stellt außerdem eine Warenästhetik vor Augen, in der sowohl die Herkunft Lynes aus der Werbebranche deutlich wird, als auch der Unterschied zwischen den Werbespots vor dem Film und diesem selbst fast bis zur Ununterscheidbarkeit verwischt. Durch die Kombination dieser, glatten' Ästhetik mit der verstörenden Erzählung evoziert der Film eine Reflexion zeitgenössischer gebrauchsästhetischer Umwelten bzw. der Lebensinterpretationen der Werbung im Verhältnis zu realen, Widerborstigkeiten' und Widersprüchen menschlichen Seins. Sowohl Lyne als auch Parker beharren dabei in ihren Produkten auf ihrer Autorenschaft und überwachen jeden Produktionschritt, so daß bei ihnen von einer Vermischung des Genrekinos mit dem Autorenkino gesprochen werden kann.

Diese Vermischung läßt sich auch bei den gegenwärtigen ,Shooting stars‘ der amerikanischen Filmproduktion, James Cameron und Kathryn Bigelow erkennen, die jedoch in ihren Filmen weniger die Werbeästhetik nutzen, sondern den vordringlich narrativ-emotiven Inszenierungsstil John Carpenters weiterentwickeln. Carpenter hat bekanntlich ein Erzählkino geschaffen, das zwar die Filmästhetik, die Möglichkeiten von Montage, textfreien Erzählpassagen, ,Bildteppichen' und ähnlichem nutzt, jedoch nicht, um der Bild- und Bewegungsästhetik selbst zum Ausdruck zu verhelfen, sondern um seine Geschichten emotional zu erschließen und dem $\mathrm{Zu}$ schauer unmittelbar erfahrbar zu machen. Seine Filme kennen zwar viele Sequenzen, in denen nur Farbe, Bildrhythmus und Musik dominieren, in denen die Kamera, der Schnitt und Geräusche den Film tragen. Doch nutzt er diese Sequenzen stets dazu, die Handlung voranzutreiben, den narrativen Zusammenhang verdichten und das erzählte Geschehen erlebnishaft mitvollziehbar zu machen. Damit unterscheidet sich Carpenters Kino sowohl von der psychologisierenden Erzählweise Hitchcocks, als auch von den Zeitgenossen Parker und Lyne: Im Unterschied zu Hitchcock arbeitet er nicht vordringlich mit reflexiv nachvollziehbarer Logik und langsam aufgebauten Spannungssituationen, sondern mit narrativen Schocks, die er hauptsächlich ästhetisch konstruiert. Seine dabei mitunter zustandekommenden logischen Fauxpas sind bekannt. ${ }^{279}$ Sie erscheinen dem Zuschauer verzeihlich, weil die perfekte Führung des emotionalen Erlebnisbogens bei Carpenter in der Regel eine eigene, überzeugende

${ }^{279}$ Etwa in „Halloween“ (1978), wo das Auto des Arztes Loomis gegen Ende wie durch Zauberhand greifbar ist, obschon es zuvor in einem ganz anderen Stadtteil abgestellt wurde. Vgl. dazu auch: Schnelle, Frank, Suspense Schock Horror. John Carpenter und seine Filme, Stuttgart 1991 
Logik entwickelt und die ,Fehler' kaum zu Bewußtsein kommen läßt. Zum anderen aber unterscheidet sich diese Ästhetisierung auch von Parkers und Lynes Formen, denn bei Carpenter ist sie stets eben dieser Führung des emotionalen Erlebnisbogens, der ,inneren' Logik von narrativ entwickelten Angst- und Schockerfahrungen untergeordnet. Nie wird bei ihm die Ästhetisierung Selbstzweck; es gibt kein ,ich zeige dich, denn du bist so schön' bei einem seiner Bilder, sondern stets nur das Zeigen des für die narrativ-emotive Durchführung der erzählten Geschichte Notwendigen. Diese Form der Ästhetisierung kehrt bei Cameron und Bigelow wieder, verbindet sich jedoch mit einer stärkeren Betonung der narrativ-abstrakten Logik einer Geschichte und längeren, psychologisierenden Textpassagen. Camerons und Bigelows Kino ist daher etwas gefälliger, weniger spröde und provozierend als Carpenters - obschon jedoch Camerons „Terminator“ (1984) noch zu einem gut Teil eine Kompromißlosigkeit und in seinen Schocks eine Widerborstigkeit aufweist, die Carpenter vergleichbar ist. Andererseits freilich erweitern beide auch Carpenters Ansatz durch ihren Inszenierungsstil, indem sie ihn für breitere, epische Erzählungen nutzbar machen und so sogar so etwas wie ein ,populäres Aussagekino' erreichen. ${ }^{280} \mathrm{Da}$ Cameron und Bigelow ebenso wie Carpenter ihre Drehbücher selbst schreiben und jeden Produktionsschritt zu überwachen suchen, jedoch dezidiert Filme für ein breites Publikum und in den eingewohnten Genres (Science fiction, Action, Kriminalfilm) inszenieren, stehen sie zudem ebenfalls in der neuen Tradition einer Verbindung von Genre- und Autorenkino.

Obgleich auch außerhalb Europas und der USA eine teilweise ebenso lange Tradition des Filmschaffens - die indische Filmgeschichte etwa beginnt ebenfalls noch im 19. Jahrhundert - zu verzeichnen ist, finden die dortigen Produkte erst in den 50er Jahren über die internationalen Festivals Beachtung. Die Internationalisierung beginnt sich damit in stilistischer Hinsicht endgültig durchzusetzen. 1951 wird Europa auf den japanischen Film aufmerksam; Akira Kurosawas „Rashomon“ (1951) findet in Venedig interessierte Aufnahme und eröffnet eine zwar zögernde (und vor allem für das Kinopublikum aufgrund der Zurückhaltung des Verleihwesens eine verzögerte) Rezeption der Werke auch anderer japanischer Regisseure. Vor allem die Filme von Mizoguchi und Ozu kommen allmählich, neben denjenigen von Kurosawa, auch in europäische und amerikanische Kinos. Besonders die Autorenfilmer lernen wiederum von ihren japanischen (und anderen) Kollegen - so etwa in Deutschland Wenders von Ozu -, so daß sich in einigen Bereichen eine internationale Mischung der Ästhetik anzudeuten scheint. Die Filme „Mishima“ (1986) und „Der letzte Kaiser“ (1987) können als zeitgenössische Beispiele für den Aufgriff japanischer bzw. chinesischer zeit- und kulturgeschichtlicher Themen im amerikanischen bzw. italienischen Film genannt und möglicherweise als Anzeichen einer In-

280 „Terminator 2“ (1991) von Cameron und „Point Break“ (1991) von Bigelow sind hierfür herausragende Beispiele. Während sich Cameron in seinem Film unter anderem mit der Verabschiedung der unmittelbaren atomaren Bedrohung durch die Auflösung des Ost-West-Gegensatzes auseinandersetzt, führt Bigelow in ihrem Film eine interessante Reflexion zeitgenössischer pseudometaphysischer und trivialisierter Spiritualitätsformen und Erlösungsfantasien (verkörpert durch einen kriminellen Surfer, der, die endgültige Welle' sucht und den Jargon der heutigen Esoterik- und Lebenshilfeliteratur spricht), sowie Kritik an patriarchalischen Strukturen durch. Beide tun dies jedoch in dezidiert auf ein breites Publikum hin konzipierten unterhaltenden Actionfilmen. 
ternationalisierung nationalhistorischer Themen gelesen werden. - Schwerer hat es noch der indische Film auf dem Weltmarkt, obgleich die indische Filmindustrie nach Japan die zahlenmäBig umfangreichste Produktion aufweist ${ }^{281}$. Das (meist vierstündige) indische Musical, das ein Genre eigener Art darstellt, gerät kaum über nationale Grenzen hinaus. In England und Italien werden indische Filme mit einer gewissen Regelmäßigkeit gezeigt; primär befördert durch Festival-Initiativen und TVAusstrahlung haben in Deutschland vor allem die stark westlich orientierten Filme Satyajit Rays Aufnahme gefunden, der sich bewußt an ein internationales Publikum zu wenden versucht. - Filme aus Mexico, Brasilien und Argentinien werden in kleinen Zahlen exportiert. Der mexikanische Film findet insbesondere durch Bunuel Verbreitung. Seine internationale Arbeitsweise - er dreht in den USA, Frankreich, Spanien und Mexico - zeigt, daß hier ebenfalls die nationale Zugehörigkeit zu verwischen beginnt. (Ein ähnlicher Fall liegt bei Peter Lilienthals letzten Filmen vor: Lilienthal, der im Neuen Deutschen Film begonnen hat, dreht fast nur noch in Lateinamerika, Chile und anderen Dritte-Welt-Ländern über deren Themen. Werner Herzog geht, obgleich an anderen Themen interessiert, einen verwandten Weg.) - So anfänglich die Rezeption des Films der Dritten Welt und Asiens in Europa und den USA auch noch sein mag, es scheint darin doch auf, da $B$ sich die internationalen Interdependenzen auch auf den Film auswirken und der Weg des Kulturaustauschs (sowie der Kulturtransformation), trotz der im Filmbereich konstatierbaren, ökonomischen Inklination zum Kampf um Vormachtsstellungen, nicht schlicht hegemonial strukturiert sein muß. Soll der Film in einer Welt des Aufeinander-Angewiesen-Seins eine konstruktive Rolle spielen, so spielt er sie dort sicherlich gut, wo der ästhetische Dialog einen politisch-kulturellen vorbereiten hilft.

Der Film zeigt sich aus der vorliegenden Skizze nun als ein vielschichtiges und flexibles Medium. Er ist in der Lage, Traditionen und Darstellungsmittel anderer Künste - transformiert in seine eigene ,Sprache - aufzunehmen; so verarbeitet er etwa beinahe alle literarischen Genres und deren Inhalte. Frühzeitig entwickelt er Misé en Scène (etwa bei Mélies) und Montage (etwa bei Porter, Griffith und den russischen Revolutionsfilmern) als seine basale Methodik. Komposition und Rhythmus werden analog zur Musik, nun aber auf der visuellen Ebene, weitere Grundkonstituenten; die geschilderte Entwicklung eines Teils des amerikanischen Films in Interaktion mit Musikvideos und dem (meist musikalisch orientierten) Werbefilm hebt besonders darauf ab. Gleichzeitig wirkt der Film auf die etablierten Künste zurück. ,Filmische‘ Darstellungsweisen im Roman können ebenso als diesbezügliche Wechselwirkung gelesen werden wie die Freisetzung der bildenden Kunst von abbildungsrealistischen ,Verpflichtungen' zugunsten abstrakter Erforschung der Wirklichkeit.

Technische Innovation verhilft im Laufe der Geschichte immer wieder zur Erweiterung der Darstellungsmöglichkeiten, wobei nicht jede Innovation erfolgreich ist, wie das Experiment mit dem 3-D-Film zeigt. Trotzdem ist es nicht einzig die Autorenschaft, welche ästhetische Wandlungen auslöst; in sehr grundsätzlicher Weise geschieht dies auch durch Einführung neuer Techniken, besonders des Lichttons und des Technicolor-Verfahrens. Interdependenz zwischen den Medien zwingt mitunter sogar zur Nutzung neuer Möglichkeiten. Die Zusammenarbeit mit dem Fernsehen

${ }^{281}$ vgl. Gregor/Patalas, Geschichte II, 460 
läßt den Schwarzweiß-Film, obgleich ästhetisch in bestimmten Fällen vielleicht sogar themengerechter, ökonomisch weitgehend indiskutabel werden.

Inhaltlich entwickelt der Film rasch eine große Bandbreite. Die Grundformen des informationell-dokumentarischen und des narrativ-fiktionalen Films differenzieren sich schon bei den Lumiéres, spätestens aber bei Mélies voneinander; der (formal-) experimentelle Film kann als dritte Grundkategorie genannt werden. Mischungen zwischen diesen allgemeinen Sparten sind jeweils möglich. Erkennbar werden dann auch zeitgebundene Genrepräferenzen, etwa des Gangsterfilms in den Dreißigern oder der Schwarzen Serie in den Vierzigern, ohne daß andere Genres völlig verschwänden. Der Herrschaft des Genrekinos, das in seinen Binnentraditionen unterschiedliche Beweglichkeit zeigt und zeitweise sehr anfällig für Schablonisierung ist, stellt sich (nicht zum ersten Mal, aber sehr betont) seit den 60er Jahren ein mehr oder minder intellektuelles Autorenkino entgegen, das individuelle Prägung und Kreativität zum Programm erklärt. Übergangsformen sind auch hier möglich: bei Fassbinder in der einen (Verwendung des Genres in dezidierter Autorenschaft) und bei Hitchcock in der anderen Richtung (Entwicklung von Autorenschaft im dezidierten Genrekino).

Internationale wechselseitige Stileinflüsse sind schon früh gegeben (Griffith etwa war stark vom italienischen Ausstattungsfilm beeinflußt). Neuerdings dehnt sich dies auf die Dritte Welt und Asien aus; dabei werden auch inhaltliche Konsequenzen deutlich. Wohin diese Entwicklung führt, bleibt noch abzuwarten. Abschließend kann aber nun aus der Beleuchtung der verschiedenen Aspekte der Entstehung und Geschichte des Films versucht werden, seinen Begriff deutlicher vor Augen zu stellen.

\subsection{Das Medium Film: Systematische Orientierung}

Der vorausgehende Aufriß hat gezeigt, daß das Medium Film ein vielschichtiges Phänomen darstellt, das, wenn es zureichend begriffen werden soll, nicht nur binnenbezogen (d.h. etwa: rein formalästhetisch) betrachtet werden kann. Das deutsche Wort ,Film', von dem ich gesagt habe, daß ihm eine gewisse Begriffsunschärfe anhaftet, hat sich so gerade wegen dieser Unschärfe als dazu geeignet erwiesen, das Phänomen umfassend in Blick zu bekommen. ,Film' ist ein inklusiver Begriff, der das Material, den Rohfilm als Bildträger und das einzelne Werk bzw. Produkt benennt, aber auch die ökonomische Determination und die Funktion als Medium zu konnotieren vermag. Während der Begriff ,Kino' aus historischen Gründen heute nicht mehr tauglich scheint, die ökonomische Komponente ausreichend zu erfassen - TV und Video sind ebenso zentrale Formen der profitablen Auswertung geworden -, und so streng genommen nur noch den ebenso genannten Ort der Aufführung von Filmen bezeichnet, haftet dieses Problem dem Wort ,Film' nicht an. Im Gegensatz etwa zum französischen ,cinéma' ist es durchaus nicht auf eine ästhetizistische Engführung fixiert und reißt daher keinen Graben zwischen ,Unterhaltungsfilm' und ,Kunstkino' auf. 'Film', von mir vorläufig eingeführt als das werkhafte Produkt, um welches sich ökonomische, technische und gesellschaftliche Bedingungen gruppieren, die es mitbedingen, kann also auch nach der Betrachtung seiner kontextuellen und binnentraditionellen Geschichte als Generalbegriff dienen. 
Die historische Binnendifferenzierung erlaubt eine inhaltliche Grobgliederung von Film in drei Sparten. Film kann zum einen dokumentarisch-informationell sein. Schon früh entwickelt sich diese Form als Mittel der Nachrichtenverbreitung in der Wochenschau und als didaktisch-bildungsbezogenes Unterfangen im Kulturfilm. Die Wochenschau verwaitet analog der redaktionellen Gliederung der Zeitungen von der politischen über die kulturelle bis hin zum Sport, zur Sensation und zum Gesellschaftsklatsch alle Nachrichtensorten. Der ,Kulturfilm' bemüht sich häufig um Vermittlung von Gegenständen der Naturwissenschaft, Technik, aber auch der bildenden Kunst. Seine thematische Orientierung ließe es zu, ihn als eine Form des Dokumentarfilms zu führen, der als eigenständige Gattung weiterlebt, als Wochenschau und Kulturfilm in die Nachrichten- und Bildungssendungen des Fernsehens transformiert werden. Der Anspruch des Dokumentarfilms schließt Engagement nicht aus; die Zielgruppenfilmbewegung in den 70er Jahren in Deutschland etwa versuchte, durch dokumentarische Filmprojekte mit bestimmten sozialen Gruppen deren Interessen bewußt zu machen und zur Durchsetzung zu bringen. Das informationelle Moment steht jedoch auch hier im Vordergrund.

Eine zweite große Sparte bildet der narrativ-fiktionale Bereich. Er existiert hauptsächlich als Spielfilm mit Unterhaltungscharakter. Hier bilden sich die verschiedenen Genres aus und entstehen Binnentraditionen des Geschichten-Erzählens. Auch das ,Kunstkino' aber findet zu einem großen Teil in diesem Bereich statt. Die Begriffe des ,Genrekinos' und des ,Autorenfilms' versuchen dabei, eine weitere Unterscheidungsmöglichkeit zu schaffen. ,Autorenfilm‘ will jene spezielle Form bezeichnen, die die individuelle ,Handschrift' eines Regisseurs bzw. Filmemachers deutlich erkennen läßt; der Begriff ,Filmemacher', der durch seine handwerklichen Assoziationen die Prägung durch ein herstellendes Individuum besonders insistiert, kann geradezu als Pendant zum französischen ,Auteur' betrachtet werden. Nicht zuletzt ist ja der Neue Deutsche Film, der diesen Begriff hervorgebracht hat, ein der Nouvelle Vague analoges Phänomen. ,Genrekino' dagegen möchte jene Gruppe von Filmen benennen, die sich durch gemeinsame Merkmale und bewußtes Verbleiben innerhalb der Grenzen einer Binnentradition auszeichnen, und wird so gerne als Konterbegriff zum Autorenfilm gebraucht. Wie zu sehen war, geschieht das nicht ganz zu Recht, da auch der Autorenfilm sich der Genres zu bedienen vermag und umgekehrt das Genrekino durchaus Autorenschaft kennt. Eine klinisch saubere Abgrenzung ist also nicht möglich; trotzdem ist die Benutzung der beiden Begriffe hilfreich zumindest für eine Verdeutlichung jener graduellen Unterschiede, die ich unter 1.5. zu beschreiben versucht habe. (Die Partikel ,-kino' in diesem und ähnlichen Begriffen macht darüber hinaus auf die interaktive Komponente aufmerksam, so da $B$ durch die Verwendung solcher kombinatorischer Begriffe auch immer wieder assoziativ daran erinnert werden kann, daß Film auf Publikum angewiesen ist.)

Als dritte Sparte möchte ich den formal-experimentellen Film vom informationelldokumentarischen und von narrativ-fiktionalen unterscheiden. Zwar finden sich experimentelle Momente auch im narrativ-fiktionalen Kunstkino, etwa den Filmen Godards, doch sind diese immer noch erzählend angelegt und oft sogar genrebezogen. Als streng formal-experimentell bezeichne ich erst jene Filme, die eine narrative Struktur völlig aufgeben und sich als streng formales Spiel mit den Möglichkeiten des Films verstehen. Walter Ruttmanns geometrische Zeichenfilme etwa, aber auch 
Werner Nekes Arbeit mit Vorspannmaterial können als besonders eindeutige Beispiele hierfür gelten. Die Materialität von Film selbst bzw. seine Darstellungstechniken als solche werden hierbei oft zentraler Inhalt. Übergänge freilich sind wiederum möglich. Alexander Kluges „Macht der Gefühle“ (1984) beispielsweise verwendet die Möglichkeiten des Films zur kulturgeschichtlichen Reflexion und weist Bezüge zum Dokumentarfilm auf; ähnliches gilt für Ruttmanns „Berlin, Sinfonie einer Großstadt" (1927), der sowohl einen Tag in Berlin dokumentiert, als auch mit einem ornamentalen Bewegungsrhythmus die formalen Möglichkeiten des Films erforscht. Sergio Corbuccis „Il Mercenario“ (1968) wiederum ist durchgängig narrativ angelegt, besteht jedoch zugleich aus lauter klassischen Schlußsequenzen des Westerngenres und kann daher auch als experimentelles Unterfangen gedeutet werden. Trotzdem scheint mir die Unterscheidung wichtig, da jene gänzlich nicht-narrativen und nichtdokumentarischen Werke doch eine recht eigenständige Gattung bilden. Sie erlaubt zudem die differenziertere Benennung der Übergangsphänomene.

Der Film nun hat sich im Durchgang durch die Geschichte seiner Entstehung und Binnendifferenzierung nicht nur als ein formalästhetisches Phänomen gezeigt. Er ist vielmehr ein genuines Produkt des ausgehenden 19. Jahrhunderts und damit der spezifischen gesellschaftlichen und kulturellen Prozesse der Moderne. Der Film entsteht, wie ich gezeigt habe, unter den Bedingungen der Dynamisierung der Technik, der Industrialisierung der Ökonomie und der damit verbundenen Ansammlung der großen Massen in den Städten. Er ist ein technisches, zumindest technisch bedingtes Produkt, das sich durch Reproduzierbarkeit und Reproduziertheit auszeichnet. Die technische Herstellungsweise hat konstitutiven Anteil an seiner Gestalt und formt ihn so wesenhaft mit; ohne Technik ist Film nicht denkbar. Er ist selbst dynamisch und erfordert neue Wahrnehmungsweisen. Die Konstitution und Rezeption von kulturellen Gehalten verändert sich damit. Film wird in Teilen selbst zu einer Kunstform und wirkt auf andere Kunst- und Kulturbereiche zurück. Zugleich fordern die Massen eine neue Form der Kulturvermittlung; sie bringen ein Bedürfnis hiernach in die Gesellschaft ein, das unter den gegebenen Bedingungen nur mehr massenmedial befriedigt werden kann. Technische Reproduktion ist eine der Antworten darauf, eine weitere ist die Kombination mit ökonomischer Organisation der Herstellungs- und Verbreitungsformen. Es etabliert sich eine Filmindustrie, die primär profitorientiert strukturiert ist. Standardisierungs- sowie Schablonisierungstendenzen sind ebenso Folgeerscheinung dieser Entwicklung wie die Ausrichtung auf Innovation und der filmgeschichtliche Wandel, der von der ökonomischen Orientierung an Publikumsakzeptanz mitbedingt ist. Ökonomisch erreichte prinzipielle Zugänglichkeit der Kulturgüter, zu denen der Film mehr und mehr auch in respektabler Hinsicht gerechnet wird, bringt zugleich eine Verbreiterung der kulturellen Öffentlichkeit mit sich, die sich auf die politische Öffentlichkeit auszuwirken beginnt. Der Film als öffentlichkeitswirksames Massenmedium ist so zu den Mitteln der sozialen Kommunikation zu rechnen; auch über den narrativ-fiktionalen Bereich findet gesellschaftlicher Austausch statt. Durch die zunehmende Internationalisierung des Film-business erhält dieser Austausch eine Tendenz zur Globalität - mit allen kulturtransformatorischen Konsequenzen, die auch in anderen Bereichen der weltweiten Vernetzung spürbar sind. Dabei zeigt sich diese Vernetzung als hegemonieanfällig; insbesondere die USA streben danach, die Kontrolle über den internationalen Markt zu erringen und 
zu halten. Gleichwohl scheint sich in den letzten Jahren eine allmähliche Veränderung durch Rezeption auch der Filme aus Asien und der Dritten Welt anzudeuten, die der Vernetzung neue Breite verschafft.

Diese gesamte phänomenologisch greifbare Prozeßstruktur ist aus einem systematischen Gesichtswinkel im Kontext des Projekts der Moderne zu sehen. Für den Bereich der Wandlung der Struktur der Öffentlichkeit ist dies von besonderer Bedeutung: Ausgehend von der grundlegenden ideengeschichtlichen Axiomatik des Projekts der Moderne, insbesondere der Subjektivierung und Autonomisierung, hat sich gezeigt, daß es diese Axiomatik ist, die letztlich die innere Triebkaft einer zunehmenden Requirierung des Subjektstatus und vernunftgeleiteter Mitgestaltung der gesellschaftlichen Verhältnisse durch alle Gesellschaftsmitglieder darstellt. Aus dem Ansatz beim Projekt der Moderne erst erhellt sich der systematische Zusammenhang der soziologisch bzw. sozialhistorisch greifbaren Verbreiterung der Öffentlichkeit und der damit konkomitanten Umschichtung politischer Mitwirkungsrechte aus festgefügten Gruppen auf alle Mitglieder eines Gemeinwesens. Ohne das Programm dieses Projekts, ohne vor allem seine anthropologische Fixierung des Menschen auf den Subjektstatus hätte sich der sozialhistorische Prozeß nicht in dieser Weise entfalten können, wäre die Bewußtwerdung der bürgerlichen Öffentlichkeit als einer Öffentlichkeit kompetenter, zu auch politischen Entwurfsleistungen befähigter Subjekte nicht möglich gewesen. An dieser Bewußtwerdung und an der zunehmenden Gestaltwerdung einer breiten Öffentlichkeit nun haben, wie zu sehen war, die Medien, auch der Film, gewichtigen Anteil. Sie sind es, die diese Bewußtwerdung zirkelübergreifend vermittelt und die ein zirkelübergreifendes Publikum erst zustandegebracht haben. Der Film, begriffen als Medium der sozialen Kommunikation, ist so in seiner gesellschaftlichen Bedeutung eng verklammert mit jenem Prozeß einer kommunikativen Konstitution einer (letztlich) demokratischen Öffentlichkeit und steht derart in unmittelbarer Verbindung mit dem Projekt der Moderne.

Darauf verweist zudem die skizzierte ökonomisch-industrielle und technische Geschichte des Films: Nicht nur Subjektivierung und Autonomisierung haben sich als zentrale Strukturmomente des Projekts der Moderne gezeigt, sondern auch die Rationalisierung. Eben die Dynamisierung der ökonomischen Verhältnisse zu einer marktwirschaftlichen und zunehmend industriellen Innovativwirtschaft läßt sich als Vorgang einer solchen Rationalisierung begreifen. Vom Hauptbuch des lombardischen Kaufmanns, der Erfindung der Buchführung, ja letztlich schon von der Tauschabstraktion des Geldes, bis zur Einführung arbeitsteiliger und methodisch durchstrukturierter, d.h. rationalisierter Produktions- und Verteilungsverhältnisse läuft eine Linie zunehmend rationaler Organisation der Ökonomie. Die ökonomische Betreuung des Films bringt diesen daher ebenfalls in Konnex mit dem Projekt der Moderne, und sie tut dies umso mehr, als sich der Film neben den anderen Medien als von rationalisierter Ökonomie geradezu zustandegebrachtes, bis in seine Struktur hinein mitdeterminiertes Medium erwiesen hat. Ähnlich verhält es sich mit dem Bereich der Technik, der durch die Übertragung naturwissenschaftlicher Methodologie und Erkenntnisse ebenfalls zunehmend der neuzeitlichen Rationalisierung unterworfen wird. Erst im Zug der Rationalisierung entsteht spezifisch technisch-instrumentelle Reflexion und ein bereichsspezifischer, segmentärer Rationalitätstyp, der die exponentiellen Erfolge in diesem Bereich ermöglicht. Wie zu sehen war, ist nun der Film 
ein äußerst technisches Medium, das seine Evolution zunächst nur durch spezifisch technische Innovationen erlebt. Auch mit Blick auf die ökonomische Betreuung und technische Determination des Films läßt sich dieser also in Verbindung zum Projekt der Moderne stellen. Er erscheint als dezidiert der von diesem Projekt und seinen Struktureigenschaften geprägten Epoche zugehöriges Phänomen.

Der Film kann damit aus der Analyse seiner kontextuellen Determinationen als spezifisch modernes Medium (wenn nicht durch seine gegenwärtige Verbindung mit TV und Video sogar als das Medium der Moderne) betrachtet werden, das an der Universalisierung der Kommunikation in den modernen Gesellschaften mitwirkt und derart das Projekt der Moderne mitträgt. Er zeigt sich in Kohärenz zu diesem Projekt und dessen struktureller Dynamik zugleich als von ökonomischer und technischer Rationalisierung bestimmt. All diese Momente, vorrangig jedoch seine universell-kommunikative Bedeutung, provozieren dabei im Verlauf seiner Geschichte intensive Auseinandersetzungen: Schon knapp zehn Jahre nach seiner Entwicklung setzt in Deutschland eine diskursive Bewegung ein, die sich intensiv mit dem Film als Kommunikationsmittel und mit seiner kulturellen Relevanz befaßt. Ab etwa 1907/1910 kommt es zu bis heute anhaltenden normativen Diskursen, die Produktion, Einsatz und inhaltliche Formung des Films, seine gesellschaftliche Funktion und individuelle Nutzung der Regelung unterziehen wollen. Angesichts der kontextuellen Verbindung des Films als Kommunikationsmittel mit dem Projekt der Moderne nimmt es nicht wunder, daß diese Diskurse zugleich Stellungnahmen zu diesem Projekt vorstellen, Stellungnahmen, die zunächst nicht bewußt und eher implizit, über die Jahrzehnte und (politischen) Epochen der deutschen Geschichte jedoch auch zunehmend deutlicher abgegeben werden. Nachdem das Phänomen Film im ersten Kapitel nun in seinen wichtigsten Bezügen vor Augen gestellt und epochensystematisch verortet worden ist, will ich im folgenden den zentralen dieser normativen Diskurse in epochentypologischer Absicht rekonstruktiv nachgehen. 


\section{DIE ERÖFFNUNG UND SYSTEMATISIERUNG DER MEDIENETHISCHEN FRAGESTELLUNG DURCH DIE KINOREFORMBEWEGUNG ZU BEGINN DES 20. JAHRHUNDERTS}

Die Geschichte des Films wird alsbald und nachhaltig von normativen Diskursen begleitet. Rasch gerät das neue Medium zum Gegenstand von Auseinandersetzungen, die in ihm Gefahren, jedoch auch Chancen ausmachen, und die versuchen, durch gesetzliche und pädagogische Maßnahmen der ihm zugeschriebenen Wirkmacht zu wehren, seine Rezipienten zu bewahren, zu bilden, oder zu engagieren, sowie seine kommunikativen Möglichkeiten im Sinn der jeweiligen eigenen Theorieprogramme zu gestalten. Die Argumente dieser Theorieprogramme sind häufig ethischer Natur, ihre normativen Ansinnen sogar meist ethische Normierungen, bzw. Normierungen aus ethischen Gründen. Blickt man also zurück auf die Historie dieser normativen Diskurse, so zeigt sich an ihnen, daB Medienethik durchaus kein neues Unterfangen ist, sondern (mindestens implizit) immer schon betrieben wurde. Ja, ein genauer Blick läßt sogar erkennen, daß sich die rahmengebenden Fragestellungen im Verlauf dieser Historie kaum verändern und die vorgebrachten Argumente gleichen. So ließe sich zum Beispiel erweisen, daß die Debatte der Fünfziger Jahre um ,jugendgefährdende Schriften' bereits einmal im 19. Jahrhundert geführt worden ist und zu ähnlichen Forderungen, Maßnahmen und Gesetzen geführt hat.

Für den Film setzt die normative Auseinandersetzung mit der Kinoreformbewegung der 10er und 20er Jahre ein und findet dort erstmals zu einer systematisch reflektierten Gestalt. Die Reformer argumentieren aus ästhetischer, politischer und pädagogischer Perspektive, legen jedoch stets ethische Maßstäbe zugrunde und bemühen sich letztlich um eine Medienethik für den Film. Ihre Fragestellungen präformieren den diesbezüglichen Diskurs weit über ihre Zeit hinaus. Die ,Filmerziehung' der 50er und 60er Jahre, durch welche die Disziplin der Medienpädagogik begründet wurde, bezieht sich sogar explizit auf die Schriften vom Anfang des Jahrhunderts zurück (vgl. 4.4.). Doch selbst in den Fragestellungen der Kritischen Medientheorie entdecken sich Momente alter Rahmenfestlegungen und Basistheoreme wieder, wenngleich sie dort auch mit einer entgegengesetzten Bewertung verbunden werden (vgl. 5.5.). Schließlich repetieren einige Medienpädagogen noch in den 90er Jahren reformerische Axiome und entdecken sich insbesondere in der gegenwärtigen Diskussion über die mediale Darstellung von Gewalt Devianzthesen und Argumente der Reformer wieder. Als erste der vier exemplarischen ,Epochen' des medienethischen Diskurses zu Film im zwanzigsten Jahrhundert in Deutschland werde ich daher den Diskurs der Kinoreformer rekonstruieren. Aus der Rekonstruktion der ersten Epoche ausgeklammert bleiben dabei die zeitgleich stattfindenden, vereinzelten Bemühungen der Kommunisten, den Film für eine revolutionäre Pädagogik nutzbar zu machen und ihm hierfür Normen zu geben. Im Unterschied zu den Reformern erlangen diese Bemühungen keine theoretisch-systematische Breite, und entfalten sie 
kaum Wirkung, während der Einfluß der Reformer schon zeitgenössisch bis in die Legislative reicht. Exemplarisch repräsentativ und entsprechend relevant ist daher der reformerische Diskurs, nicht der kommunistische.

\subsection{Kinoreform und Bildungsbewegungen der Jahrhundertwende: Kontext, Struktur und Wirkung der Kinoreformbewegung}

Die Bewegung der Kinoreformer wird ziemlich genau um 1910 herum in einer Weise tätig, die sie zu einer gesellschaftlich nicht nur wahrnehmbaren, sondern auch strukturell wirksamen Erscheinung macht. ${ }^{1}$ Sie entsteht aus dem Engagement einzelner ,Gebildeter', d.h.: Professoren, Lehrer, Richter und der oberen Mittelschicht zugehörigen Bürger, und gewinnt allmählich Breite und ein gemeinsames Selbstverständnis. Obgleich kein völlig einheitliches Phänomen ${ }^{2}$, weist sie einen in ,zentralen Fragen` weitgehenden theoretischen Konsens auf, verbindet sie sich über vereinsmäßige Selbstorganisation institutionell und versteht sie sich als Bewegung für ein gemeinsames Ziel. Ihre Verbundenheit veranschaulicht sich begrifflich in der immer wiederkehrenden Identitätsbezeichnung „Kinoreformer" sowie durch wechselseitige Zitation in der literarischen Produktion, gegenseitige Ladung zu Vorträgen etc.

\section{Der kulturreformerische Kontext der Kinoreformbewegung}

Die Kinoreformbewegung kann im Kontext der kulturpädagogischen Bewegungen der Jahrhundertwende, näherhin des Engagements für ,Volksbildung‘ und ,Beförderung der Sittlichkeit' (die dabei nicht selten mit Sitte verwechselt wird) sowie insbesondere gegen die Verbreitung von Trivialliteratur gesehen werden. Bereits im 19. Jahrhundert organisieren sich Kreise gebildeter Bürger, um sich diesen selbstgestellten Aufgaben zu widmen. Sie konstituieren eine zunächst informelle Öffentlichkeit noch eher interner Zirkel, die aber darum bemüht ist, über die eigenen Reihen hinaus Wirkung zu entfalten und öffentlichkeitsbestimmend zu werden. Damit stehen sie wiederum in systematischem Konnex mit den parallelen bzw. vorausgehenden Unternehmungen der Salon- und Kaffeehausgesellschaften, d.h. in der Tradition der gebildeten bürgerlichen Zirkel, sowie in Verbindung mit der literarischen Öffentlich-

${ }^{1} \mathrm{Zu}$ den ersten wichtigen literarischen Äußerungen über den Film und seine postulierte Reformbedürftigkeit zählt Conradts Buch, das genau 1910 erscheint: Conradt, Walther, Kirche und Kinematograph, Berlin 1910, und das in den Folgejahren mehr als häufig zitiert wird. Der Erscheinungstermin dieser frühen, bedeutsame Wirkung entfaltenden Schrift darf als Achsenpunkt des spürbar werdenden Einflusses der Reformer gelten. Erste Selbstorganisationen, wie die Kommission für „Lebende Photographien“ der Hamburger „Gesellschaft der Freunde des vaterländischen Schul- und Erziehungswesens“ 1907 oder der „Kinematographische Kongress“ 1908 in Berlin gehen freilich schon zwei bis drei Jahre voraus. Ab 1910 aber nimmt vor allem die literarische Produktion an ,Reformschriften' exponentiell zu, und gewinnt die Bewegung an öffentlicher Aufmerksamkeit. (Vgl. dazu auch: Kommer, Film, 23 und: Hellwig, Schundfilms, 83)

${ }^{2}$ Darüber klagt 1915 etwa Hermann Häfker, der meint, die Bewegung sei „einheitlich und von erfreulicher Unbedingtheit nur in der Ablehnung der jetzt herrschenden Zustände", ansonsten aber "unklar und verworren in ihren Grundbegriffen, ihren Zielen und ihren Forderungen" (Häfker, Gebildete, 26). Bei näherem Zusehen aber zeigt sich, daß doch eine größere Einheitlichkeit zumindest in den Schriften ihrer Hauptvertreter besteht, als Häfkers Klage vermuten lassen möchte. Zur Beförderung dieser Einheitlichkeit haben freilich er selbst sowie besonders auch Konrad Lange und Albert Hellwig durch ihre umfangreiche literarische Tätigkeit beigetragen. 
keit, die ihren internen Kontakt durch Druckschriften etabliert. Wie diese requirieren auch die Kulturreformer spezifische Gestaltungsansprüche, die sich jedoch zunächst weniger auf die politische Sphäre als vielmehr auf eine Bildungshoheit über die nichtbürgerlichen ,Massen' richtet. Dies schlägt jedoch dann zunehmend auch auf politische Bereiche über. Zu den organisierten Zirkeln, die auch für die Kinoreformbewegung Relevanz erhalten, zählen vor allem der „Kunstwartkreis“ und der daraus hervorgegangene „Dürerbund“.

Der erste setzt sich aus den Rezipienten und Mitarbeitern der Zeitschrift „Der Kunstwart und Kulturwart" zusammen, welche 1887 von Ferdinand Avenarius ins Leben gerufen wird. Sie stellt zunächst den Versuch dar, eine Monatsschrift für Ästhetik zu begründen, die sich nicht nur entweder der Literatur oder der Musik oder der bildenden Kunst allein, sondern integrativ allen Gebieten der Künste widmet $^{3}$ und reflexiv-theoretische Leitlinien für dieselben und ihr Publikum erarbeitet. Schon bald mündet das letzte Bemühen in zusätzliche, explizit pädagogische Unternehmungen; neben direkte Empfehlungen von Büchern, Theaterdarbietungen, Ausstellungen etc. in der Zeitschrift treten Publikationen in Form von literarischen Anthologien, Notendrucken und Loseblattsammlungen von Reproduktionen ,vorbildlicher ' Gemälde, die der „künstlerischen Selbstbildung“ dienen sollen ${ }^{4}$. Der „Kunstwart" strebt danach, „Geschmack und Lebenshaltung, Lektüre und Konzertprogramme, Theaterspielplan, Kunst- und Kunstgewerbe-Millieu“" ${ }^{\text {"5 }}$ seiner Leserschaft mitzubestimmen, ja eine „Führer-Stellung “6 in der Richtungsbestimmung von Kunst und Kultur einzunehmen. Ein kämpferischer Impetus ist dabei nicht zu verkennen?, auch ein gewisses Sendungsbewußtsein läßt sich wahrnehmen.

Kulturintegratives Bemühen und pädagogisch-kämpferisches Sendungsbewußtsein führen schließlich dazu, daß Avenarius das ,Aufgabenfeld' der Zeitschrift erweitert und seine Rezipienten und Mitarbeiter, die sich mehr und mehr als „Bewegung“ verstehen, im „Dürerbund“ organisiert. Nach eigenem Selbstverständnis ist es dem „Kunstwart“ darum gegangen, mit „dem Wollen und Suchen deutschen Bürgertums innerlich vertraut“" ${ }^{48}$, unabhängig von allen ,Moden“ „dem Ewigen zugetan" ${ }^{49}$, ,das

${ }^{3}$ Der Untertitel der frühen Ausgaben lautet entsprechend: „Rundschau über alle Gebiete des Schönen“". Vgl. Schumann, Kunstwart, 1

${ }_{5}^{4}$ vgl. Schumann, Kunstwart, 1-2

5 Schumann, Kunstwart, 1

${ }_{7}^{6}$ Schumann, Kunstwart, 1

7 vgl. Schumann, Kunstwart, 1: „Manch Kampf-Fanfare wurde geblasen, manches geistige Turnier ausgefochten, manches Kulturziel erkannt und fest errichtet.“ Der ,Kampf des „Kunstwarts" richtet sich dabei hauptsächlich gegen die ,modernen' Lebenserscheinungen, Kunstrichtungen und politischen Theoreme, wie sie unter den Schlagwörtern: „Pazifisten, Bolschewisten, Futuristen, Expressionisten" (Schumann, Kunstwart, 3) zusammengefaßt noch für den liberaleren Nachfolger Avenarius' die exemplarischen Gegner darstellen. Von der Ablehnung im künstlerischen Bereich auch jedes weniger provokativen Experiments zeugt u.a. die Auseinandersetzung um einige Ausstellungen von Skizzen, denen angelastet wird, sie seien „das chaotische Abbild euerer (der Künstler, T.H.) Biographie“, anstatt jener ewigen Werke, „die der Künstler der Welt schuldet" (Haes, K., Frage an die Künstler, in: Kunstwart 1922/1, 4-6, 5,6; „Skizzenwirtschaft“ oder mehr?, in: Kunstwart 1922/2, 74-77; Haes, K., Gegenantwort, in: Kunstwart 1922/2, 77-78). Wo freilich schon solches Anstoß erregt, kann über den zeitgenössischen Expressionismus und die Futuristen nicht mehr diskutiert werden.

8 Schumann, Kunstwart, 1

${ }^{9}$ Schumann, Kunstwart, 1 
Starke und Echte ${ }^{\text {10 }}$ herauszuheben und „deutschen Bürgertums stolze künstlerische Selbstverwaltung "11 zu schaffen. Dieses - im übrigen stark konservativ unterfutterte - Programm zielte so früh auf Praxis, auf gesellschaftliche Entfaltung, so da $\beta$ der Einbezug dieser Sphäre in die Reflexion sich bald nahelegte. Der Verwobenheit des „Schönen" mit dem „Wahren“ und dem „Guten“, d.h. der ästhetischen Diskurse mit erkenntnisbezogenen und ethischen, entsprechend tritt der „Dürerbund“ von vorneherein an, „um praktische Kulturarbeit zu leisten“" ${ }^{\text {"12 }}$, d.h. „den Ungeschmack im öffentlichen Leben zu bekämpfen“ und „,eine gesunde und bodenwüchsige Kultur (zu schaffen T.H.), deren Erscheinung wahr, klar und erfreulich ausdrücke, was ist und eben durch ihre flitter- und schminkelose Wahrhaftigkeit beständig nachprüfen lasse, ob das, was ist, auch gut ist“'13. ,Kultur' wird hier zum Angelpunkt einer sehr umfassenden Programmatik, die sich für alle Kultursachbereiche zuständig fühlt und auf eine Aufhebung von deren Trennung drängt. Als Integrationsbegriff für diese Programmatik dient der Neologismus „Ausdruckskultur“, der „alles öffentliche Leben“ als „Anzeichen der Gesinnung“ wertet, ,welche als treibende Kraft seine Formen, Bräuche und Ordnungen im Kern bestimme und so im ganzen wie im künstlerischen Wesen für sich allein erkannt, gesichtet und gerichtet werden könne und müsse ${ }^{\text {“14. }}$. Die ethische Perspektive spielt für dieses, Sichten und Richten' zweifellos eine Rolle; Sittlichkeit als Gestaltungsnorm für Kultur tritt daher explizit im programmatischen Kurztext unter jeder Titelzeile der "Dürerbund-Flugschriften“ auf, die Avenarius herausgibt ${ }^{15}$. Der Verweis auf eine alles bestimmende Kraft der „Gesinnung“ aber, die es in sämtlichen Bereichen des öfentlichen Lebens zu, richten' gelte, deutet zugleich an, daß unter dem Begriff der Sittlichkeit hier häufig auf die habituelle Beistimmung zu einem vorgegebenen, anzuerkennenden und nicht diskutablen Normund Wertekatalog rekurriert wird, der tendenziell ideologischen Charakter erhält. Gesinnung nämlich läßt sich nur durch ein Bekenntnis erweisen, kaum jedoch argumentativ einklagen. Auch der Begriff „Ausdruckskultur“ selbst weist in diese Richtung - begreift er doch alle kulturellen Erscheinungen als Oberflächenäußerungen eines Zugrundeliegenden, das bei näherem Zusehen als ,richtiges' oder ,falsches Bewußtsein' identifiziert werden kann. Während des Ersten Weltkriegs erhält die zu zeigende „Gesinnung“ dann zeittypisch national-konservative Züge; der „Kunstwart“ wird von Avenarius in ein kriegspropagandistisches Blatt unter dem Titel „Deutscher Wille" umgewandelt ${ }^{16}$. National-konservativ agiert Avenarius auch nach dem Krieg,

\footnotetext{
${ }^{10}$ Schumann, Kunstwart, 1

11 Schumann, Kunstwart, 2

12 Der Dürerbund, in: Kunstwart und Kulturwart (Sammelband: Sechsunddreißigster Jahrgang erste Hälfte Oktober 1922 bis März 1923), München 1923, o. Paginierung

14 Dürerbundprogrammatik

${ }_{15}^{14}$ Schumann, Kunstwart, 2

15 vgl. etwa: Dürerbund-Flugschrift 82/1911, 1: „Was will der Dürerbund? Eine gesunde Kultur, deren Erscheinung wahr, klar und erfreulich ausdrücke, was ist, die dadurch erkennen lasse, ob es auch gut sei, eine Kultur also, die unser Leben zugleich erfreulich, gesund, sittlich und würdig gestalte."

16 vgl. Schumann, Kunstwart, 2-3
} 
etwa in seinen neu begründeten, revanchistischen „Schriften für echten Frieden“, in denen er der Entente entgegenzutreten versucht ${ }^{17}$.

Als nach dem Krieg der „Kunstwart" neu gegründet wird, verläßt ihn Avenarius im Februar $1923^{18}$, um sich ganz dem „Dürerbund“ und dessen Arbeit zuzuwenden. Im „Dürerbund“ organisieren sich neben den Anhängern des „Kunstwarts“ zahlreiche Einzelpersonen, jedoch auch Vereine, für die der Bund gewissermaßen den Dachverband bildet, der ihre Bemühungen koordiniert. Politisch aktiv ist der „Dürerbund" hauptsächlich durch Eingaben an Regierungen und Behörden ,in Sachen der Ausdruckskultur"119. Literarische Ratgeber, Erziehungsbüchlein, Lichtbildreihen mit Vorträgen u.ä. sollen der Bildungsarbeit helfen. Von zentraler Bedeutung aber ist die Flugschriftenreihe, deren Themenspektrum von Volkskunst über Wohnungskultur, Theaterreform, Heimat- und Naturschutz, Denkmalpflege bis zu ästhetisch-theoretischen Abhandlungen reicht, und die während des Kriegs ebenfalls kriegspropagandistisches Material enthält. In dieser Reihe publizieren auch die Kinoreformer, die so in direkten Konnex mit der konservativen ,Kulturbewegung' Avenarius' gelangen.

Einen weiteren Kontext der Kinoreformbewegung stellt das Engagement gegen Trivialliteratur dar. Auch hier ist der „Dürerbund“ aktiv - eigene Jugendhefte sowie eine Jugendbuchreihe sollen derselben Konkurrenz bieten -, jedoch nicht nur er. Wie ich oben (vgl. 1.4.) gezeigt habe, entsteht im 19. Jahrhundert eine neue, verbreiterte Form von Öffentlichkeit, versammelt sich ein Massenpublikum in Städten und bildet es ein etwas unspezifisches Kulturinteresse heraus, das andere Formen der Kulturvermittlung fordert. Reproduktionstechniken, Institutionen und geeignete Räume (als ,Umschlagplatz’ zur Mehrfachverwertung, wie etwa Leihbibliotheken, oder als Versammlungsort für gleichzeitige Rezeption durch eine große Anzahl von Interessierten, wie Kinos) bieten sich als Antworten auf den gesteigerten Bedürfnisumfang an. Das im Zuge der Alphabetisierung sprunghaft angewachsene Lesebedürfnis erlaubt jedoch ab den Sechziger Jahren des 19. Jahrhunderts bereits die rein kommerzielle Produktion des Kolportageromans, welchem sich ab etwa 1900 das Serienheft zugesellt ${ }^{20}$, und damit die Etablierung und massenhafte Verbreitung spezifischer "Trivialliteratur'. So problematisch eine literaturwissenschaftlich zureichende Definition dieses Begriffs auch sein mag, so einig sind sich die gebildeten Kreise des Neuhumanismus in der Ablehnung dieser Literaturform. Es entsteht eine recht konglomerierte Front aus Sittlichkeitsvereinen, Lehrervereinen, Bünden für Jugendpflege und Volkswohl sowie allerlei gemeinnützigen und bildungsorientierten Zusammenschlüssen, die unter den neuen Schlagworten „Schmutz“ und „Schund“ gegen die Massenliteratur zu Felde ziehen. Beide Schlagworte, deren Gehalt sich

${ }^{17}$ vgl. „Konto Lügenabwehr“, in: Kunstwart 1923/4, 178-179; Avenarius eröffnet seine neue Schriftenreihe mit der ,gegenpropagandistischen“ Broschüre: „Die Mache im Weltwahn“, welche ,französische Lügen' über Deutschland im Krieg, insbesondere fotografische Fälschungen entlarven soll.

${ }_{18}$ vgl. Avenarius Abschiedsrede: An unsere Leser, in: Kunstwart 1923/5, 181-182; Weitergeführt wird der „Kunstwart“ von Wolfgang Schumann, einem engen Freund Avenarius", der jedoch in seinem programmatischen Antrittsartikel ankündigt, sich von überkommenen Werten und Idealen zu lösen. (Vgl. Schumann, Kunstwart, 4-6)

${ }_{19}$ Dürerbundprogrammatik

20 vgl. dazu: Jäger, Schmutz, 163 
schwer gegeneinander abgrenzen läßt ${ }^{21}$, werden ab 1900 allmählich zu alltagssprachlichem Allgemeingut ${ }^{22}$. Von Otto von Leixner im „Volksbund zur Bekämpfung des Schmutzes in Wort und Bild" zum Titel erhoben ${ }^{23}$, tritt der Schmutzbegriff dann fast nur noch im Verbund mit "Schund“ auf und gerät in der Weimarer Republik gar in den Gesetzestext ${ }^{24}$. Die Begriffe ,Schmutz' und ,Schund' werden von den Kinoreformern aufgegriffen und zur Bezeichnung der von ihnen kritisierten Filmformen verwendet. Doch nicht nur begriffliche Bezüge zwischen der literarischen, Schmutz- und Schundkampagne' und der Kinoreformbewegung bestehen. Auch personelle Verflechtungen zeigen sich: Einige Autoren der Bewegung gegen die Massenliteratur äußern sich später gegen den Film und stoßen so zur Kinoreformbewegung; umgekehrt agieren einige Kinoreformer zugleich gegen Trivialliteratur. $\mathrm{Zu}$ diesen ,Kämpfern an beiden Fronten' gehören etwa Ernst Schultze, der seinen vielzitierten Schriften über ,Schundliteratur ${ }^{25} 1911$ ein Buch über Gefahren und Chancen des Films beigesellt ${ }^{26}$, und Albert Hellwig, der sein Engagement wider den ,Schundfilm' auf die analogen literarischen Erzeugnisse ausdehnt ${ }^{27}$. Die beiden Bewegungen ähneln sich in ihren Intentionen einer volksbildnerischen Einflußnahme und einer diesbezüglichen Mission der ,Gebildeten'. Sie ähneln sich zudem in den Vorwürfen, die sie an die neuen Erzeugnisse der Massenkultur herantragen, in ihren Veränderungsforderungen, sowie ihren Formen der Selbstorganisation. - Insgesamt kann daher die Kinoreformbewegung als eine spezifische Spielart größerer kulturpädagogischer und ethischer Bestrebungen des 19. und beginnenden 20. Jahrhunderts gesehen werden. Sie stellt, in diesem Kontext betrachtet, eine Reaktion auf die neuartigen, massenkulturellen und -kommunikativen Bedürfnisse und Entwicklungen dar und bezieht, wie aus der Kooperation mit dem „Dürerbund“ schon jetzt geschlossen werden kann, eine konservative Stellung. Da die geschilderten Entwicklungen ihrerseits im Kontext des Projekts der Moderne zu sehen sind, legt sich die Vermutung nahe, daß diese

21 vgl. Jäger, Schmutz, 173; Zwar zeigt sich bei einigen Autoren eine Neigung, im Zusammenhang mit sexuellen literarischen oder bildlichen Darstellungen das Wort „Schmutz" zu bevorzugen, während der Schundbegriff stärker auf nicht-sexuelle behauptete Devianzen angewendet wird. Doch nimmt beispielsweise Schultze, der zu den wichtigsten Autoren der, AntiSchund-und-Schmutz-Bewegung gerechnet werden darf, eine Differenzierung von ,literarisch schlechte(n), aber moralisch ungefährliche(n) Bücher(n)“ und „literarisch wertlose(n), gleichzeitig auch moralisch gefährliche(n) Bücher(n)" vor, jedoch keine begriffliche Unterscheidung zwischen „Schmutz" und „Schund“" (vgl. Schultze, Schundliteratur, 7-8). Hellwig wiederum betrachtet den Schundbegriff als Oberbegriff, während "Schmutz" den sexuellen „Schund" bezeichne (vgl. Hellwig, Schundfilms, 21). - Eine genaue Scheidung aber ist nicht möglich; meist treten beide Begriffe ohnehin gemeinsam auf (,Schmutz und Schund“).

${ }_{23}^{2}$ vgl. Jäger, Schmutz, 173

23 vgl. Jäger, Schmutz, 173

24 Art. 118 Abs. 2 der Weimarer Reichsverfassung erklärt, im gleichen Atemzug mit dem Ausschluß jeglicher Zensur, Maßnahmen zur „Bekämpfung der Schmutz- und Schundliteratur“ für zulässig. 1926 wird auf dieser Basis das „Gesetz zur Bewahrung der Jugend vor Schund- und Schmutzschriften" erlassen. (vgl. dazu: Richter, (o. Vorn.), Der Kampf gegen Schund- und Schmutzschriften in Preußen aufgrund des Gesetzes zur Bewahrung der Jugend vor Schundund Schmutzschriften vom 18. Dezember 1926, Berlin ${ }^{2} 1931$ (= Veröffentlichungen des Preußischen Ministeriums für Volkswohlfahrt 7); und: Jäger, Schmutz, 173)

${ }^{25}$ Schultze, Ernst, Die Schundliteratur, Halle 1909; ders., Die Gefahren der Schundliteratur und ihre Bekämpfung durch die Schule, Langensalza 1910 ( = Zur Volksschulpädagogik 13)

${ }_{26}^{26}$ Schultze, Ernst, Der Kinematograph als Bildungsmittel, Halle 1911

27 Hellwig, Beziehungen, 1-32 
konservative Stellung eine kontramoderne ist oder zumindest kontramoderne Positionen impliziert. Für eine Verifikation (oder Falsifikation) dieser Vermutung müssen diese Positionen freilich erst noch genauer betrachtet werden.

\section{Strukturelle Organisation und Einflußnahme der Kinoreformer}

Neben reichhaltigem Schrifttum und der Kooperation mit bereits bestehenden Vereinen und Zusammenschlüssen bringt die Kinoreformbewegung auch eine Reihe von neuen eigenen Organisationen hervor. $\mathrm{Zu}$ den frühesten Gründungen gehört zweifelsohne die aus den Aktivitäten der Hamburger Lehrerschaft entstandene Kommission für „Lebende Photographien“ von 1907 sowie der „Kinematographische Kongreß" 1908 in Berlin, der sich mit dem Verhältnis des Films zur Schule - einem Thema, das in der Folge wieder und wieder ventiliert wird und häufig den Titel diverser Schriften ausmacht ${ }^{28}$ - befaßt (vgl. Fußnote 1). Folge dieses Kongresses ist unter anderem ein Abkommen der Hamburger Oberschulbehörde mit dem „Lokalverband Hamburger Kinematographeninteressenten", das die Bewertung und Kontrolle der diesem Verband angeschlossenen Kinos und ihrer Programme sowie diverse schulbehördliche Auflagen ermöglicht ${ }^{29}$. Überhaupt versucht man, auf dem Weg der ,Schuldisziplin' und schulbehördlicher Maßregeln wieder und wieder den Kinobesuch von Kindern und Jugendlichen zu beschränken sowie schulbehördlicherseits Zugriff auf die Programmgestaltung der Kinos zu bekommen ${ }^{30}$. - Früh aktiv ist auch Rektor Hermann Lemke, der die wohl erste Zeitschrift mit u.a. kinoreformerischer Programmatik, ,Schule und Technik“, in Storkow ins Leben ruft und später gar eine "Kinematographische Reformpartei" gründet ${ }^{31}$. Zu den bedeutendsten Ergebnissen organisatorisch-institutioneller Aktivitäten zählt jedoch die Gründung des „Bilderbühnenbunds deutscher Städte“ vom Februar/April 1918 ${ }^{32}$. Ihm gehen Einzelaktivitäten von sog. „Reformkinos“ (oder „Musterkinos“) und „Reformverleihanstalten“ (wie der „Lichtbildnerei Mönchengladbach“, welche sich um Verbreitung lehrhafter Filme bemüht) voraus. Unter Kuratel des Stettiner Oberbürgermeisters Ackermann und seines Stadtbibliothekars Ackerknecht organisieren sich einige dieser praxisorientierten Reformbestrebungen gemeinschaftlich in Stettin und gründen im April 1917 den „Deutschen Ausschuß für Lichtspielreform“"33, aus dem dann der „Bilderbühnenbund“ hervorgeht ${ }^{34}$. Seine Aufgabe sieht letzter darin, Bestrebungen seiner Mitgliedstädte zur Schaffung gemeindlich subventionierter Reformkinos zu unterstützen und allmählich ein Archiv für als geeignet befundene Filme, insbeson-

${ }^{28}$ vgl. etwa: Lolling, J., Kino und Schule, Bielefeld 1913 (= Pädagogische Abhandlungen XIII/8); Franke, Kurt, Schnalle, Karl, Die Kinematographie im Dienste der Schule, Chemnitz 1913; Sellmann, Adolf, Kino und Schule, Mönchengladbach 1914 (= Lichtbühnenbibliothek 6); Golias, Eduard (Hrsg.), Film und Schule, Berlin 1925

${ }^{29} \mathrm{vgl}$. Hellwig, Schundfilms, 84

${ }^{30}$ vgl. dazu: Hellwig, Kind, 88-93 und 2.6.

31 vgl. dazu: Kommer, Film, 23; Hellwig, Schundfilms, 82

32 Nach Nickol, Jugendpflege, 30 findet die Gründung am 1. April statt; Lange spricht jedoch vom Februar. Vgl. Lange, Kino, 181

${ }^{33}$ vgl. dazu auch Ackerknechts eigenen Bericht anläßlich einer Tagung der „Deutschen Wacht" 1917: Ackerknecht, Lichtspiel, 6-7

${ }^{34}$ vgl. dazu: Eger, Kampf, 5; Nickol, Jugendpflege, 29-30 
dere aber ein Schulfilmarchiv ${ }^{35}$ zu schaffen, aus dem die entsprechenden Kinos ihre Programme zusammenstellen bzw. Programmpakete empfangen können. Städte, die dem Bilderbühnenbund beitreten, sichern sich durch ihren Beitritt so primär eine Versorgung mit Filmen, die der Anerkennung durch die Reformer mehr oder weniger sicher $\operatorname{sind}^{36}$. Das Unterfangen ist nicht völlig zentralistisch organisiert: Eine Gemeinde, die dem Bund angehört, verpflichtet sich auf dessen Satzung, gründet jedoch unter dem Vorsitz des Bürgermeisters einen Ausschuß aus ihrer Bürgerschaft und vermag einigermaßen selbständig zu agieren ${ }^{37}$.

Außer diesen selbstorganisatorischen strukturellen Einflußnahmeversuchen ist eine Wirkung der Argumentation der Kinoreformbewegung auf die Gesetzgebung beobachtbar. Den bedeutsamsten Niederschlag findet dies im Württembergischen Lichtspielgesetz vom 1. Juli 1914 und im Reichslichtspielgesetz vom 12. Mai 1920. Das erste verdankt sich nicht zuletzt zahlreichen Aktivitäten der ,Basis', etwa der Petition des „Landesverbands für Jugendfürsorge“ in Württemberg 1910, einem Beschluß einer Lehrerversammlung, die der „Landesverband zur Bekämpfung der Schundliteratur" 1912 einberufen hat, sowie der Kundgebung einer Bürgerversammlung in Tübingen 1912, die vom Rektorat der Universität, den Schulverwaltungen und den Vereinen der Stadt unter Mitwirkung der Reformer Lange und Gaupp veranstaltet wird ${ }^{38}$. Auch auf Konstitution und Wortlaut des Reichslichtspielgesetzes nehmen die Kinoreformer Einfluß. In der Auseinandersetzung, die dem Gesetz vorausgeht, bedienen sich zahlreiche Protestversammlungen und Zeitungsartikel der von Lange und anderen vorgebrachten Argumente ${ }^{39}$; die deutschnationale Partei macht sich dabei zum Wortführer dieser Argumentationsrichtung ${ }^{40}$. Mit dem einstigen Berliner Zensor Brunner, dem Vorstand der preußischen Zentralstelle für Erziehung und Unterricht, Pallat, und insbesondere dem Juristen Hellwig sitzen diesmal Kinoreformer bzw. der Bewegung nahestehende Personen direkt im beratenden Ausschu $\beta^{41}$. Der Einfluß auf die Gesetze freilich ist kein legislatives Monopol. Beide - besonders aber das Reichslichtspielgesetz - fallen daher immer wieder harscher Kritik durch die Reformbewegung anheim (dazu mehr unten).

Faßt man das Gesagte zusammen, so läßt sich feststellen, daß die Kinoreformbewegung in den Kontext der vorwiegend konservativ ausgerichteten Kulturreformund Bildungsbewegungen der Jahrundertwende zu stellen ist, mit deren Organisatio-

35 vgl. Ackerknecht, Lichtspiel, 7

${ }^{36}$ Lange beklagt freilich schon bald, daB der Bilderbühnenbund sich „leider nicht entschlieBen (habe) können, das Drama von vornherein abzulehnen“ (Lange, Kino, 183), d.h. die von den Reformern so bekämpften Unterhaltungsfilme gänzlich auszuschließen. Tatsächlich unterscheidet der Bilderbühnenbund „moralisch und ästhetisch einwandfreie, (...) moralisch einwandfreie, aber ästhetisch anfechtbare, (und) (...) moralisch und ästhetisch verwerfliche" Filme (Lange, Kino, 183), von denen nur die letzten dem absoluten Verdikt verfallen. Lange hätte es im Gegensatz dazu gern gesehen, nur die erste Kategorie anzuerkennen und auf dramatischnarrative Filme möglichst ganz zu verzichten (dazu mehr unten).

${ }_{38}^{37}$ vgl. Lange, Kino, 185

38 vgl. dazu: Lange, Nationale, 66. Lange verweist auch später noch nicht ohne Stolz darauf, $\mathrm{da} \beta$ sein und seines Mitstreiters Gaupp Referat „einen wesentlichen Einfluß auf Einbringung und Formulierung des Württembergischen Lichtspielgesetzes gehabt" habe (Lange, Kino, 195).

${ }^{39}$ Worauf Lange wiederum nicht ohne Stolz verweist: vgl. Lange, Kino, 211

40 vgl. Lange, Kino, 212-225

41 vgl. Lange, Kino, 216 
nen sie teilweise kooperiert. Ihre Struktur ist die einer literarischen und in Vereinen organisierten, zunächst noch zirkelinternen Öffentlichkeit, die gleichwohl durch entsprechende Publikationen und Veranstaltungen auf umfassende Öffentlichkeit sowie durch Petitionen, Eingaben u.ä. auf politische Wirksamkeit zielt. Damit muß sie im Konnex mit dem Projekt der Moderne gesehen werden: Sie ist Teil jener soziostrukturellen Umschichtungsphänomene, in denen die autonomen Subjekte sich als Gestaltungsträger der gesellschaftlichen Verhältnisse und Organisation begreifen und daher auf Mitspracherechte drängen, d.h. in denen sich die ideengeschichtliche Dynamik des Projekts der Moderne strukturbezogen realisiert. Die Mitsprachebemühungen der Reformer führen teilweise zu Erfolgen, deren beachtlichste zweifellos im EinfluB auf die Gesetzgebung sowie in der Errichtung kommunaler Kinos unter der Schirmherrschaft des „Bilderbühnenbunds“ zu sehen sind. Die Kinoreformbewegung stellt so eine Form engagierter Selbstorganisation der Basis dar; sie ist damit von ihrem organisatorischen Ansatz her eine Bewegung, die auf der Linie des demokratischen Impetus des Projekts der Moderne liegt. - Ob sie diesem Ansatz auch gerecht wird, ob sie die zirkelintern requirierten Mitspracherechte - und damit den Subjektstatus - auch zirkelextern zugesteht, und ob sie derart wirklich demokratische Ziele verfolgt, muß zusammen mit der Frage nach einer affirmativen Stellung der Reformer zur Moderne oder einer kontramodernen Position der gesamten Bewegung erst noch genauer untersucht werden.

Ihre Argumente nun, mit denen sie das Kommunikationsmedium Film inhaltlich und gesellschaftlich-funktionsbezogen zu normieren trachtet, will ich im folgenden untersuchen und systematisieren. Eine erste grundlegende strukturelle Figur kann aus der ästhetischen Argumentation vor allem von Konrad Lange erhoben werden, auf den ich mich, da er unter den Reformern die konsistenteste Theorie zur Ästhetik und Kunstbedeutung des Films vorgelegt hat, hauptsächlich beziehen werde.

\subsection{Kunst und Massenkultur: \\ Ästhetik als Wurzel einer kulturpessimistischen Bewahrethik}

Das neue Medium Film bedeutet nicht zuletzt einen Einbruch in den Kanon der etablierten Künste und deren Wirkkreise. Zum einen vermag der Film Darstellungstechniken anderer Künste aufzugreifen, miteinander zu kombinieren und so analoge, jedoch über spezifische Beschränkungen der jeweiligen Künste hinausgehende Effekte zu erzielen. Er kann etwa die Geschichte eines Bühnenstücks erzählen, ohne dessen Ortsgebundenheit und Kulissenproblemen unterworfen zu sein; mit Hilfe der Montage (vgl. 1.5.) kann er zudem die Univozität der Bildaussage sprengen und einen musikalischen Rhythmus schaffen. Wie die Fotografie, die daher zuvor selbst schon eine Herausforderung für Kunst und ihre Theorie war, konkurriert der Film mit den abbildungsrealistischen Möglichkeiten der Malerei; im Unterschied zur Fotografie aber ist der Film noch der Bewegungsdarstellung mächtig, die allen bislang erreichten Realismus überschreitet. Damit weist das neue Medium eine formale Integrationskraft auf, die herkömmliche kunsttheoretische und formalästhetische Grenzziehungen, d.h. auch Begriffe in Frage stellt. - Zum anderen zieht der Film neben dem Massenpublikum der Städte, das weitgehend den unteren Schichten entstammt, auch Teile des Theaterpublikums in seinen Bann und vom Theater ab. In 
den Jahren ab 1908 beginnt allmählich ein neues Mittelschichtspublikum Interesse für den Film zu entwickeln (vgl. 1.4.); die Film-d'Art-Bewegung versucht dem durch Verarbeitung ,hochliterarischer' Stoffe sowie durch Verfilmung von Theaterstücken zu entsprechen und eine Publikumsbindung zu erreichen. Die sich dabei zeigende soziale Integrationskraft, die allmählich über die ,unteren Schichten' hinausgreift und das Rezeptionsverhalten des Kunstpublikums zu verändern beginnt, läßt aus anderer Perspektive ebenfalls die Frage nach einer ästhetischen Theorie des Films ${ }^{42}$ zunächst als Theorie seiner ästhetischen Werthaftigkeit, sodann als Bedenklichkeit seiner Bedeutung für ästhetische Bildung und ihre gesellschaftlichen Konsequenzen - stellen ${ }^{43}$. Spürbar wird eine doppelte Verunsicherung, die die Kinoreformer zu einer doppelten Reflexion nötigt. Gefragt werden muß einerseits nach dem formalästhetischen Wesen des Films, will man sein Verhältnis zu den etablierten Künsten verstehen und daraus ästhetische Normen für ihn erheben. Zu fragen ist aber aus der Konfrontation mit einer rasch etablierten Massenkultur heraus zugleich nach seiner gesellschaftlichen Wirkung und Rolle. Die letzte Frage bleibt auch unter den erklärtest formalästhetischen Bemühungen der Kinoreformer stets virulent, ja sie motiviert, wie zu sehen sein wird, geradezu die mitunter befremdlich angespannten Bemühungen um formalästhetische Kriterien. Ästhetik und Sozial- wie Individualethik verklammern sich hierbei zu einem Komplex, der von einem starken Kulturpessimismus getragen ist. Seine ästhetische Komponente und ihre Konsequenzen will ich zuerst betrachten.

\section{Der reformerische Kunstbegriff als idealisierter Kontrastbegriff zur Massenkultur}

Zunächst gilt es, den Kunstbegriff der Kinoreformer - das heißt in diesem Fall: Häfkers und Langes als den beiden profiliertesten Vertretern einer reformerischen Bemühung um eine ästhetische Theorie des Films - zu untersuchen. Beinahe ideal-

${ }^{42}$ Als erste Ästhetik des Films zählt gemeinhin die Abhandlung von Vachel Lindsay: „The Art of the Moving Picture" von 1915; als erste "Theorie der Filmkunst" nennt man häufig Béla Bálazs" „Der sichtbare Mensch" von 1924; oft läßt die Sekundärliteratur Filmtheorie schlechthin - als Theorie der Ästhetik und der gesellschaftlichen Funktion - mit den russischen Revolutionsfilmern und deren Montagetheorien einsetzen (vgl. etwa: Ceram, Archäologie, 252; Textsammlungen wie: Albersmeier, Franz-Josef [Hrsg.], Texte zur Theorie des Films, Stuttgart 1979; Witte, Karsten [Hrsg.], Theorie des Kinos, Frankfurt ${ }^{3}$ 1982; Prokop, Dieter [Hrsg.], Materialien zur Theorie des Kinos, München 1971; Albersmeier nennt zwar die Kinoreformer im Vorwort, jedoch nur als Vertreter einer Reflexion des gesellschaftlichen Bezugs des Films, und läßt die Auswahl der Texte zur Ästhetik mit den Russen beginnen. Ähnlich verhält es sich bei Witte und Prokop, wobei Prokop ohnehin nur ,kritische' Autoren in seine Sammlung aufnimmt.) Eine solche Zuordnung der ästhetischen Theorie des Films ist zumindest historiographisch nicht ganz vollständig. Schon vor Lindsay reflektieren Lange und Häfker über ästhetische Belange des Films. Mögen ihre Theorien auch unzureichend sein, so bemühen sie sich doch über die Kinoreform um Wirkung. Zwar bleibt für ihre Reformerkollegen die Ästhetik nur ein Randthema oder wird sie überhaupt ausgeklammert, doch zählen die Genannten immerhin zu den führenden Persönlichkeiten der Bewegung. Eine Rekonstruktion ihrer ästhetischen Reflexionen legitimiert sich daraus für meine Untersuchung; einer Erwähnung wären diese Reflexionen darüber hinaus auch dort wert, wo die Geschichte der Filmtheorie resümiert wird.

${ }^{43}$ Auf die Konkurrenz zum Theater und die Integrationskraft als Anlaß, ja Nötigung zu einer ästhetischen Reflexion des Films nimmt etwa Lange explizit Bezug: Diese Reflexion sei „umso notwendiger (...), als dem Kino allem Anschein nach immer mehr die eigentliche ästhetische Erziehung der großen Massen anheim fallen wird" (Lange, Kino, 132). 
typisch komprimiert setzt Hermann Häfker am Beginn seines Buchs „Kino und Kunst" die (verlorengegangene) Kunst ins Bild:

„Ehedem thronten in ihren Tempeln in erhabener Würde die Künste. (...) Der Widerschein der Schönheiten, die sie schufen, fiel spärlich und milden Glanzes auf das ganze Alltagsleben (...). Gelehrte stritten sich um höchste Schönheit und echten Stil, Kirchen, Fürsten und Reiche führten den ,Geschmack'. Wo Kunst war, war eine große Idee, großes Wollen, großes Können, Lebensverdichtung. "44

Kunst wird hier - nicht ganz historisch treu - begriffen als eine hehre, dem Alltagszusammenhang und der alltäglichen Lebenswelt enthobene Sphäre. Sie tritt als eine ,ideale‘ Bestrebung in beschränkten, überschaubaren Räumen auf, die, obgleich mit ,Kirchen, Fürsten und Reichen“ eine Dominanz der Mächtigen und ihrer Interessen anklingt, dennoch als „Festtagskunst“ von allen Verzweckungen frei gehalten scheint. „Fern von allen Alltagsleidenschaften“45 bleibt sie einer Elite vorbehalten und selbst elitär. Im Gegensatz dazu wird die Massenkultur von vorneherein kulturpessimistisch als Verfallserscheinung gebrandmarkt. Sie gilt als durch ,Geschäftemacherei', d.h. ökonomische Zwecksetzungen, und durch ihre unüberschaubare Zahl von Erscheinungen und Reprodukten korrumpiert ${ }^{46}$ :

„Bildmäßiges und Plastisches, Wort und Klang, Farben und Linien, früher die Wahrzeichen jener Festtagskunst, strömen wie Hagelwetter auf die Nerven des modernen Menschen - besonders, aber nicht allein, in der Großstadt - ein.

(...) Ladenfenster enthalten alle Kräfte der Seelengewinnung, die ihre Hersteller den raffiniertesten Erzeugnissen der Künste abgesehen haben." 47

Technische Reproduktion und ökonomisch organisierte Zugänglichkeit und Verbreitung bedrohen die Autonomie der Künste. Ihre Sphäre verformt sich unter technisch-ökonomischem Einfluß zum Kunst- und Kulturbetrieb. Nachdem bereits der Buchdruck „Kunstähnliches (...) zwangsweise, unausweichlich dem Menschen aufzudrängen“48 half, machen „neue Erfindungen“, wie Phonographie und Fotografie, die anderen Künste vollends ,,wehrlos “49. An die Stelle der Kunst und ihrer erhebenden Funktion scheint die irrlichternde Fülle der, Ausdruckskultur ${ }^{50}$ getreten zu sein, die ihre Rezipienten in „Fuselrauschstimmung ${ }^{* 51}$ versetzt und anstatt „hohen und reinen Dingen" zu dienen, die aus "hohem und reinem Geiste hervorgegangen“ sind"

${ }_{45}^{44}$ Häfker, Kunst, 5

${ }^{45}$ Häfker, Kunst, 5

${ }^{46}$ Häfker prägt hier den Begriff der „Geschäftskinematographie“ (etwa: Häfker, Gebildete, 26), um die ,Verwerflichkeit' ihres Tuns sogleich schlagwortartig faßbar zu machen. Andere Kinoreformer sprechen, obwohl sie keineswegs Sympathisanten der ,Linken' sind, in diesem Zusammenhang vom „Kinokapital“, „Kapitalismus“ und „kapitalistischen Betrieb" (vgl. etwa: Lange, Kino, 129; Schultze, Kinematographie, 8)

${ }_{48}$ Häfker, Kunst, 5

48 Häfker, Kunst, 7

${ }^{49}$ Häfker, Kunst, 7

50 Auch Häfker bedient sich dieses von Avenarius eingeführten Paradigmas, sogar in einer fast der oben zitierten, Schumannschen Formulierung identischen Weise: ,... es ist alles auch ,Ausdruck'. ,Ausdruck' von einer Wirklichkeitswelt und einer Gesinnung, die dahinter liegt." (Häfker, Kunst, 6; Hervorhebung von mir)

${ }_{52}^{51}$ Häfker, Kunst, 6

52 Häfker, Kunst, 6 
„gemeine Alltäglichkeit, in aufregende, festliche Gebärden gekleidet “53 anbietet. Das Streben der Künste verflacht zum Design; aus dem Kunstbereich wird ein unabgeschlossenes und unabschließbares Feld der (und für die) Gebrauchskultur.

Gefährdet scheint damit ein fester, überkommener Kanon von Darstellungsformen und - wie zu vermuten ist - auch -inhalten, der, von einer Elite bereitgestellt, in Werke umgesetzt und verwaltet, als Kunst gilt, und dessen Zugangsmöglichkeiten kontrollierbar gehalten werden sollen ${ }^{54}$. Die technisch vermittelte (also mediale) Massenkultur, die mit ihren Reproduktionstechniken für eine ungeahnte Verbreitung von „Kunstähnlichem“ sorgt, stellt das genannte Kunstkonzept und seine gesellschaftliche Funktion und Rolle in Frage. Sie nötigt zu einer Rechtfertigung dessen, was sie aufzulösen droht. Gleichzeitig fordert sie zu einer Reflexion ihrer eigenen strukturellen Bedeutung, d.h. ihrer Relevanz für die ästhetische Bildung und das gesellschaftliche Leben heraus. Um eine rechtfertigende Bewahrung des Kunstkanons sowie um die Orts- und Funktionsbestimmung der Massenkultur, insbesondere des Films, bemüht sich Konrad Lange mit seiner ästhetischen Theorie.

\section{Der Rezeptionsidealismus Konrad Langes: Die ethisch-ästhetische Doppelperspektive}

Im Ansatz wirkt Langes Ästhetik ${ }^{55}$ zunächst sehr breit und auch sehr offen für neue Erscheinungen auf dem Kunstsektor. Er siedelt seine Aufgabe sogar in einer doppelten Frontstellung gegen formale und inhaltliche Restriktionen an: sowohl eine „Formästhetik“, die der Kunst „,bestimmte Formen (...) als ein für alle mal ,schön“ vorschreiben “56, als auch eine "Inhaltsästhetik“, die nur bestimmte Inhalte gelten lassen will, greife zu kurz. In beiden Fällen sei eine Regelerstellung am Werk, die lediglich „,konventionelle Rezepte “57 von lokal und temporal begrenzter Gültigkeit liefere, nicht aber zu den ,ewigen Gesetzen' der Kunst vorstoße. Im Unterschied dazu will Lange das „Wesen der Kunst“ (Titel) schlechthin in Griff bekommen, um aus diesem „die Gesetze des künstlerischen Schaffens und der Kunstentwicklung festzu-

${ }_{54}^{53}$ Häfker, Kunst, 6

$54 \mathrm{Da}$ es sich um einen Kanon handelt, geht auch daraus hervor, daß beispielsweise Lange in der Auseinandersetzung mit Literaturverfilmungen fordert, einen ,literarischen Denkmalschutz" einzuführen: „Hiergegen hätte die Gesetzgebung ein volles Recht, einzuschreiten. So, wie sie nicht gestattet, $\mathrm{da} B$ eine schöne mittelalterliche Kirche durch schlechte Restaurierung verhunzt wird, so sollte sie auch verbieten, daß die Werke unserer klassischen Dichter in dieser Weise ausgebeint und verballhornt werden. Wir brauchen ein Denkmalschutzgesetz zugunsten der Werke unserer klassischen Dichter." (Lange, Nationale, 35) Ähnliches findet sich auch bei anderen Reformern, etwa Sellmann: „Man hebt dadurch den Kinematographen durchaus nicht, aber man setzt unsere Literatur herab und erniedrigt unsere guten Literaturstücke zu Schundwerken ersten Ranges." (Sellmann, Volkserzieher, 21) In beiden Fällen wird ein nicht genau definiertes, aber deutlich eingeschränktes Korpus von Literaturen (,klassische Dichter"; ,gute Literaturstücke“ - im Gegensatz zu „Schundwerken") genannt. Die Beschränkung richtet sich nicht allein gegen Trivialliteratur, wie das Studium der einschlägigen Schriften der ,Bildungsbewegten“ zeigt; schon in der Ausrichtung von „Kunstwart" und „Dürerbund“ wurde deutlich, daß auch die ,Modernen', d.h. hier vor allem: die Expressionisten, aus dem Kanon ausgegrenzt werden. Der Charakter des Kunstkanons, der denn auch festlegt, weshalb etwas dazu zu zählen ist und weshalb nicht, wird deutlicher aus Langes Ästhetikkonzept; dazu mehr unten.

${ }_{55}^{5}$ vgl. Lange, Konrad, Das Wesen der Kunst I - II, Berlin 1901

${ }^{56}$ Lange, Wesen I, 16; als Beispiele führt er den ,goldenen Schnitt‘ in der Architektur und die Harmonielehre in der Musik an.

${ }^{57}$ Lange, Wesen I, 17 
stellen ${ }^{\text {“58 }}$. Letzte seien in einem ,ästhetischen Gattungsinstinkt ${ }^{459} \mathrm{zu}$ finden, den es mit wissenschaftlichen Methoden, d.h. unter Verwendung empirischen Materials, mit der Absicht, dieses „unter allgemeine Gesichtspunkte zu bringen ${ }^{\alpha 60}$, zu erheben gelte. Als Quellen ,empirischen Materials' nennt Lange psychologische Selbstbeobachtung, allgemeinen Sprachgebrauch, Befragungen von Kunstgenießenden, Kunstgeschichte und Kunsttheoriegeschichte, Betrachtung primitiver Kunst und Beobachtung des Spiels von Kindern und Tieren ${ }^{61}$. Im systematischen Zentrum seines Vorgehens aber steht die psychologische Selbstbeobachtung, genauer: die Rezeptionspsychologie, deren Ergebnisse er dann durch Beispiele aus den anderen Quellenbereichen zu stützen sucht und die er in der Analyse zu einer idealistisch wurzelnden Formalästhetik weiterführt. Seine Ästhetik möchte ich deshalb als ,Rezeptionsidealismus" bezeichnen.

Das Gesamt seiner Konzeption erhält zu Beginn einen ethischen Rahmen. Obgleich Lange sich mehrfach gegen eine Ethisierung der Ästhetik verwahrt ${ }^{62}$, setzt er die Entwicklung des ,ästhetischen Gattungsinstinkts' in Bezug zu einer ethischen Teleologie: Er führt ein oberstes Gesetz ,alles menschlichen Thuns, Denkens, Fühlens und Wollens" ein und beschreibt es inhaltlich als Forderung, das „Wohl der Gattung, d.h. die Erhaltung und wenn möglich körperliche und geistige Steigerung des Menschengeschlechts" zu befördern ${ }^{63}$. Diesem Gesetz, das als evolutives ethisches Prinzip bestimmt werden kann, sieht Lange auch die Kunst unterworfen, und zwar nicht in der Weise, daß die prinzipielle ethische Verpflichtung von außen an sie herangetragen werden müßte, sondern so, da $\beta$ die Kunstentwicklung immer schon von ihr bestimmt sei, zumindest da, wo wirkliche Kunst vorliege. Folgerichtig

${ }_{58}^{58}$ Lange, Wesen I, 11

${ }^{59}$ Lange, Wesen I, 17 - 18

${ }^{60}$ Lange, Wesen I, 11

61 vgl. Lange, Wesen I, 32-52

62 vgl. Lange, Wesen I, 24; Dort verweist er darauf, daß es ,ganze Kunstgattungen“ gebe, die ,in Bezug auf das Ethische vollkommen indifferent“ seien, wie etwa die „Blumen-, Landschafts-, Architektur- und Tiermalerei und das Ornament". Der Hinweis greift jedoch meines Erachtens zu kurz, da auch diese Darstellungen einen Symbolcharakter erhalten können, der sie ethisch bedeutsam macht. - Weiterhin betont Lange, daß auch moralische Normen und Wertvorstellungen zeit- und kulturbedingt seien, mithin schwerlich dazu taugten, den ,Kunstwert eines Werks zu bestimmen (vgl. Lange, Wesen II, 154-155). Viele Künstler hätten sich zudem in Gegensatz zum Moralkodex ihrer Zeit gestellt, ohne daß das dem Wert ihres Werks Abbruch täte (vgl. Lange, Wesen II, 155-156). Weiterhin diskreditiere die „Darstellung des Unmoralischen“ das Kunstwerk ebensowenig, wie die Darstellung des Häßlichen ihm seine Kunstschönheit raube (Lange, Wesen II, 157). - Die Darstellung des ,Unmoralischen' allerdings findet nur deshalb Raum in seiner Ästhetik, weil es inhaltlich durch seine rezeptions-idealistische Konzeption entschärft wird (vgl. weiter unten). Lange verhält sich damit durchaus zeitkonform. Ebenso konform verhält er sich in Bezug auf die ,zeit- und kulturbedingten' Moralvorstellungen, die er trotz seiner Verwahrung später alle zur Anwendung bringt (vgl. 2.3. und 2.4.). Langes Abgrenzung gegen eine Ethisierung der Ästhetik bleibt also vordergründig und wird nicht konsequent durchgehalten. $\mathrm{Zu}$ ihrer strategischen Bedeutung vgl. weiter unten im Text.

${ }^{63}$ Lange, Wesen I, 13; Dabei sieht Lange keinen Gegensatz zwischen individuellem und kollektivem Wohl: „Das Wohl der Gattung fällt aber richtig verstanden mit dem Wohl des Individuums zusammen, einen Gegensatz altruistischer und egoistischer Ethik, altruistischer und egoistischer Ästhetik giebt es nach meiner Überzeugung nicht." (Lange, Wesen I, 14) Diese Ineinssetzung bildet eine der Wurzeln der strukturautoritären Konsequenzen von Langes Bewahrethik, auf welche ich noch eingehen werde (vgl. 2.6.). 
schließe daher „die Ermittelung ihres Wesens (...) gleichzeitig das Gesetz, unter dem sie steht, in sich." ${ }^{64}$ Der Maßstab Langes für die Kunstbewertung ergibt sich damit aus einer ethisch-ästhetischen Doppelperspektive, die zu gegenseitiger Überlagerung gebracht ist:

„Jede Kunst ist gut, die dem entwicklungsgeschichtlich gewordenen Wesen der

Kunst, d.h. dem ästhetischen Gattungsinstinkt des Menschen entspricht, jede

Kunst ist schlecht, die nicht mit ihm übereinstimmt. Oder mit anderen Worten:

Jede Kunst ist gut, die der Gattung nützt, jede Kunst ist schlecht, die ihr schadet. “65

Die Doppelperspektive dieses sehr formalen Rahmenprinzips ermöglicht es Lange einerseits, eine Selbstgesetzlichkeit der Kunstentwicklung zu behaupten und sich gegen die zeitgenössischen Bestrebungen jener Moralisten zu verwahren, die auf eine moralische Normierung und Zensur der Kunst drängen, und etwa im Kontext der Auseinandersetzung um die „Lex Heinze“ die Beseitigung des Nackten aus der Kunst (bis hin zur Bekleidung von Statuen mit Blechhöschen u.ä.) fordern ${ }^{66}$. Zugleich erlaubt es ihm, sich gegen ein platonisierendes „Schöngutes“67 zu verwahren und seine eigene Ästhetik unter Verzicht auf einen expliziten Rekurs auf ethische Termini zu konstruieren, ohne jedoch andererseits bei der anschließenden Bestimmung der gesellschaftlichen Funktion von Kunst aus dem Kontext herkömmlicher sozialethischer Vorstellungen fallen zu müssen. Was nämlich , der Gattung nützt $t^{*}$ und was ihr schadet, ist mit diesem Prinzip letztlich noch nicht ausgemacht; es bietet aber die Basis dafür, sich mit einer nützlichen oder schädlichen Funktion auseinanderzusetzen und die Ästhetik dort, wo es günstig erscheint, doch wieder explizit mit der Ethik zu verbinden.

Nach der Einführung des ethisch-ästhetischen Doppelprinzips macht sich Lange nun daran, Gattungsinstinkt und Wesen der Kunst rezeptionsidealistisch zu bestimmen. Aus der Empirie stellt er fest, daß die Rezeption (wie auch das Schaffen) von Kunstwerken mit Lust verbunden ist. Diese Lust will er - nicht zuletzt wegen der kulturkreis- und zeitbedingten Verschiedenheiten der Kunstäußerungen - als von Gestalt und Inhalt des Kunstwerks unabhängige, psychische Erscheinung verstanden

${ }^{64}$ Lange, Wesen I, 14

65 Lange, Wesen I, 14

66 vgl. dazu auch Lange, Wesen II, 159; Die „Lex Heinze“ erhielt ihren Namen nach dem Zuhälter Heinze, der 1891 eine Prostituierte ermordete, und dessen Tat eine breite Diskussion über Zuhälterei, Prostitution und die Rolle von Nacktdarstellungen in der Kunst für die Schaffung ,unsittlicher Dispositionen' entfachte. Der Versuch, eine entsprechende Zensur künstlerischer Werke und Tätigkeiten als $\$ 184$ a ins Strafgesetzbuch aufnehmen zu lassen, scheiterte jedoch am öffentlichen Widerstand, dessen Teilnehmer sich aus beinahe allen gesellschaftlichen Schichten und allen Parteien rekrutierten. (Vgl. Meyer, Michael, Theaterzensur in München. 1900-1918, München 1982, 15-17) Strukturell ist diese Diskussion ebensowenig bloßer geschichtlicher Bestand oder gar eine Kuriosität, wie es die kinoreformerische Bewahrethik ist. In der feministischen Frontstellung gegen Pornographie u.ä. findet eine Reihe von Argumenten der Lex-Heinze-Debatte gegenwärtig eine implizite Renaissance.

${ }^{67}$ vgl. Lange, Wesen II, 171: „Und wenn man in dieser Vermischung des Moralischen und Ästhetischen neuerdings sogar soweit gegangen ist, zu behaupten, ,daß es moralische Regungen seien, durch die der ästhetische Eindruck charakerisiert wird', und wenn man auf diesem Wege wieder zu dem platonisch-schillerischen Begriffe der, schönen Sittlichkeit' kommt, die schließlich nichts anderes, als die kalokagathia der alten Griechen ist, so weiß ich wirklich nicht, wie man hoffen kann, auf diese Weise Klarheit in die Dinge zu bringen." 
wissen ${ }^{68}$, die jedoch nur bei der Rezeption von Kunst auftritt, also spezifisch ,ästhetische Lust' ist. Wenn nun diese ästhetische Lust nicht auf die kontingenten Erscheinungen Gestalt und Inhalt bezogen werden kann, gleichzeitig jedoch die metaphysische Spekulation über das Kunstschöne vermieden werden soll ${ }^{69}$, dann kann sie nur auf den ,psychische(n) Vorgang selbst als (ihre) unmittelbare Ursache ${ }^{470}$ zurückgeführt werden. Damit wird das innerpsychische Geschehen an sich im Vollzug der Kunstrezeption zur Quelle der ästhetischen Lust erklärt. Erstes erscheint in der Reflexion rein, als von allen Konkreta befreite Möglichkeitsbedingung der letzten. Die vorliegende Denkfigur ist eine transzendentalphilosophische ${ }^{71}$.

Nachdem solcherart der Rezeptionsvorgang an sich als Ursprung der ästhetischen Lust dingfest gemacht ist, wendet sich Lange einer Analyse desselben zu. Jedes Kunstwerk zeichne sich, so es eines sei, durch eine „Illusionskraft“ aus, die darin beruhe, dem Betrachter den Eindruck von etwas zu vermitteln, was realiter nicht vorhanden ist. So erzeuge etwa der Diskuswerfer Myrons eine Bewegungsillusion, obgleich er sich gar nicht bewegt, und tue dies durch eben seine ,künstlerische Form “72. Letzte zeichne sich dadurch aus, daß der Betrachter mit Notwendigkeit veranlaßt werde, seine Wahrnehmung jeweils in seiner Fantasie zu ergänzen, im Fall der genannten Statue das Unbewegte sich bewegt vorzustellen ${ }^{73}$. Zugleich aber sei sich der Betrachter der Täuschung durchaus bewußt, was psychologisch bedeute, da $B$ er „eigentlich zwei Vorstellungen gleichzeitig im Bewußtsein" habe, „erstens die, daß der ästhetische Schein Wirklichkeit sei, zweitens die, daß er Schein (...) sei“'74. Aus dem Wechsel zwischen diesen beiden „Vorstellungsreihen“ quillt nach Lange die spezifisch ästhetische Lust ${ }^{75}$. Er etikettiert den ganzen Vorgang als „bewußte Selbsttäuschung ${ }^{476}$, und bestimmt das Kunstschöne als das, was jene hervorrufe ${ }^{77}$. Für ihr Zustandekommen fordert er von jedem Kunstwerk, illusionsfördernde und ,illusionsstörende' Momente zugleich $^{78}$.

${ }^{68}$ vgl. Lange, Wesen I, 17-18

${ }^{69} \mathrm{vgl}$. Lange, Wesen I, 4

${ }^{70}$ Lange, Wesen I, 18

${ }^{71}$ Lange bezeichnet sie allerdings nicht als solche, da er schon im Vorwort seiner Ästhetik das transzendentalphilosophische Vorgehen, das er mit dem metaphysischen in eins stellt, als „Wunsch, die Lehre vom ,Schönen' zusammen mit der vom ,Wahren' und ,Guten“ einem vorher schon feststehenden metaphysischen System einzugliedern" ablehnt (Lange, Wesen I, 4). Kant insbesondere wirft er vor, ,auf halbem Wege stehen geblieben“" zu sein und ,durch eine transzendentale Hinterthür doch wieder das Moralische, das besonders (...) (er) seiner ganzen Natur nach nicht entbehren konnte, in die Ästhetik wieder (einzuschmuggeln)" (Lange, Wesen II, 171). - Trotzdem beruft er sich an einigen Stellen auf den Königsberger Philosophen, nennt sein eigenes Unterfangen eine konsequente Durchführung der Ansätze von Kant und Schiller und argumentiert im vorgeführten Passus eindeutig transzendentalphilosophisch.

72 vgl. Lange, Kino, 60

73 vgl. Lange, Kino, 60

74 Lange, Wesen I, 208, auch: Lange, Kino, 60

75 vgl. Lange, Wesen I, 326-351

76 Lange, Wesen I, 204

77 Lange, Wesen I, X (Inhaltsverzeichnis)

${ }^{78}$ vgl. Lange, Wesen I, 209-214 


\section{Abbildrealismus und Ausschlu $\beta$ gesellschaftlicher Bezüge: Kunst als Stabilisator}

Die vorliegende Verbindung von transzendentalphilosophischer Reflexion und Rezeptionspsychologie hat nun ein hochgradig formalisiertes Kunstkonzept zur Folge, in dem auf den ersten Blick beinahe jedes Phänomen des Kunst- und Kulturbetriebs - bis hin zum Film - Platz zu finden scheint. Dem ist jedoch nicht so. Zunächst begrenzt das Konzept der ,bewußten Selbsttäuschung schon den Umfang des Kunstkanons. Am geeignetsten zur Erzeugung derselben nämlich erscheinen ,realistische“ Darstellungen. Lange fordert, daß „die Kunst zu der einmal vorhandenen Naturanschauung in einem Verhältnis der Übereinstimmung stehe ${ }^{\text {"79 }}$ und bezeichnet seine eigene kunsttheoretische Haltung als ,realistische ${ }^{800}$. Angezielt ist zwar kein Realismus inhaltlicher Natur, der bestimmte Wirklichkeitsbezüge (etwa gesellschaftliche) herstellt, auch keine blanke Wirklichkeitsverdopplung - wie sie dem Film unterstellt wird (vgl. unten) -, sondern ein formaler, angenäherter Abbildrealismus, dessen ,illusionsstörende Momente darin bestehen, $\mathrm{daB}$ er nicht etwas in der Wirklichkeit Schönes darstellt, sondern das, was er darstellt, ,schön' darstellt ${ }^{81}$. Die vorhandene Naturanschauung kann dabei angemessener und unangemessener sein; ihr entsprechend stuft sich auch das Korpus der ,kanonischen' Gegenstände der Kunstgeschichte $^{82}$. Zeitgenössische Erscheinungen, die davon abweichen, insbesondere der Expressionismus, finden keinen Ort mehr darin.

Ein zweiter Ausgrenzungsmechanismus liegt in dem idealistischen Moment der Langeschen Ästhetik. Auch dieses dient zunächst der Normierung des Kunstkanons; später jedoch findet es zusätzliche Anwendung für die Kritik der Erzeugnisse der Massenkultur. In Kohärenz mit dem transzendentalphilosophischen Argumentationsstrang seines Entwurfs wendet sich Lange gegen jede Form von Unmittelbarkeit, d.h. gegen Empathie ${ }^{83}$ und emotionale Beteiligung. Er fordert vom Rezipienten Distanzierung und von der Kunst völlige Abstinenz von inhaltlichen und praxisrelevanten

\footnotetext{
${ }^{79}$ Lange, Wesen I, 372

${ }^{80}$ vgl. Lange, Wesen I, 30; Auch der Untertitel seiner Ästhetik: „Grundzüge einer realistischen Kunstlehre" läßt das erkennen.

81 vgl. Lange, Wesen I, 372

82 Obgleich Lange betont, daß die eigentliche Kohärenz der Darstellung die mit der jeweiligen Naturanschauung sei, nicht aber mit der ,Natur wie sie ist', impliziert er doch eine Wertung: „Immerhin ist es nicht überflüssig, zu betonen, daß diese Naturauffassungen keineswegs gleichwertig sind. $\mathrm{Da} B$ das Kind die Natur weniger genau beobachtet als der Erwachsene, ergiebt sich schon daraus, daß es beim Zeichnen weniger in ihr sieht, beim Bilderbesehen durch ein primitiveres Formensystem in Illusion versetzt wird. Ebenso ist die japanische Naturauffassung (...) niedriger als die europäische, da der Japaner thatsächlich eine Menge Dinge in der Natur nicht sieht, die vorhanden sind und künstlerisch sehr gut dargestellt werden können." (Lange, Wesen I, 367)

${ }^{83}$ Daher greift er auch die Poetik Aristoteles` an: „Diese Theorie - wenn sie wirklich die des Aristoteles war - ist aus mehr als einem Grunde falsch. (...) Die Griechen haben sich überhaupt niemals zur Unterscheidung der Wirklichkeit und des ästhetischen Scheins in der Kunst durchgearbeitet, was besonders aus den drolligen Theorien Platos hervorgeht. So war also auch für Aristoteles der Thränenausbruch bei der Anschauung einer Tragödie genau aus demselben Grunde lusterregend, aus dem der Thränenausbruch im gewöhnlichen Leben zur Linderung des Schmerzes beiträgt. (...) Der Thränenausbruch bei der Anschauung der Tragödie ist also ohne Zweifel kein Kennzeichen des ästhetischen Genusses.“ (Lange, Wesen I, 222)
} 
Bezügen. Ähnlich Kant postuliert er, daß Kunst ein ,interesseloses Wohlgefallen ${ }^{84}$ hervorrufen solle, das von allen ,praktischen und sinnlichen Interessen des Lebens“'85 abzusehen habe. Kunst müsse ,zweckfrei‘ sein; ihr einziger Zweck sei „die Lust, die sie erzeugt ${ }^{486}$ und die selbst als inhaltslose, rein formale bestimmt worden ist. Damit ist jede Form ,engagierter' Kunst ausgeschlossen; auch ein Realismus im Sinne Brechts findet nicht mehr statt. ,Inhaltliche' Revolutionen in der Kunstgeschichte, etwa, wenn Dürer sich selbst im zuvor Christus vorbehaltenen ikonischen Typus der Frontalansicht darstellt und damit den homo creator dem deus creator zur Seite stellt, bleiben ohne Geltung. Wo immer das Langesche Konzept verlassen wird, ist für dieses nicht mehr Kunst, bzw. werden die ,Interessenbehaftungen' eines Werks als für dessen ästhetischen Wert belanglose (wenn nicht gar störende) Nebensache abgetan. In ihnen wird die Kunst zu lebenspraktisch. Zeigt sie gar gesellschaftliche Relevanz, so wird sie ihrem rezeptionsidealistisch erhobenen ,Wesen' untreu. Als einzige diesbezügliche Funktion wird ihr daher, neben der ungerichteten Lusterzeugung, eine kompensatorische zugestanden: Ihr Zweck sei nicht, „den Sinn der Menschen für das Thatsächliche zu wecken“, sondern sie „,in jenes Gefühl der Freiheit zu versetzen, das sie zur Aufrechterhaltung ihrer Persönlichkeit der Welt gegenüber brauchen“87. Das sei geradezu ihre „biologische Funktion“"88; Kunst diene dort der „Erzeugung von Surrogatgefühlen“, wo sich menschliche Bedürfnisse „nicht in normaler Weise ausleben ${ }^{489}$ könnten.

Damit ist unumstößlich deutlich gemacht, in welchen Grenzen Kunst sich zu bewegen habe und was ihren gesellschaftlichen Stellenwert ausmachen darf. Wenn also das Unterfangen der Langeschen Ästhetik zu Anfang dahin ging, das spezifisch Ästhetische in all den unterschiedlichen, zeit- und kulturkreisbedingten Ausprägungen von Kunst ausfindig zu machen, d.h. einen inklusiven Anspruch erhob, so führt es nun zu Vorschriften für ,wahre Kunst', die eine exklusive Wirkung haben. Wie für Häfker ist für Lange Kunst eine ,Festtagskunst', die ,fern aller Alltagsleidenschaften angesiedelt wird und dem ,Hohen und Reinen' zu dienen hat. Auf diese Weise findet der ,klassische‘ Kunstkanon sowohl eine Rechtfertigung als auch eine Interpretation; Lange stuft ihn zudem noch unter dem Gesichtspunkt der ,Realismustreue'. Das ,Hohe und Reine ${ }^{t}$ der Kunst wird von ihm präzisiert als Formalabstraktion, die eine ,reine', d.h. bezugs- und folgenlose, ästhetische Lust' hervorrufen soll. Über die Zuweisung einer kompensatorischen Funktion allerdings wird diese Lustproduktion durchaus bezugs- und folgenreich: Kunst erhält den Charakter eines Stabilisators. Einerseits soll sie der Wahrung der innerpsychischen Balance und des individuellen Identitätskonzepts helfen, andererseits die Bedürfnisdynamik sublimativ einhegen und so gesellschaftlich stabilisierend wirken. Verbindet man diese Funktionszuschreibung Langes mit seinem eingangs referierten ethisch-ästhetischen Doppelprin-

\footnotetext{
${ }^{84}$ Lange spricht von einer ,uninteressierten Kontemplation“ (Lange, Wesen I, 62), von „uninteressierter Anschauung“ (Lange, Wesen II, 159) und, besonders deutlich, von ,inhaltlicher Uninteressiertheit" (Lange, Wesen II, 163). Auch die Kantische Formulierung des ,interesselosen Wohlgefallens' findet sich bei ihm (Lange, Wesen I, 68).

85 Lange, Kino, 77

${ }^{86}$ Lange, Wesen I, 58

87 Lange, Nationale, 57

88 Lange, Kino, 25

89 Lange, Kino, 25
} 
zip, so läßt sich bereits daraus seine sozialethische Position bezüglich der gesellschaftlichen Rolle und wünschenswerten Wirkung von Kunst rekonstruieren: Gut ist jede Kunst, die der kompensatorisch-sublimativen Stabilisierung von individuellem Identitätskonzept und jeweiliger Gesellschaftsordnung nützt; schlecht hingegen jede Kunst, die diese Stabilitäten stört, aufbricht und aus dem Gleichgewicht bringt.

\section{Prinzipielle ethisch-ästhetische Verortung und Normierung des Films}

Dieses Kunstkonzept hat nun Folgen für Langes Orts- und Funktionsbestimmung der Massenkultur, insbesondere des Films. Während das Realismuspostulat hauptsächlich dazu dient, die ,moderne Kunst' zu kritisieren, wird das Zweckfreiheitspostulat zur Kritik der Produkte des Kulturbetriebs verwendet. Deren Unterworfenheit unter ökonomische Zwecke verstößt bereits gegen dieses Postulat; als Erzeugnisse der Gebrauchskultur haben sie viel zu ,praktische‘ und ,sinnliche‘ Bezüge, um Kunstcharakter beanspruchen zu können. Sie dienen ,interessenbehafteten' Lüsten, nicht aber ,formalen'. Als Teil der Massenkultur fällt der Film daher zunächst aus dem Kunstkanon heraus. Er wird sogar dezidiert zur ,Unkunst' erklärt, da er auch noch unfähig zur Erzeugung der ,ästhetischen Illusion' sei, die Wirklichkeit blank wiedergebe und selbst dort, wo er gestellte Szenen bietet, den Eindruck eines realen Geschehens hinterlasse. Für Lange ist es "ganz dasselbe“, ob man Handlungszusammenhänge ,in der Natur oder auf der weißen Projektionsleinwand" wahrnimmt ${ }^{90}$. Die von ihm geforderte Bewußtheit der ,bewußten Selbsttäuschung' sieht er entsprechend gefährdet, was zur Konsequenz habe, „daß die Mehrzahl der Zuschauer ein Kinobild überhaupt nicht ästhetisch anschaut" ${ }^{* 91}$. In diesem Fall aber komme „der Inhalt als solcher ungehemmt zur Wirkung“ und entfalte sich damit geradezu ,pathologisch ${ }^{92}$. Keinesfalls könne der Film also Kunst sein $^{93}$. Umgekehrt schließt Lange daraus dann, daß die „eigentliche Stärke des Kinos in den unkünstlerischen Gattungen" ${ }^{\text {"4 }}$ liege und der Film auf „einfache Registrierung der Wirklichkeit, so wie sie ist ${ }^{495}$, mithin auf schlichten Abbildrealismus zu verpflichten sei. Trotzdem kann Lange nicht daran vorbeisehen, da $B$ es auch künstlerische Ansprüche des Films gibt. Diese betrachtet er zwar als wesenhaften Selbstwiderspruch des Mediums, da dessen Naturnähe im Gegensatz zum Wesen der Kunst stehe ${ }^{\%}$, doch bleibt ihm angesichts der Faktizität filmischer Kunstansprüche nichts anderes, als sich mit ihnen auseinanderzusetzen. Er tut dies, indem er zunächst die Filmgattungen in zwei große

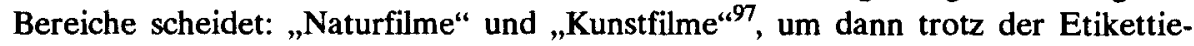
rung des Films als ,Unkunst' Forderungen an ihn zu stellen, die seinem ästhetischen Konzept von Kunst entspringen. Auf diese Weise dient seine Ästhetik nicht nur der

${ }_{91}^{90}$ Lange, Nationale, 43

91 Lange, Nationale, 44

92 Lange, Nationale, 43

93 „Die Kinematograpie ist nicht nur deshalb keine Kunst, weil sie Photographie ist und als solche die Vorstellung von der Persönlichkeit eines schaffenden Künstlers ausschließt, sondern auch deshalb, weil ihre Entwicklung in der Richtung auf absolutes Zusammenfallen mit der Natur, d.h. auf Täuschung geht." (Lange, Kino, 72)

94 Lange, Kino, 72

95 Lange, Kino, 72

96 vgl. Lange, Kino, 65-66

97 vgl. Lange, Nationale, 26; Lange, Kino, 73 
Bestimmung und Bewahrung des Kunstkanons, auch nicht nur der Ausgrenzung und Diskreditierung der Kulturbetriebsprodukte, sondern sie findet zugleich eine positivnormative Rückanwendung auf die Letzten.

Der erste der genannten Gattungsbereiche nun ergibt sich schlüssig aus Langes Theorie: Die Verpflichtung auf Abbildrealismus legt dem Film Informationsvermittlung und Naturdarstellung als primäre Funktionen nahe; das primäre Genre wäre hier der Dokumentarfilm ${ }^{98}$. Inn betrachtet Lange als legitim, ja, er verweist darauf, daß „alle Kinoreformer“ sich darin einig seien, daß hier die vorzüglichste Aufgabe des Films liege ${ }^{99}$. Wegen der angenommenen Unmittelbarkeit der abbildrealistischen Wirkung, die als ,Suggestivkraftthese' zum Kernbestand der Argumentation auch anderer Reformer zählt ${ }^{100}$, werden dann die zugelassenen Motive und Handlungsformen auf belanglose und, ungefährliche‘ eingeschränkt. In dieser Weise soll eine Annäherung der Filmwirkung an die Kunstwirkung erfolgen, genauer: das Entschärfungsmoment der ,bewußten Selbsttäuschung, das dem Täuschungsmedium Film zunächst fehle, durch eine entsprechende inhaltliche und formale Gestaltung erreicht werden. Inhaltlich schlägt Lange vor, Bewegungsabläufe in der Natur, Szenen aus dem Tierleben sowie aus Stadt und Land festzuhalten. Die wirkungsentschärfende Ausrichtung dieser Vorschläge wird an seinen Beispielen deutlich: „Das Dahintreiben der Wolken am Himmel, das Wogen der Kornfelder im Winde, das Niederfallen der Schneeflocken “101 als Filminhalte deuten ebenso, wie „das Gehen, Laufen und Reiten, das Säen, Ernten und Dreschen, das Schmieden und Rudern, das Hacken und Hobeln, das Rammen und Schaufeln, das Nähen und Stricken“102 auf konforme Beschaulichkeit. Durchaus kohärent mit dieser Beschaulichkeit fordert er in formaler Hinsicht, sich auf große Bewegungen und Rhythmus zu beschränken ${ }^{103}$. $\mathrm{DaB}$ diese Entschärfung als Bemühen, die Filmwirkung der Kunstwirkung anzugleichen, gesehen werden kann, wird nicht zuletzt daraus deutlich, daß Lange seinen Vorschlägen attestiert, der Film könne durch ihre Beachtung, obwohl seinem Wesen nach unfähig zur künstlerischen Wirkung, eine gewisse Ästhetik erzielen ${ }^{104}$. - Daneben bleibt die ihm zugemessene Aufgabe die der Registrierung zum Zweck der Speicherung wichtiger historischer Ereignisse und ihrer Überlieferung an die Nachwelt ${ }^{105}$. Hermann Häfker entwirft für diese Funktion gar einen detaillierten Plan der

${ }^{98}$ Lange selbst spricht vom „Natur- oder Wirklichkeitsfilm“. (vgl. Lange, Nationale, 26)

99 vgl. Lange, Nationale, 26

100 etwa bei: Hellwig, Kind, 29; Hellwig, Schundfilms, 51; Gaupp, Robert, Der Kinematograph vom medizinischen und psychologischen Standpunkt, in: Gaupp, Kinematograph, 9; Sellmann, Adolf, Der Kinematograph als Volkserzieher?, Langensalza 1912, 24; die These gilt als selbstverständlich; ein ausführlicherer Versuch, sie argumentativ zu belegen, findet sich bei Gaupp. Zum Wirkungskonzept der Reformer vgl. auch nachfolgend 2.4.

${ }^{101}$ Lange, Nationale, 27

102 Lange, Kino, 75

103 vgl. Lange, Kino, 75

104 ,Aber er (der Film, T.H.) soll, wenn er ästhetische Wirkungen erzielen will, die großen und einfachen Bewegungen bevorzugen ..." (Lange, Kino, 75)

${ }^{105}$ vgl. Lange, Nationale, 28 
Archivierung, Lagerung und Behandlung der Filme, um ihr Überleben auf mehrere Jahrtausende (!) zu sichern ${ }^{106}$.

Eine ähnliche Strategie wie beim „Naturfilm“ verfolgt Lange im zweiten Gattungsbereich, beim sogenannten „Kunstfilm“. Er versteht darunter jede Form der filmischen, narrativen Fiktionalität, d.h. die zeitgenössischen Burlesken, Grotesken, Melodramen, Kriminalfilme, Literaturverfilmungen etc. Beinahe all diese Genres fallen - aus im folgenden (2.3. und 2.4.) noch detaillierter zu analysierenden Gründen - dem Verdikt anheim; in der Grundstruktur sind die jeweiligen Einzelvorwürfe, die zu ihrer Verurteilung führen, jedoch immer mit dem genannten Wirkungskonzept verbunden. Langes ästhetische Normierungen sind folglich auch in diesem Bereich als Entschärfungsversuche dekodierbar, wie seine Stellungnahmen zu den einzelnen Genres zeigen. So läßt er die Humoresken weitgehend gelten, wenn sie ironisierende oder kritisierende Wirklichkeitsbezüge vermeiden, d.h. nicht etwa Erwachsene oder Autoritätspersonen in entsprechend lächerlicher Weise darstellen ${ }^{107}$. Karikierende Elemente scheiden dann freilich aus dem Kanon legitimer Darstellungsmittel weitgehend aus ${ }^{108}$, auch der anarchische Humor der zeitgenössischen amerikanischen Slapstickfilme findet nur begrenzt Gnade vor Langes Augen. Beschränkt er sich auf bezugslose komische Situationen, so darf er sein, aber eben nur aufgrund seiner Bezugslosigkeit: „Fratzenschneiden, Laufen und Rennen, Hinfallen, Übereinanderpurzeln und Aneinanderstoßen, Wiederaufstehen, Inswasserfallen usw., das sind schließlich keine besonders wichtigen Ereignisse“109. Über ",so etwas“ darf daher, „da das Publikum nun einmal solche Dinge sehen will“, auch gelacht werden ${ }^{110}$. - Während die Humoresken nur mehr oder weniger widerwillig, aus einer gewissen Kapitulation vor dem Publikumsgeschmack heraus, geduldet werden, schneiden die Trickfilme ${ }^{111}$ besser ab. Sie kommen mit ihren fantastischen, wirklichkeitsenthobenen Sujets der von Lange postulierten Kompensationsfunktion von Kunst nahe. Er nennt ihr „Prinzip als solches“ daher „,nicht unkünstlerisch“112 und attestiert ihnen sogar eine besondere Eignung für diese Funktion ${ }^{113}$. - Ähnlich verhält es sich mit Märchen. Obgleich Literaturverfilmungen pauschal abgelehnt werden (vgl. die Forderung eines „Denkmalschutzgesetzes“ für die „klassische“ Literatur), scheinen Lange Märchen besonders geeignet für die Verfilmung. Ihre Fantastik

106 vgl. Häfker, Gebildete, 21ff; um die Zeiten der Lagerfähigkeit adäquat zu verlängern, empfiehlt er, jeden Film ,zunächst einmal auf 100 Jahre gänzlich zu versiegeln“ und ihn auch dann nur alle fünf Jahre einmal zu zeigen.

107 vgl. Lange, Nationale, 56

108 Lange, Kino, 103-107 nennt zwar die Karikatur als mögliches Stilmittel der Humoreske, doch macht die dort vorgenommene Beschreibung ihrer Funktion deutlich, daß Karikieren als Übertreiben der Wirklichkeit zum Zweck der Erzeugung komischer Wirkungen, nicht aber als bewertende Stellungnahme mit Hilfe der Komik verstanden wird.

${ }_{109}$ Lange, Nationale, 56

110 Lange, Nationale, 56

111 Das meint zu dieser Zeit noch hauptsächlich fantastisch-surreale Arrangements mit Hilfe von Bühnentricks (vgl. das unter 1.5. etwa zu Mélies Gesagte).

${ }_{112}$ Lange, Nationale, 57

113 vgl. Lange, Nationale, 57: „... dazu (zur Erzeugung kompensatorischer Wirkung, T.H.) ist ein phantastischer Inhalt sehr wohl geeignet. Besonders in einer Kunst, die technisch imstande ist, das Unwahrscheinlichste und Unmöglichste als vollkommen glaubwürdig darzustellen." Auffällig ist zudem, daß Lange sich hier dazu herabläßt, den Film eine Kunst zu nennen. 
komme den Trickfilmen gleich; sie könnten also in analoger Weise dem Kompensationspostulat dienlich sein und auch noch ein Idealprogramm für Kinder darstellen $^{114}$. - Wo in den genannten Genres die Entschärfung über die inhaltliche Ebene läuft, tut sie dies in der von Lange favorisierten Pantomime und im Tanzfilm über die Formalästhetik. Beide Genres eignen sich besonders dafür, eine Verbindung mit den rezeptionsidealistischen Forderungen einzugehen. Zwar rechnet Lange die Pantomime nicht zu den ,höheren' Kunstformen ${ }^{115}$, doch darf sie als Kunstform immerhin zählen. Ihre wortlose Darstellungsweise gilt ihm nicht nur als kompatibel mit dem zu seiner Zeit noch stummen Film, sondern im Verbund mit ihren Handlungsritualisierungen und dem Hantieren mit imaginären Gegenständen als ausgesprochen förderlich für die Erzeugung der ,bewußten Selbsttäuschung‘. Sie enthält genug ,illusionsstörende' Elemente, ohne andererseits gegen das Realismusgebot zu verstoßen. Auch sind ihre Wirklichkeitsbezüge durch ihren Symbolcharakter genug verkleidet; Lange spricht davon, daß ihre Handlungen geradezu nur ,Symbol der wirklichen Handlung "116 seien. Für sie will er sogar Stoffe zulassen, die er sonst ausgrenzt; obgleich er sich ebenso wie die meisten anderen Kinoreformer gegen Kriminalfilme und erotische Sujets wendet (vgl. 2.4.), nennt er dieselben hier als mögliche „Moti$\mathrm{ve}^{\text {“117. }}$. Ihr gefährlicher Gehalt nämlich werde durch die ,Kunstform" der Pantomime „in das Niveau des ästhetisch Schönen emporgehoben“118 und damit entschärft, wie es grundsätzlich immer der Fall sei, wenn derartige Gehalte mit den Mitteln der Kunst bearbeitet werden: ,,... die Illusion, in die man versetzt wird, (ist) so stark, daß man daneben gar keine Zeit und Kraft übrig behält, sich dem Genuß des sexuellen (oder kriminellen, T.H.) Inhalts als solchen hinzugeben. Der Inhalt wird eben hier (...) ,durch die Form vertilgt'."119 - Der Tanzfilm wiederum kommt durch seine Konzentration auf Rhythmus und Bewegung der Formalisierungsforderung, wie sie schon für ,Naturfilme vorgebracht wurde, so entgegen, daß auch er ,Kunstansprüche machen' darf. Lange empfiehlt ihm freilich nicht den Gesellschaftstanz als Gegenstand, sondern den „Kunsttanz“120 . - In beiden von ihm definierten Rahmengattungen des Films zeigt sich somit als zentrale normative Absicht bei der Übertragung der rezeptionsidealistischen Ästhetik auf das massenkulturelle Medium die Entschärfung jeder möglicherweise destabilisierenden Wirkung. Mit der Fixierung des

114 vgl. Lange, Nationale, 57; Lange, Kino, 107-109 (dort wird die Kompensationseignung des Märchens genannt); in Langes Vorstellungen über Märchen spricht sich freilich die typische Verkennung ihrer lebenspraktischen Bezüge und sozialgeschichtlichen Hintergründe aus, die bis zum heutigen Tag ihre Beurteilung als besonders kindgerechte Erzählform trägt.

115 vgl. Lange, Kino, 114

116 Lange, Kino, 82; dasselbe behauptet Lange generell für den narrativ-fiktionalen Film: Aufgrund seiner Wortlosigkeit, die zu übertreibenden Gesten nötigt, wie auch durch seine Kürze, die eine Zusammenfassung von Handlungen und Ereignissen erfordert, welche sich in der Realität möglicherweise ,über Jahre“ erstrecken würden, eigne dem Film eine Tendenz zur symbolhaften' (besser wohl: paradigmatischen) Darstellung, die der der Pantomime nahekomme.

117 vgl. Lange, Kino, 114: „Wenn eine Pantomime mit strenger Beachtung der ihr eigenen Gesetze komponiert ist und in stilvoller Weise aufgeführt wird, dann liegt kein Grund vor, ihr die erotischen und kriminellen Motive vorzuenthalten."
118 Lange, Kino, 114
119 Lange, Wesen II, 165
${ }^{120}$ Lange, Kino, 111 
Tanzfilms auf den „Kunsttanz“ tritt nun noch ein weiteres, letztes Moment in Blick: die pädagogische Verzweckung an eine Hebung des ästhetischen Bildungsniveaus.

Ein bildungsbezogener Einsatz des Films deutet sich bei Lange schon an, wenn er von dessen archivarischen Eignungen spricht. Durch das ,Abfilmen' künstlerischer Darbietungen wie der Pantomime oder dem Kunsttanz aber scheint ihm zusätzlich noch die Möglichkeit gegeben, die Rezipientenschaft an eine höhere ästhetische Bildung heranzuführen. Diese Perspektive enthält eine weitere Ausblendung. Der Blick auf das ästhetische Niveau nämlich kennt nur hoch und tief. Neben der rezeptionsidealistisch charakterisierten, aller lebensweltlichen Relevanzen entkleideten Hochkunst gibt es bei Lange kaum eine mittlere oder niedrige, sondern nur Unkunst. Aufgrund dieser dichotomischen Neigung entfällt der mittlere Unterhaltungsbereich weitgehend. Die normative Übertragung der rezeptionsidealistischen, Wesenseigenschaften' von Kunst auf die Erzeugnisse der Massenkultur hat zur Folge, daB diese nur Geltung beanspruchen können, wenn sie sich der Kunst annähern. Wo sie das nicht tun, fallen sie aus dem Kanon der Legitimität heraus und damit der Bekämpfung durch die Reformer anheim. Nur mit großer Reserviertheit werden die, primitiveren` Unterhaltungsformen an einigen Stellen geduldet - etwa beim Film die $\mathrm{Hu}$ moreske - , und auch das nur, wenn sie ,harmlos' erscheinen und möglichst den Charaker von Durchgangsstadien haben. Nicht nur „ethische“, und daher zu entschärfende "Schundfilme“, sondern auch „ästhetische“ kennen einige Reformer ${ }^{121}$, und unter ihnen ist es vor allem Lange, der die ästhetischen Schundfilme nicht als tolerabel betrachtet ${ }^{122}$. Ließe man, ästhetischen Schund' $z u$, so begäbe man sich der Chance, das Publikum zu höherem Qualitätsempfinden zu erziehen. Lange sieht sich daher gefordert, auch im Bereich des Films nur möglichst Hochkunst bzw., insoweit der Film keine Kunst ist, Analogate derselben zuzulassen:

„Für das Volk ist - wie für die Kinder - das Beste gerade gut genug. Ebenso wie wir z.B. beim Bilderbuch keine Kunst zweiten Ranges dulden, in der Hoffnung, daß die Kinder dadurch allmählich zur wahren Kunst erzogen werden,

121 Vgl. etwa: Hellwig, Schundfilms, 20: „Wir werden (...) finden (...) daß sie vielmehr vielfach entweder höchst abgeschmackt und deshalb vom ästhetischen Gesichtspunkt aus zu verwerfen sind, oder daß sie gar vom ethischen Gesichtspunkt aus nicht billigenswerte Leidenschaften und Gefühle wecken, daß sic verrohend und entsittlichend wirken." Die Unterscheidung stellt eine Parallele zur Differenzierung von ,literarisch minderwertigen' und ,ethisch gefährlichen' Druckschriften im Bereich der Kampagne gegen ,Schmutz- und Schundliteratur' dar (vgl. oben).

i22 vgl. Lange, Nationale, 52-53; Lange, Kino, 92, 164-165, 202; Lange, der sich dabei hauptsächlich gegen Hellwig wendet, argumentiert mit seinem Wirkungskonzept: Da der Film schon an sich ein abbildungsrealistisches Täuschungsmedium sei, könne er keinesfalls ,ästhetisch', d.h. im Sinne der entschärfenden ,bewußten Selbsttäuschung' wirksam werden. Seine Inhalte erschienen vielmehr als Realität; sofern sie nicht ethisch unbedenklich seien, seien sie auch nicht ästhetisch unbedenklich. - Die Argumentation freilich ermangelt der Konsistenz: Ihr zufolge gibt es beim Film gar keine Ästhetik (als illusionsstörende „Schutzwehr“ gedacht; Lange, Nationale, 52), so daß sich die Entscheidung über ihren Wert nur am Inhalt bemessen ließe. Andererseits aber war zu sehen, daß Lange sich um dezidiert ästhetische ,Hebung des Films bemüht, so daß eine diesbezügliche Qualitätsentscheidung möglich wird. Tatsächlich nimmt Lange im Bemühen um ästhetische Bildung des Publikums eine solche ästhetische Qualität des Films an. (Das wird auch ex negativo deutlich, wenn er von dessen, ,ästhetischer Minderwertigkeit“ - nicht also von der Abwesenheit jeder ästhetischen Qualität -, bzw, von der „Verletzung des ästhetischen Gefühls" spricht. Vgl. Lange, Nationale, 52-54) 
ebensowenig dürfen wir beim Kino den Weg zur wahren Kunst über die Halbkunst, d.h. über den Kitsch, zu gewinnen suchen. Sonst laufen wir Gefahr, daß das Volk an der Halbkunst hängen bleibt und zur eigentlichen Kunst überhaupt nicht kommt.“"123

Die Parallelisierung des, Volks' mit den Kindern im vorstehenden Zitat zeigt, wie sich die dichotomische Neigung schichtspezifisch umsetzt. Auf der einen Seite stehen die ,Gebildeten', denen die Aufgabe der gesellschaftlichen Führung obliegt, auf der anderen Seite findet sich das ,einfache Volk‘, das der Erziehung und Führung bedarf. Diese recht simple soziologische Einteilung weist nun bereits in die Richtung der eingangs geäußerten Vermutung einer wohl kontramodernen Position der Kinoreformer. Die mit diesem Bild verbundene schichtspezifische Dichotomie nämlich, die eine Gruppe von ,Bildungsführern' der ,breiten Masse' vor- und überordnet, impliziert - so darf angenommen werden - eine Neigung der Reformer, den Status mitspracheberechtigter autonomer Subjekte nur zirkelintern für die eigene Gruppe und Schicht in Anspruch zu nehmen, den Rest der Gesellschaft hingegen für mindestens unmündig zu erklären. Obschon in Wahrheit keine ,Kinder' mehr, dürfen die Angehörigen des ,einfachen Volks' offensichtlich in keiner Weise darüber mitbefinden, was sie denn nun zu rezipieren wünschen. Eine derartige Entscheidungskompetenz bleibt ihnen schlicht abgesprochen; ließe man sie selbst ein Urteil fällen und sich im (sicher nicht nur ,Halbkunst' enthaltenden) Angebot orientieren, so scheint es sicher zu sein, daß dieses Urteil gegen die Bildung und zugunsten der ,Halbkunst‘ ausfällt. In der Dichotomie von Hoch und Tief ist das Mittlere schon gefährlich, da es offenbar die Tendenz nach oben obstruiert und die Neigung nach unten befördert. Dies aber steht dem von Lange gewählten Bild zufolge vordringlich deshalb zu befürchten, weil die ,breiten Massen', Kindern ähnlich, keine wirkliche Verfügung über ihre Neigungen haben und daher keine wirklich mündige Entscheidung zu fällen vermögen. Sie sind somit auch kaum als mündige Subjekte zu betrachten - und die Übertragung des Subjektstatus auf sie hätte gefährliche Konsequenzen für das Bildungsniveau einer Gesellschaft. Unter dem in Langes Text geäußerten Bemühen um Bildung und Kulturation des ,Volks‘ entdeckt sich damit einem rekonstruktiven Blick eine kontramoderne Implikation. Den Massen bleibt der Subjektstatus, bleiben Mitspracherechte vorenthalten und wird daher letztlich eine Teilnahme am Projekt der Moderne versagt. Im folgenden wird diese kontramoderne Implikation noch deutlicher werden und sich geradezu als Position erschließen.

Insgesamt aber hat sich so nun bereits gezeigt, wie die grundsätzliche Konzeption der Reform und ihr theoretisches Paradigma aussehen. Angesetzt wird auf der einen Seite eine elitär gedachte, von einer Elite getragene, auf Stabilisierung verpflichtete Kunst. Auf der anderen Seite steht die Massenkultur, respektive der Film als eine ihrer herausragenden Erscheinungen, die pessimistisch als Bedrohung für die Künste sowie als überbordende enthemmte und enthemmende Dynamik perhorresziert wird. Die generelle Strategie nun geht dahin, die Erzeugnisse der Massenkultur den Kunstnormen zu unterwerfen und so zu domestizieren. Sie werden damit dem Bestimmungs- und Verfügungsbereich der ,Gebildeten' einverleibt mit exklusiver Wirkung für jene, die diesem Kreis nicht angehören; das Stabilisierungspostulat, das ich

${ }^{123}$ Lange, Kino, 192 
oben als sozialethische Maxime für die Kunst rekonstruiert habe, wird auf die Produkte des Kulturbetriebs, genauer: der neuen literarischen, auditiven und visuellen Vermittlungsweisen übertragen. Aus dem Ganzen spricht eine kulturpessimistische Haltung, die in der Konfrontation mit dem nicht mehr zu stoppenden Prozeß medialer Gehalteproduktion und -verteilung auf möglichst umfassende Bewahrung des Bestehenden drängt ${ }^{124}$. Jede Destabilisierung, d.h. wohl auch: jeder Norm- und Institutionswandel, gilt ihr als gefährlich und indiziert für sie Verfall. An die Stelle des ,guten Alten' soll möglichst nichts treten; ein ,gutes Neues' ist nicht denkbar. Die Ethik, die darin liegt, nenne ich deshalb eine Bewahrethik. Der epochale Kontext, der den medialen Kommunikationsprozeß als Strukturmoment der Realisierung des Projekts der Moderne erkennbar macht, und die rekonstruierte ,Entmündigung' der breiten Massen lassen diese Bewahrethik außerdem als kontramoderne apostrophieren. Wie sich diese näherhin ausformt, will ich im folgenden an Hand der zentralen Vorwürfe zeigen, die von den Kinoreformern gegen den Film vorgebracht werden. Das kontramoderne Moment wird dabei zunehmend deutlicher vor Augen treten.

\section{Devianzvorwürfe I: Moralische Primitivierung und zivilisatorischer Kulturverfall. Anthropologischer Pessimismus und reformerisches Kulturkonzept}

Der normative Diskurs der Reformer artikuliert sich hauptsächlich in Form von Anschuldigungen, die ich unter dem Begriff "Devianzvorwürfe" zusammenfassen möchte. Mit dem Begriff der Devianz wird in der Soziologie das abweichende Verhalten von Individuen und Gruppen in der Gesellschaft beschrieben; Kriterien der Bestimmung des Abweichens sind in der Regel die jeweiligen Norm- und Wertstandards dieser Gesellschaft. Das Gros der kinoreformerischen Vorwürfe gegen den Film nun bezieht sich auf dessen Inhalte und (angenommene) Wirkungen, die vom Standpunkt solcher Standards aus kritisiert werden. Dem Film wird dabei angelastet, $\mathrm{da} B$ er den wünschenswerten Status quo störe, indem er nonkonforme Aussagen mache und so zu nonkonformem Verhalten anleite bzw. entsprechende Dispositionen und Habitus befördere. In andere Worte gefaßt bedeutet dies, da $\beta$ der Film deviant sei und Devianz hervorrufe. Ich halte diese Begrifflichkeit daher für naheliegend, um die infrage stehenden Vorwürfe generell zu charakterisieren.

Gesellschaftliche Normstandards freilich sind noch nicht sogleich ethische. Die Devianz kann auch eine ethisch zunächst irrelevante Verhaltensabweichung im Bereich der Mode oder Konvention meinen. Ein genauerer Blick auf die kinoreformerischen Vorwürfe aber zeigt, daß es sich hier in den meisten Fällen um ethikbezogene handelt ${ }^{125}$. Es liegt ihnen (wie allen Devianzvorwürfen) ein mehr oder weniger

${ }^{124}$ Dabei begreift sich diese bewahrende Haltung durchaus als Damm gegen die ,heranbrandende Flut' der neuen medialen Produktion, die diese Flut, wenn sie schon nicht ganz aufzuhalten ist, zumindest zurückzudrängen sucht: ,Niemals kann die Kinematographie zu künstlerischem Werte gelangen, solange nicht ein Übel unseres heutigen öffentlichen Lebens eingedämmt ist: das Übermaß an ganz oder fast unfreiwilligen geistigen Eindrücken überhaupt, die stündlich auf uns hereinstürmen. Deren Eindämmung wird wohl am Nächsten die Aufgabe der allgemeinen Erziehung, der Aufklärung jedes Einzelnen schon von der Schule an sein.“ (Häfker, Kunst, 70)

${ }^{125}$ Neben den ethikbezogenen Vorwürfen gibt es einen gesundheitsbezogenen Vorwurf, der eine physische Beeinträchtigung der Sehfähigkeit durch das Flimmern der frühen Filme sowie physische Schädigungen durch den Aufenthalt in schlecht belüfteten Räumen perhorresziert 
klares Bild dessen zugrunde, was sein soll und weshalb Phänomene, die davon differieren, zu verwerfen und zu bekämpfen seien; die zugehörige Kritik richtet sich dann jedoch einerseits oft auf ethosrelevante Einflüsse des Films, d.h. solche, die den sittlichen Habitus des Einzelnen und die moralischen Wertstandards der Sozietät (das ,Ethos der Gesellschaft') betreffen, und sie bedient sich andererseits häufig explizit ethischer Argumente. Zusammen mit den jeweils gezogenen Konsequenzen können die reformerischen Devianzvorwürfe sonach als konkretisierende Auslegung der oben in ihren Grundzügen skizzierten Bewahrethik betrachtet werden. Am Begriff der Devianz möchte ich dennoch festhalten, da die Vorwürfe meist über ein nicht sofort ethikbezogenes, aber ethikrelevantes kulturkritisches Halo verfügen, das auf diese Weise noch mit erfaßt werden kann. Eine Reflexion dieses Halos ist für das zureichende Verständnis der Konkretion reformerischer Bewahrethik in den Devianzvorwürfen unerläßlich.

Der Blick auf die Vorwürfe wird immer wieder zwei Argumentationsperspektiven unterscheiden lassen: Befürchtet werden einmal perniziose Folgen des Films für das Individuum, ein andermal für das gesellschaftliche Kollektiv. Obgleich diese Differenzierung eine Einteilung der Vorwürfe in sozialethische und individualethische nahelegte, werde ich meine Einteilung nicht nach diesen Gesichtspunkten vollziehen. Ein gut Teil der ,individualethischen' Vorwürfe nämlich hat unübersehbare sozialethische Implikationen und umgekehrt. In meinem Versuch einer typologischen Rekonstruktion lasse ich daher beide Aspekte unter Berücksichtigung ihrer jeweils unterschiedlichen Gewichtung innerhalb eines Vorwurfstyps beieinander.

\section{Ethoskorruption und Latenz: Die negative Anthropologie der Reformer}

Der erste Typ, den ich herausarbeiten möchte, ist der Vorwurf eines sittlich-kulturellen Verfalls, der zunächst als moralische Primitivierung unter dem Stichwort der „Verrohung" eingeführt wird. Er ist generell und steckt gewissermaßen einen Rahmen ab. Eingeführt wird der Vorwurf unter zwei Aspekten: einem kleinräumigen, der sich hauptsächlich auf konkrete Filminhalte bezieht und unter Heranziehung psychologischer Theoreme ein destruktives Zusammenspiel von Film und Publikum unterstellt, sowie einem großräumigen, der den Film als exemplarisches Phänomen eines generellen Kulturverfalls begreift und sich so zur Kulturkritik erweitert. Insbesondere im zweiten Fall wird dann auch die Formalstruktur des Films zum Thema gemacht.

Der kleinräumige Aspekt der Kritik setzt zunächst bei mehr oder minder grausamen Darstellungen und Vorgängen in Filmen an. Als Beispiele für solche nennt etwa

(vgl. dazu etwa: Gaupp, Kinematograph, 4-5; Hellwig, Kind, 75; u.a.). Alle Reformer verweisen jedoch in diesem Zusammenhang sogleich darauf, daß es sich hier um nebensächliche, da technische und technisch lösbare Probleme handle, denen im Vergleich zu den ethosrelevanten Problemen wenig Gewicht beigemessen werden solle. Wo, wie bei Hellwig, psychosomatische Wirkungen angenommen werden, werden diese bereits wieder aus den Filminhalten hergeleitet und ethisch-psychologisch ausgelegt, so daß diese Wirkungshypothese und aus ihr quellende Vorwürfe wieder zu den ,ethischen Typen' zu rechnen sind (vgl.: Hellwig, Schundfilms, 56). - Ich zähle aus diesen Gründen den physiologisch-gesundheitsbezogenen Vorwurf nicht zu den zentralen Vorwürfen der Reformer. Da es mir außerdem um die ethischen bzw. die ethosbezogenen Vorwürfe geht, empfiehlt sich auch aus methodologischen Gründen die Ausklammerung des physiologisch-gesundheitsbezogenen Typs. 
Hellwig Szenen, in denen jeweils eine Katze einmal bei lebendigem Leib verbrannt, ein andermal zwischen Walzen zermalmt wird ${ }^{126}$, einen Film, in dem eine Löwenjagd stattfindet ${ }^{127}$, sowie eine Szene, die den Sturz eines Pferdegespanns in eine Schlucht zeigt $^{128}$. Für all diese Vorgänge seien lebende Tiere real mißbraucht worden, um eine entsprechend wirklichkeitsnahe Darstellung zu ermöglichen ${ }^{129}$. Abgesehen von der ,Roheit' (und unbestreitbaren Grausamkeit) der Produzenten, die sich in einer solchen Produktionsweise äußere, sieht Hellwig daraus Gefahren für den Rezipienten erwachsen. Der ,häufige Anblick geschmackloser und direkt roher Szenen“ lasse „allmählich das Gefühl abstumpfen“130, d.h., er führe zu einer empathiebezogenen Desensibilisierung oder gar dem Verlust der Fähigkeit des Mitfühlens. Durch den Konsum ,abgefilmter" Grausamkeit werde zunehmend das Bewußtsein von der Leidensfähigkeit anderer lebender Wesen und damit das Gefühl für den „richtigen Maßstab“131 aufgehoben, der zuvor eine Unterscheidung von „Rohem und Nichtrohem“132 ermöglicht habe. Von der Gewöhnung an ,Roheit" scheint folglich der Schritt zur eigenen Tat nicht mehr weit:

„Wer tagtäglich ausgesuchte Roheiten im lebenden Bilde sieht, der wird schließlich an den ,kleinen Roheiten des täglichen Lebens' nichts besonderes mehr finden, sie gar nicht mehr als roh empfinden, ja vielleicht sogar an ihnen Gefallen finden, und selber bewußt Roheitsakte begehen, um seiner viehischen Gier zu frönen." “333

Befürchtet wird also zunächst, daß die Rezeption brutaler und grausamer Filminhalte zu einer Zerstörung der Empfindsamkeit, und in deren Gefolge zu einer Brutalisierung der Rezipientenschaft führe. Als real beobachtbare Manifestation dieser Brutalisierung erscheinen dann ,Vandalismus' und rüde Umgangsformen, wie sie etwa Lange als „Roheit unserer halbwüchsigen männlichen Jugend, (die) z.B. auf den Eisenbahnen, jedem in die Augen springt “' ${ }^{134}$, beklagt. Obgleich (im Unterschied zu Lange) Hellwig stärker betont, daß diese Phänomene, nicht allein auf Schundliteratur und Schundfilms zurückgeführt ${ }^{t}$ werden könnten ${ }^{135}$, gelten sie beiden, wie auch etlichen ihrer Kollegen, als Bestätigung der These einer entsprechenden Filmwirkung.

Neben dieser allgemeinen Verhaltenskrudisierung wird dann auch eine Wirkung auf das Ethos des Einzelnen, auf seine sittliche Disposition und seinen wertbezogenen Habitus angenommen. Schon die These von der ,Abstumpfung des Gefühls' legt

\footnotetext{
${ }^{126}$ Hellwig, Schundfilms, 58

${ }_{127}$ Hellwig, Schundfilms, 59

128 Hellwig, Schundfilms, 59

129 vgl. Hellwig, Schundfilms, 58-59

${ }^{130}$ Hellwig, Schundfilms, 58

131 Hellwig, Schundfilms, 58

132 Hellwig, Schundfilms, 58

133 Hellwig, Schundfilms, 58

134 Lange Kino, 42

135 vgl. Hellwig, Schundfilms, 58: „Fern liegt es mir, etwa alle Roheiten, die durch Kinder begangen werden, auf die Schundfilms und die Schundliteratur zurückzuführen, sie allein verantwortlich zu machen, für die heute anscheinend stärker werdende Roheit unserer Jugend ..." Lange, Kino, 42, formuliert nach einer Aufzählung entsprechender Phänomene provokativer mit einer rhetorischen Frage: ,... sollte da wirklich gar kein Zusammenhang mit der häufigen Anschauung von Sünde und Verbrechen in Lichtspieltheatern bestehen?“
} 
den Schluß nahe, daß durch den Verlust der Fähigkeit zur Empathie auch die emotionale Basis der ethischen Motivation zu altruistischem Verhalten ins Wanken gerät. Ein Ethos ohne emotionale Komponenten aber bleibt ebenso leer wie ein Begriff ohne Anschauung. Mit dem Verlust oder der Vergröberung des Mitgefühls droht sonach eine Krudisierung der Moral. Tatsächlich deutet Hellwig diese Schlußfolgerung von emotional-empathischer Desensibilisierung auf ethische Demotivierung an ${ }^{136}$. Eine genauere Durchführung der Verrohungsthese mit Bezug auf ethosrelevante Wirkungen findet sich dann insbesondere bei Conradt. Er sieht Gefahren einerseits aus einer Reizorientierung, die dem Film wesentlich eigen sei, und andererseits aus einer Empfänglichkeit des Publikums für entsprechende Suggestionen quellen. Grausame, aufreizende Szenen nämlich spekulierten in Wahrheit auf korrespondierende Dispositionen, die die Rezipientenschaft schon mitbringe:

„Die tendenziösen Schattenrisse aus dem modernen Leben werden den bösen Instinkten des Publikums angepaßt und verrohen auch die besseren Elemente zusehends. Die Effekte werden von Jahr zu Jahr raffinierter ausgeklügelt und stacheln immer stärker das Tier im Menschen auf, denn die Stammgäste werden täglich blasierter.“137

Film und Publikum werden so gleichermaßen inkriminiert und einer unheiligen Allianz bezichtigt. Die Inhalte des Films erscheinen als "Sensationsmache“, die mit ,Effekthascherei' die Rezipienten zu binden suchen. Auch bei anderen Autoren der Reform gilt der Film als von groben Reizen und plakativen Formen geprägt, die eine „Vertiefung und Erhebung (...) durch gewaltsame Mittel wie Augenrollen und grobes Mienenspiel“138 ersetzten. Wenn das zu dieser Zeit noch auf das Fehlen des Tons zurückgeführt wird und etwa bei Lange in entsprechende ästhetische Empfehlungen mündet (vgl. seine Insistenz auf der ,Filmgerechtheit' der Pantomime), so konnotieren sich damit doch eine Wertung und ein wirkungsbezogener Vorwurf. An die Stelle des „Sinn(s) für das Intime, das Genaue, das Feine“"139 nämlich trete durch die Fixiertheit des Films auf grelle Farben' und übertreibende Darstellungsweise auch eine Reizorientierung des Publikums, welche ,fortwährend Aufregungen und Abenteuer ${ }^{\prime 140}$ verlange. Vor allem bei Jugendlichen werde dadurch die Neigung befördert, statt den ,kleinen Freuden des Lebens' nur die großen Bewegungen zu suchen, und angesichts der ,Nüchternheit' der Realität unzufrieden zu werden ${ }^{141}$. Als besonders

136 vgl. das bereits aufgeführte Zitat: „Wer tagtäglich ausgesuchte Roheiten (...) sieht, der wird (...) sie gar nicht mehr als roh empfinden, ja vielleicht sogar (...) selber bewußt Roheitsakte begehen ..." (Hellwig, Schundfilms, 58) Im Anschluß an die Aufzählung filmischer Grausamkeiten spricht er dann unter Zitation Conradts davon, daß die ,verrohend wirkenden Filme' solcherart „die sittliche Zersetzung des deutschen Volkes befördern“ (Hellwig, Schundfilms, 60).

137 Conradt, Kirche, 14; Hervorhebung von mir.

${ }_{138}$ Dieckmann, Kino, 10

139 Der homo cinematicus, in: Deutsches Volkstum, 13.Oktober 1919, 319-320, zit. nach: Lange, Kino, 52

${ }_{140}^{14}$ Lange, Kino, 45

141 vgl. Lange, Kino, 44-45: „Derartige Sensationsfilme enthalten nun für die Jugend wieder eine besondere Gefahr. (...) Sie glauben schließlich, das ganze Dasein bestände nur aus solchen Sensationen. Und wenn sie dann ins Leben eintreten, sind sie sehr erstaunt und - enttäuscht, daß da alles so einfach und nüchtern hergeht, und daß für Abenteuer, wie sie sie gern erleben möchten, eigentlich gar kein Raum ist." Die Folge sei, daß dem Rezipienten „die richtige Einstellung zur Wirklichkeit völlig abhanden" komme und er „fortwährend Aufregungen und 
gefährlich aber gilt die Reizorientierung des Films, wo sie sich mit Affekten und Trieben verbindet. Sie zielt dann auf Dispositionen des Publikums, die als animalische und primitive diskriminiert werden. Das Zusammenspiel beider scheint in die Destruktion der Moral schlechthin zu münden.

Darauf insistiert wiederum besonders Conradt, der sowohl das ,noch nicht ausgefüllte Gerüst der Sittlichkeit (...) unter dem Ansturm von Wünschen und Lüsten“"142 bei Jugendlichen durch die Filmrezeption ins Wanken geraten, als auch die Moralität der Erwachsenen vom Druck solcherart angesprochener ,böser Instinkte' gefährdet sieht. Im einen Fall nämlich gehe es darum, die Grundbegriffe von Gut und Böse erst ,mühsam zu festigen ${ }^{143}$. Eine solche Festigung aber werde durch den Film bedroht - oder zumindest unterlaufen -, da seine Inhalte nur affektive Strukturen gelten ließen. So sei es im Film ,unerhört', „daß Menschen ihre Triebe zügeln, ihre Gefühle beherrschen, ihr Temperament unterdrücken, ihren Willen bilden oder gar ein Ziel für ihr Leben und Streben haben “144. Stattdessen agierten seine Protagonisten und Antagonisten rein emotional-triebhaft. An die Stelle der Sittlichkeit sieht Conradt so die Sinnlichkeit ${ }^{145}$ treten, d.h. er sieht die Normativität der Ersten durch Druck und Drang der Zweiten suspendiert. Dementsprechend sei ,der Kinematograph (...) in all seinen Darbietungen nicht sittlich indifferent, sondern ein Feind der Sittlichkeit“" ${ }^{146}$. Er leite dazu an, ,seine Wirklichkeit“ mit Moralität und ,Tatsächliches mit Erlaubtem “147 zu verwechseln. Kindern würden dabei „zu früh die Augen geöffnet über Dinge, für die sie noch gar kein Interesse haben “148, und „das köstliche Gut der Kinderseele, die Reinheit" werde hierbei „vernichtet"149. Jugendliche würden dazu aufgestachelt, ihren „neuen Trieben nachzuleben“150. Für jene, die sich bereits „,kopfüber in den Strudel des Lasters gestürzt “151 haben, habe der Film eine Verstärkungsfunktion: Sie nähmen „die lachende Selbstverständlichkeit der Sittenlosigkeit als freudige Zustimmung (...), als Anreiz zu neuen ,Taten ““152. - Bei den Erwachsenen wiederum drohe die Weckung einer "Sittenlosigkeit, wie sie nur in (...) kleineren Kreisen Deutschlands herrscht “"153. Zwar ,schlummerten' bei der Mehrheit „solche Gedanken und Gefühle noch unter der Schwelle des Bewußtseins"154, doch würden sie durch entsprechende Filminhalte hervorgerufen. Ihre beständige, gefährliche Latenz scheint dabei zwingend anzunehmen zu sein.

Die Disposition der Rezipienten erscheint so als Schutzlosigkeit einer idyllisch typisierten Kinderseele, als Triebunsicherheit und daher Verführbarkeit der Jugendli-

Abenteuer zu erleben“ verlange. Ein so verbildeter Rezipient habe „keinen Sinn mehr für die gleichmäßige und ruhige Pflichterfüllung, auf der doch das wahre Glück des Menschen beruht.“

${ }_{142}^{142}$ Conradt, Kirche, 39

143 vgl. Conradt, Kirche, 39: „... ihre mühsam gefestigten Grundbegriffe von Gut und Böse ...“

144 Conradt, Kirche, 28

145 vgl. Conradt, Kirche, 28: „Statt Sittlichkeit finden wir Sinnlichkeit!“

146 Conradt, Kirche, 33

${ }_{148}^{147}$ Conradt, Kirche, 39

148 Conradt, Kirche, 39

149 Conradt, Kirche, 39

150 Conradt, Kirche, 39

151 Conradt, Kirche, 39

152 Conradt, Kirche, 39

153 Conradt, Kirche, 33

154 Conradt, Kirche, 33 
chen sowie als trieb- und affektgeladene Inklination der Erwachsenen zum Abrutschen in ethische Devianzen. Auffällig ist die quasi-natürliche Tendenz zum Negativen, die den einzelnen Rezipientengruppen unterstellt wird: Sie insinuiert ein - je nach Gruppe unterschiedlich steiles - innerpsychisches Gefälle, das mehr oder weniger direkt in die Amoralität führe. Am stärksten wird es bei den Erwachsenen angesetzt, wohl weil diese am weitesten von dem vorfreudianischen Bild der ,kindlichen Unschuld, das in Conradts Text noch bemüht wird, entfernt sind. Doch auch die ,Reinheit der Kinderseele ist nicht völlig frei vom Makel der Latenz - wenngleich es heißt, Kindern würden von außen ,die Augen geöffnet', und also primär die Ruchlosigkeit derer, die solches tun, angeprangert werden soll, so gilt die ,Kinderseele anscheinend zugleich als schon offen für eine Entwicklung, die jenes Interesse, das sie ,noch nicht' hat, später jedenfalls entstehen lassen würde. Bei Jugendlichen ist dieses Interesse dann bereits da, und das Gefälle wird entsprechend steiler bemessen. Die Verführbarkeit derselben wird fast als Verführungsbereitschaft gezeichnet: Nicht von der Schaffung neuer, ,unsittlicher' Triebkräfte ist die Rede, sondern lediglich von einer Stimulation, den schon vorhandenen Trieben ,nachzuleben'. Triebe, Affekte und Lüste werden damit nicht neutral gesehen, sondern gelten als prekäre, gefährdende Kräfte im Menschen, die für dessen sittliche Verfassung eine Bedrohung darstellen. Die Geschichte ihrer Entwicklung vom Kindheits- zum Erwachsenenstadium erscheint als eine Geschichte des Verfalls, und zwar eines Verfalls naturaler Herkunft. Die inkriminierten Triebe und Lüste nämlich entstehen für Conradt ,von selbst'; ihr naturaler Charakter wird durch die Wortwahl (,Instinkte“, „das Tier im Menschen“) unterstrichen. Entgegengesetzt werden also letztendlich eine gefährdende, negativ gewertete Natur und eine gefährdete, erst Sittlichkeit schaffende Kultur. Positive Bezüge oder ein konstruktives Aufeinander-Verwiesensein gibt es nicht; die Verfaßtheit des Menschen als eines ,Wesens der Natur-Kultur-Verschränkung (W. Korff) ist hier aufgehoben und zu einem Antagonismus umgestellt. Sittlichkeit tritt entsprechend als Gegner der Affekte und Triebe, d.h. der naturalen Basis des Menschen, auf, Ethik gerät zur Logistik.

In dieser Konstruktion äußert sich ein anthropologischer Pessimismus, dessen Grundfigur hobbesianischer Provenienz ist: An sich genommen gilt der Mensch als Tier, das für sich und andere erst zum Menschen wird, wenn es seinen naturhaften Tendenzen Schranken setzt. Die Errichtung der Sittlichkeit besteht dann vorrangig in der kulturellen Konstruktion von Präventivmaßnahmen. Für die Moralerziehung bedeutet das die Verpflichtung auf ein zensierendes, grenzziehendes Vorgehen. Werden die menschlichen Antriebe sittlich so prekär und wird die Latenz zur Verführbarkeit so stark angesetzt, wie Conradt das tut, dann kann die moralpädagogische Hauptaufgabe nicht mehr nur darin bestehen, Leitlinien zu geben, sondern es gilt, machtvolle Dämme gegen die Flut der drohenden ,Sittenlosigkeit', d.h. entsprechend haltbare Barrieren gegen den genannten ,Ansturm von Wünschen und Lüsten' zu errichten. In Freud'sche Terminologie übersetzt heißt dies: die Implantation eines starken Über-ich ist nach Kräften zu befördern, und der Triebhaftigkeit sind entsprechend mächtige Zensurschranken entgegenzusetzen.

Mit dieser Vorstellung steht Conradt nicht allein. Ein ähnlicher anthropologischer Pessimismus und eine analoge Einschätzung gefährlicher Latenzen im Menschen, die der Beschneidung, Eingrenzung und zensierenden Kontrolle bedürfen, findet sich 
auch bei anderen Kinoreformern, dort angewandt auf die imaginative Produktion und die Freiheit der Fantasie. So malen etwa Hellwig und Pick unter dem Schlagwort der ,Fantasieüberreizung das Schreckbild eines imaginativen Wildwuchses, der nichts geringeres zur Folge haben werde als ,pathologische Tagträumerei', ,Verwirrung des Wirklichkeitssinns' und sogar ,Wahnsinn'. Hellwig führt dies unter Zitation des Prager Universitätsprofessors Pick aus: Insbesondere bei Kindern und bei Jugendlichen sei eine „außerordentliche Lebhaftigkeit“155 der Fantasie zu konstatieren, die gefährlich werden könne, wenn sie nicht, wie vorgesehen, ,mit dem Übergange in die Jugendzeit" abnehme, sondern „mit in diese hinübergenommen“"156 werde. Dann nämlich komme es leicht zu der genannten ,pathologische(n) Tagträumerei“157, die Pick als „anfallsweise auftretende Zustände“ beschreibt, welche „sich zunächst als phantastisches Spiel mit lebhaften Vorstellungen bei erhaltener Kritik“ darstellten, sich später jedoch ,zu halluzinatorischer und illusorischer Verkennung der Umgebung steigern" könnten und schließlich gar ,in schwere delirante und hysterische Dämmerzustände“ übergingen, in welchen ,die eigene Persönlichkeit wahnhaft verändert" erscheine ${ }^{158}$. Die ,Schundliteratur', auf die Pick sich bezieht, jedoch auch der Film, auf den Hellwig Picks Vorstellungen überträgt, wirke sich ,besonders fördernd“ auf diesen Prozeß aus. Überhaupt könne „alles, was im jugendlichen Alter zu einer Überspannung der Phantasie Anlaß“ gebe, ,zu solchen krankhaften Störungen führen “159. So erscheint es als eines der stärksten Gebote für die Erziehung, alsbald dafür zu sorgen, da $\beta$,jenes Übermaß (der Fantasie, T.H.) allmählich in ein entsprechendes Verhältnis", übergeleitet' werde ${ }^{160}$. Wie prekär diese Aufgabe eingeschätzt wird, zeigt sich darin, daß Pick sie eines der ,schwierigsten Probleme der Erziehung " ${ }^{\prime 161}$ nennt und zu ihrer Unterstützung ein ,Einschreiten' der „maßgebenden Stellen“162 gegen alles, was sie hindert (also gegen ,Schundliteratur“ und Film) fordert.

Auch hier drohen sich selbst überlassene Kräfte im Menschen in Verfall und Destruktion zu führen. Die anthropologische Figur, die im Hintergrund steht, ist dieselbe wie bei Conradt: Wieder wird der Mensch als gefährliches und gefährdetes Latenzwesen bestimmt, das dringend Leitstrukturen und Schranken benötigt. Macht Conradt die Latenz in der Triebhaftigkeit dingfest, so sehen Pick und Hellwig sie in der imaginativen Kreativität. Dieselbe scheint eine Tendenz zur persönlichkeitsauflösenden Überproduktion zu haben, an deren Ende die Schaffung von innerpsychischen Sonderwelten steht, welche den Wirklichkeitsbezug zerstören. Auffällig ist wiederum, daß diese destruktive Tendenz als ein Überborden skizziert und daß sie der imaginativen Kraft selbst zugeschrieben wird. Schundliteratur und Film kommt zwar eine ,wichtige', jedoch nur eine befördernde Rolle zu. Die eigentliche, schädliche Inklination liegt im ,Wesen', in der ,Natur' der Fantasie selbst. So findet letztlich

\footnotetext{
${ }^{155}$ Pick, Psychiatrie, 34ff.; zit. nach: Hellwig, Schundfilms, 54

156 Pick, Psychiatrie, nach: Hellwig, Schundfilms, 55

157 Pick, Psychiatrie, nach: Hellwig, Schundfilms, 55

158 Pick, Psychiatrie, nach: Hellwig, Schundfilms, 55

159 Pick, Psychiatrie, nach: Hellwig, Schundfilms, 55

160 Pick, Psychiatrie, nach: Hellwig, Schundfilms, 54

161 Pick, Psychiatrie, nach: Hellwig, Schundfilms, 54

162 Pick, Psychiatrie, nach: Hellwig, Schundfilms, 55
} 
auch hier eine Gegenüberstellung von (quasi-)naturaler Potentialität des Menschen und kultureller Formgebung statt. Erst die kulturelle Formgebung ermöglicht es für Pick und Hellwig, da $B$ der Mensch im Bereich der Fantasie ,zum Stand seines Menschseins' (W. Korff) kommt. Die Weise der Formgebung aber wird als Zensurierung, Beschneidung und Eingrenzung beschrieben. Das Zueinander von menschlicher Potenz und Kultur gerät damit erneut zum Antagonismus. Zwischen beiden findet nicht wirklich eine Interaktion statt, sondern die erste bekommt ihre Struktur und Ausformungsmöglichkeiten von der zweiten diktiert. Die Gegenüberstellung ist ein Gegensatz, der im Paradigma von Herrschaft und Unterwerfung gedacht ist.

\section{Kultur als Disziplinierung: Das Kulturkonzept der Reformer}

Als imaginative Kreativität bestimmt, erhält die Fantasie in diesem Entwurf einen Januskopf: Einerseits ist sie jene Kraft, aus der die schöpferischen Leistungen des Menschen fließen (wie Pick und Hellwig zugestehen ${ }^{163}$ ) und die so auch das Kulturschaffen erst ermöglicht. Andererseits bedroht ihre anarchische Latenz, das Kulturwesen Mensch und damit auch dessen kulturelle Leistungen. Ähnlich verhält es sich mit dem Film: Obgleich er selbst ein Teil der menschlichen Kultur ist, scheint er gegen dieselbe zu agieren und sie in ihrem Bestand zu gefährden. Er tut dies, dem Vorwurf zufolge, indem er sich mit den als tendenziell kulturfeindlich angesetzten naturalen Strebungen und Potenzen des Menschen verbündet und deren destruktiven Anteil verstärkt. An diesem Punkt geht der kleinräumige Vorwurf nun in einen großräumigen über: Nachdem zunächst die kulturbedrohenden Wirkungen des Films genauer und explizit als solche spezifiziert werden, wird dieser dann in den Rahmen einer generellen Kulturkritik gestellt.

Explizit kulturbedrohend schätzen Hellwig und andere den Film dort ein, wo er eine Zerstörung - oder zumindest Behinderung - des, kausal-intellektuellen' und logischen Denkens, das als eminente Kulturleistung des Menschen im Verlauf seiner Geschichte gilt, hervorzurufen scheint. Angesetzt wird hier wiederum bei Kindern: Während bei Erwachsenen durch Gewöhnung und Übung schon feste Bahnen für die ordnende Verknüpfung von Wahrnehmungen bestünden, seien die „Urteilsassoziationen bei den Kindern nur locker gebunden", wobei der "Gefühlssinn" noch eine große Rolle spiele ${ }^{164}$. Die Rezeption von Filmen, denen ein „rascher Wechsel der Erscheinungen" eigen sei, könne dann „eine gewisse Verwirrung der Assoziation" nach sich ziehen und so schon „lediglich bei der Wahrnehmung an sich" zu einer Diffusion der Eindrücke führen ${ }^{165}$. Besonders stark aber könne diese Diffusion bei der „Wertung des Wahrgenommenen“ auftreten, was zur Folge habe, daß „dadurch Vorstellungen geweckt werden, die sich von der Realität ganz entfernten“166. Zusammen mit einer „fehlerhaften Erregung der Phantasie“ seien Auswirkungen auf die intel-

163 vgl. Pick, Psychiatrie, nach: Hellwig, Schundfilms, 55: „Es wäre natürlich vollständig verfehlt, die Phantasie der Jugend ganz vernachlässigen zu wollen, wissen wir doch, welche außerordentliche Bedeutung ihr im geistigen Leben auch des Erwachsenen zukommt, und wie namentlich jede schöpferische Tätigkeit ihrer bedarf ..."

${ }^{164}$ Hellwig, Kind, 25; Hellwig bezieht sich dabei auf den Vortrag eines Dr. Baginsky von 1911 zum Thema: „Kinotheater und Schule“.

${ }_{165}$ Hellwig, Kind, 26

166 Hellwig, Kind, 26 
lektuellen Fähigkeiten zu befürchten, wie das Beispiel eines Schülers zeige, der nach häufigem Kinobesuch „eine äußerst fremdartige, eigenartige Ideenassoziation“ bemerken habe lassen, „die oftmals die Art der assoziativen Verknüpfung aufeinanderfolgender Vorstellungen auch der eingehendsten Untersuchung rätselhaft" bleiben lasse ${ }^{167}$. Spezifikum dieser defizienten ,Denkform' sei die Verknüpfung „völlig zusammenhanglose(r) Dinge ohne Aufhören“168. Die Gefahren des Films sieht Hellwig mit Drange daher in einer „Irreführung des Denkvermögens ${ }^{4169}$. Die filmische Darstellungsweise sei geradezu ein „Hohn auf Kausalität und Logik“"170. Das rasche Aufeinanderfolgen verschiedener Eindrücke, das durch die Programmzusammenstellungen der Kinos noch unterstützt werde, verleite außerdem zu einem oberflächlichen Sehen und stehe jeder gedanklichen Vertiefung entgegen ${ }^{171}$. „Unaufmerksamkeit“ und „Verhinderung der Konzentrierung “ ${ }^{\prime 72}$ werden als Folgewirkung gesehen. Schüler würden durch die Filmrezeption daher demotiviert, etwas zu lernen ${ }^{173}$; das Erziehungsziel der Schule, „den Intellekt des Schülers auszubilden “174, werde entsprechend unterlaufen. Ähnlich sieht auch Lange eine ,gründliche Urteilsbildung', deren Vorbedingung "die langsame Stetigkeit der Vorstellungsfolge“"175 sei, vom Film verhindert. Stattdessen gewöhne man sich daran, dem ,zufälligen Aneinander der Bilder nachzugehen" ${ }^{\text {176, }}$, ohne die „logische Folge eines durchgehenden Gedankens ${ }^{\prime 177}$ noch zu vermissen. Endpunkt dieser Fehlleitung sei die ,geistige Erschlaffung “178, die Erwachsenen ebenso drohe wie Kindern.

Während hier vor allem auf die ,kulturfeindliche‘ Wirkung von Programmvielfalt und entsprechenden Inkonsistenzen einerseits sowie der Reihung von Einzelszenen andererseits abgehoben wird, sieht ein weiterer, damit zusammenhängender Vorwurf Gefahren aus der Bildhaftigkeit des Films schlechthin quellen. Diese nämlich könne die Entwicklung der Sprachkompetenz und des abstrakten, begrifflichen Denkens bei Kindern und seine Erhaltung und Differenzierung bei Erwachsenen zumindest stark beeinträchtigen. Bilder gelten als leicht rezipierbar, unmittelbar verständlich und emotionsnah $^{179}$. Besonders Kinder und Erwachsene aus ,einfacheren Volksschichten zeigten daher eine Neigung zu denselben: Den ersten wird mit dem Begriff des ,Gefühlssinns' eine stärkere emotional-sinnliche Ausrichtung unterstellt, den zweiten nachgesagt, daß sie „,heftige Gemütsbewegungen“, ,rührselige Stimmungen“, „das Sentimentale und Grauenvolle “"180 bevorzugten. Dieser Neigung zu einer gefühlsori-

${ }^{167}$ Hellwig, Kind, 26

168 Hellwig, Kind, 26

169 Drange, Schuljugend, 737 ff., zit. nach: Hellwig, Schundfilms, 46

${ }_{171}^{170}$ Drange, Schuljugend, nach Hellwig, Schundfilms, 45

171 vgl. Lange, Kinematograph, 14

172 Hellwig, Kind, 22

173 vgl. Hellwig, Schundfilms, 53

174 Hellwig, Schundfilms, 45

175 Lange, Kino, 52; Lange bezieht sich dabei auf den Aufsatz eines Anonymus: Der homo cinematicus, in: Deutsches Volkstum 13. Oktober 1919, 319-320, den er zustimmend partiell zitiert.

176 Lange, Kino, 52

in Lange, Kino, 52

178 Lange, Kino, 52

179 vgl. Gaupp, Kinematograph, 3

180 Gaupp, Kinematograph, 4 
entierten Bildlichkeit komme der Film gerade entgegen. Seiner Sinnlichkeit wird dann - wiederum antagonistisch - die logische und begriffliche Strenge sprachorientierten Denkens als eigentliche Kulturleistung gegenübergestellt. Alle „höhere Kultur" nämlich gilt als ,an das Wort gebunden “181. Ihre eigentlichen Werke sind die ,Sprachwerke' der ,großen Dichter', deren, Gedankenreichtum' nur ,gedämpfte Gefühle' auslösen soll ${ }^{182}$. Den Stand dieser höheren Kultur zu erreichen, soll das Ziel jeder Kulturpädagogik sein. Zugleich gilt die Sprache als das hervorragendste Medium der Erarbeitung, Darstellung und Vermittlung differenzierterer Einsichten, Erlebnisse und Vorstellungen. Gerade im Bereich der narrativen Kunst scheint sie daher unverzichtbar zu sein, wenn diese nicht in plakativer Plattheit verbleiben will: Die feinfühlige, genaue ,Veranschaulichung' einer Handlungslogik sowie die „Glaubwürdigkeit der psychologischen Entwicklung “183 seien ohne sie nicht erreichbar. Auch die ,Geistigkeit' narrativer Kunstwerke beginne erst jenseits der Bildlichkeit in der Sprache; jene dramatischen Erzählungen nämlich, die „Anspruch auf geistige Bedeutung“" machen, seien „ohne Hinzutritt des Wortes nicht (zu) verstehen. " ${ }^{184}$ Der Film bleibe im Unterschied dazu beim emotionsgeladenen Bild und groben Handlungsformen stehen. Er leiste damit nicht nur nichts für die Beförderung einer sprachorientierten Kultur, sondern er behindere sie geradezu.

Aus dem Vorwurf wird nun deutlich, wie die Kultur beschaffen ist, die von den Kinoreformern dem Film und den mit ihm zusammenklingenden, unliebsamen menschlichen Latenzen und Potenzen entgegengesetzt wird. Es ist eine ,Kultur der Abstraktion, der Logozentrik, der kausallogischen Ordnungsbeflissenheit und der Überich-Disziplinierung. ,Abstraktion' ist dabei ein mehrdeutiger Begriff: Einerseits wird sie als begriffliche bestimmt, d.h. als Fähigkeit, in Sprachformen zu denken, die der sinnlichen Bedeutungsunmittelbarkeit enthoben sind. Andererseits wird sie über die Kritik am Film, dem letztlich ein Abstraktionsmangel vorgeworfen wird (der dann die Ausbildung der entsprechenden Fähigkeit beim Publikum verhindern soll), und über die Insistenz auf den Wortgebäuden der ,großen Dichter' als den eigentlichen Kulturwerken mit einem Kunstbegriff verbunden, der das Spezifikum von Kunst darin sieht, die Emotionalität zu temperieren. Abstraktion gilt damit nicht nur als konstitutiv für die Begriffsbildung, d.h. für eine der menschlichen Fähigkeiten, sondern zugleich als wesensbestimmend für die zentralen Kulturwerke. Das aber bedeutet, daß sie zum spezifischen Konstitutivum in jenem Bereich erklärt wird, der den Kinoreformern zufolge den Menschen erst zum Menschen macht, nämlich in dem der Kultur schlechthin. Die distanzierende ,Aufhebung von Affektivität, Emotionalität und Triebhaftigkeit in der Abstraktion wird so in den Stand einer generellen normativen Forderung für die Kulturation des Menschen erhoben. Erst wo die naturale Unmittelbarkeit der menschlichen Strebungen (um es mit Lange zu sagen) durch die kulturelle Form ,vertilgt worden ist, hebt die Kultur als Schöpferin des ,wahren Menschen' an. Dieser wird zu einem höchst artifiziellen Wesen, dessen Existenz und Eigenart ständig einer ungebärdigen, feindlichen Natur abgerungen ist.

\footnotetext{
${ }^{181}$ Gaupp, Kinematograph, 3

182 vgl. Gaupp, Kinematograph, 4

${ }^{183}$ Lange, Kinematograph, 20

${ }^{184}$ Lange, Kinematograph, 20
} 
Damit im Zusammenhang steht die Orientierung auf eine Logozentrik hin, die sich quer zur Sinnlichkeit stellt und Sprache primär als Mittel der Distanzierung begreift. Die ,Sprachkunstwerke' rangieren vor den Bildkunstwerken und sind selbst wiederum in ihrer Güte nach dem Grad ihrer Abstraktion, d.h. ihrer Entfernung von affektiver, emotionaler und sinnlicher Unmittelbarkeit bestimmbar. (Auch die Verfolgung der Trivialliteratur erklärt sich daraus: Deren Sinnlichkeit und Gefühlsgeladenheit steht - obgleich sie sprachlich verfaßt ist - ebenfalls im Gegensatz zur Vorstellung einer abstraktiven ,Temperierung der Emotionen'.) Bildlichkeit aber wird an sich prekär, insbesondere beim Film, der zu dieser Zeit noch wortlos ist und also jede Spur einer sprachlichen Barriere gegen die bildhafte Sinnlichkeit vermissen läßt. Unter der Rücksicht, daß dem, leicht rezipierbaren‘ Bild bei Lange und anderen eine distanzlose Wirkung unterstellt wird (vgl. 2.2.), ist der Film geradezu so etwas wie die Inkarnation der affektiven, triebhaften und emotionalen Unmittelbarkeit. Sein diesbezüglicher Charakter findet noch Unterstützung dadurch, daß der frühe Film auch inhaltlich, wie Ramsaye sagt, „close to the soil“ - bodennah - ist und gewissermaßen eine Art Platzhalter- und Spiegelfunktion dessen übernommen hat, das die von den ,Gebildeten' dominierte ,Hochkultur' ausgrenzt und verdrängt. Formal wie inhaltlich transportiert der Film so das Gegenstück zu dem, was der Kulturbegriff der Kinoreformer normativ etablieren will: zu einer abstraktiv-distanzierten Sprach- und Begriffskultur.

Gleichzeitig tritt damit ein weiteres, vom Film gefährdet scheinendes Moment des reformerischen Kulturbegriffs vor Augen: eine Ordnungsbeflissenheit, die sich hier in der Insistenz auf ,kausal-intellektuellem und logischem Denken', im übrigen in der mehrfach deutlich gewordenen Disziplinierungsneigung ausdrückt. Die Ordnungsbeflissenheit stellt sich gegen die Befürchtung eines assoziativen Schweifens, das günstigenfalls in ,Unaufmerksamkeit' und Unkonzentriertheit, ungünstigenfalls in ,Vorstellungen, die sich von der Realität entfernen', münden könne. Negativ ausgemalt wird eine Art Anarchie des Vorstellungslebens, der die Erzeugung ,logischer Kompetenz' als Erziehungsziel (und -auftrag) entgegengesetzt wird. Diese Erzeugung logischer Kompetenz zielt jedoch nicht nur auf eine formallogische, wie daraus hervorgeht, daß stärker noch als auf die Beherrschung von, Verknüpfungsregeln' für Eindrücke und Wahrnehmungen auf die richtige ,Wertung derselben, d.h. die rechte Interpretation abgehoben wird. Es gilt, mit Lange formuliert, die richtigen ,Urteile‘ zu fällen und die Welt aus der richtigen Perspektive zu betrachten. Selbst wenn aus der referierten Argumentation nicht deutlich wird, ob damit auch schon inhaltliche Präskriptionen für das Vorstellungsleben gemacht werden sollen und also eine bestimmte Weltinterpretation für verbindlich erklärt wird, so zeigen die angeführten Texte doch, daß zumindest eine Kriteriologie für die imaginative Produktion angezielt ist, die es erlaubt, nach ,richtig' und ,falsch', bzw. nach ,zulässig' und ,unzulässig zu unterscheiden. So erklärt sich, daß von einer ,fehlerhaften Fantasieerregung gesprochen werden kann, mit deren Begriff wohl selbst der entlastende Tagtraum in den Kontext eines Desiderats umfassender normativer Reflexion gerät.

Aus diesem Vorgehen spricht zugleich eine Disziplinierungsneigung (und -absicht), die alle Kräfte und Strebungen des Menschen eindeutigen Richtlinien unterwerfen und ihre als tendenziell überbordend charakterisierte Potenz zurückzuschneiden bzw. mit entsprechenden kulturellen Fesseln zu binden sucht. Wenn dem 
Vorstellungsleben und der imaginativen Produktion gegenüber derart auf ,logischer Kompetenz' sowie auf der Vorrangigkeit einer Sprach- und Begriffskultur, mit deren Hilfe die Fantasie in entsprechende Bahnen gelenkt werden soll, insistiert wird, so bedeutet das eine eindeutige Funktionszuschreibung. Logische Kompetenz dient dann nicht mehr nur der intellektuellen Orientierung in der Welt, sondern gerät zum Richtma $B$ jeglichen Weltzugangs. Sprache wird mehr oder weniger zur Begriffssprache verkürzt und dient keinesfalls mehr der Beförderung einer sinnlichen Kreativität oder der Anregung, Erweiterung und Bereicherung des Gefühlslebens, sondern einzig der autoritativen Reduktion und Kanalisierung. Beide - logische Kompetenz wie Sprache - werden so zu Instrumenten der Disziplinierung; ihr Geltungs- und Funktionsbereich wird darauf eingeschränkt. - Den Trieben, Emotionen und Affekten gegenüber tritt diese Disziplinierung als Implantation eines starken Überich an. ,Kulturation' bedeutet auch hier Beschneidung, Fesselung und Distanzierung; verankert wird sie jetzt noch in einer pejorativen innerpsychischen Instanz, die durch Verbot Kultur ex negativo erzeugen will.

\section{Negative Anthropologie und Modernitätskritik}

Mit dem vorstehend skizzierten Kulturbegriff üben die Kinoreformer dann auch Kritik an jenem Teil der etablierten Kultur, der als ,Moderne' bezeichnet wird. Abgezielt ist hierbei vor allem auf die Kulturerscheinungen in den Großstädten, die als Verfall schlechthin gelten und zu denen auch der Film gerechnet wird. Er gilt geradezu als einer ihrer hervorragendsten Vertreter:

„Die Psychologie des kinematographischen Triumphes ist Großstadt-Psychologie. Nicht nur, weil die große Stadt den natürlichen Brennpunkt für alle Ausstrahlungen des gesellschaftlichen Lebens bildet, im besonderen auch noch, weil die Großstadtseele, diese ewig gehetzte, von flüchtigem Eindruck zu flüchtigem Eindruck taumelnde (...) Seele so recht die Kinematographenseele ist." ${ }^{\prime 185}$

Die Klage bezieht sich - wie aus dem Zitat bereits ersichtlich - auf die ,Schnellebigkeit‘, ,Reizüberflutung‘ sowie ,Oberflächlichkeit‘ der Stadtkultur und stellt so die gegen den Film vorgebrachten Vorwürfe in den Rahmen einer allgemeinen Kritik an jenen von den ,Konservativen' bis in die Gegenwart konstatierten Phänomenen der modernen Welt, die letztlich eine Folge der technisch-ökonomischen Rationalisierung sind und im Konnex zum Projekt der Moderne stehen. Obschon freilich die Reformer noch nicht auf eine explizite und systematische Kritik an diesem Projekt abzielen, sondern in vorwiegend kulturkritischer und ästhetischer Absicht argumentieren, gerät ihre Phänomenkritik so in Berührung mit jener Modernitätskritik, wie sie später etwa die Filmerziehung - und vor allem ihr Schulgründer - dezidiert entfalten wird, bzw. weist sie auf diese Kritik voraus (vgl. 4.1., 4.2. und 4.5.). Umgekehrt erweist sich die Stellung der Reformer aus systematischem Blickwinkel erneut und noch deutlicher (da explizit gegen moderne Kulturphänomene gerichtet) als kontramoderne. Im Theoriekonzept der Reformer selbst allerdings ist der systematische Bündelungspunkt noch nicht unmittelbar die moderne Rationalisierung, sondern vielmehr erneut die negative Anthropologie und ihre Bewertung der naturalen Stre-

${ }^{185}$ Kienzl, Hermann, Theater und Kinematograph, in: Der Strom 1911/12/1, 219 
bungen des Menschen. Auf sie hin nämlich werden die reichhaltig und farbig ausgemalten Phänomene der modernen Welt interpretiert, und in den negativisierten Anthropologika, welche von der modernen Welt anscheinend reaktiviert werden, wird wieder das eigentliche Skandalon gesehen. Die kontramoderne Grundstellung wird so implizit über die Anthropologie und aus einer mit derselben ,rationalisierten Aversion gegen die Kulturerscheinungen der Moderne heraus entworfen.

So spricht etwa Gaupp zunächst von einer „Zeit nervöser Hast und Vielgeschäftigkeit, in der von allen Seiten die mannigfaltigsten äußeren Reize“ auf die Menschen ,einstürmten" und in der besonders "die Jugend so leicht blasiert" werde ${ }^{186}$. Häfker malt dann adjektivreich eine "ständige Aufpeitschung der Sinne“ und „kitzelnde Genüsse" aus ${ }^{187}$, die vor allem in der Großstadt ihre Macht ausübten. Er hebt derart auf die Naturalsphäre des Menschenwesens ab und konnotiert ihre Vitalisierung mit der modernen Zivilisation. Farbig setzt er die Straßen der Großstadt ins Bild, die sich abends in ein „Feuerwerk (verwandeln), dessen jähe und blendende Pracht unsere Sinne lange abzieht und in Bann hält" ${ }^{\text {"188 }}$. Die ,moderne Kultur" mit ihren vielfältigen Reprodukten, den „Hunderte(n) von glänzend(en), illustrierten Zeitschriften und Zeitungen “"189, den Cafés, in denen ,Musikkapellen dazu (zur Lektüre) spielten ${ }^{4190}$, den Plakatsäulen und der Werbung, die ihre Botschaften ,von den Wänden, Läden, Schaufenstern und Lichtgerüsten aller Städte “191 ,herunterschreie', gilt dabei als Unkultur mit perniziosen Wirkungen. ,Oberflächlichkeit' und ,Abstumpfung (die angesichts der Reizüberflutung als notwendige Überlebensbedingung gilt: Häfker spricht von einer ,Schutzhaut" der Großstädter ${ }^{192}$ ) erscheinen noch als die geringsten Folgen eines „bis zum Wahnsinn überhitzten öffentlichen ,Genuß'lebens"193. Als schlimmer wird hingegen der moralische Verfall apostrophiert, der durch diese ,Unkultur" hervorgerufen werde. Lange spricht von den „perverse(n) Instinkte(n) des großstädtischen Janhagels “194, und bedient sich derart der Sprache Conradts. In dieser Sprechverwandtschaft und in den negativen Apostrophierungen von Sinnlichkeit und Genuß bei Häfker aber zeigt sich der anthropologische Pessimismus, der die naturalen Triebkräfte des Menschen als Impulsgeber für die Destruktion der Sittlichkeit ansetzt, als Wurzelpunkt der Kritik. Er findet sich hier zu einem Kulturpessimismus transformiert, für den die Großstadt die Inszenierung und Aktualisierung der zerstörerischen naturalen Impulse ist. Gerade der ultimate Ausdruck der Kulturverwiesenheit des Menschen - die Stadt - erscheint so jetzt als Apokatastasis der verdrängten, antagonisierten Natur und damit als Hort der Unsittlichkeit schlechthin. In der Stadt nämlich reaktivieren sich Affektivität, Triebhaftigkeit und Sinnlichkeit mit den Mitteln der Kulturverwirklichung selbst: mit Hilfe der künstlerischen Darstellungsformen (deren designerische Korrumpierung Häfker beklagt; vgl. 2.2.) und der reproduktiven Techniken. Sie schaffen eine neue

\footnotetext{
${ }^{186}$ Gaupp, Kinematograph, 7

187 Häfker, Kunst, 6

188 Häfker, Kunst, 6

189 Häfker, Kunst, 5

190 vgl. Häfker, Kunst, 5-6

191 Häfker, Kunst, 6

192 Häfker, Kunst, 6

193 Häfker, Kunst, 70

194 Lange, Kinematograph, 31
} 
Künstlichkeit, hinter deren artifizieller Gestalt jedoch die alte Ungestalt der rohen menschlichen Antriebe lauert. Die ,Kulturation' gerät damit unter der Hand zur $\mathrm{Re}$ naturalisierung, die kulturelle Schaffung der Sittlichkeit scheint in den Naturzustand der ,Sittenlosigkeit‘ zurückgebogen. Eben darin aber liegt das eigentliche Skandalon, und die Modernitätskritik der Reformer äußert sich so als anthropologisch fixierte Kulturkritik.

\section{Versuchte Rückgewinnung der Natur über Tradition und Volkskultur}

Für die kinoreformerische Modernitätskritik auf der Basis der Konstruktion eines Gegensatzes von Natur und Kultur ergibt sich aus der großstädtischen Mischung von kulturellen Techniken und naturhaften Antrieben freilich ein dialektisches Problem: $\mathrm{Da} B$ gerade in der Stadt als dem Ausdruck der Kulturverwiesenheit des Menschen der modernitätskritisch beklagte Verfall entstehen kann, macht die Kulturation als Lösungsoption wieder zweifelhaft. Wo Kultur der ,Unsittlichkeit' in dem Maß Vorschub leistet, wie das die Moderne zu tun scheint, droht ein Widerspruch zwischen den an sie gestellten Hoffnungen und ihrer faktischen Wirkung zu entstehen. Dieses Problem versucht Lange, durch eine terminologische Differenzierung zu lösen. Dabei wird dann auch versucht, durch eine quasi-naturale Implantation in den Kulturbegriff die verlorene Natur zurückzugewinnen. Zunächst aber schlägt Lange vor, neben dem Natur-Kultur-Gegensatz einen weiteren Antagonismus einzuführen, nämlich den von Kultur und ,Zivilisation':

„Man sollte endlich einmal einsehen, daß Zivilisation und Kultur nicht identisch sind, daß technische Erfindungen, die dem Fortschritt dienen, unter Umständen die geistige Kultur schädigen können, und daß Zivilisation nur dann erwünscht und berechtigt ist, wenn sie der Kultur Vorschub leistet.“195

Diese Unterscheidung etabliert letztlich zwei Kulturen, die einander feindlich gegenüberstehen können; der Kulturpessimismus wird zum Zivilisationspessimismus umbenannt und der dialektische Widerspruch terminologisch gelöst. Nicht die Kultur erscheint nun als prekäre Beförderin der naturalen Latenzen, sondern die ,moderne Kultur, die nun als Zivilisation eigenständig dingfest gemacht werden kann. Zivilisation erhält dabei selbst wieder einen Doppelcharakter: Einerseits erscheint sie als Ort der technisch-instrumentellen Bewerkstelligung von Fortschritt, andererseits aber als Beförderin der diskriminierten Renaturalisierungsdynamik, die der ,geistigen' Kultur entgegensteht. Die technische Instrumentalität nämlich, obgleich an sich

195 Lange, Kinematograph, 47; die Begriffsunterscheidung geht auf Kant zurück: „Wir sind im hohen Grade durch Kunst und Wissenschaft kultiviert. Wir sind zivilisiert bis zum Überlästigen, zu allerlei gesellschaftlicher Artigkeit und Anständigkeit. Aber, uns schon für moralisient zu halten, daran fehlt noch sehr viel. Denn die Idee der Moralität gehört noch zur Kultur; der Gebrauch dieser Idee aber, welcher nur auf das Sittenähnliche in der Ehrliebe und der äußeren Anständigkeit hinausläuft, macht bloß die Zivilisierung aus." (Kant, Immanuel, Idee zu einer allgemeinen Geschichte in weltbürgerlicher Absicht, in: ders., Schriften zur Anthropologie, Geschichtsphilosophie, Politik und Pädagogik 1, hrsg. v. W. Weischedel, Frankfurt 1978, 31-50, 44) Bei Kant tritt die ,Zivilisation' so als Oberflächenstruktur von Verhaltenskonventionen auf, mit der die eigentliche Moralität, die in der Tiefe der "moralisch-guten Gesinnung" (ebd. 45) zu finden ist, noch gar nicht erreicht wird. ,Kultur', welcher die Moralität zugeschlagen wird, ist demgegenüber als ,Ganzheitsbegriff' gebraucht. Während Kant diese Begriffsdifferenzierung deskriptiv anwendet, nutzt Lange sie zur Wertung. 
wertneutral, dient im Kontext des Großstadtlebens dazu, den gefährdenden menschlichen Antrieben und der Sinnlichkeit - insbesondere durch Schaffung einer glimmer- und flitterhaften Medienwelt - nachhaltigen ,Ausdruck' zu verschaffen.

Auch dem Kulturbegriff aber wird dann weiter ein Doppelgesicht zugeschrieben. Oben war zu sehen, daß Kultur als abstraktive Disziplinierung ,contra naturam' bestimmt wird. Dieser ihr Charakter korrespondiert der technisch-instrumentellen Seite der Zivilisation, erfährt jedoch im Gegensatz zu derselben ungeteilte positive Bewertung, da sich die Instrumentalität der Disziplinierung gerade gegen die naturalen Latenzen wendet. Jetzt allerdings wird dem Kulturbegriff noch ein zweites, quasi-naturales Element implantiert. Im Kontext der Großstadt- und Zivilisationskritik nämlich beschwören die Reformer die ,Bodenständigkeit" der Kleinstadt, die ,Eigenart der deutschen Stämme‘ und die Traditionalität einer agrarromantisch verankerten Sitte.

Auf die ,Bodenständigkeit' hebt Lange in Auseinandersetzung mit der Zentralisierung der Filmzensur durch das Reichslichtspielgesetz ab. Diese Zentralisierung erscheint ihm ungünstig, da sie den Maßstab der Großstadt auf die kleinen Städte übertrage. Insofern das Reichslichtspielgesetz zudem das strengere württembergische Lichtspielgesetz außer Kraft setzte, sei die Folge, daß der „Großstadtfilm überall in unseren kleinen Städten“196, anzutreffen` sein werde, und ,in Zukunft unsere württembergischen Kinder dieselben Filme vorgesetzt bekommen werden, die das

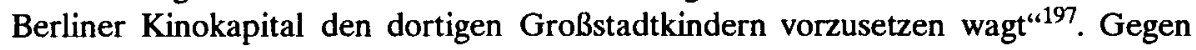
diese drohende Nivellierung will er , in Dingen der Kultur und des geistigen Lebens die Sondereigentümlichkeiten der deutschen Stämme gewahrt"198 wissen. In Langes Text, der auch andernorts immer wieder für eine Regionalzensur plädiert, klingt durch, daß den ,kleinen Städten' eine größere Moralität (und daher eine strengere Zensurhandhabung) zugeschrieben wird. Sie gelten gewissermaßen als unverdorben von den Erscheinungen der ,modernen Kultur' bzw. der Zivilisation und in ihrer Sittlichkeit aus einer ,Stämmetradition' heraus gefestigter. Die ethische Traditionsorientierung, die darin liegt, äußert sich andernorts auch in Langes Plädoyer für die „Erhaltung guter alter Sitten “199, welche er zur Hauptaufgabe der ,Gebildeten` schlechthin erklärt. Aus einer Vergangenheit, die letztlich in der Sitte kristallisiert, soll die Rettung der Kultur kommen. So wird der positiv gewerteten Kultur als weiteres Charakteristikum ein traditionales Moment beigesellt, das durch die Rückbindung an die ,Sondereigentümlichkeiten der deutschen Stämme` mit einer quasi-naturalen Valenz versehen wird.

Deutlicher noch als bei Lange tritt das naturale Moment bei Häfker zutage, der, nachdem er die ,flitterhafte', artifizielle Sinnlichkeit und das ,überhitzte' großstädtische ,Genußleben' mit einer Mischung aus Abscheu und Faszination ausgemalt hat (s.o.), inhaltliche Vorschläge für ,kulturbereichernde' Filme macht, in denen er eine agrarromantisch verklärte Volkstümlichkeit und Sitte als Gegenbild zur großstädtischen Zivilisation errichtet. Letzte nämlich, ,zusammengesetzt aus Geschrei und Gebärden, die an allen Stellen des Erdballs gleich sind, wo sich ,zivilisierte‘ Men-

\footnotetext{
${ }^{196}$ Lange, Kino, 235

197 Lange, Kino, 235

198 Lange, Kino, 235

199 Lange, Kinematograph, 47
} 
schen zusammengeballt haben“ ${ }^{200}$, sei nur ein „dünner Firnis über dem wirklichen, intimen Volksleben“201. Dieses wird als „Leben voller eigenartiger Sitten und Gebräuche, Trachten und Feste, uralter, oft zu unbewußt gewordenen Alltäglichkeiten erstarrter, seltsamer Überlieferungen “202 mit einer gewissen Distanz beschrieben, erhält aber, da „voll einstiger, tiefer Bedeutung “203, die Aura einer ehrfurchtgebietenden Würde. Die „weltstädtische Überfeinerung“‘204 wird angesichts einer solchen ,bodenständigen Verläßlichkeit‘ zur „durchsichtige(n) Lasur“205 verdünnt und im Vergleich (obwohl zuvor als gefährdende Macht perhorresziert) beinahe hinfällig. Ihr artifizieller Glanz jedenfalls scheint bei Häfker überstrahlt von der Quasi-Naturalität der Volkskultur:

„Die Tänze, die Familien-, Jahres-, und Ortsfeste schälen sich, je mehr man sie in ihrer Unberührtheit aufsuchen gelernt hat, immer reiner und glänzender in überlieferter Schönheit und altem Sinne unter Biergärten- und ,Restaurant"Betrieb heraus. “206

Sitten und Gebräuche gelten Lange und Häfker so als jener sedimentierte Untergrund, der als quasi-naturale Basis der zivilisatorischen ,Künstlichkeit', d.h. der technisch-instrumentellen ,Überreizung naturaler Antriebe, entgegengehalten werden kann, und aus dem angesichts der Gefahr das Rettende wachsen soll. Die beiden Reformer setzen damit der Liaison von ,Zivilisation' und naturalen Strebungen des Menschen einen Kampfbund von abstraktiver Disziplinierung und quasi-naturaler Traditionalität entgegen. Kontrastiert werden soll damit letztlich eine ,ungesunde‘ Renaturalisierung durch eine Zivilisation, deren Reizorientierung sich nur an die ,primitiven Instinkte' wendet, mit einer ,gesunden Natürlichkeit‘, die durch allmähliches Entstehen und Überlieferung abgesichert scheint. Die Eine gilt als Überspitzung und Aufstachelung, die Andere als bodennahes und bedächtiges Hegen der naturhaften Grundantriebe. Das Vorgehen kann als Versuch einer Überwindung des selbstgesetzten Antagonismus von Natur und Kultur und einer Rückgewinnung der Erstgenannten interpretiert werden: Obgleich gegen die pessimistisch beurteilten Latenzen der menschlichen Natur eine distanzierende Kultur gesetzt werden mußte, scheint der Anschluß an die vertriebene und ausgegrenzte mit der traditionellen ,Volkskultur' und den ,guten alten Sitten' wieder gefunden. Es ist jedoch ein scheinbarer AnschluB, denn die Quasi-Naturalität der letzten ist eine Pseudo-Naturalität. Tradition selbst ist ja bereits Kultur und ihr Begriff erlaubt eine versöhnende Verbindung nicht, wenn das dichotomische Paradigma des Natur-Kultur-Antagonismus nicht grundsätzlich aufgehoben wird. Sonst bleibt auch die Kulturerscheinung der ,Sitten' gegen die Natur etabliert und ist nicht wirklich (interaktive) Hege, sondern (diktatorische) Zähmung, d.h. eine kontra-, nicht aber eine konnaturale Größe.

Tatsächlich verbirgt sich in der kinoreformerischen Traditionsorientierung ein weiteres Mal jenes Disziplinierungsinteresse, das auch den abstraktiven Kulturbegriff

\footnotetext{
${ }^{200}$ Häfker, Kunst, 31

201 Häfker, Kunst, 31

${ }^{202}$ Häfker, Kunst, 31

${ }^{203}$ Häfker, Kunst, 31

${ }^{204}$ Häfker, Kunst, 31

205 Häfker, Kunst, 31

${ }^{206}$ Häfker, Kunst, 31
} 
motiviert hat. Wo Natur als gefährdende naturale Potenz des Menschen, d.h. als Triebhaftigkeit, Affektivität, Emotionalität und imaginative Kreativität durch entsprechende Leitstrukturen und Reduktionsmaßnahmen in feste Grenzen gebannt werden sollte, geschieht ein selbes nun gegenüber ihrem Hervorbrechen in den Produkten und Phänomenen der ,modernen Kultur', d.h. in der ,Zivilisation', durch die Rückorientierung auf die nicht minder festen Grenzen der traditionalen Ablagerungen. In beiden Fällen richtet sich die Frontstellung gegen das ,Überborden', gegen den menschlichen ,Antriebsüberschuß' (A. Gehlen) und gegen jede Veränderung und Dynamik. Die Bewahrethik der Kinoreformer wird so durch ihre Kulturkritik weiter charakterisiert und ihr Grundparadigma darin konkretisiert. Sie erweist sich in ihrem Kulturbezug als antievolutiv und statisch; angesichts einer kontingenten, geschichtlichen und unabgeschlossenen Realität, deren herausragendes Moment ihre Entwicklungsfähigkeit ist, befindet sie sich ebenso in einer ständigen (ontologischen bzw. idealistischen) Defensive, wie in der Konfrontation mit dem ,Menschenwesen', dessen anthropologische Zentralstelle seine (freilich in Unbeliebigkeiten eingebundene) Entwurfsoffenheit ist. Aufgrund ihrer prinzipiellen Statik bleibt die reformerische Bewahrethik in einem grundsätzlichen Antagonismus stecken: einem Antagonismus zur Realität schlechthin, der sie dann zur dauernden Produktion weiterer Dichotomien und Antagonismen zwingt.

\section{Die Dichotomien der Reformer}

Diese Dichotomien bzw. Antagonismen können so bislang wie folgt zusammengefaßt werden: Zunächst wird einer als anarchische Gefährdung gedachten Natur (des Menschen) eine disziplinierende, weitgehend defensive Kultur entgegengesetzt, in deren Leitstrukturen der Mensch erst zum eigentlichen Menschen werden soll. Diese Kultur wird als hochgradig abstraktive und logozentrische näher spezifiziert und von Affektivität, Emotionalität und Sinnlichkeit sowie von der Bildlichkeit abgesetzt. Damit im Zusammenhang steht ein entsprechender Begriff von Kunst, der die Qualität ihrer Werke nach dem Abstand von der sinnlichen Rezeptionsbasis bemißt und der zugleich nur die Alternative von Kunst und Unkunst kennt. Dem zweiten Bereich wird die Massenkultur zugerechnet; der mittlere Unterhaltungsbereich entfällt damit weitgehend. Umgekehrt fordert diese Dichotomisierung eine dauernde Bildungsbereitschaft und -orientierung, deren Anstrengung wiederum mit dem Natur-KulturAntagonismus zusammenhängt: Wo das Augenmerk nicht ständig auf die Kulturation, d.h. auch: die Bildung, gerichtet bleibt, drohen sofort die korrumpierenden naturalen Latenzen einzubrechen und eine günstigenfalls lediglich ,erschlaffende‘, ungünstigenfalls eine zerstörerische, primitivierende und entmenschende Wirkung zu entfalten. Mit einer weiteren Differenzierung, zu der die kooperative Gleichzeitigkeit von technischer Instrumentalität (welche als Naturbeherrschung eigentlich der Kultur positiv zuzuschlagen wäre) und reizorientierter Renaturalisierung in der Großstadt (vor allem durch Schaffung einer überbordenden Medienwelt) zwingt, wird eine ,gute' Kultur von einer ,schlechten', die dann ,Zivilisation' heißt, unterschieden. Die Renaturalisierung durch die letzte wird als ,unnatürliche', nämlich überreizende Verarbeitung der Sinnlichkeit diskriminiert und mit einer ,Natürlichkeit' der sinnlichen Volkskultur kontrastiert, die zugleich die größere Moralität zugeschrieben bekommt. Obgleich diese Kontrastierung als Versuch der Wiedergewin- 
nung des Anschlusses an die naturale Sphäre interpretiert werden kann, bleibt der Antagonismus erhalten: Die Traditionalität der Volkskultur und der guten alten Sitten' tritt selbst in Funktion der Naturbeherrschung auf und steht auf der Seite der Abstraktion gegen die (wenngleich als Künstlichkeit benannte und so vermittelt erscheinende) Unmittelbarkeit der Renaturalisierung in der Zivilisation. Im Paradigma dieser auf Disziplinierung ausgerichteten, bewahrethischen Denkfigur wird dann auch die Sittlichkeit der Kultur exklusiv zugeschlagen. Als Überich-haftes Bollwerk und weitgehend als Verbotsinstanz bestimmt, soll sie in Kooperation mit der Traditionalität kulturelle innerpsychische Statik gegen zivilisatorische naturale Dynamik durchsetzen. Damit erhellt sich auch die kontramoderne Stellung der Reformer um ein gutes Stück weiter: Die Ablehnung der insbesondere in der Stadt auffindbaren massenkulturellen Phänomene findet auf der reflexiven Basis einer negativen Anthropologie statt. Weil sie sich mit den prekären Latenzen des Menschen verbinden, werden die modernen Kulturerscheinungen diskreditiert. Die implizite Modernitätskritik der Reformer äußert sich daher (zunächst) im Gewand einer anthropologisch angesetzten Kulturkritik. Ethik gerät dabei zur Logistik bzw. zur ,Wissenschaft' von den geeigneten Strategien im Krieg gegen die moderne menschlich-gesellschaftliche Evolution und Teleologie. Dieser Krieg wird folgerichtig auch als Krieg der Institutionen gegen einen Ethoswandel geführt, wie sich aus dem Devianzvorwurf der ,Sexualisierung' erheben läßt. Zusammen mit dem Kriminalisierungsvorwurf legt er das Paradigma des Primitivierungsvorwurfs genauer aus. Der erstgenannte exemplifiziert zugleich das medientheoretische Wirkungskonzept der Kinoreformer.

\subsection{Devianzvorwürfe II: Kriminalisierung und Sexualisierung. Mimetisches Wirkungskonzept und kontramoderner Antiautonomismus}

Sowohl der Vorwurf der Sexualisierung als auch jener der Kriminalisierung stellen jeweils eine weiterführende Konkretion des Paradigmas der moralischen Primitivierung und seiner Grundoptionen dar. In ihnen werden die generell befürchteten Filmwirkungen spezifiziert und auf ,Fälle' hin ausgelegt. Der Kriminalisierungsvorwurf basiert hauptsächlich auf der These einer ethosbezogenen Korruption des Rezipienten durch ,Verrohung, während der Sexualisierungsvorwurf eine direkte Folge der Perhorreszierung triebhafter Latenzen des Menschen als moralbedrohender Strebungen ist. Beiden Vorwürfen ist ein Wirkungskonzept eigen, dessen Problembehaftetheit sich besonders deutlich im Fall des ersten Vorwurfs herausarbeiten und durch Verknüpfung mit den bereits anläßlich des Lange'schen Kunstkonzepts und des Primitivierungsvorwurfs zu Tage geförderten Basistheoremen auf seine generelle, axiomatische Gestalt zurückführen läßt.

\section{Die drei Formen der Kriminalisienungsthese}

Die Vorstellung, daß der Film, respektive das Genre des Kriminalfilms, eine kriminalisierende Wirkung mit mehr oder minder großer Notwendigkeit erzeugen müsse, gehört zum Allgemeingut der Kinoreformer - und nicht nur dieser. Schon gegen die ,Schundliteratur' ist dieser Vorwurf erhoben worden, und gegen andere Medien wird er später wiederholt: In den 50er Jahren unterstellt der amerikanische Psychiater F. 
Wertham den Comics eine solche Wirkung und nimmt mit seiner These durch Hilde Mosse großen Einfluß auf die diesbezügliche Diskussion in Deutschland ${ }^{207}$. In den $60 \mathrm{er}$ und 70er Jahren findet die Kriminalisierungshypothese unter dem Stichwort der ,Bildschirmbrutalität' Anwendung auf das Fernsehen und über Zeitungen und Zeitschriften selbst große mediale Verbreitung ${ }^{208}$. Neuerdings repetiert sie Werner Glogauer mit großer medialer Publicity und unter - in der Öffentlichkeit gleichwohl weniger beachteter - Kritik durch die wissenschaftliche Medienpädagogik. ${ }^{209}$

Die Kinoreformer bringen die These in drei Formen vor, die oft bei ein und demselben Autor nebeneinander stehen, jedoch nicht konsistent verbunden sind. Eine erste Form inkriminiert zunächst eine ,Verherrlichung des Verbrechers" durch jene Filme, in denen er die Hauptfigur darstellt. Schon die dramaturgische Struktur eines so angesetzten Films sorge dafür, da $B$ die Sympathie des Zuschauers auf den Kriminellen hin gelenkt werde. Als Hauptfigur nämlich könne er ,natürlich nicht schon bei Beginn des Stücks von der Nemesis ereilt werden "210, so daß dem Publikum gewissermaßen (zuviel) Zeit gegeben werde, ,,an dem Verbrecher Interesse“ ${ }^{\text {211 }} \mathrm{zu}$ finden. Dieser gerate dadurch zum „Heros“212, dessen „Kühnheit“ und „Geschicklichkeit“"213 bei der Ausführung der Tat und der Flucht vor „seinen Häschern“214 zur Empathie und Identifikation herausfordere. Den Vertretern des Rechts brächten die Rezipienten dagegen „ganz unwillkürlich und mit Notwendigkeit das Gefühl des Unwillens“215 entgegen. Anstatt „Genugtuung über das endliche Triumphieren des Rechts" ${ }^{\text {“216 }} \mathrm{zu}$ empfinden, stelle sich „Mitleid mit dem ,armen“ Verbrecher“217, ja selbst „Haß“ gegen die „Richter, welche sich von derartigen perversen Masseninstinkten (wie der Bewunderung des Kriminellen, T.H.) nicht leiten lassen und den Missetäter (...) seiner verdienten Strafe zuführen“"218, ein. Die Folge sei, daß der Zuschauer sich nach der Rezeption nicht sage: „Lohnt es sich, ebenso wie jener Dieb oder Mörder zu werden? ‘219, sondern vielmehr „zu dem Wunsche veranlaßt“" werde: „So wie der möchtest du es auch haben, so ein Kerl möchtest du auch werden!‘220 Als Wirkung all jener Filme, die den Verbrecher zum Protagonisten haben, wird daher ,Verrohung' und ,Anreiz zum Verbrechen' konstatiert ${ }^{221}$.

207 vgl. Wertham, Frederic, Seduction of the Innocent, New York 1954; Mosse, Hilde, Die Bedeutung der Massenmedia für die Entstehung kindlicher Neurosen, Köln-Klettenberg 1954

208 vgl. dazu: Kommer, Helmut, Früher Film und späte Folgen, Berlin 1979, 123-126

209 vgl. Glogauer, Werner, Kriminalisierung von Kindern und Jugendlichen durch Medien, Baden-Baden 1991; zur medienpädagogischen Kritik: Schorb, Bernd (Hrsg.), Medienpädagogen kommentieren populäre Thesen über die Wirkungen der Darstellungen von Gewalt und Sexualität im Fernsehen auf Kinder und Jugendliche. Dokumentation einer bundesweiten Expertenbefragung, München 1991
${ }^{210}$ Hellwig, Schundfilms, 74-75
211 Hellwig, Schundfilms, 75
212 Hellwig, Schundfilms, 74
${ }^{213}$ Hellwig, Schundfilms, 75
${ }^{214}$ Hellwig, Schundfilms, 75
215 Hellwig, Schundfilms, 75
216 Hellwig, Schundfilms, 75
217 Hellwig, Schundfilms, 75
${ }^{218}$ Hellwig, Schundfilms, 75
219 Hellwig, Schundfilms, 75
220 Hellwig, Schundfilms, 75
221 vgl. Hellwig, Schundfilms, 74, 76 
Voraussetzung dieser Wirkungsthese ist auch hier die Annahme eines destruktiven Zusammenspiels von Film und Publikum. Während dem ersten eine entsprechend unheilvolle narrative Formalstruktur angelastet wird, gilt das zweite als verderblich prädisponiert. Den Rezipienten, die vorwiegend „halbwüchsige (...) Burschen" 222 seien, ermangle der „kritische Blick“ des Psychologen oder Pädagogen, "welcher den Gehalt eines Stücks vom ethischen Gesichtspunkt aus beurteilt" ${ }^{\text {"223. }}$. Während diesen exemplarischen Vertretern der ,Gebildeten' ein ,kaltes, objektives Abwägen' dessen, ,welche Szenen aus dem Film ethisch und welche verrohend und zum Verbrechen anreizend ${ }^{\text {“2224 }}$ seien, zugemessen wird, gilt die Rezeptionshaltung des ,gewöhnlichen Publikums' als rein emotionale. Es sei ,nicht mit (dem) Verstand, sondern mit (dem) Herzen bei der Sache“'225 und verfolge die Geschichte des Kriminellen voll ,leidenschaftlicher Anteilnahme“"226. Derart in emotionaler Distanzlosigkeit befangen, scheint sich das Ethos der Zuschauer schnell in die Nachahmung der Unmoral aufzulösen. Der ,einfühlsame' Rezipient kommt nach kinoreformerischer Vorstellung offenbar als potentieller Verbrecher aus dem Kino zurück.

In einer zweiten Form wird dem Film dann nicht mehr vorgeworfen, daß er die Disposition für kriminelle Handlungen schaffe, sondern daß er detaillierte und direkte Anleitung zu deren Ausführung gebe. Er tue dies, indem er „die ganze strafbare Handlung in allen Einzelheiten vom Anfang bis zum Ende “2227 vorführe. Das Publikum bekomme so vor Augen gestellt, wie man ,die Sicherheitsorgane täuscht, den geeigneten Augenblick zur Tat erspäht, (...) elegant mit Dietrichen und anderen Einbrecherwerkzeugen arbeitet, seine Opfer mit Narkose betäubt und mit Revolver bedroht" ${ }^{\prime 228}$. Auch die Strategien der, Verheimlichung' würden genau dargelegt, wie etwa die ,Arbeit' mit Handschuhen, ,um Fingerabdrücke zu vermeiden“229, oder die Art und Weise, ,sich durch Perücken und Bärte unkenntlich “230 zu machen. Der (Kriminal-)film führe ,,auf sämtliche Gebiete des Strafrechts“‘231 und sei so „ein glänzender Unterrichtslehrgang für Anfänger wie für Fortgeschrittene im Verbrechen“'232. Das Kino müsse insgesamt „'die hohe Schule für Verbrecher heißen““233. Der Vorwurf führt in dieser zweiten Form solcherart ein kognitives Moment ein und begreift den Film als Vermittlungsinstanz für (unerwünschte) rationale, ,sachbezogene' Information. Ein entsprechendes Rezeptionsinteresse des Publikums wird generalisierend unterstellt:

„Tatsächlich ist doch der häufige Kinobesuch bei jugendlichen Verbrechern sehr oft nachzuweisen, und man begreift die Äußerung, die ein solcher kurz vor der Begehung eines Einbruchsdiebstahls zu einem Zeugen tat: ,Jetzt brau-

\footnotetext{
${ }_{222}^{223}$ Hellwig, Schundfilms, 74

${ }_{223}^{223}$ Hellwig, Schundfilms, 74

224 Hellwig, Schundfilms, 74

225 Hellwig, Schundfilms, 74

${ }^{226}$ Hellwig, Schundfilms, 74

227 Lange, Kino, 39

228 Lange, Kino, 39

229 Lange, Kino, 39

230 Lange, Kino, 39

231 Lange, Kino, 39

232 Lange, Kino, 39

233 Lange, Kino, 39; im Original gesperrt.
} 
che ich nur noch einmal ins Kino zu gehen und mir die berühmte Ein-

bruchsszene genau anzusehen, dann weiß ich, wie's gemacht wird. ““234

Daraus folgt ein Doppeltes: Während in der ersten Form ein Mangel an rationaler Reflexion zugunsten reiner Gefühlsbezüge beim Rezipienten konstatiert wurde, wird ihm nun einerseits durchaus die Fähigkeit gedanklicher Arbeit bei der Rezeption, d.h. die aktive Auffassung der Filmgehalte und ihre bewußte Eingliederung in den eigenen Wissensbereich zuerkannt, jedoch andererseits ein falsches, bzw. fehlgeleitetes kognitives Interesse angelastet. Ein Teil der Zuschauer, so wird angenommen, scheint den Film dazu zu nutzen, sich in entsprechende kriminelle Praktiken Einblick zu verschaffen, um diese danach selbst zur Anwendung zu bringen. Wo dieser Teil der Rezipientenschaft zu finden ist, wird mehr oder weniger explizit auf bestimmte soziale Schichten hin spezifiziert: Keineswegs sind es ,gebildete Erwachsene“, da diese „natürlich von solchen Vorführungen keinen Schaden“235 nehmen, sondern ,der junge Geselle und Lehrling, der keine gute Kinderstube gehabt hat, und an dem der Konfirmandenunterricht spurlos vorübergegangen ist“236, sowie „Fabrikarbeiter (...) und Fabrikarbeiterinnen “237, die hier inkriminiert werden. Gesprochen wird außerdem von „kriminell veranlagte(n) $\operatorname{Kinder}(n)^{\text {،.238 }}$ und ,wilden, ungezügelten Massen“, die im Kino „Nahrung für ihren Zerstörungstrieb““239 fänden, wenn man ihnen nicht ein Bollwerk entgegensetze. Unterstellt wird damit ein krimineller, ordnungszerstörender Charakter der ,entfesselten Volksmassen“ und ihrer „Sitten- und Zuchtlosigkeit ${ }^{\text {“240 }}$, dessen polemische Skizzierung bei Lange noch vom Kontext der Revolution von 1918 mitbestimmt ist. Schon Jahre vorher aber (nämlich 1911) tritt diese Charakterisierung auch bei Hellwig - in moderateren Worten auf. Dieser nennt im Kontext des Kriminalisierungsvorwurfs immer wieder die „Menge“ mit ihren „rohe(n) Instinkte(n)“241 und setzt sie dezidiert von den ,wohlhabenden Kreisen “242 ab. Im Gegensatz zu den letzten gelten die ,Unterschicht' (und wohl auch die untere Mittelschicht), deren Angehörige keine ,bessere Erziehung genossen “243 haben, als protokriminell; die Kinder dieser Schichten könnten daher „weder bei ihren Eltern, noch bei ihren Kameraden ein gutes Beispiel haben“244. In diesen Charakterisierungen äußert sich ein weiteres Mal ein Publikumspessimismus, der als genereller, anthropologischer oben schon vor Augen trat, der jetzt aber mit einer schichtspezifischen Zielrichtung zugeschärft und verändert ist. Zur Bedeutung dieser Zuschärfung wird weiter unten noch genaueres zu sagen sein.

Die Inklination zu einer emotionalen und kognitiven Fehlorientierung wird in einer dritten Form dann als einzig von außen verursachte gefaßt und dem bloßen Vorhandensein krimineller und brutaler Inhalte zugelastet. Die Frage nach der Art und

\footnotetext{
${ }^{234}$ Lange, Kino, 40

235 Lange, Kino, 40

236 Lange, Kino, 40

237 Lange, Kino, 6

238 Lange, Kino, 40

239 Lange, Kino, 127- 128

240 Lange, Kino, 13

${ }^{241}$ Hellwig, Schundfilms, 51

242 Hellwig, Schundfilms, 48

243 Hellwig, Schundfilms, 48

244 Hellwig, Schundfilms, 45
} 
Weise von deren Aufgriff und Verarbeitung durch das Publikum wird nicht mehr gestellt. Vielmehr gilt die Existenz an sich bereits als Erweis einer entsprechenden Wirkung. Für die spezifizierende Feststellung der Letzten scheint dann eine Inhaltsanalyse nach ausschließlich quantitativen Gesichtspunkten hinreichend. So zählt etwa Conradt die ,negativen' Szenen und Figuren in 250 Filmen aus, und schließt an dieser Stelle seiner Untersuchung - allein daraus auf die Destruktion der Moral:

„Aber wenn man die ganze Bildergattung ins Auge faßt und bedenkt, daß in 250 Stücken: 97 Morde, 51 Ehebrüche, 19 Verführungen, 22 Entführungen, 45 Selbstmorde vorkommen und 176 Diebe, 25 Dirnen, 35 Trunkenbolde, ein Heer von Schutzleuten, Detektivs und Gerichtsvollziehern auftreten, dann muß man einsehen, daß es so nicht weiter gehen kann, wenn nicht jede Sittlichkeit vernichtet werden soll. " 245

Obschon zu sehen war, daß er an anderer Stelle diese verderbliche Wirkung aus der unheilvollen Kooperation von Film und Triebdisposition der Zuschauer entspringen sieht, scheint angesichts dieser quantitativen Perhorreszierung (die im übrigen jeden situativen Kontext der Szenen und Figuren im Film selbst neglegiert) eine perniziose Latenz des Publikums irrelevant zu sein. In der Tat findet Conradts Aufzählung ohne seine anthropologisch-pessimistischen Untermauerungen bei anderen Reformern großen Nachhall und wiederholte Zitation, wobei dort oft endgültig Existenz und Häufigkeit der unliebsamen Szenen und Figuren allein für die kriminalisierende Wirkung verantwortlich gemacht und mit der Aura der Beweiskraft umgeben werden. So spricht z.B. Gaupp, nachdem er Conradts Zahlen wiedergegeben hat, davon, daß sich ,,auch der kritischste Mensch (diesen Darstellungen, T.H.) nicht immer ganz entziehen“246 könne, und die genannten Szenen notwendig und unterschiedslos ,auf alle Altersstufen nervenerregend und zerrüttend einwirken“ ${ }^{247}$ müßten. Eine besondere Disposition ist folglich nicht mehr nötig; auch eine Schichtspezifizierung entfällt. Der brutale oder kriminelle Inhalt an sich wird zum überwältigenden Agens erklärt. Häufig wird so nur noch eine rhetorische Frage gestellt, die sich der Zustimmung der Adressaten sicher fühlt, um der These von der ,verrohenden“ und insbesondere kriminalisierenden Wirkung des Films unbefragt Gehör und Geltung zu verschaffen:

„Wenn vor den Augen der Zuschauer (...) ganz deutlich ein Mensch erstochen und aus dem Fenster geworfen wird, wenn wir sehen, wie eine Braut aus Gewinnsucht kaltlächelnd ihren Bräutigam erschießt und Tausende und Abertausende im ganzen Lande diese und ähnliche Bilder sehn, dann ist die Frage recht überflüssig: Woher kommt die Zunahme der Roheitsverbrechen?“248

Die drei Formen der Kriminalisierungsthese beinhalten so drei unterschiedliche Wertungen des wirkungsbezogenen Verhältnisses von Film und Publikum und stellen damit drei Argumentationsfiguren vor Augen, die nicht völlig kompatibel sind bzw.

${ }^{245}$ Conradt, Kirche, 32

246 Gaupp, Kinematograph, 10

247 Gaupp, Kinematograph, 10; auch Schultze, Bildungsmittel, 72, zitiert Conradts Liste in diesem Sinn.

248 Conradt, Kirche, 29-30; das Verbrechen der Braut, auf das angespielt wird, ist historisch: Es handelt sich um den Mord der Grete Beyer, die ihren Bräutigam erschoß, und deren Tat um 1910 filmisch nachgestellt wurde. 
Widersprüche evozieren. In der ersten Form ist auf den Impetus zum Verbrechen schlechthin und eine diesbezügliche Schwächung oder Korrumpierung des sittlichen Habitus abgezielt. Argumentiert wird in Form einer rezeptionspsychologischen Spekulation, die schrittweise zu erheben versucht, wie jener Impetus zustandekommt. Verbunden ist diese Spekulation mit der bereits bekannten Figur eines perniziosen Zusammenwirkens von Film und Publikumsdisposition, wobei dem Film eine niederträchtige Dramaturgie, dem Publikum eine reflexionslose Emotionalität bzw. genauer: eine empathische Latenz zur Last gelegt wird. Obschon die rezeptive Empathie durch die verurteilte Dramaturgie gelenkt erscheint, entkommt auch das Publikum der Inkriminierung nicht: Das Wort von den ,perversen Masseninstinkten' impliziert wieder die Annahme eines (psychischen) Gefälles zur Unmoral. Vorgeworfen wird den Rezipienten zudem, daß sie die nötige reflexiv-rationale Distanz nicht aufbrächten und so willig den Gefühlsbotschaften des Films unterlägen. An dieser Stelle tritt nun auch die schon genannte schichtspezifische Dichotomie der Kinoreformer deutlich vor Augen, die eine ,kultivierte' und daher gegen naturale Latenzen und emotionale Verstrickung weitgehend unempfindliche Schicht der ,Gebildeten' als Führungsschicht gegen eine ,primitive', gefährdete Volksmasse setzt, die der Kulturation und Leitung erst noch bedürfe und daher als unmündige zu behandeln sei. Der Vorwurf verbleibt in der ersten Form so strukturell im Rahmen des Verrohungsvorwurfs und des anthropologischen Pessimismus, wobei die schichtspezifische Dichotomie noch gemäßigt zur Anwendung kommt, d.h. nicht zum Antagonismus verschärft wird. Die kriminalisierende, Wirkung' von Film aber ist hier eine dritte Größe, die durch das Zusammenspiel von Film und Publikum, d.h. interaktiv entsteht.

In der zweiten Form wird dann dem Film vorgeworfen, da $B$ er direkt zur Ausführung von Verbrechen anleite. Er erscheint damit als gesellschaftlich dysfunktionales, destruktives Informationsmedium, dessen Inhalte nicht nur aus dem der Gesellschaft feindlichen Bereich der Kriminalität genommen sind, sondern die es selbst diesem Bereich - gewissermaßen als Propagandainstrument und Unterrichtsmaterial - zugehören lassen. Zugleich aber tritt in dieser Form des Vorwurfs ein Publikumsbild vor Augen, das nicht mehr nur auf den anthropologischen Pessimismus allein zurückzuführen ist. So wird dem Publikum nun zwar keine emotionale, affektive oder triebhafte Inklination zur Last gelegt, ja, es wird ihm sogar eine kognitive und rationale Kompetenz zugestanden, jedoch gerade nicht, um es mit positiven Merkmalen auszustatten. Vielmehr erscheint diese Kompetenz als ganz und gar fehlorientierte, wobei nach der Herkunft dieser Fehlorientierung nicht mehr gefragt wird. An die Stelle einer rezeptionspsychologischen Analyse tritt eine pejorative, diskriminierende Bestimmung des Wesens der Rezipientenschaft: War sie eben noch die zum Verbrechen verführte, zwar mitschuldige, aber doch in einen Sog unglücklicher Kooperation gerissene, so scheint sie jetzt eine unmittelbare Bereitschaft zur Kriminalität mitzubringen, ja sich geradezu aus, Anfängern und Fortgeschrittenen im Verbrechen' zusammenzusetzen. Der Publikumspessimismus ist hier zum Schuldvorwurf und zur gezielten Diskriminierung verschärft: Die Kinogänger werden in einer schlicht feindseligen Art und Weise als ,kriminelles Gesindel' charakterisiert. Sogar den Jugendlichen, die sonst meist den Status von Opfern zugemessen bekommen, wird nun die Schuld für ihre Korrumpierung selbst angelastet und beinahe ein böser Wille unterstellt: 
„Der Jugendrichter, (...) der nach dem Grunde für die Tat forscht, hört (...) immer wieder: Er mußte ja in alle Kinos rennen und dort sieht und lernt er ja, wie er es zu machen hat.“249

Versucht also der Kriminalisierungsvorwurf in seiner ersten Form noch eine vergleichsweise differenzierte und vermittelnde Analyse der angenommenen Wirkungszusammenhänge, welche deren Zustandekommen in der Interaktion von Film und Publikum sieht, und mit der letztlich eine Schuldzuweisung an beide stattfindet, so fällt im zweiten Fall nun die Vermittlung sehr undifferenziert auseinander. Auf der einen Seite wird zwar dem Film mit nachdrücklichen Worten die alleinige Verursacherrolle zugeschoben, wenn etwa Lange ausruft:

„Wie unendlich viele Jungen hat das Kino schon vor Gericht und ins Gefängnis gebracht, und jeder Tag fordert neue Opfer! ‘250

Auf der anderen Seite aber erhält diese Rolle dort, wo das Publikum selbst als kriminell gilt, nur sehr untergeordnete, allenfalls verstärkende Bedeutung. Nach der Verursachung wird dann gar nicht eigentlich mehr gefragt; stattdessen wird auf ,schlechte Erziehung' und ,soziales Milieu' der Rezipientenschaft wie auf ontologische Gegebenheiten verwiesen. Von einer kriminalisierenden Wirkung des Films kann damit im strengen Sinn nicht mehr gesprochen werden. Richtiger wäre, stattdessen von einer kriminell orientierten Nutzung der Filminhalte durch eine ohnehin kriminelle - bzw. zumindest protokriminelle - Rezipientenschaft zu sprechen.

Mit diesem Ansatz eines bewußten, positiven Interesses des Publikums am Verbrechen und einer inhaltlichen Lernorientierung auf dieses hin ist nicht nur der Bereich der anthropologisierenden und psychologisierenden Analyse der Gründe für die Devianzen überschritten, sondern auch ein direkter Antagonismus zwischen Kinoreformer und Filmrezipienten gesetzt. Die schichtspezifische Dichotomie, die sich schon aus Langes elitärem Kunstkonzept, dem eine kunsttragende Elite korrespondieren $\mathrm{mu} B$, angedeutet hat, wird nun explizit und auf benennbare Kreise hin konkretisiert. Während nämlich bis dahin der Kampf gegen eine allgemeinmenschliche Gefährdung geführt wurde, welcher die Reformer letztlich selbst unterliegen, und der sie nur dank ihrer kulturativ erzeugten Resistenz enthoben galten, nimmt die Auseinandersetzung mit dieser Form eine personalisierende Wende und wird sie zur ausdrücklichen Gegnerschaft von gesellschaftlichen Gruppen. Freund und Feind sind recht deutlich benannt: Auf der einen Seite stehen die Kinoreformer als Repräsentanten der ,Gebildeten', d.h. genauer: des konservativen Teils des gebildeten Bürgertums, auf der anderen Seite findet sich das Kinopublikum als Repräsentant der Unterschicht und unteren Mittelschicht, d.h. jener in den großen Städten versammelten Massen, die allmählich in den Raum der Öffentlichkeit eindringen und ihre gesellschaftliche Randständigkeit zu verändern suchen. Die schichtspezifische Dichotomie wird so über die kunstbezogene Führungsrolle der ,Gebildeten' hinaus zum realen, kämpferischen Gegensatz weitergeführt. Bei Hellwig bleibt dieser Gegensatz noch weitgehend auf der theoretischen Ebene, während Lange ihn schon auf dem Hintergrund der Erfahrungen der Revolutionszeit formuliert. Die zweite Form des Kriminalisierungsvorwurfs weist damit zum ersten Mal Momente auf, die erkennen lassen,

${ }^{249}$ Lange, Kino, 39

250 Lange, Kino, 39 
da $B$ die Auseinandersetzung um den Film auch eine soziale ist (und dies bevor die Auseinandersetzung der Revolution sich mit der Aufhebung der Zensur und der Debatte in der Nationalversammlung um das Reichslichtspielgesetz auf den Film ausdehnt). In der Charakterisierung der Kinogänger als verbrecherischer Elemente schwingt bei beiden Autoren ein Angstmoment mit, das im Vorwurf der ,sozialen Destabilisierung (vgl. 2.5.) schließlich noch deutlicher zutage treten wird, und das sich auf seine eigentliche Wurzel: jene Verbreiterung der Öffentlichkeit, die ich unter 1.4. beschrieben habe, und auf ihren Kontext, das Projekt der Moderne, hin entschlüsseln läßt.

Anders verhält es sich im dritten Fall, der die Zuschauer fast völlig entlastet. Jetzt gilt der Film als schlechthinniger Übeltäter, als alleiniger Verursacher der kriminellen Korruption des Rezipientenethos. Existenz und Quantität krimineller Szenen und Figuren an sich scheinen mit Notwendigkeit die Zerstörung der Sittlichkeit nach sich zu ziehen. Der situative Kontext dieser Figuren und Szenen in den einzelnen Filmen bleibt ebenso unberücksichtigt wie Struktur, Rezeptionsinteresse und Disposition des Publikums. Stattdessen erzeugt die Quantifizierung der Filminhalte, die dieselben hierzu ihrer besonderen jeweiligen Qualität entkleidet, durch das abstraktive Auszählen und Summieren eine neue Qualität, nämlich den Eindruck einer Flutwelle aus Gewalt und Verbrechen, die alltäglich und allabendlich über eine unschuldige Zuschauerschaft hereinbrandet. Es entsteht so das Bild eines naiven, passiven Publikums, das sich, ohne recht zu wissen, was es da tut, wieder und wieder dem destruktiven ,Impact' einer ebenso unsittlichen wie sensationslüsternen ,Schmutzproduktion' ausliefert, bis seine Seele derart vergiftet, verletzt und vernarbt ist, daß sie für jegliche ethische Maximen unempfänglich wird. Das Paradigma, das im Hintergrund dieser quantitativen Perhorreszierung steht und dessen Wirkungsvorstellung bestimmt, ist erneut die ,Verrohungsthese', die - jetzt allerdings unter Auslassung des anthropologischen Pessimismus' - aus der bloßen, wiederholten Rezeption grausamer (und krimineller) Inhalte eine Abstumpfung von Gefühl und Ethos deduziert. Die Publikumscharakteristik wiederum ist dezidiert bewahrethisch: Als naive sind die Zuschauer in Schutz zu nehmen vor dem Film, aber auch vor sich selbst. Werden sie in der dritten Form des Kriminalisierungsvorwurfs von gefährlichen, ,verrohungsfreundlichen' Latenzen oder gar verbrecherischen Interessen (implizit, nämlich durch die alleinige Schuldzuweisung an den Film) freigesprochen, so geschieht das letztlich nur, um sie als führungsbedürftig erklären und der ethischbewahrenden Obhut der Reformer unterstellen zu können. Die zweite und die dritte Form der Argumentation sind daher keine analytisch-begründende mehr, sondern eine letztlich strategische: Es geht um eine Charakterisierung von Film und Publikum, die eine exklusive Stellung der kinoreformerischen Normativität gegenüber dem ersten und der Reformer selbst, sowie ihrer Schicht, als den Bildungsführern gegenüber dem zweiten legitimiert. Der strategische Charakter der Argumentation dürfte den Reformern freilich kaum bewußt sein; er erklärt jedoch, wie die Brüche und Inkonsistenzen zwischen den drei Formen des Vorwurfs zustandekommen.

\section{Die reformerische Wirkungsthetik}

Aus dem Dargestellten läßt sich nun weiter erheben, wie das Grundparadigma der kinoreformerischen Wirkungsspekulation - und um eine solche handelt es sich, da 
eine dezidierte Wirkungsforschung unter diesem Titel erst lange nach ihr entsteht beschaffen ist. Alle drei Formen des Kriminalisierungsvorwurfs fußen letztlich auf der Annahme, daß die entsprechenden Wirkungen im Sinn eines Beispiel- oder Modellernens entstehen, d.h., dadurch, daß die Rezipienten aus verschiedenen Gründen die Filminhalte internalisieren und vorgegebene Handlungsformen imitieren. Das kinoreformerische Wirkungskonzept nenne ich daher ein mimetisches. Die Gründe für die Mimesis werden freilich jeweils unterschiedlich benannt: Einmal werden sie ganz auf die Seite der ,Suggestivkraft' des Films geschoben, deren Prägewirkung man sich auch als ,Gebildeter' schwer entziehen könne (vgl. die dritte Form des Kriminalisierungsvorwurfs), ein andermal scheint die Nachahmung aus einer Korrespondenz von (auslösenden) Filminhalten und (andrängenden) Publikumsdispositionen zu fließen (vgl. die erste Form), und ein weiteres Mal sucht sich ein präformiertes Publikum direkt Anleitung für seine Nachahmungshandlungen (vgl. die zweite Form). Einmal gilt die Rezipientenschaft als passiv, einmal als kooperativ und einmal als aktiv. Nimmt man die drei Ausformungen des mimetischen Wirkungskonzepts, wie sie der Kriminalisierungsvorwurf bereitstellt, nun mit den im Langeschen Kunstkonzept und den im Primitivierungsvorwurf ausgearbeiteten Basistheoremen zusammen, dann erhält man die generelle Axiomatik der reformerischen Wirkungshypothesen. So stellt Langes Postulat einer realitätsanalogen Unmittelbarkeit der Filmwirkung aufgrund der diesem Medium zugeschriebenen abbildrealistischen Ästhetik den Versuch einer kunsttheoretischen Untermauerung der Suggestivkraftthese dar (vgl. 2.2.). Der durch Bewegtheit gesteigerte Abbildrealismus des Films scheint dem Filminhalt eine solche Eindruckskraft zu verleihen, daß der Rezipient ihn als Realität empfindet und mit dieser verwechselt. Der Kriminalisierungsvorwurf gesellt, wie zu sehen war, diesem Kriterium noch das der Häufigkeit und Fülle mißliebiger Inhalte bei und deduziert daraus die abstumpfend-verrohende Wirkung. Kombiniert man die Kriterien, so lautet das generelle Axiom: Der filmische Abbildrealismus gibt den Inhalten eine realitätsanaloge Eindrücklichkeit und sorgt zusammen mit einer an sich schon verderblichen Fülle und Häufigkeit dafür, da $ß$ der Rezipient vollkommen überschwemmt, und ohne die Möglichkeit einer Gegenwehr in die Mimesis getrieben wird. ${ }^{251}$ Dabei gilt der Film als das alleinige Agens, so daß die

251 Nicht sehr viel anders verhält es sich mit den weniger, ausgeklärten' Suggestivannahmen anderer Reformer, die eine übermächtige Eindrücklichkeit der Bildlichkeit überhaupt ansetzen, ohne dies noch im Sinn Langes weiter theoretisch auszuführen (etwa: Hellwig, Kind, 29; Hellwig, Schundfilms, 51; Sellmann, Kinematograph, 24). Die überwältigende Macht der Bildlichkeit gilt dort als mehr oder weniger selbstevident und scheint eine, visuelle Reizüberflutung' mit mimetischen Konsequenzen zu bedingen. Auch bei Gaupp findet sich diese Denkfigur: In einem ,Kombinationsargument' spannt er Bildlichkeit, Geschwindigkeit und emotionsbeladenen Inhalt zur Reizüberflutung zusammen und konstatiert er eine suggestiv wirkende Überschwemmung. „Beim Kino wird die gemütliche Erregung durch die rasche Folge der leibhaftig vor Augen geführten Bilder gehäuft und verstärkt; zum Nachdenken und Sichbefreien bleibt keine Zeit; es kommt nicht zum seelischen Ausgleich." (Gaupp, Kinematograph, 9) Der Rezipient sei einer „Hochflut des Schauerlichen“ (ebd.) ausgesetzt, die ,das Nervensystem erschüttere'. Auf diese Weise werde ,die Kritik eingeschläfert ${ }^{t}$ und „eine tiefe und oft nachhaltige Suggestivwirkung“" (ebd.) erzeugt. Die Axiomatik wird von Gaupp so durch psychologische Spekulation unterstrichen. Der Angelpunkt aber bleibt auch hier die Bildlichkeit, welche die ,schauerlichen Inhalte so sinnlich unmittelbar darbietet. Im Gegensatz zur Literatur nämlich stelle „das Kino (...) alles gewissermaßen leibhaftig vor Augen." (ebd.) Gaupps Kombinationsargument weist derart eine gewisse Nähe zu Langes Konzept wie auch zur These der Abstumpfung durch Häufigkeit und 
derart argumentativ verankerte Wirkungsthese als Verursachungsthese definiert werden kann. Sie versucht einen unmittelbaren Schluß vom Inhalt auf die Wirkung zu legitimieren. - In ähnlicher Weise kann der vor allem bei Conradt rekonstruierte anthropologische Pessimismus als Versuch gelten, das Theorem von der Korrespondenz der Filminhalte mit den Publikumsdispositionen grundsätzlich argumentativ zu stützen. Das generelle Axiom lautet hier: Die naturhafte, also allgemein gegebene und unhintergehbare triebhafte, affektive, sinnliche und imaginative Latenz des Menschen, die per se ein Gefälle zur Unmoral darstellt, kommt den triebhaften, affektiven und sinnlichen Inhalten des Films in einer Weise entgegen, da $B$ durch ihr Zusammenspiel notwendig Nachahmungshandlungen ausgelöst werden. Diese Wirkungsthese kann damit als Kooperationsthese definiert werden. Sie fordert über die Inhaltsbetrachtung hinaus eine Reflexion der Publikumsdisposition zumindest in Form der Besinnung auf die anthropologische Grundoption. - Im letzten Fall, der rein erst im Kriminalisierungsvorwurf selbst auftritt, wird eine freie, böswillige Entscheidung des Publikums zur (kognitiven) Nutzung des Films postuliert, die mit der Annahme einer schichtspezifischen Zurechenbarkeit verknüpft ist. Das (deutlich zirkuläre) Axiom lautet somit: Eine sittlich verderbte Publikumsgruppe nutzt den Film zur Verstärkung ihrer sittlichen Verderbtheit. Will man den zirkulären Charakter dadurch aufzuheben, daß man es mit dem anthropologischen Pessimismus zu verbinden sucht, so erhält man wieder die Kooperationsthese, freilich erweitert um das Moment einer bewußten, böswilligen Entscheidung zum Gebrauch des Films für die Förderung der eigenen, unmoralischen Latenzen. Das Entscheidungsmoment erlaubt es, die These sowohl in der rein zirkulären als auch in der erweiterten Form als $\mathrm{Nut}$ zungsthese von den beiden anderen zu unterscheiden. Die Wirkungsaktivität wird hier nicht den Inhalten, sondern einzig dem Publikum zugeschrieben. - Genau besehen nun enthalten diese drei Akzentuierungen des mimetischen Wirkungskonzepts in nuce bereits die Basistheoreme der späteren Wirkungsforschungen. Das Passivitäts- oder Verursachungs- und das Kooperativitätstheorem nämlich korrespondieren dem Stimulus-Response-Paradigma, das in der ,harten' Form ein direktes, unvermitteltes Reiz-Reaktions-Verhältnis zwischen ,Sender ${ }^{6}$ und ,Empfänger', in der ,weichen' Form eine Vermittlung durch bestimmte Empfänglichkeiten auf Seiten der Rezipienten postuliert. Das Aktivitäts- oder Nutzungstheorem wiederum kann als freilich sehr undifferenzierte und krude - Vorform des Uses-and-GratificationsParadigmas, d.h. des ,Nutzen-Ansatzes' betrachtet werden, der seine forschungsleitende Perspektive auf die Art und Weise der Benutzung von Medieninhalten durch das Publikum ausrichtet, wobei diesem eine eigenverantwortliche dezisive Kompetenz zugestanden wird.

Das mimetische Wirkungskonzept der Kinoreformer nun ist in allen drei Formen problematisch. Zunächst ergeben sich bereits auf der Ebene der rekonstruierten theoretischen Axiomatik einige Schwierigkeiten. So ist insbesondere das Langesche Konzept der Realitätsunmittelbarkeit des filmischen Abbildrealismus äußerst frag-

Fülle auf; die Letzten sind bei ihm als ,Hochflut des Schauerlichen' und im Terminus der Geschwindigkeit analog repräsentiert. Will man das Axiom nun im Sinn Gaupps formulieren, so lautet es: Geschwindigkeit, Bildlichkeit und emotionaler Gehalt (das ,Schauerliche') sorgen für eine Reizüberflutung, aus der die Mimesis entspringt. Eine (reflexive) Gegenwehr des Rezipienten scheint, wie bei Lange, nicht möglich. 
wirdig. Filmtheoretisch ist es durchaus nicht ausgemacht, ob und inwieweit ein von Einstellungen, Schnitten und Montage bestimmtes Werk überhaupt als abbildrealistisch gelten darf. Selbst wenn man die Langesche Hypothese aber zugesteht, bietet sie noch immanente Probleme. Letztendlich postuliert sie ja nur, daB der Film einen Eindruck erzeuge, der der Wirklichkeit gleiche, d.h. also, daß Filmerleben und Realitätserleben identisch seien. Die ,Suggestivkraft" des Films unterscheidet sich demnach nicht von der der Wirklichkeit überhaupt. Damit ist jedoch weder für die These einer mimetischen noch einer anderen Wirkung etwas bewiesen, sondern im Gegenteil dieselbe in eine theoretische Inflation geführt. Um aus dem realitätsanalogen Filmerleben nämlich eine durch dieses erzeugte Nachahmungshandlung ableiten zu können, bedarf es der Zusatzannahme, daß dem Rezipienten eine reflexive Distanz zu seinem Erleben unmöglich sei. Gerade die Gleichsetzung von Film und Realität aber führt dann in den Schluß, daß der Mensch auch in der filmexternen Realität zur reflexiven Distanz nicht fähig, sondern die willenlose Marionette des ihn Umgebenden sei. Das Langesche kunstheoretische Konzept der Filmästhetik mündet so in einen umfassenden Determinismus, der letztlich jede Bewußtheit, Reflexivität und Entscheidungskompetenz des Menschen bestreiten muB. - Etwas anders liegt der Fall bei der Annahme einer sukzessiven Abstumpfung des Rezipientenethos durch Fülle und Häufigkeit. An die Stelle einer rein deterministischen Grundoption tritt hier eine gewissermaßen ,kontingente', sich geschichtlich vollziehende Prozeßwirkung. Anzufragen ist jedoch auch hier, wie es um die Einschätzung der Möglichkeit reflexiver Distanz bestellt ist. Weiterhin bleibt ungeklärt, wodurch sich der Überschritt von der rezeptiv-passiven Abstumpfung zur aktiven Handlung ergibt, d.h., weshalb etwa eine Gewöhnung an das Sehen krimineller oder grausamer Handlungsvorgänge in deren Nachahmung führen soll. ${ }^{252}$ Die These ist an diesem Punkt noch theoretisch unvollständig und fordert zudem ihre empirische Überprüfung. Theoretisch durchaus konsistent hingegen verhält sich die Kooperationsthese. Sie bietet sogar mit ihrer Grundfigur, die Filmwirkung auf eine Kooperation von Film und Publikum zurückzuführen, einen Ansatz, der es erlaubte, differenzierter zuzusehen und eine feinstrukturellere Analyse des Zusammenwirkens vorzunehmen. Ihre Ausformulierung durch die Reformer jedoch beruht, wie in 2.3. zu sehen war, auf problematischen anthropologischen Prämissen, die eine solche feinstrukturelle Analyse präjudikativ unterlaufen. Sind Triebstruktur, Affektivität, Sinnlichkeit und Imaginativität des Menschen schlechthin als mit einem Gefälle zur Unmoral ausgestattet angesetzt, so ist das Ergebnis einer Kooperation mit diesen naturalen Strukturen vorgezeichnet: Sie kann nur negativ, d.h. in der Amoralität enden. - Theoretisch äußerst problematisch ist schließlich die zirkuläre Form der Nutzungsthese, die zwar eine dezisive Kompetenz des Publikums zugesteht, jedoch zugleich den Charakter der Rezipienten negativ als Verderbtheit und Kriminaliätsneigung präjudiziert. In ihrer Reinform verzichtet sie außerdem auf eine Reflexion der Herkunft dieses schichtspezifisch zugelasteten Negativcharakters. Die erweiterte Form der Nutzungsthese, die sie auf die Kooperationsthese zurückbiegt, unterliegt dann wiederum derselben Problematik wie die letztgenannte. In ihrer Reinform aber verweist sie, wie bereits in Blick

252 Das gilt auch für das Gauppsche Konzept, das zwar die Sukzessivität der Abstumpfung spekulativ psychologisch ausarbeitet, jedoch nicht den eigentlichen Handlungsantrieb erschließt. 
genommen wurde, darauf, daß die Gründe für ihre Formulierung anderswo, außerhalb der Wirkungsspekulation, zu suchen sein dürften.

\section{Der ideologische Charakter der Wirkungsthesen}

Die drei Wirkungskonzepte der Reformer zeigen sich damit bereits auf der axiomatischen Ebene, d.h. der Ebene ihrer theoretisch-spekulativen Prämissen und Grundoptionen als problembehaftet. Einige ihrer Grundoptionen bedürften der Revision; die Thesen insgesamt müßten theoretisch weitergeformt und mit empirischen Belegen gestützt werden. Tatsächlich aber findet weder eine Revision, noch eine empirische Überprüfung oder weiterführende Reflexion statt. Die Wirkungsthesen gelten den Reformern als selbstevident und unbezweifelbar. Das zeigt sich wiederum an ihrem Umgang mit der Wirkungsspekulation im Kriminalisierungsvorwurf. Die These von den jeweiligen kriminalisierenden Folgen der Filmrezeption nämlich gilt als so selbstverständlich, daß ein Beleg für den mimetischen Zusammenhang entweder fehlt, nur illustrativ vorgenommen, oder gar für unnötig erklärt wird. So spricht etwa Dieckmann davon, daß ,von 100 jugendlichen Verbrechern (...) nachweislich 75 die Anregung dazu im Kino“'253 empfingen, ohne jedoch diesen Nachweis zu führen. Andere Reformer zitieren Zeitungsartikel von Fällen, in denen angeblich Verbrechen durch Filme induziert worden seien, ohne diese Fälle selbst zu kennen oder vor Ort zu untersuchen ${ }^{254}$. Da jene Artikel selbst unter der darstellungsleitenden Perspektive des mimetischen Wirkungskonzepts geschrieben sind, stellen sie allenfalls ein illustratives, nicht aber ein echtes Belegmaterial dar. Hellwig schließlich, der eine umfangreiche Materialsammlung in Absicht eines wissenschaftlichen Belegs der These unternimmt, muß dabei feststellen, daß ein sauberer Erweis auf dessen Basis gerade nicht möglich ist. Er verweist zunächst darauf, daß er ,im Laufe der Jahre wohl mehr als 100 (...) Fälle“255 einer kriminalisierenden Wirkung der ,Schundliteratur' gesammelt habe, „um sie in einer eingehenden Darstellung (...) zu verwerten“،256. Von einer Veröffentlichung aber habe er absehen müsen, da „schon bei den etwa zehn Stichproben“257, die er gemacht habe, die Unzuverlässigkeit des Materials offensichtlich geworden sei. Ähnlich verhalte es sich in Bezug auf den Film: Die „meisten Fälle, die bis auf den heutigen Tag veröffentlicht“ seien, hielten „einer kritischen Prüfung nicht stand ${ }^{258}$. Gerade die „weiteren Untersuchungen“, die er zu dieser Problematik angestellt habe, hätten ergeben, daß „die in den Zeitungen und Fachzeitschriften berichteten Fälle (...) im allgemeinen als beweiskräftig nicht angesehen werden können, ja, daß man selbst Angaben von Jugendrichtern, Staatsanwälten, Psychiatern und anderen Sachverständigen nicht selten mit großer Vorsicht entgegenkommen muß“259. Das allerdings ist für Hellwig kein Grund, von der These einer mimetischen Wirkung abzugehen oder dieselbe zu modifizieren. Vielmehr betont er gegen seine eigenen Forschungsergebnisse, daß er die Richtigkeit und Stich-

\footnotetext{
253 Dieckmann, Kino, 10; Hervorhebung von mir.

254 vgl. etwa: Schultze, Bildungsmittel, 71-72

255 Hellwig, Schundfilms, 70

${ }^{256}$ Hellwig, Schundfilms, 70

257 Hellwig, Schundfilms, 70

${ }^{258}$ Hellwig, Schundfilms, 68

${ }^{259}$ Hellwig, Kind, 34
} 
haltigkeit der These aus allgemeinen, rezeptionspsychologischen Erwägungen grundsätzlich voraussetze:

„Dieser Schluß (daß kein Kausalzusammenhang zwischen Film und Kriminalität vorliege, da er nicht nachweisbar ist, T.H.) liegt nahe, ist aber doch verkehrt, weil (...) aus psychologischen Gründen eine kausale Beziehung zwischen der Kriminalität der Jugendlichen und der Darstellung von Schundfilms selbst dann angenommen werden müßte, wenn auch nicht ein einziger Fall als Beweis dafür beigebracht werden könnte. “260

Jene ,psychologischen Gründe', die Hellwig hier nennt, sind dabei selbst wieder der Spekulation zuzurechnen, wie die Skizze der Überlegungen zur empathischen Latenz und reflexionslosen Emotionalität des Publikums bei der ersten Form des Kriminalisierungsvorwurfs zeigt. Wie dieser Vorwurf nämlich sind auch sie durch keinerlei an Faktizität und Empirie orientierte Untersuchungen gestützt. Sie verbleiben im Raum reiner Hypothetik.

Die Wirkungsspekulation der Kinoreformer muß daher insgesamt als theoretisches Konstrukt mit zumindest partiell zweifelhaften axiomatischen Vorgaben bezeichnet werden, das außerdem einer empirischen Überprüfung und Absicherung durch entsprechende Forschungen entbehrt. In Form der Kriminalisierungsthese liegt sie als zeittypische Befürchtung vor, deren unbefragte Selbstevidenz bei einigen Autoren darauf verweist, da $\beta$ ihre Gründe anderswo, d.h. nicht in ihren eigenen inhaltlichen Aussagen, sondern in deren gesellschaftlichem Kontext zu suchen sind. Das gilt besonders dort, wo von der Abwesenheit einer wissenschaftlichen Überprüfung und Sicherung der These ein klares Bewußtsein vorhanden ist und dennoch auf ihr beharrt wird. In diesem Fall drängt sich der Begriff der Ideologisierung auf. Tatsächlich gerät mit der kontrafaktischen Argumentationsfigur Hellwigs das mimetische Wirkungskonzept in den Bannkreis derselben und wird vom theoretischen zum ideologischen Konstrukt. Sein diesbezüglicher Charakter macht ein weiteres Mal die eigentliche Bedeutung der Wirkungsannahmen als strategische offenbar und erlaubt den Blick auf den gesellschaftlichen Kontext als einer sozialen Auseinandersetzung: Selbst wenn der Nachweis der Kriminalisierung nie gelänge, bliebe die Geltung der These behauptet, da sie im Kampf der konservativen Bildungsschicht um ihre Führungsrolle und eine bewahrethische Hegemonie gegenüber dem um Unterschicht und untere Mittelschicht erweiterten ,Publikum' und seinen mehr oder weniger bewußten gesellschaftlichen Gestaltungsansprüchen ein treffliches Instrument darstellt. Damit aber zeigen sich die Wirkungsthesen zugleich als Folgeerscheinung der kontramodernen Grundstellung der Reformer. Sie sind gewissermaßen eine phänomenale Äußerung dieser Grundstellung auf der Theorieoberfläche.

\section{Die Sexualisienungsthese der Reformer}

Die Gestaltungsansprüche des Publikums verdeutlichen sich inhaltlich auf der Ebene des Ethos besonders in der Auseinandersetzung um Sexualität, eine Auseinandersetzung, die von Seiten der Kinoreformer mit dem Vorwurf der ,Sexualisierung' geführt wird. Auch diesem Vorwurf liegt das mimetische Wirkungskonzept zugrunde. Während die kriminelle Mimesis vor allem der männlichen Rezipientenschaft zuge-

${ }^{260}$ Hellwig, Schundfilms, 72; Hervorhebung von mir. 
schrieben wird, wird die sexuelle nun insbesondere der weiblichen unterstellt. Hellwig sieht in der Sexualisierung geradezu das geschlechtsspezifische Pendant zur Korruption des männlichen Publikums und spannt beide zugleich wieder in das Paradigma der ,Verrohungsthese' ein:

„Ein Äquivalent für die Verrohung, die meistens bei Knaben zu konstatieren sein wird, welche häufig Schundfilms sehen, ist die sittliche Laxheit, die meistens bei Mädchen auftreten wird, welche Stammgäste eines Kinos sind, in welchen Schundfilms oft vorgeführt werden. Während die Verrohung der Knaben naturgemäß besonders durch die geschmacklosen und die kriminellen Schundfilms bewirkt wird, tragen die sexuellen Schundfilms an der Entsittlichung der Mädchen die Schuld.“،261

Die Argumentationsfigur der ,moralischen Primitivierung' stellt so den Rahmen bereit, innerhalb dessen die Sexualisierung als eine der besonderen Ausfaltungen dieser grundsätzlichen, ethosbedrohenden Filmwirkung erscheint. Sie tritt zunächst als generelle ,Weckung' von ,geschlechtlicher Lüsternheit“"262 auf, die Hand in Hand mit einer ,Schwächung des Schamgefühls ${ }^{263}$ gehe. Die Folge sei dann, daß die in ihrer moralischen Widerstandskraft labilisierten Rezipienten (bzw. Rezipientinnen) ,zu leichten Opfern gewissenloser Verführer“264 gemacht würden und den „Lockungen des Wüstlings“2065 nichts mehr entgegenzusetzen hätten. Manche von ihnen freilich wollten dies auch gar nicht und benützten, nachdem sie vorher schon „durch schlechten Einfluß oder schlechte Lektüre verdorben (...) “266 worden seien, das Kino geradezu, „um sich an den lasziven Bildern zu reizen oder gar, um dort die Bekanntschaft eines Wüstlings zu machen“"267. Dasselbe erscheint so als Ort der sexuellen Begegnung, als Treffpunkt für ,unsittliche‘ Arrangements: „Vor dem Kinematographentheater' ${ }^{\prime 268}$, so malt Hellwig das Bild aus, warteten die Mädchen, und dort verkehrten auch ihre Verführer, um im Kino oder andernorts „mit oder ohne Zustimmung des Mädchens unsittliche Handlungen an ihm (vorzunehmen)“'269. Mit Sohnrey konstatiert er "das Zusammentreffen von lüsternen Unterhaltungsstoffen und dem dunklen Raum (des Kinos, T.H.) mit einem großen Teile lüsterner Menschen" und nennt „das heutige Kinematographentheater" eine „künstlich gehegte (...) und gepflegte (...) Brutstätte, von der aus das Laster seinen Anfang nimmt ${ }^{\star 270}$. Obgleich er

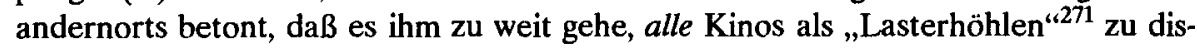

261 Hellwig,Schundfilms, 60
${ }^{262}$ Hellwig,Schundfilms, 60
263 Hellwig,Schundfilms, 61
264 Hellwig,Schundfilms, 61
265 Hellwig,Schundfilms, 61
266 Hellwig,Schundfilms, 61
267 Hellwig,Schundfilms, 61
${ }^{268}$ Hellwig,Schundfilms, 61
${ }^{269}$ Hellwig,Schundfilms, 61
${ }^{270}$ Sohnrey, Das dunkle

270 Sohnrey, Das dunkle Kinematographentheater, in: Volksbildung 1912, 64; zit. nach: Hellwig, Kind, 32

${ }^{271}$ Hellwig, Schundfilms, 63; Hellwig weist hier eine amerikanische Zeitungsnotiz zurück, die alle Kinos New Yorks „Lasterhöhlen“ nennt und meint, daß es doch auch dort „durchaus einwandfreie Vorstellungen" gebe, wie aus einer Notiz hervorgehe, „wonach freiwillige Zensoren (...) bei der Prüfung von 2900 Filmserien wenigstens 900 als vom erzieherischen Standpunkt aus vollkommen einwandfrei gefunden hätten" (ebd.). 
kriminieren, geraten damit doch die meisten von ihnen in den Geruch dezidiert unmoralischer Institutionen.

Aus diesem Ansatz, der die Wurzel des Übels in einer generellen Weckung von Lüsternheit sieht, die dann in entsprechende Verhaltensformen münde, wird dem Film vorgeworfen, $\mathrm{da} B$ er bestehende Sexualnormen zerstöre. Ex negativo werden dann diese Normen verdeutlicht: So gibt der Vorwurf, daß der Film den „außereheliche(n) Geschlechtsverkehr" begünstige, indem er ihn nicht als etwas „Verwerfliches“, sondern vielmehr „,beinahe Rühmenswertes“ darstelle ${ }^{272}$, zugleich den institutionellen Ort für die sexuelle Begegnung an. Sie hat ausschließlich Raum in der Ehe. Deren Gefährdung konstatieren Lange und andere auch in der filmischen Darstellung von Ehebrüchen, welche ,nicht als etwas Tadelnswertes“273 geschildert würden. Der "männliche oder weibliche Ehebrecher in der Mehrzahl der Stücke" gerate vielmehr zum eigentlichen Helden, ,während der Gatte (...) dem spöttischen Gelächter preisgegeben“ sei. ${ }^{274}$ Das wiederum ziehe mit Notwendigkeit ein ähnliches Verhalten des Publikums nach sich:

„Man braucht sich die Zahl der Ehebrüche, die solche kinematographischen Vorführungen verursacht haben, nicht vorzustellen, die Seitensprünge von Mann und Frau, die sich in kleinen Verhältnissen plötzlich am farbenreichen Leben der Kinoplutokratie und -gesellschaft berauschten, unzufrieden mit ihrem Dasein eben ein ,Corriger la vie‘ in irgend einer üblen Weise vorgenommen haben." “275

Unterstützt werde dieser normative Verfall durch die Häufigkeit und thematische Zentralstellung der entsprechenden Szenen und Geschichten. Da „die Sünde den Hauptinhalt" bilde, erscheine sie dem Publikum ,nicht als etwas Besonderes und Seltenes, das nur dieses eine Mal sich ereignet, sondern als etwas Gewöhnliches (...) worüber man sich nicht mehr aufzuregen braucht" ${ }^{4276}$. Während in der Kunst analoge Phänomene und Themen „etwas Individuelles, Persönliches, was für andere keine normative Gültigkeit" habe, seien, träten sie im Film als etwas „Typisches, Allgemeingültiges" vor Augen und sorgten so dafür, daß das Publikum "daraus die Lehre" entnehme: „Gehet hin und tuet desgleichen“. ${ }^{277}$ Auf diese Weise würden ,die heiligsten Gesetze der Ehe“, die immerhin ,das Fundament alles gedeihlichen menschlichen Daseins" sei, ,verhöhnt ${ }^{.278}$ Dabei gehe denn auch die Liebe verloren; an ihre Stelle trete „eine Häufung von leidenschaftlichen Liebkosungen und Küssen, ein leeres Getändel und Gespiel, das auf ernstere Naturen nur abstoßend wirken“279 könne. Den jungen Menschen werde „so die Anschauung eingeimpft, als wenn das Wesen der Liebe in der ungebändigten Leidenschaft liege ${ }^{\text {“280 }}$. Dafür brächte das Publikum freilich schon eine gewiße Bereitschaft mit. Der "großen Masse der Kinobesucher"

272 Hellwig, Schundfilms, 61

273 Hellwig, Schundfilms, 61

274 Hellwig, Schundfilms, 61

275 Spier, Ike, Die sexuellen Gefahren des Kinos, in: Neue Generation 1912, 192 - 198, zit. nach: Hellwig, Kind, 33

276 Lange, Kino, 27

27 Lange, Kino, 27

278 Lange, Kino, 16

279 Lange, Kino, 16

280 Lange, Kino, 16 
nämlich sei „natürlich nichts willkommener, als eine Schilderung, bei der sexuelle Vergehen als etwas Selbstverständliches und Gewöhnliches erscheinen“281, und „das junge Geschlecht" spiele geradezu „mit Unverstandensein“, wolle „flirten und sich ausleben, aber sich nicht binden und Treue halten “282 . An die Stelle des ,Zusammenhalten(s) der beiden Ehegatten in Freud und Leid, in Not und Tod, wie Kirche und Gesetz es fordern“ ${ }^{\prime 283}$ trete die ,ungehemmte Sinnlichkeit ${ }^{\text {“284. }}$.

Aus dieser Situation scheint dann der vollständige Verfall jeglicher Sexualethik geschlossen werden zu müssen. Lange bezeichnet „das sexuelle Kinodrama in unseren industriereichen Großstädten“ als „Vorschule der Verführung“ und „Schrittmacher der Prostitution“2285. Hebt die erste Formulierung auf den auch von Hellwig inkriminierten ,Tatbestand“ des Kinos als sexuellem Kontaktraum ab, so zielt die zweite auf die Beförderung der ,gewerblichen Verdinglichung' der Sexualität. Viele ,junge Mädchen" seien durch den Film erst damit bekannt gemacht worden, „was für Sünden es in der Welt gibt", und „mehr als ein junger Mann“ habe „erst durch ihn Kenntnis von den Stätten der Sündenlust bekommen, die ihm vorher ganz unbekannt waren “2866. Während Lange primär eine vermehrte ,Nutzung der Prostitution im Auge hat, sieht Dieckmann auch das ,Angebot' begünstigt: Nach dem „Anschauen solcher Filme in ihrer üppig verlockenden Ausstattung" nämlich hätten sich vermehrt „Mädchen der Großstadt (...) zum Eintritt in der Unsittlichkeit dienende öffentliche Häuser gemeldet ${ }^{\text {‘287. }}$. Der Film scheint damit für eine ethische Korruption des Publikums mit äußersten Konsequenzen zu sorgen. Nicht nur reizt er, diesem Bild zufolge, die Sinnlichkeit, nicht nur begünstigt er die Aufweichung der Sexualnormen, nein, er führt letztendlich durch die Bearbeitung sexueller Themen gar in den halbkriminellen Raum des Bordellwesens und kündigt so anscheinend jede Moralität auf.

Der Sexualisierungsvorwurf stellt in der vorliegenden Form einen Weg sich steigernden sittlichen Verfalls vor Augen. Er hat die Struktur eines Katastrophenarguments, in dem immer noch schlimmere Folgewirkungen ausgemalt werden, wenn den Anfängen nicht beizeiten gewehrt werde. Die bevorzugte Argumentationsfigur ist die der ,Kooperationsthese; d.h. die Annahme einer verstärkenden Interaktion der Filminhalte mit einer entsprechenden Latenz des Publikums. Letztes nämlich scheint geradezu auf die lasziven Inhalte ausgerichtet zu sein, wenn es heißt, ihm sei ,natürlich' nichts begrüßenswerter, als die Darstellung des ,Unsittlichen' als des Normalen. Es gilt als verderblich dazu disponiert, irrtümlich oder auch böswillig den Ehebrecher zu beklatschen, die Triebhaftigkeit zu begrüßen und dem, Wüstling zu verfallen. Daneben freilich wird auch die ,Nutzungsthese mit eingebracht und die mutwillige Hingabe an sinnliche Reizmöglichkeiten inkriminiert. Das Publikum scheint hier bewußt und absichtlich die sexuelle Stimulation durch den Film zu suchen und das Kino für

\footnotetext{
${ }^{281}$ Lange, Kino, 27

282 Lange, Kino, 16-17; Ähnlich Dieckmann, Kino, 13: „Selten begegnet man wahrer Liebe im Kino, um so häufiger der Verliebtheit, dem Leichtsinn, dem Laster!“"

283 Lange, Kino, 17

284 Lange, Kino, 16

285 Lange, Kino, 24

286 Lange, Kino, 32

${ }^{287}$ Dieckmann, Kino, 5
} 
entsprechende Kontakte zu benützen. Diese Nutzung kann dann mit dem Theorem von den ,bösen Instinkten' der Rezipientenschaft verbunden, und so der Kooperationsthese unterstellt werden. Sie kann auch zusammen mit der ,Verursachungsthese، auftreten, wie bei Hellwig, der zwar eine Nutzung von Film und Kino als Basis ,unsittlicher Arrangements' beschreibt, aber zugleich betont, da $B$ die Rezipienten bereits ,vorher verdorben' worden seien bzw. der Film in ihnen schon die üble ,Disposition gelegt' habe. ${ }^{288}$ Während in dieser Form wohl auf die ,Unschuld' der ,Mädchen abgehoben werden soll ${ }^{289}$ und daher besonders auf der Beeinflussung durch den Film (im Sinn einer exklusiven Verursacherrolle desselben) insistiert wird, zeigt sich an anderer Stelle, daß auch Hellwig die Vorstellung der unheiligen Allianz von Film und Publikum favorisiert, wenn er ein Zusammentreffen, lüsterner Menschen' mit ,lüsternen Unterhaltungsstoffen' konstatiert. - Von den drei Wirkungsthesen, die alle in den Argumentationen der Kinoreformer zur Sexualisierung auftauchen, stellt damit die Kooperationsthese, d.h. die Annahme einer perniziosen Entsprechung der Filminhalte und der Publikumsdisposition, deren Zusammenwirken erst die unheilvolle, dritte Qualität des Ethosverfalls mit sich bringe, die zentrale These dar.

\section{Zeitgenössischer Ethoswandel als phänomenale Basis des Sexualisierungsvorwurfs}

Im Hintergrund dessen steht wieder deutlich der anthropologische Pessimismus Conradt'scher Provenienz, der dem Menschen eine verderbliche Triebhaftigkeit und Affektivität anlastet. Wie bei diesem droht hier die Sittlichkeit durch eine ,ungehemmte Sinnlichkeit', d.h. durch eine reine Trieb- und Affektorientierung ersetzt zu werden. In die letzte hinein scheint sich auch die Liebe als Basis der sexuellen Begegnung aufzulösen. Insbesondere aber gelten die Institution der Ehe und die zugehörigen Sexualnormen, die die Sexualität ausschließlich in deren Rahmen als einzigen Ort für ihren, geregelten Vollzug verweisen, nun von einem sexuellen Wildwuchs und von Bindungslosigkeit bedroht. Das Kino als Ort der Kontaktnahme mit dem anderen Geschlecht und der Film als Promotor einer Hinwendung zur Sinnlichkeit werden daher mit einem Aufschrei des Entsetzens bedacht. Genau besehen aber zeigt sich in den inkriminierten Phänomenen ein anderes: In den 10er und 20er Jahren dieses Jahrhunderts setzen bereits ein Ethoswandel im Bereich der Sexualmoral

${ }^{288}$ vgl. Hellwig, Schundfilms, $61-63$

289 Hellwig wehrt sich an der in Frage stehenden Stelle gegen die Beobachtung des Rechtsanwalts Treitel, der darauf verweist, daß die ,Verführten' meist Mädchen seien, die zwar an den Kinos ihre Partner träfen, jedoch ohne die Filme zu besuchen. Zu vermuten wäre dann, daß das Kino zwar den Treffpunkt - aus noch näher zu untersuchenden Gründen - bildete, jedoch die ,Verführung' nicht auf die laszive Kraft des zuvor gesehenen Films zurückzuführen sei. Demgegenüber betont Hellwig, daß die ,sittlich verdorbene Haltung' der jeweiligen Mädchen auch auf früher gesehene Filme zurückgeführt werden könne, ja müsse: „Die sexuellen Schundfilms haben in dem Mädchen die Disposition gelegt, welche es den Verlockungen des Wüstlings leichter geneigt machte, darin ist der Kernpunkt des Problems zu suchen." (Hellwig, Schundfilms, 62-63) Die Vermutung legt sich nahe, daß es Hellwig dabei um das Bild der ,unschuldigen Mädchen' und ihrer ,Reinheit' geht. - Als verläßliche Deskription der historischen Realität können die Bemerkungen beider allerdings nicht gewertet werden. Festzuhalten bleibt aus ihnen lediglich, daß das Kino in einer erst noch zu eruierenden Form als Kontaktraum der Geschlechter genutzt wird. Wie dieser Kontakt sich gestaltet, darüber gibt die Studie Altenlohs Auskunft, welche ich weiter unten in der Analyse der Bedeutung der von den Reformern inkriminierten Phänomene heranziehen werde. 
und eine Neubewertung von Sexualität ein, die nach einer Phase der Behinderung durch den Nationalsozialismus und den Versuchen einer Moderatisierung in den 50er Jahren dann in den (späten) 60er Jahren breitenwirksam zur Durchsetzung gelangen ${ }^{290}$. Obgleich in den 60er Jahren erst von der ,Sexwelle' gesprochen, die Frage ,vorehelicher' Geschlechtsbeziehungen mit einer gewissen Offenheit ventiliert und über die Formen des Zusammenlebens von Mann und Frau diskutiert wird und der ProzeB seine Spiegelung, Begleitung und Beförderung in Presse und Film erfährt, gehen dem recht analoge Phänomene in den 10er und 20er Jahren voraus. Schon dort gibt es eine Welle von Aufklärungsfilmen (vgl. auch 1.5.), die sich um die Verbreitung von Information über Geschlechtskrankheiten und mögliche Vorbeugungsmaßnahmen, Empfängnisverhütung und das Thema der Homosexualität bemühen. Mag auch, wie in den 60er Jahren, ein gut Teil dieser Filme seine eigentliche Zugkraft aus einer voyeuristischen Aufbereitung gezogen haben, so ist doch nicht zu verkennen, daß darin zugleich eine gesellschaftliche Bearbeitung dieser Themen und ein diesbezüglicher sozialer Diskurs stattfinden. Sehr deutlich ist das im Fall der Diskussion um die Homosexualität, die zu dieser Zeit durch den Paragraphen 175 noch der strafrechtlichen Verfolgung unterliegt. Der Film dient hier nicht nur der Darstellung im Sinn der Information über diese sexuelle Prägung, auch nicht der abwertenden Verurteilung derselben, sondern in einer ganzen Reihe von Fällen gerade der Forderung nach Aufhebung der diesbezüglichen Strafgesetzbestimmung. So wird beispielsweise in dem Film: „Anders als die Andern“, welcher die Geschichte eines Homosexuellen erzählt, der erpreßt wird und schließlich vor Gericht gerät, die Kri-

${ }^{290}$ Zweifelsohne geht die sexuelle ,Liberalisierung', die besser als Erkenntnis der humanen Bedeutsamkeit der Sexualität, unabhängig von ihren reproduktiven Möglichkeiten und ihrer diesbezüglichen Einordnung in die Institution Ehe sowie ihrer Freisetzung in die sittliche Autonomie des Subjekts beschrieben wäre, auch durch die Zeit des Nationalsozialismus hindurch ihren Gang. Doch geschieht das mehr unter der Hand und weniger öffentlich: Die nationalsozialistische Erotik und ihr rassisch-reproduktionsorientiertes Mutterschaftsgebaren stellen den Autonomisierungsprozessen immer wieder die Kollektivierung und Heteronomie entgegen, so daß der faktisch weiterlaufende Prozeß sowohl gebremst und verdeckt als auch wohl immer weder zum rein ,sachhaft gebrauchenden' Zynismus, der eine eigenwerthafte Freisetzung von Sexualität mit ihrer Funktionalisierung verwechselt, verformt wird. - In den 50er Jahren wirkt sich der Import des französischen Existentialismus zwar fruchtbar auf die Tendenz zur ethischen Autonomisierung aus - betont doch gerade Sartre mit dem Begriff der ,Wahl' auch die Eigenverantwortlichkeit des Individuums für seine Lebensführung als einer Lebensgestaltung -, verbannt dieselbe aber zugleich als intellektuelle Modeerscheinung in den Raum der ,Avantgarde', d.h. einer ,Randgruppe‘. Die Wiederaufbauphase der werdenden Bundesrepublik zudem fordert stabile Institutionen und entsprechende familiale Verhältnisse, so daß der Slogan: „Keine Experimente" hier auch die Sexualethik zu einem gut Teil bestimmt. - Erst in den 60er Jahren vermag sich, nicht zuletzt durch die "Pille' ermöglicht (und in der Ausdrucksphäre vom Rock 'n Roll begleitet), die sexualethische Autonomisierung breitenwirksam zur Durchsetzung zu bringen. Lustvolle Gestaltung des, Sexuallebens' aus eigener ethischer Normfindung heraus und eine diesbezügliche öffentliche Diskussion bisheriger sexualethischer Maximen finden jetzt Eingang in Zeitschriften, Film und Fernsehen. Breitenwirksam wird die Autonomisierung nun nicht zuletzt dadurch, daß sie auch die Mittelschicht ergreift, die bislang im Gegensatz zur immer schon sexuell aktiveren Unterschicht stärker an institutionell geleiteter Heteronomie orientiert war. Während in der Studentenbewegung und ihrem Umfeld jetzt gerade Experimente durchgeführt werden, die für entsprechenden Diskussionsstoff sorgen, findet mit dem Mittelschichtspublikum der Kolle-Filme und ähnlicher Kristallisationsformen des sozialen Diskurses die eigentliche Durchsetzung eines autonomisierenden Ethoswandels statt. 
minalisierung dieser ,devianten' sexuellen Veranlagung als inhuman angegriffen ${ }^{291}$. Ergänzt wird die narrative Bearbeitung des Themas von einem Vortrag des Sanitätsrats Magnus Hirschfeld, der sich um ein wissenschaftliches wie auch ein soziales Verständnis der Homosexualität bemüht und sich für eine Änderung des Gesetzes engagiert. Dieser und ähnliche Filme sind damit nicht nur Ausdruck einer beginnenden ethischen Neubewertung von Homosexualität, sondern sie begreifen sich zugleich als Instrument der gesellschaftlichen Umsetzung dieser Neubewertung. Ähnlich verhält es sich im Fall diverser Filme über Geschlechtskrankheiten, wie des Mehrteilers „Es werde Licht“, der sich der Syphilis widmet. Neben dem Impetus des Films, diese Krankheit von ihrem Stigma zu befreien und nach rational-medizinischen Gesichtspunkten zu beurteilen, d.h. zu entdämonisieren und in der Folge den Betroffenen den Weg zum Arzt zu erleichtern, drückt sich in seiner Handlungskonstruktion auch eine moralische Umorientierung aus: Die Hauptfigur nämlich ist ein Vertreter eines letztlich viktorianischen Ethos, der die Syphillis nicht als zu bekämpfende Krankheit, sondern als „Schande“ empfindet, für deren Erwerb es „keine Entschuldigung“ gebe. ${ }^{292} \mathrm{Im}$ Verlauf des Films erliegt er dann jedoch den Versuchungen der Sinnlichkeit und steckt sich selbst an. Am Ende verändern sich sowohl seine Moral, die nun den ,vorehelichen Fehltritt' (Lange) nicht mehr einfach als einen solchen verurteilt, als auch seine Einschätzung der Krankheit, die nicht länger martialisch als verdiente Strafe für die Unmoral bemüht, sondern rationaler, wissenschaftlicher Einschätzung (und damit auch der Bekämpfung) zugänglich wird. - Diese filmischen Bearbeitungen und Auseinandersetzungen lassen so ein gewandeltes bzw. sich wandelndes Verständnis von Sexualität erkennbar werden. Der Triebcharakter der letzten wird hier nicht einfach negativ bewertet und mit kulturell-institutionellen Instrumenten zu bannen gesucht, sondern er darf zunächst einmal ins Bild kommen und als Realität Geltung beanspruchen. Damit eröffnet sich die Möglichkeit, nach Ethosformen zu fragen, die mit ihm konstruktiv kooperieren, anstatt ihn zu bekämpfen. Deutlich wird das etwa im ,Ethoswandel' der Hauptfigur des letztgenannten Films, die ihre alte Moral verläßt und um Verständnis für den Eigenwert der Sexualität wirbt. Obgleich der Film mit der Positivwertung sexueller Autonomie sicher noch nicht zu einer differenzierten autonomisierenden Sexualethik vordringt, eröffnet er so immerhin den Raum für eine ethische Fragestellung, die in diese Richtung zielt: Ansatzhaft tritt der Weg zu einer Sexualethik in Blick, mit der die Dichotomie von Natur und Kultur, welche nur die Alternative von Sieg oder Niederlage kennt, aufgekündigt und stattdessen eine Interaktion und Kooperation ermöglicht wird, die Kultur und Ethos im Rahmen naturaler Unbeliebigkeiten entstehen läßt und an die Stelle der Disziplinierung die Gestaltung setzt.

Dem geschilderten Impetus des Films korrespondiert auf der Ebene des Verhaltens des Publikums der von den Reformern inkriminierte ,freiere“ Umgang mit Sexualität. Begreift man das inhaltliche Geschehen der Filme insbesondere in der Zeit nach der Revolution von 1918 und der Aufhebung der Zensur als Ausdruck eines Ethoswandels und als Teil des gesellschaftlichen Diskurses darüber, so zeigt sich dieser Ethoswandel bereits vor der Revolution in den Veränderungen des zwischenge-

291 zum Inhalt vgl. Lange, Kino, 37

292 vgl. Inhaltsbeschreibung bei Lange, Kino, 33-35; Zitat hier: 33 
schlechtlichen Verhaltens in der Unterschicht und unteren Mittelschicht, die von den Reformern zwar pejorativ, jedoch bis zu einem gewissen Grad zutreffend beschrieben werden. In der Tat läßt sich beobachten, daß die sexuelle Begegnung nicht mehr einfach nur auf die Ehe beschränkt wird, und da $B$ dieses Verhalten, das freilich in der Unterschicht nicht ganz neu ist, jetzt aber mit Breitenwirksamkeit vom Geruch des Verbotenen, Unmoralischen und daher zu Verheimlichenden mehr und mehr befreit wird. Auch gerät die Kontaktnahme zwischen den Geschlechtern unverkrampfter und ,experimentierfreudiger'. Film und Kino nun spielen für den Wandel in der Bewertung von Sexualität und dem Umgang mit ihr eine nicht geringe Rolle. Dort nämlich verschafft sich das ,breite Publikum in den Städten sowohl Aufklärung über seine sexuellen Möglichkeiten wie auch Räume und Gelegenheiten zur Praxis. Die Studie Emilie Altenlohs, die als erste soziologisch-empirische Untersuchung über das Kinopublikum gelten kann, belegt diese Tatsache und macht den Zusammenhang mit dem Ethoswandel implizit deutlich: Schon bei den 15- und 16-Jährigen stellt sie fest, daß diese vorwiegend ,in Begleitung ,des Schatzes' oder der ,Liebsten““2933 ins Kino gingen, und daß das „Liebes- und Geschlechtsleben“'294 die „Richtung für die ganze Art des Lebens und für die Mittel, die als Unterhaltung geschätzt werden “295, angebe. In der Offenheit und Selbstverständlichkeit, mit der die von Altenloh Befragten darüber Auskunft geben, tritt der Aspekt einer Freisetzung von der Aura der Unschicklichkeit vor Augen: Das ,Liebes- und Geschlechtsleben' ist ,diskursfähig' geworden; man schämt sich seiner nicht mehr. Das spezifische Interesse an entsprechender Behandlung dieser Themen im Film wird ohne Scheu offengelegt. Die Auseinandersetzung mit Sexualität und Liebe ist es dabei, die für das Publikum im Mittelpunkt steht und das Movens für den Kinobesuch abgibt. Der Film dient dazu, sich emotional, empathisch und projektiv mit diesem Lebensbereich zu beschäftigen und in der Rezeption der diesbezüglichen imaginativen Angebote eine eigene imaginative und moralische Kreativität zu schulen und zu entfalten. Besonders bedeutsam ist dementsprechend die Möglichkeit, im Kino den Augen der sozialen Kontrolle zu entkommen und so Raum für eine selbstgeregelte Begegnung mit dem anderen Geschlecht zu gewinnen. Altenloh verweist darauf, daB aus diesem Grund ,für alle verliebten Paare (...) die dunklen Kinematographentheater ein beliebter Aufenthalt ${ }^{\text {‘296 }}$ sind; ihrer Untersuchung zufolge verhält sich das in allen Altersschichten gleich. Immer wieder finden sich in derselben Stellungnahmen der Befragten, die zeigen, da $B$ das Kino vor allem ,in Gesellschaft' und mit dem andersgeschlechtlichen Partner aufgesucht wird. Die Möglichkeit, zusammen mit dem oder der ,Liebsten' Formen der Beziehung eigenständig erproben und definieren zu können, hat offenbar vordringliche Bedeutung; die Selbstregelung steht im Mittelpunkt. Im Rücken einer noch weitgehend prüden, vom viktorianischen Ethos der konservativen ,Bildungsschicht' geprägten Gesellschaft, die mit dem Kuppeleiparagraphen sexuelle Autonomie unter Strafe stellt, gerät das Kino zur ,Zuflucht für die Liebenden“ (Kracauer) und zum Raum einer selbstgewählten Form zwischengeschlechtlicher Begegnung.

293 Altenloh, Soziologie, 66-67

294 Altenloh, Soziologie, 66

295 Altenloh, Soziologie, 66

296 Altenloh, Soziologie, 73 
Keineswegs aber trifft das Schreckensgemälde der Reformer von einer wüsten, exzessiven Promiskuität und dem bordellartigen Charaker der Kinos die historische Realität. Mag auch partiell das Kino Ort und Ausgangspunkt für promiskuöses Sexualverhalten gewesen sein, so läßt sich durchaus nicht belegen, daß damit der Habitus des breiten Publikums zutreffend beschrieben ist. ${ }^{297}$ Gerade die Studie Altenlohs zeigt, daß die Angehörigen der Unterschicht und unteren Mittelschicht auf feste Partnerbeziehungen abstellen ${ }^{298}$ und $\mathrm{da} ß$ sie ohnehin meist mit dem Partner das Kino aufsuchen. Sie läßt darüber hinaus vermuten, daß das Kino zwar als Ort des Kennenlernens genutzt wird, jedoch mehr in der Absicht, einen bleibenden Partner zu finden.

\section{Autonomisierung als eigentliches Skandalon der Sexualisierungsthese}

In der geschilderten Entwicklung tritt meines Erachtens daher eine Tendenz zur moralischen Autonomisienung, nicht aber ein Verfall der Sittlichkeit zutage. Die Selbstwahl der Begegnungsweisen enthält ein Moment der eigenverantwortlichen Norm- und Wertfindung, d.h. der moralischen Selbstbestimmung. In dieser scheint mir der zentrale Punkt des Ethoswandels im Bereich der Sexualität zu liegen. Es geht nicht so sehr um eine Auflösung der überkommenen Bindungsformen, auch sicherlich nicht um die Zerstörung der Liebe (die Untersuchung Altenlohs läßt im Gegenteil gerade erkennen, daB die Liebe nach wie vor Basis und Movens der Begegnung der Geschlechter ist) oder um sexuellen Wildwuchs. Sondern es geht in der skizzierten Entwicklung um die Etablierung einer subjektvermittelten (statt institutionell vorgegebenen) sittlichen Autonomie, die neben der, Gehorsamsverantwortung vor Normen' auch eine ,Gestaltungsverantwortung' (W. Korff) für dieselben kennt. Darauf richten sich sowohl das Verhalten des Publikums, das das Kino als Freiraum und den Film als Medium der Anregung, Auseinandersetzung und Information nutzt, wie auch das Engagement des Films, der mit seiner Themenwahl und -behandlung die überkommenen Wertstrukturen und Normkanones zum Gegenstand der Diskussion und damit wieder disponibel macht.

Dieser Ethoswandel und seine Autonomisierungstendenz nun sind es, gegen die sich der Kampf der Reformer mit Hilfe des Sexualisierungsvorwurfs eigentlich richtet. In ihrem Konzept ist schon von ihrem Grundparadigma her kein Platz für mora-

297 Äußerst übertrieben erscheint auch die reformerische Zeichnung eines Überbordens des Bordellwesens. Mag in Einzelfällen der Film einmal Anreiz zu einem Besuch dieser, Institution" gewesen sein, so bleibt es doch weiterhin ein in der gesellschaftlichen Realität randständiges Phänomen. Die Thematisierung desselben im Film fällt stets pejorativ aus und kann selbst eher als Hinweis auf das gewachsene Interesse an Sexualität und den Wunsch danach, diese aus dem verbotenen Bereich der Prostitution zu befreien, gelesen werden, denn als Förderung dieser sesuellen ,Verdinglichung'. Davon, daß sich Frauen in Scharen in Bordellen gemeldet hätten und dies auf entsprechende Werbewirkungen von Filmen zurückzuführen wäre, ist im übrigen nichts bekannt. Soweit Dieckmanns diesbezüglicher Schreckensruf auf Realität zurückgeht, wird es sich wohl um einen nicht generalisierbaren Einzelfall gehandelt haben.

${ }^{298}$ Altenloh macht das zwar nicht explizit. Auch ihre Untersuchung ist dort, wo sie wertende Stellung bezieht, von der zeitgenössischen Kinokritik beeinflußt und spricht etwa von der Kriminalisierung (Altenloh, Soziologie, 65), oder ciner ,sittliche(n) Gefährdung der Großstadtjugend" (Altenloh, Soziologie, 67). Das empirische Material jedoch, das sie gesammelt hat, bewahrt sie davor, auf die Linie der Reformer unvermittelt einzuschwenken und läßt insgesamt erkennen, daß es um das Ethos des Publikums durchaus nicht schlecht bestellt ist. 
lische Selbstbestimmung und Veränderung. Sittliche Autonomie nämlich ließe sich nur legitimieren, wenn jener Natur-Kultur-Gegensatz aufgehoben würde, der die Basis des anthropologischen Pessimismus (und damit auch des Publikumspessimismus) der Reformer bildet, und wenn solcherart gestattet wäre, eine ethische Potenz in der menschlichen Natur selbst anzunehmen. Das Konzept einer subjektvermittelten, autonomen Moral setzt eine Anthropologie voraus, in der der Bezug von Natur und Kultur als ,Verschränkung (W. Korff) gedacht ist, d.h. als ein Ineinander, aus dem sich das ,Wesen' des Menschen erst konstituiert. Die sittliche Verfaßtheit dieses Menschenwesens kann dann als konnaturale gedacht werden. Damit bleiben die Engführungen sowohl einer Sein-Sollens-Identität (welche aus einer wie auch immer bestimmten ,Natur' das ethisch Gebotene unvermittelt deduziert) als auch einer Sein-Sollens-Dichotomie (die das ethisch Gebotene der Natur herrscherlich entgegensetzt) vermieden. Gerade der zweiten Engführung aber unterliegen die Kinoreformer. Der Autonomisierungsprozeß, der sich im Wandel des Sexualethos äußert, kann ihnen daher nur bedrohlich erscheinen: Solange die Sittlichkeit ein kulturelles Konstrukt contra naturam bleibt, die jene Natur von außen erst mühsam bändigen und in heteronome Gehege bannen muß, kann von innen - und das heißt: aus einer Selbstgesetzgebung - nichts Gutes kommen. Die Suchwege des Arbeiters und seines ,Schatzes' nach eigenen, ihnen gemäßen Formen der Begegnung erscheinen dann als ,Spielen mit Unverstandensein', die Kontaktnahme der jungen Leute gilt als, flirten und sich ausleben wollen' und die Nutzung des Kinos als Treffpunkt macht dieses zur ,Stätte des Lasters'. Der anthropologische Pessimismus, der den Menschen als triebund affektgesteuertes Latenzwesen mit einem endogenen Gefälle zur Unmoral mißdeutet, muß die Dynamik des Ethoswandels in jedem Fall als ethische Korruption interpretieren und ihren eigentlichen Gehalt verfehlen.

Mit seiner Wende gegen die Autonomisierung erweist der Sexualisierungsvorwurf nun zugleich die Grundrichtung des kinoreformerischen Theoriekonzepts erneut und besonders deutlich als kontramoderne. Ein kontramoderner Impetus des reformerischen Konzepts ist bereits in der schichtspezifischen Dichotomie, in der Wende gegen die moderne Kunst und in der anthropologisch verankerten Kulturkritik an der Stadtkultur deutlich geworden. Dabei zeigte sich zunächst aus einem rekonstruktiven Blickwinkel, daß die schichtspezifische Dichotomie letztlich sich gegen die Mitspracherechte der Massen in Sachen Kulturgüter (hier des Films) wandte und damit den Mitgliedern dieser Massen den Subjektstatus absprach. In der Wende insbesondere gegen die Stadtkultur äußerte sich die kontramoderne Position der Reformer in Form einer anthropologisch fixierten Kulturkritik, die in der angenommenen negativen Latenzbasis des Menschen den Grund für die Gefährlichkeit moderner Kulturerscheinungen (die als zivilisatorische von einer ,guten' traditionalen Kultur unterschieden wurden) ausmacht. Problematisch scheint aus rekonstruktiver Perspektive die Moderne hier, weil ihre technisch bereitgestellten Massenkulturerzeugnisse und die subkulturellen Lebensformen in den großen Städten die mühsam eingehegte Latenzbasis wieder zu aktivieren schienen. In der Struktur und im Kontext des Sexualisierungsvorwurfs wird nun deutlich, da $B$ die Latenzbasis es auch verbietet, den Massen individuelle Selbstbestimmung, d.h. Autonomie zuzugestehen. Die Vorenthaltung des Subjektstatus findet auf diese Weise jetzt ihre reflexive Begründung: Nicht nur wären die Mitglieder der Massen zur Mitbestimmung in Sachen Kultur nicht fä- 
hig, sie würden zudem, so man ihnen gar auch noch außerhalb der Frage der Rezeption von Kulturgütern Selbstbestimmungsrechte einräumte, in sittliche Devianzen abrutschen. Mit dieser dem Sexualisierungsvorwurf inhärenten Denkfigur aber greifen die Reformer nun unübersehbar ein Zentrum des Projekts der Moderne an, nämlich die auf der Basis der Vernunftbegabtheit des Menschen eingeführte Subjektautonomie. Diese nämlich ist es, die sich hier als sittliche Autonomie auslegt und derart gewissermaßen im ethischen Bereich Gestalt gewinnt. Damit aber erweist sich das kinoreformerische Theoriekonzept als implizit gegen eine der zentralen "Ideen der Moderne und ihrer Aspirationen gerichtet, d.h. als deutlich kontramoderner Entwurf. Obschon diese Kontramodernität bei den Reformern nicht mit einer expliziten Zielrichtung auf das Projekt der Moderne in seiner Genese und Gesamtheit bzw. (noch) nicht in unmittelbarer Auseinandersetzung mit seiner Ideengeschichte und philosophisch-kulturgeschichtlichen Verankerung vorgebracht wird, liefert sie außerdem mit ihrer anthropologischen Fundierung und ihrer ethisch angelegten Gegnerschaft zur Moderne bereits zentrale Theoriestücke des systematisch weiter ausgreifenden kontramodernen Entwurfs der Filmerziehung (vgl. 4.4.). Die Reformer präformieren derart in Teilstücken eine Kontramodernität, die den medienethischen Diskurs weit über ihre eigene Epoche hinaus prägt.

Jedoch auch reformimmanent hat die kontramoderne Fixierung noch weitere Folgen. Durch ihre anthropologisch fundierte Feindschaft gegenüber einer autonomen Moral und einem hierdurch dynamisierten Ethos vermag ein Fortschritt in Sachen Sittlichkeit nicht mehr gedacht zu werden. Allenfalls ein Fortschritt in der Sicherung der Moralität ist vorstellbar, der wiederum nur als Verstärkung der Barrieren gegen die negativisierten Latenzen des Menschen möglich scheint. Das aber bedeutet, daß neben heteronom bleibenden Normgefügen insbesondere die Statik unantastbarer Institutionen gegen alle sittliche Veränderung zu setzen ist, d.h. daß die Bewahrethik der Kinoreformer zusammen mit ihrem kontramodernen auch einen institutionskonservativen Charakter erhält. Der letztgenannte ergänzt sich dabei mit einem strukturautoritären Zug, welcher unten anläßlich des Destabilisierungsvorwurfs noch deutlicher vor Augen treten und in den Lösungsvorschlägen der Reformer gänzlich offenbar werden wird. Die Institutionskonservativität nun hat beispielsweise zur Folge, daß sich die Leitidee der Institution Ehe, die für die Reproduktion der Gesellschaft zu sorgen und durch Eingrenzung der urtümlich naturalen Triebkraft der Sexualität das ,Fundament alles gedeihlichen menschlichen Daseins zu bilden hat, keinesfalls verändern darf. Auch ihre weitere normative Ausfüllung, zumindest was die zentralen Verhaltenskodices für die Partner betrifft, hat möglichst gleichzubleiben. Schon eine Veränderung der Stellung der Frau zu den Kindern oder zum Berufsleben wäre in diesem Entwurf wohl problematisch. Für die Wahrung und Erhaltung der Institutionen aber haben gesellschaftliche, staatliche und kirchliche Instanzen zu sorgen. So werden etwa ,Kirche und Gesetz' als zuständige Garanten für die ,Heiligkeit der Ehe' bemüht und wird diesen die entsprechende, normgebende Funktion zugeschrieben. Damit verbindet sich die Institutionskonservativität bereits mit einem strukturautoritären Moment. Ihm gegenüber bleibt ein Mitspracherecht der Gesellschaftsmitglieder weitgehend ausgeklammert: Sie erscheinen hauptsächlich als Adressaten für die erlassenen moralischen Vorschriften, nicht aber als Diskurspartner, deren ,fakisch gelebte Überzeugung (W. Korff) sich auf die Ebene der 
Instanzen und Institutionen transponieren und in einen Institutionswandel umsetzen ließe. Die Bewegungsräume für das Glücksstreben des Menschen sind solcherart klar definiert. Die Definitionsmacht wird übergreifenden autoritativen Instanzen in die Hand gegeben und eine Flexibilität des Gesamt theoretisch und strukturell-praktisch möglichst ausgeschaltet. Jeder Schritt aus dem starren Gefüge hinaus bleibt untersagt, denn er scheint das ganze Gefüge in Frage zu stellen.

Deutet sich auf diese Weise im Sexualisierungsvorwurf auch der strukturautoritäre Zug der Kinoreformer an, so zeigt sich in ihm außerdem zugleich schon jene Befürchtung einer sozialen Destabilisierung, die dann als expliziter Vorwurf gegen die Behandlung gesellschaftlicher Themen in Filmen und die Nutzung sozialer Gegensätze als Folie und Hintergrund für entsprechende Handlungskonstruktionen vorgebracht werden wird. Als Angst vor den städtischen Massen, wie sie sich im breiten Publikum der Kinos repräsentieren, war jene Befürchtung bereits in der zweiten Form des Kriminalisierungsvorwurfs spürbar. Dort freilich mußte, um diese Angst inhaltlich entschlüsseln zu können, über den Vorwurf hinaus auf die historische Situation der Erweiterung der Öffentlichkeit zurückgegriffen werden. Im Sexualisierungsvorwurf nun erfährt diese Angst eine erste Richtungsgebung und Konkretion: Gefürchtet werden Autonomisierung und Ethoswandel nicht nur, weil darin die Auflösung der individuellen Sittlichkeit zu drohen scheint, sondern eben auch, weil sich darin ein möglicher institutioneller Gestaltungsanspruch des Publikums ankündigt und die Autonomie über den privaten Raum hinaus auf die Strukturen, d.h. aber: die Gesellschaft, überspringen könnte. Die Inkriminierung der ,Ehebruchsgeschichten' durch die Reformer zielt derart nicht nur auf die Gefahr einer Mimesis in einem ,Seitensprung, sondern auf die Gefährdung der Institution Ehe und das allgemeine Entstehen eines Unzufriedenheitspotentials. Jenseits der Aufkündigung der Treue zugunsten egozentrischer Libertinage, d.h. eines Sittenverfalls, scheinen soziale Spannungen und die Störung des gesellschaftlichen ,Gleichgewichts von den genannten Filmen und den Publikumsreaktionen indiziert. Nicht nur die Suche nach eigenen, möglicherweise erfüllenderen Formen des ,Beziehungslebens' nämlich gilt als problematisch, auch der Blick auf Darstellungen von Ausbruchsversuchen aus dem Herkömmlichen wird als grundsätzlich destabilisierend und destruktiv gewertet. Letzte könnten schließlich als Chiffre unvollständigen Lebens und Ausdruck des Glücksstrebens begriffen werden und so eine ,sozialgefährliche' Wunschproduktion einleiten. Gerade die Angehörigen der unteren Schichten, die sich , am Leben der Kinoplutokratie berauschten', könnten beginnen, ihre ,kleinen Verhältnisse' mit jenen der oberen Schichten zu vergleichen und dann eben nicht nur ein ,Corriger la

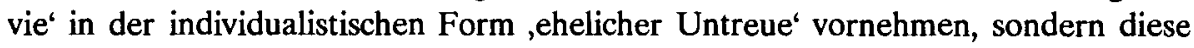
Korrektur auf gesellschaftlich-politischer Ebene fordern, und sei es nur als Mitspracherecht im öffentlichen Diskurs. Derartige Ansinnen aber bedeuten einen Angriff auf das Gesellschaftskonzept der Kinoreformer, wie es im letzten ihrer Vorwürfe zum Ausdruck kommt. 


\subsection{Devianzvorwürfe III: Soziale Destabilisierung. Bewahrethische Hegemonie und strukturautoritäres Gesellschaftskonzept}

Bereits die Rekonstruktion des sozialethischen Grundsatzpostulats, das ich aus der der Langeschen Ästhetik und ihrer Anwendung auf die Massenkommunikation und die Erzeugnisse der Gebrauchskultur erarbeitet habe, hat deutlich gemacht, daB sich die kinoreformerische Bewahrethik gegen jede Störung der gesellschaftlichen Stabilitäten richtet. An Hand der Devianzvorwürfe ließ sich dann spezifizieren, aus welchen anthropologischen Grundannahmen diese Bewahrethik sich speist und wie sich ihre Dichotomien und Antagonismen schichtspezifisch umsetzen. Der letzte der reformerischen Devianzvorwürfe nun sieht durch den Film eine soziale Destabilisierung initiiert und wendet so das Grundsatzpostulat explizit in einen Angriff gegen das mißliebige Medium um. Die Forderungen des ästhetischen Paradigmas, die Konsequenzen des anthropologischen Pessimismus und die schichtspezifische Dichotomie konvergieren in ihm und lassen zugleich die Öffentlichkeitsvorstellung und das Gesellschaftskonzept der Reformer offenbar werden.

\section{Der Destabilisierungsvorwurf der Reformer}

Die generelle und bevorzugte Formulierung des Vorwurfs ist zunächst die, daß der Film eine „Verhetzung der Stände gegeneinander“299 betreibe. Es wird ihm angelastet, daß er den sozialen Frieden gefährde, indem er schichtspezifische Gegensätze darstellt und thematisiert. Problematisiert wird bereits die Tatsache an sich, daß „die Fabel gewöhnlich in zwei einander entgegengesetzten Gesellschaftskreisen ${ }^{\text {*300 }}$ spiele, d.h. schichtspezifische Unterschiede als Antagonismen überhaupt ins Bild kommen:

„Arm und reich, Vorderhaus und Hinterhaus, $S$ chloß und Hütte, so könnte man diesen Gegensatz mit zwei Schlagworten kennzeichnen. Auf der einen Seite werden uns die Schlösser und Parks des Adels, die reichen Villen der durch Handel und Industrie emporgekommenen Finanzbarone vorgeführt, auf der anderen zeigt man uns die ärmlichen Kellerwohnungen und Dachkammern der Industriearbeiter, die Höfe und Ställe der Bauern. “301

Lange sieht die Kontrastierung dieser beiden ,Welten' zwar noch nicht politisch motiviert, sondern führt sie auf die ästhetischen Bedingungen des Films als einer wortlosen, auf „Effekt“ angewiesenen Darstellungsform zurück: Um faßbare Bilder zu erzeugen, bliebe demselben nichts anderes übrig, als mit Typisierungen und Dichotomien zu operieren. In seiner Genese, d.h. als formales Erfordernis des Films, brauche der Kontrast daher „noch keinen politischen Nebensinn zu haben“" ${ }^{\text {302 }}$. Auch sei nicht anzunehmen, daß die „Absicht (der) Kinodichter auf politische Verhetzung ${ }^{\text {‘303 }}$ gehe. Doch scheint die Nutzung der sozialen Verhältnisse als inhaltliche Füllung des formalen Kontrasterfordernisses unausweichlich eine entsprechende Wirkung nach sich ziehen, d.h. mit Notwendigkeit zur ,Verschärfung der Gegensätze

${ }^{299}$ Lange, Kino, 46; im Original gesperrt.

300 Lange, Kino, 46; im Original partiell gesperrt.

301 Lange, Kino, 46

302 Lange, Kino, 47

303 Lange, Kino, 48 
in der Realität führen zu müssen ${ }^{304}$. Die typisierende Gegenüberstellung von Arm und Reich, von Hinterhof und Palast an sich droht für Lange und andere schon einen ,sozialen Mißmut' zu befördern, der zur Disharmonie der ,Stände' und gesellschaftlichem Unfrieden führen könnte. Wo dauernd mit dem „Gegensatz Arm und Reich, Gut und Schlecht ${ }^{\star 305}$ gearbeitet werde, gehe dem Publikum ,jeder ruhige und klare Wirklichkeitssinn ${ }^{306}$ verloren und entstehe „ein ganz irriges und phantastisches Weltbild“'307. Die ,realitätsfremde‘ Schilderung der Reichen als Menschen, die ständig damit beschäftigt seien, „Sekt (zu) trinken, auf die Jagd (zu) gehen und Auto (zu) fahren, (...) Hasard (zu ) spielen, den Frauen anderer die Cour (zu) schneiden und sich von zahlreichen Domestiken bedienen (zu) lassen ${ }^{\text {‘308 }}$, bringe ein Bild hervor, das für soziales Unbehagen sorge. Zurückgekehrt „aus der Kino-Traumwelt mit der schwülen Salonluft (...) in ihre nüchterne Werkstätte und ihren Fabriksaal" müßten „Unzufriedenheit und Mißgunst“ die ,Seelen' der Zuschauer erfüllen. ${ }^{309}$

Verstärkt sehen die Reformer diese Gefahr durch die Darstellungstendenz: Stets nämlich träten die ,Reichen' als moralisch minderwertige Subjekte, die Armen als integre und unterdrückte auf. So werde gezeigt, daß die ersten „ihre Frauen nicht (lieben), denn sie haben nach Geld geheiratet“ ${ }^{\text {(310 }}$, da 3 sie „im Streit mit ihren Kindern““311 lebten, welche „ihre eigenen Wege gehen und schlimme Streiche ausführen $^{\text {‘312 }}$, daß die Töchter ,herumpoussierten', während die Söhne ,Schulden machten ${ }^{\text {‘ }}$ und „den Wucherern in die Hände ${ }^{\text {‘313 }}$ fielen, „bis der große Krach kommt und sie sich in der Verzweiflung eine Kugel vor den Kopf schießen"،314. Die zweiten aber würden stets als „brave und fleißige Leute geschildert", die es „herzlich schlecht" hätten, ,ausgebeutet“ würden und deren Lohn zu niedrig sei, während die Arbeit ,zu anstrengend“ und die „Wohnverhältnisse ungenügend“ seien. ${ }^{315}$ Besonders ärgerlich ist den Kinoreformern in diesem Kontext, daß es nicht nur die ,Reichen' sind, deren Charakerisierung so eminent moralisch negativ ausfällt, sondern daß auch die ,Gebildeten' entsprechend gezeichnet werden: Während bei den einen so die positive Arbeit für eine Verbesserung der sozialen Verhältnisse verdeckt und unglaubwürdig gemacht werde, ${ }^{316}$ entstünde von den anderen, die in den reformerischen Texten oft
304 vgl. Lange, Kino, 48
305 Lange, Kino, 48
306 Sellmann, Volkserzieher, 27
307 Sellmann, Volkserzieher, 27
308 Lange, Kino, 47
309 Sellmann, Volkserzieher, 27
310 Lange, Kino, 48
311 Lange, Kino, 48
312 Lange, Kino, 48
313 Lange, Kino, 48
314 Lange, Kino, 48
315 Lange, Kino, 47-48
316 vgl. Lange, Kino, 48-49: Zunächst beklagt er, daß sich in den Filmen ,immer (...) die Stände feindlich gegenüber" stünden, und der „Zuschauer nur die schlechten Seiten der ande- ren kennen(-lerne), da das Schlechte viel interessanter ist als das Gute“, um dann die Wohl- tätigkeit der ,Reichen“ zu insistieren und auszurufen: „Wie viele Großindustrielle und Fabri- kanten opfern Hunderttausende, um den Arbeitern eine gute Wohngelegenheit und Erho- lungsmöglichkeit zu bieten, wie sorgfältig ist bei uns die Arbeiterversicherung ausgebildet, wie zahlreich sind die Wohltätigkeitseinrichtungen und Volksbildungsvereine, nicht erst seit der Re- volution, sondern schon seit Jahrzehnten gewesen! Alles das sind Dinge, die für den Kinodichter 
als eigenständige Schicht von den ,Reichen' unterschieden, wenn auch als gesellschaftlich kongenial gehandhabt werden, ein schlicht diskriminierendes Bild. Vor allem jugendliche Filmrezipienten bekämen aus den Filmen leicht „die Vorstellung (...), als ob unsittliche Handlungen, Verführungsszenen, Feindschaft zwischen den Eheleuten, gegenseitiges Anlügen, Betrug, Scheidung und Ehebruch in den Familien der Gebildeten nur so an der Tagesordnung wären“3177. Ein solches Bild aber droht den Reformern die Autorität der ,Bildungsführer', zu denen sie sich rechnen, und ihren erzieherischen Impetus zu untergraben. Die volksbildnerischen Bestrebungen der ,Gebildeten', die immer auch Vorstellungen vom ,richtigen Leben'vermitteln wollen und mit moralischer Valenz ausgestattet sind, scheinen so in Gefahr zu geraten, unglaubwürdig zu werden.

Wird dem Film hier angelastet, daß er eine Diskreditierung der ,Reichen und Gebildeten' verursache, indem er sie als moralisch korrumpierte Schichten darstelle, so wird ihm in einem weiteren Schritt vorgeworfen, insbesondere den ,Reichen' auch noch die Schuld an den gesellschaftlichen Ungleichheiten zuzuschieben. Stets nämlich träten die ,Wohlhabenden und Besitzenden' als jene Ausbeuter auf, „die die Armen unterdrücken, ihnen das allgemeine Wahlrecht nicht gönnen, ihnen jede höhere Bildung vorenthalten, damit sie ihnen, den Herren, nicht über den Kopf wachsen “318. Thre Charakteristik wäre demzufolge nicht nur die einer sittlich verderbten, sondern geradezu sittlich bösen Schicht, auf deren Verhalten alle soziale Ungerechtigkeit zurückzuführen ist. Demgegenüber betont Lange, daB die soziale Problematik, genauer: „das Elend, das ja niemand leugnet, “319 die „einfache Folge der Industrialisierung unserer ganzen Wirtschaft, der kapitalistischen Gesellschaftsordnung, der Maschinenarbeit usw.“320 und mithin auf „Verhältnisse“ zurückzuführen sei, ,deren Schuld man nicht einzelnen aufbürden“ "könne. ${ }^{321}$ Der Film aber betreibe, weil zu „,ausführliche(m) Gedankenausdruck (...) ${ }^{\text {‘322 }}$ durch das Fehlen des Worts unfähig, eine Personalisierung dieser Probleme und so eine Verfälschung der komplexen Wirklichkeit.

Aus dieser Verfälschung, die von den kontrastiven Charakteristiken sowie dem moralischen Negativbild der ,Reichen und Gebildeten` und ihrer Handlungsweisen verursacht werde, sehen die Reformer vor allem beim jungen Publikum den Eindruck einer in ethischer Hinsicht verdorbenen Welt quellen, was in staatsgefährdende Pessimismen führen könne. Die Dramatik von „Elend und Not, Armut und Krankheit, Verzweiflung und Selbstmord““323 sorgten ,im Herzen des Kindes (für)

nicht existieren.“ Ähnlich bei Dieckmann, Kino, 12, die sich gegen das Bild müßiggängerischen und sozial parasitären Lebens der ,Reichen' wendet: „Die Leute aus einfachem Stande können durch häufigen Kinobesuch leicht zu der Meinung kommen, daß vermögende Kreise nichts weiter tun, als Sekt trinken, Zigaretten rauchen, Auto fahren und Liebschaften haben. Und doch ist in diesen Kreisen ernste, aufopfernde Arbeit ebensogut zuhause wie schlichte, gesunde Lebensführung."

${ }^{317}$ Lange, Kinematograph, 25

318 Lange, Kino, 48

319 Lange, Kino, 49

320 Lange, Kino, 49

321 Lange, Kino, 49

${ }_{322}^{32}$ Lange, Kino, 49

${ }^{323}$ Gaupp, Kinematograph, 10 
quälende Gedanken über die Ungerechtigkeit der Welt ${ }^{، 324}$. Wenn gezeigt werde, „wie der Arme, wenn er stiehlt, mit rauher Hand in den Kerker geworfen wird, während der Reiche, wenn er dasselbe tut, rücksichtsvoll behandelt wird und alles mit Geld glatt erledigt“325, so werde „das Vertrauen auf Recht und staatliche Ordnung (...) erschüttert ${ }^{\star 326}$. Derartige Filme werden daher von den Reformern mit einem Aufschrei des Entsetzens und der Empörung bedacht: Sie seien „keine Kunst mehr“, sondern ,platte Volksvergiftung mit faustdicken, unverschämten Lügen“327. Ihre Wirkung erscheint umso bedrohlicher, wenn, wie bei Schultze, ohnehin eine enorme „Verworrenheit der Vorstellungen großer Teile unseres Volkes auch in staatlichen Dingen “328 anzunehmen zu sein scheint. Der Film gerät dann zum Störfaktor für die Stabilität der gesellschaftlichen und politischen Verhältnisse, der deren Zerstörung zu evozieren droht.

Der Vorwurf der sozialen Destabilisierung setzt sich so aus vier Teilvorwürfen zusammen, die sich zusammenfassend wie folgt charakterisieren lassen: Zunächst wird befürchtet, daß die Darstellung schichtspezifischer Unterschiede und Gegensätze an sich schon eine Wirkung erzeugen könne, die den sozialen Frieden gefährdet. Bedenklich erscheint dabei vor allem die Zeichnung der Welt des Reichtums als einer Sphäre des Müßiggangs und des Luxus, die Neid und Mißgunst sowie Unzufriedenheit mit der eigenen Lage hervorufen könne. Der Film wäre hier gewissermaßen eine unwillkommene hermeneutische Brücke für die gesellschaftliche Wunschproduktion seines Publikums. In einem zweiten Schritt wird dem Film dann angelastet, $\mathrm{da} ß$ er eine schichtspezifische Diskriminierung vornähme, indem er die ,Reichen und Gebildeten' als sittlich verdorbene soziale Gruppen vorführe. Gilt dies als ärgerlich, weil dadurch zusammen mit der moralischen Integrität der Bildungsführer auch deren moralische Autorität in Frage gestellt scheint, so wird in einem dritten Schritt inkriminiert, daß der Film seine Charakterisierung der genannten Schichten zu einer mehr oder weniger kämpferisch auftretenden Gesellschaftskritik weiterführe, die an das Paradigma des Klassenkampfs erinnert. Pejorativ gewertet wird von Seiten der Reformer jedoch weniger dieses Paradigma, sondern hauptsächlich die individualisierende und personalisierende Schuldzuweisung durch den Film, während die Existenz sozialer Ungerechtigkeit(en) zwar anerkannt, aber den ,Verhältnissen' zugelastet wird. In einem vierten Schritt schließlich wird dem Film vorgeworfen, daß er beim Publikum die Vorstellung einer ethisch zutiefst korrumpierten, Welt', näherhin aber einer korrupten Gesellschaft erzeuge, und so in einen Pessimismus führe, der das Vertrauen in Recht und Ordnung in staatsgefährdender Weise erschüttere.

${ }^{324}$ Gaupp, Kinematograph, 10

325 Gaupp, Kinematograph, 10

${ }^{326}$ Gaupp, Kinematograph, 10

327 Schultze, Bildungsmittel, 43; ebenso Hellwig, Schundfilms, 37

${ }^{328}$ Schultze, Bildungsmittel, 130; Schultze bringt das an dieser Stelle nicht mit einer Negativwirkung sozial-thematischer Filme in Zusammenhang, sondern spricht einen generellen Publikumspessimismus aus, auf dessen Hintergrund er einen umfassend, volksbildenden' Einsatz des Films fordert. Das Theorem von der, Verhetzung der Stände' taucht jedoch auch bei ihm auf: vgl. ebd. 43. 


\section{Kontrast: Die zeitgenössische filmgeschichtliche Situation}

Um den Vorwurf nun angemessen beurteilen zu können, tut es not, sich der realen historischen Situation zu versichern, d.h. zu untersuchen, wie die Filme beschaffen sind, denen dieser Vorwurf gemacht wird, und welche Interaktionsformen mit dem Publikum angenommen werden können. Der Blick auf die Filme erscheint um so dringlicher, als die Reformer zumeist nicht aus eigener Anschauung ihre Wertungen und Wirkungsspekulationen unternehmen, sondern von Inhaltsskizzen der Programmankündigungen und aus Titelformulierungen ihre Stellungnahmen deduzieren. Dabei steht die Leitperspektive der Destabilisierung - insbesondere dort, wo sie keine genaueren Inhaltsangaben machen, sondern generalisierende Charakterisierungen vornehmen (etwa in Bezug auf die Darstellung der ,Reichen' und der ,Armen') - in einer Weise im Vordergrund, die die Realität eher verdeckt als enthüllt. Auf ihre Darstellung der Situation ist daher nur bedingt Verlaß. Der Blick auf die seither geleistete Filmgeschichtsschreibung ist für eine Korrektur und die adäquate Analyse des reformerischen Vorwurfs deshalb nicht nur hilfreich, sondern unverzichtbar. ${ }^{329}$

Die Filme, gegen die sich der Destabilisierungsvorwurf richtet, können zunächst in verschiedene Genres aufgeschlüsselt werden. Damit lassen sich aber auch unterschiedliche Darstellungsweisen und entsprechende Interaktionsformen mit dem Publikum unterscheiden. So stehen neben satirisch-humoristischen Produktionen Melodramen und Salonstücke sowie gesellschaftskritische Filme, wobei die letzten zum größten Teil eine Unterabteilung der Melodramen und Salonstücke darstellen. Das stärkere Gewicht jedoch, das sie auf einen kritischen Impetus legen, erlaubt es, sie als eigenes Genre zu führen. Melodramen und Salonstücke wiederum lassen sich kaum voneinander sondern; nur wenige Salonstücke, wie etwa einige von Stiller, sind nicht zugleich Melodramen. Zusammengefaßt werden sie alle, obwohl es sich bei ihnen um verschiedene Genres handelt, meist unter der Bezeichnung, soziale Dra$m^{2} n^{330}$. Die Bevorzugung dieses Titels in den kinoreformerischen Texten, der dann

${ }^{329}$ Die historiographische Materiallage freilich ist hier auch in der Gegenwart noch mit gewissen Verdunklungen behaftet: So interessieren sich die ,großen' Filmgeschichtsschreiber, wie Sadoul und Gregor/Patalas, die allesamt ein etwas elitäres Verständnis von Film als Kunst aufweisen, meist wenig für die ,trivialen' Filme dieser Zeit. Zwar sind etliche dieser Filme erfreulicherweise in Filmmuseen und Archiven erhalten, doch werden sie oft nur soweit filmgeschichtlich behandelt, wie sie für die entsprechenden ästhetischen Konzepte der genannten Autoren von Belang sind. Da Gregor/Patalas und Sadoul aber trotz ihrer ästhetizistischen Engführungstendenz zumindest sekundär die Wichtigkeit des sozialgeschichtlichen und gesellschaftstheoretischen Aspekts der ,Filmkunst' betonen, können ihre Filmgeschichten verwendet werden; ihr anders gelagerter Blickwinkel mag dabei als Korrektiv für die nicht weniger enggeführten Auslassungen der Reformer gelten. Toeplitz widmet den gesellschaftshistorischen Bezügen mehr Aufmerksamkeit und betont als marxistisch orientierter Filmhistoriker besonders die ökonomische Komponente. Auch er allerdings ist von ästhetizistischen Vorstellungen nicht frei und vernachlässigt den ,trivialen' Bereich in vielerlei Hinsicht. - Insgesamt wird die folgende Skizze so zwar keine vollständige Darstellung ergeben, immerhin jedoch ein zutreffenderes Bild der inkriminierten Phänomene ermöglichen, als dies bei alleiniger Verwendung der reformerischen Charakteristiken der Fall wäre.

${ }^{330}$ Daneben tritt für die humoristischen Filme auch noch die Bezeichnung ,humoristische Dramen' auf, die als Genrekategorie in den Programmausschreibungen der Kinos verwendet wird. Manchmal ist einfach die Rede von ,Kinodramen', deren Bedeutungsumfang ähnlich unscharf und umfassend ist, wie der der, sozialen Dramen'. Präzise Unterscheidungen bei den 
auch oft satirisch-humoristische Filme mitmeint, verdankt sich wohl nicht zuletzt dem besonderen Augenmerk, das die Reformer den Melodramen bzw. Salonstücken (und natürlich den gesellschaftskritischen Filmen) widmen, da diese am deutlichsten auf soziale Gegensätze abheben und so als besonders gefährlich eingeschätzt werden.

Die satirisch-humoristischen Filme, als erste Formengruppe der inkriminierten Verarbeitung sozialer Gegebenheiten, sind weitgehend identisch mit den zeitgenössischen Burlesken und Humoresken. Produziert werden die meisten dieser Filme in Frankreich, in Italien und den USA, wobei die französischen und amerikanischen als stilbildend gelten können. Mit den Konzernen Pathé und Gaumont besitzt Frankreich bis 1914 noch die Vorherrschaft im internationalen Filmgeschäft, dann kehrt sich das Verhältnis mehr und mehr zugunsten der USA um (vgl. 1.3.). Die Abriegelung der Grenzen im Ersten Weltkrieg sowie die Gründung der Ufa durch die Oberste Heeresleitung 1917 begünstigt über einige Jahre hinweg auch eine deutsche Produktion. Letzte jedoch orientiert sich an den ausländischen Mustern - Toeplitz spricht geradezu von „Nachahmungen“331 - und bringt nicht nur im humoristischen Bereich kaum eigenes hervor. - Als paradigmatisch und von besonderer Bedeutung können die Filmkomödien Max Linders, der von 1911 bis 1915 eine ganze Serie bei Pathé produziert, ${ }^{332}$ und die Slapstick comedies Mack Sennets (vgl 1.5.), der von 1912 bis 1917 als Schauspieler, Regisseur und Direktor bei Keystone und Triangle in den USA arbeitet, genannt werden. Auch die ersten (Kurz-)Filme Chaplins fallen in diese Zeit; 1914 stöBt er zu Sennet und tritt bei diesem innerhalb eines Jahres in 35 Slapstick comedies auf. 1915-17 entstehen bei seiner Arbeit für Essanay und Mutual bereits zentrale Werke wie „The Tramp“ (1915) und „The Immigrant" (1917), in denen nicht nur der ,Charlie'-Typus deutlicher wird, sondern sich auch Chaplins spezifische Auseinandersetzung mit gesellschaftlichen Bezügen konkretisiert. Daneben stehen die „Lehmann"-Serie aus Deutschland und die „Tontoloni“-Serie aus Italien, die ähnliche, jedoch weniger differenzierte Charaktere wie Sennet und Linder schaffen. ${ }^{333}$

Sowohl die ,anspruchsvolleren' Burlesken und Humoresken - wie Linders, Sennets und Chaplins - als auch die ,trivialeren' bedienen sich vorwiegend der Aktion, d.h. sie ziehen ihre komische Wirkung aus Kollisionen der Handelnden, Stürzen, Verfolgungen und Gegenstandsbewegungen sowie aus Übertreibungen und Unwahrscheinlichkeiten wie etwa Explosionen, die von den betroffenen Figuren unbeschadet überstanden werden. Ihr Humor ist grotesk, teilweise rüde, und entspringt nicht zuletzt realitätsüberschreitenden Widersprüchen und Bizarrerien. Er ist ein Kontrasthumor, der zum Lachen gerade dadurch reizt, da $B$ er die Wirklichkeit verzerrt und sich in offensichtlichen Gegensatz zu ihr stellt. Das rüde Moment seines Wesens in manchen Filmen ergibt sich noch aus dem Konnex mit dem ,Practical joke ${ }^{\mathbf{3 3 4}}$, jener

Reformern bestehen ohnehin meist nicht. Insbesondere in ihren bewertenden Textteilen sind, wenn von den ,sozialen Dramen' oder oft auch nur von den ,Dramen' überhaupt gesprochen wird alle Filme mit irgendwie sozialen Bezügen gemeint.

331 Toeplitz, Geschichte I, 139

332 vgl. Gregor/Patalas, Geschichte I, 16-17

333 vgl. dazu: Schultze, Bildungsmittel, $40-41$

334 Der Practical joke ist eine Form des Streichs und besitzt vor allem in den Jahren zwischen 1870 und 1910 große Popularität. Sammlungen berühmter Streiche bzw. der Streiche berühmter Persönlichkeiten (wie Edisons Practical joke, der Mark Twain in eine elektrische Ap- 
Popularität des Streichs und der Schadenfreude, die um die Jahrhundertwende den breiten Charakter des Erheiternden ausmachen. (Nicht gegen diesen wenden sich als Zeitgenossen daher auch die Kinoreformer, wie Langes Einschätzung des ,Hampelmannhumors' als zwar von niederem Geschmack, jedoch ungefährlich zeigt. Vgl. 2.2.)

Die erheiternde Kontrastwirkung nun kann auch aus sozialen Antagonismen quellen oder durch Typisierungen und Überspitzungen von Schichtspezifika als einer Form der satirischen Verzerrung erzeugt werden. Sie wird dann zu einer Art ,sozialem Humor', der in der Tat die Burlesken und Humoresken dieser Zeit neben dem ,Rough humor' des Practical joke auch kennzeichnet. So können beispielsweise bestimmte Berufsstände karikaturesk verzeichnet und geradezu zu Symbolen des Grotesken werden wie in der Burleskenserie „Keystone Cops“ von Sennet die Polizei oder in den Feuerwehrhumoresken die Feuerwehrleute. Sie geraten dann zu filmspezifischen Typen und zu Garanten für einen anarchischen, bizarren Humor. Wo immer die ,Keystone Cops' auftreten, steht zu erwarten, daß ihr übereifriges Bemühen um Ordnung genau das Gegenteil zur Folge haben wird. Aus dem Antagonismus ergibt sich das eigentlich komische Moment. Oft liegt es auch in typenimmanenten Widersprüchen, deren beliebtester der Widerspruch ,zwischen Gestalt und Geba-

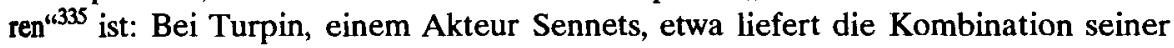
,pathetischen Gestik“ mit „seinen grausig schielenden Augen, seinem flatternden dünnen Haar und seinem bebenden Adamsapfel ${ }^{1336}$ den erheiternden Kitzel. Andererseits kann der komische Antagonismus auch auf soziale Verhältnisse bezogen sein. In Linders Komödie „Max et le quinquina“ (1911) etwa beleidigt die betrunkene Hauptfigur einen Polizeikommissar, einen Botschafter und einen General, die $\mathrm{hm}$ alle ihre Karten überreichen. Später, als ihn Polizisten wegen eines Taschendiebstahls verhaften wollen, nutzt er diese Karten, um sich Respekt zu verschaffen. ${ }^{337}$ Der Widerspruch zwischen Gestalt und Gebaren ist hier zum Widerspruch zwischen sozialem Rang und Autorität umgeformt und stellt das belustigende Element dar. Ähnlich verhält es sich in der Geschichte des ,einfachen Mannes', der in ,feine Gesellschaft' gerät und dort irrtümlich für eine Autoritätsperson gehalten wird, einer Geschichte, die als Sujet eine ganze Reihe von Humoresken trägt und noch bei Chaplin Verwendung findet. ${ }^{338}$ Auf schichtspezifische Typika und gesellschaftliche Stellung übertragen findet sich der komische Antagonismus in dem Film: „Notar auf dem Bummel“ (ca. 1910), der den Reformern ein besonderer Dorn im Auge ist und der daher bei Hellwig inhaltlich skizziert wird. ${ }^{339}$ Erzählt wird die Odyssee einer No-

paratur lockt, die diesem eine heftige Diarrhoe verursacht, oder des Prince of Wales, der dem deutschen Kaiser dessen eigenen Jagdhund als Entenbraten serviert) kursieren in den Jahren sowohl in den USA als auch in Europa. Vor allem in den USA aber bringt der Practical joke eine beinahe kultische Begeisterung hervor und prägt den Humor der Literatur, der frühen Comics und des Films.

${ }_{336}$ Gregor/Patalas, Geschichte I, 34

${ }_{337}^{336}$ Gregor/Patalas, Geschichte I, 34

337 vgl. Gregor/Patalas, Geschichte I, 17

${ }^{338}$ Der Film „City Lights“ (1931) beispielsweise enthält noch eine Szene, in der Charlie aufgrund diverser Umstände in die Lage versetzt wird, unter ,feiner Gesellschaft ${ }^{\star}$ ein Gelage mitzumachen, in dessen sozialen Rahmen er eigentlich nicht paßt und deren Verhaltensformen ihm fremd sind.

${ }^{339}$ Vgl. dazu: Hellwig, Schundfilms, 36 
tars, der sich im Lokal betrinkt und dort die Bekanntschaft zweier ,leichter Mädchen“ macht. Später torkelt er mit diesen durch die Straßen, schläft auf einer Bank ein und wird von seinen Begleiterinnen beraubt. Schließlich greift die Polizei den Betrunkenen auf und steckt ihn in die Ausnüchterungszelle. Die satirische Komik in diesem Film entsteht dabei wiederum aus dem Gegensatz von Gestalt und Gebaren, d.h. zwischen der steifen ,Contenance', die für den Typus eines Notars als Vertreter der ,Gebildeten' (genauer: der Akademiker) und des Berufsstands der Juristen eigentlich als angemessen gilt, und seinem faktischen Verhalten, in dem die verdrängte Seite der Sinnlichkeit und des Rauschs, die Sehnsucht nach dem Ausbruch aus dem Gefängnis der Etikette und der bürgerlichen Verhaltenskodices zutage tritt.

Werden die schichtspezifischen Typika und die sozialen Bezüge in den satirischhumoristischen Filmen genutzt, um entsprechend erheiternde Gegensätze und Widersprüche zu erzeugen, so stellen sie in den Melodramen und Salonstücken sowie den gesellschaftskritischen Filmen den Rahmen und die Motivbestände bereit, um im einen Fall tragische Konstellationen und Handlungsgänge zu entwickeln bzw. im anderen Fall realitätsbezogene Aussagen zu machen. Die Grenze zwischen den Genres ist nicht immer scharf zu ziehen. ,Klassische' Melodramen sind zunächst die italienischen ,psychologischen Filme' (Toeplitz). Sie stehen in den Jahren zwischen 1905 und 1914 neben den ,Ausstattungsfilmen', jenen ebenfalls italienischen Monumentalproduktionen, die reges Echo in der Presse finden und vor allem vom Mittel- und Oberschichtspublikum geschätzt werden. Ihnen gegenüber können die psychologischen Filme auf Popularität bei den breiten Massen rechnen, nicht zuletzt wohl, da sie eine „Verlängerung (...) der ,Dramen der Arena“ “340 sind, d.h. einer Form der ,volkstümlichen' Theatervorstellungen unter freiem Himmel, die ihre tragischromantischen Geschichten mit großen Gefühlsausbrüchen darbieten und sich großer Beliebtheit erfreuen. Die psychologischen Filme übernehmen den Darstellungsstil des Freilufttheaters und verbinden ihn mit opernhaftem Prunk, dem Handlungsmuster der Intrige und der Vorliebe für aristokratische ,Settings. Auf diese Weise entstehen Melodramen, welche ,,in einer in sich geschlossenen Welt aristokratischer Herren und ,femmes fatales', die meist Liebeselexiere oder Gifte bei sich (tragen ) ${ }^{، 341}$, spielen, und deren vordringliches Thema die Liebestragödie in der ,feinen Gesellschaft' ist. Wie die Monumentalfilme werden auch die psychologischen exportiert und geraten sogar zu ernsten Konkurrenten der ersten. ${ }^{342}$

Großen Einfluß haben weiter die dänischen ,Salonstücke' mit ,mondänem' Ambiente, die den erotischen Dreieckskonflikt zu ihrer Spezialität machen, ,wobei einmal der elegante Salon, ein andermal die Zirkusarena den Hintergrund “343. abgibt, und die in Deutschland einen ihrer wichtigsten Märkte finden. Das Rezept dieser Filme besteht weniger in Verarbeitungen von Realitätsbezügen, sondern mehr im „Arrangement wirkungsvoller Elemente, des luxuriösen Dekors und der attraktiven Darsteller “344. Häufig tritt in ihnen tatsächlich die von den Reformern beklagte Kontrastierung von Oberschicht und Unterschicht auf: „Arme Näherinnen (werden) von

\footnotetext{
${ }^{340}$ Toeplitz, Geschichte I, 65

341 Toeplitz, Geschichte I, 65

342 vgl. Toeplitz, Geschichte I, 65

343 Gregor/Patalas, Geschichte I, 23

344 Gregor/Patalas, Geschichte I, 23
} 
reichen Grafen geliebt“ ${ }^{345}$ und in der Regel sind die Helden „Millionäre (...), die Schlösser und Lakaien besitzen“'346. Handlungstragendes Sujet aber ist keineswegs die Diskriminierung der ,Reichen', sondern die Liebe, meist die unglückliche. Der dänische Film dieser Zeit ,erfindet' das ,Unhappy end“ (Toeplitz) und macht es „dermaßen populär, daß es zu Publikumsprotesten (kommt), wenn ausnahmsweise einmal ein Film gut (endet) ${ }^{\text {، } 347}$. Ihre Neigung zur tragischen Liebesverstrickung und zum negativen Schluß macht damit die meisten der dänischen Salonstücke zu Melodramen. Ab 1909/10 findet (nicht zuletzt wohl aufgrund der allmählichen Publikumsmischung) eine Differenzierung der Charaktere, der Milieus und der Atmosphäre statt, freilich unter Beibehaltung der Themen und Handlungsformen. ${ }^{348}$

Zu nachhaltiger Wirkung in diesem Genre bringen es dann insbesondere der Regisseur Urban Gad und seine Frau Asta Nielsen, die 1910/11 mit „Afgrunden“" großen Erfolg in Deutschland verbuchen und schließlich dorthin engagiert werden. „Afgrunden“ erzählt die Geschichte eines Bürgermädchens, das eine Zirkuskarriere versucht und dabei scheitert. Mit „Vorderhaus und Hinterhaus“ (1914) liefert das Gespann Gad/Nielsen einen Film, der sich als realistisches, ,soziales Drama' gibt, jedoch dem Melodram verpflichtet bleibt. Er ist gleichwohl eine Art Vorreiter der ,Straßenfilme' (Kracauer), die ihre Bezeichnung dem Titel des 1923 produzierten Films „Die Straße" von Karl Grune verdanken, und die eine Art deutscher Spezialităt der 20er Jahre werden. ${ }^{349}$ Die Filme mit Asta Nielsen zählen, wie die Untersu-

345 Toeplitz, Geschichte I, 71

346 Toeplitz, Geschichte I, 71

347 Toeplitz, Geschichte I, 71

348 vgl. Toeplitz, Geschichte I, 72; verfilmt wird beispielsweise Schnitzlers „Liebelei“. Schon der Titel aber weist darauf hin, $\mathrm{da} \beta$ an der literarischen Vorlage primär der melodramatisch nutzbare Erzählkern interessiert: „Elskovsleg“ (1913) ist übersetzbar als „Liebesintrige“.

${ }^{349}$ Der Handlungsgang der "Straße" erinnert auch an „Notar auf dem Bummel“: Wie die Geschichte des Notars setzt der Film abends zur Essenszeit ein. Während der Notar jedoch erst nach dem Mahl seinen Ausflug unternimmt und seine Frau allein zu Bett geht, eilt der namenlose Protagonist der "Straße“ schon vor dem Essen davon. Der Anblick seiner Frau, die die Suppenterrine hereinbringt, stellt ihm eine Alltagsmonotonie vor Augen, die unerträglich scheint und die ihn hinaustreibt. Ähnlich dem Notar gerät er an zwei Prostituierte, doch nimmt die Handlung dann einen härteren Verlauf. In einem Nachtklub lernt der namenlose Rebell gegen den ,bürgerlichen' Alltagstrott einen Zuhälter und dessen Gefährten kennen und wird von diesen nicht nur beim Glücksspiel ausgenommen, sondern auch noch in einen Mord verwickelt. Unschuldig der Tat verdächtigt und in Polizeigewahrsam genommen, versucht der Protagonist sich umzubringen, was jedoch mißlingt. Das Geständnis des wahren Mörders rettet ihn schließlich und im Morgengrauen wankt er nach Hause, wo seine Frau auf ihn wartet und ihm alles verzeihend die Suppe wärmt. (Vgl. zum Inhalt: Kracauer, Caligari, 129-130) Kracauer sieht in dem betulichen Ende des Films eine Form resignativer Regression, die jenen autoritären Charaker präfomiert, der später dem Nationalsozialismus in die Hände spielt. Selbst wenn man dieser These nicht folgt, so bleibt doch erkennbar, daß „Die Straße" ganz andere Wege geht, als „Notar auf dem Bummel“: Während der „Notar" eine soziale Satire bietet, die zur Auseinandersetzung herausfordert, leitet die "Straße“ zur Konformität und zu Unterwerfung unter die eingewohnten Verhaltenskodices an. Der "Straße“ folgen eine Reihe analoger Filme mit ähnlichen Botschaften. Sie müßten von den Reformern als Einlösung ihrer Forderungen geradezu begrüßt werden. Dazu kommt es freilich nicht mehr, denn ihre Publikationsfreudigkeit läßt zur Mitte der Zwanziger hin nach. Dieser Tatbestand kann durchaus so ausgelegt werden, daß zu dieser Zeit eine Entwicklung eingesetzt hat, die die Reformbewegung allmählich überflüssig macht. Vor allem durch die Ufa nämlich, die auch die "Straße" und ihre Nachfolger produziert, ist der Film in den Einflußbereich der Mittel- und Oberschicht sowie der konservativ-nationalen Militärs und Finanziers gezogen worden. Gegründet wird die Ufa ja von der Obersten Heeres- 
chung Altenlohs zeigt, zu den vom Unterschichts- und unteren Mittelschichtspublikum bevorzugten; gerade beim, Arbeiterpublikum' sind sie besonders beliebt. ${ }^{350}$ Stilistisch und inhaltlich fortgesetzt werden die dänischen Salonstücke und die deutschen Produktionen Gads und Nielsens von den schwedischen Gesellschaftsstücken vor allem Mauritz Stillers, die allerdings kaum Melodramen, sondern meist,mondäne Lustspiele' (Gregor/Patalas) sind. Seine frühen Werke stehen dabei sehr deutlich in der dänischen Tradition; doch auch sein berühmtester Film: „Erotikon“ (1920) ist noch zu derselben zu rechnen. Erzählt wird die Geschichte eines Biologieprofessors, der seine Frau vernachlässigt, sich aber für seine Nichte interessiert. Das Ergebnis ist ein ,erotisches Bäumchen-wechsle-dich-Spiel' (Gregor/Patalas), an dem auch noch ein Flieger und ein Bildhauer teilnehmen.

Finden die genannten Filme heute die Beachtung der ästhetischen Filmgeschichtsschreibung, so stehen neben ihnen auch ,trivialere" Elaborate, wie etwa der deutsche Film „Nachtgestalten“ (ca. 1912/13), dessen Schauplatz Berlin ist und der dem Zensor Brunner, einem Sympathisanten der Reformer, besonders auffällt. Erzählt wird die Geschichte des ,vom Genußleben übersättigte(n) Graf(en) Burg“351, der auf der Suche nach einer besonderen Attraktion für die Unterhaltung seines

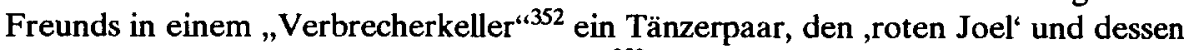
Freundin Anna, auftut. Der „Schiebetanz ${ }^{، 353}$ beider erotisiert den Grafen so sehr, daß er Anna zu einem nächtlichen Stelldichein gegen Bezahlung überredet. Joel schleicht seiner Freundin jedoch nach und ermordet aus Eifersucht den Grafen. Von der Polizei nach einer Flucht über die Dächer in die Enge getrieben wählt Joel den Freitod. ${ }^{354}$ Der melodramatische Handlungsgang kann strukturell als repräsentativ für eine ganze Reihe ähnlicher Filme dieses Genres gelten und unterscheidet sich im übrigen wenig von den heute ästhetisch gewürdigten. Sie alle arbeiten mit starken Gefühlsmomenten und sind meist Liebesgeschichten. Dabei können die Sozialbezüge mehr oder weniger stark in den Vordergrund treten. Weniger stark sind sie in den dänischen Salonstücken, stärker etwa in den Filmen, in denen die Liebe des einfachen Arbeiters zur dekadenten und zynischen Tochter aus reichem Haus, die mit den Gefühlen ihres Verehrers nur spielt, oder umgekehrt die Zuneigung der armen Werktätigen zum Fabrikantensohn, der die Frau für seine sexuellen, Ausschweifungen' mißbraucht, um sie dann geschwängert sitzenzulassen ${ }^{355}$, geschildert werden.

Anders verhält es sich mit den gesellschaftskritischen Filmen. Hier findet oft eine dezidierte Auseinandersetzung mit sozialer Not und Ungerechtigkeit, Korruption oder Ausbeutung statt. Die Darstellung ist in ihnen dann engagiert und von der Absicht getragen, über das lustvolle Erleben von ,Furcht und Mitleid' hinaus gesellschaftliche Mißstände deutlich zu machen. So illustriert etwa der Film: „Geld regiert die Welt" (ca. 1910) ${ }^{356}$ schichtspezifische Ungleichbehandlung und Korruption. Er

leitung, um später dann in die Hände des Hugenberg-Konzerns zu gelangen. (Vgl. dazu: Spiker, Jürgen, Film und Kapital, Berlin 1975 [ = Zur politischen Ökonomie des NS-Films 2], 9-79)

$350 \mathrm{vgl}$. Altenloh, Soziologie, 76

351 Brunner, Volksgefahr, zit. nach: Moreck, Sittengeschichte, 97

352 Brunner, Volksgefahr, nach: Moreck, Sittengeschichte, 97

${ }_{354}^{353}$ Brunner, Volksgefahr, nach: Moreck, Sittengeschichte, 97

354 vgl. Brunner, Volksgefahr, nach: Moreck, Sittengeschichte, 98

355 vgl. Lange, Kino, 48

356 vgl. zum Inhalt: Schultze, Bildungsmittel, 43, und: Hellwig, Schundfilms, 36-37 
erzählt die Geschichte einer armen Frau mit vier Kindern, die beim Stehlen von Schuhen ertappt wird. Nach einer „rohe(n) Behandlung“3357 durch die Polizei wird sie mit ,erhabene(m) Zorn“358 vom Gericht verurteilt und ins Gefängnis gebracht. In einer zweiten Szene wird dann der Warenhausdiebstahl einer ,Gnädigen ${ }^{359}$ vorgeführt. Auch sie findet sich ertappt, doch bewahrt sie ihr Mann mittels einer Bestechungssumme vor der Verurteilung. Die Kontrastierung der unterschiedlichen sozialen Milieus wird so nicht mehr nur als Folie und Hintergrund für ein Melodram genutzt, das letztlich recht weit von der Realität entfernt ist, sondern direkt zu einer Kritik weitergeführt, die zwar vereinfacht, jedoch die soziale Situation der ärmeren Bevölkerung dieser Zeit und die Existenz von Korruption nicht unzutreffend ins Bild rückt. Der Film ist, obschon die gesellschaftskritischen Versuche gegenüber den Melodramen einen äußerst geringen Prozentsatz ausmachen, kein Einzelfall. Mitunter geraten sogar Serienfilme zu sozialkritischen Unternehmungen. 1915 etwa produzieren Carl Laemmles ,Universal Pictures“ ein Serial mit dem Titel: „Die Kralle", in dem nacheinander ,große‘ und ,kleine“ Themen aus Wirtschaft und Gesellschaft behandelt werden. So finden sich die Auswirkungen der Monopole bei den Seetransporten, der Kampf um die Vorherrschaft auf dem Milchsektor und der Waffenhandel in Laemmles „Kralle“ ebenso bloßgestellt wie Mietwucher, Versicherungsschwindel, Finanzpiraterie und Geschäftemacherei mit Arzneimitteln. ${ }^{360}$ Durch Export erhält das Serial über die USA hinaus einen Resonanzraum, wenngleich wohl kaum jene Popularität, die anderen zeitgenössischen Serials wie „Fantomas“ aus Frankreich (vgl. 1.5.) oder „Perils of Pauline“ aus den USA zuteil wird.

Neben den genannten ,trivialeren“ Erscheinungen des gesellschaftskritischen Films stehen auch renommierte, große Produktionen, wie D.W. Griffiths Monumentalfilm „Intolerance“ (1916), der in seiner ,aktuellen' Episode: „The Mother and the Law" die schichtspezifischen Kontrastierungen der Melodramen benutzt, sie jedoch realitätsbezogen einsetzt. Thematisiert werden dort vom zeitgenössischen Justizsystem produzierte Ungerechtigkeiten und die soziale Lage der Industriearbeiter in durchaus differenzierter Form. Griffiths Versuch, durch Kombination mit drei weiteren Episoden von Spielfilmlänge eine ,Kulturgeschichte der Intoleranz' zu liefern, macht jedoch seine, gigantische Metapher' (Ramsaye) schwer rezipierbar, so daß der Film ein kommerzieller Flop wird (vgl. 1.5.). Sozialkritische Aspekte finden sich allerdings zuvor bereits in Griffiths Kurzfilmen. - Ein ähnliches Schicksal wie „Intolerance" wird "Sperduti nel buio" (1914) von Nino Martoglio zuteil, der nach einem Bühnenstück des neapolitanischen Autors Roberto Bracco gedreht wird. Erzählt wird die Geschichte einer illegitimen Grafentochter, die bei einem blinden Bettler aufwächst; das Sujet gleicht so durchaus den zugkräftigen Melodramen. Doch bleibt der Film weitgehend ohne Resonanz, möglicherweise gerade weil er seine ,Story' mit großem Realismus aufbereitet. Die Darstellung Neapels, insbesondere der Elendsviertel, besitzt beinahe dokumentarischen Charakter ${ }^{361}$ und liefert mit der Kontra-

\footnotetext{
${ }^{357}$ Schultze, Bildungsmittel, 43

${ }^{358}$ Schultze, Bildungsmittel, 43

${ }^{359}$ Schultze, Bildungsmittel, 43

360 vgl. dazu: Sadoul, Filmkunst, 123

361 vgl. dazu: Toeplitz, Geschichte I, 66-67
} 
stierung der Milieus sowie der Thematisierung der Bedrohung durch die Camorra unzweideutige Gesellschaftskritik.

Insgesamt kann damit festgestellt werden, daß zur Zeit der Reformer in der Tat eine ganze Reihe von Filmen, die sich in mehrere Sparten einordnen, die sozialen Verhältnisse als Hintergrund, Folie und mitunter auch als Thema ihrer Darstellung nutzen. Sie können eine satirische Zeichnung bestimmter Schichten und Berufsgruppen vornehmen, humoristische und ,dramatische“ Typen schaffen, die sich als solche durchaus von der Realität unterscheiden, und schließlich auch gezielt Kritik an verschiedenen gesellschaftlichen Mißständen üben. Auf der Basis dieser historischen Situation will ich die Einzelvorwürfe des Destabilisierungsvorwurfs der Reformer nun nochmals aufnehmen und beleuchten. Dazu setze ich aus zwei unterschiedlichen Perspektiven an, die jeweils den von den Reformern im Destabilisierungsvorwurf verwendeten Wirkungsthesen korrespondieren und so zugleich deren Überprüfung ermöglichen. Zwar ist bereits anläßlich des Kriminalisierungsvorwurfs die Problembehaftetheit dieser Thesen zutage getreten, und hat sich die diesbezügliche Argumentationsfigur als ideologische enthüllt, doch blieb diese Analyse auf einer grundsätzlichen, d.h. methodologischen Ebene. Für eine zureichende Kritik des Destabilisierungsvorwurfs und die Rekonstruktion seiner medienethischen Bedeutung hingegen ist eine über die Methodologie hinausgehende Untersuchung der konkreten Durchführung der Thesen, deren im genannten Vorwurf zwei zur Anwendung kommen, äußerst hilfreich. Ich kontrastiere daher zunächst die gesellschaftsbezogene Qualität der Filminhalte, wie sie aus der historiographischen Skizze deutlich wird, mit den Einschätzungen der Reformer, die diese auf der Basis der Verursachungsthese vornehmen. Sodann wende ich mich der Interaktion von Film und Publikum zu und untersuche den gesellschaftlichen Prozeß, der durch die inkriminierten Filme indiziert ist. Dabei überprüfe ich zugleich die Kooperationsthese, die als sekundäre Wirkungsthese von den Reformern ebenfalls angewandt wird, und beleuchte die bewahrethische Zielrichtung des Destabilisierungsvorwurfs sowie das ihm immanente Gesellschaftskonzept.

\section{Die Realitätsferne des Destabilisierungsvorwurfs}

Die Verursachungthese nun ist die im Vorwurf der sozialen Destabilisierung hauptsächlich verwendete Wirkungsthese. Gesprochen wird immer wieder von ,Verhetzung', ,Weltbildverfälschung', ,Irreführung' und ,Erschütterung des Vertrauens'. Die Rede ist von ,faustdicken Lügen', die offensichtlich aus sich heraus, ohne eine Überprüfung zu gestatten, eine ,Volksvergiftung' nach sich ziehen. Der Film wird kohärent mit der unter 2.4. erhobenen generellen Axiomatik der These als das alleinige Agens gehandhabt, das die entsprechenden verderblichen und realitätsfremden Vorstellungen bei einer anscheinend ebenso widerstands- wie hilflosen Rezipientenschaft hervorruft. Ebenfalls kohärent mit der Axiomatik geht die Argumentation der Reformer dabei immer wieder von den Filminhalten aus, so daß die Überprüfung der These ebenfalls bei denselben zu beginnen hat. Zu fragen ist zunächst, ob die Historiographie die Konstatierung einer verfälschten Darstellung der gesellschaftlichen Realität erlaubt, aus der Neid, Mißgunst, Haß oder Pessimismus fließen könnten.

Bei den satirisch-humoristischen Filmen nun ist eine Verzeichnung der Realität durchaus erkennbar. Sie ist geradezu konstitutiv für den satirischen und humoristi- 
schen Charakter dieser Filme, die durch Übertreibung, Verzerrung und Erzeugung von Widersprüchen ihr eigentliches Wesen gewinnen. Keineswegs aber scheint mir diese Verzeichnung in einer Weise vorgenommen zu sein, die die genannte Wirkungsspekulation stützt. So ist wohl kaum zu erwarten, daß die Ironisierung, die in den Burlesken und Humoresken in der Regel Antagonisten und Protagonisten gleichermaßen trifft, Neid hervorrufen wird, selbst wenn man annimmt, daß das Publikum die Inhalte ohne Eigenanteil internalisiert. Gerade die Welt der ,Reichen' findet sich dort ja, soweit sie vorkommt, in einen Ort der Lächerlichkeit transformiert oder wird einer anarchischen Verwüstung ausgeliefert. Mißgunst und $\mathrm{Haß}$ sehe ich durch die Darstellung ebenfalls nicht befördert. Schon auf der Ebene der symbolischen Konstruktion innerhalb der Filme zeigt sich das: Die „Keystone Cops“ etwa stehen primär für das Versprechen grotesker Aktion und erheiternder Verwicklungen, sind also Typen des Widerspruchs von Ordnung und Entropie (und damit symbolische Garanten entsprechender filmischer Handlungsverläufe), weniger aber Repräsentanten der realen Polizei. Was diesen Berufsstand geeignet macht, ist vor allem die Möglichkeit, den widersprüchlichen Typus sinnfällig und unmittelbar einsichtig zeichnen zu können. Daneben freilich läßt sich die Serie als Satire lesen, deren Charakter jedoch nur für eine bestimmte Gesellschaftskonzeption gefährlich wird, in der Satiren als illegitime Kommunikationsform gelten.

Besonders wichtig aber erscheint mir, daß weder die „Keystone Cops“-Serie, Max Linders Komödien, noch die von den Reformern gegeißelte Geschichte des Notars Darstellungsformen und -linien enthalten, die sich als gezielte, bösartige Diskriminierung eines Berufsstands oder einer Schicht interpretieren ließen. In keinem der genannten Fälle wird jener propagandistische Rufmord begangen, wie ihn später etwa die Propagandafilme der Nationalsozialisten zu ihrem Programm machen. Zwar bringen die Reformer ihren Vorwurf mit einer Schärfe vor, die den Nachgeborenen an solche Phänomene denken läßt, doch zeigt der Blick auf die historische Situation, daß keine der filmischen Charakterisierungen den Rahmen der Satire und Humoreske überschreitet. In ihnen findet wohl eine gewisse spöttische Abgrenzung gegen ,die da oben' statt; der ironisierten Gruppe oder Schicht wird damit aber nicht das Lebensrecht abgesprochen. Die Satiren, Burlesken und Humorseken zielen auf den Lacheffekt, nicht auf die Schaffung von $\mathrm{HaB}$. Selbst die Zeichnung des Notars wird man nicht als haßerfüllt bezeichnen können; ihr satirischer ,Biß' bleibt dem $\mathrm{Ma} \beta$ an Aggression eingeordnet, das jede Satire braucht, um Kraft zu besitzen.

Auch einen pessimistischen Charakter wird man den Burlesken und Humoresken nicht unumwunden attestieren können. Jene von ihnen, die das Leiden unter sozialen Verhältnissen thematisieren (wie viele von Chaplins Filmen), überwinden durch ihren Humor gerade eine pessimistische Resignation. Aus der Verursachungsthese allein läßt sich daher noch keine entsprechende Wirkung ableiten. Allerdings ist zu konstatieren, daß die Burlesken und Humoresken mit ,Recht und Ordnung' ironisierend spielen. Das wiederum kann jedoch nur unter Beiziehung eines bestimmten Gesellschaftskonzepts als Zerstörung des Vertrauens in dieselben interpretiert werden.

Etwas anders liegt der Fall bei den Melodramen und Salonstücken. Betrachtet man hier einzig die Inhalte, so ist zunächst feststellbar, daB in der Tat eine Zeichnung der Welt der ,Reichen' als einer Sphäre des Luxus und des Müßiggangs vorgenommen wird. Meist allerdings erhält diese Welt nicht ungeteilt den Charakter des 
Erstrebenswerten, und zwar gerade wegen der von den Reformern beklagten Negativzeichnung der ,feinen Gesellschaft'. Moralisch erstrebenswerter wird stattdessen in verschiedenen (keineswegs aber allen) Fällen die Sphäre der ,Armen', insbesondere der Werktätigen, ausgemalt. Mit Einschränkungen ließe sich demgegenüber bei einigen Melodramen annehmen, daß ihre Schaustellung von Luxus und Pracht Anlaß für ein diesbezügliches neiderfülltes Begehren sein könnte und mitunter vielleicht die moralische Seite übertünchen mag.

Gewichtiger als das Neid-Argument aber ist in diesem Zusammenhang der Vorwurf, die Melodramen und Salonstücke seien erfüllt von Ressentiments und erzeugten $\mathrm{Ha} B$ und Mißgunst. Tatsächlich bestätigt die Historiographie partiell den reformerischen Schreckensruf von der moralischen Negativierung der ,Reichen' (weniger der ,Gebildeten'). Es war zu sehen, daß durchaus eine Reihe niederträchtiger Grafen und herrschsüchtiger Femmes fatales auftritt, die von Wohlleben und Genußsucht sittlich korrumpiert sind und ausschließlich ihrer Egozentrik frönen. Ebenso zeigte sich, daß diesen mitunter brave Näherinnen und fleißige Werktätige gegenüberstehen. Aus dem Blickwinkel der Verursachungsthese allein betrachtet, d.h. unter der Voraussetzung, daß das Publikum diese Inhalte unvermittelt und ungefiltert internalisiert, müßte einem Teil der inkriminierten Filme die Erzeugung zumindest eines emotionsbeladenen Vorurteils gegen Grafen und Vamps sowie ungeteilter Sympathie mit den unbescholtenen Arbeitern unterstellt werden. Allerdings war auch zu sehen, daß die moralische Negativzeichnung nicht auf alle Filme der in Frage stehenden Genres zutrifft. Die kritiklose Internalisierung der einen Inhalte würde dann mit der Internalisierung der anderen konfligieren, d.h. etwa: Die Zeichnung des Lustgrafen Burg konkurrierte in der Rezipientenpsyche mit der des Millionärs, der die Näherin heiratet, oder der rote Joel widerstritte dem Arbeiter reinen Herzens, der unter der zynischen Fabrikantentochter zu leiden hat. Ähnlich stünde es mit dem Vorwurf der Erzeugung einer pessimistischen Haltung und Weltsicht. Die Melodramen mit Unhappy ends stünden dann den Salonstücken mit Happy end gegenüber. Da hier die negativen, d.h. die tragischen Ausgänge zahlenmäßiges Übergewicht zu haben scheinen, wäre unter der Voraussetzung der Verursachungsthese allerdings die Dominanz einer pessimistischen Einstellung anzunehmen, zumindest was die Chancen betrifft, einen Grafen oder eine Femme fatal mit glücklichem Resultat zu lieben und zu heiraten. Über das Liebesthema hinaus jedoch, das immerhin das Zentrum der Melodramen und Salonstücke ausmacht, läßt die Verursachungsthese wenig Schlüsse zu. Bezogen auf die Personen bzw. die von ihnen repräsentierten Schichten müßte konstatiert werden, daß sich die Wirkung äquiviert. Zur staatlichen Ordnung und deren Funktionsfähigkeit dagegen machen die Salonstücke und Melodramen aufgrund ihrer thematischen Beschränkung sowie ihrer Tendenz zur Personalisierung kaum Aussagen, so da $B$ eine diesbezügliche Wirkung streng genommen nicht vermutet werden kann. Auf der Inhaltsebene, an der allein die Verursachungsthese sich orientiert, nämlich spielt sich ein Geschehen ab, das lediglich besagt, da $B$ weder Reichtum noch Armut vor einem tragischen Scheitern in Liebesdingen schützt. Der Transfer des Liebesthemas auf das Thema Recht und Ordnung setzte dann eine Interpretationsleistung des Publikums voraus, die erst unter der Kooperationsthese postuliert werden könnte, für die jedoch auch dort kaum eine Brücke besteht. 
Tatsächlich wird der Vorwurf einer Störung des Vertrauens in Recht und Ordnung auch nicht eigentlich den Melodramen gemacht, sondern jenen Filmen, die ich als gesellschaftskritische in eine eigene Gruppe gefaßt habe. In der Formulierung Gaupps bezieht er sich zudem nur auf einen konkreten Film, nämlich „Geld regiert die Welt", welcher dort nicht explizit genannt, aber inhaltlich charakterisiert wird. Auch andere Reformer beziehen sich gerne auf diesen Film und verleihen ihm so den Status eines Paradebeispiels. Hier schärfen sich nun die Teilvorwürfe des Destabilisierungsvorwurfs ernsthaft zu. Ihr erster allerdings, der Vorwurf der Erzeugung von Neid, ist für die Wirkungspekulation bezüglich der gesellschaftkritischen Filme weniger relevant. Wenn etwa im genannten Film gezeigt wird, wie die ,feine Dame‘ nach ihrem Diebstahl freigekauft wird, so liegt darin kaum eine Darstellung, die auf Neid, sondern eher eine, die auf Verärgerung über diese Rechtsbeugung durch die ,Reichen' und die ,Herrschenden' abzielt. Der Teilvorwurf einer schichtspezifischen Diskriminierung und der Aufstachelung von $\mathrm{HaB}$ ist denn auch zusammen mit dem Pessimismusvorwurf der zentrale.

Auf dem Hintergrund der historiographischen Skizze läßt sich dazu zunächst konstatieren, daß die genannten Filme Kritik üben, d.h. aber, daß sie negative Wertungen vornehmen, pejorativ sind und sich in Gegnerschaft zu den von ihnen inkriminierten Phänomenen stellen. Selbstverständlich wird in "Geld regiert die Welt" Korruption in scharfer Form verurteilt, ebenso wie in Laemmles „Kralle“ der Versicherungsschwindel, Mietwucher etc. oder bei Griffith Justizwillkür. In ähnlicher Weise bedeutet die Dokumentierung der Elendsviertel Neapels eine wertende Stellungnahme. Es handelt sich bei all diesen Beispielen um Kritik an konkreten Tatbeständen, nicht aber um die wirklichkeitsfremde Ontologisierung einer ethisch korrumpierten Welt. In Frage gestellt werden keineswegs Recht und Ordnung schlechthin, sondern ihre Vollständigkeit; die Maßstäbe beider selbst sind es, die dabei zur Anwendung kommen und deren Geltung eingeklagt wird. Kritik an der Vollständigkeit von Recht und Ordnung zu üben aber schließt notwendig ein, das Vertrauen in das zureichende Funktionieren derselben erst einmal zu erschüttern. Die Schärfung des Blicks für Defizite bedarf einer reflexiven Distanz, welcher das reibungslose Funktionieren faktischer Verhältnisse zunächst überhaupt fragwürdig wird. Das Unterfangen der inkriminierten Filme ist so eher als Aufruf zur Verbesserung der Mißstände denn als Empfehlung von Resignation zu deuten. In ihren Inhalten läßt sich kein ,staatsgefährdender Pessimismus' erkennen, wohl aber eine dezidierte Auseinandersetzung mit den gesellschaftlichen Verhältnissen.

Auch eine schichtspezifische Diskriminierung im Sinn einer, Volksvergiftung mit faustdicken, unverschämten Lügen', die dazu geeignet wäre, realitätsfremden, ungerechtfertigten $\mathrm{Haß}$ aufzustacheln, liegt in den skizzierten Beispielen nicht vor. Freilich beziehen die Filme eine ablehnende Haltung zu den kritisierten Phänomenen und bemühen sie sich darum, diese Ablehnung dem Publikum zu vermitteln. Ihre Kritik ist dabei sowohl Strukturkritik als auch eine personell bezogene. Die Gewichtung fällt unterschiedlich aus: Griffiths sozialkritische Kurzfilme, etwa über die Auswirkungen der Weizenbörse auf die Lebensumstände der Farmer, zielen ebenso wie Martoglios Film auf strukturelle Mißstände und daraus fließendes Unrecht. Laemmles Serial pendelt je nach Thema zwischen Personalisierung und Strukturkritik hin und her - nun ist allerdings etwa die Gerechtigkeitsverletzung durch Miet- 
wucher auch eine personell verursachte und entscheidbare. „Geld regiert die Welt" wiederum personalisiert, ohne das strukturelle Moment dadurch zu übertünchen. Personalisierung findet sich auch dort, wo der harsche, mitleidlose Umgang einer ,Gnädigen', die sich im Sittlichkeitsverein engagiert, mit ihren Hausangestellten gezeigt wird. All diese Fälle sind Parteinahmen gegen mißliebige Phänomene, die Zustimmung zu ihrer Kritik erheischen, nicht aber schichtspezifische Verleumdungen, mit denen $\mathrm{Ha} B$ gegen soziale Gruppen aufgestachelt werden soll. Will man nun nicht den kritischen Impetus schlechthin diskriminieren, so ist zu fragen, ob diese Filme falsche Aussagen machen, etwa, indem Tatbestände dargestellt werden, die nicht existieren, oder indem strukturelles Unrecht durch Personalisierung verdunkelt wird. Weder das eine noch das andere scheint mir der Fall zu sein. „The Mother and the Law" von Griffith etwa beschreibt die Situation der Industriearbeiterschaft und der Kurzfilm über die Weizenbörsenspekulation deren Auswirkungen durchaus zutreffend. Ebenso stellt Martoglio die Situation in den Elendsvierteln Neapels und die Bedrückung durch die Camorra realitätsgerecht dar. Auch die Existenz der von Laemmles Serial angegriffenen Phänomene wird man kaum bestreiten können; dasselbe gilt für Korruption und Armut, wie sie in "Geld regiert die Welt" ins Bild gerückt werden. Gerade dieser mißliebige Film kann als ernsthafter Protest gegen die Lage der Armen zu Beginn dieses Jahrhunderts verstanden werden. Ähnlich verhält es sich mit der sozialen Situation der Dienstbotenschaft, die im letztgenannten Beispiel zur Darstellung kommt. Die Kritik dieses Sujets, das in verwandten Formen eine ganze Reihe von Filmen trägt, bedeutet zudem eine Rückanwendung der von den kritisierten Gruppen propagierten moralischen Normen auf diese selbst. Es kann so als Spiegelung der entsprechenden zeitgenössischen Verhältnisse und als Aufforderung zur Überprüfung derselben an den eigenen ethischen Maßstäben betrachtet werden.

In all den genannten Beispielen liegt daher wohl weder eine Realitätsverfälschung im Sinn einer Darstellung nichtexistenter Mißstände vor noch eine ungerechtfertigte Umleitung von Strukturkritik auf Schicht- oder Personenkritik. Wie Mietwucher ein personell zurechenbarer Mißstand ist, sind es auch Korruption und Umgang mit Hausangestellten. Mag auch etwa die Kritik in Laemmles Serial ein wenig naiv ausfallen, mag die Zeichnung von „Geld regiert die Welt" um der kritischen Schärfe willen auch nicht die ganze Komplexität der gesellschaftlichen Verhältnisse wiedergeben, mag die Kritik der Filme insgesamt perspektivisch sein, so läßt sich angesichts der realen historischen Situation doch nicht einfach behaupten, daß von den inkriminierten Filmen glatte Lügen verbreitet würden. Der Vorwurf der Reformer scheint mir deshalb selbst unter Voraussetzung der Stichhaltigkeit ihrer primären Wirkungsthese nicht ohne weiteres haltbar. Die Überprüfung der These läßt vielmehr deutlich werden, daß der unter 2.4. konstatierte Tatbestand der Ideologisierung nicht nur für die grundsätzliche Argumentationsfigur dieser Wirkungsspekulation, sondern auch für deren Ausführung im Einzelnen zutrifft. Die Zeichnung, die die Reformer von den Gesellschaftsbezügen der zeitgenössischen Filme vornehmen, ist äußerst einseitig und tendenziös. Sie ist bereits en avant den Folgerungsabsichten der Verursachungsthese eingepaßt und kann nicht als vorurteilsfreie Deskription gedeutet werden. So ist der Deduktion einer sozial destabilisierenden Wirkung bzw. einer Zerstörung des gesellschaftlichen Ordnungsgefüges durch die inkriminierten 
Filme nicht nur deshalb nicht zu trauen, weil der Schluß von Inhalten auf Wirkungen grundsätzlich problematisch und die deterministische Axiomatik der Verursachungsthese kritikwürdig ist, sondern auch, weil die reformerischen Charakerisierungen der ersten die Realität nur sehr bedingt treffen.

\section{Die Kritikfeindlichkeit der Reformer}

Die Kontrastierung des Destabilisierungsvorwurfs mit der historischen Realität legt daher den Verdacht nahe, daß der den Reformern eigentlich mißliebige Tatbestand gar nicht so sehr der einer unzureichenden filmischen Bearbeitung der gesellschaftlichen Probleme und Verhältnisse bzw. einer unvollständigen, zu wenig differenzierten Sozialkritik ist, sondern der eines kritischen Impetus sowie die Behandlung gesellschaftlicher Fragen schlechthin. Tatsächlich bestätigt ein genauerer Blick auf die reformerischen Formulierungen diesen Verdacht. Wenn etwa Gaupp anklagend davon spricht, daß durch die entsprechenden Filme ,quälende Gedanken über die Ungerechtigkeit der Welt' erzeugt würden, so ist das faktisch inkriminierte Phänomen nicht mehr die fehlerhafte Durchführung der Kritik bzw. eine mangelhafte Differenziertheit der Darstellung. Geklagt wird hier über das Aufzeigen von Mißständen und Defiziten an sich. Das aber bedeutet, $\mathrm{da}$ B die kritische Reflexion über Ungerechtigkeit und verbesserungswürdige Strukturen generell zu unterbleiben hat. Mag man Gaupp zwar an dieser Stelle zugute halten, daß seine Formulierung mit Bezug auf die Rezeption sozialkritischer Filme durch Kinder gewählt ist, so macht sein weiterer Text deutlich, daß er auch Erwachsene im Blick hat und eine allgemeine ,Erschütterung des Vertrauens in Recht und Ordnung' perhorreszieren möchte. Ähnlich verhält es sich bei anderen Reformern. Der wiederholt und gerne zitierte Ausruf, es handle sich bei Filmen wie "Geld regiert die Welt" um ,platte Volksvergiftung mit faustdicken, unverschämten Lügen', macht ihre Haltung deutlich: Jeder kritische Impetus wird als gefährlich eingeschätzt und diskriminiert; die Existenz der kritisierten Tatbestände wird schlicht geleugnet. Eine Auseinandersetzung mit sozialen Problemen und aktuellen gesellschaftlichen Fragestellungen soll im Film möglichst nicht vorkommen.

Diese Kritikfeindschaft der Reformer aber, wie der Destabilisierungsvorwurf in seinen spezifischen Teilvorwürfen überhaupt, bedeutet letztlich die Ablehnung einer offenen sozialen oder gesellschaftlichen Kommunikation. Die Darstellung der historischen Situation und ihre analytische Applikation auf die reformerischen Vorwürfe nämlich läßt über die Zweifelhaftigkeit der letzten hinaus auch deutlich werden, daß der Film dieser Zeit de facto Medium einer solchen Kommunikation ist. Wenn schon bei der Betrachtung des Sexualisierungsvorwurfs deutlich wurde, daß die inkriminierten Phänomene als Ausdruck und Spiegelung eines Ethoswandels, und damit als vermittelnde und befördernde Elemente eines sozialen und kommunikativen Prozesses zu verstehen sind, so zeigt sich ein analoger Tatbestand auch bei den Burlesken und Humoresken, den Melodramen und Salonstücken sowie den gesellschaftskritischen Filmen. Hier geht es nun allerdings weniger um einen Ethoswandel, als vielmehr um den schon mehrfach genannten Prozeß einer Veränderung der Öffentlichkeitsstruktur, wie er in 1.4. dargestellt wurde, und die Entstehung einer umfassenden sozialen Kommunikation. Jenen Prozeß gilt es, in den Blick zu nehmen, wenn der reformerische Vorwurf der sozialen Destabilisierung und sein bewahrethi- 
sches Paradigma recht verstanden werden sollen. Das soll geschehen, indem zunächst das Verhältnis von Film und Publikum sowie die zwischen ihnen möglichen Interaktionsformen genauer betrachtet werden.

\section{Zur zeitgenössischen Interaktionssituation von Publikum und Film}

Überprüft werden kann dabei gleichzeitig, ob und inwieweit die Kooperationsthese, die von den Reformern ebenfalls, jedoch sekundär und in sehr eingeschränkter, gemilderter Form zur Anwendung gebracht wird, den Destabilisierungsvorwurf zu stützen vermöchte. Obschon es die Verursachungsthese ist, die im Hintergrund die Argumentationsweisen hier hauptsächlich bestimmt, sprechen die Reformer an einigen Stellen nämlich auch von Publikumsdispositionen, die der Destabilisierungstendenz der Filminhalte in die Hände arbeiteten. So nennt etwa Lange ein ,Interesse‘ des ,ärmeren Zuschauers“ am „Leben der Reichen und Vornehmen“362: Jener wolle „die Verhältnisse dieser Menschen kennen lernen, die er in der Wirklichkeit kaum zu beobachten Gelegenheit“363 habe. Daher verlange das Publikum der „ärmeren Klassen“364 geradezu die Darstellung ,elegante(r) Herren in Frack und weißer Binde, mit Lackschuhen an den Füßen und Orden auf der Brust ${ }^{\star 365}$, sowie von Damen, die „seidene, weit ausgeschnittene Kleider tragen, mit Halsbändern und Armbändern aus Perlen, mit Reiherbüschen und Brillantagraffen im Haar،366. Neid und Mißgunst, die an anderer Stelle aus der Darstellung der Welt der ,Reichen' als einer Sphäre des Müßiggangs und Luxus zu fließen scheinen, wären hier die Frucht eines entsprechenden Rezeptionsinteresses, d.h. einer Latenz der Publikums, welcher der Film dann nur verstärkend entspräche. Allerdings wird dieser Schluß diesmal nicht in seiner vollen Schärfe gezogen und die Latenz nicht als böswillige diskriminiert. Die Kooperation zur Unzufriedenheit ist nur moderat angedeutet, wenn es heißt, der zuvor gescholtene ,Gegensatz von arm und reich“ im Film entspräche ,auch dem seelischen

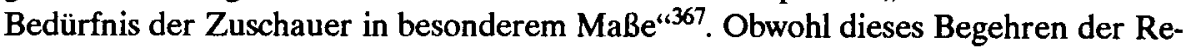
zipientenschaft nicht gerade begrüßt, sondern auch hier als Potentialität gewertet wird, die mit den Darstellungstendenzen des Films verderblich zusammenwirken kann, tritt es doch mit der mildernden Aura eines kindlichen Verlangens nach Glimmer und Glitter auf, dem Verständnis entgegengebracht werden muß. ${ }^{368}$ - Etwas anders verhält es sich mit Schultzes Klage über eine ,enorme Verworrenheit' des

362 Lange, Kino, 47
363 Lange, Kino, 47
364 Lange, Kino, 47
365 Lange, Kino, 47
366 Lange, Kino, 47
367 Lange, Kino, 47

368 Die realitätsfremde Vorstellung, „daß ,diese Leute da oben' ein sehr faules und schlemmerisches Leben führen" (Lange, Kino, 47), führt Lange dabei ebenfalls nicht in der Art der ,harten' Kooperationsthese auf eine perniziose, sozial gewendete Latenz des Publikums an sich zurück, sondern lastet sie einer weiteren,Verführung an: Dieses Bild nämlich habe die ärmere Zuschauerschaft „vom Gewerkschaftssekretär" (Lange, Kino, 47) bezogen. Wird nun gesagt, daß der Film die falsche Vorstellung bestätige (vgl. Lange, Kino, 47), so liegt auch darin weniger eine spezifische Umformung der Kooperationsthese, sondern mehr die Verstärkung des Bilds einer gewissermaßen doppelten Volksverführung oder,-vergiftung: durch die Gewerkschaften und den Film. Wenn von einer Kooperation zu sprechen ist, so von einer der Verführer; deren Wirkung auf das Publikum bleibt insgesamt jedoch der Verursachungsthese zugeordnet. 
Volks ,in staatlichen Dingen'. Zwar wird mit dem Terminus ,Verworrenheit' wiederum die Spitze des publikumspessimistischen Stachels in der Kooperationsthese gemindert. Das ,verworrene Volk‘ nämlich bedarf der Aufklärung, der Belehrung, in deren Kontext die Schultzesche Klage auch erhoben wird. Doch tritt der Publikumspessimismus hier deutlicher vor Augen und wird die schädliche Disposition dem Publikum selbst zugeschrieben, ohne zusätzlich auf eine Verursachung durch dritte abzuheben. - In der Milderung der Kooperationsthese äußert sich ein strategisches Moment, auf das ich weiter unten noch zu sprechen kommen werde. Zunächst aber will ich den Interaktionsformen von Film und Publikum sowie dem dadurch indizierten Prozeß nachgehen.

Die Bedürfnisse des Publikums, die seine Disposition ausmachen, sind genrespezifisch unterschiedlich anzusetzen. So läßt die breite Rezeption der humoristischsatirischen Filme vorerst auf ein entsprechendes Bedürfnis nach ,komischen' Filmen überhaupt und damit nach dem unmittelbaren Lustgewinn durch das Lachen schlieBen. Im Mittelpunkt des Amüsements stehen für das Publikum wohl die zeittypischen Formen des aktionsbetonten, am Practical joke orientierten Humors, dessen Dominanz selbst bei der Rezeption der ausgesprochenen Satiren angenommen werden kann. Diese Annahme rechtfertigt sich aus der Gewichtung derartiger erheiternder Effekte durch die Filme selbst, die ihnen breiten Raum zugestehen. So entspringt der primäre Lacheffekt sogar in der Geschichte des Notars vermutlich mehr den vertrauten Mustern der Burleske und ihrer derben Komik: dem Torkeln des Betrunkenen, der Schadenfreude über die Beraubung der lächerlichen Figur, seiner harschen Behandlung durch die Polizei etc. In dieser noch nicht unmittelbar auf strukturell-gesellschaftliche Problemstellungen bezogenen Erheiterung liegt eine Entlastung und eine Lust an sich, die als ein zentrales Moment des Rezeptionsinteresses festzuhalten ist. Gerade das Entlastungsmoment liefert denn auch die vordringliche Motivation für den Kinobesuch, wie die Untersuchung Altenlohs zeigt. So nennt die Mehrzahl der von ihr Befragten ,Zerstreuung und Unterhaltung ${ }^{\text {(369 }}$ als primäres Bedürfnis, dessen Befriedigung vom Film erwartet wird. Der Wunsch des Publikums richtet sich folglich zunächst darauf, mit Hilfe des Films dem Alltag und seinen Belastungen für eine Weile zu entkommen und - im Fall der humoristischen Filme - sich einer lustvollen Heiterkeit hinzugeben, ohne daß sogleich Bezüge zur Realität gesucht werden.

Ähnlich verhält es sich bei den Melodramen und Salonstücken. Deren zentrales Moment liegt in der Rührung. Sie ermöglichen eine Empathie, die den Rührstücken der Boulevardbühne und den ,Herz-Schmerz'-Romanen der Trivialliteratur gleicht. Nach ihrem ,Rührwert' bemißt sich zum größten Teil wohl auch der Grad ihrer Attraktivität. Altenlohs Studie macht darauf aufmerksam, daß insbesondere das weibliche Publikum diese Stücke schätzt und Männer zusammen mit ihren Begleiterinnen nicht zuletzt deswegen das Kino (statt einer anderen Vergnügungsstätte) aufsuchen, weil dessen meist gemischtes Programm auch Melodramen enthält: „'Er' will ,ihr doch ,etwas bieten', und die Dramen entsprechen meist ganz und gar ,ihrem' Ge-

${ }^{369}$ Altenloh, Soziologie, 95 
schmack.“370 Das Bedürfnis „ein bisschen Sensation, ergreifende Schicksale und himmlischen Edelmut (zu) erleben, um aus den engen Grenzen (der) Häuslichkeit einmal hinauszukommen “371, stellt dabei das Primärbedürfnis der Zuschauer dar. Es ist eine Mischung aus dem Wunsch nach ,Furcht und Mitleid', d.h. emotionalem Erleben, und nach Distanz zu den eigenen Lebensverhältnissen. In beiden Fällen, sowohl bei den humoristischen Filmen als auch den Melodramen und Salonstücken, scheint das Bedürfnis des Publikums folglich auf Kompensation auszugehen. Seine Disposition wäre dann weniger als gefährliche Latenz zu bestimmen, sondern eher als stabilitätsfördernde Rezeptionsbereitschaft. Gerade auch die Melodramen kämen dieser inhaltlich entgegen. Bei ihrer Rezeption begibt man sich zunächst und vordringlich in eine Welt, die romantische und märchenhafte Züge aufweist. Der ,Reiche' und der ,Arme' sind Typisierungen, die zeitenthobenen Mustern gleichen und stärker an den Prinzen und das Aschenputtel erinnern als an Krupp und den Stahlgießer. Auf der Ebene der ersten werden sie vom Publikum denn auch primär wahrgenommen und gebraucht, um den Alltag für die Dauer der Vorstellung zu verlassen. Die Kooperationsthese wäre dann aus Sicht der Reformer dahingehend zu präzisieren, daß Film und Publikum diesmal im Sinn der reformerischen Forderungen zusammenarbeiten; statt einer gefährlichen Latenz müßte eine befriedende angenommen werden. Der Destabilisierungsvorwurf dürfte sich nur noch gegen die gesellschaftskritischen Filme richten.

Dort nämlich findet tatsächlich eine wechselseitig verstärkende Interaktion von Film und Publikum statt, die sich als eindeutige, kritische und partiell sogar engagierte Auseinandersetzung mit den gesellschaftlichen Verhältnissen zeigt. In bezug auf die Inhalte des Films habe ich das oben bereits erarbeitet. Auf der Ebene des Publikums nun lassen sich sowohl ein Interesse an diesbezüglichen Fragestellungen als auch ein Wunsch nach Mitsprachemöglichkeiten im sozialen Diskurs erkennen. Wie die sozialkritischen Filme jedoch nur einen kleinen Prozentsatz des Gesamtangebots ausmachen, so stellt auch das eigentlich engagierte und aktive Publikum einen kleineren Kreis dar. Es handelt sich vorwiegend um gewerkschaftlich organisierte Arbeiter, die auch außerhalb des Kinos auf Mitspracherechte drängen, und in denen Altenloh geradezu einen neuen Typus des Arbeiters ausmacht. ${ }^{372}$ Diesen attestiert sie einen „Drang aus der Enge der eigenen Sphäre herauszukommen“373, ein "Teilhabenwollen' an den geistigen Gütern“374, das sowohl eine starke kulturelle Regsamkeit zur Folge habe als auch entsprechendes politisches Engagement. Entgegen der These vom ,dumpfen Volk' stellt Altenloh fest, daß ,von einer Abstumpfung durch den Beruf, wenigstens in den mittleren Jahren von 30-40, nichts zu verspüren ${ }^{، 375}$ sei. Stattdessen finde sich bei den Arbeitern dieser Altersstufe ein ,differenzierterer Geschmack ${ }^{376}$, der auch ein gewisses Bildungsbestreben mit sich bringe. -

370 Altenloh, Soziologie, 74, auch: 89 (zur Bevorzugung von Melodramen und Liebesgeschichten durch ,Gehilfinnen im Kaufmannsstand")

${ }^{371}$ Altenloh, Soziologie, 74

372 vgl. Altenloh, Soziologie, 71: „Dagegen differenziert sich innerhalb der Arbeiter ein neuer Typus heraus: der des organisierten Gewerkschaftlers.“

373 Altenloh, Soziologie, 72

374 Altenloh, Soziologic, 72

375 Altenloh, Soziologie, 72

376 Altenloh, Soziologie, 72 
Bei dieser Gruppe wäre nun in der Tat eine Kooperation mit dem Film zu konstatieren, die in reformerisch unerwünschte Aktivität führt. So spricht sich denn auch Lange mehrfach gegen die Gewerkschaften aus und sieht er in ihnen neben dem Film weitere Agenten einer Gefährdung der gesellschaftlichen Ordnungsstrukturen. Die Latenz des Publikums allerdings erscheint im Sinn der Milderung der Kooperationsthese nicht als eigenständige, mündige Mitsprache- und Gestaltungsforderung, sondern als gewerkschaftlich erzeugte: Der ,Gewerkschaftssekretär' gilt als der verderbliche Ideologe, durch dessen Agitation das unschuldige Volk in diese Latenzsituation getrieben wurde. ${ }^{377}$

Die Kooperationsthese, die solcherart auf die Verursachungsthese zurückgebogen wird, zeigt sich damit kaum weniger ideologisiert als die letztgenannte. Zwar ist sie mit der Tendenz ihres Grundparadigmas, ein Zusammenwirken von Film und Publikum anzunehmen, noch die fruchtbarste der drei Wirkungsthesen. Unter Absehung von ihrer mimetischen Engführung ließe sie sich sogar zur Interaktionsthese, d.h. zu der Annahme weiterführen, da $B$ zwischen Film und Publikum ein wechselseitiger Einfluß und Austausch stattfindet, der über mehrere Ebenen (heute von der Marktforschung bis zur Filmförderung bzw. von Genrepräferenzen bis zu lebensweltlichen und biographischen Umständen) vermittelt ist und der insgesamt als Teilmoment der sozialen Kommunikation begriffen werden kann. Doch steht bei den Reformern in der Kooperationsthese nicht nur das undifferenzierte Axiom der von gefährlichen (hier: sozial-imaginativen) Latenzen bedingten mimetischen Rezeptionshaltung des Publikums einer solchen Weiterbildung entgegen. Im vorliegenden Fall wird die These vielmehr in einer Weise angewandt, die den tatsächlich stattfindenden Prozeß, das reale Zusammenspiel von Film und Publikum eher verdeckt als enthüllt. Weder wird das stabilisierende Moment des primären Rezeptionsinteresses wahrgenommen, noch das Verhalten des gewerkschaftlich engagierten ,Arbeiterpublikums', das im übrigen ohnehin nur die am deutlichsten sichtbare Spitze der Interaktion von Film und Publikum darstellt, zureichend gedeutet. Die Mündigkeit, die sich darin äußert, sowie das eigenständige und in der Form selbstgewählte Bildungsbestreben, welche schließlich die Forderung eines Mitspracherechts in gesellschaftlichen Fragen zur Konsequenz haben, bleiben völlig aus dem Blick. Stattdessen wird die genannte Publikumsgruppe als verführte gezeichnet und so durch die Ausformulierung der Kooperationsthese ebenso entmündigt wie das ,Unterschichtspublikum' schlechthin, das erneut mit Kindern gleichgesetzt wird. Die ideologisierende Perspektivierung der These und ihre Moderatisierung zeigen sich in diesem Zusammenhang als strategische Absicht. Die Zielrichtung der Letzten erhellt aus dem pädagogischen Kontext, in den die Kooperationsthese bei Schultze gestellt ist: Gezeichnet wird dort das Bild einer notwendigen ,Aufklärung' von oben, derer ,das Volk' bedürfe. Obschon bei Schultze die ,Latenz' des Publikums nicht durch Dritte verursacht scheint, mißt der Terminus der ,Verworrenheit' diesem denselben Status zu, wie es Lange mit seiner Skizze einer Sehnsucht nach Glimmer und Glitter tut. So erscheint das Publikum einmal als doppelt verführtes und kindlich spielsüchtiges, ein andermal als ,verworrenes', in jedem Fall aber als eines, das nicht weiß, was es tut. Was die Verursachungsthese ohnehin voraussetzt, wird solcherart auch in die Kooperationsthese einge-

${ }^{377}$ vgl. etwa: Lange, Kino, 47 
bracht: Dem Publikum wird der Charakter eines hilf- und willenlosen Objekts filmischer Beeinflussung zugeschrieben. Seine ,Latenz' wird wie die Latenz von Kindern gedacht. Sie bleibt zwar angenommen und als gefährdend genug für den sozialen Frieden gewertet, doch aller bewußten Momente entkleidet. Die Notionen, Meinungen und Tendenzen des Publikums aber gelten damit nur noch als fehlerhafte Disposition, die der Manipulation durch den Film in die Hände spielt, ohne daß diese Disposition als bewußtes Begehren oder mündiges Interesse diskussionswürdig wäre. Das Publikum wird vom Manipulationsobjekt des Films zum schutzbedürftigen Objekt einer bewahrethischen Hegemonie der ,Gebildeten' erklärt. Sein Subjektstatus muß in diesem Modell weder an- noch ernstgenommen werden. Die Frage nach seiner Mündigkeit erledigt sich auf diese Weise probat, und seine Belehrung und Führung durch die ,Gebildeten' erscheint als notwendige und einsichtige Konsequenz. Die Wirkungsthesen erhalten damit den Charakter von Legitimationsinstrumenten. Sie sind nicht eigentlich mehr Spekulationen und Aussagen über das Zusammenspiel von Film und Publikum, sondern argumentatives Material im Dienst einer bewahr. ethischen Strategie der Reformer, die auf Behauptung der eigenen gesellschaftlichen Stellung als den ,Bildungsführern' zielt. - Genaueres Zusehen aber zeigt, daß sich diese Strategie gegen einen übergreifenden Gesamtprozeß richtet, den sie zwar nicht direkt in Blick bekommt, jedoch letztendlich zusammen mit den inkriminierten Phänomenen bekämpft. Dieser Prozeß reicht über die Interaktion von Film und Publikum hinaus, ist aber durch dieselbe indiziert und befördert.

\section{Demokratisierung und kommunikative Öffentlichkeit als eigentliches Skandalon im Destabilisierungsvorwurf}

Zunächst läßt sich, was als bewußter Gestaltungsanspruch durch die gewerkschaftlich engagierten Arbeiter und was in der Existenz der gesellschaftskritischen Filme als Tendenz vor Augen tritt, als weniger bewußter, jedoch über diese Gruppe und ihre Schicht hinausgreifender Proze $B$ auch in der Interaktion des breiten Publikums mit den anderen Genres dekodieren. Obschon das primäre Rezeptionsbedürfnis dort auf kompensatorische Lust und entlastende Distanz zur Alltagsrealität ging, ist auch eine sekundäre Rezeptionsaffinität erkennbar, die mit der (dort ebenfalls sekundären) Bearbeitung der sozialen Realität durch die Filme korrespondiert. So war zu sehen, $\mathrm{da} B$ in den satirisch-humoristischen Filmen wie auch in den Melodramen und Salonstücken die gesellschaftliche Realität aufgegriffen und bearbeitet wird. Obwohl die Melodramen und Salonstücke mehr in einer Welt mit märchenhaftem Gepräge spielen und primär wohl auf dieser Ebene rezipiert werden, bieten sie die Möglichkeit, realweltlich bezogene Fragestellungen mit zu transportieren oder auch an entscheidenden Stellen ins Genre der sozialkritischen Filme zu wechseln. Besonders die Filme mit Asta Nielsen stellen oft solche Übergangsphänomene dar. Bei den Burlesken und Humoresken entdeckte sich neben dem aktionsbetonten Humor ein Moment sozial orientierter Erheiterung, die zudem in einigen Fällen zur entschiedenen Satire weitergeführt werden kann. Vor allem Chaplins Filme sind meist auch deutliche Auseinandersetzungen mit der zeitgenössischen sozialen Realität und gesellschaftlichen Problemstellungen. So ist beispielsweise "The Immigrant" eine Stellungnahme zur Situation der fremdsprachigen Einwanderer in den USA. Auch bei Sennet und Linder finden sich entsprechende Bezüge. Das satirische Element etwa 
in „Max et le quinquina“, der den Zusammenhang von Autorität und gesellschaftlicher Stellung ironisiert, ist unverkennbar. Wenngleich in diesen Bezügen keineswegs eine schichtspezifische Diskriminierung oder Anlaß zu ,sozialer Verhetzung' gesehen werden kann, so liefern sie doch Gelegenheiten, vom Publikum als Kommentar zu den gesellschaftlichen Verhältnissen interpretiert und mit der eigenen Situation in Verbindung gebracht, bzw. als Reflexions- und DiskussionsanstoB genützt zu werden. Tatsächlich zeigt Altenloh, daß auf der Publikumsseite eine entsprechende Disposition, d.h. ein diesbezügliches Interesse und eine gewisse Auseinandersetzungsbereitschaft, angenommen werden können. Ihrer Studie zufolge bevorzugt die Rezipientenschaft jene Filme, ,zu denen Anknüpfungspunkte aus dem eigenen Millieu“ gefunden werden können - ,sei es, indem sie das eigene Leben schildern, wie es ist oder so, wie sie es sich wünschen" -, da diese Filme „stärker mitempfinden" lieBen. ${ }^{378}$ Auf diese Weise entsteht eine, relativ deutliche Vermittlung der Filminhalte mit den ,Lebenszusammenhängen' des primären Publikums. ${ }^{379}$ Zugleich aber ergibt sich damit - zunächst auf der Ebene der Emotion und des projektiven Mitfühlens der Anfang einer Auseinandersetzung mit den jeweiligen Fragestellungen. Vor allem beim Arbeiterpublikum sieht Altenloh im ,gefühlsmäßige(n) Aufnehmen und Einfühlen“ bei der Rezeption von Filmen die diesem Publikum ,adaequate Form, den Anschauungskreis zu erweitern" ${ }^{380}$ Insofern auch die emotionale Spiegelung in Figuren und Geschichten sowie die empathische Erprobung diesbezüglicher Erlebnisse und Handlungen Momente der Reflexion aufweisen, läßt sich die Rezeption der Filme als Prozeß einer Selbstverständigung deuten, die in den gesellschaftlichen Diskurs einmünden kann. Altenloh vergleicht die Filme mit sozialen Bezügen daher mit den „Zeitungsneuigkeiten“ und „Wochenberichte(n) im Kinobild“ und postuliert, $\mathrm{da} a$ das Interesse an den „Kinodramen“ und an den ,Nachrichten“ „gar nicht so verschieden" voneinander seien. ${ }^{381}$ In beiden Fällen, bei den Wochenschauen wie bei den ,sozialen Dramen', äußert sich eine neue Regsamkeit, ein gesellschaftlich-diskursives Verständigungsinteresse, das sich einmal auf der informationellen und ein andermal auf der imaginativen Ebene ansiedelt. Der Film tritt in diesem Zusammenhang als Medium der sozialen Kommunikation auf, dessen realweltliche Bezüge und Bearbeitungen gesellschaftlicher Fragestellungen einer Publikumsdisposition korrespondieren, welche als mehr oder weniger bewußtes Interesse an der Auseinandersetzung mit den ,sozialen Probleme(n) der Gegenwart“382 sowie an emotional-empathischer und reflexiver Selbstverständigung bestimmt werden kann. Der Interaktionsprozeß von Film und Publikum läßt damit neben der vom primären Rezeptionsinteressse der Entlastung und lustvollen Unterhaltung geleiteten Kooperation, die letztlich eine Abstraktion von der Realität darstellt, auch eine sozialkommunikative Kooperation erkennen, die auf Beschäftigung mit der gesellschaftlichen Realität zielt und einen übergreifenden Prozeß indiziert, welcher selbst dort stattfindet, wo das sozialkommunikative Rezeptionsinteresse nur sekundär und kaum bewußt ist.

${ }^{378}$ Altenloh, Soziologie, 58
379 Kommer, Film, 44
380 Altenloh, Soziologie, 72
381 Altenloh, Soziologie, 57
${ }^{382}$ Altenloh, Soziologie, 56 
Dieser übergreifende Prozeß nun ist jener Demokratisierungsprozeß, der bereits in der Entstehung der bürgerlichen Öffentlichkeit aus der literarischen grundgelegt ist (vgl. 1.4.) und in Konnexion mit dem Projekt der Moderne gesehen werden muß. Schon die bürgerliche Öffentlichkeit drängt auf Teilnahme aller am gesellschaftlichen Diskurs und enthält wurzelhaft die Tendenz zur Aufsprengung schichtspezifischer Begrenzungen. Über die Beschränkungen zirkelinterner Öffentlichkeiten etwa der ,Gebildeten` - hinaus zielt sie auf eine umfassende Öffentlichkeit, in der jeder mit jedem kommunizieren kann und ein Mitspracherecht in gesellschaftlichen, d.h. sozialen, kulturellen und politischen Fragen hat. Damit aber richtet sie sich auf eine schicht-aspezifische Ausweitung der sozialen Kommunikation und letztlich die Etablierung einer demokratischen Verfassung für Gesellschaft und Staat. Die Bedeutung der Medien für diesen Prozeß ist bereits bei der Herausbildung der literarischen Öffentlichkeit vor Augen getreten (vgl. 1.4.). Wie zu sehen war, stellen sie eine der zentralen Vermittlungsinstanzen dieser neuen Öffentlichkeit dar, wenn ab Mitte des 19. Jahrhunderts die durch Industrialisierung und Verstädterung entstandenen ,Massen' beginnen, an der medialen Kommunikation teilzunehmen und (auch) in diesem Bereich in den Raum der Öffentlichkeit einzudringen. Das Publikum der Salons und literarischen Zirkel wird auf diese Weise zum umfassend medialen, und damit vom internen zum öffentlichen Publikum. Neben Vereinswesen und Wirtshäusern (als den ,Salons des kleinen Mannes') tragen Zeitungen und Zeitschriften sowie ab 1895/96 eben auch Film und Kino zu dieser Entwicklung bei und bilden neue Foren für eine städtische Masse, die an der Verbreiterung der Öffentlichkeit und der Ausweitung der sozialen Kommunikation teilhat. Die von den Reformern inkriminierten Filme wiederum spiegeln und flankieren diesen Prozeß und können so, freilich mehr aus der Rückschau denn für die zeitgenössischen Rezipienten, als Begleitphänomen der medialen Durchsetzung des Projekts der Moderne und einer damit verbundenen ersten Demokratisierungstendenz der deutschen Gesellschaft betrachtet werden, einer Tendenz, die zum Zeitpunkt der reformerischen Bemühungen allerdings noch keine etablierte Selbstverständlichkeit ist. Tatsächlich gehen ja den zaghaften und inkonsistenten Versuchen der Weimarer Republik das wilhelminische Kaiserreich und der Erste Weltkrieg voraus, in welchen die bürgerliche Öffentlichkeit noch unter dem Paradigma hierarchischer Strukturen und einer Befehlsobrigkeit ihre Identität und ihr gesellschaftliches Bewußtsein gewinnt. Gleichzeitig aber deuten das Lachen des Publikums über die Burlesken und Humoresken wie auch die Ironisierungen einer steifen, aristokratischen Oberschicht in diesem Zusammenhang auf einen Abschied vom noch oligarchisch denkenden, an militärischen Hierarchien und ihrer Unveränderbarkeit orientierten Wilhelminismus und auf die Heraufkunft einer demokratischen Öffentlichkeit, die die ,Standesunterschiede' zumindest von ihrem Prinzip her nicht mehr kennt. So ergeben sich Brüche und Inkonsistenzen in einem UmschichtungsprozeB, der die zeitgenössische Situation als Übergangssituation kennzeichnet.

Die Reformer beziehen darin eine rückwärts gewandte Stellung. Sie wenden sich gegen den Prozeß der Entstehung einer schicht-aspezifischen Öffentlichkeit und einer umfassenden sozialen Kommunikation. Dieser Prozeß ist auf der Ebene der Gesellschaftstheorie der eigentliche Gegenstand ihrer diffusen Angst, wie sie im Kriminalisierungsvorwurf spürbar ist, bzw. auf den sich die modernitätskritischen 
Ressentiments gegenüber dem Ethoswandel und der darin aufscheinenden sittlichen Autonomie richten. Angelpunkt der reformerischen Angst und Abwehrgesten ist so das Projekt der Moderne. Tatsächlich hängen die von diesem Projekt eingeleitete subjektvermittelte Autonomisierung, eine offene gesellschaftliche Kommunikation und die einsetzende Demokratisierung sowohl historisch als auch theoretisch-systematisch wesenhaft zusammen. Ein autonomer Selbstentwurf des Subjekts impliziert Autonomie auch im Bereich der Moral und damit - innerhalb eines konsensfähigen, universalisierbaren ,Rahmenethos ${ }^{\prime}$ - einen dynamischen, fortschrittsbereiten Begriff von Sittlichkeit sowie wandelbarer Normen und Institutionen. Eine solche Beweglichkeit im Feld unbeliebiger, aber nicht starrer, aller Gestaltbarkeit entzogener Rahmenbedingungen wiederum bedarf über die Sphäre einer offenen Moralität hinaus offener Kommunikationsstrukturen und eines flexiblen Gesellschaftssystems, wie sie auf der Strukturebene nur demokratisch bereitgestellt werden können. Zur Zeit der Reformer nun erreicht diese Systematik zugleich als historischer Prozeß ein Stadium, in dem die von ihm erforderten Veränderungen auf eben eine strukturelle, d.h. politische Umsetzung drängen. Da dieser historische Prozeß aber aus systematischer Perspektive letztlich als strukturelle Konkretion wieder des Rationalisierungs- und Subjektivierungsprojekts der Moderne verstanden werden kann, ruft er die bereits spürbar gewordene kontramoderne Grundoption der Reformer auf den Plan. Der Destabilisierungsvorwurf der Reformer ist deshalb sowohl als Vorwurf der Auflösung einer überkommenen und überholten Gesellschaftsform zu lesen - wie nicht zuletzt die der aristokratischen Welt entstammende Wendung von der, Verhetzung der Stände" sprachlich belegt - als auch als erneute implizite Stellungnahme gegen das Projekt der Moderne zu werten.

Damit zeigt sich die kinoreformerische Bewahrethik als eine von den historischen Umständen regressiv bestimmte, (erneut) kontramoderne Theoriekonstruktion. Ihr Gesellschaftskonzept ist vertikal, autoritär, aristokratisch und antidemokratisch. Ihre Öfentlichkeitsvorstellung bleibt auf eine zirkelinterne Öffentlichkeit fixiert und von der schichtspezifischen Dichotomie bestimmt, welche zugleich das zirkelinterne Publikum dem zirkelexternen mit herrscherlichem Führungsanspruch überordnet. Die ,Aristokratie', die von den Reformern bemüht wird, ist zwar keine echt ständische mehr, sondern die der ,Gebildeten', d.h. jener gesellschaftlichen Gruppe, die schon in den kulturpädagogischen Bewegungen des 19. Jahrhunderts eine Führungsrolle für sich in Anspruch nimmt. Sie ist weiterhin auch nicht durch geburtsoriginären Status miteinander verbunden, sondern durch vereinsmäßige Selbstorganisation, mit deren Hilfe sie die strukturelle Durchsetzung und gesellschaftliche Wirksamkeit ihres Führungsanspruchs zu erreichen und zu sichern sucht. Doch beansprucht ihr Zirkel für sich eben jene Exklusivität und jenen Elitestatus, wie es einst die Aristokratie tat. Die Selbstorganisation, die eigentlich als demokratische Artikulationsform einer gesellschaftlichen Mitsprache- und Gestaltungsforderung anzusehen ist, dient so hier keinen demokratischen Zielen. Auch bleibt der Kreis der Organisierten beschränkt und in sich geschlossen: Zwar schreiben die Reformer wie die kulturpädagogischen Bewegungen das Bestreben, bildend auf die breiten Volkskreise einzuwirken, auf ihr Banner, doch sind diese Volkskreise immer Objekt der Bildungsbemühungen, d.h. $z u$ Bildende, und scheinen nie einen Status erreichen zu können, der es erlaubte, sie in die Gruppe der,Gebildeten' einzubeziehen. Innerhalb 
dieser Gruppe ist der Diskurs, sieht man von der unausweichlich hierarchischen Gliederung der Organisationen selbst ab, in mehr oder weniger horizontalen Bahnen eingerichtet, über ihre Schichtgrenzen hinaus aber gibt es nur vertikale Kommunikationsschächte. Die Bildungsvermittlung verläuft stets von oben nach unten; eigenes Bildungsbestreben, wie es etwa Altenloh beim Arbeiterpublikum ausmacht, sowie eine Selbstwahl der Bildungsmittel, -form und erst recht der Bildungsziele bleiben ausgeschlossen. Eine Autonomie des ,breiten', d.h. zirkelexternen Publikums ist - im Doppelsinn des Wortes - unannehmbar. Allzuviel Bildung bzw. solche, die zu gesellschaftlichem Handeln befähigte, ist daher trotz Betonung der Dringlichkeit einer Volksbildung nicht erwünscht. Das äußert sich zum einen in der ablehnenden Haltung der Reformer (und Kulturpädagogen) gegenüber den sich etablierenden, Volkshochschulen', die nicht zuletzt dazu gegründet werden, um ein breites Bildungsniveau zu erzeugen, das die Basis gerade auch für eine kompetente Teilnahme am öffentlichen Leben und am gesellschaftlichen Diskurs schaffen soll. ${ }^{383}$ Zum anderen zeigt es sich in der qualitativen Bestimmung der Bildungsgehalte selbst, die, wie mehrfach zu sehen war, aller strukturellen, gesellschaftlichen wie lebenspraktischen Bezüge entkleidet und vulgäridealistisch auf eine ,Erhebung' und ,Erhabenheit' verpflichtet werden, welche wiederum eine kompensatorisch-stabilisierende Funktion zugemessen bekommen. Die Forderungen des ästhetischen Paradigmas, das eine wirklichkeitsenthobene Funktion und Wirkung des Films vorschreibt, die Konsequenzen des anthropologischen Pessimismus, der den ,naturhaften', kulturell ,unbearbeiteten Menschen als gefährliches Latenzwesen mit einem endogenen Gefälle zur Unmoral ansetzt und der zu einem Publikumspessimismus transformiert diesen ,schlechten Wilden' in den großstädtischen Massen ausmacht, sowie die schichtspezifische Dichotomie, die einen herrscherlichen Antagonismus zwischen die ,Gebildeten' und das ,Volk' setzt, konvergieren so im Destabilisierungsvorwurf und dem ihm inhärenten kontramodernen Gesellschafts- und Öffentlichkeitskonzept. Sie fordern für den Film, daß er gesellschaftliche Dynamik und Entwicklung sowie soziale Probleme weder spiegeln noch bearbeiten soll, um die Verbreiterung der Öffentlichkeit nicht voranzutreiben und die Stellung der ,Gebildeten' nicht zu gefährden. Die großstädtischen Massen zeichnen sie als potentielle Raubtiere, die in bewahrethische und strukturelle Gehege gebannt werden müßten. Den Zirkel der ,Gebildeten' riegeln sie vertikal gegen personelle Erweiterungen ab und erklären sie zum alleinigen Verwalter der Bildungsinhalte und -zugangsmöglichkeiten. Letztlich führen sie auf dem Hintergrund des eigentlich verabschiedeten Wilhelminismus in eine autoritäre Zwei-

383 vgl. dazu für die Stellung der Reformer: Lange, Kino, 94-95; für die kulturpädagogischen Bewegungen: Münchhausen, Börries Freiherr von, Gegen die Volkshochschulen, in: Kunstwart 1920/33, 1-4; Langes Text macht dabei nochmals das aristokratische Moment des reformerischen Denkens und den Rückbezug auf die zugehörige, vergangene Gesellschaftsform deutlich, wenn er pejorativ vermerkt, daß es ,symbolisch“ sei, daß für die neugegründeten Volkshochschulen "die freigewordenen Fürstenschlösser als Unterkunft angewiesen werden“. (Lange, Kino, 95) Das Standesbewußtsein der Reformer erhellt auch an anderer Stelle, wenn Lange darüber klagt, daß die Revolution von 1918 gewissermaßen die ,Ränge vertauscht' habe: „Das Blättchen hat sich gewendet. Jetzt sind sie (die ,Massen', T.H.) die Aristokraten (...). Jetzt sollen die Gebildeten für sie arbeiten." (Lange, Kino, 299) Das letzte aber gilt ebenso als „Größenwahn, der sich der Massen infolge des Umsturzes bemächtigt hat" (Lange, Kino, 299), wie die Anhebung der Löhne, die nach der Revolution durchgesetzt worden ist. 
Klassen-Gesellschaft, die eine Führungsschicht von einer geführten unterscheidet und ihre rückwärts orientierte Stabilität nur wahren kann, indem sie die Festigkeit und Statik von Instanzen gegen die Beweglichkeit und Dynamik der historisch längst angelegten Demokratisierungstendenz setzt. Die strukturbezogenen normativen Forderungen, d.h. die gesellschaftlich-institutionellen Umsetzungsformen der kontramodernen reformerischen Bewahrethik sind daher strukturautoritäre.

\subsection{Das Gesicht der Reform: \\ Strukturautoritäre Lösungsvorschläge und totalitäre Konsequenzen}

Die Vorschläge und Forderungen der Kinoreformer, die einer Lösung der von ihnen eröffneten Problemlage dienen sollen, richten sich, wie die Formulierung ihrer Bestrebungen in der negativen Form von Devianzvorwürfen nicht anders vermuten läßt, auf Maßnahmen der Beschneidung, der Kontrolle, der Zensur und der Schaffung autoritärer, hierarchischer Strukturen. Andere Formen der Einflußnahme auf die Produktion und Rezeption des Films sowie Etablierung und Ausbau diskursiver Vernetzungen zwischen Produzenten, Film und Publikum werden entsprechend minder bewertet. Sie liegen auf der Linie jener impliziten Demokratisierungstendenz, der sich die Reformer gerade entgegenstellen. Die Interaktionsnetze auf der Verständigungs- wie auf der Handlungsebene, die zur Zeit der Reformer bereits existieren, werden daher selbst dann, wenn durch sie eine Veränderung der bestehenden filmischen Situation erreicht werden soll oder gar Bildungsbemühungen wahrnehmbar sind, mindestens abqualifiziert. Außerreformerische Unternehmungen gelten ohnehin als verdächtig und leicht korrumpierbar. So erscheinen weder die Filmbewertung in der Presse, die auf ,Erziehung des Publikums zum besseren Geschmack abstellt, noch die Etablierung erster Filmzeitschriften (wie „Der Kinematograph“), die den ,Filmfabrikanten' ebenso wie den Autoren, den Künstlern, Intellektuellen und dem ,populären' Publikum Artikulationsmöglichkeiten bieten, und die so einen fachbezogenen, spezifischen Diskurs einrichten, begrüßenswert. Sie alle räumen der zirkelexternen Öffentlichkeit zu breiten Raum ein, um Gefallen bei den Reformern zu finden. ${ }^{384}$ Selbst das Aussetzen erster Filmpreise ${ }^{385}$, das die Möglichkeit einer qualitätsbezogenen Veränderung der Angebotslage durch Filmförderung in Blick treten ließe, gilt nicht als adäquates Vorgehen, da hierdurch zwar bestimmte Filme be-

${ }^{384}$ Meist wird die Korrumpierung reformanaloger Bestrebungen freilich nicht auf die Demokratisierungstendenz direkt geschoben, da, wie zu sehen war, die Reformer von dieser Tendenz keinen expliziten Begriff haben und sich nur mittelbar gegen sie stellen, sondern auf die ökonomisch vermittelte Interaktion zwischen Produzenten und Rezipienten, durch welche die Angebotslage bestimmt ist. So klagt etwa Lange über den einseitigen „Geldbeutelstandpunkt" (Lange, Kino, 369) der Produzenten und sieht auch „unsere Finanzminister und Bürgermeister“ (Lange, Kino, 121) in ihren filmbezogenen Aktivitäten davon beeinträchtigt. Den außerreformerischen Gruppen, ihrem Engagement und den dortigen Diskursen wird daher keine positive Wirksamkeit zugetraut: Weder, ,von den Kinointeressenten, noch von den Künstlern, noch auch von dem Publikum, das bisher die Kinos füllte, (ist) etwas zu erwarten" (Lange, Kino, 125). Lediglich „einzelne, ethisch hochstehende und ästhetisch gebildete Menschen, die gegen den Strom schwimmen" (Lange, Kino, 125), können noch als Hoffnungsträger fungieren. Die ,wahre' Reform bleibt entsprechend dem internen Zirkel vorbehalten.

${ }_{385}$ vgl. Hellwig, Schundfilms, 89; Hellwig bezieht sich auf die vom Turiner Erzbischof anläßlich der kinematographischen Ausstellung von 1911 ausgeschriebenen Preise. 
günstigt werden, die übliche Produktion aber nicht ausgeschaltet wird. Im Gegensatz zu diesen (demokratieaffinen) Einflußnahmeversuchen fordern die Reformer ,durchgreifende Maßnahmen'.

Unter dieser Prämisse gelten sogar die eigenen Bildungsunternehmungen als nicht ausreichend. Hellwig unterscheidet bei den „Gegenmitteln“ gegen den ,Schundfilm' zwei Arten: „gütliche Mittel“" und „Zwangsmittel“ ${ }^{386}$ wobei er die bildungsorientierten Reformbestrebungen (und verwandte außerreformerische Unternehmungen) den ,gütlichen Mitteln“ zurechnet und diese als zwar ,außerordentlich verdienstlich“'387 bezeichnet, jedoch sogleich darauf verweist, da $\beta$,ein unverbesserlicher Idealist ${ }^{\text {“388 }}$ sei, wer sich davon wirklich positive Änderungen im Sinn der Reformer erhoffe. Alle Vereinsgründungen und selbstorganisatorischen Einflußnahmeversuche gelten als gutwillig, jedoch für sich genommen hilf- und wirkungslos. So bescheinigt etwa Häfker der Reformbewegung mit harschen Worten, ,im allgemeinen erfolglos in ihren Besserungsversuchen “ ${ }^{\star 389}$ zu sein, und führt dies auf eben das Moment der Selbstorganisation und mangelnde strukturelle Autorität zurück. Gegenüber der straffen, profitfunktionalen Organisation der Filmindustrie biete die Reformbewegung ,ein ungleich kläglicheres Bild“390, da sie „unklar und verworren in ihren Grundbegriffen ${ }^{\star 391}$ sei und auf ,mehr oder minder lauer (...), sogenannter gemeinnütziger Tätigkeit““392 aufbaue. Derartige Organisationsformen aber sind für Häfker lediglich ,Spiegelungen' einer ,unglaublich oberflächliche(n) Spielsucht، ${ }^{\text {393 }}$ kaum jedoch produktive Unternehmungen.

Gegen die ,Spielsucht' und ,mangelnde Wirksamkeit' der gemeinnützigen Selbstorganisation und ihre bildungsbezogenen Veränderungsbemühungen setzen die Reformer die Forderung strukturautoritärer Lösungen durch ,Zwangsmittel'. Mit ihnen

${ }^{386}$ Hellwig, Schundfilms, 89

387 vgl. Hellwig, Schundfilms, 91

388 Hellwig, Schundfilms, 93

389 Häfker, Gebildete, 26

390 Häfker, Gebildete, 26

391 Häfker, Gebildete, 26

392 Häfker, Gebildete, 26

393 Häfker, Gebildete, 26; Das Verdikt Häfkers bezieht sich zunächst lediglich auf die zeitgenössische Reformhektik, welche allenthalben neue Bewegungen zur Veränderung und Verbesserung der Lebensformen und -situationen entstehen läßt und entlockt dem Nachgeborenen im Anblick gegenwärtiger, analoger ,Reformismen' und ,alternativer Lebensformen' ein gewisses Schmunzeln. Doch trifft Häfkers Angriff zusammen mit den Reformbewegungen auch die darin aufscheinende Demokratisierungstendenz. Tatsächlich drängen die entsprechenden Bewegungen und Vereine ja auf gesellschaftliche Mitgestaltung und können selbst als protodemokratische Übungsformen auf dem Weg zur Durchsetzung des Projekts der Moderne interpretiert werden. Von ihrer historischen Herkunft aus den Bildungs- und Kulturreformbewegungen der Jahrhundertwende her eignet der Selbstorganisation der Kinoreformer potentiell selbst ein solcher demokratieaffiner Charakter, obschon sich ihre Ziele und ihr zirkelinternes Abriegelungsbestreben gegen diese Affinität sperren. Die Selbstkritik der Kinoreformbewegung, wie sie sich bei Häfker äußert, kann daher auch als Kritik an den modernitätsfreundlichen demokratischen Merkmalen der eigenen Organisationsform verstanden werden. Im Gegensatz zu diesen Merkmalen soll der Zusammenschluß der Reformer ja ein Kampfbund sein, der sich um Durchsetzung seiner Ziele gegen den sozialen Diskurs bemüht und der dabei keine Mitsprache einfordern will, sondern die exklusive Stellung des Wortführers im Sinn eines Befehlsgebers beansprucht. Organisationsform und Organisationsmotivation stehen so in einem Widerspruch zueinander, von dem die Reformer auch ein anfängliches Bewußtsein haben (siehe unten). 
soll die Bewahrethik gesellschaftlich umgesetzt, die Einmischung zirkelexterner Gesellschaftsmitglieder weitgehend ausgeschaltet und die Festigung der eigenen Position, Zielvorstellungen und Einflußnahmemöglichkeiten gewährleistet werden. $E r$ klärte Absicht der Lösungsvorschläge ist es, der Reform effiziente Instrumente und Verfahrensmöglichkeiten an die Hand zu geben. Das Effizienzargument dient dabei als Legitimation der strukturautoritären Ausrichtung; Hellwig etwa verweist darauf, $\mathrm{da} ß$ es schlicht zu lange dauere, auf gemeinnützigem Weg eine Volksbildung zu erreichen, die den inkriminierten Filmen die Rezeptionsbasis rauben soll. ${ }^{394}$ Im Unterschied zu diesem gelten die autoritären Maßnahmen als wirkungsvollere Abkürzungsverfahren für die Durchsetzung der Reform. ${ }^{395}$ In letzter Konsequenz aber zielen diese Verfahren auf die Errichtung der strukturellen Basis für eine als Kulturpädagogik angesetzte, jedoch über diese hinausreichende Kommunikationskontrolle, die tendenziell in ein ,Social engineering' mit Hilfe der Medien, hier des Films, mündet. Liest man nämlich die strukturbezogenen Lösungsvorschläge der Reformer im Konnex, so ergeben sie eine Stufenleiter von Überwachungs- und Einflußnahmeformen auf verschiedenen Ebenen, die insgesamt einen umfangreichen Verbund von Steuerungsmöglichkeiten bilden. Wie ich zeigen will, etabliert sich so mit den Realisierungsforderungen der Reform das Strukturmodell einer bewahrethischen Sozialtechnologie durch Medienkontrolle, die über den aristokratischen Charakter der Bewahrethik hinaus in Totalisierung führen kann.

\section{Umfassende Ermächtigung und Flexibilisienung der Zensur durch Gesetze}

Erste Vorschläge zur strukturellen Verwirklichung der Reform sind auf der Ebene der Gesetzgebung angesiedelt. Als , hervorragendes Instrument' kommt nach Hellwig nämlich ,zunächst das Strafgesetz in Betracht “39\%. Wünschenswert erscheint ihm und anderen „eine Sonderstrafbestimmung gegen den Schund in Wort und Bild ${ }^{4397}$. Mit ihrer Hilfe soll die Möglichkeit für eine umfangreiche Zensur und Kontrolle geschaffen werden, die es ,durch einheitliche staatliche Zwangsmaßregeln dem Unternehmer und Fabrikanten unmöglich macht, Schundfilms zu verwerten“398. Primär be-

${ }^{394}$ vgl. Hellwig, Schundfilms, $92-93$

395 Das Bedürfnis, die strukturautoritären Lösungsvorschläge mit Hilfe des Effizienzarguments zu legitimieren, kann als weiteres Indiz dafür gelesen werden, daß die Reformer sich des Widerspruchs zwischen (modernitätsfreundlicher demokratieaffiner) Organisationsform und (kontramoderner autoritärer) Organisationsmotivation bewußt sind. So betont Hellwig mit fast atemloser Beflissenheit die Verdienstlichkeit der Selbstorganisation: „Damit soll all diesen gemeinnützigen, außerordentlich anerkennenswerten Bestrebungen durchaus nicht die Daseinsberechtigung abgesprochen werden, im Gegenteil sind sie durchaus anzuerkennen, wie all' und jedes, was dazu beitragen will, unser Volk geistig zu heben, denn all diese Bemühungen werden sicherlich ihre Früchte tragen, jede Arbeit wird ihren Lohn erhalten", um dann fortzufahren: „aber nur langsam und allmählich, erst nach Jahrzehnten, vielleicht nach Jahrhunderten.“ (Hellwig, Schundfilms, 92; Hervorhebung von mir) Das Bild von der ,Jahrhundertarbeit" soll dann die Bevorzugung strukturautoritärer Zwangsmaßnahmen als ,Abkürzungswege‘ legitimieren: „So lange aber können wir nicht warten, wenn wir nicht die Flinte von vornherein ins Korn werfen und den Schundfilmfabrikanten das Feld räumen wollen." (Hellwig, Schundfilms, 92) In der atemlosen Beteuerung zuvor aber scheint das Bewußtsein von der genannten Selbstwidersprüchlichkeit, wie auch möglicherweise von der eigenen historischen Obsoletheit auf.

${ }^{396}$ Hellwig, Schundfilms, 90

397 Hellwig, Schundfilms, 90

398 Hellwig, Schundfilms, 93 
zieht sich diese Forderung auf die von den Devianzvorwürfen der Kriminalisierung und der Sexualisierung angegriffenen Filmformen. Sie versteht sich so als moralpädagogisches Erfordernis. Daneben aber ist auch schon eine entsprechend ,sensible Anpassung des Films an diverse soziale und politische Situationen in Blick genommen. Zunächst bezieht sich diese Anpassung auf die Vorführung von Filmen. So verweist Hellwig darauf, daß Filme ,,an bestimmten Orten und zu gewissen Zeiten gefährlich sein'“399 könnten und dann wie ,Schundfilme' zu behandeln seien. Als Beispiele nennt er „Streikbilder, wenn gerade ein Streik die Gemüter erregt, oder Films, welche in Grenzbezirken zu politischen Demonstrationen Anlaß geben können “400. Auch ,wissenschaftliche Filme; die der Belehrung dienen wollen, könnten zu bestimmten Zeiten oder in bestimmten Situationen negativ wirken und daher entsprechende gesetzliche Handhaben erfordern, die ihre situationsspezifische Zensur erlauben. So sieht Hellwig etwa aus einer „Filmserie über den Erreger der Schlafkrankheit“401, in der Tierversuche vorkommen, ,schädliche Wirkungen“ quellen, ,da, ohne da $B$ ihre Fabrikanten dies vermutlich beabsichtigt haben, durch sie die Antivivisektionsbewegung gestärkt" ${ }^{402}$ werde. Das aber gehe nicht an: „Trotz seines lehrreichen Charakters kann der Film mithin nicht gebilligt werden. “" ${ }^{403}$ Er klinkte sich sonst (ungesteuert) in eine thematische Auseinandersetzung ein, die von einer Gruppe selbstorganisiert begonnen wurde, ohne durch entsprechende staatliche Autorität gedeckt zu sein, und die daher als ganze abgebogen werden soll. Entsprechend der Lange'schen Maxime, daß Kunst der Kompensation zu dienen habe, und ihrer Übertragung auf die Produkte der Gebrauchskultur, müssen die Belehrung durch wissenschaftliche Filme und die Information durch Wochenschauen politisch und gesellschaftlich folgenlos bleiben und dürfen beide keineswegs in gesellschaftliche Auseinandersetzungen führen bzw. solche befördern. Wie zu sehen war, gilt die Rezipientenschaft zudem als politisch prekär: Wo der anthropologische Pessimismus verderbliche Latenzen mit vornehmlich individualethischen Konsequenzen annahm, setzt seine Umwendung in einen Publikumspessimismus große Teile der Öffentlichkeit als politisch inkompetent, daher verführbar und tendenziell ordnungszerstörend an. Obschon die ,soziale Latenz' im Destabilisierungsvorwurf wie die von Kindern gezeichnet und das Publikum weitgehend von Schuld entlastet worden ist (vgl. 2.5.), bleibt die Gefahr eines (diskursiven) Abgleitens in anarchisch-chaotische Veränderungsbestrebungen, des Entstehens ,unkontrollierbarer Prozesse‘ und des Umsturzes bestehender Strukturen offenbar dennoch immer erhalten und groß genug. Das Strafgesetz soll daher den ,zuständigen Autoritäten` die Handhaben geben, situationsspezifisch für die Wahrung der Lange'schen Maxime zu sorgen und die Interaktion von Film und Publikum präventiv in einem bestimmten Rahmen zu halten. Alle politischen Fragen und Probleme sowie sämtliche öffentlich relevanten Themen

${ }^{399}$ Hellwig, Schundfilms, 24

400 Hellwig, Schundfilms, 24-25; auch Lange sieht die Möglichkeit, daß „Darstellungen von Streiks oder Plünderungen (...) besonders in Industriestädten die Volksmassen aufreizen können" und verweist sofort auf die ,segensreiche“ Möglichkeit, daß dies „wenigstens bei uns in Württemberg durch Zensur der Ortsbehörde verhindert werden“ könne (vgl. Lange, Kino, 46).

${ }_{401}$ Hellwig, Schundfilms, 23

402 Hellwig, Schundfilms, 23; die in Frage stehende Agitation der Antivivisektionsbewegung stellt einen zeitgenössischen Vorläufer der gegenwärtigen Tierversuchsdiskussion dar.

${ }^{403}$ Hellwig, Schundfilms, 23 
bleiben darin staatlich reserviert, d.h. einer Führungsschicht vorbehalten, die als allein kompetente streng von der ,Volksmasse' als einem ,Pool' wimmelnder, naiver und gefährlicher Latenzen geschieden wird. Um diese Reservierung wirksam durchzusetzen, gilt es, alle diskursiven Anreize aus der sozialen Kommunikation zu entfernen. Die angezielte Steuerungsmöglichkeit ist folglich hier noch eine negative: Es geht vorerst nur darum, bestimmte Interaktionen zu verhindern und befürchteten Wirkungen vorzubeugen, nicht aber schon darum, gezielt bestimmte Wirkungen zu erzeugen. Ein dezidiert propagandistischer Effekt ist an dieser Stelle noch nicht im Blick; entsprechend der bewahrethischen Ausrichtung wird primär auf Repression und weniger auf Kreation abgestellt.

Einen Schritt weiter geht die Ausdehnung der Zensur von der Filmvorführung auf die Produktion, obgleich sich diese Ausdehnung selbst auf der selben Linie wie die Vorführungszensur sieht. Hellwig empfiehlt, ,um den Filmfabrikanten entgegenzukommen, ihnen gegen Zahlung einer bestimmten Gebühr die Ermächtigung zu erteilen, das Stück, welches kinematographisch aufgeführt werden soll, vorher in einer besonderen Probeaufführung vor dem Zensor aufzuführen“404. Er begründet dies mit der möglichen Kostenersparnis für die Produzenten, die auf diese Weise davor bewahrt blieben, Filme herzustellen, die sie dann aufgrund der Zensur nicht auswerten könnten. Die Herstellung eines ,Probefilms' unter Verzicht auf die ganze Ausstattung käme im Vergleich dazu billiger; auch sei dem Produzenten das ,Gutachten' des Zensors eine Hilfe zu möglichen Korrekturen. Darüber hinaus ergebe sich ,nach einer gewissen Übergangsperiode (...) ein ziemlich sicherer Maßstab dafür (...), ob der Zensor bei einem bestimmten Stück einschreiten werde oder nicht ${ }^{\star 405}$, so daß schon für die Auswahl der Manuskripte und Treatments entsprechende Selektionsmechanismen entstünden. Die Souveränität des Zensors will Hellwig freilich dadurch nicht angetastet wissen. Selbst bei positivem Gutachten über die Probevorführung solle diesem das Recht gewahrt bleiben, dennoch das Endprodukt negativ zu beurteilen. ${ }^{406}$

\section{Der protototalitäre Charakter des reformerischen Zensurkonzepts}

Diese Ausdehnung des Zugriffsbereichs scheint, wie es dem Primärcharakter von Zensur entspricht, zunächst ebenfalls noch präventiv-ausschließend gedacht. Nach Hellwigs Beteuerungen soll es darum gehen, daß bestimmte Filme nicht produziert, bestimmte Themen und Anreize nicht öffentlich angeboten werden. Die Erweiterung des Zugriffsbereichs gibt sich produktionsfreundlich als Einsparungs- und Orientierungshilfe: Was gar nicht existiert, muß nicht mehr beschlagnahmt und zum Verlustgeschäft gemacht werden. Die ,entstehenden Maßstäbe wiederum gelten als implizite, gegen Extreme gerichtete Grenzmarkierungen, nicht aber als positiver Normkatalog mit inhaltlichen Produktionsvorschriften. Die Produktionszensur bleibt so verbal im Rahmen der bewahrethischen Reservierungs- und Ausschlußbemühungen. Ein staatlicher Auftragsfilm scheint noch nicht in Blick genommen; die genannten Maßstäbe zielen weniger auf politische, denn auf ,sittliche' Wirkung. Trotzdem reichen die Implikationen der Produktionszensur weit über die der Vorführungszensur

\footnotetext{
${ }^{404}$ Hellwig, Schundfilms, 122

${ }^{405}$ Hellwig, Schundfilms, 122

406 vgl. Hellwig, Schundfilms, 122-123
} 
hinaus. Zunächst bedeutet die Tatsache, daß der Zugriff der Zensur schon bei der Produktion ansetzen soll, eine hohe Verdichtung der interaktiven Nähe von Filmschaffen und staatlicher Einflußnahme. Während die Vorführungszensur immer noch die autonome Fertigstellung eines möglicherweise mißliebigen Werks erlaubt, das dann selbst bei Verbot als ,Fait accompli‘ zumindest eine Auseinandersetzung und öffentliche Diskussion möglich macht oder vielleicht gar die Rücknahme des Verbots nach sich zieht, und während sie eine gewisse Distanz zwischen Produktion und Kontrolle setzt, die den Produzenten noch ermutigen kann, seine Grenzen auszureizen, verklammert der skizzierte Entwurf die Produktion mit der Zensur zu einem heteronomisierten, hierarchischen Verbund. Die angezielte gutachterliche Tätigkeit des Zensors nämlich, die über Zustimmung oder Ablehnung hinaus ja Korrekturanregungen geben und für die Schaffung von Maßstäben sorgen soll, erhebt diesen mindestens in die Stellung eines inhaltlich und detailwirksam zuständigen Produktionsberaters. Aus der mittelbar maßstäblichen Wirkung der Zensur wird eine unmittelbare: Der Zensor gerät vom Exekutivorgan des Staats zum staatlichen Koproduzenten, das heißt aber: vom Grenzwächter zum Regenten. Trotz der Beteuerung des Grenzsteincharakters der Maßstäbe ist damit die Basis für eine staatliche Lenkung des Filmschaffens bis in die Feinstrukturen der Filme hinein gelegt. Aus den ,Grenzmarkierungen' des Zensor-Regenten vermögen sehr rasch eindeutige ,positive' Normkataloge zu werden, die denn doch gezielten Produktionsvorschriften gleichkommen. Ebenso rasch kann die moralbezogene Kommunikationskontrolle von einer politischen flankiert und die Heteronomisierung auf die politisch-gesellschaftliche Rolle des Films ausgedehnt werden. Die Überlegungen Hellwigs zur situationsspezifischen Vorführungszensur legen diese Flankierung ohnehin nahe; der Destabilisierungsvorwurf liefert hierfür die argumentative Basis. Das bewahrethische Paradigma, das auf Zuständigkeitsreservierung, Schutzmaßnahmen und Leitstrukturen abhebt, erhält so über seinen aristokratisch-autoritären Charakter hinaus einen Zug zur Totalisierung. Der Gedanke einer Verklammerung von Zensur und Filmproduktion nämlich kommt einer Aufhebung von Zuständigkeitsbereichen gleich, die die Aufhebung einer Gewaltenteilung impliziert. Produktionsspezifische, d.h. ökonomische und ästhetische subsumieren sich zensurspezifischen, d.h. moralischen und politischen Kriterien durch strukturelle und personelle Verflechtung. Die kommunikative Macht der Filmproduktion koinzidiert potentiell mit der Herrschaftsmacht des Staats. - Tatsächlich verwundert eine solche protototalitäre ${ }^{407}$ Konsequenz-

407 „Protototalitär“ nenne ich, was der Totalität den Weg bereitet. Totalität ist erreicht, wenn alle gesellschaftlichen Bereiche in einen dirigistisch-monopolistischen Umgriff genommen sind und die gewaltenteilend wirksamen Grenzen zwischen den Kultursachbereichen dadurch aufgehoben werden. Die strukturautoritären Lösungsvorschläge der Reformer beziehen sich demgegenüber nur auf einen Kultursachbereich, den der Medien und darin wiederum nur auf den Film (obschon durch die personelle Verkettung mit der literarischen Schmutz- und Schunddebatte Überschritte zu den Printmedien gegeben sind). Zudem sind sie faktisch in den Kontext einer politischen Demokratisierung Deutschlands eingebettet, die mit der Weimarer Republik dann erstmals ihre explizite Gestalt findet. Dieser historische Kontext nötigt die Reformer im. mer wieder zur Reflexion der Möglichkeiten, demokratische Momente in ihre Konzeptionen einzubeziehen. Aus diesen beiden Gründen: Beschränkung auf Film bzw. Medien und historischer Kontext, können die Lösungsvorschläge noch nicht als völlig totalitär bezeichnet werden. Innerlich aber zielen sie, wie zu sehen sein wird, auf totalitäre Strukturen, so daß sich der Verdacht nahelegt, daß es oft nur der thematischen Beschränkung der Reformer zu verdanken ist, 
ziehung der reformerischen Bewahrethik nicht: Sowohl der anthropologische als auch der publikumsspezifische Pessimismus lassen lediglich strukturautoritäre Lösungsvorschläge zu. Wo die individuelle Kompetenz und Mündigkeit nicht mehr angenommen werden können, weil der Mensch schlechthin bzw. bestimmte gesellschaftliche Gruppen und Schichten als durch verderbliche Latenzen korrumpiert gelten, bleibt nur die Möglichkeit, durch Institutionen und Strukturen das zu ersetzen, was Vernunft und Ethos zu leisten hätten. Von einer solchen Orientierung auf strukturautoritäre Lösungen hin aber ist der Schritt zur totalitären als der endgültigen Strukturautorität nicht weit.

Entsprechend fallen auch die Vorschläge der Reformer zur Organisationsform der Zensur aus. Plädierte schon Hellwig für eine unumschränkte Souveränität des Zensors, d.h. eine Rechtsmacht, die diesen auch nicht an vorab gegebene gutachterliche Einschätzungen bindet, so wendet sich Lange gegen jede Beschränkung und ,Untergrabung der Strukturautorität durch ihren personellen Aufbau, d.h. gegen demokratieaffine Inklinationen wie etwa die Beiziehung von ,Sachverständigenausschüssen', die den zensierenden Ortspolizeibehörden vor Erlaß des Reichslichtspielgesetzes 1920 zur Seite standen. Obschon der Personenkreis dieser Ausschüsse der Schicht der ,Gebildeten' entstammte - Lange nennt Lehrer, Ärzte, Geistliche, Beamte, Schriftsteller, Künstler ${ }^{408}$-, wird deren Tätigkeit negativ beurteilt, da die Erfahrung lehre, ,daß, wenn sich die Veranwortung auf mehrere verteilt, keiner sie in vollem Maße fühlt ${ }^{\star 409}$ und die Tätigkeit entsprechend ineffizient ausfalle. Stattdessen werde „ein feingebildeter literarisch und künstlerisch interessierter Polizeiamtmann (...) meistens mehr leisten“410. Ähnlich negativ beurteilt Lange auch die Zusammensetzung der Sachverständigenausschüsse der Prüfstellen, wie sie das Reichslichtspielgesetz vorsieht. ${ }^{411}$ Dort wird bestimmt, da $\beta$ Vertreter der Filmindustrie, der Arbeiter und der Jugendlichen zu bestimmten Anteilen an der Arbeit der Ausschüsse beteiligt werden sollen. Lange sieht die Ausschüsse so durch ,Profitinteressen' der Produzenten, ,Unverstand' und ,Bildungslosigkeit' der Arbeiter sowie ,Unreife' der Jugendlichen korrumpiert, obschon das Gesetz eine durchaus abgewogene Beteiligung anziel ${ }^{412}$ und letztlich nur auf demokratische Mitsprache relevanter und betroffener Gruppen abstellt. Gegenüber diesen demokratieaffinen Organisationsformen der Zensuraufgaben bevorzugt er die personelle ,Zentralisierung in Händen der polizeilichen und staatlichen Autorität. Statt Ausschüssen fordert er den ,feinsin-

wenn nicht ein totalitärer Umgriff aller gesellschaftlichen Bereiche explizit durchkonstruiert wird. Im übrigen wird sich zeigen, daß trotz des historischen Kontexts die ,Entelechie‘ der Reformkonzeptionen auf Totalität zumindest im Bereich Film zielt. Aufgrund dieser wegbereitenden ,Entelechie' nenne ich sie protototalitär.

408 Lange, Kino, 158

409 Lange, Kino, 158

${ }^{410}$ Lange, Kino, 158-159

411 vgl. Lange, Kino, 236-239

412 vgl. Reichslichtspielgesetz vom 12. Mai 1920, § 9; Abdruck in: Lange, Kino, 225-230. Beigezogen werden sollen zu einem Viertel Personen ,aus den Kreisen des Lichtspielgewerbes", wobei die Arbeiter und Angestellten in dieses Viertel fallen. Ein weiteres Viertel sollen Personen aus „Kunst und Literatur“ sein. Die Hälfte des Ausschusses soll aus „auf den Gebieten der Volkswohlfahrt, der Volksbildung oder der Jugendwohlfahrt besonders erfahrenen Personen" bestehen. Jugendvertreter im Alter von 18 bis 20 Jahren sollen in Belangen von Jugendvorstellungen, gehört' werden. 
nigen' Polizisten bzw. den staatsbediensteten Zensor. Nicht minder autoritär verhält sich Hellwig, wenn er gegen die zeitgenössische Kritik am ,Polizeistaat' fordert, „endlich wieder eine gesunde Mittellinie einzuschlagen" und diese dann als Haltung bestimmt, die „nicht im geringsten zögert, sich im Kampfe gegen soziale Mißstände der Hilfe des Gesetzes und der Polizei zu bedienen". ${ }^{413}$

Die zeitgenössischen demokratieaffinen Tendenzen, die hier ohnehin nur sehr zaghaft zu Tage treten (nämlich lediglich in der Organisation der Zensur, die ansonsten unbefragt legitim erscheint) werden damit erneut zurückgewiesen; der Strukturautorität wird der Vorzug gegeben. Argumentiert wird wiederum bewahrethisch aus den Prämissen der Devianzvorwürfe heraus, die dann über das Effizienzargument zu protototalitären Konsequenzen weitergeführt werden: Zunächst werden ,Latenzen ${ }^{6}$ beschworen, die bei den ,gutwilligen', d.h. den reformfreundlichen Gruppen als Neigung zu Untätigkeit aufgrund der Verteilung von Verantwortung, bei den mißliebigen (bzw. zu schützenden, da noch unkulturierten) Gruppen als Interessengebundenheit, bzw. als Naivität und Unverstand angesetzt werden. Dann wird die demokratieaffine Organisationsform als Schwachstelle im Damm der kulturwahrenden Zensur, wenn nicht gar als präformierter Einbruchsbereich für die Flut der Devianzen gezeichnet und schlieBlich die Konzentration der Zensuraufgaben in der einen, staatsbediensteten Hand zur ,sauberen' Lösung erhoben. Das Effizienzargument dient erneut als Legitimationsinstrument. Protototalitär wird die strukturautoritäre Lösung dadurch, da $B$ sie mit der exklusiven Requirierung der Entscheidungsmacht für die polizeiliche, bzw. staatliche Autorität auf Aufhebung der gewaltenteilend wirksamen Grenzen zwischen den Zuständigkeitsbereichen des Filmschaffens, der Filmwirtschaft und der politischen Organisation der Gesellschaft im Staat, d.h. aber: der Grenzen zwischen den Kultursachbereichen ${ }^{414}$ drängt.

\section{Faktisch-historische Konkretion: Zur Wirkung der Kinoreform}

Faktisch-historisch bleibt der reformerische Ruf nach Gesetzesbestimmungen nicht ohne Wirkung. Zwar werden die Vorschläge der Reformer vor 1933 nicht vollständig und bis in ihre letzten Konsequenzen umgesetzt, doch kommt es mit dem württembergischen Lichtspielgesetz von 1914, in diversen analogen länder- und stadtrechtli-

${ }^{413}$ Hellwig, Schundfilms, 136. Als solchen, sozialen Mißstand‘ betrachtet Hellwig den zeitgenössischen Film.

${ }^{414}$ Der von W. Korff geschaffene Begriff der „Kultursachbereiche“ ist hier als Doppelbegriff gebraucht: Der Bereich der Medien (hier repräsentiert durch den Film) stellt zunächst einen Kultursachbereich dar, der auf dieser Ebene von anderen (Kunst, Wirtschaft, Wissenschaft, Politik etc.) unterschieden wird. Die Unterscheidung, die sich in - etwa personell vermittelte Trennung von Zuständigkeiten umsetzen muß, ermöglicht Interaktionen zwischen den relativ selbständigen Zuständigkeiten, hält diese insgesamt aber beweglich. Sie kommt so einer Gewaltenteilung gleich, die den totalitären Umgriff verhindert. Im Bereich der Medien bzw. des Films treten nun einige der anderen Kultursachbereiche wieder in Erscheinung - etwa die Wirtschaft. Auch dort ist wiederum eine Scheidung wahrnehmbar und notwendig, wenn totalitärer Umgriff verhindert werden soll: Filmschaffen als Repräsentation des Bereichs der Kunst ist mit seinen sachspezifischen Kriterien beispielsweise zu trennen von Filmschaffen als wirtschaftliche Unternehmung mit dessen Kriterien (vgl. dazu 6.2.). Insofern nun Langes Konzeption all diese Zuständigkeiten in die Hände des Staats bzw. der Polizei gelegt sehen will, drängt er für den Kultursachbereich des Films auf Aufhebung der Grenzen zwischen den dort repräsentierten Kultursachbereichen und wird protototalitär. 
chen Bestimmungen und schließlich mit dem Reichslichtspielgesetz von 1920, die sämtlich Zensurgesetze sind, tatsächlich zu ,Sonderstrafregelungen' gegen ,Schmutz und Schund" (vgl. 2.1.). Der reformerische Einfluß ist in diesen Bestimmungen bis in die Formulierungen hinein spürbar. ${ }^{415}$ So spricht bereits vor 1914 etwa ein Erlaß des preußischen Kultusministers davon, daß der Film „auf das sittliche Empfinden dadurch schädigend" wirke, daß er ,unpassende und grauenvolle Szenen" vorführe, die „die Sinne erregen, die Phantasie ungünstig beeinflussen, und deren Anblick daher auf das empfängliche Gemüt (...) ebenso vergiftend einwirkt, wie die Schund- und

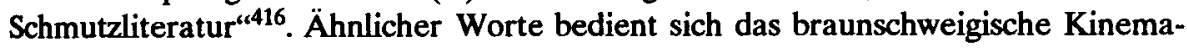
tographengesetz von 1911, das in Abs. 2 \& 2 verfügt, Filme einzuziehen, die ,geeignet sind, in sittlicher (...) Beziehung Anstoß und Ärgernis zu erregen ${ }^{4417}$. Dort wird auch explizit auf eine ,kriminalisierende Wirkung' des Films eingegangen: So heißt es, die Genehmigung zur Vorführung sei zu versagen, ,wenn durch die Darbietung der Bilder (...) zur Verübung einer strafbaren Handlung angereizt wird“418. Eine im Großherzogtum Sachsen-Weimar 1913 erlassene Ministerialverordnung verbietet die Vorführung von Filmen, die "gegen die guten Sitten verstoßen oder die geeignet sind, verrohend zu wirken "“419. Sowohl der allgemeine Vorwurf der moralischen Primitivierung durch empathiebezogene Desensibilisierung wie auch die latenzbezogene $\mathrm{Be}-$ fürchtung einer ,Fantasieüberreizung und der Kriminalisierungsvorwurf werden damit reformkohärent in Gesetzesbestimmungen gefaßt. Die oft weit angelegten Formulierungen räumen den ,zuständigen Autoritäten' einen nicht geringen Ermessensspielraum ein. - Sehr präzise und direkt hingegen formuliert die Dresdener Polizeiverordnung schon 1909, die Beispiele für ,zensurwürdige‘ Filminhalte gibt: „Hinrichtungsszenen, Darstellungen von Selbstmorden und Unglücksfällen mit aufregenden oder abstoßenden Begleiterscheinungen oder von sonstigen Schreckensszenen, die Darstellung von Tierquälereien (Stierkämpfe und dgl.) und vor allem die Darstellung von Verbrechen, namentlich von Mordtaten, Raubüberfällen, Einbrüchen usw.“420 fallen dem Verdikt anheim. Während alles Aufregende und Grausame als ,abstumpfend' und ,verrohend' gilt, wird im Verbot der filmischen Inszenierung von Selbstmord und Kriminalität das mimetische Wirkungskonzept spürbar. Die Kraft, die der

${ }^{415}$ Freilich entstehen diese nicht immer unter ihrem direkten Einfluß, sondern sind vom Kontext der ,Schmutz- und Schundkampagne' gegen die Trivialliteratur mitbestimmt. Beide Unternehmungen interagieren ja, wie unter 2.1. zu sehen war. Mit ihrem Engagement aber bestimmen sie die zeitgenössische Situation und Stimmungslage in einer Weise mit, die ihren Einfluß auch dort noch spürbar sein läßt, wo sie keinen direkten Zugriff haben.

${ }_{416}$ Erlaß des preußischen Kultusministers vom 8. März 1912, zit. nach Abdruck in: Hellwig, Kind $92-93,92$

${ }_{117}$ Braunschweigisches Gesetz betreffend Sicherheitsvorschriften, Filmzensur, Dauer der Vorstellungen, Kinderbesuch, Schankbetrieb in Kinematographentheatern, Sonntagsheiligung vom 5 . Dezember 1911, zit. nach Abdruck in: Hellwig, Rechtsquellen, 143

418 Braunschweigisches Gesetz betreffend Sicherheitsvorschriften, Filmzensur, Dauer der Vorstellungen, Kinderbesuch, Schankbetrieb in Kinematographentheatern, Sonntagsheiligung vom 5. Dezember 1911, zit. nach Abdruck in: Hellwig, Rechtsquellen, 147

${ }^{419}$ Verordnung des Ministeriums des Innern von Sachsen-Weimar betreffend Sicherheitsvorschriften, Kinderbesuch, Filmzensur, Plakate vom 4. Januar 1913, zit. nach Abdruck in: Hellwig, Rechtsquellen, 137-143, 138

420 Polizeiverordnung der Polizeidirektion zu Dresden betreffend Sicherheitsvorschriften, Dauer der Vorstellungen, Sonntagsheiligung, Filmzensur, Kinderbesuch, Plakate vom 8. Mai 1909, zit. nach Abdruck in: Hellwig, Rechtsquellen, 100-103, 102 
Mimesis auch durch die Verordnung zugemessen wird, erhellt nicht zuletzt aus dem Verbot der Darstellung der Selbsttötung. - Die genannte Polizeiverordnung enthält neben ihrer detaillierten Aufzählung auch schon die Bestimmung, jene Filme, die in ,politischer Beziehung Ansto $B$ erregen ${ }^{421}$ könnten, einzuziehen und ermöglicht so in ihrem Geltungsbereich die von Hellwig zwei Jahre später generell geforderte Vorführungszensur zum Zweck situationsspezifischer Anpassung des Filmangebots an soziale und politische Umstände. - Gesammelt treten die Devianzparadigmen der Reformer dann im württembergischen Lichtspielgesetz zutage, das auf Drängen re. formerischer Protestversammlungen und einer Veranstaltung in Tübingen unter Beteiligung Gaupps und Langes zustande kommt. ${ }^{422}$ In Art. 2 verfügt das Gesetz, daB die Zulassung eines Films zur Vorführung dann zu versagen sei, wenn die „dargestellten Vorgänge (...) geeignet" seien, die „Sittlichkeit der Zuschauer zu gefährden oder (...) eine verrohende oder die Phantasie verderbende oder überreizende oder den Sinn für Recht und öffentliche Ordnung verwirrende oder abstumpfende Einwirkung auf sie auszuüben “423. Nicht nur die Befürchtung einer generellen Korrumpierung der Sittlichkeit, also der moralischen Primitivierung, sondern auch der allgemeine Verrohungsvorwurf sowie das Bedenken einer Fantasieüberreizung und der Kriminalisierungsvorwurf - gemäßigt zur ,Verwirrung des Sinns für Recht und Ordnung - finden so Eingang in den Gesetzestext. Das württembergische Lichtspielgesetz ist denn auch jenes, das von den Reformern gerne als positives Beispiel weitgehend geglückter Gesetzgebung zitiert wird. Es bietet mit seinen elaborierten, jedoch unpräzisen Formulierungen die am weitesten ausgreifenden Zensurmöglichkeiten und kommt den reformerischen Repressionsbestrebungen am meisten entgegen. ${ }^{424}$

\section{Besteuerung, Konzessionspflicht und schulisches Monopol als flankierende Maßnahmen}

Mit Gesetzen und Verordnungen freilich sind die Forderungen der Reformer noch längst nicht vollständig eingelöst. Auch gilt die faktische Zensur, die bis 1933 immer eine Vorführungszensur ist, als nicht ausreichend, insbesondere da ihre Durchführung und Wirksamkeit zu lax erscheinen. ${ }^{425}$ Nicht der Gesichtspunkt, daß Beschneidung noch keine ,positiven' Filmformen hervorbringen kann, sondern die als mangelhaft beurteilte Repression durch die Zensurgesetzgebung initiiert deshalb zunächst weitere Forderungen. So gruppiert sich um die Auseinandersetzung mit zeitgenössischen Gesetzen eine Reihe von Überlegungen zu flankierenden Maßnahmen, welche auf der Seite des präventiv-ausschließenden wie auch der des

${ }^{421}$ Polizeiverordnung der Polizeidirektion zu Dresden betreffend Sicherheitsvorschriften, Dauer der Vorstellungen, Sonntagsheiligung, Filmzensur, Kinderbesuch, Plakate vom 8. Mai 1909 zit. nach Abdruck in: Hellwig, Rechtsquellen, 100-103, 102

422 vgl. Lange, Kino, 195 und 2.1 .

423 Württembergisches Lichtspielgesetz, zit. nach Abdruck in: Lange, Nationale, 63-66, 63

${ }^{424}$ Kritik, die von den Reformern, insbesondere Lange, am württembergischen Gesetz noch geübt wird, bezieht sich daher nicht auf dessen allzu große, sondern seine noch stellenweise als mangelhaft bewertete Rigidität. Vgl. dazu: Lange, Nationale, 68 - 70; Lange, Kino, 199-203

${ }^{425}$ So Lange, Kino, 245: „Im ganzen wird man aus der Kritik (...) den Eindruck gewonnen haben, daß Zensurgesetze überhaupt auf Dauer nicht wirksam sein können. Nicht weil sie die freie Meinungsäußerung knebelten - solange das Volk für eine solche nicht reif ist, können wir eine „Knebelung' nun einmal nicht entbehren - sondern umgekehrt, weil sie anscheinend nicht so streng formuliert werden können, daß eine Umgehung oder eine laxe Anwendung ausgeschlossen wäre." 
protototalitären Zugs der Bewahrethik angesiedelt sind. Auf breitem Raum diskutiert etwa Lange die Möglichkeiten der Konzessionspflicht, der Besteuerung und schulischer Einflußnahme zum Zweck der Beschneidung und Veränderung des filmischen Angebots. Dabei erscheinen ihm die ersten beiden als ebenfalls recht unzureichende und in ihrer faktischen Handhabung korrumpierte Instrumente. Die Konzessionspflicht für das Kinogewerbe, deren reichsweite Einführung ohnehin ständig verzögert wird, ${ }^{426}$ hält Lange in der vorgeschlagenen Formulierung für ineffizient. Zwar findet sich in der Vorlage ein Passus, der die Zulassung für die Gründung eines Kinos versagt, wenn anzunehmen sei, daß die Vorführungen "den guten Sitten zuwiderlaufen'427. Doch ist Lange das zu wenig scharf; er fordert stattdessen ein explizites Verbot der Vorführung von ,Kinodramen' sexuellen oder kriminellen Inhalts. ${ }^{428}$ Nur auf diese Weise scheint ihm noch einigermaßen einer Angebotslage gewehrt, die ein kulturfeindliches Bedürfnis beim Publikum erst entstehen lasse und die von einem Personenkreis vertreten werde, der ohnehin zur ,Volkserziehung ungeeignet sei. ${ }^{429}$ Die Konzessionspflicht gerät derart bei den Reformern zu einem weiteren Zensurgesetz, das sich direkt auf bestimmte mißliebige Filmgenres bezieht. Sie liegt in dieser Form, wie die Vorführungszensur, auf der präventiv-ausschließenden Linie der Bewahrethik. - Ähnlich verhält es sich mit den Lange'schen Überlegungen zur Besteuerung. Auch hier sieht er die faktische Situation als unzureichend und aus der Perspektive der Reform ineffizient an, ja, er konstatiert hier sogar ein verderbliches Zusammenwirken von Staat und Filmindustrie. Beide nämlich hätten ein Interesse daran, möglichst viel Gewinn zu machen, die Kinos durch hohe Besucherzahlen, der Staat durch großes Steueraufkommen. Das aber führe dazu, daß „um des pekuniären Erfolges willen die Qualität der Filme herabgesetzt, ihre Unanständigkeit und ihre sensationelle Aufmachung gesteigert ${ }^{\text {(430 }}$ worden seien. Denn das ,unmündige‘ und ,unerzogene' Publikum fordere, schlechte‘ Unterhaltung, nämlich das ,Kinodrama'. Solcherart

${ }^{426}$ Erst 1917 soll eine vom Bundesrat erarbeitete erweiterte Fassung des $\$ 33$ a der Reichsgewerbeordnung in Kraft treten, die explizit auch die Kinos berücksichtigt, doch führen Auseinandersetzungen um eine entsprechende Kompetenz des Bundesrats zur Rücknahme derselben. Erst im Zusammenhang mit dem Reichslichtspielgesetz wird das Thema erneut aufgegriffen. Vgl. Lange, Kino, 139-140.

427 Lange, Kino, 141

428 Lange, Kino, 141

429 Lange zeichnet in diesem Zusammenhang die Filmrezeption als ,falsches Bedürfnis', das erst durch die findige Industrie einem Publikum suggeriert worden sei. ,Früher' habe ein solches Bedürfnis gar nicht entstehen können, weil dem Publikum „die anständigeren und feineren Unterhaltungen ähnlicher Art zur Verfügung standen." - Der Personenkreis der Kinobesitzer wiederum rekrutiere sich aus Kaufleuten, Mechanikern, Schlossern, Monteuren, Schreinern, Maurern, Zahntechnikern, Packern, Konditoren, Schuhputzern, Köchen und Karusselbesitzern, mithin aus Leuten, „denen niemand eine besondere Eignung für die Direktion eines ,künstlerischen' Unternehmens oder für eine fruchtbare Tätigkeit auf dem Gebiete der Volkserziehung zutrauen" werde. (vgl. Lange, Kino, 136-137) Die Verpflichtung des Films auf Kulturpädagogik und Volkserziehung steht für Lange dabei außer Frage. Wie zu sehen war, fordern der anthropologisch grundgelegte Publikumspessimismus und der zugehörige Begriff der Kultur als Prävention ständige Bildungsanstrengungen. Eine freie Herausbildung des Kinowesens und eine nicht primär bildungsverpflichtete Unterhaltung können in diesem Paradigma deshalb nicht gedacht werden; die Kombination mit der schichtspezifischen Dichotomie requiriert das gesellschaftliche Projekt ,Kino' für die ,Gebildeten' und schließt den aufgeführten Personenkreis als einen selbst bildungsbedürftigen aus.

${ }^{430}$ Lange, Kino, 145 
aber wirke die Steuer geradezu ,reformfeindlich, d.h. kulturwidrig، ${ }^{\text {‘31 }}$. Der Staat gerate zum „Kinointeressenten“432 und verfehle seinen ,Erziehungsauftrag im Sinn einer Kulturpädagogik. Demgegenüber fordert Lange eine Staffelung der Steuer, die durch besonders hohe Besteuerung der reformerisch unerwünschten Filmformen deren allmähliche Beseitigung aus dem Geschäftsbetrieb und hierdurch eine Umorientierung auch des Publikums nach sich ziehen solle. ${ }^{433}$ Die Besteuerung erhält auf diese Weise ebenfalls einen zensierenden Effekt, wenngleich nicht mit jener Absolutheit und Direktwirkung, wie dies bei (erwünschter) Zensurgesetzgebung und Konzessionspflicht der Fall ist. Begründet wird diese ,progressive Steuer‘ wieder mit dem Effizienzargument.

Über die zensierende Wirkung hinaus gehen dann allerdings die Vorschläge zum Einbezug der Schulen in die Reformbestrebungen. Was sich bei der Produktionszensur bereits als generelle, umfassende Lenkungsmöglichkeit durch protototalitäre Verklammerung von Zensur und Filmschaffen gezeigt hat, wird hier nun in kleinerem Maßstab, jedoch nicht minder wirkungsvoll umgesetzt. Jenseits der Beschneidung und Verhinderung mißliebiger Filmformen soll in der Schule ein als förderlich erachtetes Filmangebot gemacht und der Film ,konstruktiv genutzt werden. Zwar betrachtet Hellwig den Weg, über die ,Schuldisziplin' Zugriff auf den Kinobesuch Jugendlicher zu bekommen, noch einzig unter negativem Aspekt, d.h. als Verbotsmöglichkeit, und diskutiert er entsprechend deren ausschließende Wirksamkeit. ${ }^{434}$ Lange jedoch fordert die Einrichtung und Förderung von schulisch betreuten Kinos. Auch er formuliert dies zunächst in Form eines Verbots: das „öffentliche Kino“ dürfe für Schüler „überhaupt nicht existier(en)“4335, bleibt aber nicht dabei stehen. Den Schülern soll vielmehr „der Besuch des Kinos (...) in der Form des Schulkinos“ gestattet werden, wenn auch „nur in der Begleitung der Lehrer“436. Zugleich solle „Volksschüler(n), die die Schule schon mit 14 Jahren verlassen" das Recht eingeräumt werden, „die Schulkinos bis zum 18. - 19. Lebensjahre (...) zu besuchen“.437 Auf diese Weise wird über das Kinoverbot durch die Schule hinaus versucht, die Filmrezeption der Jugendlichen nachhaltig in Griff zu bekommen. Geregelt kann so nicht nur werden, was diese nicht sehen, sondern auch, was sie sehen sollen. Primärzweck des Schulkinos ist dabei freilich zunächst die Vermittlung von Lehrinhalten durch den Film. Zusätzlich dazu aber will Lange die Tätigkeit der Schulkinos auch auf ,den unterhaltenden Film, den sogenannten Spielfilm “438 ausgedehnt sehen. Zwar betont er, daB es vorzuziehen sei, wenn das Kind abends spazieren gehe, bastle und „allerlei Sport" treibe, „um seinen Körper zu stählen“439, doch sei es von großem Wert, wenn die Schule auch die Unterhaltung zu ihrem Aufgabengebiet mache. Zumindest nämlich könne sie so eine wirkungsvolle „Konkurrenz gegen die Privatkinos“440 etablieren.

${ }^{431}$ Lange, Kino, 147; im Original gesperrt.

432 Lange, Kino, 146

433 vgl. Lange, Kino, 147-148

434 vgl. Hellwig, Schundfilms, $109-110$

435 Lange, Kino, 178; im Original partiell gesperrt.

436 Lange, Kino, 178; im Original gesperrt.

${ }^{437}$ Lange, Kino, 178

438 Lange, Kino, 253; im Original partiell gesperrt.

439 Lange, Kino, 253

440 Lange, Kino, 253; im Original partiell gesperrt. 
Da es auch unter dem Reichslichtspielgesetz und seinen Altersschranken kaum zu verhindern sei, daß Jugendliche in Kinos ihre Unterhaltung suchten, ${ }^{441}$ erscheint ihm ein Unterhaltungsangebot durch das Schulkino als durchaus geeignete Strategie für die Errichtung und Festigung einer möglichst umfassenden Rezeptionskontrolle. Für deren nachhaltige Wirksamkeit soll dann die Hinzuziehung der Polizei sorgen. Durch Überwachung der Kinos sollen die Durchsetzung und die Einhaltung der filmbezogenen Schulverbote erreicht werden.

Obschon die reformerischen Forderungen nicht vollständig eingelöst werden, entfalten sie doch eine gewisse historische Wirkung. So existieren nicht nur derartige Schulverbote, sondern mehrfach arbeiten die Schulbehörden im genannten Sinn mit der Polizei zusammen, bzw. übernimmt die Polizei die Aufgabe, für eine Einhaltung der Verbote zu sorgen. 1911 etwa erläßt die Stadtschulkommission Augsburg ein Verbot für die „gesamte (...) werktag- und sonntagschulpflichtige (...) Jugend“, zwei beanstandete Kinos zu besuchen und teilt über die Zeitung mit, daß die Vorstellungen „durch die Polizeiorgane kontrolliert und die betroffenen Schulpflichtigen mit disziplinären Strafen belegt" würden. ${ }^{442}$ In München wird die Bestimmung, daß der Kinobesuch schulpflichtiger Kinder bei Sondervorstellungen an die Zustimmung der Lokalschulkommission gebunden sei, in die polizeilichen Bedingungen aufgenommen, die den Kinobesitzern für den Betrieb ihres Kinos auferlegt werden. ${ }^{443}$ Auch in anderen Bezirken gibt es nach 1911 wiederholte Repressivkooperationen von Schulen, Schulbehörden und Polizei, die den reformerischen Vorstellungen entgegenkommen und etwa von Hellwig als „bahnbrechend“444 begrüßt werden. Besonders weit geht dabei 1912 ein Erlaß des preußischen Innenministeriums, der es als ,unbedingt erforderlich“ erachtet, die „Bestrebungen der Schulbehörden polizeilich zu unterstützen", und der den Einflußbereich dieser schulischen Maßregeln auch auf die "schulentlassene oder noch nicht schulpflichtige Jugend“ ausgedehnt sehen will. ${ }^{\mathbf{4 4 5}}$ Der Wunsch Langes, die Schulentlassenen in bezug auf den Film nochmals dem Einfluß- und Verfügungsbereich der Schule zu unterwerfen, findet so zumindest in der ,negativen“ Form der Schulverbote Unterstützung.

Ungeachtet ihrer nur partiellen historischen Einlösung liegen die reformerischen Vorstellungen zu Schulverboten, Schulkino und flankierenden Polizeimaßnahmen eindeutig auf der Linie der protototalitären Konsequenzen ihrer Bewahrethik. Langes Vorschläge zum Schulkino zielen auf eine vollständige Erfassung des jugendlichen Filmkonsums durch dasselbe und ermöglichen damit nicht nur eine gezielte inhaltliche Steuerung der Rezeption zum Zweck der Belehrung, sondern auch im Bereich der Unterhaltung. Das aber bedeutet die Ausschaltung jeder Selbstwahl in beiden filmischen Bereichen, dem informationellen wie auch dem imaginativen, und damit eine weitgehende Verunmöglichung einer diesbezüglichen autonomen Meinungs- und Maßstabsbildung bei Jugendlichen. Verschärft wird diese Verunmögli-

441 vgl. Lange, Kino, 253

442 Mitteilung der Augsburger Abendzeitung 1911, zit. nach: Hellwig, Kind, 90

443 vgl. Hellwig, Kind, 88-89

444 Hellwig, Kind, 93

445 Erlaß des preußischen Ministers des Inneren betreffend Kinderbesuch und Plakate der Kinematographentheater vom 3. Mai 1912, zit. nach: Hellwig, Rechtsquellen, 46-49, 47 
chung noch durch die Bestimmung, daß der Filmbesuch unter ,Begleitung' der Lehrer stattzufinden habe. Interaktionen der Jugendlichen untereinander im Kino, wie auch die Spielräume für ihre inhaltlichen Interpretationen des Gesehenen werden dadurch zusätzlich eingeschränkt und regelbar gemacht. Die Ausweitung der Zuständigkeit der Schule auf Schulentlassene und die polizeiliche Absicherung der schulischen Verfügungsmacht sorgen dafür, daß ein Ausweichen unmöglich wird und die ,Effizienz' der Rezeptionskontrolle gewährleistet ist. Bei vollständiger Durchführung der reformerischen Vorstellungen wäre so für die gesellschaftliche Gruppe der Jugendlichen als erster die Hegemonie der ,Gebildeten' um einer abstraktiv-präventiven Kulturation willen umfassend strukturell eingerichtet. Die ,gefährliche Latenz der Jugendlichen wäre dann, zumindest in Bezug auf den Film, ganz in pädagogischen Griff genommen und könnte entsprechend gesteuert werden. Bildungsmöglichkeiten werden in diesem Konzept zur ,Zwangsbildung, d.h. zum Oktroi einer pädagogisch-bewahrethischen Totalkontrolle.

Das protototalitäre Moment zeigt sich auch in der Beschneidung des Elternrechts durch ein derartiges Konzept. Tatsächlich bedeutet ja schon das ,Schulverbot' einen Eingriff in die Erziehungsgewalt der Eltern. In diesem Zusammenhang stößt auch der Jurist Hellwig auf das Problem, betont aber sogleich das Recht der Schulbehörden, ,im Interesse der Schuldisziplin, wie das Betreten von Schanklokalen und anderen Vergnügungsstätten, so auch den Besuch der Kinematographentheater ganz oder unter gewissen Bedingungen zu verbieten, trotzdem sie dadurch nicht unbeträchtlich in das Selbstbestimmungsrecht der Eltern eingreifen"446. Für gerechtfertigt hält er dies um so mehr, als ihm die Eltern inkompetent erscheinen, wenn es darum geht, den Kinobesuch der Kinder zu regeln. Er bezeichnet es geradezu als „Hauptfehler (...), daß man den Eltern die Fähigkeit zutraue, richtig zwischen Schundfilms und guten Films zu unterscheiden “447. Die ,Medienpädagogik“ wird so der Zuständigkeit der Eltern entzogen, welche durch die Form der Argumentation implizit selbst von Erziehungsberechtigten zu Erziehungsbedürftigen erklärt und solcherart entmündigt werden. Über die Schule wird ein Teil elterlicher Erziehungsmacht aus der Familie hinaus in eine staatliche bzw. staatsnahe Institution verlagert; Kinder und Jugendliche werden in bezug auf den Film mittelbar dem Staat, jedenfalls aber einer übergreifenden Strukturmacht unterstellt. Nun bedeutet die Übernahme von Erziehungsaufgaben durch die Schule an sich noch kein Abgleiten in eine protototalitäre Entwicklung. Auch eine schulische Flankierung der immer streitbaren pädagogischen Kompetenz von Eltern muß noch nicht gleich als solche verdächtigt werden. Prekär aber erscheint es, wenn die schulisch-staatliche Zuständigkeit für Medienpädagogik mit einer solchen Ausschließlichkeit, und ihre Verfügungsgewalt mit polizeilichen Maßnahmen durchgesetzt werden sollen. Wo es in anderen Bereichen, die als Bildungsaufgaben von der Schule übernommen worden sind, der Familie immer noch unbenommen bleibt, den Schulunterricht in ihrem Sinn zu ergänzen oder zu korrigieren, und wo sich derart eine pädagogische Kooperation ergibt, wird die ,Filmerziehung (als Erziehung durch den Film, wie auch zur Filmrezeption) dem familialen Raum in einer Weise entzogen, die geradezu einen Antagonismus zwischen Familie

${ }^{446}$ Hellwig, Schundfilms, 110

${ }^{447}$ Hellwig, Schundfilms, 107 
und Schule setzt. Verschärft wird dieser Antagonismus noch dadurch, daß entsprechende medienpädagogische Eigenanstrengungen unter Strafe gestellt sind. In dieser kooperationsfeindlichen Exklusivität der strukturellen Zuständigkeits- und Verfügungsrequirierung bezüglich filmischer Information und Unterhaltung liegt das eigentliche protototalitäre Moment des Eingriffs in das Elternrecht.

\section{Kommunalisierung als antidemokratische prozessuale Realisierungsform der Reform}

Ergibt bereits dieses bislang skizzierte Bündel der erwünschten und partiell historisch durchgeführten Maßnahmen zur Realisierung der Reform recht umfassende, strukturautoritäre Einfluß- und Steuerungsmöglichkeiten mit protototalitären Konsequenzen, so stellen sie für die Reformer doch nur die erste Stufe einer ,Lösung der Kinofrage' dar. $\mathrm{Zu}$ einem vollständigen Netz verknüpft werden nämlich sollen all diese Maßnahmenstränge in einer Kommunalisierung und schließlich Verstaatlichung des Filmwesens. Dort erst scheint den Reformern allem ökonomisch begünstigten Wildwuchs einer demokratisch-prozessualen Konstitution der filmvermittelten sozialen Kommunikation so gesteuert, daB die erwünschte abstraktiv-deduktive Kulturpädagogik, wie sie in den Devianzvorwürfen angezielt ist, möglich wird. So weist Lange darauf hin, daß „weder die Konzessionspflicht noch die Steuer, weder die Zensur noch das Gemeindekino noch auch die Gesetzgebung “448 dazu ausreichend seien, ,die ganze Industrie auf eine höheres Niveau zu heben, aus dem alten unmoralischen und unkünstlerischen Kino ein neues moralisches und künstlerisches zu machen “449. Wolle man dies erreichen, so gelte es vielmehr, dafür zu sorgen, „da $\beta$ Filmerzeugung und Kinobetrieb in absolut sichere Hände gelegt und in feste Beziehung zu der tatkräftigen Intelligenz der geistig Schaffenden gebracht werden“450. Das aber soll durch Kommunalisierung und Verstaatlichung geschehen.

Unter Kommunalisierung versteht Lange den „Übergang aller Kinotheater aller Städte in den Besitz und die Verwaltung der Gemeinden“451. Er unterscheidet dies vom ,Gemeindekino', dessen Errichtung etwa der Bilderbühnenbund (vgl. 2.1.) anstrebt, da dies die ,Privatkinos' nicht beseitige. In der Diskussion der Gemeindekinos und ihres Werts für die Durchsetzung und Verwirklichung der Reform widmet er sich daher vor allem dem Projekt von Schulkinos (vgl. oben) und weist im übrigen den Gemeindekinos den Status flankierender und vorbereitender Maßnahmen zu. Sie könnten eine gewisse Wirksamkeit als Konkurrenz zu den Privatkinos entfalten und sich eventuell ,ihr besonderes Publikum unter den Gebildeten erobern “452, so $\mathrm{daB}$ sich eine gewisse „Scheidung (...) zwischen solchen Kinos, die ein anständiger Mensch besucht, und solchen, die er meidet ${ }^{\text {“453 }}$, ergeben könnte. Darüber hinaus aber erwartet sich Lange von den Unternehmungen der Gemeindekinos wenig. Anders verhält es sich mit der Kommunalisierung. Mit ihr ist eine völlige Ausschaltung jeder privatunternehmerischen Tätigkeit zum Zweck der umfassenden Kontrolle des Programmangebots angezielt. Die erwähnten Schulkinos stellen dabei für Lange

\footnotetext{
448 Lange, Kino, 246

449 Lange, Kino, 246

450 Lange, Kino, 246; Hervorhebung von mir.

451 Lange, Kino, 249

452 Lange, Kino, 192

${ }^{453}$ Lange, Kino, 192
} 
einen ersten Schritt dar. Da sie ,ihrer Natur nach' von Lehrern verwaltet werden sollen, die meisten Schulen aber städtisch (unter staatlicher Aufsicht) unterhalten werden und Lehrer städtische Beamten sind, seien Schulkinos ohnehin ,in die Hände der Gemeinde übergegangen"454. Die jugendliche Filmrezeption untersteht damit bereits der Kommune. Kinos für Erwachsene sollen nachfolgen, wobei es als unumgänglich gilt, da $\mathrm{B}$ alle Kinos kommunalisiert werden, wenn der Film „nicht wieder auf die schiefe Ebene ${ }^{\text {“455 }}$ geraten solle. Schon bei Weiterexistenz einiger weniger Privatkinos nämlich stehe eben das zu befürchten, was auch die Gemeindekinos in ihrer wünschenswerten Wirkung beeinträchtigt: Die Entwicklung, „daß die große Masse des Volkes und auch die Kinder nur in diese, interessanten' Kinos gehen, die Gemeindekinos dagegen als ,belehrend, gouvernantenhaft und langweilig' ablehnen würden“456. Eine „gründliche Reform“ aber könne ,sich nur anbahnen, wenn das Volk überhaupt nichts Schlechtes zu sehen bekommt ${ }^{4457}$, d.h. die Programmgestaltung vollständig den Kommunen obliegt. Zugleich erhofft sich Lange davon, da $B$ auch der Filmindustrie, so ihre Verstaatlichung nicht gelänge, nichts anderes bliebe, als ihre Produktion an der streng nach Reformgrundsätzen gestalteten Nachfrage der Gemeinden auszurichten. ${ }^{458}$ Dem eingemeindeten Kino soll ein Direktor vorstehen, wobei es als möglich betrachtet wird, das ,alte‘ Personal zu übernehmen, sofern es sich zu einer Arbeit nach Reformgrundsätzen bereit erklärt. Um die Wahrung dieser Grundsätze zu gewährleisten, schlägt Lange eine Kombination von Überwachungsund Dispositionsmöglichkeiten vor: Der Direktor soll nicht auf Lebenszeit (wie andere Beamte) bestellt werden, sondern ,alle fünf Jahre neu gewählt werden“459. Zusätzlich soll „,ihm ein Beirat zur Kontrolle an die Seite ${ }^{460}$ gestellt werden, der aus „Mitgliedern des Gemeinderats und aus Lehrern, Geistlichen, Ärzten, Künstlern, Schriftstellern usw. bestehen ${ }^{\text {"461 }}$ soll. Dieser Beirat allerdings ist durchaus nicht als eine Art pluralistisches, protodemokratisches Gremium zum Zweck der Kulturförderung gedacht, sondern einzig als zensierendes Überwachungsinstrument. Lange betont daher auch, daß „dafür gesorgt“ werden müsse, „daß die Tätigkeit des Beirats nicht lähmend auf die Initiative des Direktors einwirkte" und derselbe ,wie bei der Zensur nur in Ausnahmefällen zu Rate gezogen" werden solle, ,d.h. dann, wenn die Zulassung eines Films zweifelhaft sein kann““ ${ }^{462}$ Nach Verstaatlichung sei der Beirat dann ohnehin unnötig, da „schon an der Zentralstelle eine strenge Sichtung stattgefunden hätte" ${ }^{\text {(463 }}$.

Bei vollständiger Durchführung des Langeschen Kommunalisierungskonzepts läge so das Kinowesen in den Händen städtischer Beamter und ihrer ,Souveränität', die im Auftrag der Kommune darüber wachen, daß das ,Volk' nur Filme zu sehen bekommt, die im Sinn der Reform als ,bildend' oder ,edel unterhaltend' gelten können.

\footnotetext{
454 Lange, Kino, 249

455 Lange, Kino, 255

456 Lange, Kino, 256

457 Lange, Kino, 256

458 vgl. Lange, Kino, 267

459 Lange, Kino, 265

460 Lange, Kino, 265

461 Lange, Kino, 265

462 Lange, Kino, 266.

463 Lange, Kino, 267
} 
Die städtischen Kinobeamten treten dabei als Vormünder des Publikums zwischen dieses und die Produktion. Sie monopolisieren die Nachfrage und hegemonialisieren die Rezipienten in einer Weise, die jede ökonomisch vermittelte Interaktion zwischen Produzenten und Publikum unterbindet bzw. nur als beamtlich vermittelte zuläßt. So sollen die Reformgrundsätze für beide Seiten, die Produktion wie die Rezeption, durchgesetzt, und kultureller Pluralismus sowie eine bewegliche, prozessuale und interaktive Konstitution der Filmproduktion weitgehend ausgeschaltet werden. Gedacht ist diese ,Lösung wiederum im Paradigma der kulturierenden Herrschaft einer abgegrenzten Schicht, welcher die übrigen Gesellschaftsmitglieder als nicht nur unmündige, sondern mit kulturfeindlichen Neigungen ausgestattete Bildungsbedürftige gegenüberstehen. Die getroffene Option ist, wie sich zeigen läßt, dezidiert undemokratisch und strukturautoritär. Das demokratische Moment der Wahl bleibt demgegenüber eine rein verbale Beteuerung.

Zunächst nämlich ist schon das Unterfangen der dirigistischen Nachfragemonopolisierung durch Beamte und entsprechenden Einflußnahme auf die Produktion an sich problematisch. Jeder Monopolisierungsversuch richtet sich gegen den Pluralismus, der Voraussetzung und Wesenszug einer demokratisch verfassten Gesellschaft und ihrer prozessualen, kommunikativen Aktualisierung in den verschiedenen Kultursachbereichen ist. Aus einem pluralen ,Pool' innerhalb eines dieser Bereiche kann sich je und je eine mehrheitliche Tendenz herauskristallisieren, die jedoch selbst wiederum nicht auf Beseitigung, sondern allenfalls auf Marginalisierung oder Binnengruppierung von anderen Tendenzen darin drängt. Die Entfaltungschancen nichtmehrheitlicher Optionen bleiben damit grundsätzlich erhalten. Anders in der hier vorgesehenen Beamtenstruktur. Diese versteht sich ja als Vormundschaft für jene Pluralität und tritt zwischen diese und das Publikum. Sie zielt auf autoritative Durchsetzung einer Tendenz gegen die Chancen der übrigen und ohne Berücksichtigung der Publikumsoptionen. Das Moment der Wahl, das bei Lange mit Bezug auf die Kinobeamten skizziert wird, verändert den undemokratischen Beamtenmonopolismus deshalb keineswegs in die Richtung einer demokratisch-repräsentativen Publikumsvertretung. Vielmehr verstehen sich die Kinobeamten statt als Anwälte der Rezipientenschaft als hegemoniale Wahrer der Reformgrundsätze gegen dieselbe. Die Wahl dient damit nicht der stellvertretenden Verwirklichung von Publikumsansprüchen, sondern der Einsetzung eines gegen diese gerichteten Aufsichtspersonals. Das Recht, sich seinen Vormund zu wählen, aber kann schwerlich schon als Verwirklichung von Demokratie gelten. Dezidiert undemokratisch wird das Konzept dann zusätzlich dadurch, daß die eigentliche Wahlmöglichkeit einzig eine der $A b w a h l$ ist und durch sie keine Inhalte zur Disposition gestellt werden. Die Wahl insgesamt soll, wie zu sehen war, ja als negatives, rein personalbezogenes Kontrollinstrument fungieren, mit dessen Hilfe ein Verstoß gegen die keineswegs wähl- oder abwählbaren Reformgrundsätze ahndbar gemacht wird. Im Sinn dieser Grundsätze sollen die Gewählten dann ihre Vormundschaft über das Publikum ausüben. Die Wahl ist so nur als Instrument der Disziplinierung und der Wahrung eines ideologischen Programms vorgesehen, das unantastbar außerhalb der demokratischen Einflußnahme angesiedelt wird. Die Direktoren sind lediglich als Repräsentanten dieses Programms wählbar und geraten in die Rolle austauschbarer Funktionäre. Ihre kulturelle Initiative und ihr programmatisches Profil werden durch die Verpflichtung 
auf die Reformideologie völlig heteronom präformiert. Eine Wahl aber, die keine inhaltlichen Alternativen bietet, korrumpiert zur Farce und verliert ihren demokratischen Charakter vollständig.

Ähnlich verhält es sich mit dem Charakter des Beirats, dessen Aufgaben nicht in künstlerischer oder kultureller Beratung, sondern in der Überwachung zweifelhafter Direktoren und deren möglicher Koketterie mit dem umzuerziehenden Publikum bestehen. Auch dieses Gremium ist als heteronom präformiertes Instrument der Reformgrundsätze gedacht, dessen programmatische Möglichkeiten entsprechend festgeschrieben sind. Sein Aktionskreis ist zusätzlich auf Zensur eingeschränkt und soll im übrigen die ,Souveränität' des Kinobeamten nicht ,positiv', etwa durch eigene Vorschläge für die Programmgestaltung, antasten können. Das bedeutet eine doppelte Absicherung gegen jede konstruktiv-flexible Mitwirkung des Gremiums: Seine kulturelle Initiative wird zum einen durch Verpflichtung auf die Reformgrundsätze kriteriologisch und inhaltlich starr festgelegt, zum anderen als zensierende Überwachungsaufgabe jeder Konstruktivität beraubt. ,Repräsentiert' ist das Publikum so durch das Gremium allenfalls negativ als zusätzliche Zensurinstanz, deren Kriterien gerade nicht die Präferenzen des Publikums sind, so daß die eigentliche Aufgabe der Repräsentation in ihr Gegenteil verkehrt wird. Kultureller Pluralismus und demokratische Mitwirkung sind also nicht nur nicht vorgesehen, sondern werden mit Hilfe der engen Zuständigkeits- und Aufgabenumgrenzung gezielt ausgeschaltet. Beide demokratisch scheinenden Maßnahmen: Wahl des Direktors wie Einsetzung eines pluralen Gremiums, erweisen sich als in Wahrheit gegen Demokratisierung und Pluralität gerichtete Präventionen. Sie entsprechen genau besehen zwar verbal dem historischen Kontext der politischen Demokratisierung Deutschlands, faktisch aber setzen sie die kontramoderne antidemokratische innere Stoßrichtung der reformerischen Absichten um.

Gleichzeitig wendet sich diese Konstruktion gegen die Kunstfreiheit für den Film. Zwar wird das nicht unter diesem Titel behandelt, da etwa Lange den Film nicht explizit als Kunst anerkennt (vgl. 2.2.). Doch stellt es sich auch systemimmanent insoweit als diskutables Problem dar, als die Reformgrundsätze, wie zu sehen war, eine präzise Vorstellung von der gesellschaftlichen Funktion der Kunst auf den Film übertragen und zudem genaue Kriterien für dessen inhaltliche und formale Gestaltung kennen. Die Kommunalisierung nun soll ja gerade der vollständigen Durchsetzung dieser Grundsätze dienen. Lange behandelt im Zusammenhang mit derselben daher den Film implizit, als ob er Kunst wäre, und stellt sich die Frage, ob die reformerische Kriteriologie und ihre strukturelle Verwirklichung seine Entwicklung beeinträchtigen könnten. Er vergleicht zu diesem Zweck das kommunalisierte Kino mit kommunalisierten Schulen und Theatern als den ,nächstliegenden Analogien für eine gleichzeitig volkserzieherische und volksunterhaltende Einrichtung wie das Lichtspielwesen “464. Dann räumt er ein, „daß städtische Theater manchmal den höchsten Anforderungen nicht genügen"465 und im Gegensatz dazu Privattheater „für die freie Entwicklung der Schauspielkunst und der dramatischen Poesie von

\footnotetext{
${ }^{464}$ Lange, Kino, 262

465 Lange, Kino, 262
} 
einem gewissen Nutzen“466 seien. Auch bei den Schulen sei festzustellen, daß Privatschulen ,ihren guten Sinn als Stätten des Experiments und des Fortschritts، ${ }^{\text {‘667 hät- }}$ ten. Tatsächlich also scheinen derartige ,private', von strukturell-obrigkeitlichen Regeln freigesetzte Unternehmungen sowohl für die Erziehung, als auch besonders für die Kunst förderlich zu sein, ja geradezu einer begrüßenswerten Weiterentwicklung zu dienen. Trotzdem aber insistiert Lange auf der Präferenz kommunaler Einbindung und beamtlicher Verwaltung. Schon bei den Theatern nämlich zeige sich, da $B$ das städtische ,in der Regel anständiger“468 sei als das private, wo sich doch ,auch vieles Problematische und Minderwertige“469 fände. Letztes führt Lange auf die private Organisation zurück. Das ,deutsche Beamtentum' hingegen sei ,wenigstens früher immer fleißig, gewissenhaft und unbestechlich gewesen “470, scheint also als Garant für eine ,seriöse' Programmgestaltung geeignet. Die beamtliche Organisation des Kinowesens gilt deshalb nicht nur als legitim, sondern, da das Kino ohnehin im Unterschied zum Theater „bisher weniger auf Kunst als auf Sensation eingestellt war'“471, geradezu als geboten.

Die Option für die beamtete Durchsetzung der Reformgrundsätze bedeutet letztlich eine Option für die Aufhebung der Kunstfreiheit des Films. Zunächst zeigen sich ja schon diese Grundsätze als problematisch: Sie beinhalten den Ausschluß ganzer Genres, das Verbot jeder Destabilisierung und - bei Lange - gezielte ästhetische Vorschriften. Selbst wenn man annimmt, daß die Langesche Filmästhetik, die beispielsweise die Großaufnahme untersagt und sich in ihrem frühen Stadium auch gegen perspektivische Wirkungen wendet, ${ }^{472}$ nicht normativ festgeschrieben würde, bleiben die anderen Bestimmungen repressiv genug. Weder im Bereich des Kriminalfilms, noch in der Auseinandersetzung mit Liebe und Erotik ließen sich künstlerische Werke schaffen, da diese Filmgattungen, wie zu sehen war, explizit per se verboten werden sollen. Die Vorstellung einer Destabilisierung, die einmal individuell als ,Fantasieüberreizung im Zusammenhang mit dem Vorwurf der moralischen Primitivierung und seiner anthropologischen Basis auftritt, aber auch Eingang in Gesetzestexte findet, zum anderen als sozial-gesellschaftlicher Balanceverlust ausgemalt wird, treibt in beiden Fällen Verbotsmaximen hervor, welche sich gegen die avantgardistische Weiterentwicklung von Kunst und damit gegen einen ihrer zentralen Wesenszüge richten. In der Tat besteht ja das Wesen des ,künstlerischen Fortschritts', jedenfalls der Schaffung von etwas künstlerisch neuem, in der Aufsprengung von Stilgrenzen, Wahrnehmungsgewohnheiten und Empfindungskanones. Das aber bedeutet zunächst eine ,Destabilisierung', eine verunsichernde Reizgebung und imaginative Umwälzung. Nicht nur für die individuelle Kunstrezeption trifft das zu, sondern auch für ihre sozial-gesellschaftliche Wirkung und Stellungnahme. So kann Kunst auch dort Wahrnehmungsgewohnheiten, Chiffren und symbolische Interaktionen transparent machen oder sprengen sowie ihren eigenen Blickwinkel der gesell-

\footnotetext{
${ }^{466}$ Lange, Kino, 262

${ }^{467}$ Lange, Kino, 262

468 Lange, Kino, 262

${ }^{469}$ Lange, Kino, 262

${ }^{470}$ Lange, Kino, 262

${ }^{471}$ Lange, Kino, 262

472 vgl. Lange, Nationale, 20-21
} 
schaftlichen Realität anbieten. Mit ihren Devianzvorwürfen wenden sich die Reformer gegen diesen avantgardistischen Wesenszug und versuchen sie, die Aufgabe der Kunst auf Konformität und Reproduktion des Status quo bzw. sogar kompensatorische Ablenkung von Konfliktstoffen festzuschreiben. Sie folgen der Langeschen Stabilisierungsmaxime (vgl. 2.2.) und benehmen sich geradezu kunstfeindlich. Schon die Reformgrundsätze selbst erweisen sich damit als gegen die Freiheit der Kunst, da gegen deren avantgardistisches Wesensmoment gerichtet.

Davon besitzt, wie der zitierte Text zeigt, zumindest Lange ein gewisses Bewußtsein. Im Zusammenhang mit dem Kommunalisierungskonzept stößt er implizit auf den entwicklungshindernden Charakter der Reformgrundsätze sowie seines eigenen kategorischen Kunstimperativs und stellt er sich die Frage, ob deren strukturelle Verpflichtendmachung wünschenswert sei. Eine explizite Reflexion der Grundsätze vermeidet er jedoch ebenso, wie eine Analyse der Widersprüchlichkeit seines Kunstkonzepts $^{473}$. Stattdessen versucht er das Problem zu umgehen, indem er den Film wie auch das Theater den Schulen gleichstellt und ihren Aufgabenbereich als den der Unterhaltung und Belehrung bestimmt. Die Durchsetzung der konservierenden Grundsätze gilt dann, obschon die Auschaltung von ,Experiment und Fortschritt bemerkt wird, als unproblematisch. Wo es ohnehin nur um Information und Zeitvertreib geht, scheint man ohne großen Schaden auf ,traditionsüberschreitende` Weiterentwicklung verzichten zu können. An deren Stelle tritt die strukturell verankerte Garantie einer verbeamteten ,Anständigkeit'. Die Frage nach dem Kunstcharakter des Films, der Möglichkeit künstlerischer Unterhaltung und der Rolle avantgardistischer Entwicklungen für Kunst und Unterhaltung sind derart aus dem expliziten Argumentationsgang ausgeklammert, implizit aber werden sie abschlägig beschieden. Für den Film soll es keine Kunstfreiheit und im Bereich der Unterhaltung keine Avantgarde geben. Beide unterliegen, obschon als Kunst gar nicht akzeptiert, der Stabilisierungsmaxime, die letztlich auch für die Kunst selbst die Kunstfreiheit auflöst. Während das dort aber ,nur' im Rahmen der ästhetischen Theorie geschieht, zielt das Kommunalisierungskonzept auf strukturelle Umsetzung dieser Auflösung, d.h. auf praktische Ausschaltung jeder anderen Option. Mittelbar soll durch die Nachfragehegemonialisierung ja ein entsprechender, die Reformgrundsätze durchsetzender Einfluß auf die Produktion genommen werden. Zwar reicht dieser Einfluß allein vermutlich noch nicht hin, um die Kunstfreiheit vollständig (faktisch) zu beseitigen; Spiel mit dem Risiko und Ausreizen der eigenen Möglichkeiten gegenüber den städtischen Kinobeamten durch die Produzenten scheint noch möglich. Die Stoßrichtung der Kommunalisierung aber zielt auf eine solche Beseitigung. Sie will eine zwangskulturierende Kommunikationskontrolle etablieren, die ihre Normvorstellungen gegen die Eigenständigkeit des Kultursachbereichs Kunst obrigkeitlich durchsetzt und dessen Autonomie und Freiheit zumindest optional aufgekündigt. - Die antidemokratische Struktur des Kommunalisierungskonzepts wird damit komplet-

${ }^{473}$ Diese Widersprüchlichkeit, die bereits in der Rekonstruktion der Anwendung des ästhetischen Konzepts Langes auf die Erzeugnisse der Massenkultur zu Tage getreten ist, ist eine doppelte: Sie liegt einerseits in dem Antagonismus eines normativ auf Stabilisierung verpflichteten Kunstkonzepts, mit dem zugleich das Bewegungsgesetz der Kunstgeschichte und ihre Verändenungen erklärt werden sollen, andererseits im Ausschluß der Films aus dem Kunstkanon unter gleichzeitiger Übentragung der Wesensbestimmungen des letzten auf das neue Medium. 
tiert. Es stellt sich insgesamt als Modell einer obrigkeitlichen Usurpation des Films nach indiskutablen, d.h. dem sozialen Diskurs entzogenen Grundsätzen unter Beseitigung aller pluralen Einflüsse, der demokratischen Mitwirkungs- und Gestaltungsmöglichkeiten sowie der Autonomie der Kunst dar. Unter dem Mäntelchen der Demokratieaffinität und Kulturrettung zeigt es sich geradezu als Konzept der Demokratieprävention und Kulturgleichschaltung, d.h. als protototalitär.

\section{Verstaatlichung als Zielkonsequenz der Kinoreform}

Gleichwohl ist es nur der erste Schritt einer strukturautoritären Vereinnahmung des Films. Tatsächlich bleibt die Kommunalisierung ja noch auf die Kontrolle über die Filmvorführung beschränkt und ist ihr Einfluß auf die Produktion nur ein mittelbarer. Lange betrachtet es daher als notwendig und naheliegend, für eine vollständige Umsetzung der Reform zu fordern, ,auch das Anfangsstadium, nämlich die Fabrikation, und das Mittelstadium, d.h. das Verleihgeschäft zu sozialisieren“474, also zu verstaatlichen. Im Anschluß an eine längere Diskussion zeitgenössischer Sozialisierungsvorschläge skizziert er deshalb sein eigenes Konzept, das er als „Vollsozialisierung, d.h. die Verstaatlichung in ihrer reinen Form “475 bezeichnet. Darunter versteht er den Wunschzustand, „da $B$ es überhaupt keine Privatkapitalisten, die Filmfabrikation betreiben, mehr gibt“", sondern vielmehr ,der Staat der einzige Filmproduzent sein“ würde. ${ }^{476}$ Für die faktische Organisation stellt er zunächst als Maximen auf, die Filmproduktion länderübergreifend ,in den Händen des Reichs ${ }^{\star 477}$ zu zentralisieren sowie dafür zu sorgen, „da alle leitenden Kräfte und Angestellte ohne Ausnahme Staatsbeamte sind“478. Zum Zweck einer Beschreibung der feinstrukturellen Durchführung des filmwirtschaftlichen ,Staatsmonopols' teilt er die am Filmschaffen beteiligten Personenkreise in drei Gruppen auf, eine „kaufmännische, technische und künstlerische ${ }^{6479}$. Die letzte Gruppe, die Autoren, Regisseure, Schauspieler, Komponisten und Musiker umfaßt, soll ,überhaupt keinen Beamtencharakter haben“480, da es „im Interesse eines gesunden Fortschritts“ liege, „da $B$ sie in ihrem Schaffen möglichst frei von bürokratischem Zwang bleiben“481. Anders hingegen die „Direktoren“ der „Filmfabriken“, welche ,in erster Linie“ „zu den eigentlichen Beamten gehören “482 sollen. Ihnen obliegt die wirtschaftliche Organisation des Filmgeschäfts, weshalb Lange sie sich ,als tüchtige und geriebene Kaufleute“483 denkt. Freilich müssen sie seiner Vorstellung nach „,auf dem Boden der Reform stehen“, ja „,kein Direktor dürfte angestellt werden, der sich nicht ausdrücklich auf sie verpflichtet

474 Lange, Kino, 279; Den Begriff der ,Sozialisierung' entnimmt Lange der zeitgenössischen, von den Linksparteien geführten Diskussion um die Verstaatlichung der Filmindustrie. Nicht ohne Stolz verweist er jedoch darauf, diese Forderung bereits 1916 vorgetragen zu haben. (vgl. Lange, Kino, 277 und Lange, Nationale, 14-15)

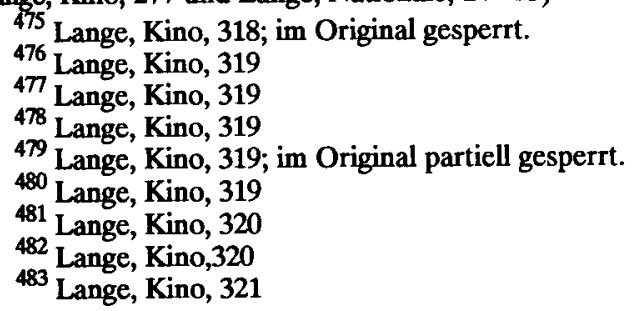


hätte“. ${ }^{484}$ Die entsprechenden Grundsätze will Lange von einem ,Reichsfilmamt‘ genauestens formuliert, und ihre Einhaltung durch dieses Amt beaufsichtigt sehen. Für das Reichsfilmamt, dem so die Direktoren unterstellt sein sollen, sieht er vor, daß es „sich aus Vertretern der Industrie und Delegierten der verschiedenen Reichsmini-sterien und der Ministerien der Einzelstaaten, sowie aus anderen Sachverständi.

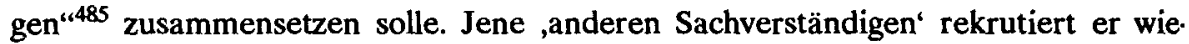
derum aus den Kreisen der ,Gebildeten“: „Lehrer, Geistliche, Ärzte, Vertreter der Volkswohlfahrt, der Jugendorganisationen, der Kunst und der Wissenschaft " ${ }^{\text {(486 }}$ werden genannt. Gliedern soll sich das Amt dann in ,Unterausschüsse‘ mit verschiedenen Zuständigkeitsbereichen, d.h. einen Ausschuß für „Beaufsichtigung der Fabriken und für Personalien, einen für Lehrfilme, einen für Unterhaltungsfilme, einen für Jugendfilme, einen für Kinoschulen, einen für Exportfragen, einen für Preisfestsetzungen“487. Aufgabe des Amts und seiner Ausschüsse sei es, im einzelnen „die eingehenden Filmmanuskripte zu prüfen, Anregungen zu neuen Entwürfen zu geben, Aufgaben zu stellen, Preisausschreiben ergehen zu lassen usw.“488 Manuskripte, die die Prüfung bestünden, seien vom Reich anzukaufen und zur Ausführung an eine Filmfabrik weiterzugeben; partiell beanstandete könnten mit entsprechenden Anweisungen versehen „,zu neuer Bearbeitung zurückgegeben werden“489. Ebenso wie ein Autor „müßte auch ein Komponist oder ein Tanzkünstler dem Reichsfilmamt Entwürfe vorlegen ${ }^{\star 490}$, so daß auch deren Arbeit geprüft werden kann. Die Manuskripte und Entwürfe sollen dabei nach vom Filmamt zu erlassenden Normen gestaltet sein, um ,die Arbeit zu erleichtern“491, d.h. sie sollen bereits ,,so ausführlich im Texte und so ausgiebig mit Illustrationen und Notenbeilagen ausgestattet sein, daß man ihnen mit Bestimmtheit ansehen könnte, ob der betreffende Film gleichzeitig den moralischen Anforderungen genügen und künstlerisch wirken wird“492. Mit Hilfe dieser Prüfungen will Lange durch das Filmamt „falsch orientierte Filmdichter durch sanften Druck, d.h. durch Nichtgenehmigung ihrer Manuskripte zur Reform erziehen ${ }^{\star 493}$. „Alte Filmroutiniers“, die versuchen könnten, ihre eigenen Wege wieder zu beschreiten, würden solcherart bald ,wissen, in welcher Richtung sie künftig ihren Pegasus zu satteln haben“494. „Junge, unverdorbene Filmdichter“ hingegen, „die sich von der Notwendigkeit der Reform durch eigenes künstlerisches Bedürfnis und durch die Lektüre der Reformschriften überzeugt haben", würden ohnehin ,ihren Ehrgeiz darein setzen, einwandfreie Manuskripte zu liefern und ihre Ausführung zu überwachen, daß wenn auch keine große Kunst, so doch wenigstens anständige und geschmackvolle Unterhaltung dabei herauskommt “495. Auf diese Weise hofft Lange,

\footnotetext{
${ }^{484}$ Lange, Kino, 321

485 Lange, Kino, 320

486 Lange, Kino, 320

487 Lange, Kino, 320

488 Lange, Kino, 320

489 Lange, Kino, 322

${ }^{490}$ Lange, Kino, 323

491 Lange, Kino, 323

492 Lange, Kino, 323

493 Lange, Kino, 323

494 Lange, Kino, 323

495 Lange, Kino, 323
} 
die Reformmaximen mit kategorisch normativer Wirksamkeit für den Bereich der Filmproduktion zu etablieren. Sowohl die alte Generation als auch die heranwachsende junge wären via staatliche Organisation und Beaufsichtigung des Filmschaffens so in Dienst genommen, daß trotz Verzicht auf ihre Verbeamtung ihre Linientreue garantiert, ja bei der nachwachsenden Generation sogar als Vorausleistung aus eigenem Antrieb möglich scheint. Durch die zusätzliche Verstaatlichung des Verleihwesens soll dann auch die effiziente Verbreitung der ,Reformfilme' erreicht, und die Konkurrenz in diesem Bereich zugunsten zentraler Planung ausgeschaltet werden. ${ }^{496}$

Die Konstruktion Langes liefert damit das Modell einer umfassenden, staatlichen Lenkung des Films im Sinn zentralisierter Überwachung und Planung von Produktion und Verbreitung. Mit diesem Konzept wird die Bewahrethik in ihre äußersten strukturellen Konsequenzen geführt. Was in der Analyse von Hellwigs Vorstellungen zur Produktionszensur bereits deutlich wurde, findet bei Lange nun seine endgültige, bis in die Feinorganisation hinein durchreflektierte Gestalt: An die Stelle einer Koproduzentenschaft des Zensors und der impliziten Schaffung bzw. Durchsetzung von reformgerechten Maßstäben treten die exklusive Produktionsbetreuung durch den Staat sowie das Diktat der Produktionskriterien und deren dirigistische Durchsetzung durch ein Filmamt. Das dichotomische Paradigma vom unmündigen bildungsbedürftigen Publikum und der kulturverordnenden Schicht der ,Gebildeten' wird auf diese Weise in gesellschaftsübergreifende, politische Strukturen übersetzt und organisatorisch festgeschrieben. Die Schicht der ,Gebildeten' soll durch den Staat repräsentiert und mit einer entsprechenden Herrschaftsmacht ausgestattet werden. Das Kulturmonopol dieser Schicht wird auf den Staat übertragen, die Aufgabe der Kulturierung dadurch mit autoritärer Durchsetzungskraft versehen und durch das staatliche Filmamt statt einer gesellschaftlichen einer politischen Institution anvertraut. Die Struktur der ganzen Konstruktion ist erneut protototalitär: Ziel des Unterfangens ist es nämlich, den Film so, in feste Beziehung zur tatkräftigen Intelligenz' (Lange), d.h. unter die Kontrolle der Reformer als den Repräsentanten der ,Gebildeten in diesem Bereich zu bringen, daß die Mitsprache zirkelexterner Gesellschaftsmitglieder, damit aber demokratische Einflußmöglichkeiten und Kunstfreiheit, endgültig ausgeschaltet werden.

Auf der Produktionsebene setzt sich das protototalitäre Moment zunächst als Staatsmonopol um, das die künstlerische und die wirtschaftliche Eigeninitiative verhindert bzw. absolut kontrollierbar macht. So bedeutet der Zwang zur Einreichung aller Filmvorhaben schon im Manuskript gegen alle Beteuerung, es gelte, das kreative Personal von Bürokratisierung freizuhalten, in der Tat nichts anderes als die Aufhebung von deren Freiheit. Zensur und Normierung durch das Filmamt sorgen für Durchsetzung der ,Reformgrundsätze ' und sollen zudem der ,Erziehung möglicher Abweichler zur Linientreue dienen. Nimmt der Staat so mittels Zurückweisung und Korrekturauflagen zensierenden, d.h. ausschließenden Einfluß auf die Produktion, so ergänzen Preisausschreiben, dezidierte Aufgabenstellungen und Themenvorgaben seine Steuerung des Films, positiv'. Der staatliche Auftragsfilm, der bei Hellwig nur implizit als Konsequenz einer Produktionszensur aufscheint, ist im Langeschen Konzept explizit vorgesehen; kreative Eigeninitiative hingegen nur als Rekrea-

${ }^{496}$ vgl. Lange, Kino, 289-290 
tion reformerischer Normativität zugelassen, d.h. ihres innovatorischen Moments beraubt. Analog verhält es sich mit der wirtschaftlichen Unternehmung: Die Direktoren der Filmindustrie sollen Staatsbeamte sein und geraten als solche zu weisungsgebundenen Ausführungsorganen, denen das eigentlich unternehmerische Moment der Innovation ebenfalls genommen ist. Nicht mehr entwirft die Filmwirtschaft ihre Projekte nach ihren eigenen, multifaktoriell entstehenden Kriterien, sondern das Filmamt weist die Produktionsvorhaben zentral zu.

Damit ist auch eine ökonomisch vermittelte Rückkopplung zum Publikum weitgehend verhindert. Die verstaatlichte, von Beamten geführte Filmindustrie unterliegt keinem Wettbewerb mehr, welcher die Orientierung der Produktion an den Wünschen des Publikums befördern könnte. Eine solche Orientierung ist freilich ohnehin nicht vorgesehen: Das Konzept des Staatsmonopols soll ja gerade der Wahrung und Durchsetzung der Reformgrundsätze gegen Neigungen und Wünsche des Publikums dienen. Der finanzielle Gesichtspunkt, der in einer Wettbewerbswirtschaft privatwirtschaftliche Organisationen dazu zwingen könnte, mit dem Publikum interaktiv zu kooperieren, berührt zudem den Staat als Filmproduzenten kaum. Zum einen ermöglicht ihm seine Monopolstellung großen Einfluß auf den Publikumsgeschmack. Wie die Reformer sehr richtig vermuten, wird das Publikum sich der Rezeption auch bei wenig Übereinstimmung des Angebots mit seinen Wünschen nicht völlig verweigern. Zum anderen steht dem Staat immer noch die Möglichkeit offen, durch Steuern und diversifikatorische Umverteilung von Geldern sein filmisches Kulturierungsunternehmen zu erhalten, selbst wenn dieses sich als schlechtes Geschäft erweisen sollte.

Verstärkt wird die monopolistische Zurückdrängung der Interaktionsmöglichkeiten von Produktion und Publikum noch durch die staatliche Übernahme des Verleihwesens. ,Systemexterne' Forderungen an die Produktion und deren Durchsetzung etwa mittels Boykottierung von Filmen durch privatgeschäftliche Organisation, das heißt aber eben: rückkoppelnde, strukturell wirksame Einflußnahmen auf das staatliche Produktionsgebaren bleiben dann auch auf dieser Ebene unmöglich. Die Vermittlung von Publikumsansprüchen, zu deren Anwalt sich kommerzielle Verleiher mittels Zurückweisung bestimmter Filme und Forderung anderer, nachfragegerechterer machen könnten, ist nicht mehr möglich. Der Staat bleibt Souverän des Angebots. Einzig über Zusammenschluß der Kinobesitzer oder von Publikumsgruppen könnte in diesem Konzept noch sehr mittelbar ein derartiger Einfluß angestrebt werden. Die Kombination mit der Kommunalisierung freilich schaltet die erste Möglichkeit weitgehend aus, so da $B$ die Rezipientenschaft unmittelbar, ohne vorgängige ,Deckung und Verstärkung durch bereits bestehende Organisationen dem staatlichen Filmangebot gegenübersteht. Das Publikum findet sich so in die Rolle eines Adressaten gedrängt, dem außer der individuellen (oder in Gruppen organisierten) Rezeptionsverweigerung bzw. entsprechenden Meinungsäußerung kaum eine Möglichkeit bleibt, auf das Angebot gestaltend einzuwirken. Die Wirksamkeit individueller Rezeptionsverweigerung und Meinungsäußerung jedoch ist, wie zu sehen war, unter staatsmonopolistischen Bedingungen allenfalls verschwindend gering anzusetzen, sofern sie überhaupt angenommen werden kann. Auch die organisierte Verweigerung und Selbstäußerung wird nur wenig Erfolg gegenüber einer solchen Monopolstruktur erzielen können. 
Ein demokratisches Moment allerdings scheint durch Langes Vorstellungen zur personellen Zusammensetzung des Filmamts und den historischen Hintergrund der Weimarer Republik eingebracht. So soll das Amt aus Vertretern der diversen Ministerien, insbesondere der preußischen Zentralstelle für Erziehung und Unterricht ${ }^{497}$ sowie der ,Gebildeten', näherhin Ärzten, Lehrern, Kunst- und Wissenschaftsvertretern, Geistlichen, Vertretern der Volkswohlfahrt und der Jugendorganisationen bestehen. Durch den historischen Kontext erhält diese Struktur einen demokratischen Anstrich. Tatsächlich scheint es denkbar, daß über Parteienwahl und Repräsentation sowie die Jugend- und Volkswohlfahrtsvertreter eine Rückkopplung des Amts an die ,Basis', also das Publikum erfolgt und durch die Wahl auch eine gewisse einflußnehmende Kontrolle der staatlichen Filmverwaltung möglich sei. Die protototalitäre Konzeption scheint dann von innen her aufgebrochen, zumindest aber angekratzt. Doch täuscht dieser Eindruck aus zwei Gründen: Zunächst löst die Möglichkeit, durch Wahl Einfluß auf die personelle Besetzung einer totalitären Struktur zu nehmen, diese Struktur nicht auf. Ist sie besetzt, so gibt sie den repräsentativ Gewählten zumindest für die Dauer ihrer Wahl unumschränkte Verfügungsmacht über diese Struktur und ihre Möglichkeiten, damit etwa auch über deren Nutzung zum Zweck der Erhaltung der eigenen Machtstellung. Will man sie also nicht totalitär nennen, weil sie demokratisch besetzt worden ist, so bleibt sie doch mindestens protototalitär und kann entsprechend in Totalität gekippt werden. Zum anderen zielt die Stoßrichtung der reformerischen Vorstellung durchaus nicht auf Einflußmöglichkeiten des Publikums über Wahl, sondern auf möglichst personenunabhängige Wahrung der Reformgrundsätze und die Herrschaft der Schicht der ,Gebildeten'. Das demokratische Moment der Wahl gilt in diesem Zusammenhang geradezu als hinderlich und gefährdend für das Konzept. So sieht Lange, daß auf diese Weise auch seine Gegner eine entsprechende Position im Filmamt erreichen könnten und macht er die darin liegende Gefahr aus: In der Tat könne „das Kino in völlige Abhängigkeit von der jeweils herrschenden Regierung ${ }^{498}$ geraten. Problematisch sei dies jedoch erst, wenn "die politische Entwicklung noch weiter nach links gehen“499 sollte. Dann nämlich stehe zu befürchten, daß die Reformgrundsätze über Bord geworfen werden und das Kino „zu einer so maßlosen Verhetzung der Stände gegeneinander, zu einer so schrankenlosen Aufpeitschung der Volksleidenschaften mißbraucht ${ }^{4500}$ werden könne, „daß man wünschen müßte, nicht für seine Verstaatlichung eingetreten zu sein $^{\text {“501 }}$. Die Beherrschung durch die „Linke“ nämlich sei die Beherrschung „durch die Gasse “502. Im Gegensatz dazu gilt ihm der vergangene wilhelminische Beamtenstaat als Idealbild für die Verwirklichung seiner Vorstellungen, denn in ihm sei sichergestellt, „da $\beta$ der Film nur zu guten Zwecken verwendet werden, und da $\beta$ der Staat ihn agitatorisch nur im nationalen Sinne (...) benutzen würde “ ${ }^{\text {503 }}$. Als gefährlich betrachtet Lange das totalitäre Moment seiner Konzeption also erst, wenn sie in die

\footnotetext{
${ }^{497}$ vgl. Lange, Kino, 320

498 Lange, Kino, 329

499 Lange, Kino, 320

${ }_{500}^{500}$ Lange, Kino, 320

501 Lange, Kino, 320

502 Lange, Kino, 320

${ }^{503}$ Lange, Kino, 320
} 
Hände seiner Gegner gerät. Dies aber scheint nur durch Wahl möglich, so daß die eigentliche Gefahrenquelle wiederum nicht in der Totalität selbst, sondern in ihrer disponibilisierenden Unterhöhlung durch Demokratie gesehen wird. Die Besetzung des Filmamts mit Vertretern der Volkswohlfahrt, Jugendverbände, Akademiker etc. richtet sich entsprechend gerade nicht auf eine Repräsentation des Publikums zum Zweck der Umsetzung seiner Ansprüche - solches hieße, das Konzept der ,Gasse in die Hände spielen -, sondern auf Repräsentation der ,Gebildeten' zum Zweck der Festschreibung ihrer Hegemonie über das Publikum gegen dessen Ansprüche. Die Stoßrichtung des Verstaatlichungskonzepts zielt so trotz der scheindemokratischen Implikationen der Langeschen Überlegungen zur Besetzung des Filmamts ebenso wie das Kommunalisierungskonzept auf protototalitäre Strukturautorität, welche die kulturierende Herrschaft der ,Gebildeten' staatlich sicherstellen und jede Mitsprache zirkelexterner Gesellschaftsmitglieder ausschalten soll.

Das strukturautoritäre Lösungskonzept der Reformer: Film als Instrument eines staatlich gesicherten Social engineering durch die, Gebildeten"

Insgesamt zeigen sich die reformerischen Lösungsvorschläge damit als Stufenfolge strukturautoritärer Maßnahmen, deren Endpunkt die ,saubere' Lösung der Totalität ist. Zunächst werden die zeitgenössischen Möglichkeiten der Zensur ventiliert und bei Hellwig schon auf eine protototalitäre Verklammerung von Staat und Filmproduktion hin ausgezogen. Konzessionspflicht und Steuer finden sich dann zu weiteren Zensurmöglichkeiten mit dem Ziel der Ausschaltung ganzer Genres ausgebaut. Die Errichtung von Gemeindekinos, deren Wirksamkeit jedoch als marginal bewertet wird, gilt als flankierende Unternehmung der Publikumserziehung. All diese Maßnahmen aber erscheinen im Rang einer subsidiären Vorbereitung der eigentlichen, strukturellen Realisierung der Reform durch Schulkino, Kommunalisierung und Verstaatlichung.

Vor allem im Schulkino findet die reformerische Bewahrethik ihre hervorragende, paradigmatische Gestalt: Das Maßnahmenbündel, das dort idealiter als totale Kontrolle und Steuerung des Filmkonsums der Jugendlichen bis hin zur situativen Überwachung sowie interpretativen Begleitung der aktuellen Rezeption selbst entworfen wird, verwirklicht idealtypisch die Prämissen der Bewahrethik und ihre Konsequenzen. So repräsentiert der Jugendliche in besonderer Weise das von den Vorwürfen hypostasierte Latenzwesen Mensch und dessen ,Bildungsbedürftigkeit', d.h. die anthropologischen Vorgaben der Devianzvorwürfe und den zugehörigen Kulturbegriff. Schutzbedürftig als unmündiges Kind und leitungsbedürftig im Sinn der ÜberichKonstitution und Logozentrik als triebgefährdeter, sinnlich bezogener Jugendlicher veranschaulicht der Schüler den Prototyp des kulturationsbedürftigen Entwicklungswesens Mensch in reformerischer Perspektive. Der bildungsbedürftigen Unmündigkeit desselben korrespondiert dabei von der Seite des Films her das mimetische Wirkungskonzept in seinen drei Formen, das einmal eine Kooperation von Latenzen und Film, ein andermal eine (u.U. latenzbezogene) Manipulation durch Film und schließlich eine Nutzung des Films zur (u.U. latenzbezogenen) Selbstmanipulation annimmt. Um nun zu entsprechender Erziehung angesichts der postulierten mimetischen Wirkung des Films und der menschlichen Latenzen zu kommen, scheint der pädagogische Totalumgriff die geeignete Lösung zu sein. So können alle Latenzen 
des Menschen kontrolliert, gesteuert und beschnitten, die mimetische Wirkung des Films aber kann derart sogar ,positiv' der Kulturation dienstbar gemacht werden. Wo Kultur ohnehin gegen die Latenznatur und zugleich gegen die Autonomie durchgesetzt werden soll, also eine kontranaturale Manipulation darstellt, legt es sich nahe, die manipulativen Möglichkeiten des Films selbst ,protokulturel' zu nutzen. Mit dem Konzept des Schulkinos findet diese dirigistisch-manipulative monopolisierte Kulturation ihre äußerste strukturelle, nämlich protototalitäre Gestalt.

Zugleich präformiert es als ,Cultural engineering' im Bereich der Jugenderziehung das, was mit Kommunalisierung und Verstaatlichung als ,Social engineering“ mit Bezug auf alle Gesellschaftsmitglieder möglich wird. Zwar zielen beide, als einander ergänzende Maßnahmen gedachte Konzepte dort zunächst ebenfalls ,nur` auf eine Verwirklichung des ,Cultural engineering', d.h. die autoritative Kulturbestimmung, -gestaltung und -vermittlung durch die ,Gebildeten' unter Ausschaltung jeder zirkelexternen Mitsprachemöglichkeit. Wie zu sehen war, bezwecken Kommunalisierung und Verstaatlichung in erster Linie die strukturelle Bereitstellung und Sicherung einer entsprechenden, schichtspezifischen Kulturhoheit, welche garantieren soll, daß das kulturative Unternehmen gelingt, und nicht von jenen Latenzen gefährdet wird, die über die Transformation des anthropologischen zum sozialen Pessimismus dem Publikum zugeschrieben werden. Analog den Jugendlichen erscheint dieses Publikum vorerst ebenfalls als unmündig-bildungsbedürftiges, und analog dem Schulkino scheint die monopolistisch-autoritäre Struktur lediglich um der Bildungsaufgaben willen errichtet. Doch verweisen schon die Hellwigschen Überlegungen zur Anpassung des Films an politische Erfordernisse sowie die Konsequenzen des Destabilisierungsvorwurfs und die Funktionszuweisung, die das Langesche Kunstkonzept an Kunst und Gebrauchskultur vornimmt, darauf, daß das Publikum zugleich als leitungsbedürftiges gedacht ist, und die autoritäre Struktur mit Bezug auf entsprechende Steuerungsmöglichkeiten errichtet werden soll. Der antiautonomistischen Ausrichtung des Schulkinos korrespondiert so die antidemokratische des Kommunalisierungs- und des Verstaatlichungskonzepts. Alle drei Entwürfe zielen auf einen möglichst vollständigen Umgriff der jeweils bildungs- und leitungsbedürftig angesetzten Gruppe. Mit dem Kommunalisierungs- und dem Verstaatlichungskonzept aber ist ein Umgriff angesetzt, der sich auf die Gesamtgesellschaft bezieht. Die Forderungen Hellwigs und Langes überführen zudem das kulturative ,Social engineering' in ein politisches und damit totales. Die aristokratisch-regressive Gesellschaftskonzeption der kontramodernen reformerischen Bewahrethik mündet so mit ihren strukturautoritären Lösungsvorschlägen in totalitäre Konsequenzen. Sie präformiert mit diesen Vorschlägen und deren theoretischer Untermauerung durch die Axiomatik der Devianzvorwürfe den Entwurf eines totalitären ,Social engineering' mit Hilfe der $\mathrm{Me}$ dien, hier des Films.

\subsection{Die Medienethik der Kinoreformbewegung. Zusammenfassung}

Mit dem normativen Diskurs der Kinoreformbewegung ist die medienethische Fragestellung für den Film historisch eröffnet und systematisiert. In Form einer sozialethisch perspektivierten Rekonstruktion habe ich im Vorangehenden die zentralen ethischen bzw. ethikbezogenen Argumente zu Argumentationstypen kristallisiert, die 
wirkungsspekulativen Basistheoreme offengelegt, die anthropologischen und kunsttheoretischen Vorgaben herausgearbeitet sowie das Gesellschaftskonzept der Reformer und die Postulate zur strukturellen Umsetzung ihrer Medienethik analysiert. Dabei hat sich als generelle methodische Grundfigur des reformerisch-ethischen Denkens die Aufspaltung der darzustellenden und zu analysierenden Sachverhalte in Dichotomien gezeigt, die zumeist in Antagonismen führen. Konsequenz dieses Denkstils und seiner materialen Axiome und Grundoptionen ist eine heteronomdeontologische kontramoderne Bewahrethik, die zum totalitären Umgriff auf der Strukturebene tendiert.

Auf einer ersten Ebene der Rekonstruktion haben sich die medienethischen $A r$ gumentationstypen zum Film aus den Devianzvorwürfen der Reformer ergeben. Darin unterstellen sie dem Film, er führe zu einer moralischen Primitivierung seiner Rezipienten, die sich neben einer allgemeinen Amoralität und Verhaltenskrudisierung in kriminellen und sexuellen Abweichungen niederschlage. Weiter erzeuge der Film eine gesellschaftliche Unzufriedenheit und revolutionäres Sprengpotential, welche in soziale Destabilisierung mit den möglichen Konsequenzen des Umsturzes und der Anarchie mündeten. Der Film scheint also einmal das Ethos der Rezipienten auf der individuellen Ebene zu korrumpieren und die Zerstörung der sittlichen Integrität und Identität des Einzelnen sowie der zwischenmenschlichen (besonders der zwischengeschlechtlichen) Begegnung nach sich zu ziehen. Zum anderen scheint von inm auch das soziale Ethos angegriffen zu werden, so da $B$ aus beiden Korruptionen schließlich kollektive Destruktionen bzw. Destruktionen des Kollektivs hervorzugehen drohten, die nicht allein in politischen Angriffen auf die Gesellschaftsordnung, sondern etwa auch in der Auflösung bestehender gesellschaftstragender Institutionen (wie der Ehe) oder der Rechtsnormen (wie des Schutzes von Leben und Eigentum) gesehen werden. Gegen diese befürchteten ethosbezogenen Wirkungen setzen die Reformer ihre medienethische Maxime, da $B$ der Film grundsätzlich der Stabilisierung und Statifizierung von individueller sittlicher Identität und kollektiver jeweiliger Gesellschaftsordnung zu dienen habe. Verbürgt soll diese Stabilität dann durch feste Institutionen und eine protototalitäre Struktur der Kontrolle und Steuerung medialer Kommunikation, damit aber der sozialen Kommunikation überhaupt, sein.

Die Argumentation der Reformer geht so primär von ethischen Devianzen aus, die durch den Film hervorgerufen würden. Ihre Medienethik konstituiert sich am und aus dem Beispiel der Verirrung, d.h. ex negativo, und gerät bereits aus diesem Ansatz heraus zur kämpferischen Logistik. Die Wurzel dieser Logistik aber liegt in jenen dichotomisch-antagonistischen Grundoptionen, welche die Benennung der Verirrung als einer solchen erst erlauben, und aus denen, wie auf einer zweiten Ebene der Rekonstruktion deutlich wird, die Bewahrethik der Reformer mit Notwendigkeit fließt. Hier werden jene Rahmenbedingungen festgelegt, die das medienethische Geschehen unter die Alternativen von Untergang und Rettung ohne Mittelbarkeit bannen. - Als erste und zentrale Grundoption habe ich den anthropologischen Pessimismus der Reformer herausgearbeitet, der sich in Form eines NaturKultur-Antagonismus konstituiert. Als ,Natur' werden dabei die Sinnlichkeit, Triebhaftigkeit, Emotionalität, Affektivität und Imaginativität des Menschen angesetzt, welchen jede kulturative Entelechie, d.h. jede innere Hinordnung auf Kultur, sowie 
jede kulturschaffende Potenz abgesprochen werden. Die genannten menschlichen Wesensstrukturen gelten als mit verderblichen Energien ausgestattet, überbordend und mindestens amoralisch, wenn nicht gar antimoralisch. ,Kultur' hingegen wird als abstraktive, logozentrische, kausal-diachrone und disziplinierende Ordnungsstruktur charakterisiert und den perniziosen Latenzen der menschlichen Natur entgegengesetzt. Der so definierten Kultur wird dann die Moralität exklusiv zugeschlagen und die Aufgabe erteilt, für die sittliche Menschwerdung des Menschen zu sorgen. Kulturation und ,Sittlichung fallen in eins. Etabliert aber ist damit eine strenge SeinSollens-Dichotomie, die eine ethische Potenz der menschlichen, Naturseite' prinzipiell leugnet, nicht also als erst nachträglich durch Umfeldfaktoren gestörte denken kann, und die die naturalen Antriebsstrukturen per se als antimoralisch begreift. Wie die Kultur als abstraktives Gehege und die Kulturation als dirigistische Verordnung, d.h. autoritär-disziplinatorisch gedacht sind, sind die Sittlichkeit als Bollwerk und die Gewinnung sittlicher Identität im Modus des Befehlsgehorsams, d.h. streng deontologisch, vorgestellt. Die ethische Forderung steht der naturalen Realität grundsätzlich ohne Vermittlung entgegen und drängt auf unbedingte Submission. Wo aus der Natur nichts gutes kommen kann und derart eine gewissermaßen ontologische Störung der ethischen Integrität des Menschenwesens angenommen werden muß, bleibt für so etwas wie sittliche Autonomie freilich kein Raum. Sittlichkeit kann dann nur deduktiv-heteronom garantiert werden. Gleichzeitig scheidet in diesem Konzept jede Möglichkeit moralischer Kreativität und einer sittlichen Weiterentwicklung aus. Zusammen mit den menschlichen Antrieben sind ja auch der Antriebsüberschu $\beta$ und seine imaginative Verarbeitung als prekär diskriminiert und als der heteronomen Einhegung bedürftig angesetzt. Die definitorisch vorgenommene ,Naturalisierung und damit dichotomische Ausgrenzung der Fantasiedynamik aus dem Bereich kulturell-ethischer Legitimität aber sorgt dafür, daß die heteronome, sittliche Integrität nur statifizierend durchgesetzt werden kann.

Mit ihrer Wende gegen die sittliche Autonomie ließen die Reformer zugleich eine Wende gegen das Kernstück des Projekts der Moderne, die umfassende Autonomie des Subjekts erkennen. Zwar findet sich diese Wende bei ihnen noch nicht in Form einer unmittelbaren Bezugnahme auf das genannte Projekt und ist ihre modernitätskritische Stellung noch nicht systematisch und umfassend als Auseinandersetzung mit Theorie und Genese der Moderne ausgearbeitet. Doch richtet sich ihre Konzeption mit einer durchaus dekodierbaren Verve gegen das neuzeitlich-moderne Subjektivierungs- und Autonomisierungsunterfangen. Die Position der Reformer ist damit grundsätzlich optional als kontramoderne festgelegt. Wie zu sehen war, bedingt das zugleich eine kontramoderne Kulturkritik, die gezwungen ist, die technisch-städtische Dynamik als zivilisatorische Renaturalisierung aus der Kultur evaluativ auszugliedern und zu verdammen. Im theoretisch inkonsistenten und deshalb scheiternden Versuch einer Wiedergewinnung der antagonisierten Natur über die Pseudonaturalität der ,Volkskultur' zeigt sich dabei der konkret-geschichtliche Herkunftsbereich einer materialen Füllung der Heteronomie: Gewonnen werden soll diese aus der VerläBlichkeit von Traditionalität sowie einer agrarromantisch verankerten Sitte. Die letzte gibt denn auch die paradigmatische Gestalt kinoreformerischer Moralität ab und läßt dadurch deren ethische Theoriekonzeption als regressive und auch materialiter kontramoderne zu Tage treten. 
Der anthropologischen Grundoption korrespondiert, wie ich gezeigt habe, auf einer weiteren Ebene eine soziologische, die sich als Publikumspessimismus im Horizont einer schichtspezifischen Dichotomie auslegt. Dichotomisch angesetzt werden auf der einen Seite die Schicht der ,Gebildeten', deren Zugehörigkeitsmerkmale zwar nie näher spezifiziert werden, die jedoch wohl das gebildete Bürgertum und vorzugsweise dessen konservativen Teil meint, und auf der anderen Seite das ,Volk', das primär in Form der großstädtischen ,Massen' auftritt, mithin also Unterschicht und Teile der Mittelschicht bezeichnet. Wo auf der anthropologischen Ebene der Mensch schlechthin als gefährdetes und gefährliches Latenzwesen gilt, das erst kulturativ eingehegt und domestiziert werden muß, wird hier das vage Publikum, das die ,Massen in den großen Städten bilden, als gewissermaßen kollektives Latenzwesen bewertet, dem ähnliche, nämlich gesellschaftliche und politische ,entelechiale‘ Gefährdungen eigneten und das deshalb einer analogen, leitstrukturellen Disziplinierung bedürfe. Die ,Gefährdungen' werden dabei als chaotische, wirre und ordnungsbedrohende Neigungen und Antriebe gezeichnet, die entweder als naive, unaufgeklärte Notionen und Wünsche (etwa nach Glimmer und Glitter der ,Paläste') oder aber auch als böswillige, schichtspezifische Verderbtheit (etwa als kriminelle Neigung) gelten und die durch Festschreibung im Sinn einer ,Sozialontologie' der gesellschaftstheoretischen Hinterfragbarkeit entzogen werden. So, wie die Genese des derart festgelegten Publikumscharakters nicht interessiert oder aber den ,Verführern' Film und Gewerkschaften angelastet wird, wird auch die Möglichkeit einer prozessualen, interaktiven ,Lösung' der in dieser Weise skizzierten Problemlage nicht in Blick genommen bzw. abschlägig beschieden. Eine Mitsprache des Publikums in gesellschaftlichen und politischen Fragen ist ebensowenig vorgesehen wie in Bezug auf den Film. Vielmehr wird das Publikum als unmündiges (oder, wo böswillig-verderbt, als zu ,resozialisierendes') gehandelt, dem durch Vormundschaft der ,Gebildeten' erst zu einem entsprechenden Bewußtseinsstand und Sozialcharakter verholfen werden müsse und dem daher der Zugang zur Öffentlichkeit, also Publizität, nicht zugestanden werden dürfe. Öffentlichkeit bleibt zirkelintern reserviert; soziale Kommunikation tritt nur als von den ,Gebildeten' hegemonialisierte ,Einwegkommunikation' mit dem Zweck der Bildungsvermittlung und Publikumserziehung auf, welcher die Medien, bzw. hier: der Film, als hervorragende Vermittler des gesellschaftlichen Diskurses exklusiv dienstbar gemacht werden sollen. Die antiautonomistische Deontologie der anthropologischen Grundoption setzt sich so durch ihre soziologische Transformation in eine antidemokratische Oligarchie um, für welche die Medien eine herausragende Rolle spielen. Das Gesellschaftskonzept der Reformer zeigt sich damit als zweischichtig-autoritäres, das letztlich einem aristokratischen Paradigma verhaftet ist. Wie zu sehen war, bildet den Hintergrund hierfür die historische Entwicklung in Deutschland, welche die durch Herausbildung der bürgerlichen Öffentlichkeit aus der literarischen längst angelegte Demokratisierungstendenz in der Ablösung vom wilhelminischen Kaiserreich erstmals endgültig aufgreift und politisch einzulösen sucht. In ihrer Verhaftung an die wilhelminische Zeit und ihren gegen die historische Tendenz gerichteten Optionen erweisen sich die Reformer auch hier als regressiv und kontramodern. Sie wenden sich erneut implizit gegen das Projekt der Moderne, dessen Subjektivierungs- und Autonomisierungsunterfangen sich in dem genannten 
historischen Prozeß als Mitspracheforderung wiederentdecken läßt und dem sie durch ihre aristokratisch-privative Öffentlichkeitsbegrenzung entgegentreten.

Als dritte Grundoption, die freilich mit dem reformerischen Kulturbegriff zusammenhängt, korrespondiert den bereits genannten ein Kunstkonzept, das durch seine Übertragung auf die Produkte der Massenkultur sowohl der Kunst als auch den Erzeugnissen der letzten eine gesellschaftliche Funktion zuweist, die der medienethischen Maxime entsprechend nur Stabilisierung zuläBt. Kunst und Gebrauchskultur, damit auch der Film, sollen diesem Konzept entsprechend alle individuellen wie kollektiven ,destabilisierenden' Strebungen kompensatorisch-sublimativ einhegen, bzw. den gesellschaftlichen Status quo bestätigend stützen, und geraten derart entweder zum Surrogat nicht gelebten Lebens und kreativer Weiterentwicklung oder zum bloßen Reflex der ohnehin bestehenden Verhältnisse. Der reformerische Kunstbegriff richtet sich so gegen eines der zentralen Wesensmomente von Kunst überhaupt, nämlich die avantgardistische Überschreitung oder Sprengung eingewohnter Grenzen, und versucht gegen den neuzeitlich-autonomen Charakter der Kunst als primär individueller Expression die Verpflichtung auf kollektiv-heteronom bestimmte Reproduktivität zu setzen, d.h. aber geradezu sie zum Instrument einer doppelten, Künstler und Rezipienten treffenden Repression zu machen. Die Kunstfreiheit wird auf diese Weise schon im Kunstbegriff selbst aufgehoben. Für die Massenkultur bedeutet die normative Übertragung des Kunstbegriffs und seiner gesellschaftsbezogenen Funktionsimplikate auf ihre Erzeugnisse dann die Beseitigung jeder kreativen Neuerung und der Möglichkeit, den Gesellschaftsprozeß zu flankieren oder gar inspirativ zu befördern.

Eine vierte Grundoption stellt das Wirkungskonzept der Reformer dar, das sich als mimetisches erwiesen hat. Es geht davon aus, daß die Filmwirkung im Sinn der Erzeugung von Nachahmungshandlungen zu denken sei, wobei die Reflexion des Zustandekommens derselben zu drei Formen dieses Konzepts führt. So wird einmal mit der Verursachungsthese ein Verhältnis von Film und Publikum postuliert, in dem einzig der Film, und hier wieder primär dessen materialer Inhalt, ein Verhalten des Publikums präformiere und auslöse. Der Film gilt als das alleinige Agens, gegen dessen infiltrierende Kraft eine Gegenwehr kaum möglich scheint. In einer zweiten Form, der Kooperationsthese, wird ein Zusammenwirken von Film und Publikum angenommen, bei dem die Korrespondenz der Inhalte des ersten mit den Latenzen des letzten entsprechende Verhaltensformen nach sich ziehe. Der Film gilt dabei gewissermaßen als Verstärker bereits vorhandener Inklinationen und Dispositionen. Im dritten Fall, bei der Nutzungsthese, nun wird die Wirkungsaktivität ausschließlich dem Publikum zugeschrieben, das den Film aus freier Entscheidung zur Information oder Selbstmanipulation verderblich gebrauche. Alle drei Formen freilich erklären nicht wirklich, was sie zu erklären vorgeben. Obschon nämlich die Reformer in diesen Thesen die Gründe für die Mimesis ausgearbeitet sehen, ist es letztlich die Mimesis selbst, mit der der Überschritt von Verursachung, Kooperation und Nutzung zur Handlung ,begründet' wird. Tatsächlich könnte auch lediglich eine Wirkung auf das Vorstellungsleben ohne Verhaltenskonsequenzen aus den drei Thesen abgeleitet werden; eine Ausnahme bildet allenfalls die Kooperationsthese, wo sie die Latenzen des Publikums als Handlungsdispositionen ansetzt und ein Zirkelargument vorträgt. Insgesamt aber gerät die Mimesis zum durchaus unbegründeten Axiom, d.h. zur 
Grundoption, die, wie bei Hellwig zu sehen war, ideologisch gewahrt wird. Weiter verbinden sich die Thesen partiell mit den anderen Grundoptionen und präjudizieren sie damit (zusätzlich) das Ergebnis der Wirkungsspekulation. So fließen sowohl in die Kooperations- als auch in die Nutzungsthese die Basispessimismen von den anthropologisch und sozialontologisch konstatierbaren Latenzen ein und lassen sie nur mehr den Schluß auf eine mit diesen kohärente Wirkung zu, die über das Mimesistheorem dann als Verhaltensdetermination ausgelegt wird. Die Verursachungsthese hingegen verlagert gewissermaßen die anthropologisch-pessimistische Diagnose auf den Film und lastet diesem die Korruption der menschlichen Natur an. Insgesamt nehmen derart weder die Verursachungsthese noch die Kooperationsthese den Subjektcharakter der Rezipienten ernst und stellen sie sich so ebenfalls in den Kontext der kontramodernen Grundoption. An die Stelle der Subjektivität setzen sie einen Wirkungsmechanismus, dessen Automation bei der ersten These kunsttheoretisch, bei der zweiten anthropologisch prinzipiell verankert wird. Die Nutzungsthese kennt dann zwar eine Eigenentscheidung und damit Selbstverantwortlichkeit des Publikums, erklärt dieses jedoch allenfalls zum bösen Subjekt. Eine Differenzierung der Nutzungsabsichten unterbleibt hier ebenso wie eine Weiterführung der Kooperationsthese zur Interaktionsthese, mit welcher verschiedene (diskursive) Vermittlungsebenen zwischen Film und Publikum beleuchtet werden könnten, und in der zusammen mit einer (responsiven) Eigenleistung der Rezipienten auch ihr Subjektcharakter Berücksichtigung finden könnte.

Die rekonstruierten Grundoptionen und ihre Dichotomien präformieren nun die Medienethik der Kinoreformer von vorneherein als kontramoderne deontologische Bewahrethik. Wo schon auf der anthropologischen Ebene in der gezeigten Weise apriorisch-pessimistisch angesetzt wird, kann jede autonome, nicht von den Kulturnormen der ,Gebildeten' bedingte Regung des Publikums nur mehr als verderbliches Abrutschen in die zugrunde liegenden, amoralischen Strukturen gedeutet werden, denen eine doppelt bewahrende, nämlich das unkulturierte Publikum vor den eigenen Neigungen und seine Umgebung vor seinen Ansprüchen schützende Barriere der Kultur und Sittlichkeit entgegengesetzt werden muß. Analog gilt es dann, den politisch-gesellschaftlichen Mitspracheforderungen und einer diesbezüglichen Wunschproduktion zu wehren. Die auf einer ersten Rekonstruktionsebene zu Tage tretenden Devianzvorwürfe sind so die logische Konsequenz der auf einer zweiten Ebene herausgearbeiteten Basistheoreme. Diese determinieren denn auch den Charakter der reformerischen Lösungsvorschläge, mit denen die kontramoderne Bewahrethik gesellschaftlich umgesetzt werden soll, als strukturautoritären mit totalitären Konsequenzen. So kann unter den Prämissen der beiden Basispessimismen eine Konstitution der medialen Kommunikation, insbesondere aber der medialen Gehalte, durch Mitsprache oder Mitwirkung des Publikums nicht zugelassen werden. Vielmehr gilt es, möglichst überhaupt jeden Einfluß desselben auf die Produktion dieser Gehalte zu verhindern und die Kulturhoheit der ,Gebildeten', die hier mit einer sittlichen zusammenfällt, monopolistisch zu sichern sowie mit entsprechender Autorität und Durchsetzungsmacht auszurüsten. Um das zu erreichen, und vor allem auch die Möglichkeit einer ökonomischen Vermittlung von Publikumsansprüchen und Produktion zu unterbinden, bleibt kaum eine andere Option als die der staatlich-kommunalen Verankerung des Kulturmonopols unter tendenziell vollständiger Ausschal- 
tung aller (hier nur im Sinn der Unterhöhlung denkbaren) demokratischen Momente. Darüber hinaus führt die Reichweite des Publikumspessimismus, wie zu sehen war, tendeziell zu einer Ausweitung des kulturativen ,Social engineering' in ein generelles, gesellschaftlich-politisches, in dem die Medien, hier zunächst: der Film, einer je als wünschenswert erachteten Stabilität, d.h. aber auch der manipulativen Akzeptanzlenkung in strittigen, gesellschaftlichen Fragen, der Verschleierung mißliebiger Sachverhalte und der Wahrung politischer Herrschaft gegen die Aufgabe demokratischer Repräsentanz und die Möglichkeit der Einflußnahme durch Wahl dienstbar gemacht werden kann. Im Extremfall bietet die reformerische Konstruktion einer Einlösung ihrer medienethischen Forderungen damit die ,Chance', durch monopolisierte, dirigistische mediale Gehalteproduktion zumindest eine gravierende Behinderung der Wahrnehmung gesellschaftlicher Realität hervorzurufen, wenn nicht gar potentiell eine propagandistische Ersetzung dieser Realität selbst einzuleiten, ohne daß freilich eine solche Konsequenz von den Reformern selbst schon gezogen oder als wünschenswert bezeichnet worden wäre. 


\section{TOTALITÄRE MEDIENETHIK: TRANSFORMATION UND FLEXIBILISIERUNG DER REFORMERISCHEN STRUKTURAUTORITÄT IM KULTURFUNKTIONALISMUS DER NATIONALSOZIALISTEN}

Die Geschichte des medienethischen Diskurses in Deutschland läßt als zweite wirkmächtige Epoche, die einen eigenen Diskurstyp schafft, nach den Reformern die Phase des Nationalsozialismus erkennbar werden. Einen Blick auf diese Epoche zu werfen, empfiehlt sich zunächst schon aus den Ergebnissen der Auseinandersetzung mit den strukturautoritären Lösungsvorschlägen der Kinoreformer, die sich als protototalitär erwiesen haben. Obschon die Totalitarismusthese, wie sie vor allem in den 50er und 60er Jahren gern zur Gesamterklärung von Faschismus und Kommunismus zusammen verwendet wurde, inzwischen als unvollständiges hermeneutisches Instrument zumindest für das Verständnis des Nationalsozialismus gelten muß, bleibt doch unbestreitbar, daß letzterer auch ein totalitäres Konzept vorstellt und deshalb Bezüge (wenn nicht gar gewisse Kontinuitäten) zur Zeit der Reformer ebenso vermutet wie andererseits Bezüge (und seien es nur die der Abgrenzung) über die ,Stunde Null hinaus nicht geleugnet werden können. Pointiert gegen eine Forschungsperspektive, die den Nationalsozialismus als bezugslosen ,Einschnitt' oder unerklärlichen ,Einbruch der Barbarei‘ in die ansonsten tadellos scheinende deutsche Gesellschafts- und Ideengeschichte betrachtet, soll daher auch unter der leitenden Prämisse meiner Rekonstruktion, nur exemplarische und zentrale Epochen bzw. Diskurse zu erarbeiten, dieser Zeitabschnitt mit untersucht werden. Denn nur wer im Gelände dieser Geschichte die Entgleisungsmöglichkeiten kennt, wird die Schienen der ethischen Theorie umsichtig genug legen können.

\section{Methodologische Vorüberlegung}

Die Auseinandersetzung mit einer möglichen Medienethik der Nationalsozialisten bietet sich zunächst als mit zwei Schwierigkeiten behaftet dar: Zum einen mutet es auf den ersten Blick etwas kühn an, gerade dem menschenverachtenden Nationalsozialismus zuzuschreiben, daß er eine ,Ethik', d.h. eine prinzipiengeleitete normative Theorie über das menschliche Handeln unter der Differenzsetzung von Gut und Böse besessen habe. Als selbst ,durch und durch böse' scheint er zu einer solchen Differenzsetzung wesenhaft unfähig zu sein. Zum anderen ist bekannt, daß eine der zentralen politischen und gesellschaftlichen Handlungsmaximen des Nationalsozialismus die Funktionalisierung der Wahrhaftigkeit zum Mittel für die Erreichung seiner Ziele war, damit aber nicht nur Vertrags- und Versprechensbruch zum Handlungsrepertoire gehörte, sondern auch der strategische Einsatz von Theorien. In bezug auf meine Fragestellung bedeutet das, daß bei den theoretischen Äußerungen der Nationalsozialisten - anders als bei den Reformern - nicht von vorneherein davon ausgegangen werden kann, daß gemeint war, was gesagt wurde. Die entsprechenden Theorien scheinen mithin nur bedingt die Rekonstruktion der tatsächlichen 
Grundlagenaxiomatik einer möglichen nationalsozialistischen Medienethik zuzulassen.

Der ersten Schwierigkeit nun ist entgegenzuhalten, daß zwar dem Nationalsozialismus keinerlei ethische Dignität attestiert, ebensowenig aber der Versuch einer prinzipiengeleiteten normativen Handlungstheorie unter der genannten Differenzsetzung a priori abgesprochen werden kann. Tatsächlich bedienen sich auch die Nationalsozialisten ja der Begriffe ,Ethos', ,Sittlichkeit' (bzw. spezifisch und häufiger noch: ,Sitte') und ,Ethik'. So, wie ein Verbrechersyndikat durchaus gruppenspezifische Handlungsmaximen und normative Bindungen entwickeln kann, die systemimmanent als ,gut' etikettiert werden und das ,Ethos` des Syndikats darstellen, hat auch das kriminelle Regime der Nationalsozialisten ein derartiges Konglomerat ausgeformt und mit theoretischen Versatzstücken versehen, die dann als ,Ethik' auftreten. In diesem eingeschränkten Sinn erscheint es mir daher legitim, von einer nationalsozialistischen ,Ethik' zu sprechen, die freilich mindestens als extreme Defizitärform ${ }^{1}$ bzw. angesichts der organisierten Massenvernichtung auf der Basis ,rassischer Theoreme als pervertierte ,Ethik' zu betrachten ist. ${ }^{2}$

Der zweiten Schwierigkeit wiederum kann damit begegnet werden, für die Erhebung der Theorie nur zentrale, programmatische Texte zu verwenden und ihren programmatischen Gehalt aus der Kohärenz mit dem faktisch-historischen Handeln zu rekonstruieren. Für die nationalsozialistische Filmpolitik und -theorie können als programmatische Texte vor allem die Filmreden Goebbels' und die Filmtheorie des Reichsfilmintendanten Fritz Hippler gelten. Diese Auslassungen nämlich werden auch in Praxis umgesetzt. Jene Partien der Reden Goebbels', die als eindeutig strategische Verschleienung der tatsächlichen Handlungsmaximen zu werten sind und die daher für die vorzunehmende Rekonstruktion allenfalls ex negativo Relevanz beanspruchen können, lassen sich aus eben der Konfrontation mit der von der Forschung inzwischen offengelegten historischen Realität leicht von den programmatischen unterscheiden und aus der Darstellung ausschließen. Die genannten Texte decken im übrigen den Zeitraum der immanenten Entwicklung des nationalsozialistischen Regimes diachron $a b$ und verbürgen die historische Vollständigkeit der zentralen Momente nationalsozialistischer Medienethik. Durch Einbettung ihrer Analyse in eine Skizze der generellen Staats- und Gesellschaftskonzeption sowie der Kunsttheorie und -politik des Nationalsozialismus können Engführungen vermieden werden.

\section{Generelle These und Vorgehensweise}

Meine These ist, daß das nationalsozialistische Organisationsprogramm für die Medien, damit auch den Film, bei allen situationsspezifischen Modifikationen den an-

${ }^{1}$ Der Begriff ethischer Defizitärform verdankt sich Wilhelm Korff, der unter Heranziehung der Neurosentypologie Riemanns vier solche Defizitärformen entwickelt. (vgl. Korff, Wilhelm, Die Frage nach dem Glück als Frage nach einer humanen Ethik, in; ders., Wie kann der Mensch glücken?, München 1985, 9-32)

${ }^{2}$ Auch der Genozid als Programm war ja noch mit einer pervertierten ethischen Valenz versehen: Er galt seinen Organisateuren und Schlächtern als, weltgeschichtlicher Auftrag' mit Gebotscharakter und schien denselben die eigene ethische Integrität nicht in Frage zu stellen (wenngleich die Sprache der berüchtigten, Wannseekonferenz' auch zeigt, daß hierzu entsprechende Verschleierungsmaßnahmen, wohl nicht nur um der Täuschung der ,Uneingeweihten“ willen, notwendig waren). 
haltenden Versuch der Perfektionierung einer strukturautoritären, jedoch flexibel gestalteten, umfassenden Funktionalisierung der medialen Kommunikation zum Zweck eines totalen Social engineering unter dem antiautonomistischen Prinzip der Gemeinschaftsverpflichtung, dem dichotomisierenden strukturell-personellen Prinzip der Führung und dem Kommunikationsprinzip der Propaganda darstellt. Aus diesen Prinzipien und dem Kommunikationsziel des Social engineering sehe ich sowohl die Maximen der nationalsozialistischen Filmpolitik und Filmtheorie fließen, als auch den ständigen organisatorischen und personellen Umbau erklärbar, der sich aus den Schwierigkeiten ihrer jeweiligen Einlösung ergibt. Gemeinschaftsprinzip, Führungs-, bzw. genauer: ,Führerprinzip‘ und Propagandaprinzip konstituieren dann auch die Grundoptionen der parallel zur Strukturorganisation entwickelten Theoriestücke und konfigurieren zusammen mit den daraus abgeleiteten Maximen und Theoremen die NS-Medienethik. Ihr Unterfangen zeigt sich ähnlich dem reformerischen als Versuch einer statifizierenden, kontramodernen Wende gegen moderne Dynamisierungs- und Demokratisierungsprozesse, bemüht sich jedoch aus Effizienzgründen im Unterschied zu den Reformern um eine partielle Assimilation an diese Prozesse. Der Nationalsozialismus zeigt darin auch ein spezifisches Verhältnis zum Projekt der Moderne, von dem die genannten Prozesse letztlich verursacht sind: An die Stelle einer bloß regressiven Konzeption tritt der Versuch, sich die technisch-instrumentellen Errungenschaften der Moderne zunutze zu machen und zugleich eine kontramodern-statische Herrschaftsorganisation gesellschaftlich durchzusetzen. In der strukturellen Umsetzung der totalitären Medienfunktionalisierung wiederum können die Nationalsozialisten auf ein nicht geringes Angebot gesetzlicher, personeller und theoretischer Vorgaben zurückgreifen, die durch die partielle Umsetzung der strukturautoritären Forderungen der Kinoreformer schon in der Weimarer Republik gegeben sind und aus denen eine zumindest mittelbare und teilweise Kontinuität zu den Reformbestrebungen erhellt.

Diese These will ich entfalten, indem ich zunächst das Gemeinschafts- und das Führerprinzip als generelle organisatorisch-ethische Ordnungsprinzipien des Nationalsozialismus in ihren grundsätzlichen Dimensionen charakterisiere, um dann die nationalsozialistische Strategie zu umreißen, die mit diesen Prinzipien eine kontramoderne, herrschaftseffiziente Wende gegen moderne Prozesse bei gleichzeitiger partieller Assimilation an dieselben vollziehen will. Daraus erhebe ich dann das totalitäre Gesellschaftskonzept der Nationalsozialisten und seine Bezüge und Unterschiede zu dem der Reformer. Im Anschluß daran zeige ich, wie mit dem Gemeinschaftsprinzip eine kontramoderne Kunst- und Kulturnormierung auf der Basis einer rassistisch gefüllten und gegenüber der reformerischen umgestellten Natur-KulturDichotomie erfolgt, die letztlich zur Unterwerfung der individuell-expressiven Ästhetik unter ethisierte Kollektivnormen und zur Aufkündigung der neuzeitlichen Autonomisierung der Kunst führt. Über die Zuordnung des Kunstkonzepts zum Führerprinzip läßt sich dann die politische Funktionszumessung für Kunst im Nationalsozialismus skizzieren, die bereits auf die politische Funktion von Kultur überhaupt verweist. Diese Linie ziehe ich zum Film als massenkulturelles Erzeugnis weiter und bestimme dessen Funktion und Rolle im totalitären Staat als die eines sowohl ideologisch-gemeinschaftsformierenden als auch dichotomisch-herrschaftsfunktionalen Social engineering unter dem Propagandaprinzip. Abschließend skizziere ich noch die 
Umsetzung dieses Programms in die strukturelle Organisation des Films, um dann die nationalsozialistische Medienethik in ihren Grundlinien zusammenzufassen.

\subsection{Führerprinzip und Gemeinschaftsprinzip als generelle organisatorisch-ethische Ordnungsprinzipien des Nationalsozialismus}

Führerprinzip und Gemeinschaftsprinzip stellen zunächst die grundlegenden, nicht nur für den Medienbereich, sondern für alle gesellschaftlichen Bereiche konstitutiven, je und je ethisch-legitimativ oder organisatorisch verwendeten Prinzipien des Nationalsozialismus dar. Mit ihnen versuchen die Nationalsozialisten sowohl, immer wieder die Gestalt ihrer Herrschaft zu bestimmen, zu legitimieren und zu festigen, als auch spezifische Strategien für den Umgang mit neuzeitlich-modernen Dynamisierungsprozessen zu entwickeln.

\section{Das Führerprinzip als oberstes Ordnungsprinzip des Nationalsozialismus}

Das Führerprinzip wird von Hitler im Mai 1926 innerparteilich strukturell durchsetzt und später im nationalsozialistischen Staat zum übergreifenden Organisationsprinzip erklärt. Es gilt als „Grundgesetz der nationalsozialistischen Weltanschauung ${ }^{63}$ und wird von Hitler in "Mein Kampf“ legitimativ grundgelegt. Auf der Basis der ,rassetheoretischen', bio-ontologischen Vorstellung einer bis ins Konkrete reichenden Festlegung des Individuums durch sein genetisches Material kontrastiert er dort eine ,nicht denkfähige, nicht tüchtige, keinesfalls aber begnadete' „Masse“ mit jenen, die zur „Führung (...) von Natur aus mit besonderen Gaben“ befähigt seien. ${ }^{4}$ Obschon nämlich innerhalb eines Volks ,die blutsmäßigen Bestandteile wohl in großen Linien die gleichen“"5 seien, unterlägen sie ,im einzelnen doch tausendfältigen feinsten Differenzierungen "6, und führten sie damit zu unterschiedlichen Befähigungen. Daraus ergebe sich dann die ,Notwendigkeit", „die innerhalb der Volksgemeinschaft als rassisch besonders wertvoll erkannten Elemente maBgeblichst zu fördern "7 und ihnen eine Führungsstellung zu sichern. Auf diese Weise wird eine Gruppe von Führungspersönlichkeiten als natural präformierte bestimmt und von einer ebenso natural definierten Gruppe Führungsbedürftiger (oder zumindest Führungsungeeigneter) abgetrennt. Das Recht zur Führung wird mit der naturalen Begründungsfigur letztlich ontologisiert, da die definitive Präformation als ,Wesenseigenschaft" erscheint und nicht mehr hintergehbar ist. Die ,tausendfältigsten Differenzierungen“ geraten dabei $\mathrm{zu}$ lediglich ,zwiefältigen' und begründen eine rein dichotomische Ordnungsfigur, welche eine Elite von einer ,massa damnata' sondert und ihr oligarchisch überordnet.

Diese elitebezogene Zweiteilung zum Zweck der Staats- und Gesellschaftsorganisation erinnert an die Dichotomie der Kinoreformer, stellt jedoch im Unterschied zu derselben keine schichtspezifische, sondern eine charismatische Dichotomie dar. Ihre Führungslegitimation beruht nicht auf dem Antagonismus von ,Bildung' und ,Ungebildetheit', sondern ordnet sich in den generellen Begründungsduktus der pseudo-

\footnotetext{
${ }^{3}$ Meyers Lexikon 4, 1938, Sp. 802

${ }^{4}$ Hitler, Kampf, 497

${ }_{6}^{5}$ Hitler, Kampf, 492

${ }^{6}$ Hitler, Kampf, 492

${ }^{7}$ Hitler, Kampf, $492-493$
} 
biologischen Theoreme von der ,natürlichen Überlegenheit' der ,nordischen Rasse' und des biologistisch-sozialdarwinistischen Paradigmas, sowie der mit dem Schicksalsbegriff gefaßten historischen Erwählung ein. Der strukturbezogene Folgerungseffekt ist jedoch derselbe; wie bei den Reformern sollen die „schöpferischen Köpfe ${ }^{\text {‘8 }}$, die „,besten Köpfe der Volksgemeinschaft zu führender Bedeutung und zu leitendem Einflu $\beta^{\prime \prime 9}$ gebracht und sollen solcherart der Raum der Öffentlichkeit und die Führungsrechte zirkelintern, d.h. für die nationalsozialistischen Führungspersönlichkeiten, vor allem ,den Führer' selbst, exklusiv requiriert werden.

In der konkreten Auslegung bedingt das so gefaßte Führerprinzip ein Herrschaftsverhältnis, das die vollständige Autokratie des ,Führers' und blinden Gehorsam der Geführten impliziert. Es etabliert eine Organisationsstruktur, die im Modus des Befehlsgehorsams gedacht ist und die derart ein militärisches Paradigma auf Staat und Gesellschaft überträgt. Anordnungen der Führer, vor allem Hitlers, geraten zu einer unhinterfragbaren, keiner sachlogischen Auseinandersetzung mehr zugänglichen Order. ${ }^{10}$ Mit der Erklärung des Führerprinzips zum generellen Ordnungsprinzip des Staats und seiner Übertragung auf die Staatsgewalt findet sich dann die letztgenannte zur willkürlich handhabbaren, jeder Kontrolle enthobenen ,Führergewalt ${ }^{11}$ totalisiert. Der Weimarer Rechtsstaat wird damit zum spezifisch nationalsozialistischen Regime transformiert. Zugleich aber wird die bedingungslose Unterordnung unter Führerweisungen zur unmittelbar, sittlichen Verpflichtung ${ }^{12}$ gemacht und aus dem sachlogischen Raum der Rechtsverpflichtung in den der Moral übertragen. Das Führerprinzip hebt damit die Trennung von Staat und Moral auf und zeigt sich neben seiner Rolle als Organisationsprinzip auch explizit als nationalsozialistisch-, ethisches' Prinzip, das eine absolute Gefolgschafts- und Treuepflicht als moralische Handlungsmaxime aus sich hervortreibt. Der ,kategorische Imperativ des $\mathrm{Na}$ tionalsozialismus lautet dementsprechend: ,Führer befiehl, wir folgen' und ersetzt die selbstverantwortliche sittliche Handlungsvernunft des Einzelnen durch eine Heteronomie, die explizit das ,sacrifizium intellectus' zugunsten des Vertrauens in die rein personenbezogene, je größere (Willkür-),Vernunft' des ,Führers' fordert.

\section{Das Gemeinschaftsprinzip als Integrationsprinzip}

Während das Führerprinzip so eine prinzipielle Dichotomie etabliert, stellt das $G e$ meinschaftsprinzip zunächst ein Integrationsprinzip dar, das von den Nationalsozialisten gegen den Gesellschaftsbegriff und seine gesellig-ungesellige Ratio als nationalsozialistisches Spezifikum emotiv-totalisierend bemüht wird. Das Gemeinschaftsprinzip wird ebenso wie das Führerprinzip ,rassetheoretisch' angesetzt und derart natural-ontologisch bestimmt. Der Gemeinschaftsbegriff wird hierzu mit dem Volksbegriff gekoppelt und das Wesen beider ,genetisch“ erhoben. So beschwört Hitler in

${ }_{9}^{8}$ Hitler, Kampf, 497

9 Hitler, Kampf, 500

${ }^{10}$ So formuliert etwa Robert Ley: „Wenn der Führer befiehlt, gehorchen wir. Dann darf niemand innerlich Bedingungen haben. Niemand darf fragen: hat der Führer Recht und ist in Ordnung, was er sagt.“ (zit. nach: Glaser, Hermann, Das Dritte Reich, Freiburg 1961, 129)

11 vgl. Huber, Verfassungsrecht, 230: „Die Führergewalt ist umfassend und total; (...) Die Führergewalt ist nicht durch (...) Kontrollen (...) gehemmt, sondern ist frei und unabhängig, ausschließlich und unbeschränkt".

${ }^{12}$ Meyers Lexikon 4, 1938, Sp. 1085 
zahlreichen Reden immer wieder eine ,Volksgemeinschaft', die sich ,über Klassen und Stände, Berufe, Konfessionen und alle übrige Wirrnis des Lebens hinweg“ erhebe, da sie ,im Blute fundiert" und „durch ein tausendjähriges Leben zusammengefügt" sei. ${ }^{13}$ Nicht in einer konkret-kontingenten Erscheinung wie der Sprache, sondern „im Blute“ und in der Rasse ist für ihn „das Volkstum", die Wesenheit eines Volks zu finden. ${ }^{14}$ So gilt hier die Tradierung eines bestimmten genetischen Materials, dessen Kernbestand auf die Arier zurückgeführt wird, als das eigentliche Konstituens eines Volks und damit zugleich als fundamentierendes Einheitsmoment der Gemeinschaft. Wie beim Führerprinzip ist diese angebliche biologische Verbürgtheit von Wesen und Integrität der Gemeinschaft letztlich eine Ontologisierung, die das behauptete Konstituens unhintergehbar macht. Mit seinem ,genetischen' Ansatz stellt der Nationalsozialismus dabei Bezüge zu den ,rassetheoretischen' Vorstellungen des 19. und beginnenden 20. Jahrhunderts her, die in agrarromantischen Kreisen, konservativen Kulturphilosophien und auch in den Kulturreformbewegungen (vgl. 2.1.) beheimatet sind. Wie zu zeigen sein wird, entledigt er sich jedoch zunehmend des Zivilisationspessimismus der Agrarromantiker und ersetzt mit seiner Ontologisierung deren ,rassehygienisches' Konzept durch ein ,anthropologisches' (vgl. weiter unten).

Das einheitsstiftende ,genetische' Material der ,arisch-germanischen Entwicklungslinie' gilt nun nicht nur als Definiens der Gemeinschaft, sondern zugleich als ihre essentielle ,Entelechie'. So sieht Hitler gerade in der kollektivierenden Orientierung auf Gemeinschaft hin das Spezifikum der Arier und betont den angeblich generell altruistischen Charakter der letztgenannten. Nicht nur in seinen ,geistigen Eigenschaften an sich“ sei der Arier ,am größten“, sondern „im Ausmaße der Bereitwilligkeit, alle Fähigkeiten in den Dienst der Gemeinschaft zu stellen“. ${ }^{15}$ Der ,Selbsterhaltungstrieb' habe bei ihm ,die edelste Form erreicht, indem er das eigene Ich dem Leben der Gesamtheit willig unterordnet und, wenn die Stunde es fordert, auch zum Opfer bringt “ ${ }^{16}$ Derartige Opferbereitschaft für die Gemeinschaft aber gilt nicht nur als arisches Spezifikum, sondern zugleich als oberste ethische Maxime. Auf diese Weise wird der nationalsozialistische Grundsatz, der das Gemeinwohl dem Eigenwohl überordnet, mit einer biologistischen Rückbindung eingeführt und das Gemeinschaftsprinzip als ethisches Prinzip verdeutlicht. Es erscheint mit der Zuordnung zum Ariertum außerdem als gruppenspezifisches ethisches Prinzip, als ,das deutsche Prinzip schlechthin' (Wendland), von dem her die ethische Grundorientierung und Grundverpflichtung der, deutschen Volksgemeinschaft' als Gemeinschaftsverpflichtetheit bestimmt wird.

Die rassistische Füllung des Gemeinschaftsprinzips führt dann weiter zur Ausgrenzung aller nicht zu ihr Gehörenden und mündet in die ,Verpflichtung zur ,Reinerhaltung' der ,Volksgemeinschaft', d.h. in eine , anthropologische' Form der ,Rassehygiene ${ }^{6}{ }^{17}$ Die Ausgrenzung schlägt sich zunächst in Punkt 4 des Parteiprogramms

${ }^{13}$ Hitler, Heldengedenktag, 184

${ }_{14}^{14}$ Hitler, Kampf, 428

${ }^{15}$ Hitler, Kampf, 326

${ }_{16}^{16}$ Hitler, Kampf, 326

${ }^{17}$ Das Zueinander des ,rassehygienischen' Erbes des 19. Jahrhunderts mit seinen spezifischen eugenischen Vorstellungen und der , anthropologischen Wende' des rassistischen Kon- 
nieder, das bestimmt, daß lediglich der ,rassisch' definierte ,Volksgenosse' Staatsbürger sein könne, und das den Angelpunkt der ,Rassegesetzgebung' bildet. ${ }^{18}$ Es dient auf diese Weise zugleich dem Verbot jeder ,rassischen Vermischung der Gemeinschaftsmitglieder mit ,Rassefremden` und schließlich auch der Legitimation der Vernichtung aller gruppenexternen Personen. Über den Begriff des ,Volksempfindens', der 1935 ins Strafrecht eingeführt wird, erhält das Gemeinschaftsprinzip methodologische Relevanz für die Rechtssprechung und stützt u.a. die Unrechtsprechung des ,Volksgerichtshofs'. Nicht zuletzt in diesen beiden rechtswirksamen Auslegungen zeigt es sich als Prinzip für eine pervertierte Ethik. Mit den pseudobiologischen Rassetheoremen des Gemeinschaftsprinzips nämlich wird das Recht der hypostasierten ,Volksgemeinschaft‘ zur Beseitigung aller nicht zu ihr Gehörenden als ,moralisches Recht ,begründet', und mit den von ihr hergeleiteten Begriffen, vor allem dem des ,Volksschädlings‘ und des ,Volksempfindens', die Willkürisierung der Rechtsprechung ,sozialethisch“ - d.h. als moralische Notwendigkeit für den Erhalt der Gemeinschaft bzw. als die größere moralische Sicherheit der Gemeinschaft - ,fundiert'.

Mit dem so bestimmten Gemeinschaftsbegriff soll dann auf der Organisationsebene die funktional-sachliche Intrarelativität der Gesellschaft durch die personalunmittelbare der Gemeinschaft ersetzt werden. Die natural-ontologisch definierte Gruppe nämlich gilt nicht als eine (nur) von äußeren Notwendigkeiten, also aus sachspezifischen und -logischen Gründen zusammengehaltene, sondern als durch einen innersten Wesenskern geeinte. Ihre Gemeinverstrickung kann daher keineswegs aus der Figur des Gesellschaftsvertrags allein erklärt werden, sondern ,gewinnt ihre ,Dignität' erst als ,schicksalhafte Vereinigung' und durch die rassenontologisch festgelegte, intime Bindung der Gemeinschaftsglieder aneinander. Den letztgenannten wird damit eine weitaus größere Nähe zueinander sowohl attestiert als auch vorgeschrieben. Ihr Verhältnis gerät zu personalen Verpflichtungen. Absicht dieser Ersetzung von Gesellschaft durch Gemeinschaft ist nicht zuletzt die Integration gesellschaftlicher Differenzen und Spannungen durch eine rassenontologische Egalisierung und Inpflichtnahme für einen schrankenlosen ,Zusammenhalt'. So betont Hitler, daß das rassenontologische Einheitsmoment der Gemeinschaft über „alle Klassen und Stände, Berufe (und) Konfessionen“ hinweg gehe, und daß damit auch „die soziale Einheit der deutschen Menschen ohne Ansehung des Standes und der Herkunft" verbürgt sei. ${ }^{19}$ Die konfligierenden gesellschaftlichen Gruppen, d.h. das verunsicherte, konservative, ständisch orientierte Bürgertum, die aufstrebende, mobile, jedoch ökonomisch frustrierte Mittelschicht und die unruhig vagierende, partiell kämpferisch organisierte Arbeiterschaft, welche die Weimarer Republik noch nicht demokratisch zu binden vermochte, werden derart zu unterschiedslosen Teilen der rassenontologisch definierten, Volksgemeinschaft' erklärt und zum Zweck der Inte-

zepts im Nationalsozialismus veranschaulicht sich sehr deutlich etwa in der, wissenschaftlichmedizinischen' Programmatik, die führende deutsche Mediziner unter Herausgeberschaft von Schottky entwickeln. Vgl. Schottky, Johannes (Hrsg.), Rasse und Krankheit, München 1937

${ }^{18}$ Vgl. Punkt 4 des Parteiprogramms, der den Ausgangspunkt der späteren ,Rassegesetzgebung bildet: „Staatsbürger kann nur sein, wer Volksgenosse ist. Volksgenosse kann nur sein, wer deutschen Blutes ist, ohne Rücksichtnahme auf Konfession. Kein Jude kann daher Volksgenosse sein." (Rosenberg, A. (Hrsg.), Das Parteiprogramm, München 1941, zit. nach: Hofer, Walther, Die Diktatur Hitlers, Wiesbaden 1965, 28)

${ }^{19}$ Hitler, Heldengedenktag, 184 
gration egalisiert. In dem ,einen Volkskörper', der ,einen Gemeinschaft' gibt es dieser ideologischen Vorstellung zufolge keine Widersprüche und sozialen Antagonismen mehr. Jede Möglichkeit gesellschaftlicher Reibungen wird, völkisch' aufgehoben. In den großen Inszenierungen des öffentlichen Lebens, wie Parteitagen, Aufmärschen, Fackelzügen, Heldenfeiern etc. soll diese Aufhebung dann sinnlich-erfahrungsnahe Plausibilität erhalten. In der Tat dienen diese Inszenierungen auch der Herstellung unmittelbarer ,Gemeinschaftserlebnisse' und so der emotiven Plausibilisierung des Theorems von der spannungslos verschweißten ,Volksgemeinschaft'. Gleichzeitig nehmen sie das öffentliche Leben in staatlich-parteigebundene Zuständigkeit und zielen sie dadurch auf eine Suspendierung der Hegelschen Trennung von Staat und Gesellschaft.

\section{Die Zuordnung von Führer- und Gemeinschaftsprinzip}

Das so präzisierte und material gefüllte Gemeinschaftsprinzip wird dann dem Führerprinzip auf zwei Ebenen jeweils zugeordnet, ohne seiner integrativen Kraft verlustig zu gehen. Zunächst bedeutet die rassistische Begründungsfigur eine Verbindung beider Prinzipien auf der gruppenexternen Ebene: Die in der genannten Weise ontologisierte ,Volksgemeinschaft' wird hier zur Führungselite unter den Völkern erklärt und als ,blutmäßig' und ,geschichtlich' zusammengeschweißte ,Schicksalsgemeinschaft' mit einer globalhistorischen Mission beschworen. ${ }^{20}$ Aus den ,Volksgenossen werden hier die ,Helden' der arisch-germanischen Rasse, denen qualitative Überlegenheit über alle übrigen Rassen attestiert wird. Auch diese Beschwörung kann integrativ genutzt werden, um soziale Spannungen egalistisch zu überspringen, oder führungsfunktional und emotiv-motivationell zum Einsatz kommen, um etwa kriegsnotwendigen Kampf- und Durchhaltewillen zu stärken und die Frustrationstoleranz zu erhöhen. Auf der gruppenexternen Ebene nämlich gelten alle als gleichermaßen elitär, bzw. zum ,arttypischen Heroismus' verpflichtet. Auf der gruppeninternen Ebene wird die Gemeinschaft jedoch als durchaus geschichtete, letztlich dichotomisch verfaBte gedacht, ${ }^{21}$ die auf Führung durch eine Elite ausgerichtet ist; die integrative Nivellierung wird hier zunächst scheinbar aufgehoben. So sind es bei Hitler zwar die ,besten Köpfe der Volksgemeinschaft', die in Führungspositionen tätig werden sollen, doch sind es zugleich die besten Köpfe und ragen sie in dieser Position über die Gemeinschaft des Volks hinaus. In derselben Weise verstehen sich auch seine Polemik gegen den ,Parlamentarismus' als eine Regierungsform, „die das letzte Bestimmungsrecht einer Massenversammlung von Menschen überträgt, von der immer nur ein ganz winziger Bruchteil Kenntnisse und Erfahrung in den zur Behandlung stehenden Angelegenheiten besitzt ${ }^{\text {‘22 }}$, und die Aufgabenbestimmung des ,völkischen

${ }^{20}$ Die genannte Beschwörung findet sich in zahlreichen Reden Hitlers, als deren Beispiel hier die bereits zitierte ,Heldenrede' von 1940 genannt sei. vgl. Hitler Heldengedenktag, 184

${ }^{21}$ Dieses dichotomische Moment enthält etwa ein Leitartikel Goebbels' schon 1928: „Wir sind keine Gleichmacher und Menschheitsanbeter (...) Wir wollen Schichtung des Volkes, hoch und niedrig, oben und unten." (Goebbels, in: Angriff vom 23. 7. 1928, zit. nach: Schoenbaum, David, Die braune Revolution, Köln 1968, 290) Der Artikel Goebbels' verweist gleichzeitig darauf, daß es im ,Führerreich' durchaus nicht um Beseitigung der sozialen Differenzen gehen sollte, sondern weitaus mehr deren emotiv-irrationales Überspielen - durch etwa die genannte Pathetik auf Ebene 1 - zugunsten der Führungsorientierung im Blick stand.

${ }_{22}^{2}$ Hitler, Kampf, 96-97 
Staats', der „die gesamte, besonders aber die oberste, also politische Leitung restlos vom parlamentarischen Prinzip der Majoritäts-, also Massenbestimmung zu befreien (habe, T.H.), um an Stelle dessen das Recht der Person einwandfrei sicherzustellen ${ }^{\text {‘23 }}$. Gegen das Bild einer demokratischen ,Selbstorganisation der Inkompetenten' wird so die elitäre Führungsdichotomie gesetzt und dem Gemeinschaftsprinzip die Möglichkeit der Integration durch Egalisierung vorerst genommen. Zugleich aber gelten die Führungspersönlichkeiten, vor allem ,der Führer', als ideale höchste Inkarnation und Repräsentation der Gemeinschaft und wird eine „schicksalhafte Einheit von Führer und Gefolgschaft ${ }^{\prime 24}$ beschworen. Einer ,Masse', die sonst eine Ansammlung von Einzelpersonen bliebe, wird die Gestalt des ,Führers' als die eigentlich ,vereinigende, d.h. erst gemeinschaftsbildende Projektionsfigur gegenübergestellt und zur Identifikation angeboten. Das egalisierende Moment wird derart rückwärtig wieder eingeschleust - dem ,Führer' gegenüber haben alle dieselbe Stellung - und die elitäre Dichotomie projektiv-integrativ genutzt - im ,Führer' ist die Gemeinschaft reibungslos realisiert. Insofern das Gemeinschaftsprinzip bereits begriffslogisch ein nur personal zu denkendes Relationsprinzip vorstellt, das, wie zu sehen war, im Nationalsozialismus gerade die funktional-sachliche Intrarelativität der Gesellschaft ersetzen soll, bedarf es denn auch dieser projektiven, personalen Repräsentanz: Gemeinschaft kann nur als individuell-unmittelbares Verhältnis von Personen gefaßt werden; soll Gesellschaft in diesem Sinn umgedeutet (und ihres eigentlichen Wesens beraubt) werden, so bleibt nichts anderes als eine integrative Repräsentation durch eine Person. Das nationalsozialistische Gemeinschaftsprinzip ist deshalb auf die Zuordnung zum Führerprinzip notwendig angelegt und findet über das letztgenannte seine gruppeninterne organisatorische Verwirklichung.

Das autokratische Moment des Führerprinzips bleibt in dieser Verbindung unverändert erhalten. So nennt der Verfassungsrechtler Huber ,den Führer‘ „Vollstrecker des völkischen Gemeinwillens ${ }^{\text {“25 }}$ und betont er zugleich die unantastbare Autokratie dieses ,Führers', der ohne Einschränkung definieren kann, was dieser ,Gemeinwille sei, oder bestimmt Freisler die Aufgabe des Richters im nationalsozialistischen Staat dahingehend, ,in erster Linie die autoritären Willenskundgebungen des Führers als Ausdruck des gesunden Volksempfindens anzuschauen und seinen Entscheidungen zugrunde zu legen“"26. Egalistische Integration über das Gemeinschaftsprinzip und elitäre Willkürherrschaft durch das Führerprinzip widerstreiten einander im nationalsozialistischen Staat nicht, sondern gehören zusammen. Auf der ethischen Ebene wiederum findet die Zuordnung der beiden Prinzipien über den Topos der ,Gefolg. schaft' statt. Hier ist es die moralisch verankerte unbedingte, Treuepflicht' dem ,Führer' gegenüber, die die Brücke bildet und zu einer, sittlichen Integration' führt: Durch die genannte Pflicht wird die prinzipielle, projektive Egalisierung aller ihr Unterworfenen ethisiert und auch die aus dem Gemeinschaftsprinzip abgeleitete sozialethische Maxime, die das Gemeinwohl dem Eigenwohl überordnet, vordringlich als Gemeinhaftung (statt Gemeinansprüchen) dem ,Führer' gegenüber, d.h. aber als

${ }^{23}$ Hitler, Kampf, 500; Hervorhebung von mir.

${ }_{24}^{24}$ Meyers Lexikon 4, 1938, Sp. 802; Hervorhebung von mir.

25 Huber, Verfassungsrecht, 230

${ }^{26}$ Gürtner, F., Freisler, R., Das neue Strafrecht, Berlin 1936, 77; zit. nach: Püschel, Wilhelm. Der Niedergang des Rechts im Dritten Reich, Reutlingen 1947, 70; Hervorhebung von mir. 
unterschiedslose ,Gefolgschaftsverantwortung ausgelegt. Diese Gefolgschaftsverantwortung als unbedingt-sittliche substituiert erneut die sittliche Handlungsvernunft der einzelnen Subjekte durch eine deontologische Heteronomie personaler Führungswillkür und wendet die Integration in Unterwerfung. Das Gemeinschaftsprinzip wird derart auf der gruppeninternen Ebene mit dem Führerprinzip geradezu synonym und seine moralische Verpflichtungskraft der des Führerprinzips unterstellt.

\subsection{Partielle Assimilation an moderne Dynamisierungsprozesse und kontramoderne Gesamtstrategie}

Aus dem integrativen Bemühen dieser spezifischen Zuordnung kann auch das scheinbar moderne, d.h. rational-funktionelle und technikfreundliche Verhalten des Nationalsozialismus begriffen werden, das im Lauf seiner Herrschaft die agrarromantische, zivilisationskritische, statisch-ständische Rhetorik unterläuft und die Vertreter der letztgenannten Richtung zur faktisch einflußlosen Randgruppe macht. Damit läßt der Nationalsozialismus, obschon er es nicht unter diesem Titel zum Thema macht, zugleich ein spezifisches Verhältnis zum Projekt der Moderne erkennen und bezieht er sich deutlicher als die Reformer auf dieses. Die zu integrierenden sozialen Spannungen und der soziale Wandel dieser Zeit finden ihre Wurzel ja in jenen modernen Dynamisierungsprozessen, welche einerseits von der technisch-industriellen Entwicklung verursacht werden und die andererseits die Folge der Veränderung der Öffentlichkeitsstruktur durch die Herausbildung der bürgerlichen aus der literarischen Öffentlichkeit sowie der darin angelegten Demokratisierungstendenz sind. In diesen beiden Prozessen aber realisieren und aktualisieren sich - wie zu sehen war (vgl. 1.4) - letztlich das Rationalisierungs- und das Autonomisierungsprogramm des Projekts der Moderne. Obschon nun der Nationalsozialismus ebenso wie die Reformer keine unmittelbare theoretische Auseinandersetzung mit dem Projekt der Moderne anzielt, setzt er sich doch im letzten zu diesem in Bezug, wenn er den genannten Prozessen zu begegnen sucht. Da der Nationalsozialismus zudem nicht nur (mittelbar) die Autonomisierung, sondern recht unmittelbar auch die technischinstrumentelle Rationalisierung in Blick nimmt, ist seine Konfrontation mit dem Projekt der Moderne noch deutlicher erkennbar und umfangreicher, als dies bei den Reformern der Fall ist.

Im Gegensatz zu den Reformern versucht der Nationalsozialismus dabei, für beide modernen Entwicklungen - die technisch-industrielle und die autonomistisch-demokratische - spezifische Anpassungsformen zu finden, die seine in der Grundtendenz durchaus antimoderne Staats- und Gesellschaftskonzeption stützen. Die Aufgabe, die sich ihm dadurch stellt, ist eine doppelte: Er muß sich einerseits die nicht mehr zu stoppende erstgenannte Entwicklung legitimativ eingliedern und diese seinen eigenen Zielen dienstbar machen, d.h. eine Technik- und Ökonomieintegration leisten, die gesellschaftsbezogen zumindest mit einer Duldung der verstädternden und funktionell sozial mobilisierenden Dynamik einhergeht und welche die auf den technischindustriellen ProzeB rückbezogene Kulturkritik von diesem abkoppelt. Andererseits aber muß er die mit diesem Prozeß zusammenhängende zweite Entwicklung unterlaufen, um seine antidemokratische Herrschaftsorganisation erhalten zu können. Das wiederum soll durch Flexibilisierung der nationalsozialistischen Führungsdicho- 
tomie und Egalisierung über das Gemeinschaftsprinzip erreicht werden. Implizit beabsichtigt ist so eine Art Assimilation an das Projekt der Moderne, durch die dieses Projekt gleichzeitig entschärft und der nationalsozialistischen Kontramoderne unterworfen werden soll. Diese Assimilationsversuche lassen sich auf der gruppenexternen, wie der gruppeninternen Ebene auch theoriebezogen dingfest machen.

\section{Versuchte Integration von technisch-instrumentellen Errungenschaften der Moderne durch anthropologischen Rassismus}

Die technik- und ökonomieintegrativ wirksame Legitimation der ersten Entwicklung findet vordringlich auf der gruppenexternen Ebene statt. Hier geht es darum, die letztlich technik- und fortschrittsfeindliche kulturkritische Entgegensetzung von Stadt und Land, wie sie die ,rassehygienischen'Theoreme des späten 19. und beginnenden 20. Jahrhunderts, aber auch die kulturpessimistischen Auslassungen der Kinoreformbewegung über die Großstadt (vgl. 2.3.) unternahmen, zu mildern. ${ }^{27}$ In beiden Fällen bildete die moderne Stadt den Kristallisationspunkt der jeweils angemahnten Verfallserscheinungen: Für die ,Rassehygiene' galt die Stadtkultur als Ergebnis eines negativen Ausleseprozesses, in welchem die in höhere soziale Positionen gelangten, durchsetzungsfähigen und daher wertvollen Individuen sich durch geringe Fruchtbarkeit, also auch durch geringe Vererbung ihrer hochwertigen Eigenschaften auszeichneten. Ergebnis des Prozesses waren dann eine Verschlechterung des Erbgutstandards der Gesamtheit und ein daraus fließender Kulturverfall. Als Lösung dieses Problems schien nur eine agrarromantische Beförderung des Landlebens mit seiner ,naturgegebenen' Fruchtbarkeit auch der ,wertvollen Eigenschaftsträger‘ möglich. Diese Beförderung freilich bedeutete zugleich eine regressive Wende gegen die technisch-industrielle Weltgestaltung und geriet letztlich zu einer Bedrohung der hierdurch erreichten Fortschritte. Die Kinoreformer wiederum erblickten in der technischen Zivilisation der Großstadt die Beförderin einer kulturzerstörenden und zugleich ,widernatürlichen' Renaturalisierungsdynamik, welche sie mit der ,gesunden Bodenständigkeit‘ des Lands kontrastierten. Sie gerieten dabei in ein Dilemma von Kulturpessimismus und Technikfreundlichkeit, das sie nicht konsistent theoretisch zu lösen vermochten (vgl. 2.3.). So führten beide Positionen, die der Rassehygiene und die der Reformer, in einen Zwiespalt. Letztlich nämlich setzten sie sich (implizit) dem Projekt der Moderne entgegen und vermochten sie entsprechend die mit diesem konnotierten technisch-rationalen Errungenschaften nicht mehr zu legitimieren.

Diesem Dilemma versucht der Nationalsozialismus kontramodern-integrativ zu entkommen, indem er gegen beide Positionen nun seinen anthropologischen Rassismus setzt, der das gesamte ,deutsche Volk‘ zur ,Herrenrasse' und mit seiner Verbindung von Gemeinschafts- und Führerprinzip zu einer Führungselite erklärt, welcher ,nur‘ noch ,andere Völker‘ als defiziente kontrastieren. Der integrative Gewinn liegt darin, daß die Rettung ,ethnischer', kultureller und sittlicher Integrität nicht länger exklusiv in einer Rückkehr zur durch Bodenständigkeit verbürgten Traditionalität,

${ }^{27}$ vgl. dazu: Sieferle, Fortschrittsfeinde, 193-224, dem ich die Begriffsdifferenzierung des ,anthropologischen' und des ,hygienischen' Rassismus, sowie den Gedanken einer nationalsozialistischen rassetheoretischen Verschiebung des Zivilisationspessimismus zur Assimilation entnehme. Der Transfer auf die Kinoreformer findet sich freilich nicht dort, wie auch die Reflexion auf das Verhältnis zum Projekt der Moderne von Sieferle nicht vollzogen wird. 
d.h. zur ländlich-,urwüchsigen', quasi-naturalen Volkskultur und ihrer Kristallisation in der Sitte, damit aber auch in einem generellen antitechnischen und antiindustriellen rationalisierungsfeindlichen Affekt gesehen werden muß. Zur ,Herrenrasse' gehören nämlich jetzt auch die Städter, während die Verfallserscheinungen aus der Gruppe der ,Deutschen' ausgegliedert und der Vermischung mit ,minderwertigen Rassen' angelastet werden können. Sowohl das Land als auch die Stadt gelten als Quellen der hervorragenden Eigenschaften der ,arischen Rasse', die sich in beiden Räumen in ihrer spezifischen Kultur auslegt und auslegen darf. Wenn man so will, ist auf diese Weise das Projekt der Moderne rassetheoretisch sowohl legitimiert als auch pervertiert: Es gilt als Errungenschaft einer genetisch-spekulativ ontologisierten Gruppe und wird derart entgegen seinen universalen Aspirationen auf technischrationale Verbesserung der Lebensverhältnisse des Menschen zum privativen „Besitz einiger Weniger erklärt. Gegenüber der reformerischen und rassehygienischen Position freilich ermöglicht diese Perversion einen strategischen Gewinn: Die Rettung der Kultur muß nicht mehr gegen die Zivilisation und ihre technisch-ökonomische Ratio erfolgen, sondern durch ,Reinerhaltung' der führungselitären ,Volksgemeinschaft' und in aggressiver Frontstellung gegen die übrigen Völker und ihre Kulturen verwirklicht werden. Technischer Fortschritt aber kann dann geradezu als auszeichnendes und den Elitestatus bestätigendes Merkmal der ,Gemeinschaft' im Sinn der ,Herrenrasse‘ interpretiert und der globalen Durchsetzung ihrer ,Führungsmission ebenso dienstbar gemacht werden wie die Industrieproduktion; Verstädterung und soziale Mobilisierung können als legitime Begleiterscheinungen des technisch-industriellen Prozesses gehandhabt oder als unvermeidbare, aber marginale Nebeneffekte der durchaus legitimen technisch-industriellen Überstiege der ,Herrenrasse zumindest geduldet werden. Wo die Dynamisierung unannehmbar erscheint, bleibt den Nationalsozialisten mit dieser theoretischen Wende trotzdem die Möglichkeit erhalten, Kritik an der Stadtkultur zu üben. Insbesondere die ,modernen Kulturerscheinungen' können über das Theorem einer Überfremdung durch die ,minderwertigen Rassen' weiterhin diskriminiert werden, ohne in ein Dilemma zur Techniknutzung zu geraten. Das kulturkritische Potential vor allem der Reformer (weniger der Agrarromantik, deren Vertreter im Lauf der Geschichte der Nationalsozialisten zur Randgruppe geraten) wird so konsistent ,gerettet' und zugleich eine partielle theoretische Assimilation an den Gesellschaftsprozeß der Moderne versucht.

\section{Destruktion der Autonomisierung und Subjektivierung bei Assimilation an soziale Mobilität und organisatorischer Flexibilisierung der kontramodemen Gesamtkonzeption}

Die Frontstellung gegen die Verbreiterung der Öffentlichkeit und die darin angemeldeten Mitspracherechte wiederum findet vorwiegend auf der gruppeninternen Ebene statt. Hier wird versucht, gegen die genannte Demokratisierungstendenz und ihre soziale Dynamik, also gegen ,unannehmbare Momente' der Dynamisierung, die elitäre Dichotomie des Nationalsozialismus über die Zuordnung des Gemeinschaftsprinzips zum Führerprinzip herrschaftswahrend durchzusetzen. Damit sind gleichzeitig die vom Projekt der Moderne intendierte Autonomisierung und Subjektivierung (wieder) unterlaufen und aufgekündigt. Eingeleitet wird das mit einer sozial-integrativen Nivellierung. Zunächst ebnet der egalisierende Charakter des Gemeinschaftsprinzips die soziale Mobilität als Ausdruck eines selbstbestimmten, also autonomen Sozial- 
verhaltens politisch ein, ohne sie in ihrer Faktizität aufzuheben: Die Überschreitung der Schichtgrenzen durch ökonomischen Aufstieg und durch Bildung bleibt legitime Bewegung innerhalb der Gemeinschaft, verändert jedoch weder den Status als ,Volksgenosse', der ja rassisch-ontologisch bestimmt ist, noch erlaubt sie die Interpretation dieser selbstbestimmten Verortung im sozialen Gefüge als Konkretion autonomer Subjektivität. Die vom Individuum inszenierte Bewegung innerhalb der Gemeinschaft kann unter dem rassenontologisch fixierten Gemeinschaftsprinzip nicht als Ausdruck einer autonomen Definition der eigenen sozialen Identität gewertet werden, sondern bleibt eine ,zufällige', im letzten bedeutungslose Ortsverände-

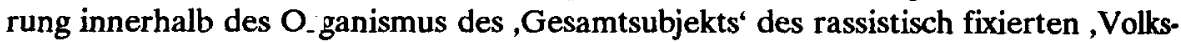
körpers'. Die Gemeinschaft der ,Volksgenossen' ist außerdem insgesamt auf Führung durch eine ebenfalls ontologisch bestimmte Elite hingeordnet, wodurch alle Gemeinschaftsmitglieder zur egalitären Gefolgschaft geraten und zunächst die Nivellierung verstärkt wird. Gemäß der Definition dieser Zuordnung finden dann, wie zu sehen war, die Gefolgsleute erst in der Elite ihre, eigentliche' Gestalt als Gemeinschaft. Damit wird zugleich der Raum der Öffentlichkeit zirkelintern den nationalsozialistischen Führungspersönlichkeiten reserviert, die als Repräsentanten der Gemeinschaft ihre eigentlichen Konstituenten sind und deren Status als ontologisch-charismatischer kein sozial-kontingenter ist, daher auch nicht über kontingente soziale Mobilität erreicht werden kann. Mitspracherechte können folglich nicht auf diesem Weg angemeldet werden, und eine Wirkung von Verstädterung und Dynamisierung auf die Struktur der Öffentlichkeit bleibt theoriebezogen ausgeschlossen. Damit ist auch die Autonomisierung, die sich in den sozialen Mobilisierungsprozessen ausdrückt, zusammen mit den Mitspracheforderungen verabschiedet bzw. wird sie zirkelintern für die Führungsriege requiriert und gegenüber den Geführten in Heteronomie umgebogen. Nicht neuzeitliche Subjekte organisieren hier ihre Gesellschaft, sondern zu Objekten reduzierte Untertanen werden einer dichotomisch präformierten Sozialstruktur eingegliedert und ihres durch Autonomie verbürgten Subjektstatus beraubt. Ähnlich den Reformern, wenngleich auf der gesellschaftlichen Ebene weitaus deutlicher und umfassender als diese, beziehen die Nationalsozialisten so Stellung gegen die neuzeitliche Autonomisierung der Subjekte, und darin gegen das Kernstück des Projekts der Moderne. Im Unterschied zu den Reformern aber versuchen sie erneut, die daraus hervorgehenden konkreten Phänomene ihrem Konzept zu assimilieren und zugleich die kontramoderne Grundrichtung durchzusetzen.

Die hierzu verwendete dichotomische Ontologie freilich reicht noch nicht hin, um die antiautonomistische Gesellschaftsorganisation und die theoretisch beanspruchte Herrschaftsstellung auch faktisch zu sichern. Organisatorisch findet diese Sicherung daher durch eine flexibilisierende Umsetzung des Führerprinzips statt, die der Durchsetzung einer funktionalen, rationalen Struktur unter dynamisierten Bedin: gungen dienen und die Unterordnung der Gemeinschaft unter die Führung garantie. ren soll. In der Strukturanalyse lassen sich dabei drei interagierende Komponenten erkennen: hierarchisch übergreifende Zugriffsunmittelbarkeit, personelle Garantic der Linientreue und delegative Flexibilisierung des Gesamtapparats. ${ }^{28}$ Zunächst wird

${ }^{28}$ Aus soziologischer Perspektive hat diese Struktur bereits 1969 Albrecht erarbeitet, auf dei ich mich hauptsächlich stützen werde. Vgl. Albrecht, Filmpolitik 
entsprechend der oben genannten Synonymität von Führer- und Gemeinschaftsprinzip das erstgenannte nach 1933 über den Raum der Partei auf Staat und Gesellschaft ausgedehnt und zum Organisationsprinzip des öffentlichen Lebens als des „Gemeinschaftsleben(s) des Volkes“29 überhaupt erklärt. Die Tatsache, daB alle staatlichen Einrichtungen, aber auch die gesellschaftlichen Institutionen der Wirtschaft, der Kultur und die diversen vereinsmäBigen Organisationen (,Arbeitsfront', ,Betriebsgemeinschaften') diesem Prinzip unterworfen sein sollen, impliziert zugleich, daß Führungsaufgaben an ,Unterführer', nämlich die Leiter der einzelnen Verbände, Abteilungen und Gruppenorganisationen, delegiert werden und das Führerprinzip derart eine Diversifizierung erfährt. Der Gesamtapparat nationalsozialistischer Herrschaft soll auf diese Weise sowohl der Durchdringung und feinstrukturellen Kontrolle aller gesellschaftlichen Bereiche dienen, als auch flexibel und anpassungsfähig gehalten werden. Nach der Maxime: ,Autorität jedes Führers nach unten“30 wird jeder ,Unterführer' mit einer autokratischen Befehlsmacht ausgestattet, die ihm situationsspezifisches Agieren in seinem Bereich ermöglichen soll. Gleichzeitig aber wird er mit der Maxime absoluter „Verantwortung nach oben ${ }^{\text {“31 }}$ selbst in die Herrschaftshierarchie gespannt und restlos kontrollierbar gehalten. Dabei gilt für den ,Instanzenzug", $\mathrm{daB}$ nicht nur die jeweils oberste, sondern jede oberhalb liegende Instanz durch Befehl in die unter ihr liegenden eingreifen kann. ${ }^{32}$ Die ganz oben angesiedelte Instanz, d.h. etwa Hitler oder in allen dem Propagandaministerium untergeordneten Organisationen Goebbels, ist hierbei selbst nicht mehr nach oben verantwortlich und kontrollierbar, sondern bis in die Willkür autokratisch und mit einer Zugriffsmacht über alle hierarchischen Ebenen hinweg ausgestattet. Sorgt dies bereits strukturell für eine Verantwortlichkeitsinflation und Angstspirale, die der Linientreue dienstbar gemacht wird, ${ }^{33}$ so soll die letzte auch personell verankert und jede Führungsposition mit ideologisch ,verläßlichen` Personen besetzt werden. Da die nationalsozialistische Führungsorganisation an sich, ähnlich wie die von den Kinoreformern entworfene autoritäre Systemstruktur, noch keine vollständige Garantie für ideologische Stabili-

${ }^{29}$ vgl. Huber, Verfassungsrecht, 198: „Das Führertum ist eine allgemeine Gestaltungsform im offentlichen Leben des völkischen Reiches. Es (...) ergreift alle Organisationen, Einrichtungen und Verbände, die am Gemeinschaftsleben des Volkes teilhaben. (...) Die staatlichen Einrichtungen (...) werden ebenso wie die Ordnungen des ständischen Lebens (...) durch das Prinzip der Führung bestimmt." vgl. auch: Albrecht, Filmpolitik, 242-245

${ }^{30}$ Hitler, Kampf, 501

31 Hitler, Kampf, 501

32 vgl. Albrecht, Filmpolitik, 274

${ }^{33}$ Albrecht sieht daher die Stabilität und Funktionalität des nationalsozialistischen Systems nicht so sehr ,,in der etwa vorhandenen nationalsozialistischen Überzeugung vieler Einzelner" verankert, sondern in der durch die skizzierte Struktur erzeugten Dauersituation einer ,unspezifischen Bedrohung“, wobei die ,steigende Angst dem jeweiligen Führer mehr Autorität, seiner Gefolgschaft wachsende ,Verantwortung, d.h. erhöhte Abhängigkeit brachte“. (vgl. Albrecht, Fimpolitik, 260-261) - Das Gesamtsystem der unvorhersehbaren und unüberblickbaren möglichen Zugriffe und Relegationen von oben führt freilich auch, wie Albrecht ebenfalls nachweist, zu einer Störung der Systemstabilität: Die Zuständigkeitsdiffusion und die Ämterverflechtung des nationalsozialistischen Regimes machen für die ,Unterführer" oft schwer durchschaubar, welche Anpassungsleistungen jeweils gefordert sind, und bedingen so Dysfunktionalitäten. Das nationalsozialistische System zeigt sich so als weder rein ,eufunktional', d.h. völlig selbststabilisierend, noch als ganz und gar dysfunktional, d.h. ausschließlich mit selbstauflösenden strukturellen Widersprüchen ausgestattet. (vgl. Albrecht, Filmpolitik, 276-282) 
sierung, bzw. Selbstreproduktion der ideologischen Herrschaft darstellt, muß (in beiden Fällen) eine Personalpolitik nach dem Prinzip der Ideologietreue entsprechende Stützfunktionen übernehmen. Die antiautonomistische, dichotomische Führungsorganisation der nationalsozialistischen Gesellschaft wird damit strukturell flexibel fixiert. Auf diese Weise soll die Stabilität der Herrschaftsstellung der nationalsozialistischen Führung, v.a. Hitlers, unter dynamisierten Bedingungen sichergestellt und die zirkelinterne Requirierung des Raums der Öffentlichkeit befestigt werden.

Die Konzeption des Nationalsozialismus aber läßt sich in ihrer Stellung zur Moderne nun insgesamt als Versuch dekodieren, deren technisch-instrumentelle Errungenschaften für sich nutzbar und den hierzu nötigen GesellschaftsprozeB legitimierbar zu machen, ohne wirklich eine Einlösung des Projekts der Moderne insgesamt zuzulassen. Zwar werden Industriekultur, Verstädterung, soziale Mobilität und Dynamisierung als moderne Phänomene, d.h. letztlich auch: als phänomenale Konkretionen dieses Projekts, realisiert und assimilativ der nationalsozialistischen Gesellschaft eingegliedert. Doch führt die Assimilation zugleich zu einer Destruktion der in den Phänomenen anwesenden Leitvorstellungen von Autonomie, Subjektivität und Demokratisierung. Gegen diese Vorstellungen nämlich setzt der Nationalsozialismus seine kontramodern-autoritäre, rassistische Gesamtkonzeption, die die Assimilation an moderne Prozesse zugleich als Perversion der Aspirationen des Projekts der Moderne enthüllt. Über die flexibilisierte Sicherung der Führungsdichotomie und den letztlich totalen Umgriff, der darin intendiert ist, weist die Perversion zudem auf den totalitären Charakter der nationalsozialistischen Gesellschaftsorganistation hin.

\subsection{Das nationalsozialistische Staats- und Gesellschaftskonzept als totalitäre, dichotomisch-fïhrungsfunktionale und regressiv-statische Konzeption}

Aus den grundsätzlichen Dimensionen von Gemeinschafts- und Führerprinzip als den generellen organisatorisch-ethischen Prinzipien des Nationalsozialismus und aus ihrer kontramodernen Ausrichtung läßt sich damit nun zusammenfassend das Staatsund Gesellschaftskonzept des Nationalsozialismus und dessen Verhältnis zu dem der Reformer verdeutlichen. Die vorangehende Skizze der Prinzipien erweist dabei zunächst die Staats- und Gesellschaftskonzeption der Nationalsozialisten als totalitäre, dichotomisch-führungsfunktionale sowie regressiv-statische.

\section{Die nationalsozialistische Gesellschaft als totalitäre Struktur}

Der totalitäre Charakter ergibt sich aus drei spezifischen Grenzauflösungen: In einem ersten Schritt wird, wie zu sehen war, durch die Redefinition von Gesellschaft als Gemeinschaft die funktional-sachliche Intrarelativität der ersten durch die personal-unmittelbare der zweiten ersetzt, damit aber die gesellschaftliche Existenz der Individuen ihrer distanzierten Sozialität entkleidet. Das Gesellschaftsverhältnis wird als Personenverhältnis gefaßt und in den Kategorien der Authentizität personaler Begegnung und ihrer Verpflichtungen gedacht. Scheint dies zunächst zu einer entsprechend veränderten Anforderung an Sozialität zu führen und die ,kalte Sachlichkeit' der Gesellschaft in die ,Stallwärme' der Gemeinschaft zu transformieren, so zeigt sich bei näherem Zusehen, da $B$ damit auch die personale Authentizität in eine neue kontextuelle Form gebracht und unter veränderte Anforderungen gestellt wird. 
Die nationalsozialistische Redefinition des Gesellschaftsbegriffs nämlich bedeutet eine Aufhebung der Differenzierung von sozialer Identität, die sich auf der Verhaltens- und Pflichtseite in gesellschaftlichen Rollen ausdrückt, und personaler Identität, welche als existenzialer Selbstentwurf ein Moment intimer Unmittelbarkeit bei sich führt, das in Rollen keineswegs aufgehen kann. Obschon Hitler in der Charakterisierung des Führerprinzips das ,Recht der Person' betont, löst die gesellschaftstheoretische Verwendung des Gemeinschaftsprinzips dieses Recht wieder auf: Durch die Identifizierung der gesellschaftlichen mit der personalen Existenz wird die intime Unmittelbarkeit der letzten nach außen gezogen und der existenziale Selbstentwurf zum Gegenstand primär, ja exklusiv sozialer Relevanz gemacht. Die Person in der nationalsozialistischen ,Gemeinschaftsgesellschaft' ist erst durch ihre Mitgliedschaft in derselben als Person denkbar und erhält daraus ihre spezifischen Eigenschaften. Personalität wird damit aus dem Schutzraum der Privatheit herausgelöst und in den Raum der Öffentlichkeit gestellt, d.h. es wird die Grenze zwischen privat und öffentlich aufgehoben. Die normative Auslegung des Gemeinschaftsprinzips erklärt aus der sozialen Relevanz dann die gesellschaftliche Zuständigkeit für den individuellen Selbstentwurf und sorgt so für eine grundsätzliche und ausnahmslose Unterwerfung der kreativen Bewegungsspielräume des Individuums unter die Bestimmungsgründe des Kollektivs, also für eine normative Kolonisierung der lebensweltlich-existenzialen Privatheit durch das System der Öffentlichkeit.

In einem zweiten Schritt wird der Raum der Öffentlichkeit dann exklusiv dem Staat als Zuständigkeitsbereich reserviert und derart die Hegel'sche Trennung von Staat und Gesellschaft beseitigt. Dies geschieht primär durch die Zuordnung von Gemeinschafts- und Führerprinzip, welche die Schicht der ,Führer', durch die der Staat vertreten ist, zu den eigentlichen Repräsentanten der Gemeinschaft erklärt. Das ,Gemeinschaftsleben' wird so durch die Führungsoligarchie an sich gezogen und als Zuständigkeitsbereich requiriert. Damit gerät nicht nur jedes öffentlich relevante, sondern auch jedes lebensweltlich-private Verhalten zum Belang von Partei und Führungsschicht und wird bei den Gemeinschaftsmitgliedern ein Gefühl unbegrenzter Verantwortung und Belangbarkeit bis in die letzten Räume der eigenen Person hinein erzeugt. Sowohl die bürgerliche als auch die personale Existenz wird derart in eine ausschließlich staatsbürgerliche transformiert und der staatlichen Zugriffs- und Definitionsmacht unterworfen. Die genannte Requirierung und ihre Identifikation von Gesellschaft und Staat veranschaulicht sich dann auf der Außenseite in einer ,Regie des öffentlichen Lebens' in Parteitagen, Aufmärschen, Heldenfeiern etc. und auf der Innenseite in einem stets staatsbürgerlichen Bewußtsein und Habitus, dessen Verantwortungsbereitschaft sich sogar noch im negativen geflügelten Wort (,Wenn das der Führer wüßte ...") äußert.

Damit sind, zum Dritten, auch die Grenzen zwischen individueller Sittlichkeit und kollektivem Universalethos sowie zwischen Staat und Moral zerstört. Letztlich nämlich ist es die individuell-sittliche Existenz, die mit der staatsbürgerlichen in eins gesetzt wird. Diese Konsequenz fließt aus der spezifischen Doppelverwendung von Gemeinschafts- und Führerprinzip als organisatorische und ethische Begriffe. So führt zunächst das Gemeinschaftsprinzip nicht nur zu einer Aufhebung der Trennung von privat und öfentlich auf der organisatorisch-rollenbezogenen Ebene, sondern als ethische Maxime, die das Gemeinwohl dem Eigenwohl überordnet, zugleich zu einer 
öfentlich-sittlichen Indienstnahme des privaten Selbstentwurfs, d.h. einer exklusiven Öffentlichkeits- und Kollektivverpflichtetheit des privaten Ethos. Eine Bildung von Binnenmoralen und eine Pluralität moralischer Überzeugungen unterhalb der Ebene eines universellen ,Rahmenethos' ist damit nicht mehr möglich. Das Ethos der ,Gemeinschaftsöffentlichkeit' wird normativ identisch mit dem des Individuums. Durch die Verbindung mit dem Führerprinzip und die Erklärung der organisatorischen Unterordnung der Gemeinschaftsmitglieder unter die Führung zur unbedingten sittlichen Pflicht gerät weiter die Verantwortung gegenüber den Führern zu einer Gefolgschaftsverantwortung, d.h. zur unmittelbar moralischen. Gleichzeitig damit wird die Zuständigkeit für die Bestimmung des ,Gemeinschaftsethos‘ in die Hände der Führungsschicht gelegt und die Übernahme jeder von den ,Führern' dekretierten moralischen Norm selbst nochmals zur sittlichen Verpflichtung erklärt. Insofern die Führungsschicht den Staat repräsentiert, ist damit die Grenze zwischen Staat und Moral in doppelter Hinsicht aufgelöst: Das Individuum ist gegenüber dem Staat sowohl moralisch verpflichtet als auch zur Identifikation mit einer bestimmten staatlich verordneten Moral angehalten. Der totalitäre Charaker der nationalsozialistischen Staatsund Gesellschaftskonzeption zeigt sich derart als Verknüpfung von gesellschaftlichem Dasein, moralischem Habitus und staatsbürgerlich-politischer Existenz zu einer unlösbaren Einheit, die keine partielle Nichtidentifikation, keine Bildung von Binnenmoralen und keinen politischen Pluralismus zuläßt.

\section{Die dichotomisch-führungsfunktionale Einrichtung der nationalsozialistischen Gesellschaft}

Die grundsätzliche Hinordnung auf Führung zeigt weiter, daß die Konzeption dichotomisch eingerichtet ist, d.h. ein zweischichtiges Gesellschaftsmodell vorstellt. Unterschieden werden in diesem Modell eine kleine Gruppe elitärer Führungspersönlichkeiten von einer Masse Geführter, die zugleich als führungsbedürftig gelten. Der Status beider wird, wie zu sehen war, mit ,rassetheoretischen 'Axiomen als quasi-natural vorgegebener bestimmt und auf diese Weise ontologisiert. Insbesondere der charismatische Stand der Elite findet sich mit dieser Legitimationsfigur unantastbar gehalten und dauerhaft etabliert. Das Modell zielt damit auf eine Oligarchie bzw. Monokratie, die sich als statisch-hierarchische Herrschaftsorganisation darstellt. Gesichert werden soll diese dann durch die organisatorische Verwendung des Führerprinzips und seine Auslegung in die drei genannten Komponenten, welche einen totalen führungsfunktionalen Umgriff bis in Feinstrukturen garantieren und so der realen Etablierung des dichotomischen, theoretischen Gesellschaftskonzepts dienen sollen.

Der regressiv-statische Charakter der nationalsozialistischen Gesellschaftskonzeption und dessen Verhältnis zu dem der reformerischen

Damit zeigt sich das nationalsozialistische Staats- und Gesellschaftskonzept ähnlich dem reformerischen als kontramodernes und regressives. Ebenso wie das reformerische stellt es sich gegen die modernen Dynamisierungs- und Demokratisierungsprozesse und die darin anwesende Subjektivierung und Autonomisierung, die als Kernbestände des Projekts der Moderne zu gelten haben. Analog dem reformerischen Konzept bemüht sich das nationalsozialistische außerdem um eine rückwärtsgewandte, statisch-ständische Lösung, deren Dichotomie denn auch an Monarchie und 
Ständestaat erinnert. Doch bedienen sich Nationalsozialisten und Reformer unterschiedlicher Prinzipien und einer jeweils anderen Grundlagenaxiomatik: So ist die nationalsozialistische Dichotomie, wie zu sehen war, keine schichtspezifische, sondern eine via ,Rassetheorie“ natural gegründete, charismatische und ontologische Dichotomie. Nicht der Gegensatz von Bildung und Unbildung ist daher der tragende, sondern jener von natural-ontologischer Elitestellung und ebensolcher Unterlegenheit. Die Reformer wiederum verfügen nicht über ein unbedingt-sittliches Führerund Gemeinschaftsprinzip. Ihr Führungsanspruch beruht auf dem aristokratischen Paradigma der Ständegesellschaft, das im Kontext der Heraufkunft des ,dritten Stands', des gebildeten Bürgertums, seine Legitimationsfigur von einer geburtsoriginären Bestimmung der Standesrechte auf eine ökonomisch-erfolgsbezogene und bildungsbezogene umgestellt hat. Nicht auf eine moralische Verpflichtung der leitungsbedürftigen Schichten zur ,Gefolgschaft', sondern auf eine rational-sachspezifische Führungskompetenz stützen die Reformer daher ihren Anspruch. Ebenso geht es bei ihnen nicht um eine Ersetzung von Gesellschaft durch Gemeinschaft, sondern eine Gesellschaftsorganisation, welche deren funktional-sachliche Intrarelativität keineswegs auflösen will. Das reformerische Konzept etabliert deshalb keineswegs jenen totalen, bis in die Kolonisierung der Person und ihrer Sittlichkeit reichenden Umgriff wie der Nationalsozialismus, sondern verbleibt auf der Ebene der Strukturautorität. Trotzdem aber weist auch diese Strukturautorität bereits Berührungspunkte mit einer totalitären Lösung der Gesellschaftsfrage auf und enthält sie eine Tendenz, um der Garantie der haltbaren Durchsetzung ihrer Regression willen auf totalitäre Strukturen zu setzen. Wie zu sehen war, bemüht sie sich um einen möglichst totalen Umgriff zumindest der Kommunikationsstruktur Film, und darin um eine durchaus totale Etablierung der schichtspezifisch eingegrenzten, gesellschaftlichen Herrschaftsstellung der ,Gebildeten' gegen jede Demokratisierung und soziale Dynamik. Diese totalitäre Tendenz scheint mir in der Logik der gesellschaftsorganisatorisch regressiven Ausrichtung zu liegen. Um die historischen Prozesse mit einer rückwärts gewandten Absicht in Griff zu bekommen oder gar rückgängig zu machen, muß ihnen total, d.h. auf allen Ebenen entgegengearbeitet werden. Während die $\mathrm{Re}-$ former dies noch durch eine Zementierung ihrer ,grobstrukturellen', d.h. institutionellen Stellung versuchen, setzen die Nationalsozialisten mit einer feinstrukturellen Durchdringung im Sinn partieller Anpassung und massiver Indoktrination zum Zweck ihrer gleichermaßen institutionellen Selbsterhaltung an. Sie sind, wenn man so will, konsequenter als die Reformer, doch ziehen beide aus ihren unterschiedlichen Prämissen heraus am selben Strang.

Unter diesem Blickwinkel zeigt sich dann die nationalsozialistische Konzeption als Versuch der Effizienzsteigerung und damit als der, einen strategischen ,Fortschritt' gegenüber den Reformern zu erreichen. Ein solcher ,Fortschritt' ist zunächst mit jenem Schritt angezielt, mit dem die Dynamisierung auf der Theorieebene durch eine Umlagerung der dichotomisch-statischen Herrschaftsorganisation von der soziologischen auf die ontologische Ebene unterlaufen wird. Während die Reformer mit ihrer schichtspezifischen auf einer soziologisch faßbaren, und damit auf der faktisch-sozialen Ebene angreifbaren Dichotomie beharren, die nur durch Verstärkung der Bollwerke gegen den sozialen Wandel aufrechterhalten werden kann, bemühen sich die Nationalsozialisten durch Etablierung einer schichtunabhängigen, ontologi- 
sierten Führungsdichotomie, die den sozialen Wandel als für die Herrschaftsorganisation irrelevant erklärt und seiner politischen Bedeutung beraubt, um dessen faktische Integration unterhalb der Führungsebene. Zeigt sich der Versuch eines strategischen ,Fortschritts' hier zunächst primär als größere theoretische Unangreifbarkeit - schichtbezogene Dynamisierung scheidet im Unterschied zur reformerischen Theoriekonstruktion als Argument für Mitspracherechte aus -, so stellt die Flexibilisierung des Führerprinzips ein Unterfangen der Effizienzsteigerung in der Sicherung der totalitär-strukturautoritären Organisation dar. Mit Hilfe der Diversifizierung der Führung bei gleichzeitiger Wahrung zentraler, ebenenübergreifender Einflußnahmemöglichkeiten wird der Gesamtapparat von jener Schwerfälligkeit entlastet, die die Folge der reformerischen Konstruktion wäre, und beweglicher sowie in der feinstrukturellen Durchdringung totaler gehalten, als dies bei den Reformern vorgesehen ist. Zum Dritten schließlich ist ein ,Fortschrittsversuch' in der Totalisierung durch die skizzierten Grenzaufhebungen zu sehen, mit welchen über die reformerischen strukturellen Maßnahmen der Herrschaftssicherung und über eine ,Bildungsorientierung hinaus auf den generellen, vollständigen Umgriff von Kollektiv und Individuum abgestellt wird. Durch die Identischsetzung von staatsbürgerlicher Existenz, Gemeinschaftsverpflichtung und individuellem moralischem Wesen werden die verschiedenen Existenzebenen des Individuums im Kollektiv ,gleichgeschaltet' und der führungsorientierten Kolonisierung zugänglich gemacht. Die Abgrenzung einer Ebene gegen eine andere, und damit gegen eine heteronomistische Indienstnahme von dort her, ist nicht mehr möglich. Die Gesamtgesellschaft und ihre Mitglieder sollen so zu einer restlos plastischen Materie werden, der jede gewünschte Form verliehen werden kann.

Das nationalsozialistische Staats- und Gesellschaftskonzept kann derart auch als zugespitzte Einlösung sowie transformative Fortführung der bereits von den Reformern aufgestellten Forderungen und ihrer ständischen Herrschaftsvorstellung gelesen werden. Obschon die Staats- und Gesellschaftskonzeption der Reformer auf der Stufe einer strukturautoritären Formierung stehenblieb, war doch deutlich zu erkennen, daß jene Strukturautorität eine vollständige Realisierung ihrer Forderungen nicht hätte erbringen können. Auch unter den Prämissen ihrer Dichotomien, der schichtspezifischen wie jener von Natur und Kultur, war bereits eine tendenzielle Notwendigkeit des Überschritts zu totalitären Lösungsstrukturen erkennbar. Unter Etablierung anderer Prinzipien, nämlich des Gemeinschafts- und Führerprinzips, sowie der zugehörigen, rassistisch begründeten, charismatischen Dichotomie führt der Nationalsozialismus deshalb in gewisser Weise ein Programm durch, auf das die Reformer mit ihren anders gelagerten Prämissen schon gedrängt haben. Er ,beerbt' so die Kinoreformer und ihr agrarromantisch-kulturkritisches Umfeld, ohne bei der Erbschaft stehenzubleiben.

\subsection{Das Kunst- und Kulturkonzept des Nationalsozialismus und seine gesellschaftlich-politische Funktion}

Der Totalisierung und ihrer kontramodernen Ausrichtung werden dann auch Kunst und Kultur unterworfen. Hier dient vorwiegend das ,rassetheoretisch'-natural gefüllte Gemeinschaftsprinzip einer entsprechenden Normierung; freilich wird später 
auch wieder das Führerprinzip hinzugezogen. Wie zu sehen war, gilt Gemeinschaft im Nationalsozialismus als ,Volksgemeinschaft', die mittels rassischer Theoreme ontologisch bestimmt und durch die Verbindung mit dem Führerprinzip gruppenextern zur Elite, gruppenintern zur Gefolgschaft erklärt wird. Vor allem aus den ersten beiden Wesensperspektiven der Gemeinschaft werden auch Wesen und Aufgabe der Kunst deduziert sowie das Verhältnis von Natur und Kultur erhoben. Unter Heranziehung des Führerprinzips wird dann die politische Funktion von Kunst und Kultur normativ fixiert.

\section{Der nationalsozialistische Kunst- und Kulturbegriff unter dem Gemeinschaftsprinzip und das nationalsozialistische Natur-Kultur-Verhältnis}

Zunächst legt Hitler selbst in seiner programmatischen Rede auf der ,Kulturtagung، des Reichsparteitags im September 1933 mit der rassistischen Komponente des Gemeinschaftsbegriffs den Quellort von Kunst und Kultur, damit aber auch den prinzipiellen Ansatzpunkt der nationalsozialistischen Kunsttheorie fest: Alle Kunst und Kultur komme aus der ,Erbmasse‘ einer jeweils bestimmten Rasse und finde in der möglichst unmittelbaren Nähe zu deren Spezifika ihre eigentliche Einheit und Qualität. ${ }^{34}$ Kunst und Kultur gelten so als biologisch gegründete, ja geradezu biologisch faßbare Leistungen des Menschen, d.h. als Ergebnis und Austrag eines vorgegebenen materiellen Substrats. Die jeweilige Spezifität dieses Substrats wiederum gilt als gruppenbezogen zurechenbare, welche keine Gruppe mit einer anderen teilt. Aus diesem Basisaxiom entfaltet dann etwa Scholz seine Kunsttheorie, die statt einer ,individual-psychologischen und soziologischen Ästhetik“ die "neue Grunderkenntnis“ einer rassetheoretisch fortgeführten Vererbungslehre auf die Frage nach dem Schönen angewendet sehen und eine ,rassebiologische Ästhetik ${ }^{*}$ als „Lehre von dem schöpferischen Gestaltungswillen der Rasse“ begründen will. ${ }^{35}$ Kunst wird hier als "blutgebundene Selbstdarstellung der Rasse und ihres schöpferischen Ingeniums" charakterisiert, und die ,Einheit des Schönen', mit der allein sich der „Anspruch auf Allgemeingültigkeit eines Geschmacksurteils“ begründen lasse, gilt als in einem „rassisch-völkischen Schönheitsideal" verbürgt. ${ }^{36}$ Das ästhetische Repertoire der Kunst wird also als angeblich genetisch verankertes bio-ontologisch präformiert und zum gruppenspezifischen erklärt. Das Wesen der Kunst liegt nach dieser Vorstellung im Wesen der Gemeinschaft als, rassisch' begründeter ,Volksgemeinschaft".

Damit richtet die nationalsozialistische Kunsttheorie zugleich ihren Naturbegriff ein, zieht ihn in seiner spezifischen, nämlich biologistisch-spekulativen Fassung zur Begründungsreflexion der Ästhetik heran und stellt ihn, ähnlich wie die Kinoreformer, zur Kultur in Opposition. Die Zuordnung der Begriffe vollzieht sich jedoch anders als bei den Reformern und führt zu einer Umkehrung der Begriffswertung und normativen Zielrichtung. Auch bei den Nationalsozialisten zeigt sich die letztgenannte dann wieder als ethische. Zunächst wird dem Gemeinschaftsprinzip mit der rassetheoretischen Füllung ein naturaler Kerngehalt gegeben, der sich mit (pseudo-) naturwissenschaftlichen Begriffen terminologisch zu legitimieren, zumindest aber zu

\footnotetext{
${ }_{35}^{34}$ vgl. Hitler, Zukunftsaufgabe, $9-19$

35 Scholz, Kunst, 43

${ }^{36}$ Scholz, Kunst, 43
} 
plausibilisieren sucht. Dieser naturale Kern erscheint unter den Prämissen der Rassetheorie, wie zu sehen war, als genetisch faßbare Größe, d.h. auf der Basis des informationellen Charakters der Gene als inhaltlich definiertes Programm. Die Informationalität der Gene wird dabei spekulativ zu einer generellen, deterministischen Entelechie ausgezogen, aus welcher der gesamte ,Volkscharakter', damit aber auch die Kultur eines Volks ableitbar sei. Sämtliche Kulturleistungen der Völker gelten als ,Ausdruck ${ }^{`}$ und Folge eben dieser genetischen, d.h. naturhaften Determination. So finden sich Kultur und Natur erneut einander gegenübergestellt, jedoch nun mit einer umgekehrten Rangfolge und einer modifizierten inhaltlichen Füllung: War bei den Reformern Natur eine ungestalte, gefährdende Sphäre von Triebkräften und Strebungen, welcher die Kultur ,hominisierend' entgegengesetzt werden mußte, so betrachten die Nationalsozialisten Kultur als Ausfluß der Natur und ordnen die letzte der ersten über. Der Naturbegriff wird dabei inhaltlich verschoben und ontologisiert. Natur gilt nun nicht mehr primär als Bündel von zwar vagierenden, aber empirisch konkretisierbaren Antrieben, sondern von klar definierbaren, jedoch ,metaempirisch' spekulativ bleibenden, ontologisierten Eigenschaften. Statt von qualitativen Ausrichtungen mit moralischer Verfallsinklination wird nun von ,genetisch' verbürgten, qualitativ-programmatischen Befindlichkeiten, von (später genauer ausgeführten), Wesenszügen' mit werthafter Auszeichnung gesprochen. Da auch den letztgenannten eine Entelechie zugeschrieben wird, läßt sich freilich in beiden Fällen ein Realisierungsdrang erkennen, der normativ-wertbezogen, d.h. letztendlich ethisch eingeholt werden muß. Auf diese Weise enthält die nationalsozialistische Natur-Kultur-Dichotomie schon in ihrer Grundcharakteristik ebenso wie die reformerische eine moralische Problemstellung, die auf ethisch-argumentative Einlösung drängt. Im Unterschied zu den Reformern, die ihre normative Zuordnung von Natur und Kultur in einem explizit ethischen Diskurs durchführen, geschieht dies zwar bei den Nationalsozialisten in einem scheinbar von naturwissenschaftlich-ontologischen Notwendigkeiten handeinden Diskurs. Doch obschon bei Hitler und Scholz auf den Gebrauch ethischer Termini verzichtet wird, zielen ihre Überlegungen genau besehen auf eine ,sittliche' Gebotenheit der Umsetzung bestimmter naturaler Determinationen in Kulturleistungen (dazu mehr unten). Konsequenz der nationalsozialistischen normativen Umkehrung der Natur-Kultur-Dichotomie ist, daß die ,Hominisierung des Menschen nun nicht mehr als ,Bildung und Kulturation verstanden werden kann, sondern als ,Besinnung' auf die ,natürliche Abkunft' und als identifikative Einfügung in ihre Strebungen, Bedingungen und Grenzziehungen gesehen werden muB. Kultur gerät derart in der nationalsozialistischen Kunsttheorie zum exklusiven Produkt der Natur und Kulturation versteht sich als (Re-)Naturalisierung.

\section{Kontramoderne Normierung von Kunst, Kultur und ihrer Aufgabe als Konsequenz der Rassenontologie}

Entsprechend dieser Bestimmung von ,Menschwerdung“ und ,Kulturation“ legt sich der bio-ontologisierende Ansatz näherhin in drei grundsätzliche kunstnormative Konsequenzen aus, die schließlich in eine kontramoderne Grundstellung münden. Zusammen mit diesen Normierungen wird den naturalen Grenzziehungen und Bedingungen implizit ein moralischer, zumindest aber moralanaloger, Sollenscharakter verliehen und derart eine (verdeckte) Einlösung der ethischen Problemstellung ver- 
sucht. - Zunächst führt die Bindung des Kunstbegriffs an das rassenontologisch naturalisierte Gemeinschaftsprinzip zur normativen Forderung der ,Volkstümlichkeit und ,Rassespezifität" der Kunst in Form und Inhalt. Als ,volkstümlich' erscheinen einerseits die bereits von der Agrarromantik bevorzugten Kunstbestände, andererseits aber vor allem jene Formen und Gehalte, die auf der Basis des anthropologischen Rassismus als ,besonders typisch' für die dadurch definierte ,Volksgemeinschaft' gelten. Während die Agrarromantik hier noch eine gewisse Geschlossenheit und einen Zusammenhang aufwies, entgrenzt der anthropologische Rassismus das Feld für einen Kunstkanon und erlaubt er eine eklektizistische Willkür, welcher mit dem Terminus der ,Rassespezifität' dann eine (rein) ideologische Konsistenz verliehen wird: Sowohl Hitler als auch etwa Rosenberg begründen zunächst die Forderung einer ,rassespezifischen' Form- und Inhaltsbindung der Kunst ,rezeptionsästhetisch' mit dem ,erkenntnistheoretischen' Axiom, daß lediglich der Angehörige einer Rasse deren Kunst verstehen und schätzen könne, sie für ,Rassefremde' hingegen völlig irrelevant bleibe. ${ }^{37}$ Bereits aus dieser ideologischen Grundfigur wird ein Katalog ,kanonischer' Inhalte abgeleitet. So betrachtet etwa Wendland das rassisch gefüllte Gemeinschaftsprinzip als ,das deutsche Prinzip“ schlechthin und sieht er in „der Familie, der Sippe, dem Stamm und dem Volk“ seine exemplarische, ,naturnahe" Realisierung, damit aber auch die idealtypischen Topoi und Themenvorgaben der Kunst. ${ }^{38}$ Diese können entsprechend von agrarromantischen Szenen um Heim und Herd bis zur Appräsentation des ,arttypischen Heroismus" in den Kriegsdarstellungen reichen. So werden Form- und Inhaltsbindung durch eine eklektizistische Näherbestimmung des ,Rassespezifischen' weiter ausgelegt, ideologietreue Themen konkretisiert und Stilvorbilder konstruiert. Hitler selbst bezieht sich stilistisch, neben der Kunst des 19. Jahrhunderts, bekanntlich gerne auf die Kunst der dorischen Griechen und der hadrianischen Römer, in der er das ,heroische Lebensideal' der ,arisch-germanischen Entwicklungslinie' bereits verkörpert sieht. Die Verbindung zu diesen südländischen Volksgruppen, deren Kunst unter dem erkenntnistheoretischen Axiom für den ,nordischen Menschen' ja eigentlich unverständlich bleiben müßte, sucht er über den Begriff des ,Rassekerns' zu schlagen. Dieser Kern sei bereits bei einer,Grundrasse‘ vorhanden gewesen, aus welcher wiederum Griechen, Römer und Germanen gleichermaBen hervorgegangen seien. ${ }^{39}$ Auf der Basis einer solchen ,Wurzelidentität' betrachtet Hitler seine exemplarisch-eklektizistische Vereinnahmung der griechischen und römischen Kunst für den ,nordischen' Stil als legitim und beutet er sie normativ für die Etablierung eines nationalsozialistischen Kunstkanons aus. Mit der Bezugnahme auf den lediglich, genetisch' faßbaren ,Rassekern' wird bei dem ideologischen Brükkenschlag erneut der Naturbegriff für die an die Kunst als Kulturleistung gerichteten Vorschriften zur Anwendung gebracht und die formale wie inhaltliche Ausformung

${ }^{37}$ vgl. Hitler, Zukunftsaufgabe, 13. Ähnlich formuliert Rosenberg: Da Kunst „Schöpfung eines bestimmten Blutes" sei, könne ihr „formgebundene(s) Wesen“ auch nur „von Geschöpfen des gleichen Blutes wirklich verstanden" werden. (Rosenberg, Mythus, 120)

${ }_{38}$ Wendland, W., Nationalsozialistische Kulturpolitik, in: Deutsche Kulturwacht, 1933, zit. nach; Pröstler, Ursprünge, 31

${ }^{39}$ vgl. Hitler, Zukunftsaufgabe, 15: „Griechen und Römer werden dann plötzlich den Germanen so nahe, weil alle ihre Wurzeln in einer Grundrasse zu suchen haben, (...)“ 
dieser Kulturleistung normativ aus dem nationalsozialistischen ,Naturverständnis erhoben.

Damit ist zugleich auch die ,erste' und ,hervorragende' Aufgabe der Kunst benannt. Der Künstler nämlich soll Hitler zufolge das ,kulturelle Bild des Volks‘ „nach seinen besten Bestandteilen“40 ,formen“ und derart „durch das bewußte Herausstel-

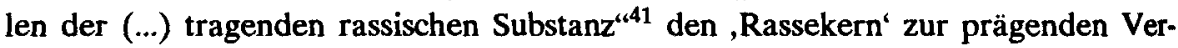
wirklichung bringen. Ziel des nationalsozialistischen Kunstkanons und der diesbezüglichen Kunstnormierung ist also zugleich die Bestimmung der Funktion von Kunst als Repräsentation der, rassespezifischen' Eigenschaften, und so die konkrete Benennung der Verpflichtung von Kunst und Künstler. Die Gebotenheit der Orientierung am ,Rassekern" und der ,Herausarbeitung seiner spezifischen kunstprogrammatischen Merkmale durch den Künstler in Orientierung an den ,artverwandten' Stil- und Inhaltsvorbildern aber zeigt sich trotz der scheinbar rein ,naturwissenschaftlich'-ontologischen ,Argumentation" als sittliche. Gerade die Verwirklichung dieses Kerns nämlich ist Hitlers Überlegungen zufolge für das Gelingen der ,rassespezifischen' Hominisierung, d.h. der eigentlichen Menschwerdung des rassenontologisch bestimmten Menschen notwendig. Nicht nur finden nach seiner Theorie die Kunst und Kultur eines ,Volks‘ ihre Einheit und Qualität erst in der Nähe zum ,Rassekern', sondern sie sollen diese auch dort finden und deshalb in ihrem Schaffen eine entsprechende ,Treue‘ zu diesem Kern beweisen. Die naturale ,Determination' erhält derart einen moralischen Sollenscharakter; die stilistischen und inhaltlichen Vorschriften geraten zu solchen für ein , sittlich richtiges Kunstschaffen'. Damit wird die Kunst als stilistisch und inhaltlich gebundene zunächst sowohl ideologischen Vorgaben unterstellt, als auch auf die repräsentative Realisierung derselben festgelegt, d.h. ideologisch verpflichtet. Die Ideologieverpflichtung aber wird als moralisch gesollte vorgestellt und derart ethisiert.

Tatsächlich scheint sich das ,sittlich richtige Kunstschaffen' im Sinn dieser Ideologieverpflichtung, d.h. die künstlerische Realisierung des ,heroischen' Lebensideals und die Aktivierung des ,genetisch' verankerten Eigenschaftskanons im Kunstkanon auch nicht von selbst zu verstehen, sondern einer zusätzlichen moralischen und juridischen Einschärfung zu bedürfen, um vor Verfall geschützt zu sein. Das zeigt sich in einer zweiten Konsequenz des bio-ontologisierten, gruppenspezifischen Schönheitsbegriffs. So treibt die Insistenz auf ihm das kunstnormative Verbot jeder Vermischung mit gruppenexternen Kunstformen als moralisches und in Gesetze gefaßtes aus sich hervor, da eine solche Vermischung unter den genannten kunsttheoretischen Prämissen nur als Authentizitätsverlust und Defizienz erscheinen kann. Die nationalsozialistische Kunsttheorie wendet sich polemisch gegen die Internationalität von Kunst (und Wissenschaft), welche eigentlich Ausdruck und Folge der modernen Dy namisierungs- und Globalisierungsprozesse sind, und verketzert insbesondere die ,moderne' Kunst, d.h. Expressionismus und Kubismus, als ,demokratische Verirrung im Sinn kultureller Entfremdung. Eine solche ,Entfremdung aber darf keinesfalk statthaben, da sie als Verfehlung der gruppenspezifischen ,Naturalkultur“ zur "rase

${ }^{40}$ Hitler, Zukunftsaufgabe, 12

41 Hitler, Zukunftsaufgabe, 16 
losen Wertelosigkeit “42 führe. Diese Verfehlung zeigt sich in solcher Formulierung wieder als moralischer Tatbestand, dem entsprechend durch moralische Normierung begegnet werden muß. Es gilt geradezu als ,sittliche Pflicht', dem ,rassischen Werteverfall' entgegenzuwirken und eine entsprechende ,Reinerhaltung von Kunst und Kultur zu befördern. Durch Verbindung mit dem Führerprinzip auf der gruppenexternen Ebene und die naturale Elitisierung der ,Volksgemeinschaft' zur ,Herrenrasse ${ }^{t}$ wird der internationale Austausch dann nicht nur illegitim, sondern geradezu kriminell: Auf der Basis der rassistischen Elitisierung nämlich gerät jede Kunst anderer Gruppen zum Unterwertigen, jedes,Artfremde' zum ,Entarteten'. Der Naturbegriff wird dabei in sich nochmals dichotomisiert, d.h. in eine ,hochwertige und eine ,minderwertige' Natur aufgespalten, und in dieser Dichotomie für die Bewertung der Kulturen und Kulturleistungen herangezogen. Wie die biologische ,Vermischung mit anderen ,Rassen' kriminalisiert wird, weil sie zur Verschlechterung des Erbguts führe, wird es nun auch die kulturelle, weil sie das natural begründete Kunst- und Kulturniveau absenke. Die ,moderne' Kunst ist deshalb als ,krankhaft minderwertige Erscheinung auszurotten und fält einer ,kulturellen Eugenik', meist zusammen mit ihren Produzenten, anheim. ${ }^{43}$ Der Bestand der älteren Kulturkritik, die gegen ,moderne' Erscheinungen wie die Großstadtkultur und den Expressionismus vorging, wird auf diese Weise erhalten und zum ,Kulturkrieg weitergeführt. Die Begründungsfigur wird, wie schon bei der grundsätzlichen Bestimmung des Gemeinschaftsbegriffs, von der Agrarromantik auf die Rassetheorie umgestellt und auch hier für die ,moralische' Vernichtungslegitimation herangezogen.

Zum Dritten folgt aus der kunstnormativen Bio-Ontologisierung der AusschluB jeder wirklichen Stilentwicklung und Geschichtlichkeit. Hitler betont, da $B$,in der Zeit (...) keine Kunst begründet“ liege, „sondern in den Völkern“.44 Daher seien „Jahrtausende (...) einflußlos, solange nicht die Erbmasse selbst blutmäßig verdorben ${ }^{\text {"455 }}$ werde. Die metaempirische Spekulativität des nationalsozialistischen Naturbegriffs kommt hier zum Tragen und bedingt eine geschichtslose Statifizierung: Da die angeblich ,genetisch' in einem materiellen Substrat verankerten Eigenschaften der Völker als detaillierte, programmatische Vorgaben für die Kulturleistungen gehandelt werden, kann bei einer geschlossenen, materiell unveränderten Weitergabe des Substrats auch eine Wandlung und Entwicklung des kulturellen,Ausflusses' nicht gedacht werden. Dasselbe qualitative Programm muß auch immer dieselben qualitativen Äußerungen aus sich hervorbringen. Kunst wird auf diese Weise zur formal und material zeitlosen Erscheinung erklärt und zugleich auf diese Zeitlosigkeit verpflichtet. Jede avantgardistische Entwicklung ist in diesem Konzept illegitim und allenfalls als Ergebnis einer Überfremdung durch Verfälschung des spekulativ ontologisierten Substrats zu fassen.

Insgesamt führen somit die ersten beiden kunstnormativen Konsequenzen der nationalsozialistischen Natur-Kultur-Dichotomie in eine Sein-Sollens-Dichotomie, deren normativer Duktus gegenüber der reformerischen ebenso umgestellt ist wie die

\footnotetext{
${ }^{42}$ Rosenberg, Mythus, 120

43 vgl. dazu etwa: Hitler, Zukunftsaufgabe, 16

${ }_{45}^{44}$ Hitler, Kunstausstellung, 26

45 Hitler, Adolf, Rede auf dem Kulturtag des Parteitages 1933; zit. nach: Pröstler, Ursprünge, 41
} 
Zuordnung von Natur und Kultur. Nicht nur erscheint die Kultur, insbesondere die Kunst, jetzt als Ausfluß naturaler Grundlagen und ebensolcher programmatischer Bedingungen, sondern es gerät zusammen damit auch das spekulativ erhobene, ontologisierte naturale Sein als ,eigentliches' Sein der Gemeinschaft zur sittlichen Normierungsinstanz für die Kulturleistungen, d.h. zum normativen Quellort und zur inhaltlichen Bestimmungsgröße für das kulturell Gesollte. Das Gemeinschaftsprinzip wird auf diese Weise eigenschaftsbezogen präzisiert und erneut zu einer doppelten, nämlich ,sachspezifischen' wie ethischen Normierung herangezogen, die sich nun auf die Kunst richtet. Als ,sachspezifische' Aufgabe der letztgenannten gilt jetzt aus natural-ontologischen Gründen, durch die exemplarische Realisierung des ,Rassekerns', d.h. die inhaltliche und stilistische Heraushebung der in diesem hypostasierten ,Eigentlichkeit' der Gemeinschaft, auf die ,rassetheoretisch' konkretisierte, gruppenspezifische Hominisierung des Menschen hinzuarbeiten. Diese ,sachspezifische' Aufgabe aber ist, da es in ihr um die Hominisierung, also um die Menschwerdung des Menschen, geht, zugleich eine ethische, und ihre Gebotenheit ist eine sittliche. Im Letzten bedeuten damit sowohl die kunsttheoretischen Bemühungen, den Ursprung von Kunst und Kultur, genetisch' aufzusuchen, als auch die daraus abgeleitete stilistische und inhaltliche Normierung der Kunst, die auf eine Konkretion des Charakters der ,wahren' Gemeinschaft und die Festschreibung der sittlichen Pflicht zu dessen repräsentativer Verwirklichung zielt, eine Vermischung der künstlerischen mit der moralischen Aufgabe. Die Ästhetik wird so mit der Ethik identifiziert, und die Kunstnormen zeigen sich als ethisierte Kollektivnormen.

Verbunden damit ist eine regressive Wende gegen die neuzeitliche Emanzipation der Kunst, d.h. eine kontramoderne Zielrichtung der kunsttheoretischen Gesamtkonzeption. In der antiemanzipativen Orientierung äußert sich wiederum die nationalsozialistische Totalisierung. Vor allem die Forderungen der ,Volkstümlichkeit' und ,Rassespezifität', in denen sich die sittliche Pflicht der Gemeinschaftsrealisierung primär auslegt, zeigen sich als solches kontramodern-totalisierendes Unterfangen. Mit ihrer statifizierenden und gruppenspezifischen Orientierung an ethisierten Kollektivnormen führen sie zur Rückverlagerung der Kunst aus der individuellexpressiven in die kollektiv-universale Sphäre, d.h. zu einer erneut grenzauflösenden, diversifizierungsfeindlichen Einbindung in heteronomistische Interrelationen und damit zur Aufkündigung der zunehmenden Autonomisierung der Kunst. Die neuzeitlichen Prozesse nämlich zeichnen sich gerade durch Diversifizierung von Aufgaben, Bereichsabgrenzung von Zuständigkeiten und damit Schaffung von relativen Autonomien aus. So beginnt im Zusammenhang mit der modernen Dynamisierung und Rationalisierung der Lebens- und Gesellschaftsverhältnisse sowie dem Einsatz der neuen Reproduktionsmittel für eine Massenkultur die Kunst sich von rituellsymbolistischen, moralischen und kommunikativen Aufgaben gerade zu entlasten. Sie grenzt diese Aufgaben aus ihrem Bereich aus und läßt sie anderen Bereichen zugewiesen sein. Während etwa im Mittelalter noch die Verpflichtung für die Kunst bestand, den kollektiven ,Ordo' symbolträchtig zu reproduzieren, sich derart dem sittlich-religiösen Weltverhältnis der Gesamtheit unter- und einzuordnen und mit ihren Darstellungen der diesbezüglichen gesellschaftlichen Selbstverständigung zu dienen, werden diese Aufgaben in der Neuzeit zunehmend voneinander gesondert und bestimmten Kultursachbereichen zugewiesen. Gleichzeitig wird die Aufgabe der 
gesellschaftlichen Selbstverständigung zu einem nicht geringen Teil von den Massenreproduktions- und Kommunikationsmitteln an sich gezogen. Die Aufgabenstellungen haben sich außerdem gewandelt: Es geht nicht länger um die Vermittlung und Wahrung eines sinnstiftenden statischen Kulturmodells der und für die Gesamtheit (wie es der mittelalterliche Ordo war), sondern um eine dynamikfreundliche Verbindung der Mitglieder dieser Gesamtheit ohne Gefährdung der jetzt pluralistischen Ausrichtung des übergreifenden Kulturmodells. Hier dienen nun einerseits die plastischen Medien einer kommunikativen ,Vereinigung', d.h. einer wandelbaren, prozessualen Einheit. Andererseits finden sich die Sinnangebote ,regionalisiert', d.h. etwa dem Kultursachbereich der Religion zugewiesen und von der kontingent-sachbezogenen Intrarelativität der Gesellschaft und ihrer ,Dachorganisation' im Staat unterschieden. Kunst kann deshalb mehr und mehr zum Bereich individueller, keineswegs mehr gesamtverpflichteter oder -verpflichtender Expression werden und gewinnt erst ihre Autonomie und Freiheit.

Eben dieser Prozeß wird von der nationalsozialistischen Kunsttheorie rückgängig gemacht und zur erneuten Kollektivverpflichtetheit der Kunst umgebogen. Als ,rassespezifische‘ und ,volkstümliche‘ ist die Kunst wiederum Repräsentantin eines in diesen Begriffen gegründeten Kulturmodells, das auf ständigen, selbstbestätigenden Ausdruck seiner ontologisch-naturalen Kollektivgründe durch die Hervorbringungen der Kunst drängt. Die letztgenannte erhält zusammen mit der ästhetischen und expressiven erneut eine sittliche, sinnstiftende und general-kommunikative Aufgabe und wird entsprechend heteronomistisch in Dienst genommen. Sie kann nicht länger unwillkürlicher, kontingenter oder zeitbezogener Bedeutungsausdruck sein, sondern muß statt Bedeutungen und individuellen Innenweltäußerungen kollektive und zeitübergreifende Sinnsymbole bereitstellen, durch die die Gemeinschaft und ihr Weltverhältnis, ja Grund und Ziel ihres Daseins verkörpert werden. Mit der Verpflichtung zur Gruppenspezifität wird sie zudem auf eine Binnenkommunikation festgeschrieben, die ihr den internationalen Austausch untersagt und sich so auch der Globalisierungstendenz der neuzeitlichen Dynamisierung widersetzt. Stattdessen wird sie zur zeitlosen Erscheinung ontologisiert und auf eine statifizierende, kollektivritualistische Rolle fixiert. Damit ordnet sich das nationalsozialistische Kunstkonzept dem regressiven, rückwärtsorientierten Gesellschaftskonzept konsistent zu und führt es wie dieses in eine antiautonomistische Totalisierung, die jede Grenze zwischen Sittlichkeit, Individualität, Gesellschaft und Staat, damit aber auch zwischen Binnenund Universalmoral, individueller Kreativität bzw. Expression und allgemeiner Kommunikabilität, unpolitischer und politischer Tätigkeit sowie Sinnstiftung und Bedeutungsäußerung auflöst. Die kunsttheoretische Überordnung der rassistisch gefaßten, ontologisierten Natur über die kontingente Kultur, die ideologische Festschreibung inhaltlicher und formaler Kanons sowie die generelle Unterwerfung der Kunst unter die moralische Normativität des natural gefüllten Gemeinschaftsprinzips führen deshalb letztlich zugleich zu einer Aufhebung der Trennung der Kultursachbereiche, vor allem der von Politik und Kunst, und zu einer entsprechenden weiteren Funktionsbestimmung, die später auf sämtliche Kulturleistungen ausgedehnt wird. 


\section{Die politische Funktion von Kunst und Kultur unter dem Führerprinzip}

Bereits die moralische Gemeinschaftsverpflichtung der Kunst sowie die rassenontologisch-naturale Konkretion der "Eigentlichkeit' der Gemeinschaft im ,Rassekern" drängt auf die Konkretion auch der gesellschaftlich-politischen Rolle und Funktion der Kunst. Diese Funktionszumessung findet primär durch die Verbindung von Gemeinschafts- und Führerprinzip auf der gruppeninternen Ebene und eine damit Hand in Hand gehende Vermischung, ja Identifizierung der politischen mit der kulturellen ,Führungsaufgabe' statt. Zunächst wird mit dem Begriff des, Rassekerns' die Basis für die Einführung der elitären Dichotomie des Führerprinzips in die Gemeinschaft geschaffen. So betont Hitler, daß der ,Rassekern' als eigentliche Wesenheit eines Volks durchaus nicht in allen seinen Mitgliedern gleichermaßen verwirklicht und dominierend sei. Obschon das ganze deutsche Volk auf der gruppenexternen Ebene zur Elite erklärt wurde, muß demzufolge „nicht jeder (...) schöpferischer Künstler (...) sein, weil er rassisch gesehen zu dieser befähigsten Art zu rechnen

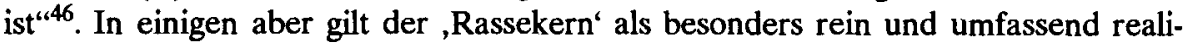
siert, und in dieser Realisierung wird die Wurzel ihrer überragenden, kulturschaffenden Begabung gesehen. Sie gelten als jene Elitepersönlichkeiten, die die elitäre Gruppe nochmals übersteigen und ihr dichotomisch gegenüberstehen.

Zugleich damit wird deutlich, daß die ,wahre' Gemeinschaft nur in einigen, nicht aber in allen Gruppenmitgliedern schon da ist. Sie muß daher, wie bereits die Verpflichtetheit des Künstlers zur ,exemplarischen Herausarbeitung ' des ,Rassekerns' in seinen Schöpfungen nahelegt, von den ,Elitepersönlichkeiten' beispielhaft realisiert und durch deren Führung in der Gesamtgruppe hergestellt werden. Dementsprechend wird, nachdem die elitäre Dichotomie etabliert ist, über den Brückenbegriff des ,Genies' das Führerprinzip eingeführt. Analog zu seiner politischen Theorie insistiert Hitler darauf, daß auch ,die Kultur der Menschheit (...) nicht ein Produkt der Majorität" sei, sondern ,ausschließlich auf der Genialität und Tatkraft der Persönlichkeit“" beruhe ${ }^{47}$ Dieser ,Person', die „das kulturell-schöpferische Element verkör$\operatorname{per}(\mathrm{e})^{\text {“48 }}$, müsse daher eine führungselitäre Stellung gegenüber der ,Masse` zugesprochen werden. Diese Stellung soll der Künstler ausfüllen, indem er, wie zu sehen war, dem ,Rassekern' zum Ausdruck verhilft. Als erste Aufgabe des Künstlers und als vordringliche Funktion der Kunst aber gilt nun die kontingente Umsetzung der Rassenontologie nicht allein um der Reinheit der gruppenspezifischen Selbstdarstellung willen, sondern zum Zweck der kulturellen Gemeinschaftsformung und -bildung. Entsprechend erhält Kunst neben der oben geschilderten Funktion der Repräsentation der ,rassespezifischen' Kunst- und Kulturform auch eine kulturelle Erziehungsaufgabe. Sie soll jetzt die natural gegründete Gemeinschaft auf ihre ,Wurzelidentität hinweisen und sie durch zunehmende Orientierung an eben dieser Identität als Kulturgemeinschaft konstituieren.

Diese Aufgabe der Schaffung der, eigentlichen' Kulturgemeinschaft aber gerät bei näherem Zusehen zur Aufgabe politischer Formung. Als Ausdruck des, eigentlichen Gemeinschaftswesens' nämlich wird die, rassespezifische‘ Kunst zum über den kultu-

\footnotetext{
${ }^{46}$ Hitler, Zukunftsaufgabe, 13

${ }^{47}$ Hitler, Kampf, 379

${ }^{48}$ Hitler, Kampf, 387
} 
rellen Bereich hinausreichenden Konstituens dieser Gemeinschaft, d.h. zu einer auch politisch formenden und daher politisch verpflichteten Kraft erklärt. Das veranschaulicht sich zunächst in der Gleichstellung der ,Führer' in den einzelnen Bereichen. Nachdem nämlich dem Künstler eine entsprechende Führungsstellung zugesprochen worden ist, werden der ,große Dichter und Denker, der große Staatsmann und der große Feldherr'“49 in einem Atemzug genannt und als Angehörige ein und derselben ,Menschenart', der führungselitären ,Genies', apostrophiert. Ihre gemeinsame auszeichnende Qualität wird dabei wieder mit dem biologistischen Paradigma als ,nicht mechanisch anerzogen, sondern durch göttliche Gnade angeboren“50 legitimativ verankert. Der Künstler wird so zur herausragenden Figur stilisiert und in die Führungsschicht des Nationalsozialismus eingereiht. Sodann wird über den ,Staatsmann' und den ,Feldherrn' gesagt, daß deren Tätigkeit ohnehin ,immer auf dem Gebiete der Kunst ${ }^{\text {‘51 }}$ liege und eine entscheidende weitere Brücke geschlagen: Nicht nur aufgrund ihres gleichermaßen elitären Wesens rücken Politiker und Künstler in unmittelbare Nähe zueinander, sondern auch durch das (formal) identische Wesen ihrer Tätigkeit. Politiker und Künstler werden beide als ,Formende' bestimmt, die sich der Schaffung des ,einen Volks', der rassenontologisch definierten ,Herrenrasse widmen. Damit aber erhält Kunst dieselbe Funktionszumessung wie Politik, d.h. die Aufgabe der Herausarbeitung, Formung und Führung dieser rassenontologisch bestimmten ,Volksgemeinschaft'. Die ästhetische Aufgabe gerät derart zur politischen und die politische zur ästhetischen. Kunst und Politik fallen zusammen und die Trennung der beiden Kultursachbereiche ist aufgehoben.

Die Totalisierung setzt sich damit auch hier als Grenzauflösung durch. Nicht nur die Grenzen zwischen individueller Expression, gesellschaftlicher Kommunikation, sittlicher Verpflichtung und Sinnstiftung fallen, sondern das Kunstschaffen wird durchaus kohärent zu den übrigen Bereichsvermischungen - mit der politischen Aktivität identifiziert. Beide Unternehmungen nämlich, die der Politik wie die der Kunst, richten sich im Nationalsozialismus auf dasselbe Ziel: die Herstellung jener elitären ,Volksgemeinschaft', die ebenso wie der ,genetisch' hypostasierte ,Rassekern' nur wurzelhaft, aber nicht endgültig vorhanden ist und die daher von den jeweiligen ,Repräsentativinkarnationen' so exemplarisch wie normativ verwirklicht werden muß. Kohärent zu Hitlers eklektizistischer Bestimmung der ,eigentlichen' Kunst des ,arischen Volks', die lediglich als Konglomerat der dorischen Griechen, hadrianischen Römer und ,heroischen' Germanen aus der Geschichte erhebbar ist, muß auch dieses Volk erst hervorgebracht werden. Die ,wahre' Gemeinschaft der ,Herrenrasse‘ ist durch Politik und Kunst erst zu schaffen. Beide, Politik wie Kunst, stehen deshalb unter dem Diktat derselben ,kreativen' Aufgabe, d.h. aber auch: unter denselben normativen Bindungen. Aus diesem Grund werden die Unternehmungen der Kunst an die entsprechenden, jeweiligen politischen Notwendigkeiten gekoppelt. Die Grenze zwischen den beiden Kultursachbereichen Kunst und Politik ist aufgehoben. Kunst erhält unter den Prämissen der Rassenontologie eine politische Erziehungsaufgabe und wird zum politischen Instrument.

${ }^{49}$ Hitler, Kampf, 387
${ }^{50}$ Hitler, Kampf, 387
${ }^{51}$ Hitler, Kampf, 387 


\subsection{Nationalsozialistische Filmpolitik und Social engineering unter dem Propagandaprinzip}

So, wie Kunst politisch in Dienst genommen wird und eine gemeinschaftsrepräsentative bzw. -stiftende sowie ideologisch-sinnvermittelnde Rolle zugemessen bekommt, wird dann auch der Massenkultur, insbesondere der medial vermittelten wie dem Film, eine entsprechende Funktion zugeteilt. Der Akzent liegt hier stärker als bei der Kunst neben der generellen politischen Erziehungsfunktion auf der besonderen, d.h. den jeweiligen situationellen Erfordernissen angepaßten politischen und ,sozialen' Führung (bzw. Steuerung) der, Volksgemeinschaft' in der totalen Struktur. Obwohl auch für den Film freilich immer wieder auf die Schaffung eines ,deutschen Stils' abgehoben und gegen Anpassungsversuche an internationale Standards gesprochen wird, geht es im Kontext medialer, massenkultureller Kommunikation faktisch weniger um die Appräsentation der rassenontologisch bestimmten Gruppenspezifika, sondern um ein feines Abwiegen der filmischen Formen und Gehalte mit der jeweiligen, aktuellen gesellschaftlichen Situation und ihren Erfordernissen. Dieses Abwiegen soll einen optimalen führungsfunktionalen Einsatz des Films in der totalisierten Struktur und zum Zweck ihres Erhalts erlauben. Nicht das Gemeinschaftsprinzip kommt deshalb bei der Funktionsbestimmung des Films in erster Linie zur Anwendung, sondern das Propagandaprinzip, wobei Theorie und Praxis hier eine etwas unterschiedliche Gewichtung der Strukturmomente dieses Prinzips aufweisen. Ich will daher zunächst der Grundlegung des Prinzips bei Goebbels und seiner Ausarbeitung zu einer nationalsozialistischen Filmtheorie bei Hippler nachgehen, um dann im Vergleich mit dem faktischen Filmschaffen im Nationalsozialismus Kohärenz und unterschiedliche Akzentsetzung von Theorie und Praxis zu skizzieren.

\section{Die Fixierung des Propagandaprinzips als oberstes Prinzip der Medienfunktion im Nationalsozialismus durch Goebbels}

Eingeführt wird das Propagandaprinzip von Goebbels bereits in seiner ersten Filmrede vom 28. 3. 1933. Allerdings macht er es hier noch nicht explizit, sondern läßt es lediglich unter den zahlreichen Wendungen und Windungen seines vordringlich strategisch angelegten Texts spürbar werden. ${ }^{52}$ Doch die entscheidenden Begriffe und ihre Weichenstellungen sind schon vorhanden und werden in den späteren Reden nur noch präzisiert bzw. unverschleierter zum Ausdruck gebracht. So wendet sich Goebbels schon in der ersten Rede gegen eine ,Tendenzlosigkeit' der Filmkunst, welche eine ,Reform des deutschen Volks an Haupt und Gliedern' verhindern wolle, ${ }^{53}$ und legt damit den Einsatz des Films für eben diese ,Reform', d.h. die Durchsetzung des Nationalsozialismus und seiner Ideologie fest. Weiter betont er, daB Kunst schlechthin nur möglich sei, wenn sie „mit ihren Wurzeln in das national-

52 vgl. Goebbels, Kaiserhof, 439-442 - Goebbels sprach hier noch vor den Vertretern der ,alten' Filmwirtschaft und damit vor einem Publikum, das noch nicht durch die Personalpolitik des Nationalsozialismus, gleichgeschaltet' war. Die Doppelabsicht, dieses Publikum zu gewinnen und dennoch seine Programmatik einzuführen, bedingt daher Unklarheiten, Verschleierungen und Inkonsistenzen des strategischen Texts. Kenntnis der späteren Filmpolitik und Vergleich mit den weiteren Reden läßt jedoch auch hier schon die Goebbels'sche Programmatik erkennen.

${ }^{53}$ vgl. Goebbels, Kaiserhof, 440 
sozialistische Erdreich eingedrungen “ ${ }^{44}$ sei, und daß die Vorbedingung jeden künstlerischen Schaffens „der engste Zusammenhang mit dem neuen Wollen“55 sei. Fortan solle es keine Kunst mehr geben „ohne diese Willensrichtung, ohne diese Absicht und Tendenz". ${ }^{56}$ Schließlich weist er darauf hin, da 3 es jedoch keineswegs erwünscht sei, jetzt „,sogenannte nationalsozialistische Filme herzustellen “57, sondern daß es darum gehe, ,den inneren Sinn und die innere Gestaltung einer neuen Welt lebendig zu machen " 58 . Er deutet damit an, was die dritte Rede präzisiert, nämlich, daB der ,eigentliche' nationalsozialistische Film unter dem Propagandaprinzip nicht mit „Zurschaustellung nationalsozialistischer Embleme und Symbole“ entsteht, sondern durch „Aufraffen nationalsozialistischer Probleme" und deren Vermittlung in ,unauffälliger Weise ${ }^{69}{ }^{59}$ Die Vermittlungsabsicht soll ,als Tendenz, als Charakter, als Haltung im Hintergrund“60 bleiben, denn Propaganda werde in dem Moment unwirksam, da sie bewußt wird. Stattdessen werden die nationalsozialistischen „Probleme (...) das Gefühlsleben der Deutschen und anderer Völker um so wirksamer durchdringen, je unauffälliger sie behandelt werden". ${ }^{61}$ Sowohl für den Zweck der Vermittlung spezifisch ideologischer ,Problemstellungen', als auch um einer generellen Publikumswirksamkeit willen betrachtet es Goebbels wiederum schon in der ersten Rede als notwendig, „dem Volk aufs Maul (zu) schauen“62, d.h. sich ,volksnah" und ,volkstümlich' zu orientieren. Zweck des Films nämlich sei nicht nur die, Gesinnungsformung', sondern auch „das Schaffen des kleinsten Amüsements, des Tagesbedarfs für die Langeweile und der Trübsal ${ }^{163}$. In diesem Sinn habe sich der Film, wie die sechste Rede später unter Kriegsbedingungen präzisiert, auch auf die jeweiligen, zeit- und umständeabhängigen ,seelischen Erfordernisse“64 einzustellen und für Entlastung, Entspannung und Vergnügen zu sorgen.

Aus dieser Skizze ergeben sich die drei grundsätzlichen Strukturmomente des Propagandaprinzips: Zunächst wird mit dem Begriff der ,Tendenz' die Verpflichtung auf eine Botschaft festgelegt und deutlich gemacht, da $B$ es im Film keineswegs um eine Weltdarstellung, sondern um Weltdeutung gehen soll. Diese Weltdeutung wird unmißverständlich auf die nationalsozialistische festgelegt und derart als ideologieverpflichtete charakterisiert. Dann wird die Strategie zur Vermittlung der Botschaft als die einer verdeckten Vermittlung gezeichnet, welche auf explizite Kundgebung ihrer ideologischen Absicht verzichtet und sich stattdessen um einen ,inneren', d.h. impliziten Sinn nicht nur der ,neuen Welt', sondern auch der filmischen Gehalte bemüht. Absicht dieser Strategie ist eine unmerkliche Beeinflussung des Publikums, deren Wirksamkeit durch ,Volkstümlichkeit', d.h. eine Orientierung an den Notionen der ,Basis' garantiert werden soll. In der letztgenannten Detaillierung der Strategie deu-

\footnotetext{
${ }_{55}^{54}$ Goebbels, Kaiserhof, 440

55 Goebbels, Kaiserhof, 441

${ }_{57}^{56}$ Goebbels, Kaiserhof, 441

${ }^{57}$ Goebbels, Kaiserhof, 439

${ }^{58}$ Goebbels, Kaiserhof, 440

${ }^{59}$ Goebbels, Krolloper, 456

${ }^{60}$ Goebbels, Krolloper, 456

61 Goebbels, Krolloper, 456

62 Goebbels, Kaiserhof, 441; ebenso die dritte Rede: vgl. Goebbels, Krolloper, 457

${ }^{63}$ Goebbels, Kaiserhof, 441

${ }^{64}$ Goebbels, Berlin, 486
} 
tet sich dann als drittes Moment des Propagandaprinzips seine Plastizität an. Tatsächlich soll die genannte Orientierung nämlich nicht nur eine eingängige Ideologievermittlung fördern, welche ,das Publikum dort abholt, wo es steht', sondern auch ein flexibles und feinstrukturelles Reagieren auf die „Bedürfnisse' der Rezipientenschaft ermöglichen. Jene ,Bedürfnisse' aber werden, wie die Präzisierung durch die sechste Rede offenlegt, wiederum nicht vom Publikum selbst definiert, sondern gemäß der Goebbels'schen Formulierung von den ,seelischen Erfordernissen' (des Kriegs) aus den gesellschaftlich-historischen Gegebenheiten und ihren Notwendigkeiten als deren psychische Komponente abgeleitet. Auf diese Weise wird sowohl das erste Strukturmoment des Propagandaprinzips relativiert als auch das zweite zentrale medienpolitische Telos des Prinzips festgelegt: Der Film soll neben der ideologischen Indoktrination auch eine kompensative, gratifikative und deflektorische Funktion erfüllen, welche eine subtile Steuerung der filmunabhängigen, alltäglichen Gestimmtheit des Publikums ermöglicht und so die psychisch-gesellschaftliche Situation beherrschbar macht. Das Kommunikationsziel des Propagandaprinzips kann damit vorerst als herrschaftsorientiertes, führungsfunktionales Social engineering bestimmt werden, das einerseits durch ideologische ,Gesinnungsformung, andererseits durch flexibles Einstellen der Filmgehalte auf gesellschaftliche Situationen und schließlich durch eine in beiden Fällen verschleiernde Vermittlungsstrategie erreicht werden soll.

\section{Die filmtheoretische Ausarbeitung der Goebbels'schen Vorgaben bei Hippler}

Die konkretisierende Übertragung dieser Grundstruktur des Propagandaprinzips auf den Film und eine detaillierte Näherbestimmung seiner Funktion wird dann vor allem von Fritz Hippler als ,nationalsozialistische Filmtheorie' vorgelegt, wobei einige Konkretionen auch schon in Goebbels' Reden enthalten sind. Hippler, der als treuer ,filmtheoretischer Gefolgsmann' seines Propagandaministers gelten kann, ${ }^{65}$ bedient sich zugleich auch wieder des Führer- und des Gemeinschaftsprinzips, ordnet diese jedoch dem Propagandaprinzip zu und ein. Die theoretisch-medienpolitische Ausformung des Propagandaprinzips sowie die Aufgabenbestimmung für die Massenkultur werden dadurch deutlicher. - Zunächst zeigt sich, daß auch Hippler den Film generell der Ideologieverpflichtung unterstellt. Er wendet sich nachdrücklich gegen „Filme, die gleichsam um ihrer selbst willen gemacht worden zu sein scheinen“, und fordert, daß jeder Film ,seine ,Moral' haben“ und die Kunst ,grundsätzlich nichts absolut Zweckloses schaffen“ solle. ${ }^{66}$ Es gehe darum, jedem Filminhalt „eine gewisse wegweisende ,Tendenz، “67 zu geben. Diese Anforderung gilt ihm als ,,selbstverständlich“, zumal in Deutschland „über den Zustand (...) ja wohl alle hinaus“ seien, „in dem Wort ,Tendenz' etwas Anrüchiges (zu) erblicken“" ${ }^{68}$ Damit übernimmt Hippler die erste Forderung Goebbels‘ und verpflichtet den Film auf die Vermittlung von Botschaften, die sich nicht unmittelbar aus den Eigengesetzlichkeiten des Mediums und seiner Geschichte, oder der ästhetischen Binnenkommunikation der Filmschaffenden ableiten. Indem er sich pointiert gegen die ,l'art pour l'art'-Konzeption sowie

\footnotetext{
${ }^{65}$ vgl. dazu: Brandt, Filmtheorie, 13

${ }^{66}$ Hippler, Betrachtungen, 98

${ }^{67}$ Hippler, Betrachtungen, 98

68 Hippler, Betrachtungen, 99
} 
das kantianische Kunstkonzept wendet, legt er fest, daß die normative Inhaltsbindung des Films aus einem anderen, filmexternen Bereich kommen müsse. Diesen Bereich bestimmt Hippler dann mit dem Gemeinschaftsprinzip näher, wobei er sich zugleich um eine gewisse argumentative Stützung der behaupteten ,Selbstverständlichkeit' der Ideologieverpflichtung bemüht.

Er unterstreicht zunächst, daB „die Gemeinschaft aller Zeiten, repräsentiere sie sich nun durch den Staat, die Kirche oder eine sonstige Gemeinschaftsform", stets "an den schaffenden Künstler ihre Forderungen zu stellen" gehabt habe ${ }^{69}$ Die ,herkömmliche' Vorstellung von Kunstfreiheit, wie sie im ,'art pour l'art'-Konzept vorliege, erweise sich so als Illusion. Die ,eigentliche' Freiheit der Kunst entstehe vielmehr dadurch, daß in dem $\mathrm{Ma} B$, in dem ,sich die Forderungen der Gemeinschaft in der spontanen Haltung des Einzelwesens ausdrücken“, auch „die Gegensätzlichkeit in Ergänzung und der Zwang in Freiwilligkeit" übergehe. ${ }^{70}$ Entsprechend sei jeder Künstler „am Ende so frei, wie er sich fühlt" ${ }^{71}$ Kunstfreiheit erweist sich derart in Hipplers Entwurf als ,Einsicht in die Notwendigkeit ${ }^{72}$ und daraus entspringendes Freiheitsgefühl. Sie wird auf eine kunstexterne subjektive Gestimmtheit des Künstlers, auf eine psychische Befindlichkeit reduziert, die lediglich durch Anpassung und Submission erreichbar ist. Die vorgängige ,Notwendigkeit' aber wird von der Gemeinschaft und ihren durchaus kunstexternen Normen gesetzt. Das Recht zu solcher Setzung sucht Hippler, nicht ganz stringent, mit einem historischen Argument zu belegen. So habe es nämlich nicht nur diese normativen Bindungen immer gegeben, sondern es sei auch nachweislich, daB von ihnen das Schaffen echter Kunst keineswegs behindert worden sei. ${ }^{73}$ Gemeinschaft gilt deshalb als legitime und zuständige Normierungsinstanz für Kunst- und Filminhalte, wobei der Legitimitätsstatus dieser Instanz durch Herkommen und Historie gesichert scheint. Im Hintergrund dieser Vorstellung steht zweifelsohne die kunstnormative Verwendung der ethischen Maxime des Gemeinschaftsprinzips, welche das Gemeinwohl dem Eigenwohl überordnet und damit eine grundsätzliche ,Gemeinschaftsverpflichtung' der Kunst ansetzt. Der Film als massenkulturelles Erzeugnis wird damit letztlich dem nationalsozialistischen Kunstkonzept unterstellt und von dessen totalitärem Paradigma her in Dienst genommen. Die Forderungen der Gemeinschaft wiederum beziehen sich nach Hippler vorwiegend auf den Inhalt, der jedoch gerade beim Film mit der Form eine unlösbare Einheit bilde. ${ }^{74}$ Die ideologische Inhaltsbindung muß sich also bei diesem Medium ebenso wie in der Kunst inhaltlich und formal ausdrücken.

Nachdem so die Ideologieverpflichtung mit dem Gemeinschaftsprinzip als Gemeinschaftsverpflichtung ausgelegt und legitimiert ist, leitet Hippler sie an anderer Stelle aus der ,formenden Kraft" des Films nochmals her und bestimmt daraus dann auch die Aufgabe des Films in der Gemeinschaft. Die ,formende Kraft' definiert er als „persönliche Verbindung des Zuschauers zum Hauptdarsteller" und als „Bestre-

\footnotetext{
${ }^{69}$ Hippler, Betrachtungen, 3; der zweite Teil des Zitats im Original gesperrt.

${ }^{70}$ Hippler, Betrachtungen, 4

71 Hippler, Betrachtungen, 5

7 vgl. dazu: Brandt, Filmtheorie, 18

73 vgl. Hippler, Betrachtungen, 3-4

74 Hippler, Betrachtungen, 4,7
} 
ben, diesem gleich zu sein" ${ }^{75}$ Auf die Rezeption von Filmen folge so eine gewisse Formung des Zuschauers durch das Gesehene, die ,eine der nicht nur kulturell, sondern auch zivilisatorisch erheblichsten Tatsachen" sei. ${ }^{76}$ Damit aber entstehe einerseits die Notwendigkeit, solche formende Wirkungen nicht nur planend vorauszubestimmen, sondern auch normativ in entsprechende Verpflichtungen zu nehmen. Im Hintergrund steht hier zweifelsohne die schon von den Reformern überkommene Vorstellung von der ,Suggestivkraft ${ }^{\prime}$ des Films, die es erfordere, seine Wirkungen durch Inhaltsnormierung lenkend zu präformieren. Andererseits sieht Hippler in der ,formenden Kraft' die herausragende Eignung des Films für eine kulturelle und politische Erziehungs- und Führungsaufgabe sowie eine entsprechende Hinordnung auf diese Aufgabe grundgelegt. Er rekurriert damit wieder auf Goebbels, der von einer „ungeheuere(n) Breiten- und Tiefenwirkung " 7 des Films spricht und den letztgenannten deshalb mit den ,Erziehungsinstitutionen' Universität, Gymnasium und Volksschule vergleicht. ${ }^{78}$ Der Film ist für Goebbels eine „nationale Erziehungskunst“'79, die aus diesem Grund ,eine Tendenz zu besitzen habe, allerdings eine staatsmoralische Tendenz, die Tendenz, ein Volk für die Durchsetzung seiner Lebensansprüche mit zu befähigen und zu erziehen" ${ }^{\prime 80}$.

Wie Goebbels auf diese Weise die ,erzieherische' Funktion der Ideologieverpflichtung präzisiert, nämlich im Kontext des Kriegs als die der moralischen Aufrüstung der ,Herrenrasse' durch die Filminhalte, so detailliert auch Hippler die Erziehungsfunktion und ihre genaue Füllung. Er weist einmal dem Film die Aufgabe einer gemeinschaftsformierenden Menschenbildung und ein andermal der Schaffung eines spezifischen identitätsbildenden Geschichtsbewußtseins zu. Die erste Aufgabe setzt er im Zusammenhang mit der „Menschenführung und Nachwuchspflege“81, d.h. der Organisation der Regie und der Auswahl der Schauspieler im Film-business an. Nachdem er mehrfach darauf insistiert hat, daB die Suche nach geeigneten Filmdarstellern im Sinn einer systematischen ,Durchforstung der ,Volksgemeinschaft' zu geschehen habe, ${ }^{82}$ benennt er das Kriterium dieser Eignung. So gelte es, aus den ,ungezählten Millionen (...) diejenigen aufzuspüren, die ihrem äußeren Erscheinungsbild nach für die Darstellung im Film geeignet zu sein scheinen " ${ }^{483}$. Solche Menschen aber seien jene, deren ,Erscheinungsbild“ „Weltformat“ besitze und zugleich „dem Schönheitsideal des modernen deutschen Menschen“ entspreche. ${ }^{84}$ Zielt schon diese Doppelcharakteristik, die internationale Achtung und binnenästhetische Definition verklammert, auf eine elitäre Wesensbestimmung des Schauspielers, so zieht die weitere Beschreibung angeblich nötiger Eigenschaften für diesen Beruf das elitäre Moment zu einem allgemeinen, durchaus nicht mehr nur filmbezogenen, Vorbildcharakter aus. Der ideale deutsche Schauspieler nämlich müsse einen „hohen Grad von Intelli-

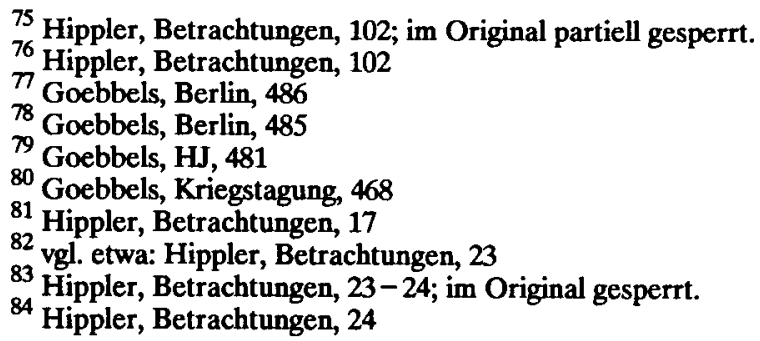


genz" mit „einem gesunden Menschenverstand“, „psychologisches Einfühlungsvermögen" mit „Gefühl für Massenwirkung“, „künstlerische Veranlagung“ mit „praktischem Sinn für die Gegebenheiten des Lebens", und "menschliche Kontaktfähigkeit" mit „der Kraft zu notwendiger Distanz" verbinden. ${ }^{85}$ Er soll also eine Persönlichkeit vorstellen, die Intelligenz mit ,Tatkraft" und ,Lebenstüchtigkeit" in herausragender Form vereint, und die nicht zuletzt deshalb ,Weltformat' besitzt. Die beschriebenen, normativen Eigenschaften reichen derart über fachspezifische Erfordernisse hinaus und machen aus dem Schauspieler eine Art prototypischen Repräsentanten der ,Volksgemeinschaft‘. Hipplers Konzeption des idealen Schauspielers erinnert damit wieder an die generelle kunsttheoretische Bestimmung des Künstlers als führungselitäre Person mit gemeinschaftsformierenden, kunstexternen erzieherischen Aufgaben. Wie der Künstler soll der Schauspieler die Gemeinschaft ideal verkörpern und durch ,Vorausdarstellung auf eine entsprechende Umformung zu ihrem,wahren Wesen' hinarbeiten.

Dieses umformende Hinarbeiten wird von Hippler dann aber nicht nur als idealische Repräsentation wünschenswerter charakterlicher Eigenschaften des ,neuen Menschen' verstanden, denen es nachzueifern gälte, sondern zugleich als ,materielle Reform der Gemeinschaft, in deren Hintergrund die Axiomatik der ,Rassetheorie steht. Die Exemplarität soll hier einer ,ästhetischen Erziehung in bevölkerungspolitischer Absicht' dienen, bei der das genannte, elitäre ,äußere Erscheinungsbild‘ dafür sorgt, daß das ,deutsche Schönheitsideal' für die Masse der Filmrezipienten geschmacksnormativ wirksam werde und deren Partnerwahl beeinflusse. Gelänge dies, so könne es ,,im besonderen Sinn einer qualitativen Hochziehung wertvoll wirken “86, da die sich wechselweise wählenden ,schönen Menschen' auch wieder ,schöne Menschen' hervorbrächten. ${ }^{87}$ Besonders bei der Besetzung weiblicher Filmrollen müsse dieser Gesichtspunkt beachtet werden, denn „die im Film dargestellte Frau“ bedinge zu einem gut Teil „das Schönheitsideal der breiten Masse“ ${ }^{88}$ Der Film soll so für ein bevölkerungspolitisches Social engineering eingesetzt und die Realisierung des ,rassetheoretisch" konstruierten Schönheitsideals mit seiner Hilfe befördert werden. Die Herstellung der ,Zielgemeinschaft', wie sie die ,Rassetheorie' als Aufgabe für Kunst und Politik festlegt, gerät auch zur Aufgabe für den Film und wird als Eugenik via Erziehung bestimmt. Die erzieherische Rolle des Films wird damit in doppelter Weise als gemeinschaftsformierende ausgelegt, nämlich einmal als exemplarischappräsentative Präformation erwünschter Fähigkeiten und Charaktereigenschaften, und einmal als Beförderung eines eugenisch-ästhetischen Selektionsverhaltens. Die Ideologieverpflichtung gerät derart zur Verpflichtung auf die Ziele der ,Rassetheorie' und ihrer gesellschaftlich-politischen Umsetzung über das Gemeinschafts- und das Führerprinzip. Ästhetik, (Bevölkerungs-)Politik und Pädagogik werden dabei unmittelbar miteinander verklammert; unter den Prämissen des ,rassetheoretisch gefüllten Gemeinschaftsprinzips und seiner kunsttheoretischen Verwendung wird so

${ }_{86}^{85}$ Hippler, Betrachtungen, 24; im Original gesperrt.

${ }^{86}$ Hippler, Betrachtungen, 103

${ }^{87}$ vgl. zu dieser analytischen Schlußfolgerung auch: Brandt, Filmtheorie, 24-25. Brandt macht hierbei auf die Parallelen in der Lessing'schen Ästhetik aufmerksam und sieht dort die Wurzeln der Theorie Hipplers.

${ }^{88}$ Hippler, Betrachtungen, 103 
erneut eine grenzauflösende Totalisierung vollzogen, die der Totalisierung im Kunstkonzept korrespondiert.

Als zweite Konkretion der Erziehungsaufgaben des Films erscheint bei Hippler dann die Gemeinschaftsformierung durch Schaffung eines identitätsbildenden Geschichtsbewußtseins. In der Tat dient der ,historische Spielfilm' ja im Nationalsozialismus der Erzeugung eines ,Wir-Gefühls', eines Nationalstolzes und Selbstbewußtseins, welche die gruppenspezifische Identität aus ihrer historischen Genese und ,Größe‘ ableiten. Entsprechend charakterisiert Hippler als Wirkungsziel historischer Filme, daß das Publikum sich „von ihm erheben und begeistern lassen“ können müsse. ${ }^{89}$ Für die Herstellung von Filmen mit solcher Funktion und Wirkung legt er fest, sie „aus den Notwendigkeiten und für die Bedürfnisse der Gegenwart (zu) machen" 90 . Das aber bedinge einerseits, sich an „dem normalen Begriffsvermögen des heutigen Menschen“ zu orientieren und alles auszuschalten, ,was ihn innerlich nicht anspricht““.91 In dieser Weise sei der ,unklare (...) Gesamtdurchschnitt von ungefähren Vorstellungen" ${ }^{\text {"92 }}$, die bei der zeitgenössischen Rezipientenschaft in bezug auf ein historisches Datum vorherrschen, die Voraussetzung jedes historischen Films. Andererseits gelte es, die gegenwartsrelevante Bedeutung des historischen Stoffs herauszuarbeiten und „die Wertsetzung, die der Geist der nationalen Gegenwart daran legt ${ }^{493}$ zu verdeutlichen. Damit tue es nicht nur not, bei den populären Vorstellungen über eine Vergangenheit anzusetzen, sondern auch, die Vergangenheit für die Zwecke der Gegenwart auszulegen und derart die Kenntnisse und Ansichten des Publikums erzieherisch weiterzubilden. ${ }^{94}$ Der historische Stoff müsse hierzu jedoch ,gestaltet ${ }^{*}$ werden, da er lediglich den ,Vorwand "95 bilde, und die Frage nach historischer Richtigkeit müsse durch die nach der (gegenwartsbezogenen) ,höheren Wahrheit' ersetzt werden. ${ }^{96}$

Damit legt Hippler eine Theorie des historischen Spielfilms grund, die dessen Aufgabe als Geschichtsklitterung unter ideologischen Prämissen bestimmt. Die Historie wird ihrer Eigenwirklichkeit beraubt und zum plastischen Stoff erklärt, dem unter Rücksicht externer Botschaften jede Form verliehen, ja dessen realer Bedeutungsgehalt selbst ausgetauscht werden kann. Die Ideologieverpflichtung zeigt sich hier zugleich als ,Ideologisierungsverpflichtung', d.h. als Pflicht, eine ,Interpretation“ faktischer Zusammenhänge vorzulegen, welche sich um der zeitgenössischen Erfordernisse willen auch gegen diese Zusammenhänge richten oder sie zumindest verfälschen kann. Um des Erziehungsziels der Schaffung eines ideologiekonformen, keineswegs mehr an Faktizität orientierten gruppenspezifischen Selbstverständnisses willen findet mit Hipplers Theorie eine Willkürisierung der interpretativen Verarbeitung historischer Zusammenhänge statt, die der von Orwell mit Blick auf den russischen Staat als Fingierung von Geschichte beschriebenen gleicht. Letztlich nämlich

${ }^{89}$ Hippler, Betrachtungen, 80

${ }_{91}^{90}$ Hippler, Betrachtungen, 80

91 Hippler, Betrachtungen, 77

92 Hippler, Betrachtungen, 77

93 Hippler, Betrachtungen, 79

94 vgl. Hippler, Betrachtungen, 78-79

95 Hippler, Betrachtungen, 77

${ }^{6}$ vgl. Hippler, Betrachtungen, 77-79 
bedeutet die dezisionistische Flexibilisierung von historischer Faktizität für ideologische Ziele die Ersetzung von Wirklichkeit durch Fiktion, d.h. eine funktionell-heteronomistische Verformung des Realitätsbegriffs mit der Konsequenz der Korruption des Realitätsbewußtseins. In zahlreichen Spielfilmen des Nationalsozialismus, von denen stellvertretend nur Harlans „Kolberg“ (1945) oder die beiden Bismarckfilme Liebeneiners genannt seien, läßt sich die direkte Umsetzung dieser Theorie oder zumindest ihr Einfluß nachzeichnen. ${ }^{97}$

Hipplers Vorgabe, sich zum Zweck ihrer erziehenden Weiterformung an den ,Vorstellungen der Basis' zu orientieren, zeigt dann auch, daß er seine Filmtheorie unter das zweite Strukturmoment des Propagandaprinzips stellt, nämlich die Strategie einer unmerklichen Steuerung, welche ihre Fruchtbarkeit und Wirkung aus eben der Nutzung von Basisnotionen ziehen will. Die Norm einer ,unmerklichen Steuerung spricht er explizit aus, wenn er für die Botschaft eines Films generell fordert, „sie nicht offensichtlich zu bezwecken, wohl aber sie nachdrücklich zu bewirken". 98 Wie Geobbels will er die eigentliche Wirkmacht und ,formende Kraft des Films in verdeckter Weise entfaltet sehen, auf daß eine nachhaltige Beeinflussung garantiert sei. Neben der skizzierten Anknüpfung an Wissens- und Meinungsbestände des Publikums führt Hippler als geeignete Methode hierzu ein, sich am „Erlebniskreis des Durchschnitts und der Masse“99 zu orientieren. Ausgangspunkte filmischer Indoktrination sind nach Hippler damit nicht die intellektuelle Reflexion einer kleinen Schicht Gebildeter und ihrer Probleme, sondern das nichtreflexe Erleben der ,breiten Masse ${ }^{6}$ und (in meiner Terminologie) deren lebensweltliche Verfaßtheit. ${ }^{100}$ Entsprechend gilt es für ihn, ,,auf das Optische und Gefühlsmäßige, also Nichtintellektuelle einzuwirken", wozu der Film als pictoriales Medium hervorragend geeignet sei. ${ }^{101}$ Hippler kennt so zwei Arten von ,Basisnotionen', an die der ideologieverpflichtete Film strategisch anknüpfen solle: Zum einen soziologisch faßbare, die in schichtspezifischen Wissens- und Meinungsbeständen sowie ebensolchen Problemstellungen zu finden sind, und zum anderen psychologisch beschreibbare, die als Sinnlichkeit, Emotionalität und bildliche Ansprechbarkeit erscheinen. Goebbels' Vorgabe, dem ,Volk aufs Maul zu schauen', wird damit ausgearbeitet und das strategische Moment des Propagandaprinzips konkretisiert. Gleichzeitig wirft diese Konzeption ein bezeichnendes Licht auf den nationalsozialistischen Erziehungsbegriff. Zweck der Anknüpfung ist ja nicht eine ,Mäeutik', welche vom Gegebenen ausgehend zu einer bewußten Neueinsicht und damit zu einer reflexen Bildungs- oder Einsichtserweiterung fortschreiten will, die den Adressaten zu mehr Autonomie befähigt, sondern gerade die nichtreflexe, unbewußt bleibende Meinungs- und Überzeugungsver-

97 vgl. dazu auch: Happel, hist. Spielfilm, bes. 39-44. Der erste der genannten Filme Liebeneiners, „Bismarck“ (1940), zeichnet unter ausschließlicher Konzentration auf Bismarcks Außenpolitik die Titelfigur als Vorläufer Hitlers, und schließt mit den suggestiven Worten: „Mein Werk ist getan. Es war nur ein Anfang. Wer wird es vollenden?“ (Happel, hist. Spielfilm, 40) Wegen der eindeutigen Propaganda lag nach 1945 ein Spielverbot auf dem Film, das 1987 erlosch. - Die Geschichtsfälschungen in „Kolberg“ sind bekannt; vgl. auch dazu: Happel, hist. Spielfilm, 42

\footnotetext{
98 Hippler, Betrachtungen, 98

${ }^{99}$ Hippler, Betrachtungen, 31

100 vgl. Hippler, Betrachtungen, 31

101 Hippler, Betrachtungen, 9
} 
änderung mit der Absicht einer Fremdsteuerung. Erziehung wird auf diese Weise methodologisch mit Propaganda synonym, und ihr Ziel ist das Social engineering. ${ }^{102}$

Schließlich findet sich auch bei Hippler das Moment der Plastizität, mit dem Propaganda als gesellschaftsbezogene Stimmungsregulation verstanden und die Ideologieverpflichtung relativiert wird. Der plastische Einsatz des Films wird hier einerseits in Auseinandersetzung mit der filmtheoretischen ,Berechtigung der Groteske reflektiert, welche oftmals ja keine Botschaft transportiert, sondern, lediglich' der Erheiterung dienen möchte. Hippler nun sieht ihre Legitimität eben darin, daß auch das ,befreiende Lachen" „ein sehr wichtiger und staatspolitischer Effekt“ sei. ${ }^{103}$ Auf diese Weise deutet er die Möglichkeit, den Film zur Steuerung und Beeinflussung gesellschaftlicher Stimmungslagen sowie zur Ableitung entsprechender Unzufriedenheitspotentiale in Dienst zu nehmen, zunächst einmal an. Er rekurriert dabei wieder implizit auf Goebbels, der den ,staatspolitischen Wert' der Unterhaltung betont ${ }^{104}$ und vor allem während des Kriegs auf eine entlastende und ,launeförderliche‘ Rolle des Films abhebt. ${ }^{105}$ Dann führt Hippler die genannte Möglichkeit als Bevorzugung ,positiver Grundhaltungen' in Filmen, sowie des ,Happy end" methodologisch genauer aus. Er betont, da $\beta$ der Film gerade auch, wenn er ,nicht immer der grausamen Realistik des Lebens" entspreche, der „Vermittlung von Lebenskraft und -bejahung“ dienen könne. ${ }^{106}$ Das aber gilt als dringend erforderlich, wie Hipplers Auslassung über das ,kontraproduktive‘ Beispiel Frankreichs zeigt. Dort nämlich, so führt er zur Stützung seiner Forderung, positiver Filme an, seien äußerst pessimistische Filme gemacht worden, welche „bei Ausbruch des Krieges selbst von der absolut liberalistischen französischen Regierung verboten werden mußten". ${ }^{107}$ Nicht zuletzt deshalb brauche es auch nicht zu verwundern, daß Frankreich den Krieg verloren habe. ${ }^{108}$ Film gilt Hippler damit also jenseits aller ideologischen Verpflichtung auch als stimmungsbezogene Wirkmacht, die nicht nur der Indoktrination, sondern ebenso der ,sozial-psychologischen Balance' und der Steuerung gesellschaftlicher Gestimmtheit dienstbar gemacht werden kann und soll. Das Erfordernis solcher Dienstbarmachung kann in Hipplers Theorie ebenso wie bei Goebbels unter Umständen das ideologische Erfordernis überwiegen.

Die Zuständigkeit für den propagandistischen und erzieherischen Einsatz des Films wiederum wird bei Hippler und bei Goebbels in den Händen des Staats als Repräsentant der Gemeinschaft zentriert. Die Begründungsfigur ist jeweils dieselbe: Aus der hypostasierten ,Suggestivkraft" des Films wird sowohl eine gefährliche Wirkmacht, die der Staat zu bändigen habe, als auch eine besondere Eignung als Erziehungs- und Führungsinstrument, die vom Staat genutzt werden müsse, abgeleitet. So spricht Hippler von der ,massenpsychologisch und propagandistisch besonders eindringliche(n) und nachhaltige(n) Wirkung“ des Films, die es ,geradezu frevelhaft

102 Goebbels setzt daher auch explizit Erziehung und Propaganda gleich. Vgl. dazu: Goebbels, Kriegstagung. 468

${ }^{103}$ Hippler, Betrachtungen, $98-99$

104 vgl. Goebbels, HJ, 480

105 vgl. etwa: Goebbels, Berlin, 495

106 Hippler, Betrachtungen, 107

107 Hippler, Betrachtungen, 105

108 vgl. Hippler, Betrachtungen, 105 
und leichtsinnig“ erscheinen lasse, wenn sich „ein verantwortungsbewußtes Staatsregiment (...) des Führungsanspruchs über dieses wichtige Führungsinstrument begeben würde". ${ }^{109}$ Bei Goebbels taucht diese Argumentation bereits in der ersten Filmrede auf, in der er aus den „gefährlichen Wirkungen des Films“ die ,Pflicht" des Staats ableitet, „regulierend einzugreifen“. ${ }^{110}$ In beiden Fällen wird damit zwar nicht explizit über die elitäre Dichotomie des Führerprinzips die exklusive Staatszuständigkeit für die Normierung und Nutzung des Films legitimiert, doch steht die Dichotomie im Hintergrund auch dieser Begründungsform. Weder die Filmschaffenden scheinen hier nämlich fähig zu sein, eine sachadäquate Verantwortung zu übernehmen, noch gilt das Publikum als mündig und reflexiv genug, mit der ,Suggestivkraft" des Films umzugehen. Vielmehr bedarf es wieder einer übergeordneten Instanz, die ,gefährlichen' Auswirkungen steuert und das Potential des Films ,positiv' nutzt. Einmal mehr wird so das dichotomische Gesellschaftskonzept des Nationalsozialismus wirksam, das über die Zuordnung von Gemeinschafts- und Führerprinzip eine Masse Geführter von den Führern unterscheidet und das die letztgenannten mit dem Staat identifiziert. In welchem Grad die Zuordnung inzwischen als selbstverständlich gilt, zeigt sich nicht zuletzt daran, daß Hippler die Dichotomie nicht mehr weiter begründet, sondern sogleich mit dem Führerprinzip die Organisationstruktur des staatlich gelenkten Film-business beschreibt. ${ }^{111}$

\section{Zur scheinbaren Dissonanz von Filmtheorie und faktischem Filmschaffen im Nationalsozialismus}

Die so verfaßte Filmtheorie des Nationalsozialismus wird, wie ich mit Bezug auf den historischen Spielfilm bereits angedeutet habe, auch medienpolitisch realisiert und formiert in der Tat das Filmschaffen zwischen 1933 und 1945 mit, wobei sich jedoch etwas unterschiedliche Akzentsetzungen ergeben. So scheint es zunächst in der faktischen Produktion nicht das erste Strukturmoment des Propagandaprinzips zu sein, das vordringlich umgesetzt wird, obwohl ihm vor allem bei Hippler großes Gewicht in der theoretischen Ausarbeitung zuteil wurde. Die Auswahl von Filmstoffen nämlich findet nicht primär und exklusiv unter dem Kriterium ihrer Eignung für den Transport spezifisch nationalsozialistischer Topoi und Anschauungen statt, und es wird über die Kontrollinstitutionen auch nicht versucht, Treatments und Drehbücher penetrant auf Ideologievermittlung ,hinzutrimmen'. Die Zahl der expliziten Propagandafilme, d.h. jener Filme, die mit der Absicht einer konkreten ideologischen Aussage produziert werden und meist Auftragsproduktionen des Propagandaministeriums sind, ist vielmehr relativ gering. Selbst der historische Spielfilm, bei dem die Verwirklichung der Hippler'schen theoretischen Vorgaben in einigen Fällen ziemlich deutlich ist, entsteht nicht ausschließlich mit der Absicht historiographisch-symbolischer Indoktrination. Zudem erweist die Filmgeschichte, daß im Nationalsozialismus eine große Zahl von Filmen produziert wurde, die von Ideologemen frei sind.

Allerdings bedeutet das keinen vollständigen Verzicht auf eine diesbezügliche Formierung der produzierten Filme, sondern zunächst einmal eher eine Modifikation

\footnotetext{
${ }^{109}$ Hippler, Betrachtungen, 9

${ }_{110}$ Goebbels, Kaiserhof, 440

111 vgl. Hippler, Betrachtungen, 2
} 
in der Realisierung der Ideologieverpflichtung. Ideologische Bindungen nämlich sind, wie ein genauer Blick zeigt, auch wieder nicht gänzlich abwesend in der breiten Gebrauchsfilmproduktion. Sie entdecken sich dort jedoch meist nur in kleinen Szenen, einzelnen Sätzen oder unterschwelligen Charakterisierungen und nicht, wie man aus Hipplers Theorie zunächst erwarten möchte, im aussagerelevanten Hauptstrang der Erzählung oder dem ,Plot' insgesamt. Wenn man so will, erscheinen sie gegenüber der theoretischen Betonung ihrer Wichtigkeit marginalisiert, sind aber in etlichen Fällen vorhanden. Weiter sind es, wie Albrecht in seiner breit angelegten Inhaltsanalyse nationalsozialistischer Spielfilme zeigt, oft nicht die zentralen Ideologeme, also grundsätzliche Theorien der Nationalsozialisten, die in die Filme Eingang finden. ${ }^{112}$ Doch entdecken sich etwa in zahlreichen Filmtiteln ideologische Konnotationen, assoziative Verknüpfungen mit nationalsozialistischen Theoremen und lassen sich einige weniger zentrale, jedoch bereits ,populäre' Ideologeme des Nationalsozialismus in Filminhalten rekonstruieren. ${ }^{113}$ Festzustellen ist also zunächst eine eigentümliche Einschränkung der Realisierung der Ideologieverpflichtung. In vielen Fällen fehlt die Ideologie ganz und in einigen anderen tritt sie nur im Hintergrund auf, so $\mathrm{da} B$ man von einer quantitativen und qualitativen Marginalisierung sprechen muß, die sich bei näherem Zusehen als medienpolitische Modifikation des theoretischen Anspruchs erweist. Angesichts der starken Betonung der Ideologieverpflichtung in der Filmtheorie Hipplers bedarf diese Gewichtsverschiebung einer Erklärung.

Eine solche Erklärung liegt zunächst in Goebbels' Ablehnung ,sogenannter nationalsozialistischer Filme‘. Er betont, da $B$ er "keinen gesteigerten Wert" darauf lege, daß etwa die "SA über die Bühne oder die Leinwand marschiert", vielmehr solle dieselbe „über die Straße marschieren“. ${ }^{114}$ Der Film hingegen soll, wie zu sehen war, seiner Ideologieverpflichtung durch ,Aufraffen nationalsozialistischer Probleme' und deren implizite, oft nur atmosphärische Thematisierung gerecht werden. Insofern Propaganda nach Goebbels' Definition ihre Wirksamkeit in dem Maß einbüße, in dem sie bewußt wird, scheint eine auffällige Gegenwart der NS-Symbole und nationalsozialistischer Doktrine in Filmen gar nicht, wünschenswert'. Die Zurücknahme expliziter, kognitiver ideologischer Gehalte in vielen Filmen kann so als durchaus prinzipienkohärentes Phänomen gedeutet werden. Sie erscheint näherhin als Modifizierung der Ideologieverpflichtung durch das zweite Strukturmoment des Propagandaprinzips, nämlich die Strategie einer verdeckten Vermittlung, welche sich von lediglich partieller Anwesenheit ideologischer Gehalte und peripherer, assoziativer Konnotation eine wirksamere Indoktrination verspricht. Weiterhin war zu sehen, daB die Strategie von Goebbels selbst - und schließlich auch von Hippler - zusätzlich als Anknüpfen an die Notionen des Publikums beschrieben wurde. Dieses Anknüpfen nun erfolgt nicht nur im Sinn einer Orientierung an der Sinnlichkeit und Affektivität, d.h. der angenommenen größeren Nähe der ,breiten Masse` zu diesen naturalen, anthropologischen Grundstrukturen, sondern auch, wie besonders für den historischen Spielfilm zu sehen war, als Orientierung an den Meinungs- und Über-

112 vgl. Albrecht, Filmpolitik; zu dieser Aussage besonders 310

113 vgl. Albrecht, Filmpolitik, 123-143, 284-324

114 Goebbels, Tennishallen, 442 
zeugungsbeständen der Rezipienten. Das läßt vermuten, daß für die Ideologievermittlung grundsätzlich dieser ,lebensweltliche' Bestand, das jeweils sozial vorherrschende Wissens- und Meinungskonglomerat normativ relevant ist, d.h. nicht nur einen Ansatzpunkt für die indoktrinatorische Weiterformung, sondern auch ein Auswahlkriterium für günstig vermittelbare, weil bereits partiell und tendenziell populäre ideologische Gehalte ist. In der Tat belegt etwa Albrechts Untersuchung eben diesen Befund, wenn er seine Analyseergebnisse in der Schlußfolgerung zusammenfaßt, daß „nicht nur die Ideologie, sondern ,die breite Masse“ “ bestimme, „was nach Inhalt wie Gestaltung in die Propaganda Eingang finden“ darf. ${ }^{115}$ So ist für ihn „das Auswahlprinzip, das gegenüber der Ideologie angewandt (wird), sobald und soweit sie in die Medien integriert werden“ soll, „nicht durch die Ideologie selbst, aber auch nicht allein durch das Medium bestimmt", sondern aus strategischen Gründen eben im ,antizipierten Bild der Empfänger ‘ fundiert. ${ }^{116}$ Das zweite Strukturmoment des Propagandaprinzips liefert damit in seiner Konkretion einer Orientierung an den Notionen der Basis zugleich ein medienpolitisches Selektionsprinzip gegenüber den ideologischen Gehalten und wirkt sich derart restriktiv und modifizierend auf die Ideologieverpflichtung aus.

Doch reicht diese Erklärung noch nicht hin, um das Verhältnis von Theorie und faktischer Filmproduktion im Nationalsozialismus zu erfassen, bzw. die Kohärenz der letzten mit der ersten zu belegen. Wie ich erwähnt habe, entbehren ja zahlreiche Filme auch der genannten Konnotationen und scheinen gänzlich ,a-nationalsozialistische' Produktionen zu sein. Der Blick auf die diachrone Entwicklung der nationalsozialistischen Filmproduktion zeigt weiter, daß der Anteil der ,unpolitischen', d.h. ideologiefreien Unterhaltungsfilme mit Kriegsbeginn gegenüber der message-orientierten Propaganda noch zunimmt. Er ist auch vorher nicht gering zu veranschlagen und findet sich von Goebbels sogar explizit gefordert, wenn dieser schon in der ersten Rede betont, es gehe auch darum, den ,Tagesbedarf ${ }^{*}$ an ,kleinstem Amüsement ${ }^{\star}$ zu decken. Auf der Kriegstagung spricht er ebenfalls deutlich aus, daß der Film ,in einer Zeit, in der der gesamten Nation so schwere Lasten und Sorgen aufgebürdet" werden, ,in stärkster Weise (...) der Unterhaltung zu dienen“ habe. ${ }^{117}$ Im Jahr 1942 legt er dann sogar den quantitativen Vorrang der Unterhaltungsproduktionen gegenüber den ideologietragenden Filmen fest und nennt die Herstellung der erstgenannten als die eigentliche Aufgabe der Filmschaffenden. Um die „Großfilme nationalpolitischen Charakters" nämlich werde er sich schon selber kümmern; ${ }^{118}$ neben „diesen $20 \%$ Großfilmen“ aber sei es nötig, „80\% gute, qualitätssichere Unterhaltungsfilme zu schaffen““. ${ }^{119}$ Die zitierte Äußerung auf der Kriegstagung macht nun aber deutlich, wie die faktische Entwicklung und ihre Beförderung durch Goebbels Anweisung theoriebezogen einzuschätzen sind: Es veranschaulicht sich in ihnen die Realisierung des dritten Strukturmoments des Propagandaprinzips, nämlich dessen Plastizität, mit der eine grundsätzliche Relativierung der Ideologieverpflichtung vorgenommen und ein stimmungsregulativer, ,sozial-psychologischer' Einsatz des Films

\footnotetext{
${ }^{115}$ Albrecht, Filmpolitik, 309

${ }_{116}$ Albrecht, Filmpolitik, 309

${ }_{117}$ Goebbels, Kriegstagung, 480

118 Goebbels, Berlin, 495

119 Goebbels, Berlin, 495
} 
möglich wird. Zugleich verdeutlicht die (eher im Sinn eines grundsätzlichen Relevanzverhältnisses als einer konkreten Verteilung der Quantität zu verstehende) Prozentangabe darin das Gewicht, das dieses Strukturmoment für die faktische Organisation der nationalsozialistischen Filmpropaganda besitzt. Es gerät letztlich beinahe zum zentralen Moment des Propagandaprinzips schlechthin.

Das zeigt sich für die faktische Produktion auch jenseits des Spielfilms. Dort setzt sich die die plastische Anpassung an ,sozial-psychologische' Erfordernisse im ,Dokumentarfilm' und in der Wochenschau um. Zwar können ,Dokumentarfilme' auch als Ideologieträger fungieren, etwa, wenn mit dem Film Hipplers „Der ewige Jude“ (1940) die Rassendiskriminierung gestützt werden soll. Doch dienen sie zu einem gut Teil einer Verschleierung faktischer Politik, die als ,sozialunverträglich' erscheint, und damit der Beförderung, sozialer Akzeptanz' durch plastische Adjustierung des Politikbilds mit Rücksicht auf die Stimmung der Öffentlichkeit. So fingiert etwa der ,Dokumentarfilm“ „Feuertaufe“ (1941), der realiter den Überfall auf Polen zum Gegenstand hat, anstelle des Angriffskriegs eine heldenhafte deutsche Verteidigung und bemüht sich derart sowohl darum, nationales Selbstbewußtsein zu stimulieren, als auch die Akzeptanz des Kriegs zu fördern. Die Wochenschau wiederum dient, wie hinreichend bekannt ist, über den gesamten Zeitraum des nationalsozialistischen Regimes hinweg als plastisches Steuerungsinstrument. Auch sie transportiert immer wieder Ideologie, doch daneben wird sie stärker noch zur Verschleierung unliebsamer Entwicklungen und skandalöser Politik genutzt sowie zur Desinformation eingesetzt. Als Beispiel hierfür können die Serien von ,Kriegsberichten“ in der Wochenschau gelten, die lange Zeit noch Siege vorgaukeln, wo Fronten längst zusammengebrochen sind. Beide, ,Dokumentarfilme' wie Wochenschau, nehmen so eine funktionelle Verfälschung von Realität vor, die sich an den ,Erfordernissen` der gesellschaftlichen Situation und Gestimmtheit orientiert und sich durch Etablierung einer ,sekundären Realität' um Stimmungsregulation und Social engineering bemüht.

An der faktischen Entwicklung des Filmschaffens im Nationalsozialismus läßt sich somit ablesen, daß sowohl die plastische Anpassung der Filmproduktionen an die jeweilige gesellschaftlich-historische Situation, insbesondere die psychische Gestimmtheit des Kollektivs, als auch die Vermittlungsstrategie Vorrang vor der Ideologieverpflichtung besitzen bzw. zunehmend gewinnen. Gerade die Realisierung dieser beiden Strukturmomente und ihre normative Einschärfung durch Goebbels aber zeigen, $\mathrm{da}$ das Propagandaprinzip in der Tat die eigentliche filmpolitische Maxime des Nationalsozialismus abgibt und von der Produktion auch realisiert wird. Die nationalsozialistische Filmproduktion zeigt sich so, anders herum formuliert, als durchaus kohärent mit der von diesem Prinzip geleiteten NS-Filmtheorie, wenngleich sie bei deren Übertragung in die Praxis den primären Akzent anders setzt.

\section{Die prinzipienkohärente Struktur der nationalsozialistischen Filmpolitik}

Auf diesem Hintergrund kann die Filmpolitik des Nationalsozialismus nun prinzipiell und in ihren Grundstrukturen zusammengefaßt werden. Sie läßt sich als von den Maximen des Propagandaprinzips geleitetes Unterfangen beschreiben, das mit einer doppelten Zielrichtung versehen ist. Zum einen nämlich richtet sie sich auf eine sinnstiftend-identitätsstabilisierende Gemeinschaftsformierung durch politisch-ideologische Indoktrination und exemplarisch-redundante Appräsentation erwünschter 
Charaktereigenschaften und Verhaltensweisen. Diese Funktion des Films im Sinn der Ideologieverpflichtung wird vor allem auf der Theorieebene betont und läßt Rückbindungen an die generelle theoretische Axiomatik der nationalsozialistischen Gesellschaftskonzeption sowie der Kunsttheorie erkennen. So bedient sich die Filmtheorie zunächst - in der typisch organisatorisch-ethischen Doppelverwendung des Gemeinschafts- und des Führerprinzips. Mit dem ersten legitimiert sie die normative Hinordnung des Films auf das Kollektiv und seine Überzeugungen, d.h. sie wendet die ethische Maxime des Gemeinwohlvorrangs auf die gesellschaftliche Rolle des Films an und hebt damit die Möglichkeit subjektiver Expression sowie die Kunstfreiheit auf. Ähnlich der Kunst wird damit der Film letztlich in das heteronome Verpflichtungsgeflecht der totalitären Struktur genommen. Er ist nun prinzipiell auf Sinnstiftung, Weltdeutung und Erziehung verpflichtet, deren inhaltliche Füllung ideologisch vorgegeben ist und nicht, etwa im Sinn eines ästhetischen Diskurses konkurrierender Positionen, medienimmanent gefunden werden kann. Ziel ist die Hervorbringung der ,wahren Gemeinschaft', die von Hitler mit einem ,rassetheoretisch'geschichtsphilosophischen Konglomerat bestimmt wurde. Um sie zu erreichen, soll der Film einerseits der Vermittlung eines identitätstragenden Selbstverständnisses der Gemeinschaft durch etwa den historischen Film dienen, andererseits aber mit dem Transport eines gruppenspezifischen Schönheitsideals einer ästhetischen Eugenik Vorschub leisten. Auch die ,rassetheoretische` Füllung des Gemeinschaftsprinzips wird auf diese Weise zur Anwendung gebracht. Mit dem zweiten Prinzip dichotomisiert die Filmtheorie dann die Gemeinschaft und weist sie kohärent zu der vertrauten Argumentationsfigur einer notwendigen personal-elitären Repräsentanz (und Vormundschaft) die Zuständigkeit für die skizzierten normativen Indienstnahmen einer Führungsschicht zu, die an oberster Stelle mit dem Staat identisch ist. Sie rekurriert damit letztlich auf die Vorstellung einer inkompetenten, leitungsbedürftigen Masse und läßt kohärent zur Ausrichtung des nationalsozialistischen Gesellschaftskonzepts auch hier spürbar werden, daß ihre Annahmen auf kontramoderne Paradigmenbestände zurückgehen. Schließlich beschreibt sie die Strategie der Ideologievermittlung und Gemeinschaftsformierung als verdeckte, unmerkliche Beeinflussung der Rezipienten und empfiehlt dazu die Orientierung an und Nutzung von lebensweltlichen Beständen sowie anthropologisch erhobenen Grundstrukturen und Antriebskräften. Die letztgenannte Konkretion der Strategie verweist dabei wieder auf die kunsttheoretisch verwendete Natur-Kultur-Dichotomie, welche aus dem natural-ontologisch gesetzten Sein das kulturell Gesollte deduziert und so die Nutzung naturaler Basalstrukturen für ,kulturelle' Ziele ohnehin nahelegt.

Zum zweiten aber hebt die nationalsozialistische Filmpolitik in praxi besonders auf ein gemeinschaftssteuerndes Social engineering ab, das die Ideologieverpflichtung partiell aufkündigt, zumindest jedoch stark relativiert, und das auf der Theorieebene seinen Ausdruck vor allem in der Plastizität des Propagandaprinzips findet. Der Film erhält hier die vordringliche Aufgabe, sowohl durch Camouflage faktischer Politik und Realität als auch durch stimmungswirksame, kompensative Bedürfnisbefriedigung, der sozial-psychologischen Balance und gesellschaftlichen Ruhe sowie der Rekreation und der Mobilisierung energetischer und motivationaler Reserven bei der Bevölkerung zu dienen. Das rekreative und kompensative Moment gewinnt insbesondere im Krieg an Bedeutung, wie nicht zuletzt Goebbels' Insistenz auf der Not- 
wendigkeit umfangreicher Unterhaltungsproduktionen zeigt, während die Realitätsverschleierung und -verfälschung von Beginn an zum zentralen propagandistischstrategischen Instrumentarium des Nationalsozialismus zählt. Sie wird neben den ,Dokumentarfilmen', die ein kontrafaktisches Bild nationalsozialistischer Politik zeichnen oder der Rassendiskriminierung dienen, vor allem durch die Wochenschau realisiert. Ziel dieser Realitätsverfälschungen, die letztlich versuchen, eine ,sekundäre Realität' zu etablieren, ist die Erzeugung, bzw. Sicherung sozialer Akzeptanz für das politische Handeln der ,Führung sowie letztlich die Sicherung der Herrschaftsstellung der letztgenannten.

Diese zweite, immer wichtiger werdende Ausrichtung der nationalsozialistischen Filmpolitik aber zeigt, daß im Feld der medialen Kommunikation und der Massenkultur nach anderen Maximen gehandelt wird als etwa im Bereich der Kunst. Geht es dort nämlich um sinnstiftende, Führung mit den Ziel der Herausarbeitung der ,wahren Gemeinschaft', also ein ideologisch präformiertes, d.h. von zwar inkonsistenten und falschen, aber doch im Anspruch theoretisch-reflexiven Prämissen geleitetes Unterfangen, so richtet sich die Filmpolitik mit ihrer zweiten Absicht auf eine reine Steuerung, deren Prinzipien nicht mehr in theoretischen Anstrengungen zu finden, sondern die lediglich herrschaftsfunktional und aktuellen Erfordernissen entsprechend angelegt sind. Es kann deshalb genau genommen auch nicht mehr von Prinzipien, sondern es muß von kurzfristig wechselnden Zwecken gesprochen werden. Statt einer heteronom bestimmten führungsfunktionalen Zielorientierung, wie sie bei der Kunst und bei den ideologisch verpflichteten Filmproduktionen vorliegt, läßt sich damit hier eine kurzfristig-flexible steuerungsfunktionale Zweckorientierung konstatieren. Die letztgenannte aber verweist darauf, da $B$ die der Filmpolitik zugrunde liegende Medienethik des Nationalsozialismus zu einem gut Teil nutzenorientierten Maximen folgt, d.h. in nicht unbeträchtlichem $\mathrm{Maß}$ utilitaristisch ausgerichtet ist (dazu mehr unten).

\subsection{Nationalsozialistische Filmorganisation unter dem Führerprinzip}

Bevor ich die nationalsozialistische Medienethik abschließend skizziere und zur reformerischen ins Verhältnis setze, will ich noch die Organisation des Films im Nationalsozialismus nachzeichnen. Nicht nur das Gebot der Vollständigkeit, sondern auch die schon für die Filmpolitik sichtbar gewordene Relevanz des faktischen Handelns der Nationalsozialisten für die gesicherte Erkenntnis ihrer Maximen legt diese deskriptive Ergänzung nahe. Die nachfolgende Darstellung wird dabei zunächst zeigen, $\mathrm{da} B$ in der Tat die gesellschaftstheoretischen Prinzipien und die filmpolitischen Maximen auch filmorganisatorisch realisiert werden. Vor allem die steuerungsfunktionale Ausrichtung der Filmpolitik soll hierdurch gesichert und die Steuerungsmacht in den Händen der Führungsschicht unangreifbar zentriert werden. Daher ist das organisationsstrukturell realisierte Prinzip vordringlich das Führerprinzip, dessen drei skizzierte Komponenten institutionell und verwaltungstechnisch umgesetzt werden. Mit ihrem Versuch, die Steuerungskompetenz zirkelintern zu requirieren, zeigen die Nationalsozialisten außerdem erneut Bezüge zu den medienpolitischen Forderungen der Reformer. Die strukturbezogenen ,Erfolge' der Reformer nämlich, d.h. ihre Einwirkung auf Gesetzgebung und Argumentation, liefern dem Nationalsozialismus 
günstige Vorgaben, die partiell nur noch ergänzt oder den nationalsozialistischen Prinzipien und Ideologemen gemäß interpretiert werden müssen. Zugleich aber stellt die strukturelle Organisation der Filmproduktion nach dem Führerprinzip einen komplizierten Prozeß dar, der vielfältigen Wechselfällen, sowie ,regionalen', bereichs- und situationsspezifischen Umstrukturierungen unterworfen ist und der sich derart über die gesamte Zeit der nationalsozialistischen Herrschaft erstreckt. Diese ständigen Umbauten lassen deshalb weiter erkennen, daß die Strategie der Nationalsozialisten hier ebenso wie ihr Gesellschaftskonzept auf eine assimilative Etablierung und Festigung der totalen Kontrolle und Steuerung zielt sowie, daß die letztlich kontramoderne, statifizierende Intention der Gesamtkonstruktion immer wieder in Widersprüche zur historisch anders positionierten Tendenz der Gesellschaftsentwicklung in der Moderne gerät und zu dauernden Reparaturen und Neuanpassungen genötigt ist. ${ }^{120}$

\section{Die Einrichtung des Propagandaministeriums und der Reichskulturkammer}

Seinen Anfang nimmt der Prozeß der nationalsozialistischen steuerungsfunktionalen Organisation des Films bereits 1933 mit der Errichtung des ,Reichsministeriums für Volksaufklärung und Propaganda' (RMVP). Durch Erlaß des Reichspräsidenten vom 13.3. 1933 werden sämtliche Medienbereiche eben diesem Ministerium unter der Leitung Goebbels' unterstellt; das ,Lichtspielwesen' wird zu diesem Zweck sogar eigens aus der Zuständigkeit des Reichsministeriums des Innern herausgelöst und dem RMVP angegliedert. ${ }^{121}$ Nachdem so die prinzipielle Zuständigkeit der Nationalsozialisten für die Medienpolitik strukturell verankert ist, wird im Juli desselben Jahres die ,Reichsfilmkammer' (RFK) als öffentlich-rechtliche Körperschaft per Gesetz ins Leben gerufen und der erste Schritt zur ,berufsständischen Organisation“ getan. ${ }^{122}$ Ende 1933 findet diese ihre endgültige Gestalt in der Etablierung der ,Reichskulturkammer' (RKK). Die berufsständische Organisation saugt die Arbeitnehmerund Arbeitgeberverbände in sich auf und stellt ein typisches totalitäres Assimilationsunterfangen auf der institutionellen Ebene dar: Zunächst überspringt sie die Spannungen zwischen den genannten Verbänden und den durch sie repräsentierten sozialen Gruppen, indem sie diese gegen die moderne Dynamik zu statischen, in sich wiederum fest gegliederten, ständischen Ordnungsgefügen erklärt und mittels Zentralisierung der organisatorischen Zuständigkeiten eine egalisierend-integrative ,soziale Ruhe' erzwingt. Dann erlaubt sie eine personalpolitische Steuerung, welche sich einerseits sogleich in Ausschlüssen mißliebiger Personen (nicht zuletzt jüdischer Filmschaffender) niederschlägt, und deren Zugriffsmacht sich andererseits darin ausdrückt, daß Nichtmitgliedschaft mit einem Berufsverbot identisch ist und jede privatinitiative Tätigkeit im Filmbereich kriminalisiert wird. ${ }^{123}$ Wo die definitorische

${ }^{120}$ Diese Umstrukturierungen und Anpassungsversuche schildern aus primär ökonomischer Perspektive Becker und Spiker, auf welche ich hier verweise: Becker, Herrschaft; Spiker, Kapital. In ihren Texten wird deutlich, da $B$ und wie der Versuch eines totalen Umgriffs auch auf der ökonomischen Ebene in dauernde Widersprüche zur modernen Dynamisierung gerät.

${ }_{121}$ vgl. Becker, Herrschaft, 32

122 vgl. Becker, Herrschaft, 47

123 So bestimmt das Gesetz, daß jeder Filmschaffende Mitglied der berufsständischen Organisation in der Filmkammer sein muß. Die Aufnahme aber ,kann abgelehnt, oder ein Mitglied ausgeschlossen werden, wenn Tatsachen vorliegen, aus denen sich ergibt, daß der Antragsteller 
und zentralistische Integration also nicht herrschaftsstabilisierend und steuerungsintensiv genug scheint, können Friktionen und Konflikte durch Elimination der entsprechenden Personen beseitigt werden. Die skizzierte Organisation ist dabei von Anfang an umfassend: sie schließt sämtliche Bereiche des Filmwesens, von der Produktion bis zum Verleih und zu den Kinos ein. ${ }^{124}$ Ihre Binnenstruktur wird dem Führerprinzip unterworfen, und das Verhältnis der jeweiligen Institutionsvorstände wird in dessen Sinn bestimmt. So ist der Präsident der RFK dem Präsidenten der RKK und dem Minister für Volksaufklärung und Propaganda ,verantwortlich', und schuldet der Präsident der RKK dem RMVP Rechenschaft. Zugleich aber ist jeder mit absoluter, nur an seine Person gebundener Autorität nach unten ausgestattet und von sämtlichen Empfehlungen oder gar Weisungen von Gremien freigesetzt. ${ }^{125} \mathrm{Im}$ Sinn der flexibilisierenden Diversifizierung des Führerprinzips wird damit versucht, eine Assimilation an dynamisierte Produktionsbedingungen vorzunehmen, situationsspezifisches Agieren zu erlauben und zugleich die Kontrolle in der Hand zu behalten; die letztinstanzliche und instanzenübergreifende Autorität bleibt Goebbels reserviert.

\section{Die Übernahme und Modifikation des Reichslichtspielgesetzes}

Flankiert werden diese strukturellen Zugriffsmaßnahmen von der Schaffung einer staatlichen ,Filmkreditbank', welche die Kreditvergabe über die Prüfinstanz eines ,dramaturgischen Büros‘ an politische Kontrolle koppelt. ${ }^{126}$ Mit den Änderungen des Reichslichtspielgesetzes (RLG) ab 1934 werden die Möglichkeiten dieser Kontrolle dann festgeschrieben und zunächst als umfassende Prüf-, Zensur- und Beratungsmaßnahmen des ,Reichsfilmdramaturgen' vom Treatment und Manuskript an bis hin zum fertigen Film gefaßt. ${ }^{127}$ Die Vorstellungen der Kinoreformer in bezug auf eine zentralisierte Produktionszensur und -mitgestaltung durch eine staatliche Stelle werden so erst einmal exakt realisiert. Bei ihrer Gesetzesänderung können sich die Nationalsozialisten auf mehr als zureichende Vorgaben der Weimarer Republik stützen, welche ihnen mit dem zuletzt 1931 erweiterten RLG weitreichende Handlungsmöglichkeiten und mit ihrer Zensurpraxis Beispiele harscher politischer Restriktion gibt. Schon die in der alten Fassung des RLG von 1920 enthaltenen Zensurgründe etwa erlauben eine Interpretation und Applikation, die den Nationalsozialisten gelegen kommt: Unter Berufung auf das Gesetz können Filme verboten werden, wenn sie ,geeignet scheinen', „die öffentliche Ordnung oder Sicherheit zu gefährden“ oder

die für die Ausübung des Filmgewerbes erforderliche Zuverlässigkeit nicht besitzt." (vgl. Gesetz über die Errichtung einer vorläufigen Filmkammer, in: RGB1 I 1933, 483, und: Becker, Herrschaft, 49)

124 vgl. Becker, Herrschaft, 58

125 vgl. Becker, Herrschaft, $51-52$

126 vgl. Becker, Herrschaft, $38-39$

127 So bestimmt das neue RLG, daß alle Filmvorhaben „,vor der Verfilmung dem Reichsfilmdramaturgen im Entwurf und im Drehbuch zur Begutachtung eingereicht" werden müssen. Aufgabe des Reichsfilmdramaturgen wiederum ist es u.a., „die Filmherstellung bei dem Entwurf (Manuskript) und bei der Umarbeitung von Filmstoffen zu beraten“. (vgl. Reichslichtspielgesetz vom 16. 2. 1934, zit. nach: Albrecht, Filmpolitik, 510-511; vgl. auch: Becker, Herrschaft, 67-95) 
das „deutsche Ansehen“ zu schädigen. ${ }^{128}$ Der erste Grund läßt sich probat für jede zur Herrschaftsstabilisierung nötig scheinende Zensur nutzen, während der zweite bereits eine Umdeutung der ,nationalen Interessen* im Sinn der Rassetheorie möglich macht. Die Änderung von 1931 durch Notverordnung des Reichspräsidenten verschärft dann die politischen Möglichkeiten mit dem Zusatz der „Gefährdung lebenswichtiger Interessen des Staates ${ }^{\text {129 }}$ als weiterer Zensurgrund und etabliert mit dieser unpräzisen Formulierung einen an Willkür grenzenden Ermessenspielraum für die staatliche Stelle. Gleichzeitig setzt diese Bestimmung die liberale Formel von 1920, welche das Verbot eines Films allein wegen seiner weltanschaulichen, religiösen, sozialen, ethischen oder politischen Tendenz zumindest verbal ausschloß und die Grundlage für einen möglichen Rechtsstreit bildete, außer Kraft. ${ }^{130}$

So wird den Nationalsozialisten mit dem RLG bereits ein wirksames Kontrollinstrument in die Hände gelegt. Die nationalsozialistische Gesetzesänderung von 1934 präsentiert sich daher nur als Erweiterung, die freilich die vorhandenen Steuerungsmöglichkeiten totalisiert. Im Bereich der Verbotsgründe werden u.a. als bedeutsame Zusätze die ,Verletzung des nationalsozialistischen Empfindens' und die ,Verletzung des künstlerischen Empfindens‘ neu eingeführt. ${ }^{131}$ Schließt der erste Grund jede Kritik am Nationalsozialismus aus, und legt er überhaupt Vorsicht im Umgang mit entsprechenden Themen nahe, so schafft der zweite die Kunstfreiheit nun nicht nur theoretisch, sondern per Gesetz ab und liefert die Basis für eine juridische Normierung des Schönen. Die totalisierende ,Gemeinschaftsverpflichtung der Kunst, wie sie von der nationalsozialistischen Kunsttheorie festgelegt wird, gerät damit zum einklagbaren Zwang und wird von einer ethisch-ästhetischen zusätzlich zu einer Rechtsverpflichtung. Über die Dichotomie des Führerprinzips findet sich die Kompetenz zur Entscheidung darüber, wann das ,künstlerische Empfinden“ verletzt ist, wieder in den Händen der Führungsschicht zentriert.

\section{Zentralistisch-flexible Organisation der Zensur}

Im institutionellen Bereich wird dann die von den Reformern bereits geforderte Zentralisierung der Prüfstellen verfügt und die Zensur nach Berlin verlegt. ${ }^{132}$ Die Münchner Zensurstelle wird dadurch aufgelöst; zusammen mit regionalen Ermessensspielräumen schwinden auch die (schon seit der Zeit der Reformer beklagten) regionalen Freiheiten. Das Prüfverfahren selbst wird offen entdemokratisiert: Wo

128 \& 1 Reichslichtspielgesetz vom 12.5.1920 in: Lange, Kino, 225-230, 225

$129 \S 1$ Reichslichtspielgesetz vom 12. 5. 1920 in der Fassung vom 6. 10. 1931, zit. nach: Albrecht, Filmpolitik, 512; Becker, Herrschaft, 93

${ }^{130}$ vgl. § 1 Reichslichtspielgesetz vom 12. 5. 1920, in: Lange, Kino, 225-230. Freilich gab es auch in der Weimarer Republik bereits vor 1931 politische Zensur, zumal der genannte Passus eine von der Linken erzwungene Kompromißformel in einem recht widersprüchlichen Gesetz darstellt, die mit Berufung auf andere Passagen des Gesetzes unterlaufen werden konnte.

131 \& 7 Reichslichtspielgesetz vom 12. 5. 1920 in der Fassung vom 6. 10. 1931, zit. nach: Albrecht, Filmpolitik, 512. Der ebenfalls neu eingeführte Verbotsgrund der ,Verletzung des sittlichen Empfindens', der eine Zensur nach dem ,Kriterium' der Wahrung einer rassetheoretisch gedeuteten ,Volkssitte' ermöglicht, stellt eigentlich eine Dopplung dar. Schon die alte Gesetzesfassung nennt Filme, bei denen eine ,verrohende oder entsittlichende Wirkung' auch nur zu befürchten sei, zensurwürdig und wäre bei entsprechender, nationalsozialistischer Uminterpretation Basis genug für die genannte, sittebezogene Zensur.

132 \&16 Reichslichtspielgesetz vom 16. 2. 1934, zit. nach: Albrecht, Filmpolitik, 515 
die reformerische Konzeption noch das demokratieaffine Mäntelchen einer Organisation in Gremien trug, verfügt das nationalsozialistische RLG eine ,Entscheidungsfindung ${ }^{6}$ nach dem Führerprinzip. An die Stelle von Abstimmungen tritt das apodiktische Urteil des Vorsitzenden, der Beamter des RMVP zu sein hat. ${ }^{133}$ Neben der inhaltlichen Ausweitung der Zensurmöglichkeiten richtet das RLG von 1934 auf diese Weise eine Struktur ein, die das Eingreifen des Staats schon bei der Filmproduktion ermöglicht, und die über das Führerprinzip eine autoritäre Durchsetzung der jeweiligen staatlichen Optionen sichert. ${ }^{134}$ Damit wird ein Strukturprogramm realisiert, das von der Kinoreformbewegung bereits gefordert wurde. Deren Strukturautorität wird so in die letzte, nämlich totalitäre Konsequenz gebracht. Allerdings belastet die Bestimmung der ersten Änderung, alle Filmvorhaben schon vom Manuskript an zur zentralen Prüfung einzureichen, die Reichsfilmdramaturgie mit allzu umfänglichen Aufgaben. Am 13. 12. 1934 wird deshalb nach dem Diversifizierungsprinzip eine ,Dezentralisierung, d.h. Delegation an ,Unterführer', möglich gemacht, ohne da 3 freilich das dritte Strukturmoment des Führerprinzips, die ebenenübergreifende Zugriffsmacht aufgekündigt würde. ${ }^{135}$ Wie auch in anderen institutionellen Bereichen erkennen die Nationalsozialisten bald die Schwerfälligkeit zentralistischer Apparate und bemühen sie sich, einer entsprechenden Dysfunktionalität assimilativ zu wehren. Ihre Totalisierung gerät daher flexibler und effizienter als die reformerische.

\section{Ausschaltung der Kunstinterpretation und Einrichtung der Prädikatisierung}

Einen weiteren Schritt zum totalen Umgriff stellt dann 1936 ein Erlaß Goebbels' dar, der die Kunstkritik verbietet und durch den ,Kunstbericht' ersetzt. Das Vorgehen ist analog zur Einrichtung der ,Reichspressekonferenz;, die für die Presse insgesamt eine inhaltliche Weisungsbindung etabliert und mit ,Tagesparolen' die aktuelle publizistische Grundrichtung im Sinn der, Gleichschaltung' vorgibt. Der ,Kunstbericht‘ dehnt dies auf die ,kunstexegetische' Publizistik aus und nimmt damit auch für den Film jede wertbezogene Interpretation der ohnehin schon gelenkten Produktionen in staatlich-parteigebundene Zuständigkeit. ${ }^{136}$ Kunstkritik gilt als nicht länger ,private', sondern „öffentliche (...) Aufgabe, die (...) der nationalsozialistische Staat und die nationalsozialistische Weltanschauung stellen ${ }^{\star 137}$, d.h. als ideologisch verpflichtetes Unterfangen, das ebenso wie die Kunst selbst aus der subjektiv-expressiven in die kollektive Sphäre rückverlagert ist. Die Interpretation von Kunst wird auf diese Weise der Ideologieverpflichtung unter der Maxime des Gemeinschaftsprinzips unterstellt. Mit der Requirierung der normativen Macht durch die Führungsriege, welche die Vorgaben für die Kunstexegetik liefert, wird dabei zugleich die Dichotomie

$133 \S \S 17$ u. 18 Reichslichtspielgesetz vom 16. 2. 1934, zit. nach: Albrecht, Filmpolitik, 515; vgl. auch: Albrecht, Filmpolitik, 25

134 vgl. dazu auch: Albrecht, Filmpolitik, 25

135 Die ,Muß'-Vorschrift des Gesetzes wird am 13. 12.1934 bereits in eine ,Kann'-Vorschrift geändert. Stattdessen wird eine Meldepflicht für alle Filmvorhaben eingeführt. Als 1935 auch diese Meldepflicht aufgehoben wird, bietet inzwischen die Personalpolitik die Gewähr ideologietreuer Produktion; zudem bleibt die Möglichkeit direkten Zugriffs des Reichsfilmdramaturgen erhalten. (vgl. Albrecht, Filmpolitik, 25-26; Becker, Herrschaft, 67-95)

136 vgl. Erlaß vom 26. 11. 1936, in: Glaser, Reich, 79; Albrecht, Filmpolitik, 27-28

137 Weiß, Wilhelm, Kritik der Kritik, in: Deutsche Presse 1935/51/52, zit. nach: Kliesch, Filmkritik, 19 
des Führerprinzips wirksam und die Gemeinschaftsverpflichtung zur führungsorientierten Funktionalisierung der Kunstkritik für das Social engineering umgebogen.

Als weiteres Steuerungsinstrument bauen die Nationalsozialisten dann die Vergabe von Prädikaten, die bereits zur Zeit der Weimarer Republik von der ,Bildstelle des Zentralinstituts für Erziehung und Unterricht' sowie der ,Bayerischen Lichtbildstelle' vorgenommen wurde, zum zentralisierten System aus. Das RLG verankert die Zuständigkeit beim Staat und sorgt für eine institutionelle Identität von Zensur und Prädikatisierung. ${ }^{138}$ Auch dieses Vorgehen bedeutet letztlich eine Fortführung und Perfektionierung von strukturellen Möglichkeiten, die von den Reformern und der Weimarer Republik bereits vorgegeben wurden. So trägt beispielsweise das Prädikat ,volksbildend wertvoll' der Bildungsverpflichtung Rechnung, die im Kontext reformerischer Agitation zu einer Art selbstverständlichem Anspruch an die Filmproduktion geworden ist, oder erinnert das Prädikat ,kulturell wertvoll' an die kulturativen Intentionen der Kinoreformbewegung. Freilich legen sich die Prädikate spezifisch nationalsozialistisch aus: ,Volksbildend' ist, was etwa im Sinn der Geschichtsklitterung der ,historischen Spielfilme‘ der Ideologie von der historisch verbürgten ,Volksgemeinschaft' nützt, und als kulturell wertvoll gilt, ähnlich dem als ,künstlerisch wertvoll prädikatisierten Material, was das nationalsozialistische Kunst- und Kulturkonglomerat transportiert. Mit den Prädikaten ,staatspolitisch wertvoll' und später (um dieses Prädikat noch überbieten zu können) ,Film der Nation' liegt das nationalsozialistische Prädikatisierungsverständnis dann offen zu Tage. Ausgezeichnet werden Filme, die der politischen Lenkung des Publikums und dem Social engineering dienlich sind und die als beispielgebende Richtschnur für die Filmproduktion dienen sollen.

\section{Sukzessive Verstaatlichung}

Von den Reformern freilich wurden die Chancen einer ,positiven' Beeinflussung des Filmschaffens durch prädikatisierende Förderung noch als schwaches Instrument eingeschätzt, solange die Produktion nicht gänzlich in den Händen des Staats zentralisiert und jede Abweichung derart verhinderbar gemacht ist. Auf der Linie dieser Logik liegt daher auch das weitere Vorgehen der Nationalsozialisten, die sich ab 1937 um eine sukzessive mittelbare Verstaatlichung der wesentlichen Teile der Filmindustrie bemühen. Entsprechend der Flexibilisierung, jedoch auch der Assimilation an die ökonomischen Verhältnisse, findet diese Verstaatlichung verdeckt und unter Aufrechterhaltung der Führungsdiversifizierung statt. Verschleiert durch die von Winkler geleitete Cautio-Treuhandgesellschaft, die nach den Weisungen des RMVP und des Reichsfinanzministers arbeitet, sichert sich der Staat die Aktienmehrheit der Ufa und bringt auch die Verleihe Terra und Tobis-Rota sowie die Tobis-Filmkunst und den Bavaria-Konzern unter seine Verfügungsmacht. ${ }^{139}$ Nicht nur über die RFK und den Reichsfilmdramaturgen, sondern auch über das ,Büro Winkler' sind so die größten Firmen an die Weisungen des RMVP gebunden, ohne daB der Organisationszusammenhang die Gestalt eines deutlich sichtbaren schwerfälligen

${ }^{138}$ vgl. Albrecht, Filmpolitik, 24; Becker, Herrschaft, 96-98

139 Ausführlich dargestellt finden sich die Einzelschritte bei Becker, Herrschaft, 128-230 und Spiker, Kapital. 
Apparats annähme. ${ }^{140} 1942$ wird die Verstaatlichung dann mit der Gründung der Ufa-Film GmbH (einer Neuschöpfung, die mit der Ufa-Filmkunst GmbH nicht zu verwechseln ist) als einer übergreifenden Organisation vollendet. Zugleich wird damit die Stelle eines ,Reichsfilmintendanten“ eingerichtet, dem „die allgemeine Produktionsplanung, die Ausrichtung der künstlerischen und geistigen Gesamthaltung der Produktion und (...) die Überwachung des künstlerischen Personaleinsatzes und der Nachwuchserziehung “141 obliegt. Damit erfolgt die Steuerung und Überwachung der Filmproduktion nun über vier Institutionen: die Reichsfilmkammer, den Reichsfilmdramaturgen, den Reichsbeauftragten für die deutsche Filmwirtschaft (Büro Winkler) und den Reichsfilmintendanten, die letztlich alle Goebbels unterstehen. ${ }^{142}$ Auf diese Weise wird jede der drei Komponenten des Führerprinzips in dieser Struktur verwirklicht. Goebbels Oberherrschaft sichert die ebenenübergreifende $\mathrm{Zu}-$ griffsmöglichkeit im Sinn der Zentralisierung, die relative Autonomie der Autorität jedes ,Unterführers' nach unten erlaubt rasche, situationsspezifische Entscheidungen im Sinn der Flexibilisierung und die Besetzung der Leitstellen mit Beamten des RMVP, bzw. ideologisch ,verläBlichen' Personen garantiert die Linientreue bei Diversifizierung der Führungsverantwortung.

\section{Die nationalsozialistische Filmorganisation als strukturelle Realisierung der generellen Ordnungsprinzipien}

Die eingangs angestellte Überlegung, daß der Nationalsozialismus in seiner Filmorganisation die Prinzipien seiner Gesellschaftstheorie zu realisieren sucht sowie daß er hierbei auf Vorgaben rekurrieren kann, die von den Reformern mitkonstituiert wurden, bestätigt sich so. Gleichzeitig läßt sich aus dem skizzierten Prozeß erheben, $\mathrm{da} B$ es die beiden Zielrichtungen der nationalsozialistischen Medienpolitik sind, die von der strukturellen Organisation gesichert und durchsetzbar gemacht werden sollen. Das zeigt sich zunächst in der organisationsstrukturellen Verwendung des Führerprinzips. Mit ihm versuchen die Nationalsozialisten, sukzessive das (ja bereits vor 1933 existente und in gefestigten Strukturen etablierte) Film-business auf eine Weise in den Griff zu bekommen, die es zu einem plastischen, steuerungsfunktional einsetzbaren Instrument umformt. Zu diesem Zweck realisieren sie zunächst eine primäre Forderung der Reformer, nämlich die der Einrichtung und Zentralisierung einer staatlichen Produktionsüberwachung und -mitgestaltung. Sie erkennen jedoch bald die kontraproduktive Schwerfälligkeit dieses Vorgehens und ersetzen es durch eine assimilative Strategie, die über Diversifizierung des Führerprinzips die nötige Flexibilität und zugleich die Wahrung des Kompetenzmonopols erreichen will. Im Hintergrund der Anpassungstrategie steht freilich unverändert die kontramoderne Gesamtausrichtung, die nicht zuletzt über die ,berufsständische‘ Organisation ihr re-

${ }^{140}$ vgl. Albrecht, Filmpolitik, 30; Weisungen erfolgen selten auf den Briefbögen der Cautio, sondern mit Winklers Briefkopf. Den Verschleierungscharakter der Strategie der mittelbaren Verstaatlichung macht Goebbels in seiner Rede vor den Filmschaffenden am 15. 2. 1941 selbst deutlich (vgl. Abdruck in: Albrecht, Filmpolitik, 465-479, 472).

${ }^{141}$ Erlaß des Reichsministers für Volksaufklärung und Propaganda zur Steigerung der Leistungsfähigkeit des deutschen Filmschaffens vom 28. 2. 1942, zit. nach: Albrecht, Filmpolitik, $529-530,530$

142 vgl. Albrecht, Filmpolitik, 32-33 
gressives Paradigma offenbart. Ausschlußverfahren aus und soziale Zementierung in der ,berufsständischen' Organisation veranschaulichen dabei erneut, daß die kontramoderne Position unter neuzeitlichen Bedingungen sich nur durch Totalisierung des Umgriffs und Elimination aller Dissidenten durchzusetzen versuchen kann und daß sie ihren ,historischen Irrtum' selbst mit einem hohen Aufwand bezahlt. Sie kann jedoch, wie ebenfalls deutlich wurde, 1933 bereits auf eine Reihe von Vorgaben durch die Weimarer Republik und die Reformer zurückgreifen. Als wichtigste Vorgabe erwies sich dabei das RLG, dessen Fassung von 1931 nur noch einiger Ergänzungen bedarf, um vollständig für die Ziele der Nationalsozialisten dienstbar zu sein. Die Realisierung einer steuerungsfunktionalen Struktur sowie die Requirierung der Nutzungsrechte an derselben durch den Staat und seine Maximen ist somit zusammen mit der kontramodernen Ausrichtung und den totalitären Konsequenzen vor 1933 schon präformiert. Die Präformation und ihre Realisierung aber zielen auf die zweite medienpolitische Absicht der Nationalsozialisten, nämlich die Nutzung der Medien für ein gemeinschaftssteuerndes Social engineering.

Neben der Umsetzung dieser Absicht über das Führerprinzip läßt sich in der Erweiterung der Zensurbestimmungen des RLG um die ,Verletzung des künstlerischen' sowie des ,nationalsozialistischen Empfindens' und die Ersetzung der Kunstkritik durch den ,Kunstbericht' erkennen, daB auch die erste medienpolitische Maxime der Nationalsozialisten strukturbezogen realisiert wird. Eingesetzt wird hierbei das kunstnormativ gewendete Gemeinschaftsprinzip und sein bereits gesellschaftstheoretisch zu Tage getretener totalisierender Charakter. So wird mit diesem einerseits eine Verpflichtung der Kunst auf die Normen der Gemeinschaft vorgenommen, andererseits diese Normativität ,kultursachbereichsextern' festgelegt. Den Kunstnormen des Nationalsozialismus gehorchend und auf seine Weltdeutung verpflichtet soll der Film der ideologietreuen Konstitution der Gemeinschaft dienen. Seine Interpretation wird über den ,Kunstbericht' ebenfalls der Ideologietreue unterstellt. Damit aber ist auch die genannte erste medienpolitische Maxime, nämlich die Ideologieverpflichtung zum Zweck der Gemeinschaftsformierung strukturell festgeschrieben und verwirklicht. Insgesamt bestätigt so die Nachzeichnung des Prozesses der nationalsozialistischen Filmorganisation außer der kontramodern-assimilativen Generalstrategie einer führungsfunktional-totalitären, statifizierenden Reorganisation der Gesellschaft und außer den Rückbezügen zu den Reformern auch die zentrale Stellung und faktische Verwendung der von mir erarbeiteten beiden medienpolitischen Maximen. Diese können deshalb als die eigentlichen Angelpunkte der nationalsozialistischen Filmpolitik und ihrer zugehörigen Medienethik gelten.

\subsection{Nationalsozialistische ,Medienethik' und reformerisches Erbe}

Aus dem vorangehend Erarbeiteten läßt sich nun die Medienethik der Nationalsozialisten zusammenfassend rekonstruieren und mit der reformerischen kontrastieren. Wie die Filmpolitik sehe ich diese Medienethik in zwei Bereiche zerfallen bzw. genauer: sich als auf zwei Ebenen angesiedelt zeigen. Zunächst nämlich konstruiert sie sich, wie ich ausführen will, im Konnex mit der prinzipiell-reflexiv als Filmtheorie gefaßten Filmpolitik, die sich der generellen Ordnungsprinzipien des Nationalsozialimus bedient, aus den ethischen Maximen eben dieser Prinzipien. Sie erscheint auf 
einer Theorieebene daher als Prinzipienethik, die ich näherhin als deontologische charakterisieren werde. Daneben aber läßt das tatsächliche Verhalten des Nationalsozialismus in Sachen Film nicht nur auf andere oder jedenfalls zusätzliche, filmpolitische, sondern auch auf differierende ethische Maximen schließen. Dieses Verhalten nämlich weicht, wie die Analyse der Filmpolitik gezeigt hat, von den generellen Prinzipien und ihren Maximen ab und vollzieht in der Praxis eine andere Akzentsetzung, wenn nicht gar eine Revision der prinzipiellen Maximen. Die eingangs angestellte methodologische Überlegung, da $B$ aufgrund der generellen Differenzen und Spannungen zwischen nationalsozialistischer Theorie und Praxis auch für eine verläßliche Rekonstruktion der nationalsozialistischen Medienethik eine exklusive Konzentration auf die Theoriegeschichte (als Prinzipienkonstitution) nicht hinreicht, wird so von der analogen Situation in der Rekonstruktion der filmpolitischen Maximen unterstützt. Ebenso wie dort will ich deshalb auch für die Medienethik die dem faktischen filmpolitischen Verhalten zugrunde liegenden Optionen berücksichtigen. Für die Filmpolitik nun habe ich darauf verwiesen, da 3 auf der faktischen Ebene eine funktionale Flexibilisierung nach Nutzenmaximen stattfindet. Das legt es nahe, als medienethische Grundfigur einen Utilitarismus anzusetzen, den ich näherhin als totalitären charakterisieren werde. Die nationalsozialistische Medienethik scheint mir also zunächst auf zwei Ebenen parallel konstruiert zu werden, nämlich einer prinzipiengeleiteten Theorieebene und einer von Nutzenmaximen determinierten Praxisebene. Neben der Entfaltung der zugehörigen ,Ethiktypen' will ich daher auch Verbindung und Kontrast beider Ebenen reflektieren. Die Flexibilisierung im zweiten Fall verweist dabei darauf, daß diese Verbindung und der Kontrast aus dem nationalsozialistischen Versuch einer Beherrschung und vereinnahmenden Nutzung der modernen Dynamisierungsprozesse begreifbar sein könnten.

\section{Die Ebene der rassistisch-deontologischen Prinzipienethik}

Die deontologische Prinzipienethik wird zunächst in einer generellen, nicht allein medienbezogenen Grundfigur über das ,rassetheoretisch' gefüllte Gemeinschaftsprinzip und seine ethische Maxime der Gemeinschaftsverpflichtung installiert. Mit der ,Rassetheorie' wird sie natural-ontologisch fundiert, und mit der ethischen Maxime wird diesem Fundament ein sittlicher Sollenscharakter verliehen. So legt die ,Rassetheorie zunächst das ,wahre Wesen' der Gemeinschaft in einem ,Rassekern' fest. Dieser gilt als ,genetisch verbürgtes materielles Substrat, erweist sich jedoch genau besehen als spekulativ-eklektizistische Ansammlung von Charakeristika, die derart den Status anthropologischer Grunddaten erhalten und unhintergehbar gemacht werden. Da der in dieser Weise definierte ,Rassekern' als nur wurzelhaft, aber nicht vollständig phänomenal realisiert gilt, geraten die genannten Grunddaten zugleich zu normativen Zieldaten, in denen die innerste ,Entelechie' der Gemeinschaft gesehen wird. Die Verwirklichung dieser Entelechie wiederum wird zur primären Aufgabe für die Gemeinschaft wie den Einzelnen erklärt, und die Gemeinschaftsverpflichtung wird so prinzipiell material gefüllt. Als oberste Sollensvorschrift erscheint damit die Verpflichtung zur Herausarbeitung und Realisierung der erst in nuce vorhandenen Zielgemeinschaft und ihrer Eigenschaften. Sie gilt als generelle Verpflichtung für alle Handlungsbereiche der Gemeinschaft und ist unbedingt, d.h. sie setzt sich als prinzipielle, deontologische Norm. Der deontologische Charakter ergibt sich dabei aus der 
ontologisierenden ethischen Argumentationsfigur. Wie im Zusammenhang mit der Kunsttheorie zu sehen war, arbeitet diese mit einer Sein-Sollens-Identität, die aus dem natural-ontologisch bestimmten Sein das Gesollte unmittelbar deduziert und derart die Ontologie mit der Ethik identifiziert. Durch die Ineinssetzung der gesollten Zieldaten mit ontologisierten Grunddaten aber wird das Gesollte zum ausdefinierten Programm, das keinen Spielraum für Kontingenzen, Modifikationen oder Kreativität läßt, und das so Unbedingtheitscharakter erhält, d.h. als gesolltes zum unbedingt verpflichtenden gerät. Für die Mitglieder der realen zeitgenössischen Gemeinschaft bedeutet das, daß die Zielgemeinschaft von ihnen in keiner Weise ,miterfunden', sondern nur durch Realisierung des vorgegebenen Daten- und Eigenschaftskanons herauskristallisiert werden kann und daB der geforderte moralische Habitus der der Submission ist. Diese deontologische Konzeption setzt so eine grundsätzliche Dichotomie von unbedingter Vorschrift auf der einen und unbedingtem Gehorsam auf der anderen Seite an. Dem korrespondiert auf der Ebene der nationalsozialistischen Gesellschaftstheorie die Dichotomisierung der Gemeinschaft mit dem Führerprinzip in Führer und Geführte und im Bereich der zugehörigen,Sozialethik' die Aufspaltung der Gemeinschaftsverpflichtung in eine Führungsverpflichtung (der vordringlich ein Führungsrecht zur Seite gestellt ist) und eine Gefolgschaftsverpflichtung. Führungspflicht und -recht werden, wie zu sehen war, mit der Naturalontologie als autokratische und unbedingte gefaßt, während die Gefolgschaftsverpflichtung zur blind deontologischen erklärt wird. Damit ist der moralische Habitus der Submission auf das sittliche Verhältnis der Geführten zu den Führern ausgedehnt und in der durch ihre Deontologie bereits formallogisch dichotomisierten ethischen Konzeption der Status der moralischen Subjekte ebenfalls dichotomisch bestimmt. Die Deontologie wird dabei in eine ,Zwei-Klassen-Ethik' überführt. Im ganzen erweist sich die so angesetzte, natural-ontologisch fundierte und über das Gemeinschafts- und das Führerprinzip ausgeführte Ethik daher als statische, einzig im Modus von Befehlsgewalt und Pflichtgehorsam denkbare, entwicklungslose, deontologisch-dichotomische Prinzipienethik.

Die Verpflichtungen dieser Prinzipienethik werden dann zunächst auf die Kunst übertragen und über die Kunsttheorie in Einzelnormen für das Kulturschaffen ausgelegt. Das argumentative Paradigma bleibt dabei dasselbe. Mit Rückbezug auf den ,Rassekern', der nicht nur für die Erhebung anthropologisch-typologischer und charakterlicher Eigenschafien der ,Herrenrasse' genutzt wird, sondern auch als Wurzelgrund kultureller Spezifika gilt, wird unter Beiziehung eines kunsthistorischen Eklektizismus ein ästhetischer Kanon konstruiert und normativ verbindlich gemacht. Seine Realisierung gilt zunächst als für die Schaffung einer ,authentischen', weil gruppenspezifischen Kunst notwendig. Diese ,kanonische Kunst' wird jedoch dann dem rassenontologischen Ansatz gemäß zugleich als für die gruppenspezifische Hominisierung erforderlich ausgelegt und so ebenfalls für die Herstellung der Zielgemeinschaft in Dienst genommen. In der Kunst nämlich soll die ,Rassespezifität' in gemeinschaftsformierender Absicht repräsentativ realisiert und die Gemeinschaft durch solche Formierung auf ihren Zielcharakter hin orientiert werden. Der letztgenannte soll deshalb von der Kunst formal und inhaltlich vor Augen gestellt werden. Insofern die Herstellung dieses Charakters zugleich als sittliche Pflicht gehandelt wird, erhalten dann die formalen und inhaltlichen Kunstnormen ebenfalls sittlichen Sollenscharak- 
ter. Sie sind derart nicht nur durch die Ontologisierung als statisches, entwicklungsloses Gefüge sachspezifischer Präformationen festgelegt, sondern zugleich über das Grundprinzip der Gemeinschaftsverpflichtung auf die kunstexterne Aufgabe der Gemeinschaftsformierung heteronom verpflichtet und selbst ethisiert. Weiter war zu sehen, daß die Gemeinschaftsherstellung auch als politische Aufgabe gehandelt und Kunst derart zum politisch verpflichteten Instrument gemacht wird. Sie wird damit sowohl politischen Normen unterstellt, als auch zur politisch-normativen Formierung genutzt. Das verdeutlicht zum einen erneut die spezifisch nationalsozialistische Grenzauflösung zwischen politischer, sachspezifischer und sittlicher Normativität, d.h. den grundsätzlich totalitären Charakter der nationalsozialistischen Prinzipienethik. Zum anderen zeigt das ontologisch-exklusive Vorgehen bei der Erhebung der konkreten Kunstnormen aus der Rassenontologie bzw. ,rassetheoretisch` ideologisierten Kunstgeschichte, mit dem diese Normen als Wesensbestimmungen einer angeblich gruppenspezifischen Kunst festgeschrieben werden, daß auch die diesbezüglichen Einzelnormen der Prinzipienethik keineswegs nur bedingte, in der konkreten Einlösung modifizierbare Zielgrößen, sondern deontologisch verpflichtende sind. Die Ontologisierung nämlich macht sie wiederum zum unhintergehbaren Programm, dessen Gruppenspezifität jede Grenzüberschreitung noch zusätzlich untersagt, und stellt die Kunst so unter unbedingte normative Einzelverpflichtungen. Zum dritten aber bedeutet die heteronome, sittlich-politische Indienstnahme der Kunst für die Herstellung der Zielgemeinschaft durch Vorausdarstellung ihrer Eigenschaften zugleich eine Verpflichtung auf Sinnstiftung und Identitätsschaffung. Diese vollziehen sich vor allem durch thematische und inhaltliche Appräsentation der ,rassetheoretisch' festgelegten gruppenspezifischen Wesenszüge, charakterlichen Eigenschaften und Lebensformen. So trat in der Analyse der Kunsttheorie vor Augen, daß die ,Rassespezifität' neben der stilistischen Normierung auch zu Themenvorgaben führt, die von der Agrarromantik bis zum ,arttypischen Heroismus' und seiner Konkretion in Kriegsdarstellungen reichen können. Die Kunst wird auf diese Weise nicht nur formbezogen ideologisch in Dienst genommen, sondern auch inhaltlich ideologieverpflichtet, d.h. auf Vermittlung einer Botschaft, nämlich der nationalsozialistischen ,Weltdeutung' festgelegt. Sie wird derart für eine politisch-gemeinschaftsformierende sowie lebensweltprägende Sinn- und Identitätskonstitution heteronom gebraucht und in die totalitäre Struktur eingespannt.

Die so grundgelegte und kunstnormativ ausgefaltete Prinzipienethik wird schließlich auf den Film übertragen und derart zur Medienethik gewendet. Auch der Film nämlich soll, wie die Filmtheorie Goebbels' und Hipplers gezeigt hat, der Herstellung der Zielgemeinschaft dienen und wird hierzu den rassenontologischen und kunstnormativen Forderungen unterstellt. Obschon bei Hippler zu sehen war, daß er die Gemeinschaft als normative Instanz für den Film einführt, und ihn derart zunächst den von der Gemeinschaft definierten Zielen zuordnet, zeigten sich diese Ziele ja wieder als die der Rassenontologie und der Kunsttheorie, d.h. im Letzten als die ideologisch vordefinierte Zielgemeinschaft und ihre Realisierung. Auf diese soll der Film ebenso wie die Kunst durch Appräsentation ,rassespezifischer ${ }^{`}$ Ästhetik und durch Transport der nationalsozialistischen Ideologie hinarbeiten, d.h. er soll der Vermittlung des heterogenen Konglomerats der, nationalsozialistischen Weltanschauung' dienen, die sich über die ,Rassetheorie' charakterlich-eigenschaftsbezogen 
auslegt und im Gemeinschafts- und Führerprinzip sowie deren jeweiligen anthropologischen, ästhetischen, moralischen und politischen Füllungen gipfelt. Der Film wird so einerseits diesen Prinzipien und Theoremen normativ unterworfen und andererseits zugleich zu deren staats-, gesellschafts- und lebensweltprägendem Medium, also einem selbst normativ wirksamen Transportmittel erklärt. Seine normative Wirksamkeit freilich ist wieder als Realisierung vorgegebener ideologischer Gehalte gedacht und jede kreative Mitschöpfung derselben ist ausgeschaltet. Die präformative Figur der deontologischen Dichotomie scheint damit in dieser Funktionsverpflichtung wieder auf. In ihrem Sinn soll der Film mit seinen Inhalten, wie vor allem für den historischen Spielfilm sichtbar wurde, weiter die Konstruktion und Beförderung eines gruppenspezifischen Selbstverständnisses, d.h. eine ideologische Identitätskonstitution betreiben. Wie die Kunst wird er auf diese Weise zur Sinnvermittlung und politisch-gesellschaftlichen Formierung herangezogen, d.h. ,kultursachbereichsextern' heteronomisiert und in die totalitäre Struktur gespannt. Damit setzt die nationalsozialistische Prinzipienethik eine totalitär-gemeinschaftsformierende, Sinnund identitätsstiftende Funktion und Wirkung auch für den Film als medienethisch gebotene an und leitet sie diesen Gebotscharakter zusammen mit den gebotenen Formen und Inhalten aus ihren natural-ontologischen Ordnungsprinzipien bzw. deren ethischen Maximen und aus kunsteklektizistischen Ideologemen her. Die letztgenannten freilich besitzen, wie genaueres Zusehen zeigt, wenig Kohärenz und Realitätsgehalt, sondern stellen letztlich eine dezisionistische Spekulativität vor, die ihre Kriterien beinahe wahllos zusammenstellt und über ihren eigentlichen Gehalt hinausdehnt. Das ist besonders in den ,rassetheoretischen' Behauptungen einer genetischen Verbürgtheit konkreter Charaktereigenschaften, wie etwa des ,arttypischen Heroismus', oder auch in der schlicht willkürlichen Verknüpfung diverser Kunststile zum Kanon über den hypostasierten ,Rassekern' deutlich. Die nationalsozialistische Prinzipienethik, die derart auf argumentativ inkohärenten, nur durch Behauptung gesetzten und so in ihrem Geltungsanspruch ideologischen Prämissen beruht, erweist sich deshalb selbst als Ideologie.

\section{Die Ebene des totalitären Utilitarismus}

Während diese ideologisch-deontologische Prinzipienethik auf der Theorieebene dennoch großes Gewicht bewies, zeigte sich auf der Praxisebene, daß die nationalsozialistische Filmpolitik dort anderen Prämissen folgt, damit aber auch auf anderen oder zumindest zusätzlichen medienethischen Maximen fundiert sein muß. Der Film wurde hier vordringlich einer Verschleierung unliebsamer Entwicklungen sowie skandalöser und deshalb sozialunverträglicher Politik dienstbar gemacht, zur gezielten Desinformation eingesetzt oder für eine ersatzweise Bedürfnisbefriedigung und rekreative Stabilisierung genutzt, d.h. er wurde deflektorisch, desorientierend und kompensativ gebraucht. In all diesen Fällen läßt sich dahinter kaum ein Interesse ,konstruktiver' Ideologievermittlung, der identitätsbildenden Gemeinschaftsformierung oder der Herstellung der Zielgemeinschaft finden. Vielmehr geht es um Stimmungsregulation, Ablenkung und Realitätsdiffusion, deren ,Gebotenheit' aus mehr oder weniger kurzfristigen Entwicklungen und aktuellen Gegebenheiten, die weder idologische noch filmspezifische sind, hergeleitet wird. In der faktischen Filmpolitik entdeckte sich daher vordringlich die Absicht eines Social engineering, d.h. ein 
Steuerungsinteresse, das zunächst kein prinzipienethisch festgelegtes Ziel zu verfolgen scheint. Vielmehr zeigt sich in diesem Social engineering ein Bündel von je und je wechselnden Einzelabsichten, die nur schwer unter ein übergreifendes, durchgängig wahrnehmbares Ziel subsumierbar scheinen. Ich habe daher für die Grundfigur dieses Teils der faktischen nationalsozialistischen Filmpolitik von einer steuerungsfunktionalen Zweckorientierung gesprochen, die auch als herrschaftsfunktionale bezeichnet werden könnte. Ihre Maximen ergeben sich aus den jeweiligen Notwendigkeiten der gesellschaftlichen Stimmungslage, der aktuellen politischen Erfordernisse und der vagierenden Kompensationsbedürfnisse. Sie sind damit jeweils konkrete Nutzenmaximen, d.h. utilitäre Normgrößen. Sucht man also in der faktischen Filmpolitik die zugrunde liegende Medienethik, so kann dieselbe deshalb als utilitaristische bestimmt werden. Ihr generelles ,Prinzip“ lautet, da $B$ gut und geboten sei, was nutzt, wobei dieser Nutzen jeweilig und situationell bestimmt wird. Die generelle ,ethische' Sollensvorschrift dieser utilitaristischen Medienethik ist so eine rein formale Bestimmung, ein Formalprinzip, dessen inhaltliche Konkretion zu Einzelvorschriften kontingent erfolgt.

Die utilitaristische Nutzenfestlegung aber bemüht sich mit ihrer situationsspezifischen Orientierung um einen flexibilisierten Umgriff, der sie zum einen als totalitären Utilitarismus enthüllt und zum anderen eine mittelbare Rückbindung die Ebene der Prinzipienethik erkennen läßt. Totalitär ist dieser Utilitarismus zunächst, weil er sich mit seiner steuerungsorientierten, situationsspezifischen Nutzenbestimmung letztlich auf einen totalen Umgriff der zu steuernden Situation und ihrer eigentlichen Subjekte richtet. Die Flexibilisierung nämlich soll ja eine möglichst nahtlose Adjustierung des Films an die jeweiligen Gegebenheiten erlauben, um diese dann deflektorisch, kompensativ oder desorientierend in Griff $\mathrm{zu}$ bekommen und zu verändern. Ziel ist eine vollständige, funktionale, heteronome Beherrschung der jeweiligen individuellen, sozial-gesellschaftlichen und politischen Befindlichkeiten zum Zweck eines totalen Social engineering, das der gesteuerten Sozialität weder Raum zu reflexiver Distanz und abweichenden Außenstandpunkten noch zur Mitsprache einräumt. Damit steht der Utilitarismus zusammen mit seinem Formalprinzip selbst nochmals unter einem nicht von ihm selbst konstituierten Prinzip, nämlich dem der totalen Herrschaft, die den obersten ,Nutzen' bildet. Über diesen ,Nutzen' aber ist er schließlich zugleich wieder, wenn auch nur mittelbar, an die Ebene der Prinzipienethik angeschlossen. Dort nämlich wurde, wie zu sehen war, über das Führerprinzip ein autokratisches Führungsrecht zusammen mit einer Führungspflicht von einer deontologischen Gefolgschaftsverpflichtung unterschieden. Eben diese prinzipiell festgeschriebene autokratische Führung nun legt sich über den totalitären Utilitarismus als autokratisches Steuerungsunterfangen aus. Wird auf der Ebene der Prinzipienethik eine Art ,metaethische', nämlich natural-ontologische Legitimation und Grundlegung des Führungsrechts bzw. der Führungspflicht vollzogen, so findet damit auf der Ebene des totalitären Utilitarismus gewissermaßen die ,kontingenzspezifische ethische Konkretion bis zu Einzelmaximen statt. Wie die ,Nutzenmaxime' der totalen Herrschaft dem metaethisch-legitimativ festgelegten autokratischen Führungsrecht korrespondiert und dieses ,einlöst', so korrespondiert der prinzipienethisch definierten deontologischen Gefolgschaftsverpflichtung der totale heteronom-fremdbestimmende Steuerungsumgriff und stellt deren ,Einlösung sozusagen zwangsweise her. 
Insgesamt läßt sich der totalitäre Utilitarismus so zwar nicht als vollständige, konkretisierende Umsetzung der Prinzipienethik lesen, doch erhält er durch seinen Konnex mit der ethischen Wendung des Führerprinzips eine zumindest partielle Rückbindung an deren Ebene. Die beiden Ebenen bleiben damit deckungsungleich, zeigen sich jedoch durch die skizzierte Korrespondenz als keineswegs verbindungslose.

\section{Die kontramoderne Position des Nationalsozialismus als Wurzel der Aufspaltung der beiden Ebenen}

Die Aufspaltung der nationalsozialistischen Medienethik in zwei partiell verknüpfte Ebenen nun scheint mir weiter eine Folge der kontramodernen Gesamtausrichtung des Nationalsozialismus bei gleichzeitigen partiellen Assimilationsversuchen an die moderne Dynamisierung zu sein. So stellt zunächst die Prinzipienethik durchaus entsprechend der kontramodernen Gesamtausrichtung ein statifizierendes und regressives, letztlich selbst kontramodernes Unterfangen dar. Wie zu sehen war, überspringt die ethische Maxime des Gemeinschaftsprinzips ebenso wie dessen gesellschaftstheoretische Anwendung den sozialen Wandel und die aus der Dynamisierung entspringenden sozialen Differenzen und Spannungen durch ihr ethisch-integratives Bemühen. Sie versucht damit kontramodern statifizierend zu wirken und soziale wie sittliche Konflikte negierend auszuräumen, d.h. aber zugleich: die Konstitution von Binnenmoralen zu verhindern, welche als Begleiterscheinung moderner Autonomisierungs- und Diversifizierungsprozesse gelesen werden können. Die nationalsozialistische Grundvorstellung ist im Unterschied hierzu die eines geschlossenen, hierarchischen Gesellschaftskörpers, dem ein geschlossenes Pflichtethos korrespondiert. Sie ist damit dem mittelalterlichen Ordo-Denken verwandt und vorneuzeitlich. In ähnlicher Weise zeigt sich auch die ethische Ausformung des Führerprinzips als vorneuzeitliches Unterfangen. Mit seiner dichotomischen Gliederung der Rechte und Pflichten sowie mit der deontologischen Festschreibung von Verantwortungen stellt dieses Prinzip in seinen ethischen Maximen gleichfalls auf kontramoderne Statifizierung ab und will es die gesellschaftliche Gliederung in Führer und Geführte ethisch zementieren. Es setzt sich, wie zu sehen war, derart der modernen Demokratisierungstendenz entgegen und versucht, diese auch auf der ethischen Ebene zu konterkarieren. Nicht anders verhält es sich mit den normativen Auslegungen der Prinzipien für die Kunst und den Film. In beiden Fällen wird als Maxime die deontologische Verpflichtung auf die Hervorbringung der fest umrissenen Zielgemeinschaft durch Realisierung vorgegebener Charakteristika und Befolgung unumstößlicher Vorschriften festgelegt, also eine pluralismen- und kreativitätsfeindliche, antiautonomistische Statifizierung beabsichtigt. Zusammen mit den ,integrativ-statifizierenden' Versuchen des Überspringens von Dynamisierung und Diversifizierung sowie ihren gesellschaftlich-strukturellen und ethosbezogenen Folgen zeigt sich die Prinzipienethik damit als durchgängige, kontramoderne Deontologie, welche durch Beseitigung jeder sittlichen Kreativität und jeder Legitimität eigenverantwortlicher Normschöpfung, ja sogar jeder derartigen Normanpassung, auf Nivellierung, Submission und einen Gehorsamshabitus zielt. Sie stellt sich letztlich gegen die vom Projekt der Moderne intendierte Subjektivierung und die Freisetzung der vormals in statische Weltdeutungskonzepte bzw. Normgerüste eingebundenen Individuen. Ihre diversifizierungsfeindliche Statifizierung und Zementierung wirken sich deshalb trotz der 
ständigen Betonung von Verantwortung letztlich verantwortungsverhindernd aus und erzeugen eine moralische Regression. An die Stelle selbstverantwortlicher, sittlichreflexiver Subjekte treten die Befehlsempfänger vorgegebener Normen. Die deontologische Prinzipienethik entspricht aus diesen Gründen allenfalls noch einer ständischen, nicht aber einer auf Flexibilität, Selbstverantwortung und die Autonomie sittlicher Vernunft gebauten Gesellschaft. - Parallel zu seiner kontramodern-statifizierenden Ausrichtung aber versucht der Nationalsozialismus, wie die Flexibilisierung des Führerprinzips gezeigt hat, eine Assimilation an die modernen Dynamisierungsprozesse vorzunehmen. Absicht dieser Assimilation ist, wie ebenfalls an dieser Flexibilisierung zu sehen war, keineswegs eine echte Integration der Dynamisierung in die eigene Gesamtkonzeption oder gar eine Modifikation der letztgenannten, sondern gerade die Sicherung der kontramodernen Ausrichtung durch einen feinstrukturellen, totalen Umgriff. Eben dies wiederum geschieht auf der ethischen Ebene auch durch das Flexibilisierungsunternehmen des totalitären Utilitarismus. Die kontramoderne regressiv-statische Ausrichtung ist dabei hier ebenfalls gewahrt. Durch sein Steuerungsunternehmen will der Utilitarismus ja gerade entmündigend die jeweilige Situation in Griff bekommen. Aus diesem Grund betrachte ich ihn ähnlich wie bei der Flexibilisierung des Führerprinzips als einen Versuch der Effizienzsteigerung und sehe ich ihn derselben spezifisch nationalsozialistischen, d.h. letztlich kontramodernen Grundstellung entspringen, die das Projekt der Moderne durch eine pervertierende Assimilation zu zerstören trachtet.

\section{Nationalsozialistische und reformerische Medienethik}

Auf diesem Hintergrund läßt sich das Verhältnis von nationalsozialistischer und reformerischer Medienethik so nun einerseits als ein Verhältnis der Unterscheidung in den Prämissen und Prinzipien bzw. einer differenten normativen Rangordnung von deren Gehalten, andererseits jedoch auch als das einer partiellen, transformatorischen Fortschreibung und Einlösung reformerischer Forderungen durch den Nationalsozialismus bestimmen. Auf der Prinzipienebene zeigte sich zunächst, daß sowohl die Reformer als auch die Nationalsozialisten dichotomisch ansetzen. Beide kennen in ihrer Gesellschaftstheorie zwei Klassen, von denen eine ein Führungsrecht für sich reklamieren will. Doch findet die Selbstlegitimation der Führungsschicht auf sehr unterschiedliche Weise statt. Während die Reformer mit einer sachlogischen Argumentationsfigur eine kompetenzbezogene Begründung des Führungsanspruchs für eine soziologisch bestimmte, aristokratisierte Schicht vornehmen, bedienen sich die Nationalsozialisten einer ontologischen Begründungsfigur für die Rechte einer charismatisierten, soziologisch nicht faßbaren Riege. Der Führungsanspruch der Reformer richtet sich dann vorwiegend als pädagogischer und wertsetzender ein, für dessen Sicherung entsprechende politische Strukturen als notwendig gelten. Im Unterschied dazu ist der Führungsanspruch der Nationalsozialisten ein primär politischer, dem pädagogische Maßnahmen flankierend zur Seite gestellt werden. Wo die Reformer die gesamtgesellschaftliche Durchsetzung der, rechten Sittlichkeit', also die Herstellung einer Zielmoral der Gesellschaft beabsichtigen und den Status der Geführten als den unmündiger Zöglinge bestimmen, richtet sich die nationalsozialistische Konzeption auf eine Zielgemeinschaft, deren Herstellung die Moral dienen soll, und erklären sie den Status der Geführten als den einer deontologisch verpflichteten Ge- 
folgschaft. Auf der Ebene der Ontologie bzw. Anthropologie setzen beide einen NaturKultur-Antagonismus an, der jedoch jeweils unterschiedlich gefüllt wird und dessen inneres Verhältnis genau umgestellt ist. So gelten für die Reformer bestimmte, empirisch faßbare Triebstrukturen, Strebungen und Kräfte als Natur, denen die logozentrisch und abstraktiv bestimmte Kultur disziplinatorisch gegenübergestellt wird. Kultur erscheint als das kontradiktorische Gegenüber der Natur. Für den Nationalsozialismus hingegen sind einige durchaus nicht mehr empirisch faßbare, ontologisierte Eigenschaften und Verhaltenscharakteristika jene Natur, aus denen die Kultur gerade abgeleitet wird. Kultur ist hier Ausfluß der Natur. Die naturalen Bestimmungsstücke der reformerischen Anthropologie zeigen sich so als negative, während die der nationalsozialistischen ,positiven' Status besitzen. Das führt dann auf der ethischen Ebene ebenfalls zu divergenten Bestimmungen. So setzen beide eine SeinSollens-Dichotomie an, doch ordnen die Reformer dem naturalen Sein das Sollen über, während die Nationalsozialisten dieses Sollen gerade aus dem Sein deduzieren. Wo die Hominisierung bei den Reformern moralisch durch eine kontranaturale Normativität erfolgen soll, soll sie es bei den Nationalsozialisten gerade durch eine naturale. Die reformerische Ethik habe ich deshalb als Bewahrethik charakterisiert, die durch Kulturation den als moralisch prekär geltenden naturalen Latenzen zu wehren sucht. Ihr Vorgehen orientiert sich an Defizitärerscheinungen, an Devianzbefürchtungen, deren Eintreten verhindert werden soll. Sie konstituiert sich daher fast ausschließlich in Form von Devianzvorwürfen und ist präventiv. Die Medienethik der Nationalsozialisten hingegen habe ich als Prinzipienethik, welche von einem partiell eigenständigen Utilitarismus flankiert wird, bezeichnet und als Steuerungsunterfangen charakterisiert. Mit einem anderen Begriff könnte man daher von einer Steuerungsethik sprechen. Ihr Vorgehen ist prinzipiengeleitet und richtet sich weniger auf Verhinderung, als auf Herstellung bestimmter Zustände. Devianzvorwürfe spielen in ihr daher kaum eine Rolle, sondern sind durch Präskriptionen ersetzt, deren Normativität ,konstruktiv‘ ist.

Neben diesen durchaus beachtlichen Unterschieden jedoch kommen die Reformer und die Nationalsozialisten in der kontramodernen Gesamtausrichtung ihrer Konzeptionen und partiell in ihren strukturbezogenen Forderungen überein. Obschon die kontramoderne Position als eine gegen das Projekt der Moderne gerichtete bei den Nationalsozialisten aufgrund ihrer Auseinandersetzung mit der technischinstrumentellen Rationalisierung der Lebens- und Gesellschaftsverhältnisse deutlicher und umfassender ist, war ja auch bei den Reformern eine vor allem anthropologisch fixierte Wende gegen die Moderne erkennbar. Zudem richten sich beide auf eine Statifizierung des gesellschaftlichen Status quo, der näherhin als regressiv definierter, nämlich ständischer deutlich wird, und folgen sie der ,sozialethischen' Maxime, da $ß$ all das gut sei, was die Befestigung dieses ständisch-statischen Gesellschaftskonzepts befördert, böse hingegen, was dessen Stabilität stören könnte. Sie setzen sich derart den mit dem Projekt der Moderne konnotierten modernen Dynamisierungs- und Demokratisierungsprozessen entgegen und versuchen, die daraus erwachsenden gesellschaftlichen Spannungen und Friktionen rückwärtsorientiert zu lösen. Weder die Reformer noch die Nationalsozialisten können daher politische, künstlerische, weltanschauliche und moralische Pluralismen sowie diesbezügliche Autonomie und Kreativität wirklich zulassen. Sie müssen stattdessen Diskurse in den 
verschiedenen Bereichen durch deduktive Instruktion und sittliche Autonomie durch Deontologie ersetzen und vom Projekt der Moderne entweder Abstand nehmen oder dieses destruieren. Durchsetzung und Erhaltung der deontologisch-instruktiven Normativität müssen dabei möglichst umfassend strukturell gesichert werden. Das reformerische Konzept führt entsprechend in strukturautoritäre Lösungsvorschläge, deren partielle Realisierung von den Nationalsozialisten genutzt und im Sinn ihrer eigenen Prämissen fortgeschrieben wird. Wie zu sehen war, werden hierbei reformerische Forderungen, wie die Errichtung einer staatlich-zentralen Zensur und Kontrolle des Films durch ein Amt, einer situationellen Anpassung an politisch-aktuelle Steuerungserfordernisse, sowie einer zensuralen Souveränität und Unabhängigkeit von Gremien oder Optionen der Filmwirtschaft realisiert. Dabei zeigte sich jedoch, daß der Nationalsozialismus effizienter agiert, sich um partielle Assimilation an moderne Dynamisierung bemüht und diverse Vorgaben der reformerischen ,Erfolge‘ der eigenen Ideologie entsprechend reinterpretiert. Die Prinzipien, von denen diese Realisierung getragen ist, haben sich als von den reformerischen Grundoptionen durchaus verschiedene gezeigt. Gleichzeitig aber läßt die Realisierung der kontramodernen Gesamtausrichtung durch den Nationalsozialismus sowohl erkennen, daß die strukturautoritär verfaßten Institutionen, wie sie die Reformer forderten, auch einer anderen Ideologie dienstbar gemacht werden können, sofern diese dieselbe Gesamtausrichtung besitzt, als auch, daß diese Gesamtausrichtung bereits auf eine totalitäre strukturelle Umsetzung zielt. Auf der Ebene der kontramodernen Gesamtausrichtung und ihrer zugehörigen Strukturforderungen kann das nationalsozialistische Konzept deshalb als transformative Einlösung reformerischer Strukturautorität gelten, wenngleich sich ihre Prinzipienebenen unterscheiden. Insgesamt kann damit festgestellt werden, daß zwischen der nationalsozialistischen Konzeption einer Medienethik und der reformerischen unübersehbare Unterschiede bestehen, die jedoch nicht hindern, daß beide demselben , historischen Irrtum' einer kontramodernen Gesamtausrichtung unterliegen und daher trotz divergenter Prämissen in ihren Strukturforderungen übereinkommen. Vor allem die Anknüpfung an reformerische Vorgaben durch die Nationalsozialisten verweist hierbei auf den prekären und problematischen Charakter der reformerischen Paradigmen und Optionen. 


\section{REDUNDANZ UND METAPHYSISCHE KEHRE: DIE PSEUDOAUTONOME EIGENTLICHKEITS- UND BEFÄHIGUNGSETHIK DER FILMERZIEHUNG IN DEN SOER UND 6OER JAHREN}

Die Schwierigkeiten der Deutschen mit den modernen Dynamisierungs- und Diversifizierungsprozessen bleiben nach 1945 erhalten. Noch immer bereiten sozialer Wandel, prinzipielle Abwesenheit schichtspezifischer Barrieren, Demokratisierung, Autonomisierung und Ethoswandel sowie die im Zusammenhang damit entstandene Gebrauchs- und Medienkultur Probleme vor allem für die pädagogische Reflexion und die kulturelle Gesellschaftsorganisation. Und wieder ist es zunächst der Film, dem als Ausdrucksträger und Promotor dieser Entwicklungen besonderes Augenmerk gewidmet wird, bevor die breitenwirksame Durchsetzung des Fernsehens dann für eine Ausweitung der Reflexion zur generellen Medientheorie und -pädagogik sorgt. Zusammen mit der werdenden Bundesrepublik etabliert sich so in den 50er und 60er Jahren eine pädagogische Forschungsrichtung, die unter dem Titel „Filmerziehung“ (später dann „Film- und Fernseherziehung“ und mit Ende der 60er „Medienkunde"), konzentriert vor allem auf Kinder und Jugendliche, Erziehungsprogramme für den Umgang mit Film und Fernsehen zu entwerfen sucht. Ein Zentrum dieser Forschungsrichtung bildet die sogenannte ,Keilhacker-Schule; d.h. der sich um den Hochschullehrer Martin und seine Frau Margarete Keilhacker gruppierende Kreis von Pädagogen, sowie das von Keilhacker gegründete „Wissenschaftliche Institut für Jugendfilmfragen“ (später: „Wissenschaftliches Institut für Jugendfragen in Film und Fernsehen ") in München. Mit ihren Forschungen und umfänglichen Publikationen - Zeitschriften und Buchreihen - bestimmt diese ,Schule' nachhaltig das reflexive Geschehen dieser Zeit und entfaltet eine Wirkungsgeschichte, die sich bis in die Gegenwart verfolgen läßt (vgl. 4.7.). ${ }^{1}$ Die Forschungen richten sich hierbei vor allem auf die Wirkungen von Film, die durch ein Bündel ,empirischer' Methoden von der Beobachtung Jugendlicher beim Filmkonsum mit einer Infrarotkamera und nachfolgender spekulativer Deutung der dabei entstandenen Bildreihen über Fragebogenaktionen bis zu wortassoziativen Tests - erhoben werden sollen und aus denen Folgerungen für ,altersgerechte' Filme abgeleitet werden. Neben den umfänglichen, meist als positivistische Daten aufgelisteten Ergebnissen solcher Forschungen, die den numerisch umfangreichsten Teil der filmerzieherischen Literatur ausmachen, bemüht sich die Filmerziehung jedoch auch um die Konstitution von Erziehungszielen und um eine Bestimmung der Funktion und Rolle des Films für Individuum und Gesellschaft. In diesem Bemühen treten die eigentlichen handlungs- und auch forschungsleitenden Grundoptionen der Schule Keilhackers vor Augen und erweist sich

\footnotetext{
${ }^{1}$ Das ,Institut Jugend Film Fernsehen' (wie die von Keilhacker gegründete Institution heute heißt) hat sich inzwischen vom genuin Keilhackerschen Programm getrennt und eine eigenständige Forschung etabliert, die von Jugendarbeit und Dokumentation flankiert wird.
} 
ihr Unterfangen als normatives. Es basiert auf - in der Regel ohne systematische Herleitung eingeführten - ethischen Axiomen und zeigt sich in seiner primären Stoßrichtung als ethisch-pädagogisches Doppelprojekt. Die Filmerziehung enthält so im Kern eine Medienethik, d.h. ethische Maximen für die Medien selbst, sowie eine bestimmte Vorstellung von Moralität, deren Herstellung und Vermittlung als vordringliche mediale Aufgabe gilt. In der impliziten Konstitution dieser Medienethik und der, epochalen' Bestimmung der Moralität liegt ihre eigentliche Bedeutung und Prägekraft für den medienethischen Diskurs der 50er und 60er Jahre.

Bei der Schaffung ihrer diesbezüglichen Grundoptionen und Theoreme aber bezieht sich die Filmerziehung zum einen sowohl explizit als auch implizit auf die Kinoreformbewegung und deren Argumentationsformen zurück. Zum anderen gewinnt sie ihre Paradigmen aus der pädagogischen Theorie des Schulgründers, der sein eigenes Unternehmen in Form einer Kulturtheorie und Zivilisationskritik grundlegt und dabei die Auseinandersetzung mit modernen Rationalisierungs- und Dynamisierungsprozessen sucht. Da ohne diese zweite, in ihrem Theorieumfang mindestens ebenso wichtige Paradigmenquelle für die Filmerziehung und ihre Optionen auch ihre Medienethik undeutlich bleiben müßte, nicht zuletzt, weil in dieser die Axiomatik zugunsten der ,positivistischen' Forschung selten durchgeklärt wird, setze ich zunächst mit einer Rekonstruktion der Kulturtheorie und Zivilisationskritik Keilhakkers an. Dort findet sich bereits auch ein ethisches Lösungskonzept, das von den Filmerziehern später rekapituliert und partiell modifiziert wird. Im Anschluß daran werde ich den Aufgriff der reformerischen Devianzkritik und die hierdurch geschehende Einwanderung der darin enthaltenen Optionen in die Filmerziehung skizzieren. Daneben läßt sich freilich auch eine ,eigene' Devianzkritik der letztgenannten erkennen, die sich den Keilhackerschen Vorgaben verdankt und die ebenfalls herausgearbeitet werden soll. Danach erhebe ich dann die ethischen und medienethischen Prinzipien und normativen Grundoptionen der Filmerziehung und suche hieraus ihre implizite ethische Systematik rekonstruktiv zusammenzusetzen. In einem Exkurs werde ich schließlich noch knapp auf die gegenwärtige Rekapitulation und transformatorische Wiederbelebung der reformerisch-filmerzieherischen Theoreme und Axiome exemplarisch eingehen.

\subsection{Kulturtheoretische Grundfigur: Modernitätskritik als ,Wertkritik}

Keilhacker trägt seine Kulturtheorie zwischen 1958 und 1967 in drei zentralen Schriften als pädagogische Theorie für das Zeitalter der Technik bzw. für die Industriegesellschaft vor. ${ }^{2}$ Die Grundfigur seiner Kulturtheorie entsteht in der Auseinandersetzung mit Technik, Ökonomie und Naturwissenschaften als den generellen Bewegungsprinzipen der Entwicklung eines spezifisch neuzeitlich-modernen Weltverhältnisses und dessen determinierender Bedeutung für Kultur- und Gesellschaftsformen. Ausgeklammert bleiben bei ihm die Veränderungen in der Struktur der Öffentlichkeit und die von diesen bedingten Demokratisierungstendenzen und -prozesse. Stattdessen nimmt Keilhacker die zunehmende globale Vernetzung in Blick, die von der internationalen Ausbreitung der ,technisch-wissenschaftlich-industriellen Kultur ${ }^{*}$

\footnotetext{
${ }^{2}$ vgl. Keilhacker, Technik; ders., Grundprobleme; ders., Erziehung
} 
mitverursacht ist. Mit diesem Ansatz steht seine Kulturtheorie zunächst in einem deutlichen, durchaus zeittypischen Konnex mit den technikphilosophischen Überlegungen Friedrich Dessauers und Arnold Gehlens. ${ }^{3}$ Darüber hinaus weist sie Bezüge zu der kulturphilosophischen Theorie der Industriegesellschaft bei Raymond Aaron, den soziologischen Analysen Helmut Schelskys und der persönlichkeitspsychologischen Zivilisationskritik von Philipp Lersch auf. ${ }^{4}$ Während der Konnex mit Dessauer und Gehlen, partiell auch mit Lersch, das kulturtheoretische Grundparadigma bestimmt, veranlaßt die Rezeption von Aaron und Schelsky eine Fortführung desselben zu einer stärker soziologisch orientierten Zivilisations- und Gesellschaftskritik. Der prinzipielle kulturtheoretische Ansatz wird von Keilhacker derart sowohl zur Auseinandersetzung mit Grundtendenzen und Basalstrukturen der Industriegesellschaft genutzt, als auch durch eine soziologisch perspektivierte Gesellschaftskritik ergänzt. Für die Rekonstruktion will ich daher im folgenden zunächst die kulturtheoretische Grundfigur und ihre Kritikmomente herausarbeiten, um dann die ergänzende Weiterführung zur Gesellschaftskritik zu skizzieren.

Die Rekonstruktion der Grundfigur der kulturtheoretischen Reflexion Keilhakkers und ihrer Kritik läßt sich nun unmittelbar in den Kontext der gegenwärtig geführten Diskussion um Gehalt, Gestalt und Sinn der Moderne stellen. Mit dieser Reflexion nämlich ist das Projekt der Moderne systematisch in seinen Wurzeln, seinen Kernmomenten und seiner gesellschaftlich-sozialen Konkretion in Blick genommen und kritisch behandelt. Anders als bei Reformern und Nationalsozialisten stellt es in Keilhackers Texten nicht nur den mittelbar tangierten Gegenstand, sondern das letztlich zentrale Thema dar. So bezieht sich Keilhacker (wie zu sehen sein wird) mit seinem Ansatz bei Technik, Ökonomie und Naturwissenschaften als den Prägekräften eines Weltverhältnisses direkt auf jenen epochalen Formierungszusammenhang, der kulturphilosophisch zunächst mit Max Weber als Rationalisierung gefaßt werden kann und der als konstitutiv für die neuzeitlich-abendländische Kultur gilt. Um die recht detaillierte Theoriebildung Keilhackers entsprechend verorten zu können, sei dieser Formierungszusammenhang nochmals knapp umrissen: Er stellt einen Prozeß dar, dessen Wurzeln zwar bereits vorneuzeitlich in der Werkzeugtechnik gesehen werden können, der jedoch erst in der Neuzeit und Moderne seine eigentliche, die Gesamtheit der individuellen und gesellschaftlichen Lebensverhältnisse umgreifende Gestalt ausbildet: So ermöglicht zunächst die Entwicklung von Werkzeugtechnik die Freisetzung vom Naturzwang und die Verbesserung der Existenzchancen sowie die Konstitution eines zugehörigen objektivierend-instrumentellen Rationalitätstyps. Dessen Differenzierung und Ausweitung zusammen mit der Entwicklung objektivierender, abstraktiver und empirischer Wissenschaften im Übergang zur Neuzeit bedingen eine zunehmende ,Entzauberung' der Welt und allmählich eine generelle Rationalisierung der Lebens- und Gesellschaftsverhältnisse sowie eine produktive Steigerung materieller Lebensqualität. Unter der Rücksicht der Vermittlung der Grundzüge dieser Entwicklung mit den und über die philosophischen, anthropologischen

${ }^{3}$ vgl. etwa: Dessauer, Streit; Gehlen, Arnold, Die Seele im technischen Zeitalter, Reinbek 1957

${ }^{4}$ vgl. etwa: Aaron, Raymond, Die industrielle Gesellschaft und die drei Welten, Zürich 1961; Schelsky, Helmut, Wandlungen der deutschen Familie in der Gegenwart, Stuttgart ${ }^{3} \mathbf{1 9 5 5}$; Lersch, Mensch 
und gesellschaftstheoretischen Überlegungen der Aufklärung und ihres Gefolges erscheinen die Rationalisierungsprozesse dann weiter als Autonomisierungs- und Individualisierungsprozesse, die in die Auflösung eines statisch-metaphysischen Weltverständnisses sowie der Ständegesellschaft und in die Vorherrschaft säkularer Sachorientierung sowie schließlich in die Industriegesellschaft einmünden. Die internationale Ausbreitung von Technik, Wissenschaft und Ökonomie entfaltet außerdem eine kulturtransformatorische und vernetzende Wirkung, die die gesamte Welt zusammenrücken läßt und die vor allem nach dem Zweiten Weltkrieg, wie oben angedeutet, unter dem Stichwort ,Globalisierung diskutiert wird. Autonomisierung und Individualisierung wiederum stellen, wie zu sehen war (vgl. 1.1.), zusammen mit der Rationalisierung der Lebens- und Gesellschaftsverhältnisse das Projekt der Moderne dar. Keilhacker nun bezieht sich in den genannten Schriften ebenfalls auf diesen Entwicklungsprozeß, zeichnet ihn insbesondere mit Bezug auf die kulturell-gesellschaftliche Transformationswirkung der Naturwissenschaften als Rationalisierungsvorgang und nimmt zu dessen Gestalt und Konsequenzen Stellung. Seine Auseinandersetzung mit dem von Technik, Ökonomie und Naturwissenschaften konstituierten Weltverhältnis kann daher als unmittelbare Auseinandersetzung mit dem Projekt der Moderne betrachtet werden. Obschon er die Errungenschaften des skizzierten Prozesses sieht und sich von einem ,Kulturpessimismus' distanziert, übt Keilhacker, wie erwähnt, auch Kritik an den modernen Entwicklungen und er setzt sich einem aufklärerischen, emanzipationstheoretischen Optimismus entgegen. Seine Kritik kann deshalb im vorgängigen Kontext als dezidierte Modernitätskritik bewertet und unter dieser Rücksicht rekonstruiert werden. Die Filmerziehung wiederum erhält dadurch einen theoretischen Hintergrund, der von nun an jede ihrer medienethischen Überlegungen umfassend determiniert und diese zum Projekt der Moderne unvermeidlich in Beziehung setzt.

\section{Technik als Initiatorin von Fremdbestimmung und Werteverfall}

Keilhacker widmet sich zunächst der Technik und versteht sie, ähnlich Gehlen, als jene spezifisch menschliche Handlungsform, mit welcher der Mensch sich in der naturalen Welt einzurichten und über deren Zwänge und Notwendigkeiten zu erheben sucht. Aus dieser Perspektive betrachtet ist die technische Weltbewältigung bereits im Ansatz ein Autonomisierungsunterfangen. Dessen Kern umreißt Keilhacker, wenn er mit Wendt Technik als „,bewußte Gestaltung der Materie“s definiert, d.h. als eine souveräne Handlungsweise, durch die der Mensch sich der materiellen Umwelt gegenüberstellt und sich diese ,zuhanden' macht. Erstes Wesensmerkmal der Technik ist so die tätige Bearbeitung vorhandener materieller Stoffe zum Zweck der Erzeugung neuer Gegenstände, deren primäre Qualität in einer Erleichterung des Lebens gesehen wird. ${ }^{6}$ Mit dieser Entlastungs- und Erleichterungsfunktion ist folglich auch der primäre Zweck der technischen Weltbewältigung benannt. Dann verweist Keilhacker darauf, daß eine solche Bestimmung von Technik „ein deutliches Heraustreten des Menschen aus der früheren Einheit mit der Natur“, die eine ,instinktive‘ ge-

${ }^{5}$ Keilhacker, Technik, 8; Keilhacker, Grundprobleme, 25; Keilhacker entnimmt das Zitat bei: Dessauer, Streit, 230-231, der ,Urtext' findet sich bei: Wendt, Ulrich, Die Technik als Kulturmacht, Berlin, 1906

${ }^{6}$ vgl. zur Lebenserleichterung: Keilhacker, Technik, 31-33; Keilhacker, Erziehung, 49-51 
wesen sei, einschließe. ${ }^{7}$ Die technische Handlungsform erscheint damit als Ablösung eines ,ursprünglichen', naturalen Zusammenhangs zwischen Mensch und Welt durch ein kontranaturales, objektivierendes Abgrenzungsverhalten, das weiter als Herrschaftsverhalten bestimmt wird. Bereits Wendts Definition enthält diese Bestimmung, wenn er von einer Unterwerfung der Natur unter menschliche Zwecke, näherhin von der „Umgestaltung der Rohstoffe für die Zwecke der Kultur“8 spricht. Keilhacker sieht diese herrscherliche Unterwerfung dann geradezu als ,Wesenskern' der Technik, die „immanent den Gedanken in sich“ trage, „daß der Mensch von jetzt an die Dinge machen, von sich aus entwickeln könne, daß er nicht mehr auf das Wachsen, das vom Menschen in der Hauptsache unabhängige Werden in der Natur, angewiesen sei““. ${ }^{9}$ Entsprechend strebe der Mensch nun danach, durch die Technik (und die Wissenschaft) die Natur ,zu zähmen, in seinen Dienst zu stellen und zu seinem eigenen Vorteil zu verwenden" ${ }^{10}$ Das Autonomisierungsunterfangen der Technik wird so als technisch erzeugte, souveräne Unabhängigkeit vom Naturzwang präzisiert, die sich dieser Vorstellung zufolge mit innerer Notwendigkeit in eine Herrschaft über die Natur und in deren funktional-instrumentelle Verplanung für menschliche Zwecksetzungen transformiert. Diesem Prozeß wird eine Dynamik attestiert, die mit der Entstehung der Naturwissenschaften und dem Überschritt von der Werkzeugtechnik zur Maschinentechnik in ihre ,Endschaft' gebracht gilt. Beide nämlich zielen für Keilhacker auf eine Perfektionierung der Souveränität gegenüber den Bedingungen der Natur und auf die umfassende produktive Verwertung der letztgenannten. Während der Mensch bis dahin ,trotzdem mehr ein Teil und Glied der Natur, innerhalb einer mehr dienenden und pflegenden, den Gesetzen der Natur mehr instinktiv nachspürenden als bewußt forschenden Grundhaltung" gewesen sei, zerrissen zum einen die Naturwissenschaften die, instinktive Einheit mit der Natur' ganz, indem sie die letztgenannte „mit Hilfe von Theorien und Experimenten“ ,zwängen', auf vom Menschen gesetzte Fragen zu antworten, also völlig in den Status des Objekts drängten. ${ }^{11}$ Zum anderen ermögliche die Erfindung von ,selbsttätigen Maschinen', unter denen zunächst als bedeutendste die Dampfmaschine zu gelten habe, ${ }^{12}$ eine ungeahnte ,Leistungssteigerung in der Produktion von lebenserleichternden Gütern und die allmähliche Etablierung der Industriewirtschaft. ${ }^{13}$ Vor allem die damit zusammenhängende neue Form der Energieproduktion erlaube endgültig, ,, den zwangsläufigen Rhythmus der Natur zu durchbrechen "14, d.h. die autonomisierende Abkoppelung von naturalen Rhythmen wie Wachsen und Ernten, jahreszeitlicher Wechsel oder Tag und Nacht zu vervollständigen. Mit diesem endgültigen Durchbrechen naturaler Determinationen und der Heraufkunft der Industriegesellschaft aber scheint für Keilhacker eine spezifisch menschliche Welt als Zivilisation errichtet, in der der Mensch beginnt, die Gesetze seiner Existenz ungebunden selbst zu bestimmen,

\footnotetext{
${ }_{8}^{7}$ Keilhacker, Grundprobleme, 25

8 Wendt, Ulrich, Die Technik als Kulturmacht, Berlin 1906; zit. nach: Dessauer, Streit, $230-231$

${ }_{9}^{9}$ Keilhacker, Grundprobleme, 25

${ }_{10}^{10}$ Keilhacker, Grundprobleme, 25

${ }_{11}^{11}$ Keilhacker, Grundprobleme, 25

12 vgl. Keilhacker, Technik, 8, 12

13 vgl. Keilhacker, Grundprobleme, 14 - 16, 22

${ }^{14}$ Keilhacker, Technik, 18
} 
gleichzeitig jedoch den Grund seiner Existenz zu verlieren. Obschon Keilhacker die via Technik erreichte Autonomie positiv bewertet und auf die Unverzichtbarkeit ihrer lebenserleichternden Funktionen verweist, ${ }^{15}$ übt er daher auch Kritik.

Die Gefahr der Technik liegt für ihn vordringlich in einer einseitigen Ausrichtung auf ihre Möglichkeiten und einer daraus hervorgehenden Hinordnung aller Lebensund Gesellschaftsverhältnisse auf technische Erfordernisse. Das „Bedürfnis des Menschen, die ganze Welt unter einem einheitlichen Prinzip zu sehen“, nämlich sei ,so stark', daß die Gefahr bestehe, „die moderne Technik mit ihren Gesetzmäßigkeiten (...) zum einheitlichen Prinzip zu erklären“ und alles diesen Gesetzmäßigkeiten anzupassen. ${ }^{16}$ Diese Gesetzmäßigkeiten aber ergeben sich aus Keilhackers oben skizzierter, kulturgeschichtlicher Herleitung des Technikbegriffs als primär materieller Weltzugang, als Instrumentalität der ,Zuhandenmachung und als mechanistische Funktionalität, die um das Moment der ,Statik', d.h. der Gleichförmigkeit schematisierter Abläufe, wie sie vor allem durch die ,Maschine‘ verkörpert werden, zu ergänzen ist. ${ }^{17}$ Von ihnen scheint ihm nun die Industriegesellschaft hauptsächlich geprägt zu sein und in eine eindimensionale Orientierung gedrängt zu werden. Diese gesellschaftliche Orientierung und den zugehörigen menschlichen Habitus bewertet Keilhacker negativ und sucht er mit zwei Schlagworten zu fassen: Zunächst sieht er aus dem materiellen Weltzugang einen,Materialismus' fließen, der sich lediglich am Außen materieller Gegebenheiten orientiert und das menschliche Leben ausschließlich daraufhin ausrichtet. ${ }^{18}$ Insbesondere die Welt der ,geistigen Werte' scheint ihm davon bedroht. Als Negativergebnis der technisch bewerkstelligten, materiellen Lebenserleichterung nämlich konstatiert Keilhacker eine ,materialistische' Gesellschaft, die sich lediglich auf „Freizeit und Lebensstandard“ hin orientiere, jene ,höheren, geistigen Ziele' aber, für welche der materielle Wohlstand nur „Hilfsmittel“ sein solle, verlorengehen lasse. ${ }^{19}$ Die "geistige Befriedigung, die Befriedigung unseres Ichs" werde in einer solchen Gesellschaft entsprechend auf den „Verbrauch von Gütern" hin umgestellt, so daB an die Stelle, immaterieller' Wertbesetzungen materielle Gegenstände träten, deren Erwerb, Besitz und Gebrauch jedes andersgeartete Streben ersetze. ${ }^{20}$ Unter diesen Bedingungen aber droht für Keilhacker ,vom Wesenhaften der Kultur und des Menschseins der letzten Jahrtausende nicht mehr viel übrig“ zu bleiben. ${ }^{21}$ Gerade Kultur nämlich betrachtet er als ,wertbezogene“ „Durchseelung und Vergeistigung des rein Faktischen“22 und die derart erfolgende ,Überhöhung der ,materiellen Güterwerte' zu ,geistigen Kulturwerten'. Die Kritikfigur, die Keilhacker unter dem Schlagwort des ,Materialismus' hier vorträgt, führt damit eine Dichotomie von Materie und Geist ein, der eine Dichotomie von,Gütern' und ,Werten' korrespondiert. Der Kern der Kritik besteht im Verlorengehen der einen Seite der

15 vgl. Keilhacker, Technik, 31; Keilhacker, Erziehung, 49-51

${ }_{17}^{16}$ Keilhacker, Technik, 18

17 vgl. etwa: Keilhacker, Technik, 16-23; zur Statik und mechanistischen Funktionalität bes. 17

18 vgl. Keilhacker, Erziehung, 44-45

${ }^{19}$ Keilhacker, Erziehung, 141

20 vgl. Keilhacker, Grundprobleme, 16; Keilhacker rekurriert hier auf die Zivilisationskritik von Packard: Packard, Vance, Die große Verschwendung, Düsseldorf 1961, 40, der mit der Äußerung des Marketing-Beraters Lebow die zitierte Umorientierung illustriert.

${ }_{21}^{21}$ Keilhacker, Technik, 11

22 Keilhacker, Grundprobleme, 118 
Dichotomie aufgrund der Dominanz der anderen, genauer: in der Aufkündigung des Geltungsanspruchs der einen Seite zugunsten dessen der anderen. Als Klage über einen Geltungsverlust aber zeigt sich Keilhackers Kritik als Kritik an einer ,Umwertung, die als Werteverfall ausgelegt ist: So wird zunächst beklagt, daß die ,materiellen Güter' auf der Ebene der gesellschaftlichen Orientierung an die Stelle der ,geistigen Werte' träten und deren Status beanspruchten. Damit rücken sie genau besehen selbst in den Stand von, Werten', die als ,neue' vorgängige ,alte' ablösen. In Keilhakkers Texten jedoch scheinen Werte und Güter auf zwei verschiedenen Ebenen angesiedelt zu sein, so daß die Umwertung als substituierende Beseitigung der Werte schlechthin gilt. Entsprechend tritt als Konsequenz des Geltungsverlusts der Werte eine Ersetzung der Wertorientierung durch eine materialistische Orientierung auf, und scheinen derart die Werte dem Verfall preisgegeben zu sein. Die ,materiellen Güter' aber erhalten in dieser terminologischen Figur den Charakter von ,NichtWerten', die den Wertstatus zu unrecht für sich in Anspruch nehmen und daher allenfalls als ,Scheinwerte' gehandhabt werden können.

Ähnlich verhält es sich mit seinem zweiten Kritikpunkt, mit dem er die souveräne ,Zuhandenmachung von Welt durch Technik problematisiert. Aus ihr nämlich sieht er ein ,Machbarkeitsprinzip' hervorgehen, das jeden Weltzugang unter seine Herrschaft nimmt und die Fragen nach dem Sinn und nach der Legitimität technischen Handelns durch die Fragen nach Nutzungsmöglichkeiten und Durchführbarkeit ersetzt. ${ }^{23}$ Zunächst scheinen Keilhacker die Abkoppelung von der Natur und deren technisch-naturwissenschaftliche Beherrschung das Bewußtsein von ,Grenzen für die Erforschbarkeit und Machbarkeit der Dinge aufzuheben ${ }^{24}$ Sie erzeugten stattdessen einen „Taumel der Fortschrittsgläubigkeit und des Aufstiegsoptimismus“25, der schließlich die Einordnung in naturale Prädispositionen und Unbeliebigkeiten obsolet erscheinen lasse. Damit aber drohe der Mensch als ,gläubiger Diener des Unfaßbaren“ vom Menschen als „Herr und Schöpfer der Dinge“, d.h. letztlich also die Submission unter den deus creator und die Einordnung in dessen Schöpfung durch die Selbstinthronisation des homo creator ersetzt zu werden. ${ }^{26}$ Gegenübergestellt werden derart die "grandiosen, nie völlig erforschbaren Schöpfungen Gottes“, die aus sich heraus zu, ehrfürchtiger Selbstbeschränkung aufrufen und Wertstatus erhalten, und der ,Mensch als Forscher und Gestalter der Materie ohne jede, auch nur gedankliche Einschränkung ${ }^{\text {“ }}{ }^{27}$ Beklagt wird wieder eine einseitige Dominanz, diesmal des homo creator, und darin letztlich eine spezifische Umwertung, die erneut den Charakter eines Werteverfalls trägt: So scheint nun der Natur als ,Schöpfung Gottes' ihr ,Eigenwert' und daraus fließender Anspruch an den Menschen genommen und dieser Wert bzw. Anspruch durch die funktionelle Verplanung für menschliche Zwecke, also durch die Beurteilungsperspektive der Nutzbarkeit und daraus hervorgehende ,Gebrauchswerte' substituiert. Diese, Gebrauchswerte' sind dem Gehalt der Kritikfigur zufolge dabei wieder kaum als, Werte' zu betrachten, sondern es

23 vgl. Keilhacker, Technik, 21-23

24 vgl. Keilhacker, Technik, 22

25 Keilhacker, Technik, 22; Keilhacker erinnert hier v.a. an die diesbezügliche Zeitstimmung vor dem Ersten Weltkrieg.

${ }_{26}^{26}$ Keilhacker, Grundprobleme, 26

${ }^{27}$ Keilhacker, Grundprobleme, 26 
scheint die Nutzenperspektive die Wertorientierung durch Zweckorientierung zu ersetzen und derart zu zerstören. Die naturalen Eigenwerte erleben damit ihre Auflösung, und die Umwertung erscheint als Werteverfall. Gleichzeitig scheint die moralische Haltung des Menschen, deren Charakteristik implizit als Orientierung an den naturalen ,Eigenwerten', d.h. an einem letztlich vom Menschen unabhängigen ,Wertereich' auftritt, von einer erfolgsorientierten ,schlechten Autonomie' des ,Machens' und Nutzens ersetzt. Damit verweist diese Kritikfigur bereits auf die antiautonomistische Dichotomie der Wertethik voraus, mit der zwei divergente Welten konstituiert werden, wie sie von Keilhacker später als Korrigens der modernen Prozesse eingeführt wird (vgl. weiter unten).

Stellen schon die Konstatierung einer defizienten, einseitigen Ausrichtung der Gesamtgesellschaft auf Technik und ihre Erfordernisse sowie deren Konsequenzen in ,Materialismus' und ,Machbarkeit' massive kritische Momente dar, so spitzt Keilhacker diese Kritik noch zu, wenn er mit einer weiteren Überlegung die Eigendynamik der Maschinentechnik als generelle Gefahr ausmalt. Dieser Gefahr widmet er sich besonders in Auseinandersetzung mit Automaten, d.h. der ,selbsttätigen Maschine'. Zunächst stellt er fest, daß Technik von sich aus bereits über ihre Anfänge in der Werkzeugtechnik hinausdränge auf die ,Maschinentechnik'. Sie zeigt damit eine Qualität, die sie - in Gehlen'scher Terminologie - vom Organersatz und der Organentlastung zu bislang ungeahnter Organüberbietung steigert, d.h. aber, die Souveränität der Naturunabhängigkeit nochmals ausweitet. ${ }^{28}$ Liegen auch darin für Keilhacker zunächst positive, lebensverbessernde Möglichkeiten, die er vor allem in der ,Leistungssteigerung' sieht (vgl. oben), so stellt er diesen zugleich negative Implikationen gegenüber. Mit der organüberbietenden „selbsttätigen Maschine“ nämlich sieht er einen Zustand erreicht, in dem der Mensch aufgehört hat, „ausschließlich Herr der Maschine" zu sein, und ,gleichzeitig ihr Diener" geworden ist. ${ }^{29}$ Im Unterschied zu den ,urtümlichen Werkzeugen' des Menschen, „die ruhten, wenn er selbst ruhte, die keine Ansprüche von sich aus an den Menschen stellten", nämlich zwinge die Maschine ihren ,Bediener' dazu, sich ihrem Rhythmus, ihren Erfordernissen und ihren Gesetzmäßigkeiten anzupassen. ${ }^{30}$ Die ,Gesetze der Maschine und der Maschinenwelt' geraten demzufolge zu den eigentlichen Gesetzen der Menschenwelt und ihres ,ganzen Lebens..$^{31}$ Damit aber droht die autonomisierende Kraft der Technik in Fremdbestimmung umzuschlagen und die ,Maschine' sich heteronomistisch an die Stelle der menschlichen Subjekte zu setzen. Nicht weniger als die neuzeitliche Errungenschaft des Subjektstatus des Menschen selbst also scheint letztlich auf dem Spiel zu stehen, und das Projekt der Emanzipation durch technische Weltbewältigung scheint sich in ihr demanzipatives Gegenteil zu verkehren. ${ }^{32}$ Diese Verkehrung aber

28 vgl. Gehlen, Technik, 94

${ }^{29}$ Keilhacker, Technik, 12

${ }^{30}$ Keilhacker, Technik, 17

31 vgl. Keilhacker, Technik, 18; auch: ebd. 19-20, wo Keilhacker die daraus fließende ,Entfremdung' von Natur und Wesen des Menschen am Beispiel ,des Amerikaners' ironisch exemplifiziert.

${ }^{32}$ Die ,Kolonisierung des Subjekts durch die normative Kraft der Maschinengesetze exemplifiziert Keilhacker hierbei auch spekulativ-psychologisch, wenn er die geforderten Anpassungsleistungen bei der ,werktätigen Bevölkerung' an maschinisierte Arbeitsprozesse und -strukturen nachzeichnet und daraus die Entstehung eines ,Maschinenmenschen' herleitet, der sich an 
gilt für Keilhacker als fast notwendige Entwicklung, da mit der Maschinentechnik ein Prozeß eingeleitet sei, der „,beinahe zwangsläufig in der einmal eingeschlagenen Richtung" weiterführe. ${ }^{33} \mathrm{Da}$ aber schon die Werkzeugtechnik, wie zu sehen war, auf Maschinentechnik hindrängt, wird so dem Prozeß der technischen Weltbewältigung als ganzem eine gewissermaßen immanente Gefährdung, eine entelechiale Defizienz attestiert. Keilhackers Kulturtheorie schlägt damit in eine generelle und umfassende Kritik um, die das Projekt der Autonomisierung durch Technik von sich selbst konteragiert sieht.

In der skizzierten Auseinandersetzung mit der Technik sind bei Keilhacker so die grundlegenden Begriffe eingeführt und ist seine Kulturtheorie zu einer Kritik ausgezogen, die letztlich eine Modernitätskritik ist. Die darin angesetzte Begriffsperspektive zeigt sich als dichotomische, die den gesamten Prozeß der Technikgenese und des zugehörigen Weltverhältnisses sowie seiner Auswirkungen auf die Lebens- und Gesellschaftsverhältnisse mit antagonistischen Gegensatzpaaren zu fassen sucht. Zunächst wird die Konstitution des technischen Weltverhältnisses als Abkoppelung von der Natur und Herrschaft über dieselbe mittels materiell-funktioneller Orientierung nach außen beschrieben, d.h. es tritt vorerst als Verhältnis objektivierendinstrumenteller ,Zuhandenmachung auf, das die Natur als Mittel zu menschgesetzten Zwecken betrachtet. Die in dieser Zwecksetzung liegende Souveränität läßt die Entstehung der Technik und ihres Weltverhältnisses dann als Unterfangen der Autonomisierung und menschlichen Emanzipation erscheinen. Zugleich aber wird diesem Unterfangen ein Doppelcharakter attestiert: Der Technik nämlich scheint eine Entelechie eigen zu sein, die mit der Maschinentechnik in der Industriegesellschaft zu ihrer (vorläufigen) Vollgestalt gekommen ist und dort zugleich in Heteronomie und Fremdbestimmung zu kippen droht. ,Autonomisierung und ,Fremdbestimmung' sind so das erste antagonistische Begriffspaar, mit dem der Entstehungsprozeß der technischen Zivilisation und des zugehörigen Weltverhältnisses kategorisiert wird. Die Zuordnung der Begriffe als eine Abfolge, die die Autonomisierung durch die Fremdbestimmung zunehmend abgelöst sieht, transformiert diese Kategorisierung in Kritik. Insofern das Autonomisierungsprojekt erst mit Neuzeit und Moderne zu seinem Begriff kommt und als durchgesetzt gilt, Keilhacker aber gerade in der modernen Industriegesellschaft die Fremdbestimmung drohen sieht, ist seine Kritik eine spezifische Modernitätskritik.

Mit den Termini der ,Machbarkeit' und des ,Materialismus " wird dann die Umsetzung des technischen Weltverhältnisses in eine gesellschaftliche Orientierung beschrieben. Derselben werden nun ,Einordnung' bzw. Submission und ,Geist' antagonistisch gegenübergestellt und derart zwei weitere gegensätzliche Begriffspaare eingeführt. Dabei zielt die Kritik, die mit diesen Paaren durchgeführt wird, letztlich auf Umwertungsvorgänge, die als Werteverfall erscheinen, und läßt ihre Leitperspektive als wertphilosophische deutlich werden, die auf die Dichotomie von ,Wert' und ,Unwert' rekurriert. Entsprechend scheinen jetzt zum einen ,materielle Güter ${ }^{\star}$ an die Stelle ,geistiger Werte' zu treten und den Geltungsanspruch des ,Geistigen' gesell-

,affektlose Sachlichkeit' gewöhnt und diese zu seiner Existenzform macht. vgl. etwa: Keilhacker, Technik, 69-72

${ }^{33}$ Keilhacker, Technik, 22 
schaftlich zu ersetzen, zum anderen drohen die Perspektiven der Nutzbarkeit und Herstellbarkeit den ,Eigenwert' der den Menschen umgebenden Welt, insbesondere der Natur, aus dem Blickfeld zu verdrängen. In beiden Fällen drohen so bestimmte, werthaft besetzte Orientierungsformen und Haltungen (Submission, Einordnung) sowie werthafte Entitäten (Natur) ihrer Werthaftigkeit entkleidet zu werden, d.h. aber, es scheint durch die gesellschaftlichen Neuorientierungen ein spezifischer Werteverfall eingeleitet. Der Autonomisierungsproze $\beta$ der Neuzeit und Moderne wird derart als gewissermaßen ,falsche Emanzipation' gezeichnet, nämlich als Ablösung von den werthaft besetzten, geistigen Zielen' und der ,geistigen Kultur' sowie von einem ,gläubigen', submissiven Weltverhältnis, das sich an religiös rückgebundenen, naturalen ,Eigenwerten' orientiert. Gleichzeitig deutet sich in dieser Kritikfigur an, $\mathrm{daB}$ die Orientierung an ,Werten', insbesondere den verlorengegangenen, als die eigentliche Moralität verstanden wird und der neuzeitliche Prozeß so zusätzlich noch in ,fehlgeleitete Moralität' oder gar ,Amoralität' zu führen droht.

\section{Zerstörung der Wertorientierung durch die naturwissenschaftliche Rationalisierung}

Während das veränderte Weltverhältnis, auf das die beklagten Umwertungen zurückgeführt werden, in Keilhackers Technikkritik als Habitus des Herrschens und Orientierung am Materiellen skizziert wird, sucht seine Auseinandersetzung mit den Naturwissenschaften das veränderte Weltverhältnis als eine spezifische Form der Rationalisierung zu fassen. Der wiederum konstatierte Werteverfall wird nun aus dieser Rationalisierung hergeleitet, bzw. mit ihr gar identisch gesetzt. Hierzu charakterisiert Keilhacker zunächst generalisierend die Naturwissenschaften als die ,geistigen Voraussetzungen des technischen Zeitalters ${ }^{\text {‘34 } 34}$ überhaupt, um dann ihr Spezifikum als zunehmende Rationalisierung durch Quantifizierung und durch methodisches, an experimenteller Nachprüfbarkeit orientiertes Denken zu präzisieren. Die Wurzel der Naturwissenschaften sieht Keilhacker dabei, ähnlich jener der Technik, im Streben nach Unabhängigkeit und Autonomie, diesmal nicht gegenüber der Natur allein, sondern auch gegenüber dem vorneuzeitlichen Weltverhältnis und Gesellschaftszusammenhang. So skizziert er die Naturwissenschaften als „eine neue Art des Denkens und der Weltbetrachtung“, deren Ausformung mit dem Ende des Mittelalters als „Aufbruch des Individuellen, des religiösen Zweifels, der Unzufriedenheit mit dem Überlieferten überhaupt" beginne. ${ }^{35}$ Diese skeptische Haltung münde in den „Anspruch auf eigenes Forschen statt gläubiger Hinnahme des Überlieferten" und begründe damit einen Autonomieanspruch. ${ }^{36}$ Sie lege zugleich jedoch auch die grundsätzliche Ausrichtung der Naturwissenschaften und das von ihnen konstituierte Weltverhältnis fest, die sich als spezifische Form der Rationalisierung zeigen: Konsequenz der ,Skepsis‘ nämlich ist die ,Entzauberung' der Welt, welche nun zum Gegenstand erforschbarer Sachverhalte gerät und derart einer rationalen Perspektive zugänglich gemacht wird. ${ }^{37}$ Das ,Numinose ist im naturwissenschaftlichen Weltver-

${ }^{34}$ Keilhacker, Technik, 36

${ }_{36}^{35}$ Keilhacker, Technik, 36; im Original partiell kursiv.

${ }^{36}$ Keilhacker, Technik, 36

37 Der Begriff der, Entzauberung' taucht bei Keilhacker nicht explizit auf, doch ist ihr Vorgang in seinem Text enthalten, wenn er davon spricht, daß von den Naturwissenschaften eine „strenge Kausalität im Ablauf der Vorgänge der Natur" zugrunde gelegt werde, die „keinerlei 
hältnis des ,neuen' Forschers ebenso prinzipiell ausgeschlossen, wie es Metaphysik und Transzendenzbezug sind. Seinem Blick bietet sich nur mehr dar, was die naturwissenschaftliche Betrachtungsweise erkennbar macht. Diese Betrachtungsweise erhebt Keilhacker allgemein als „Reduzierung alles Qualitativen auf das Quantitative“ und der „Wertkategorien auf die einzige Alternative: richtig oder falsch, beweisbar oder nicht beweisbar“ “38 Damit ist zum einen die Spezifität der naturwissenschaftlichen Rationalisierung benannt und auf ihren Kerngehalt als Ersetzung von Assoziativität, analogem Denken und religiös-metaphysischer Wesensschau durch die Methodik definierter Experimentalsituationen und ihrer nachprüfbaren Kausalität verwiesen. ${ }^{39}$ Zum anderen aber wird dieser Rationalisierung zugleich ein spezifischer Werteverfall angelastet, der jetzt noch näher charakterisiert werden kann: Die ,qualitati$v^{\prime}$ ' Wertung, d.h. die Wertung nach religiösen, ästhetischen, emotionalen oder empfindungsmäßigen Kategorien (Göttlichkeit, Schönheit, Freude, Angenehmes) erscheint von der Beurteilung nach ,quantitativen' und sachrationalen, d.h. nach ,subjektlosen' ding- und verhältnisorientierten Kriterien (Richtigkeit, universelle Wiederholbarkeit) substituiert. Diese Substitution wird von Keilhacker zunächst als Umwertung behandelt, wenn er die naturwissenschaftlichen Kriterien als ,Wertkategorien“ apostrophiert, und so als Kategorien der Wertkonstitution anstatt der Wertabstinenz behandelt. Die Rationalisierung der Naturwissenschaften scheint also vorerst nicht eine Wertfreiheit schlechthin, sondern nur eine Freiheit von bestimmten, nämlich dem vorangehenden Weltverhältnis verpflichteten ,Qualitätswerten' zugunsten anderer, die von den quantitativ-methodischen Kategorien geschaffen werden, hervorzubringen. Diese anderen ,Werte' der Beweisbarkeit und Nachprüfbarkeit aber gelten dann nicht wirklich als Werte, sondern erhalten erneut den Charakter von ,Scheinwerten', die zu Unrecht den Wertstatus usurpieren, und die ,echten', d.h. die ,Qualitätswerte' verdrängen. Lediglich die verlorengehende, ,qualitative' Wertung nämlich ist nach Keilhacker in der Lage, die ,wesenhafte Beschaffenheit" eines Gegenstands, die ,gleichbedeutend mit Vollkommenheit" sei zu treffen, und wirklich Werte zu schaffen. ${ }^{40}$ Mit der neuen, quantitativen Wertung hingegen scheint das ,Wesen' einer Sache gerade verfehlt zu werden und erneut kein Wert, sondern ein Zweck oder Nutzen konstituiert. Die Verdrängung der, qualitativen Werte' zeigt sich damit als Vorgang des Werteverfalls, in dem die ,eigentlichen` Werte, die jetzt als vorneuzeitliche epochal zugeordnet werden können, durch ,uneigentliche‘ ersetzt werden sollen, genau besehen aber ein ,Wertevakuum' zurückgelassen wird. Auf diese Weise gerät die hier zunächst explizit konstatierte Umwertung doch zum Verfallstheorem und rekurriert Keilhackers Kritik letztlich auf die konservative Figur, die durch das Wertfreiheitspostulat der Naturwissenschaften jede Wertorientierung verlorengehen sieht. Kohärent dazu treten in seinem wertehischen Lösungsprogramm die Naturwissenschaften ohnehin nur noch als Agenten einer verderblichen, weil wertzerstörenden Wertfreiheit auf (vgl. weiter unten). Auch hier aber übt Keilhacker noch zusätzliche Kritik. Zwar betont er wiederum, daß die mit der naturwissenschaftlichen

Eingreifen von Seiten außer- oder übernatürlicher Kräfte mehr nötig“ sein lasse. (vgl. Keilhakker, Technik, 37-38)

${ }^{38}$ Keilhacker, Technik, 40; im Original partiell kursiv.

${ }^{39}$ vgl. etwa: Keilhacker, Technik, 37-40

${ }^{40}$ vgl. Keilhacker, Grundprobleme, 28 
Denkform einhergehende ,qualitätswertbezogene‘ Neutralisierung, datenorientierte Vereinheitlichung und sachlich-distanzierte Perspektive unbestreitbare Erfolge für die Menschheit nach sich gezogen haben, die keinesfalls zurückgezogen werden sollten oder verzichtbar seien, doch sieht er daneben perniziose Auswirkungen. ${ }^{41}$

Als besonders verderblich betrachtet es Keilhacker zunächst, daß die naturwissenschaftliche Rationalisierung nicht auf die Erforschung der ,Naturgesetze ${ }^{\natural}$ beschränkt geblieben sei, sondern sich zusammen mit ihrer, Wertzerstörung' im 18. Jahrhundert auf die Philosophie, insbesondere die Anthropologie und Psychologie, ausgedehnt und diese in ihren ,Sog gezogen habe, daß also die Rationalisierung und ihre Konsequenzen für die ,qualitativen Werte' sich auf das Gebiet der Geisteswissenschaften ausgeweitet haben. ${ }^{42}$ Entsprechend sieht er mit der Konstitution des ,Rationalismus der Aufklärung eine Blickverengung vom ,Qualitativen' auf das ,Quantitative‘ etabliert, als deren letzte, eindimensionale Konsequenz Positivismus und Monismus sowie erneut der ,Materialismus' erscheinen. ${ }^{43}$ Nicht nur die Herrschaft einer ,materialistischen' Orientierung aber werde dadurch befestigt. Als weitaus problematischer erscheint in Keilhackers Text, daß die Rationalisierung auch die „Fragen des Gemeinschaftslebens, des Verhältnisses von Individuum und Staat, dem Zusammenleben der Völker, aber auch (...) des Verhältnisses des Menschen zu Gott" ${ }^{\text {‘44 }}$ an sich gezogen haben. Darin liegt für ihn ein unzulässiger Übergriff in ,qualitative' Bereiche, dessen Folgen er vor allem am Beispiel von, philosophischen Biologismen' expliziert. So verweist er zunächst auf die Beförderung der letztgenannten durch vor allem die Evolutionstheorien von Lamarck und Darwin und deren Entwicklungsbegriff und setzt er als ihre letzte Konsequenz die Rassetheorien an. ${ }^{45}$ An ihnen versucht er die besondere, inhumane Wirkung der Rationalisierung und ihrer ,Wertzerstörung nachzuweisen. Gerade die Biologismen nämlich ermöglichten eine ,Wiedereinführung des von den Naturwissenschaften ursprünglich ausgegrenzten ,qualitativen Wertens', ohne nun jedoch noch auf eine „metaphysische oder gar religiös-gläubige“ ,Wertungsgrundlage' rekurrieren zu müssen. ${ }^{46}$ Unter Vorspiegelung von ,sachrationaler' Objektivität werden nach dieser Vorstellung in den Biologismen (und den daraus hervorgehenden Rassetheorien) letztlich Wertentscheidungen unter den Kriterien Gut und Schlecht gefällt, um dann jedoch in der Terminologie von Richtig und Falsch ausgesagt zu werden. Derart aber gerate man mit Nietzsche ins „Jenseits von Gut und Böse", d.h. für Keilhacker: ins abgrundtief Amoralische. ${ }^{47}$

Die Ausdehnung der Rationalisierung auf die Geisteswissenschaften scheint nach dieser Kritikfigur also die ,qualitativen‘ Gegenstände der letztgenannten zu usurpieren und der ohnehin prekären Herrschaft ihrer Kategorien zu unterwerfen. Nicht die Usurpation der Gegenstandsbereiche der Geisteswissenschaften aber stellt für Keilhacker dabei das eigentliche Skandalon dar, sondern die Verdrängung eines dort angesiedelten Wertekorpus und die Übernahme von dessen Aufgabe. So werden die

\footnotetext{
41 vgl. zu dieser Doppelbewertung etwa: Keilhacker, Technik, 46

42 vgl. Keilhacker, Technik, 41-42

43 Keilhacker, Technik, 41

44 Keilhacker, Technik, 42

45 Keilhacker, Technik, 46

${ }^{46}$ Keilhacker, Technik, 46

${ }^{47}$ Keilhacker, Technik, 46
} 
Geisteswissenschaften zunächst offenbar als ,qualitativ wertende' Wissenschaften verstanden, die auf der Basis vorgegebener Werte zugleich Hort qualitativer Werturteile sind. Der Ursprungsort dieser Werte und zugehörigen Werturteile wird jetzt als ,metaphysische und religiös-gläubige Grundlage' benannt, d.h. offen als traditional überkommenes Korpus, das letztlich aus vorneuzeitlichen Gesellschaftszusammenhängen - wohl mittelalterlichen und deren ,Ordo-Denken' - stammt. Dieses traditionelle Wertekorpus nun scheint in der Neuzeit nicht nur zurückgedrängt, sondern seine Aufgabe scheint von der naturwissenschaftlichen Rationalisierung an sich gezogen. So findet auch in den Geisteswissenschaften zunächst ein Verfall der, qualitativen' Werte statt, der durch die Etablierung einer quantifizierend-methodischen Kriteriologie ins Werk gesetzt ist und ein entsprechendes, Wertevakuum' zurückläßt. Die besondere Gefahr liegt jedoch nun darin, daß dieses Vakuum sofort gefüllt wird, ohne als Füllung zu erscheinen. So wird die vormalige qualitativ-wertende Funktion der Geisteswissenschaften keineswegs beseitigt, also etwa durch ,quantifizierende Urteile und sachrationalen Diskurs ersetzt, sondern lediglich verdeckt: Die ,qualitative' Wertung bleibt trotz der Rationalisierung der Geisteswissenschaften erhalten, gibt sich aber als solche nicht mehr zu erkennen, sondern inszeniert sich als ,wertfreie‘ Objektivität. Mit einer solchen Übertragung der sachrational-methodischen Kriteriologie auf die Geisteswissenschaften aber scheint dann sowohl die Möglichkeit ethischer Reflexion als auch moralischen Entscheidens ausgelöscht. Als anscheinend sachrationale Urteilsfindung und -fällung nämlich ist der geisteswissenschaftliche Diskurs dem moralischen nicht mehr zugänglich, sondern ebenso wie die Naturwissenschaften lediglich durch Verifikation oder Falsifikation zu beeinflussen. Da Moralität sich außerdem im Vorangehenden mehrfach als über Werte konstituierte angedeutet hat, scheint durch den Verfall der ,qualitativen' Werte dem moralischen Diskurs hier zudem seine Basis geraubt. Ging es also in der ersten, grundsätzlichen Kritik am Verfall ,qualitativer' Werte zugunsten einer ,quantitativen', sachrationalmethodischen Orientierung um die Verfehlung des ,Wesens' einer Sache überhaupt, so scheint die Rationalisierung nun zu einer Verstellung der Ethik als reflexiver Theorie qualitativen Wertens und zu einer Aufhebung der Sittlichkeit durch (Pseudo-) Sachlichkeit zu führen.

In einem weiteren Kritikpunkt greift Keilhacker schließlich noch die Ausweitung der Rationalisierung zur methodischen Organisation des ,Lebendigen' an. Auch dort scheint wieder ein verderblicher Werteverfall die Folge zu sein. Zunächst stellt Keilhacker fest, daß Rationalisierung generell dazu tendiere, sich ,auf die Gebiete des Lebendigen und Menschlichen ${ }^{448}$ zu übertragen, die jedoch als schlechthin inkommensurabel mit ihr gelten. Die weiter oben genannte perspektivische Verengung bedinge dabei eine Umorientierung in der Lebensführung der rationalisierenden Subjekte auf umfassende Effizienz und Erfolg hin, deren messende Bestimmung nach denselben Kriterien wie das naturwissenschaftliche Experiment und deren Herstellung auf dieselbe methodische Weise wie die Organisation dieses Experiments erfolgten. Konsequenz sei zum einen eine gesellschaftliche Leistungsorientierung, welche die Leistungen der Subjekte nur noch unter den Gesetzen von ,Maß und Zahl ${ }^{\circ}$ betrachte, derart aber die eigentlich schöpferischen Leistungen verlorengehen lasse

${ }^{48}$ Keilhacker, Erziehung, 154 
und zu „bloßen Reproduktionen und schließlich zu geistiger Sterilität“ führe. ${ }^{49}$ Die ,qualitative', schöpferische Leistung nämlich beruhe auf ,gesamtpersönlichen Eigenschaften " ${ }^{\text {s0 }}$ und sei, ,je höher die zu beurteilenden Leistungen in geistiger Hinsicht (ästhetisch, wissenschaftlich, sittlich) stehen “51, umso weniger mit quantitativen Kriterien zu erfassen oder gar durch derartige Beurteilungen zu fördern. Wenn die industrielle Gesellschaft daher ,nicht steril und völlig kulturlos werden“ wolle, gelte es, das "quantifizierende Leistungsdenken“" wieder in seine Schranken zu weisen. ${ }^{52}$ Als zweite Konsequenz der ,quantifizierenden' Rationalisierung des ,Lebendigen' erscheint dann, daß wechselnde qualitative Zustände wie „Gesundheit und Krankheit, Freude und Leid, Leben und Tod" unter die Methodik der Ratio gezwungen bzw. von ihr schlicht negiert werden sollen. ${ }^{53}$ Statt diesen qualitativen Befindlichkeiten und ihrem Wechsel Raum zu geben nämlich, versuche der leistungsorientierte ,rationale Mensch', sie geradezu widernatürlich durch sein erfolgsorientiertes Lebenskalkül zu verdrängen. Die große Gefahr bestehe dann darin, unter den Prämissen von technisch-wissenschaftlicher Rationalisierung „einen Menschen züchten und erziehen zu wollen, der reibungslos funktioniert, gleichzeitig aber zum Zerrbild alles Menschlichen deformiert wird“. ${ }^{54}$ Die Rationalisierung erscheint damit in fast Spengler'scher Schärfe ${ }^{55}$ als Feind des Lebendigen, dessen Spezifität natural als Rhythmik des Wachsens, Entfaltens und Vergehens bestimmt wird ${ }^{56}$ und das schematisierender Planung und Kontrolle entzogen bleiben soll. Keilhackers Kritik trifft so gerade ein Kernmoment der Moderne schlechthin, nämlich jene ,Rationalisierung der Lebensführung' zur ,methodischen', wie sie von Max Weber epochenanalytisch herausgearbeitet worden ist.

In der Folge richtet sich diese Kritik dabei wieder auf einen spezifischen Werteverfall, der von der quantifizierend-methodischen Lebensorganisation und -führung verursacht scheint und bei dem genau besehen, eigentliche Werte von ,Scheinwerten', also von zu Unrecht Wertstatus beanspruchenden Orientierungen verdrängt werden. Die verwendeten ,neuen' Kriterien ,Effizienz' und ,Erfolg', deren Meßbarkeit sich begrifflich als ,Aussto $\beta^{6}$ faßt, ${ }^{57}$ gelten nämlich für Keilhacker als ,Maßstäbe', mit denen fälschlich werthaft besetzte Orientierungen konstituiert werden und die damit ,ältere', ,qualitative' Werte in den Verfall treiben. Das zeigt sich zunächst darin, da $B$ er von der "Wertschätzung" einer durch ,quantifizierendes Leistungsdenken' beförderten ,vita activa' spricht, deren ,wertförmiger' Status den der, älteren', nämlich mittelalterlichen, ,vita contemplativa verdrängt habe. ${ }^{58}$ Die Kernmomente

\footnotetext{
${ }^{49}$ Keilhacker, Grundprobleme, 33

50 Keilhacker, Grundprobleme, 32

51 Keilhacker, Grundprobleme, 33

52 Keilhacker, Grundprobleme, 38

53 Keilhacker, Erziehung, 155

${ }_{55}^{54}$ Keilhacker, Erziehung, 152

55 vgl. Spengler, Oswald, Die Jahre der Entscheidung 1, München 1933, 5-6: „Wir befinden uns heute noch im Zeitalter des Rationalismus, das im 18. Jahrhundert begann, und das im 20 . rasch zu Ende geht. (...) Empfängnis und Geburt sind ihm fremd. Deshalb ist sein Werk künstlich und leblos und tötet, wenn es mit wirklichem Leben zusammentrifft."

${ }_{57}^{56}$ vgl. etwa: Keilhacker, Erziehung, 152

57 vgl. hierzu auch: Keilhacker, Grundprobleme, 31

58 Keilhacker, Grundprobleme, 30
} 
der vita contemplativa, ,Beschaulichkeit' und ,Besinnlichkeit', würden dadurch zu „Müßiggang“ und „Zeitvergeudung" umgewertet, ${ }^{59}$ d.h. also letztlich zu ,Unwerten erklärt und dem Verfall preisgegeben, während Aktivität und meßbare Produktivität ihren Platz als positiv werthaft besetzte Eigenschaften einnähmen. Weiter verweist Keilhacker darauf, daß in dem Slogan "The Highest, the Biggest, the Most" eine „Bewunderung für das quantitativ Große“ und eine „Hochachtung vor dem Äußerlichen" ausgedrückt seien. ${ }^{60}$ Auch in diesem Slogan äußert sich mithin eine ,Wertschätzung, welche andersgeartete Orientierungen und zugehörige ,Qualitätswerte‘ verlorengehen zu lassen scheint. Schließlich treten noch ,Jugend“ und ,Leistungsfähigkeit' unter der Kriteriologie rationalisierter Lebensführung und ihrer Verdrängung ,naturaler Rhythmen' als werthaft besetzte Eigenschaften auf, die andere, nicht unter ihren Kriterien erreichbare Werte, wie die ,Weisheit des Alters' und leistungsfremde ,Qualitäten' zerfallen lassen. ${ }^{61}$ Die quantifizierende Kriteriologie und die dem naturwissenschaftlichen Experiment nachkonstruierte Methodik der Rationalisierung treiben so nach dieser Kritikfigur eine Reihe von wertbesetzten Eigenschaften und Charakteristika auf Kosten ,älterer' aus sich hervor, die dadurch verfallen. Die Kritik an den konstatierten Rationalisierungsvorgängen zeigt sich so wieder als Kritik an einem Werteverfall, der als Verfall bestimmter, nämlich älterer Werte gezeichnet wird.

Damit zeigt sich die Auseinandersetzung Keilhackers mit den Naturwissenschaften und dem von diesen konstituierten Weltverhältnis insgesamt als Rationalisierungskritik. Sie ist zugleich wieder eine Kritik an einer ,falschen Autonomisierung durch Verabschiedung bestimmter Werte und bezieht sich derart modernitätskritisch auf neuzeitliche Prozesse, deren historische Wurzeln konsequent in der Zeit der Aufklärung aufgesucht werden. Die Begriffsperspektive bildet wieder eine Dichotomie, diesmal von ,Qualität' und ,Quantität', denen jeweils spezifische Orientierungen und ein spezifisches Weltverhältnis zugeschlagen werden. Als Marken der, qualitativen' Orientierung treten die Kategorien des Numinosen, Ästhetischen und Emotional-Empfindungsmäßigen auf, während die Kriteriologie der ,quantitativen' Orientierung in Meßbarkeit und ,Beweisbarkeit', d.h. argumentativer Einlösbarkeit bzw. empirischer Nachprüfbarkeit durch Wiederholung gesehen wird. Das zugehörige Weltverhältnis ist entsprechend einmal ein metaphysisches und religiös-gläubiges, ein andermal ein mundan-sachliches und methodologisches. Gerade durch seine Methodologie zeigt sich das zweite dabei als Form der Rationalisierung, und auch Keilhacker skizziert mithin das neuzeitlich-moderne Weltverhältnis als rationales. Dessen Konsequenz wird dann in einer ,Entzauberung' der Welt gesehen, die im Sinn der ,Austreibung' einer numinos-metaphysischen Weltbetrachtung, d.h. durch Ablösung des ersten Weltverhältnisses, durchgeführt wird. Der ProzeB der Entzauberung erscheint dabei zugleich als Verfall einer mit dem vorneuzeitlichen Weltverhältnis verknüpften ,Wertewelt', der als durch die Konstitution quantifizierend-methodischer Kategorien und einer zugehörigen Sachrationalität verursacht gilt. Obschon durch die rationale Kriteriologie zunächst neue Werte konstituiert scheinen, die an

${ }^{59}$ Keilhacker, Grundprobleme, 30

${ }^{60}$ Keilhacker, Grundprobleme, 31

61 vgl. dazu etwa: Keilhacker, Technik, 20 
die Stelle der alten treten, werden diese dann als ,Scheinwerte' behandelt und wird als Konsequenz des Verfalls des älteren Wertekorpus ein ,Wertevakuum' angesetzt. Damit aber zeigt sich auch der Autonomisierungsvorgang, der sich über diese Rationalisierung vermittelt, als fehlgehendes Unternehmen. So ist er nach dem vorgängig rekonstruierten Zusammenhang in Keilhackers Konzept nicht nur eine Ablösung von dem vorneuzeitlichen Weltverhältnis und der zugehörigen Lebens- und Gesellschaftsorganisation, sondern mit besonderer Betonung eine Ablösung von dem zugehörigen Wertekorpus und -kosmos. Das heißt aber, daB er in eben das genannte Wertevakuum führt und so die Autonomie in Nihilismus transformiert. Die an die Stelle der zerfallenen Werte gesetzte gesellschaftliche Orientierung nach Erfolg und Leistung wird dabei als dehumanisierende Zerstörung naturaler Rhythmen und, qualitativer' Befindlichkeiten diskriminiert, so daß mit ihr ein Ausweg aus dem Vakuum nicht gefunden werden kann. Die Autonomisierung tritt derart als ,schlechte Emanzipation'vor Augen und scheint das Ziel der ursprünglich angestrebten Humanisierung zu verfehlen. Mit der Ausdehnung auf die Geisteswissenschaften und der verdeckten Revitalisierung ,qualitativen Wertens' scheint die Rationalisierung außerdem eine Zerstörung der Moralität zu entfalten: Der eigentliche Charakter dieser Moralität wird dabei dezidiert als Orientierung an einem vorneuzeitlichen Wertekorpus deutlich gemacht. Die Rationalisierung aber ist so in Keilhackers Theorie primär eine Wurzel von Übeln, und seine Kulturtheorie erweist sich erneut als Modernitätskritik, die jetzt neben der Autonomisierung durch technische Weltbewältigung das zweite Kernstück des Projekts der Moderne angreift.

\section{Nivellierung, Kommerzialisierung und Fremdbestimmung durch Ökonomie}

Analog zu seiner Auseinandersetzung mit Technik und Naturwissenschaften führt Keilhacker auch die mit dem dritten Bewegungsprinzip des neuzeitlich-modernen Weltverhältnisses, der Ökonomie. Von ihr wird zunächst gesagt, daß sie durch das Medium Geld ein Universalisierungsinstrument der Tauschbarkeit und durch Verbindung mit der Technik eine Lebensqualität steigernde Produktion geschaffen habe, die erst über die bloße Notwendigkeit hinaus Bedürfnisbefriedigung und Genuß ermöglichen. Zugleich jedoch führe sie in eine Nivellierung und Kommerzialisierung, die ständig überzuborden und in universelle Fremdbestimmung umzuschlagen drohten. Bereits der „Tauschmaßstab“ Geld an sich erscheint Keilhacker problematisch. Er verweist darauf, daß es ,zu allen Zeiten' Bereiche des menschlichen Lebens gegeben habe, ,auf die sich die Gesichtspunkte der Tauschbarkeit und der Käuflichkeit als unanwendbar erwiesen haben“ ${ }^{62}$ Mit der „fortschreitenden Auflösung der patriarchalischen Gesellschaftsordnung“ und der „Einebnung der Standes- und Klassenunterschiede“ jedoch habe das Bewußtsein unkäuflicher Entitäten ,sehr an Raum (...) und vermutlich auch an Tiefe des Empfindens verloren ". ${ }^{63}$ Eine Nivellierung von Gegenständen, vor allem aber auch von ,menschlichen Beziehungen' unter dem quantifizierenden und derart vereinheitlichenden Übersetzungsmaßstab des Geldes sei die Folge. ${ }^{64}$ Daneben konstatiert Keilhacker dann als Wesen der sich entwickeln-

\footnotetext{
${ }^{62}$ Keilhacker, Technik, 24

${ }^{63}$ Keilhacker, Technik, 25

64 vgl. Keilhacker, Technik, 24-25
} 
den industriellen Ökonomie eine maschinelle, serialisierte Produktion, die um der Rentabilität willen Massenabsatz verlange und als deren oberstes, Wesensgesetz ${ }^{6}$ (offensichtlich) die Profitmaxime zu betrachten sei. Aus ihr gehe eine grundsätzliche Orientierung auf Wachstums- und Produktionssteigerung hervor, die Absatznot und Zwang zur Schaffung neuer Nachfrage nach sich ziehe. ${ }^{65}$ Im Gegensatz zum „Lob der Bedürfnislosigkeit früherer Zeiten" setze die moderne Wirtschaft deshalb auf „Bedürfnisweckung und Bedürfnissteigerung“ mittels Werbung. ${ }^{66}$ Statt die Produktion an den Bedürfnissen zu orientieren, versuche sie die Bedürfnisse an die Produktion anzupassen und derart zu kommerzialisieren. Dies aber bedeute zum einen, daB die ,heutigen Lebensgewohnheiten' nicht mehr auf ,ursprünglichen Lebensbedürfnissen ${ }^{467}$ beruhten, sondern auf ,künstlicher' Bedürfnissteuerung, und zum anderen, $\mathrm{da} B$ diese Steuerung in eine umfassende heteronomistische AuBengeleitetheit führe. Um des erforderlichen Massenabsatzes willen nämlich sei „das Ziel der Wirtschaft“" der „in jeder Hinsicht gefügige Konsument, der berühmte außen-geleitete Mensch“ ${ }^{68} \mathrm{Um}$ seiner Verplanbarkeit und Steuerbarkeit willen werde er zudem nicht mehr als Subjekt betrachtet, sondern gewissermaßen als ,Faktorenbündel', das es mit Hilfe der ,wissenschaftlichen Psychologie' in Griff zu bekommen gelte. ${ }^{69}$ Nicht anders verhalte es sich mit den für die Produktion notwendigen ,Arbeitskräften', die ebenfalls als ,Faktorenbündel', diesmal als Träger bestimmter, für die schematisierten Arbeitsprozesse der Fabriken benötigter Fähigkeiten betrachtet würden. ${ }^{70}$ In beiden Fällen scheinen so die Subjekte in den ökonomischen Schemata zu verschwinden. Nicht nur die ,Ursprünglichkeit', d.h. wohl: eine natural gedachte Authentizität der Bedürfnisse, sondern auch die ,Eigentlichkeit' und ,Ganzheit' der Person sieht Keilhacker damit bedroht, und die letztgenannte scheint als fungible Größe in funktionell-profitablen Planungsstrukturen aufzugehen. Das aber bedeutet, $\mathrm{da} B$ die vormals angezielte Autonomie der modernen ökonomisierenden Subjekte in ungewollte Heteronomie umschlägt. Sollte durch Güterproduktion und Handel Souveränität gegenüber der Natur und den durch diese induzierten Notständen erreicht werden und sollte die Möglichkeit, durch selbsttätige ökonomische Prosperität sich einen besseren sozialen Stand zu verschaffen, d.h. aber der heteronomistischen Festlegung der Ständegesellschaft zu entkommen, eine selbstbestimmte Lebensgestaltung garantieren, so scheinen diese erstrebte Unabhängigkeit und Selbstbestimmung erneut in eine andere Abhängigkeit zu kippen und scheint das Projekt der Autonomisierung durch sich selbst vereitelt.

Damit einher geht wieder ein spezifischer Verfall, der als ,Werteverfall' erscheint und dessen Skizze nun letztlich auf die ,Materialismuskritik' zurückführt. So klagt Keilhacker zunächst, daß die vormals werthaft besetzten habituellen Orientierungen der „Sparsamkeit und Konsumeinschränkung“ von „ständiger Konsumausweitung“

${ }^{65}$ vgl. Keilhacker, Grundprobleme, 16-18

${ }^{66}$ Keilhacker, Technik, 28

${ }^{67}$ Keilhacker, Technik, 28

68 Keilhacker, Grundprobleme, 18

${ }^{69}$ vgl. Keilhacker, Grundprobleme, 18, 47; beklagt wird, daß nicht mehr der Mensch,Ausgangspunkt' sei, sondern, die Technik' (und Ökonomie).

${ }^{70}$ vgl. Keilhacker, Technik, 26 
ersetzt seien. ${ }^{71}$ Insofern diese Konsumausweitung eine entsprechende Kommerzialisierung der Bedürfnisse erforderlich mache, sei die Konsequenz nicht zuletzt eine enorme Senkung des Niveaus. Die ,quantitative Bedürfnissteigerung der Kommerzialisierung nämlich sei keineswegs mit einer Differenzierung der Bedürfnisse identisch, sondern es stehe zu befürchten, daß die ,Analyse' der letztgenannten (durch die Werbepsychologie) letztlich den ,primitiven' als den „elementaren, triebkräftigeren" Bedürfnissen zur Durchsetzung und ungeahnten Ausweitung verhelfen werde." Im Gegenzug dazu drohten die ,geistigen Bedürfnisse' zu verschwinden, jedenfalls aber in ihrer Werthaftigkeit zurückgesetzt zu werden. Ihre Stelle scheint außerdem wieder illegitim von einer ,materialistischen' Orientierung usurpiert, welche den „Kauf und Verbrauch von Gütern zum Ritual“ erhebe. ${ }^{73}$ Erneut tritt so implizit ein Verfall des ,Geistigen', das Wertstatus besitzt, zugunsten des ,Materiellen', das mit dem Terminus der ,Güter auf einer anderen Ebene angesiedelt ist, vor Augen und ist die Konsequenz des Verfalls eine Art ,Wertevakuum'. Hierbei gerät nun die Werbung für Keilhacker direkt zum Agenten des Verfalls, wenn sie durch Slogans wie: „Wer fotografiert, hat mehr vom Leben“74, materielle Güter mit ,Wertcharakter ausstattet, und damit der ,materialistischen' Orientierung durch Etablierung von ,Scheinwerten' zur Herrschaft verhilft. Da die derart konstituierten ,Scheinwerte' die ,echten Werte' keinesfalls vollgültig ersetzen können, bleibt am Ende ein Werteverfall zu konstatieren. Durch ihre ökonomisch begründete Schlüsselrolle in der Industriegesellschaft gerät die Werbung so geradezu zur herausragenden Instanz der Wertzerstörung. Keilhackers Kritik enthält damit also wieder die Grundfigur eines Werteverfalls, der von einer Verdrängung ,geistiger Werte' durch ,materielle Güter ${ }^{\text {‘ }}$ eingeleitet wird. Dieser Verfall geht nun zugleich mit einem Niveauverfall durch die Vorherrschaft ,primitiver Bedürfnisse' einher. Außerdem scheint, wie die grundsätzliche Kritik an der Ökonomie nahelegt, zum einen der ,Wert' der Person durch verplanbare und verrechenbare Eigenschaften substituiert, d.h. letztlich auch in ,materialistisch-quantifizierbare' Größen transformiert und so als Wert aufgelöst. Zum anderen scheint durch die Abstraktion des Geldes an die oberste Stelle der Werteskala der ,Tauschwert' gesetzt, der sich jedoch wieder als ,Scheinwert' entpuppt und derart eine Wertzerstörung betreibt. Unter seiner Dominanz, so legt diese Kritik nahe, drohen nämlich auch die ,Unverrechenbarkeiten' menschlicher Beziehungen in TauschScheinwerte verwandelt und mit materiellen Gütern gleichgesetzt zu werden. Sowohl Personalität als auch Interpersonalität verlieren dann ihren Eigenwert und transformieren sich in Waren. Obschon die Keilhackersche Kritik keineswegs auf marxistische Paradigmen zurückgreifen will, nähert sie sich so aus der Perspektive des in ihr konstatierten Werteverfalls unabsichtlich marxistischer Kritik an.

Insgesamt zeigt sich die Begriffsperspektive der Auseinandersetzung Keilhackers mit der Ökonomie wieder als dichotomische. Im Hintergrund steht zunächst die bereits bekannte Differenzierung von ,Qualität' und ,Quantität', die zugleich für zwei divergente Weltverhältnisse und habituelle Orientierungen stehen und deren Auf-

\footnotetext{
${ }_{72}^{71}$ Keilhacker, Grundprobleme, 16

72 vgl. Keilhacker, Technik, 30

${ }^{73}$ Keilhacker, Grundprobleme, 16; Keilhacker zitiert hier Lebow nach Packard. (vgl. Fußnote weiter oben)

${ }^{74}$ Keilhacker, Technik, 28
} 
einanderfolge wieder einen Werteverfall indiziert. So werden auf der einen Seite die Personenwürde und die ,Unverrechenbarkeiten' interpersonaler Beziehungen angesiedelt und diesen auf der anderen Seite eine abstraktiv-quantifizierende, Faktorisierung' personaler Eigenschaften und Fähigkeiten sowie die Tauschbarkeit gegenübergestellt. Die eine Seite wird dann unter Rekurs auf die Ständegesellschaft illustriert und läßt so das angezielte Weltverhältnis als statisches Verhältnis zur Sozialität und zugehörigen traditionalen Verhaltensregeln, d.h. primär als Sozialverhältnis deutlich werden. Dem gegenüber steht das neue, ökonomisch verursachte Weltverhältnis, das nun die gesamte Welt inklusive der sozialen und personalen Größen als Ensemble miteinander vergleichbarer, ineinander übersetzbarer und derart tauschbarer Entitäten betrachtet, d.h. ein Verhältnis zu abstraktiv konstituierten Gegenständen ist. Die zugehörigen Orientierungen erscheinen entsprechend einmal als Achtung und ,Empfindungstiefe', denen eine Strebung nach ,Bedürfnislosigkeit' zur Seite gestellt ist, ein andermal als funktionale Sachlichkeit und Streben nach Profit. Die erste erhält dabei werthaften Status, während die zweite lediglich ,Scheinwerte' begründet. Die Ablösung der ersten durch die zweite Orientierung erscheint daher als Werteverfall, und wird auf die Materialismuskritik zurückgebogen. Entsprechend scheinen erneut materielle Güter, denen jetzt als Basis ,primitive Bedürfnisse‘ zugrunde gelegt werden, die ,geistigen Werte' zu verdrängen, wobei diesem Vorgang mit der Werbung zusätzlich noch ein spezifisches ,Propagandainstrument' zu Diensten ist. Durch den Gesamtproze $B$ der Einrichtung eines derart abstraktifizierenden und ,wertzerstörenden ${ }^{6}$ ökonomischen Systems aber scheint erneut die Autonomie, die ursprünglich durch produktive Emanzipation vom Naturzwang und die Flexibilisierung des ständischen Gesellschaftskonzepts erreicht werden sollte, infrage gestellt, ja sogar durch eine neue Heteronomie der Bedürfnisplanung und des profitablen, absatzsteigernden Wachstumszwangs korrumpiert. Nicht zuletzt mit dieser Kritik an der ,fehlgehenden Autonomisierung, die durch die Etablierung des Bürgertums als ,dritter Stand" und die soziale Flexibilisierung durch Auflösung der Ständegesellschaft indiziert sein sollte und die derart Teil des Projekts der Moderne ist, zeigt sich Keilhackers Theorie einmal mehr als Modernitätskritik.

\section{Entwertung von Metaphysik und Religion durch Globalisierung}

Neben den modernitätskonstitutiven Momenten von Technik, Naturwissenschaft und Ökonomie widmet sich Keilhacker schließlich noch der Globalisierung. Auch dort findet er gefährdendes Potential. Zunächst freilich nennt er das ,Zusammenrücken aller Menschen und aller Völker zu einer Welt (,one world') “75 als einfache Tatsache, die von der modernen Technisierung und Industrialisierung und ,vor allem' den ,modernen Transportmitteln', wie Eisenbahn, Auto und Flugzeug, sowie den ,modernen Kommunikationsmitteln', wie Telefon, Telegraph, Rundfunk und Fernsehen verursacht worden sei. ${ }^{76}$ Die globale Verknüpfung als ein weiteres Signifikum der von den modernen Weltbewältigungsstrategien hervorgerufenen Entwicklungen, die aus „,den verschiedenen Ländern und Erdteilen “ ${ }^{\text {T7 }}$ Mitglieder einer entstehenden, Weltgesell-

\footnotetext{
${ }_{76}^{75}$ Keilhacker, Erziehung, 11

76 vgl. Keilhacker, Erziehung, 41

77 Keilhacker, Grundprobleme, 48
} 
schaft' werden lassen, wird so erst einmal konstatiert. Dann allerdings verweist Keilhacker darauf, daß mit dem ,Zusammenrücken“ auch ein „Aufeinanderprallen“ und eine „Auseinandersetzung der Wertsysteme aller Völker, Rassen, Religionen, sozialen Gruppen und Klassen untereinander" gegeben seien, „wie sie in gleicher Weise in der Geschichte der Menschheit noch niemals vorgekommen sind“.78 Darin aber erkennt er eine fundamentale Gefährdung. Nachdem schon das technisch-naturwissenschaftliche Weltverhältnis zu einer ,Zerstörung der Werte' im Sinn des ,Materialismus' geführt hat und die metaphysisch-religiöse ,Wertungsgrundlage' zweifelhaft werden ließ, und nachdem bereits die Ökonomie diese Situation zur Nivellierung, Kommerzialisierung und, veroberflächlichenden' Außensteuerung verschärft hat, droht dieser Prozeß nun durch die Globalisierung eine weitere Zuspitzung oder zumindest Unterstützung zu erfahren. In der internationalen Begegnung der verschiedenen ,Wertsysteme' der einzelnen Kulturen und ihrer Religionen nämlich sieht Keilhacker die Gefahr, daß deren Interaktionen, statt zu einer (wünschenswerten) Vertiefung der Auseinandersetzung mit den „letzten Fragen des Menschseins“ beizutragen, in eine „fortschreitende Relativierung und Gleichgültigkeit gegenüber der Welt der Werte" münden, die „bis zur Reduzierung auf ein allgemeines Wohlstandsdenken“ reichen. ${ }^{79}$ Folge der Globalisierung also könnte eine Gesellschaft sein, „deren Gott der ständig steigende Lebensstandard sein würde und nichts darüber hinaus“. ${ }^{80}$ Die Chancen eines interreligiösen Dialogs, einer kommunikativen Zusammenarbeit mit dem Ziel der Erforschung der letzten Gestalt und Sinnhaftigkeit von Mensch und Welt, also gewissermaßen eines internationalen metaphysischen Kolloquiums wären damit verspielt. Die Herrschaft der ,materialistischen' Orientierung der Gesellschaften aber wäre dann in einer Weise zementiert, die nicht einmal mehr ,extrakulturelle Fluchtmöglichkeiten' offenläßt.

Der eigentliche Gefährdungsimpetus der Globalisierung scheint dabei allerdings kaum in der Begegnung der divergierenden ,Wertsysteme ${ }^{6}$ und Religionen allein zu liegen. Tatsächlich bedeutet die daraus möglicherweise fließende Relativierung der jeweils eigenen kulturbedingten Position zwar mit großer Wahrscheinlichkeit eine Verunsicherung ihres dogmatischen Gehalts, jedoch noch nicht die Aufkündigung der in ihr beschlossenen ,metaphysischen Strebung' schlechthin. Im Gegenteil, es könnte diese Relativierung ja auch jene Toleranz und Rücksichtnahme befördern, die Keilhacker selbst als notwendige Entwicklungskonsequenz des Globalisierungsprozesses fordert, ${ }^{81}$ und derart gerade die nötige Gesprächsbereitschaft und -grundlage schaffen. Der Gefährdungsimpetus ergibt sich vielmehr wieder aus den von Technik, Naturwissenschaft und Ökonomie hervorgebrachten Weltverhältnissen und ihrer Wertauflösung. Diese haben nach Keilhackers Theorie ja bereits unabhängig von der Globalisierung für ,verkürzte 'Orientierungen gesorgt, d.h. das ,qualitative Wertekorpus durch eine nivellistische, abstraktive und ,materialistische Ausrichtung der Gesellschaft zerstört. Von der Globalisierung wird dieser Verfall dann nur noch weitergetrieben: Unter dem binnengesellschaftlichen und binnenkulturellen Primat der genannten Orientierungsperspektiven nämlich droht die interkulturelle Ausein-

${ }_{78}^{78}$ Keilhacker, Erziehung, 11

${ }^{79}$ Keilhacker, Grundprobleme, 48

${ }_{81}^{80}$ Keilhacker, Grundprobleme, 48

81 vgl. Keilhacker, Grundprobleme, 41 
andersetzung die Relativierung der eigenen ,qualitativen', weltanschaulich-metaphysischen Position von der Erkenntnis ihrer Relationalität in eine nivellierend-nihilistische ,Gleichgültigkeit' zu kippen und im subjektiven Bewußtsein durch die ohnehin dominanten ,säkularen Orientierungen' des ,Materialismus', der ,Machbarkeit', der Leistung, der Tauschbarkeit etc. zu ersetzen. Bedrohlich ist also nicht die Globalisierung an sich, sondern eben dieser binnenkulturelle und -gesellschaftliche Primat des neuzeitlich-modernen Weltverhältnisses und seiner Wertauflösung. So rekurriert die Kritik an der Globalisierung wieder auf die skizzierte Kritik an modernen Prozessen und läßt sie ebenfalls Keilhackers Grundhaltung als diesbezüglich modernitätskritische deutlich werden.

\section{Die Keilhackersche Modernitätskritik}

Zusammengefaßt kann Keilhackers Kulturtheorie damit aus der Perspektive einer systematisierenden und dekodierenden Rekonstruktion wie folgt auf den Begriff gebracht werden: Als Kritik an den angeblich fehlgehenden Autonomisierungsbemühungen von Technik, Naturwissenschaft und Ökonomie erweist sie sich zunächst als emanzipationspessimistische Modemitätskritik. Diese zeigt sich dann weiter durch ihre in wertphilosophische Termini gefaßte Kritik an der Umsetzung des technischwissenschaftlich-ökonomischen Weltverhältnisses in gesellschaftliche Orientierungen als Kritik an einem Ethoszerfall. Beide Kritiken rekurrieren auf ein dichotomisches Paradigma, das jeweils ein älteres Weltverhältnis und dessen gesellschaftliche Konkretion von einem neueren abgelöst sieht, und legen sich in entsprechenden dichotomischen Begriffsperspektiven aus. So erscheinen zunächst die technisch bewerkstelligte Freisetzung vom Naturzwang und die Möglichkeit menschlicher Zwecksetzungen als emanzipative Beförderung menschlicher Autonomie. Abgelöst wird hier ein älteres Weltverhältnis zwangsläufiger Submission durch ein neueres des instrumentellen ,Zuhandenmachens'. Ebenso tritt die naturwissenschaftliche Entzauberung der Welt als Freisetzung der letztgenannten in ihre Erforschbarkeit und derart als Beförderung der Autonomie der Wissenschaft auf. Das ältere, metaphysisch-religiöse Weltverhältnis, das jetzt bereits als Gesellschaftsverhältnis autoritativer Wahrheitskonstitution gefaßt ist, wird abgelöst durch ein neues der Rationalisierung, in dem Wahrheit sich durch Nachprüfbarkeit und empirische Einlösbarkeit erweisen muß und keinen apodiktischen Gehorsamsanspruch mehr stellen kann. Zum dritten schließlich flankiert die Ökonomie mit ihrer Produktivität die Emanzipation vom Naturzwang und naturalen Grenzen, also auch die diesbezügliche Autonomisierung, und hilft sie über das Aufbrechen der ständisch zementierten Sozialverhältnisse der gesellschaftlichen Emanzipation. Ein mehr noch durch Sitte und Ständeordnung geprägtes Weltverhältnis wird abgelöst durch ein neues, von Profitabilität und Kommunikabilität (Tauschbarkeit) geprägtes. Trotz der freisetzenden Momente aber scheint die Autonomisierung dann mit der Entstehung der Neuzeit und vor allem der Industriegesellschaft entweder sich in ihr Gegenteil zu transformieren, wie etwa die Heteronomie der Maschine und die verplanende, desubjektivierende Fremdbestimmung durch ökonomische Eigengesetzlichkeiten, oder in die Zerstörung naturaler Rhythmen und die Aufhebung der Moral durch Rationalisierung zu führen. Die emanzipative Ablösung von den jeweils älteren Weltverhältnissen erscheint nach Keilhackers Konzept daher als ,schlechte Emanzipation', in der entweder das Auto- 
nomisierungsunterfangen selbst gegen sich gekehrt und derart unterlaufen wird, oder aber als Moralzerstörung und Denaturierung ihr Ziel der Humanisierung verfehlt. Seine Kritik erweist sich damit als emanzipationspessimistische Kritik an vorwiegend neuzeitlich-modernen Autonomisierungsprozessen, die sich sowohl auf ein Scheitern der Autonomisierung, als auch auf von ihr hervorgebrachte Defizienzen bezieht. Sie ist mit dieser Zielrichtung letztlich eine autonomiefeindliche Modernitätskritik.

In ihrer weiteren Auslegung kann diese Modernitätskritik dann auch als Kritik an einem Ethoszerfall begriffen werden. So war zu sehen, daß in Keilhackers Text die Ablösung des jeweils älteren Weltverhältnisses durch ein neues zugleich als Ablösung von bestimmten, werthaft besetzten Orientierungen und einer vorneuzeitlichen ,Wertewelt‘ erscheint. Die Umsetzung eines Weltverhältnisses in ein Wertekorpus und zugehörige gesellschaftliche Orientierungen nun kann als Umsetzung in ein gesellschaftliches Ethos verstanden werden. In Keilhackers Texten erscheinen dabei lediglich die dem ,älteren` Weltverhältnis zugehörigen Werte als solche, während die von den neuzeitlichen Prozessen konstituierten Orientierungen einen derartigen Status nicht beanspruchen können oder dies zumindest zu Unrecht tun. Die Folge ist, daß dann die Ablösung des, älteren' Wertekorpus durch ,Scheinwerte erfolgt und der Gesamtprozeß nicht als (epochaler) Ethoswandel begriffen werden kann, sondern als Ethoszerfall interpretiert werden muß. Zerstört erscheint aus dieser Perspektive ein Ethos, das sich an ,Geistigkeit', metaphysisch-numinosen Bezügen, naturalen Eigenwerten, Besinnlichkeit, Beschaulichkeit etc. als werthaft besetzten Eigenschaften, Bezugsformen, Haltungen etc. orientiert, und angelastet wird diese Zerstörung der gesellschaftlichen Dominanz materieller Güter, der Meßbarkeit, der Leistung, des Profits etc. Durch die von der Globalisierung verursachte, internationale Begegnung der kulturell divergenten ,Wertsysteme' und die daraus abgeleitete, wechselseitige Relativierung, die nun als ,Entwertung' auftritt, wird dieser Ethoszerfall dann verstärkt. Im schlimmsten Fall aber scheint die Folge des Zerfallsprozesses der völlige Verlust eines Ethos zu sein, also der Ethoszerfall totalisiert zu werden, wenn mit der Ablösung, qualitativer' Kategorien der Wertkonstitution durch ,quantitative', sachrationale Kriterien gleichzeitig der moralische Diskurs durch einen scheinbar sachrationalen ersetzt wird. Der Ethoszerfall erreicht dann seine letzte Konsequenz in einer vollständigen Amoralität und diskreditiert die modernen Prozesse und das moderne Weltverhältnis endgültig. Die Kritik an der Moderne wird damit in eine moralische Kritik gewendet und die Neuzeit zu einer Epoche der Defizienz erklärt. Entsprechend stellt die vorstehende Kritik zugleich wieder einen Angriff auf die Autonomisierung dar, die einmal als Ablösung vom ,älteren Wertekorpus' nun als ,schlechte Emanzipation' von einem Ethos - und damit von Sittlichkeit überhaupt - erscheint und ein andermal durch ihre Rationalisierung die Moralität aufzulösen droht. Die Modernitätskritik zeigt sich so als Kritik an einem gesellschaftlichen Ethoszerfall, der letztlich wieder den Autonomisierungsprozessen angelastet wird und mit der Figur drohender Amoralität seine schärfste Form erhält. 


\subsection{Gesellschaftskritische Fortschreibung: Dynamisierungskritik und Verlust der ,Eigentlichkeit}

Wie bereits eingangs erwähnt, führt Keilhacker seine Kulturtheorie dann zur Gesellschaftskritik weiter und ergänzt er die bereits in der erstgenannten enthaltenen zivilisations- und gesellschaftskritischen Momente aus einer stärker soziologisch orientierten Perspektive. Seine Modernitätskritik wird derart auf gesellschaftlich-soziale Prozesse und deren individuell-identitätsbezogene Auswirkungen hin konkretisiert und präzisiert. Die hierbei von Keilhacker konstatierten Devianzen werden später von der Filmerziehung aufgegriffen und für eine ,eigene', von der reformerischen unabhängige filmbezogene Devianzkritik genutzt. Nicht zuletzt deshalb tut eine ergänzende Skizze der wichtigsten gesellschaftskritischen Theoreme Keilhackers not. - Zunächst widmet er sich insbesondere den von Technik, Ökonomie und Naturwissenschaften mitbedingten sozialen Dynamisierungsprozessen sowie der von Technik und Ökonomie entfalteten ,Eigendynamik' und übt er an beiden wiederum Kritik. Während er aus der Dynamisierung und der damit einhergehenden Diversifizierung von Lebens- und Handlungsbereichen einen Verlust stabilisierender Traditionalität hervorgehen sieht, die einen überfordernden ,Zwang zum Entwurf' etabliert, scheint ihm die Eigendynamik von Technik und Ökonomie in desubjektivierende Manipulation und ,Uniformierung' zu führen. Seine Kritik gerät deshalb im ersten Fall zur Kritik an der neuzeitlichen Entwurfsautonomie und im zweiten zur Klage über den Verlust von ,Eigentlichkeit‘.

Dynamisierungs- und Diversifizierungskritik: Pessimistische Bewertung der Entwurfsautonomie

Die erste Kritik führt Keilhacker ein, indem er sich zunächst der sozialen Dynamisierung widmet. Deren Wurzel sieht er einmal in der forschenden Grundhaltung der Wissenschaften, näherhin wieder der Naturwissenschaften, und zum anderen in der modernen Ökonomie. So konstatiert Keilhacker zunächst, daß jede „neue wissenschaftliche Entdeckung, wie sie täglich in den Tausenden von naturwissenschaftlichen Instituten unserer Hochschulen und Industriebetriebe gemacht werden", die Industriegesellschaft vorwärtstreibe und „unablässig ihre Grundlagen, die Möglichkeiten ihrer Weiterentwicklung, ihres Wohlstands oder Verfalls" verändere ${ }^{82}$ Schon der Grundansatz der Wissenschaft bedingt demnach einen dauernden Wandel und nötigt zu ständiger Umorientierung und Neuanpassung. Diese Dynamik aber erscheint in Keilhackers Konzept als anhaltende Krisensituation, als unablässige Gefährdung, die von einer parallelen Wirkung der modernen Ökonomie verstärkt wird. Auch diese sorge mit ihren ,fortlaufenden Gärungen, Umschichtungen, gelegentlich auch stürmischen Eruptionen" für ständige, nicht vorausberechenbare Veränderungen. ${ }^{83}$ Die Industriegesellschaft befinde sich daher ,,in einem dauernden Zustand der Unsicherheit und Unberechenbarkeit für die Zukunft“, d.h. aber „,in einem Zustand ständiger Bedrohung, auf den sie sich bis jetzt, vor allem allgemeinmenschlich (...)

\footnotetext{
${ }_{83}^{82}$ Keilhacker, Erziehung, 80

83 Keilhacker, Grundprobleme, 69
} 
höchst unzulänglich vorbereitet" habe. ${ }^{84}$ Die von der Dynamisierung durch Wissenschaft und Ökonomie erzeugte Unwägbarkeit gilt damit als äußerst prekär, vor allem, weil sie entsprechende Auswirkungen auf soziale Gegebenheiten und das individuelle Identitätskonzept hat. Der wissenschaftliche und ökonomische Wandel nämlich fordert eine dauernde Umstellungsbereitschaft, Lernfähigkeit und horizontale wie vertikale Mobilität, denen von Keilhacker negativ bewertete Phänomene wie Auflösung der Familienstrukturen, Bindungslosigkeit und, Wendigkeit' korrespondieren.

So skizziert Keilhacker zunächst die Forderung horizontaler Mobilität in der Industriegesellschaft, also jene ,Beweglichkeit' ihrer Mitglieder im Sinn der Ortsunabhängigkeit, die nötig ist, um Arbeitskräfte dort einsetzen zu können, ,wo sie gerade gebraucht werden". ${ }^{85} \mathrm{Im}$ Zusammenhang damit verweist er dann auch auf die frühzeitige Aufhebung der "Seßhaftigkeit der vorindustriellen, abendländischen Großfamilie“, und die Initiierung einer ,bis heute nicht mehr zur Ruhe gekommen Völkerwanderung" der Fremdarbeiter ${ }^{86}$ Dann umreißt er die vertikale Mobilität, also die grundsätzliche Aufhebung schichtspezifischer und berufsständischer Grenzen, die Hand in Hand mit der Verabschiedung der ,Bindung an den Heimatort' geht und die ,sippenmäßige‘ und ,ständische Gesellschaftsordnung beseitigt, in der noch eine „Bindung an den väterlichen Beruf" und ,an ständische Organisationen“ herrschten. ${ }^{87}$ SchlieBlich nennt er noch die Umstrukturierung der Familie von „Produktionsgemeinschaften zu Konsum- oder Erwerbsgemeinschaften “88 sowie die damit zusammenhängende Ablösung der Großfamilie durch die ,städtische Kleinfamilie und die Divergenz der Generationen, näherhin die Ausgliederung der Alten aus dem Familienverbund und die Beschränkung auf zwei Generationen (Eltern und Kinder) ${ }^{89}$

In all diesen soziologisch geläufigen und auch von Keilhacker als durchaus unhintergehbar anerkannten Entwicklungen macht er dann spezifische Devianzen aus. Zunächst sieht er in der Verabschiedung der Großfamilie den Erfahrungsraum der Familie beschnitten, da dieser sich auf das Eltern-Kind-Verhältnis beschränke und zudem oft durch die ,Ein-Kind-Familie' noch zusätzlich verringert werde. Während nämlich ,früher' in der Großfamilie eine Vielzahl von Interaktionsmöglichkeiten bestanden und derart dem Kind eine Reihe von Vorbildern zum Zweck der Identitätsbildung zur Verfügung gestanden hätten, die aber doch innerhalb einer ,einheitlichen Gesamtatmosphäre' traditionaler Strukturen eine konsistente Erziehung gewährleistet sein ließen, müsse sich das Kind nun seine Vorbilder außerhalb der Familie suchen, was die Erziehung ,unnötig erschweren und verwirren “ könne. ${ }^{90}$ Auch bedinge die Auslagerung der Produktion aus dem familialen Raum eine zumindest ,vaterlose', oft sogar ,elternlose Gesellschaft', in der Kinder ihre Eltern kaum noch erlebten, und die derart zu einer weiteren Gefährdung einer einheitlichen, familialen Erziehung beitrage. Die Auflösung der Familie als Produktionsgemeinschaft sorge weiter für eine Reorganisation der Bindungsformen zwischen den Geschlechtern, die

\footnotetext{
${ }^{84}$ Keilhacker, Grundprobleme, 69

85 Keilhacker, Technik, 13-14

${ }_{87}^{86}$ Keilhacker, Erziehung, 18

${ }^{87}$ Keilhacker, Technik, 13

88 Keilhacker, Erziehung, 20

${ }^{89}$ vgl. Keilhacker, Erziehung, 18-19

${ }^{90}$ Keilhacker, Erziehung, 19
} 
sich bei näherem Zusehen für Keilhacker als, Desorganisation' oder zumindest prekär erweist. Zwar sieht er durch sie „lebendigere, persönlich stärker durchlebte Beziehungen zwischen den Partnern" befördert, doch zugleich einen ,Zwang zum Entwurf" etabliert, der zu dauernder Eigenanstrengung für die Aufrechterhaltung dieser Beziehung anhalte. ${ }^{11} \mathrm{Da}$,feste, durch Tradition erprobte und sanktionierte Strukturen" im Zug dieser Reorganisation beseitigt worden seien, also die Entlastungsfunktion von Traditionalität wegfalle, befinde sich die moderne Ehe in einer dauernden Gefährdungssituation. ${ }^{92}$

Einen ,Zwang zum Entwurf und eine entsprechende Gefährdung konstatiert Keilhacker dann auch als Folge der Mobilisierung. Zusammen mit der Ständegesellschaft schwindet die Möglichkeit fester, vorgegebener Identitätskonzepte durch einen geburtsoriginären Status, Zunft- und Berufszugehörigkeit. Aber auch die identitätsstützende „Bindung an eine bestimmte Heimat, Landschaft, Stammeszugehörigkeit, bestimmte Sitten und Gebräuche" hat sich wegen der ,geforderten und geförderten Mobilität wesentlich gelockert" und vermag nicht mehr entlastend wirksam zu werden. ${ }^{93}$ An ihrer Stelle muß das moderne Individuum seine jetzt überaus individuelle Identität selbst herstellen und erhalten. Es ist gezwungen, sein Selbstkonzept weitgehend autonom zu entwerfen und dabei insbesondere seine Bindungen selbst zu wählen und durchzuhalten. Dem aber scheinen Keilhacker die wenigsten Menschen gewachsen zu sein. Er nimmt daher sowohl eine gewisse Identitätslosigkeit, eine ,Äußerlichkeit' und ,Oberflächlichkeit', als auch einen Hang zur Bindungslosigkeit oder gar Bindungsunfähigkeit bei den modernen Individuen wahr. So verweist er darauf, da $\beta$ etwa ,die Jugend“ sich „,nicht mehr gern festen Vereinsbindungen, vielfach mit weltanschaulichem oder politischem Hintergrund unterwirft, sondern den lockeren, unverbindlichen Formen jugendlicher Gruppen- und Gemeinschaftsbildung den Vorzug gibt“, oder „überhaupt keine festen Bindungen für längere Zeit eingeht " ${ }^{94}$ Kaum anders scheint es sich mit den Erwachsenen zu verhalten, da generell in der Industriegesellschaft ,die Zahl und Bedeutung mehr lockerer und loser Kontakte stark zugenommen" haben. ${ }^{95}$ Damit allerdings wachse „die Gefahr, wegen (der) zahlreichen, rasch wechselnden Begegnungen vielleicht nie $\mathrm{zu}$ dauerhaften menschlichen Bindungen zu kommen, oder im Fall einer für das ganze Leben gedachten Bindung, zum Beispiel in Ehe und Familie, zu versagen". 96 Die eigene Identitätskonzeption aber drohe dann ebenfalls ohne ,Tiefe‘ zu bleiben.

Verschärft scheint diese Situation dadurch, $\mathrm{da} B$ auch im Berufssektor weitaus mehr Flexibilität und Umstellungsbereitschaft als feste Identitätsbildung und Bindung an Überkommenes gefordert sind. Neben der Mobilisierung sieht Keilhacker hier nun auch die Technik am Werk und durch sie eine weitere Form der, Oberflächenidentität', Äußerlichkeit und Bindungslosigkeit befördert, die als besonderen Typus den ,wendigen Menschen hervorbringe. Beide nämlich, Flexibilitäts- oder Mobilitätsforderung und die Anforderungen der Technik, bedingten eine Orientie-

${ }^{91}$ Keilhacker, Erziehung, 23

92 Keilhacker, Erziehung, 23

93 Keilhacker, Technik, 94

${ }^{94}$ Keilhacker, Erziehung, 33

95 Keilhacker, Erziehung, 39

${ }^{96}$ Keilhacker, Erziehung, 40 
rung des Subjekts nach außen und eine hohe Anpassungsbereitschaft an heteronome und heterogene Situationen. So verlange der ,Umgang mit der Technik‘ eine „hohe Wachheit und Wachsamkeit der Sinne, sowie rasche Reaktionsfähigkeit", welche eine anpassungsbereite Extraversion erzwängen. ${ }^{97}$ Eben diese Form der Extraversion aber konstituiere den ,wendigen, anpassungsfähigen Menschen ${ }^{\text {“98 }}$, der letztlich der Prototyp des überflexibilisierten, aber bindungsunfähigen Individuums ist.

Obschon die Industriegesellschaft nun Keilhackers Theorie zufolge mit ihren Angeboten ständig wechselnder, frei wählbarer und unverbindlicher Kontakte für eine weitgehende Abpufferung des Leidens an der Bindungslosigkeit sorge, ${ }^{99}$ sieht er doch zugleich eine ,Entwurzelung daraus hervorgehen, die nicht ohne Folgen bleibe. Nach Keilhacker ist das moderne Individuum daher sowohl ,der ,entbundene', der ,befreite' aber auch der einsame, der entleerte, hin- und hergeworfene, dem Nichts ausgelieferte Mensch “100. Seiner, existenziellen Angst" und seiner ,Geworfenheit', die ihn „ohne Gott“" dem „Schicksal ausgeliefert" sein lassen, entsprächen folglich nichts mehr, als die "moderne Existenzphilosophie“ und ihr Versuch, „sowohl die Freiheit wie die Einsamkeit des Menschen philosophisch zu fassen, zu deuten und zu bewältigen ". ${ }^{101}$ Doch betrachtet Keilhacker dieses Unterfangen nicht mit ungeteilter Sympathie, sondern eher als eine Art negativer Verstärkung der problematischen Prozesse, die zweifelhaft sein lasse, ob die ,Freiheitsbewältigung der Existenzphilosophie gelänge und ,mit welchem Erfolg" dabei zu rechnen sei. ${ }^{102}$

Keilhacker moniert so in diesem ersten Paket von Devianzvorwürfen die Auswirkungen der von Technik, Wissenschaft und Ökonomie mitbedingten modernen $D y$ namisierungs- und Diversifizierungsprozesse. Die Begriffsperspektive, mit der die Kritik an diesen Prozessen vorgebracht wird, etabliert dabei wieder spezifische Dichotomien, die formal analog zu den bereits bekannten Dichotomien der kulturtheoretischen Modernitätskritik konstruiert sind. So wird zunächst mit der Auslagerung der Produktion aus der Familie eine Konkretion der modernen Diversifizierung der Lebens- und Handlungsbereiche skizziert. Insofern diese Diversifizierung für die Etablierung der Kleinfamilie mit ihrem verminderten Erfahrungsraum - und derart für die Nötigung der Kinder zur Leitbildsuche auch außerhalb der Familie in der Öffentlichkeit - verantwortlich zeichnet, führt sie zugleich zu einer Diversifizierung von Orientierungsmöglichkeiten. Die letztgenannten erscheinen bei Keilhacker jedoch als erziehungsgefährdende Zersplitterung, der entsprechend die traditionale Einheitlichkeit der Großfamilie gegenübergestellt wird. Das erste, antagonistische Begriffspaar ist so das von Pluralität und Einheit, wobei die Pluralität mit negativer Wertung als spezifisch modernes Phänomen auftritt und die Einheit mit positiver Wertung in den ,vorindustriellen', sprich vormodernen Gesellschaftszusammenhang zurückverlagert wird. Dann wird mit der horizontalen und vertikalen Mobilität die soziale, und mit der Flexibilität des ,wendigen Menschen' die individuelle Konkretion der technisch-wissenschaftlich-ökonomischen Dynamisierung eingeführt und diese

\footnotetext{
${ }_{97}^{97}$ Keilhacker, Technik, 74

98 Keilhacker, Technik, 75

99 vgl. Keilhacker, Erziehung, 39-40

100 Keilhacker, Technik, 93

101 Keilhacker, Technik, 81-82

102 Keilhacker, Technik, 81-82
} 
mit ebenfalls traditionalen sowie mit gruppenspezifischen Bindungsformen kontrastiert. Das zweite, antagonistische Begriffspaar ist daher das von Dynamik und Statik bzw. von Flexibilität und Stabilität. Dynamik und Flexibilität werden wieder mit negativer Wertung als spezifisch moderne Momente behandelt, denen die mit positiver Wertung versehene, vormoderne Statik der Ständegesellschaft sowie die Stabilität der zunftgebundenen Berufszugehörigkeit und des geburtsoriginären sozialen Status gegenübergestellt werden. Auf der einen Seite stehen so jeweils spezifische, diskriminierte Auswirkungen der modernen Prozesse, auf der anderen wieder letztlich vormoderne Organisations- und Orientierungsformen, deren Verlorengehen beklagt wird. Auch die Gesellschaftskritik Keilhackers hat so einen modernitätskritischen Impetus, der nun als (familial gewendete) Pluralismuskritik und identitätsbezogene Dynamisierungs- und Flexibilisierungskritik seine Wirkung entfaltet.

Über die letztgenannte Kritik zeigt sich dieser Impetus dabei als ein gegen die moderne Entwurfsautonomie gerichteter. In der Tat ist das von ständischen und zunftmäßigen Definitionen freigesetzte Individuum ja erst das im Sinn der Aufklärung autonome Subjekt, das jetzt auch auf der gesellschaftlich-sozialen Ebene in den Stand der Mündigkeit übertritt und dort die Gestalt seines Lebens, seiner Identität und bis zu einem gewissen Grad auch die Maximen seines Handelns selbst entwirft. Gerade in der Moderne, d.h. mit dem Überschritt von einer noch regressiv-statischen Gesellschaftsform in eine individualisierende, dynamische und zunehmend demokratisierte findet die Idee personaler, sozialer und sittlicher Autonomie seine strukturelle Ermöglichungsgestalt und seine Realisierungschancen. Eben diesen Chancen aber scheint der Mensch bei Keilhacker nicht gewachsen zu sein, so daß sich die Entwurfsautonomie für ihn in Geworfenheit, in einen Nihilismus der Bindungs-, Profil- und Haltlosigkeit zu transformieren droht. Bedingt scheint diese Gefahr durch eine spezifische Überforderung, die darin gesehen wird, daß zusammen mit einem festen Orientierungsrahmen und den traditionalen Beständen der älteren Gesellschaftsform auch die Basis für das Entwerfen geschwunden sei. Die pluralen Weltinterpretamente der modernen Gesellschaft und ein rationaler Diskurs konkurrierender Positionen hingegen vermögen eine solche Basis anscheinend nicht zu bilden, vielmehr gilt diese Pluralität entweder als Verwirnis oder als gegenseitiger Relativierungs- und Entwertungszusammenhang. Entsprechend erhält die Aufgabe des Entwurfs für das neuzeitliche Subjekt den Charakter einer Art Schöpfung aus dem Nichts, zumindest aber über dem Abgrund des Nichts, die jener äußersten Autokreation und in Freiheit gesetzter Selbstbindung gleicht, wie sie vor allem bei Sartre reflektiert wird. Eine solche Entwurfsleistung aber hält Keilhacker nicht für möglich. Daher spricht er auch der Existenzphilosophie kaum eine Lösungspotenz zu. Eben dieser mißtrauische Rekurs auf die letztgenannte verweist darauf, daß Keilhackers freiheitskritische Problematisierung der Entwurfsautonomie letztlich die neuzeitliche Konstruktion des autonomen Subjekts selbst für eine Fehlkonstruktion hält und dem Menschen eine entsprechende Potenz schlicht abspricht. Seine Theorie nämlich konstruiert mit dem vorgängigen Zusammenhang wieder eine antagonistische Dichotomie, die entweder einen festen Orientierungsrahmen für das menschliche Entwerfen kennt oder dieses Entwerfen blind ins Nichts taumeln und scheitern sieht. Damit scheint weder das neuzeitliche Subjekt positive Potenzen für die Realisierung seiner Autonomie mit sich zu bringen, noch scheint es in der Lage zu sein, 
auf der Basis pluraler und konkurrierender Orientierungsmöglichkeiten zumindest eine Wahlautonomie auszuüben. Das überforderte Subjekt Keilhackers ist so zugleich das unfähige. Nicht zuletzt deshalb gilt auch das Angebot,öffentlicher‘ Leitbilder, die mit den familialen und untereinander konkurrieren, für Kinder als gefährlich und wird auch hier das Verlorengehen einer einheitlichen Erziehungsatmosphäre beklagt. Sowohl die Dynamisierungskritik als auch die Diversifizierungskritik erweist sich im Kern also als Kritik an der modernen Entwurfsautonomie und an der philosophischen Konstruktion des autonomen Subjekts schlechthin.

\section{Kritik am Verfall der, Eigentlichkeit' durch Manipulation und Uniformierung}

Ein zweites Paket von gesellschaftskritischen Devianzvorwürfen bezieht sich dann auf den angenommenen Verlust von "Eigentlichkeit' in der modernen Industriegesellschaft, der einerseits von einer generellen, grundsätzlichen Manipulation durch die Massenmedien, andererseits von einer besonderen Manipulationsform der ,Uniformierung durch serialisierte Produktion medialer Gehalte und industrieller Produkte überhaupt verursacht werde. Die Gefahr der Manipulation ist bereits unter dem Begriff der Außenleitung als generelle Inklination der ökonomischen Dynamik in der Kulturtheorie Keilhackers aufgetaucht. Diese Außenleitung scheint ihm nun besonders durch die ,modernen Massenkommunikationsmittel' befördert, die einerseits die ohnehin im Menschen angelegte Extraversion auf Reize der Außenwelt hin verstärkten, andererseits eine vermittelte Existenz in ,sekundären Systemen' zur Folge hätten. Die Omnipräsenz der Massenkommunikationsmittel nämlich führe in Kooperation mit dem „Erlebnisdrang“ des Menschen zu einem ,übermäßigen Gebrauch“ und einer „Dauerberieselung“ ${ }^{103}$ Mit dieser Orientierung nach außen versuche der Mensch zumeist, eigentlich anstehenden Auseinandersetzungen mit sich und seiner Lebenssituation, also etwa „einer auf die Nerven gehenden Leere in der Familie oder dem Alleinsein auf der Junggesellenbude“, zu entgehen. ${ }^{104}$ Damit aber gewöhne er sich an eine Ablenkungsbereitschaft und einen Fluchthabitus, der die Gefahr mit sich bringe, "sein eigentliches, tieferes Menschsein zu verlieren“. ${ }^{105}$ An dessen Stelle trete eine extravertierte ,Reizorientierung', die im Kontext einer in der Industriegesellschaft gegebenen „Reiz- und Erlebnisüberflutung ${ }^{\text {“106 }}$ von einer äußerlichen Attraktion zur nächsten hasten lasse. ${ }^{107}$ Gleichzeitig werde er ein williges und bewußtloses Opfer jeglicher Manipulation. Die letztgenannte Gefährdung sieht Keilhacker dann zusätzlich verstärkt durch die von den Kommunikationsmitteln errichteten ,sekundären Systeme', d.h. dem Angebot vermittelter Information und rezeptiver Erlebnisse. Mit Rückbezug auf Günter Anders' Kulturkritik ${ }^{108}$ betrachtet er die massenmedialen Angebote als „Zwischenreich“, das dem Menschen ,sekundäre Erlebnisse biete und ihn so in ein "Reich der Phantome, nicht der Wirklichkeit" entführe. ${ }^{109}$ Aus dem Umfang dieses Angebots und seiner Nutzung aber ergebe sich,

\footnotetext{
${ }^{103}$ Keilhacker, Erziehung, 68; im Original partiell kursiv.

${ }^{104}$ Keilhacker, Erziehung, 68

105 Keilhacker, Erziehung, 69

${ }_{106}$ Keilhacker, Erziehung, 69

107 vgl. Keilhacker, Technik, 105

108 vgl. Anders, Antiquiertheit

${ }^{109}$ Keilhacker, Erziehung, 63
} 
daß der Mensch der Industriegesellschaft „einen großen Teil seines Lebens nicht mehr aus erster, sondern aus zweiter Hand" lebe, und damit die erschreckende Perspektive, daß er dadurch „seine Fähigkeit, zwischen primären und sekundären Erlebnissen zu unterscheiden, mehr und mehr verliert und schließlich nur noch oder vorzugsweise von den Lieferungen der Kommunikationsmittel lebt, ohne es auch nur richtig zu merken". 110

Droht die Gefahr des Verlusts der ,Eigentlichkeit' also hier durch eine grundsätzliche Manipulation und Existenz in einer ,abgeleiteten Wirklichkeit', so droht sie andererseits auch durch eine besondere Ausprägung der Fremdsteuerung, nämlich der ,Uniformierung', welche sowohl von der massenweisen Vermittlung gleicher Inhalte durch die Medien als auch durch die massenweise Herstellung von Serienartikeln in der Industrieproduktion verursacht scheint. Die erste Form der Uniformierung gilt Keilhacker zunächst als eine in zwei Richtungen wirksame Nivellierung. So betont er einmal, daß der ökonomische Zwang, ein möglichst umfangreiches Publikum zu interessieren und zu binden, bereits die Medienproduzenten dazu nötige, ihre Inhalte auf den ,gemeinsamen Nenner' einer heterogenen Masse hin zu orientieren, und derart Nivellierung auf einen „Durchschnitt" hin zur Folge habe. ${ }^{111}$ Im Gegenzug dazu sorge die massenhafte Verbreitung derartig ,durchschnittlicher' Gehalte für eine zunehmende Durchschnittlichkeit ihrer Konsumenten. Unter Zitation von Günter Anders nennt er sie daher ,unbezahlte (...) Heimarbeiter für die Herstellung des Massenmenschen “112. Die zweite Form der Uniformierung leitet Keilhacker aus der Ablösung des unter der Profitabilitätsmaxime und ,quantifizierender Produktivitätskategorisierung allzu aufwendigen Handwerks durch die arbeitsteilige und maschinelle Industrieproduktion ab. Während das Handwerk noch, individuelle Gegenstände - in allerdings zu geringer Zahl - hervorgebracht habe, liefere die maschinisierte Industrie Massen völlig gleicher Serienartikel. Aus dem Gebrauch serialisierter Gegenstände aber sieht Keilhacker die Serialisierung ihrer Benutzer hervorgehen. Es sei nämlich nicht nur ,naheliegend‘, sondern geradezu „unausbleiblich, daß das häufige Sehen und der ständige Gebrauch gleicher Gegenstände gleichmachend, d.h. uniformierend wirkt" ${ }^{113}$ Massenmedien und Industrieproduktion scheinen so, obgleich sie für die Industriegesellschaft und ihre Standards unverzichtbar sind, den Untergang des Individuums und seiner ,Unverwechselbarkeit“ in der Welt des ,Man' zur Folge zu haben. Keilhacker rekurriert mit dieser Kritikfigur letztlich implizit auf Heideggers Zivilisationskritik: Nicht nur ,in der Benutzung des Nachrichtenwesens (Zeitung) ist jeder Andere wie der Andere ${ }^{\text {114 }}$, sondern auch mit seiner industriegefertigten Kleidung und den Gegenständen seines Alltags. Ebenso wie für Heidegger droht daher für Keilhacker die Herrschaft anonymer Uniformität, in der sich alle allen angleichen und jeder sich der Austauschbarkeit mit dem Anderen unterwirft.

${ }^{110}$ Keilhacker, Erziehung, 63-64

111 vgl. Keilhacker, Erziehung, 65

112 Keilhacker, Erziehung, 65; Anders, Antiquiertheit, 101

113 Keilhacker, Technik, 78

114 Heidegger, Martin, Sein und Zeit, Tübingen ${ }^{15} 1979$, 126; eben jener Topos des Zeitunglesens und der öffentlichen Verkehrsmittel, die Heidegger an dieser Stelle gemeinsam nennt, taucht auch bei Keilhacker auf, allerdings ohne ausdrücklichen, zitativen Bezug. (Vgl. Keilhakker, Erziehung, 65) Die Parallele aber ist überdeutlich. 
Auch das zweite Paket von zivilisationskritischen Vorwürfen läßt nun wieder dichotomische Begriffsperspektiven erkennen. Diese liegen zum einen im Antagonismus von Introversion und Extraversion, zum anderen von Unmittelbarkeit und Vermittlung, zum dritten von Unikaten und Serienprodukten und schließlich von Selbstund Fremdbestimmung. Angemahnt wird von den Vorwürfen genau besehen der Verfall der einen Seite der Antagonismen zugunsten der anderen, und konstituiert werden derart drei Komponenten von ,Eigentlichkeit', die durch den Verfall durch ,Uneigentlichkeit' ersetzt scheinen. Darüber hinaus wird dann noch eine spezifische Autonomiekritik geübt, die Autonomie sowohl in Manipulation untergehen sieht, als auch pessimistisch ohnehin für schwer möglich hält.

Zunächst zeigt sich hierbei der erste Antagonismus als Parallele zu dem Gegensatz von vita activa und vita contemplativa in der Kulturtheorie, wo dem aktiven, außenorientierten Leben als moderner Vereinseitigung ,Besinnlichkeit' und ,Beschaulichkeit' als ältere Orientierungen verlorenzugehen drohen. Schien dort dieser Verlust in ein überbordendes Leistungsverhalten zu führen, so scheint er nun eine Reizorientierung zur Folge zu haben, die den extravertierten Menschen zum bewußtlos den Stimulantien hinterherjagenden, willigen Opfer jedes Reizangebots macht. Derart scheint der Mensch dann die introvertierte Auseinandersetzung mit seiner Lebensaufgabe zu verdrängen und sein ,tieferes Menschsein' zu verfehlen. Vom Verfall bedroht ist in dieser Figur damit vorerst eine ,Eigentlichkeit', in der durch Rückwendung auf den Personkern die eigene Authentizität gefunden und gesichert werden soll und die deshalb als personale Komponente von den nachfolgenden unterschieden werden kann. - Weiter wird der medialen Welt die Etablierung einer sekundären Wirklichkeit angelastet, die ihren Rezipienten auch nur sekundäre Erlebnisse und Erfahrungen zu vermitteln vermag. Der Umfang der Rezeption und die offenbar vorhandene verderbliche Neigung der Individuen zu einer vorzugsweisen Nutzung dieser Sekundärlieferungen scheint dann eine Diffusion des Unterscheidungsvermögens und den Verlust der Authentizität von unmittelbaren Erfahrungen nach sich zu ziehen. In den Verfall getrieben ist nach dieser Figur so eine als Erlebnisunmittelbarkeit und Erfahrungsauthentizität bestimmte Komponente der ,Eigentlichkeit'. - Zum Dritten wird der medialen Produktion eine Nivellierung von Inhalten angelastet, die jede Differenzierung gefährde sowie eine Senkung des Niveaus evoziere. Die Medienprodukte scheinen so die Erzeugung eines von mittleren Vorstellungen und Meinungen geprägten, durchschnittlichen Bewußtseins nach sich zu ziehen, das als gesellschaftliches eine, schlechte Einheitlichkeit' vorstellt. Befördert scheint diese ,schlechte Einheitlichkeit' dann noch durch die serialisierte Güterproduktion, die eine Nivellierung der Verbraucher zur Folge habe. In dieser Figur ist so eine differenzierte Individualität von einer in der Serialisierung anwesenden Kollektivität bedroht. Konstituiert wird derart eine dritte Komponente der ,Eigentlichkeit', nämlich die individuelle.

Das gesamte zweite Paket zeigte sich dabei zugleich als Manipulationstheorem. Deutlich war das zunächst im ersten Teil des Pakets, wo einmal die Extraversion zu einer Außenleitung verstärkt und weitergeführt schien und ein andermal die Massivität und der Umfang der sekundären Wirklichkeit eine Diffusion und damit eine fremdgeleitete Existenz in vermittelten Erfahrungen begünstigen sollte. Das extravertierte Individuum gerät hier gewissermaßen vom reizorientierten zum reizgesteu- 
erten und verliert in den Kunstwelten und Scheinwirklichkeiten der Medienprodukte die Basis für eine autonome Urteils- und Entscheidungsfindung. Ist im ersten Fall die Manipulation direkt als solche angesetzt, so gilt die im zweiten Fall ausgezogene Struktur als Flankierung und Verstärkung derselben. Auch die Uniformierung aber war als Manipulationsform angesetzt, wenn durch die serialisierten Produkte eine Art ,Gleichschaltung' der Individuen auf die Normen des ,Man' geschehen soll. Sie zeigte sich gewissermaßen als spezifizierte Form der Manipulation. Zusammen mit der ,Eigentlichkeit' scheint also auch die Autonomie in den Verfall getrieben zu werden und stellt sich das Paket als ein manipulationskritisches dar.

Im Hintergrund dieser manipulationskritischen Klage über den Verlust der Autonomie wiederum werden bei näherem Zusehen autonomiepessimistische Optionen erkennbar. So scheint das manipulierte Individuum zunächst sich gegen eine Fremdsteuerung gar nicht wehren zu können und kaum eine Potenz für autonomes Verhalten mitzubringen. Bei entsprechender Massivität und Umfänglichkeit der manipulativen Umstände, die Keilhacker modernitätskritisch schon in den Bedingungen zivilisierter Existenz und ihres strukturellen Umfelds gegeben sieht, ist der Verfall an Außenleitung offenbar kaum noch aufzuhalten. Eine Chance des Subjekts für ein etwa medienunabhängiges Verhalten oder eine nonkonforme Selbstkonstitution tritt an keiner Stelle seines Texts vor Augen. Im Gegenteil wird der Mensch dann außerdem noch als geradezu für eine manipulative Hegemonialisierung anfällig gezeichnet. Gerade das extravertierte Individuum nämlich scheint durch seine schon vorgängig vorhandene Neigung zur Extraversion, die ja nur ,verstärkt' wird, und seinen ,Erlebnisdrang' gewisse Dispositionen für den Verfall an Fremdsteuerung mitzubringen. Die Manipulationskritik enthält auf diese Weise zugleich eine Kritik an der Möglichkeit von Autonomie überhaupt und unterstreicht nochmals die autonomiepessimistische Stellung Keilhackers, wie sie schon im ersten Vorwurfspaket deutlich geworden ist. Durch ihre Koppelung mit der ,Eigentlichkeitskritik' verweist sie zudem darauf, daß umgekehrt in den Lösungsvorschlägen vermutlich kaum eine Wiedergewinnung von Autonomie im Sinn der neuzeitlichen Subjekt- und Entwurfsautonomie angezielt sein wird, sondern primär die Rückgewinnung von ,Eigentlichkeit". Soweit Autonomie wiedergewonnen werden soll, kann diese dann nur im Modus einer begrenzten, durch spezifische Maßnahmen abgesicherten Selbstbestimmung gedacht werden, die die autonomiepessimistischen Optionen berücksichtigt und das Individuum nicht, überfordert'.

\subsection{Metaphysische Kehre, Wertethik und Askese: Versuchte Wiedergewinnung von Selbstbestimmung, Moralität und Eigentlichkeit durch Etablierung einer ,Kontramoderne}

Keilhackers Konzept erschöpft sich nicht in der Modernitäts- und Gesellschaftskritik, sondern sucht dieser Kritik Lösungsvorschläge an die Seite zu stellen, die mit den ungeliebten und dennoch als irreversibel erkannten modernen Prozessen und Errungenschaften zusammen bestehen und zugleich ein rehumanisierendes Korrektiv für dieselben bilden sollen. Dieses Korrektiv führt er zunächst als Forderung des ,Aufbaus einer Wertewelt' ein, welche dem Ethoszerfall entgegenwirken und neben den unhintergehbaren Orientierungsforderungen der Industriegesellschaft und ihrem 
Weltverhältnis eine Art Humanbereich schaffen soll, in dem das Subjekt wieder Subjekt wird und zu seiner Moralität zurückfindet. Flankiert wird diese Forderung von zwei weiteren, deren erste auf die Implantation handwerklicher und anderer Kreativität in den Freizeitraum und deren zweite auf die Förderung eines askesebereiten Habitus zielt. Soll mit der ersten Forderung ein Nischenbereich für die Rückgewinnung von Eigentlichkeit eingerichtet werden, so will die zweite Distanz zu den heteronomistischen Verplanungsstrukturen der Industriegesellschaft schaffen und so für die Rückgewinnung einer (begrenzten) Form von Selbstbestimmung sorgen. Alle drei Forderungen richten sich, wie zu sehen sein wird, letztlich auf die Etablierung einer Art ,Kontramoderne' durch Reaktivierung der entschwundenen, vorneuzeitlichen Orientierungsformen, die die Devianzen und Defizienzen der modernen Prozesse und Strukturen mildern sollen, und führen in eine Dichotomie zweier Welten, zwischen denen kaum interaktive, sondern allenfalls deontologische Bezüge bestehen.

\section{Ansatz: Versuchte Rückgewinnung der Moralität durch Etablierung zweier Welten}

Die erste Forderung ist die logische Konsequenz der in der Kulturtheorie zu Tage getretenen Interpretation neuzeitlicher Defizienzerscheinungen als Formen eines Werteverfalls, der zugleich einen Ethoszerfall vorstellt. Entsprechend kann dann die Lösung nur im Aufbau einer spezifischen, in ihrer Herkunft noch näher zu charakterisierenden ,Wertewelt' bestehen, mit der zusammen auch Moralität erst wieder ermöglicht werden soll. Bevor ich nun die Herkunft der Wertewelt aufweise, will ich jedoch ihre Formalstruktur deutlich machen, die von Keilhacker nun präzise umrissen wird und sein Lösungskonzept als wertethisches erweist. Eingeführt wird die Forderung der ,Erstellung der Wertewelt', indem Keilhacker zunächst die Notwendigkeit konstatiert, ,gemeinsam den Theorien der Wertfreiheit, des ,Jenseits von Gut und Böse', der Gleichgültigkeit gegenüber allen verbindlichen Werten, sowie dem offenen oder versteckten Primat des Wirtschaftlichen entgegenzutreten “115. Diese nämlich seien „der Feind schlechthin“"116, und nicht zuletzt ihnen gegenüber gilt der Aufbau einer Wertewelt als "unumgänglich und unaufschiebbar". ${ }^{117}$ Dabei läßt Keilhacker von Anfang an keinen Zweifel daran, daß es ihm bei diesem Aufbau um eine „feste Wertordnung“"118 geht, die „überzeitliche Werte (...), die nicht ohne tiefgehende menschliche Verluste beseitigt oder aufgegeben werden können“119, enthält und als „Hierarchie“"120 gedacht ist. Jene hierarchisch gestuften Werte werden weiter als ,wesenhafte Bestandteile des Seins der Dinge“ charakterisiert, die "nach ihren verschiedenen Beziehungen und Möglichkeiten unabhängig vom menschlichen Dasein existieren “. ${ }^{121}$ Insofern das ,wesenhafte', wieder mit dem Qualitätsbegriff konnotierte ,Sein der Dinge' dabei nicht von der ,quantifizierend'-objektivierenden Methodik der Naturwissenschaften erfaßt werden kann, d.h. aber, als für deren sachlogische Rationalisierung unzugänglich definiert wird, tritt die Wertordnung

\footnotetext{
115 Keilhacker, Technik, 50

116 Keilhacker, Technik, 50

117 Keilhacker, Technik, 59

118 Keilhacker, Technik, 50

119 Keilhacker, Technik, 64

${ }^{120}$ Keilhacker, Technik, 59

121 Keilhacker, Technik, 61
} 
auch als eine von methodischer Rationalität und empirischer Erforsch- und Überprüfbarkeit unabhängige auf. Gerade die naturwissenschaftliche Rationalisierung hat ja die Zerstörung der Wertewelt mit verursacht. So betont Keilhacker zunächst nochmals, daß die Naturwissenschaften mit ihrer sachlogisch-rationalen Methodik keinen ,Ausblick in das Wesen der Dinge, sondern in die Korrelation ihrer Erscheinungen in der materiellen Welt “122 geboten haben und der Aufbau der Wertewelt deshalb „außerhalb der Naturwissenschaften vollzogen“"123 werden müsse. Weiter aber gilt, wie schon in seiner Kulturtheorie zu sehen war, auch die Übertragung der Rationalisierung in die Geisteswissenschaften als verderblich und unzulässig, so daB die Wertewelt auch dort nicht unter den Prinzipien einer methodischen, an empirische Bedingungen geknüpften und argumentativer Einlösbarkeit verpflichteten Rationalität konstituiert oder behandelt werden kann. Keilhacker nennt diese Übertragung vielmehr erneut ,unheilvoll (...) für das geistig-kulturelle Leben“, dem die ,geistigen Werte' zugeschlagen werden, und fordert „eine klare Beschränkung des quantitativen Denkens", also der von ihm unter dieser Begriffschiffre gefaßten Rationalisierung, ,auf die Bereiche der anorganischen Natur“" ${ }^{24}$ Lediglich dort darf nach methodisch-rationalen Kriterien verfahren werden, keineswegs aber bei der Konstitution und Behandlung der Wesens- und Wertewelt.

Damit ist die Formalstruktur der von Keilhacker angestrebten, ,herzustellenden“ Wertewelt deutlich. Sein Konzept richtet eine weitgehende Autarkie des angezielten Wertekorpus sowohl gegenüber sachrationalen Kontexten und empirischen Bedingungen als auch gegenüber geschichtlichen Zusammenhängen ein. Die ,Wertewelt erscheint als zeitunabhängige, ewige Ordnungsstruktur, die dem Menschen mit einem eigenständigen Anspruch gegenübertritt und von dessen Kontingenzen abgetrennt ist. Sie erweist sich als wertphilosophische Konzeption eines, Kóouos vơtós der Werte, der als selbständige Wirklichkeit gilt. Zwischen diese Wirklichkeit und sachlogische Zusammenhänge legt Keilhackers Entwurf seiner kulturtheoretischen Kritik entsprechend einen breiten Graben, der auch die ,Werterfassung und die rationale ,Welterfassung voneinander trennt. Weder können Sachlogik und Werte miteinander vermittelt werden, noch sind die Werte rational zu konstituieren oder zu erreichen. Erreichbar scheinen die letztgenannten vielmehr einzig in einem ,Reich der Wesenheiten', das lediglich durch ein ,Werterleben' betreten werden kann. ${ }^{125}$ Dieses aber ist als ,Erleben' ein nicht-rationaler Akt, der sich von rational-methodischem Erfassen bewußt unterscheidet. Die Werte erhalten deshalb zugleich einen numinosen Charakter und gelten als ,wunderbar “. ${ }^{126}$ Insofern die Realisierung der Werte, wie schon in der Kulturtheorie zu sehen war, zugleich als Realisierung von Moralität gilt, bedeutet dies also, daß die Normativität der sittlichen Vernunft und ihre systematische Reflexion als Ethik von der Weltkonstitution mittels sachlogischer Rationalität und ihrer Reflexion in den Wissenschaften abgeschnitten ist. Sachbezüge haben für sittliche Bezüge keine Relevanz mehr, und Rationalität ist der Moralität extern. Die Moralität der Wertewelt tritt stattdessen der rationalen Sachlichkeit

\footnotetext{
${ }^{122}$ Keilhacker, Technik, 52

${ }_{123}$ Keilhacker, Technik, 59

${ }_{125}$ Keilhacker, Technik, 50

125 vgl. zum Werterleben: Keilhacker, Technik, 60

${ }^{126}$ Keilhacker, Technik, 60
} 
der Menschenwelt als extrarationale Autarkie gegenüber und kann von dieser nicht erreicht und nicht mitbedingt werden. Eine Verständigung zwischen beiden ist kaum noch möglich; Ethik und Empirie, Moral und Ratio, Sittlichkeit und Geschichtlichkeit klaffen auseinander. Mit dieser formalen Konzeption sollen dann sowohl die Moralität reetabliert, als auch die strukturellen Defizienzen der modernen Welt als rationalisierter und ökonomisierter ausgeglichen werden. So gilt nicht nur die Dignität der Moralität durch die ,unverrückbaren' Werte als gesichert, sondern es erscheint die Festigkeit und Überzeitlichkeit der Wertewelt zugleich als Korrigens der Wandelbarkeit und Entwicklungsorientierung der modernen Welt. Mit der Wertewelt scheinen feste und einheitliche Maßstäbe etabliert, die klare Orientierungen ermöglichen und derart eine unumstößliche, ,verläßliche' Basis für den sittlichen Entwurf liefern. Auch sorgt die Trennung der Wertewelt von rational-sachlogischen Bezügen nicht nur für ihre (und der Moralität) Absicherung gegen eine erneute Auflösung durch Rationalisierung, also gegen einen weiteren Ethoszerfall, sondern es tritt generell die Irrationalität der ,qualitativen` Werte der Rationalität ,quantifizierend-wertfreier' Sachlogik ,korrektiv' gegenüber und sorgt für eine Revitalisierung ,qualitativer' Bezüge überhaupt. Der Versuch eines solchen Ausgleichs aber erweist sich bereits hier als Etablierung einer ,Gegenwelt', die die Parallelexistenz zweier unverbundener Welten zur Folge hat, und die auch das moderne Individuum zu einer solchen Parallelexistenz zwingt.

In der Tat zieht Keilhacker diese Konsequenz explizit, wenn er betont, daß ,bei klarer Sicht der Dinge‘ der „,Mensch des technischen Zeitalters (sich) zwei völlig verschiedenen Welten gegenüber" sehe. ${ }^{127}$ In diesem Zustand könne er sich jedoch nur ,einrichten', denn weder sei „die Erhaltung des früheren, einheitlichen Prinzips, nach dem der Mensch der vortechnischen Zeit die ganze Welt und sein eigenes Leben aufgebaut dachte“ möglich, noch dürfe eine ,neue Einheitlichkeit" „durch grundsätzliche Anpassung des Menschen und des menschlichen Lebens an die Welt der Maschine“ erfolgen. ${ }^{128}$ So bliebe "nichts möglich, als den Glauben an die Möglichkeit eines einheitlichen Prinzips aufzugeben“ und eine ,zweigeteilte Welt zu bejahen““ ${ }^{129}$ Damit bekennt sich Keilhacker unumwunden zur Aufspaltung der menschlichen Existenzräume in zwei divergente Welten, deren erste von den Prinzipien der ,Maschinisierung', Rationalisierung und Ökonomisierung geprägt, und die in seinem Konzept identisch mit der Industriegesellschaft ist, während die zweite, wie zu sehen war, als ,überzeitliche' Wertewelt unabhängig davon konstituiert wird. Ein vermittelnder Überschritt von der einen in die andere Welt schien bereits oben schwer möglich und wird nun dort, wo er versucht, beide Welten prinzipiengeleitet zusammenzudenken, sogar direkt untersagt. Auf diese Weise überträgt sich die Dichotomie von Moral und Sachrationalität in eine theoretische und praktische Dichotomie von Moral und Gesellschaft. Das bedeutet zunächst, da $B$ das Subjekt der modernen Welt gezwungen ist, eine Art Doppelleben zu führen: Einerseits muß es in den rational-sachlichen Strukturen der Industriegesellschaft existieren und sich deren Gegebenheiten anpassen, andererseits aber soll es seine Moralität aus einer diesen Strukturen fremden

${ }_{127}^{127}$ Keilhacker, Technik, 67; im Original partiell kursiv.

128 Keilhacker, Technik, 67

129 Keilhacker, Technik, 67 
Wertewelt beziehen und derart sein sittliches Leben zumindest neben der gesellschaftlichen Realität - wenn nicht gar gegen sie - leben. Weiter bedeutet diese Dichotomie, daß der gesellschaftliche ProzeB irrelevant für die Konstitution sittlicher Normativität ist, d.h., daß das geschichtlich-gesellschaftliche Leben keinerlei Einfluß auf die Entwicklung eines Ethos nehmen kann und darf. Sowohl ein Ethoswandel, der durch faktisch gelebte, veränderte Überzeugungen (W. Korff) induziert wird, als auch ein sittlicher Fortschritt durch neue Einsichten ist in diesem Konzept nicht mehr denk- und legitimierbar.

\section{Individuelle Vermittlung und gesellschaftliche Verankerung der Wertewelt durch kontra- moderne Orientierungsformen und soziale Repräsentanz}

Für den Aufbau der konträr zur gesellschaftlichen Wirklichkeit angesetzten, numinosen Wertewelt nennt Keilhacker dann als zwei wesentliche ,Voraussetzungen' den Habitus der ,Ehrfurcht' und den der ,Ehrerbietung', die den Charakter des ,Kóouos vontós' und die Zielrichtung seiner wertethischen Konzeption weiter verdeutlichen. Die erste ,Voraussetzung führt er ein, indem er zunächst betont, daß Menschsein „von Geheimnissen umgeben sein" heiße und diese ,Geheimnisse' „von der Zeugung und Geburt angefangen bis zum Tod und über den Tod hinaus" reichten. ${ }^{130}$ Anstatt also „die Geheimnisse der Natur und des menschlichen Lebens" einfach ständig „entschleiern und den Menschen selbst an die Stelle des Weltschöpfers (...) setzen" zu wollen, ${ }^{131}$ sei ein anderer, nämlich ,ehrfurchtsvoller Habitus geboten: „Da wir nicht wissen, woher wir kommen und wohin wir gehen, auch nicht, wann wir von hier fortgehen, und da wir dies weder von uns selbst, noch von denen wissen, die mit uns

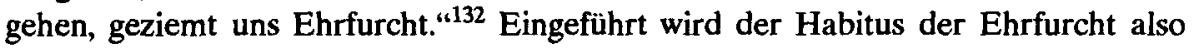
vorerst auf der Basis der nur partiellen Existenzverfügung des Menschen und seiner Bedingtheitsstrukturen. Diesen Habitus, den Keilhacker näher als „,heilige Scheu“133 charakterisiert, empfiehlt er dann als adäquate Haltung auch der Wissenschaft bei der Durchdringung ihrer Gegenstände. ${ }^{134}$ Er scheint ihm hier zunächst angebracht, weil die ,Rätsel der Welt' in ihrem, Wesen' als nie völlig durch Forschung aufklärbar gelten. So nennt er etwa in Kontrapunktik zur instrumentellen Objektivation der wissenschaftlichen Medizin Gesundheit und Krankheit ,wesenhafte Erscheinungsweisen dessen, was wir Leben nennen" und attestiert ihnen letzte ,Unerklärlichkeit“ ${ }^{135}$ Bereits der "Tatbestand des Gesund- oder Krankseins" an sich reiche ,weit über die Grenzen menschlichen Verstehens hinaus" und könne folglich trotz aller medizinischen Erfolge in seinem, Wesen durch diese nicht erfaßt werden. ${ }^{136}$ Im Habitus der Ehrfurcht hingegen scheint man sich dem ,Wesenhaften und damit zugleich dem ,Wert' von Gesundheit und Krankheit, die hier offenbar als ,Existenzialien' verstanden sind, nähern zu können. Das aber gilt für Keilhacker dann weiter als generelle Bedingung für das ,Werterleben' überhaupt. Erst durch Ehrfurcht scheinen ihm die

\footnotetext{
${ }^{130}$ Keilhacker, Technik, 60

131 Keilhacker, Technik, 60

132 Keilhacker, Technik, 60

133 Keilhacker, Technik, 61

134 vgl. Keilhacker, Technik, 61

135 Keilhacker, Technik, 60

${ }^{136}$ Keilhacker, Technik, 60
} 
Werte erfaßt, verwirklicht und derart Moralität realisiert. So nennt er unter Bezugnahme auf die Tierversuchsproblematik, artifizielle Insemination und Euthanasiediskussion „Zurückhaltung und Ehrfurcht" als Bedingungen, um die dort gefährdeten Werte des Lebens und der menschlichen Person erkennbar werden zu lassen und dann zu wahren. ${ }^{137}$ Analoges konstatiert er in Auseinandersetzung mit medialer Berichterstattung, die nur unter diesen Bedingungen den Wert der ,Privatsphäre cr $^{\natural}$ kennen und respektieren könne. ${ }^{138}$ Aus den Eigengesetzlichkeiten der wissenschaftlichen Forschung oder des Journalismus hingegen sind derartige ,Werthaltungen' anscheinend nicht ableitbar, sondern durch diese eher bedroht. Ein entsprechendes Ethos in diesen Bereichen muß daher als persönliches, über die Ehrfurcht vermitteltes ,Wertbewußtsein' von außen an sie herangetragen werden, und Moralität kann wieder nur in einer autark gesetzten Kontrapunktik entstehen. Ehrfurcht gilt also als die „Voraussetzung jedes Werterlebens" ${ }^{\text {(139 }}$, die die „Welt der Werte“ erst ,zugänglich" macht, und als Bedingung der daraus hervorgehenden Sittlichkeit. ${ }^{140}$ Die letztgenannte wird als Frucht der ,zweiten Welt' der ,ersten' korrektiv entgegengesetzt. Zusammen mit der als Ehrfurcht präzisierten Vorbedingung der Sittlichkeit wird erneut auch der Zugang zur Wertewelt als nicht-rationaler fixiert.

Als zweite Voraussetzung nennt Keilhacker dann die ,Ehrerbietung und überträgt so die moralitätskonstitutive Bedeutung der Ehrfurcht in den Bereich der Sozialität. Während nämlich Ehrfurcht auf etwas „Überpersönliches gerichtet ist, auf Göttliches, Geheimnisvolles und was daran teilhat", sei Ehrerbietung der entsprechende Habitus gegenüber Personen. ${ }^{141}$ Die Ehrerbietung bezieht sich hier jedoch nicht auf alle Personen, d.h. der von Keilhacker intendierte Gehalt ist nicht schlechthin identisch mit der Achtung der Personwürde, sondern zeigt sich in seinem weiteren Text als spezifisches Sozialverhältnis, näherhin als Verhältnis zu bestimmten Gruppen oder ,Ständen“. So listet er als ,Ehrerbietungswürdige‘ zunächst die ,Alten‘, die Repräsentanten der „Weisheit des Alters“ seien, und die Frauen, genauer die Mütter, die den „Geheimnissen, der Schöpferkraft des Lebens“ nahe stünden, auf. ${ }^{142}$ Weiter sieht er auch die Kinder als Gruppe, denen als Vertreter des ,noch Werdenden“ und der ,Geheimnisse“ einer ,noch unerschlossenen Zukunft" Ehrerbietung entgegengebracht werden müsse. ${ }^{143}$ Alle drei Gruppen definieren sich dabei mehr oder weniger deutlich aus naturalen Bezügen und können deshalb als ,Naturalständer bezeichnet werden. So entsteht die erste Gruppe primär auf der Basis des biologischen Alterungsprozesses, obschon der Grund für die Ehrerbietung dann in der (möglicherweise) erworbenen ,Weisheit' gesucht wird. Da der Erwerb von Weisheit insbesondere in der dynamischen ,Lerngesellschaft' keineswegs mehr notwendige Frucht des Alterns ist, bleibt der eigentliche Angelpunkt freilich das Alter schlechthin. Die Frauen werden direkt biologisch, nämlich als Gruppe der Gebärfähigen definiert, und die Ehrerbietung bezieht sich auf ihre ,Naturnähe‘. Auch die Kinder schließlich treten

\footnotetext{
${ }^{137}$ Keilhacker, Technik, 62-63

138 Keilhacker, Technik, 62-63

139 Keilhacker, Technik, 60

${ }^{140}$ Keilhacker, Technik, 61

141 Keilhacker, Technik, 63

142 Keilhacker, Technik, 65

143 Keilhacker, Technik, 65-66
} 
qua Natur als Gruppe auf, wenn sie als Repräsentanten des Werdens und Wachsens ,ehrfurchtgebietend‘ genannt werden. In allen drei Fällen sollen so natural rückgebundene ,Geheimnisse‘ und ,Werte‘ verehrt werden, die durch ihre Repräsentation in Gruppen dann sozial greifbar werden und einen sozialen Status bzw. Stand erhalten. Auf diese Weise soll die ,Numinosität' bestimmter naturaler Werte sozial umgesetzt und gesellschaftlich relevant gemacht werden. Über die ehrerbietende, habituelle Beziehung zu bestimmten Gruppen wird in Keilhackers Entwurf also gewissermaßen der Versuch unternommen, die abgespaltene ,zweite Welt' in die ,erste' einzupflanzen, und dadurch ihre Korrektivfunktion für die dort beklagten Defizienzen wirksam werden zu lassen.

Ähnlich verhält es sich mit drei weiteren, nicht natural definierten, wertrepräsentativen' Gruppen, die Keilhacker zusätzlich zu den ,Naturalständen' aufführt, und die ausschließlich sozial definiert sind, jedoch ebenfalls Ehrerbietung verdienen. Hier nennt er die „Großen der Welt", zu denen er dann die politisch Herrschenden, Kirchenmänner und Lehrer zählt. ${ }^{144} \mathrm{Er}$ widmet dabei besonders den Lehrern seine Aufmerksamkeit und führt die gebotene Ehrfurcht auf ihre Rolle als ,Stellvertreter der Eltern', als ,Wissende und Weise' und als ,Besitzer hoher und geistiger Kultur zurück. ${ }^{145}$ Sie werden derart als Repräsentanten von ,Kulturwerten“ gehandelt und geraten gewissermaßen zu einem sozialen Stand, der diese Werte gesellschaftlich verkörpert und für ihre wirksame Umsetzung sorgt. Bei den Kirchenmännern kann vermutet werden, daß sie für die ,Werte der Religion‘, und bei den politischen Herrschern, daß sie für ,Autorität' und ,Ordnung' stehen. Sowohl über die ,Naturalstände als auch über die letztgenannten ,Sozial-‘ oder ,Prinzipalstände' soll also offenbar bestimmten Werten gesellschaftliche Geltung wiederverschafft und dieser Geltung über die Ehrerbietung habituelle, auf das individuelle Ethos bezogene, sowie über die gruppenspezifische, soziale Realdarstellung strukturelle Prägewirkung gesichert werden. ${ }^{146}$ Gleichzeitig soll auf diese Weise die ,Verflachung der zwischenmenschlichen Beziehungen $\mathrm{zu}$,rein wirtschaftlichen“ und allenfalls noch ,kameradschaftlichen“ oder ,partnerschaftlichen' überwunden werden. ${ }^{147}$ In diesen modernen Beziehungsformen nämlich sieht Keilhacker eine unzulässige Versachlichung und Eindimensionalität am Werk, die aus dem Versuch, ,alle zwischenmenschlichen Beziehungen auf eine einzige Ebene projizieren zu wollen“ entsprängen, und die „Ausfluß jener allgemeinen Einstellung, qualitative Unterschiede und Variationen möglichst zu negieren", seien. ${ }^{148}$ Dagegen soll die Revitalisierung der Ehrerbietung gegenüber be-

${ }^{144}$ Keilhacker, Technik, 66

145 vgl. Keilhacker, Technik, 66

${ }^{146}$ Zwar referiert Keilhacker die ,Prinzipalstände‘ im Modus der Vergangenheit und betont er, daß ein ,Abbau unzeitgemäßer Beziehungsformen' legitim sei, doch sieht er gerade auch in diesem Abbau "tiefergehende geistige Zerstörungen" angelegt, gegen die er die Forderung eines ,geistigen Neuaufbaus‘ setzt. Die Legitimität des Abbaus wird zudem auf die „löbliche Beseitigung von Mißbrauch" eingeschränkt. (Keilhacker, Technik, 66) Obschon also hier keine direkte Revitalisierung einer ständischen oder monarchischen Gesellschaft als politisch-institutioneller beabsichtigt zu sein scheint, zielt Keilhackers Text doch auf eine Revitalisierung zumindest der dortigen personalen Beziehungsformen minus ihrer ,Mißbrauchsmöglichkeiten'.

${ }_{147}$ Keilhacker, Technik, 63-64

148 Keilhacker, Technik, 64 
stimmten Gruppen also auch gesetzt und so eine verlorengegangene Beziehungstiefe und -qualität wiederbelebt werden.

Damit zeigt sich ein Dreifaches: Zum einen soll über die Einführung des Habitus der Ehrfurcht bzw. der Ehrerbietung die Welt der Werte zugänglich und die daraus fließende Moralität möglich gemacht werden. Lediglich Ehrfurcht und Ehrerbietung erlauben ja nach Keilhackers Theorie den moralitätskonstitutiven Kontakt mit dem Wertekosmos. Beide Haltungen nun liegen auf der Ebene der Gefühlsbeziehungen und ordnen sich vordringlich dem Bereich der Emotion und Empfindung, nicht aber der Ratio zu. Auf diese Weise wird der nicht-rationale Charakter von Moralität doppelt festgeschrieben: Wie oben zu sehen war, wird der Kontakt mit der Wertewelt mit dem Begriff des ,Werterlebens' und damit prinzipiell als nicht-rationaler Akt beschrieben. Insofern dieser nun Ehrfurcht (und Ehrerbietung) zur Voraussetzung haben soll, wird die nicht-rationale Konstitution der Moralität bestätigt und verdeutlicht. Das aber unterstreicht, daß es bei Keilhacker nicht einfach um die Relevanz emotionaler Verankerungsbezüge für ein Ethos geht, sondern daß er die Moralität als Frucht extrarationaler Erkenntnisbezüge durchgängig extrarational denkt.

Zum zweiten soll dann durch die Konkretion bestimmter Werte in gesellschaftlichen Gruppen und die reale Etablierung der zugehörigen Beziehungsformen und habituellen Orientierungen, d.h. der Ehrerbietung und des Respekts sowie der Ehrfurcht als ,heiliger Scheu', die ,zweite Welt' der Werte und der Moralität in die ,erste eingepflanzt bzw. ihr partiell übergeordnet werden. Der Graben zwischen beiden Welten soll derart von einer Seite her überspannt und die Korrektivfunktion der ,zweiten Welt' innerhalb der ,ersten' wirksam gemacht werden, ohne daß die erste auf die zweite zurückzuwirken vermag. Zunächst ist hierbei mit der Ehrerbietung eine Wiederbelebung ,älterer' sozialer Beziehungsformen und zugehöriger Wertstrukturen angezielt, die kontrapunktisch zu den existierenden sachrationalen Bezugsformen der modernen Gesellschaft gestellt ist. Sie soll gewissermaßen durch Rückbezug auf ältere Sozialverhältnisse eine größere Beziehungstiefe schaffen sowie den dort geltenden ,naturalen' und sozialen Werten zur Durchsetzung verhelfen und derart zu einer ,Wiedergesundung' der gesellschaftskritisch konstatierten Defizienzen führen. Daneben scheinen hier auch die Dynamisierung und der Wandel in der Industriegesellschaft im Blick zu sein, denen dann die Statik ehrfurchtgebietender Stände und in ihnen verankerter bleibender Werte korrektiv gegenübergesetzt wird. Weiter aber soll über die Ehrfurcht diese Korrektur auch in den sachrationalen Bereichen der Wissenschaft greifen und die Moralität dort trotz der Trennung der beiden Welten wirksam werden. Das zeigt sich etwa in Keilhackers Überlegung zur ,wertverwirklichenden' Wirkung von Ehrfurcht in den Problemfällen der artifiziellen Insemination, der Tierversuchsproblematik etc. Der ,ehrfürchtige‘ Wissenschaftler scheint hier ,sittliche Werte' zu ,erfühlen' und diese aus ihrem erlebten Anspruch heraus den sachrationalen Überlegungen überzuordnen. Moralität gerät derart zum Korrektiv der Sachrationalität mit der Aufgabe, deren defiziente ,Eindimensionalität' auszugleichen. Obschon der Sachrationalität keinerlei Relevanz für die Normkonstitution zugestanden wird, wird also jetzt der Versuch gemacht, umgekehrt doch die ,wertfühlende‘ Moralität normativ bestimmend für Sachbezüge werden zu lassen. Die Dichotomie der beiden Welten bleibt dabei durchaus aufrechterhalten, jedoch wird eine Zuordnung vollzogen, die den Anspruch der zweiten Welt der ersten nor- 
mativ überordnet. Der Graben zwischen beiden wird damit nun von einer Art deontologischer Brücke überwölbt.

Zum dritten schließlich zielt die Einführung von Ehrfurcht und Ehrerbietung auf eine ,Wiederverzauberung der Welt, die die ,Entzauberung durch die von den Naturwissenschaften gesponsorte, moderne Rationalisierung wenigstens partiell rückgängig machen oder jedenfalls ergänzen will. $\mathrm{Da} B$ es Keilhacker gerade um eine solche Wiederverzauberung geht, läßt nicht nur seine Charakterisierung der Ehrfurcht als ,heilige Scheu' erkennen, sondern auch seine Auseinandersetzung mit der modernen Medizin, die größen Wert darauf legt, daß das ,Wesen' von Krankheit und Gesundheit durch instrumentell-objektivierendes Gemächte eben nicht erreicht werden könne. Die Wesenheiten liegen in einem jenseitigen Reich, um das der Schleier des ,Geheimnisses' gerafft wird. Das ,Geheimnisvolle' zu retten, den ,Zauber' in der Welt wieder einzuführen, dazu sollen Ehrfurcht und Ehrerbietung neben ihrer moralitätsschaffenden Rolle folglich ebenfalls dienen. Zusammen mit der wiederverzauberten Welt freilich erhält dann auch die ohnehin schon aller rationalen Bezüge entkleidete Moralität noch etwas zauberhaftes und gerät Sittlichkeit in den Bannkreis des Numinosen. Sind schon die Werte ,wunderbar, so ist es jetzt auch die im Habitus von Ehrfurcht und Ehrerbietung vollzogene Moralität.

Mit der Revitalisierung ständischer Wertverkörperung und der Absicht einer Wiederverzauberung der Welt erweist sich Keilhackers Wertethik nun zugleich als regressives, kontramodernes Unterfangen. Zusammen damit zeigt sich auch der Herkunftsort der Wertewelt als vorneuzeitlicher und enthüllt sich, kohärent zur Modernitätskritik der Kulturtheorie, der Versuch ihres Aufbaus als der einer Revitalisierung des vorneuzeitlichen, insbesondere des mittelalterlichen Wertekosmos und der zugehörigen gesellschaftlichen Orientierungsformen. Eine derartige, kontramoderne Zielrichtung der Lösungsvorschläge Keilhackers hat sich bereits aus der Klage der Kulturtheorie über das Verlorengehen des älteren Weltverhältnisses, das stets als vorneuzeitliches beschrieben wurde, nahegelegt. Sie liegt nun offen zu Tage und wird von Keilhacker sogar selbst bestätigt, zunächst wenn er schreibt, daß seine ,Auffassung von der Notwendigkeit einer wiederbelebten Wertewelt „den Anbetern des Fortschritts rückschrittlich und restaurativ erscheinen" mag. ${ }^{149}$ Dies sei er jedoch "bewußt und mit Nachdruck, soweit es um die Wiederherstellung einer Wertordnung“" gehe, in der „der Vorrang der geistigen Werte“ gälte. ${ }^{150}$ Weiter betont er in seinen Schriften, daß der „Neuaufbau einer Wertewelt im abendländischen Kulturkreis" nur ,möglich' sei, ,wenn bis zum Anfang der Neuzeit zurückgegangen und der „Beginn einer neuen geistesgeschichtlichen Entwicklung dort angesetzt" werde, „wo die von den Naturwissenschaften zwar nicht angestrebte, aber mühelos erreichte Vorherrschaft“" begonnen habe. ${ }^{151}$ Eben jener Sündenfall am Beginn der „sogenannten Neuzeit“152 soll derart wenigstens partiell rückgängig gemacht werden. Damit ist der geschichtliche Herkunftsort der ,überzeitlichen Werte offen- und festgelegt und explizit in jenes ältere Weltverhältnis rückverlagert, dessen Verlust ohnehin als bedauerlich gehandelt wurde. Der Lösungsversuch Keilhackers für den Umgang mit

${ }^{149}$ Keilhacker, Technik, 104

150 Keilhacker, Technik, 104

151 Keilhacker, Technik, 50

${ }^{152}$ Keilhacker, Technik, 49 
den Defizienzen und Devianzen aber, die von den modernen Prozessen verursacht scheinen, zeigt sich so nun als Versuch, mit der ,zweiten Welt' eine Kontramoderne zu etablieren, die das ,verlorengegangene' Ethos des älteren Weltverhältnisses zurückholt und den epochengeschichtlichen Ethoszerfall umkehrt. In den Räumen einer revitalisierten ,festen, unumstößlichen Wertordnung vorneuzeitlicher Herkunft sowie habituell-ständischer Bezüge und der Wiederverzauberung sollen dann die neuzeitlichen Subjekte wieder zu ihrem Stand als moralische Wesen und zu ihrem ,Menschsein' zurückfinden. Lediglich mit der Etablierung dieser Kontramoderne scheint die Rückgewinnung der ,qualitativen` Orientierung und der Moralität garantiert zu sein, durch die allein eine humane Existenz möglich ist. Der Bogen schließt sich so: Wie die Perspektive Keilhackers in seiner Kulturtheorie sich als modernitätskritische erwiesen hat, die ihre Kriteriologie aus vorneuzeitlichen, ,verlorengegangenen' Orientierungsformen gewann, so zeigt sich nun auch seine Lösungsperspektive als vorneuzeitlich ausgerichtete, also kontramoderne.

\section{Versuchte Stützung der Kontramoderne durch Metaphysik und Religion}

Die Wiedergewinnung des ,Menschseins“ als moralische Existenz wird schließlich noch flankiert von einer metaphysischen Kehre, durch die eine Art existenzieller Tiefe und ,Eigentlichkeit' ${ }^{\prime}$ gewonnen sowie die ,wertgebundene‘ Moralität gesichert werden soll. Diese Kehre zeigt sich dabei ebenfalls als gegen die modernen Prozesse gerichtet. So verweist Keilhacker zunächst darauf, daß der Mensch sich in einem "den Tieren nicht zugänglichen Bereich der Wertungen" bewege, der zugleich der "Bereich des Geistigen“ sei und „dessen Prinzipien und Kriterien nicht aus den Eigenschaften des Seelischen abgeleitet werden" könnten. ${ }^{153}$ Eben jene Zugehörigkeit zum Bereich des Geistigen aber mache den Menschen zu einem Wesen, dem „letzte Entscheidungen, nicht nur nach den Grundsätzen von nützlich oder schädlich, gesund oder krank, schön oder häßlich, sondern auch letzte sittliche und religiöse Entscheidungen (nach den Grundsätzen: gut oder böse, heilig oder unheilig) nicht erspart werden" könnten. ${ }^{154}$ In diesen ,Wertentscheidungen" gewinne er erst sein eigentliches Personsein. ${ }^{155}$ Wolle der Mensch also mehr als „nur ein zerebral bevorzugt ausgestattetes Tier“"156 sein, so gelte es, eben die Tiefe dieser ,Letztbezüge‘ zu revitalisieren. Denn in der ,individuellen Auseinandersetzung mit den letzten Fragen des Menschseins, mit den Fragen nach dem Sinn des Lebens" liege der „höchste Wert alles Menschlichen“. ${ }^{157}$ Entsprechend sei ,gerade im Zeitalter der Technik‘, das durch Nivellierung und Uniformierung diese individuelle Auseinandersetzung gefährde, die Rückorientierung auf diese ,letzten Fragen' „als unentrinnbare Aufgabe gestellt“"158. Sie zu lösen aber scheint nur ,auf dem Boden von Ethik, Metaphysik und Religion" möglich. ${ }^{159}$ Darüber hinaus garantiere eine Besinnung auf die beiden letztgenannten eine haltbare ,Wertbindung،, die der beklagten ,Bindungslosigkeit" der

\footnotetext{
${ }^{153}$ Keilhacker, Technik, 53

154 Keilhacker, Technik, 59

155 vgl. Keilhacker, Technik, 59

156 Keilhacker, Technik, 59

157 Keilhacker, Technik, 58

158 Keilhacker, Technik, 58

${ }^{159}$ Keilhacker, Technik, 59
} 
modernen Welt entgegengesetzt werden könne. Jede Bindung nämlich gehe „um so tiefer" und sei „um so fester verankert, je mehr sie in den Bereichen des Metaphysischen und Religiösen wurzelt". ${ }^{160}$ Religion selbst wird von Keilhacker sogar ausschließlich unter diesem Aspekt eingeführt und als „Rückbindung“ definiert. ${ }^{161}$ Dadurch scheint dann auch die Moralität gesichert, die für Keilhacker ja durch Bindung an „letzte, unverrückbare Werte“ erst entsteht. ${ }^{162}$ Entsprechend betont er, daB ihm nichts wichtiger erscheine als ,eine metaphysisch-religiöse Grundhaltung“ “ ${ }^{163}$ Sie gilt für ihn als geeignetes ,Bindemittel', das die Haltbarkeit der Moralität absichern kann, und als Hort all jener Orientierungen, die der defizienten Moderne not tun. Wegen ihrer ,eigentlichkeitsgewinnenden' und ihrer moralitätsschaffenden Rolle nennt Keilhacker sie daher schließlich generell das hervorragendste „Gegengewicht gegen den Geist der Technik"164 und apostrophiert er sie als das wirksamste Gegengift gegen den „Glauben an die Machbarkeit der Dinge“, die „Kommerzialisierung der Bedürfnisse“ und eine ,positivistisch-vordergründige Einstellung“ 165

Religion und Metaphysik werden so in Keilhackers Konzept ebenfalls gegen die modernen Prozesse und ihre gesellschaftliche Konkretion ins Feld geführt und derart in die kontramoderne Ausrichtung seiner Lösungsvorschläge eingespannt. Zunächst wird hierzu auf den Transzendenzbezug des Menschen abgehoben und dessen Realisierung als ,religiöse Entscheidung und ,Sinnsuche' zum anthropologischen Konstitutivum von Personalität erklärt. Die Basis, auf der diese Realisierung vollzogen werden kann, wird dann als Metaphysik und Religion benannt. Diese aber erscheinen wieder als Sonderbereich, d.h. genauer: als ,Gegenwelt', die hier zudem individualisiert und von der Gesellschaft abgezogen wird. So scheint die Sinnsuche und -konstitution eine rein individuelle Angelegenheit zu sein, die unabhängig vom Kollektiv durchgeführt wird und die dann eine ,letztbezügliche Tiefe‘ als Refugium und Nische neben dem Gesellschaftszusammenhang generiert. In dieser Nische soll das Individuum seine ,Eigentlichkeit' wiedergewinnen und derart der modernitätskritisch beklagten Nivellierung und Uniformierung entrinnen. Auch die geforderte Überwindung einer ,positivistisch-vordergründigen Einstellung' soll auf diese Weise in einer individuellen Nische geschehen. Metaphysik und Religion werden also zunächst formal als individuelle Gegenwelt zur modernen Gesellschaft eingeführt und in diesem Sinn der ,zweiten Welt' als Korrektiv der ,ersten' zugeschlagen.

Sie sollen weiter dann spezifische inhaltliche Orientierungen ermöglichen, die den devianten Orientierungen der Neuzeit und Moderne entgegengesetzt sind. So ist bereits mit der Überwindung der, vordergründig-positivistischen' Einstellung in eine ,hintergründig-tiefe' hinein eine solche Orientierung benannt, die wohl identisch mit der schon in der Kulturtheorie vor Augen getretenen Korrektur der ,Außenorientierung' und Aktivität durch eine kontemplative Introversion ist. Weitere geforderte Orientierungen lassen sich aus der Funktion der ,religiös-metaphysischen Grundhaltung' als ,Gegengewicht‘ gegen ,Machbarkeit‘ und ,Kommerzialisierung sowie aus

\footnotetext{
${ }^{160}$ Keilhacker, Technik, 96

161 vgl. Keilhacker, Technik, 96

${ }^{162}$ Keilhacker, Technik, 95

163 Keilhacker, Technik, 120

164 Keilhacker, Technik, 120

165 Keilhacker, Technik, 120
} 
dem Konnex des Transzendenzbezugs mit dem Bereich des ,Geistigen' dekodieren. Gegen die erstgenannte soll vermutlich eine der Ehrfurcht analoge, submissive Orientierung auf Unverfügbarkeiten und ,Eigenwerte' erzeugt werden, während die zweite wohl durch Bescheidenheit und Verzichtsbereitschaft korrigiert werden soll. Die ,Geistigkeit' schließlich ist eindeutig als Korrektiv des ,Materialismus' zu entschlüsseln. Zusammen mit dem Charakter dieser Umorientierungen wird Keilhakkers Verständnis von Metaphysik und Religion weiter verdeutlicht. Diese erscheinen als Hort vorwiegend jener Orientierungen, die dem älteren Weltverhältnis eigen waren. Dadurch aber geraten sie zugleich zu Agenten für eine Revitalisierung des diesem Weltverhältnis eigenen Ethos. Die skizzierten Umorientierungen nämlich sind letztlich eine Wiederherstellung der ,zerfallenen' Wertorientierungen des vorneuzeitlichen Ethos. So ist, wie zu sehen war, die kontemplative Introversion in der Kulturtheorie ein werthaft besetzter Habitus. Nicht anders verhält es sich mit der Submission, die dort als Einordnung in den Schöpfungszusammenhang und zugehörige Orientierung an naturalen Eigenwerten verstanden ist, sowie mit Bescheidenheit und Verzichtsbereitschaft. Auch das ,Geistige' tritt als Wertform auf, die der ,materialistischen' Orientierung entgegengesetzt wird. Mit der Wiederbelebung der Orientierungen des älteren Weltverhältnisses wird also zugleich dessen Ethos wiederbelebt, und Metaphysik und Religion werden so der Etablierung der Kontramoderne dienstbar gemacht. Die Wiedergewinnung der personalen Eigentlichkeit aber zeigt sich dann als eine über das vorneuzeitliche Ethos vermittelte, und die individuell-private Gegenwelt ,entbirgt‘ ihre Herkunft als kontramoderne.

Nicht nur als Agenten für die Wiederherstellung des älteren Ethos aber sollen Metaphysik und Religion dienen, sondern auch als Garanten für seine Stabilität, d.h. eine diesbezügliche unverrückbare ,Wertbindung. Sie geraten damit zum Garanten für Moralität überhaupt, die Keilhacker ja als Bindung an ,unverrückbare Werte' definiert. Eingeführt wird diese Rolle der beiden zunächst dadurch, daß die metaphysisch-religiöse Entscheidung als ,Wertentscheidung gehandelt wird. Transzendenzund Sinnbezug werden so mit dem wertphilosophischen Paradigma verknüptt und als ,Wertbezug' gezeichnet, der sich in der Wertentscheidung konkretisiert. Als religiösmetaphysische Entscheidung erhält diese eine besondere Festigkeit, und der Bestand der darin übernommenen Wertbindung scheint gesichert. Der zentrale Stellenwert des Bindungsaspekts und seiner Festigkeit wird nochmals dadurch unterstrichen, daB Keilhacker Religion exklusiv als ,Rückbindung' definiert. Die unverrückbare Bindung scheint geradezu das Zentrum von Religion zu sein, die so der Befestigung und Sicherung der als Wertbindung verstandenen Moralität und des älteren Ethos dienstbar gemacht werden kann. Aus dem Blick freilich geraten einem solchen Verständnis der unter Umständen normstürzende Aspekt des Glaubens und seine prophetischkritische Kraft sowie die Flexibiliätsforderung der Nachfolge im Neuen Testament. ,Prophetisch-kritisch' ist allenfalls, bzw. einzig, die Wertewelt gegenüber der modernen Gesellschaft, wenn sie über den Verlust des älteren Ethos klagt. An dieser Kritik freilich sollen Metaphysik und Religion partizipieren und so eine entsprechende Reetablierung sowie Beständigkeit des älteren Ethos stützen. Damit werden Metaphysik und Religion in dreifacher Weise für die Ziele des kontramodernen Unterfangens eingespannt: Zum einen sollen sie einen Nischenbereich darstellen, der die individuelle Rückgewinnung von Eigentlichkeit ermöglicht. Zum zweiten sollen sie 
dann der Revitalisierung des älteren Ethos dienen und zum dritten dessen Bestand sowie den der Moralität überhaupt durch ihre besondere Bindekraft garantieren. Sie werden derart Teil und Sicherungsinstanz der ,zweiten Welt' der Kontramoderne.

\section{Versuchte Rückgewinnung der ,Eigentlichkeit' durch handwerkliche Kreativität}

Die Bestrebungen, mit dieser zweiten Welt einer wertethischen, durch Religion und Metaphysik abgesicherten Kontramoderne dem Menschen zum Stand seines Menschseins neben den und gegen die modernen Prozesse wieder zu verhelfen, werden, wie eingangs bereits angedeutet, schließlich noch von zwei weiteren, regressiven Forderungen gestützt. Auch sie zielen auf die Einführung von Korrektiven, mit denen einmal - jetzt nicht aus einer religiösen Perspektive - die an Nivellierung und Uniformierung verlorene ,Eigentlichkeit‘ und ein andermal eine spezifische Form der in den ökonomischen Verplanungs- und Manipulationsstrukturen untergegangenen Autonomie wiedergewonnen werden soll. So verweist Keilhacker zunächst noch einmal darauf, daß die „maschinenmäßige Herstellung" von Gebrauchsgegenständen die „menschliche Individualität und die Vollständigkeit unseres Menschseins" bedrohe. ${ }^{166}$ Diese Bedrohung wird dann in zweifacher Hinsicht präzisiert. Einmal scheint die serialisierte Produktion zur Uniformierung, näherhin zur ,Einengung der Fantasie‘ zu führen und zum anderen die ,handwerklich-künstlerischen Fähigkeiten fast völlig brachliegen“ zu lassen. ${ }^{167}$ Damit aber scheint eine spezifische Form von Eigentlichkeit, nämlich die fantasievolle, aus dem innersten und ,eigensten' schöpfende Kreativität, an eine gleichmachende, manipulative Umwelt verlorenzugehen. Konsequenz dessen ist für Keilhacker, daß „,bei den Industrievölkern die großen Massen in ihrem Geschmack (...) immer unselbständiger werden, vornehmlich von Mode und Reklame gelenkt, und immer tiefer absinken“. ${ }^{168}$ Gegen diese Bedrohung will er dann die „bei uns noch vorhandenen Reste des Handwerks“169 erhalten und ,die eigenen handwerklichen und künstlerischen Fähigkeiten in der Herstellung von Gegenständen, teils nachschaffend, teils selbstschöpferisch“"170 betätigt sehen. Entstehen soll auf diese Weise zugleich eine ,volksnahe Kunst', die wohl weitgehend als Gebrauchskunst gedacht ist und die die serialisierte Industrieproduktion korrektiv ergänzt. ${ }^{171}$ Mit dieser Gebrauchskunst soll dann eine Umwelt, etwa im Sinn eines, geschmackvoll und persönlich eingerichteten Heims', gestaltet werden, die dazu beiträgt, „Echtes von Unechtem (...), Einfaches und Schlichtes von Unwahrem und Aufgeblasenem" unterscheiden zu können. ${ }^{172}$ Sie soll aber weiter auch ein Korrektiv zur Abspaltung der Hochkunst vom Handwerk, also letztlich der Trennung von Kunst und Technik, bilden. Jene Hochkunst nämlich sei eine ,exklusive Kunst für Kunstspezialisten und Kunstsnobs“ und als solche weitaus ,weniger wichtig' als die angezielte ,volksnahe' Gebrauchskunst. ${ }^{173}$ Deren Wiederherstellung,

\footnotetext{
166 Keilhacker, Technik, 82

${ }_{167}$ Keilhacker, Technik, 82

168 Keilhacker, Technik, 84

169 Keilhacker, Technik, 83

170 Keilhacker, Technik, 82

${ }_{171}$ vgl. Keilhacker, Technik, 82, 84

172 Keilhacker, Technik, 84

${ }^{173}$ Keilhacker, Technik, 84
} 
d.h. eine Rückkehr in jene Zeit, ,als Kunst und Handwerk noch nicht voneinander getrennt waren ${ }^{\text {“174 }}$, gilt entsprechend als ,wesentliche kulturelle Aufgabe der europäischen Völker". 175

Keilhacker rekurriert also zunächst auf seine Zivilisationskritik und präzisiert den dort konstatierten Verlust von Eigentlichkeit an die Welt des ,Man' nun zusätzlich noch als heteronomistische Besetzung der individuellen Fantasie sowie als damit einhergehenden Kreativitätsverlust. Die Wiedergewinnung der schöpferisch-individuellen Eigentlichkeit soll dann durch eine Revitalisierung handwerklicher Betätigung, ja des Handwerks überhaupt geschehen. In dieser Form aber zeigt sich diese Wiedergewinnung erneut als kontramodernes Unterfangen, das letztlich auf die Technikkritik der Kulturtheorie rekurriert. So ist mit der Bewahrung und Förderung des Handwerks zugleich eine wenigstens partielle Zurücknahme der Technik auf Werkzeugtechnik im Blick, die neben den Angeboten der serialisierten ,Massenproduktion' für die Etablierung eines nicht industriell betreuten Marktbereichs für ,Handarbeit' sorgen will. Aus diesem Marktbereich sollen dann wohl auch vordringlich die Produkte für die Gestaltung einer ,schlichten' und ,echten' Umwelt genommen werden, durch die die rehumanisierende Wiedergewinnung von Eigentlichkeit befördert werden soll. Die Forderung einer ,Handwerkskunst' gegen Hochkunst unterstreicht dabei nochmals den technikkritischen Aspekt, wenn mit ihr die Aufhebung der Trennung von Kunst und Handwerk, die genau besehen die Trennung von Kunst und Technik war, intendiert wird. Gleichzeitig verdeutlicht sie mit der Apostrophierung dieser Aufhebung als, kultureller Aufgabe der europäischen Völker $^{6}$ Keilhackers Kulturbegriff als kontramodernen und regressiven. In diesem Kontext aber enthüllt sich schließlich auch der Eigentlichkeitsbegriff selbst als kontramodern gefüllter. Diese soll ja durch Kreativität und eine spezifisch ,kulturierte‘ Umwelt gewonnen werden. Kreativität jedoch scheint in Keilhackers Konzept lediglich als handwerkliche - selbst dort, wo sie sich künstlerisch ausformt - gedacht werden zu können. Eine ,moderne', etwa medial-reproduktive oder technisch gestützte Kreativität existiert für ihn nicht. Ebenso verhält es sich mit der Kulturation der Umwelt, die von technisch-industrieller Produktivität eher behindert erscheint. Die Bestimmungsstücke der Eigentlichkeit werden so wieder aus vormodernen Zusammenhängen und Weltbewältigungsformen geholt und lassen eine, moderne‘ Gestalt der Eigentlichkeit nicht $\mathrm{zu}$.

\section{Versuchte Rückgewinnung begrenzter Autonomie durch Askese und Verzicht}

Neben der Wiedergewinnung der Eigentlichkeit versucht Keilhacker mit einer zweiten Forderung auch zumindest einen Teil der menschlichen Autonomie zurückzuholen. Wieder verweist er zunächst auf seine Zivilisationskritik und die dort konstatierte Heteronomie der ,Kommerzialisierung der Bedürfnisse‘ und den Untergang des Subjekts in ökonomisch-instrumentellen Planungsstrukturen. ${ }^{176}$ Dann betont er, $\mathrm{da} \beta$ die einzige Lösung des Problems in einer freiwillig gewählten und geübten Konsumaskese sowie einer diesbezüglichen Erziehung zu finden sei. Gerade „im Zeital-

\footnotetext{
174 Keilhacker, Technik, 84

175 Keilhacker, Technik, 85

176 vgl. Keilhacker, Technik, 111
} 
ter der Industrie und ihrer von allen Seiten lockenden Versuchungen" nämlich müsse die „Erziehung von klein auf darauf gerichtet sein, den Menschen nicht zum Sklaven seiner Umgebung werden zu lassen “ ${ }^{177}$ Dies jedoch sei nur durch eine „Erziehung zum Verzicht" möglich. ${ }^{178}$ Allein der Verzicht könne eine ,innere Freiheit" garantieren, in der die modernen Individuen nicht länger „Sklaven ihrer eingebildeten, von der Industrie hochgezüchteten und immer von neuem angestachelten $\mathrm{Be}$ dürfnisse ${ }^{\text {“179 }}$ seien. Daneben scheint mit der Konsumaskese auch eine Rückwirkung auf die Produktion angezielt, die deren Umorientierung auf „wirklich lebensnotwendige Gegenstände und Verbrauchsgüter" zur Folge haben soll. ${ }^{180}$ Dies scheint einerseits notwendig, da ,heute die Mehrheit der Bevölkerung an lebensnotwendigen Gütern noch ausgesprochen Mangel leidet ${ }^{\prime} .{ }^{181}$ Andererseits soll zusammen damit wohl auch eine den industriellen Konsumzwängen entgegengesetzte ,Wertstruktur ${ }^{*}$ wiederbelebt werden. Darauf verweist etwa Keilhackers Schelte für „berufstätige Mütter, die ihre Kinder allein lassen, nicht, um das unbedingt fürs Leben Notwendige zu verdienen, sondern um ihren Lebensstandard aufzubessern". ${ }^{182}$ Dieser Lebensstandard gilt ihm in der Industriegesellschaft ohnehin als übertrieben, und der Versuch seiner Steigerung erscheint entsprechend als weiterer Verfall an die Sklaverei durch die Industrieproduktion und an deren ,materialistische` Orientierung.

Damit zeigt sich zunächst, daß die Autonomie, die Keilhacker zurückgewinnen will, als rein negative gedacht ist. Sie ist einzig eine ,Freiheit von', nicht aber eine Freiheit zur positiven Setzung. So geht es mit dem Lösungsvorschlag der Konsumaskese keineswegs um die Rettung der Entwurfsautonomie oder überhaupt wirklich um die neuzeitliche Subjektautonomie, sondern um die Etablierung einer weiteren Nische im modernen Gesellschafts- und Produktionszusammenhang sowie einer Gegenwelt. Gefüllt ist diese Gegenwelt zunächst nur durch das, Nein' des Konsumverzichts. Sie erhält dann jedoch eine weitere Bedeutung als Instrument einer ,Produktionskorrektur' auf ,lebensnotwendige' Güter hin und wird derart an die Gegenwelt der Kontramoderne angeschlossen sowie für deren Inhalte geöffnet. Deutlich wird das letzte vor allem durch Keilhackers Negativwertung der Orientierung auf gesteigerten Lebensstandard hin, in deren Hintergrund wieder die Materialismuskritik der Kulturtheorie mitschwingt. So legt sich nahe, daß zusammen mit der Umorientierung der Produktion auch eine Umorientierung auf der ,Wertebene' angezielt ist, die den werthaft ausgezeichneten Haltungen der Bescheidenheit und Verzichtsbereitschaft wieder gesellschaftlich relevante Geltung verschafft. Die ,Reautonomisierung durch Konsumaskese führt damit wieder in die Räume der Kontramoderne und ihrer ,Wertewelt' zurück und zeigt sich ebenfalls als gegen die moderne Gesellschaft und ihre Strukturen gerichtetes Unterfangen. Sie ist außerdem keine eigentliche Autonomisierung, da sie keineswegs die ursprünglich mit dem Projekt der Moderne angezielte Subjektautonomie reetablieren will, sondern eine negative Pseudoautonomie der inneren Emigration errichtet und so auf eine volle Wiederherstellung des Auto-

${ }^{177}$ Keilhacker, Technik, 111

178 Keilhacker, Technik, 113

179 Keilhacker, Technik, 112

${ }^{180}$ Keilhacker, Technik, 112

181 Keilhacker, Technik, 112

182 Keilhacker, Technik, 112 
nomiegedankens verzichtet. An die Stelle des letztgenannten tritt die begrenzte Form einer ,inneren Freiheit und einer Selbstbestimmung, die sich nur im Nein, nicht aber in der Konstruktion äußern kann. Keilhackers Entwurf bleibt damit seiner autonomiepessimistischen Ausrichtung in Kulturtheorie und Zivilisationskritik treu.

\section{Die kontramoderne Kritik- und Lösungskonzeption Keilhackers}

Insgesamt erscheinen Keilhackers Theoreme und seine Lösungsvorschläge so als Modernitätskritik, die die gesamte Neuzeit primär als Epoche des Verfalls, oder zumindest destruktiver ,Einseitigkeiten' begreift, ihre Kritikperspektive aus vormodernen Bereichen gewinnt und den rehumanisierenden Ausweg in einer Kontramoderne sucht. So zeichnet Keilhacker zunächst die moderne Welt als Ergebnis hypertropher, fehlgehender Autonomisierungsversuche, deren Hypertrophie am deutlichsten in der Beseitigung einer aus der Bindung an mittelalterliche ,qualitative' Wertstrukturen hervorgehenden Moralität durch Schaffung sachrationaler Orientierungen und Strukturen sowie eines rationalen Diskurses in den Geisteswissenschaften vor Augen zu treten scheint. Die Autonomisierung gilt hier als ,falsche‘ oder ,schlechte Emanzipation' nicht einfach von Humanität hindernden Heteronomien und Zwängen, sondern von einem spezifischen Ethos, das, obschon geschichtlich auffindbar, zugleich als zeitlos gültiges, einzig wahres gehandelt wird. Durch die Autonomisierung sieht Keilhacker dieses Ethos dem Verfall preisgegeben und von einer ethisch minderwertigen, ja pseudoethischen Wertstruktur des ,Materialismus', der ,Machbarkeit' und der ,Quantifizierung' ersetzt. Aus dieser Perspektive erweist sich die Autonomisierung und damit das Projekt der Moderne als anscheinend moralzerstörendes und derart sittlich schlechtes, wenn nicht gar böses Unternehmen. Daneben scheint sich die Autonomisierung mit ihrer Hypertrophie auch gegen sich selbst zu kehren und in neue Heteronomien der abstraktifizierenden Sachrationalität und funktionellen Verplanung zu führen. Nicht nur der ,Zauber' der Welt geht dadurch verloren, sondern auch ,Eigentlichkeit' und Selbstbestimmung drohen sich aufzulösen. An ihre Stelle sieht Keilhacker entsprechend eine fast totale Manipulation treten, die er zivilisationskritisch als ökonomische und mediale konkretisiert. Von ihr allein scheint das moderne Individuum bestimmt und konstituiert und derart als Subjekt aufgelöst. Im Kontext der Zivilisationskritik zeigt sich jedoch zugleich, daß es dieses Subjekt im Sinn der Neuzeit ohnehin nicht geben soll, da es zum einen als überfordertes, zur Entwurfsautonomie nicht befähigtes gilt, das fester, traditionaler Rahmen und normativer Vorgaben bedarf, um zu einem ,gültigen' und haltbaren Entwurf zu gelangen. Zum anderen schien es nicht nur kaum eine Potenz zu autonomem Verhalten mitzubringen, sondern gar auch noch Dispositionen für den Verfall in Fremdbestimmung zu besitzen. Die Konstruktion des neuzeitlichen, autonomen Subjekts selbst wird so in Keilhackers Theorie als Fehlkonstruktion behandelt, und die Korrektur der defizienten Erscheinungen der Moderne kann auf der Basis der Neuzeit nicht eingeleitet werden.

Daher wird als Lösung ein Rückgang hinter den Beginn des, Verfalls‘ vorgeschlagen, mit dem eine zweite Welt der Kontramoderne errichtet werden soll, in der dann ,Eigentlichkeit', Moralität und eine begrenzte Form von Selbstbestimmung als wiedergewonnen gelten. Etabliert werden auf diese Weise zwei Welten, die sich durch gegensätzliche Strukturmerkmale voneinander abheben, und die einander um der 
Korrektur der modernen Defizienzen willen einlinig zugeordnet sein sollen. So steht auf der einen Seite die ,moderne Welt', repräsentiert durch die Industriegesellschaft, die im Zusammenhang mit den Autonomisierungsprozessen entstanden ist und deren ,lebenserleichternde' Errungenschaften trotz der begleitenden Defizienzen nicht zurückgenommen werden sollen. Auf der anderen Seite steht die Welt der Kontramoderne, die durch Rückgriff auf das vorneuzeitliche Weltverhältnis und seine Auslegung in normative Orientierungsformen sowie gesellschaftliche Strukturelemente aufgebaut werden soll. Zeichnet sich die erste Welt durch Außenorientierung, Sachrationalität und Dynamisierung aus, so tut dies die zweite durch Introversion, ,Wiederverzauberung und festgefügte Orientierungsgerüste. Die Zuordnung der beiden Welten erfolgt dann so, daß die erste keinerlei Einfluß auf die zweite, die zweite jedoch durchaus Einfluß auf die erste nehmen soll. Zwar wird zunächst eine bezugslose Parallelexistenz beider angesetzt, doch dient dies primär der Negation irgendeiner Relevanz der ersten für die zweite Welt, während dann die zweite über ,ständische Realdarstellung, den Habitus der Ehrfurcht bzw. Ehrerbietung und eine Revitalisierung individueller ,Rückbindung' an Metaphysik und Religion in die erste eingepflanzt und wirksam werden soll. Diese Wirksamkeit entsteht dabei in zwei Schritten, und die Zuordnung der Welten vollzieht sich derart in doppelter Weise: Zunächst wird durch die ,Wiederverzauberung' und die Reetablierung einer metaphysisch-religiösen Grundhaltung eine ,Eigentlichkeitsnische‘ eingerichtet, die später mit Rekurs auf handwerkliche Kreativität weiter ausgestattet wird. In ihr soll das neuzeitliche Individuum sein ,Menschsein“ wiedergewinnen und zuerst einmal Kraft für die Existenz in den ,entfremdenden', weil ,einseitigen' Strukturen der ersten Welt finden. Der Einfluß der zweiten auf die erste Welt ist hier vorerst ein mittelbarer, nämlich kompensativ stabilisierender. Weiter aber vermittelt sich über die Ehrfurcht eine spezifische Form von Moralität, die als Orientierung an einem vorgegebenen, im Rekurs auf vorneuzeitliche Orientierungsformen gewonnenen Wertekorpus gedacht ist und die metaphysisch-religiös gefestigt werden soll. Die zweite Welt revitalisiert derart das vorneuzeitliche Ethos, erklärt es zum zeitlosen und konstituiert eine deontologische, weil an unumstößliche, aus sich heraus gültige und zu realisierende ,Werte' gebundene Moral, die nun der ersten Welt mit unbedingten Sollensansprüchen übergeordnet wird. Obschon die erste Welt für die Konstitution von Moralität als irrelevant und unzuständig gilt, wird sie so der moralischen Normativität der zweiten unterworfen und wird der zweiten Welt jetzt auch ein unmittelbarer Einfluß auf die erste eingeräumt. Mit diesem Doppelschritt soll die zweite Welt also einerseits einen rehumanisierenden Fluchtort in Form einer Nische in der ersten Welt bilden, andererseits als Hort der Moralität eine spezifische Prägewirkung für dieselbe entfalten.

Weder durch Wiederbelebung der Moralität noch durch die ,Eigentlichkeitsnische aber ist eine Wiedereinsetzung der Subjektautonomie intendiert, sondern lediglich eine ,Rehumanisierung' im Sinn der Bereitstellung von ,Existenzbedingungen' für einen traditionaler Entlastung und sichernder Prädefinitionen bedürftigen Menschen beabsichtigt. Die Selbstbestimmung, die von der Kontramoderne wieder ermöglicht werden soll, ist daher nur die begrenzte des Verzichts, wie sie eine konsumasketische Distanzierungsfähigkeit garantieren soll. Damit ist die ursprünglich vom Projekt der Moderne angezielte Autonomie letztlich verabschiedet. Zum einen ist an ihre Stelle 
eine ,Eigentlichkeit' gesetzt, die durch Submission unter die prädefinierten Bestimmungsgrößen der Kontramoderne entstehen soll, zum anderen ist der Autonomiebegriff in eine negative Freiheit der inneren Emigration umdefiniert, die mit dessen originär konstruktiver Bedeutung nichts mehr gemein hat. Keilhackers Entwurf bleibt so bis in die Lösungsvorschläge hinein modernitätskritisch und autonomiepessimistisch. Entsprechend sucht er auch seine ethische Lösung nicht in einer autonomen Moral, sondern in einem deontologisch-heteronomistischen Paradigma, das weder Geschichtlichkeit noch sachrationale Relevanzen kennt. Dem Subjekt wird darin aus sich heraus keinerlei sittliche Kompetenz zugestanden, sondern dessen Sittlichkeit kann sich nur durch Befolgung externer Sollensansprüche der präformierten Wertewelt realisieren. Das ethische Paradigma Keilhackers vermag deshalb weder sittlichen Fortschritt, eine Teilnahme der Subjekte an der Konstitution von Moral und einen Ethoswandel zu legitimieren, noch kann unter seinen Bedingungen ein rationaler Diskurs der Ethik mit sachspezifischen Gegebenheiten geführt werden. Moral bleibt der Wirklichkeit ebenso fremd wie der Gesellschaft und ihren Mitgliedern, und Sittlichkeit konstituiert sich durch eine externe, ,weltfremde' Heteronomie.

\subsection{Redundanz I: Wiederaufgriff der reformerischen Devianzvorwürfe und ihrer Pessimismen durch die Filmerziehung}

Die von Keilhacker in seiner Kulturtheorie und Zivilisationskritik bereitgestellten Theoreme und Paradigmen sowie die Intentionen seiner Lösungsvorschläge bestimmen nun auch das Unternehmen der ,Filmerziehung, wie sie vor allem von seinen Schülern und Mitarbeitern als eigenständiges pädagogisches Arbeitsgebiet konstituiert wird. Daneben rekurrieren die Filmerzieher auf die Kinoreformbewegung und revitalisieren sie deren Vorwürfe gegen den Film. Sie schaffen so zunächst zwei partiell miteinander gekoppelte und sich als kongenial erweisende Devianzkritiken, nämlich ein Korpus von Devianzvorwürfen, das primär von den Reformern übernommen wird, und ein weiteres, das sich vorwiegend aus Keilhackers Kritik speist. Diesen beiden Kritiken stellen sie dann eine ,positive' Konzeption von Lösungsvorschlägen entgegen, die sich als letztlich ethische zeigt und zu einem gut' Teil die Lösungsoptionen Keilhackers bereichsspezifisch weiterführt. Ich will nun zunächst den Rückgriff auf die Devianzvorwürfe der Reformer skizzieren, um dann die (modifizierte) Übertragung der Keilhackerschen Modernitäts- und Zivilisationskritik auf den Film aus den filmerzieherischen Texten zu erheben, und schließlich die darin gesetzte, ,positive‘ ethische Konzeption zu rekonstruieren.

$\mathrm{Zu}$ bemerken ist jedoch zuvor noch, daß sich das pädagogische Unterfangen der Filmerzieher dabei primär auf Kinder und Jugendliche richtet und, im Unterschied zu den Reformern, Erwachsene als Zielgruppe weitgehend ausklammert. Zum Zweck der ,sachlogischen' Stützung und Legitimation der pädagogischen Maßnahmen flankiert die Filmerziehung ihre Unternehmungen außerdem - wie zu Beginn des Kapitels erwähnt - durch umfängliche ,empirische;, wirkungsforschende Modellversuche und Aktionen. Ich werde im folgenden jedoch weder auf die altersspezifischen pädagogischen Zuschreibungen und Untersuchungen noch auf die Einzelergebnisse ,empirischer` Studien und ihre Tragfähigkeit eingehen. Die erste ,Vernachlässigung' legitimiert sich methodologisch daraus, daß es mir in der vorzuneh- 
menden Rekonstruktion nicht um eine altersspezifisch differenzierende Kasuistik der Eignung bestimmter Filme und Filmgehalte für bestimmte Altersklassen geht, sondern um die in der filmbezogenen Devianzkritik und den dagegen gesetzten Lösungsvorschlägen enthaltenen ethischen und ethikkonstitutiven Grundoptionen, die den Hintergrund der filmerzieherischen Pädagogik bilden. Diese Grundoptionen aber sind weder von der Wirkungsforschung konstituiert noch zielgruppenspezifische Festlegungen, sondern ethische, anthropologische und kulturtheoretische Axiome von grundsätzlicher Bedeutung, die bei den Reformern und bei Keilhacker präformiert sind und aus dem Rückbezug zu diesen beiden,Quellen' in die filmerzieherische Theorie einwandern. Mit ihnen ist die Theoriebasis für eine Medienethik festgelegt, deren Bedeutungsumfang über den pädagogisch angezielten Kreis der Kinder und Jugendlichen hinausgedehnt ist und allgemeine Relevanz beansprucht. Nicht zuletzt deshalb sind etwa dort, wo über die anthropologischen Grunddaten der Gewaltrezeption verhandelt wird, auch für die Filmerziehung selbst die Erwachsenen doch wieder mit im Blick (vgl. unten). Auf der Ebene der Grundoptionen gibt es hier keine gruppen- oder altersspezifischen Beschränkungen. Ebenso kann zwar eine altersspezifische Moral und Moralerziehung konstruiert, nicht aber eine solcherart eingeschränkte Ethik angesetzt werden. Sie greift als umfassende Theorie der Moralität bzw. menschlichen Handelns unter normativen Prämissen per definitionem über Gruppengrenzen hinaus. Um Ansatz und Grundlinien dieser Ethik, um ihre Formalkonstruktion geht es mir, so da $B$ der kasuistische Auszug in konkrete, altersspezifische Einzelnormen weitgehend unberücksichtigt bleiben kann.

Auch die zweite Vernachlässigung legitimiert sich aus dieser Rekonstruktionsperspektive. Gegenstand meines Unternehmens ist nicht die Stichhaltigkeit oder Zweifelhaftigkeit der filmerzieherischen Wirkungsforschung. Deren Einzelergebnisse können entsprechend ebensowenig einer Diskussion unterzogen werden, wie ihr $\mathrm{Zu}$ standekommen. Nicht die in sukzessiver Fotografie festgehaltenen Mimiken und Gesten jugendlicher Filmrezipienten, auch nicht Fragebögen und Antworten zu bestimmten Filmen oder assoziative Tests stehen für mich im Blick, sondern die ethische und ethikkonstitutive Axiomatik. Hierbei ist allerdings die theoretische Leitperspektive der normativen Aussagen der Devianzkritik von Bedeutung und damit die Formalstruktur der den Forschungen zugrundegelegten Wirkungsaxiomatik. Obschon ich auf Einzeluntersuchungen - etwa zum Erregungsgrad eines Jugendlichen bei der Rezeption eines Kriminalfilms - nicht eingehe, werde ich durchaus die der daraus gefolgerten Wirkung - etwa einer kriminellen Nachamungshandlung - vorausgehende anthropologische oder schichtbezogene Grundannahme betrachten. Ähnlich wie bei den Reformern skizziere ich so die Optionen, die der filmerzieherischen Wirkungsspekulation zugrundeliegen, durchaus mit. Dabei wird sich rasch erkennen lassen, daß diese Optionen ebenfalls von den Reformern übernommen werden. Im Ganzen greife ich also sowohl hinter die altersspezifischen als auch hinter die empirischen Aussagen der Medienpädagogik bei den Filmerziehern zurück und suche in beiden Fällen die zugrundeliegenden Paradigmen zu fassen.

Wiederanknüpfung an die Kinoreform

Zunächst nun finden sich in den Texten der Filmerzieher deutliche, partiell explizite Rückbezüge zu den Kinoreformern. Deren Schriften werden von den Filmerziehern 
recht rasch ,wiederentdeckt' und gelten als durchaus aktuell. Ihre Thesen werden als verläßlich gehandhabt, wenig hinterfragt und im Sinn eines selbstverständlichen Argumentationsbestands rezipiert. Die Reformliteratur erhält dabei den Status einer wissenschaftlichen Quellenliteratur, die eine gewisse Autorität besitzt, eigene Theoreme dadurch zu stützen vermag und zudem die Sicherheit gewährende Einordnung in eine ,unverdächtige` Tradition ermöglicht. Gerade die letztgenannte Möglichkeit scheint mir ein wichtiges Movens für die Rezeption zu sein: Wie die Rede von der ,Stunde Null' nach 1945 eine (freilich psychosozial nicht unverständliche) gesellschaftliche Verdrängungsneigung indiziert, welche die Epoche des Nationalsozialismus gerne als geradezu fremdartigen ,Einbruch der Barbarei‘ in die deutsche Geschichte sehen will, so neigt auch die Filmerziehung dazu, die Jahre zwischen 1933 und 1945 auszuklammern. Die nationalsozialistische Epoche erscheint dabei als erratischer Block, der weder mit der vorausgehenden noch der nun nachfolgenden Zeitgeschichte etwas zu tun haben soll. Entsprechend werden im Zeitraum vor der sogenannten ,Machtergreifung' nicht Momente der Kontamination gesucht, aus denen der Nationalsozialismus hervorging, sondern es wird gerade diese Zeit als noch ,saubere', giftfreie‘ Phase behandelt, auf die man sich guten Gewissens zurückbeziehen kann und die auch der Wissenschaft eine traditionale Basis wieder verschafft. Die Ausklammerung der nationalsozialistischen Epoche läßt dann zugleich die Jahre vom Anfang des Jahrhunderts recht nahe rücken, und macht für die Filmerzieher aus den Reformern fast Zeitgenossen. So rezensiert etwa Zielinski im Jahr 1959 eine Reformschrift von 1912 und insistiert er nachhaltig auf deren unüberholter Aktualität, die gerade die Lektüre der älteren Literatur empfehle und ihre Relevanz für die neueren Unternehmungen nachweise. ${ }^{183}$ Ähnlich nennt Kerstiens die Schriften Sellmanns von 1913 ,fast modern“ (wenngleich ein wenig zu belehrend) und sieht er sich in seinen pädagogischen Zielvorstellungen mit ihnen einig. ${ }^{184}$ Tröger wiederum verbindet sich methodologisch mit den Reformern, wenn er den unvergänglichen, wissenschaftlichen Wert einer Fragebogenaktion als Untersuchungsform durch Zitation ebensolcher reformerischer Unternehmungen legitimiert. ${ }^{185}$ Und Wasem schließlich, der sich Seite an Seite mit der ,Kunsterziehungsbewegung der Jahrhundertwende im Kampf gegen den Kitsch sieht, stellt sein filmerzieherisches Projekt direkt in die Tradition der Kulturreformbewegungen des späten 19. und beginnenden 20. Jahrhunderts, zu denen ja die Kinoreform ebenfalls zählt. ${ }^{186}$ Die so entstehende ,Zeitgenossenschaft' und die supponierte ,Unverdächtigkeit' der Reformer erlaubt dann auch die erwähnte Verwendung ihrer Argumente für die Stützung der eigenen Position. Das zeigt sich schon in Trögers methodologischer Konnexion. Nicht anders verhält es sich, wenn Kerstiens auf Ackerknecht verweist, um die ,Auslösung von Gefühlsreaktionen' schon allein durch ein bewegtes Bild zu belegen. ${ }^{187}$ Autoritativ untermauert wird hier ein Einzelargument durch den zitativen Rückbezug auf einen Reformer. Weiter aber werden auch reformerische ,Untersuchungen' zur Filmwirkung oder zur Motivation des Publikums als quasi-empirisches Belegmaterial für die eige-

183 vgl. Zielinski, Johannes, „Kino und Jugend““, in: Jugend, Film, Fernsehen 1959/2, 21-28

184 Kerstiens, Filmerziehung, 74

185 vgl. Tröger, Film, 26

186 vgl. Wasem, Jugend, 114

187 vgl. Kerstiens, Filmerziehung, 17 
nen Thesen gebraucht. ${ }^{188}$ Die methodologische Absicherung, auf die sonst bei eigenen Untersuchungen viel Wert gelegt wird, tritt hier in den Hintergrund, obschon die materialen Wirkungsthesen bei den Reformern selbst nicht unumstritten waren, wie Hellwigs Auslassungen zur Frage der empirischen Belegbarkeit der Kriminalisierungsthese gezeigt haben (vgl. 2.4.). Zum dritten schließlich werden alle Devianzvorwürfe der Reformer repetiert, wobei der Bezug zu den letztgenannten zwar nicht immer zitativ hergestellt, jedoch bis in die Terminologie hinein unverkennbar ist. In der Repetition der Devianzthesen liegt denn auch der zentrale und für die ethische Rekonstruktion wichtigste Konnex der Filmerziehung mit der Kinoreform.

\section{,Moralische Primitivierung: Anthropologie und Natur-Kultur-Verhältnis}

Folgt man den von mir in der Rekonstruktion der reformerischen Devianzvorwürfe herauskristallisierten vier Grundtypen der Argumentation, so läßt sich zunächst auch bei den Filmerziehern als Generalthese der Vorwurf der moralischen Primitivierung entdecken. Ebenso wie bei den Reformern wird mit ihm hier die Gefahr eines Verfalls der Sittlichkeit durch ,Verrohung und Weckung,primitiver Instinkte auf der Basis einer negativen Anthropologie ausgemalt. Als Verrohungsargument trägt zunächst Margarete Keilhacker den Vorwurf vor, wenn sie von ,brutalen' und grausamen' Filminhalten, zu denen in dieser Zeit vor allem Schlägereien in Western und Schießereien in Kriminalfilmen zählen, eine „Schockwirkung“ hervorgehen sieht, die „abstumpfend und dadurch vergröbernd“ sei. ${ }^{189}$ Während die Abstumpfung zu einer „Enthemmung“ führe, die mit der „Zersetzung der höheren Gefühle - Schamgefühl, Gewissen, Ehrfurcht - verbunden" sei, riefen die ,schockierenden' Szenen zudem eine „nachhaltige Erregung des Trieblebens“ hervor. ${ }^{190}$ Mit diesem würden die Rezipienten in einer "primitiven und aufreizenden Form" konfrontiert, wodurch "die weicheren und differenzierteren“ ,höheren' Gefühle ,verkümmerten', und sich „,nur der robustere Teil" halte. ${ }^{191}$ Der Film scheint so also eine, weiter unten' angesiedelte Triebhaftigkeit bloßzulegen, die an sich schon undifferenziert und ,roh' ist, und derart „zu einem stimulierenden Mittel von hoher Dauerwirkung" zu geraten. ${ }^{192}$ Aus der Erregung dieses ,tiefer gelegenen“ Trieblebens gehe dann eine „Tatbereitschaft“", also die Bereitschaft zu einer Nachahmungshandlung, hervor. ${ }^{193}$ Für diese Handlung stelle der Film außerdem "das dazugehörige Nachahmungsschema" bereit, das zeige, „wie man die Sache anpackt“, und so gewissermaßen den Rezipienten umfassend für das Abgleiten in moralische Primitivität und Defizienz ausstattet. ${ }^{194}$

Bereits diese Argumentationsfigur Margarete Keilhackers stellt eine recht präzise Wiederholung des reformerischen Devianzvorwurfs dar. Ebenso wie dort wird die These spekulativ-psychologisch angesetzt, und zunächst eine graduelle Verderbnis durch ,Abstumpfung und ,Vergröberung', also durch eine allmähliche Krudisierung der Gefühlswelt postuliert. Sahen die Reformer dabei insbesondere Empathie und

\footnotetext{
188 vgl. Kerstiens, Filmerziehung, 58

189 Keilhacker, Kino, 149

190 Keilhacker, Kino, 149

191 Keilhacker, Kino, 149

192 Keilhacker, Kino, 149

193 Keilhacker, Kino, 149

${ }^{194}$ Keilhacker, Kino, 149
} 
Mitleid als emotionale Basis der Moralität zerstört, so betrachtet auch Margarete Keilhacker moralrelevante Gefühle als gefährdete Potenzen und sieht sie reformanalog mit ihrer Zersetzung die Verankerung der Sittlichkeit schwinden. Gleichzeitig veranschaulicht die Nennung der ,Ehrfurcht' als ein solches Gefühl den Theoriekonnex mit dem wertethischen Entwurf ihres Mannes, in dem dieser emotionale Habitus ja als ,Voraussetzung' des ,Werterlebens' und der darin gründenden Moralität gilt. Auf diesem Hintergrund der Destruktion, psycho-moralischer' Vorbedingungen im Menschen wird dann die eigentliche Korruption des moralischen Verhaltens zu einem unmoralischen mit einer spezifischen Wirkungsthese ausgeführt. Dabei erscheint in Margarete Keilhackers Text - wiederum reformkohärent - das mimetische Wirkungskonzept, das hier sowohl die Nutzungsthese als auch die Kooperationsthese erkennen läßt. Die Nutzungsthese tritt in Blick, wenn dem Film vorgeworfen wird, gewissermaßen informationell ein Handlungsrezept zur Verfügung zu stellen, das lediglich ,zeigt', wie die Tat ausführbar ist, ohne sogleich manipulativ zur Ausführung zu zwingen. Die Kooperationsthese ist es dann jedoch, die als zentrales Argument durchgeführt wird. Auch mit ihr wird kein manipulativer Handlungszwang behauptet, sondern neben der abstumpfenden eine erregende Wirkung des Films angenommen, die mit einer negativ belasteten ,Triebbasis' als Latenzanteil des Publikums zusammenspielt. Aus dem Zusammenspiel entsteht erst die ,Handlungsbereitschaft ${ }^{\prime}$ und daraus wiederum die Tat. Nachdem also zunächst ein gewisses Vakuum durch die Destruktion moralitätsdisponierender Gefühle konstatiert wurde, wird diesem Vorgang nun zusätzlich mehr oder weniger deutlich eine negative Basis der Triebhaftigkeit unterlegt, die vom Film aufgegriffen und stimuliert zu werden scheint. Aus dieser Basis geht dann die unmoralische Tat und damit die eigentliche moralische Primitivierung hervor. Die spekulativ-psychologische Einführung der moralischen Korruption als graduelle ,Verrohung' findet so über die hier implizit revitalisierte Kooperationsthese erst ihr eigentliches Fundament. Mit der Triebbasis nämlich scheint bei Margarete Keilhacker ein primitiver und offenbar antimoralischer Grund auf, der anscheinend allgemein mit dem Menschsein mitgegeben ist und die Möglichkeitsbedingung des Verfalls bildet. An dieser Stelle verweist die Argumentationsfigur daher auf eine anthropologische Verankerung der Publikumslatenz, wie sie auch von den Reformern vollzogen wurde.

Stärker und deutlicher als bei Margarete Keilhacker ist diese anthropologische Grundlegung dann etwa bei Neuhäusler, Hennig, Tröger oder Wasem ausgearbeitet. Alle vier dehnen, entsprechend einer solchen Bestimmung der Gefährdungsbasis, die Latenz über den Rezipientenkreis der ,Jugend hinaus auf Erwachsene aus und sehen bei allen Gruppen dieselbe, perniziose, ontologisch gegründete Latenz anwesend. So spricht Neuhäusler nicht nur von Kindern und Jugendlichen, sondern vom „,iederen Bürger", der sich im Kino „den unerhörten Wind des Kampfes auf Leben und Tod, des Verbrechens um die Ohren, bzw. durch die verwinkelte Seele wehen" lasse und eines solchen ,existenziellen Exzesses' anscheinend bedürfe. ${ }^{195}$ Am Werk sieht er bei den Zuschauern jeglicher Couleur und jeder Altersstufe eine ,sadistische Kontemplation $^{4196}$, deren Existenz er auf ,die Bestie in uns ${ }^{4197}$ zurückführt. Auf diese spekuliere

195 Neuhäusler, Verrohung, $12-13$
196 Neuhäusler, Verrohung, 12

${ }^{197}$ Neuhäusler, Verrohung, 11 
der Film, der letztlich nichts anderes tue, als „der latenten Brutalität und dem Sadismus des Publikums Tribut zu zollen" und die "finsteren Mächte unseres Seins" ,herauszufordern'. ${ }^{198}$ Diese Mächte scheinen dabei ,von Natur aus' dem Menschen eigen zu sein. So zeichnet Hennig den Menschen in seinen naturalen Wurzeln als Schlächter und Mörder, der ,in der allgemeinen Natur" „raubt und mordet“ ${ }^{199}$ An dieser seiner ,Schlächternatur` ändere auch die Zivilisation nichts, wenn sie seine Destruktivität in „menschliche Regeln, Gesetze, Sitten, gewerbliche Rechte und Besitzrechte" kleide, um sie zu , legalisieren. ${ }^{200}$ Unter der Decke zivilisatorischer Hege und Selbstlegitimation bleibt die äonenalte Ungestalt am Leben und oft auch noch am Werk. ${ }^{201}$ In ähnlicher Weise spricht Tröger von den, asozialen Neigungen und Antrieben', welche zum „Erbe des Menschen überhaupt" gehörten und nur unvollkommen vom „Lack der Zivilisation“ überdeckt werden, ${ }^{202}$ oder nennt Wasem die „Gefährdung durch den Film" als ,,in der allgemeinen Gefährdung des Menschen begründet “203. Für Neuhäusler bringt dies dann durch die Einwirkungen des Films einen ,Teufelskreis" hervor, in dem „Roheit im Gemüt" nach „Roheit im Spiel“ verlange, die wiederum die ,Roheit im Gemüt' steigere. ${ }^{204}$ Der Überschritt zur Tat scheint daraufhin leicht, denn der "Reizschrei“ verlange "nach der Wirklichkeit selbst" und die „reale Katastrophe“ werde „fällig“. ${ }^{205}$ Die „Barrieren der normalen Alltagsperson “206 nämlich ,verschwämmen" nicht nur in der Rezeptionssituation, sondern auch danach. Die negative Inklination scheint vom Film zu einem Drang verstärkt bzw. als urtümlicher Drang wiedererweckt zu werden, der sich in eine Handlung auslegen muß. So stark scheint die dranghafte Latenz zu sein, daß Neuhäusler sie durch einen Vergleich mit der Sexualität illustriert und eine ähnliche,Anregung der Gewalttätigkeit durch Gewaltszenen, wie der Sexualität durch erotische Szenen konstatiert. ${ }^{207}$

Die Basis für die verderbliche Handlung wird also nun direkt in einer anthropologisch auffindbaren, mehr oder weniger triebhaften Latenz gesucht, die absolut negativ erscheint und als ,Sadismus', ,Brutalität', bzw. ,asoziale Neigung sowohl präzisiert, als auch diskriminiert wird. Wiederum ist der Konnex mit den Reformern überdeutlich und bis in die Sprechform hinein spürbar. War bei Conradt von den ,bösen Instinkten des Publikums', oder bei Hellwig von der, viehischen Gier' der Rezipienten die Rede, so sind es bei Neuhäusler die ,Bestie in uns' und die ,finsteren Mächte unseres Seins', oder ist es bei Hennig der, urzeitliche Schlächter'. Die Figur ist in beiden Fällen dichotomisch und hebt einen (noch unbestimmt bleibenden), hu-

198 Neuhäusler, Verrohung, 18

199 Hennig, Aggression, 12

200 Hennig, Aggression, 12

201 Dieses ihr Werk sieht Hennig dabei etwa im Fleischverzehr, dessen vorgängige ,Schlächterei' durch die zivilisatorische Spezialisierung und Regionalisierung in Schlachthöfen und Metzgereien nur unvollkommen verhüllt sei. (vgl. Hennig, Aggression, 12)

202 Tröger, Film, 161

203 Wasem, Jugend, 48

204 Neuhäusler, Verrohung, 13-14

${ }^{205}$ Neuhäusler, Verrohung, 14

206 Neuhäusler, Verrohung, 12

207 vgl. Neubäusler, Verrohung, 14 
manen' Menschen von einem ,Erbe' der ,Tierhaftigkeit' bzw. bestimmten ,ererbten', bösartigen Antriebsstrukturen und Wesenszügen ab. Die Negativa können dabei in drei Formen gegliedert werden. Zunächst zeigen sie sich in der Figur der, Tierhaftigkeit' als animalische Triebbasis, die stammesgeschichtlich verankert und tradiert ist. Der Kern dieser Animalität scheint in einer blindwütig destruktiven Aggression und Grausamkeit zu bestehen. Weiter werden pathologische Deformationen, wie etwa der Sadismus, genannt und zu ontologischen Gegebenheiten erklärt. Sie werden so ihres Kontingenzgehalts entkleidet und statt als Pathologien als ,Anthropologika' gehandhabt. Schließlich werden noch , asoziale Neigungen', grundsätzliche Gefährdungen` und ,finstere Mächte‘ aufgeführt. Die negativen Wesenszüge treten damit gewissermaßen, rein' auf und erhalten (mit der dritten Formulierung) fast metaphysisches Gepräge. In allen drei Fällen aber gelten diese Negativa als mit dem Menschsein selbst mitgegeben, d.h. sie erweisen sich als naturale Prädispositionen, die die ,Natur ${ }^{\circ}$ des Menschen entscheidend prägen. Sie scheinen eine grundverdorbene, antimoralische Region im Menschen zu bilden, aus der, wenn sie sich selbst überlassen bleibt oder gar an die Oberfläche geholt und ,verstärkt' wird, kaum etwas anderes als ein sittlich schlechtes, ja böses Verhalten hervorgehen kann. Die menschliche Natur wird so erneut als mit einem Gefälle zur Amoralität ausgestattet gezeichnet, und der anthropologische Pessimismus der Reformer findet sich recht ,originaltreu' revitalisiert. Wiederbelebt wird auch die Kooperationsthese, die erneut die Rolle des Films für den Ausbruch der Amoralität als Reizung und ,Verstärkung' der anthropologischen Basis skizziert. Zunächst in der menschlichen Natur verankert, tritt das Böse dann gewissermaßen durch filmische Förderung und Stimulation zu Tage.

Entgegengesetzt wird den Negativa dann die ,Zivilisation;, die einmal als dünne ,Lackschicht' und ein andermal als Korpus kultureller Regelgruppen skizziert ist. Dieser ,Counterpart' kulturell-zivilisatorischer Strukturen aber scheint seine Funktion einer ,Einhegung، der gefährlichen Natur nur unvollkommen auszuüben und partiell ohnehin lediglich einer legitimativen Verdeckung der Aktivitäten der alten Ungestalt zu dienen. Ausgemalt wird also nicht nur ein Bild vom Menschen, in dem er als Raubtier auftritt, sondern auch einer ,Selbstdomestizierung', von der weder sein altes Wesen beseitigt noch seine ,Humanität' gegen ,Rückfälle' verläßlich gesichert ist. In diesem Bild ist damit noch ein doppeltes erkennbar: Zunächst verweist die Entgegensetzung von ,Zivilisation' und menschlicher Natur darauf, daß auch hier wieder eine Art Natur-Kultur-Antagonismus vorliegt. Nicht anders als bei den Reformern dient die zivilisatorisch-kulturelle ,Hege‘ einer Beschneidung und Zurückdrängung der gefährlichen Latenzen. Während die Reformer freilich hierbei zwischen dem kulturellen Bollwerk und der Zivilisation unterscheiden, findet sich diese Differenzsetzung bei den Filmerziehern nicht explizit und mit derselben Deutlichkeit. Vielmehr werden Kultur und Zivilisation häufig synonym gebraucht und eignet dem Zivilisationsbegriff eine Unschärfe, die in ihm noch zwei weitere Bedeutungsgehalte erkennen läßt. So wird mit ihm in den filmerzieherischen Texten einmal auch die ,moderne Welt' benannt, die der Kritik unterzogen wird (vgl. weiter unten). Ein andermal wird er zur Bezeichnung moralanaloger, aber vormoralischer Sitten genutzt und derart implizit auf die eine Seite der Kantischen Unterscheidung von Zivilisation und Kultur (vgl. 2.3.) rekurriert. Scheint im erstgenannten Gebrauch eine gewisse Nähe zum reformerischen zu liegen, der ja Zivilisation ebenfalls negativ wer- 
tet, so zeigt ein genauerer Blick, daß außer der Negativwertung kaum Parallelen bestehen. Während sich die Wertung bei den Reformern auf die zivilisatorische Vitalisierung der anthropologisierten Negativa bezieht, greifen die Filmerzieher hier auf die Keilhackersche kulturtheoretisch-soziologische Kritik zurück. Der zweitgenannte Gebrauch wiederum läßt sich zunächst in Hennigs summarischer Charakterisierung als ,Regeln, Sitten und Gesetze' vermuten, so da $B$ dann statt von einem Natur-Kultur-Gegensatz von einem Natur-Zivilisations-Antagonismus gesprochen werden könnte. Doch zeigt Hennigs Reihung nicht die Absicht, Moralität als Gesinnung der Kultur zuzuschlagen und derart streng beide Seiten der Kantischen Unterscheidung anzuwenden. Es wird damit weder die reformerische noch die Kantische Differenzierung von den Filmerziehern wirklich aufgegriffen und durchgehalten. Aus diesem Grund, und da zudem die ,Regeln, Sitten und Gesetze selbst durchaus Kulturleistungen sind, scheint es mir legitim, hier ebenfalls von einem Natur-Kultur-Antagonismus zu sprechen. Durch die Bestimmung der ,Kulturseite' als Bollwerk ist dieser Antgonismus dem reformerischen durchaus analog konstruiert.

Läßt sich also zunächst wieder eine Revitalisierung der reformerischen Basisparadigmen bis in ihre Neigung zu Dichotomien hinein feststellen, so ist dann jedoch weiter erkennbar, da $B$ die Kultur in der filmerzieherischen Figur etwas anders eingeschätzt wird. Wie zu sehen war, erscheint Kultur bei den Reformern als erfolgreiche Konstruktion gegen das naturale Gefälle zur Amoralität und erhält sie selbst eine moralitätskonstitutive Funktion. Kultur ist dort Garant und exklusiver Hort der Sittlichkeit. Ihr wird damit eine Leistung zugetraut, die ihr von den Filmerziehern nicht attestiert wird. Vielmehr scheint das kulturell-zivilisatorische Bollwerk recht schwach und weist der Antagonismus ein Übergewicht auf der Naturseite auf. Schon aus diesem Grund wirkt die Kultur bei den Filmerziehern tendenziell ungeeignet, die nötige Moralisierung (allein) zu vollziehen. Das legt dann den Verdacht nahe, da $B$ bei ihnen Moralität eine (zusätzliche) kulturexterne Quelle hat. In der Tat wird sich zeigen, daß Moral und Sittlichkeit in ihrem ,positiv' gesetzten Konzept der ,Eigentlichkeitsund Befähigungsethik' nicht nur jenseits der ,Zivilisation', sondern überhaupt der Kultur als kontingentem Menschenwerk angesiedelt ist.

\section{Die bewahrethische Inklination der Filmerziehung}

Trotzdem ist die Erstellung kultureller Bollwerke gegen die negativen Latenzen nicht völlig ohne Relevanz für die Moralität. Unter den Bedingungen der vorstehenden Anthropologie kann als Bedingung für den ,humanen', d.h. sittlich lebenden Menschen die Forderung einer Zurückdrängung der negativen Latenz und einer Absicherung gegen ihre Kraft gar nicht vermieden werden. Ähnlich den ,moralrelevanten Gefühlen' bei Margarete Keilhacker erhält die Konstruktion solcher Bollwerke deshalb eine flankierende Funktion, die zwar allein Moralität noch nicht erzeugt oder garantiert, aber trotz aller Schwäche sichern hilft. Entsprechend tritt bei allen Autoren zunächst der kooperativ erzeugte moralische Verfall zugleich als Zerstörung von ,Barrieren' auf. Schon Neuhäusler spricht, wie zu sehen war, davon, daß bei der Filmrezeption solche ,Barrieren' fielen und derart gewissermaßen die böse Unterströmung, der Drang des animalischen Wesens freigesetzt werde. Ähnlich sieht Margarete Keilhacker das "moralisch Zweideutige und Verwerfliche“ vom Film als ,selbstverständlich dargeboten und derart neben den , höheren Gefühlen' auch sittli- 
che Hemmungen und eine davon gesicherte, Anständigkeit der Rezipienten destruiert. ${ }^{208}$ Daraus ergibt sich dann, daß für die Sicherung moralischen Verhaltens und die über dieses vermittelte Humanität des Menschen eine Reetablierung solcher ,Barrieren' und hemmender ,Anständigkeitsschwellen' erforderlich wird. Neuhäusler fordert gegen die ,demoralisierende‘ Wirkung des Films deshalb eine „Härte zu uns selbst", eine „Selbstbeherrschung“, die verhindern soll, ,in den Strudel des Lasters“ gezogen zu werden. ${ }^{209}$ Auch bei Tröger und Wasem ist der moralische Verfall nur durch „ein System von Warnungen und Versagungen“'210 aufzuhalten. Kohärent zu den Reformern weist das filmerzieherische Konzept daher im Kontext der Revitalisierung des ersten Devianzvorwurfs einen bewahrethischen Zug auf, demzufolge Moralität vorerst nur im Modus der Negation, nämlich durch eine Wendung gegen die naturale anthropologische Basis, gesichert werden kann, wenngleich im Unterschied zu den Reformern die Bollwerke allein hier die Moralität noch nicht schaffen. In der Tat wird dieser bewahrethische Zug auch in der ,positiven' Setzung der Eigentlichkeits- und Befähigungsethik wieder spürbar werden.

\section{,Sexualisierung': Konkretion der negativen Anthropologie und Stellungnahme gegen einen Ethoswandel}

Ebenso wie bei den Reformern legt sich die These der moralischen Primitivierung dann auch bei den Filmerziehern in die Devianzvorwürfe der Sexualisierung und der Kriminalisierung aus. Dort wie hier stellt diese Auslegung eine Art Konkretion des generellen Primitivierungsarguments dar. Sehr deutlich ist das zunächst im Fall der Sexualität, die als Trieb angesetzt wird und eine konkrete, anthropologisch auffindbare, als prekär geltende Basis bildet, aus der moralischer Verfall unter geeigneten Bedingungen hervorzugehen scheint. Die Bereitstellung solcher Bedingungen wird von den Filmerziehern wie von den Reformern sowohl dem Film als Inhaltsträger als auch dem Kino als sozialem Raum angelastet. So nimmt zunächst Tröger beim Film „über alles MaB ausgewalzte Gebiete sexuellen Zur-Schau-Stellens“211 wahr oder werfen Stückrath/Schottmayer dem Film vor, „Anschauungsunterricht über das Gebiet der Liebe“" zu geben und derart "mit den Trieben das Leben“" zu ,inspirieren'. ${ }^{212}$ Gerade die letztgenannten sehen von den Filminhalten „unerfülte Antriebe" aufgegriffen und stimuliert, so da $\beta$ durch die Rezeption ,sexuelle, asoziale und kriminelle Taten ihre geheime Vorbereitung finden ". ${ }^{213}$ Die verderbliche Wirkung stellt hierbei wieder die Frucht eines kooperativen Zusammenwirkens von Trieblatenz und Film dar, die in den moralischen Verfall führt, und die angewandte Wirkungsthese ist erneut die Kooperationsthese. Ebenso findet auch hier der Überschritt vom Zustand der Stimulation der negativen Region im Menschen zur unmoralischen Tat durch einen postulierten ,Dammbruch' statt. So betrachtet Kerstiens die Darbietung sexueller Reize als eine Art Terror durch „,immer wieder vor Augen“ stehende erotische

\footnotetext{
208 Keilhacker, Kino, 149

209 Neuhäusler, Verrohung, 17

${ }^{210}$ Tröger, Film, 161; vgl. auch Wasem, Jugend, 86: Hier soll ein „Halt des Menschen in der Bindung an das christliche Sittengesetz" vor dem Abrutschen bewahren.

211 Tröger, Film, 130

212 Stückrath/Schottmayer, Psychologic, 140

${ }^{213}$ Stückrath/Schottmayer, Psychologie, 166
} 
Szenen, mit denen der Mensch ,immerzu fertig werden' müsse. ${ }^{214}$ Der dadurch entstehenden „Dauerbelastung“ aber könne das Individuum nur „mit Mühe standhalten“215, so daß es nicht weiter verwunderlich sei, wenn der Widerstand bräche und ein ,Verlust des seelischen und sittlichen Gleichgewichts' einträte. ${ }^{216}$ Wasem wiederum fordert, um dem ,Gleichgewichtsverlust‘ vorzubeugen, eine entsprechende Dammverstärkung durch ,geistige Gegenwerte“, die der Appellation ,an den Machtund Geschlechtstrieb" entgegenzustellen seien. ${ }^{217}$ Die Argumentationsfigur ist also dieselbe wie bei der generellen These moralischer Primitivierung und enthält alle dort wahrnehmbaren Elemente, vom anthropologischen Pessimismus gegenüber der Triebsphäre sowie der Befürchtung einer Zerstörung der Moralität durch ,Dammbrüche' bis hin zur bewahrethischen Forderung der Verstärkung von Barrieren. Sie zeigt sich außerdem als exakte Repetition des gleichlaufenden reformerischen Devianzvorwurfs.

Wie angedeutet, wird dem Vorgängigen dann der Vorwurf zur Seite gestellt, daß das Kino als ,sozialer Raum' die sexuelle Kontaktnahme befördere und derart die filmrezeptiv konstituierte Verfallsinklination umsetzen helfe. In einer weiteren, impliziten Wiederholung der reformerischen Argumentation malt so Kerstiens das „stimmungsgeladene Halbdunkel“" aus, in dem „,besonders (...) die Heranwachsenden beider Geschlechter" in unerwünschter Weise zueinander fänden, und „die Hemmungen" fielen. ${ }^{218}$ Noch deutlicher zeichnet Wasem das Bild vom „Lichtspieltheater", das ,zur Filmerotik, die erotisch induziert, noch die Gelegenheit zur Kinoerotik“ bringe und den „Pärchen unter günstigen Umständen“ eine ,erste Tuchfühlung“ ermögliche. ${ }^{219}$ Kerstiens sieht daraus dann ein verändertes Sexualverhalten hervorgehen, durch das nicht zuletzt die ,Heiligkeit der Ehe' gefährdet werde. ${ }^{220}$ Beide, Kino und Film, nämlich scheinen ihm derart „enthemmend auf das Tun der Menschen" einzuwirken und die Kraft von "Sitte und Gebot" aufzulösen. ${ }^{221}$ Damit aber scheint „ein durch den Film verändertes Weltbild, eine neue Wertauffassung" Platz zu greifen, die er als Verfall interpretiert. ${ }^{222}$

Mit dieser ergänzenden Fortführung des Vorwurfs wird nun nicht nur deutlich, daß das reformerische Argument vollständig, bis hin zur Perhorreszierung einer Gefährdung der Ehe, wiederholt wird, sondern auch spürbar, daß darin noch immer eine Frontstellung gegen einen Ethoswandel und gegen sittliche Autonomie enthalten ist. So zeigt sich in den sechziger Jahren, wie ich bereits in der Auseinandersetzung mit den Kinoreformern vorausgreifend angedeutet habe, ein Wandel des Sexualethos, der auf eine partielle Freisetzung der Sexualität von einer exklusiven, institutionellen Bindung an die Ehe und von einem diesbezüglich vorgegebenen Normkanon zielt. An die Stelle der traditionalen Orientierung tritt zunehmend eine frühzei-

${ }^{214}$ Kerstiens, Filmerziehung, 24

215 Kerstiens, Filmerziehung, 24

216 vgl. Kerstiens, Filmerziehung, 25

217 Wasem, Jugend, 76

218 Kerstiens, Filmerziehung, 59

219 Wasem, Jugend, 60

220 vgl. dazu etwa: Kerstiens, Filmerziehung, 51-52, wo er reformkohärent wieder ein irregeleitetes Publikum den ,Ehebrecher beklatschen' und davon die Treue zerstört sieht.

221 Kerstiens, Filmerziehung, 51

222 Kerstiens, Filmerziehung, 52 
tigere und selbstgeregelte Kontaktnahme der Partner, die damit auch ihre diesbezügliche Normkonzeption selbst in die Hände nehmen. Die zu dieser Zeit intensiv geführten, zu einem gut Teil auch öffentlichen Diskussionen verweisen dabei darauf, $\mathrm{da} ß$ der Normwandel von veränderten Überzeugungen getragen ist, keineswegs aber eine Frucht von ,Gewissenlosigkeit" darstellt. Indiziert ist vielmehr ein sittlicher Wandlungsprozeß, in dem sich die Überzeugungsträger als autonome sittliche Subjekte verhalten. Realiter liegt mit den inkriminierten Phänomenen ein Ethoswandel vor, in dessen Kontext vor allem junge Menschen ein Mitspracherecht bei der Konstitution moralischer Normen einfordern und ihre diesbezügliche sittliche Kompetenz beanspruchen. Der Film, der den Ethoswandel sowohl mit seinen Inhalten spiegelt als auch mit vorantreibt, hat hierbei wieder ebenso eine flankierende Rolle, wie das Kino, das erneut als günstiger Kontakt- und ,aufsichtsloser' Freiraum dient.

Dieser Prozeß nun wird von der filmerzieherischen Devianzkritik angegriffen und diskriminiert. So erscheint in ihr der Wandel nicht als sittliche Veränderung, sondern als moralischer Verfall. Mit einer solchen Interpretation aber stellt sich die Filmerziehung implizit gegen die skizzierte Beanspruchung sittlicher Autonomie. In der Tat ist eine solche Autonomie in ihrem Konzept auch schwer denkbar. Der Grund hierfür findet sich in der Revitalisierung des anthropologischen Pessimismus der Reformer durch die Übernahme ihrer Devianzvorwürfe. So scheinen die Subjekte wegen ihrer Latenzgefährdung generell gar nicht in der Lage zu sein, kompetent und mit moralischer Dignität norm- bzw. wertkonstitutiv oder -verändernd tätig zu werden. Der anthropologischen Axiomatik entsprechend besitzen sie kaum eine eigene moralische Potenz, sondern es werden ihre moralisch prekären Antriebe gerade von einer (anscheinend) durch externe Normierung geschaffenen Sittlichkeit im Zaum gehalten. Die Auflösung traditionaler Normen, der ,Kraft von Sitte und Gebot', muß dann als Zerstörung der Hemmschwellen und Barrieren gegen die negative Basis und damit als Beseitigung des Ethos schlechthin erscheinen. Unter diesen Bedingungen aber können die ,faktisch gelebten Überzeugungen' niemals als Teil eines sittlichen Wandlungsprozesses oder gar eines sittlichen Fortschritts interpretiert werden und gibt es für die Annahme einer darin tätigen sittlichen Autonomie keine Basis. Das gefährdete Latenzwesen Mensch kann eine solche Autonomie per definitionem nicht mehr entfalten. Die Möglichkeit der letztgenannten ist deshalb von der Devianzkritik implizit negiert, und die verfallstheoretische Interpretation des Wandlungsprozesses erhält erst durch den anthropologischen Pessimismus ihre Begründungsbasis.

Mit ihrem Rückbezug auf einen traditionalen Normbestand in ,Sitte und Gebot', dessen Veränderung als Verfall gilt, findet der Sexualisierungsvorwurf dann außerdem AnschluB an die Keilhackersche ,Wertkritik'. Damit kann die Gesamtfigur des Sexualisierungsvorwurfs auch als Ausdruck der ,Kongenialität" des reformerischen Vorwurfs und der Keilhackerschen ,Wertkritik' begriffen werden bzw. läßt sie mit deren spezifischer Verbindung die Verwandtschaft und partielle Identität der beiden Theoriesysteme deutlich werden. In beiden Fällen nämlich handelt es sich um Verfallstheoreme kontramoderner Ausrichtung, die jeweils die Moralität unter dem Einfluß - letztlich - der modernen Autonomisierung und Dynamisierung zerstört sehen. Die Reformer verwenden dabei den Begriff der Sittlichkeit, die sie zugunsten der negativ besetzten Sinnlichkeit verfallen sehen (Conradt), während die Filmerzieher meist auf das wertethische Paradigma Keilhackers zurückgreifen und die Kor- 
ruption als ,Werteverfall' auslegen. Der dynamische Prozeß des Ethoswandels wird beide Male diskriminiert. Während der reformerische Vorwurf durch die wertethische Begrifflichkeit deutlicher gefaßt wird und durch den impliziten Konnex mit den Keilhackerschen Paradigmen in den größeren Horizont der dort geübten Modernitätskritik gerät, erhält die filmerzieherisch aufgegriffene ,Wertkritik' durch die negative reformerische Anthropologie eine zusätzliche Begründung und wird ihr Antiautonomismus gestützt. Beide Konzepte aber zeigen sich so als kongenial, und ihr Konnex erweist sich als wechselseitige Ergänzung.

\section{,Kriminalisierung: Sozialontologische Konkretion des anthropologischen Pessimismus}

Als zweite Konkretion des Primitivierungsvorwurfs tritt dann weiter der Kriminalisierungsvorwurf auf. Er stellt wieder eine Ausführung der These einer, Verrohung dar, welche einerseits aus einer demoralisierenden ,Abstumpfung durch Häufung brutaler Filminhalte und andererseits aus einer gleichzeitig erfolgenden Stimulation pernizioser Publikumslatenzen entspringe. Während die ,Abstumpfung' die moralitätssichernden Barrieren zu beseitigen scheint, soll die Stimulation für die Erzeugung einer Handlungsbereitschaft sorgen. Die Latenzen des Publikums werden dabei einmal erneut anthropologisch als das „Tier im Menschen“ gefaßt, das anscheinend eine naturale Inklination zur Kriminalität verursacht. ${ }^{223}$ Andererseits treten sie auch als sozial gegründete Neigung zum Verbrechen auf, die durch ,Milieuschädigung, wie etwa „schlechte Familienverhältnisse“" entstehen könne. ${ }^{224}$ Auch diese Latenzbestimmung, die über das ,Milieu' an die schichtspezifische Zuschreibung bei den Reformern erinnert, erhält jedoch eine, wenn nicht eindeutig anthropologische, so doch quasi-ontologische Stützung. Die milieubedingte „äußere Verwahrlosung“ nämlich folgt für Wasem ,auf das Sich-von-der-Wahrheit-lösen durch vernachlässigte Erziehung", also durch eine mangelhafte ,Barriereverstärkung' gegen grundsätzlich vorhandene Negativa. ${ }^{225}$ Auf diesem Hintergrund einer generell supponierten anthropologischen oder (sozial-)ontologischen Latenz neigen die Filmerzieher dann dazu, die Kriminalisierung stets in nuce beim Publikum vorhanden zu sehen und, im Unterschied zu den Reformern, von den Wirkungsthesen hauptsächlich die Kooperations- und die Nutzungsthese zu verwenden. Der Kooperationsthese entsprechend betont Wasem, daß „der Film niemals die Alleinschuld an den Verbrechen" tragen könne, ${ }^{226}$ oder verweist Vogg darauf, daß die kriminelle Handlung „oft erst letzter Ausdruck einer längst vorhandenen Gesinnung ${ }^{\text {“227 }}$ sei. Die supponierte Kriminalitätsdisposition wirkt hier also mit einer ,Kriminalitätsinduktion' des Films kooperativ zusammen. Die Nutzungsthese findet sich bei Wasem geradezu in Reinform, wenn er es ,als gesichert“ apostrophiert, da $B$,bei Labilen Kriminalfilme als Lehrfilme gelten“ ${ }^{228}$ Ähnlich formuliert Hennig die Möglichkeit, daß ,Jugendlichen, die verbrecherisch gesonnen sind, lediglich eine Methode, ihre Verbrechen durchzuführen“

\footnotetext{
${ }^{223}$ Hennig, Aggression, 18

224 vgl. dazu etwa: Wasem, Jugend, 59

225 Wasem, Jugend, 59

${ }^{226}$ Wasem, Jugend, 59

${ }^{227}$ Vogg, Bedeutung, 15

${ }^{228}$ Wasem, Jugend, 60
} 
vom Film ,an die Hand gegeben` werde. ${ }^{229}$ Ein mehr oder minder böswillig präformiertes Publikum scheint sich hier wieder bewußt Handlungsanleitung aus den Filmen zu holen. Bestätigt sieht Hennig das etwa daran, daß es nach dem Film ,Riffi$\mathrm{fi}^{{ }^{\prime}}$, ,13 formgleiche Einbrüche“ in Bayern gegeben habe, oder daß nach ,Saat der Gewalt' sich „von zweiunddreißig Schülern (...) innerhalb kürzester Zeit 28 Messer und Pistolen" beschafft hätten. ${ }^{230}$ Die Verursachungsthese tritt gegenüber solchen Kooperativ- und Nutzungsannahmen in den Hintergrund. Sie taucht nur am Rand auf, wenn psychologisierend darüber spekuliert wird, inwieweit der Film durch eine spannende Handlungsinszenierung über den kriminellen Gehalt hinwegzutäuschen vermag und damit den Rezipienten zu einer gewissermaßen irrtümlichen Identifikation mit dem Verbrecher verleitet, oder wenn die Positivdarstellung von Verbrechern inkriminiert werden soll. ${ }^{231}$

Um nun der Gefahr der Kriminalisierung entgegenzuwirken, fordern die Filmerzieher wieder ,barriereverstärkende' und bewahrende Maßnahmen. So soll der Film keinesfalls ,positive' Verbrecher darstellen, sondern ,positive Vorbilder““ ${ }^{232}$ Durch Identifizierung mit ihnen soll die Widerstandskraft gegen kriminelle Inklinationen befördert werden. Das freilich bedeutet zugleich, daß für die Taten eines Kriminellen kaum Verständnis entstehen darf, sondern dieser die böse Negativfigur bleiben muß. ${ }^{233}$ Zum Sieg gebracht werden sollen stattdessen stets die Anstrengungen des Guten. Hierbei ist es dann auch ,ethisch vertretbar“, ,Aggressionen' ins Bild zu setzen, wenn diese „eindeutig als Abwehr einer ungesetzlichen Aggression, eines Ver-

${ }^{229}$ Hennig, Aggression, 15

230 Hennig, Aggression, 15 - Die Frage darf gestellt werden, wieviel Vertrauen derartigen ,empirischen' Tatsachenbehauptungen entgegengebracht werden kann. Zunächst nämlich ist das Setting des Einbruchs in ,Riffifi äußerst kompliziert: Die Diebe dringen durch eine über dem eigentlichen Zielort gelegene, zu diesem Zeitpunkt unbewohnte Wohnung ein, deren Boden sie aufbrechen. Es erscheint doch etwas unwahrscheinlich, daß sich in Bayern kurz nach Veröffentlichung des Films wirklich 13 Juweliergeschäfte, Büros oder Banken gefunden haben, die eine darübergelegende, leerstehende Wohnung als Einbruchsmöglichkeit zu bieten hatten und bei denen zudem diese Möglichkeit die einzige oder günstigste darstellte. Das in „Riffifi gezeigte Aufbrechen des Tresors mit Bohrwerkzeugen wiederum ist als Methode so ungewöhnlich nicht, so daß es etwas kühn erschiene, jede gewaltsame Öffnung eines Safes zu dieser Zeit gerade auf das Konto des Films zu buchen. - Noch unwahrscheinlicher mutet die Behauptung an, es hätten sich nach ,Saat der Gewalt' sogleich 28 von 32 Schülern einer Klasse mit Messern und Pistolen bewaffnet. Zum einen wirkt schon die Zahl übertrieben - nur 4 Schüler hätten demnach den Film ,normal' rezipiert -, und wäre zu fragen, wieviele der Messer schlichte Taschenmesser gewesen sind. Zum anderen aber ist die Behauptung, unter den ,Waffen' seien auch Schußwaffen gewesen, schlicht unglaubwürdig. Sich in der Bundesrepublik ohne Autorisierung eine Handfeuerwaffe zu verschaffen, dürfte ohne Kontakt mit dem entsprechenden Milieu selbst für einen Erwachsenen schwierig sein. $\mathrm{Daß}$ es normalen Schülern gelingt, ist entsprechend erst recht kaum anzunehmen. Auch die Annahme, daß ein Schüler auf den Film hin bewußt Kontakt zu kriminellen Kreisen sucht, um an eine Pistole zu kommen, mutet arg kühn an. - Es dürfte sich bei Hennigs Behauptung vielmehr um eine jener von den Reformern bis zum heutigen Tag auftretenden Legendenbildungen handeln, an deren Anfang meist ein sensationeller, gleichwohl wenig recherchierter Zeitungsartikel steht, der dann ,wissenschaftlich' als Faktum kolportiert wird und dessen Tatsachengehalt bei konkreter Nachforschung meist zerfällt. Wie zu sehen war, wußte dies Hellwig schon - bereits zehn Stichproben in seiner Fallsammlung ergaben, daß die in Artikeln angegebenen ,Tatsachen' sich nicht als tragfähig erwiesen (vgl. 2.4.).

231 vgl. dazu: Hennig, Aggression, 19; Kerstiens, Filmerziehung, 30

232 Vogg, Bedeutung, 15

233 vgl. dazu: Wasem, Jugend, 70 
gehens, eines Überfalls, einer Beraubung, oder einer Gewalttat charakterisiert und motiviert sind“ “. ${ }^{234}$ Die Identifikation ist hier ebenfalls erwünscht und hilft gewissermaßen, ,das Gute' affektiv zu festigen, indem sie der ohnehin anthropologisch vorhandenen Aggression eine Richtung gibt und für die Barriereverstärkung eingesetzt werden kann. Flankiert werden sollen diese Maßnahmen von solchen der Bewahrung, die, wie bei den Reformern, zensierend ausgelegt sind. So sollen ,Verherrlichung' wie ,Verharmlosung' von Verbrechen verboten sein, soll kein „Anschauungsmaterial für strafbare Handlungen “235 gegeben werden und soll generell die Verbrechensdarstellung nur der Illustration einer moralischen Aussage dienen.

Die Kriminalisierungsthese trägt so den Pessimismus der Primitivierungsthese weiter und nimmt sowohl eine anthropologisch, als auch eine sozialontologisch gegründete, negative und prekäre Latenzbasis beim Publikum an, das entsprechend für ein ,Abrutschen' in die Kriminalität disponiert zu sein scheint. Sie repetiert auf diese Weise die ersten zwei Formen des reformerischen Vorwurfs, wobei das sozialontologische Moment nicht ganz so deutlich, nämlich zu einer schichtspezifischen Auslegung weitergeführt ist. Der Grund hierfür findet sich vermutlich darin, da $B$ der ,harte' Schichtgegensatz, den die sich auflösende ständische Gesellschaft zu Beginn des Jahrhunderts noch kannte und der zusammen mit einem stärkeren Standesbewußtsein sowohl der ,Gebildeten' als auch der Unterschicht jene sozialen Spannungen aus sich hervortrieb, die die Revolution von 1918 mit begünstigten, in der deutschen Gesellschaft der 50er und 60er Jahre aufgeweicht ist. ,Vollbeschäftigung', ,Wirtschaftswunder' und eine breiter gewordene Mittelschicht haben hier das Bild verändert. Stattdessen rückt das ,Halbstarkenproblem 'in Blick, das denn auch seinen Ausdruck in Hennigs Stellungnahme zu ,Saat der Gewalt' findet und das über den Terminus der ,Jugendkriminalität' $\mathrm{zu}$ einer weniger schichtabhängigen Thematisierung des Verhältnisses von Film und Kriminalität führt. Auch unter diesem Terminus aber versammeln sich die Vorstellungen von einer prekären Situation, die zu pessimistischen Grundannahmen und entsprechenden Gegenmaßnahmen nötigt. Reformkohärent fallen diese Gegenmaßnahmen im Sinn einer Barriereverstärkung gegen die negativen Latenzen und einer zensierenden Bewahrung vor deren möglicher Stimulation aus. Insgesamt bleibt daher festzuhalten, da $B$ mit der Kriminalisierungsthese in den filmerzieherischen Schriften die pessimistische Basis ihrer Argumentation weiter ausgelegt und gefestigt wird. Der bewahrethische Zug, der durch die Revitalisierung der reformerischen Theoreme in die Filmerziehung einwandert, findet sich dabei begünstigt und verstärkt.

\section{,Soziale Destabilisienung: Zeitentsprechende Modifikation des reformerischen Vorwurfs und Verbindung mit der Keilhackerschen Wertkritik}

Entsprechend den genannten Veränderungen in der deutschen Gesellschaft und der nun endlich durchgesetzten Demokratisierung tritt auch der letzte der reformerischen Vorwürfe, nämlich der, daß der Film eine soziale Destabilisierung hervorrufe, in einer modifizierten Form auf. Für die Reformer enthielt hier der Film, der sich mit dem Genre der ,sozialen Dramen' recht direkt auf die Realität sozialer Dramatik

${ }^{234}$ Hennig, Aggression, $17-18$
Wasem, Jugend, 76 
in der industrialisierten und dynamisierten, jedoch noch ständisch-privilegisch geprägten Gesellschaft bezog, ja eine wirkliche gesellschaftliche Sprengkraft. Durch den endgültigen Umbau der Gesellschaft und die Auflösung der Statik der Stände zugunsten sozialer Mobilität und zunehmender, Chancengerechtigkeit' (W. Korff) schwindet zunächst der Streitpunkt um die Gesellschaftsorganisation und die damit zusammenhängende schichtspezifische Verortung der Rechte der Gesellschaftsmitglieder. Eine ,Verhetzung der Stände gegeneinander' kann nun nicht mehr in derselben Form das Zentrum der Auseinandersetzung und damit auch nicht mehr unmittelbar Kern des Destabilisierungsvorwurfs sein. Sie klingt wohl noch an, wenn etwa Margarete Keilhacker vom „Luxusfilm“ ein „Ressentiment (...) gegen die elegante Welt" erzeugt sieht und beklagt, daß im Gegenzug dazu ,nun der Film aus dem einfachen Milieu als das allein Seligmachende gepriesen" werde. ${ }^{236}$ Die Klage erinnert an die Reformer, die ebenfalls eine Diskriminierung der ,Reichen' durch Filme inkrimierten. Spürbar ist bei Margarete Keilhacker außerdem die Sehnsucht nach der ,alten Gesellschaft', wie sie auch in der Modernitätskritik ihres Mannes sichtbar geworden ist. Entsprechend tritt die Konfrontation mit der Wirklichkeit nach der Rezeption des ,Luxusfilms' in ihrem Text als „kalte Dusche“ und „schreckliches Erwachen" auf ${ }^{237}$ und erhält der Luxusfilm trotz seiner Präformation von ,Enttäuschungen' weitaus mehr Sympathie als der Film mit sozialem Realismus. Weder die ,kalte Dusche' des Widerspruchs zwischen ,Luxusfilm' und Realität, noch der ,Sozialrealismus' aber zieht dann noch dieselbe Befürchtung einer Erzeugung unmittelbar sozialgefährlicher Wünsche oder eines Umsturzes nach sich, wie dies bei den Reformern der Fall war. Problematisiert wird jetzt vielmehr eine ,Wirklichkeitsverfälschung, die zunächst zu Enttäuschung und Unzufriedenheit als individualpsychischen Folgen zu führen scheint. Die daraus wiederum deduzierte mißliebige Konsequenz wird statt als revolutionäres Bewußtsein als falsche ,Wertorientierung' angesetzt. Der in Anlehnung an die Reformer formulierte Devianzvorwurf wird so transformiert und mit der Keilhackerschen Modernitätskritik vermittelt. Er gerät vom Vorwurf sozialer Destabilisierung zu dem einer Destabilisierung des, Wertekosmos . Entsprechend leitet Margarete Keilhacker zwar (reformanalog) aus Befragungen von Jugendlichen ab, daß „der Film vom schöneren Leben“ nicht halte, was er verspreche, sondern „schmerzliche soziale Gegensätze“ aufreiße, ${ }^{238}$ und konstatiert sie, daß der ,sozialrealistische' Film eine gewisse, ambivalente Spiegelung der eigenen sozialen Realität enthalte, die sowohl affirmativer Beruhigung dienen soll, als auch ungern erfahren wird. ${ }^{239}$ Doch sieht sie dann aus, vorgespiegeltem Reichtum‘ wie aus ,gespiegelter

${ }^{236}$ Keilhacker, Kino, 77

${ }^{237}$ Keilhacker, Kino, 77; Keilhacker wertet hier Befragungen von Jugendlichen aus und entdeckt in deren Äußerungen solche Wertungen. Doch erst ihre Interpretation der ,empirischen Daten verleiht diesen dann den eigentlichen Stellenwert als ,schreckliche' Konfrontation mit einer modernen Welt, der man nur „mit zusammengebissenen Zähnen“ (ebd.) begegnen könne und der sie recht deutlich die in den Luxusfilmen revitalisierte, elegante Welt' mit ihren ständischen Bezügen vorzieht.

238 Keilhacker, Kino, 74

239 Keilhacker, Kino, 77; Keilhacker sieht hier den ,sozialrealistischen' Film von den Jugendlichen in Reaktion auf den ,Luxusfilm' favorisiert und genutzt. Im Unterschied zu den Reformern, die hier mißliebige Gesellschaftskritik am Werk sahen, interpretiert Keilhacker diese Nutzung als Ausdruck einer ,Neugier auf Wirklichkeit', eines Wunsches, durch den Film ,das 
Realität‘ lediglich „Unzufriedenheit, das Gegenteil eines positiven Lebensgefühls“, hervorgehen, dessen perniziose Folge nicht sozialrevolutionäre Sprengkraft, sondern eine ,Aufsteigermentalität' sei. ${ }^{240}$ Der jugendliche Rezipient nämlich sehe vom Film „starke Impulse ausgehen, die dazu anspornen, auf der sozialen Stufenleiter höherzusteigen und dafür alle erdenklichen Mittel in Bewegung zu setzen“. ${ }^{241} \mathrm{Er}$ verhält sich also sehr ,gesellschaftskonform', und die zu übende Kritik kann nicht mehr in einem filmisch erzeugten Gegensatz der Rezipientenschaft zur Gesellschaft bestehen, sondern fällt mit der an der modernen Gesellschaft selbst geübten Kritik zusammen. Daher beklagt Margarete Keilhacker die „Förderung einer falschen und ungesunden Vorstellungs- und Wertewelt“, in der die „Wertakzente in Richtung einer materialistischen Lebensauffassung" verschoben seien. ${ }^{242}$ Ähnlich verhält es sich bei Wasem, der zunächst aus Filmen, die ,mit dem Gegensatz von arm und reich" arbeiten, die „Gefahr, die eigene soziale Lage unnötig zu dramatisieren“, hervorgehen sieht. ${ }^{243}$ Erzeugt würden so „Haltungen der Unzufriedenheit mit dem eigenen Dasein“, die in „falsche Lebenserwartungen“ führten. ${ }^{244}$ Jene Erwartungen aber erscheinen dann ebenfalls wieder als falsche Wertorientierungen, in denen ,äußerer Glanz, Macht und Reichtum als die höchsten Güter" angesetzt sind. ${ }^{245}$ Die eigentlich perniziose Wirkung des Films wird so in einer ,Verführung zur „Steigerung des Lebensstandards" gesehen, gegenüber welchem „Keuschheit und Armut als Tugenden ,aus der Mode' gekommen" seien. ${ }^{246}$ Statt einer sozialen wird damit nun eine Destabilisierung der traditionalen Wertorientierung, und statt eines Zerfalls der Ständegesellschaft ein Zerfall des Ethos konstatiert.

Der Vorwurf der sozialen Destabilisierung erfährt also in den Schriften der Filmerzieher zwar eine Revitalisierung und läßt eine gewisse kontramoderne Wehmut gegenüber der entschwundenen Gesellschaftsform spüren, doch wird er aus Gründen einer veränderten historischen Situation der Gesamtgesellschaft modifiziert und transformiert. Die Kontrastierung von ,Palast und Hütte' (Lange) gilt nicht mehr als prekär, weil dadurch ein revolutionäres Bewußtsein erzeugt und stimuliert scheint, das zudem ,vom Gewerkschaftssekretär' verderblich weitergetrieben und genutzt werden könnte, sondern weil die Darbietung der ,eleganten Welt' ebenso wie der kontrastiv dazu stehende, Sozialrealismus' dazu angetan scheinen, eine Unzufriedenheit mit der eigenen Situation hervorzurufen, die in die Favorisierung ,falscher Werte' sowie den Verfall ,echter' zu münden droht. So bleibt zwar der Ansatz bei den Filmerziehern derselbe wie bei den Reformern und wird in beiden Fällen eine Störung ,sozialen Einverständnisses', eine ,unnötige Dramatisierung der eigenen Lage konstatiert, jedoch nun aus dieser Störung kein umstürzlerischer Gegensatz zur Gesellschaft mehr abgeleitet. Stattdessen ist das eigentliche Ärgernis nun die Kohärenz

Leben kennenzulernen', der sowohl Bestätigung als auch eine nicht als sozialgefährlich eingeschätzte, sondern lediglich eigene Aufstiegsanstrengungen befördernde Unzufriedenheit evoziert. (vgl. auch: ebd. 74)

240 Keilhacker, Kino, 74

241 Keilhacker, Kino, 74

242 Keilhacker, Kino, 74

243 Wasem, Jugend, 52

${ }^{244}$ Wasem, Jugend, 50

${ }^{245}$ Wasem, Jugend, 50

${ }^{246}$ Wasem, Jugend, 55 
mit einer falschen Orientierung der Gesellschaft selbst und das ,aus der Mode kommen' wünschbarer Tugenden. Die Devianzkritik wird damit in die ,Wertkritik' des Schulgründers der Filmerziehung umgeleitet, und das reformerische Paradigma wird mit dem Keilhackerschen verbunden. Die Auseinandersetzung mit dem Film aber findet sich auf diese Weise zugleich in eine generelle Auseinandersetzung mit der modernen Gesellschaft eingebettet, und die letztgenannte scheint hier bereits wieder als Ort eines, Werteverfalls' auf, als dessen Agent der Film jetzt gehandhabt wird.

\section{Filmerziehung und Kinoreform: Redundanz der Vorwürfe und Kongenialität der} Konzepte

Insgesamt kann damit festgestellt werden, daß die Filmerziehung unter partiell zitativem, meist jedoch implizitem Rückbezug sämtliche Devianzvorwürfe der Kinoreformbewegung wieder aufgreift und in weitgehender Treue zur ursprünglichen Gestalt tradiert. Diese Revitalisierung läßt dabei ein Vierfaches erkennen: Zunächst zeigt sich, daß mit den Vorwürfen auch der anthropologische Pessimismus der Reformer wiederbelebt wird. Der Mensch wird erneut als gefährdetes Latenzwesen gezeichnet, dem negative, moralisch prekäre Antriebsstrukturen und Wesenszüge eignen. Diese Negativa werden einmal als Triebstrukturen aufgeführt, von denen explizit die Aggression und die Sexualität genannt sind und denen in dieser Charakterisierung jede Neutralität abgesprochen ist. Weiter gelten bestimmte Pathologien, etwa der Sadismus, als mit dem Menschsein mitgegebene Negativa und werden sie entsprechend nicht als kontingente Deformationen, sondern als naturalontologische Größen gehandelt. Schließlich wird noch eine undeutliche, allgemeine Negativität als ,grundsätzliche Gefährdung، oder ,finstere Macht‘ angesetzt. Über den wiederkehrenden Terminus der ,Bestie ${ }^{‘}$ oder des ,Tiers' im Menschen wird in allen drei Fällen die Negativität als stammesgeschichtlich gegebene Prägung der menschlichen Natur behandelt, und der Mensch als mit einem quasi ,natürlichen' Gefälle zur Amoralität ausgestattetes Raubtier und hedonistisches Lustwesen gezeichnet. Ein Abrutschen in moralische Primitivierung, Kriminalität und unkontrolliertes Sexualverhalten scheint entsprechend ständig zu befürchten zu sein. Lediglich die ,Zivilisation“ und ihre kulturellen Regelungen gelten als gewisse, wenngleich schwache Bande für die zerstörerische Kraft der Latenzen. Auf dem Hintergrund dieser zwar unvollkommenen, aber vorhandenen zivilisatorisch-kulturellen Domestikation ist im filmerzieherischen Wiederaufgriff der Devianzvorwürfe ebenfalls ein paradigmatischer Natur-KulturAntagonismus erkennbar. Die Unvollkommenheit der Domestikation freilich läßt vermuten, daß in diesem Entwurf eine kulturelle Konstruktion allein noch nicht für die Konstitution von Sittlichkeit ausreicht (vgl. dazu weiter unten).

Trotz der letztgenannten Vermutung findet sich jedoch auch im filmerzieherischen Entwurf zunächst die Forderung einer Verstärkung der Barrieren gegen die prekären Latenzen und damit ein bewahrethischer Zug: Auf die genuin reformerischen Vorwürfe wird zunächst eine bewahrethische Antwort gegeben, für welche die Moralität contra naturam zu denken ist und zumindest kultureller Flankierungsmaßnahmen bedarf. Die geforderten Maßnahmen der ,Selbstzucht' und eines ,Systems von Warnungen und Versagungen' können hierbei durchaus als solche flankierende kulturelle Konstruktionen interpretiert und als zusätzlicher Ausdruck des reformanalogen, paradigmatischen Natur-Kultur-Antagonismus verstanden werden. Mit der Bar- 
riereverstärkung durch ,geistige Gegenwerte' und ,positive Leitbilder' hingegen ist, wie zu sehen sein wird, auf einen anderen Bereich, jenseits der Kultur, verwiesen. Die erstgenannten Maßnahmen wiederum stellen sich ebenso wie die reformerischen als rein beschneidende, disziplinatorische dar und machen deutlich, daß auch im filmerzieherischen Konzept Moralität vorerst ex negativo, zumindest aber auf der Basis negativer Vorbedingungen und Sicherungen sowie kontranatural gedacht ist. Selbst die zweite Gruppe weist durch ihre Funktion als Gegenmaßnahmen ein solches Moment negativer Moralitätssicherung auf und verstärkt den bewahrethischen Zug.

Weiter legt sich die anthropologische Axiomatik in einen Autonomiepessimismus aus, der gegen einen Ethoswandel gerichtet ist und implizit auf eine deontologische Ethikkonzeption der Filmerziehung vorausweist. So kann aus der anthropologisch festgelegten, prekären Natur des Menschen, wie bei den Reformern, nichts Gutes hervorgehen und entsprechend eine moralische Kompetenz schwerlich abgeleitet werden. Qua Natur muß jede sittliche Autonomie, die ein Mitspracherecht bei der Normkonstitution beansprucht, zumindest als äußerst gefährlich erscheinen und ein daraus hervorgehender Ethoswandel zurückgewiesen werden. Darüber hinaus aber ist unter diesen Bedingungen auch schon die autonome Konstitution eines individuellen Ethos prekär und kann die Legitimität von Binnenmoralen hier kaum behauptet werden. Eine individuelle oder gruppenspezifische Auswahl - und erst recht eine Variation - von Normen muß zwangsläufig in den Geruch des Defizitären geraten. Soll Moralität dennoch möglich sein, so kann sie auf dem Hintergrund dieser beiden Konsequenzen des Autonomiepessimismus fast nur noch im Modus einer universellen, objektivistischen Deontologie gedacht werden. Neben dem bewahrethischen Zug enthält die filmerzieherische Devianzkritik also eine gewisse Determination für ein deontologisch-objektivistisches Ethikkonzept.

Schließlich hat die Rekonstruktion der wiederbelebten Devianzkritik gezeigt, da $B$ diese eine spezifische Verbindung mit der Keilhackerschen ,Wertkritik' eingeht. Zunächst war erkennbar, daß schon Margarete Keilhacker im Primitivierungsvorwurf die Korruption moralrelevanter Gefühle mit den Paradigmen ihres Mannes als Zerstörung der emotionalen Vorbedingungen für das ,Werterleben' interpretiert. Weiter hat der Sexualisierungsvorwurf darauf verwiesen, daB das reformerische und das Keilhackersche Konzept durch ihre Gestalt als Verfallstheorien kongenial sind und in ihrer Ablehnung eines Ethoswandels sowie dem Mißtrauen gegenüber sittlicher Autonomie übereinkommen. In der Rekonstruktion des Destabilisierungsvorwurfs war dann sichtbar, da $B$ auch genuin Keilhackersche Theoreme tradiert und mit dem reformerischen Konzept zusammengespannt werden. Der Destabilisierungsvorwurf (wie auch der der Kriminalisierung) zeigte sich dabei außerdem als unter veränderten gesellschaftlichen Bedingungen modifiziert und derart den aktuellen Gegebenheiten angepaßt. Neben der ,wertkritischen` Anpassung der Devianzkritik an die zeitgenössische Situation und der Kongenialität der beiden Theoriekonzepte aber findet sich in der Filmerziehung auch eine mehr oder weniger unabhängige Tradierung der Keilhackerschen Überlegungen. Diese will ich noch darstellen, bevor ich die ,positive' Setzung der filmerzieherischen Ethik skizziere. 


\subsection{Redundanz II:}

\section{Fortschreibung der Keilhackerschen Modernitäts- und Zivilisationskritik}

Die Tradierung und Fortschreibung der Keilhackerschen Modernitäts- und Zivilisationskritik in der Filmerziehung nun stellt sich als eine Art bereichsspezifische Konkretion und Umsetzung dieser Kritik dar. Sie nimmt die Theoreme und Paradigmen des Schulgründers auf und rekapituliert sie zum Teil treu, variiert sie jedoch auch oder bildet kongeniale Parallelen und Weiterführungen aus. Neben der von den Reformern übernommenen entsteht auf diese Weise eine ,eigene' Devianzkritik mit ,eigenen', ergänzenden Vorwürfen. Aus einer systematisierenden Perspektive lassen sich dabei drei Hauptvorwürfe rekonstruieren, nämlich jeweils der Vorwurf des eindimensionalen ,Materialismus', des sinnverloren-haltlosen und moralischen ,Nihilismus‘ sowie der eigentlichkeitsfeindlichen ,Außenleitung‘ durch ,Reizorientierung‘, die weitere Teilvorwürfe enthalten, wie etwa den der ,Überforderung' durch Pluralität oder der ,Bindungslosigkeit‘.

\section{Materialismus und Werteverfall als generelle Zeitsignatur}

Der Materialismusvorwurf, der eine Etablierung von ,Scheinwerten' anmahnt, ist bereits im Kontext des transformierten Destabilisierungsvorwurfs aufgetaucht. Er wird auch unabhängig davon vorgebracht, wenn etwa Wasem modernitätskritisch beklagt, $\mathrm{da}$, ,in einer krisenhaften Zeit" (wie dieser) „die Wertskala nicht mehr in ihrem richtigen Aufbau und als Ganzes gesehen“ werde, sondern stattdessen ein Verfall an ,Einseitigkeiten“ stattfinde, der „die materiellen Werte“ zur Herrschaft bringe. ${ }^{247}$ Der ,Materialismus' erscheint hier unmittelbar als gesellschaftliches Krisensymptom und wird als zeittypische Devianzerscheinung gehandelt. Er gilt als nicht allein filmbedingter, sondern genereller Verfall an ,Eindimensionalität ${ }^{4}$, die von einer fehlgeleiteten Orientierung der Gesamtgesellschaft bedingt ist. Entsprechend betont Wasem auch, daß ,der Film nicht isoliert betrachtet" werden könne, sondern vielmehr ,in seiner Verknüpfung mit der Zeitsituation gesehen werden“ müsse. ${ }^{248}$ Die Devianzkritik am Film wird auf diese Weise in eine generelle Devianzkritik an der modernen Gesellschaft eingebettet. Dem Film selbst wird dann vorgeworfen, sowohl „Symptom" der zeittypischen ,Krise' als auch ein Element ihrer ,Begünstigung' zu sein, d.h. er gilt wieder als Ausdruck und Beförderer der beklagten Situation. ${ }^{249}$ Angewendet wird auf diese Weise eine modifizierte Kooperationsthese, die nun das verderbliche Zusammenspiel der Moderne und dem Film anlastet.

Mit dieser ,reformunabhängigen' Konstitution des Materialismusvorwurfs schafft die Filmerziehung einen gewissermaßen ,eigenen' Devianzvorwurf und greift sie zugleich die Keilhackersche Modernitätskritik wieder auf. Die letztgenannte wird hierbei tradiert und ,bereichsspezifisch', nämlich auf den Film hin, konkretisiert. So

${ }^{247}$ Wasem, Jugend, 63; vgl. auch: Wasem, Jugend, 60; die Begrifflichkeit ist hier, wie so häufig in der Keilhacker-Schule, etwas unklar, wenn Wasem die materielle Orientierung nicht als Dominanz von ,Scheinwerten', sondern von ,Werten' apostrophiert, doch bleibt das Paradigma dasselbe. Auch hier nämlich erscheint die ,einseitige Herrschaft' des, Materiellen' als Verfall, der an die Stelle der ,eigentlichen', d.h., geistigen' Werte, uneigentliche' setzt.

248 Wasem, Jugend, 60

249 Wasem, Jugend, 60 
gilt der Film auch hier, wie bereits im Destabilisierungsvorwurf, als Ausdrucksträger und Agent eines allgemeinen gesellschaftlichen Verfalls der Wertorientierung und einer einseitigen Dominanz des ,Materiellen'. Damit ist nicht nur das Theorem des ,Werteverfalls' in die Filmerziehung übertragen, sondern die Devianzkritik derselben zugleich in den größeren Horizont der Gesellschaftskritik Keilhackers und einer epochalen Negativwertung der Neuzeit und Moderne gestellt. Das Konzept der Filmerziehung erhält dadurch einen zumindest tendenziell modernitätsfeindlichen, also kontramodernen Zug.

\section{Moralischer und letztbezüglicher Nihilismus als Frucht von Werteverfall und Sinnverdrängung}

Als weiterer ,eigener' Vorwurf kann der eines, Nihilismus" rekonstruiert werden, der in eine moralische Orientierungs- und eine generelle Sinnlosigkeit zu münden scheint. Als Verursacher dieses Nihilismus tritt auch hier eine ,Krise der geistigen Wertewelt ${ }^{\star}$ auf. Das modernitätskritische Theorem des, Werteverfalls', der ein ,Wertevakuum erzeuge, wird damit fortgeschrieben und weiter ausgelegt. Daneben wird die ,zeittypische‘ Krise jedoch auch als Folge von ,Entwertungsprozessen' durch ein plurales Überangebot interpretiert und der Keilhackersche Pluralismuspessimismus in die Filmerziehung übertragen. Als Klage über ein ,Vakuum` ist der Vorwurf zunächst bei Margarete Keilhacker erkennbar, wenn sie in Auseinandersetzung mit den ,Halbstarkenfilmen' die Existenz einer „Jugend, für die überkommene Bindungen und Wertordnungen zerbrochen, nicht mehr als wertlose Scherben sind", nicht nur als filmisches Sujet, sondern als reales, gesellschaftliches Problem konstatiert. ${ }^{250}$ Der allgemeine ,Werteverfall' scheint hier eine ,neue Generation' der ,Halbstarken' hervorzubringen, die unter seinen Bedingungen aufgewachsen ist und als soziale Verkörperung wie Opfer dieses Verfalls gilt. Mit der traditionalen,Wertordnung' scheint dieser Generation nun zunächst die Moralität verlorenzugehen. So sieht Margarete Keilhacker in der Lösung von ,überkommenen Bindungen` zugleich eine Lösung „von jeder traditionellen Moral ${ }^{\text {‘251 }}$ und enthält ihre Argumentation das bereits bekannte Keilhackersche Paradigma, das die Moralität als Orientierung an einem Wertekorpus definiert. Weiter aber scheint im Verlust des traditionalen Bestands auch der Verlust jeden Halts, jeder Sinnhaftigkeit und Sinnorientierung enthalten zu sein. So stellt Margarete Keilhacker fest, da B die Jugend sich selbst als ,arm an Bindungen, umhergetrieben, nirgends recht verankert" sehe und sich gerade deshalb in den „Halbstarkenfilmen' wiederfinde. ${ }^{252}$ Nicht nur die Sittlichkeit (die ,moralische Bindung') sondern auch die Erfüllung des darüber hinausgreifenden Verlangens ,nach Halt und Geborgenheit“"253 scheint in der modernen, vom ,Wertevakuum' gezeichneten Welt nicht mehr möglich zu sein. In Keilhackers Auseinandersetzung mit der genannten Filmgattung tritt so das Bild einer ungeborgenen, orientierungslosen Generation vor Augen, die trotz ihrer Suche, ihres ,dauernden Fragens, Zweifelns, Weiterbohrens ${ }^{254}$ sowohl in ihrem moralischen Orientierungsbedürfnis als auch in ihrer

\footnotetext{
${ }^{250}$ Keilhacker, Kino, 96

${ }^{251}$ Keilhacker, Kino, 96

252 Keilhacker, Kino, 93

253 Keilhacker, Kino, 93

254 Keilhacker, Kino, 93
} 
Sehnsucht nach einem lebenstragenden Grund und Halt sowie letztlich nach Sinn frustriert und alleingelassen bleibt. Der ,Nihilismus' erweist sich damit als doppelte, nämlich als moralische und ,letztbezügliche‘ Desorientierung. Diese wird als gesellschaftlicher Zustand gezeichnet, der den (durch die Jugend repräsentierten) Gesellschaftsmitgliedern letztlich aufgezwungen ist.

Auch Wasem sieht, wie bereits oben erkennbar war, zusammen mit „Theologen und Philosophen (...) den Menschen unserer Tage in einer selbstverschuldeten Krise“, die sich als „Krise der geistigen Welt" manifestiert, ${ }^{255}$ und definiert den (in Filmen vorfindbaren) ,Nihilismus“ als „Auswegslosigkeit durch die fehlende Orientierung an einer höheren Ordnung“, d.h. als Frucht des, Wertevakuums‘. ${ }^{256}$ Die ,höhere Ordnung' wird dann in ,religiöse, sittlich-moralische und soziale Werte' spezifiziert, und es wird so erneut das wertphilosophische Paradigma zur Anwendung gebracht. $^{257}$ Mit dieser Differenzierung liegt auch hier eine Doppelgestalt des ,Nihilismus' als moralische und letztbezügliche Desorientierung vor: So können die ,sittlichmoralischen' und auch die ,sozialen' Werte (wie etwa,Mitmenschlichkeit') der Moralität zugeschlagen werden, während die ,religiösen' für solche des ,Letztbezugs' stehen. Das jeweilige Fehlen mündet dann in einen moralischen und einen letztbezüglichen ,Nihilismus'. Ein ,letztbezügliches Sinn- und Orientierungsdefizit' konstatieren auch andere Autoren geradezu als Signum der zeitgenössischen Gegenwart. So spricht etwa Tröger vom ,Untergehen der Sinnfrage‘ unter den Bedingungen der ,modernen Welt ${ }^{*}$ und sieht er daraus eine ,innere Leere‘ entspringen ${ }^{258}$ oder klagt Kerstiens weit über die sechziger Jahre hinaus über die „Erfahrung der Sinnlosigkeit", die von dem, allgemeinen Prozeß der Sinnverdrängung in der ,technisch-wissenschaftlichen Welt' verursacht sei. ${ }^{259}$ Vor allem bei Wasem und Tröger ist die Klage über die Orientierungskrise dabei mit dem Materialismusvorwurf verknüpft, wenn ,geistige Werte' durch, materiellen Nutzen' ersetzt scheinen, doch greift ihre Argumentation durch ihre Kritik an dem ,Zeitsymptom' einer ,inneren Leere' und an der Suspension der Sinnfrage über diesen Vorwurf hinaus.

Aus dem Theorem des, Werteverfalls' wird also nicht nur eine fehlgeleitete, materialistische Orientierung der Gesamtgesellschaft deduziert, sondern auch ein ,Nihilismus', der in einer Doppelgestalt als Verfall von Moralität und als Entstehung eines Sinndefizits vor Augen tritt. Gezeichnet wird das Bild vor allem einer jungen Generation, die durch die Auflösung der traditionalen Bestände in eine innere und äußere Haltlosigkeit gerät und deren Orientierungsbedürfnis keine Befriedigung mehr erfährt. Die moderne Welt scheint, leer' und zugleich selbst in einer Leere zu hängen. Als verschuldet gilt diese Leere von den Menschen selbst, die (vermutlich mit Beginn der Neuzeit) jene Krisensituation erzeugt haben. Ausgemalt ist damit ein fast nietz-

255 Wasem, Jugend, 60

${ }^{256}$ Wasem, Jugend, 75-76

257 vgl. Wasem, Jugend, 76

258 vgl. Tröger, Film, 214; Tröger hebt hier besonders auf die Arbeitswelt und ihre ,materialistischen Nutzenmaximen' ab, die keinen Raum mehr für die Sinnfrage lasse. Vgl. zum Sinndefizit auch Trögers Stellungnahme zur ,Freizeitnot' der Jugendlichen und ihrer ,inneren Leere': Tröger, Film, 90, 214

vgl. Kerstiens, Erziehungsziele, 82-83; Kerstiens liefert hier zugleich ein Beispiel dafür, wie sich die Modernitätskritik der Fünfziger und Sechziger weit über diese Jahrzehnte hinaus tradiert. 
scheanisches Bild, in dem die Erde, mutwillig von der Sonne losgekettet, nur noch stürzt. Diese Sonne aber wird wieder von einer traditionalen Wertordnung repräsentiert, die allein zumindest die Moralität garantieren und sittlichen Halt geben, sowie möglicherweise sogar Sinn stiften zu können scheint. Auf diese Weise werden erneut die Paradigmen Keilhackers aufgegriffen und zugleich fortgeschrieben. So gilt zunächst der ,Werteverfall' wieder als ,zeittypische' Erscheinung der modernen Welt und wird der filmerzieherische Entwurf in den größeren Horizont der Modernitätskritik gestellt. Gerade über den nietzscheanischen Anklang wird dieser Horizont im Hintergrund sichtbar. Auch wird die Moralität implizit bereits als Bindung an ein festes, traditionales Wertekorpus skizziert und so auf die Keilhackersche Lösungsstrategie verwiesen. Über die Moralität hinaus scheint dieses Korpus dann zugleich ,Sinn' geben zu können. Der Keilhackersche Entwurf wird damit ausgeweitet und mit einer ,Sinnkritik' verknüpft, die partiell auch unabhängig vom ,wertkritischen' Paradigma geübt wird. Eine solche, unabhängige Kritik liegt etwa bei Kerstiens in den 70er Jahren vor, der sich auf Frankl bezieht. Selbst seine Überlegungen aber enthalten noch einen Rückbezug zu Keilhacker, wenn er die Klage über das Sinndefizit im Kontext einer Technikkritik vorbringt und sie derart mit der Kulturtheorie des Schulgründers verknüpft. Der zweite, eigenständige Devianzvorwurf der Filmerzieher läßt also bislang eine enge Verbindung mit dem Keilhackerschen Konzept erkennen, das sowohl tradiert, als auch in Erweiterung zur ,Sinnkritik' fortgeführt wird.

Der Film wird dann wieder zugleich als Ausdrucksträger und als verderblicher $\mathrm{Be}$ förderer der beklagten Verfallssituation behandelt. Er scheint einerseits eine Spiegelfunktion zu haben, andererseits damit die Situation keineswegs zu bessern, sondern eher zu verstärken. So sieht Margarete Keilhacker vom Film das aufgegriffene ,Zeitproblem' einer ,desorientierten', ,nihilistischen' Jugend ,in ein allzu grelles Scheinwerferlicht" gerückt, „das das Auge geblendet hat für die bürgerlichere und positivere Ausrichtung“", mit der die nötige ,Heilung` zu gewinnen wäre. ${ }^{260}$ Aus der ,Blendung' droht dann entsprechend eine Verblendung zu werden, die den ,Nihilismus' als Resignation vor der ,sinnentleerten' und orientierungslosen modernen Gesellschaft zementiert und ihn derart nicht nur als gesellschaftlichen Zustand, sondern auch als persönlichen Habitus festschreibt. Die Spiegelfunktion des Films gilt damit zugleich als negative Verstärkung der gesellschaftlichen Defizienzen. Aus diesem Grund wendet sich Tröger scharf gegen Filme, ,die sich existenzialistisch und nihilistisch geben“, und verurteilt er ihre Haltung als „Pose“, welcher bei den „Fragen nach der Wahrheit des Menschen der Ernst“ fehle. ${ }^{261}$ Von ihnen kann weder das ,Wertevakuum' gefüllt, noch der als ,so dringlich nötig' geltende „Wille zum Sinn“"262 befördert werden.

Verwendet wird also bei der Spezifizierung der Devianzkritik auf den Film hin wieder die modifizierte Kooperationsthese, die ein verderbliches Zusammenwirken von Film und Zeitsituation konstatiert. Der Film gilt nicht nur als Indikator für diese Situation, indem er sie zu seinem Gegenstand macht und vor Augen stellt, sondern gleichzeitig als ihr Promotor, der die defizitäre Wirklichkeit lediglich verdoppelt und

${ }^{260}$ Keilhacker, Kino, 96-97; im Original partiell kursiv.

261 Tröger, Film, 194

262 Tröger, Film, 61; Tröger zitiert hier Frankl. 
in negativer Weise affirmiert. Die Möglichkeit der Reflexion und der situationsverändernden Kritik, wie sie die von den Filmerziehern herangezogenen ,Halbstarkenfilme‘, wie ,Saat der Gewalt' oder ,Denn sie wissen nicht, was sie tun“ durchaus enthalten, kommen dabei nicht in Blick. Eine positive Beeinflussung der Defizienzen durch ihre kritische Bearbeitung scheint nicht möglich. Lediglich eine ,positive‘, ,bürgerliche“ Ausrichtung, also letztlich wohl die Vermittlung des traditionalen Bestands der ,Werte' und Orientierungsformen wird als mögliches Heilmittel genannt. Dieser traditionale Bestand wird als ,zeituntypischer' und, genau besehen, zeitexterner, der Problematisierung entzogener, den aktuellen Gegebenheiten und Veränderungen entgegengestellt. Er gilt als Korrektiv der ,zeitspezifischen' Defizienzen und sollte wohl vom Film entsprechend vermittelt werden. Das aber verweist darauf, daß der Film nicht als Teil und Ausdruck des gesellschaftlichen Diskurses, sondern als Instrument der Belehrung begriffen wird (vgl. 4.6.) und daß dem Diskurs überhaupt kaum eine Lösungspotenz in defizitären Situationen zugetraut wird. Er scheint als aus dieser Situation kommend diese immer nur zementieren zu können, und die Überwindung der Situation scheint einen konträren und externen Rückbezug auf gesicherte, traditionale Bestände (vgl. weiter oben) zu verlangen. Im Hintergrund der negativen Einschätzung der Filmwirkung läßt sich somit eine pessimistische Beurteilung der kontingenten, diskursiven Kompetenz der Gesellschaft schlechthin wahrnehmen, die darauf hindeutet, daß eine eigentlich moralische und sinnhafte Ausrichtung nicht aus kontingenten Diskursen und diskursiven Veränderungen erwachsen kann, sondern jenseits derselben gesucht werden muB. Die Argumentationsfigur weist damit in dieselbe Richtung wie die Unvollkommenheit der Domestikation der anthropologisch konstatierten Negativa des Menschen, nämlich darauf hin, daß die Lösung für den Verfall nicht in kontingenten kulturellen oder diskursiven Konstruktionen gesucht werden kann, sondern aus anderen, unantastbaren Bereichen kommen muß.

\section{Letztbezüglicher Nihilismus als Folge der Globalisierung und der modernen Pluralität}

Erscheint nun der doppelte, vom Film beförderte ,Nihilismus' in den Texten der Filmerzieher bis hierher als Orientierungslosigkeit durch fehlende ,Werte', so tritt seine ,letztbezügliche 'Variante dann auch als ,Desorientierung‘ durch ein allzu vielfältiges Angebot von Orientierungsmöglichkeiten auf, deren Wirkung durch die schon bei Keilhacker problematisierte Globalisierung verstärkt werde. Beide gelten nun zunächst nicht unmittelbar als Beförderer des Sinn- und Orientierungsdefizits als prekär, sondern als Überangebot, das durch seine Wirrnis und einen daraus hervorgehenden Entwertungszusammenhang sowohl in mittelbare Desorientierung als auch in Gleichgültigkeit führe. Eine entsprechende Wirkung der Pluralität thematisiert Wasem, wenn er der ,weltanschaulichen Vielgestaltigkeit in der Gesamtheit des Filmangebots“ eine „Verwirrung und Verwässerung“ der „Wertvorstellungen“ anlastet. ${ }^{263}$ Der Rezipient nämlich stehe einem ,gesinnungsmäßigen Tohuwabohu“ gegenüber, ${ }^{264}$ das als ,,verwirrende Vielfalt der subjektiven, auf zeitgenössische Egoismen spekulierenden Daseinsauslegungen "265 auftritt. Dem aber ist er offenbar kaum noch

\footnotetext{
${ }^{263}$ Wasem, Jugend, 49-50

264 Wasem, Jugend, 50

265 Wasem, Jugend, 9
} 
gewachsen, so da $\beta$ die notwendige Konsequenz eine Konfusion seiner eigenen, Wertorientierung' sein muß. Seine ,Daseinsauslegung' sieht sich vor ein Chaos gestellt, angesichts dessen die Lösung dann in einer subjektiven Gleichgültigkeit oder in der nivellistischen Annahme einer Austauschbarkeit der ,weltanschaulichen Optionen gesucht wird. Verstärkt wirkt die Austauschbarkeit ohnehin von der Globalisierung, die eine „weltumspannende Nivellierung durch die ,Massenmedien “ “ auslöse. ${ }^{266}$

Der ,Nihilismus' wird so nun auch als durch den modernen Pluralismus geförderter gezeichnet, wo an die Stelle einer einheitlichen Weltinterpretation und Daseinsordnung die Vielheit divergenter und konkurrierender Interpretamente tritt. Diese Vielheit scheint sowohl einen Überforderungszusammenhang zu konstituieren als auch zu wechselseitiger Nivellierung und Entwertung der Optionen zu führen, so da $B$ das Individuum einer Stellungnahme auszuweichen geneigt ist und in Unverbindlichkeit flüchtet. Die Argumentationsfigur parallelisiert und spezifiziert derart Keilhakkers Klage über das Verlorengehen einer einheitlichen Entwurfsbasis und Erziehungsatmosphäre, welche dem Individuum noch zur Orientierungskonsistenz verhalfen und deren Auflösung in eine Vielfalt zur Überforderung führen soll. Wurde die Auflösung dort soziologisch geläufigen Diversifizierungsprozessen angelastet, so tritt nun der Film als Ausdrucksträger dieser Diversifizierung und als Transporteur ihrer Vielfalt auf. Er stellt gewissermaßen einen Teil jenes öffentlichen Raums dar, in dem den familialen (und traditionalen) Leitbildern weitere, mit ihnen und untereinander konkurrierende, ,vorbildhafte' Daseinsauslegungen zur Seite treten, und das Argument zeigt sich derart als Spezifizierung des Keilhackerschen Theorems auf den Film hin. Wie schon Keilhacker vom Verlust der Einheitlichkeit Störungen des Selbstentwurfs begünstigt sieht, scheint das Subjekt auch hier von der Diversifizierung und ihrer Vielfalt in eine ,Verwirrung getrieben zu werden und dem widerspruchsvollen Überangebot nicht gewachsen zu sein. Zusammen mit der spezifizierenden Parallelisierung enthält das Argument deshalb implizit auch den Keilhackerschen Pessimismus gegenüber der Entwurfsautonomie, welcher dem Subjekt eine Potenz der Auswahl und der selbsttätigen Konstitution einer zusammenhängenden, ,seriösen' Orientierung und weltanschaulichen Selbstbindung nicht zutraut. Schließlich übernimmt das Argument noch explizit die modernitätskritische Bewertung der Globalisierung, die schon in Keilhackers Konzept eine wechselweise ,Entwertung und ,Nivellierung der divergierenden, Wertsysteme' verschiedener Gesellschaften befürchtete. Es vervollständigt so den Pessimismus gegenüber dem modernen Pluralismus, der neben der Diversifizierung ja auch der Internationalisierung entspringt. Der Vorwurf tradiert damit den Pluralismuspessimismus des Schulgründers der Filmerziehung in all seinen Formen und konstituiert mit seiner filmspezifischen Auslegung eine weitere Form des ,eigenen' Devianzvorwurfs des ,Nihilismus'.

\section{Manipulation und Zerstörung der ,Eigentlichkeit : Extraversion, sekundäre Welten, Uniformierung}

Als dritter, ,eigener' Vorwurf läßt sich schließlich noch der einer Außenorientierung, die in ,Außengeleitetheit' und den Verlust von, Eigentlichkeit' umschlagen kann, rekonstruieren. Der Vorwurf legt sich in zwei Richtungen aus, nämlich als eigentlichkeits-

${ }^{266}$ Wasem, Jugend, 61 
und als manipulationskritischer. Zugrunde liegt ihm der Antagonismus von Extraversion und Introversion, mit dem zugleich der Konnex zur Keilhackerschen Zivilisationskritik hergestellt ist. Wie zu sehen war, sieht Keilhacker durch die Bedingungen der modernen Welt eine ,Außenorientierung und damit einen ,extravertierten Typ begünstigt, der in ,Oberflächlichkeit‘, Unverbindlichkeit und ,Wendigkeit‘ abzurutschen droht. In ähnlicher Weise konstatiert auch Margarete Keilhacker, zunächst in eigentlichkeitskritischer Weise, einen gegenwärtig gesellschaftlich begünstigten, extravertierten Typ, den sie mit einem introvertierten kontrastiert. Den Extravertierten kennzeichnet sie als den „Betriebsameren“, der „Unterhaltung und Vergnügungen“ suche und so recht der ,Kinotyp' sei. ${ }^{267}$ Er stelle ein Wesen vor, das ständig unterwegs sei, ,Geselligkeit im größeren Kreis“ liebe ${ }^{268}$ und wegen seiner psychischen „Veranlagung vom Film besonders angezogen“"269 werde. Im Gegensatz dazu neige der introvertierte Typ zu „Besinnlichkeit“, suche „zu den Dingen wie zu den Menschen ein mehr persönliches Verhältnis zu gewinnen“ und habe „Freude an eigener, gestaltender Betätigung". ${ }^{270}$ Während der Extravertierte also offensichtlich die ,sekundäre Wirklichkeit‘ der Films präferiere, lege der Introvertierte „Wert auf direktes, ursprüngliches Erleben“. ${ }^{271}$ Gerade das letzte nun gilt als von der Extraversion und ihrer Verstärkung durch den Film gefährdet. Dieser nämlich scheint mit seinen ,äußeren Reizen' von der Außenorientierung in eine ablenkungsbereite Veräußerlichung zu führen, die sich mit vermittelten, rezeptiven Erlebnissen zufriedengibt. So spricht Margarete Keilhacker an anderer Stelle davon, daß der „totale Einbruch der technischen Produktion (...) ganz allgemein zur Herabminderung des zwischen Original und Reproduktion unterscheidenden Gefühls" beigetragen habe. ${ }^{272}$ Diese ,Herabminderung aber ,entfremde“ „auf allen Gebieten den Menschen immer mehr dem direkten Erleben“, und lasse ihn „damit auch dem Film zutreiben“. ${ }^{273}$ Der entfremdete, an den Film gewöhnte Rezipient drohe dann, sich ,mit dem Erleben aus zweiter Hand" zufriedenzugeben. ${ }^{274}$ Die Extraversion führt derart über die Verstärkung durch den Film in eine spezifische Defizienz, und der typologische Gegensatz von Extraversion und Introversion wird für ein Verfallstheorem genutzt.

Dieses Verfallstheorem enthält zunächst eine spezifische Eigentlichkeitskritik, die sich auf den Verfall zweier Formen von ,Eigentlichkeit" bezieht und die zusammen mit dem Konnex zu Martin Keilhackers Modernitäts- und Zivilisationskritik verdeutlicht werden kann. Zunächst wird mit der letztgenannten Kritik Margarete Keilhackers dem Film, ebenso wie bei ihrem Mann den Medien insgesamt, die Etablierung einer Sekundärwirklichkeit angelastet und dann aus deren Zusammenwirken mit der psychischen Disposition der Extraversion der Verfall einer Erlebnis- und Erfahrungsauthentizität abgeleitet. Der Verfall entsteht so wieder durch eine verderbliche Kooperation des Films mit einer Publikumsdisposition, und explizit bedroht

${ }_{267}^{267}$ Keilhacker, Kino, 30

268 Keilhacker, Kino, 30

269 Keilhacker, Kino, 30; Keilhacker zitiert hier Muth, H., Landjugend und Kino, in: Wollenweber, H. u.a., Die Lebenslage der westdeutschen Landjugend 1, München 1956, 293-377

${ }_{270}$ Keilhacker, Kino, 30

271 Keilhacker, Kino, 30

272 Keilhacker, Kino, 28

273 Keilhacker, Kino, 28

${ }^{274}$ Keilhacker, Kino, 111 
scheint vorerst einmal eine als Erlebnisunmittelbarkeit definierte ,Eigentlichkeit', wie sie auch bereits bei Martin Keilhacker als gefährdete auftaucht. Durch ihre Begünstigung der Bedrohung aber erhält dann die Extraversion selbst (wieder) den Charakter einer Devianzinklination und wird die Introversion im Gegensatz dazu aufgewertet. Diese implizite Wertung findet sich außerdem durch einen mittelbaren Rückbezug auf den modernitätskritischen Antagonismus von vita activa und vita contemplativa bestätigt. So wird auch bei Margarete Keilhacker mit ,Betriebsamkeit und ,Besinnlichkeit' letztlich eine aktiv-außenorientierte mit einer kontemplativinnenorientierten Lebensform kontrastiert und ist die Argumentationsfigur kategorial mit der Modernitätskritik ihres Mannes verbunden. Dieser Verknüpfung entsprechend bleibt die Kontrastierung nicht wertfrei, sondern erhält die Introversion den Charakter eines dringlich nötigen Korrektivs in einer extraversionsfreundlichen Welt. Damit aber wird zugleich neben der Authentizität der Erfahrung und des Erlebens implizit eine zweite Form der ,Eigentlichkeit' konstruiert. So war zu sehen, daß der kontemplativ-besinnlichen Introversion eine Affinität zum ,Persönlichen' und zur Kreativität attestiert wird. Der Introvertierte gilt als jener, der aus seiner Mitte heraus personale Beziehungen zur Welt und zu Menschen etabliert und der ,aus dem eigenen' schöpft. Er veranschaulicht derart eine ,Eigentlichkeit', die sich als ,personale‘ Authentizität bestimmt und deren Bedrohung ebenfalls bereits bei Martin Keilhacker auftritt. Die Bedrohung ist hier als filmische Begünstigung der Extraversion und der Existenz in sekundären Welten gefaßt, und der konstatierte Verfall entsteht erneut kooperativ. Dabei erscheint der Film jetzt vor allem im zweiten Fall nicht nur als ein Agent des Verfalls, der diesen durch Vermittlung defizienter gesellschaftlicher Erscheinungen befördert, sondern selbst als Defizienzphänomen. Angegriffen wird diesmal nämlich nicht die inhaltliche Vermittlung zeittypischer Verfallsphänomene, wie des Materialismus oder Nihilismus, sondern die Formalstruktur des Films. Dieser kann gar nicht anders, als sekundäre Wirklichkeiten zu schaffen und findet eben darin seine spezifische (ästhetische) Potenz. Eben das scheint auch der Extraversion gehalteunabhängig in die Hände zu arbeiten, die mit ihrer Suche nach dem ,Unterhaltsamen' offenbar schon von der Vielfalt sekundärer Angebote angezogen wird und die Innerlichkeit verlorengehen läßt. Der Fïm ist so jetzt selbst ein modernes Defizienzphänomen, das als Ganzes der Eigentlichkeit entgegenwirkt und deshalb grundsätzlich kritisiert werden muß. Die gefährdete Eigentlichkeit aber läßt aus dem Vorstehenden zwei voneinander unterscheidbare Formen bzw. Komponenten erkennen, nämlich eine erlebnisbezogene und eine personale, die beide bereits in Martin Keilhackers Konzept enthalten sind, und deren Gefährdung nun dem Film angelastet wird. Margarete Keilhackers Text kann so als Fortführung und bereichsspezifische Konkretion der Kritik an der Auflösung der ,Eigentlichkeit', wie sie in der Zivilisationskritik ihres Mannes geübt wird, verstanden werden, und der Konnex beider Theorien ist rekonstruktiv deutlich.

Dem Konnex mit der Keilhackerschen Zivilisationskritik entsprechend wird weiter ein ,Umkippen' der Außenorientierung in ,Außengeleitetheit' konstatiert und der Gefährdung ein weiterer Aspekt beigesellt. Er führt nun explizit eine an die Eigentlichkeitskritik gekoppelte Manipulationskritik durch, die sich bei Margarete Keilhakker in der Figur der Sekundärwirklichkeit oben ebenfalls ankündigt, jedoch an anderer Stelle als ,Außengeleitetheit' deutlicher ausgeführt ist. Vermittelt scheint diese 
,Außengeleitetheit' zunächst wieder durch eine Reizorientierung, die von der modernen Welt und ihrer ,Reizfülle' geradezu provoziert werde. So bestimmt Margarete Keilhacker die Reizorientierung an sich als Teil ,unserer Zivilisationskrankheiten“ und zeichnet sie den "Griff nach dem Reizmittel Film" als Ausdruck der letztgenannten. ${ }^{275}$ Daraus sieht sie dann eine kooperativ konstituierte ,Sucht" hervorgehen, unter deren Diktat der Rezipient sich den Film ,zuführe ${ }^{6}$,wie eine Droge, von der man eine bestimmte, stimulierende Wirkung erwartet". ${ }^{276}$ Durch seine Extraversion verderblich disponiert, fällt das Publikum dem Film anheim und verliert es sich in einer spezifischen Abhängigkeit von äußeren Reizen. In ähnlicher Weise sieht auch Kerstiens vom Film eine „Reizfülle“ dargeboten, die eine bereits vorhandene Reizorientierung befördere und den Zuschauer veranlasse, „nur noch den stärkeren Reizen zu folgen". ${ }^{277}$ Konsequenz scheint hier eine ,Sensationslust" zu sein, die nach immer größeren äußeren Stimulanzien verlangt. ${ }^{278}$

Auch dieses Argument zielt zunächst tendenziell über die Vermittlungsfunktion des Films hinaus und nimmt nicht nur seine, aufreizenden' Gehalte in Blick, sondern wohl auch seine Formalstruktur, d.h. seine Dynamik, Bewegtheit und Geschwindigkeit, die per se schon als Reizmomente erscheinen. Der Film ist hier wieder implizit selbst als modernes Devianzphänomen behandelt, das sich gut mit der ebenfalls mißtrauisch beurteilten Dynamik der modernen Welt ergänzt. Damit droht dann weiter nicht nur wieder eine kontemplative ,Innenorientierung und eine von dieser garantierte ,personale Tiefe' und ,Eigentlichkeit' verlorenzugehen. Vielmehr ist nun auch die ,innere Freiheit' und Selbstbestimmung des Rezipienten von Sucht und Abhängigkeit gefährdet. Unter den Bedingungen einer reizüberfluteten Zivilisation und ihrer Filmindustrie scheint der extravertierte Mensch so zum willig den Stimulantien hinterherjagenden, addictiven Individuum zu werden, und seine Außenorientierung scheint ihn zum Opfer einer zunehmenden Außenleitung zu machen. Neben dem Verlorengehen von ,Eigentlichkeit' zeigt sich damit zugleich die Bedrohung von Autonomie, und der Vorwurf koppelt sich, wie schon bei Keilhacker, mit einer Manipulationskritik. Auf diese Weise wird also auch hier die Keilhackersche Zivilisationskritik tradiert und bereichsspezifisch konkretisiert. Wo Keilhacker die Medien generell als Förderer einer extravertierten Fremdorientierung und Außenleitung bestimmte, legen die Filmerzieher dies nun konsequent auf das Medium Film um und sehen sie in ihm zusammen mit einer eigentlichkeitszerstörenden auch eine manipulative Instanz. Ähnlich wie bei Keilhacker aber wird damit nicht nur der mediale Zusammenhang als verblendender Fremdbestimmungszusammenhang gezeichnet, der die hilflosen Subjekte in seinen Sog zieht, und die Manipulation nur dem Medium allein angelastet. Vielmehr findet sich mit der Hilflosigkeit der zur Sucht fast disponierten, extravertierten Filmrezipienten erneut auch ein Autonomiepessimismus fortgeführt, der das Gelingen der Manipulation zusätzlich den Subjekten vorwirft. So scheinen die Rezipienten mit ihrer extravertierten Disposition hier ebenfalls eine gewisse Bereitschaft zur Reizabhängigkeit und damit für die Wirksamkeit und den Erfolg der Manipulation mitzubringen, deren Kehrseite eine supponierte Abwesen-

\footnotetext{
275 Keilhacker, Kino, 81

276 Keilhacker, Kino, 81

277 Kerstiens, Filmerziehung, 44

278 vgl. etwa auch: Kerstiens, Filmerziehung, 34
} 
heit jeder kritisch-distanzierenden Potenz und Fähigkeit zur selbstbestimmten Stellungnahme ist. Sie treten angesichts der Reizfülle nicht nur als überforderte Opfer im Objektstatus, sondern auch wieder als zur Autonomie unfähige Subjekte auf. Ebenso wie in Keilhackers Zivilisationskritik scheint ihnen auch hier keine Potenz zum medienunabhängigen Verhalten und einer entsprechenden Selbstgestaltung eigen zu sein.

Diese Frage nach einer ,eigentlichen' und autonomen Selbstgestaltung greift dann auch Kerstiens auf. Er konstatiert die Korrumpierung des subjektiv-,eigentlichen Entwurfs durch die Bereitstellung von ,Idolen' und das in ihnen repräsentierte ,Man'. Die Außenleitung scheint diesmal zu einer ,Uniformierung' durch serialisierte Leitbilder und einem entsprechenden Verfall der ,Eigentlichkeit' zu führen. So liefere der Film mit seinen ,Stars' solche ,Leitbilder", die eine „absolute Nachfolge“ bei den Rezipienten evozierten. ${ }^{279}$ Er konstituiere damit einen Fremdbestimmungszusammenhang, der ,in die Hörigkeit" führe. ${ }^{280}$ Die bereitgestellten Leitbilder seien zudem in Rücksicht auf die ,großen Massen' produziert worden und zwangsläufig „oberflächlich“. ${ }^{281}$ In ihnen scheint, wie bei allen massenorientierten Produkten, nur ein möglichst breit rezipierbarer ,Durchschnitt' von Leitvorstellungen zum Ausdruck zu kommen, der in seiner Rückwirkung auf das Publikum zur Nivellierung führt und dessen Verfall an das ,Man' begünstigt. Der Rezipient, der eigentlich „,beginnen soll, von innen heraus sein Leben zu führen", gerät so durch seine Orientierung an den filmischen "Idolen' ,zu dem absolut außengeleiteten Menschen“ und findet sich außerdem durch diese Orientierung ,uniformen' Vorstellungen unterworfen. ${ }^{282}$ Verloren gehen derart sowohl seine Selbstbestimmung als auch seine als ,Innerlichkeit‘ angesetzte, personale und schließlich seine individuelle ,Eigentlichkeit'.

Damit wird auch das letzte Moment der Keilhackerschen Zivilisationskritik filmerzieherisch umgesetzt und konkretisiert, nämlich die Kritik an einer ,Uniformierung, die Keilhacker aus serialisierten Industrie- und Medienprodukten hervorgehen sah. Das Argument stellt sich dabei im ganzen wieder als Manipulations- und Eigentlichkeitskritik dar, die jetzt am Film geübt wird. Um der breiten Rezipierbarkeit und entsprechenden Profitabilität willen nämlich scheint auch dieser nur serialisierte, auf den ,Durchschnitt' hin nivellierte Gehalte anbieten zu können. Diese Nivellierung gilt dabei vor allem als in der Zeichnung der handlungstragenden Personen und dem filmextern weitergeführten ,Starwesen' faßbar. Über die projektive Identifikation mit den ,Stars' soll sie sich dann publikumsprägend realisieren und von der ,Durchschnittlichkeit' der filmischen Gehalte und ,Leitbilder' zur ,Durchschnittlichkeit' der Rezipienten führen. Die Orientierung am, Man' scheint so generalisiert und dessen Herrschaft unausweichlich befestigt zu sein. Nicht genug damit aber droht die ,manhafte' Inszenierung auch eine ,Hörigkeit' nach sich zu ziehen und derart die ,Suchtstruktur' der Filmrezeption als Sucht nach dem ,Man`zu verstärken. War oben zu erkennen, daß dem Rezipienten eine extravertierte Disposition zur Addictivität gegenüber Reizen unterstellt wird, so tritt dieser nun noch eine Abhängigkeit von repräsentierter Kollektivität an die Seite. Zustande kommt diese wieder ko-

${ }^{279}$ Kerstiens, Filmerziehung, 40

280 Kerstiens, Filmerziehung, 40

${ }_{281}^{281}$ Kerstiens, Filmerziehung, 40

282 Kerstiens, Filmerziehung, 40 
operativ, durch ein Zusammenwirken des geschickt, nivellistisch'-breitenwirksam gestalteten Films und den ,manhaften' Neigungen des Publikums, das sich begierig wiederzuerkennen bzw. wunschhaft zu identifizieren sucht. Verloren aber sind damit zunächst zwei Komponenten von ,Eigentlichkeit‘, nämlich einmal die Individualität an die Kollektivität des ,Man' und ein andermal die personale Innerlichkeit an die Außenorientierung an ,Idolen‘. Weiter ist auch die Selbstbestimmung dem Verfall preisgegeben und kippt die Außenorientierung in Außenleitung. Dieses Kippen trägt dabei durch die supponierten ,manhaften' Neigungen des Publikums wieder ein autonomiepessimistisches Moment in sich. Der dritte ,eigene' Devianzvorwurf der Filmerziehung tradiert so die Keilhackersche Eigentlichkeits- und Manipulationskritik in großer ,Originaltreue‘ und erweist sich ebenfalls als deren ,bereichsspezifische‘ Konkretion.

\section{Die Devianzkritik der Filmerziehung und das Erbe des Schulgründers}

Insgesamt kann so festgestellt werden, daß die Filmerziehung nicht nur auf die Argumentation der Kinoreformer zurückgreift, sondern auch die Paradigmen und Theoreme Martin Keilhackers aufnimmt und partiell in treuer Rekapitulation, partiell in kongenialer Fortschreibung und Transformation auf den Bereich Film anwendet. Sie setzt derart die Vorgaben des Schulgründers um und schafft eine ,eigene Devianzkritik, die an die Seite der revitalisierten reformerischen tritt und deren Rahmen erweitert. Aus einer systematisierenden Perspektive habe ich diese Kritik typologisch in drei Vorwürfe gefaßt, die sich wiederum in einzelne Komponenten zerlegen. So war zunächst der Materialismusvonwurf erkennbar, der eine fehlgehende, gesamtgesellschaftliche Orientierung anmahnt, welche durch den Film befördert werde. Er stellt eine unmittelbare Rekapitulation des gleichlautenden Vorwurfs in der Kulturtheorie des Schulgründers dar und überträgt das Hintergrundparadigma des ,Werteverfalls' in die Filmerziehung. - Der zweite Vorwurf trat in doppelter Gestalt auf und sah durch den Film einen ebenfalls allgemein gesellschaftlich konstatierten moralischen und letztbezüglichen ,Nihilismus' unterstützt. Auch er ist vom Paradigma des ,Werteverfalls' bestimmt, stellt diesem jedoch in der letztbezüglichen Komponente eine ,Sinnkritik' an die Seite, die neben der ,Wertorientierung' auch die ,Sinnorientierung‘, ja die ,Sinntiefe' selbst verlorengehen sieht. Er ergänzt so das wertkritische Paradigma, ohne freilich völlig bezugslos zur Keilhackerschen Theorie zu bleiben. Mit Kerstiens technikkritischer (oder Trögers ökonomiekritischer) Herleitung der ,Sinnkrise' erhält die Ergänzung vielmehr wieder eine entsprechende Rückbindung an die Kritik des Schulgründers. Eine solche Rückbindung liegt dann auch in der pluralismuspessimistischen Komponente des Vorwurfs vor, der zum einen eine Parallele zu Keilhackers Klage über das Verlorengehen einer einheitlichen ,Erziehungsatmosphäre‘ und Entwurfsbasis etabliert, zum anderen die Problematisierung der Globalisierung rekapituliert. - Mit dem dritten Vorwurf schlieBlich zeigte sich die Befürchtung eines filmisch beförderten Verfalls der ,Eigentlichkeit;, welche sowohl als erlebnisbezogene Unmittelbarkeit als auch als personale Innerlichkeit und als individuelle Besonderheit vor Augen trat. Zugleich war deutlich, daß der Vorwurf mit einer Manipulationskritik gekoppelt ist, die eine innengeleitete Selbstbestimmung verlorengehen sieht. Rekapituliert und bereichsspezifisch fortgeschrieben wird hier die zivilisationskritische Auseinandersetzung Keilhackers mit der 
modernen Industrieproduktion und Medienwelt, die schon dort die ,Eigentlichkeit an sekundäre Erlebnisse, ablenkungsbereite Außenorientierung und eine ,manhafte Kollektivierung sowie die Selbstbestimmung an fremdbestimmende Außenleitung verlorengehen sah. Im Hintergrund findet sich als Grundparadigma hierbei der schon bei Keilhacker vorfindbare Gegensatz von Extraversion und Introversion, der zugleich mit dem Gegensatz von vita activa und vita contemplativa konnotiert ist.

Nicht zuletzt der im letzten Vorwurf auffindbare Gegensatz verweist weiter darauf, daB mit der Fortschreibung der Keilhackerschen Paradigmen auch weitgehend dessen dichotomische Perspektive tradiert wird. Sehr deutlich ist das neben dem genannten Antagonismus im ,Eigentlichkeits'-Vorwurf etwa beim Nihilismusvorwurf in der Übernahme des Pluralismuspessimismus, der Vielheit und Einheit kritisch kontrastiert. Selbst im Theorem des ,Werteverfalls', das einen Teil dieses Vorwurfs und den Materialismusvorwurf trägt, läßt sich die dichotomische Perspektive aufspüren. So ist einmal dem ,Nihilismus' die ,traditionale' Wertorientierung entgegengesetzt, und ein andermal deutet sich in der Rede von der ,Einseitigkeit' der Herrschaft ,materieller Werte' eine gegenüberliegende Seite, geistiger Werte' an, wie sie an anderer Stelle, im Zusammenhang mit der Kriminalisierungsthese, schon einmal genannt wurde. Kohärent zur Funktion der Dichotomien in der Keilhackerschen Theorie läßt sich dann auch bei den filmerzieherischen Devianzvorwürfen erkennen, daß sich deren Klage jeweils auf den Verfall der einen Seite der Dichotomie zugunsten der anderen und daraus hervorgehende Defizitärphänomene bezieht. So verfallen die ,Werte' zugunsten des ,Materiellen', erzeugt die Auflösung der Einheit in die Vielheit eine Gefährdung der Orientierungskonsistenz und sorgt das Verlorengehen der ,Besinnlichkeit' und Introversion zugunsten der ,Betriebsamkeit' und Außenorientierung für eine Zerstörung der ,Eigentlichkeit' etc. Selbst die Konstatierung der ,Sinnkrise enthält zumindest dort, wo sie im wertkritischen Paradigma gedacht ist, diese Struktur. Zusammen mit dem traditionalen Wertekorpus schwindet dann auch der Sinn zugunsten (vermutlich) materieller oder technischer Maximen. Die ,eigenen Devianzvorwürfe der Filmerziehung zeigen sich so mit ihrer Fortschreibung und Tradierung der Theoreme Keilhackers ähnlich dichotomisch angesetzt wie diese. In der Übernahme dieser Perspektive deutet sich außerdem an, daß die Lösung der in der Devianzkritik konstatierten Probleme dann unter anderem und ähnlich wie bei Keilhacker durch eine entsprechende Wiederbelebung der verlorengegangenen Seite erreicht werden soll.

Der Rückbezug der ,eigenen` Devianzkritik der Filmerziehung auf den Schulgründer bedeutet jedoch nicht nur eine bereichsspezifische Konkretion von dessen Theoremen und eine Revitalisierung seiner Dichotomien, sondern er stellt außerdem die Devianzvorwürfe gegen den Film in einen größeren Rahmen. Mit der Konnotation zu Keilhackers Modernitäts- und Zivilisationskritik nämlich konstituieren die Filmerzieher ihre Devianzkritik am Film zugleich als Modernitätskritik und geben sie der schon bei den Reformen spürbaren modernitätskritischen Haltung eine umfassendere theoretische Basis. So war zu sehen, daß der Film immer wieder als Ausdrucksträger und Agent von Entwicklungen gehandhabt wurde, die als von ihm zugleich unabhängige gesamtgesellschaftliche Phänomene gelten. In der Tat wird ja der die beiden ersten Vorwürfe konstituierende, Werteverfall' als spezifisch moderne Erscheinung gehandelt und in diesem Zusammenhang etwa von Wasem die Notwen- 
digkeit einer Einbettung der filmbezogenen Devianzkritik in eine umfassende ,Zeitkritik' betont. Selbst in der ,Sinnkritik' war die übergreifende modernitätskritische Grundstellung, etwa in der technikkritischen Rückbindung bei Kerstiens, spürbar. Etwas anders freilich verhielt es sich in der Eigentlichkeitskritik. Zwar trat der Film hier ebenfalls als Ausdrucksträger zeittypischer Defizienzen auf, wenn seine Beförderung der ,Uniformierung' und "Manhaftigkeit' auf Produktionsbedingungen zurückgeführt und derart in den Kontext der Ökonomiekritik gestellt wurde. Auch erhielten die ,Außenleitung und ,Reizorientierung' durch ihre Apostrophierung als ,Zivilisationskrankheiten' den Charakter von zeittypischen Phänomenen. Doch wurde die Förderung dieser Zivilisationskrankheiten hierbei nicht nur den filmischen Gehalten, sondern partiell auch seiner Formalstruktur, d.h. der Erstellung sekundärer Welten und den formalen Reizen der Dynamik, Bewegung und Geschwindigkeit, angelastet. Der Film ist in diesem Devianzvorwurf daher nicht mehr bloß in den Rahmen einer Modernitätskritik gestellt, sondern gerät zugleich unmittelbar zum Gegenstand dieser Kritik. Er ist nicht mehr nur Agent defizienter Phänomene, sondern selbst ein Defizienzphänomen. Die filmerzieherische Argumentation läßt so auf ihren beiden Ebenen: der Ebene der rahmengebenden Modernitätskritik und der Ebene der filmbezogenen Devianzkritik, eine dreifache Strategie erkennen: Einmal greift sie moderne Defizienzphänomene selbst an. Dann transformiert sie diese Kritik in den Bereich des Films und sucht dort die Spiegelung der Defizienzen. Schließlich zieht sie den Film selbst auf die modernitätskritische Ebene und erklärt ihn per se zur Defizienz. Diese dreifache Strategie wird in den Lösungsoptionen wieder wirksam werden.

Der modernitätskritischen Haltung entsprechend zeigte sich in den Devianzvorwürfen dann auch ein Autonomiepessimismus, der dem Keilhackerschen analog ist. Dieser Autonomiepessimismus war zunächst in der pluralismuskritischen Komponente des Nihilismusvorwurfs erkennbar und stellte dort eine Parallele zu Keilhakkers negativer Einschätzung der Entwurfsautonomie dar. Hier wie dort scheint das Subjekt der diversifikativ und global-interaktiv erzeugten Pluralität nicht gewachsen und weder zur Auswahl noch zur Selbstbindung wirklich in der Lage zu sein. Es zeigt sich derart nicht nur als überfordertes, sondern auch als unfähiges Subjekt. Weiter war in der Extraversion nicht nur eine prekäre psychische Disposition erkennbar, von der die ,Eigentlichkeit' gefährdet schien, sondern auch eine Inklination zum Verfall an Fremdbestimmung. Sie stellt derart eine prekäre Befindlichkeit bzw. Prägung dar, die ebenfalls Anla $B$ zu einer pessimistischen Bewertung der Autonomiefähigkeit (zumindest der so Disponierten) gibt. Diesem Autonomiepessimismus entspricht es weiter, daß auch dem gesellschaftlichen Diskurs für die Lösung der Devianzphänomene des moralischen und letztbezüglichen Nihilismus kaum eine positive Potenz zugetraut wird und da $\beta$ kontingente, kulturell-diskursive Konstruktionen vermutlich nicht als ausreichend für deren Beseitigung gelten können. Ähnlich wie bei der Rekonstruktion der Revitalisierung der reformerischen Vorwürfe verweist deshalb der Nihilismusvorwurf der Filmerziehung ebenfalls auf eine Lösung voraus, in der die Wiedergewinnung des Verlorenen, also von Moralität und ,Letztorientierung', aus unantastbaren, der Kontingenz entzogenen Bereichen erfolgen soll. Dieser Lösung will ich mich im folgenden widmen. 


\subsection{Die pseudoautonome Eigentlichkeits- und Befähigungsethik der Filmerziehung}

Ähnlich wie Keilhacker seiner Modernitäts- und Zivilisationskritik ein ,positives‘ Lösungskonzept entgegensetzt, mit dem die beklagten Defizienzen ,geheilt' werden sollen, beläßt es auch die Filmerziehung nicht bei der Devianzkritik, sondern bemüht sie sich darum, auf deren Basis zu Lösungsstrategien zu kommen. Den beiden Devianzkritiken entsprechend, die mit den reformerischen Vorwürfen und dem Theorem vom ,Werteverfall" die Korruption der Sittlichkeit sowie mit der Zivilisationskritik den Verlust von ,Eigentlichkeit‘ und Autonomie anmahnten, geht es in diesem Lösungskonzept um die Rückgewinnung des Verlorenen, d.h. von Moralität, ,Eigentlichkeit' und einer spezifischen Form von Selbstbestimmung. Die Aufgabenstellung gleicht so jener, vor die auch Keilhacker sich in seiner pädagogischen Kulturtheorie gestellt sah. Daher verwundert es nicht, daß der filmerzieherische Lösungsversuch erneut einen Rückgriff auf die Keilhackerschen Paradigmen und Theoreme enthält. Die Filmerzieher revitalisieren und parallelisieren die dort getroffenen Optionen und Vorschläge, modifizieren und ergänzen sie aber auch und versuchen derart, das Lösungskonzept des Schulgründers für das eigene Unterfangen fruchtbar zu machen. Eine Ergänzung und Weiterführung findet sich etwa dort, wo über die Keilhackersche Wert- und Eigentlichkeitskritik hinaus eine Antwort auf die Sinnkritik gegeben werden muß. Freilich weist auch diese noch Bezüge zur metaphysischen Kehre bei Keilhacker auf. Modifiziert wiederum werden die Vorgaben vor allem durch ihre bereichsspezifische Transformation auf den Film hin. Da die Kritik am Film jedoch, wie zu sehen war, in den Rahmen einer generellen Modernitätskritik gestellt war, richtet sich der Lösungsversuch der Filmerziehung nicht allein auf filmspezifische Devianzen, sondern zusätzlich immer auch auf die ,moderne Welt' schlechthin. Die Filmerziehung trägt so die Keilhackersche generelle, kulturtheoretische Lösungsabsicht ebenfalls weiter. In ihrem Unternehmen lassen sich daher zunächst erneut zwei Ebenen unterscheiden: Auf einer Ebene wird versucht, der Moderne und ihren Defizienzen allgemein entgegenzutreten, und auf einer zweiten Ebene soll dies dann für den Bereich Film umgesetzt werden.

\section{Prinzipienethischer Ansatz: ,Gültiges Menschsein' als oberste Zielmaxime}

Im Unterschied zu Keilhackers Entwurf ist dabei das Lösungskonzept der Filmerzieher von vorneherein unter ein oberstes ethisches Prinzip gestellt. Keilhacker setzte seine Theorie ja unter wertethischen und kulturtheoretischen Prämissen an, die nicht nochmals deutlich in einem übergeordneten ethischen Prinzip verankert sind. Es ging ihm um eine Rückgewinnung von Moralität durch Reetablierung der ,Wertewelt', deren Sicherung dann von den moralpädagogischen Maßnahmen der Revitalisierungen von Ehrfurcht, Ehrerbietung und Religion gewährleistet sein sollte, sowie von Eigentlichkeit und Selbstbestimmung durch kontramoderne Orientierungsformen. Die Notwendigkeit dieser Rückgewinnung galt, ebenso wie die von Eigentlichkeit und Selbstbestimmung, als aus sich selbst heraus evident und abgesichert. Lediglich in dem von mir herausgearbeiteten Gedanken der ,Rehumanisierung' scheint implizit eine prinzipielle Rückbindung all dieser Unternehmungen auf, doch war dieser Gedanke bei Keilhacker selbst nicht zu einem Prinzip weitergeführt. Anders verhält es sich bei den Filmerziehern, die an die Spitze ihres Unterfangens ein ethisch- 
pädagogisches Doppelprinzip stellen, das alle weiteren Theoreme mit einer ethischen Valenz ausstattet. Explizit führt dieses Doppelprinzip etwa Kerstiens ein, wenn er als ,oberstes Ziel' der Pädagogik wie auch der menschlichen Existenz schlechthin ein ,erfülltes' und ,als gültig anerkanntes Menschsein' nennt. ${ }^{283}$ Auf dieses Ziel soll ,alles', jede menschliche Strebung, gerichtet sein, und ihm soll auch jede Form der Erziehung dienen. ${ }^{284}$ Das Doppelprinzip setzt so sowohl ein oberstes ethisches Prinzip für den menschlichen Lebensvollzug als auch eine Maxime für die Pädagogik, die jede ihrer Unternehmungen grundsätzlich ethisch normiert, motiviert und rückbindet. Beide, die Pädagogik wie auch der individuelle Lebensvollzug, sind grundsätzlich und unbedingt auf die Schaffung und Förderung des ,gültigen Menschseins' verpflichtet. Diese Verpflichtung gilt absolut und stellt eine deontologische Zielforderung dar. Mit dem Doppelprinzip ist das Konzept der Filmerziehung also zugleich unter einer deontologischen Prämisse angesetzt. Die erste Bedeutung des Prinzips, die dem menschlichen Existenzvollzug überhaupt eine Zielmaxime überordnet, läßt dabei erkennen, $\mathrm{da} B$ in den Texten der Filmerzieher nicht nur eine fachspezifische Ethik, die das pädagogische Handeln normieren will, sondern auch ein genereller ethischer Anspruch, der sich auf das menschliche Leben und Handeln überhaupt bezieht, enthalten ist. Entsprechend bilden, unter der Maxime des Doppelprinzips betrachtet, auch die Lösungsforderungen der Filmerzieher für die modernen wie die filmspezifischen Devianzphänomene letztlich ethische Postulate. Außerdem zeigt sich, daß mit dem pädagogisch-ethisch gedoppelten, prinzipiellen Ansatz zusätzlich zu den beiden Ebenen der Modernitätskritik und der filmbezogenen Devianzkritik zwei ethische Ebenen, nämlich eine der generellen und eine der pädagogischen Ethik konstituiert sind. Obschon von den Filmerziehern selbst eine ethische Systematik des Lösungskonzepts im weiteren dann nicht explizit und konsistent entfaltet wird, kann diese von ihrem Doppelprinzip her rekonstruktiv erarbeitet werden.

\section{Die Grundfigur: Pseudoautonome Befähigungsethik}

Zunächst wird aus der genaueren Ausführung der Maxime des Doppelprinzips und ihrer Verpflichtung der Pädagogik der Charakter der pädagogischen Ethik deutlicher. Hierbei zeigt sich zugleich, daB in der Filmerziehung, ebenfalls im Unterschied zu Keilhackers Entwurf, die Autonomieproblematik bereits auf der Prinzipienebene angegangen wird und nicht (nur) in eine gewissermaßen kasuistische ,positive Wendung der Manipulationskritik verschoben ist. Festgelegt wird nämlich im Kontext des pädagogisch-ethischen Doppelprinzips eine spezifische Form von Selbstbestimmung, durch die der Mensch wieder zu seinem Stand gelangen und zu der die Pädagogik befähigen soll. Kohärent zu Keilhackers Theoremen aber bleibt diese Selbstbestimmung begrenzt und wird sie letztlich unter den Prämissen der autonomiepessimistischen Grundoption der Devianzkritiken angesetzt. Sie läßt damit zugleich die Zielrichtung der Konzeption des ,gültigen Menschseins' vor Augen treten und macht von daher dann auch den Charakter des generellen Ethikansatzes deutlicher. Eingeführt wird die Problematik dadurch, daß Kerstiens zunächst als hervorragende Aufgabe

283 vgl. Kerstiens, Filmerziehung, 5, 7; auch bei anderen Filmerziehern steht diese Maxime im Hintergrund, so etwa bei Wasem, wenn er den Kitsch als Gefährdung eines „vollwertigen Lebensvollzugs" sieht und ihm deshalb pädagogisch entgegenwirken will (Wasem, Jugend, 54-55).

284 vgl. Kerstiens, Filmerziehung, 5, 7 
der Pädagogik die Befähigung zum ,gültigen Menschsein' umreißt und die erzieherischen Unternehmungen als „Lebenshilfe ${ }^{\text {“285 }}$ apostrophiert. Auf diese Weise ist nun nicht nur das ,gültige Menschsein' an sich als Ziel angesetzt, sondern zugleich die grundsätzliche pädagogische Anstrengung als Befähigung zur Verwirklichung dieses Ziels genauer benannt. Die Form der Befähigung wird dann dadurch näher charakterisiert, daß Kerstiens Erziehung - wieder ethisch-pädagogisch gedoppelt - als „Beistand zum Selbstand“ definiert und im Selbstand den „Charakter des erfültten Menschseins akzentuiert“ sieht. ${ }^{286}$ Die Selbständigkeit des Menschen scheint also eine wesenhafte Bestimmung des vom Doppelprinzip angesetzten Ziels zu sein. Das unterstreicht Kerstiens auch nochmals dadurch, daB er den Menschen als ,auf Eigenständigkeit und Mündigkeit angelegt" bestimmt ${ }^{287}$ und so eine autonomistische Determination quasi anthropologisch verankert. Dann jedoch betont er sogleich nachdrücklich, daß Mündigkeit und Selbstand ,nicht Selbstzweck“" sein könnten. ${ }^{288}$ Stattdessen definiert er Mündigkeit als „die Befähigung, die Wirklichkeit selbst zu erkennen, ihre Ansprüche zu vernehmen, und die so erfaßten und angenommenen Aufgaben zu erfüllen “. ${ }^{289}$ Die Mündigkeit ist damit von außen her, subjektextern, in Dienst genommen und scheint darin erst ihr Wesen zu finden. Nur auf diese Weise gilt dann auch das ,als gültig anerkannte Menschsein' gewonnen und die Mündigkeit als in der rechten Weise ausgeübt. Eben durch die genannte Definition nämlich scheint Kerstiens erst ,der Akzent' deutlich genug ,auf die Zielbestimmung gesetzt“ ${ }^{290}$ Auch weit nach den 50er und 60er Jahren repetiert er noch diese Definition von ,Mündigkeit' und ,Selbstbestimmung'. Jetzt setzt er sich damit vor allem pointiert der ,emanzipativen Pädagogik und ihren Autonomisierungsbemühungen entgegen. ${ }^{291}$ Zielmaxime ist nach wie vor das ,gültige Menschsein', zu dem befähigt werden soll. ${ }^{292}$ Dabei ist es jetzt vorwiegend die Selbstbestimmung, deren Begriff Gegenstand der Auseinandersetzung ist. Auch sie wird als ,Annahme‘ eines vorgegebenen ,Anspruchs' definiert und gilt als Disposition, die ,an sich' keinesfalls „oberstes Ziel“ sein könne. ${ }^{293}$ Gewehrt werden soll derart ,Ausuferungen des Selbstbestimmungsbegriffs“, die „nur die verstärkte Isolation des reinen, autonomen Subjekts zur Konsequenz haben“" würden. ${ }^{294}$,Mündigkeit" wiederum erscheint hier als Fähigkeit des Menschen, ,die Wirklichkeit in seiner Umgebung hinreichend zu erkennen, um aufgrund dieser Erkenntnis zu entscheiden, was er zu tun hat, mit andern Worten: welcher Anspruch an ihn in dieser gegebenen Situation gestellt ist“" ${ }^{295}$ Sie tritt damit als Kompetenz auf, sich in gegebenen Situationen und in der Welt generell anspruchsad-

${ }^{285}$ Kerstiens, Filmerziehung, 5
286 Kerstiens, Filmerziehung, 5
287 Kerstiens, Filmerziehung, 5
288 Kerstiens, Filmerziehung, 5
289 Kerstiens, Filmerziehung, 5
290 Kerstiens, Filmerziehung, 5
291 vgl. Kerstiens, Erziehungsziele, 9-16, 177-182
292 vgl. Kerstiens, Erziehungsziele, 148-153; statt dem Adjektiv ,gültig' nimmt Kerstiens nun ,erfüllt', ,eigentlich' und ,voll', die weniger normativ zu sein scheinen. Sie werden jedoch sofort als Gegensatz zum ,verfehlten Menschsein' benannt und lassen erkennen, daß ihre normative Funktion dieselbe geblieben ist. (vgl. ebd. 148)

${ }^{293}$ vgl. Kerstiens, Erziehungsziele, 180

${ }^{294}$ Kerstiens, Erziehungsziele, 181

295 Kerstiens, Erziehungsziele, 182 
äquat zu verhalten. Dafür scheint zwar eine gewisse subjektive ,Selbstsicherheit‘ nötig, die eine ,Durchsetzung des erkannten Handlungsauftrags ermöglicht, doch entsteht dieser Auftrag aus dem ,subjektexternen' Anspruch. ${ }^{296}$ Die ,Durchsetzung dient so nicht den eigenen Zielen des Subjekts, sondern den von außen an es herantretenden ,Ansprüchen'.

Mit der vorliegenden Argumentationsfigur wird so zunächst der prinzipielle Ansatz der pädagogischen Ethik weiter verdeutlicht. Nachdem die Maxime des Doppelprinzips das ,gültige Menschsein' als oberstes ethisches Ziel sowohl der menschlichen Existenz als auch der Pädagogik übergeordnet und derart beide auf dieses Ziel verpflichtet hat, wird nun der Pädagogik zusätzlich der Auftrag der Befähigung zu diesem Ziel verbindlich zugewiesen und werden derart die pädagogischen Anstrengungen grundsätzlich charakterisiert. Primäre verpflichtende Aufgabe der Pädagogik ist die Befähigung zum ,gültigen Menschsein'. Die Verpflichtung wird hierbei vom Doppelprinzip gesetzt und als ethische Verpflichtung gezeichnet. Mit dieser Zeichnung erweist sich die vom Doppelprinzip bedingte pädagogische Ethik der Filmerziehung also zunächst als Befähigungsethik. Sodann wird über die Konstitution des Erziehungsziels des ,Selbstands', das mit der Zielmaxime des ,gültigen Menschseins' verbunden wird, in diese Maxime ein autonomistisches Moment eingebracht. Der Mensch gilt nun als auf ,Eigenständigkeit' hin angelegtes Wesen, das mit seinem eigenen Stand und seiner Mündigkeit erst in den von der Zielmaxime geforderten Stand eintritt. Umgekehrt erscheint dadurch das ,gültige Menschsein' als Menschsein in Autonomie und erhält die Autonomie den Status sowohl einer Möglichkeitsbedingung als auch einer Realisierungsform des ,gültigen Menschseins'. Die Befähigung muß sich demzufolge auf die Herstellung der Autonomie richten und ist zu dieser Herstellung wiederum ethisch verpflichtet. So scheint mit der autonomiebezogenen Ausführung der Maxime des Doppelprinzips also vorerst eine Befähigungsethik grundgelegt, die auf Autonomisierung zielt, und die dadurch dem Subjekt wieder zu seinem Stand verhelfen will.

Mit der Näherbestimmung der Begriffe ,Selbstbestimmung' und ,Mündigkeit‘ wird jedoch dann die Autonomie in einer Weise begrenzt, die letztlich die Auflösung ihrer Kernbedeutung zur Folge hat, und werden die genannten Begriffe gegen ihren ursprünglichen Gehalt redefiniert. Die Befähigungsethik der Filmerziehung enthüllt sich dabei als pseudoautonomes Unterfangen. So wird zunächst betont, daß Mündigkeit und Selbstbestimmung, obschon als ethisch-pädagogisches Ziel formuliert, kein

296 vgl. Kerstiens, Erziehungsziele, 182; Kerstiens spricht dabei in dieser Schrift immer wieder von der Selbstbestimmung als ,freiem Akt' (vgl. etwa ebd. 180). Er scheint so eine autonomiefreundlichere Haltung einzunehmen als in den 60er Jahren und sich trotz Abgrenzung zur emanzipativen Pädagogik deren Autonomieverständnis auch wieder anzunähern. Doch tritt der ,freie Akt' in seinem Text zugleich immer wieder als ein durch Orientierung an präformierten Ansprüchen konstituierter auf und erscheint er so mehr als,Akt freier Zustimmung' zum Vorgegebenen, so daß die Selbstbestimmung letztlich heteronom überformt wird. Auch andere Textpassagen weisen in diese Richtung, etwa, wenn Kerstiens mit Nachdruck auf der Notwendigkeit der vorbehaltslosen ,Zustimmung zur Wirklichkeit' insistiert (vgl. ebd. 154-164) oder sich gegen eine „Pathologie der Kritik“ wendet (vgl. ebd. 113). Obschon sein Text Modifikationen erkennen läßt, setzen sich derart doch die objektivistischen Optionen der 50er und 60er Jahre, die das Subjekt vor präformierte, normativ-ontologische Ansprüche stellen, immer wieder durch. 
,oberstes' Ziel und kein ,Selbstzweck' sein könnten. Sie werden auf diese Weise implizit als auf andere Ziele und einen übergeordneten Zweck hingeordnet skizziert, von denen her sie ihre Funktion und wohl auch ihre Legitimität erhalten. Explizit ausgeführt wird diese Hinordnung dann mit der Definition, daß Mündigkeit und Selbstbestimmung sich als Erkenntnis- und Entscheidungsfähigkeit realisierten, mit der ,Ansprüche' und ,Aufgaben' der ,Wirklichkeit' wahrgenommen, übernommen und erfüllt würden. Damit ist der übergeordnete Zweck der beiden genannt und als Aufgaben- und Anspruchserfüllung festgelegt. Obschon der Wirklichkeitsbegriff hierbei noch nicht näher entfaltet wird und außerdem unklar bleibt, ob es sich bei den Aufgaben und Ansprüchen um sittliche oder sachliche handelt sowie ob Sittlichkeit und Sachlichkeit interagieren (vgl. dazu weiter unten), erhalten diese Ansprüche und Aufgaben durch ihre Zuordnung zur Wirklichkeit jedenfalls einen subjektexternen, objektivistischen Status. Sie treten als vorgegebene Anforderungsmuster dem Subjekt gegenüber und nehmen es derart in Dienst. Die Entscheidungsfähigkeit des Subjekts, in der sich seine Mündigkeit realisieren soll, ist damit in eine Obödienz transformiert, zumindest jedoch auf eine Zustimmungs- oder Ablehnungsfähigkeit reduziert. Mündigkeit und Selbstbestimmung aber erscheinen in dieser Zeichnung als reaktive und responsorische Kompetenzen, die dem Zweck der Weltbewältigung unter anspruchs- und forderungshaften Prädispositionen dienen und das Individuum zum In-der-Welt-sein befähigen. Sie treten einzig als Haltungen der Entsprechung und Orientierung an vorgegebenen Forderungen und subjektextern gesetzten Zwekken auf. Auf diese Weise werden sie in einen objektivistischen Rahmen gespannt und derart äußerst begrenzt. Im Hintergrund scheint die Vorstellung zu stehen, daß aus einer freigesetzten Selbstbestimmung nur ein ,Running wild' des Handelns sowie aus der losgelassenen Mündigkeit blanke Willkür hervorgehen könne und da $B$ aus diesem Grund die menschliche,Anlage ${ }^{`}$ zum eigenen, mündigen Stand kein ,oberstes Ziel' oder ,Selbstzweck' sein dürfe.

Mit einer solchen Definition und Begrenzung freilich ist die Kernbedeutung von Autonomie aufgelöst und der ursprüngliche Begriffsgehalt von Mündigkeit und Selbstbestimmung redefinitorisch unterlaufen. In der Tat nämlich realisiert sich Autonomie in ihrem Kerngehalt erst durch die eigenständige Zwecksetzung und die ,Selbstgesetzgebung' des Subjekts. Sie meint die Fähigkeit zur Konstruktion von Verhaltensnormen und -anforderungen, nicht aber zur Erkenntnis und Befolgung vorgegebener Anspruchsmuster. Ebenso bedeuten die Begriffe ,Mündigkeit' und ,Selbstbestimmung' eigentlich die Fähigkeit eines Subjekts, seine ,Aufgaben' selbst zu setzen und ,Ansprüche' (an sich und die ,Wirklichkeit') zu stellen. Sie erschöpfen sich gerade nicht in der Entdeckung und Erfüllung prädisponierter, ,objektiver' Aufgabenstellungen einer vorgegebenen Realität, sondern finden ihr Wesen erst in der kreativen Etablierung neuer Wirklichkeit und zielen derart auf ein aktives, ,sponsorisches' Verhalten. Mündig ist nicht, wer sich in der Welt ihren Prädispositionen gemäß, sondern wer sich zur Welt mit eigenen Prädispositionen verhalten kann, und selbstbestimmt ist, wer seine Prädispositionen selbst setzt. Damit sind ,Mündigkeit' und ,Selbstbestimmung' durchaus ,Selbstzwecke', insofern sie nämlich ihre Aufgaben und Zwecke selbst schaffen. Sie sind andere Begriffe für Autonomie und finden mit dieser erst ihren begrifflichen Kern. Werden sie hingegen vorgegebenen Aufgaben, d.h. anderen Zwecken, grundsätzlich unterstellt, so verlieren sie, ebenso wie die Auto- 
nomie, zusammen mit der Möglichkeit selbständiger Zwecksetzung ihre ursprüngliche begriffliche Bedeutung. Etabliert ist mit ihrer Redefinition stattdessen eine Pseudoautonomie, die verbal auf Autonomie abhebt und diese dabei mit einer heteronomistischen Semantik aushöhlt.

Auf diesem Hintergrund zeigt sich jetzt der befähigungsethische Ansatz der Filmerziehung als pseudoautonomer und werden nun auch Charakter und Zielrichtung des Konzepts des ,gültigen Menschseins' deutlicher. Befähigt werden nämlich soll zu einer Kompetenz der Einordnung, Reaktivität und Anspruchserfüllung, durch die dann das ,gültige Menschsein' als erreicht gilt. Ziel der Befähigung ist nicht das autonome Subjekt, sondern das kontextbestimmte Individuum, das sich durch Obödienz und nicht durch Stellungnahme als ,mündig‘ erweist. Damit zeigt sich auch das ,gültige Menschsein' als pseudoautonome Konstruktion. So wurde es zwar zunächst als in der Mündigkeit und Selbstbestimmung bzw. durch diese erreicht und realisiert gezeichnet und erhielt es derart ein autonomistisches Moment. Gleichzeitig aber galten die beiden Begriffe erst durch ihre heteronomistische Begrenzung und Redefinition der Zielmaxime recht zugeordnet und galt das ,gültige Menschsein' als erst hierdurch gewonnen. Das autonomistische Moment, das von den beiden Begriffen in die Zielmaxime eingebracht schien, wird auf diese Weise gewissermaßen begriffschirurgisch daraus sogleich wieder entfernt und das Konzept pseudoautonom gewendet. Das ,gültige Menschsein' entsteht nun ebenfalls durch Orientierung an prädisponierten Ansprüchen und Forderungen und bemißt sich aus seiner Adäquanz gegenüber subjektextern gesetzten Zwecken.

Auf diese Weise aber ist mit ihm zum einen der pseudoautonome Ansatz von der pädagogischen Ethik jetzt auch in die generelle Ethik übertragen und zum anderen eine Kontraststellung zur neuzeitlichen Subjektautonomie bezogen. Einmal nämlich gelten die Orientierung an und Befolgung von subjektexternen Ansprüchen nun nicht nur als ethische Ziele für die pädagogische Befähigungsleistung, sondern auch als sittliche Verpflichtung für das Individuum, das das ,gültige Menschsein' erreichen will. Die Erfüllung der ,Aufgaben' und ,Ansprüche' ist jetzt von der Zielmaxime her generell sittlich geboten. Der allgemeine ethische Entwurf aber ist damit ebenfalls auf die pseudoautonome Bestimmung von Mündigkeit und ihre Verhaltensnormierung festgelegt und kann keine davon abweichende Bestimmung vornehmen. Angesetzt ist so über die pädagogische Befähigungsethik hinaus ein allgemein pseudoautonomes Ethikkonzept. Zum anderen ist mit dieser Pseudoautonomie des gültigen Menschseins' die modernitätskritische Haltung Keilhackers gegenüber der Subjektautonomie filmerzieherisch fortgeführt und der Versuch unternommen, eine Kontrastkonstruktion zu diesem Konzept einzurichten. Statt der ,einsamen', ,im Leeren hängenden' Subjektautonomie und ihrer (wohl mit den ,Ausuferungen' supponierten) Willkür soll hier eine gewissermaßen weniger ,gefährdete' Form menschlicher Existenz erreicht werden, die sich gerade durch eine Bereitschaft zu heteronomer ,Einordnung und Bestimmtheit auszeichnet und die derart die Erfüllung der ,objektiven' Aufgaben sichert sowie der Gefahr der Hybris entgeht. Die Kontraststellung ist dabei nicht nur eine Implikation, sondern zugleich eine zentrale Intention der Konzeption des ,gültigen Menschseins', wie die Wendung gegen die ,emanzipative Pädagogik' und die explizite Negativwertung der Subjektautonomie als ,Isolation' belegen. Damit wiederum bezieht die Maxime des Doppelprinzips eine durch ihre 
Pseudoautonomie zwar camouflierte, jedoch erkennbare kontramoderne Grundstellung und wird ihr Entwurf des ,gültigen Menschseins' bereits auf dieser prinzipiellen Ebene als Versuch deutlich, das Kernstück des Projekts der Moderne durch ein ,eigenes', projektiertes Kernstück zu ersetzen. Der modernitätskritische Impetus setzt sich derart fort und bringt eine Art ,alternatives' Konzept zu dem des autonomen Subjekts hervor.

Mit der Maxime des Doppelprinzips und der ihr beigegebenen Bestimmung von ,Mündigkeit 'ist also sowohl ein deontologisches Prinzip an die Spitze des generellen und des pädagogischen Ethikentwurfs gesetzt als auch die neuzeitliche Autonomisierung ausgehöhlt und ein letztlich kontramoderner Entwurf projektiert. Die Autonomieproblematik ist diesmal schon auf der obersten Theorieebene angegangen. Gleichzeitig ist damit aber ein jeweils spezifisches Verhältnis zu den Autonomiepessimismen der beiden Devianzkritiken etabliert, das noch genauer betrachtet werden muß. Zunächst zeigt sich das pseudoautonome Konzept als durchaus kohärente Antwort auf den anthropologischen Pessimismus der ersten Devianzkritik, der ja bereits eine autonomiepessimistische Grundoption darstellt. Nicht nur, weil bei einer ,reinen` Verwirklichung der, Anlage‘ des Menschen auf ,Eigenständigkeit' hin anscheinend eine Art Willkür droht, kann Autonomie nicht ,Selbstzweck' sein, sondern auch, weil die vielen anderen,Anlagen' der anthropologisierten Negativa diese Willkür sogleich in eine antimoralische zu überführen drohen. Der pseudoautonome Ansatz fügt sich also schlüssig an diese anthropologische Option an. Ein Widerspruch jedoch scheint zur zweiten Devianzkritik gegeben zu sein. Dort wurde eine autonomiepessimistische Haltung bezogen, die das Individuum als tendenziell unfähig zur Auswahl und zum Entwurf sowie als mit einer Inklination zur Fremdbestimmung ausgestattet definierte. Während die ersten beiden Momente des Autonomiepessimismus zwar noch kohärent zur vorliegenden pseudoautonomen Konstruktion sind, mutet das letztgenannte eigenartig an. So ist es zwar schlüssig, ein überfordertes, wahl- und entwurfsunfähiges Subjekt in einen vorgegebenen Rahmen einzuordnen, doch wirkt es zunächst widersprüchlich, dann andernorts die Neigung des Subjekts zur Anpassung und Einordnung zu kritisieren. Bei näherem Zusehen aber erweist sich dieser Widerspruch als scheinbarer. Kritisiert wurden ja die Anpassung an das ,Man' und die ,Uniformierung' durch Orientierung an Idolen, während der pseudoautonome Ansatz auf ,Ansprüche' und ,Anforderungen' abhebt, deren Erfüllung einem ethischen Ziel dient. Nicht um Uniformierung geht es hier, sondern um Aufgaben, die mit dem Charakter der Notwendigkeit und Gebotenheit ausgestattet sind. Konstituiert werden derart zwei verschiedene Leitungsangebote, deren eines (das ,Man') als illegitim und deren anderes (die ,Ansprüche') als legitim gehandhabt werden. Die Unterordnung unter das zweite und die Übernahme der Aufgaben sind dann für ein autonomiepessimistisch definiertes Subjekt durchaus anzustreben. Darüber hinaus zeigt sich das als mit einer unvermeidlichen Inklination zur ,Außenleitung' ausgestattete Individuum aus ethischem Gesichtswinkel ebenso unvermeidlich als leitungsbedürftiges. Gerade, weil es diese Inklination besitzt und zu rein' autonomem Verhalten unfähig ist, bedarf es um des ethisch legitimen Verhaltens willen der Vorgaben. Auch aus dem Autonomiepessimismus der zweiten Devianzkritik geht so der pseudoautonome Ansatz schlüssig hervor. 
Der Ansatz der Rückgewinnung von Moralität: Erkenntnistheoretische Einführung des Zwei-Welten-Konzepts

Unklar jedoch bleiben noch die Herkunft der ,Ansprüche' und der Realitätsbegriff. Wo die Normativität verankert ist, wie sich Sittlichkeit und Wirklichkeit sowie wie sich Sittlichkeit und Sachlichkeit zueinander verhalten, muß noch genauer geklärt werden, wenn die Konstitution der Moralität des Subjekts deutlich werden soll. Mit dem Ansatz auf der Prinzipienebene allein ist sie noch nicht präzise genug gewonnen. Die Filmerziehung versucht daher, unterhalb der Prinzipienebene, jedoch freilich in Rückbindung an sie, die Moralität, ihre Herkunft und ihren Charakter näher zu beschreiben. Hierbei werden jetzt die Theoreme und Paradigmen Keilhackers treu tradiert und ausgezogen. Gleichzeitig wird der pseudoautonome Ansatz der Prinzipienebene weiter ausgeführt und werden über eine Klärung des Wirklichkeitsbegriffs sowohl die Heteronomie als auch die Herkunft und der Charakter der Normativität genauer gefaßt. Eingeführt ist dies zunächst bei Kerstiens, der mit einer Art erkenntnistheoretischer Prämisse den Angelpunkt der Moralität in der ,Wertung sieht und derart auf das wertphilosophische Paradigma Keilhackers rekurriert. $^{297}$,Werten' gilt hierbei vorerst als konstitutiv für das, Verstehen' insbesondere von Handlungen, die ohne ,Wertung offenbar unverständlich und rätselvoll bleiben. ${ }^{298}$ Durch das ,Werten' erst wird demzufolge ,Realität' erkennbar und begreiflich. Darüber hinaus aber gilt es als notwendig, um die ,Realität' in einer Weise aufzufassen, die dem Verfall in Amoralität wehrt. Ohne ,Wertung' nämlich sieht Kerstiens die Gefahr einer Gewöhnung daran, ,alles hinzunehmen wie es ist“. ${ }^{299}$ Aus dieser Gewöhnung scheint dann eine „sittliche Gleichgültigkeit, die das Wirkliche mit dem Sittlichen verwechselt", hervorzugehen und die Moralität nicht nur nicht gewonnen, sondern geradezu zerstört zu werden. ${ }^{300}$ Damit aber scheint der Mensch zugleich seine Bestimmung, d.h. das ,gültige Menschsein` zu verfehlen. Als „wichtigste Aufgabe des Menschen" nämlich gilt es, die Realität "dem sittlichen Maßstab gemäß" aufzufassen und ,einzuordnen' ${ }^{301}$ Keinesfalls könne daher das „Verstehen aus weiteren Zusammenhängen“ das ,Werten' ersetzen, ,mag auch die Verführung dazu sehr hoch sein“" ${ }^{302}$ Um dieser ,Verführung', beim, Verstehen' Halt zu machen und derart auf die abschüssige Bahn einer Verwechslung von Realität und Sittlichkeit zu geraten, prinzipiell zu wehren, betrachtet es die Filmerziehung als ihre vordringliche Aufgabe, umfassend zur ,Wertung zu befähigen. Entsprechend wird es als herausragende Forderung an den ,Erzieher' eingeführt, „den jungen Menschen davor (zu) bewahren (...), Werten und Verstehen miteinander zu verwechseln", ${ }^{303}$ sowie ihm zu ,helfen', das ,Werten' zu erlernen. ${ }^{304}$

In der vorliegenden Argumentationsfigur fällt nun zunächst ein Widerspruch ins Auge. So erscheint einmal das ,Werten' als Bedingung für die Realitätswahrnehmung

\footnotetext{
297 vgl. Kerstiens, Filmerziehung, 29

298 vgl. Kerstiens, Filmerziehung, 29

299 Kerstiens, Filmerziehung, 29

300 Kerstiens, Filmerziehung, 29

301 Kerstiens, Filmerziehung, 47

302 Kerstiens, Filmerziehung, 49

303 Kerstiens, Filmerziehung, 49

304 Kerstiens, Filmerziehung, 47
} 
schlechthin und ,Realität' derart durch den Akt des ,Wertens' erst konstituiert. Ohne ,Wertung bleibt sie hier, streng genommen, unerkennbar. Zum anderen aber wird ,Werten' als eine Art ,Grundakt' des Sittlichen gehandhabt, durch den Moralität entsteht und diese Moralität dann der Realität kontrastiv gegenübergestellt. Die Wirklichkeit tritt jetzt als durchaus erkenn- und verstehbare auf und wird als mit einem Gefälle zur Amoralität ausgestattet gezeichnet. Auf diesem Hintergrund werden dann ,Werten' und ,Verstehen' kontrastiert und das ,bloße‘ Verstehen als Gefährdung angesetzt. Obschon unter der ersten Prämisse ein Amoralität erzeugendes Verstehen gar nicht möglich ist, gilt es im zweiten Fall als durchaus mögliche, korrekturbedürftige Verfallsinklination. Dieser Widerspruch läßt sich nur dahingehend auflösen, $\mathrm{da} B$ die zentrale Intention des Arguments von vorneherein in der Illegitimisierung einer ,Wertneutralität" bestand und mit der Konstitution der Realitätsauffassung durch die ,Wertungt die rechte, zulässige Konstitution, kaum aber die Konstitution schlechthin, gemeint war. Absicht des Arguments ist es, ein ,wertfreies' Realitätsverständnis auszuschließen, da dies als äußerst prekär gilt. Dem Grad dieser Prekarität entsprechend scheint es notwendig, immer sogleich nicht nur eine Ergänzung, sondern geradezu die Überformung des, Verstehens' durch die ,Wertung' zu fordern. Einzig auf diese Weise gilt die Wirklichkeit als in der ,richtigen' Weise ,verstanden', und einzig dadurch scheint es möglich, die unter den Bedingungen der modernen Welt verlorengegangene Moralität umfassend genug zurückzugewinnen. Damit läßt die Figur nun zugleich einen deutlichen Rückbezug zu Keilhacker erkennen. Ihre grundsätzliche, erkenntnistheoretisch eingeführte Ablehnung der Wertneutralität nämlich gleicht dessen Verwahrung gegen die, Theorien der Wertfreiheit', die freilich dort kulturtheoretisch auf die Naturwissenschaften zurückgeführt und derart in ihrer Herkunft zusätzlich begründet wurden. In beiden Fällen jedoch scheint die ,Wertneutralität' prekär zu sein und wird aus ihr die Gefahr eines Verfalls jeglicher Moralität deduziert sowie die Notwendigkeit der, Wertung betont.

Die Form der Wertung und die dadurch erfolgende Restitution der Moralität werden dann in der vorliegenden Argumentation mit einer spezifischen Dichotomie ausgeführt, die ebenfalls bereits bei Keilhacker vorhanden ist. Auf diese Weise wird zugleich das Verhältnis von Sittlichkeit und Wirklichkeit festgelegt und der Wirklichkeitsbegriff genauer gefaßt. So ist mit der Kontrastierung von ,Werten' und,Wirklichkeit‘ erneut eine Sein-Sollens-Dichotomie etabliert und zunächst das Verhältnis von Realität und Moralität bestimmt. Dabei zeigt bereits die Entgegensetzung von ,Verstehen' und wertend erzeugter Moralität, da $\beta$ der Realität offenbar keinerlei sittliche Entelechie und Bedeutung innewohnt und ein Konnex von ,Verstehen' und ,Werten nicht angenommen wird. Das wird dann durch die Unterstellung eines tendenziell amoralischen Charakters der Realität noch verschärft und derart eine eher unsittliche Entelechie angesetzt, der moralisch entgegengewirkt werden muß. Nicht nur eignet der Realität jetzt kaum eine moralische Relevanz - bzw. genauer: kaum eine Relevanz für die Konstitution von Moralität und Normativität - sondern Moralität erweist sich als korrektive Kontrastkonstruktion, die der Realität extern ist und erst durch wertende Überformung des Realen zustandekommt. Der Realitätsbegriff zeigt sich als Gegenbegriff zu dem der Sittlichkeit, und die Wirklichkeit kann aus sich selbst heraus keinen sittlichen Anspruch stellen, sondern muß sich diesem unterordnen. 
Damit aber können zum einen auch die normativen Bestände für diese Überformung, die hier als anzulegende ,Maßstäbe' ei-geführt sind, nur noch aus realitätsexternen, ja -konträren Bereichen kommen. Mit der Etablierung der Sein-SollensDichotomie errichtet die Argumentationsfigur also zugleich den Gegensatz einer ,neutralen Wirklichkeit' und ,moralischen Sphäre' und deutet sie so auf den Antagonismus zweier Welten, einer kontingent-empirischen Wirklichkeit und einer ,Wertewelt', hin, wie er bereits bei Keilhacker paradigmatisch geschaffen ist. Zum anderen ist nun deutlich, wie sich Sittlichkeit und Wirklichkeit in der Mündigkeitsdefinition zueinander verhalten, bzw. genauer: wie die dort aufgeführten ,Ansprüche' zu verstehen sind und woher ihre Normativität kommt. Die Bestimmung des Wirklichkeitsbegriffs durch das vorliegende Argument und die erkenntnistheoretische Prämisse nämlich lassen nur zu, diese ,Ansprüche', so sie sittlich verpflichtend sein sollen, als die einer bereits normativ moralisch aufgefaßten und überformten Realität $\mathrm{zu}$ verstehen. Das bedeutet weiter, daß auch Sachnotwendigkeiten nicht mit einem sittlichen Anspruch auftreten können. Obschon im Realitätsbegriff der Mündigkeitsdefinition 1.och unklar bleibt, ob es sich bei den ,Ansprüchen' und Zwecksetzungen der Wirklichkeit um sittliche oder sachbezogene handelt, ob also moralische Erfordernisse und Gebotenheiten oder Notwendigkeiten aus Sachgründen im Blick sind, wird aus dem Vorliegenden deutlich, daß die eigentlich sittliche Anspruchsdimension realitätsextern, ja -konträr zustande kommt. Den sittlichen Anspruch stellt exklusiv eine ,moralische Sphäre', nicht aber die ,neutrale Wirklichkeit'. Das Doppelprinzip ordnet damit zwar das Subjekt den Ansprüchen einer ,Realität' unter und statuiert diese Unterordnung als moralisch gebotene, doch kann es sich bei dieser Realität, wo sie eine sittliche Forderung stellt, jetzt letztlich nur mehr um die ,moralische Sphäre' handeln. Darüber hinaus kann es durchaus (allgemein) sittlich geboten sein, Sachnotwendigkeiten zu folgen (und derart die Autonomie beschränkt werden), doch verleiht das diesen selbst noch keinen sittlichen Charakter. Sittlichkeit und Sachlichkeit bleiben unter der Sein-Sollens-Dichotomie grundsätzlich auseinandergehalten, und die Sachdimension kann keinerlei Einfluß auf die sittliche beanspruchen. Ebenso bleiben das ,Man' und die ,Idole' aus der sittlichen Anspruchsdimension ausgeschlossen. Ihr Leitungsangebot liegt auf der Ebene der Mode und ist selbst der ,moralisch aufzufassenden' Realität zuzuordnen, d.h. aber der sittlichen Normierung zu unterwerfen. Eine unmittelbare Orientierung an diesen Wirklichkeiten hingegen gilt der Devianzkritik gemäß als Verfall und illegitim. Das im Unterschied zum ,Man' legitime Leitungsangebot stellt einzig die ,moralische Sphäre', und die Forderung der Unterordnung und Entsprechung bezieht sich letztlich exklusiv auf diese.

Die Rückgewinnung der Moralität des Subjekts aber geschieht so nun auf eine doppelte Weise: Zum einen etabliert das Subjekt seine Moralität durch Orientierung an den Maßstäben der ,moralischen Sphäre', d.h. durch Unterordnung unter deren Normativität, und zum anderen findet es sie in der Anwendung dieser Maßstäbe auf die Wirklichkeit. Diese Gewinnung der Moralität ist dabei, wiederum im Unterschied zu Keilhacker, prinzipiell rückgebunden und selbst ein ethisches Erfordernis. Auf dem Hintergrund ihres prinzipienethischen Ansatzes bleibt es für die Filmerziehung nicht allein bei der Forderung einer ,Wertewelt', sondern gerät erneut sowohl das Subjekt als auch die Pädagogik unter eine grundsätzliche ethische Verpflichtung. Das vorliegende Argument läßt diese Perspektive im Hintergrund wahrnehmen, wenn es 
die wertende Gewinnung von Moralität als ,wichtigste Aufgabe‘ des Menschen zeichnet. Zugleich freilich ist es auf diesem Hintergrund auch eine zentrale Aufgabe der Pädagogik, die nun alles in ihren Kräften stehende zu tun hat, um das Subjekt zum moralischen Verhalten zu befähigen. Die Ethik der Filmerziehung zeigt sich damit aus diesem Blickwinkel erneut als Befähigungsethik: Die Befähigung zum sittlichen Handeln ist selbst nochmals ethisch geboten und stellt sich als prinzipielles Erfordernis um der Erreichung der Zielmaxime des, gültigen Menschseins‘ willen dar.

Schließlich wird darin noch die pseudoautonome Option wieder spürbar. So tritt das Subjekt zunächst keineswegs schon als sittliches oder zur Sittlichkeit bereits befähigtes auf, sondern exklusiv als sittlichkeitsbedürftiges. Eine vorhandene moralische Potenz wird in dem vorliegenden Argument durchaus nicht genannt oder angenommen, vielmehr müssen alle Maßstäbe erst gelernt und vermittelt werden. Ebenso wie der Realität ist die Moralität auch dem Subjekt vorerst einmal extern und bedarf dieses einer entsprechenden ,Überformung. Die Notwendigkeit einer solchen Überformung leitet sich wiederum nicht nur aus der ,Zielgruppe' der Pädagogik her, die aus Kindern und Jugendlichen besteht, sondern ruht zugleich auf einem darunter fühlbaren, bewahrethischen Zug auf. So wird explizit davon gesprochen, daß vor einem Fehlverständnis der Realität als schon sittlicher ,bewahrt' werden müsse. Ein solches, etwa hedonistisches Fehlverständnis scheint dabei dem ,unbearbeiteten Wesen' der zu Befähigenden durchaus nahezuliegen. Auch die Insistenz auf der Dringlichkeit und der herausragenden Rolle der Moralerziehung, die ja als eines der zentralen Aufgabengebiete der Pädagogik in der Filmerziehung erscheint, verweist in diese Richtung. Vor allem aber unterstreicht der anthropologische Pessimismus der Devianzkritik, daß in der Befähigungsethik kaum eine sittliche Eigenpotenz der zu Befähigenden anzunehmen ist. In Entsprechung hierzu ist außerdem die Form der Moralitätsgewinnung, also das ,Werten', ebenfalls nicht als eine norm- bzw. maßstabssetzende Leistung des Subjekts, sondern eine Leistung der Befolgung und Anwendung von vorgegebenen Normen gedacht. Die Pseudoautonomie des ethischpädagogischen Ansatzes wird so fortgeschrieben.

\section{Die Formalstruktur der, moralischen Sphäre‘}

Sowohl die Realitätsexternität der moralitätskonstitutiven ,Maßstäbe als auch die pseudoautonome, heteronomistische Grundstellung der filmerzieherischen Ethik bestätigt sich dann aus der Formalkonstruktion der ,moralischen Sphäre', die sich auch bei den Filmerziehern als eigenständige, empirieunabhängige und aller Kontingenz enthobene ,Werte-' und Normenwelt darstellt. Sie bildet einen Fundus von ,Wertmaßstäben', der erst die ,wertende Auffassung von Wirklichkeit' und damit die Konstitution der Moralität ermöglicht. Bei der Charakterisierung dieser Maßstäbe lassen die Filmerzieher wie Keilhacker nun von vorneherein keinen Zweifel daran, daß es sich hierbei um unverrückbare, überzeitliche Größen handelt. Wie der Schulgründer entwerfen sie einen ,Werte-' bzw. Normenkosmos, dessen Formalstruktur ontologisierend konstruiert wird. So betont Wasem knapp und unumwunden, da $\beta$ es für das ,Werten“ eines „,absoluten Wertmaßstabs“ bedürfe. ${ }^{305}$ Genauer führt dann Kerstiens diese Absolutheit aus, wenn er darauf insistiert, „daß das Maß überhaupt nicht durch

${ }^{305}$ Wasem, Jugend, 63 
Menschenwillkür oder Mode gesetzt oder geändert werden kann, sondern absoluten Charakter hat " ${ }^{306}$ Dieser ,absolute Charakter" wird dann nicht nur behauptet, sondern ontologisch verankert. So sieht Kerstiens die „gültigen Maßstäbe“ als in der „Ordnung der Welt“ begründet, ${ }^{307}$ nennt er sie die in der „Weltordnung gegründeten Maßstäbe des Sittengesetzes“308 und führt er sie als erfahrungsenthobene und letztlich auch zeitenthobene aus. ${ }^{309}$ Wasem wiederum stellt zwar einen Bezug zwischen den ,Wertmaßstäben' und kulturellen Spezifika her, wenn er fordert, da B, ,was in unserem Kulturkreis allgemein als gut oder schlecht erachtet“ werde, „im Film nicht verkehrt sein" dürfe ${ }^{310}$ Doch verweist er zugleich darauf, daß diese Forderung am besten dort erfüllt sei, ,wo klare und überzeugende Wertmaßstäbe gesetzt“ seien, und die "gemeinte überwirkliche Sinnbedeutung einer Situation" erkennbar werde. ${ }^{311}$ Die zunächst kulturell verankert scheinenden ,Wertmaßstäbe finden sich so schnell wieder der Wirklichkeit entzogen und mit einer ,überwirklichen Bedeutung konnotiert. Die ontologische Prädisposition der ,Wertmaßstäbe' hat dann freilich zur Folge, da $B$ mit ihnen eine Idealmoral konstituiert wird, die nur durch stetige Anstrengung angezielt, kaum jedoch vollständig erreicht werden kann. Entsprechend betont Tröger "den status viatoris, das nie abgeschlossene Unterwegssein des Menschen, der nie, vor allem nicht in der moralischen Entwicklung, sagen kann: ich bin fertig “. ${ }^{312}$ Um diese Entwicklung zu fördern und die Wirksamkeit bereits erkannter Maßstäbe zu sichern, gilt es hierbei als günstig, sie emotional zu verankern. Auf diese Weise scheint es möglich, einen bereits erreichten Stand auf dem Weg zur Idealmoral zu festigen. So weist Tröger wiederholt auf die Notwendigkeit dieser emotionalen Verankerung hin. ${ }^{313}$ Ähnlich insistiert auch Schubert auf der Notwendigkeit einer empfindungsorientierten, Wertvermittlung, die mehr Erfolg zeitige als eine kognitiv-rationale. ${ }^{314}$ Dabei scheinen die ,Werte' eine besondere Affinität zum ,Bildhaften' und ,Symbolischen' zu besitzen und sich über diese am nachhaltigsten zu realisieren. ${ }^{315}$

Die Formalstruktur der ,moralischen Sphäre‘ zeigt sich damit zunächst als Parallelkonstruktion zu der des Wertekosmos bei Keilhacker. Sie bestätigt derart die Realitätsexternität der in ihr enthaltenen ,Maßstäbe' und konstituiert eine,zweite Welt ${ }^{\star}$ der Normen und Werte, die der, ersten Welt' der kontingenten, geschichtlichen und

${ }^{306}$ Kerstiens, Filmerziehung, 36

307 Kerstiens, Filmerziehung, 36

308 Kerstiens, Filmerziehung, 35

309 Kerstiens, Filmerziehung, 35

${ }^{310}$ Wasem, Jugend, 73

311 Wasem, Jugend, 73

312 Tröger, Film, 188; der Passus wird zwar dort nicht im Zusammenhang mit der ,Wertewelt' geäußert, sondern in Auseinandersetzung mit dem, psychologischen Verständnis' für unmoralische Handlungen in Filmen, das zwar erstrebenswert, aber zugleich als Bedrohung für die ,Klarheit des moralischen Urteils' erscheint. Mit der Voraussetzung eben dieser an unumstößlichen Maßstäben ausgerichteten ,Klarheit', die schwer erreichbar und allzuoft vom ,psychologischen Verständnis' kontingenter und empirischer Handlungsbedingungen bedroht scheint, basiert der Text ebenfalls auf der Vorstellung einer ,Idealmoral', die nur approximativ und strebend erreicht werden kann.

313 vgl. Tröger, Film, 169, 171

314 vgl. Schubert, Filmgespräch, 35-36

315 vgl. Schubert, Filmgespräch, 36 
veränderlichen Realität entgegengesetzt werden kann. Entsprechend bietet sich die ,moralische Sphäre' als Hort absoluter Normativität dar, der jeder Zeitbedingtheit, allen Empiriebezügen und jeglicher subjektiven Einflußnahme entzogen ist. So sollen weder ,Mode' noch ,Menschenwillkür' Einfluß auf die Normkonstitution nehmen können und wird diesen die Unveränderbarkeit des vorgegebenen ,Maßstabs' gegenübergestellt. Auch Empiriebezüge aber sind ausgeschlossen. Zwar nennt Kerstiens die ,Maßstäbe' als in der ,Weltordnung' gegründete, doch zielt dies nicht auf eine Verklammerung mit empirischen Gegebenheiten, sondern auf Ontologisierung und Exklusion des Empiriebezugs. Die, Weltordnung tritt als normative Vorgabe für die ,Welt' auf und soll der letztgenannten ihre moralische Idealkonstruktion vorzeichnen, nicht aber wird sie aus den Strukturen der empirischen Welt erhoben. In der Tat ließe die Sein-Sollens-Dichotomie eine solche Erhebung auch nicht zu. Sachbezüge sollen für sittliche keine Relevanz besitzen, sondern der sittlichen Normativität unterworfen werden. Damit aber bleibt die ,moralische Sphäre' realitätsextern und zeigt sie sich in ihrer ,Überwirklichkeit' auch als transkulturelle sowie transdiskursive Sphäre. Zwar hebt Wasem kurz auf eine Kulturspezifität ab, doch werden die Maßstäbe durch ihren ontologischen Status der kulturellen Kontingenz rasch wieder enthoben und sowohl als überzeitliche als auch als universale gehandhabt. Die Formalkonstruktion bestätigt so die aus der Rekonstruktion der Devianzkritik hervorgegangene Vermutung, da $B$ die Moralität nicht auf einer kontingenten, kulturellen Konstruktion beruht, bzw. keine solche Konstruktion ist, sondern weniger veränderungsund ,störungsanfälligen' Bereichen entstammt. Diese Bereiche sind dann in dieser Form auch nicht mehr durch einen Diskurs erreichbar und sollen es wohl auch nicht sein. Bereits die Devianzkritik hat ja gezeigt, daß dem Diskurs keine Potenz für die Herstellung der Sittlichkeit und der ,rechten' Normativität zugetraut wird. Die ,rechten' Normen und Werte können entsprechend nur jenseits diskursiver Zugänglichkeit und insbesondere jenseits diskursiver Veränderbarkeit angesiedelt werden.

Mit dieser Charakteristik des Werte- und Normenkosmos sind nun auch die Deontologie und Pseudoautonomie des Ethikansatzes der Prinzipienebene fortgeführt bzw. nochmals unterstrichen. War schon oben erkennbar, daß sich Moralität durch Orientierung an und Anwendung von realitätsexternen Maßstäben konstituiert, so wird jetzt deren Unantastbarkeit und Unhinterfragbarkeit festgeschrieben. Moralität ist die Frucht ausschließlich der zweiten Welt der ,moralischen Sphärec, die die eigentlich moralischen Anforderungen stellt. Auf diese moralische Realität aber kann das Subjekt jetzt in keiner Weise mehr Einfluß nehmen. Die Möglichkeit einer Normkonstitution durch die menschlichen Subjekte ist nun vielmehr explizit ausgeschlossen, und die normativen Bestände sind jeder Modifikation, Veränderung und Diversifizierung entzogen. Für die Herstellung seiner Moralität ist dem Subjekt daher ein submissiver, obödienter Habitus abgefordert. Es soll (erneut) eine ,Entsprechungsleistung erbringen und sich vorgegebenen Strukturen einpassen, um seine Moralität zu gewinnen. Die Absolutheit der Maßstäbe verleiht denselben außerdem eine deontologische und universale Geltung, so da $B$ mit der Formalkonstruktion eine deontologische Ethik grundgelegt und auch der deontologische Ansatz der Prinzipienebene fortgeführt ist. Gleichzeitig ist hierdurch die Tendenz der Devianzkritik, die für die ,positive‘ Konstruktion von Lösungsmöglichkeiten auf eine objektivistische, deontologische Ethik verwies, konsistent umgesetzt. Das bedeutet weiter, daß mit 
dieser Konstitution von Moralität jeder Ethoswandel und jeder sittliche Fortschritt ausgeschlossen sind. Moralität bleibt die unwandelbare Frucht einer prädefinierten Struktur, die keine Entwicklung oder Evolution kennt. Einzig die Imperfektion der subjektiven Realisierung dieser Struktur bringt noch ein zeitliches Moment in die Sittlichkeit ein, das dann durch stetige Anstrengung auf dem Weg zur zeitlosen Moralität überwunden werden soll. Auch die Möglichkeit von Binnenmoralen, also einer diversifizierten Normativität und des Entstehens von gruppenspezifischen Ethosformen, ist mit diesem Entwurf unterlaufen. Deontologie und Universalität des unwandelbaren, zeitenthobenen Werte- und Normenkosmos setzen vielmehr eine normative, idealmoralische Einheit, der gegenüber jede Divergenz als Defizienz erscheinen muß. Die Moralität besitzt als Frucht der ,moralischen Sphäre' nicht nur eine unbedingte Festigkeit, sondern auch eine unbedingte Geschlossenheit, von der kein Abweichen legitim sein kann.

Ergänzt wird diese Zeichnung der Normativität und der Moralität dann noch durch eine moralpädagogische Strategie, die den befähigungsethischen Auftrag umsetzen helfen soll, sowie durch ein daraus deutlich werdendes, weiteres Charakteristikum der Werte- und Normenwelt. So sollen die Maßstäbe der ,moralischen Sphäre' nicht einfach nur erklärt und informativ vermittelt werden, sondern über symbolische Repräsentanz und Emotionsbezug eine nachhaltigere Einwohnung bei den zu Befähigenden ermöglichen. In der Tat bleibt ein Ethos ohne Empfindung und Emotion ja ebenso leer wie ein Begriff ohne Anschauung. Den emotional verankerten Werten und Normen kann daher eine verläßlichere Wirksamkeit zugetraut werden als den nur ,eingesehenen'. Freilich geht es dabei wiederum nicht um eine echte Beteiligung der Subjekte an der Moralitätskonstitution, sondern nur um die Effizienz dieser Konstitution. Nicht eine Gewinnung von Maßstäben, sondern ihre verläßliche Übernahme ist das Ziel, und eine Einflußnahme auf die Normkonstitution bleibt ausgeschlossen. Die Pseudoautonomie der Befähigungsethik tradiert sich so auch über die moralpädagogische Strategie. Außerdem aber zeigt die Einführung dieser Strategie, daß die Werte- und Normenwelt eine gewisse Affinität zur Emotionalität und zum Symbolischen besitzt. Diese Affinität wirft nun noch ein zusätzliches Licht auf die Transdiskursivität der ,moralischen Sphäre'. So zeigt sich jetzt, daß die Transdiskursivität nicht nur aus der ontologischen Absolutheit der Maßstäbe hervorgeht und derart auf deren Unveränderbarkeit zielt, sondern daB sie auch einer tendenziell transrationalen Strukturierung des Werte- und Normenkosmos zu verdanken ist. Ähnlich wie bei Keilhacker, wenn auch nicht in derselben expliziten Deutlichkeit, erhält die ,moralische Sphäre' aus der moralpädagogischen Strategie einen transrationalen Charakter, der sie in den Stand einer erfühlbaren und symbolnahen Wirklichkeit erhebt. Die Rückbindung an die Wertethik des Schulgründers ist darin noch spürbar, obschon die Filmerziehung auch den (einer rationaleren Ethikkonstruktion zugehörigen) Normbegriff verwendet.

Mit dieser Konstruktion der Werte- und Normenwelt sowie der über sie vermittelten Moralität kann nun nicht einfach nur der veränderlichen geschichtlichen Realität schlechthin, sondern insbesondere auch der modernen Welt sowie den anthropologischen Negativa entgegengetreten werden. Zunächst gewährt die Festigkeit und Unverrückbarkeit der, absoluten Maßstäbe' Sicherheit und Halt angesichts der modernen Dynamisierungsprozesse und des ständigen Wandels von Beziehungsformen, 
Institutionen und subjektiven Ansprüchen. Der prekäre, vor allem in Auseinandersetzung mit dem Sexualisierungsvorwurf mißliebig aufgefallene Ethoswandel und das Begehren der jungen Generation' nach Mitspracherechten bei der diesbezüglichen Gestaltungsnormierung kann jetzt theoretisch konsistent zurückgewiesen und die Forderung nach einheitlicher, obödienter Orientierung ebenso konsistent aufgestellt werden. Auch der moderne Pluralismus ist mit der ontologischen Konzeption eines festgefügten Wertekosmos unterlaufen und auf eine einheitliche moralische Basis rückverpflichtet. Es gibt keine Vielheit divergenter, kulturspezifischer und kontingenter Maßstäbe mehr, sondern nur noch transreale und transtemporale, die jeder Pluralismen schaffenden ,Menschenwillkür' entzogen sind. Außerdem ist damit noch eine Möglichkeit geschaffen, dem Nihilismus des Werteverfalls und dem Materialismus entgegenzutreten. Die überzeitlich strukturierte Wertewelt kann nicht mehr verfallen oder sich als überlebt erweisen und auflösen, sondern nur (mehr oder minder böswillig) verdrängt und verleugnet werden. Sie hat zudem keinerlei Bezug zur Empirie und ihrer materiellen Perspektive, sondern stellt sich als ,geistige' Realität dar, die den empirisch-materiellen Bezügen immer schon mit einem normativen Anspruch übergeordnet ist. Bereits ihre Formalstruktur wehrt so dem Verfall an Empirie und Materialismus. Schließlich sichert sie noch gegen die negativen, anthropologisch erhobenen Inklinationen im Menschen selbst. Da sie jeder Empirie und diskursiven Antastbarkeit enthoben ist, können diese Negativa ebenfalls keinen korrumpierenden Einfluß auf die moralische Realität mehr ausüben, sondern sind vielmehr der Prüfung an deren Maßstab unterworfen. Die negative Latenz des Menschenwesens ist damit nicht bloß durch eine verletzliche, kulturelle Konstruktion in die Schranken gewiesen, sondern stößt an eine ontologisch gesicherte Barriere. Auf diese Weise transportiert sich der bewahrethische Zug der Devianzkritiken über beschneidende Maßnahmen hinaus zusätzlich in eine ,positive' Normativität, die der Zurückdrängung der Latenzen und der Sittlichkeit durch ,konstruktive' Orientierungsvorgaben dient.

\section{Der kontramoderne Charakter der, moralischen Sphäre}

Mit ihrer Zielrichtung gegen die modernen Phänomene des Ethoswandels, der Pluralität, Diskursivität und Autonomie erweist sich die ,moralische Sphäre' dabei nun bereits in ihrer Formalstruktur als kontramoderne Konstruktion. Dieser ihr Charakter bestätigt sich dann auch aus ihrer Materialstruktur, die regressiv ausgeführt ist. So hat schon die Kritikperspektive der Devianzthesen wiederholt darauf verwiesen, $\mathrm{da} ß$ die verlorengehende Normativität eine ,traditionale und vormoderne war sowie, daß die Lösung in deren Resurrektion gesehen wird. In der Tat bestätigt sich das, wie ebenfalls schon in der Devianzkritik wiederholt wahrnehmbar, aus den Äußerungen der Filmerzieher zur Materialität des Werte- und Normenkosmos. So tritt in Margarete Keilhackers Text die ,traditionelle Moral' als Garant der Moralität schlechthin auf und wird auf die ,überkommenen Bindungen und Wertordnungen abgehoben, von denen anscheinend die Gesundung zu erwarten ist. ${ }^{316}$ Kerstiens bemüht im Kontext des Sexualisierungsvorwurfs gar die älteste Form der Normativität, die Sitte, als Garant für die Sittlichkeit. ${ }^{317}$ Wasem nennt „Armut und Keuschheit“ als

316 vgl. Keilhacker, Kino, 96

317 vgl. Kerstiens, Filmerziehung, 51 
nötige Tugenden, um dem Materialismus moralisch entgegenzutreten, und bemüht derart mönchische Orientierungsformen. ${ }^{318}$ Und wiederum Kerstiens schlägt dann noch in den 70er Jahren einen rückwärtsorientierten, tugendethischen Entwurf vor, den er spezifisch in Reaktion auf und in Kontraststellung zu den Defizienzen der modernen Welt konstruiert. Er nennt hierbei die Tugenden eine zwar ,ganz alte, aber im Grunde hoch moderne Lehre ${ }^{\text {"319 }}$ und will die beklagten Devianzerscheinungen des Materialismus, des Nihilismus und des moralischen Verfalls von ihnen geheilt sehen. Tröger schließlich nimmt mit Bedauern zur Kenntnis, daß es keine „so sichere und festgefügte allgemeine Wert- und Lebensordnung wie die des Mittelalters" mehr gebe, und fügt daran an, daß es jedoch unter diesen Bedingungen dennoch darum gehe, ,vom ,alten Wahren“ aus die noch verborgenen Aufgaben der Zukunft zu finden“ “. ${ }^{320}$ Auch hier bildet also die Normativität einer vormodernen ,Wertordnung' zumindest die Basis für die Konstitution der zukünftigen ,Aufgaben', und stellt sie den eigentlichen, materialen Orientierungsrahmen dar.

Die Materialität der ,moralischen Sphäre‘ ist so zwar nicht in derselben Deutlichkeit wie bei Keilhacker, der sich explizit zu einer ,unzeitgemäßen' Rückwärtsorientierung bekannte, kontramodern bestimmt und in ihrer Herkunft regressiv festgelegt, doch läßt sie einen diesbezüglichen Charakter dennoch erkennen. Es geht wiederholt um die Revitalisierung des ,Überkommenen', der traditionalen Normbestände, mit denen die modernen Defizienzen geheilt werden sollen und die so in den ontologischen Status der zweiten Welt der Normen und Werte erhoben werden. Deutlicher und gewichtiger noch als durch ihre Materialität freilich ist die ,moralische Sphäre“ von ihrer Formalstruktur her eine kontramoderne Konstruktion, die in ihrer ontologisierten, transtemporalen und objektivistischen Gestalt sich gegen die Kernstücke des Projekts der Moderne, nämlich gegen Subjektivität, Autonomie und diskursive Mitspracherechte bei der Normkonstitution wendet. Sie stellt derart in ähnlicher Weise wie bei Keilhacker eine ,zweite Welt' der Kontramoderne vor und bestätigt den kontramodernen Charakter des filmerzieherischen Ethikkonzepts, wie er schon auf der prinzipiellen Ebene in der Konstruktion des ,gültigen Menschseins ${ }^{6}$ vor Augen getreten ist.

\section{Transformation des filmerzieherischen Ethikansatzes in eine medienethische Grundkonzeption}

Dieser generelle ethisch-pädagogische Entwurf wird dann filmbezogen umgesetzt und dabei eine Medienethik umrissen. Zunächst wird hierzu die Maxime des Doppelprinzips auf den Film übertragen und derart eine Art medienethisches Prinzip geschaffen. Der Film nämlich gilt als ebenso wie die Pädagogik und die Subjekte auf die Herstellung und Förderung des ,gültigen Menschseins‘ verpflichtet. Dieser Herstellung soll er dienen, indem er zunächst „die gültige, gleichnishafte Wesensschau

${ }^{318}$ Wasem, Jugend, 55; damit ist über die Zeitgemäßheit dieser beiden Teile der evangelischen Räte für eine moderne mönchische Spiritualität kein Urteil gefällt. Sie sind jedoch vorneuzeitlicher Herkunft und werden von Wasem hier keineswegs Mönchen, sondern dem ,modernen Menschen' anempfohlen. Eine solche Empfehlung nun hat durchaus kontramodernen Charakter.

${ }^{319}$ Kerstiens, Erziehungsziele, 187

320 Tröger, Film, 206 
des Menschen und der Dinge im rechten Lichte zeigt“ ${ }^{321}$ Das tut er am besten dort, wo er auf das ,ewig Menschliche' rekurriert und selbst in ,kontingenten' Handlungen noch dieses ,Ewige' zum eigentlichen Thema und zum primären Objekt der Darstellung macht. ${ }^{32}$ Seine Aufgabe ist es, damit „einen Beitrag zur seelischen und geistigen Lebensbereicherung " zu liefern. ${ }^{323}$ Das wiederum bedeutet näherhin, daB er „Einsichten vermitteln, Zusammenhänge schaffen, Wertungen ermöglichen" soll. ${ }^{324}$ Der letztgenannte Gesichtspunkt gilt dabei als besonders wichtig. Soll die Beförderung des Menschseins mit Erfolg geschehen und derart die Forderung des Doppelprinzips filmbezogen umgesetzt und eingelöst werden können, so muß die ,gleichnishafte Wesenschau' zur ,gleichnishaften Wertung' weitergeführt werden. Wenn „aus dem Filmerleben wirklich Menschen- und Welterkenntnis erwachsen sollen", erscheint es als unumstößlich notwendig, daß „das Gesehene gewertet" wird. ${ }^{325}$ Will der Film hierzu beitragen, so muß er selbst eine Struktur aufweisen, die eine ,Wertung des Gesehenen' zumindest ermöglicht, wenn nicht gar veranlaßt. Darüber hinaus soll der Film ,Vorbilder' vor Augen stellen, die als Symbolgestalten sowohl die ,rechte Lebensorientierung verkörpern, als auch der Verankerung normativer Einzelmaximen dienen. Schon der anläßlich des Kriminalisierungsvorwurfs vorgebrachte Lösungsvorschlag hat in diese Richtung gewiesen, wenn dort die Darstellung ,positiver Vorbilder' gefordert wurde. ${ }^{326}$ In ähnlicher Weise heben Storck und Zöchbauer auf die Vorbildproduktion durch den Film ab und sehen sie hierin eine seiner zentralen Aufgaben ${ }^{327}$ Kerstiens wiederum unterscheidet das ,Vorbild' von den bereits in der Devianzkritik (unter anderem Aspekt) problematisierten ,Leitbildern' und „Idolen', und favorisiert das ,Vorbild‘. Während nämlich Leitbilder und Idole kollektive kontingente Muster repräsentierten, die vor allem beim Leitbild „eher modisch“328 seien und beim Idol die Gefahr böten, ,, selbst als Maß aufgefaßt, und nicht als Repräsentation des absoluten Maßes gesehen ${ }^{\text {“329 }}$ zu werden, stelle das Vorbild in der rechten Weise ein ,Ideal' vor Augen. ${ }^{330}$ Im Unterschied zu den ,manhaften' Orientierungsangeboten und ihrer Kontingenz ist das Vorbild die wünschenswerte Re-

${ }^{321}$ Wasem, Jugend, 56

322 vgl. dazu etwa: Tröger, Film, 193; die Insistenz der Filmerzieher auf dem ,ewig Menschlichen' und ihre darin deutliche Ontologisierungsneigung ist hier auf besonders amüsante Weise augenfällig: Tröger lobt den Film „Ladri di biciclette“ (1948) besonders, weil in ihm ,auf etwas Letztes, Allgemeines, vom Verstand und seinen Begriffen nicht mehr Faßbares“ gezielt sei, das ,jenseits aller individuellen, sozialen und nationalen Grenzen“ liege (ebd.). Nun ist der genannte Film von Vittorio de Sica jedoch eines der ,klassischen' Werke des italienischen Neorealismus, der gerade nicht auf ,Letztes', jenseits des Sozialen' Gelegenes zielt, sondern vielmehr die zeitgenössische soziale Realität kritisch ins Bild bringen und dem,Verstand' begreifbar machen will. Keine ,ewigen' Strukturen werden thematisiert, sondern gesellschaftliche, die gerade aufgrund ihrer begrifflichen Faßbarkeit auch veränderbar sind.

323 Wasem, Jugend, 77

324 Wasem, Jugend, 77

325 Kerstiens, Filmerziehung, 29

${ }_{326} \mathrm{vgl}$. Vogg, Bedeutung, 15

327 vgl. Storck, Henri, Der Unterhaltungsfilm für jugendliche Zuschauer, Wiesbaden - Bieberich 1954, 41 (= Film und Jugend II, Schriftenreihe des deutschen Instituts für Filmkunde); Zöchbauer, F., Jugend und Film, Emsdetten 1960, 200

328 Kerstiens, Filmerziehung, 37
${ }^{329}$ Kerstiens, Filmerziehung, 38
${ }^{330}$ Kerstiens, Filmerziehung, 38 
präsentanz des absoluten Maßstabs und steht es nur für diesen. Das erweist sich für Kerstiens auch daraus, daß ein Vorbild verworfen werde, wenn es gegen „das absolute Ideal“" verstoße und den Vorbildsuchenden derart, enttäusche‘. ${ }^{331}$ Wünschenswert nun ist daher, daß der Film Vorbilder liefere, nicht aber Idole und modische Leitbilder. ${ }^{332}$ Entsprechend wenden sich Kerstiens und andere Autoren, wie schon die Devianzkritik gezeigt hat, wiederholt gegen den ,Starkult‘, in dem sie eine übermächtige Produktion solcher defizienter Orientierungsangebote am Werk sehen. ${ }^{333}$

Der Film wird also im vorliegenden Argumentationszusammenhang zunächst der Maxime des Doppelprinzips unterstellt und auf die Herstellung des ,gültigen Menschseins' verpflichtet. Der medienethische Ansatz der Filmerziehung geht so aus ihrem generellen Ethikansatz hervor und erweist ihre Medienethik als eine spezialisierte Konkretion des allgemeinen Ethikkonzepts. Sodann werden dem Film drei miteinander verzahnte Funktionen vorgeschrieben, die befähigungsethisch ausgerichtet und von einer diesbezüglichen speziellen Strategie flankiert sind. In den drei Funktionen soll der Film der Realisierung des Gebots der Zielmaxime dienen. Hierzu soll er einmal durch paradigmatische Gehalte und Darstellungen zu einer Weltund Menschenkenntnis verhelfen und derart ,Zusammenhänge schaffen'. Seine Aufgabe ist es, eine Art ontologischer ,Wesensschau' von Welt und Mensch zu bieten, die durch ihren ,gleichnishaften Charakter' einen Interpretationszusammenhang von umfassenderer Relevanz erstellt und derart der Weltauslegung der Rezipienten einen Rahmen bietet. Zum zweiten soll dieser Interpretationszusammenhang Welt und Mensch in einem ,rechten Licht', d.h. unter bestimmten inhaltlich-normativen Prämissen zeigen und derart ,Einsichten schaffen'. Welt und Mensch sollen nicht einfach nur ins Bild gesetzt, sondern ,richtig' dargestellt werden, um den Rezipienten einen normativen Erkenntnisgewinn zukommen zu lassen. Die filmische Realitätsverarbeitung erhält hier die Aufgabe, der ,Daseinsauslegung dienlich zu sein und diese Auslegung in die gewünschte Richtung zu führen. Als Drittes wird vom Film dann noch gefordert, daß er zur, Wertung befähigen bzw. eine Wertung nahelegen solle. Nicht nur die Erkenntnis: So ist die Welt, sondern die Erkenntnis: So soll die Welt sein, ist das Ziel. Das Verständnis der ontologischen Verfaßtheit von Welt und Mensch, das den Interpretationsrahmen bereitstellt, sowie die rechte Daseinsauslegung allein reichen noch nicht aus, sondern werden zu einer moralischen Auffassung weitergeführt, deren Herstellung und Förderung als vordringliche Aufgabe des Films gilt. Über die Wertung soll die Realität moralisch interpretiert werden und der Film entsprechend einer Erkenntnis der moralischen Weltverfaßtheit sowie der Konstitution von Moralität dienstbar gemacht werden. Alle drei Funktionen sind auf die Herstellung des ,gültigen Menschseins‘ ausgerichtet und unter die Maxime des Doppelprinzips genommen. Sie sind daher unbedingt deontologisch gebotene Funktionen

${ }^{331}$ Kerstiens, Filmerziehung, 38

${ }^{332}$ Kerstiens selbst bezieht im Unterschied zu anderen Autoren hierbei allerdings eine zwiespältige Stellung. Er beurteilt einmal die Eignung des Films zur Vorbildpräsentation kritisch und attestiert ihm eine Inklination zur Idolproduktion. Sein Text läßt damit ein grundsätzliches Ressentiment gegen das Medium insgesamt erkennen. Zum anderen insistiert er darauf, daß es „,in vielen Filmen beste Vorbilder für den Jugendlichen“ gebe, „denen nachzustreben ein Gewinn sein würde“. (vgl. Kerstiens, Filmerziehung, 41-42)

${ }^{333}$ vgl. Kerstiens, Filmerziehung, 38-40; Glogauer, Vorbilderleben, 172-191 
und prinzipiell ethisch verankert. Auf diese Weise wird die Medienethik an die Prinzipienebene der generellen Ethik rückgebunden. Weiter aber zeigen sich die Funktionen als befähigungsethische, da sie jeweils auf spezifische Befähigungen zielen, durch die dann die Realisierung der Zielmaxime erreicht werden soll. So will die Bereitstellung des ontologischen Interpretationsrahmens zur Welterkenntnis und seine normative Perspektive dabei zur rechten Deutung dieser Erkenntnis führen. Ebenso richtet sich die Ermöglichung von Wertungen auf eine Befähigung, nämlich die der Moralität. Der befähigungsethischen Perspektive entsprechend werden die drei Funktionen dann von einer spezifischen Strategie ergänzt, die über die Darbietung von Vorbildern, d.h. durch symbolische Repräsentanz der ,rechten' Welt- und Daseinsinterpretation, sowie der Moral für Verankerung des Repräsentierten in der Psyche des Rezipienten sorgen und so die Funktionserfüllung garantieren will. Die Medienethik der Filmerziehung setzt so also prinzipiengeleitet an, führt die gebotenen Funktionen befähigungsethisch aus und ergänzt sie durch eine befähigungsethische Strategie.

Dabei ist ihrem grundsätzlichen Konzept entsprechend auch die Medienethik pseudoautonom angesetzt. Sowohl die Rezipienten als auch der Film unterliegen ja dem deontologischen Gebot der Zielmaxime, und weder die einen noch der andere dürfen von ihrer Realisierung abweichen. Beide müssen sich um die Herstellung des ,gültigen Menschseins' bemühen, das in spezifischer Weise festgelegt ist. Entsprechend kann zum einen der Film nur der ,Vermittlung' bestimmter Gehalte dienen und der Rezipient nur durch Belehrung befähigt werden. Eine abweichende Stellungnahme oder Option der Rezipienten ist gerade nicht erwünscht, sondern soll möglichst verhindert werden. Die Zusammenhänge, Einsichten und die Moralität sind nicht nur im Film, sondern auch im Rezipienten herzustellen, und der Film soll diese Herstellung möglichst garantieren. Einer Dissidenz der Rezipienten gegenüber den jeweils intendierten Vermittlungszielen muß daher effizient entgegengewirkt werden. Das ,Lernziel' ist prädefiniert und die Autonomie der Rezipienten entsprechend eingeschränkt. Sie treten im medienethischen Konzept einzig als Objekte erzieherischer Formung durch den Film, nicht aber als Subjekte auf, und die Befähigung ist wiederum pseudoautonom als Übernahme und Anwendung präformierter Gehalte angesetzt. Zum anderen ist auch der Film selbst in seiner Autonomie beschränkt. Zunächst ist er funktional festgelegt und kann er seine Rolle in der Gesellschaft nicht selbst bestimmen oder verändern. Unter dem hochgespannten Ziel der Befähigung zum ,gültigen Menschsein' entfällt dadurch etwa weitgehend seine Unterhaltungsfunktion. Ähnlich wie bei den Kinoreformern, die ihn einer exklusiven Bildungsverzweckung unterstellten, ist diese Funktion auch hier zugunsten einer andersgearteten, medienethisch fixierten Funktionszumessung aus dem Blick geraten und ethisch zumindest nicht reflektiert. Außerdem aber sind die Gehalte und Aussagen des Films recht umfassend festgelegt und präformiert. So ist schon durch die Fixierung auf eine ontologisierende, ,gleichnishafte' Welt- und Menschendarstellung der Spielraum für die Gehalteproduktion und Darstellung eingeschränkt. Es muß stets das ,Ewige', ,Überzeitliche' im Kontingenten aufleuchten und eine entsprechende Bedeutungstiefe erreicht werden. Diese Beschränkung wird dann noch durch die Bestimmung verschärft, da $B$ dies ,im rechten Licht' zu geschehen habe und eine ,gültige Wesensschau' darzubieten sei. Der Interpretationsspielraum ist derart zu- 
sätzlich normativ festgelegt, und Divergenzen oder gar Dissidenzen sollen möglichst ausgeschlossen sein. Auch die ,Ermöglichung der Wertung und die Moralitätskonstitution sind prädefinitorisch fixiert. So kann der Film seine diesbezügliche Funktion unter Voraussetzung des filmerzieherischen Ethikkonzepts nur in zwei Formen erfüllen, nämlich indem er entweder direkt die Maßstäbe der ,moralischen Sphäre vermittelt oder aber zumindest AnlaB gibt, diese auf seine Gehalte anzuwenden. Auch er darf in seinen Gehalten weder maßstabsverändernd, noch -diversifizierend tätig werden, sondern ist er, wie die Rezipienten, auf die Werte- und Normenwelt verpflichtet. Ein Ethoswandel, Binnenmoralen oder gar eine Anfrage an überkommene Normen bleiben aus den Darstellungs- und Thematisierungsmöglichkeiten des Films ausgeschlossen. Seine moralische Rolle erschöpft sich notwendig in der Repräsentation der ,moralischen Sphäre'. Das bestätigt sich dann auch aus der befähigungsethischen Strategie, nach welcher der Film ,Vorbilder' anbieten soll. Diese Vorbilder werden gerade als Repräsentanz der ,absoluten Maßstäbe', also vordringlich der ,moralischen Sphäre', sowie der ,rechten Welt- und Daseinsauslegung' definiert und dadurch von (auch schon in der Devianzkritik negativ aufscheinenden) Fehlformen unterschieden. Mit der Verpflichtung auf Vorbildproduktion ist der Film so zusätzlich nochmals auf die präformierten, moralischen und ontologisierten Gehalte festgelegt, die zur Erfüllung der drei Funktionen notwendig scheinen. Die Autonomie des Films ist damit ebenso wie die der Rezipienten durch normative Präformationen unterlaufen und pseudoautonom in Entsprechungsleistungen gewendet. Film und Rezipienten sollen der ,rechten Welt- und Daseinsauslegung sowie der ,moralischen Sphäre‘ entsprechen und so das ,gültige Menschsein' zur Realisierung bringen.

Mit ihrer Befähigungsstrategie läßt die Argumentation außerdem erneut die Differenzierung zweier Leitungsangebote erkennen, von denen eines als illegitim und das andere als legitim gilt. Illegitimisiert sind die kontingenten Angebote, die als ,manhafte und, uniformierende in der Devianzkritik aus der Perspektive der Eigentlichkeit kritisiert wurden. Sie unterliegen der Mode, den ,Zeitströmungen' und der Wandelbarkeit. Ihnen sich anzupassen gilt nach wie vor als defizient, als Verfall in Oberflächlichkeit und an Manipulation. Im Unterschied dazu aber wird ein legitimes Leitungsangebot konstruiert, das durch Ontologisierung und ,Absolutheit ${ }^{\text {jeder }}$ Kontingenz und Einflußnahme entzogen ist. Die Anpassung daran wird als erstrebenswert, ja sogar als über das Doppelprinzip geboten gehandelt und gilt keineswegs als Verfall an ,manhafte' Allgemeinheit oder Manipulation. Die Legitimität wird so also den kontingenzentzogenen, absoluten Gehalten zugesprochen, und von ihnen wird die Herstellung der ,rechten' Orientierung erwartet. Die Argumentation wendet so erneut die devianzkritisch und autonomiepessimistisch konstatierte Inklination zur ,Außenleitung' in eine Leitungsbedürftigkeit und gibt dieser dann legitimisierte Vorgaben.

Der Film aber ist damit nun medienethisch nicht als Medium der sozialen Kommunikation begriffen, das dem gesellschaftlichen Diskurs dient, sondern als Transmissionsinstanz, die auf Vermittlung selbst dem Diskurs enthobener Gehalte verpflichtet ist. Auf diese Weise scheint den in der Devianzkritik beklagten Erscheinungen dann begegnet werden zu können. So wäre mit Filmen, die der medienethischen Maxime gehorchen, sowohl dem ,Werteverfall' als auch dem daraus fließenden Ma- 
terialismus und dem moralischen Nihilismus gewehrt. Auch der Ethoswandel und die verderbliche Kriminalitätsdarstellung wären konterkariert. Die vorstehende Befähigungsstrategie weist zudem darauf hin, daß durch Übernahme des zweiten Leitungsangebots wohl auch eine spezifische, nämlich moralische und daseinsauslegende Eigentlichkeit gewonnen wäre, obschon diese beiden Formen devianzkritisch nicht entwickelt wurden und die Antwort auf die Eigentlichkeitsproblematik in anderer Weise gegeben wird (vgl. weiter unten). Insgesamt aber wäre mit Filmen, die der medienethischen Maxime gehorchen, die Befähigungsethik aus der Pädagogik in den Raum der Öffentlichkeit transponiert und in diesem Raum ein Instrument geschaffen, mit dem das ethisch-pädagogische Unterfangen der ,Heilung der Defizienzerscheinungen der modernen Welt breitenwirksam verfolgt werden könnte. Diese Möglichkeiten nun verweisen weiter darauf, $\mathrm{da} B$ es in der filmerzieherischen Lösungsstrategie mit dem zweiten Leitungsangebot und seiner filmischen Vermittlung nicht zuletzt um die Rückgewinnung jener ,einheitlichen Erziehungsatmosphäre geht, deren Verlorengehen besonders Keilhacker beklagt hat. Mit ihrer Verpflichtung des Films auf die Schaffung des, gültigen Menschseins' und mit den medienethisch festgelegten Funktionen, die auf die Vermittlung eines einheitlichen, ,gleichnishaften' Welt- und Menschenbilds sowie der ,moralischen Sphäre' gerichtet sind, stellt das Unternehmen der Filmerziehung letztlich einen Versuch dar, die Dynamik, Diskursivität und Diversifizierung der modernen Welt und Gesellschaft zu unterlaufen. Nicht nur das ,Manhafte', sondern überhaupt die Pluralität der Deutungen und der ,Daseinsinterpretationen', die Veränderlichkeit der Weltauslegung und der Ethosformen und die Mitsprachemöglichkeiten in einem diskursiv geschaffenen Raum sollen möglichst zurückgenommen und durch Belehrung ersetzt werden. Letztlich geht es in der Filmerziehung um die Reetablierung eines Ordo, in dem sich die Subjektautonomie als ,selbständige' Realisierung präformierter Orientierungsformen darstellt und sich die identitätsbezogenen und sittlichen Entwürfe der Individuen nach Vorgaben ausrichten sowie unter ethisch-pädagogischer Leitung konstituieren. Hierbei nun ist gerade der Raum öffentlicher Kommunikation jener prekäre Bereich, von dem und in dem Einheit und Festigkeit eines einheitlichen ethisch-pädagogischen Ordo ständig gefährdet scheinen. Folgerichtig muß sich die Medienethik darum bemühen, seine Konsistenz und Einheit eben dort mit Hilfe der Medien, und das heißt für die Filmerziehung: mit dem Film, wiederherzustellen.

\section{Versuchte Rückgewinnung von Sinnhaftigkeit und Orientierungskonsistenz unter partieller Nutzung des Films}

Über die Schaffung einer ,einheitlichen Erziehungsatmosphäre' und die Verpflichtung des Films auf Vermittlung der, rechten Daseinsauslegung' gemäß den ontologischen Gründen des Menschseins sowie der ,moralischen Sphäre' scheint dann noch eine weitere Funktion erfüllt, nämlich die Restitution des Sinns und Sinnerlebens. Die medienethische Maxime wird so erweitert und eine Antwort auf die Sinnkritik der Devianzdiskussion versucht. Hierbei allerdings zeigt der filmerzieherische Entwurf eine gespaltene Haltung, die einerseits den Film der Sinngewinnung dienstbar machen will, andererseits jedoch seine Nutzung gerade als Verfallserscheinung bewertet, die der Sinnkonstitution entgegengesetzt ist. Der Kontext der medienethischen Maxime ist darin auf die generelle Modernitätskritik und Lösungsanstrengung 
hin (rückwärts) überschritten. Der generellen Ebene entsprechend wird das Problem zunächst auch eingeführt: Im Kontext der Freizeitdiskussion und unter Rückbindung an die Devianzkritik wird das Sinndefizit als ,zeittypische' Erscheinung skizziert. So verweist etwa Tröger darauf, daß sich „,in der Ratlosigkeit vor der freien Zeit (...) nichts anderes als die Ratlosigkeit vor dem Leben überhaupt" äußere. ${ }^{334} \mathrm{Zu}$ lösen sei das Freizeitproblem daher letztlich nur durch die Sinngewinnung. Wem es nämlich gelänge, „den Sinn seines Lebens zu erkennen", der wisse auch, ,was er mit seiner freien Zeit anzufangen" habe. ${ }^{335}$ Die Abwesenheit des Sinns aber führt er auf die technisch-rationale und ökonomisierte moderne Welt zurück, in der produziert werde, „damit produziert wird“, und in der der Sinn durch „,den Zweck, den Nutzen, die Brauchbarkeit" verdrängt sei. ${ }^{336}$ Der Rahmen für die Sinnproblematik wird also auf der generellen Ebene der Modernitätskritik abgesteckt. Sodann insistiert Tröger darauf, daß Sinngewinnung und Sinnerleben zu den zentralen, ethisch gebotenen Aufgaben des Menschen und der Pädagogik gehören und daß hierzu der Film einen nicht zu unterschätzenden Beitrag leisten könne und müsse. Die Sinngewinnung als „wichtigste Aufgabe des Menschen“ nämlich könne ihm „kaum eindringlicher vor Augen geführt werden, als in Verbindung mit einem Film““ ${ }^{337}$ Entsprechend erhält dann der Film die Aufgabe zugemessen, ,,dem Jugendlichen zum Anlaß“ zu werden, „über so etwas wie Sinn überhaupt erst einmal nachzudenken“. ${ }^{338}$ Das wiederum erfordert freilich Gehalte, die dazu geeignet sind, den ,Willen zum Sinn` ,zu wecken, wachzuhalten, aktiv und bestimmend werden zu lassen“. ${ }^{339}$ Als solche Gehalte erscheinen bei Tröger die Darstellung des ,ewig Menschlichen‘, seiner ontologischen Verfaßtheit, sowie jene Darstellungen, die zeigen, „was und wie der Mensch zu sein hat, um ein Mensch zu sein“. ${ }^{340}$ Tröger rekurriert hier also indirekt auf zwei der medien- und befähigungsethisch gebotenen Funktionen und leitet die Sinngewinnung aus ihnen her. So soll wohl mit dem, ewig Menschlichen' und dem ,Was' des Menschen eine ,gleichnishafte' Schau des Menschenwesens geboten werden, die seiner ,rechten Daseinsauslegung und Selbstinterpretation dienlich ist, während mit dem normativen ,Wie ${ }^{6}$ auf seine sittliche Selbstkonstitution und seine Moralität gezielt ist. Durch Beförderung von Selbstinterpretation und Moralität soll dann auch der Sinn als gewissermaßen sekundäre Frucht bzw. ,Metaergebnis ${ }^{4}$ der Befähigungsanstrengungen entstehen. Damit ist, aus ethischer Perspektive betrachtet, implizit sowohl auf die medienethische Maxime zurückgegriffen, als auch diese auf Sinnvermittlung hin erweitert.

Gleichwohl gilt diese Sinngewinnung als noch nicht ausreichend und scheint der Sinn noch aus anderen Bereichen zu kommen, die filmisch nicht zugänglich sind oder als Gegengewicht zu ihm erscheinen. So sieht Tröger ein Wesensmerkmal des Sinns auch in der ,Selbstzweckhaftigkeit', die den ,Nutzen- und Brauchwerten' entgegengesetzt ist. Er verweist deshalb auf die Kunst und das Kunsterleben, die beide „,ihren

\footnotetext{
334 Tröger, Film, 210

335 Tröger, Film, 210

336 Tröger, Film, 210

337 Tröger, Film, 211

338 Tröger, Film, 210

339 Tröger, Film, 211

340 Tröger, Film, 211
} 
Sinn in sich" haben und derart Sinn geben. ${ }^{341}$ Sinn entsteht jetzt aus einer ,Schau, die nur auf sich selbst gerichtet und derart weiterer Verplanung entzogen ist. Sie hat ihren Zweck in sich und gleicht als Vertiefungsform der ,meditativen Versenkung. Der Sinngewinnung eignet damit ein kontemplatives Moment, das weder sich in der reinen Gehaltevermittlung erschöpfen, noch über den Film realisiert werden kann. Zwar erwähnt Tröger, daß die Selbstzwecklichkeit der Rezeption auch beim ,guten Film', d.h. dort, wo er Kunst ist, gegeben sein könne, doch betont er kurz darauf, daß die Formalstruktur des Films dem kontemplativen Moment darin andererseits auch wieder entgegengesetzt sei. Das „ruhige Sich-Versenken des Meditierenden“ nämlich sei „von dem Mitgerissen-Werden eines Filmzuschauers doch sehr verschieden “ ${ }^{342}$ so daB diese Form der Sinngewinnung (hauptsächlich) filmextern angegangen werden muß. Kerstiens wiederum stellt den Sinn in den Kontext der Religion und des ,Metaphysischen' und sieht durch die rechte Sinngewinnung den Film geradezu substituiert. So hebt er zunächst grundsätzlich in einer Skizze des Bedingungsrahmens menschlicher Existenz darauf ab, daß der Mensch ,zuerst und zuletzt (...) in allem in Beziehung zu Gott" stehe. ${ }^{343}$ Aus dieser Beziehung fließt für ihn der lebenstragende Sinn, den zu gewinnen „das erste Ziel der Erziehung“ und des Menschen sein müsse. ${ }^{344}$ Nicht umsonst laute daher auch ,die erste Katechismusfrage: Wozu sind wir auf Erden? ${ }^{\prime 345}$ Ist diese Frage jedoch mit Hilfe der Erziehung metaphysischreligiös beantwortet, so scheint der Film überflüssig geworden und das Freizeitproblem gelöst zu sein. Wer nämlich den Sinn gewonnen habe, der „braucht nicht ins Kino zu gehen, weil er mit seiner Zeit etwas anzufangen wei ${ }^{\text {“. }}{ }^{346}$ Entsprechend sei „nur aus der Antwort auf die letzte Sinnfrage (...) die Flucht ins Kino eigentlich zu bekämpfen “ ${ }^{347}$ Zwischen den Sinn und den Film ist so ein Antagonismus gesetzt, der einmal den Sinn einem filmisch kaum zu realisierenden Bereich, nämlich der Kontemplation, zuweist und ihn ein andermal in einen metaphysischen Wurzelgrund verlegt, der den Film überflüssig zu machen scheint. Metaphysik und Religion treten hier als eine Art Gegengewicht zum Film auf und rücken ihn ins Licht einer Verfallserscheinung, die überwunden werden muß. Darin äußert sich eine etwas zwiespältige Stellung der Filmerziehung, die den Film einerseits der Sinngewinnung nutzbar machen will und ihn andererseits anscheinend lieber substituiert sähe. Diese Stellung muß noch genauer betrachtet werden.

Zunächst jedoch zeigt sich, daß der in der Devianzkritik beklagten Sinnkrise der modernen Welt in der Tat eine Lösungsform gegenübergestellt wird, die einmal als Erweiterung der medienethischen Maxime begriffen werden kann, zum anderen jedoch auch wieder auf die generelle Ebene der Modernitätskritik sowie auf das Keilhackersche Lösungskonzept rekurriert. Auf der generellen Ebene wird das Problem zunächst auch angesetzt. So wird die Lösungsstrategie unter Rekurrenz auf die Modernitätskritik in einer Kontraststellung gegen die modernen Prozesse eingeführt,

341 Tröger, Film, 210

342 Tröger, Film, 212

343 Kerstiens, Filmerziehung, 10

344 Kerstiens, Filmerziehung, 65

${ }^{345}$ Kerstiens, Filmerziehung, 65

${ }^{346}$ Kerstiens, Filmerziehung, 63

${ }^{347}$ Kerstiens, Filmerziehung, 65 
von denen besonders die technische Rationalisierung und die Ökonomisierung im Blick stehen und die zu einer ,Sinnverdrängung zu führen scheinen. Diese Verdrängung, die schon von der Devianzkritik beklagt wurde, soll durch eine entsprechende Sinngewinnung überwunden und rückgängig gemacht werden. Die Sinngewinnung gilt hierbei als ,wichtigste Aufgabe، sowohl des Menschen als auch der Pädagogik und gerät derart zur ethischen Verpflichtung für beide. Auf diese Weise entsteht zugleich erneut ein grundsätzlicher Konnex zur Maxime des Doppelprinzips, der aus ethischsystematischem Gesichtswinkel nun auch die Sinngewinnung zuzuordnen ist. Letztlich bedarf es des Bemühens um Sinn wegen des ,gültigen Menschseins', das als generelles Ziel allen menschlichen und pädagogischen Unternehmungen übergeordnet ist.

Die vorliegende Argumentationsfigur läßt dann drei Sinnbegriffe erkennen, die jeweils ins Verhältnis zum Film gesetzt werden. Dabei wird einmal auf die ,gleichnishafte‘ Menschendarstellung zum Zweck der, rechten Daseins- und Selbstinterpretation' und die Moralität, bzw. unter Voraussetzung des Ethikkonzepts genauer: die ,moralische Sphäre', abgehoben. Aus der Vermittlung des paradigmatisch ,Menschlichen' und der Moralität soll, gewissermaßen als zusätzliche, darüber hinausgreifende Qualität, der Sinn entstehen. Wer die ontologische Verfaßtheit des Menschen kennt, sein Dasein daher recht zu interpretieren versteht und weiß, wie er sich moralisch zu verhalten hat, dem fällt auch der Sinn zu. Konstituiert wird auf diese Weise ein erster Sinnbegriff, in dem dieser als Frucht der Übernahme bestimmter anthropologisch-ontologischer Interpretamente und moralischer Orientierungsformen durch das Subjekt verstanden wird. Hierbei wird der Film (erneut) der Vermittlung dieser Gehalte dienstbar gemacht und derart für die Sinngewinnung in Dienst genommen. Der erste Sinnbegriff konstituiert sich so im Kontext der medienethischen Maxime, und die Verpflichtung zu seiner Herstellung leitet sich nicht unmittelbar aus dem Doppelprinzip, sondern aus der Medienethik her, die jetzt auf Sinngewinnung hin erweitert ist. Gleichzeitig bestätigt sich die schon in der Devianzkritik aufgestellte Vermutung, da $B$ das traditionale Werte- und Normenkorpus, das jetzt die ,moralische Sphäre' stellt, Sinn zu geben vermag, und daß entsprechend der Versuch einer Lösung des letztbezüglichen Nihilismus auch für eine Restitution der Werte- und Normenwelt optieren muß.

Dann aber tritt der zu gewinnende Sinn als etwas auf, das jenseits aller Bedeutungsgehalte durch Kontemplation zu erreichen ist bzw. in einem metaphysisch-religiösen Wissen um den Grund der eigenen Existenz beschlossen liegt. Auf diese Weise werden ein zweiter und dritter Sinnbegriff geschaffen, die mit dem Film nun kontrastiert werden. Der zweite Begriff läßt den Sinn aus der inneren Versenkung hervorgehen und betrachtet ihn derart als eine letztlich jenseits der rationalen Faßbarkeit gelegene Größe. Er stellt eine Verbindung zum Konzept der vita contemplativa her und bindet den Entwurf an das Paradigma von Introversion und Extraversion in der Devianzkritik zurück, das auch für die ,Eigentlichkeitsgewinnung' nochmals Relevanz entfaltet (vgl. weiter unten). Abgestellt ist dem Konnex entsprechend auf eine Innerlichkeit und eine besinnliche Schau, die der Dynamik, Reizgebung und Außenorientiertheit des Films konträr ist. Diese Art der Sinngewinnung kann daher vom Film kaum geleistet werden, sondern muß zum überwiegenden Teil jenseits dieses Mediums und seiner pädagogischen Nutzbarkeit angestrebt werden. Der zweite Sinnbegriff und sein Verhältnis zum Film verweisen so darauf, daß die ,Heilung der mo- 
dernen Defizienzen auch filmextern angegangen werden muB. Die Sinngewinnung fällt hier hauptsächlich in den Bereich der generellen Lösungstrategie und der allgemeinen Ethik der Filmerzieher. Dem korrespondiert weiter, daß die Kontemplation als selbstzweckliche Tätigkeit bestimmt und unmittelbar in bewußten Kontrast zur technischen Rationalität und ökonomischen Verzweckung gestellt wird. Auch hier geht es um eine grundsätzliche, generelle Konterkarierung moderner Defizienzen. Beides läßt so erkennen, daß die Sinngewinnung hier auch auf der allgemeinen Ebene angegegangen wird und die systematisch-ethische Verankerung der Lösungsstrategie unmittelbar im Doppelprinzip zu suchen ist. Der Antagonismus von Film und Sinn, den der zweite Sinnbegriff einführt, aber zeigt sich dabei noch nicht als ausschließender, sondern als komplementärer, in dem sich die ,filmische' und die filmexterne kontemplativ-selbstzweckliche Sinngewinnung ergänzen können und der sogar die Möglichkeit einer partiellen Realisierung dieses Sinns durch den Film andeutet.

Anders verhält es sich beim dritten Sinnbegriff, der nun einen kontradiktorischen Gegensatz zwischen Film und Sinn setzt und dessen Konstitution mit einer speziellen Reflexion nur noch auf der generellen Ebene geschieht. Sinn erscheint jetzt als metaphysische bzw. religiöse Konstruktion und entsteht durch Angebot und Übernahme eines metaphysisch-religiösen Interpretationsrahmens bzw. durch Vertiefung in einen diesbezüglich garantierten Letztbezug. Die Vermittlung dieses Rahmens und Letztbezugs wird als weitere Aufgabe der Pädagogik eingeführt und gerät unter der Maxime des Doppelprinzips wieder zu einer ethischen Verpflichtung für dieselbe. Allerdings könnte der Film der Sinngewinnung hierbei ebenso dienstbar gemacht werden wie im Fall des ersten Sinnbegriffs und erneut eine Erweiterung der medienethischen Maxime durchgeführt werden. Metaphysische bzw. religiöse Bedeutungsgehalte und Interpretamente nämlich ließen sich filmisch durchaus vermitteln und die Pädagogik könnte ihrer ethischen Verpflichtung hier unter Nutzung des Films sowie durch Übertragung dieser Verpflichtung auch auf ihn gerecht werden. Doch werden Metaphysik und Religion dem Film entzogen und beinahe feindlich gegenübergestellt. Ist durch sie der Sinn gefunden, so scheint der Film an Relevanz zu verlieren und seine Nutzung fast aufgegeben zu werden. Das Freizeitproblem ist dann durch die Sinnfindung in einer Weise gelöst, die den Film aus dem Kanon der Freizeitaktivitäten fast ausschließt. Umgekehrt erhält der Film dabei den Charakter eines ,Fluchtorts', an dem der Sinnkonstitution geradezu entgegengearbeitet wird. Nicht nur das Rezipientenverhalten der Filmnutzung aber gerät so zu einer Devianzerscheinung, sondern der Film selbst scheint Teil, Ausdruck und Förderungsinstanz der modernen ,Sinnverdrängung' zu sein. Die Filmerziehung bleibt so mit dem dritten Sinnbegriff auf der generellen Ebene der Modernitätskritik und ordnet dort den Film den Defizienzphänomenen zu, die einer Überwindung bedürfen. Sie läßt eine ablehnende Haltung zum Film erkennen, die diesen im Grund negativ bewertet und ihn eigentlich ausgeschaltet sehen will. Ihre modernitätskritische, filmexterne Lösungsstrategie totalisiert sich derart und überschreitet die Medienethik in einer Weise, die letztlich die Beseitigung des Films zur ethischen Forderung erhebt. In dieser allgemein ablehnenden Haltung wird, genau besehen, auch ein Anklang an die kontramoderne Kulturkritik der Kinoreformer wieder wahrnehmbar, die den Film ebenfalls als defizientes Medium behandelten und in ihrer Diskussion um den Schulfilm etwa betonten, daß es ,vorzuziehen' sei, wenn in der Freizeit gebastelt oder spa- 
zierengegangen werde (vgl. 2.6.). Die ,sinnvolle‘ Freizeitnutzung liegt dort gerade jenseits der Mediennutzung und konträr zu ihr. In der Filmerziehung ist dies jetzt noch verschärft, wenn nicht allein auf die Vorzugswürdigkeit einer, sinnvollen' Freizeitbeschäftigung abgehoben wird (vgl. dazu auch weiter unten), zu der der Film gerade nicht zählt, sondern ein Antagonismus zwischen mediale Beschäftigung und Sinngewinnung schlechthin gesetzt ist. Gleichwohl ist in beiden Fällen, bei den Reformern wie bei den Filmerziehern, nun eine im Grund konträre Haltung zum Film sichtbar, die dieses Medium als mißliebiges Phänomen empfindet.

Deutlich aber ist damit, daß die Filmerziehung in ihrem Bemühen um eine Lösung für das konstatierte Sinndefizit eine dreifache Strategie verfolgt, die der bereits in der Devianzkritik spürbar gewordenen kohärent ist. So rekurriert sie einmal auf das medienethische Prinzip und zielt sie eine Sinngewinnung durch mediale Vermittlung bestimmter Bedeutungsgehalte an, stellt sie zum anderen eine notwendige filmexterne Sinnkonstitution der filmischen zur Seite und legt sie zum dritten darüber hinaus auch einen prinzipiellen, ausschließenden Gegensatz zwischen Film und Sinn. Im ersten Fall wird dabei hier das medienethische Prinzip auf der Ebene der gebotenen Funktionen weitergeführt, während im zweiten Fall die Medienethik auf der generellen Ebene ergänzt wird. Im dritten Fall aber ist der Film selbst Teil und Agent der Sinnverdrängung, auf die keine medienethische, sondern nur eine medienfeindliche Antwort gegeben werden kann. Diese Antwort ist ebenfalls der generellen ethischen Lösungsstrategie zuzuordnen und enthüllt dort eine modernitätskritische Option, die den Film verwirft. Das entspricht der dreifachen Strategie in der Devianzkritik, die einmal generell modernitätskritisch ansetzt, ein weiteres Mal die Modernitätskritik filmbezogen transformiert und schließlich den Film selbst zum Devianzphänomen erklärt. Auf der Lösungsebene muß nun demnach im ersten Fall eine über den Film hinausreichende Option getroffen werden, für die jetzt die allgemeine Ethik zuständig ist, im zweiten der Film einer Lösungsstrategie eingeordnet werden, die medienethisch anzusetzen ist, und im dritten das Medium als Ganzes durch eine von ihm unabhängigen Lösung ersetzt bzw. überwunden werden, was wiederum nur in der allgemeinen Ethik möglich erscheint.

Weiter aber bestätigt die vorliegende Lösungsstrategie für die Sinnproblematik auch die in der Rekonstruktion der Devianzkritik aufgetauchte Vermutung, daB nicht nur die Lösung für den moralischen, sondern auch für den letztbezüglichen Nihilismus jenseits kontingent-kultureller und diskursiver Bereiche gesucht werden wird. So liegen sowohl die ,moralische Sphäre' als auch die ontologischen Gründe des Menschseins, die filmisch vermittelt werden sollen, explizit außerhalb dieser Kontingenzen. Auch die Kontemplation soll in eine elementare Tiefe und transrationale Erfahrung führen, die zusammen mit der Selbstzwecklichkeit gerade die Kontingenz überwinden will. Sie richtet sich ebenfalls auf eine Sinnkonstitution, deren Verläßlichkeit und Allgemeinheit nicht mehr in Frage gestellt werden kann und die Halt in den Veränderlichkeiten sowie jenseits kultureller ,Zufälligkeiten' gibt. Selbst mit dem ,Metaphysischen' und der Religion verhält es sich ihrer Zeichnung nach ähnlich. Sie erhalten den Charakter von transzendenten Bezügen und deuten auf einen jenseits der Vergänglichkeit gelegenen Wurzelgrund oder erscheinen als unbezweifelbarer Katechismusinhalt. Der von ihnen bereitgestellte Interpretationsrahmen ist mit seinen letztbezüglichen Antworten derart sehr wahrscheinlich ebenfalls den Kontingenzen und der diskursiven Veränderbarkeit entzogen. 
Schließlich läßt die vorliegende Strategie noch erkennen, daß in ihr auch wieder auf die Keilhackerschen Paradigmen und Lösungsoptionen rekurrriert wird. So treten in Analogie zur Modernitätskritik des Schulgründers Ökonomie und Technik als Verursacher von Defizienzen, diesmal der Sinnverdrängung, auf. Weiter wird mit dem zweiten Sinnbegriff erneut auf den Gegensatz von vita activa und vita contemplativa zurückgegriffen und kohärent auch zur Perspektive der Devianzkritik die Lösung in der Revitalisierung der Kontemplation gesucht. Sodann findet sich auch ein Bezug zur ,metaphysischen Kehre' Keilhackers. Diese wird nun jedoch nicht primär der Wertevermittlung und der Moralitätskonstitution (bzw. -verankerung) dienstbar gemacht, sondern zur Sinngewinnung herangezogen.

\section{Versuchte Rückgewinnung von, Eigentlichkeit' durch Restitution der vita contemplativa}

Die filmerzieherische Antwort auf die Sinnkrise der modernen Welt hat nun bereits darauf verwiesen, daß den modernen Defizienzen nicht nur über den Film begegnet werden kann, sondern auch Maßnahmen erforderlich sind, die ohne den Film bzw. zusätzlich zu seiner Normierung und Nutzung durchgeführt werden müssen. Daher stellt die Filmerziehung ihrem medienethischen Unterfangen, wiederum hauptsächlich auf der generellen Ebene der Lösungsvorschläge, zwei Strategien zur Seite, mit denen einmal die verlorengegangene ,Eigentlichkeit' wiedergewonnen und zum anderen auch unterhalb der Prinzipienebene eine spezifische Form von Selbstbestimmung etabliert werden soll. Die Wiedergewinnung von Eigentlichkeit setzt hierbei mit einer Revitalisierung spezifischer Orientierungsformen an, die gegen die modernen Devianzen gestellt werden und so als Teil einer korrektiv zu verstehenden Kontramoderne erscheinen. Zunächst soll der Wiedergewinnung der Eigentlichkeit die Kontemplation dienstbar gemacht werden, die schon im Kontext der Sinngewinnung als wesentliches Element der Lösungsstrategie vor Augen trat. Hierbei spielt der Film auch noch eine mittelbare Rolle. Eingeführt wird die Kontemplation erneut von Tröger, der sie als ,ruhiges Sich-Versenken ${ }^{، 448}$, ,zweckfreies Schauen ${ }^{349}$ und ,Sammlung $^{350}$ definiert. Ihre Wurzel und Herkunft verortet er in der ,,Muße', wie sie die Alten verstanden“ ${ }^{351}$ Darin und in der mit der Muße verbundenen "meditativen Schaukraft “ ${ }^{\prime 352}$ scheint ihm etwas ,allgemein Menschliches' erkannt, das es „für unsere Zeit zu retten“ gelte ${ }^{353}$ Die genannten Begriffe nämlich bewahrten ein ,alte(s) Wissen um das Wesen des Menschseins، ${ }^{\prime 354}$ auf, dessen Revitalisierung ,wieder neue Wege in die seelische Tiefe erschließen “355 könne. Damit scheint es möglich, der „moderne(n) Überschätzung der Aktivität" entgegenzutreten ${ }^{356}$ und die „Begegnung mit sich selbst, mit einem Menschen, einem Gedanken, einem Bild“" in ihrer vollen Authentizität zurückzugewinnen. ${ }^{357}$ Der Film scheint hierzu partiell und mittelbar

\footnotetext{
${ }_{349}^{348}$ vgl. Tröger, Film, 212

349 vgl. Tröger, Film, 213

350 vgl. Tröger, Film, 213

351 Tröger, Film, 214

352 Tröger, Film, 212

353 Tröger, Film, 214

354 Tröger, Film, 215

355 Tröger, Film, 214

356 Tröger, Film, 212

357 Tröger, Film, 213
} 
genutzt werden zu können. Zwar wird noch immer betont, daß in ihm ,die Handlung zu rasch fortschreitet", als daß aus seiner Rezeption unmittelbar eine Förderung der kontemplativen Orientierung hervorgehen könne, doch scheint es möglich, „hernach einige bleibende Bilder aus der Erinnerung zu holen" und über ein ,Filmgespräch“ im Schulunterricht „zu Formen der Besinnung“ zu gelangen, die sich „mit der Meditation vergleichen" ließen. ${ }^{358}$ Dies müsse geradezu eines der Ziele des Filmgesprächs sein, denn sonst sei "das Hereinnehmen eines Kunstwerks, also auch eines guten Films, in den Unterricht verfehlt"“. ${ }^{359}$ Freilich gilt die Kontemplation auch unabhängig vom Film als zu befördernde und zu übende Orientierungsform.

Die vorliegende Argumentationsfigur läßt nun zunächst erkennen, daß mit ihr die Rückgewinnung zweier Komponenten der Eigentlichkeit versucht wird, deren Verlorengehen in der Devianzkritik beklagt wurde, sowie daß diesen dann noch eine neue dritte Komponente zur Seite gestellt ist. So soll einerseits eine ,Begegnung des Individuums ,mit sich selbst' wieder ermöglicht und derart die personale Eigentlichkeit restituiert werden. Zum anderen richtet sich die Unmittelbarkeit der Begegnung mit einem ,Gedanken' oder Bild auf eine Erlebnis- und Erfahrungsauthentizität. Beide Komponenten galten als unter den Bedingungen der modernen Welt verlorengegangen, wobei der Film einmal als Agent dieser Welt und ein andermal selbst als eine ihrer Bedingungen auftrat. Die genannten Bedingungen wurden als Förderung der Aktivität und Außenorientierung gezeichnet, aus der dann eine in den Selbstverlust führende Betriebsamkeit sowie eine ablenkungsbereite Veräußerlichung und Oberflächlichkeit hervorgingen. Diesen Defizienzen soll nun entgegengewirkt und die beiden Komponenten der Eigentlichkeit sollen wiederhergestellt werden. Über sie hinaus wird nun jedoch zusätzlich noch die personale Begegnung als dritte Komponente der Eigentlichkeit aufgeführt und zugleich die Erlebnis- und Erfahrungsauthentizität in den zwischenmenschlichen Bereich ausgedehnt. Die zusätzliche Komponente kann als eine Mischform der beiden anderen betrachtet werden, in der eine personale Eigentlichkeit durch authentisches Erleben einer anderen zur intersubjektiven Eigentlichkeit erweitert wird. Alle drei Komponenten werden dann in Konnex zur Kontemplation gebracht. Durch Einübung einer kontemplativen Orientierungsform scheinen Selbstbegegnung, intersubjektive Unmittelbarkeit und geistigästhetische Erfahrungsauthentizität möglich. So soll die ,Versenkung in sich selbst wohl zum personalen Kern führen, die ,gesammelte‘ Begegnung mit Anderen Echtheit und Offenheit garantieren und die ,meditative Vertiefung` in ,Gedanken` und Bildhaftigkeit eine Innenschau oder Innenerfahrung derselben ermöglichen. Dabei gilt die Kontemplation als etwas, das dem Menschen ,wesentlich' eigen ist. Sie wird derart ontologisiert und gerät zusammen mit der daraus fließenden Eigentlichkeit zu einem zentralen Bestimmungsstück des Menschseins. Ihre Ermöglichung muß aus einer systematisch-ethischen Perspektive dann wieder der Maxime des Doppelprinzips unterstellt werden. Die Befähigung zur Kontemplation und die Herstellung der Eigentlichkeit sind ethisch geboten. Zugleich aber wird die Kontemplation als ontologischer ,Bestand' auch ,historisch' verankert und als ,altes Wissen' aus vormodernen Bereichen herbeigeholt. Sie ist derart sowohl kontramodern, nämlich in Front-

358 Tröger, Film, 213-214

359 Tröger, Film, 214 
stellung gegen den modernen Eigentlichkeitsverlust, als auch regressiv, nämlich durch Rückholung aus einer unvordenklichen Vergangenheit, bestimmt. Damit rekurriert das Argument außerdem wieder auf die Modernitätskritik und die Paradigmen Keilhackers. So enthält es sowohl das dichotomische Schema von vita activa und vita contemplativa als auch von Extraversion und Introversion. Die zweite Dichotomie tritt zwar nur mittelbar auf, wenn mit der ,Versenkung und der ,seelischen Tiefe' auf die Innenorientierung verwiesen wird, liegt jedoch dem Argument paradigmatisch zugrunde. Von der ersten Dichotomie sind dann mit Aktivität und Kontemplation bzw. Meditation beide Seiten des Kontrasts genannt.

Für die Herstellung der Eigentlichkeit über die Einübung der Kontemplation scheint dann zunächst auch partiell der Film herangezogen werden zu können. Als Mitverursacher der Defizienzen eignet er sich jedoch nicht unmittelbar zur Überwindung des Eigentlichkeitsverlusts. Daher wird nochmals auf seine extraversionsund aktivitätsfreundliche Formalstruktur reflektiert und die eigentliche kontemplationsbezogene Befähigungsstrategie filmextern in einem Gespräch verankert. Genau besehen ist die mittelbare Nutzung des Films für die Schaffung der Eigentlichkeit damit eine Nutzung, die sich gegen den Film wendet und dessen ,Eigentlichkeit' unterläuft. Die Eigenart des von der Formalstruktur bedingten Erlebens und seine spezifische ,Authentizität' besteht der filmerzieherischen Vorstellung zufolge ja gerade in einem ,Mitgerissen-Werden' und einer Ästhetik der Aktion, Bewegung und Dynamik. Ungeachtet dessen, daß diese Vorstellung selbst schon dem Film nicht ganz gerecht wird - es gibt auch stille, ,kontemplative' Filme -, wird es dann auch die postrezeptive Umorientierung auf die statischen, ,bleibenden' Momente in einem Film nicht. Konsequent nämlich müßte die Förderung der Erlebnis- und Erfahrungsauthentizität hier auf das spezifische Filmerleben angewendet und eine ,Vertiefung der dynamischen Ästhetik angezielt werden, um den Rezipienten die Eigentlichkeitskonstitution zu ermöglichen. Stattdessen aber wird versucht, diese Dynamik zu unterlaufen und gerade die ,filmunspezifischen' Momente hervorzuheben. Dadurch gilt dann die ,Hineinnahme' des Films in den Unterricht erst als legitimiert und der pädagogisch-ethische Befähigungsauftrag als in der rechten Weise erfüllt. So soll letztlich zum Zweck der Herstellung der Eigentlichkeit die prekäre Struktur des Films pädagogisch in Griff genommen und beherrschbar gemacht bzw. eine Möglichkeit der korrektiven Konteraktion geschaffen werden. Dem entspricht es durchaus folgerichtig, da $B$ darüber hinaus die Wiederbelebung und Einübung der kontemplativen Orientierung auch unabhängig vom Film betrieben und die Lösungsstrategie auch filmextern verfolgt werden muB. Der Film aber gerät in dieser Argumentation selbst zu einem tendenziell defizienten, nämlich eigentlichkeitshindernden Medium, das dann eine Lösungsstrategie erfordert, die sich gegen ihn wendet.

Auf diese Weise wird im Vorliegenden zunächst der Versuch gemacht, sowohl auf der generellen ethischen Ebene als auch auf der der pädagogischen Ethik zu einer Lösungsstrategie zu kommen. Entsprechend gilt es einmal als allgemein ethisch geboten, eine kontemplative Orientierungsform wiederzubeleben und einzuüben, und ein andermal, dies pädagogisch-befähigungsethisch zu fördern. Die letztgenannte Forderung scheint dann auch unter Nutzung des Films erfültt werden zu können. So werden die beiden ethischen Ebenen den beiden Kritikebenen zugeordnet und wird versucht, neben einer allgemein ethischen Antwort auf die Modernitätskritik auch 
eine befähigungsethische Antwort auf die filmbezogene Devianzkritik zu geben. Dabei setzt sich der Lösungsversuch zunächst in Widerspruch zu der devianzkritisch getroffenen Option, die sowohl die erlebnisbezogene als auch die personale Komponente der Eigentlichkeit durch den Film schlechthin bedroht sah. So war dort die erlebnisbezogene Komponente durch die Etablierung von Sekundärwelten und die personale durch die Vielfalt, Dynamik und Reizgebung, welche zur Extraversion und zum Selbstverlust zu führen schienen, gefährdet. In beiden Fällen galt die Formalstruktur des Films als defizienzfördernd und geriet der Film derart selbst zum Defizienzphänomen. Eine Lösung kann dann aber nicht mit seiner Nutzung, sondern nur durch seine Überwindung und ohne ihn gefunden werden. Dieser Widerspruch nun löst sich im Vorliegenden durch eine sukzessive Anwendung der drei in der Devianzkritik deutlich gewordenen Strategien für die Lösungsoptionen. Zunächst ist die erste Strategie einer grundsätzlichen Modernitätskritik in eine grundsätzliche Forderung der Wiederbelebung der Kontemplation umgesetzt. Dann wird versucht, die zweite Strategie fruchtbar zu machen und den Film für die Kontemplation zu nutzen. Hierbei jedoch setzt sich die devianzkritische Option wieder durch, die seine Formalstruktur angegriffen hat, und er erweist sich als ungeeignet. Entsprechend wird er implizit verworfen und seine spezifische Nutzung mit einer dieser entgegengesetzten Befähigungsstrategie unterlaufen. Der vorliegende Versuch einer Rückgewinnung der Eigentlichkeit zeigt sich so als subtile, jedoch konsequente Antwort auf die Devianzkritik und läßt neben der Umwendung der beiden Kritikebenen zu Lösungsebenen auch die dreifache Strategie wieder erkennen.

\section{Versuchte Rückgewinnung von, Eigentlichkeit' durch handwerkliche Kreativität und unmittelbare Weltbegegnung}

Bereits mit der Kontemplation galt im Vorstehenden die als Erlebnis- und Erfahrungsauthentizität bestimmte Eigentlichkeit wiedergewonnen. Auf ihre Wiederherstellung richten sich jedoch auch noch weitere Lösungsvorschläge, die jetzt in offener Konsequenz auf eine Nutzung des, sekundärweltlichen' Films verzichten. Stattdessen sollen eine unmittelbare ,Weltbegegnung' sowie handwerkliche Kreativität der Eigentlichkeitsrestitution dienen, die dann neben der erlebnisbezogenen Komponente noch eine weitere zurückgewinnen will. Zunächst betont hierbei Kerstiens, da $B$ denjenigen, der „in seinem Leben bereits etwas erlebt, (...) das Kinoerlebnis weniger" reize. ${ }^{360}$ Dieses filmunabhängige Erleben gerät dann zu einem weiteren ethischpädagogischen Auftrag. Denn wer nicht wolle, daß „der Mensch zu oft ins Kino getrieben" werde, der müsse dafür ,,sorgen, daß dieser Mensch etwas zu sehen und zu erleben findet, und zwar außerhalb der Kinosäle“ ${ }^{361}$ Als Beispiel für solche Erlebnisangebote nennt Kerstiens dann Jugendgruppen unter entsprechender Leitung, die ermöglichten, ,,auf Fahrt oder im Lager“ , die Welt' zu ,erobern“. ${ }^{362}$ In ähnlicher Absicht verweist Margarete Keilhacker auf die Notwendigkeit, „die Sehnsucht nach echtem Naturgenuß zu steigern", us. "varnt sie hierbei davor, dies über den Film zu versuchen, da dies wieder , in ein Zufr. Jensein mit dem Erleben aus zweiter Hand“

\footnotetext{
${ }^{360}$ Kerstiens, Filmerziehung, 61

${ }^{361}$ Kerstiens, Filmerziehung, 62

362 Kerstiens, Filmerziehung, 62
} 
münden könne. ${ }^{363}$ Die Authentizität der Naturerfahrung und die dadurch konstituierte Eigentlichkeit wären so gerade wieder nicht erreicht. Den beiden Vorschlägen zur Eigentlichkeitsgewinnung stellt Kerstiens dann noch die Förderung der handwerklichen Kreativität zur Seite, um die sich ,der Erzieher' ebenfalls bemühen müsse. ${ }^{364}$ Denn erst die „,sichtbare Leistung, das geschaffene Werk befriedigt ${ }^{\star 365}$ wirklich, und in diesen kann Kerstiens zufolge „der Mensch die Erfahrung (...) seiner kreativen Kräfte machen“ ${ }^{366}$ Damit gilt zugleich einer ,Spontaneität“ der Raum eröffnet, die „Kennzeichen für die im Menschen erreichte Stufe der Individualität“ sei. ${ }^{367}$ Der filmextern erlebende und kreative Mensch gilt dann auch als jener, der seine Freizeit ,sinnvoll' nützt. Die diesbezüglich befähigende Tätigkeit des Erziehers wird von Kerstiens deshalb als ,Anleitung zu ,rechter Freizeiterfüllung“" apostrophiert. ${ }^{368}$

Die Rückgewinnung von Eigentlichkeit richtet sich im vorstehenden Zusammenhang wieder auf zwei ihrer Komponenten. Zunächst soll die aus der Erlebnis- und Erfahrungsauthentiziät hervorgehende Komponente, die schon über die Kontemplation vermittelt wurde, jetzt auch durch Jugendgruppen und Naturerlebnisse befördert werden. Sodann soll eine spontane und originäre Schaffenskraft unterstützt werden, die der individuellen Komponente der Eigentlichkeit dient. Mit dieser Rekurrenz auf die Kreativität ist zugleich auf die Lösungsstrategie Keilhackers zurückgegriffen, der ebenfalls eine spezifische, nämlich aus der individuellen Fantasieproduktion entspringende Eigentlichkeit durch handwerkliche Tätigkeit wiederherstellen wollte. Die Rückgewinnung beider Komponenten gilt dabei im filmerzieherischen Konzept erneut als pädagogische und menschliche Aufgabe, da zum einen der Erzieher als zentrales Agens der Wiederherstellung des Verlorenen erscheint und zum anderen erst hierdurch ,wesenhafte' Bestimmungsstücke des Menschseins gewonnen sind. Aus ethisch-systematischem Gesichtswinkel ist diese Aufgabe so wieder der Maxime des Doppelprinzips zu unterstellen, obschon dieselbe hier nicht explizit genannt wird. Mit den eigentlichkeitsfördernden Tätigkeiten und Orientierungen scheint dann zugleich die ,rechte‘ und ,sinnvolle' Freizeitgestaltung gefunden, und die Lösung des Freizeitproblems auch hierdurch vorangetrieben. Diese Freizeitgestaltung ist dabei, wie sich schon in der Sinnproblematik zeigte, filmextern angesetzt, und die Rückgewinnung von Eigentlichkeit erfolgt unabhängig vom Film sowie in bezug auf die erfahrungsbezogene Komponente gegen ihn. Nicht nur nämlich ist mit der Forderung einer filmunabhängigen, unmittelbaren Weltbegegnung eine Lösungsstrategie auf der generellen Ebene angezielt, die die filmbezogenen Strategien ergänzt, sondern es erscheint der Film kohärent zur Devianzkritik hier selbst als das zu lösende Problem bzw. genauer: als die zu überwindende Defizienz. Seine Errichtung von Sekundärwelten wird erneut als Gefährdung der Erfahrungsauthentizität und der dadurch konstituierten Eigentlichkeit behandelt, um dieser dann die Begegnung mit der ,Primärwelt' entgegenzusetzen. Die Wiederherstellung der individuellen Komponente freilich richtet sich lediglich gegen den Film als Inhaltsträger, nämlich die serialisier-

\footnotetext{
${ }^{363}$ Keilhacker, Kino, 111

364 vgl. Kerstiens, Filmerziehung, 63

365 Kerstiens, Filmerziehung, 63

366 Kerstiens, Erziehungsziele, 89

${ }^{367}$ Kerstiens, Erziehungsziele, 89

368 Kerstiens, Filmerziehung, 63
} 
ten, ,manhaften' Gehalte, deren Erstellung nicht seiner Formalstruktur, sondern den Produktionsbedingungen, d.h. Ökonomie angelastet wird. Die Lösungsoption für die handwerkliche Kreativität kann so als filmunabhängige, jedoch nicht filmfeindliche Option betrachtet werden. Mit beiden Lösungsvorschlägen aber ist die Devianzkritik konsequent umgesetzt.

\section{Versuchte Rückgewinnung von Selbstbestimmung durch Askese und Verzicht}

Schließlich bemüht sich die Filmerziehung noch um die Rückgewinnung einer spezifischen, begrenzten Form von Selbstbestimmung und eine Antwort auf die Manipulationskritik. In Kohärenz zum Versuch der Schulgründers stellt sich diese Lösungsoption als Konsumaskese dar. Eingeführt wird sie von Kerstiens, der darauf abhebt, daß in der ,außengeleiteten Gesellschaft" eine Konsumabstinenz sowohl gegenüber dem Film als auch gegenüber anderen Konsumgütern notwendige Bedingung jeder Strategie gegen den Verfall an Manipulation sei. ${ }^{369}$ In ähnlicher Weise betont auch Tröger, daß unter den Bedingungen der modernen Welt „eine Konsumaskese (...) immer dringlicher" werde. ${ }^{370}$ Um zumindest einen Teil der Selbstbestimmung des Subjekts zurückzugewinnen, muß - wiederum Kerstiens zufolge - ein „VerzichtenKönnen“ eingeübt werden, denn „nur so kann der Mensch frei bleiben“ “ ${ }^{371}$ Entsprechend werde eine „Erziehung zur Selbstbeherrschung" unabdinglich, die den so Erzogenen befähige, durch Verzichtsleistungen diese Freiheit zu gewinnen und sich zu erhalten. ${ }^{372}$ Dabei muß sich das Subjekt offenbar auch gegen sich selbst durchsetzen, und möglichst frühzeitig jene Verzichtsbereitschaft erwerben. ${ }^{373}$ Die hierdurch gewonnene Freiheit wird dann näher als „Freiheit, über etwas entscheiden“ zu können, bestimmt. ${ }^{374}$ Dabei ist die Entscheidung jedoch keineswegs eine ,ungebundene', sondern ,aufgrund der erkannten rechten Ordnung der Dinge“ zu vollziehen. ${ }^{375}$

Die Rückgewinnung der Selbstbestimmung gegen die Manipulation geschieht im vorstehenden Argument derart sowohl mit impliziter Orientierung am analogen Vorschlag Keilhackers als auch in Rücksicht auf den eigenen pseudoautonomen Ansatz und die aus dem Autonomiepessimismus fließende, bewahrethische Option der ersten Devianzkritik. Der Bezug zum Schulgründer zunächst liegt offen zu Tage. Ebenso, wie dieser optiert auch die Filmerziehung angesichts des Fremdbestimmungszusammenhangs der modernen Welt, zu dem der Film als spezielle, manipulative Instanz zu rechnen ist, für eine Selbstbestimmung ex negativo, d.h. eine subjektive Freiheit, die sich allein im Verzicht zu konstituieren und zu äußern vermag. Damit ist eine Nische geschaffen, eine Art Lücke im System der Manipulation, die jedoch keineswegs die Subjektautonomie wiederherstellt. Vielmehr wird im weiteren der pseudoautonome Ansatz wieder lebendig und selbst die konsumasketisch gewonnene Freiheit auf die Unterordnung unter die ,rechte Ordnung der Dinge verpflichtet, die zweifelsohne mit dem zweiten Leitungsangebot der ontologisierten

\footnotetext{
${ }^{369}$ Kerstiens, Filmerziehung, 61

370 Tröger, Film, 172

371 Kerstiens, Filmerziehung, 60

372 Kerstiens, Filmerziehung, 60

373 Kerstiens, Filmerziehung, 60

374 Kerstiens, Filmerziehung, 60

375 Kerstiens, Filmerziehung, 60
} 
Welt- und Daseinsauslegung sowie der ,moralischen Sphäre identisch ist. Was auch immer zur Entscheidung im Raum der asketisch gewonnenen Nische ansteht, ist von vorneherein den dort präformierten Maßstäben zu unterstellen, und die Entscheidung muß durch deren Anwendung getroffen werden. Schließlich ist durch die Askese nicht nur Freiheit gegenüber der modernen Welt gewonnen, sondern auch gegenüber den eigenen Neigungen, Inklinationen und Latenzen, die dieser Welt und ihren ,Lockungen' in die Hände spielen. Da diese Neigungen dem Subjekt inhärent sind, bedeutet dies, da $B$ auch Askese ,nach innen' geübt und Selbstbeherrschung erlernt werden muß. Mit diesem Terminus bindet sich der Versuch der Rückgewinnung von Selbstbestimmung mittelbar auch an die bewahrethische Option der ersten Devianzkritik und ihre Pessimismen zurück. Zwar wird nun nicht direkt auf perniziose Latenzen abgehoben, doch parallelisiert das Argument den dort gemachten Vorschlag, eine ,Härte zu uns selbst' und eine Selbstbeherrschung zu etablieren, die verhindern, ,in den Strudel des Lasters' gezogen zu werden. Die perniziosen Latenzen treten jetzt nicht unmittelbar als anthropologische, jedoch immerhin, der zweiten Devianzkritik zufolge, als kaum weniger verderbliche ,manhafte' Neigungen auf, und das Laster erhält dort das Aussehen einer willigen Hingabe an die Manipulation. Hiervor soll durch eine entsprechende Befähigungsleistung der Erziehung bewahrt werden, die aus der Perspektive der pädagogischen Ethik dann zu deren ethischem Auftrag gerät. Die Rückgewinnung der Selbstbestimmung zeigt sich so als die einer äußerst begrenzten Form derselben. Der Rückgewinnungsversuch aber schließt sich damit konsequent an die Optionen der Devianzkritiken an und fügt sich ebenso konsequent in den filmerzieherischen Gesamtentwurf ein.

\subsection{Exkurs: Partielle Repetition und Transformation reformerisch- filmerzieherischer Axiome und Theoreme in den 80er und 90er Jahren}

Wie eingangs in diesem Kapitel bemerkt, beschränkt sich die Wirksamkeit der Filmerziehung nicht auf ihre eigene Zeit. Zwar tritt nach den 60er Jahren die Medienkritik der Kritischen Theorie allmählich in den Vordergrund (vgl. das nachfolgende Kapitel) und nimmt zunehmend Einfluß auf vor allem die in den 70er Jahren entworfenen Medientheorien der Pädagogik, Kommunikationswissenschaft, Soziologie und Politikwissenschaft. Auch beginnt sich die Medienpädagogik als Disziplin zu wandeln. Sie verliert ihre in den 50er und 60er Jahren noch mehr oder weniger vorhandene paradigmatische Geschlossenheit und erlebt eine Diversifizierung, die nicht allein nur mit einer Ablösung einer ,geisteswissenschaftlichen` durch eine ,empirische Pädagogik zu kennzeichnen ist, sondern auch zu einer kombinatorischen und interdisziplinären Arbeitsweise führt. Doch erhalten sich trotz dieser Prozesse vor allem dort, wo es um spezifisch ethische Reflexionen des Medienbereichs geht, diverse Axiome und Theoreme der Filmerziehung über die Phase einer Kritischen Medientheorie hinweg und neben der methodologischen und reflexiven Weiterbildung der Medienpädagogik bis heute am Leben. Nachdem zur Mitte der 80er Jahre hin allmählich der Wirkeinfluß der Kritischen Theorie auch in den letzten Ausläufern zu versickern beginnt, treten die Axiome und Theoreme der Filmerziehung - und vermittelt über diese sogar der Reformer - geradezu verstärkt wieder in den Vordergrund. Sie prägen insbesondere einen Teil der zeitgenössischen Diskussion um Sexu- 
alität und Gewalt in Film, Fernsehen und Video sowie partiell die in diesem Zusammenhang angestellten Reflexionen über Umfang, Begründungsbasis und Strategien des medienbezogenen Jugendschutzes. Dabei koppeln sich die Restbestände der ,Tradition' mitunter mit der argumentativen Abstützung auch des institutionellen Handelns in diesem Bereich. Der Versuch, dem nötigen Jugendschutz nicht nur institutionelle Realisationsmöglichkeiten, sondern auch eine haltbare theoretische Fundierung zu geben (bzw. anzubieten), evoziert vor allem bei diversen Medienpädagogen nicht selten einen Griff in den Fundus der von Reformern und Filmerziehern bereitgestellten Argumentationsformen. Auf Seiten der Institutionen, die zu konkretem Handeln angehalten sind und nicht selbst zugleich noch theoriebildend tätig werden können, entspricht dann bisweilen diesem Griff eine Bereitschaft, solche angebotenen Theoreme in die Begründung des eigenen Handelns einzubeziehen. Als wirkmächtig haben sich dabei in den letzten Jahren vor allem zwei Formen der Repetition bzw. Verarbeitung der ,Tradition' erwiesen: Zum einen haben im Bereich der gegenwärtigen Medienpädagogik die Überlegungen einiger weniger Pädagogen öffentliche Aufmerksamkeit gewonnen, die bruchlos die Theoreme - insbesondere die anthropologische Axiomatik und die Devianzthetik - der Reformer und Filmerzieher repetieren. Vollzogen wird diese Repetition meist von einstigen Adepten der Filmerziehung, die bereits in den 50er und 60er Jahren tätig waren. In der Gegenwart erhalten diese repetitiven Theorieunternehmungen nicht zuletzt durch mitunter recht medienwirksame Selbstpräsentation und einen verfallstheoretisch-sensationellen Charakter große Verbreitung und Popularität. Sie finden sich zudem atmosphärisch günstig flankiert durch modische Verschwörungs- und Defizienztheorien, wie sie etwa Neil Postman mit hoher Auflage verbreitet. ${ }^{376}$ Die weniger sensationellen und unprätentiöseren Forschungsarbeiten anderer Medienpädagogen treten demgegenüber in der populären Rezeption meist zurück. Zum zweiten hat sich eine bestimmte Form der lerntheoretischen Interpretation medialer Wirkungen etabliert, die zwar von den bisherigen Wirkungstheorien sich distanziert, jedoch damit vor allem den Nutzenansatz (uses and gratifications) der neueren Wirkungsforschung neglegiert und letztlich durch implizite Rekurrenz auf ein Stimulus-response-Paradigma der Devianzthetik der ,Tradition“ wieder Eingang in die Wirkungsspekulation verschafft. Diese lerntheoretische Interpretation bestimmt dabei vor allem die im Zusammenhang mit der Diskussion um gewalthaltige Darstellungen in Medien angestellten Wirkungsvermutungen mit und gilt nicht selten als unumstößliche wissenschaftliche Begründungsbasis für entsprechend restriktive Forderungen der Beschränkung, Zurücknahme oder gar Beseitigung gewalthaltiger Medieninhalte. Während die Repetition der reformerisch-filmerzieherischen Theoreme sich meist als solche explizit zu erkennen gibt, tritt die lerntheoretische Wirkungsspekulation als neue Theorie auf. Sie stellt gleichwohl meines Erachtens nicht eine Überwindung, sondern eine Transformation der ,Tradition' dar: Wo die Reformer und Filmerzieher im Menschen eine negative Basis für perniziose Medienwirkungen anthropologisch-prinzipiell ansetzten, sucht das infrage stehende lerntheoretische Konzept eine zwingend geschehende Herstellung dieser Basis zu erweisen und bietet es dadurch

${ }^{376}$ vgl. Postman, Neil, Wir amüsieren uns zu Tode, Frankfurt 1989; ders., Das Verschwinden der Kindheit, Frankfurt 1987 
der Revitalisierung der ,klassischen` Devianzthesen eine veränderte, gleichwohl nicht weniger feste axiomatische Grundlage. Die anthropologische Ontologie der Reformer und Filmerzieher wird dabei gewissermaßen zur unausweichlichen Ontogenese transformiert, in Effekt und Funktion jedoch erhalten. Da sowohl die Repetition als auch die - zu erweisende - Transformation nicht geringe Wirkungen in der Gegenwart gezeitigt haben, will ich im folgenden beiden exemplarisch, d.h. unter Konzentration auf ihre herausragenden Vertreter nachgehen.

\section{Die ,Aktualität' der, Tradition': Fortwirken reformerisch-filmerzieherischer Optionen im Bereich der Medienpädagogik}

Aus der zwar kleinen, aber aktiven Zahl der noch der Filmerziehung verpflichteten Medienpädagogen ragt eine Gestalt zur Zeit besonders hervor. Werner Glogauer, der 1958 noch bei Martin Keilhacker promoviert hat, ${ }^{377}$ und der sich bis in die 80er und 90er Jahre mit der (vordringlich als schädlich eingestuften) Wirkung von Filmen auf Kinder und Jugendliche sowie auf junge Erwachsene beschäftigt, ist durch eine Veröffentlichung von 1991 selbst Gegenstand medial vermittelter öffentlicher Aufmerksamkeit geworden. Eine Studie zum Thema der Wirkung von gewalthaltigen, horriblen und erotischen Darstellungen in Filmen hat im genannten Jahr eine Reihe von größeren Zeitungs- und Zeitschriftenartikeln sowie eine weniger beachtete Gegenreaktion von 30 mit Medienpädagogik und Kommunikationswissenschaft befaßten Forschern provoziert. ${ }^{378}$ In Glogauers Studie sowie seinen anderen zeitgenössischen Veröffentlichungen lassen sich dabei nun die Optionen der Filmerziehung und - wiederum vermittelt durch diese - auch der Reformer recht ungebrochen wiederentdecken. Darauf verweist nicht nur bereits der Titel seiner neuen Studie: „Kriminalisierung von Kindern und Jugendlichen durch Medien", der die Kriminalisierungsthese als zentralen Inhalt des Buchs erkennen läßt, sondern auch die Tatsache, $\mathrm{da} B$ sich Glogauer explizit selbst als Traditor der filmerzieherischen Theoreme und Überlegungen versteht. So spricht er wiederholt von ,überwältigenden Beweise(n) der Forschung über die schädlichen Wirkungen" von (über das Fernsehen und Video vermittelten) Filmen ,auf die Zuschauer“379 und sieht er diese Beweise gerade auch durch die filmerzieherische Forschung erbracht. ${ }^{380}$ Schon „die Jugendfilmforschung der 50er und 60er Jahre“ nämlich habe diverse Wirkungen „eindeutig nachgewie-

${ }^{37}$ Glogauer, Vorbilderleben

${ }^{378}$ Die in Frage stehende Studie ist das bereits oben in 2.4. zitierte Buch Glogauers über die ,Kriminalisierung von Kindern und Jugendlichen durch Medien'. Es fand mediale Beachtung vor allem in einem mehrseitigen Artikel in der Zeitschrift ,Der Spiegel 17/1991, 101-105, und durch einen ,Aufmacher' (Titelseite) in der Boulevardzeitung ,tz' am 28. Juni 1991. Aus der Befürchtung heraus, daß die Thesen Glogauers die ,weniger spektakulären Anstrengungen in der Forschung und in der medienpädagogischen Praxis (...) desavouieren“ könnten, publizierte die ,Gesellschaft für Medienpädagogik und Kommunikationskultur, Regionalgruppe Bayern ‘ unter Herausgeberschaft von Bernd Schorb und Wolfgang Swoboda eine Sammlung von 30 Stellungnahmen anderer in diesem Bereich tätiger Wissenschaftler gegen Glogauers Studie (Schorb, Bernd, Swoboda, Wolfgang (Hrsg.), Medienpädagogen kommentieren populäre Thesen über die Wirkungen der Darstellungen von Gewalt und Sexualität im Fernsehen auf Kinder und Jugendliche, München 1991).

${ }_{380}^{379}$ Glogauer, Kriminalisierung, 59

380 vgl. Glogauer, Video 
sen“, 381 so daß es als beinahe böswillige Verschleierung und ,Irreführung' erscheint, wenn daran in den späteren Jahren Kritik geübt und die ,Eindeutigkeit' durch eine methodologische Selbstreflexion der Wirkungsforschung in Frage gestellt wurde. ${ }^{382}$ Entsprechend rügt Glogauer wiederholt, daß die durch die Filmerzieher "gewonnene(n) Erkenntnisse zur Medienwirkung gegenwärtig vielfach ignoriert werden“. ${ }^{383} \mathrm{Im}$ Gegenzug hierzu zitiert er dann häufig seine eigenen Theoriebildungen - besonders seine Dissertation - als Beleg für entsprechende Filmwirkungen. ${ }^{384}$

Eine rekonstruktive Analyse von Glogauers Texten läßt nun zunächst erkennen, daß seine medienkritischen Thesen grundsätzlich im Kontext einer Modernitätskritik vorgebracht werden, die er ungebrochen der Keilhackerschen und reformerischen Tradition entnimmt. So ist etwa die zwiespältige Haltung Keilhackers zur modernen Technik und die in diesem Kontext geübte Kritik an einem ,Eigentlichkeitsverlust auch bei Glogauer spürbar. Sie äußert sich bei ihm jedoch vor allem in Form einer Kritik an den technisch ermöglichten Medien, die den Menschen der tatsächlichen Realität entfremdeten und ihn in ,abgeleitete Kunstwelten' bannten. So sieht er durch die Medien eine ,sekundäre Realität' und ,künstliche Umwelt' konstituiert, von denen ,unsere unmittelbare Welterfahrung zurückgedrängt“ werde. ${ }^{385} \mathrm{Die} \mathrm{Me}$ dien scheinen dabei so ,überhand‘ zunehmen, daß sich folgerichtig ,unsere Fähigkeit zu solcher Welterfahrung (...) nicht entfalten“ kann und sogar ,zurückbildet ${ }^{386}$ Anstelle der ,unmittelbaren Weltbegegnung werden dann ,künstliche Bedürfnisse‘ konstituiert, die Glogauer, um ihre Abseitigkeit deutlich zu machen, als „Quasi-Bedürfnisse“ etikettiert, und die als ,völlig artifiziell“ gelten. ${ }^{387}$ Befördert gilt diese Bedürfniskonstitution vor allem durch die Werbung, die gewissermaßen als Agent der auch ökonomisch gestützten modernen Dynamik der Ersetzung von ,herkömmlichen' Orientierungs- und Befriedigungsformen des Menschen durch manipulative Produktion neuer Wünsche zuarbeitet. Folgerichtig scheint im Kontext dieser technisch-medial erzeugten, künstlichen Umwelten und der mit ihnen verbundenen Bedürfnisse weiter auch - wie bei Keilhacker - ein Lebensstil befördert zu werden, der rastlos nach ,besser, schneller, höher' verlangt und eine ständig auf neue Sensationen gerichtete Extraversion evoziert. Besonders die Sehnsucht nach Gefühlserlebnissen, ja nach ,Gefühlsschauern', scheint dabei in der ,rationalisierten" modernen Welt diese Extraversion zu verstärken. So beschreibt Glogauer die Reizorientierung wiederholt als Streben (und mitunter als Sucht) nach ständiger Stimulanz und ,emotionalen Gewitterschauern', die das moderne Individuum anscheinend brauche, um überhaupt noch etwas zu erleben. Diesen ,Schauern' gäben sich die Filmnutzer gesteigert hin, um so der „Überbetonung rationaler Anforderungen des modernen Lebens und der emotionalen Unterversorgung in der mitmenschlichen Welt" etwas entgegensetzen zu können. ${ }^{388}$ In der Konsequenz sieht Glogauer daraus dann eine Fixierung an diese

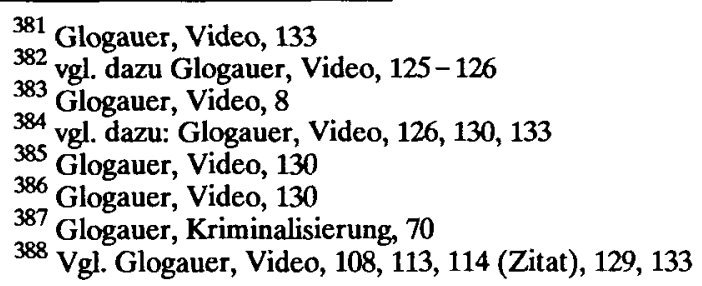


,Schauer quellen und auch die Fähigkeit zu personaler Kommunikation verkümmern. Die Filmnutzung nämlich drohe unter Umständen dazu zu führen, daß ,z.B. emotionale Befriedigung im mitmenschlichen Bereich immer weniger gesucht und erwartet wird“ “389 Der ,Verlust der unmittelbaren Weltbegegnung dehnt sich damit durch die Medien auf die emotional-personale Begegnung aus. Gesucht werden die emotionalen Affektationen nur noch in den Medien, also nicht einfach - wie beim Keilhackerschen extravertierten Typus - im generellen ,Außen', sondern in einem ,künstlichen', rein medial vermittelten Außen, und gefährdet bzw. zerstört sind eine personale wie eine ,weltunmittelbare' Eigentlichkeit. Die vita contemplativa geht erneut in einer überbordenden vita activa unter, die auch noch eine ,künstliche' ist.

In diesem Kontext ist dann auch die Verfügbarkeit von Filmen auf Video nicht positiv zu bewerten, da die Möglichkeit eines aktiven, technikvermittelten Umgangs mit diesem Medium - die Nutzung von Vor- und Rücklauf, Zeitlupe, Standbild etc. - nicht als Autonomisierung und bewußte Nutzung interpretiert wird, sondern als Verstärkung des Verfalls an die ,Technisierung der Welt und den Verlust von Unmittelbarkeit und ,Eigentlichkeit'. Für Glogauer nämlich scheint durch diese Möglichkeit die Fixierung an die Kunstwelten des Films und die dadurch evozierten künstlichen Erfahrungen und künstlichen Emotionen verstärkt zu werden. So sorge die „Nutzung der technischen Möglichkeiten des Videorecorders“ dafür, daß „das filmisch Dargestellte (...) mit besonderer Konzentration, differenzierter Wahrnehmung und längerer Betrachtung aufgefaßt wird“" ${ }^{390}$ Dies aber deutet Glogauer gerade nicht als Form bewußter - und das heißt auch: distanzierender und distanzierter - Verarbeitung des Gesehenen, sondern vielmehr als weiteren Verfall an die Faszination des Mediums, deren Gehalte durch Video ,intensiver erlebt“ würden. ${ }^{391}$ Statt einer zunehmend subjektvermittelten, mündigen Nutzung des Mediums deduziert Glogauer so zunehmende Bewußtlosigkeit und Sucht. Dabei gelten dann auch die trick- und maskentechnischen Möglichkeiten des modernen Films als zusätzliche negative Verstärker: Gerade diese Möglichkeiten nämlich würden vor allem von jugendlichen Videonutzern mit Hilfe der Rekordertechnik exploriert. ,Wie ist das gemacht' sei eine Leitfrage, die eine entsprechende Beschäftigung mit dem Film befördere. Auch hieraus aber sieht Glogauer wieder nicht eine distanzierende, durch cineastische Kenntnis und Kompetenz vermittelte Autonomisierung und Bewußtheit der Rezeption hervorgehen, sondern neuerliche Fixierung und BewuBtlosigkeit. ${ }^{392}$ Schließlich - und das gilt aus dem Blickwinkel der Modernitätskritik als ebenso verderblich - scheint durch die technischen Möglichkeiten von Video noch ein generelles neues ,artifizielles‘ Bedürfnis befriedigt zu werden, das „Bedürfnis nach technischer Bestätigung“ “ ${ }^{393}$ Mit Glogauers Formulierung dieses Bedürfnisses ist die Defizienz damit endgültig auf den Punkt gebracht: Die Technik letztlich ist es, die in ihrer Künstlichkeit und durch die von ihren Möglichkeiten erzeugte Sogwirkung die neuen Bedürfnisse hervorbringt und den Menschen in die Entfremdung treibt. Entsprechend faßt Glogauer auch seine Beurteilung dieses Bedürfnisses, der techni-

\footnotetext{
${ }^{389}$ Glogauer, Video, 114

390 Glogauer, Video, 81

391 Glogauer, Video, 81

392 vgl. Glogauer, Video, 81

${ }^{393}$ Glogauer, Video, 81
} 
schen Mittel des Films selbst und der Möglichkeiten der Videonutzung in der Conclusio zusammen, daß ,die Jugend (...) heute nicht nur durch die Inhalte der filmischen Darstellungen fehlgeleitet [werde], sondern zusätzlich und vielleicht noch mehr durch Technik und Elektronik“، ${ }^{394}$

Im Kontext der These von der Sucht nach künstlich erzeugten emotionalen Erlebnissen, nach ,Gefühlsschauern' und stets neuen Sensationen scheint es dann auch nicht verwunderlich, wenn die Aktivität der Rezipienten in Aggressivität übergeleitet wird. So findet Glogauer zunächst „deutliche Hinweise dafür“", daß schon „der Umgang mit der Technik den Menschen aggressiver macht" ${ }^{395}$ Technik ,an sich" erhält damit eine aggressivierende Wirkung zugeschrieben. Gesteigert findet sich diese unterstellte Wirkung für Glogauer dann, wenn sich die moderne Technik medial auslegt. Die technisch zustandegebrachten Medien, besonders die ,Bilderfluten“ von Film und Fernsehen, treiben - so legen seine Texte nahe - die Außenorientierung in eine Reizsucht, die nach immer größeren ,Emotionsschauern' und entsprechend stärkeren gefühlsprovokativen Darstellungen ruft. Die Reizorientierung des Publikums und die Reizgebung durch eine am Publikum und seinen Wünschen orientierte Medienproduktion bilden demnach eine Spirale, die sich ständig höher schraubt. Aus der Statuierung einer entfremdeten Orientierung des Menschen auf sekundäre Erlebnisse hin geht so beinahe mit Notwendigkeit die These einer unvermeidbaren Zunahme der Darstellungen von Aggressivität und Gewalt als entsprechenden Reizgebern hervor. Diese Zunahme jedenfalls ist für Glogauer nicht zu leugnen, ja sie ,hat in den letzten Jahren ein erschreckendes Ausmaß angenommen“. ${ }^{396}$ Film, Fernsehen und Video scheinen sich seinen Texten zufolge zu einer Flutwelle von Gewalt- und Verbrechensdarstellungen zusammengeschlossen zu haben, wie sie die Menschheit bislang noch nie gesehen hatte. Konsequenz der technisch-medialen Etablierung ,künstlicher Welten' und Bedürfnisse ist deshalb eine umfassende Defizienz und ein genereller Verfall. Von den reizgebenden Gewaltfluten nämlich gilt dann auch das Ethos der Gesellschaft ausgehöhlt und zunehmend korrumpiert, bis der ,Verfall der Werte' in jene Barbarei zurückführt, aus der sich der Mensch so mühsam gelöst hat (dazu mehr unten). Entsprechend sieht Glogauer eine völlige „Zerstörung der sozialethischen, moralischen Grundlagen unserer Gesellschaft“ durch den Film „schon längst (...) in Gang gesetzt" ${ }^{397}$

Diese destruktive Entwicklung wird dabei in typischer Reproduktion der kulturpessimistischen Optionen der ,Tradition' vor allem für ,die Großstadt' behauptet, während die ,kleineren Städte‘ und das ,Landleben“ wieder als Hort der wahrhaft menschlichen Lebensformen, zumindest aber als vom modernen Verfall weniger betroffen gelten. Medienkonsum und „Entfremdung gegenüber den natürlichen und sozialen Grundlagen des Lebens" nämlich scheinen vordringlich ,,in den Großstädten und Ballungsgebieten der Industrie" ihr eigentliches Realisationsfeld $\mathrm{zu}$ finden. ${ }^{398}$ Dort sei die „Befriedigung der ursprünglichen Bedürfnisse nicht mehr möglich“" ${ }^{399}$

\footnotetext{
394 Glogauer, Video, 81

395 Glogauer, Video, 133

${ }^{396}$ Glogauer, Kriminalisierung, 7

397 Glogauer, Kriminalisierung, 7

398 Glogauer, Kriminalisierung, 70

399 Glogauer, Kriminalisierung, 70
} 
so da $B$ anscheinend nur ,abgeleitete Bedürfnisse zu Produktion und Erfüllung kommen können, also die ,uneigentlichen' und destruktiven Phänomene der medial bestimmten Welt übrigbleiben. Hingegen sollen „Ausmaß und negative Auswirkungen des Medienkonsums (...) in der Regel im mittelständischen, kleinstädtischen und noch mehr im dörflichen Bereich (...) abgeschwächt" sein. ${ }^{400}$ Der ,bürgerlich-mittelständische' und insbesondere der agrarnahe Bereich gilt somit wieder als jener, der auch den ,heilen Strukturen' am nächsten ist, und die Modernitätskritik Glogauers schließt sich auch in ihren Lösungsvorstellungen bruchlos an die der Reformer und Filmerzieher an.

Damit aber reproduziert Glogauer in seinen Texten recht deutlich eine Grundhaltung, die ihn in der Tat als Traditor und Repräsentanten der Filmerziehung und sogar noch der Reformer in der Gegenwart ausweist. Er überträgt zunächst die Eigentlichkeitskritik Keilhackers in die Gegenwart und läßt hierbei auch den entsprechenden antitechnischen Affekt der Filmerziehung spürbar werden. Die (mediale) Technik gilt als Produzent künstlicher, letztlich als falsch gezeichneter Bedürfnisse und Zerstörerin der ,wahren', die wiederum ,unmittelbare', naturnahe und dem Menschsein vorgegebene, keineswegs aber vom Menschen erfundene Bedürfnisse zu sein scheinen. Die von der Technik bedingte moderne Welt gerät - wie bei Keilhakker - zu einem Ort zunehmender Selbstentfremdung des Menschenwesens. Konsequent finden sich weiter die Vorwürfe gegenüber der Etablierung einer sekundären, von Innerlichkeit und unmittelbaren Erfahrungen sowie darin gefundener Eigentlichkeit abduzierenden Realität durch den Film ungebrochen repetiert. Gerade der Film nämlich scheint den Menschen durch seine überbordende Präsenz in TV und Video in eine entfremdete und entfremdende Welt zu stellen, die eine , authentische Weltbegegnung ebenso wie die personale Kommunikation verstellt und destruiert. An die Stelle dieser unmittelbar-authentischen Begegnungsformen tritt der Kritik zufolge eine zunehmende Reizorientierung, die nach stets größeren, medial erzeugten und artifiziellen ,Gefühlsschauern' verlangt. Der zu ,natürlicher', aus personaler Kommunikation und Weltbegegnung quellender Gefühlsproduktion unfähige moderne Mensch scheint auf diese künstliche Reizgebung geradezu fixiert zu sein. Dabei gilt diese Fixierung als von den technischen Möglichkeiten des Films ebenso, wie von denen einer videovermittelten Nutzung desselben nur verstärkt; eine Autonomisierung des Rezeptionsverhaltens und eine Steigerung von Rezeptionskompetenzen hingegen nimmt Glogauer darin nicht wahr. Stattdessen deduziert er aus der These der Verhaftung des modernen Menschen an künstliche Reize und deren Steigerung eine exponentiell anwachsende Aggressivität der Inhalte, die in entsprechend aggressives Verhalten führe. Aus einer Welle medial appräsentierter Darstellungen von Gewalt und Verbrechen droht dann nicht weniger als die Zerstörung der sittlichen Grundlagen der Gesellschaft selbst hervorzugehen. Die Moderne, repräsentiert durch die 80er und 90er Jahre, wird auf diese Weise als Ort umfassender Defizienzen und völligen Verfalls gezeichnet, wobei die Medien an der Evozierung dieses Verfalls herausragenden Anteil zugemessen bekommen. Im Gegenzug dazu gelten die traditionaler und geschlossener verfaßten Lebenswelten von Land und Kleinstadt als Horte noch geringerer Zerstörung - weil sie die modernen medialen Möglichkei-

${ }^{400}$ Glogauer, Kriminalisierung, 70 
ten angeblich noch nicht im selben Ausmaß nutzten wie die Großstädte - und in der Folge auch als jene Bereiche, aus denen vermutlich die Heilung zu gewinnen ist.

Mit der bedürfnisbezogenen Argumentationsfigur und der Kontrastierung von Stadt und Land ist dabei eine schon vor der Filmerziehung vertraute Dichotomie wiederbelebt, die mit der Keilhackerschen Kritikfigur verbunden wird. Sie geht letztlich auf die Reformer zurück, die im Kontext der Natur-Kultur-Dichotomie versuchten, mit der Einführung ,ursprünglicher‘, d.h. traditionaler und ruraler Orientierungsformen die in der anthropologisch-ethischen Axiomatik antagonisierte Natur zurückzugewinnen. Die ,Ursprünglichkeit‘ fand sich dabei dort in ländlich-kleinstädtischen Bereichen, während in der Großstadt als Brennpunkt der ,Zivilisation' die Defizienz zuhause zu sein schien. Die Tatsache, daß diese Entgegensetzung auch bei Glogauer greifbar ist, weist ihn nun zunächst als der ,Tradition' in umfassender Weise verpflichtet aus. Darüber hinaus klingt in der Zurückweisung und Diskriminierung der städtisch-medialen Dynamik und ihrer ,künstlichen Bedürfnisproduktion' jedoch noch ein Moment an, das als regressive, generell gegen Fortschritt und (allzuviel) Kreativität gerichtete Haltung dekodiert werden kann und die Modernitätskritik als solche auf den Punkt bringt. Glogauers Text nämlich scheint sich mit der Revitalisierung der reformerischen Entgegensetzung von Stadt und Land genau besehen auch gegen die menschliche Entwurfspotenz zu richten sowie gegen die Autonomie des Subjekts, die darin aufscheint und sich realisiert. So wird das, gute Alte ' in dieser Entgegensetzung ja gegen die vor allem in den Städten greifbare, medial vermittelte Produktion neuer Bedürfnisse gesetzt. Diese Bedürfnisse scheinen dabei nur negative zu sein: Erfunden werden gemäß Glogauers Text offenbar nur aggressive und destruktive Bedürfnisse - nicht aber beispielweise neue ästhetische. Dem gezeichneten Bild nach scheint, sobald der Mensch einmal von seinen traditionalen Wurzeln, von Landleben und kleinstädtischer Gemeinschaft abgeschnitten ist, der Strudel zunehmender Entfremdung und in deren Gefolge die (Selbst-)Vernichtung zu drohen. Die Lösung kann unter diesen Bedingungen nur in der Rückorientierung auf vortechnische, vorindustrielle und damit vormoderne Zusammenhänge und in der Zurückweisung der spezifisch modernen Entwicklungsdynamik liegen. Damit aber sind letztlich der Erfindungsgeist des Menschen, seine Offenheit nach vorne und seine Fähigkeit zu evolutiver Veränderung, zur geschichtlichen Fortentwicklung seiner selbst und seiner Lebensbedingungen mißtrauisch beurteilt. Vor allem die Weiterentwicklung und Veränderung der menschlichen Neigungen, Strebungen und Wünsche gilt ja als prekär und wird von Glogauer recht restriktiv gehandhabt. Sein Text zielt derart zumindest tendenziell auf eine Statifizierung des menschlichen Wesens und ist getragen von einem nicht geringen Mißtrauen gegenüber der menschlichen Entwurfspotenz und Autonomie. Eine gedeihliche Ausübung dieser Potenz und Autonomie wird dem Menschen anscheinend nicht recht zugetraut. Daher ist auch die einlinig pessimistische Bewertung der Möglichkeiten etwa von Video, die dort nur Fixierung, nicht aber Kompetenz und selbstbestimmte, bewußte Nutzung wahrnehmen will, nur konsequent. In der Tat zeigt sich in der Nutzung von Video auch durch Jugendliche, wie sie Glogauer durchaus trotz entgegengesetzter Wertung beschreibt, ein zunehmend subjektvermittelter Umgang mit Film, der wachsende cineastische Kenntnisse und recht wache, bewußte Verarbeitungsformen der Rezipienten erkennen läßt. In ihm äußert sich zudem eine spezifische ,Rezipienten- 
autonomie', die jedoch von Glogauer nicht entsprechend reflektiert und gewürdigt werden kann. Sie würde der These zunehmenden Verfalls im Weg stehen. Im Hintergrund der These künstlicher und verderblicher Bedürfnisproduktion sowie einer Gewaltspirale in den Medien, aber läßt sich damit insgesamt eine pessimistische Einschätzung der neuzeitlich-modernen Entwurfsautonomie des Menschen entdecken. Wie bei Keilhacker wird dem Menschen eine Potenz zu gedeihlichem Selbstentwurf (und selbstentworfener Mediennutzung) kaum zugetraut und scheint jedes Bemühen darum fast a priori in den modernen Defizienzen unterzugehen. Gerettet werden kann der Mensch entsprechend nur durch einen Rückgang in geschlossenere Orientierungsformen und Lebenswelten. In Glogauers Text koppelt sich so letztlich die agrarromantische Inklination der Reformer in der Stadt-Land-Entgegensetzung mit dem Pessimismus des Schulgründers der Filmerziehung gegenüber der menschlichen Konstruktivität. Im ganzen aber führt Glogauers explizit gemachte Absicht, die ,Erkenntnisse' der Filmerziehung in die 80er und 90er Jahren zu transponieren und für eine entsprechende Auseinandersetzung mit dem zeitgenössischen Film sowie insbesondere mit dessen Verbreitung durch Fernsehen und Video fruchtbar zu machen, zu einer recht deutlichen Revitalisierung der von Keilhacker und den Reformern her vertrauten Modernitätskritik.

Dem schon in dieser Rekonstruktion spürbaren Pessimismus entsprechend reproduziert Glogauers Theorie dann auch die anthropologische Axiomatik der Reformer und Filmerzieher. Wie in der ,Tradition' bildet diese Axiomatik dabei die Basis für eine Reihe von Behauptungen unvermeidlich negativer medialer Wirkungen. So führt Glogauer unter Zitation Postmans in unverhüllter Deutlichkeit aus, daß dem Menschen ,an sich' nicht über den Weg zu trauen sei. Zunächst gilt dabei die Sexualität als paradigmatisch für die Gefährdung des Menschen durch naturale Latenzen und Triebstrebungen. So sei es ,gemeines Wissen aller gesunden Menschen', „daB in der Sexualität eine gewisse Raserei liegt“, die als äuBerst prekär einzustufen sei. ${ }^{401}$ Diese ,Raserei' dürfen „wir uns zu erregen nicht erlauben“, vielmehr müsse die Sexualität des Menschen ,stets von einem gewissen Geheimnis und einer Scheu umgeben sein (...), wenn wir bei gesundem Verstande bleiben wollen" ${ }^{402}$ Nicht weniger als Wahnsinn und Chaos also scheinen zu drohen, wenn diese ,urtümliche Triebkraft' nicht beizeiten in ein entsprechendes Gehege gebannt wird. Dieses Gehege aber sei ,das Schamgefühl', das exklusiv eine Barrierefunktion zugewiesen bekommt. Es schütze nämlich vor „,sexuellen Kurzschlüssen und Ausschweifungen“403, die ansonsten offenbar stets zu befürchten sind. Gleichwohl ist es nicht nur die Sexualität, die als gefährlich und gefährdend eingschätzt wird. Dem Menschen eignen darüber hinaus auch noch weitere negativ gezeichnete und verderbliche Strebungen. So steht der Mensch - nach Glogauer und Postman - ,ständig in der Gefahr, von Barbarei, Gewalt, Promiskuität, Instinkt und Egoismus überwältigt zu werden" ${ }^{404}$ Auch hier wird das ,Schamgefühl' als einzig rettende Barriere bemüht. Es sei geradezu „der Mechanismus, mit dem die Barbarei eingedämmt wird“ “ ${ }^{405}$ Die Folgerung aus dieser

\footnotetext{
${ }^{401}$ Glogauer, Kriminalisierung, 36

402 Glogauer, Kriminalisierung, 36

403 Glogauer, Kriminalisierung, 35

404 Glogauer, Kriminalisierung, 36

${ }^{405}$ Glogauer, Kriminalisierung, 36
} 
anthropologischen Axiomatik liegt deutlich auf der Hand: Wie bei den Reformern bedarf es starker Dämme und Barrieren, um die negativen Latenzen und Strebungen des Menschen zurückzudrängen, in Schach zu halten und einzugrenzen. Nur so kann dann ein gedeihliches Zusammenleben der von ihrer Natur her wolfsähnlichen Individuen garantiert werden. „Ohne Kontrolle der Triebregungen und insbesondere der aggressiven und auf direkte Befriedigung zielenden Regungen“" hingegen, so betont Glogauer mit Postman, "kann es keine Zivilisation geben. “406 Dabei sind es nun wieder die Medien, allen voran der Film, die diese Kontrolle gefährden, ja zerstören, und die damit einer perniziosen Freilegung der urtümlichen asozialen Strebungen des Menschen in die Hände arbeiten. Der anthropologischen Figur entsprechend erscheint diese verderbliche Wirkung der Medien einmal mehr als ,Enthemmung‘. Der „Enthemmungsprozeß“ besteht nach Glogauer näherhin darin, „daß die Hemmungen gegen Gewaltanwendung, die in den Jugendlichen durch Eltern und andere Sozialisationsinstanzen aufgebaut werden, durch ständigen Konsum von TV-Gewalt abnehmen, so daß schließlich der in den Jugendlichen vorhandene Drang nach Gewaltanwendung viel eher als sonst in Form von gewalttätigem Verhalten nach außen bricht". 407

Die anthropologische Argumentationsfigur der Reformer und Filmerzieher wird so bei Glogauer in einer derart expliziten Form repetiert, daß sie nicht einmal erst aus anderweitigen Äußerungen dekodiert werden muß. Der Mensch gilt unverhohlen als höchst gefährdetes Latenzwesen, dem eine natural begründete Inklination zur Amoralität, rücksichtslosen Egozentrik und Destruktivität von Beginn seiner Existenz an mitgegeben ist. Diese Latenz wird sowohl in der Sexualität, die an sich genommen auch ein höchst unsoziales und destruktives Phänomen zu sein scheint nicht weniger als Wahnsinn droht ja, wenn sie losgelassen ist -, als auch in den aggressiven Strebungen des Menschen gesucht. Aggression wird dabei als materiale, d.h. als mit einem konkreten Inhalt und Ziel versehene Strebung aufgefaßt und mit Gewalt und Barbarei in eins gesetzt. Daneben finden sich weitere Phänomene wie Egoismus und Promiskuität aufgeführt, die eigentlich bereits moralisch bewertete Verhaltensformen bezeichnen, hier jedoch als Anthropologika gehandhabt werden. All diese Strebungen müssen dann zivilisatorisch durch Errichtung entsprechender Barrieren eingegrenzt und zurückgedrängt werden. Erst aus dieser Eingrenzung resultiert auch die Zivilisation selbst, während der Mensch an sich offenbar ein Barbar ist, dessen naturale Neigungen, wenn sie einmal losgelassen sind, unvermittelt und zielstrebig in die Barbarei führen. Auf dieser axiomatischen Basis werden dann auch die Medienwirkungen prinzipiell schlüssig gemacht. Die modernitätskritisch perhorreszierte Flut aus Gewalt und Verbrechen, die alltäglich und allabendlich auf eine nur allzu interessierte Rezipientenschaft hereinzubrechen scheint, tut nicht mehr und nicht weniger, als die mühsam errichteten Dämme beiseite zu spülen. Dahinter aber kommt dann, gewissermaßen in lustvoller Anamnesis und Wiedererkenntnis der eigenen basalen Wesensnatur, die alte Ungestalt des ,urzeitlichen Schlächters' zum Vorschein, der sich sogleich nach einer Gelegenheit zur Realisierung seiner destruktiven Strebungen umsieht. Daher bedarf im Grunde auch die Wirkung medialer Ge-

${ }^{406}$ Glogauer, Kriminalisierung, 36

${ }^{407}$ Glogauer, Video, 139 
waltdarstellungen kaum einer besonderen empirischen Erarbeitung - der ,Drang zur Gewaltanwendung ist in Jugendlichen und Erwachsenen immer schon geradezu als Triebkraft da und scheint auch ,sonst' nach ,außen zu brechen', nur sorgen die Medien dafür, daß dies jetzt, viel eher' geschieht.

Auf dem Hintergrund dieser Axiomatik verwundert es nicht weiter, daß Glogauer dann insbesondere eine kriminalisierende und sexualisierende Wirkung der Medien diagnostiziert. In bezug auf die Kriminalisierung verläßt er dabei mitunter die anthropologische axiomatische Basis und spricht er von einer direkten Induzierung kriminellen Verhaltens durch die Medien. So betont er etwa unter Rekurs auf Lukesch, ${ }^{408}$ daß vor allem „Kleinkriminalität (...) durch den Gewaltkonsum im Kino, Fernsehen und Videofilmen bewirkt" werde. ${ }^{409}$ Hier sei ,sogar eine ,kausale Bedeutung des Konsums gewalttätiger Videofilme ermittelt" worden. ${ }^{410}$ Die Tatsache, daB er in einer Auswertung von 37 Gerichtsprotokollen in vier Fällen Aussagen der Delinquenten gefunden hat, daß sie ,durch einen Film' auf die Idee ihres Verbrechens ,gekommen' seien oder kurz vor einem Verbrechen einen gewalthaltigen Film gesehen haben, läßt ihn schlußfolgern, daß in ,über $10 \%$ “ aller Tötungsdelikte von jugendlichen Straftätern im Grunde die Medien die Schuld trügen. ${ }^{411}$ In diesem Sinn ist zweifelsohne auch seine häufig auftretende Formulierung zu verstehen, Jugendliche seien „,durch Medieneinflüsse straffällig geworden“412, oder es gehe darum, ,im einzelnen jene Medien zu bestimmen, die in erster Linie die Straffälligkeit Heranwachsender bedingen ". ${ }^{413}$ An anderen Stellen freilich wird dann auch wieder (deutlicher) die anthropologische Axiomatik im Hintergrund spürbar, wenn es etwa heißt, die ,Aggressionsbereitschaft' sei durch Medieninhalte ,erhöht' worden, ${ }^{414}$ also mithin zuvor bereits dagewesen, oder wenn einem jugendlichen Mörder attestiert wird, seine „kriminelle Energie“ sei zweifellos „eine weitere entscheidende Bedingung" für die Tat gewesen, freilich ,aber erst durch den Film aktiviert worden“415. In ähnlicher Weise wird auch z.B. in Bezug auf einen Konnex zwischen einer Mordtat und Rockmusik bemerkt, da $B$,Jugendliche durch stundenlanges Hören dieser Musik (...) Hemmungen abbauen", ${ }^{416}$ mithin also die anthropologisch fixierte Latenz bloßgelegt werde. Schließlich findet sich auch jene Argumentationsfigur in seinen Texten, die eine aktive Nutzung von Medieninhalten, insbesondere Kriminalitätsdarstellung, für

408 vgl. Lukesch, Helmut u.a. (Hrsg.), Jugendmedienstudie. Medienforschung 1, Regensburg 1989; Lukesch, Helmut u.a. (Hrsg.), Video im Alltag der Jugend. Medienforschung 2, Regensburg 1989; Lukesch, Helmut u.a. (Hrsg.), Wenn Gewalt zur Unterhaltung wird ... Medienforschung 3, Regensburg 1990

${ }^{409}$ Glogauer, Kriminalisierung, 74; Hervorhebung von mir.

410 Glogauer, Kriminalisierung, 73

411 vgl. Glogauer, Kriminalisierung, 77; nach dem Artikel der tz soll Glogauer diese Schlußfolgerung sogar für alle Gewaltverbrechen gezogen haben. So heißt es dort: „, Mindestens jedes zehnte Gewaltverbrechen, das Jugendliche begehen, geht eigentlich auf das Konto der Medien', stellte Glogauer fest, der für eine weitere Untersuchung zum Thema ,Mediengewalt und Gewalttaten' Gerichtsuntersuchungen des bayerischen Justizministeriums auswertete." (tz vom 28. Juni 1991, Titelseite)

412 Glogauer, Kriminalisierung, 114

413 Glogauer, Kriminalisierung, 113; Hervorhebung von mir.

414 Glogauer, Kriminalisierung, 111

415 Glogauer, Kriminalisierung, 84

${ }^{416}$ Glogauer, Kriminalisierung, 78 
die eigene ,kriminelle Weiterbildung annimmt. So soll eine eigentlich mit präventivaufklärerischer Intention produzierte Sendereihe im Fernsehen geradezu als ,Anleitung' oder ,Gebrauchsanweisung für entsprechende Delikte genutzt worden sein. ${ }^{417}$

Im Bereich der Sexualisierung wiederum sind es vorwiegend ein Abbau von Hemmungen und die Provokation der mit dem Menschen mitgegebenen entelechialen Triebregungen, die als Grund entsprechender Medienwirkungen angenommen werden. So ist die Rede von „ständige( $r$ ) sexuelle(r) Stimulierung der Heranwachsenden“, die unweigerlich „zu einem überall zu beobachtenden Abbau des Schamgefühls“ führe. ${ }^{418}$ Deutlich werde dieser ,Abbau' vor allem ,in der ,jugendspezifischen“ Sprache, in der Kleidung, im Umgang zwischen Knaben und Mädchen"“ ${ }^{419}$ Dabei scheint nach Glogauer heute schon im Kindesalter ,von beiden Seiten dem anderen Geschlecht mit direkten oder versteckten sexuellen Ansprüchen begegnet" zu werden. ${ }^{420}$ Die „Phase erotischer und rücksichtsvoller Annäherung“ der Geschlechter „im Kindesalter und in der frühen Jugend“ jedenfalls werde „durch die unverhüllte Mediensexualität und -pornographie heutzutage verhindert oder verkürzt ${ }^{4}{ }^{421}$ Es droht mithin erneut jene, Verfrühung', die schon von den Filmerziehern in Bezug auf die sich wandelnde Haltung der Jugend zur Sexualität diagnostiziert wurde. In diesem Kontext braucht es dann Glogauer zufolge nicht zu verwundern, wenn es „nicht beim bloßen Wünschen“ bleibe, sondern "die geweckten Triebe“ in die blanke Tat umgesetzt würden. ${ }^{422}$

Glogauer repetiert so die Kriminalisierungsthese und die Sexualisierungsthese in der von den Reformern und Filmerziehern vertrauten Form ungebrochen. Dabei läßt sich im Fall der Kriminalisierungsthese, wie die zitierten Textteile zeigen, sogar erkennen, daß Glogauer alle drei Formen dieser These, wie sie von den Reformern entworfen sind, zur Anwendung bringt: Einmal scheint die Kriminalisierung durch entsprechende Darstellungen direkt hervorgerufen zu werden und sich die Rezipientenschaft gegen einen entsprechenden Sog kaum zur Wehr setzen zu können. Zum anderen läßt sich die Annahme eines destruktiven Zusammenspiels der prekären negativen Latenzen im Menschen mit entsprechenden medialen Gehalten als Wirkungsbegründung entschlüsseln. Ein weiteres Mal wird schließlich wieder eine verderbliche Nutzung von Kriminalitätsdarstellungen durch ein bereits kriminelles oder zumindest protokriminelles Publikum angesetzt. In jedem Fall aber scheint der Ausgang des Zusammentreffens des Publikums mit entsprechenden Filminhalten gewiß zu sein - aus der Konfrontation mit der Darstellung von Kriminalität und Gewalt kann, so läßt Glogauers Text deutlich erkennen, für ihn nur die reale Reproduktion des Gesehenen quellen. - Ähnlich verhält es sich mit der Sexualisierung. Hier ist es jedoch vordringlich die Kooperationsthese, also das destruktive Zusammenspiel der Trieblatenz des Publikums mit den erotischen Inhalten, das die entsprechenden Wirkungen hervorruft. Kohärent zur anthropologischen Axiomatik wird dieses Zusammenspiel dabei als negativ bewerteter ,Abbau' von Hemmungen gezeichnet und gilt

\footnotetext{
${ }^{417}$ Glogauer, Kriminalisierung, 106

418 Glogauer, Kriminalisierung, 35

${ }^{419}$ Glogauer, Kriminalisierung, 35

420 Glogauer, Kriminalisierung, 35

421 Glogauer, Kriminalisierung, 35

422 Glogauer, Video, 138
} 
die Bloßlegung der an sich immer prekär eingeschätzen Regungen und Strebungen als Ursache des Verfalls. Gleichzeitig zeigt sich jedoch in den Formulierungen Glogauers, daß es erneut und selbst in den 80er und 90er Jahren immer noch der schon in den 60er Jahren realisierte Ethoswandel zu einer zunehmend selbstbestimmten Form der Ausübung von Sexualität ist, der den zentralen Stein des AnstoBes vorstellt. Der freiere Umgang mit Sexualität, die weniger verklemmten Begegnungen und die offenere Thematisierung dieses Bereichs menschlicher Existenz gelten als ebenso sprachlich wie in der Kleidung greifbarer Verfall an (so darf vermutet werden) ,Unanständigkeit', die ,rücksichtsvolle‘ Annäherung der Geschlechter scheint einer wohl als rücksichtslos bewerteten gewichen zu sein und hinter den Kontaktnahmen von Kindern werden fast aggressive ,Ansprüche‘ und unverblümte sexuelle Forderungen vermutet. Auch Glogauer kommt so offensichtlich mit dem Ethoswandel und einer subjektvermittelten Sexualität nicht zurecht. Für den Filmerzieher der 50er und 60er Jahre ist die Gegenwart der endgültige Austrag schon längst eingeleiteter Verfallsprozesse.

Damit zeigt sich insgesamt also, daß Glogauer nicht nur die modernitätskritische Grundhaltung Keilhackers und der Filmerziehung in Kombination mit reformerischen Paradigmen wiederholt, sondern daß er auch auf die anthropologische Axiomatik der ,Tradition' rekurriert und schließlich auf diesem Hintergrund die Devianzvorwürfe der Kriminalisierung und Sexualisierung erneut vorbringt. Er erweist sich auf diese Weise in der Tat als treuer Traditor der reformerischen und filmerzieherischen Reflexionsbestände und der darin fixierten Wirkungsvermutungen. Die recht schlichte und kaum durch methodologische Fortentwicklung gebrochene Rekapitulation der reformerisch-filmerzieherischen Axiome und Devianzvorwürfe aber ist nun um so bedauerlicher, als Glogauer immer wieder betont, es gehe gerade darum, monokausale Wirkungsschlußfolgerungen zu vermeiden und multiperspektivisch anzusetzen. ${ }^{423}$ Nicht in einer einlinigen Konzentration auf die zweistellige Relation Medium-Rezipient nämlich solle die Forschung ihre Ergebnisse suchen, da einer so angesetzten Untersuchungsperspektive mit Recht der Vorwurf gemacht werden könne, eine ungleichgewichtige Einschätzung der Medieneinflüsse vorzunehmen. In der zweistelligen Relation bleiben die unter Umständen wesentlich bedeutsameren Einflußfaktoren des sozialen Umfelds, der persönlichen Lebenssituation und der psychischen Konstitution des Rezipienten aus dem Blick und kann mithin etwas als Medienwirkung fälschlich eingeschätzt werden, was in Wahrheit ganz anderer Herkunft ist. Deshalb gehe es darum, die gesamte lebensweltliche Situiertheit des Rezipienten einschließlich der situationellen Bedingungen der Medienrezeption zu berücksichtigen. Einbezogen in die wirkungstheoretische Reflexion müßten insbesondere werden „die Bedingtheiten für Wirkungen (Persönlichkeit des Rezipienten, sein soziales Umfeld, Qualität und Quantität des Medienkonsums u.a.)“ und die „bei der Rezeption ablaufenden Prozesse“" ${ }^{424}$ Glogauer insistiert damit verbal durchaus schlüssig auf der Notwendigkeit einer Differenzierung der medienwissenschaftlichen Theoriebildung, die dann letztlich in die Reflexion der Mediennutzung im Kontext eines Sozialisationssettings münden könnte (und die Devianzthesen der ,Tradition“

423 vgl. etwa: Glogauer, Video, 126, 128-129

${ }^{424}$ Glogauer, Video, 128 
sprengen müßte). Gerade auch seine unzweifelhaft ,engagierten' Studien könnten so dem bereits in Auseinandersetzung mit den Wirkungsthesen der Reformer genannten, dringlichen Erfordernis komplexer und realitätsgerechter empirischer Untersuchungen dienstbar gemacht werden.

Gleichwohl scheint mir das Engagement diese Komplexierung in seinen Texten stets zu unterlaufen und die Multiperspektivität durch eine Fixierung zu ersetzen, die dann die Glogauersche Wirkungsforschung in die Vorgaben der ,Tradition' zurückfallen läßt. Statt einer ausgewogenen Reflexion der Medien als Teilmoment der subjektiven lebensweltlichen Situation nämlich vollzieht Glogauer immer wieder eine Kehre gegen die Medien, die dann eher die Lebenswelt als marginales Teilmoment der alles bestimmenden Medienrezeption erscheinen lassen. Die Medienrezeption wird dabei wieder auf die ,traditionale' axiomatische Basis gestellt und erlaubt so die Interpretation auch der lebensweltlichen Prozesse in den vertrauten Paradigmen. Damit sind bei Glogauer genau besehen nicht die Medien in die Struktur eines lebensweltlich verfaßten Sozialisationssettings eingebettet, das dann auch die Reflexion ihres Stellenwertes, ihrer Rolle und Funktion in diesem Setting erlaubte, sondern die von der reformerisch-filmerzieherischen Axiomatik prädefinierte Medienrezeption in der zweistelligen Relation Medium-Rezipient scheint das umfassende Setting zu sein, in das dann die übrige Sozialisation und die Lebenswelt eingebettet sind. Mit einem solchen Ansatz aber sind differenzierte Ergebnisse nicht zu bekommen, sondern lassen sich nur die - eigentlich erkannte - Ungleichgewichtigkeit und die ,Tradition' reproduzieren. Insbesondere das aktive Verhalten des Rezipienten, der seine Mediennutzung als Nutzung in bestimmten Kontexten vollzieht, die Medien in sein eigenes lebensweltliches Strukturgefüge einbaut und diesen dort einen bestimmten Ort und bestimmte Funktionen zuweist, bleibt aus der Theoriebildung ausgeblendet. In der Folge erscheint dann jedes Verhalten des Menschen, das sich irgendwie mit einem Medieninhalt assoziativ verbinden läßt, als medial verursacht und wird der Rezipient als hilflos den Vorgaben der Medien sowie ihrem Zusammenspiel mit den skizzierten Latenzen ausgeliefertes Wesen gezeichnet. Die Selbstbestimmtheit des Menschen in einem komplexen Bedingungsfeld seiner Selbstrealisation wird derart doppelt aus dem Blick gelassen: Einmal dadurch, daß er den Medien gegenüber nur als fremdbestimmtes Opfer erscheint, und einmal dadurch, daß der von seinen eigenen Latenzen manipuliert wird. Zum Sieg gebracht aber ist damit gegen die verbale Insistenz auf der Notwendigkeit einer differenzierten, multiperspektivischen Analyse von Medienrelevanzen in lebensweltlichen Kontexten die einlinige Devianzthetik der ,Tradition'.

So verweist Glogauer beispielsweise im Vorwort seines Kriminalisierungsbuchs zunächst darauf, es sei ihm darum gegangen, „über die Einzelfallanalysen hinaus die psychischen und sozialen Bedingungen herauszuarbeiten", 425 und läßt er damit in den Blick treten, daß diese Bedingungen für eine zureichende Erkenntnis medialer Wirkungen kaum zu unterschätzende Faktoren darstellen. Doch macht bereits die Fortsetzung dieses Satzes deutlich, welchen Stellenwert diese Bedingungen in seiner Theorie wirklich einnehmen. Sie stellen nämlich nichts anderes vor, als jene Bedingungen, „unter denen Kinder und Jugendliche durch Medien aggressiv und kriminell

\footnotetext{
${ }^{425}$ Glogauer, Kriminalisierung, 8
} 
werden“. ${ }^{426}$ Damit aber gelten sie lediglich als Randphänomene, die die schon vorher feststehende perniziose Medienwirkung flankieren und stützen. Die Formulierung zeigt zudem, worin der hermeneutische Schlüssel besteht, der für den Aufschluß entsprechender relevanter Umfeldphänomene benützt wird: Herausgearbeitet werden lediglich jene Umfeldfaktoren, die die ,Tatsache' zu unterstützen scheinen, daß Menschen ,durch Medien kriminell werden'. Die Leitperspektive für die Bearbeitung des Sozialisationssettings ist also recht deutlich die Kriminalisierung durch Medieninhalte, und die ,Auswahl' der in diesem Setting enthaltenen Momente geschieht exklusiv unter der Fragestellung, welche Momente diese a priori den Medien zugeschriebene Kriminalisierung gestützt haben könnten.

Dabei zeigen besonders Glogauers Einzelfallanalysen die Fixierung auf die unterstellte perniziose Rolle der Medien und eine entsprechende Unterordnung anderer Faktoren. So schildert er etwa den Fall eines 17-jährigen Gymnasiasten, der seine Mutter getötet hat. Der Jugendliche scheint nun der von Glogauer aus Gerichtsakten übernommenen Fallbeschreibung nach zu seiner Mutter eine spezifisch sadomasochistische Beziehung gehabt zu haben. Von ihm wird berichtet, daB er seit seinem 10 . Lebensjahr „,bei seiner dominanten Mutter aufgewachsen war, ,der er auf einen Blick hin zu gehorchen“ pflegte“ ${ }^{427}$ Auch am Abend der Tat unterwirft er sich den recht willkürlichen Direktiven seiner Mutter, die ihn aus einer ,,ihr nicht genehmen Feier mit Gleichaltrigen" einfach ,herausholt" und ,mit nach Hause nimmt". ${ }^{428}$ Dieser erneute „Übergriff auf seine altersadäquate Selbständigkeit“" wird zunächst in gewohnter Docilität hingenommen, hat jedoch spät nachts Folgen, als der Junge - unter Alkoholeinfluß und zweifellos im Zustand einer Verwirrung - zum Messer greift und die Mutter tötet. ${ }^{429}$ Glogauer deutet nun in seiner Analyse die Umfeldfaktoren, die familiale Geschichte und die Genese und Struktur der Mutter-Sohn-Beziehung nur an. Von großer Bedeutung nämlich ist ihm diese psychopathologische und sozialisationsspezifische Seite des Falls nicht. Den eigentlichen Impetus zur Tat sieht er daher auch nicht aus der Beziehungsstruktur quellen, sondern vielmehr durch einige Platten mit Rockmusik gegeben, die der Junge an diesem Abend in seinem Zimmer gehört hat. Sie interessieren ihn fast ausschließlich, und unter dem Eindruck der erneut scheinbar belegbaren perniziosen Wirkung von Medien entschwindet ihm die familiale Pathologie beinahe aus dem Blick. Stattdessen erscheint es ihm ungemein wichtig und geradezu vordringlich, über die gehörten Platten bis ins Detail Genauestes zu wissen. Mit äußerst dringlichem Interesse fragt er deshalb: „Welche Rockmusik hat der Jugendliche gehört? Hardrock/Heavy Metal? Welche Texte enthielten die gehörten Platten? In welchen Situationen hat er in den Wochen und Monaten vor der Tat intensiv diese Musik gehört? Wie war die Rezeptionssituation? usw.“.430 Die Beantwortung dieser Fragen erscheint ihm um so unabdingbarer notwendig, als „bekannt ist, daß Hardrock/Heavy Metal aggressive Musik und aggressive Texte bieten und Jugendliche durch stundenlanges Hören dieser Musik, die wie eine Droge

\footnotetext{
${ }^{426}$ Glogauer, Kriminalisierung, 8, Hervorhebung von mir.

427 Glogauer, Kriminalisierung, 77

${ }^{428}$ Glogauer, Kriminalisierung, 77

${ }^{429}$ Glogauer, Kriminalisierung, 77

${ }^{430}$ Glogauer, Kriminalisierung, 78
} 
wirkt, Hemmungen abbauen“ “ ${ }^{431}$ Keine einzige Frage hingegen widmet er der Beziehung von Mutter und Sohn. Die ,dominante Mutter bleibt ein nebenher erwähntes sozialisationsspezifisches Begleitphänomen, das nur genannt wird, um die verderbliche Medienwirkung zu stützen, d.h. im vorliegenden Fall letztlich: plausibel zu machen, weshalb die mörderische Aggression des Jugendlichen die Mutter und nicht eine andere Person traf. Die eigentliche ,Verursachung der Tat wird den Medien zugeschoben. Deren Wirkung wird dabei - wie die Formulierung des ,Hemmungsabbaus' zeigt - wieder mit der anthropologisch fixierten Latenz zur Gewalttätigkeit kooperativ hergeleitet. Damit aber ist die angekündigte sozialisationstheoretische und psychopathologische Erweiterung der Wirkungsforschung sogleich zurückgenommen und die Wirkungsthese auf die Axiomatik der ,Tradition' zurückgebogen. Ähnlich verfährt Glogauer in anderen Fallanalysen, wenn etwa der Angriff eines geistig behinderten (!) Mädchens auf einen kleinen Jungen und später auf eine Erzieherin auf Filmrezeption zurückgeführt wird. ${ }^{432}$ Die Behinderung findet dabei nur insoweit Erwähnung, als dem Mädchen dadurch „die letzten Konsequenzen einer solchen Tat (...) nicht bewußt werden konnten“. ${ }^{433}$ Trotz der spezifischen Situation einer Behinderung des Mädchens wird der Fall zudem als exemplarisch (und damit verallgemeinerbar) für mimetische Filmwirkungen gehandelt. An weiterer Stelle wiederum wird der Angriff eines Jugendlichen, der mit seinem als ,tyrannischer Alkoholiker" charakterisierten Stiefvater zusammenlebt und selbst „seit längerem übermäBig Alkohol konsumierte", auf zwei Frauen geschildert und der Rezeption von Ninja-Filmen angelastet. ${ }^{434}$ Der Stiefvater und der Alkoholismus werden dabei lediglich gegen Ende der Fallbeschreibung ,angemerkt" “35 während der Text zuvor in breiten Schilderungen versucht, Parallelen zwischen den Filminhalten und der Tat herzustellen. Kaum anders verhält es sich mit einem guten Teil der weiteren Fallbeschreibungen Glogauers.

Entgegen der erklärten Absicht, monokausale Engführungen und eine einlinige Konzentration auf die zweistellige Relation Medium-Rezipient zu vermeiden und stattdessen zu einer differenzierten Erforschung der wirkungsbezogenen Einbettung der Medienrezeption in ein lebensweltliches Setting vorzudringen, bleibt Glogauer so letztlich doch bei der zweistelligen Relation stehen und kehrt er im Kern seiner Wirkungsforschung zu weitgehend monokausalen Annahmen zurück. Er nennt zwar mitunter sozialisationsspezifische Bedingungen der in (übrigens extremen und meist pathologischen) Fällen aufgesuchten Medienwirkungen, fixiert sich dabei jedoch so ausschließlich auf eine herausragende Verursacherrolle der Medien, daß diese Bedingungen letztlich an den Rand der Theoriebildung gedrängt und nur zur Stützung der These von perniziosen Medienwirkungen genützt werden. Nicht selten schrumpft die Bedeutung des Sozialisationssettings dabei darauf zusammen, daß durch seine Skizzierung genau besehen lediglich die faktische Richtung einer kriminellen oder gewalttätigen Handlung plausibilisiert wird - wie im Fall des 17-jährigen Jungen, der seine Mutter tötete -, nicht aber die Genese der Handlung wirklich aufgeschlüsselt

${ }^{431}$ Glogauer, Kriminalisierung, 78

432 Glogauer, Kriminalisierung, $78-79$

433 Glogauer, Kriminalisierung, 79

434 Glogauer, Kriminalisierung, 81

${ }^{435}$ Glogauer, Kriminalisierung, 81 
werden kann. Statt einer differenzierten Reflexion der Einbettung der Medienrezeption in ein lebensweltliches Gesamtsetting, durch die dann auch Rolle, Funktion und insbesondere Stellenwert der Medien für den Lebensvollzug erhellt werden könnte, biegt die Glogauersche Untersuchung von Einzelfällen sich stets wieder auf die reformerisch-filmerzieherische Axiomatik zurück. Diese Axiomatik und ihre Devianzvorwürfe liefern die eigentliche Folie, auf der Wirkungen entschlüsselt und plausibilisiert werden. Damit ist es auch diese Folie, die letztlich die Struktur des vorgeblich in den Blick genommenen Settings definiert. Entsprechend kann dann nicht mehr auf die Eigenaktivität von Rezipienten, auf ihren bewußten Gebrauch und Einsatz von Medien in bestimmten Kontexten geblickt werden, sondern wird anstelle eines Nutzungsverhaltens ein schlichtes Reiz-Reaktions-Schema angesetzt, in dem entweder die Medieninhalte aus sich heraus einen verhaltensformierenden ,Impact' zugeschrieben bekommen oder wieder ein kooperatives Zusammenwirken von anthropologisch fixierten Latenzen und Strebungen mit diesen Inhalten postuliert wird. Die Rezipienten bleiben dabei in doppelter Hinsicht als ,Opfer' der Medienwirkungen gezeichnet, da sie einmal gewissermaßen von außen überrollt werden und ein andermal ihren eigenen Latenzen erliegen. Der Subjektcharakter und die Autonomie der Rezipienten können in diesem Theorieschema weder in den Blick noch ernst genommen werden. Glogauers Theoriebildung aber verfehlt damit sowohl den eigenen Anspruch einer multiperspektivischen Medienwirkungsanalyse als auch die Realität der Rezipienten. Durchaus kohärent hingegen ist dieses Schema mit der antiautonomistischen, pessimistischen und modernitätskritischen Grundhaltung der Reformer und Filmerzieher, deren Tradition Glogauer ja auch explizit - zumindest bezüglich der Filmerziehung - fortführen will. Mit seiner Fortführung bleibt zugleich die ,Tradition' in der Gegenwart lebendig. Durch ihren sensationellen Charakter und ihre daraus quellende zeitweilige Popularität aber bestätigt sie populäre, ebenfalls aus der ,Tradition' stammende Vorurteile über die ,Mediengefahr" und behindert sie sowohl eine differenzierte wirkungstheoretische und medienpädagogische Reflexion als auch eine modernitätsgerechte medienethische Theoriebildung, die nach den besonderen Nutzungsformen und medienspezifischen Kompetenzen der Rezipienten fragt und dabei die Subjektivierungs- und Autonomisierungsprozesse in der Moderne zu fördern sucht.

\section{Transformative Revitalisierung des reformerisch-filmerzieherischen Pessimismus mit lerntheoretischen Mitteln}

Nicht unproblematisch scheint mir jedoch jenseits der deutlichen und expliziten Repetition der reformerisch-filmerzieherischen Theoreme auch jene Form der lerntheoretischen Wirkungsspekulation zu sein, wie sie Herbert Selg von 1972 bis in die Gegenwart vorträgt. ${ }^{46}$ Genau besehen nämlich sucht dieser Ansatz nicht so sehr

${ }^{436}$ vgl. Selg, Gewalt; Bauer, Mathilde, Selg, Herbert, Gewaltdarstellungen im Fernsehen kennen wir die Folgen?, in: BPS-Report 5/1981, 6-15; Selg, Herbert, Irreführungen der Öffentlichkeit über Wirkungen von Gewaltdarstellungen in Medien, in: BPS-Report 4/1984, 9-11; Selg, Herbert, Über Auswirkungen der Brutalität in den elektronischen Medien auf Kinder und Jugendliche, in: BPS-Report 1/1987, 1-3; programmatisch ist der erste der genannten Aufsätze, während die weiteren die Kernthese lediglich repetieren oder sich - nicht gerade unpolemisch - gegen Gegner einer entsprechenden Wirkungsvermutung wenden. Ich werde mich daher auf 
Wirkungen bestimmter - näherhin gewalthaltiger - medialer Darstellungen erst aufzufinden, sondern vielmehr ihre bereits vorausgesetzte Existenz zu plausbilisieren. Die Existenz pernizioser Wirkungen nämlich gilt Selg als durch verschiedene experimentelle Studien längst nachgewiesen, so da $B$ ohnehin nur eine nachvollziehende Erklärung des Wirkungszusammenhangs, der Genese der Wirkungen not zu tun scheint. Andere Studien, die der angenommenen Wirkung widersprechen, sowie methodologische Reflexionen oder Problematisierungen der experimentellen Versuche des Nachweises negativer Medienwirkungen werden dabei zurückgewiesen oder als ,Irreführungen' der Öffentlichkeit apostrophiert. Sie gelten entweder als ,schuldhafte, also beinahe böswillige Unternehmungen oder werden ironisch einem realitätsfremden, in theoretischen Leerlauf mündenden Szientismus zugerechnet ${ }^{437}$ An ihrer Stelle wird dann eine bestimmte Form der Lerntheorie dargelegt und als Erklärungsinstrument für Medienwirkungen empfohlen. In der vorliegenden Form hat diese Theorie insbesondere den Status einer prognostischen Wirkungstheorie, die ihre Wirkungen mit einer gewissen Wahrscheinlichkeit voraussagen zu können beansprucht. Sie legt damit die Basis nicht allein für eine rekonstruktive Analyse bereits eingetretener Wirkungen sondern - und darin liegt ihre eigentliche Absicht - für aufgrund der prognostischen Wahrscheinlichkeit gebotene Präventivmaßnahmen. In diesem Sinn will Selg mit seiner Theorie auch wirken, wie die Ableitung konkreter Maßnahmenempfehlungen in seinem zentralen Aufsatz zeigt. Diese Empfehlungen aber sowie die spezifische implizite Methodik seiner Argumentation führen meines Erachtens vom lerntheoretischen Ansatz aus zurück in die Devianzthesen und Lösungskonzepte der Reformer und Filmerzieher. Die Selg'sche Form der lerntheoretischen Wirkungsspekulation scheint mir daher eine Art transformative Revitalisierung reformerisch-filmerzieherischer Optionen zu sein. Aus diesem Grund will ich sie im folgenden einer rekonstruktiven Analyse unterziehen und ihren Bezug zur ,Tradition' genauer beleuchten.

Die Theorie Selgs nun richtet sich - wie erwähnt - vor allem auf die Wirkung gewalthaltiger Mediendarbietungen und versucht, die verderblichen Konsequenzen solcher Darbietungen argumentativ zu erweisen. Sie geht dabei zunächst nicht - wie die Reformer und Filmerzieher - von einer bereits vorhandenen negativen Latenzbasis im Menschen aus, sondern versucht, die Herstellung dieser Basis zu beschreiben. Dabei lautet das Grundaxiom: Aggressives Verhalten wird - „ebenso wie andere Verhaltensweisen" - durch Appräsentation von erfolgreichen Verhaltensformen (hier: aggressiven) und nachfolgende eigene Erfolge gelernt. ${ }^{438}$ Intermittierend

die ausführliche argumentative Darlegung der These Selgs in diesem ersten Aufsatz konzentrieren und deren Stichhaltigkeit prüfen.

${ }^{437}$ So stellt Selg etwa unter Bezugnahme auf die Äußerung, die Wirkungshypothesen der einschlägigen Literatur seien widersprüchlich, die Frage: „Wie gehen Autoren vor, die eine solche Bewertung verschulden?" (Selg, Irreführung, 9; Hervorhebung von mir) und stellt er mithin jeden, der die Kontroversität der Wirkungsforschung auch nur benennt, unter Schuldverdacht. Nach einer Aufzählung von Wirkungsthesen, die er ,in der Literatur angetroffen" habe, wiederum erklärt er sich ironisch „bereit, bei jedem Frühstück diese ,Hypothesen" um eine weitere aus dem Stegreif zu ergänzen“, und beschließt er mit eingestandenem „Sarkasmus“ eine Reihe parodistisch gemeinter eigener Wirkungsthesen „mit der These der rotierenden Szientologen“ (Selg, Irreführung, 9).

${ }^{438}$ Selg, Gewalt, 14 
auftretende Mißerfolge und Frustrationen gelten dabei nicht als Behinderungen des Lernens eines bestimmten Musters, sondern als Förderungsinstanzen, da die Bewältigung der Mißerfolge und die ,Durchsetzung' des Musters gegen Widerstände als Verstärker wirke. ${ }^{439}$ Dieses Erlernen von aggressiven Verhaltensweisen entschlüsselt der Theorie zufolge geradezu das ,Entstehen' von Aggression. Tatsächlich nämlich gehe es dabei nicht allein um die reproduktive Übernahme ,einzelner Verhaltensweisen', die noch keinen Anlaß zu ,besonderer Besorgnis' gäbe, sondern um das Erlernen der ,Eigenschaft Aggressivität" ${ }^{440}$ Dies aber bedeute geradezu die Konstitution einer „Bereitschaft, vermehrt in verschiedenen Situationen aggressiv zu handeln“. 441 Auf lange Sicht sieht Selg daraus dann ,bei Einigen“ sogar eine „Ausbildung von Aggressivität als (...) Lebensstil“ hervorgehen. ${ }^{442}$ Dies aber erscheint als katastrophale Folge geglückten Lernens, denn Aggression ist in Selgs Theorie identisch mit Destruktion. Er setzt schon zu Beginn seiner Überlegungen einen materialen Aggressionsbegriff an und definiert Aggressionen als „Handlungen, durch die dem Aggressionsobjekt Schaden zugefügt werden soll“, sowie „alle größeren, ernsthaften Aggressionen als Gewalttaten"“443 Den klassischen psychoanalytischen Aggressionsbegriff, der formal ausgelegt ist und Aggression als Impuls zur Durchsetzung begreift, lehnt er explizit ab. ${ }^{444}$

Die so bestimmte Aggression kann nun nach Selg auch durch die Beobachtung von erfolgreicher Aggressionsausübung in Filmen entstehen. Der Mechanismus ist dabei zunächst so zu denken, daß die Rezeption gewalthaltiger Filme eine Bereitschaft zu entsprechendem Verhalten im Menschen erzeugt, der dann dieses Verhalten bei erfolgreicher Repetition in der Realität zu seinem ,Lebensstil' macht. So sieht Selg durch Beobachtung in breiten Kreisen der Bevölkerung gelernt, „daB man Mitmenschen mit E 605, mit einem Halstuch oder mit einer Pistole umbringen kann““ ${ }^{445}$ Folge sei „die Einstellung, das Leben sei nicht viel mehr als eine Kette aggressiver Szenen, von Schlägerien und Mordtaten durchsetzt““ ${ }^{446}$ Dieser Mechanismus scheint unaufhaltsam und unausweichlich zu sein, um so mehr, als gelegentliche Mißerfolge per definitionem ja nur als Verstärker der Einübung aggressiven Verhaltens auftreten können und es mithin schon sehr massiver und lang anhaltender Frustrationen bedürfte, um die Lernrichtung rechtzeitig umzukehren. Ist das Verhalten einmal eingewohnt, schwinden nach Selg die Chancen einer ,Deprogrammierung ohnehin völlig. Letzte Konsequenz der Appräsentation von Gewalt in Filmen ist demnach unzweifelhaft die Katastrophe: Aus der Rezeption gewalthaltiger Filme quillt offenbar mit Notwendigkeit ein gesellschaftsweiter aggressiv-destruktiver Lebensstil. Mit einer verschwörungstheoretischen Wende sieht Selg diese Aggressivierung der Gesellschaft gleichwohl als durchaus ,trendgerecht', denn „es scheint mäch-

\footnotetext{
439 vgl. Selg, Gewalt, 14

${ }^{440}$ Selg, Gewalt, 14

${ }^{441}$ Selg, Gewalt, 14

${ }^{442}$ Selg, Gewalt, 14

$443 \mathrm{Selg}$, Gewalt, 13

444 vgl. Selg, Gewalt, 13

445 Selg, Gewalt, 24

${ }^{446}$ Selg, Gewalt, 24
} 
tige Kräfte zu geben, welche die Gesellschaft als aggressive erhalten wollen “. ${ }^{447}$ Diese Kräfte vermutet er unter anderem in „Waffenproduzenten““ 448

Dabei muß sich freilich auch Selg der Tatsache stellen, da $B$ der angeblich gelernte destruktive Lebensstil nicht ständig und insbesondere nicht unmittelbar nach den ,attraktiven' gewalthaltigen Filmen in brachiale Gewaltausübung führt. Den Grund hierfür sieht er zunächst in einem „Gewöhnungseffekt“, der es mit sich bringe, daß „durch Mediengewalt allmählich keine starken Emotionen (Affekte) mehr geweckt und keine unmittelbaren Aggressionen mehr provoziert werden. "449 Gleichwohl gilt ihm das nicht als ,Entschärfung' der Situation etwa im Sinn einer bestimmten erworbenen Rezeptionskompetenz, die Distanzierung und entsprechende Verarbeitung des Gesehenen ermöglicht. Vielmehr bedeutet für ihn die Abwesenheit unmittelbarer Gewaltexzesse nach gewalthaltigen Filmen lediglich, daß dort, ,wo bereits aggressives Verhalten und zugehörige Tendenzen oder Stile gelernt sind, (...) allmählich kein weiteres Lernen von Aggressionen und Aggressivität mehr möglich“ ist. ${ }^{450}$ Denn: „Wer schon alles kann, kann nichts mehr dazu lernen.“451 Daher ist die docile Ruhe nach der Rezeption gewalthaltiger Filme für ihn nicht als ,Befriedung aggressiver Strebungen und auch nicht als Folge einer distanzierenden Rezeptionskompetenz zu verstehen, sondern lediglich als Ausdruck der Tatsache, daß die bereits erworbene Potenz zum Einsatz destruktiver Energien weiteres ,Üben“ überflüssig macht. Die Destruktivität lauert jedoch unter der Decke und kann jederzeit mobilisiert werden.

Dieser Konsequenz entsprechend spricht Selg von der „Gefährlichkeit der Gewaltdarstellungen in Massenmedien “452 und fordert er deren völlige Entfernung oder zumindest die sofortige medienimmanente Bestrafung jeder gewalttätigen Handlung. Denn ,wer Aggressionen erlaubt, erlaubt Erfolge durch Aggressionen““53 und demnach die Entstehung einer Flut erlernter Gewalttätigkeit bei den Rezipienten. Augenblicklich bestrafte Gewalthandlungen hingegen zählen zu den ,erfolglosen' und können mangels Attraktivität keine entsprechende Lernwirkung mehr entfalten. ${ }^{454}$ Umgekehrt gilt die Appräsentation auch positiver Gewaltausübung - etwa in einem Kriminalfilm durch die Polizei oder den Detektiv - als äußerst verderblich. Selg scheint es sogar möglich, durch solche Darstellungen, zumindest aber „mit einigen der auf dem Markt befindlichen Filme die Zahl der Sadisten systematisch [zu] erhöhen“ ${ }^{455}$ Davon sind auch Erwachsene nicht ausgenommen, vielmehr gilt die von Selg entworfene Variante der Lerntheorie als für alle Mitglieder einer Gesellschaft zutreffende Begründung der ,Gefährlichkeit' der Gewaltrezeption durch Filme und andere Medien. ${ }^{456}$ Nachdem auf diese Weise der urzeitliche Schlächter als neuzeitlicher medial erzeugt worden ist, bleibt dann umgekehrt erneut nur die Bekämpfung

447 Selg, Gewalt, 18
448 Selg, Gewalt, 18
449 Selg, Gewalt, 23
450 Selg, Gewalt, 23
451 Selg, Gewalt, 23
452 Selg, Gewalt, 27
453 Selg, Gewalt, 13
454 vgl. Selg, Gewalt, 22
455 Selg, Gewalt, 24
456 vgl. Selg, Gewalt, 27 
seiner prekären Stimulanzien: „Man unterlasse die Detailschilderungen von Gewalttaten aller Art in Massenmedien; sie sind zur Information im allgemeinen nicht nötig; vor allem schildere man nicht mehr die geglückte Aggression.“457

Die Selg'sche Form der Lerntheorie ist nun recht problematisch. Ein genauer Blick zeigt, daß sie sich im Kern auf ein reines Stimulus-Response-Paradigma zurückzieht und derart unter die Verursachungsthese begibt. So steht am Beginn des negativen Lernprozesses exklusiv der gewalthaltige Film, dessen Inhalt einen offenbar durch keine selektiven und interpretativen Mechanismen gefilterten Einfluß auf den Rezipienten ausübt. Die einzige Folie, die der Rezipient für seine Auffassung des Films mitzubringen scheint, ist die Fähigkeit zur Wahrnehmung und zum Verständnis des Erfolgs oder der Erfolglosigkeit einer dargestellten Aggression/Destruktion. Erkennt der Rezipient eine Aggression im Film als erfolgreich, so scheint die Inkorporation derselben ins eigene reale Verhaltensrepertoire schon unaufhaltsam. Selbst die Frage nach der Realitätsgerechtheit des Aggressionserfolgs in einer mit der eigenen Lebenserfahrung kohärenten Wirklichkeit, also die Frage, ob der Held etwa eines Actionfilms mit seiner gewalttätigen Handlung in einer vergleichbaren realen Situation denselben Erfolg haben würde, wird nach Selgs Theorie nicht mehr gestellt. Stattdessen scheint die Beobachtung fiktiven Erfolgs einer fiktiven Handlung fiktiver Figuren unmittelbar die Übernahme in den Habitus des Rezipienten und die Umsetzung in wirkliches Handeln realer Personen zur Folge zu haben. Damit aber ist letztlich das Stimulus-Response-Paradigma der älteren Wirkungstheorien angesetzt und das mimetische Wirkungskonzept der Reformer reproduziert. Der Filminhalt scheint eine realitätsprägende Entelechie zu besitzen und als solcher ungehemmt zur Wirkung' zu gelangen (Lange). Während Lange diese ungehemmte Wirkung auf den Abbildrealismus des Films zurückführt und derart ästhetisch-theoretisch zu plausibilisieren sucht, entsteht die Realistik bei Selg gewissermaßen aus der Transposition des filmisch appräsentierten ,Modells' ins Verhaltensrepertoire des Rezipienten, der nun zum Abbild der Filmwirklichkeit in der Realwelt gerät. Die Wirkung des Films wird in beiden Fällen als überwältigende gezeichnet, gegen die eine Gegenwehr kaum möglich erscheint, und der Rezipient gilt jedes Mal als schrankenlos für jede Beeinflussung offenes Objekt des Films. Zur Anwendung gebracht ist jeweils die Verursachungsthese (vgl. 2.4.), die jedes aktive, eigenständige Verhalten des Rezipienten übergeht.

Ist der Wirkungszusammenhang einmal derart mit dem mimetischen StimulusResponse-Paradigma angesetzt, so kann dann in der Folge auch die Kooperationsthese wieder eingeführt werden. Einmal aggressiviert, stellt der Rezipient weiterer Filmnutzung ja nun eine negative Latenz zur Verfügung, die die Einführung aller mit der Kooperationsthese verbundenen Devianzvorwürfe gegen den Film ermöglicht. Da zudem auch die Pathologien von Selg nicht als solche, sondern als mit anderen Verhaltensschemata gleichrangige Lernerfolge gehandelt werden, können auch die ,sadistischen' Instinkte des Publikums auf der Basis der Lerntheorie einer entsprechenden Beurteilung von Filmwirkungen axiomatisch dienstbar gemacht werden. Die Beschreibung der mimetischen Herstellung der Latenz in den Persönlichkeitsstrukturen der Rezipienten liefert damit die Basis für die darauf aufbauende Revitalisie-

${ }^{457}$ Selg, Gewalt, $30-31$ 
rung auch aller einer antezedenten negativen Latenz, bedürftigen' Devianzthesen. Im Ganzen droht dann der Theorie zufolge erneut und durchaus konsequent nicht weniger als eine gesellschaftsweite Katastrophe: Wo Gewalt im Film geboten wird, bleibt dem Rezipienten ja offenbar keine Wahl mehr; entweder ist er gezwungen, einzig und allein die Vorgabe zu übernehmen und durch Einübung in sich verwurzeln, bis daraus ein Lebensstil geworden ist, oder er wird in der bereits erzeugten Verhaltensausrichtung bestärkt und so ebenfalls und weiter in den circulus vitiosus der Destruktivität getrieben. Da der Film große Verbreitung besitzt, werden wohl fast alle Gesellschaftsmitglieder von ihm erfaßt und stürzt die Gesellschaft als Ganze in einen Strudel der Gewaltbereitschaft und Gewalttätigkeit.

In dieser Argumentationsfigur aber wird weder der Eigenanteil der Rezipienten in der Medienrezeption beachtet noch das lebensweltliche Umfeld, das soziale Setting, in die Reflexion einbezogen. Angesetzt ist wieder einzig die zweistellige Relation Film-Rezipient, wobei der Rezipient als formbare plastische Masse oder leere Verhaltenshülle gilt. Die Tatsache, daß der Rezipient aktiv den Film nutzt und mit eigenen interpretativen Vorgaben auf ihn zugeht, daß er das Gesehene weiter in einen lebensweltlich-sozialisativen Kontext einbindet und aus diesem Kontext sowie seiner eigenen Subjektivität heraus Stellung zu Filminhalten bezieht, wird hierbei schlicht aus dem Blick ausgegrenzt. Den Filmnutzern wird in keiner Weise die Fähigkeit zu aktiver, bewuBter Auffassung und interpretativer, stellungnehmender Verarbeitung des Gesehenen zugetraut. Damit aber wird (erneut) ihr Subjektcharakter weder an- noch ernstgenommen. Die einzige ,subjektive‘ Aktivität des Rezipienten besteht in der Übernahme und Einübung des Rezipierten, d.h. in ihrer freiwilligen Unterwerfung unter die Filmwirkung als deren Objekt. So aber bleibt der Inhalt eines Films das alleinige Agens. Der Rezipient wird als bewußtlose Maschine der Mimesis gezeichnet und theorieimmanent desubjektiviert. Die Tatsache, daß selbst Erwachsene sich diesem mechanischen Zusammenhang nicht entziehen zu können scheinen und mithin nicht nur Jugendliche im Fokus der Wirkungstheorie stehen, belegt dabei die Beobachtung dieser theorieimmanenten Ausgrenzung des Subjektcharakters der Rezipienten. Unter dieser Voraussetzung reicht dann freilich auch für die Einschätzung medialer Wirkungen der Blick auf den Filminhalt. Wo der Blick auf den Rezipienten und seine Subjektivität, seine Kompetenzen und lebensweltlichen Bedingungen vollständig unterlassen wird, ist es ja genau besehen ohnehin nur dieser Inhalt, der vermittelt durch Übung und Durchsetzung seiner modellhaften Verhaltensdarstellung gegenüber zeitweiligen realen Behinderungen am Ende im Rezipienten einwohnt und dessen leere Verhaltenshülle ausfüllt, um dann das induzierte Verhalten durch weitere Einwirkung zu verstärken und zu bestätigen. Die Konsequenz eines solchen Theorieparadigmas aber ist dann, daß letztlich eine Wirkungsforschung und Reflexion von Wirkungen überhaupt nicht weiter stattfindet. Filminhalt und Wirkung sind identisch geworden. Damit muB schließlich auch die umgekehrte Forderung einer solchen Theorie dieselbe werden wie bei den Reformern und Filmerziehern: Erlaubt ist im Film nur, was auch in der Realität erlaubt ist. Die Fiktionalisierung real unzulässiger Verhaltensweisen, selbst wenn die fiktionale Appräsentation Reflexion erzeugen will, kann dort, wo das Publikum per definitionem nicht mehr als reflexives, sondern lediglich als mimetisches angesetzt ist, keinesfalls mehr geduldet werden. Mußten also bei den Reformern und Filmerziehern alle in- 
haltlich prekär erscheinenden Filme (meist) deshalb beseitigt werden, weil sie mit den Latenzen des Menschen zusammenzuwirken drohten, so müssen sie es jetzt, weil sie diese Latenzen hervorbringen - und später deren Verstärkung evozieren.

Auf diese Weise aber liefert die Selg'sche Theorie letztlich nicht wirklich ein differenziertes Instrumentarium zur Einschätzung der Wirkung gewalthaltiger Filme. Sie stellt vielmehr eine transformative Revitalisierung des reformerisch-filmerzieherischen Paradigmas der gefährlichen Latenzen des Menschenwesens dar und neglegiert erneut den menschlichen Subjektcharakter. Sie ermöglicht auf diese Weise ebenso die Wiederbelebung der zugehörigen Devianzvorwürfe wie die ungebrochene Wiedereinführung aller zugehörigen bewahrethischen Maßnahmenforderungen. Die Transformation besteht dabei in der Konstruktion eines Theorieparadigmas, das die negative Latenz nicht negiert, sondern deren Herkunft zu beschreiben versucht. Wo die Reformer und Filmerzieher die negative Basis mit einer anthropologischen Figur aus der Phylogenese des Menschen ableiteten, unternimmt Selg seine Herleitung aus der Ontogenese des Individuums. Nicht die Frage nach der Realität medial erzeugten gewalttätigen Verhaltens wird jedoch bei ihm gestellt, sondern unter Voraussetzung der unbefragten Plausibilität einer medialen Erzeugung von Destruktivität wird einzig der mögliche Gang einer solchen Genese unter Verwendung lerntheoretischer Überlegungen aufgesucht. Es geht mithin weniger um die Überprüfung der Möglichkeit mimetischer Handlungsvollzüge auf der Basis von Medienrezeption, sondern mehr um die Konstruktion eines möglichst unmittelbaren Wirkungszusammenhangs, dessen Ergebnis schon feststeht. Die negative Latenz des Menschenwesens ist damit zwar eine kontingente Erscheinung ex post, jedoch entsteht sie nach Selgs Theorie mit einer derart unausweichlichen Notwendigkeit, daß sie letztlich dieselbe ,Festigkeit' besitzt, wie die reformerische Ontologisierung von negativen Strebungen und Pathologien zu Anthropologika. Dabei wird wie bei den Reformern - und hierin liegt das eigentlich Problematische des Selg'schen Ansatzes - im Zuge der Annahme einer Unausweichlichkeit negativer Filmwirkungen zugleich jede Eigenleistung der Rezipienten aus der Theorie ausgegrenzt und eine beinahe ,automatische' Mimesis statuiert. Auf diese Weise führt die Argumentationsfigur Selgs nicht nur zur Einführung einer quasi-ontologischen negativen Latenzbasis im Menschen, sondern zudem zu einer Abstraktion vom menschlichen Subjektcharakter, die der kontramodernen Negation dieses Charakters bei den Reformern gleichklingt. Auch und gerade weil Selg den Menschen - darunter selbst den Erwachsenen - als schrankenlos beeinflußbares Objekt der Filmwirkung, als hilflose Mimesismaschine zeichnet und so die Fähigkeit zur Stellungnahme gegenüber dem Gesehenen leugnet, begibt er sich mit seiner Theorie in die Paradigmen der, Tradition' zurück. Die Negation der Möglichkeit eines aktiv-wertenden Verhaltens des Rezipienten nämlich übergeht zusammen mit der bewußten Mediennutzung und -verarbeitung auch das Kernmoment der menschlichen Subjektivität: die Fähigkeit zur Autonomie. Selbstbestimmung gibt es bei Selg nicht; an ihre Stelle tritt die Fremdbestimmung durch den Inhalt des Films. Es erscheint nur logisch und schlüssig, daß Selg dann die Medieninhalte ebenso ,gefährlich' einschätzt, wie es die Reformer taten, und daB er eine entsprechende Beseitigung aller fiktionalen Darstellungen fordert, deren Inhalte keinesfalls Realität sein dürften. Setzt man jedoch so an, dann sind große Teile der Filmgeschichte, insbesondere in den Genres des Western, des Kriminalfilms, der Science-fiction und des Ac- 
tionfilms ob ihrer Gefährlichkeit zu löschen. Verwundern hingegen muß umgekehrt, weshalb die filmnutzenden Teile der Menschheit in den beinahe $100 \mathrm{Jahren}$ der Existenz des Films noch nicht in einem gewaltigen mimetischen Gemetzel zugrunde gegangen sind.

Im Unterschied zu der recht einlinigen Interpretation lerntheoretisch erforschbarer Wirkungsmöglichkeiten durch Selg müßte es hingegen meines Erachtens um eine Konstruktion differenzierterer und komplexer Wirkungsparadigmen gehen. Mit ihnen ließen sich dann auch differenzierte Maßnahmen zum Jugendmedienschutz einrichten und argumentativ stützen. Dabei wäre beim Subjektcharakter des Menschen und bei seinen selbstbestimmten Nutzungsformen und -kompetenzen anzusetzen. Es ginge näherhin zunächst darum, sich ein Bild von diesem als Subjekt bestimmten Rezipienten zu machen und differenzierte anthropologische Grundlinien auszuziehen. Mit Blick auf die gegenwärtig (wieder) ventilierte Gewaltproblematik gälte es dabei besonders auch dem Aggressionsbegriff genauer nachzugehen und die basalen menschlichen Strebungen faßbar zu machen, in die auch die Aggressivität eingebettet ist. Hierzu halte ich den formal angelegten psychoanalytischen Aggressionsbegriff für weitaus geeigneter als den materialen der Selg'schen Theorie (dazu mehr in 6.1.). Auf dem anthropologischen Hintergrund müßte dann weiter eine entwicklungspsychologisch geleitete Rekonstruktion altersspezifischer medienbezogener Kompetenzen erfolgen, insbesondere im Bereich der Wahrnehmung und der Fähigkeiten zu logischer Verknüpfung. Dies erlaubte dann zunächst einmal eine Einschätzung je und je formal geeigneter bzw. ungeeigneter Medienformen und -gehalte. Eine so erarbeitete Einschätzung kann dann in den Dienst einer Erziehung zur Mündigkeit gestellt werden, also einer Pädagogik, die auf der Basis des Subjektgedankens ansetzt. Hilfreich für die Erarbeitung von mediennutzungsspezifischen Kompetenzniveaus könnte beispielsweise die empirisch geleitete Erforschung der Genese kognitiver Fähigkeiten sein, wie sie Jean Piaget äußerst differenziert geleistet hat. Dieses Vorgehen wäre dann weiter durch eine Reflexion der im Verlauf der Entwicklung zum mündigen Erwachsenen geschehenden Identitätsbildungsprozesse zu ergänzen. In der Tat ist das Anliegen Selgs, der Auffassung bestimmter Verhaltens- und Identitätsmodelle durch Kinder und Jugendliche nahezukommen, ja durchaus wichtig. Die Ausbildung der eigenen Persönlichkeit vollzieht sich schließlich nicht im leeren Raum, sondern im lebensweltlichen Kontext eines Sozialisationssettings, das Identifikationsangebote enthält und in dem durch Nutzung dieser Angebote die Strukturierung der eigenen gegebenen und sich entwickelnden Strebungen, Inklinationen und Triebkräfte erfolgt. In diesem Setting spielen zweifelsohne auch die Medien eine nicht geringe Rolle. Doch bleibt der von Selg zur Klärung dieser Rolle verwendete Mimesisbegriff zu einlinig, um diese Strukturierungsprozesse wirklich begreifbar zu machen. $\mathrm{Zu}$ berücksichtigen ist neben unterscheidbaren Entwicklungsstufen insbesondere auch hier wieder die (wachsende) Eigenständigkeit des sich zu einer Persönlichkeit formenden Menschen. Eine differenzierte Entwicklungsleiter könnte meines Erachtens unter Heranziehung der lebensgeschichtlich orientierten Psychologie Erik Eriksons sowie etwa auch der auf die Genese moralischer und überzeugungsbezogener Einstellungsniveaus ausgerichteten Reflexionen James Fowlers konstruiert werden. Hier können dann auch lerntheoretische Erkenntnisse und Überlegungen Anwendung finden, die gleichwohl das schlichte Mimesisparadigma in eine 
kombinatorische, mit den genannten entwicklungspsychologischen Theorien kooperierende Theoriebildung hinein überschreiten müßten. Die entwicklungspsychologisch geleitete Konstruktion von mediennutzungsbezogenen Kompetenzniveaus wäre schließlich noch zu ergänzen durch empirische sozialpsychologische Untersuchungen, die das jeweilige Sozialisationssetting in Blick nehmen und das Nutzungsverhalten von Kindern und Jugendlichen genauer erforschen. Auch solche Studien liegen bereits vor, wie aktuell etwa die eben veröffentlichte Studie des Instituts Jugend Film Fernsehen beweist. ${ }^{458}$

Eine so angesetzte Entwicklung einer Wirkungstheorie, die sich zum einen durch entwicklungspsychologische Erkenntnisse fundiert, zum anderen durch empirische Forschungen sichert und zum dritten dabei dem selbstbestimmten Nutzungsverhalten und den Nutzungskompetenzen der noch auf dem Weg zu ihrer Mündigkeit befindlichen Rezipienten gerecht zu werden sucht, lieferte dann eine weitaus detailliertere und realitätsgerechtere Basis für entsprechende prognostische Wirkungsvermutungen als die lerntheoretische Variante von Selg. Sie erlaubte auch erst eine kohärente und differenzierte theoretische Stützung konkreter Maßnahmen im Bereich des zweifellos unverzichtbaren Jugendmedienschutzes. Es wäre daher wünschenswert, da $\mathrm{B}$ im Bereich der Wirkungstheorie zu einer Theorie der Nutzung von Medien durch mit bestimmten Rezeptionskompetenzen ausgestattete und zur Stellungnahme befähigte Subjekte im Rahmen eines Sozialisationssettings vorgedrungen wird. Gerade dort, wo es sich um jugendliche Rezipienten handelt, die erst auf dem Weg zu ihrer Mündigkeit und damit zur aktiven Realisierung ihres Subjektcharakters sind, ist dieses Vordringen geboten. Es erlaubt erst die Erkenntnis spezifischer, in Verbindung mit bestimmten Altersstufen und bestimmten lebensweltlichen Umräumen gegebener Kompetenzstufen in der Mediennutzung sowie ein maßnahmenwirksames Verständnis für die Funktion von bestimmten Medieninhalten in bestimmten jugendspezifischen Lebenswelten. Damit können dann auch differenzierte Maßnahmen entworfen werden und läßt sich ein auf Erziehung zur Mündigkeit gerichteter Jugendschutz entsprechend einrichten. Wo es um Erwachsene geht, ist hingegen ohnehin anders zu operieren. Im Unterschied zu der Tendenz Selgs, auch Erwachsene als schrankenlos beeinflußbare Wesen zu behandeln und in effectu zu entmündigen, sind diese ja gerade als mündige Subjekte mit entsprechenden Kompetenzen,

458 vgl. Theunert, Helga, Pescher, Renate, Best, Petra, Schorb, Bernd, Zwischen Vergnügen und Angst - Fernsehen im Alltag von Kindern, Berlin 1992 - Die Studie erlaubt u.a. einen konkreten Einblick in Nutzungsformen und -kompetenzen von Kindern und zeigt beispielsweise, daß Gewalt von Kindern meist aus der Opferperspektive wahrgenommen wird. Die Identifikation in der Rezeption von Gewaltdarstellungen erfolgt demnach - auf dem Hintergrund der realen lebensweltlichen Situation der Kinder, auch im Alltag eher Betroffene als Agierende zu sein - nicht ohne weiteres und immer, wie Selgs Theorie ansetzt, mit der gewalttätigen Figur, sondern mit jener, die Gewalt erleidet. Dies zieht freilich eine ganz andere Reflexion auch für den Jugendschutz nach sich: Die Fernhaltung entsprechender Darstellungen ist dann unter Umständen zwar immer noch geboten, doch empfiehlt sie sich jetzt um des Schutzes vor Versehrungen willen, nicht aber, weil im anderen Fall die Gesellschaft in den Strudel eines ,systematisch erzeugten Sadismus' gezogen zu werden droht. Vor allem die These des Erlernens eines aggressiven Lebensstils ist damit konterkariert, und eine Ausdehnung der Fernhaltung entsprechender Darstellungen auch auf Erwachsene, wie Selg sie fordert, bedürfte zumindest einer anderen Begründung als die Forderung des Jugendschutzes. - Genaueres zu Jugendschutz, Institutionen und inhaltsethischen Kriterien für den Film wird in 6.2. gesagt werden. 
Rechten und Pflichten anzusetzen. Hier stellen sich entsprechend vor allem inhaltsethische Fragen auf der Basis einer freiheitlich-demokratischen Gesellschaftsordnung, die jedem der Gesellschaftsmitglieder das Recht zu freier Entfaltung und Information gewährt. Das Problem dennoch unzulässiger Medieninhalte ist daher nicht mehr unmittelbar unter dem Aspekt pernizioser Wirkungen und nötiger Schutzvorkehrungen zu betrachten, sondern muß vordringlich im Kontext einer prinzipiell ethischen Reflexion geklärt werden (vgl. dazu 6.1. und 6.2.). 


\section{STANDPUNKTSWECHSEL: DIE NEGATIONSETHIK DER MEDIENTHEORIE DER KRITISCHEN THEORIE}

Nachdem der medienethische Diskurs im 20. Jahrhundert zu beinahe zwei Dritteln vorrangig von kontramodernen und regressiven Optionen geprägt war, von denen sogar noch in der Gegenwart Folgewirkungen erkennbar sind, tritt mit der Kritischen Theorie ein anders gelagerter Diskurstyp in den Raum der Auseinandersetzung ein, der für sich beansprucht, jetzt in ,progressiver" und ,emanzipatorischer' Weise das Medienproblem zu reflektieren. In diesen Diskurs ordnen sich vor allem in den 70er Jahren Autoren verschiedener Disziplinen - der Soziologie, Kunsttheorie und Pädagogik - ein, die jedoch zumeist nur die Paradigmen und Argumentationsformen der Kritischen Theorie wiederholen. Gleichwohl konstituiert sich hierdurch eine Epoche, die diesen Theoremen und Argumenten eine Wirksamkeit bis etwa in die Mitte der 80er Jahre verleiht, obschon ihre Blütezeit um $1980 \mathrm{zu}$ Ende geht. Der von den Autoren der Kritischen Theorie grundgelegte Diskurs kann entsprechend als die - vorerst - letzte abgeschlossene Epoche des medienethischen Gesamtdiskurses in diesem Jahrhundert betrachtet werden.

Auch dieser Diskurs nun setzt modernitätskritisch an und ordnet die Diskussion über den Film (und andere Medien) einer diesbezüglichen, generellen theoretischen Anstrengung ein, die sich jedoch von den vorangegangenen bzw. parallel laufenden Bemühungen ,konservativer' Modernitätskritik - zu der auch die Filmerziehung gezählt werden kann - polemisch distanziert. Diese Bemühungen gelten jetzt als reaktionäres und zudem an den eigentlichen Gründen der angemahnten Defizienzen vorbeigehendes Unterfangen, das sich in Einzelphänomenen verliert, ohne das ,Wesen' der Moderne und ihrer Gebrechen in Blick zu bekommen. Im Unterschied dazu will der ,neue' Diskurs sowohl die ,wahren“ Wurzeln der modernen Defizienzen bloßlegen als auch sich unmißverständlich auf die Seite der Moderne stellen. Im zweiten liegt sein eigentlich Neues: Nicht länger soll aus kontramodernen Gründen heraus Stellung gegen das Projekt der Moderne bezogen werden, wie es mit der Aufklärung anhebt, sondern dieses Projekt als einziges, das Freiheit und Subjektivität zu garantieren vermag, in seinem Fehlgehen untersucht und in seiner Dignität durch radikale Kritik der Gründe des Fehlgehens bzw. partiell durch ,emanzipative‘ Strategien der Korrektur wiederhergestellt werden. Anders als Kinoreformer, Nationalsozialisten und Filmerzieher machen sich die Kritischen Theoretiker so zu Anwälten der Aspirationen von Aufklärung und Moderne und ziehen für die unverkürzte Subjektautonomie und deren gesellschaftliche Garantie zu Feld. Sie wechseln damit zunächst deutlich den Standpunkt in der rahmengebenden Auseinandersetzung. Wie sich zeigen wird, wechseln sie ihn allerdings in einer Weise, die den durch die ,konservative‘ Modernitätskritik abgesteckten Bereich der Phänomenkritik nicht überschreitet, so daß sich trotz aller polemischen Abgrenzung von derselben Bezüge und Parallelen nicht übersehen lassen. Obschon die Kritische Theorie dabei zwar 
keineswegs auf die Filmerziehung als Repräsentant dieser ,konservativen' Kritik eingeht, ergeben sich so auch Bezüge zu dieser. Gleichzeitig totalisiert sich im Bemühen, die endgültigen Wurzeln moderner Defizienzen in Blick zu bekommen, die Kritikperspektive derart, da $B$ die angestrebte Autonomie der Subjekte beinahe nur noch im Modus der Negation ausgesagt werden bzw. ihre gesellschaftliche Herstellung nur noch gegen die Gesellschaft und ihre Strukturen erfolgen kann. Die im Diskurs der letzten abgeschlossenen Epoche enthaltene und aus seinen Positionen fließende Medienethik konstituiert sich daher vordringlich als eine Ethik der Negation, die ich im folgenden rekonstruktiv erarbeiten will.

Hierzu nun beschränke ich mich methodisch auf Horkheimer und Adorno. Diese Beschränkung begründet sich wie folgt: Das Theorem von der Kulturindustrie, das für eine medienethische Perspektive auf die Kritische Theorie zentrale Bedeutung hat, stammt bekanntlich aus der Feder der beiden erstgenannten Autoren, die zudem die eigentlichen Väter und Repräsentanten der Kritischen Theorie überhaupt sind. Auf sie werde ich mich daher, nicht zuletzt um der Konsistenz der Rekonstruktion willen, ausschließlich beziehen. Auf eine Rekonstruktion des Aufgriffs der Theoreme dieser Autoren durch die Medientheoretiker im pädagogischen, soziologischen und kunsttheoretischen Bereich verzichte ich, da dort lediglich eine Repetition der weitaus griffiger und konsistenter bei Horkheimer und Adorno vorliegenden Theoreme erfolgt und eine diesbezügliche Rekonstruktion mithin allenfalls illustrativen Charakter haben könnte. Die ermüdende Redundanz dieser Illustration will ich vermeiden. Vollständig ausgeklammert bleibt außerdem auch jene Theoriebildung der 70er Jahre, die in orthodox marxistisch-leninistischer Tradition sich mit Medien beschäftigt; ähnlich den heterogenen Auseinandersetzungen der Kommunisten in der Weimarer Republik um den,Arbeiterfilm' stellen sie eine Marginale dar, die für den medienethischen Diskurs kaum Relevanz besitzt und gegenüber der Kritischen Theorie in den Hintergrund tritt.

\subsection{Ansatz: Die determinative Bedeutung der zeitgenössischen Situation für den Entwurf der Kritischen Theorie}

\section{Methodologischer Aufriß}

Die Kritische Theorie reflektiert den Bereich der Medien, und damit auch den Film, unter dem Begriff ,Kulturindustrie'. Ausgearbeitet und kontextuell systematisiert ist dieser Begriff in der „Dialektik der Aufklärung“, also zu einem Zeitpunkt, als die Kritische Theorie endgültig eine rationalitätstheoretische Wende durchmacht, von der sie vor allem in ihrer Gestalt bei Adorno bis zu dessen Lebensende geprägt bleibt. Zwar findet sich der Kulturindustriebegriff auch früher schon bei Horkheimer - ebenso, wie sich Vorgedanken zur Kritik der instrumentellen Vernunft schon in älteren Aufsätzen entdecken lassen -, doch steht er dort noch neben dem identisch mit ihm verwendeten Massenkulturbegriff und fehlt ihm jene Einbindung in einen theoretischen Gesamkontext, wie ihn die „Dialektik der Aufklärung“ vollzieht. Ich setze daher meine Rekonstruktion erst mit der genannten Schrift und in dem von ihr eingeleiteten Stadium der Kritischen Theorie an. Das bedingt, daß ich sowohl wenig Rücksicht auf die ,Epochengeschichte' der Kritischen Theorie nehmen werde, als 
auch Divergenzen zwischen Horkheimer und Adorno, die in der neueren Forschung zur gesamten ,Frankfurter Schule' für einige Untersuchungen leitend geworden sind, vernachlässige und gemäß Horkheimers Diktum in der „Dialektik“": seine und Adornos Philosophie seien eine, ${ }^{1}$ vordringlich auf die Gemeinsamkeiten der beiden Theoretiker abziele. Die Konsequenz, mit der Adorno dann später den Ansatz der Kritischen Theorie bei der instrumentellen Vernunft weitergetrieben hat, scheint es mir zu legitimieren, zusätzlich für die Fortführung des Kulturindustrietheorems, wie auch für die Rekonstruktion der rationalitätstheoretischen Grundlegung einer Gesellschaftstheorie, verstärkt auf Adorno zurückzugreifen.

Die Kritische Theorie nun versucht zum genannten Zeitpunkt, den Bereich der Medien - und damit auch des Films - im Rahmen einer umfassenden Gesellschaftstheorie zu reflektieren. Sie begreift ihn derart von vorneherein als gesellschaftliches Phänomen, das hierdurch auch in einer bestimmten historischen Situation und Entwicklung steht. Ihre Gesellschaftstheorie wiederum setzt sie im Kontext einer grundsätzlichen Reflexion der Versprechungen und Intentionen des Projekts der Moderne, näherhin der Ziele der Aufklärung, an. Diese Ziele und Intentionen, die knapp als Herstellung von Subjektivität, Autonomie und einer freiheitlichen Gesellschaftsordnung auf der Basis der Vernunft gefaßt werden können, jedoch scheinen ihr in der Gegenwart des 20. Jahrhunderts verraten zu werden. Die Diagnose eines Verrats, des Fehlgehens und Scheiterns führt die Kritische Theorie dann zu dem Versuch einer geschichtsphilosophischen Klärung der Gründe hierfür, die Horkheimer und Adorno primär in der „Dialektik der Aufklärung“ ausarbeiten. Im Rahmen dieser Klärung entwickeln sie vor allem das von Horkheimer bereits früher entworfene Modell der instrumentellen Vernunft systematisch zum Kerngedanken der Kritischen Theorie und verleihen der letztgenannten derart einen rationalitätstheoretischen Grundzug, der auch ihre Gesellschaftstheorie prägt und determiniert. In der unter dem Label ,Kulturindustrie' geführten Auseinandersetzung mit dem Medienbereich finden sich das rationalitätstheoretische Basisparadigma und seine gesellschaftstheoretischen Begleitüberlegungen schließlich auf einen Kultursachbereich konkret angewendet und zugleich fortgeführt. Konstruiert wird hierbei eine Art struktureller Verblendungszusammenhang, dessen systematische Geschlossenheit die Kritische Theorie in die Schwierigkeit führt, für die von ihr konstatierten Probleme kaum noch eine Lösung anbieten zu können. Wo sie dennoch eine Lösungsreflexion versucht, mündet diese entsprechend primär in eine Haltung der Negation.

Ich werde nun in der Rekonstruktion bei der historischen Situation, in der Horkheimer und Adorno das Scheitern der Aspirationen des Projekts der Moderne konstatieren, ansetzen und ihre geschichtsphilosophische Fragestellung skizzieren, um dann die Genese der instrumentellen Vernunft, die daraus hervorgehende Aufklä. rungskritik und das Gesellschaftskonzept der Kritischen Theorie zu umreißen. Im Anschluß daran entwickle ich zunächst die Struktur der Kulturindustrie und ihrer spezifischen angemahnten Defizienzen, um dann die in der gesamten Theoriebildung enthaltene Ethik der Negation zu rekonstruieren. Dabei verweise ich auch auf die Rolle der Kunst als Platzhalterin der verlorengegangenen Humanität.

${ }^{1}$ vgl. Horkheimer/Adorno, Dialektik, ix 


\section{Die Verkehrung der emanzipativen Intentionen der Aufklärung in Totalitarismus: Die geschichtsphilosophische Fragestellung der Kritischen Theorie}

Das Anliegen und die Problemstellung der Kritischen Theorie werden deutlich zum einen aus ihrer unverhüllten Parteinahme für die Aspirationen und Ziele der Aufklärung, und zum anderen aus der historischen Situation, in der sie ihre eigene theoretische Grundstellung entwickelt. ${ }^{2}$ Durchaus modernitätsfreundlich nämlich stellen sich Horkheimer und Adorno zunächst auf die Seite der Aufklärung und betonen sie, „daß die Freiheit in der Gesellschaft vom aufklärenden Denken unabtrennbar ist“ ${ }^{3}$ Nicht anders als durch dieses ,Denken' selbst und seine Weiterentwicklung scheint es möglich, das Ziel einer gesellschaftlichen Herstellung und Garantie der Subjektautonomie zu erreichen und eine menschenwürdige Existenz freiheitlich zu sichern. Aus ihrem Bemühen, ,von den Menschen die Furcht zu nehmen und sie als Herren einzusetzen“"4, empfängt die Aufklärung von jeher ihre Dignität, und durch ihre ,Ideen“ der Freiheit, Gleichberechtigung und ,Brüderlichkeit‘ bleibt ihr Projekt auch für Horkheimer und Adorno unaufgebbar das hervorragendste Realisierungsziel.

Gleichwohl sehen sich die beiden Autoren zum Zeitpunkt ihrer Überlegungen über die Aufklärung mit einer Situation konfrontiert, die sie als endgültiges Scheitern der genannten Ideen und Ziele interpretieren. ${ }^{5}$ Die zeitgenössischen Umstände nämlich sind die der 40er Jahre, in denen in Europa einerseits der Faschismus ${ }^{6}$ tri-

${ }^{2}$ Die Relevanz der historischen Situation, in der sich die Genese der Basisparadigmen der Kritischen Theorie vollzieht, hat vor allem Helmut Dubiel nachgewiesen: Dubiel, Wissenschaftsorganisation, 15-133. In letzter Zeit wurde diese These vor allem von Habermas und Honneth aufgegriffen und weiteren Studien zugrundegelegt: Habermas, Theorie I, 489-534; Honneth, Kritik, 9-111. Mit den Interpretationen der Kritischen Theorie durch die beiden letztgenannten Autoren weiß ich mich auch sonst auf weite Strecken einig, so daß ich im folgenden wiederholt darauf zurückgreifen werde. Vor allem Honneths theoriegeschichtliche Rekonstruktion scheint mir dabei Anliegen wie Aporien der Kritischen Theorie in hervorragender Weise auf den Punkt zu bringen.

${ }^{3}$ Horkheimer/Adorno, Dialektik, 3

${ }_{5}^{4}$ Horkheimer/Adorno, Dialektik, 7

5 vgl. zum Folgenden auch: Honneth, Kritik, 47; Habermas, Theorie I, 490

${ }^{6}$ Die Kritische Theorie verwendet bekanntlich den Faschismusbegriff als Oberbegriff sowohl für die spezifisch faschistischen Konzepte in Spanien und Italien, als auch für den Nationalsozialismus, und versucht, all diese Phänomene aus einer Wurzel mit einer Faschismustheorie zu klären. Um die Mitte der 80er Jahre hat sich jedoch in der historischen Forschung endgültig die Differenzierung zwischen den ,originären' Faschismen und dem nationalsozialistischen System durchgesetzt, die gerade auch die Divergenzen der entsprechenden Gesellschaftskonzeptionen und ihrer theoretischen Axiomatiken zu berücksichtigen sucht. Um der historischen Genauigkeit willen bin ich dieser Differenzierung terminologisch bislang ebenfalls gefolgt, obschon sowohl der Faschismus als auch der Nationalsozialismus spezifisch kontramoderne Entwürfe vorstellen und derart gewisse Verwandtschaften erkennen lassen. Im vorliegenden Kapitel läßt sich die terminologische Differenzierung zwischen Nationalsozialismus und Faschismus jedoch nun zumindest dort nicht mehr aufrechterhalten, wo es um die Rekonstruktion der Faschismustheorie (und Nationalsozialismusinterpretation) der Kritischen Theorie geht. Ich werde daher in diesem Zusammenhang nun übergreifend auch dort vom Faschismus sprechen, wo der Nationalsozialismus mitgemeint - ja oft sogar in besonderer Weise angezielt - ist. Da es in der Faschismustheorie der Kritischen Theorie ohnehin vordringlich um die Stellung der faschistischen Konzepte und des Nationalsozialismus zum Programm der Aufklärung und zur Moderne geht, mithin also das den genannten Gesellschaftskonzepten inhärente gemeinsame Moment der Kontramodernität im Zentrum der Überlegungen steht, scheint mir diese Anpassung an die Terminologie der Kritischen Theorie hier nicht nur sinnvoll, sondern auch systematisch legitim. 
umphiert und andererseits die russische Revolution in den Stalinismus gekippt ist. Gleichzeitig hat sich in den USA das mit dem Kapitalismustheorem gefaßte sozioökonomische System als überlebensfähig erwiesen. Damit aber scheinen mehrere Hoffnungen erloschen zu sein: Gescheitert scheint zunächst die Hoffnung, daß sich die aufklärerischen Intentionen der Herstellung von Subjektivität und Autonomie, sowie einer durch Vernunft regierten und vernünftig organisierten Gesellschaft über die ,bürgerliche Revolution“ in einer bürgerlichen Gesellschaft realisieren ließen. Diese Revolution als Trägerin der fortschrittlichen Ideen scheint im 20. Jahrhundert einmal im Totalitarismus der Nationalsozialisten unterzugehen und ein andermal im reüssierenden Kapitalismus der Amerikaner zu verebben. Zwar war nach orthodox marxistischer Theorie von der bürgerlichen Revolution die Realisierung der Freiheitsideen ohnehin nicht zu erwarten, doch lassen beide Entwicklungen bedrohlich erkennen, daß auch die prognostischen Aspirationen dieser Theorie, die der bürgerlichen ja noch eine proletarische Revolution nachfolgen sah, sich nicht in gewünschter Weise erfüllt haben. Diese zweite Revolution, von der die - auch in der marxistischen Theorie noch der Aufklärung verdankten - Ideen von Subjektivität, Autonomie und Freiheit nun endgültig realisiert werden sollten, ist in der zeitgenössischen Situation einmal vom stalinistischen Staatsbürokratismus korrumpiert und findet ein andermal im nationalsozialistischen und kapitalistischen System offenbar nicht mehr statt. Enttäuscht ist damit zugleich die zweite Hoffnung, daß über den historischen Träger der befreienden Revolution, das Proletariat, ein Reich der Freiheit hergestellt werden könnte. Stattdessen sehen Horkheimer und Adorno eine Konjunktur der Totalitarismen, die zunächst zwei staatsbürokratische Formen hervorgebracht hat. Daneben scheint ihnen der Totalitarismus jedoch auch im kapitalistischen System anwesend zu sein, das sie auf ein totalitäres Paradigma hin interpretieren. Die Fesselung und Kanalisierung der Produktivkraftentwicklung, die orthodox marxistisch noch als Sponsorin einer notwendigen Systemsprengung gehandelt wurde, sowie die geglückte Integration sozialer Konflikte und die derart erfolgende Auflösung des Klassenkampfs nämlich gelten ihnen als Strukturmerkmale eines zwar weniger sichtbaren, jedoch ebenfalls totalitären Gesellschaftszusammenhangs. ${ }^{7}$ Die zeitgenössische Situation scheint so die allenthalben in der aufgeklärten Welt herrschender Totalitarismen zu sein, und die neuzeitlich-modernen Programmatiken für die Herstellung eines menschenwürdigen, eines individuellen und kollektiven ,guten Lebens‘ scheinen sich aus dieser Perspektive als leere Versprechungen zu enthüllen.

Aus der Konfrontation der Aspirationen, Ziele und Intentionen der Aufklärung mit der so skizzierten Gegenwart ergibt sich für die Kritische Theorie ein Erklärungsbedarf, den Horkheimer und Adorno mit der „Dialektik der Aufklärung“ zu erfüllen suchen. Die Frage, die sich ihnen hierbei stellt, ist die, „warum die Menschheit, anstatt in einen wahrhaft menschlichen Zustand einzutreten, in eine neue Art von Barbarei versinkt ${ }^{\text {“8 }}$. Geklärt werden soll, wie es dazu kommen konnte, daß die Absichten der Aufklärung in den genannten Totalitarismen zu verenden und die „technologisch erzogenen Massen“ der aufgeklärten Welt eine ,rätselhafte Bereit-

\footnotetext{
${ }^{7}$ vgl. hierzu auch: Honneth, Kritik, 47

${ }^{8}$ Horkheimer/Adorno, Dialektik, 1
} 
schaft' dazu aufzuweisen scheinen, ,in den Bann jeglichen Despotismus zu geraten“.9 Die Kritische Theorie kontrastiert so die aufklärerischen Intentionen mit der zeitgenössischen Situation und stellt sich daraus dann die Aufgabe einer geschichtsphilosophischen Reflexion der Gründe für das Scheitern des Projekts der Moderne in den totalitären bzw. als totalitär interpretierten Systemen. Ihre zentrale Problemstellung besteht darin, die Wurzeln der Korruption des emanzipativen Potentials der Aufklärung durch die Gegenwart zu finden, und die leitende Perspektive des Unterfangens ist entsprechend die einer Totalitarismustheorie.

Diese Problemstellung und ihre Form nun legen den Ansatz der Kritischen Theorie in dreifacher Weise fest und konstituieren ihre spezifische Grundcharakteristik. Die erste Festlegung besteht darin, daß zunächst die geschichtsphilosophische Grundausrichtung zweier bereits existenter Theoriekonzepte, in deren Tradition Horkheimer und Adorno ursprünglich stehen, für die Durchführung des Klärungsvorhabens ausscheidet. Nicht länger nämlich kann die Geschichte bei einem derartigen, aktuellen Ergebnisstand im Sinn Hegels und Marx als Fortschrittsgeschichte gedacht werden (wie es der frühe Horkheimer noch tat) ${ }^{10}$. Aus der Perspektive der als totalitärer Endpunkt interpretierten zeitgenössischen Gegenwart erscheint die gesamte vorangehende Geschichte vielmehr als Verfallsgeschichte. ${ }^{11}$ Damit aber bleibt der vorzunehmenden Rekonstruktion nur die Möglichkeit, Gründe dieses Verfalls zu erarbeiten, und gerät sie notwendig zu einer pessimistischen Geschichtsphilosophie der Defizienz. Auf der Basis einer Parteinahme für die Ziele der Aufklärung kann sie zudem ihre Defizienzrekonstruktion nur im Modus der Kritik durchführen. Die Kritische Theorie ist damit einmal auf den Grundduktus einer kritisch-pessimistischen Verfallstheorie fixiert.

Diese Fixierung bedingt zum zweiten einen spezifischen Umgang auch mit der Aufklärung selbst. Aus der Problemstellung heraus, die den emanzipativen Anspruch der Aufklärung mit den zeitgenössischen Totalitarismen kontrastiert, ist die Kritische Theorie zunächst genötigt, Gestalt und Rolle der Aufklärung neu zu bestimmen. Hierbei versuchen Horkheimer und Adorno nun, in der letztgenannten den Verfallsprozeß, der in der Gegenwart ausmündet, wiederzuentdecken. Die Gegenwart soll derart nicht einfach nur als kontradiktorisches Gegenstück zur Aufklärung begriffen werden, sondern das Scheitern ihrer emanzipativen Aspirationen soll auf in ihr ursprünglich beschlossene Momente zurückgeführt werden können. Anstatt auf der Basis der Parteinahme zunächst eine Fortschrittsgeschichte zu konstruieren und dieser dann im Sinn eines Bruchs die Gegenwart feindlich entgegenzusetzen, bemühen sich Horkheimer und Adorno darum, die Kontinuität des Verfalls aufzufinden. Einzig dann, wenn dies gelingt, scheint die Rekonstruktion gegenwärtigen Scheiterns der

${ }^{9}$ Horkheimer/Adorno, Dialektik, 3

${ }_{11}^{10}$ vgl. dazu auch: Honneth, Kritik, 53

11 Freilich bleibt die Tradition hegelianischer Reflexion wie die marxistisch-materialistischer Realitätsexegese in Horkheimers und Adornos Texten trotzdem spürbar und partiell bestimmend. Die geschichtsphilosophische Rekonstruktion der „Dialektik“ etwa findet in einem formal ähnlichen Wechsel zwischen Spekulation, Bewußtseinsphilosophie und Historiographie statt wie Hegels „Phänomenologie des Geistes“, und das herrschaftskritische Pathos Marx" bleibt zusammen mit einer Reihe seiner Überlegungen erhalten. Zur Stellung der Kritischen Theorie zu Hegel vgl. etwa: Adorno, Theodor W., Drei Studien zu Hegel, Frankfurt 1974; die Bezüge vor allem Adornos zu Marx finden sich etwa bei Schmucker herausgearbeitet: Schmucker, Adorno 
Emanzipation aus ihrer Sicht geschichtsphilosophisch stringent; andernfalls müßte die Herkunft der Gründe des Scheiterns geschichtsextern und ,zufällig angesetzt werden, d.h. aber: das Scheitern unbegriffen bleiben. Die verfallstheoretische Perspektive bedingt dabei, daß die Aufklärung jetzt vom Horizont der Parteinahme zum Gegenstand der Kritik gerät. So werfen Horkheimer und Adorno der Aufklärung auf der Basis eben jener Freiheitsversprechungen, die sie selbst gemacht hatte, deren Korrumpierung und eine „Selbstzerstörung ${ }^{\text {“12 }}$ vor, und sehen sie im ,eigensten Denken“ der Aufklärung "nicht weniger" als in den "konkreten historischen Formen“, den „Institutionen der Gesellschaft (...) schon den Kern zu jenem Rückschritt enthalten, der heute überall sich ereignet" ${ }^{13}$ Auf diese Weise erhält die Parteinahme Horkheimers und Adornos für die Aufklärung ein dialektisches Gepräge, bzw. genauer: sie entpuppt sich als aus einer dialektischen Grundstellung hervorgehende. Zum einen nämlich geben die positiven Intentionen der Aufklärung sowohl das Raster ihrer Untersuchung als auch die Zielvorstellung ihrer Gesellschaftstheorie ab; zum anderen aber gerät die Aufklärung selbst ins Kreuzfeuer. Der modernitätsfreundliche Ansatz wird so auf weiten Strecken der Rekonstruktion in eine Modernitätskritik transformiert, mit der die Intentionen der Aufklärung gegen diese selbst angemahnt werden und die verfallstheoretische Perspektive in den Vordergrund rückt. Zwar betonen Horkheimer und Adorno, daß das Ziel ihrer Defizienzkritik die Rettung der positiven Intentionen der Aufklärung sei; durch die ,an der Aufklärung geübte Kritik“ soll ein „positive(r) Begriff von ihr“ vorbereitet werden, „,der sie aus der Verstrickung in blinde Herrschaft löst“ ${ }^{14}$ Doch sorgt die verfallstheoretische Fixierung dafür, daß die dialektische Rekonstruktion hauptsächlich im Aufweis der Defizienzen steckenbleibt und kaum diesen ,positiven Begriff und Möglichkeiten seiner Realisierung vor Augen treten läßt.

Zum dritten schließlich bedingt die Ausscheidung der Fortschrittsperspektive des orthodoxen marxistischen Paradigmas, daß die Rekonstruktion auch hier neu ansetzen muß. Keineswegs nämlich kann die marxistische Geschichtsinterpretation, die Revolution und Freiheit als Konsequenz ökonomisch bedingter Klassenkonflikte versprach, jetzt noch als (allein) zureichend betrachtet werden, um die Auflösung der Revolutionshoffnung und die Repression der Konflikte im totalitären Staat bzw. ihre Integration im Kapitalismus begreifbar zu machen. Bei der Erarbeitung der Gründe hierfür, also in der Rekonstruktion des Verfalls revolutionärer Befreiungsaspirationen, muß daher hinter die rein ökonomische Geschichtsinterpretation zurückgegriffen und das marxistische Paradigma auf tieferliegende Wurzeln hin überschritten werden. Die Kritische Theorie ist so neben ihrer verfallstheoretischen und modernitätskritischen Perspektive auch darauf fixiert, einen genuin materialistischen Horizont zu übersteigen. Im diesem, Überstieg kündigt sich dabei bereits eine Neigung an, mit dem materialistischen auch einen empirisch-soziologischen Horizont hinter sich zu lassen. ${ }^{15}$ Dies prägt sowohl die Rekonstruktionsperspektive der Kritischen Theorie, die rationalitätstheoretisch ausgerichtet ist, als auch ihre Gesellschaftskon-

\footnotetext{
${ }_{13}^{12}$ Horkheimer/Adorno, Dialektik, 3

${ }_{13}^{13}$ Horkheimer/Adorno, Dialektik, 3

${ }_{15}^{14}$ Horkheimer/Adorno, Dialektik, 5

15 vgl. hierzu auch: Honneth, Kritik, 26, 68; Habermas, Theorie I, 507
} 
struktion, die konkrete soziale Interaktion ausblendet und in eine dichotomische Idealtypik mündet (vgl. 5.4.).

Die geschichtsphilosophische Fragestellung der Kritischen Theorie sowie ihr Ansatz und ihre Grundrichtung sind damit deutlich. In einer historischen Situation, die von Nationalsozialismus, Stalinismus und dem Überleben des amerikanischen ,Kapitalismus' gekennzeichnet ist, setzen Horkheimer und Adorno zu einer Klärung der Gründe für die Heraufkunft dieser Situation an. Hierbei interpretieren sie ihre zeitgenössische Gegenwart als allseitige Konjunktur von Totalitarismen, die den historischen und systematischen Endpunkt einer geschichtsphilosophisch zu rekonstruierenden Entwicklung des ,aufgeklärten' Teils der Welt darzustellen scheint. Diese Interpretation verbietet es der Kritischen Theorie dann von vorneherein, ihr rekonstruktives Unterfangen noch unter einer Fortschrittsperspektive zu beginnen und fixiert ihre Grundausrichtung auf die einer pessimistischen Verfallstheorie. Da der Verfall gerade im ,aufgeklärten` Teil der Welt stattzufinden scheint, ist sie weiter genötigt, Rolle und Gestalt der Aufklärung, deren Intentionen sich auf Emanzipation und Subjektautonomie richteten, neu zu reflektieren. Horkheimer und Adorno wählen dazu eine dialektische Grundstellung, die die Wurzeln des Verfalls in der Aufklärung selber vermutet und die Gegenwart entsprechend nicht als kontradiktorischen Gegensatz zu derselben, sondern als konsequenten Austrag in ihr enthaltener Dispositionen versteht. Sie setzen so aus der Perspektive einer Totalitarismustheorie an und versuchen, die Moderne kritisch als Präformationsfeld totalitärer Systeme zu begreifen. Für ihr Klärungsunterfangen hat sich daher auch die marxistische Fortschrittsperspektive als ungeeignet erwiesen, die sie zusammen mit einer rein materialistisch-ökonomischen Realitäts- und Historienexegese ausscheiden.

Der totalitarismustheoretische Horizont und die damit verbundene Verfallsperspektive bedingen dabei nun eine grundsätzliche Schwierigkeit, welche die Kritische Theorie von Beginn an mit sich führt, und die sie bis in ihre Spätform bei Adorno hinein prägt. Wie sich zeigen wird, hindert sie - trotz ihrer modernitätsfreundlichen Parteinahme für die Ziele der Aufklärung - beides durchgängig daran, ein differenziertes oder gar positives Verhältnis zur Moderne in ihrer realen Ausprägung zu gewinnen (vgl. 5.3.). Obschon sich die Kritische Theorie auf die Seite der Moderne schlägt, vermag sie deren Gestaltwerdung in den konkreten Phänomenen gesellschaftlicher Organisation und (insbesondere) kultureller Produktion kaum noch affirmativ zu würdigen, sondern muß sie diese auf die negative Seite der konstatierten Dialektik schlagen. Da die Gegenwart ihres Ansetzens als umfassende Defizienz, als total gewordener Verfall erscheint, bleibt ihr auch dort, wo Nationalsozialismus und Stalinismus nicht wirksam sind oder überwunden wurden, keine Möglichkeit mehr, in den empirisch greifbaren Fortführungen und Ausformungen des aufklärerisch begonnenen Projekts der Moderne legitime kontingente Realisierungen desselben zu sehen. Für den, der ausschließlich den Verfall erklären will, ist der Blick auf mögliche erhalten gebliebene oder gar weitergeführte emanzipative Bestände getrübt. Das wirkt sich nun dort besonders prekär aus, wo der totalitarismustheoretische Horizont auch die demokratische Gesellschaft der USA in sich einbegreift. Die Interpretation des amerikanischen ,Kapitalismus als totalitäres System bringt es mit sich, daß der Versuch einer Realisierung des Projekts der Moderne in einem demokratischen System und einer industrialisierten Gesellschaft nicht mehr auf Emanzipations- 
momente und Fortschrittschancen hin untersucht werden kann. Vielmehr muß durch diese Betrachtungsweise jedes subjekthafte und autonomisierende Moment aus dem interpretativen Raster herausfallen. Die Kritische Theorie legt sich so auf eine Perspektive fest, die den Strukturzusammenhang demokratischer Gesellschaften verfehlt (vgl. 5.4.) und sich im Aufweis der Defizienzen ebenso totalitär, nämlich einlinig einrichtet wie ihr supponierter Gegenstand.

\subsection{Die Herrschaft der instrumentellen Vernunft: Der rationalitätstheoretische Kern der Kritischen Theorie}

Horkheimer und Adorno unternehmen ihren Versuch, die Gründe für das Scheitern der aufklärerischen Ambitionen aufzufinden, indem sie in einer Mischung aus Kulturtheorie, Spekulation und Bewußtseinsphilosophie die Geschichte der Subjektivität und Rationalisierung entfalten. Sie bemühen sich, hierdurch einmal die Korruption der Aufklärung in Prozessen dingfest zu machen, die ihr vorausgehen, und zum anderen, hinter die materialistisch-marxistische Realitätsexegese zurückzugreifen, um die Wurzeln des ökonomisch determinierten Geschichtsprozesses aller Klassenkämpfe in einer Rationalität zu finden, aus der auch die Ökonomie erst hervorgeht. Hierzu nun setzen sie mit einer rückwärtigen Extrapolation an, die die Entstehung des neuzeitlichen Subjekts und das Rationalisierungsprogramm bis an die Anfänge der Hominisierung zurückverfolgt. Sie supponieren dabei einen Subjektbegriff, der das damit bezeichnete Wesen als Vernunftwesen definiert und diesem daraus Autonomie und Freiheit zuspricht. Unter Voraussetzung dieses Begriffs suchen sie dann, den Versuch des Menschen einer Emanzipation zum Subjekt nachzuzeichnen. Da das Subjekt per definitionem nur als vernünftiges gedacht werden kann, erhält die Nachzeichnung des Subjektivierungsprozesses von vorneherein einen rationalitätstheoretischen Grundzug und wird die Geschichte der Subjektivität über die Geschichte der Rationalisierung bzw. zusammen mit ihr entfaltet. Rekonstruiert wird hierbei ein bestimmter Rationalitätstyp, die instrumentelle Vernunft, sowie dessen Subjekt, das sich als herrscherliches entpuppt, und die Geschichte von Subjektivierung und Rationalisierung wird derart als Ausbildung spezifischer Typen interpretiert. Den entstehenden Subjektivitätstyp und seine Rationalität messen Horkheimer und Adorno dann mit dem untersuchungsleitend vorausgesetzten Subjektbegriff und den Rationalisierungszielen der Aufklärung. Sie prüfen so, ob die rekonstruierte Entwicklungsgeschichte von Subjektivität und Rationalität den später von der Aufklärung insistierten Begriffen und Intentionen gerecht wird und die Menschheitsgeschichte als Geschichte der Emanzipation des Menschen zum freien und autonomen Subjekt begriffen werden kann oder ob sie als Verfallsgeschichte bewertet werden muß. Als Ergebnis der Prüfung erscheint eine verderbliche Inkongruenz des faktisch entstandenen Subjekts und seiner Vernunft mit den emanzipativen Intentionen, und das Projekt der Subjektivierung und Rationalisierung scheint fehlzugehen. Da die rekonstruierte instrumentelle Vernunft und ihr Subjekt dann zugleich als historisch-faktischer Kernbestand der aufklärerischen Rationalisierung und Subjektivierung gelten, scheint so auch das Scheitern der Aufklärung erklärt.

Horkheimer und Adorno setzen derart erneut aus der Perspektive ihrer Parteinahme für die Ziele der Aufklärung an und bemühen sich dann, deren ,Selbstverhin- 
derung' verfallstheoretisch zu rekonstruieren. Die Menschheitsgeschichte wird hierbei durch die rückwärtige Extrapolation als Präformation des aufklärerischen Unterfangens gehandhabt, und die Aufklärung erhält den Status einer besonderen Kristallisationsform eines längst vor ihr anhebenden Prozesses versuchter und mißglückender Emanzipation. Das Fehlgehen des aufklärerisch begonnenen Projekts der Moderne erscheint auf diesem Hintergrund als Teil einer äonenalten Verfallsgeschichte, die die Humanisierung von Welt und Mensch ab initio durch eine fehlgeleitete Rationalisierung und Subjektivierung unterläuft. Unterscheidbar aber sind damit in Horkheimers und Adornos Theorie vorerst eine genealogische Entfaltung der instrumentellen Vernunft und ihres Subjekts sowie eine daran gefügte und darauf aufbauende Aufklärungs- und Modernitätskritik. Beiden werde ich mich in diesem und im nächsten Abschnitt widmen. ${ }^{16}$

Der genealogische Duktus in Horkheimers und Adornos Text nun läßt ebenfalls zwei Stränge der Argumentation voneinander unterscheiden. Zum einen nämlich werden mit einem bewußtseinsphilosophischen Paradigma ${ }^{17}$ in einer Mischung von Erkenntnis- und Kulturtheorie die Herstellung von Subjektivität durch Objektkonstitution und die Entstehung einer theoretischen Rationalität rekonstruiert. Horkheimer und Adorno entfalten dies, indem sie in einer Art Verklammerung von Phylogenese und Ontogenese die allmähliche Auflösung einer archaischen Identifizierung zugunsten einer Subjekt-Objekt-Differenz und die zunehmende Gewinnung eines ersten Selbst- und Weltverhältnisses nachzeichnen. Das sich hierbei konstituierende theoretisierende Subjekt wird dann bereits problematisiert. Zum anderen verankern Horkheimer und Adorno diesen spekulativ rekonstruierten Prozeß von vorneherein im Prinzip der Selbsterhaltung und rekonstruieren sie die Subjektivierung aus der Perspektive der Selbstbehauptung des Menschen gegenüber der natürlichen Umwelt. Sie überlagern den ersten Strang der Argumentation so mit einem zweiten und supponieren, da $B$ Subjektivierung und Objektkonstitution in dem anscheinend Eigenständigkeit schaffenden und daher mit emanzipativem Gepräge ausgestatteten Prozeß des ersten Strangs nur um der Selbstbehauptung des Menschen willen geschehen. Die Objektivierung scheint hierbei aus einer funktional-instrumentellen Perspektive zu erfolgen und zugleich scheint für die Herausbildung eines herrscherlichen und repressiven Habitus gesorgt zu werden. Das Selbst- und Weltverhältnis des Menschen erhält

${ }^{16}$ Die „Dialektik der Aufklärung“ freilich nimmt diese Entfaltung und Kritik keineswegs getrennt und nacheinander vor, sondern vermischt beides. Um der Klarheit willen jedoch lege ich beides in logische Schritte auseinander und versuche ich zudem, die etwas rhapsodische Dialektik des Texts von Horkheimer und Adorno in eine argumentative Stufenfolge zu übertragen.

${ }^{17}$ Auf die im Hintergrund der „Dialektik der Aufklärung“ wirksame Subjekt- oder Bewußtseinsphilosphie Horkheimers und Adornos hat besonders Habermas aufmerksam gemacht: vgl. Habermas, Theorie I, 517-518. Die Spezifität dieses Paradigmas besteht hierbei darin, daß es Intersubjektivität und Kommunikation als eigenständige Wirklichkeit ausgrenzt und die Konstitution des Subjekts als Herausbildung eines Subjekt- und Objektbewußtseins nachzeichnet, dessen Genese einen gewissermaßen ,einsamen Akt ${ }^{6}$ vorstellt, der sich nur zwischen Subjekt und Objekt vollzieht. Habermas sieht darin eine Eindimensionalität, die idealtypisch eine Welt konstruiert, in der sich nur noch alleingelassene Subjekte unter Objekten bewegen und die Kontaktnahme der Subjekte untereinander nicht mehr oder zumindest nur im Modus einer SubjektObjekt-Beziehung (bzw. zum Zweck einer kollektiven Objektkonstitution) gedacht werden kann. ,Intersubjektive Authentizität' scheint damit zu einer in diesem Paradigma nicht reflektierbaren Kategorie zu werden. 
dadurch eine spezifische Gestalt, und rekonstruiert sind in diesem zweiten Strang die instrumentelle Vernunft und das herrscherliche Subjekt. Als Folge wird verfallstheoretisch eine Verengung der menschlichen Rationalität konstatiert, die mit einer Verengung der Entfaltungschancen menschlicher Existenz einhergehe. Das letzte scheint schließlich sogar in die Selbstauflösung der Subjektivität zu führen. Obschon beide Stränge der Genealogie in Horkheimers und Adornos Theorie stets miteinander verwoben und so eng verknüpft sind, daß sie beinahe identisch werden, nehme ich sie im folgenden (weitgehend) auseinander, um ihre Spezifität besser verdeutlichen zu können.

\section{Das subjektphilosophische Paradigma: Subjekt-Objekt-Differenzierung}

Zunächst also sind bei Horkheimer und Adorno der Prozeß einer graduellen Ablösung des Subjekts von der Objektwelt und die allmähliche Gewinnung eines ersten Selbst- und Weltverhältnisses beschrieben. Idealtypisch vorausgesetzt ist die Situation eines in die Welt geworfenen Menschenwesens, das nun beginnen muß, sich dort zu orientieren, d.h. die Außenwelt als von ihm geschiedene wahrzunehmen und sich in ihren Eigenschaften begreifbar zu machen. Dieser Prozeß des Unterscheidens und Begreifens ist einmal mit einer Art Kulturtheorie der Bewußtseinsformen stufenweise von der ,anähnelnden Mimesis' über magische Benennung und Mythos bis hin zur wissenschaftlichen Abstraktion ausgezogen. Die Mimesis wird als vorbewußte Reaktion auf eine Situation der Bedrohung eingeführt. Sie ist noch im Kontext jener „reflexartigen Bedingungen“ angesiedelt, ,in denen vorhumane Lebewesen in Situationen des Schreckens dem bedrohlichen Naturobjekt sich physisch anähneln“"18, und hat die Stufe der Identifikation noch nicht verlassen. Schon im „Ruf des Schreckens“ aber, „mit dem das Ungewohnte erfahren wird“, sehen Horkheimer und Adorno diese Stufe überwunden, wenn aus dem Ruf der ,Name' der schreckenden Gegebenheit werde und eine erste Form bewußtseinsbildender distanzierender Abgrenzung gegen die Umwelt entstehe. ${ }^{19}$ Mit der Benennung gilt erstmals die sinnliche Eindrucksfülle des Begegnenden, auf die nur die reflexhafte und bewußtlose mimetische Reaktion blieb, durch Übertragung des Reaktionsanlasses vom psycho-physischen Erlebnis in ein anderes Medium - die Sprache - als distanziert und ist sie zugleich von der bloßen Sinnlichkeit abstrahiert. Die Umwelt scheint derart ihres überwältigenden Charakters entkleidet und als das, was außen, nicht aber innen ist, durch apotropäisches Bezeichnen objektiv konstituiert zu werden. Für Horkheimer und Adorno liegt daher hier schon der Ursprung des Begriffs und der Abstraktion überhaupt; Objektivierung und Abstraktion, die die Außenwelt schaffen, gehen demzufolge Hand in Hand und erwachsen aus derselben Wurzel des ,Namen-Gebens'. Die Herstellung der Außenwelt als Objektwelt wird damit von Horkheimer und Adorno über eine Spekulation zur Entstehung von Sprache und Sprachnutzung eingeführt.

Gleichzeitig ist dadurch ein Schritt zu einer spekulativen Genese des Theoretisierens über die sprachlich erfaßte Objektwelt, d.h.: deren Rationalisierung, getan. Ist das Außen als solches durch Bezeichnen erst einmal hergestellt, so können in ihm allmählich auch Zusammenhänge objektiviert und durch deren Versprachlichung

\footnotetext{
${ }_{18}^{18}$ Honneth, Kritik, 50

${ }^{19}$ Horkheimer/Adorno, Dialektik, 17; Hervorhebung von mir.
} 
Theorien geschaffen werden. Dies sehen Horkheimer und Adorno durch Magie und Mythos sukzessiv eingeleitet: Vom Namen-Geben scheint der Schritt zur Verknüpfung der Namen und zur Magie als einer kollektiv inszenierten rituellen Mimesis in apotropäischer Absicht nicht mehr weit zu sein. Als Zwischenstufe zwischen Identifikation und Objektivierung enthält die Magie zwar nur ein noch schwaches, gebrechliches Bewußtsein von der Externität der Objektwelt, doch stellt sie bereits Zusammenhänge in derselben her und weist sie so ein theoretisches Moment auf, das im Mythos dann ausgeprägt wird. Horkheimer und Adorno verweisen deshalb darauf, daß in Zauberei und Ritus bereits eine anfängliche Theorie über die subjektexterne Realität enthalten sei, ${ }^{20}$ die im Mythos zur (narrativen) Systematik finde. ${ }^{21}$ Mit dieser anfänglichen Theoriebildung scheinen Keim und Grund für eine Rationalisierung gelegt, die die externe Welt und ihre Konnexionen zunehmend zum Gegenstand von Wort- und Begriffszusammenhängen macht. Schon die keimhafte Rationalisierung gilt dabei als von einer Entelechie getragen, die auf ,Entzauberung drängt, da sie durch Entfaltung von Theorien über die Wirklichkeit versucht, der letztgenannten ihre überwältigende Eigenbedeutung, ihren ,Zauber', zu nehmen und sie in eine humanisierte Wirklichkeit, d.h. eine Wirklichkeit für den Menschen, zu überführen. Aus diesem Blickwinkel betrachtet enthalten Magie und Mythos die Tendenz zu ihrer Auflösung, zu ,säkularisierender' und entmythologisierender Überwindung ihrer Gestalt, bereits in sich. Die rationalisierende Entzauberung, die die Aufklärung Jahrtausende später vollzieht, wird von Horkheimer und Adorno deshalb als Befreiung einer theoretischen Kraft begriffen, die schon in der magisch-mythischen Artikulation anwesend war. Der Weg dazwischen, der von der bereits entzaubernden, da ,entgöt-

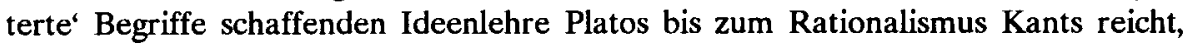
wird von ihnen entsprechend als Weg zunehmender Auflösung der identifikativen Mimesis und Ausbildung distanzierender Objektivation der Außenwelt durch Begriffsbildung und Abstraktion skizziert. ${ }^{22}$ Es ist ein Weg, auf dem sich eine Art ,theoretische Vernunft' herauszubilden scheint, deren Merkmale eben die Objektivierung und die Abstraktion sind und durch die sich das Subjekt als solches konstituiert.

Die Entstehung des Subjekts ist hierbei stets als Gegenstück zur abspaltenden Gewinnung der Außenwelt gedacht und bleibt entsprechend von diesem Mechanismus abhängig und bestimmt. ${ }^{23}$ Neben der kulturtheoretischen Linie wird diese Entwicklung von Horkheimer und Adorno auch psychogenetisch durchgezeichnet und als psychischer Vorgang zu fassen gesucht. So wird in Form einer rudimentären Theorie der Ich-Entwicklung ${ }^{24}$ die innerpsychische Funktionsstruktur als allmähliches Unterscheiden von inneren und äußeren Sensationen beschrieben, die in ihrer Differenzierung voneinander zugleich objektiviert und dem dadurch entstehenden Ich gegenübergestellt werden. Die Ich-hafte Subjektivität des Menschen geht damit aus einer doppelten Abspaltung, nämlich der äußeren wie inneren sinnlich-empfin-

${ }^{20}$ Horkheimer/Adorno, Dialektik, 11

21 vgl. Horkheimer/Adorno, Dialektik, 12

$22 \mathrm{vgl}$. Horkheimer/Adorno, Dialektik, 9, 74-78

23 vgl. Horkheimer/Adorno, Dialektik, 168-170

${ }^{24}$ Diese findet sich vor allem im Exkurs zum Antisemitismus. Mein Versuch, sie in die Rekonstruktion der Genese der Subjektkonstitution einzubeziehen, verdankt sich Honneths eigener Rekonstruktion (vgl. Honneth, Kritik, 55-57). 
dungsmäßigen Gegebenheiten, hervor. Sie entwirft sich „,im Spiegel einer konstanten Außenwelt" als das „Gegenüber einer allmählich fixierten Natur", die sie in sich und außer sich vorfindbar macht. ${ }^{25}$ Gleichzeitig ist sie das Produkt eines abstraktiven Vorgangs, der von den sinnlichen Konkreta absieht und Subjektivität gerade im Gegenzug zu diesen herstellt. Das Nicht-Ich, an dem sich - mit Fichte gesprochen das Ich herausbildet, ist in Horkheimers und Adornos Text stets das Naturhaft-sinnliche und das Ich der sich hiervon abgrenzende Geist; Abstraktion bestimmt sich zunächst als das ,Andere' zur Sinnlichkeit. ${ }^{26}$ Damit konstituiert sich das Subjekt vorerst durch eine abspaltende Objektivierung und eine abstraktive Entsinnlichung, die sich über die Sprache vermitteln. Es ist derart ein theoretisches und theoretisierendes Subjekt, das Außen- und Innenwelt objektivierend-abstraktiv zu fassen sucht.

Im ersten Strang der Genealogie wird so die Konstitution des Subjekts und seiner Rationalität einmal in Form einer kulturtheoretischen Spekulation und ein andermal mit einer erkenntnistheoretisch angesetzten Psychogenese durchgezeichnet. Beide Skizzen werden unter einem bewußtseinsphilosophischen Paradigma entworfen und richten sich derart auf das Geschehen zwischen einem Subjekt und einem Objekt, die einander idealtypisch gegenübergesetzt sind. Selbst dort, wo im magischen Ritus ein Kollektiv objektkonstitutiv und, theoretisierend' zu Werk geht, interessiert nicht das soziale Moment der kollektiven Handlung, sondern einzig die Differenzierung des Subjektiven von der Objektivität. Rekonstruiert wird im ersten Strang derart die Genese der Subjekt-Objekt-Spaltung, durch welche das Subjekt sich mittels Abgrenzung herstellt und die Außenwelt als äußere im Objektstatus fixiert. Der Prozeß dieser Differenzierung erscheint dabei zugleich als Rationalisierungsproze $B$, in dem Rationalität einmal überhaupt ausgebildet wird und sich zum anderen als theoretische Vernunft erweist, die bereits entelechial auf ,Entzauberung drängt. Damit wird ein zentrales Moment des aufklärerischen Rationalisierungsprogramms schon in dieser frühen Stufe der Genese von subjektiver Vernunft ausgemacht. Diese Vernunft zeigt sich dann weiter als abstraktive, die ihre Objektivierung der Realität durch Absehen vom Sinnlichen erreicht. Über die sprachgenetische Spekulation erscheint sie außerdem als sich sprachlich vermittelnde, die unter den Bedingungen der Entzauberung von der bloßen Bennenung zunehmend auf Begriffsbildung und ein begriffsorientiertes Theoretisieren zielt. Das von ihr vermittelte Selbst- und Weltverhältnis des Subjekts ist deshalb ebenfalls als abstraktives und begriffsbildendes zu fassen. Die Emanzipation des Menschen zum Subjekt, mit der dieser sich der Überwältigung durch eine unspezifisch-reichhaltige und bedrohliche Umwelt entwindet sowie den Stoff der Wahrnehmung zu ordnen und als Stoff, d.h. in seiner Externität, zu begreifen beginnt, zeigt sich so zunächst als Vorgang der Abgrenzung und Abstraktion.

Bereits in diesem ersten Strang nun sind zwei Momente wahrnehmbar, die für die weitere Entfaltung der Theorie Horkheimers und Adornos konstitutiv sind. Zum einen nämlich wird schon hier eine Defizienz entdeckt und deutet sich derart die grundsätzlich verfallstheoretische Determination in der „Dialektik der Aufklärung“ an. So wird eine erste Verengung der Vernunft problematisiert, die mit einer Beschränkung der Entfaltungschancen des subjektivierten Menschen einherzugehen

${ }_{26}^{25}$ vgl. Honneth, Kritik, 54

26 vgl. etwa: Horkheimer/Adorno, Dialektik, 27 
scheint. Zum anderen zeigt sich in der spekulativen Herleitung der Sprache und ihrer Rolle aus der Situation der Bedrohung bereits, daß die genealogische Theorie Horkheimers und Adornos unter das Prinzip des Selbsterhalts genommen ist. Der über den ersten gelegte zweite Strang wird damit bereits fühlbar. - Die genannte erste Verengung wird zunächst in der Ausgrenzung der ,sinnlichen Eindrucksfülle', d.h. der Sinnlichkeit des Begegnenden gesehen, die sowohl der entstehenden menschlichen Vernunft als auch ihrem Subjekt einen Teil der Realität, und damit einen Teil ihrer Selbstrealisierungsmöglichkeiten zu entziehen scheint. Um sich selbst zu gewinnen, müssen offenbar beide den Unmittelbarkeitsbezug zur sinnlichen Wirklichkeit verlieren. Hergestellt scheint auf der Vernunftseite damit bereits jener Graben, der es später Kant erlaubt, ,Begriff' und ,Anschauung' als Zusammengehörige dennoch in zwei Begriffen zu nennen und die Vernunft als formal-abstraktes Vermögen der sinnlichen Realität transzendental-logisch vorauszusetzen; Sinnlichkeit kommt für die Vernunft jenseits des Grabens nur mehr als bereits abstraktiv überformte und damit entsinnlichte, d.h. ihres Wesens beraubte vor. Hergestellt scheint gleichzeitig die Spaltung des Menschen in das vernünftige Subjekt abstraktiver Wirklichkeitsauffassung und ein Bündel vagierender sinnlicher Strebungen und Eindrücke, die der Vernunft häufig im Weg sind. Der Mensch gerät zu einem zweischichtigen Wesen, das sich als Subjekt von seiner sinnlichen Vitalschicht ebenso wie von der Sinnlichkeit der Außenwelt abschneidet und die Bezugsmöglichkeiten zu beiden verliert. Dem auf diese Weise konstituierten Subjekt und seiner Rationalität haftet für Horkheimer und Adorno daher ein grundsätzlicher Makel an, der als, Abwesen“ von Unmittelbarkeit und Sinnlichkeit bestimmt werden kann und sowohl das Subjekt als auch die Vernunft vom ,Reichtum' sinnlich-unmittelbarer Bezüge auf die Konsistenz abstraktiver Selbstkonstitution hin verengt. Nach dem ersten Strang der rationalitätstheoretischen Genealogie scheint so Rationalität ein notwendig sinnlichkeitsfremdes Vermögen sowie das Subjekt ein von sinnlichen Bezügen getrenntes Konstrukt zu sein und beide Male ein umfassenderer Horizont verlorenzugehen. ${ }^{27}$ Die Emanzipation des Menschen zum Subjekt, obschon in ihrem Anhub als Emanzipation immerhin angesetzt, ist derart bereits im ersten Strang um einen Preis erkauft und fordert ihre Kosten ein.

In der sprachbezogenen Herleitung der theoretischen Vernunft und seines Subjekts wird dann weiter deutlich, daß der erste Strang der Genealogie von einem zweiten überlagert wird, der unter das Prinzip des Selbsterhalts genommen ist. So machen Horkheimer und Adorno die sprachlich geleistete Objektfixierung und darin geschehende Subjektivierung nicht am, reinen' Bezeichnen, sondern am apotropäischen Benennen fest. Das entstehende Subjekt scheint einzig aus der Situation der Angst und Bedrängnis die nennende Fähigkeit zu entfalten, und als Movens tritt sogleich der Zwang, sich etwas erwehren zu müssen, exklusiv in Blick. Nicht aus Neugier oder lustbetontem Interesse scheint der Mensch seine theoretische Vernunft mittels Sprache zu entwerfen, sondern in Panik und Furcht. Die auf der Wahrnehmungsebene bedrängende Realitätsfülle wirkt zugleich als psychophysisch bedrängende und scheint den Charakter einer Existenzbedrohung zu haben. Das ,Setting, in das Horkheimer und Adorno ihren Menschen zu Beginn der Subjektivierung stel-

${ }^{27}$ vgl. hierzu etwa: Horkheimer/Adorno, Dialektik, 51 
len, ist so das eines unbarmherzigen Kampfs alles mit allem, und die abstraktivsprachliche Objektkonstitution des Subjekts gerät zur Notwendigkeit um des menschlichen Selbsterhalts und der menschlichen Selbstbehauptung willen. Damit ist die Möglichkeit einer Objektkonstitution allein zum Zweck des Ordnens und Appräsentierens der sinnlichen Eindrucksfülle in nuce ebenso aus der Genealogie ausgeschieden wie der Zweck der Mitteilung und Kommunikation. Nicht, weil das Subjekt sich mit sich oder anderen über etwas verständigen will, scheint es rhetisch-objektkonstitutiv tätig zu werden, sondern um sich gegen eine Bedrohung zur Wehr zu setzen und sich psychophysisch erhalten zu können. Die Objektkonstitution und die damit einhergehende Subjektivierung sind derart schon in den Horizont der Selbstbehauptung gestellt und werden dann mit Kampf, Repression und Herrschaft wesenhaft verbunden. Vernunft gerät aus diesem Blickwinkel betrachtet zur Frucht einer dranghaften Situation und unterliegt unter deren Determinationen weiteren Begrenzungen und Verengungen. Diese nun sind im zweiten Strang der Genealogie durchgezeichnet, der hierzu explizit unter das Prinzip der Selbsterhaltung gestellt ist und daraus die instrumentelle Vernunft herleitet.

Die Genese der instrumentellen Vernunft: Funktionalisierung, Herrschaft und Repression unter dem Selbsterhaltungsprinzip

Der zweite Strang der rationalitätstheoretischen Genealogie wird, wie sich im ersten schon andeutete, unter dem Selbsterhaltungsprinzip entwickelt. So ist in Horkheimers und Adornos Text immer wieder die „Unterstellung des gesamten Lebens unter die Erfordernisse seiner Erhaltung ${ }^{\text {c2 } 28}$ als Prinzip angesetzt, das den Prozeß der Subjektwerdung des Menschen prägt und durchzieht, ja gar als dessen eigentliches Movens auftritt. Von Beginn an scheint alle Weltbegegnung des Menschen dieser Ausrichtung auf Selbsterhaltung ,verhaftet ${ }^{29}$ zu sein und die spezifische Form der

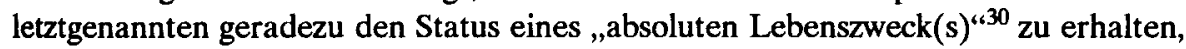
der alle anderen Zwecke verblassen läßt. Bis in die Gegenwart - und insbesondere nach dem Urteil der Aufklärung - scheint daher jeder Mensch, der „ohne rationale Beziehung auf Selbsterhaltung dem Leben sich überläßt (...) ins Vorgeschichtliche zurück" $\mathrm{zu}$ fallen. ${ }^{31}$ Damit wird die Selbsterhaltung, die zweifelsohne gattungsgeschichtlich als Trieb immer schon mitgegeben ist, von Horkheimer und Adorno als eine Art Grundprinzip des menschlichen Selbst- und Weltverhältnisses überhaupt ausgelegt und zugleich in den Stand einer normativen Vorgabe erhoben. Zum einen nämlich gilt der Selbsterhaltungstrieb in ihrem Text als der Motor, als die eigentliche Triebkraft des Subjektivierungsprozesses, durch die auch Objektivierung und Abstraktion erst veranlaßt werden. Die geschilderte Distanzierung der Außenwelt erscheint als nötig, um dem dabei entstehenden Subjekt seine selbsterhaltende Behauptung in der Welt zu ermöglichen, nicht aber nur, um die andrängende Stoffülle zu ordnen. Der Emanzipationsprozeß erhält dadurch den Charakter einer Erringung von Souveränität statt eines ,reinen', durch Abgrenzung erreichten Selbstands, und das Subjekt sucht sich durchzusetzen, nicht nur gegenüberzustehen. Konstituiert wird

${ }_{28}^{28}$ Horkheimer/Adorno, Dialektik, 31

29 vgl. Horkheimer/Adorno, Dialektik, 32

${ }^{30}$ Horkheimer/Adorno, Dialektik, 32

${ }^{31}$ Horkheimer/Adorno, Dialektik, 30 
demnach ein defensiv-aggressives Subjekt, das seinen Eigenstand kämpferisch anstrebt. Zum anderen wird dieser Behauptungsvorgang auch zum Kriterium für ,vernünftiges' Verhalten gemacht, d.h. als normative Prämisse der Konstitution von Rationalität eingesetzt. Rational ist nun, was der Selbsterhaltung und -behauptung dient, und Rationalität selbst muß sich an ihrer Eignung hierzu überprüfen lassen. Die sich ausbildende Vernunft des Subjekts ist derart kein zweckfreies ,Vermögen (mehr), sondern eine Fähigkeit, die zu einem bestimmten Zweck ausgebildet wird und diesem Zweck unterworfen ist.

Unter diesen Bedingungen nun kann auch das Theoretisieren des Subjekts keineswegs als reine theoria, reines Schauen und Vernehmen gedacht werden, sondern scheint es von Beginn an einer bestimmten Perspektive eingeordnet zu sein, die das Theoretisieren zu etwas nutze sein läßt, genauer: die es der erhaltenden Selbstbehauptung des Subjekts dienstbar macht. Gefragt ist offenbar nicht eine Theorie, die die Wirklichkeit begreifbar, sondern immer schon jene Theorie, die die Wirklichkeit fungibel für den menschlichen Selbsterhalt werden läßt. Die theoretische Vernunft des Subjekts wird derart in Horkheimers und Adornos Text vordringlich als instrumentelle rekonstruiert, die durch ihre Objektivation der Gegenstände deren Manipulation für den genannten Zweck erlaubt. Ihre spezifische Objektivation geschieht nicht ,rein' als bloße Distanzierung, sondern ist selbst immer schon einem manipulativen Interesse unterstellt. Auch das Abstrahieren geschieht entsprechend unter dem spezifischen Interesse von Manipulation und Funktionalisierung, das den Abstraktionsvorgang eigentlich erst zu veranlassen scheint und ihm seinen spezifischen Charakter verleiht. Nicht nur nämlich scheint der Mensch zu versuchen, in dem ihn Umgebenden Verbindendes und Unterscheidendes auszumachen, um es hierdurch für seine Wahrnehmung abstraktiv zu ordnen, sondern sich zugleich, ja vordringlich um Erkenntnis jener ,Regelmäßigkeiten' zu bemühen, welche es erlauben, „die Naturvorgänge operativ zu kontrollieren“" ${ }^{32}$ Der Versuch, sich durch Distanzierung in der Fülle der umgebenden Natur zu orientieren, geht offenbar sogleich in den Versuch über, dies mittels funktioneller Objektivation, also der Bestimmung der Eingriffs- und Manipulationsmöglichkeiten zu erreichen. Entsprechend wird das Wesen der rationalen Abstraktion im Objektivierungsvorgang als Heraushebung und Feststellung solcher Möglichkeiten bestimmt: Abstraktion wird bei Horkheimer und Adorno mit dem Bemühen identisch gesetzt, die „Realität auf wiederkehrende, den manipulativen Eingriffszielen entgegenkommende Ereignisse zu fixieren“333. Damit scheint nun auch die abstraktiv geschehende Begriffsbildung des Menschen grundsätzlich auf Manipulation gerichtet. Der Begriff gleicht Horkheimer und Adorno zufolge „dem materiellen Werkzeug, das in verschiedenen Situationen als dasselbe festgehalten wird“, und gilt als ,das ideelle Werkzeug, das an die Stelle an allen Dingen paßt, wo man sie packen kann" ${ }^{34}$ Die unter das Prinzip der Selbsterhaltung genommene Rekonstruktion setzt also Objektivation und Instrumentalisierung, Abstraktion und Funktionalisierung, Begriffsbildung und Manipulation in eins und unterscheidet Erkenntnis- und Handlungsinteresse nicht voneinander.

\footnotetext{
32 Honneth, Kritik, 51

33 Honneth, Kritik, 51

34 Horkheimer/Adorno, Dialektik, 38
} 
Beide Interessen werden schließlich noch mit einem Herrschaftsinteresse identifiziert. So scheint das entstehende Subjekt in der Situation der Selbstbehauptung seine Überlegenheit durch eine aggressive Instrumentalisierung anzustreben. Die funktionell begriffene und manipulierte Realität wird nach Horkheimers und Adornos Sprachgebrauch derart nicht nur für den Selbsterhalt genutzt, sondern diesem Zweck unterworfen und in den Stand des Gehorsams gedrängt. Das ,sachhafte Gebrauchen (W. Korff) erhält den Charakter des herrscherlichen Gebietens, und Objektivation, Abstraktion und Begriffsbildung werden mit Herrschaft gleichgesetzt. Alle drei ,gründen' der Theorie zufolge nun ,in der Distanz zur Sache, die der Herr durch den Beherrschten gewinnt“".35 Sie zielen auf eine „Weltherrschaft über die Natur“36, um den Subjekten eine dauerhafte Existenz zu garantieren. Die entstehende theoretische Vernunft der Subjekte ist so zunächst als instrumentelle bestimmt, und deren primäres Merkmal wird dann als funktionalistisch-manipulative Abstraktion im Gestus des Herrschens dingfest gemacht. Als Opfer der so hergeleiteten und definierten instrumentellen Vernunft gilt die äußere Natur, die in den verkürzenden Umgriff des instrumentellen Gemächtes zu geraten und deren „Fülle der Qualitäten“ darin zu ,erliegen' droht. ${ }^{37}$ Auf diese Weise wird eine erste Repression konstatiert, nämlich die der äußeren Natur. Korrespondierend dazu aber bestimmt sich eine erste Herrschaft, die Naturbeherrschung. Damit erhält der Emanzipationsvorgang zunächst eine weitere Note: Das souveräne, sich gegen die Umwelt durchsetzende Subjekt wird jetzt als jenes bestimmt, das sich die Natur unterwirft. Seine Durchsetzung gerät offen zur Herrschaft und seine Souveränität ist die des Herrschers. Nicht nur bestimmt sich Subjektivität demzufolge dadurch, daß sie der Objektivität gegenübersteht, auch nicht nur durch ihre bloße Selbstbehauptung, sondern durch Unterwerfung und den Status des Präsidierens.

Zusammen damit aber ergeben sich für Horkheimer und Adorno noch eine zweite Repression und eine zweite Herrschaft, die sie als von der ersten unablösbar betrachten. Im Zug der Objektivation und Zurückdrängung der äußeren sehen sie nämlich auch die innere, die menschliche Natur verobjektiviert und reprimiert. Eine solche Repression im Sinn der Ausgliederung deutete sich bereits in der abstraktiven Selbstkonstitution des theoretisierenden Subjekts an, das die Sinnlichkeit zu distanzieren sucht. Das eigentlich repressive Moment aber sehen Horkheimer und Adorno wieder im Moment der Verfügung und Herrschaft unter dem Zweck der Selbsterhaltung. So scheint eine diesbezügliche Repression zunächst schon durch eine Vereinseitigung der Wahrnehmung zu geschehen, die ,auf den kognitiven Schematismus der Verfügung zusammengezogen “ ${ }^{\prime 38}$ werde und derart nur noch ,ins Bild bringe ${ }^{6}$, was dieser instrumentellen Perspektive zugepaßt ist. Um seine an der Konstitution der Objektwelt durch die instrumentelle Vernunft gewonnene Identität wahren, also Subjekt bleiben und den Zweck des Selbsterhalts verfolgen zu können, müsse der Mensch all jene Sinnesempfindungen ausgrenzen, „die die zielgerechte Verfolgung des Verfügungsprinzips zu beeinträchtigen drohen“39. Parallel zu dieser ,sensori-

\footnotetext{
${ }^{35}$ Horkheimer/Adorno, Dialektik, 16

${ }^{36}$ Horkheimer/Adorno, Dialektik, 27

${ }_{38}^{37}$ Horkheimer/Adorno, Dialektik, 13

${ }^{38}$ Honneth, Kritik, 57

${ }^{39}$ Honneth, Kritik, 57
} 
schen Vereinseitigung (Honneth) erfolgt der Theorie nach jedoch auch eine Repression der menschlichen Triebnatur. Diese begründen Horkheimer und Adorno nun über die instrumentelle Genese der Arbeit. So werde die objektivierend-abstraktive Herrschaft über die äußere Natur, die zugleich der menschlichen Selbsterhaltung diene, primär in Form der Arbeit ausgeübt und als solche gesellschaftlich organisiert. ${ }^{40}$ Arbeit als instrumentell-zweckgerichtete Tätigkeit aber fordere den Menschen, die sich über sie als Subjekte erhalten, „gerichtete Aufmerksamkeit und gebündelte Handlungsenergien“ ab, die zu einer entsprechend „dauerhaften Kanalisierung der amorphen Bedürfnisregungen" nötigten. ${ }^{41}$ Folge dessen scheint dann zu sein, daß das Subjekt nur noch jene „Impulse seines organisch andrängenden Triebpotentials“ zulassen darf, die „in seine instrumentalen Verrichtungen einfließen können“. ${ }^{42}$ Die Triebsphäre des Menschen gilt dadurch als von vorneherein instrumentell deformiert und zugerichtet. Um sich arbeitend erhalten zu können, scheint es für die Subjekte unumgänglich, sich eines gut Teils ihrer menschlichen Triebbasis zu entledigen. Damit aber ist für Horkheimer und Adorno eine zweite Repression konstituiert, nämlich die der menschlichen Triebhaftigkeit und des ,sensorischen Reichtums', der eine zweite Herrschaft korrespondiert, die Selbstbeherrschung.

Der Prozeß der Subjektivierung und Rationalisierung wird so im zweiten Strang der Genealogie unter das Prinzip der Selbsterhaltung und Selbstbehauptung gestellt. Die Emanzipation des Menschen zum Subjekt erhält damit ein verändertes Gepräge: Sie scheint zunächst motiviert allein von der Situation der Bedrohung und Bedrängnis, der der Mensch sich zum Zweck seines blanken Bestands in der Welt zu entwinden sucht. In diesem Versuch bildet er dann seine Vernunft aus und entwirft sich selbst als Subjekt. Nicht aus neugierigem Interesse , an der Sache', sondern anscheinend nur für seine Erhaltung und Behauptung in einer übermächtigen Umwelt formt er jene objektkonstitutive und abstraktive Fähigkeit aus, die ihn sich als abgegrenztes, eigenständiges Wesen begreifen läßt. Sowohl die Rationalität als auch das Subjekt sind deshalb vom Prozeß der Selbstbehauptung determiniert und definieren sich von ihr als primärem und exklusivem Zweck her. Das scheint zum einen zur Folge zu haben, daß die Vernunft sich jetzt als instrumentelle konstituiert und einzig auf die Funktionalität ihrer Gegenstände richtet. Zum anderen scheint das Subjekt in seinem Kampf mit der bedrohlichen Umwelt nicht nur den Status der Eigenständigkeit und Unabhängigkeit anzustreben, sondern auf Herrschaft und Überlegenheit abzustellen. Die Rationalisierung bestimmt sich derart als Instrumentalisierung, und das Subjekt definiert sich als souveräner Herrscher. Der Emanzipationsprozeß mündet hierdurch in zwei Formen von Herrschaft, der Natur- und der Selbstbeherrschung, welchen zwei Repressionen korrespondieren, und die Geschichte der Rationalisierung und Subjektivierung ist als Herrschaftsgeschichte reskribiert.

Dies nun bedingt für Horkheimer und Adorno weitere spezifische Defizienzen, die über die im ersten Strang wahrnehmbaren hinausgehen und die tendenziell schon dort als Verfallsgeschichte perspektivierte Genealogie zunehmend in eine solche überleiten. So sehen die beiden Autoren den herrscherlichen Stand des Subjekts

40 vgl. Horkheimer/Adorno, Dialektik, 20: „Natur soll nicht mehr durch Angleichung beeinflußt, sondern durch Arbeit beherrscht werden."

${ }^{41}$ Honneth, Kritik, 58

42 Honneth, Kritik, 58 
teuer erkauft, nämlich um den Preis einer doppelten Verengung der Vernunft und eines gestörten Verhältnisses des Menschen zur Natur. - Die Verengung der Vernunft wird dabei an zwei (sukzessiven) Bestimmungsmomenten der Ausbildung der theoretischen zur instrumentellen Rationalität dingfest gemacht: Zum einen scheint Vernunft ja nun von vorneherein kein sich zweckfrei entwerfendes Vermögen zu sein, das um der ,reinen' Erkenntnis willen entsteht und auf die ,Schau' des Realen sich richtet, sondern eine Fähigkeit, die für einen bestimmten Zweck, den Selbsterhalt, ausgebildet worden ist. Damit erweist sich für die Kritische Theorie ein Vernunftbegriff, der im Sinn etwa der griechischen Philosophie die theoria, die Erkenntnis an sich und ohne Richtung auf Verwertbarkeit, als höchstes Ziel ansetzt, als Illusion, die ab initio von der genannten Zweckbestimmung konteragiert wird. Von dieser Bestimmung aus betrachtet kann Vernunft niemals ,Zweck an sich selbst' sein, sondern ist sie stets Mittel für die Erreichung des prinzipiell gesetzten heteronomen Ziels der Selbsterhaltung, d.h. sie ist nicht frei, sondern fremdbestimmtes Werkzeug, Instrument. Auf den Status eines Instruments zurückgedrängt aber, so kann gefolgert werden, verliert Vernunft ihre Souveränität als selbst zwecksetzende und zweckbefragende. Sie ist nicht länger jene Instanz, die rational Ziele festlegt und festgelegte Ziele auf ihre Rationalität hin prüft, sondern wird ein Mittel für Ziele und selbst in ihrer Rationalität am Selbsterhaltungsprinzip gemessen. Die Zuordnung von Vernunft und Zweck hat sich anscheinend verkehrt und Vernunft ist hierbei zweckbestimmt beschnitten worden.

Die zweckbestimmte Festlegung und Beschneidung scheint dann zum anderen zu bedingen, daß Vernunft auch bei ihrer abstraktiven Verarbeitung der Wirklichkeit und der Objektkonstitution eingeschränkt wird. Nicht nur entgeht ihr durch Abstraktion der ,Reichtum ${ }^{6}$ des Sinnlichen, sondern sie bekommt nicht einmal die ganze mögliche abstrakte Bestimmungsfülle der Realität in den Blick, da sie lediglich auf den Aspekt der Tauglichkeit des Begegnenden für den genannten Zweck gerichtet ist. Die abstraktive Verengung der Rationalität, die ihr bereits nur einen Ausschnitt aus der Fülle des Realen zukommen ließ, scheint so nochmals verschärft durch eine präzise Festlegung der ausschnittkonstitutiven Perspektive: Abstraktion und Objektivation sind nun prinzipiell unter ein Interesse am Manipulativen und Funktionellen gestellt, das nicht Erkenntnis, sondern Einfluß zum Ziel hat und derart an der Realität nur wahrnimmt, was diese ,zuhanden' macht. Vernunft droht demnach auf den Stand des Machens zu regredieren und es zu verfehlen, Kompetenz für alles zu gewinnen, was jenseits instrumenteller Fungibilität gelegen ist. Selbst Werkzeug der Selbsterhaltung bildet sie im zweckbestimmten Vollzug Werkzeuge begrifflicher Art aus, und von ihrer möglichen Erkenntnisbreite scheint nur der schmale Streif der Funktionalität und Instrumentalität übrig zu bleiben. Sie ist auf diese Weise in einem doppelten Sinn als instrumentelle Vernunft definiert und determiniert, nämlich einmal als instrumentalisierende Fähigkeit für die Zuhandenmachung von Wirklichkeit und zum anderen als Instrument für den ihr externen Zweck des Selbsterhalts. Ein umfassenderer Vernunftbegriff aber gilt damit als doppelt aufgelöst: Seine Möglichkeit schwindet sowohl durch die Festlegung der Vernunft auf manipulativ verwertbare (und keine anderen) Erkenntnisse, als auch durch die Unterwerfung der Vernunft unter den Zweck des Selbsterhalts, der sie ihrer zwecksetzenden und -befragenden Kompetenz entkleidet und zum Mittel herabwürdigt. 
Das Subjekt wiederum, das sich durch die instrumentelle Vernunft als herrscherliches zu konstituieren und zu wahren sucht, scheint seinen erstrebten souveränen Stand hierbei durch ein zweifach gestörtes Verhältnis zur Natur zu bezahlen. Kehrseite seiner Herrschaft nämlich sind die beiden genannten Repressionen, in denen einmal die äußere und einmal die innere Natur zurückgedrängt und in den Griff genommen wird. Damit ist die Defizienz neu bestimmt: Schien im ersten Strang der Genealogie durch die Konstitution des vernünftigen Subjekts einmal der sinnliche Reichtum des Begegnenden aus dem Blick zu geraten und ein andermal auch die eigene Sinnlichkeit dem Begreifen zu entschwinden, so werden jetzt die äußere Natur wie die inneren sensorischen Möglichkeiten und triebbestimmten Regungen aktiv zurückgedrängt und der Vernunft des Subjekts unterworfen, die dabei zur instrumentellen verengt wird. Das entstehende Verhältnis zur Natur aber tritt dann als Gewaltverhältnis auf, in dem das Subjekt aus einer zunächst defensiven Aggression heraus diese Unterwerfung versucht und die Überwältigung durch die äußere und innere Welt durch deren Bezwingung zu überwinden trachtet. Beide Naturen werden in den Status des Gehorsams gedrängt, und die herrscherliche Souveränität des Subjekts wird damit erkauft, die äußere und innere Natur nicht einfach nur verloren zu haben, sondern als durch die Repression widerborstig gewordene dauernd in Schach halten, d.h. ausgrenzen und wegdrängen zu müssen. Das Subjekt schafft sich so zunächst einen doppelten Verlust: nämlich den eines ,zwanglosen' Bezugs zu beiden Naturen, und einen doppelten Kampf: nämlich den um Aufrechterhaltung seiner Herrschaft an beiden Fronten. Die Geschichte des Subjekts erhält damit den Charakter einer Geschichte von Gewalt, Herrschaft und Unterdrückung, in der das Subjekt unter Beschädigung der Natur und seiner eigenen Vernunft entsteht. Es scheint so auf dem Rücken eines Prozesses von Defizienzen und zu ungeheueren Kosten in die Welt einzutreten.

Die Auflösung der Subjektivität im instrumentellen Gemächte: Das endgültige Scheitern des Emanzipationsversuchs der Menschheitsgeschichte

Unter den vorstehend rekonstruierten Bedingungen der Defizienzgeschichte des zweiten genealogischen Strangs aber stellt sich schließlich die Frage, ob das Subjekt der instrumentellen Vernunft überhaupt noch als Subjekt zu betrachten ist und der derart rekonstruierte Prozeß von Subjektivierung und Rationalisierung noch als Emanzipationsvorgang bewertet werden kann. Um diese Frage zu beantworten, untersuchen Horkheimer und Adorno zunächst, ob im Zug der Naturbeherrschung Autonomie und Freiheit als wesenhaft dem Subjekt zugehörige Eigenschaften gewonnen wurden. Sie ziehen damit jetzt explizit die beiden kategorialen Bestimmungen der Subjektivität heran, wie sie von der Aufklärung und in Neuzeit und Moderne gefaßt sind, und fragen, ob der unter den großen Opfern der Deformation von Natur und Vernunft hergestellte Status des Subjekts in diesem Sinn zu interpretieren ist, d.h. näherhin, ob zumindest der versprochene Selbsterhalt und die Souveränität schaffende Herrschaft als Rudimentärformen von Autonomie und Freiheit geglückt sind. Das nun scheint Horkheimer und Adorno keineswegs der Fall zu sein. Vielmehr sehen sie den Prozeß einer Subjektivierung mittels Herrschaft durch eben dieses Mittel korrumpiert und gegen sich selbst gekehrt. Die als kämpferische Überlegenheit erstrebte Subjektivität scheint sich in ihren Begleiterscheinungen, den beiden 
Repressionen, zu verfangen und dadurch einmal ihre Autonomie und Freiheit an heteronome Prozesse zu verlieren sowie ein andermal sich durch den herrscherlichen Gestus die menschliche Basis zu rauben. In beiden Fällen scheint sich die Subjektivität aufzulösen und die Subjektivierung von ihren Kosten gefressen zu werden. Horkheimer und Adorno rekurrieren damit wieder auf die dialektische Grundstellung ihrer Theorie und suchen in dem emanzipativen Begehren die Momente seiner Selbstverhinderung auf. Gleichzeitig ziehen sie derart die Geschichte der Subjektivität als Geschichte eines Scheiterns aus und führen sie ihren verfallstheoretischen Ansatz konsequent zuende.

So sehen Horkheimer und Adorno zunächst durch die Herrschaft mittels instrumenteller Vernunft keineswegs Freiheit und Autonomie ins Werk gesetzt, sondern diese von eben dieser Herrschaft wieder desavouiert und die Emanzipation durch die Erhebung des Selbsterhaltungstriebs in den Status eines obersten Zwecks im ,Betrieb des Selbsterhalts' verenden. Da nämlich die Beherrschung der äußeren Natur, die dem Subjekt seine zu ihm gehörige Souveränität und Autonomie verschaffen sollte, ohne jene der inneren Natur nicht zu denken zu sein scheint - vermittelt sich die erste ja über die notwendig die zweite bedingende Arbeit -, bringt der emanzipative Vorgang, mit dem der Mensch der Überwältigung durch die naturale Umwelt, oder mit einem anderen Wort: dem Naturzwang, zu entrinnen sucht, zugleich ein neues Zwangsverhältnis hervor, in dem das Erstrebte wieder verschwindet. Kaum nämlich hat der Mensch sich der Abhängigkeit von der umgebenden Natur enthoben und deren ,Heteronomie' überwunden, fältt er bereits wieder in eine neue Abhängigkeit von jenen instrumentellen Prozessen, die diese Überwindung leisten sollten. Zwar nicht von der äußeren Natur, doch von der gesellschaftlich organisierten Arbeit und ihren Notwendigkeiten ist das Subjekt jetzt determiniert und derart in den Status eines Objekts zurückversetzt. Statt in Autonomie und Freiheit sich entwerfen zu können, wird das Subjekt den heteronomen Bestimmungen, den ,Entwürfen' der Arbeitswelt unterstellt und in ein ,zweites Zwangssystem' eingegliedert. Die Zwänge des instrumentellen Selbsterhalts erscheinen Horkheimer und Adorno daher als eine Art ,Fortsetzung des Naturzwangs mit anderen Mitteln', und ,jeder Versuch, den Naturzwang zu brechen, indem die Natur gebrochen wird“, scheint nur „um so tiefer in den Naturzwang hinein" zu führen. ${ }^{43}$ Jedes emanzipative Moment in der Geschichte der Subjektivität wird damit von der Selbsterhaltung durch Arbeit korrumpiert und die erwünschte Selbstbestimmung kippt in Fremdbestimmung. Der Selbsterhalt setzt sich in den Zwängen der Arbeit dominant und gerät von der motivationalen Wurzel dieser strukturellen Einrichtung zu deren determinativem Zweckprinzip, das die Emanzipation aus dem Zielstatus verdrängt. Die in der Herrschaft über die Natur angezielte Freiheit wird derart mit dem ,Betrieb der Selbsterhaltung verwechselt, ${ }^{44}$ und die durch Arbeit beabsichtigte Autonomie scheint an den mit ihr einhergehenden Zwängen zu scheitern. Ein seiner Freiheit und Autonomie enthobenes Subjekt aber ist auch seines Subjektstatus enthoben, und der Prozeß der Sub-

\footnotetext{
${ }^{43}$ Horkheimer/Adorno, Dialektik, 15; im Hintergrund dieser Argumentationsfigur steht das analoge Theorem Marx $x$, das durch Arbeit den Menschen sich der ersten Entfremdung im Naturzwang nur zugunsten einer zweiten in der Arbeitsteilung entwinden sieht.

44 vgl. Horkheimer/Adorno, Dialektik, 39-40; dort findet sich die Wendung zwar in bezug auf die Aufklärung, doch trifft sie auch den hier skizzierten Sachverhalt.
} 
jektivierung geht fehl. Das via instrumentelle Vernunft durch Naturbeherrschung geschaffene Subjekt entpuppt sich daher als Scheinsubjekt.

Unter den Bedingungen des ,zweiten Zwangs' sehen Horkheimer und Adorno jedoch nicht nur Autonomie und Freiheit verloren gehen, sondern die innermenschliche Basis für den Prozeß der Subjektivierung zerstört. So nötigt, wie im zweiten Strang der Genealogie schon zu sehen war, der Arbeitsprozeß dem Menschen die Repression und Instrumentalisierung seiner inneren Natur ab. Hierdurch aber scheint dieser Mensch sich zusammen mit seinem naturalen Grund auch seiner eigenen ,Substanz' zu entfremden und seine Selbstrealisierung als Subjekt (nochmals) zu verfehlen. Dies führen Horkheimer und Adorno vor, indem sie zunächst den „Prozeß der Selbsterhaltung durch bürgerliche Arbeitsteilung“ als „Selbstentäußerung der Individuen, die sich an Leib und Seele nach der technischen Apparatur zu formen haben“, apostrophieren. ${ }^{45}$ Die ,Selbstentäußerung" trifft dabei die innere Natur des Menschen, die jetzt als dessen ,Substanz' gehandelt wird. Diese innere Natur nämlich gilt als die „,beherrschte, unterdrückte und durch Selbsterhaltung aufgelöste Substanz", die eben "das Lebendige" vorstellt, "dessen Funktion die Leistungen der Selbsterhaltung" eigentlich sein sollten. ${ }^{46}$ Durch den Arbeitsprozeß sollte also gerade die lebendige innere Natur des Menschen geschützt und seine autonome Selbstentfaltung aus ihr heraus sichergestellt werden. Anstatt jedoch das zu tun, seine ,Lebendigkeit' frei zu entfalten, löst der Mensch sie instrumentell und repressiv in den ProzeB der Selbsterhaltung durch Arbeit auf. Damit verliert er nicht nur seine Autonomie, sondern entfremdet er sich zugleich seiner selbst, und es gerät ihm das Ziel seiner eigenen Realisierung, seiner Selbstverwirklichung als Subjekt, aus den Augen. So droht dem Menschen durch die Repression seiner Natur „das Telos des eigenen Lebens verwirrt und undurchsichtig ${ }^{447} \mathrm{zu}$ werden, d.h. er scheint mit dem naturalen Grund seiner Existenz auch deren Ziel, die Subjektivierung, aus dem Blick zu verlieren. Die Repression der inneren Natur des Menschen trifft derart auch das Leben des Subjekts und zerstört damit das, was durch den herrscherlichen Emanzipationsversuch gesichert werden sollte, nämlich die lebendige und autonome Selbstentfaltung des Subjekts aus seinem vitalen menschlichen Grund heraus. Ist die Basis dieser Entfaltung zerstört, scheint auch das Subjekt, das sich in ihr erst realisieren sollte, nicht mehr zustandezukommen. Für Horkheimer und Adorno enthült sich deshalb die „Herrschaft des Menschen über sich selbst“ als ,allemal virtuell die Vernichtung des Subjekts, in dessen Dienst sie geschieht" ${ }^{48}$

Damit ist der verfallstheoretische Bogen der genealogischen Rekonstruktion Horkheimers und Adornos geschlossen und erscheint die rekonstruierte Defizienz als totale. Nachdem zunächst schon im ersten Strang einer subjektphilosophischen Rekonstruktion eine erste Verengung der Vernunft und eine Beschneidung der menschlichen Entfaltungschancen durch Ausgrenzung der Sinnlichkeit konstatierbar waren und nachdem diese Defizienzen im zweiten Strang über die Einführung des Selbsterhaltungsprinzips und des Herrschaftsbegriffs zu einer weiteren Rationalitätsbegrenzung auf Funktionalität sowie zu einer doppelten Repression verschärft

\footnotetext{
${ }^{45}$ Horkheimer/Adorno, Dialektik, 30

${ }^{46}$ Horkheimer/Adorno, Dialektik, 51

${ }^{47}$ Horkheimer/Adorno, Dialektik, 51

48 Horkheimer/Adorno, Dialektik, 51
} 
schienen, gilt jetzt zusätzlich zu den Beschädigungen von Vernunft und Natur auch das hierbei entstehende Subjekt als defizitäres und seines Wesens beraubtes. So schien zwar durch den Prozeß der Herausbildung der instrumentellen Vernunft immerhin noch ein zugehöriges Subjekt zu entstehen, das über eine manipulativ vermittelte Herrschaft Souveränität, d.h. Freiheit vom Naturzwang und Autonomie in der Welt zu gewinnen sucht, doch erweist sich für Horkheimer und Adorno dieses Subjekt nun als Illusion, das seinen Gewinn gar nicht wirklich erhält und deshalb den Status der Subjektivität nicht erreicht. Die Geschichte der Emanzipation des Menschen durch Naturbeherrschung scheint sich vielmehr selbst zu desavouieren und die Herstellung von Subjektivität, Autonomie und Freiheit gegen ihr eigenes Unterfangen zu kehren. Nicht nur also gelten die Kosten für die instrumentell-rationale Subjektivierung als enorm hoch, sondern sie drohen nun auch noch das um sie Erworbene zu verschlingen. Zum einen nämlich scheint unter den Bedingungen der gesellschaftlich organisierten Arbeit, die gegenüber der Natur den menschlichen Selbsterhalt und einen souveränen Stand strukturell garantieren sollte, die Autonomie heteronom korrumpiert und die Freiheit gegen neue Zwänge eingetauscht zu werden. Die rekonstruktiv aufgesuchte Emanzipation versackt dann im betriebenen bloßen Selbsterhalt und stellt weder Zweck noch Ziel dar. Zum anderen schneidet sich das Subjekt unter den Bedingungen der zweiten Repression, die zugleich Bedingungen seiner Selbstkonstitution sind, von seiner menschlichen Basis ab und verliert es gerade das, woraus es sich lebendig und autonom entfalten sollte. Es ist dadurch doppelt desavouiert: Einmal ist es in Strukturbedingungen gespannt, die es heteronomisieren, und ein andermal wird ihm die psychophysische Basis für seine Selbstentfaltung entzogen. Die Geschichte der Rationalisierung und Subjektivierung aber scheint sich so als Geschichte eines zunehmenden Verfalls zu erweisen, der mit der Destruktion des Subjekts auf die Spitze getrieben ist: Nicht nur ist die Natur vergewaltigt, nicht nur die Rationalität ihres zwecksetzenden, bzw. -befragenden, Status beraubt und auf den Stand eines Mittels reduziert, sondern auch das Subjekt in heteronomen Netzen entwürdigt und von innen heraus zerstört. Der Versuch der Emanzipation des Menschen zum Subjekt tritt derart als vollständiger Fehlschlag auf und am Ende bleibt nichts als die Konstatierung eines totalen Scheiterns.

Die Gründe für dieses Scheitern sind nun ebenfalls deutlich. Sie liegen der Rekonstruktion zufolge in der Genese von Subjekt und Rationalität durch Objektivierung, die zusätzlich unter das Selbsterhaltungsprinzip genommen ist und mit Herrschaft zu koinzidieren scheint. So war zunächst schon in der, reinen' Objektivierung durch Abstraktion eine erste Defizienz namhaft zu machen, die dem entstehenden Subjekt unmittelbare sinnliche Bezüge entzieht und es zugleich selbst spaltet. Schon im Ursprung von Subjekt und Rationalität scheint derart die verderbliche Entwicklung zu einer Desavouierung der Emanzipation durch Vernunftverengung und Hinderung menschlicher Selbstentfaltung zu gründen und anzuheben. Sodann trägt in Horkheimers und Adornos Theorie die nachhaltige Insistenz des Menschen auf seiner Erhaltung Schuld daran, daß die Rationalität sich zur instrumentellen zusammenzieht und ein umfassenderer Vernunftbegriff verlorengeht. Die wurzelhafte Defizienz wird damit verschärft und weiter ausgezogen. Schließlich führt das Herrschaftsbegehren, das mit dem Selbsterhalt Hand in Hand zu gehen scheint, dazu, daß die beiden verderblichen Repressionen entstehen, unter deren Bedingungen das Subjekt einen zwanglosen 
Bezug zu den beiden Naturen zu gewinnen endgültig versäumt und sich durch Verstrickung in Heteronomie sowie durch Abspaltung von seiner menschlichen Basis, selbst aufzulösen beginnt. Damit ist der Verfall nun in seine ,Endschaft' gebracht und zum Extrem eines vollständigen Scheiterns aller Aspirationen auf Subjektivität fortgeführt. Er kann für Horkheimer und Adorno entsprechend in der abstraktiven Subjekt-Objekt-Spaltung, dem Selbsterhalt und der Herrschaft dingfest gemacht, sowie unter Kontrastierung des rekonstruierten Prozesses mit dem Subjektivitätsbegriff und Rationalisierungsverständnis der Aufklärung als solcher erwiesen werden.

Der Bogen der Vernunftkritik: Realisierung der geschichtsphilosophischen Prämissen und Verankerung des Verfalls durch Begriffsidentifikationen

Mit der oben skizzierten Verortung und Interpretation der Gründe nun hat die Kritische Theorie gleichzeitig alle drei paradigmatischen Prämissen realisiert, wie sie sich aus ihrer geschichtsphilosophischen Fragestellung ergeben, d.h. zusammen mit der verfallstheoretischen Perspektive verwirklicht sie zugleich ihre dialektische Grundstellung und ihren Rückgriff hinter die marxistisch-ökonomistische Realitätsexegese. Alle drei Prämissen können dabei schon in der spezifischen Auslegung der subjektphilosophischen Reflexion faßbar gemacht werden, so daß ihre Rolle im zweiten Strang lediglich als Fortführung erscheint. So ist bereits die Reflexion der Subjekt-ObjektDifferenzierung als die eines Defizienzprozesses angesetzt und wird sie derart aus der ersten Prämisse heraus unternommen. Gezeichnet werden ja die Spaltung des Subjekts und eine abstraktive Reduktion der Vernunft, also zwei Defizienzen, durch die dann auch die spätere Interpretation der Repression der inneren Natur und der Verengung der Rationalität auf eine bestimmte abstraktive Perspektive hin präformativ grundgelegt ist. Indem die Kritische Theorie die genannte Differenzierung und damit die Emanzipation des Menschen zum Subjekt - selbst als von Verfall gezeichnete interpretiert, legt sie die projektierte Emanzipation mit der Verhinderung des Projekts zusammen und kann sie dann von dessen Selbstdesavouierung sprechen. Auch die dialektische Grundstellung geht derart bereits in den ersten Strang ein und wird im zweiten dann entsprechend weitergeführt. Schließlich verankert die Kritische Theorie mit dem subjektphilosophischen Paradigma den Prozeß zugleich rationalitätstheoretisch und damit vor aller strukturell-organisatorischen Herkunft des Verfalls. Noch ehe ökonomische und empirische Entwicklungen den Subjektstatus des Menschen korrumpieren können, hat dies immer schon anfanghaft die Herstellung dieses Status selbst für sich besorgt. Jede ökonomistische Defizienzdiagnose erscheint dann als Derivat eines ursprünglicheren Prozesses. Auch hier bleibt der Auszug des Prozesses im zweiten Strang rationalitätstheoretisch eingerichtet und der Rückgang hinter die Ökonomie erhalten. Die Theorie Horkheimers und Adornos aber realisiert derart schon in ihrem subjektphilosophischen Strang die genannten Prämissen, nämlich die verfallstheoretische Perspektive, die dialektische Grundstellung und den Rückgang hinter die marxistische Ökonomie, und zieht dies dann im zweiten Strang entsprechend weiter aus.

Insbesondere das verfallstheoretische Moment wird dabei durch einige Begriffsidentifikationen verschärft, die die Defizienz erst umfassend und vollständig werden lassen und die derart die Dialektik konsequent in ihre ,Endschaft' führen. Diese Identifikationen gehen mit der Vermischung verschiedener Reflexionsbereiche bzw. 
Gegenstandsebenen einher und erlauben später den Übergang zu einer Gesellschaftstheorie. So lassen sich in Horkheimers und Adornos zweistrangiger genealogischer Herleitung der instrumentellen Vernunft und ihres (Schein-)Subjekts drei Schritte unterscheiden, die drei solche Identifikationen enthalten. Zunächst werden mit dem ersten Strang die Begriffe der Objektivierung und Abstraktion eingeführt und diese gemä $ß$ dem subjektphilosophischen Paradigma einmal als bloße dichotomisierende Abgrenzung gedacht. Im Zentrum der Reflexion steht hier vorerst nur die Subjekt-Objekt-Differenzierung, die zum einen eine (eigentlich) erkenntnistheoretische Problematik vorstellt und zum anderen durchaus eine Interpretation der entstehenden Vernunft als umfassend theoretischer zuließe. Auch die Abgrenzung des Subjekts müßte nicht notwendig als Verdrängung und feindselige Ausgrenzung von Sinnlichkeit gedacht werden, sondern könnte ebenso als situationell gewählte und wieder verlaßbare vorgestellt werden. Kohärent zur verfallstheoretischen Prämisse wird freilich stattdessen schon die Differenzierung als Spaltung gezeichnet. Dann aber wird durch die Einführung des Selbsterhaltungsprinzips die Konstitution von Subjektivität und Objektwelt, noch ehe sie genuin subjektphilosophisch-erkenntnistheoretisch zuende reflektiert ist, mit einer Zuhandenmachung der abgrenzend konstituierten Gegenstände kontaminiert, und Objektivation und Abstraktion werden mit Instrumentalisierung und Funktionalisienung gleichgesetzt. Durch diese Gleichsetzung wird die Perspektive von der erkenntnistheoretisch angesetzten zu einer handlungsorientierten Rationalitätstheorie verschoben und die ohnehin bereits konstatierte abstraktive Beschädigung des Vernunft- und Subjektbegriffs verstärkt, d.h. der Verfall zugeschärft. Tatsächlich freilich ist diese Verengung die Folge der Identifizierung der genannten Begriffe, die wiederum ihre Schlüssigkeit nur aus der exklusiven theorieleitenden Stellung des Selbsterhaltungsprinzips gewinnt. Die indizierte Defizienz erhält ihre volle Schärfe jedoch vor allem über eine dritte Begriffsidentifikation, die nun Objektivierung, Abstraktion, Instrumentalisierung und Funktionalisierung mit Herrschaft und Repression gleichsetzt und - wenn man so will - von der handlungsorientierten Perspektive in die einer politischen ,Theorie des Habitus wechselt. Vernunft wird hierbei jetzt statt als Erkenntnisorgan als Herrschaftsinstrument gedacht, und die durch sie gewonnene Subjektivität tritt entsprechend als gewalttätige und unterdrückende auf. Erst unter dieser Gleichsetzung erscheinen unmittelbare und ,freie‘ Bezüge zur inneren und äußeren Natur wirklich verloren, und kann die Verdrängung konsistent als Repression interpretiert werden. Selbst die instrumentelle Perspektive nämlich grenzt eine andere lediglich aus, Herrschaft aber verdrängt und unterdrückt sie. Rationalität wie Subjekt gelten jetzt als in ein usurpatorisches Gemächte verstrickt, das über die bereits geschehene Verengung der Vernunft hinaus die Auflösung des Subjekts bedingt. Damit sind die Rationalitätstheorie und die Subjektivitätsgeschichte auf drei verschiedenen Reflexionsebenen entworfen: einer subjektphilosophisch-erkenntnistheoretischen, einer handlungsorientierten und einer auf den politischen Habitus bezogenen. Der Herrschaftsbegriff verankert dabei zusammen mit dem Selbsterhaltungsprinzip den eigentlichen Verfall und läßt die Grundrichtung der Kritischen Theorie als die einer rationalitätstheoretischen „Kritik der Macht“ (Honneth) erkennbar werden. Er erlaubt dann schließlich auch die Überleitung zu einer Reflexion kollektiv-struktureller Organisation, d.h. der Gesellschaft, und ermöglicht es, den rationalitätstheoretischen Argumentationszu- 
sammenhang auf die Gesellschaftsentwicklung zu übertragen. Gesellschaft wird dort als strukturelle Umsetzung und Ausformung der instrumentellen Vernunft begriffen (vgl. 5.4.).

Die derart durch die Begriffsidentifikationen vorgenommene Vermischung dreier Ebenen hat freilich einige problematische Folgen. So läßt zunächst die Gleichsetzung von Objektivierung und Instrumentalisierung keine Möglichkeit mehr, eine jenseits der Funktionalität operierende theoretische Vernunft auch nur experimentell oder hypothetisch zu denken. Sie scheidet von vorneherein als potentielle Größe aus der Rekonstruktion aus. Weiter verunmöglicht es die Identifikation dieser beiden Begriffe mit Herrschaft, einen ,herrschaftsfreien' Rationalitätsbegriff oder ein rein ,sachhaft-gebrauchendes' Funktionalisieren vorzustellen. Da die Begriffe gleichgesetzt sind und die Ebenen ständig ineinander übergehen, scheint jedes Instrumentalisieren schon ein Überherrschen und Vergewaltigen zu sein, ja selbst die Objektivierung bereits auf diese zu zielen. Herrschaft und Repression gelten jetzt als im einzig möglichen, da im Ursprung der Subjekt-Objekt-Differenzierung verankerten rationalen Denken selbst verwurzelt und erhalten damit einen totalisierten Status. Das wiederum hat, wie sich zeigen wird, zur Folge, daß dann auch in der Gesellschaftstheorie Horkheimers und Adornos jede strukturelle Objektivität und Funktionalität im Sinn von Gewaltverhältnissen bewertet werden muß. Die Genealogie der instrumentellen Vernunft präformiert so bereits eine Gesellschaftsinterpretation, die dann auch dort nur noch Verfall konstatieren kann. Damit biegt sie sich in ihrem rationalitätstheoretischen Kern nicht nur konsequent auf die geschichtsphilosophisch eingeführten Prämissen zurück, auch legt sie nicht nur die Wurzel für die dort angesetzte Problematik durch Begriffsidentifikationen und Vermischung von Reflexionsbereichen bzw. Gegenstandsebenen fest, sondern sie sorgt zugleich für die Möglichkeit eines Überschritts in die Gesellschaftstheorie. Zunächst jedoch nimmt sie auf der Basis der verfallstheoretisch rekonstruierten und interpretierten Geschichte der Subjektivität und Rationalisierung noch ihre Aufklärungs- und Modernitätskritik vor.

\subsection{Konkretion I: Die Aufklärungs- und Modernitätskritik der Kritischen Theorie}

Die Genealogie der instrumentellen Vernunft liefert Horkheimer und Adorno die Basis für eine konkretisierende Auseinandersetzung mit den Aspirationen der Aufklärung und ihrem angesichts der zeitgenössischen Gegenwart konstatierten Scheitern. Das Kernproblem der geschichtsphilosophischen Fragestellung, wie es angesichts der Aspirationen der Aufklärung zu einem Verfall in totalitäre Heteronomien kommen konnte, wird so nun mit unmittelbarem Bezug auf die Aufklärung selbst angegangen und die genealogische Grundstellung hierzu weiter ausgezogen. Die Auseinandersetzung mit der Aufklärung ist dabei zugleich eine Auseinandersetzung mit dem in ihr anhebenden Projekt der Moderne, und die Kritik an der Aufklärung treibt entsprechend eine Modernitätskritik aus sich hervor. In dieser Kritik fält auf, daB sie nicht nur die Intention der genealogischen Rekonstruktion zu Ende führt, das Scheitern der aufklärerischen Aspirationen dialektisch in denselben faßbar zu machen, sondern zugleich eine Reihe von Devianzvorwürfen schafft, die eine eigentümliche Verwandtschaft mit jenen der ,konservativen' Modernitätskritik aufweisen, wie sie etwa bei Keilhacker vorliegt. Beidem - der Kritik an Aufklärung und Mo- 
derne und den Verwandtschaften dieser Kritik mit der ,konservativen' - will ich im folgenden nachgehen, bevor ich dann das Gesellschaftskonzept der Kritischen Theorie rekonstruiere.

\section{Aufklärung und Moderne als Kristallisation der instrumentellen Vermunft}

Horkheimer und Adorno stellen ihre Auseinandersetzung mit dem von der Aufklärung begonnenen Projekt der Moderne und seinem Scheitern auf die Basis des Axioms, daß die Aufklärung als Bewußtwerdung und bewußte Fortführung des vor ihr beginnenden Prozesses der Subjektivierung und Rationalisierung zu begreifen sei. Die genealogisch in einer Art spekulativer Gesamtschau des menschheitlichen Zivilisationsprozesses rekonstruierte instrumentelle Vernunft und die zusammen mit ihr hergestellte (Pseudo-)Subjektivität gelten daher als Voraussetzung des aufklärerischen Unterfangens und scheinen in Aufklärung und Moderne gewissermaßen ,zu sich selbst zu kommen'. In der Tat setzen ja erst Neuzeit und Moderne das Subjekt mit Bewußtsein als Zentrum ihres Projekts an und richten sie sich auf Realisierung einer durch Vernunft garantierten Autonomie und Freiheit dieses Subjekts sowie einer zugehörigen Gesellschaftsorganisation. Ist also die dialektische (Vor-)Geschichte der Subjektwerdung und Rationalisierung erfaßt, so scheint von ihr aus auch die Bewußtwerdung und Weiterführung dieser Geschichte in der Aufklärung konsistent begriffen sowie der immanente Grund für das Scheitern des dort verankerten Projekts der Moderne herausgehoben werden zu können.

Hierzu nun wird insbesondere die Fortführung der Rationalisierung durch die Aufklärung untersucht und gefragt, ob und inwieweit die von ihr geleistete ,Entzauberung' die Autonomie des Subjekts und eine Humanisierung der individuellen und kollektiven Lebensumstände herzustellen vermag. Im Zentrum der Auseinandersetzung steht dabei eine positivistische Vernunft', die als Zuspitzung der instrumentellen ausgelegt wird, und durch die - Horkheimer und Adorno zufolge - die Aufklärung eben jene ,entzaubernde' und daher autonomisierende Rationalisierung durchzuführen sucht. Gleichwohl scheint vom positivistischen Rationalitätstyp zum einen lediglich die Reduzierung der Vernunft zum Mittel für Zwecke, über die sie nicht mehr bestimmt, perfektioniert zu werden und derart die Aktivität der instrumentellen Vernunft in die eines unkontrollierbaren und letztlich irrationalen Selbstläufers übergeleitet zu sein. Die bereits in instrumentelles Gemächte verstrickten Subjekte gelten nun als vollständig einer blinden Eigendynamik ausgeliefert und desubjektiviert. Zum anderen scheint die positivistisch unternommene Entzauberung auch die ,Ideen * der Aufklärung entmythologisierend auszutreiben und sich gegen die ursprünglichen Aspirationen der letztgenannten zu wenden. Am Ende steht dann erneut die Selbstdesavouierung des Projekts von Aufklärung und Moderne, die das emanzipative Ziel von Autonomie und Freiheit durch eine fehlgeleitete Rationalisierung und Subjektivierung von innen heraus zerstört.

Diese erneut dialektisch angesetzte Reflexion von Aufklärung und Moderne führen Horkheimer und Adorno durch, indem sie zunächst die positivistische Vernunft aus der instrumentellen als deren Fortführung ableiten und diese Fortführung über den Entzauberungsbegriff mit den autonomisierenden Intentionen der Aufklärung verbinden. Der etwas krude ${ }^{49}$ und rein pejorativ verwendete Positivismusbegriff der

\footnotetext{
${ }^{49}$ zu dieser Beurteilung des Positivismusbegriffs vgl. auch: Honneth, Kritik, 83
} 
beiden Autoren zeichnet sich hierbei durch eine Doppelgestalt aus, die einerseits als spezifisch für das positivistische Vorgehen die Zuwendung zur empirischen Realität via Experiment und registrative Verfahren betrachtet sowie andererseits diese $\mathrm{Zu}$ wendung von einer hoch abstraktiven und formalisierten Methodik und ,Sprache' determiniert sieht. So faßt etwa Adorno in seiner umfangreichen Einleitung des Sammelbands zum Positivismusstreit diesen Begriff als ,paradoxale‘ Koinzidenz eines behaupteten „Vorrang(s) der Einzelgegebenheit vor den ,Ideen“", d.h. der empirischen Orientierung an und Konzentration auf „Faktizität“, mit der „absolute(n) Eigenständigkeit eines rein idealen Bereichs" den er hierbei als den "mathematischen" präzisiert. ${ }^{50}$ Der Positivismusbegriff leitet sich derart aus der Methodik der Naturwissenschaften und der formalisierten ,Sprachregelung' und ,Sprachgestalt' der Mathematik her. Das ,Paradox' entsteht für Adorno dabei daraus, daß sich der Positivismus einerseits vollständig auf die ,gegebene' Wirklichkeit stützt und vorgibt, aus dieser seine Erkenntnisse zu schöpfen, jedoch andererseits die ,Begriffe für die Formulierung dieser Erkenntnisse aus einer ,rein idealen' Sphäre mathematischer Axiomatik gewinnt. Mit diesen ihren beiden widersprüchlichen Merkmalen versucht Horkheimer und Adorno zufolge dann die positivistische Vernunft sich der Wirklichkeit zu bemächtigen, indem sie sich bemüht, der letztgenannten ,ihre abstrakten raumzeitlichen Beziehungen abzumerken, bei denen man sie (...) packen kann".51 Durch experimentelle Erforschung dieser Seite der Realität und eine methodologisch restlos ausdefinierte, formale Fixierung gewonnener Erkenntnisse soll ein von allen möglichen nicht-funktionalen Beimengungen gereinigter Realitätsbegriff konstituiert werden, der zugleich die umfassende Beherrschung des Wirklichen erlaubt. Ziel der positivistischen Vernunft ist so, die Realität dem herrscherlich-funktionalistischen Gemächte der Menschen dienstbar werden zu lassen. Damit aber erweist sie sich als spezialisiert zugespitzte Form der instrumentellen Vernunft.

Obschon Mathematik und Naturwissenschaften bereits weit vor der Aufklärung anheben, sehen Horkheimer und Adorno in derselben dann die positivistische Vernunft ebenso umfassend wie verderblich realisiert und in einen besonderen Stand erhoben. Jetzt nämlich scheint die positivistische Vernunft eine neue, über die Naturwissenschaften hinausreichende Funktion zu erhalten, durch die sie sich gleichzeitig zur einzigen Gestalt von Vernunft aufschwingt. So leitet Horkheimer und Adorno zufolge die Aufklärung Rationalisierung und Subjektivierung nun in eine Inthronisation des Positivismus über und sucht sie derart ihr emanzipatives Unterfangen mittels desselben zu verwirklichen: Mit der positivistischen Rationalität soll jene, Entzauberung' von Welt vollendet werden, die bereits im Anfang der Hominisierung durch die Ausbildung einer theoretischen Rationalität angezielt war und die über die Auflösung übermächtiger Eigenbedeutungen begegnender Realitäten dem Subjekt Autonomie und Freiheit zu garantieren suchte. In der „Identifikation der zuende gedachten mathematischen Welt mit der Wahrheit", wie sie der Positivismus vollzieht, nämlich scheint die zauberische Eigenbedeutung vollständig in eine funktionell begreif- und beherrschbare überführt. ${ }^{52}$ Die Realität hat unter solchem Begreifen dem

\footnotetext{
${ }^{50}$ Adorno, Positivismusstreit, 13

51 Horkheimer/Adorno, Dialektik, 27

52 Horkheimer/Adorno, Dialektik, 26
} 
Menschen dann anscheinend keine Widerständigkeit mehr entgegenzusetzen und ist dessen subjektiver ,Zuhandenmachung vollständig unterworfen. Ihre Instrumentalisierung scheint ebenso vollendet wie der nach Horkheimers und Adornos Ansatz hierdurch intendierte Status einer herrscherlichen Souveränität des subjektivierten Menschen. Zusammen mit der übermächtigen Eigenbedeutung des Wirklichen gelten dann auch die geschlossenen Weltdeutungen metaphysischer und religiöser Ontologie in einer freisetzenden Weise aufgelöst bzw. ihres bislang unbefragten Geltungsanspruchs enthoben. Der positivistische Realitätsbegriff weist ihre Gehalte als irreale und irrationale zurück, und die Aufklärung scheint ,vor der Rückkehr des Mythischen sicher zu sein “ ${ }^{53}$ Der Mensch aber scheint dann zu einer rationalen und realistischen Weltgestaltung befreit, und seine Subjektivierung scheint vollendet zu sein. Durch ,Entzauberung' des Begegnenden und ,Entmythologisierung' der vormodernen (im Kern ohnehin ebenfalls schon ,entzaubernden', da theoretischen) Weltauslegungen mittels der positivistischen Vernunft müht sich Aufklärung also, ihr emanzipatives Programm durchzuführen und Autonomie und Freiheit auf vernünftiger Basis herzustellen. Endgültig soll „der Verstand, der den Aberglauben besiegt, (...) über die entzauberte Natur gebieten ${ }^{\text {“S4 }}$ und zugleich die Subjekte zu einer selbstgewählten Organisation ihres eigenen Lebens befreien.

Dieses Projekt sehen Horkheimer und Adorno gleichwohl erneut an seinen Prämissen scheitern. Da die positivistische Vernunft als Zuspitzung der instrumentellen gilt, ist sie ebenso wie diese jener perniziosen Reduktion zum Mittel unterworfen, die ihr Recht und Chance für eine Bestimmung oder Kritik der Zwecke, denen sie dient, unvermeidlich raubt. ${ }^{55}$ Durch ihre paradoxale Doppelgestalt scheint die heteronomistische Verengung außerdem noch gesteigert und der gesamte Prozeß werkzeughafter Verwendung von Vernunft blind zu werden. Während in der Genealogie als zwecksetzende Instanz immerhin noch ein einheitsstiftendes Prinzip, nämlich das des Selbsterhalts, genannt werden konnte und die Reduktion von Vernunft ein Ziel hatte, droht sich nun eine Eigendynamik zu entfalten, die keine Einheit und kein Steuerungsprinzip mehr kennt. Die positivistische Vernunft scheint vielmehr durch ihre spezifische Gestalt doppelt an das ,Vorfindliche', die ,gegebene' empirische Wirklichkeit zu verfallen und die Zweck- und Zielsetzung je und je unkontrolliert aus dieser Wirklichkeit hervorzugehen. Konzentriert auf das ,Faktische‘ unter der Perspektive seiner instrumentellen Verwertbarkeit nämlich gerät zunächst der Vernunft das Wozu des Verwertens aus dem Blick und beschränkt sie sich auf das „Geschäft,

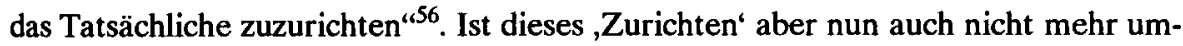
fassend vom Selbsterhaltungsprinzip determiniert, so wird seine Zweckbestimmung nur noch von den dem Gegebenen inhärenten funktionellen Möglichkeiten gesetzt. Die an der funktional-empirischen Wirklichkeit orientierte Rationalität und ihr Experimentieren verfallen dieser Wirklichkeit damit vollständig und lassen sich exklusiv von dieser Reflexions- und Entwicklungsmöglichkeiten vorgeben. Die Vernunft gerät

\footnotetext{
${ }^{53}$ Horkheimer/Adorno, Dialektik, 26

${ }_{55}^{54}$ Horkheimer/Adorno, Dialektik, 8 $30-31$

55 vgl. auch: Horkheimer, Max, Zur Kritik der instrumentellen Vernunft, Frankfurt 1985,

${ }^{56}$ Horkheimer/Adorno, Dialektik, 26
} 
in die Netze einer ,schlechten Unmittelbarkeit' und verkommt zu einer Funktion des ,Machbaren'.

Das scheint dann von dem zweiten Bestimmungsstück der positivistischen Vernunft, der Mathematisierung, verstärkt zu werden, die durch ihre hoch formalisierte ,Sprache ${ }^{\imath}$ keinen sich kritisch von der funktional-empirischen Realität distanzierenden Begriff mehr zu entfalten vermag. Interessiert nämlich scheint die positivistische Vernunft einzig an dem, was „dem Maß von Berechenbarkeit und Nützlichkeit sich (...) fügen will “57, was ,quantifizierbar' ist und durch registrative Verfahren erfaßt werden kann. Der hierzu entworfene „mathematische Formalismus aber, dessen Medium die Zahl ist“, gilt Horkheimer und Adorno als ,die abstrakteste Gestalt des Unmittelbaren“ selbst und hat daher zur Konsequenz, ,den Gedanken bei der bloBen Unmittelbarkeit“ festzuhalten ${ }^{58}$ Er ersetzt „den Begriff durch die Formel, Ursache durch Regel und Wahrscheinlichkeit“ und droht derart „auf Sinn Verzicht“ zu leisten. ${ }^{59}$ Damit scheint der Verfall der Vernunft an vorgegebene Empirie und Funktionalität auch auf der Theorieebene festgeschrieben sowie jede Distanzierung, die eine kritische Rückfrage oder eigenständig-rationale Zwecksetzung ermöglichte, unterlaufen zu sein. Die Aktivität der zur positivistischen fortgebildeten instrumentellen Vernunft scheint deshalb schließlich in eine blinde Dynamik der Instrumentalisierung und Nutzung des Gegebenen zu münden, ohne noch einen Zweckbegriff dieser Nutzung gewinnen zu können, und der Gesamtprozeß funktionalistischer Bearbeitung und Verarbeitung von Realität erhält hierdurch das Gepräge eines vernunftentleerten, d.h. letztlich irrationalen Gemächtes. In diesem Gemächte scheitert zugleich erneut das Unternehmen der Subjektivierung, da die Subjekte nun zu Objekten, zur Funktion in jener vernunftlosen Dynamik zu geraten und als deren Büttel tätig zu sein scheinen. Außerdem löst sich zusammen mit der zwecksetzenden und -befragenden Rolle der Vernunft auch die Subjektautonomie wieder auf, die sich ja gerade über subjektive Zwecksetzung realisieren sollte. Das emanzipative Projekt der Aufklärung mißglückt derart durch eine fehlgehende Rationalisierung und reißt die Subjekte mit sich in dieses Mißglücken hinein.

Dieses Mißglücken scheint schließlich noch dadurch auf die Spitze getrieben zu werden, da $\beta$ der Versuch einer Freisetzung der Subjekte durch ,Entzauberung' der Welt mittels positivistischer Vernunft anscheinend auch noch die humanitären Leitideen der Aufklärung zu korrumpieren droht. So gilt nach Horkheimer und Adorno „dem Positivismus, der das Richteramt der aufgeklärten Vernunft antrat", jedes ,Ausschweifen“ ,in intelligible Welten (...) nicht mehr bloß als verboten, sondern als sinnloses Geplapper" ${ }^{60}$ Einzig was sich berechnen und mathematisch-formalistisch objektivieren läßt, kann nun noch als vernünftig gelten, während jede davon abweichende Denkbewegung und Begriffsbildung als schlicht unsinnig gilt, mindestens aber unter Ideologieverdacht fällt. Die ,Entzauberung, wie sie die positivistische Vernunft leistet, läßt ausschließlich deren Form der Objektivierung gelten und tendiert entsprechend dazu, sich von den ontologischen ,Ideen' der Metaphysik und der Religion auch auf die Gedanken der Subjektivität und der Autonomie sowie auf die Ideen von

${ }_{58}^{57}$ Horkheimer/Adorno, Dialektik, 9

58 Horkheimer/Adorno, Dialektik, 27

${ }^{59}$ Horkheimer/Adorno, Dialektik, 9

${ }^{60}$ Horkheimer/Adorno, Dialektik, 26 
Freiheit, Gleichheit und Brüderlichkeit auszudehnen. Zusammen mit den ideologischen Weltauslegungen der Vergangenheit entmythologisiert die positivistisch gewendete Aufklärung so auch ihre eigene Weltdeutung und gibt sie ihre humanitären Vorstellungen, ihre „Ideen von Menschenrecht" ${ }^{\text {661 }}$ preis. Durch die zunehmende ,Positivierung' des Vernunftbegriffs scheint die Aufklärung daher ,ihrer eigenen Verwirklichung entsagt" zu haben und sich in „totalen Betrug der Massen“ zu verwandeln. ${ }^{62}$

Der aufklärungskritische Bogen der Rekonstruktion Horkheimers und Adornos ist damit geschlossen, und der Prozeß der Rationalisierung und Subjektivierung wird an seinen begriffslogischen Herkunftsort zurückgebracht. Die Verfallsgeschichte der rationalitätstheoretischen Genealogie findet sich auf die Aufklärung und ihr emanzipatives Unterfangen gewendet, um dort erneut ein vollständiges Scheitern dieses Unterfangens konstatierbar zu machen. Horkheimer und Adorno bringen so auch die Prämissen ihrer Reflexion der Aufklärung, d.h. die verfallstheoretische Fixierung, die dialektische Grundstellung und den rationalitätstheoretischen Grundduktus, ,nach Hause' und führen ihre Theorie der versuchten und scheiternden Emanzipation des Menschen zum Subjekt in die Apokatastasis. Erneut nämlich wird die rekonstruierte Geschichte von Rationalisierung und Subjektivierung als Defizienzgeschichte gezeichnet und diese Defizienz zum einen jenseits marxistisch-ökonomischer Realitätsexegese in einem bestimmten Rationalitätstyp dingfest gemacht sowie zum anderen dialektisch der Form der emanzipativen Emphase selbst angelastet. Der Rationalitätstyp ist nun die positivistische Vernunft, die zugleich das Zentrum der apokatastatischen Rückkehr darstellt und als Fortbildung der instrumentellen Vernunft behandelt wird. Das Emanzipationsbegehren wiederum sucht sich in Form der ,Entzauberung' und der Perfektion der Naturbeherrschung zu realisieren, welche durch die positivistische Vernunft geschehen soll.

So wird zunächst die letztgenannte in einer ,paradoxalen` Doppelgestalt eingeführt, die sich einmal durch experimentelle Orientierung an der empirischen Wirklichkeit, und zum anderen durch theoretische Begleitung bzw. Verarbeitung dieser Orientierung in mathematisch-abstraktiven und registrativen Verfahren definiert. Sie scheint dann in ihrer spezifischen Zuwendung zur Realität gleichzeitig einen Realitätsbegriff zu konstituieren, der die schon in der vormodernen Geschichte auffindbare ,Entzauberung praktisch und theoretisch weitertreibt. Hergestellt scheint damit sowohl eine Befreiung von der übermächtigen (und daher zauberischen) Eigenbedeutung der Wirklichkeit, als auch die Verabschiedung vormoderner Weltdeutungskonzepte, die durch eine nicht vollständig aufgehobene mimetisch-identifikative Reproduktion des Bedeutungsüberhangs der Realität noch einen Rest des Zaubers enthielten. An deren Stelle tritt jetzt eine methodologisch gereinigte, perfekt den funktionalen Aspekten der Wirklichkeit zugepaßte instrumentelle Vernunft, die in ihrer positivistischen Gestalt zugleich eine Perfektionierung der Herrschaft über die (äußere) Natur und derart die Realisierung von Autonomie und Freiheit verspricht. Ähnlich wie in der Genealogie scheint damit zunächst eine Emanzipationsgeschichte angesetzt, in der der Mensch durch Ausbildung eines bestimmten Ra-

\footnotetext{
${ }^{61}$ Horkheimer/Adorno, Dialektik, 9

${ }^{62}$ Horkheimer/Adorno, Dialektik, 40-41
} 
tionalitätstyps Souveränität zu erringen sucht. Die Form des emanzipativen Unterfangens ist rationalitätstheoretisch in der Herleitung der positivistischen Vernunft als Instrument zur ,Entzauberung' und Naturbeherrschung dingfest gemacht.

Aus dieser Form aber scheint dann gleichzeitig auch der Verfall der Emanzipation hervorzugehen. So stellen Horkheimer und Adorno der emanzipativen Emphase sofort das Scheitern gegenüber und entwickeln sie eine dialektische Kontrarität, in der die dialektische Grundstellung und die verfallstheoretische Perspektive der Kritischen Theorie wiederkehren. Zum einen nämlich gilt die positivistische Vernunft als Fortführung auch der Vernunftverengung, da sie als Perfektion der instrumentellen Vernunft sowohl nur instrumentelle Gehalte in Blick bekommt, als auch selbst zum Instrument reduziert wird. In ihrer spezifischen Form nimmt sie jetzt nur noch empirische Funktionalität wahr und läßt sie sich zugleich von derselben Zwecke und Ziele setzen. Sie gerät derart zur Funktion des ,Machbaren` und verliert sogar die Hinordnung ihrer Erkenntnisse auf Selbsterhaltung aus den Augen. Konsequenz scheint ein blinder und derart irrationaler Prozeß bloßen instrumentell-funktionalen Gemächtes zu sein, in dessen Strudel auch die Souveränität der Subjekte verloren geht und sich deren Status auflöst. Der Versuch, durch ,Positivierung' Herrschaft zu erringen und zu festigen, d.h. auch: sich Autonomie und Freiheit zu verschaffen und zu sichern, scheitert wieder an sich selbst und endet in der Destruktion des erstrebten Subjektstatus. Zum anderen scheint die positivistische Vernunft mit ihren hoch formalisierten Verfahren und Kriterien nicht nur die Ideologeme vormoderner Weltdeutungen auszutreiben, sondern im selben Zug die humanitären Ideen von Aufklärung und Moderne zu beseitigen. Diese nämlich lassen sich ebensowenig wie die Inhalte der genannten Deutungen positivistisch-formalisiert begründen und müssen angesichts eines auf empirisch-mathematisch Faßbares reduzierten Realitätsbegriffs irreal sowie angesichts einer hierdurch konstituierten Vernunft irrational erscheinen. Der Versuch der Emanzipation schlägt so erneut und endgültig fehl, und die Befreiung durch die positivistische Vernunft verkehrt sich in Defizienz. Das Subjekt in Autonomie und Freiheit kommt wieder nicht zustande, und die vernünftige Lebens- und Gesellschaftsorganisation scheitert in einem vernunftentleerten, ziellosen Betrieb. Horkheimer und Adorno sehen derart das Projekt von Aufklärung und Moderne durch sich selbst korrumpiert und realisieren zusammen mit dem rationalitätstheoretischen Grundzug sowohl ihre verfallstheoretische Perspektive als auch ihre dialektische Grundstellung. Sie wenden die kritische Rekonstruktion der fehlgehenden Rationalisierung und Subjektivierung auf den Ort der Herkunft dieser beiden Begriffe zurück und schließen damit den Bogen ihrer Untersuchung der Wurzeln für die ,Selbstverhinderung der Aufklärung. Die Theorie Horkheimers und Adornos bleibt also die eines dialektisch verstandenen, in der Konstitution von Rationalität selbst aufgesuchten Verfalls, und ihre prinzipielle modernitätsfreundliche Parteinahme mündet in eine harsche Modernitätskritik.

\section{,Kritische' und ,konservative' Modernitätskritik}

Sowohl die Aufklärungs- und Modernitätskritik als auch bereits die zweistrangige Genealogie Horkheimers und Adornos nun läßt einige Parallelen zu und Verwandtschaften mit der ,konservativen' Modernitätskritik erkennen, wie sie etwa bei Keilhacker vorliegt. So ist zunächst deutlich, daß auch Horkheimer und Adorno mit ihrer 
dezidierten Modernitätskritik bei der Rationalisierung ansetzen, die sie historisch an der Heraufkunft der Naturwissenschaften dingfest machen. Weiter zeigt sich eine Reihe paralleler und verwandt anmutender Vorwürfe gegen konkrete Ausprägungen der Moderne, d.h eine Reihe (im weiteren Sinn) kulturkritischer Devianzthesen, die an Keilhackers Devianzkritik erinnern. In beiden Konzepten nämlich werden eine aus der Rationalisierung abgeleitete Verdrängung des, Lebendigen' und eine Entzweiung mit der Natur sowie der Verfall an Fremdbestimmung, die Heraufkunft einer ,Machbarkeitsorientierung' und der Verlust, idealer' Gehalte moniert. Auf der Ebene konstatierter Phänomene ergeben sich derart eigentümliche Konnexionen zwischen Horkheimers und Adornos Rekonstruktion und Keilhackers Kritik. Daneben jedoch steht eine grundsätzlich divergente Position beider Konzepte zu den Aspirationen des Projekts der Moderne, näherhin eine divergente Stellungnahme zu Autonomie und Subjektivierung: Während Keilhacker sich gegen Subjektautonomie ausspricht und derart prinzipiell die Subjektivitätsidee und das Emanzipationsunterfangen der Neuzeit und Moderne in Frage stellt, beziehen sich Horkheimer und Adorno prinzipiell affirmativ auf diese und beklagen dann deren mangelnde bzw. gescheiterte Realisierung. Diese Mischung aus phänomenaler Kongenialität und prinzipieller Divergenz will ich im folgenden noch kurz umreißen, bevor ich mich dem Gesellschaftskonzept der Kritischen Theorie zuwende.

Zunächst also ist erkennbar, daß sowohl Keilhacker als auch Horkheimer und Adorno mit ihrer Modernitätskritik bei der Rationalisierung ansetzen und diese jeweils historiographisch mit der Heraufkunft der Naturwissenschaften sowie der Mathematik verbinden. Aus deren Methodologie leiten sie einen spezifischen Rationalitätstyp her, der dann im folgenden als Initiator einer Verfallsgeschichte auftritt. Hierbei hebt Keilhacker (etwas undeutlich) auf eine von der Rationalisierung hervorgerufene und zur Herrschaft gebrachte ,Abstraktifizierung' ab, die zur Verdrängung des ,Qualitativen' aus der Wahrnehmung, dem Theoretisieren und der Lebensund Gesellschaftsorganisation führe (vgl. 4.1.). Die genannte Abstraktifizierung führt er dann als quantifizierende Methodik des Messens und Zählens aus, welche von einer Orientierung an experimenteller Nachprüfbarkeit flankiert werde. Er hat damit eben jene beiden Grundmomente quantifizierend-registrativer und experimenteller Verfahren im Blick, die Adorno als Definiens der positivistischen Vernunft präzisiert. Die beiden Konzepte kommen so in der Grundbestimmung der von ihnen als Wurzel der Defizienzen gehandelten Rationalisierung überein und zeigen sich kongenial. Auch die Intention der Rationalisierung wird von beiden identisch historiographiert und zunächst analog bewertet: Sowohl Keilhacker wie Horkheimer und Adorno skizzieren den intentionalen Habitus der Rationalisierung als emanzipative Emphase und bestimmen die letztgenannte formal als ,Entzauberung und Naturbeherrschung. Beide sehen durch die Form dieses Emanzipationsbegehrens etwas verlorengehen und beurteilen es daher als prekär. Im historiographischen Ansatz, d.h. der Verortung der Wurzel des Verfalls, sowie in der Definition des hierbei verantwortlich gemachten Rationalitätstyps und in der grundsätzlichen Bewertung der Emanzipationsgestalt kommen die beiden Konzepte damit vorerst überein.

Divergent jedoch fällt dann die Charakteristik des Verlorenen, des von der Rationalisierung Verdrängten aus. Keilhacker nämlich hat mit dem Begriff des ,Qualitativen' spezifische Bestände im Blick, deren Herkunft sich als vormoderne erwiesen hat 
und die ein kontramodernes Weltverhältnis sowie eine kontramoderne Moralität begründen (vgl. 4.1. und 4.3.). Für ihn liegt der ,Sündenfall' gerade in der Durchführung der ,Entzauberung' und der Destruktion des Geltungsanspruchs der vormodernen Weltdeutungssysteme, näherhin von Metaphysik, Religion und ontologischer Reflexion. Er bedauert die Auflösung von deren ,Festigkeit' und den Verlust einer mythisch-ontologisch garantierten Orientierungskonsistenz. Daher wendet er sich gegen das Emanzipationsbegehren der Aufklärung und Neuzeit in genere und verwirft er die Aspirationen auf Subjektivität und Autonomie als moderne Verirrung. Nicht nur das Fehlgehen von Emanzipation bildet für ihn den Stein des Anstoßes (obschon auch er den Verlust von Autonomie an Fremdbestimmung und derart eine Verkehrung des emanzipativen Unterfangens moniert; vgl. unten und 4.1.), sondern das emanzipative Ziel selbst wird von ihm problematisiert. Der Mensch nämlich scheint Keilhacker zur Subjektivität und Autonomie gar nicht fähig zu sein, und das Projekt der Moderne entpuppt sich hierdurch als auf unzureichenden anthropologischen Prämissen aufruhender Irrtum. Anders hingegen bei Horkheimer und Adorno, welche für die Ziele der Emanzipation Partei ergreifen und dann in Kontrastierung mit der instrumentell erreichten Subjektivität und Autonomie die Korruption dieser Ziele perhorreszieren. Nicht das Emanzipationsunterfangen an sich, sondern seine falsche Einrichtung, sein Scheitern an den untauglichen Mitteln einer instrumentell-positivistischen Vernunft und repressiver Herrschaft steht im Zentrum ihrer Kritik. Die ,Ideen' von Subjektivität, Autonomie und Freiheit gelten ihnen hingegen als durchaus realisierungswürdig, und das Projekt der Moderne stellt in ihren Texten nicht einen Irrtum, sondern eine verratene Hoffnung dar. Die Kritik der beiden Konzepte geht derart aus divergenten, ja antagonistischen prinzipiellen Grundstellungen hervor. Es ergibt sich deshalb das Bild eines eigentümlichen Doppelverhältnisses der Aufklärungs- und Modernitätskritik Horkheimers und Adornos zu der Keilhackers: Unter Parteinahme für die ,Idealität' des Projekts der Moderne stellen sie sich konträr zur ,konservativen' Modernitätskritik, in der Verortung und Bewertung der Wurzeln für die kritisch angemahnten Phänomene jedoch finden sie sich Seite an Seite mit dieser. Dieses Doppelverhältnis zieht sich entsprechend auch durch die konkreten Vorwürfe, d.h. durch die Herausarbeitung und Anmahnung spezifisch moderner Defizienzphänomene. Dabei läßt die kongeniale Seite des Doppelverhältnisses zur ,konservativen' Kritik jedoch später die dialektische Rückfrage an die Kritische Theorie stellen, ob die Idealität ihrer prinzipiellen Parteinahme für das Projekt der Moderne noch mehr ist als ein Lippenbekenntnis. Aus der Totalität, die ihre Kritik zudem durch die rationalitätstheoretische Verankerung erfährt, stellt sich zugleich die Frage, ob dies nicht letztlich eine analoge Unmöglichkeit der Realisierung des Projekts der Moderne impliziert wie die ,konservative' Position (dazu mehr unten).

So zeigt sich zunächst, daß in Horkheimers und Adornos Genealogie und in ihrer Aufklärungs- und Modernitätskritik eine Reihe von Devianzthesen enthalten sind, die das genannte Doppelverhältnis aufweisen und mitunter ein Übergewicht auf der Seite der Korrespondenz mit der ,konservativen' Modernitätskritik erkennen lassen. Eine erste solche These, die fast nur Kongenialität aufweist, ist jene der Verdrängung des ,Lebendigen' und der Entzweiung mit der Natur. Horkheimer und Adorno führen dabei die Verdrängung des Lebendigen bereits in ihrer Genealogie ein und leiten sie als spezifische Defizienz aus der Rationalisierung unter dem Selbsterhaltungsprinzip 
und deren Fixierung im gesellschaftlich organisierten Arbeitsprozeß her. Wie zu sehen war, gilt dabei einmal die innere Natur des Menschen, die als seine Vitalsphäre sowie als Triebhaftigkeit und Sensitivität inhaltlich bestimmt wird, als repressiv in Griff genommen und sowohl verdrängt wie instrumentell dem Arbeitsprozeß dienstbar gemacht. Konsequenz sind eine Entfremdung des Menschen von seinen naturalvitalen Strebungen und eine ,sensorische Vereinseitigung. Zum anderen scheint auch die äußere Natur reprimiert und in ein ,Gewaltverhältnis' eingegliedert. Keilhacker wiederum konstatiert in durchaus ähnlicher Weise einmal die Instrumentalisierung und Verdrängung der Naturalsphäre, die er näherhin in ,qualitativen $\mathrm{Zu}$ ständen' wie Gesundheit, Krankheit, Freude und Leid inhaltlich faßbar macht sowie in naturalen Rhythmen sucht. Die Instrumentalisierung liegt bei ihm in einer auf Effizienz ausgerichteten, methodischen Lebensführung, die durch die Arbeitsorganisation verstärkt scheint. Zum anderen führt Keilhacker neben der Klage über die Verdrängung der menschlichen Vitalsphäre und Naturalität noch eine Klage über den Verlust des Geltungsanspruchs naturaler ,Eigenwerte‘ ein. Freilich wird Keilhacker im ersten Fall kaum die Repression der Triebsphäre bedauern, die in seiner Schule ja eher zu den anthropologischen Negativa und Gefährdungspotentialen zählt, sondern hebt er seiner kontramodernen Grundoption entsprechend auf den Verlust vormoderner Orientierungsformen und Wertstandards, wie der Kontemplativität, zugunsten moderner, wie der Leistung und des Fortschritts, ab und geht es ihm auch im zweiten Fall um eine kontramodern verortete ,Wertsphäre'. Horkheimer und Adorno hingegen zielen mit ihrer Kritik auf eine Befreiung der reprimierten Naturen und lassen in ihrer Option für eine Freisetzung des Triebhaften eine moderne Position spüren, die auf Verschränkung von Natur und Vernunft - statt eines Antagonismus - zielt. Trotz dieser Divergenzen aber sind die Übereinstimmungen umfangreich. In beiden Fällen wird die Nötigung des naturhaften Lebens, seiner Zustände, Befindlichkeiten und Antriebe unter das Diktat eines rational organisierten Lebensvollzugs moniert und ist die Argumentationsfigur derart analog ausgerichtet: Verloren scheint jeweils ,das Menschliche', die natural-vitale Basis des Menschseins, die zugleich erst die ,Lebensqualität' zu liefern vermag, an die neuzeitliche ,methodische Lebensführung', wie sie Max Weber beschreibt. Auch deuten sich in Horkheimers und Adornos Charakterisierung des Verhältnisses zur Natur als illegitimes Gewaltverhältnis und als Entfremdung von einer Sphäre mit Eigenbedeutung sogar so etwas wie naturale ,Eigenwerte‘ an und ergibt sich eine weitere Kongenialität der Konzepte. Tatsächlich müssen aus Gründen der Logizität Formen von Normativität in der Naturalsphäre angenommen werden, muß dieser Sphäre eine normative Bedeutung zuerkannt werden, wenn deren Instrumentalisierung und ,Verwertung' für menschliche Belange in Horkheimers und Adornos Sinn als illegitimer Gewaltakt erscheinen soll. Die genannte Devianzthese läßt somit also eine weitgehende Übereinkunft der beiden Kritiken erkennen, und die Korrespondenz überwiegt hier die Divergenz.

Etwas anders verhält es sich mit einer zweiten Devianzthese, die mit der ersten verbunden auftritt, jedoch noch einen weiteren Aspekt in die Kritik einbringt. Sie ist auf der Seite der Phänomenkritik in beiden Konzepten wiederum fast völlig identisch, läßt jedoch zugleich auch die Divergenz der Grundoptionen deutlicher vor Augen treten. So kritisieren Horkheimer und Adorno in der Instrumentalisierung des Menschen durch den Arbeitsprozeß ja nicht nur die Repression der Natur, son- 
dern auch seinen Verfall an heteronome Zwänge und derart jene Auflösung von Autonomie und Freiheit, die letztlich auch die Subjektivierung in der Moderne scheitern läßt. Die Argumentationsfigur zeigte sich dabei als analog zu Marx eingerichtet, d.h. konstatiert wurde ein Fehlgehen der Emanzipation, die den Menschen nach Überwindung der ersten Entfremdung unter dem Naturzwang in die zweite der Arbeitsteilung verstrickt sieht. Dabei entdeckt sich in der Ausführung bei Horkheimer und Adorno zugleich ein technikkritischer Zug, der als Agenten dieser zweiten Ent-

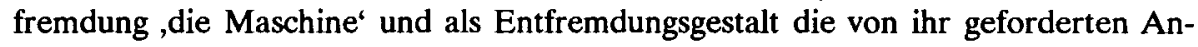
passungsleistungen namhaft macht. Fast völlig identisch liegt dieser phänomenale Teil des Devianzvorwurfs bei Keilhacker vor. Auch er bedient sich implizit der Marxschen These und sieht den Versuch der emanzipativen Autonomisierung in Fremdbestimmung scheitern und auch er malt eine Maschinisierung des Arbeitsverhaltens aus. Ein marginaler Unterschied besteht allenfalls in der Verteilung der Gewichtung von Technik und Arbeit in ihrem Verhältnis zur konstatierten Defizienz: Bei Keilhacker steht zunächst die Technikkritik im Zentrum und wird der Arbeitsprozeß sekundär bemüht. Davon abgesehen jedoch sind die Vorwürfe deckungsgleich. Die Divergenz wiederum zeigt sich auf der Ebene der Grundoptionen. So zielt Keilhackers Vorwurf intentional nicht auf eine Positivwertung der Subjektautonomie, sondern versucht er, wie zu sehen war, seiner kontramodernen Haltung entsprechend später lediglich die Rückgewinnung einer begrenzten Form von Selbstbestimmung (vgl. 4.3.), während Horkheimers und Adornos kritischer Impetus sich gerade auf die Verhinderung einer Realisierung dieser Autonomie richtet. Keilhacker versucht derart, trotz der Klage über Phänomene mit emanzipationsverhindernder und desubjektivierender Qualität eine Forderung der Realisierung genuiner Subjektautonomie zu vermeiden, wohingegen Horkheimer und Adorno diese implizit gerade stellen und daraus ihre Folie für die Kritik gewinnen. Die Divergenz der prinzipiellen Stellung zum Projekt der Moderne bleibt so erhalten, und das genannte Doppelverhältnis ist im zweiten Devianzvorwurf deutlicher wahrnehmbar als im ersten. Gleichwohl läßt sich konstatieren, daß die Übereinstimmungen in der Phänomenkritik wieder eigentümlich umfassend sind.

Ähnlich verhält es sich bei einer dritten Devianzthese, die nun eine ,Machbarkeitsorientierung' anmahnt. In der Kritik an der Etablierung der genannten Orientierungsform zeigt sich wieder eine weitgehende Identität, während in der Klage über das hierdurch Ausgegliederte und Wiederzugewinnende die Divergenz der Grundstellung durchschlägt. So monieren Horkheimer und Adorno im Kontext des Verlusts der zwecksetzenden und -kritisierenden Souveränität der Vernunft an die instrumentell-funktionalistische Perspektive, die in ihrer positivistischen Perfektionierung nur noch diesen Aspekt der Realität wahrzunehmen scheint, daß hierdurch gleichzeitig die funktionalen Möglichkeiten der Realität in die Rolle der zwecksetzenden Instanz gerieten. Auf die instrumentelle Verwertbarkeit und die funktionalen Qualitäten des Begegnenden gerichtet scheint die Vernunft zum ausführenden Organ einer Selbstrealisierung dieser Verwertbarkeit und Qualitäten zu geraten, die dann zugleich der Vernunfttätigkeit ihre Zwecke setzen. In diesem Zusammenhang sprechen Horkheimer und Adorno von einem Verfall der Vernunft an das ,Machbare und einer Auflösung des ,Sinns'. Keineswegs philosophisch so elaboriert, jedoch in einer analogen Form erscheint diese Argumentationsfigur auch bei Keilhacker. $\mathrm{Er}$ 
setzt gleichwohl nicht (primär) rationalitätstheoretisch, sondern technikkritisch an und sieht aus den technischen Möglichkeiten ein Machbarkeitsprinzip hervorgehen, das die Frage nach der Legitimität technischen Handelns durch die Frage nach Nutzungsmöglichkeiten der materiellen Realität und nach der Durchführbarkeit technischer Projekte ersetzt. Hervorgebracht scheint derart eine Orientierungsform, die sich ausschließlich von den ,äußeren' funktionalen Möglichkeiten bestimmen läßt. Damit scheint auch hier die Zwecksetzung unter funktional-instrumenteller Perspektive an die derart wahrnehmbare Seite der Realität selbst delegiert und der ,Sinn dem Gebot technischer Realisierungschancen unterworfen zu sein. Allerdings gewinnt Keilhacker seine Kritikperspektive wieder aus seiner kontramodernen Grundoption und richtet sich seine Mahnung auf den Verlust vormoderner Orientierungsformen. Die Soll-Herkunft der Zwecke und des Sinns ist entsprechend bei ihm in der Sphäre der ontologisierten Wertewelt angesiedelt, und die Vernunft bleibt, konsequent weitergedacht, daher bei ihm auch unter den Bedingungen der erwünschten Überwindung technischer Machbarkeitsorientierung in den Stand eines Ausführungsorgans (wenn auch von erwünschten, Werten') zurückversetzt. Horkheimer und Adorno hingegen ist gerade dieser Status der Vernunft generell ein Stein des AnstoBes. Damit greift die Argumentationsfigur in beiden Fällen eine analoge Orientierungsform an, die als defizient diskriminiert wird, und erweist sie sich derart auf der Ebene der Phänomene wieder als kongenial. In der Zielrichtung ihrer Kritik und in der Herkunft ihrer kritikleitenden ,positiven' Kriteriologie jedoch, d.h. im Bereich dessen, was sein soll und verlorengegangen zu sein scheint, laufen die beiden Konzepte auseinander und wird erneut die divergente Grundoption spürbar. Während Keilhacker eine kontramoderne Wertewelt reetablieren will, der auch die Zwecksetzung der Vernunft unterstellt sein soll, richten sich Horkheimer und Adorno intentional gerade auf die Wiederherstellung der zwecksetzenden Souveränität der Vernunft selbst, die von allen heteronomen Vorgaben freigesetzt sein soll. Kongenialität und Divergenz sind derart in diesem Devianzvorwurf mit gleicher Deutlichkeit wahrnehmbar, wobei gleichwohl die Kongenialität auf der Phänomenseite wieder erstaunlich weit geht.

Ein Übergewicht allerdings erhält die Divergenz in einer vierten Defizienzthese, die nun den Verlust, idealer Gehalte anmahnt. Mit ihr werden nun nämlich die Grundoptionen selbst Thema der Defizienzkritik und liefern sie die Basis für das kritisierte Phänomen. Diese dialektische Koinzidenz von Grundoption und Phänomenkritik findet sich bei Horkheimer und Adorno im Kontext der Kritik an der Wirkung der positivistischen ,Entzauberung' auf die ,Ideen' der Aufklärung. Das reflektierte historische Phänomen ist hier identisch mit der Auflösung des Gegenstands der prinzipiellen Parteinahme von Horkheimer und Adorno. Die Defizienzkritik richtet sich entsprechend auf der Basis dieser Parteinahme für die aufklärerischen ,Ideen' gegen den Verrat der letztgenannten. Die bemühte Sphäre der Idealität liefert so die Folie für die Klage über das Phänomen ihres Verschwindens. Ähnlich verhält es sich bei Keilhacker, der auf der Basis einer ontologisierten Sphäre vormoderner Gehalte das Phänomen von deren Verabschiedung moniert und daraus geradezu den Grundduktus seiner Devianzkritik gewinnt. Erkennbar ist damit einmal, daB in beiden Fällen eine Sphäre der Idealität bemüht wird und da $\beta$ offensichtlich auch für Horkheimer und Adorno eine Humanisierung und die Verwirklichung des Projekts der Moderne 
in seiner ,ursprünglich gemeinten' Form ohne sie nicht denkbar ist. Tatsächlich scheint auch in Horkheimers und Adornos Konzept eine ,Idealität' im Unterschied zum ,Faktischen' und zur Empirie not zu tun, um Subjektivität, Autonomie und Freiheit in humaner Form gewinnen und garantieren zu können. Doch ist diese Idealität inhaltlich gerade konträr zu derjenigen Keilhackers bestimmt. Dieser nämlich etabliert mit seinem Zwei-Welten-Konzept eine ontologisierte Sphäre vormoderner Orientierungsformen und stellt sich mit ihm diametral gegen die ,Ideen' von Subjektivität und Autonomie. Seine ,Wertsphäre' ist ein Kontrastkonstrukt zu der idealen Sphäre, wie sie in Horkheimers und Adornos Text als Folie der Kritik erscheint. Erkennbar ist derart im vierten Defizienzvorwurf zwar eine (formale) Parallele, die darin besteht, daß beide Konzepte den Verlust einer Idealität beklagen, der sie zugleich bedürfen, um ihre Kritikfolie zu gewinnen. Doch steht dieser eine (materiale) Divergenz gegenüber, die aus den divergenten Grundoptionen hervorgeht und die formale Kongenialität diesmal überwiegt.

Insgesamt nun läßt sich damit erkennen, daß die Modernitätskritik Horkheimers und Adornos ein eigentümliches Doppelverhältnis zu der Keilhackers aufweist. Auf der Ebene der Grundoptionen zeigt sich eine Divergenz, in der Subjektivierung und Autonomisierung als Kernmomente des Projekts der Moderne von Horkheimer und Adorno bejaht werden und die beiden Autoren sich dezidiert auf deren ,ideale' Seite stellen, während Keilhacker eine ablehnende Position bezieht. Auf der Ebene der Phänomenkritik (und ihrer Verwurzelung in einer spezifischen Form von Rationalisierung) hingegen kommen Horkheimer und Adorno, mit Ausnahme des vierten Devianzvorwurfs, weitestgehend mit Keilhackers Kritik überein und monieren beide Konzepte zumeist dieselben Sachverhalte. Obschon also die Grundstellung, aus der heraus die Modernitätskritik geübt wird, disparat ist, koinzidieren eigentümlicherweise die Konkretionen der Kritik selbst. Tatsache und Umfang dieser Koinzidenz nun lassen mit einer dialektischen Wende die Rückfrage an die Kritische Theorie stellen, wie es um ihr Bekenntnis zu den Aspirationen von Aufklärung und Moderne eigentlich bestellt ist, näherhin, ob es sich hierbei noch um eine tragfähige und überzeugende Parteinahme handelt oder ob diese den Charakter eines Lippenbekenntnisses annimmt, unter dessen Deckmantel identisch mit der erklärt modernitätsfeindlichen ,konservativen' Position agiert wird. Zu fragen ist also, ob die Disparatheit der Grundstellungen über den Status einer behaupteten, jedoch für die Konkretion der Kritik folgenlosen Disparität hinausreicht oder die Folgenlosigkeit gar die Grundstellung aufweicht. In der Tat scheint mir ein solches Aufweichen, zumindest aber eine weitgehende Irrelevanz der modernitätsfreundlichen Emphase und daher eine Tendenz zur faktischen Modernitätsfeindlichkeit in der Kritischen Theorie aus drei Gründen zu konstatieren zu sein.

Zum einen nämlich scheint mir schon die weitgehende Identität der Phänomenkritik eine Deplausibilisierung der emphatischen Parteinahme und eine tendenzielle Ablehnung der Moderne an sich zu implizieren. In dieser Kritik nämlich fällt auf, da $B$ sich die Vorwürfe beider Positionen gegen Versuche einer konkreten Einlösung der idealen Aspirationen richten, d.h. gegen die Versuche einer realen Herstellung von Bedingungen und Strukturen für Subjektivität und Autonomie etwa durch die technischen Errungenschaften, durch die Effizienzsteigerung der Arbeit mittels Arbeitsteilung und ,Maschinisierung, durch Kulturierung der naturalen Umwelt und 
durch Schaffung einer effizienten wissenschaftlichen Methodologie. Gelten aber alle diese Versuche einer kulturell-gesellschaftlichen Realisierung der idealen Versprechungen als bloßer Verfall, als Ausdruck eines umfassenden Prozesses der Selbstverhinderung emanzipativer Bestrebungen, wie es die Kritische Theorie konstatiert, so bleibt auch ein Bekenntnis zu den idealen Forderungen letztlich in der Idealität hängen und wird es leer. Die faktisch geübte Modernitätskritik erhält angesichts dieser Leere dann ein Übergewicht, das die Überlegungen von Horkheimer und Adorno mit einem tendenziell modernitätsfeindlichen Zug belastet und die Kritische Theorie in den Verdacht geraten läßt, durch ein beinahe vulgäridealistisches, zumindest jedoch aristokratisches Agieren ihre Grundstellung aufzuweichen oder jedenfalls deren Relevanz zu schmälern: So kehrt sie sich unter zwar ferventer Parteinahme für die reinen ,Ideen', für die Ziele der Aufklärung und Moderne, dennoch von den Versuchen einer kontingenten Einlösung derselben ab, als ob sie diese als Kontaminationen mit dem Vorläufigen empfände, die unter ihrer Würde sind. Den reinen Anspruch festhaltend gelangt sie daher nur noch im Modus des Verwerfens zur Realität und schlägt sie ihr eigenes Festhalten mit weitgehender Bedeutungslosigkeit. Damit aber unterscheidet sich ihre faktische Position zur Moderne tatsächlich nicht mehr sehr von der Modernitätsfeindlichkeit der ,Konservativen', sondern droht die unter dem blassen Bekenntnis zur Idealität geübte Kritik an den Phänomenen zu einer impliziten Verkehrung auch der dieser Kritik zugrundeliegenden intentionalen Option zu führen: Diese Intention einer Stärkung der aufklärerisch-modernen Forderung nach Herstellung von Subjektivität und Autonomie wird von der Kritik an allen tatsächlichen Versuchen einer Einlösung der Forderung derart angegriffen, daß von ihr nichts mehr bleibt und der Impetus der Kritik selbst für die eigentliche Intention gehalten werden kann. Es entsteht der Eindruck einer zwar verbalen Parteinahme für die Aspirationen der Moderne, die jedoch unter der faktischen Defizienzkritik zerbricht und eine antimoderne Intention als eigentlich theorieleitende zu Tage treten läßt. Als Unterschied zur ,konservativen' Position bleibt dann lediglich übrig, daß diese noch versucht, durch eine kontramoderne Konstruktion Lösungen zu schaffen, während die Kritische Theorie sich auf die Kritik beschränkt.

Der genannte Eindruck einer intentionalen Dominanz impliziter Modernitätsfeindlichkeit in der Kritischen Theorie bestätigt, ja verstärkt sich dann zum zweiten dadurch, daß über die Phänomenkritik hinaus auch die Wurzel des Verfalls identisch in der spezifisch neuzeitlichen Rationalisierung, d.h. näherhin in der Schaffung einer mathematisch-naturwissenschaftlichen Methodologie, verankert wird. Diese identische Verankerung des Verfalls nämlich bedeutet zugleich einen Angriff auf die Rationalisierung und damit auf ein (weiteres) Kernmoment des Projekts der Moderne selbst. In der Tat zeichnet sich dasselbe ja nicht nur durch Subjektivierung und Autonomisierung aus, sondern eben auch durch Herstellung einer vernünftigen Lebens- und Gesellschaftsorganisation, d.h. durch eine Rationalisierung der Lebensverhältnisse, wie sie von Horkheimer und Adorno nicht anders als von Keilhacker kritisiert wird. Damit scheint jetzt sogar in der Grundoption für das Projekt der Moderne ein dialektisches Moment gleichzeitiger Kritik an diesem Projekt enthalten zu sein, das die fervente Parteinahme ab initio modernitätsfeindlich bricht. Zwar läßt sich diese Kritik, dadurch daß sie sich auf einen bestimmten Rationalitätstyp bezieht, wieder als Kritik an einer phänomenalen Gestalt der Rationalisierung verstehen, von 
der die ideale Parteinahme nicht in Frage gestellt ist. Mit ihrer Klage über den Verlust eines umfassenden Vernunftbegriffs lassen Horkheimer und Adorno außerdem erkennen, daß sie sich nicht gegen Rationalisierung schlechthin, sondern gegen eine spezifische Form derselben wenden. Das Doppelverhältnis bliebe unter dieser Perspektive betrachtet erhalten. Aber selbst dann weist noch immer die Form der spezifizierten Rationalisierungskritik darauf hin, daß die Parteinahme hier zumindest wieder in der bloßen Idealität zu verblassen, wenn nicht gar vom Umfang des Kritikansatzes geschluckt zu werden droht. Tatsächlich ist ja die kritisierte instrumentellpositivistische Vernunft die einzige, die sich im Prozeß der Menschheitsgeschichte ausbildet, und es bleibt der angemahnte umfassendere Vernunftbegriff eine unpräzise, nur ex negativo geschaffene Größe, d.h. eine Art transzendentale Idee ohne Konkretionsmöglichkeit. Wenn aber die zu favorisierende Rationalisierung dunkel ist und ihr gegenüber nur der Angriff auf die faktische Rationalisierung der Moderne bleibt, so gerät die modernitätsfreundliche Intention zugunsten der Modernitätskritik wieder in den Hintergrund und erhält die letztgenannte den Status der in Wahrheit theorieleitenden Option. Die emphatische Parteinahme der Kritischen Theorie für das Projekt der Moderne erstarrt unter diesen Bedingungen erneut zur bloßen Geste, und der Eindruck einer blanken Verbalität dieser Parteinahme, hinter welcher ein massiver, feindseliger Angriff auf die Moderne überhaupt geführt wird, verstärkt sich so.

Unterstrichen wird dies schließlich zum Dritten durch die rückwärtige Extrapolation des Rationalisierungsunterfangens bis an den Beginn der Hominisierung und des daraus abgeleiteten, ab initio unvermeidlichen Scheiterns der Emanzipation des Menschen zum Subjekt. Der derart beinahe totale Umfang der Defizienzgeschichte und -kritik läßt die Emphase der Parteinahme für das Projekt der Moderne endgültig kraftlos erscheinen und treibt den Vorwurf aus sich hervor, daß die Schwierigkeit der Kritischen Theorie, eine gelingende Subjektivierung angesichts dieses frühzeitigen Scheiterns noch denken zu können, letztlich virtuell identisch mit der modernitätsfeindlichen, ,konservativen“ Option einer prinzipiellen Unmöglichkeit der Realisierung der Subjektivierung überhaupt wird. Die Einlinigkeit nämlich, mit der die Kritische Theorie jeden emanzipativen Anhub in der Menschheitsgeschichte nur auf die darin enthaltenen Momente der Selbstverhinderung untersucht, gibt diesen Momenten einen ähnlich apodiktisch-axiomatischen Status, wie ihn die anthropologischen Grundannahmen der ,Konservativen' aufweisen. Der anthropologische Pessimismus als Begründungsbasis für eine Modernitätskritik scheint so in der Kritischen Theorie durch einen rationalitätstheoretischen Pessimismus, der die Genese von Rationalität einzig als Geschichte von Verengung, Herrschaft und Repression zu denken vermag, durchaus effizient und mit derselben Wirkung ersetzt. Aus ihrer verfallstheoretischen Prämisse heraus enthält die Kritische Theorie eine im Effekt der ,konservativen' Position vergleichbare Negativwertung der Chancen des Menschenwesens, in dieser Welt seinen Subjekstatus zu gewinnen. Die identische Verankerung der Wurzel des spezifisch modernen Verfalls in der positivistischen Vernunft erscheint dann als nur logischer Auszug der Parallele zwischen Kritischer Theorie und der ,konservativen' Position in der Negativwertung dieser genannten Chancen. So betrachtet erweist die Kritische Theorie in der analogen Diskriminierung der neuzeitlichen Rationalisierung noch einmal und verschärft, da grundsätzlich, ihre prinzi- 
pielle Parteinahme für die Aspirationen der Aufklärung als idealisch leer, und bestätigt sie, da $B$ sie unterhalb dieser Parteinahme den Realisierungen der Moderne nicht weniger feindselig gesinnt ist als ihr ,konservatives‘ Gegenüber.

\subsection{Konkretion II: Das Gesellschaftskonzept der Kritischen Theorie}

Aus der Genealogie der instrumentellen Vernunft und den darin grundgelegten Paradigmen leitet sich nun nicht nur die Aufklärungs- und Modernitätskritik der Kritischen Theorie her, sondern auch ihr Gesellschaftskonzept. Mit ihm schließt sich ein weiterer - und letzter - Bogen von der geschichtsphilosophischen Fragestellung zur Ausarbeitung des Untergangs aller humanitären Aspirationen der Moderne in den zeitgenössischen Totalitarismen und zeigt sich umgekehrt, da $B$ auch die modernen demokratischen Gesellschaften totalitarismustheoretisch interpretiert werden. Insbesondere das letztgenannte bildet hierbei den Kern der gesellschaftstheoretischen Überlegungen Horkheimers und Adornos: So geben die nationalsozialistische und die stalinistische Gesellschaft primär den Horizont der Entwicklung eines Gesellschaftskonzepts ab, während im Zentrum des rekonstruktiven Interesses der ,Kapitalismus' steht, wie er Horkheimer und Adorno in den USA begegnet. Gleichwohl wird die ,kapitalistische Gesellschaftsform dann aus dem genannten Horizont heraus interpretiert und als Inbegriff eines besonders gefährlichen, da versteckten Totalitarismus gehandhabt. Als Ziel der Gesellschaftstheorie Horkheimers und Adornos kann daher eine Kapitalismusanalyse in totalitarismustheoretischer Absicht betrachtet werden. In dieser Analyse wird nun, nachdem in der Genealogie die Wurzel des Verfalls rationalitätstheoretisch erarbeitet worden ist, die strukturelle Fixierung der Verfallssituation reflektiert. Die instrumentelle Vernunft erhält hierbei die Rolle des Prinzips dieser Fixierung, oder anders formuliert: die Gesellschaft gilt als strukturelle Realisierung bzw. Strukturgestalt der instrumentellen Vernunft.

Das Gesellschaftskonzept der Kritischen Theorie setzt daher auf der Basis der rationalitätstheoretischen Rekonstruktion an und leitet zunächst eine geschichtsübergreifende Grundfigur von Gesellschaft aus dem Paradigma der instrumentellen Vernunft ab. Den Überschritt von der Rationalitätstheorie zur Gesellschaftstheorie ermöglicht hierbei - wie schon angedeutet - der Herrschaftsbegriff, bzw. genauer: das Begriffspaar von Herrschaft und Repression. Mit ihm wird ein idealtypisches Basisparadigma geschaffen, das der Opposition der beiden Begriffe entsprechend eine Opposition zweier ,Klassen', der Herrschenden und Beherrschten, als Determinante der ,Sozialität' aller Gesellschaften axiomatisch festlegt. Es konstituiert hierbei zugleich ein axiomatisches Interessenprinzip, nämlich den Herrschaftserhalt, von dem alle Gesellschaften der Menschheitsgeschichte geprägt zu sein scheinen. Damit scheint außerdem ein Angelpunkt für die einheitliche Interpretation der Konfliktgeschichte der Menschheit gefunden. Die spekulative Ableitung aus der Rationalitätstheorie freilich hat gleichzeitig eine soziologische Ungreifbarkeit und einen ontologisierten Status der beiden Klassen zur Folge, die den Bezug zu historischer Konkretheit wieder entrücken. Aus dem Basisparadigma und seinem Interessenprinzip wird dann die Genese der Arbeitsteilung und gesellschaftlicher Institutionen hergeleitet. Den beiden erstgenannten wird durch die letzten eine Art soziologische Konkretheit verliehen, die gleichwohl der Idealtypik verhaftet bleibt. Von dieser ,Soziologisie- 
rung der rationalitätstheoretisch verankerten Gesellschaftstheorie aus findet schließlich der Überschritt zur Konstruktionsanalyse der kapitalistischen Gesellschaft statt und werden vor allem das Grundgesetz von deren Warenwirtschaft, die Tauschabstraktion, und die zunehmende Bedeutung der Verwaltung aus der instrumentellen Vernunft abgeleitet. Auf diese Weise sind sowohl das ökonomische ,Lebensgesetz' der kapitalistischen Gesellschaft als auch die Weiterentwicklung der letztgenannten zur ,Dienstleistungsgesellschaft' rationalitätstheoretisch verankert, d.h. es ist mit der instrumentellen Vernunft anscheinend der Kern auch der modernen Gesellschaften gefunden. Der derart rekonstruierte Gesellschaftszusammenhang gilt dann als totalitärer, von welchem Faschismus und Stalinismus lediglich modifizierte Auslegungen sind. Mit dem Basisparadigma und seiner Ausformung ist so einmal der Bogen zur geschichtsphilosophischen Fragestellung hergestellt, und zum anderen der Rückgang hinter die ökonomistische Perspektive Marx in einer Weise von der rationalitätstheoretischen Genealogie in die Gesellschaftstheorie übertragen, die das gesellschaftliche Scheitern der dort gehegten Aspirationen auf Fortschritt und Freiheit begründbar macht.

\section{,Hersschende und ,Beherrschte': Das dichotomische Basisparadigma der kritischen Gesellschaftstheorie}

Das idealtypische Basisparadigma und sein Interessenprinzip werden von Horkheimer und Adorno in der „Dialektik der Aufklärung“ rationalitätstheoretisch über das Begriffspaar von Herrschaft und Repression eingeführt und später von Adorno mit dem Axiom einer ,Urspaltung der menschlichen Gesellschaft axiomatisch-spekulativ verwurzelt. So assoziieren, wie schon in der Genealogie erkennbar war, zunächst Horkheimer und Adorno die Ausbildung der instrumentellen Vernunft in der Subjektivitätsgeschichte mit dem Habitus des Herrschens, der sich dort vorerst nur auf die (innere und äußere) Natur bezieht und durch den die Menschen ihren Subjektstatus zu gewinnen suchen. Die instrumentell begründete Herrschaft und die mit ihr einhergehende Repression jedoch scheinen nun eine Tendenz zu haben, sich über die Natur hinaus auf die entstehenden Subjekte selbst auszudehnen und den Subjektstatus nur für eine kleine Gruppe von Herrschenden zu requirieren. Horkheimer und Adorno nämlich sehen „das Erwachen des Subjekts (...) durch die Anerkennung der Macht als des Prinzips aller Beziehungen “ ,erkauft', ${ }^{63}$ d.h. nicht nur die Beziehung zur Natur, sondern auch die Beziehungen der Subjekte untereinander scheinen von der ,Machtseite der instrumentellen Vernunft geprägt zu sein. Da die instrumentelle Vernunft nach Horkheimer und Adorno die einzige im Lauf der Geschichte ausgebildete Form von Vernunft ist und derart auch als einziger Weltzugang des Menschen und als primäre Prägekraft für seinen Weltumgang gilt, scheint sich ihr Habitus auch auf den Umgang des Menschen mit dem Menschen zu übertragen. Das intersubjektive Verhältnis ergibt sich daraus als das einer wechselseitigen herrscherlichen Instrumentalisierung des je Anderen für die eigenen Ziele und Zwecke. Die Folge dessen jedoch ist anscheinend nicht unausweichlich ein ,Krieg aller gegen alle', sondern vielmehr eine Assoziation von wenigen, kooperierenden Herrschenden gegen viele miteinander uneinige Beherrschte. Die strukturelle Festschreibung dieser

${ }^{63}$ Horkheimer/Adorno, Dialektik, 12; Hervorhebung von mir. 
Kooperation mündet dann in eine oligarchische ,Zwei-Klassen-Gesellschaft ${ }^{\star}$ von Herrschenden und Reprimierten, in der eine Gruppe die andere für ihre Zwecke funktional gebraucht und sie hierbei unterdrückt.

Diese Konstellation gilt Horkheimer und Adorno nun als Grundkonstellation jeder menschlichen Gesellschaft überhaupt. So sehen die beiden Autoren schon frühzeitig ,Macht und Unterwerfung',,auf verschiedene Klassen der Menschheit verteilt: die Macht ist auf der einen, der Gehorsam auf der anderen Seite", und diese Verteilung „in späteren Perioden“ erhalten. ${ }^{64}$ Mit ihr scheint sich über die gesamte Menschheitsgeschichte hinweg die instrumentelle Repression der Natur gesellschaftlich zu wiederholen, und die Geschichte der Naturbeherrschung erhält eine Parallele in jener der Menschenbeherrschung. Die Unterworfenen geraten damit gewissermaßen zur gesellschaftlichen Repräsentanz der Natur, deren Repression sich in der historischen Unterdrückung eines Teils der Menschheit „nach dem Takt von Keule und Prügelstock" auf einer anderen Ebene wiederhole. ${ }^{65}$ Aus dieser Perspektive betrachtet aber erscheint dann die Konfliktgeschichte der Menschheit als Folge der Ausdehnung der instrumentellen Vernunft von der Naturbeherrschung in die gesellschaftliche Organisation, und ihre Interpretation findet mit diesem Ansatz zugleich seine einheitsstiftende Verankerung: Wie die Menschheit zunächst über die Ausbildung der instrumentellen Vernunft sich zur Herrschaft über die Natur aufschwang, scheint aus derselben Wurzel heraus alsbald ein Teil von ihr kooperativ zur gesellschaftlichen Herrschaft überzugehen und die Gesellschaft als instrumentelles Herrschaftsgebilde zu organisieren. Konsequenz ist ein Klassenantagonismus, der den Antagonismus zwischen Vernunft und Natur wiederspiegelt und jede historische Gesellschaftsbildung durchzieht. Damit scheinen alle Gesellschaften der Menschheitsgeschichte als Strukturgestalt der instrumentellen Vernunft begreifbar zu sein, und mit der letztgenannten scheint das übergreifende Bewegungsprinzip ihrer Historie dingfest gemacht.

Mit der Übertragung des instrumentell-rationalen Umgangs von der Naturbeherrschung auf die Menschenbeherrschung und die kooperative Sicherung dieser Übertragung als gruppenspezifischer nun gelingt es den Herrschenden in diesem historischen Prozeß gleichzeitig, sich von den durch die instrumentelle Vernunft Depravierten zu Teilhabern ihrer Macht aufzuschwingen. Damit aber ist das generelle Scheitern der durch Naturbeherrschung und gesellschaftliche Arbeit angezielten Subjektivierung, wie es die Rationalitätstheorie für alle Gesellschaftsmitglieder konstatierte, von einem Teil derselben durchbrochen. Zwar bleibt die eigentliche Herrschaft nach wie vor die der instrumentellen Vernunft selbst, von der jede strukturelle Einrichtung und Selbstinstallierung des Menschen in der Welt determiniert ist. Doch gelingt es der Gruppe der Herrschenden, diese instrumentelle Einrichtung nun für sich zu nutzen und ihre eigene souveräne Stellung durch Instrumentalisierung der $\mathrm{Be}$ herrschten zu etablieren. Auf diese Weise erlangen die Herrschenden eine spezifische Form von Autonomie und Freiheit, d.h. sie erreichen eine Subjektstellung. Die von der instrumentellen Vernunft ermöglichte Form der Subjektivität findet sich derart in der Gesellschaftsbildung doch für zumindest einige Subjekte realisiert.

${ }^{64}$ Horkheimer/Adorno, Dialektik, 12

${ }^{65}$ Horkheimer/Adorno, Dialektik, 12 
Zusammen damit aber ist die Gesellschaftsbildung gleichzeitig erneut als Defizienzproze $\beta$ gezeichnet, denn die Subjektivierung des Menschen ist nun durch den Klassenantagonismus gruppenbezogen begrenzt bzw. auf Kosten anderer Gruppen hergestellt, die jetzt zu Objekten der Herrschaft und der Ziele der Herrschenden werden. Die strukturelle Kristallisation des Subjektivierungsunterfangens schließt damit die Desubjektivierung eines großen Teils der Gesellschaftsmitglieder ein, und die Geschichte der Gesellschaftsbildung wird weniger als (doch noch) geglückte Subjektivierung eines Teils der Subjekte, sondern vielmehr als Prozeß des Scheiterns der Subjektivierung einer großen Zahl potentieller Subjekte bewertet. Terminologisch ist das aus dem Paradigma der instrumentellen Vernunft hergeleitete, geschichtsübergreifende Gesellschaftskonzept deshalb als Systematik von Privilegierung ${ }^{66}$ und Depravation angesetzt und als Unrechtszustand designiert: Subjektivität erscheint gesellschaftlich als illegitimes ,Requisit' der Herrschenden und stellt sowohl sich durch Privilegierung her als auch selbst ein Privileg dar. Illegitim ist es, da es sich auf der Basis der ,Deprivilegierung' der Beherrschten konstituiert und der Subjektstatus der Herrscher dadurch zustandekommt, da $\beta$ er den Beherrschten genommen wird. Gespielt wird gewissermaßen ein Nullsummenspiel, in welchem der Gewinn der einen Seite der Verlust der anderen ist. Da es hierbei um den Subjektstatus des Menschen geht, bedeutet die strukturelle Fixierung dieses Spiels in Form eines Gesellschaftssystems zugleich die Errichtung eines verwerflichen Zustands. Neben die beschädigte Natur und Vernunft tritt so in Horkheimers und Adornos Theorie durch das Basisparadigma auch eine beschädigte Gesellschaft, die in zwei antagonistische ,Klassen' zerfällt, und die durch die desubjektivierende Herrschaft der einen Gruppe über die andere ab initio von Unrecht gezeichnet ist.

Die Konstellation der beschädigten Gesellschaft begründet dann zugleich ein primäres Interessenprinzip der Herrschenden, nämlich das des Erhalts ihrer Stellung und Privilegien. Als gruppenspezifisches Prinzip tritt es neben das grundsätzliche Prinzip der Selbsterhaltung, wie es in der Genealogie angesetzt worden ist: Während die Selbsterhaltung das Prinzip eines jeden Einzelsubjekts und der Gesamtgesellschaft ist, tritt der Herrschaftserhalt als Prinzip eines Teils der Subjekte bzw. eines gesellschaftlichen Teilsubjekts auf und muß er gegen das andere Teilsubjekt durchgesetzt werden. Das Prinzip des Herrschaftserhalts ist damit eine Art partikulare Auslegung des generellen Selbsterhaltungsprinzips auf den Selbsterhalt des Status einer gesellschaftlichen Gruppe hin. Trotz seiner Partikularität jedoch scheint es Horkheimer und Adorno durch seine Konnexion mit dem Basisparadigma eine nicht weniger umfassende determinative Kraft für die Gesellschaft zu entfalten als das Selbsterhaltungsprinzip für die Einzelsubjekte und die Form der Rationalität. Durch die Nötigung zu seiner Durchsetzung nämlich gerät der Herrschaftserhalt geradezu zu einem Bewegungsprinzip innergesellschaftlicher Prozesse und Interaktionen, und die Gesellschaftstheorie Horkheimers und Adornos scheint mit ihm auch die Dimension sozialer Konflikte in sich aufzunehmen. So, wie die Konfliktgeschichte der Menschheit als vom Klassenantagonismus gezeichnet und motiviert gilt, erhält die innerge-

${ }^{66}$ Die Kategorie des Privilegs spielt ihre theorieleitende Rolle vor allem in Adornos Texten und bezeichnet dort die Herrschaftsstellung. Auch wird die Gruppe der Herrschenden bei ihm häufig mit dem Begriff der ,Privilegierten' bezeichnet. Vgl. hierzu: Schmucker, Adorno, 37-38; 53-55 und: Honneth, Kritik, 61 
sellschaftliche Dynamik jetzt durch das Interessenprinzip eine theoretische Verankerung. Die Nähe des Interessenprinzips zum gesamtgesellschaftlichen Selbsterhalt freilich bedingt für Horkheimer und Adorno zugleich eine dialektische Tendenz zur Interessendiffusion von Herrschenden und Beherrschten und hierdurch zur Verschleierung der grundsätzlichen Konfliktkonstellation (vgl. unten).

Trotz der scheinbaren Verankerung einer sozialen Dimension im Gesellschaftskonzept durch das Interessenprinzip erhält die gesamte Konstitution des Basisparadigmas schließlich jedoch einen quasi-ontologischen Status, der sich aus der geschichtsphilosophischen Determination der Kritischen Theorie zur Verfallstheorie begründet. Tatsächlich nämlich bleiben der rationalitätstheoretisch eingeführte Klassenantagonismus und das hiervon geschichtsübergreifend fixierte Unrechtssystem aller Gesellschaften unabhängig von allen realen sozialen Gegebenheiten festgeschriebene, theorieleitende Bestimmungsstücke der Kritischen Theorie, die unter Abstraktion von faktischen historischen Gegebenheiten formuliert werden und unter sehr deutlichem Absehen von soziologischer Faktizität auch die Analyse des ,Spätkapitalismus' prägen. Dieser trotz aller Feindschaft der Kritischen Theorie gegenüber Ontologien spürbare Hang zur Ontologisierung des Basisparadigmas und seiner Unrechtsimplikation zeigt sich im Vorliegenden durch den Wechsel von einer historisch-illustrativen Verankerung des Übergangs einer gesellschaftlichen Gruppe von der Naturbeherrschung zur Menschenbeherrschung zu einer rein axiomatischen Begründung, die unmittelbar auf die verfallstheoretische Perspektive des geschichtsphilosophischen Ansatzes rekurriert. Der Wechsel markiert zugleich eine Divergenz zwischen Horkheimer und Adorno, die bei Horkheimer ein stärkeres Interesse an ,empirischen (sozialpsychologischen und ökonomischen) Beständen wahrnehmen läßt und bei Adorno dessen primär spekulative Theorieoption deutlich macht. In der „Dialektik der Aufklärung“ nämlich bemühen sich beide Autoren zunächst noch um eine rudimentäre Anbindung des genannten Übergangs an konkrete Forschungsbestände und Daten, während Adorno später auf einen solchen Versuch verzichtet.

So sehen Horkheimer und Adorno zunächst den Akt der Herrschaftsergreifung in der Genese von ,Priesterschichten ' verankert, die die Welt ,in einen Bezirk der Macht und in Profanes" teilen und hierbei den „Verkehr mit Geistern", d.h. die Machtsphäre, für sich monopolisieren. ${ }^{67}$ Durch historiographischen Rückschluß von ethnologischen Forschungen an primitiven Gesellschaften suchen sie derart, ihrer These zumindest ansatzhaft bzw. illustrativ ein materiales Fundament beizugeben. Adorno hingegen setzt dann in der „Negativen Dialektik“ den Akt der ,Machtergreifung' hypothetisch rein an und supponiert spekulativ eine Urspaltung der menschlichen Gesellschaft in unvordenklichen, historiographisch nicht mehr faßbaren Zeiten durch einen Willkürakt. Er gibt dem Übergang zur gesellschaftlichen Herrschaft und damit dem Paradigma einen axiomatischen Status, dessen Logizität auf die geschichtsphilosophische Fragestellung und die daraus hervorgehenden Prämissen der Kritischen Theorie zurückgeht. So wendet sich Adorno in einem ,Exkurs zu Hegel zunächst gegen jede ,positive' Konstruktion einer Universalgeschichte und betont er, $\mathrm{da} ß$ keine solche „vom Wilden zur Humanität“, wohl aber „von der Steinschleuder

${ }^{67}$ Horkheimer/Adorno, Dialektik, 12 
zur Megabombe" führe. ${ }^{68}$ Damit setzt er treu zur verfallstheoretischen Perspektive die Menschheitsgeschichte als Defizienzprozeß an. Dann führt er knapp das gesellschaftstheoretische Basisparadigma ein und verankert es nun "gleichsam kontingent" in ,archaischen Willkürakten von Machtergreifung“ ${ }^{69}$ Irgendwo ,im Trüben der Frühgeschichte ${ }^{\text {“70 }}$ scheint nun eine Gruppe selbständig von der Naturbeherrschung zur Menschenbeherrschung geschritten zu sein und derart die dichotomische Urspaltung hervorgerufen zu haben. Für die Annahme dieser arbiträren Spaltung bedarf es anscheinend keiner weiteren faktischen Gründe, sondern sie gilt als logische Notwendigkeit angesichts der zeitgenössischen Situation. Dieser nämlich als einer „heraufziehenden Katastrophe“ korrespondiert Adorno zufolge „die Vermutung einer irrationalen Katastrophe in den Anfängen ". ${ }^{71}$ Das Basisparadigma einer ,Zwei-Klassen-Gesellschaft', die in eine Gruppe Herrschender und eine Gruppe Beherrschter zerfällt, ist so jetzt spekulativ-axiomatisch grundgelegt und konsequent in Entsprechung zur ersten Prämisse der Kritischen Theorie formuliert. Sie erhält mit ihrer im Rückschlußverfahren eingeführten Gestalt einen beinahe ontologischen Status. Die Formulierung des Rückschlusses macht zugleich deutlich, da $\beta$ die Kritische Theorie vor allem bei Adorno auch über die Zeit des Nationalsozialismus hinaus ihrer verfallstheoretischen Prämisse treu bleibt und auch die zeitgenössische Situation der sechziger Jahre, in denen die „Negative Dialektik“ entsteht, als Katastrophensituation bewertet.

Das Basisparadigma und das primäre Interessenprinzip der Gesellschaftstheorie Horkheimers und Adornos aber sind damit fixiert. Unter Ansatz bei der instrumentellen Vernunft wird zunächst über das Begriffspaar von Herrschaft und Repression ein geschichtsübergreifender Antagonismus zweier Klassen eingeführt, der eine Gruppe Herrschender von einer Gruppe Beherrschter und Unterdrückter differenzierbar macht. So scheint ein Teil der Menschheit bei der Gesellschaftsbildung von der Naturbeherrschung zur Menschenbeherrschung fortzuschreiten und einen anderen Teil instrumentell den eigenen Zielen und Zwecken zu unterwerfen. Das ,Gesamtsubjekt' Menschheit scheint sich derart gesellschaftlich zu spalten, und die entstehende Gesellschaftsorganisation tritt als instrumentell-repressive Einrichtung auf. Sie ist damit eine Realisierungsform der instrumentellen Vernunft, oder mit einem anderen Begriff: deren Strukturgestalt. Dabei scheint eine Gruppe der Gesellschaftsmitglieder an der Herrschaft der instrumentellen Vernunft teilhaben zu können und aus deren struktureller Fixierung Nutzen zu ziehen. Die desubjektivierende Kraft der instrumentellen Vernunft scheint sich für die Herrschenden aufzuheben, ja geradezu in ihre eigene Subjektivierung umzukehren. Doch werden die in der gesellschaftlichen Struktur instrumentalisierten und den Zielen der Herrschenden unterworfenen Gesellschaftsmitglieder hierbei ihres Subjektstatus beraubt, so daß die universelle Grundkonstellation aller Gesellschaften eine umfassende Emanzipation wieder verhindert und gleichzeitig als die eines Unrechtssystems erscheint. Trotz der Subjektivierung einiger scheint so die antiemanzipative Kraft der instrumentellen Vernunft auch gesellschaftlich wirksam zu sein, und das pessimistische Paradigma

\footnotetext{
${ }^{68}$ Adorno, Dialektik, 314

${ }_{70}^{69}$ Adorno, Dialektik, 315

${ }_{71}^{70}$ Adorno, Dialektik, 315

${ }^{71}$ Adorno, Dialektik, 316
} 
der Rationalitätstheorie findet sich in die Gesellschaftstheorie übertragen. Dadurch ist zugleich bereits in das Basisparadigma aller Gesellschaftsformen ein weitgehendes, erneutes Scheitern der Aspirationen auf Freiheit und Subjektivität eingetragen, und die Kritische Theorie bleibt schon im Ansatz ihrer Gesellschaftsreflexion der verfallstheoretischen Perspektive treu.

Als Bewegungsprinzip der so verfaßten Gesellschaften erscheint dann ein primäres Interessenprinzip der Herrschenden, das sich auf Erhalt ihrer privilegierten Stellung bezieht. Der Herrschaftserhalt, der ein gruppenspezifisches Partikularinteresse neben dem generellen Selbsterhalt der Gesellschaft vorstellt, kann dabei als gruppenspezifische Auslegung dieses generellen Prinzips gelesen werden. Er gerät zu einer weiteren Determinante der instrumentellen Organisation der Gesellschaft neben dem generellen Selbsterhalt und damit zu einem der Ziele der gesellschaftlichen Einrichtungen. Das primäre Interessensprinzip markiert außerdem den schon in der basisparadigmatischen Grundstellung enthaltenen Konflikt zwischen den NutznieBern des gesellschaftlichen Systems und denjenigen, zu deren Lasten der Nutzen entsteht, d.h. zwischen Herrschern und Beherrschten. Es scheint hierdurch eine soziale Komponente in die Gesellschaftstheorie Horkheimers und Adornos zu tragen und die innergesellschaftliche Konfliktdynamik theoretisch faßbar zu machen. Gleichwohl eignet dem Basisparadigma ein quasi-ontologischer Charakter, in dem diese Konkretheit wieder verschwindet. Dieser Charakter zeigt sich zunächst in der Begründung des Übergangs einer Subjektgruppe von der Naturbeherrschung zur gesellschaftlichen Herrschaft: Der Übergang nämlich wird in einen hypothetisch-spekulativ angesetzten Willkürakt archaischer ,Subjekte' verlagert und axiomatisch verankert. Der von ihm erzeugte Klassenantagonismus ist damit zu einer nicht hintergehbaren Konstante der Gesellschaftstheorie vor allem Adornos erklärt. Obschon das Basisparadigma zunächst noch eine zumindest illustrative Anbindung des Antagonismus an historisch-ethnologische Forschungsbestände versucht, wird es später ,rein' formuliert und auf die immanenten Notwendigkeiten des verfallstheoretischen Ansatzes der Kritischen Theorie bezogen. ${ }^{2}$ Es gerät so zu einer Art ontologischer Grundlage der ,kritischen Gesellschaftstheorie'.

\footnotetext{
72 Mit dem Verzicht auf eine weitere historiographische Begründung und dem Rückzug auf eine schlicht behauptete logische Notwendigkeit der Axiomatik tritt zugleich eine gewisse Inkonsistenz der Kritischen Theorie vor Augen, die sich in den Begriffsidentifikationen der Genealogie schon andeutet. Durchaus unbegründet nämlich blieb dort, weshalb die instrumentalisierende Handhabung der Natur mit Herrschaft und Repression identifiziert werden muß. Analog dazu bleibt nun recht wenig untermauert, weshalb die instrumentelle Einrichtung der Gesellschaft als defizienter Zusammenhang von Herrschaft und desubjektivierender Unterwerfung gedacht werden muß sowie aus welcher Notwendigkeit heraus die instrumentell tätigen Subjekte zur Menschenbeherrschung übergehen müssen und die kooperative Vereinigung in der Naturbeherrschung derart von Einigen durchbrochen wird. Zunächst nämlich könnte selbst der rein instrumentelle Umgang der Subjekte miteinander ja auf der Strukturseite sich in einer rein funktionalen, auf Sicherung der Souveränität über die Natur ausgerichteten Gesellschaft bescheiden. Zwar auf sachhaftes Gebrauchen und Objektivieren in ihrem Umgang miteinander reduziert, fänden die so bestimmten Subjekte dennoch ihre spezifische Subjektivität und blieben sie einander gleichgestellt: Gemeinsam errängen sie Souveränität über die Natur und nutzten sie einander für ihre Subjektivierung. Weshalb diese paritätische instrumentelle Kooperation in eine Oligarchie münden muß, ist damit noch nicht begründet. Erst die Identifikation der Instrumentalisierung mit Herrschaft gibt dem Schritt Einiger zur Unterwerfung der Meisten eine gewisse Plausibilität: Die Zugkraft des Herrschens zieht dann wohl einige Gesellschaftsmitglie-
} 
Weiter aber zeigt sich das quasi-ontologische Moment auch in der spezifischen Bedeutung des Basisparadigmas für eine Interpretation der Konfliktgeschichte der Menschheit und einem mit ihm vollzogenen Rückgang hinter den geschichtsphilosophischen Ökonomismus Marx'. So scheint mit dem Paradigma ein einheitsstiftender Angelpunkt für diese Interpretation gefunden zu sein, der einen spezifischen Bezug zur Marx'schen Theorie hergestellt und zugleich dessen Perspektive unterläuft. Durch die Herleitung zweier antagonistischer Klassen, deren Anwesenheit durch die ganze Geschichte der Menschheit hindurch angenommen wird, nämlich ist zunächst die Konfliktgeschichte unter dem Theorem des Klassenkampfs als Primärphänomen der Menschheitsgeschichte gesehen und gemä $ß$ dem kommunistischen Manifest angesetzt. Die gesellschaftstheoretische Konzeption Horkheimers und Adornos scheint so eine Interpretation der Konfliktgeschichte der Menschheit in ähnlicher Weise anzustreben, wie Marx es tut, und ihr Gesellschaftskonzept entsprechend zu entwerfen. Gleichzeitig aber ist durch die rationalitätstheoretische Verankerung des Klassenantagonismus der Rückgang hinter die ökonomistische Perspektive Marx aus der Genealogie in die Gesellschaftstheorie hinübergenommen. Dies entrückt die Konkretheit der Konfliktgeschichte wieder. Der Klassenantagonismus erhält nun statt der Verankerung in historisch-empirisch faßbaren Phänomenen, wie eben den ökonomischen Verhältnissen, einen spekulativen Status und scheint die Folge der Rationalisierung sowie eines theoretisch nicht ganz konsistent (siehe vorangehende Fußnote) eingeführten Entschlusses zur Ausdehnung der Naturbeherrschung auf einen Teil der gesellschaftlichen Subjekte zu sein. In dieser spekulativen Form aber eignet dem Antagonismus jetzt wieder das ontologische Gepräge, das schon in seiner axiomatischen Einführung sichtbar war. Folge dieses Gepräges ist, daß das schichtspezifische (oder in anderer Weise soziologisch benennbare), Wer der Herrschenden in der Kritischen Theorie meist schwer zu fassen ist.

\section{Arbeitsteilung und Institutionalisienung: Die Fixierung der quasi-ontologischen Grundkonstellation der Gesellschaft}

Die Urspaltung der Gesellschaft und das partikulare Interessensprinzip determinieren für Horkheimer und Adorno dann auch die weitere Ausfaltung der gesellschaftlichen Organisation in der Arbeitsteilung und der Schaffung gesellschafticher Institutio$n e n .{ }^{73}$ So scheinen den beiden Autoren die letztgenannten Phänomene auf dem Weg zum Kapitalismus eine Fixierung des quasi-ontologischen Klassenantagonismus und eine Zementierung der hiervon bestimmten gesellschaftlichen Grundkonstellation zur Folge zu haben. Gleichzeitig damit sehen sie auch eine verderbliche Diffusion der Interessen der Herrschenden mit denen der Beherrschten gegeben, die dem Gesellschaftszusammenhang bereits einen tendenziell totalitären Charakter verleihen. -

der in ihren Bann. Doch diese Plausibilität ist dünn - wie nämlich schon in der Genealogie die Assoziation der instrumentellen Vernunft mit Herrschaft und Repression recht arbiträr gesetzt anmutet, wirkt auch jetzt die ,Tendenz' dieser Vernunft, in einigen Subjekten von der Instrumentalisierung der Natur zur gesellschaftlichen Herrschaft fortzuschreiten, etwas willkürlich. Während in der „Dialektik der Aufklärung" diese Arbitrarität noch mit den Überlegungen zur Entstehung einer Priesterherrschaft recht unvollkommen überdeckt werden soll, scheint Adorno sie später deutlich gesehen und daher einer blanken Axiomatik den Vorzug gegeben zu haben, die mit dem Begriff des, Willkürakts' implizit auch ihre eigene Willkür eingesteht.

${ }^{73}$ vgl. zum Folgenden auch: Honneth, Kritik, 61-69 
Zunächst nun wird von Horkheimer und Adorno die Arbeitsteilung in der instrumentellen Vemunft verankert, sowie in Entsprechung zum Basisparadigma als dichotomische Teilung eingeführt. So gilt, wie schon in der Genealogie zu sehen war, die Arbeit als strukturelle Gestalt des rational-instrumentellen Selbsterhalts aller Menschen, der durch sie zugleich gesellschaftlich organisiert wird. Diese gesellschaftliche Organisation scheint dann dichotomisch auszufallen und mit der Verteilung von Herrschaft und Repression zu koinzidieren. In diesem Sinn konstatieren Horkheimer und Adorno, daß „,mit dem Ende des Nomadentums die gesellschaftliche Ordnung auf der Basis festen Eigentums hergestellt" sei und zugleich „Herrschaft und Arbeit" auseinanderträten. ${ }^{74}$ Die Gruppe der Herrschenden scheint sich von ,grober Handarbeit zunehmend freizumachen und den Arbeitsprozeß generell an die Beherrschten zu delegieren. Hierbei wird „Vertretbarkeit das Maß von Herrschaft" und erhält jener den Status des ,Mächtigsten', „der sich in den meisten Verrichtungen vertreten lassen kann“. ${ }^{75}$ Gegenüber stehen sich demnach eine Gruppe Herrschender, die eben diese Herrschaft (und ihren Erhalt) als ihre ,Arbeitsaufgabe betrachten, und eine Gruppe (vorwiegend) handarbeitend Tätiger, die den gesellschaftlichen Reichtum bereitstellt und dadurch für den Selbsterhalt der Gesellschaftsmitglieder sorgt. Freilich bleibt hierbei die Arbeitsaufgabe der Herrschenden nicht legitimativ leer, sondern tritt sie als mit organisatorischen, verwaltungsbezogenen und politischen Problemstellungen befaßte auf. Sie konstituiert sich als eine Form notwendiger ,geistiger' Arbeit, die ihr ,eigentliches' Wesen, in Wahrheit aus ,Kontrolleistungen“ zusammengesetzt zu sein, hierdurch verschleiert. ${ }^{76}$

Daraus ergibt sich bereits eine erste verderbliche Diffusion der Interessen der Herrschenden mit denen der Beherrschten. Zum einen nämlich stellt ja der generelle Selbsterhalt ein gemeinsames Interessensprinzip beider Gruppen dar und ist hierdurch der Notwendigkeit der Arbeit überhaupt eine entsprechende Evidenz verliehen. Sie kann zusammen mit ihren repressiven Begleiterscheinungen der Selbstinstrumentalisierung und des Verzichts auf freie Entfaltung der inneren Natur der Subjekte nicht einfach verworfen werden. Die Freisetzung der Herrschenden von gesellschaftlicher (Hand-)Arbeit zum anderen und die Realisierung eines Partikularinteresses in der Behauptung der Herrschaftsstellung sind als solche nicht unmittelbar wahrnehmbar, sondern verschwinden hinter der scheinbaren Notwendigkeit der verwaltenden, organisierenden und delegativen Aufgaben der Herrschaft selbst. Auf diese Weise scheint den Beherrschten das partikulare Interesse der Herrschenden mit dem generellen des kollektiv eingerichteten Selbsterhalts identisch zu sein oder zumindest weitgehend zu koinzidieren. Neben einer Herrschaftswahrung durch Gewalt, wie sie von Horkheimer und Adorno immer wieder in der Geschichte der Menschheit konstatiert, sowie durch Manipulation, wie sie von den beiden Autoren im Kulturindustrietheorem ausgearbeitet ist, ergibt sich hier also tendenziell ein Verblendungszusammenhang, der den Beherrschten die Wahrnehmung ihrer eigenen Situation verunmöglicht und dadurch herrschaftsstabilisierend wirkt. Weder scheint es so möglich, gegen die entfremdenden Begleiterscheinungen der Arbeit

\footnotetext{
${ }^{74}$ Horkheimer/Adorno, Dialektik, 16

75 Horkheimer/Adorno, Dialektik, 34

${ }^{76}$ vgl. Honneth, Kritik, 62
} 
selbst Klage zu erheben, noch die Herrschenden in ihrer Stellung anzugreifen. Stattdessen tritt der Gesamtzusammenhang gesellschaftlich organisierter Arbeit und Herrschaft als bestmögliche Realisierung des gemeinsamen Erhalts in der Welt auf und ,schlägt' er durch seinen Schein der Notwendigkeit die Reprimierten mit einer spezifischen ,Betriebsblindheit‘. Die später im Kulturindustrietheorem beklagte „böse Liebe des Volks zu dem, was man ihm antut" $" 7$, ist derart bereits durch die Verblendungstendenz, die mit der Arbeitsteilung einhergeht, präformiert. In dieser Verblendung aber, die der Herrschaft und Repression ihre Selbstzementierung erlaubt, sehen Horkheimer und Adorno eine Wurzel der Totalisierung. Die scheinbare Interessenkongruenz und die effiziente Funktionalität der gesellschaftlichen Arbeitsteilung konstituieren ihnen zufolge eine ,schlechte Totalität', welche die unterdrückten Subjekte in ihrem Stand festhält und jede Chance auf Subjektivierung und Freiheit schluckt.

Ähnlich wie die Arbeitsteilung, die gemäß dem Vorstehenden eine gewissermaßen entelechiale Kraft totalisierender Herrschaftsstabilisierung entfaltet, scheint dann auch die gesellschaftliche Institutionsbildung für Horkheimer und Adorno eine stabilisierende Funktion unter dem Partikularprinzip zu besitzen. Auch die Institutionen treten hierbei zugleich als Kristallisationsformen der instrumentellen Vernunft auf, von der jede Herrschaft erst begründet und vermittelt ist. So sieht Honneth in den Institutionen bei Horkheimer und Adorno eine Analogkonstruktion zu den „technischen Instrumenten“, in denen die instrumentelle Vernunft „die Regeln beliebig wiederholbarer Operationen in der Natur" materiell objektiviert. ${ }^{78}$ Wie diese Instrumente „Herrschaftsapparaturen ${ }^{\text {“79 }}$ vorstellten, seien auch die institutionellen Organisationsformen der Gesellschaft gemäß der Kritischen Theorie als solche ,Apparate' zu verstehen: Sie gäben das Pendant zur Naturbeherrschung ,auf der Seite sozialer Herrschaft" ab und verkörperten entsprechend „die erfolgreichen Verfahren der Kontrolle und Manipulation der unterworfenen Gesellschaftsmitglieder auf Dauer" ${ }^{80}$ Horkheimer und Adorno interpretieren demnach jede institutionelle Organisation in der Gesellschaft als ,geronnene Herrschaft', als ,objektive' Gestalt reüssierender Beherrschungsstrategien, durch welche eine zunehmend totale Repression gesichert und die eigene Stellung garantiert erscheint. Die Bewertung der Institutionsbildung durch die Kritische Theorie scheint so die Gruppe der Herrschenden zu den ausschließlichen Schöpfern institutioneller Gestalten, zumindest aber zu deren einzigen Nutznießern zu machen. Genau besehen bildet sich darin die ontologisierende Grundstellung des gesellschaftstheoretischen Ansatzes wieder ab: Konsistent mit dem Entwurf des Basisparadigmas und seines Interessensprinzips scheint der Herrschaftserhalt die organisatorische Einrichtung der Gesellschaft a priori in ihren Institutionen zu determinieren. Eine wirkliche Analyse empirisch erhebbarer, sozialer Prozesse der Genese von Institutionen hingegen tut dann nicht mehr not. Unter den Prämissen des ,ewigen Gegensatzes' der quasi-ontologischen Klassen und einer geschichtsübergreifend wirksamen Repression bzw. Verblendung kann vielmehr die Institutionsbildung nur noch im Sinn der Herrschaftsstabilisierung

${ }_{78}^{77}$ Horkheimer/Adorno, Dialektik, 120

${ }^{78}$ Honneth, Kritik, 65

${ }^{79}$ Honneth, Kritik, 65

80 Honneth, Kritik, 65 
gedacht werden. Die Supposition des Antagonismus als in allen Gesellschaften prägend wirksamen schließt die Annahme einer Störung des Herrschaft-RepressionsZusammenhangs durch eine dysfunktionale Institutionalisierung (die etwa aus Subkulturen in die Gesamtgesellschaft überschlägt) per definitionem aus.

Gleichwohl wäre eine ,herrschaftsfreie‘ Institutionalisierung auch außerhalb der Gesellschaftstheorie und ihres Basisparadigmas für die Kritische Theorie kaum zu denken. Schon von der Genealogie wurde ja mit den Begriffsidentifikationen eine Stellung zu allen objektiven Formen bzw. zur Form der Objektivierung überhaupt angesetzt, die durch die Gleichsetzung von Objektivation mit Instrumentalisierung und Herrschaft eine herrschaftsfreie Objektivierung (und Instrumentalisierung) nicht mehr in Blick zu bekommen vermag. Unter dieser Prämisse freilich muß dann auch jede objektive Strukturgestalt schon per se als verdächtig gelten. Sie kann jetzt nur noch als Hinweis auf Unterwerfung und Repression gelesen werden und sie müßte es selbst dann, wenn ein unterwerfendes Subjekt gar nicht erkennbar wäre. Ihre entlastende Bedeutung, wie sie etwa Arnold Gehlen in seiner Institutionstheorie herauspräpariert, tritt nicht mehr vor Augen. Die durch Arbeitsteilung und Institutionalisierung formierte Gesellschaft aber erhält damit bereits tendenziell den Charakter einer totalitären Struktur. Von den Notwendigkeiten der ersten geblendet und in den Netzen der zweiten gefangen nämlich scheint den beherrschten Subjekten kein Entkommen mehr möglich und sind sie in ein System umfassender desubjektivierender Herrschaft gespannt.

Das idealtypische Basisparadigma ist damit ,soziologisierend' umgesetzt und zugleich auf Totalisierung von Herrschaft hin weitergedacht. So scheint nun die gesellschaftliche Realisierung der instrumentellen Vernunft in der Arbeit von den Herrschenden - durch wohl wieder einen ,Willkürakt ${ }^{\star}$ - zur Arbeitsteilung fortgesetzt zu sein. Die Aufgabe der Produktion und die Nutznießung des gesellschaftlichen Reichtums scheinen auf zwei divergente Gruppen aufgeteilt zu werden. Die eine Gruppe der Beherrschten, die selbst gegenüber der Natur instrumentell handelt und sich für den gesellschaftlichen Selbsterhalt arbeitend instrumentalisiert, gerät dadurch zum Gegenstand der Instrumentalisierung durch die andere der Herrschenden. Sie dient nun nicht einfach mehr nur durch ihre Arbeit dem gesamtgesellschaftlichen Ziel, das vom Selbsterhaltungsprinzip vorgegeben ist, sondern den Zielen der Herrscher, die gleichwohl ihr Herrschaftsinteresse hinter dem Gesellschaftsinteresse zu verbergen wissen und ihrer Tätigkeit zudem den Anstrich der Notwendigkeit verleihen. Das instrumentelle Gemächte der Menschen gegenüber der Natur wird so jetzt von einem Gemächte gegenüber einem Großteil der Gesellschaftsmitglieder nochmals überstiegen. Damit scheitert der Versuch, gesellschaftsbildend Souveränität zu erringen, wieder durch den Verlust dieser Souveränität der Meisten an die Wenigen, und die verfallstheoretische Grundstellung erhält sich. Neben das in der Genealogie schon heteronomistisch desubjektivierende ,Subjekt Maschine' tritt in der Gesellschaftstheorie das soziale Teilsubjekt ,Herrscher', und die Aspirationen auf Freiheit und Autonomie sind doppelt verhindert.

Verstärkt scheint diese Verhinderung dann durch die Schaffung von Institutionen, die als Kristallisationen instrumenteller Strategien der Herrschaft gelten und daher einzig als Herrschaftsapparate gehandhabt werden. In ihnen scheinen sich ausschließlich die reüssierenden Verfahren der Manipulation und des Herrschafts- 
erhalts zu ,materialisieren', so daß der Eindruck entsteht, die Institutionen seien exklusive Schöpfungen der herrschenden Schicht. Gleichwohl bedingt schon die Grundstellung der Rationalitätstheorie, die jede Objektivation mit Herrschaft und Repression gleichsetzt, daß auch ohne böswillige Tätigkeit dieser Schicht die objektiven Gestalten der Institutionalisierung nur noch als Instrumente der Unterdrückung bewertet werden können. Selbst wenn ein unterdrückendes Subjekt nicht auffindbar erscheint, untersagt es diese Grundstellung, die Institutionsbildung als Verfestigung von Entlastungsweisen der Subjekte zu deuten, und nötigt sie dazu, aller Objektivität eine desubjektivierende Kraft zuzuschreiben. Die gesellschaftstheoretische Auslegung, die nun die Herrschenden als gewissermaßen die Vertreter und Ausübenden der instrumentellen Vernunft für den repressiven Charakter der Institutionalisierung verantwortlich macht, stellt sich daher lediglich als spezifizierende Umsetzung dieser Grundstellung dar.

Der Gesamtzusammenhang gesellschaftlicher Arbeitsteilung und Institutionalisierung gilt schließlich als tendenziell totalitäre Struktur. So scheint die erste in einer Weise organisiert, die eine Verblendungswirkung aus sich hervortreibt und den desubjektivierenden Herrschaftsgestus darin nicht mehr wahrnehmbar sein läßt. Stattdessen gelingt es der Herrschaft, sich sogar mit dem Schein der Notwendigkeit zu umgeben und sich durch Behauptung spezifischer eigener gesellschaftlicher Aufgaben der Organisation, Politik und Verwaltung zu legitimieren. Das Interesse am Selbsterhalt der Herrschaft scheint dadurch mit dem gesellschaftlich vermittelten Erhaltungsinteresse der Subjekte zu koinzidieren, so da $B$ Herrschaft einen unangreifbaren Status erhält. Die scheinbare Koinzidenz und die hierdurch geleistete Stabilisierung der Herrschaftsstellung aber legen Horkheimer und Adorno als Totalisierung aus, der auf der Seite der Institutionalisierung die ,Durchwirktheit' aller Institutionen mit Herrschaft und Repression korrespondiert. Die Herrschaftsbedeutung der Institutionen erhält damit den Status eines Verstärkers der, schlechten Totalität'.

\section{Kapitalismus als Strukturgestalt instrumenteller Vernunft}

Die Entwicklung der arbeitsteiligen, von delegativ tätiger verwaltender Herrschaft und Institutionalisierung geprägten, tendenziell totalitären Gesellschaft führt dann Horkheimer und Adorno zufolge zum Kapitalismus und vollendet sich in ihm. Auch der Kapitalismus gilt als von der instrumentellen Vernunft determiniert, ja er erscheint geradezu als ihre kristalline Strukturgestalt. Dies zeigt sich in der Kritischen Theorie vor allem in der Rückführung der Tauschabstraktion als dem Grundprinzip der kapitalistischen Warenwirtschaft sowie der jetzt an Bedeutung noch zunehmenden Verwaltung auf die instrumentelle Vernunft. Mit der ersten Rückführung wird dabei das marxistische Paradigma einer gesellschaftsbezogenen Erkenntnistheorie exakt umgedreht und gleichzeitig wieder der rationalitätstheoretische Rückgang hinter die ökonomistische Perspektive wirksam. Auch die totalitäre Tendenz der kapitalistischen Gesellschaft findet sich mit dieser Rückführung argumentativ verankert bzw. näherhin: von der Tendenz zum totalitären Grundzug dieser Gesellschaft erklärt. Dieser Grundzug wird dann in der zweiten Rückführung bestätigt; außerdem wird eine Anwendung des rationalitätstheoretischen Paradigmas auf die moderne Dienstleistungsgesellschaft angedeutet. 
Zunächst nun sehen Horkheimer und Adorno im Tauschprinzip und seiner Abstraktionsleistung die instrumentelle Vernunft verwirklicht. Diese Realisierung beginnt für beide Autoren mit der „Ausbreitung der bürgerlichen Warenwirtschaft“", 81 die dann im Tauschprinzip die spezifische Abstraktionskraft der instrumentellen Vernunft entfaltet. So scheint in eben dieser Wirtschaftsweise der instrumentelle Zugang zur Welt zusammen mit der Herrschaft über Natur und Menschen „zu Gesetz und Organisation verdinglicht", d.h. in eine objektive Handlungsgestalt gebracht. ${ }^{82}$ Diese Handlungsgestalt aber, der Warentausch, gilt, wie Honneth vermerkt, lediglich als ,die geschichtlich entfaltete Handlungsfigur instrumenteller Rationalität", d.h. als deren Umsetzung in einen gesellschaftlichen Handlungszusammenhang. ${ }^{83}$ Über den Warentausch und die Tauschabstraktion ,verlängert' sich gewissermaßen „die im ursprünglichen Prozeß der menschlichen Selbstbehauptung gegenüber der äußeren Natur ausgebildete Rationalität in die Gesellschaft hinein", und der Warentausch erhält dadurch die Rolle eines "sozialen Mediums", das diese Verlängerung ermöglicht und transportiert. ${ }^{84}$ Damit aber ist die Argumentationsfigur einer marxistischen Erkenntnistheorie, wie sie etwa bei Lukács oder SohnRethel vorliegt, gerade umgedreht: Dort werden Instrumentalisierung, ,Verdinglichung und repressive Abstraktifizierung von Natur und Mensch aus den ,Abstraktionszwängen des Warentauschs' hergeleitet und stellt die zugehörige Form von ,verdinglichender' Vernunft derart die Konsequenz einer ökonomischen Handlungsform dar. ${ }^{85}$ Horkheimer und Adorno hingegen setzen die Kausalität exakt umgekehrt an und leiten das Tauschprinzip als Handlungsprinzip der kapitalistischen Gesellschaft aus der instrumentellen Rationalität ab. Der Rückgang hinter die ökonomistische Perspektive Marx, der jenseits der Ökonomie ein noch ursprünglicheres Bewegungsgesetz der menschlichen Geschichte zu entdecken sucht, wirkt sich derart erneut in der Gesellschaftstheorie aus.

Zusammen mit der Herleitung des Tauschprinzips aus der instrumentellen Vernunft ist außerdem auch wieder deren Herrschaftsqualität in die Gesellschaftstheorie übertragen und wird gleichzeitig auf die totalitäre Entwicklung der Gesellschaft abgehoben. So sieht Adorno zunächst in der „Abstraktheit des Tauschwerts“, a priori' die „Herrschaft des Allgemeinen über das Besondere, der Gesellschaft über ihre Zwangsmitglieder" grundgelegt. ${ }^{86}$ Durch die Kristallisation der spezifischen Abstraktion der instrumentellen Vernunft in der Handlungsform des Warentauschs scheint ihm zugleich die herrscherliche Repression alles Nichtinstrumentellen (d.h. in diesem Fall: alles nicht auf die instrumentell-funktionale Qualität der Tauschbarkeit Reduzierbaren) gesellschaftlich festgeschrieben und der Umgang der Gesellschaftsmitglieder miteinander auf Tausch und Abstraktion reduziert. Die gesamte Gesellschaft scheint dann ständig damit beschäftigt zu sein, die Wirklichkeit auf Tausch-

${ }^{81}$ Horkheimer/Adorno, Dialektik, 32

${ }_{83}$ Horkheimer/Adorno, Dialektik, 36

${ }^{83}$ Honneth, Kritik, 49

${ }^{84}$ Honneth, Kritik, 50

85 vgl. etwa: Sohn-Rethel, Alfred, Geistige und körperliche Arbeit, Frankfurt 1970; SohnRethel, Alfred, Warenform und Denkform, Frankfurt 1971; Lukácz, Georg, Geschichte und Klassenbewußtsein, in: ders., Werke 2, Neuwied - Berlin 1968; zur Umkehrung dieser Ansätze bei Horkheimer und Adorno auch: Honneth, Kritik, 49

${ }^{86}$ Adorno, Positivismusstreit, 21 
barkeit hin zu instrumentalisieren und tauschbare Gegenstände, ja Tauschbarkeit schlechthin hervorzubringen. Das eigentlich herrschende ,Subjekt' ist hierbei vorerst die im Warentausch verkörperte instrumentelle Vernunft selbst, und das Argument knüpft derart an das Theorem eines durch kein menschliches Subjekt mehr kontrollierten Running wild des instrumentellen Gemächtes an, wie es in der Aufklärungsund Modernitätskritik aufgestellt wurde. Horkheimer und Adorno sprechen daher schon dort davon, daß die Verselbständigung der instrumentellen Vernunft „,im späten Kapitalismus den Charakter des offenen Wahnsinns" annehme und derart gewissermaßen in seiner Defizienz zu sich selbst komme. ${ }^{87}$ Ähnlich, wie bei Marx das Kapital die wirkliche Herrschaft in der kapitalistischen Gesellschaft ausübt, erhält bei Horkheimer und Adorno so die instrumentelle Vernunft die Rolle des wahren Herrschers. In beiden Fällen ergibt sich das Bild eines selbständigen Prozesses, der sich alle Gesellschaftsmitglieder unterwirft. Aus diesem Bild einer quasi eigendynamischen gesellschaftlichen Selbstrealisierung der instrumentellen Vernunft über den Warentausch und die Tauschabstraktion deduziert Adorno schließlich den Grundzug der kapitalistischen Gesellschaft als totalitäre. So sieht er in dieser Gesellschaft einen „totale(n) Zusammenhang“, der ,die konkrete Gestalt“ habe, „daß alle dem abstrakten Tauschgesetz sich unterwerfen müssen, wenn sie nicht zugrunde gehen wollen, gleichgültig, ob sie subjektiv von einem Profitmotiv geleitet werden oder nicht. “88 Herrschende wie Beherrschte gelten derart als in ein totalitär-instrumentelles Gemächte verstrickt, das von einer zum Selbstläufer (und dabei blind) gewordenen instrumentellen Vernunft, die sich im Tauschprinzip ökonomisch realisiert, angetrieben und dominiert ist.

Wie bei Marx die Gruppe der Kapitalisten von der ,Kapitallogik‘ aber scheint dann bei Adorno die Gruppe der Herrschenden von der im Tauschprinzip gesellschaftlich verkörperten instrumentellen Vernunft dennoch profitieren und an deren Herrschaft teilhaben zu können. So betont Adorno, daß „durch die Reduktion der Menschen auf Agenten und Träger des Warentauschs hindurch" sich auch die „Herrschaft von Menschen über Menschen“ realisiere. ${ }^{89}$ In der Tat nämlich sei die Basis des Tauschs, auf der Herrschende und Beherrschte ökonomisch interagieren, nicht äquivalent eingerichtet, sondern setze sich die Herrschaftsstellung der Herrschenden durch eine Ungleichverteilung des Tauschwerts instrumentalisierter Entitäten wieder durch. Diese Durchsetzung realisiert sich der Theorie zufolge vordringlich über den Tauschwert der Arbeit(skraft), die einzig auf der Seite der Beherrschten angesiedelt wird, und deren Bewertung ein Ausbeutungsverhältnis zu konstituieren scheint: Keineswegs nämlich scheinen die Beherrschten einen adäquaten Gegenwert für ihre Arbeit zu erhalten, sondern der Profit der gesellschaftlichen Arbeit scheint hauptsächlich den Herrschern zuzufließen. Adorno sieht daher „die Behauptung der Äquivalenz des Getauschten, Basis alles Tauschs, (...) von dessen Konsequenz desavouiert“ und durch die Ausdehnung des Tauschprinzips ,auf die lebendige Arbeit von Menschen“ dieses Prinzip „zwangvoll in objektive Ungleichheit, die der Klassen“, ,verkehrt ${ }^{90}$ In der totalitären Struktur der kapitalistischen Waren-

${ }^{87}$ Horkheimer/Adorno, Dialektik, 51

88 Adorno, Positivismusstreit, 21

89 Adorno, Positivismusstreit, 21

${ }^{90}$ Adorno, Positivismusstreit, 34 
gesellschaft bleibt derart die dichotomische Urspaltung erhalten und gelingt es den Herrschenden offenbar, ihre Stellung zu festigen und ihren Profit daraus über die gesteigerte Produktivität des Kapitalismus sogar noch zu erhöhen.

Die totalitäre Struktur wie die gesellschaftliche Umsetzung der instrumentellen Vernunft werden schließlich von Horkheimer und Adorno noch in der Rolle der Verwaltung in den modernen Gesellschaften verankert. Damit scheint zugleich der Überschritt in die ,spätkapitalistischen' Gesellschaften - oder, mit einem soziologischen Begriff: in die Dienstleistungsgesellschaft - getan. Tatsächlich weist eine soziologische Strukturanalyse der modernen Gesellschaften ja nach, da $B$ vor allem im 20. Jahrhundert der Anteil der industrieproduktiven Arbeit am Umfang der gesamtgesellschaftlichen Arbeit überhaupt gegenüber dem Anteil der Dienstleistungs- und Verwaltungsaufgaben numerisch zurückgeht. Nicht zuletzt durch die rasche und effiziente Technisierung wird es hier möglich, die gesellschaftliche Produktivität unter Reduzierung der hierfür nötigen menschlichen Arbeitskraft aufrecht zu erhalten, während gleichzeitig der Umfang der Verwaltungs- und Dienstleistungsaufgaben einen Zuwachs an Arbeitskraft nötig werden läßt. Schichtbezogen eröffnet sich dem soziologischen Blick hierdurch eine Abnahme von Zahl und Bedeutung der werktätigen Arbeiterschaft und eine Zunahme der Mittelschicht. Dieses Phänomen ist es, das in Horkheimers und Adornos Texten unter dem genannten Titel des ,Spätkapitalismus' anklingt, den sie unter anderem als ,Verwaltungsgesellschaft' charakterisieren. Gleichwohl stehen für sie in der Betrachtung dieser Gesellschaft nicht soziologische Phänomene, sondern die Realisation der instrumentellen Vernunft und die Verfestigung des supponierten totalitären Grundzugs im Zentrum.

So scheinen in der modernen Gesellschaft die ,Massen' der Beherrschten ,zu bloBen Objekten des Verwaltungswesen " ", herabgesetzt' zu werden und scheint diese Herabsetzung ,jede Sparte des modernen Lebens bis in Sprache und Wahrnehmung" zu ,präformieren', ${ }^{91}$ d.h. es scheint die Verwaltung eine zentrale Rolle in dieser Gesellschaft zu erhalten und eine vordringliche Prägekraft für alle gesellschaftlichen Bereiche zu entfalten. In diesem mit Bedeutungszuwachs versehenen Verwaltungswesen aber realisiert sich letztlich wieder die Abstraktion der instrumentellen Vernunft, die nun ihre funktionalistischen und instrumentellen ,Zurichtungsleistungen' durch Verwaltungsakte vollzieht. Damit scheint die Verwaltung gerade in der spätkapitalistischen Gesellschaft die strukturelle Repräsentanz dieser Vernunft zu sein. Gleichzeitig kristallisiert sich auch die Herrschaft der Herrschenden in der Verwaltung und scheint die letztgenannte vordringlich deren Interessen zu dienen, d.h. sie scheint nicht Ordnungs- und Organisationsinstrument, sondern Herrschaftsinstrument zu sein. Darauf verweist etwa Honneth, wenn er vor allem in Adornos Texten „die Ausübung sozialer Herrschaft als einen Vorgang“ begriffen sieht, „in dem das Makrosubjekt des zentralisierten Verwaltungsapparats mit den Mitteln direkten und indirekten Zwangs auf die Gesellschaftsmitglieder einwirkt, um sie den Absichten seiner Globalplanung gefügig zu machen. “92 Der ,Verwaltungsapparat' erhält derart den Charakter eines Herrschaftsapparats, dessen Funktion zusammen mit der Planung gesellschaftlicher Aufgaben die Unterwerfung der Gesellschaftsmit-

\footnotetext{
${ }_{91}^{91}$ Horkheimer/Adorno, Dialektik, 38

92 Honneth, Kritik, 109
} 
glieder unter die Ziele der Herrschenden und damit die Ausübung und der Erhalt der Herrschaft selbst ist. Von dieser Bewertung der Verwaltung als Herrschaftsinstrument und der umfassenden Gewichtung ihrer Rolle aus ist dann der Schritt zur Konstatierung eines totalitären Grundzugs des Spätkapitalismus nicht mehr weit. Der verwaltenden Struktur nämlich wird hier eine derart weit ausgreifende Wirkmacht zugesprochen und ihre Prägekraft wird als derart bereichsübergreifend angesetzt, da $B$ sie bis in die Sprachformen einer Gesellschaft hinein zu reichen scheint (vgl. oben) und sich in der Tat niemand mehr der verwaltenden Gewalt entziehen kann. Der Wille der Herrschenden, gepaart mit der repressiven Kraft der instrumentellen Vernunft, scheint sich über die Verwaltungseinrichtungen ungebrochen realisieren zu können. Mit der rationalitätstheoretischen Auslegung sowohl des Tauschprinzips als auch der Verwaltung wird so der kapitalistischen bzw. der spätkapitalistischen Gesellschaft ein totalitärer Grundzug unterstellt, der in der instrumentellen Vernunft verankert ist und gleichzeitig von den Herrschenden für ihre Ziele genützt werden kann.

Das kapitalistische Gesellschaftssystem erscheint so also in Horkheimers und Adornos Theorie als Strukturgestalt der instrumentellen Vernunft und stellt derart lediglich eine Fortführung der Verkörperung der letztgenannten in allen Gesellschaften dar. Gleichwohl kristallisiert sich diese Vernunft nun diesmal besonders effizient im Tauschprinzip als dem Grundprinzip der kapitalistischen Ökonomie selbst und perfektioniert sich der schon in der Institutionalisierung und den verwaltenden Anstrengungen vorhandene repressive Umgriff der Gesellschaftsmitglieder durch die Verwaltungseinrichtungen, welche im Spätkapitalismus an Bedeutung gewinnen. Die Realisierung der instrumentellen Vernunft über das Tauschprinzip läßt dabei erkennen, da $B$ gemäß der Grundfigur der rationalitätstheoretischen Genealogie dieser Vernunfttyp selbst das eigentliche ,Subjekt' der Herrschaft ist, und der Kapitalismus tritt hierbei als blinder, ja blindwütiger Prozeß beständiger Produktion von Tauschwerten ohne zwecksetzende Kontrolle durch die menschlichen Subjekte auf. Als Strukturgestalt der instrumentellen Vernunft nämlich verfällt der Kapitalismus deren eigendynamischer Verselbständigung, und entfaltet er sich demzufolge in ähnlicher Weise zum Selbstzweck wie bei Marx, obschon freilich nun keineswegs mehr das Kapital selbst die treibende Kraft ist. In seiner Eigendynamik und Unkontrolliertheit erhält er zugleich den Charakter einer totalitären Struktur, die sich die gesellschaftlichen Subjekte und den Gesellschaftsprozeß vollständig und ohne einen Ausweg zu lassen unterwirft. Analog zu den Kapitalisten bei Marx jedoch gelingt es dann den Herrschenden, von der Tauschwertproduktion zu profitieren und an der Herrschaft der instrumentellen Vernunft teilzuhaben. Sie setzen sich so gewissermaßen an die Spitze des totalitären Systems und usurpieren, vermittelt durch die instrumentellkapitalistische Einrichtung der Gesellschaft, den Status totalitärer Herrscher. Hierbei erhält schließlich die Verwaltung in den spätkapitalistischen Gesellschaften eine herausragende Rolle, da sie nun das Medium einer unmittelbaren und zugleich ,sachlichen' Umsetzung der Herrschaft in der Gesellschaft vorstellt. Mit ihr scheint jene Form von Institutionalisierung gefunden zu sein, die - endgültig von allen mißliebigen sozialen Einflüssen ferngehalten - es den Herrschenden erlaubt, die für die Herrschaftsausübung und -erhaltung notwendigen Institutionen selbst zu schaffen. 


\section{Faschismus und Stalinismus als Strukturgestalten der instrumentellen Vernunft}

Von dieser Theorie des Kapitalismus als eines totalitären Gesellschaftssytems ist dann der Schritt zu einer analogen Erklärung der faktischen totalitären Gesellschaften, mit denen sich Horkheimer und Adorno in den vierziger Jahren konfrontiert sehen, als ebenfalls aus der Wurzel der instrumentellen Vernunft hervorgehenden Defizienzerscheinungen nicht weit. So scheint mit der „Ausbreitung der bürgerlichen Warenwirtschaft" jene von Horkheimer und Adorno ironisch apostrophierte „Sonne der kalkulierenden Vernunft" aufzugehen, „unter deren eisigen Strahlen die Saat der neuen Barbarei heranreift" ${ }^{43}$ Diese Barbarei gehorcht entsprechend denselben von der instrumentellen Vernunft begründeten Paradigmen und Gesetzlichkeiten wie der Kapitalismus. Aus diesem Grund scheint insbesondere auch die „Verwaltung totalitärer Staaten, die unzeitgemäße Volksteile der Ausrottung zuführt",94 lediglich eine Spielart der ,spätkapitalistischen‘ Verwaltung zu sein. Unter der Prämisse der unausweichlich in allen Gesellschaften der menschlichen Geschichte anwesenden und wirksamen instrumentellen Vernunft treten so die totalitären Systeme des Nationalsozialismus und Stalinismus ebenfalls als Inkarnationen derselben auf. Der Stalinismus erhält dabei den Status einer recht unmittelbaren Realisierung instrumenteller Herrschafts- und Repressionsausübung, da seine Bürokratisierung geradezu mit dem instrumentellen Gemächte identisch zu sein scheint. Der rationalitätstheoretische Rückgang hinter die ökonomische Perspektive Marx macht auf diese Weise das Scheitern der proletarischen Revolution doppelt erklärbar: Zum einen ist hierdurch „der Primat der Ökonomie“ bei Marx aufgekündigt, der „mit historischer Stringenz das glückliche Ende als ihr immanent begründen“ sollte, ${ }^{95}$ und kann die angesichts des Scheiterns dieses glücklichens Endes problematisch gewordene Fortschrittsperspektive verlassen werden. Der faktische Verfall ist nun keine dem geschichtsphilosophischen Denken völlig inkompatible Erscheinung mehr. Zum anderen aber liefert der Ansatz bei der instrumentellen Vernunft als dem eigentlichen und einzigen Bewegungsgesetz der Menschheitsgeschichte - und vor allem ihrer Defizienzen - nun auch das Bewegungsgesetz der revolutionären Gesellschaftsbildung und kann deren Versacken in einer totalitär-bürokratischen Reproduktion der instrumentellen Repression der bürgerlichen Gesellschaften schlüssig begründet werden.

Der Nationalsozialismus hingegen, dem die Kritische Theorie vor allem in den faschismustheoretischen Untersuchungen des Instituts für Sozialforschung breite Aufmerksamkeit gewidmet hat ${ }^{96}$ wird als eine spezifische Spielart des Kapitalismus gehandhabt, mit der sich dieser aus seiner noch von Marx prognostizierten Krisensituation zu erretten sucht. Er gilt zugleich als Versuch, die von der instrumentellen Vernunft und ihrer Rationalisierung der Lebensverhältnisse hervorgerufenen Defizienzen, näherhin die Repression der inneren Natur, durch eine agrarromantische und naturalmystische Wendung im Bereich von Kultur und psychischer Selbstverständigung bei gleichzeitiger Fortführung der strukturellen Rationalisierung abzufangen. ${ }^{97}$

${ }^{93}$ Horkheimer/Adorno, Dialektik, 32

${ }_{94}^{94}$ Horkheimer/Adorno, Dialektik, 185

95 Adorno, Dialektik, 315

96 vgl. hierzu: Horkheimer, Nationalsozialismus

${ }^{97}$ vgl. hierzu auch: Habermas, Theorie 1, 492-495 
So sieht etwa Horkheimer im Nationalsozialismus von der Rationalität „eine Stufe erreicht, auf der sie sich nicht mehr begnügt, einfach die Natur zu unterdrücken“, sondern auf der sie versucht, die Natur auszubeuten, ,indem sie ihrem eigenen System die rebellischen Potentialitäten (...) einverleibt" ${ }^{98}$ Der Nazismus erscheint als Unterfangen einer Perfektionierung der Herrschaft der instrumentellen Rationalität, die jetzt auch noch das von ihr repressiv Ausgegrenzte instrumentell zu verplanen sucht und sich hierdurch in einen umfassenden Umgriff der gesellschaftlichen Subjekte hinein totalisiert. In beiden Fällen aber, sowohl beim Stalinismus als auch beim Nationalsozialismus, erhält die instrumentelle Vernunft wieder den Status der eigentlich bewegenden Kraft und des Kerns dieser Gesellschaftsformen. Der rationalitätstheoretische Ansatz wird so zur geschichtsphilosophischen Fragestellung zurückgeführt, und die Heraufkunft auch der faktischen totalitären Systeme gilt als (letzte) Konsequenz der $a b$ initio in die Instrumentalisierung hinein fehlgehenden Rationalisierung und Subjektivierung.

Gesellschaftstheorie als Totalitarismustheorie: Der Bogen der geschichtsphilosophischen Fragestellung

Damit ist der letzte Bogen von der geschichtsphilosophischen Fragestellung und der Ausarbeitung des Scheiterns aller Aspirationen des Projekts von Aufklärung und Moderne bis zu den Anstoß gebenden Totalitarismen zurück mit einer gesellschaftstheoretischen Reflexion geschlossen. Wie zu Beginn des Kapitels zu sehen war, suchten Horkheimer und Adorno, konfrontiert mit Nationalsozialismus und Stalinismus sowie mit dem als desubjektivierendem Zusammenhang gewerteten Kapitalismus nach der Wurzel für das Versacken des einst so hoffnungsvollen und emphathischen Aufbruchs der europäischen Aufklärung, die Subjektivität, Autonomie und Freiheit in einer vernünftigen Gesellschaftsorganisation versprach. Da diese Vernunft sich in Unvernunft zu verkehren schien, setzten sie ihre Untersuchung rationalitätstheoretisch an und mühten sie sich um eine Rekonstruktion des Verfalls aus der Genese der Vernunft heraus, die sie als instrumentelle spezifizierten. Ziel der Untersuchung war es, in der Konstitution dieser Vernunft selbst die Momente der Verhinderung des emanzipativen Projekts der Moderne aufzufinden, d.h. den instrumentellen Rationalitätstyp als Wurzel allen Übels zu erweisen. Dabei bedingte es der rationalitätstheoretische Ansatz, daß Horkheimer und Adorno in ihrer Rekonstruktion bis an den Beginn der Hominisierung zurückgriffen und dort den Ursprung des Verfalls ausmachten, so daß die ,Selbstverhinderung' der Aufklärung dann lediglich als Konsequenz und Fortführung des längst vor ihr anhebenden Defizienzprozesses erschien. Mit der gesellschaftstheoretischen Applikation der Rationalitätstheorie ist dieser Defizienzprozeß nun auf seine strukturelle Umsetzung und Fixierung hin konkretisiert und der geschichtsphilosophischen Fragestellung eine Antwort gegenübergesetzt: Eben jene instrumentelle Vernunft, die schon , an sich' jede Subjektivierung und Autonomisierung zum Scheitern verurteilte, wird jetzt auch für das Scheitern des gesellschaftlichen Versuchs einer Realisierung von Subjektivität und Autonomie verantwortlich gemacht. Entsprechend der geschichtsphilosophischen Fragestellung

${ }^{98}$ Horkheimer, Nationalsozialismus, 118 
erscheint das Scheitern zugleich als Scheitern in totalitären Systemen und ist die dabei entstehende Gesellschaftstheorie eine Totalitarismustheorie.

In Konnexion mit der Rationalitätstheorie kann diese Gesellschaftstheorie nun wie folgt zusammengefaßt werden: Zunächst gelten dem rationalitätstheoretischen Ansatz gemä $B$ alle menschlichen Gesellschaften als spezifische Strukturgestalten der instrumentellen Vernunft und scheint diese die geschichtsübergreifende Determinante jeder Gesellschaftsbildung überhaupt zu sein. Mit ihr gilt jene Rationalität als gefunden, die in den menschlichen Gesellschaften gewissermaBen das Strukturgesetz all ihrer Formen und Ausprägungen darstellt, und sämtliche gesellschaftlichen Einrichtungen scheinen von dieser Vernunft determiniert, ja geradezu deren je spezifische Kristallisation zu sein. Diese Determination führen Horkheimer und Adorno partiell bereits in der Genealogie sowie dann in der Gesellschaftstheorie konkretisierend aus, indem sie die gesellschaftliche Arbeit, die Institutionen, den Warentausch und die Verwaltung auf die instrumentelle Vernunft zurückführen und damit sowohl die Produktivität als auch die Ökonomie und die institutionell-administrative Organisation der Gesellschaft zu Gestalten dieser Vernunft erklären. In diesen Gestalten entdecken sie jeweils totalitäre Zusammenhänge, die sich die Gesellschaftsmitglieder, oder zumindest deren größten Teil, vollständig unterwerfen. Dabei scheinen die Subjekte zunächst im Arbeitsprozeß nicht anders als unter dem Grundgesetz der kapitalistischen Ökonomie, dem Tauschprinzip, sowie gegenüber den Institutionen und den Verwaltungseinrichtungen zu Objekten des darin anwesenden Gemächtes der instrumentellen Vernunft selbst zu werden und ihren Subjektstatus zu verlieren. Sie geraten derart zu bloßen Funktionen eines von der instrumentellen Vernunft dominierten Gesellschaftszusammenhangs, der sich hierdurch zugleich als totalitärer zu erweisen scheint. So betrachtet ist es zunächst die totale Herrschaft der instrumentellen Vernunft selbst, die den totalitären Charakter des Gesellschaftszusammenhangs begründet, und stellt im Letzten diese Vernunft das eigentlich herrschende Subjekt dar. Das zeigt sich in der Gesellschaftsanalyse besonders deutlich dort, wo der Kapitalismus zum Gegenstand derselben gemacht wird und sich über das Tauschprinzip ein von keinem Subjekt mehr kontrollierter oder zweckgesteuerter Prozeß instrumenteller Tauschwertproduktion realisiert, in dessen Dienst die Gesamtgesellschaft gestellt ist. Gerade der Kapitalismus gilt als herausragende Kristallisation der instrumentellen Vernunft und scheint über seine Ökonomie, aber auch über die Verwaltungseinrichtungen, deren ,schlechte Totalität' $\mathrm{zu}$ verwirklichen. Zum anderen freilich ist die letztlich herrschende Instanz auch in der vorkapitalistischen Arbeit und der Arbeitsteilung (die eine Gruppe instrumentell versklavt) die instrumentelle Vernunft. Schließlich gelten die erklärt totalitären Systeme von Nationalsozialismus und Stalinismus ebenfalls als Inkarnationen der instrumentellen Vernunft, die dort einmal zusammen mit einem Selbstrettungsversuch des Kapitalismus darauf abzielt, sich die repressiv ausgegliederte Naturalität wieder dienstbar zu machen, und ein andermal die antikapitalistische Revolution in eine totale Administration zurückfallen läßt.

Obschon insbesondere im Kapitalismus deutlich wird, daß die instrumentelle Vernunft die eigentliche Herrschaftsstellung innehat, scheint gleichwohl bereits in der Ursituation der Ausbildung der instrumentellen Vernunft, befördert vermutlich durch die ihr unterstellte Herrschaftsmacht, außerdem eine Gruppe der Gesell- 
schaftsmitglieder dem Sog dieser Macht zu verfallen und sie kooperativ über die anderen Gesellschaftsmitglieder auszudehnen, so daB eine ,Zwei-Klassen-Gesellschaft ${ }^{\star}$ von Herrschern und Beherrschten entsteht. Dabei gelingt es den Herrschern anscheinend, an der eigendynamischen, totalitären Herrschaft der instrumentellen Vernunft teilzuhaben und die instrumentelle Einrichtung der Gesellschaft für sich zurechtzumachen und zu nutzen. Sie erheben sich derart - in Nationalsozialismus und Stalinismus offen, im Kapitalismus versteckt - in den Stand totalitärer Herrscher. Die ,schlechte Totalität' vermittelt sich nun einmal über eine verschleiernde scheinbare Interessenkongruenz von Beherrschten und Herrschenden, die neben der gesellschaftlichen Arbeit und ihrer evidenten Unverzichtbarkeit die Herrschaft durch deren administrative Funktion mit dem Schein der Notwendigkeit ausstattet. Zum anderen scheint in den instrumentellen Charakter der Institutionen und Verwaltung auch der gruppenbezogene Herrschaftserhalt eingehen zu können und scheinen beide den Interessen der Herrschenden zu dienen. Schließlich scheint insbesondere der kapitalistisch erwirtschaftete gesellschaftliche Reichtum vorwiegend zu den Herrschenden umgeleitet zu werden. Der aus der instrumentellen Vernunft hervorgehende totalitäre Gesellschaftszusammenhang erweist sich derart als totalitäre Herrschaft einer Gruppe, die stets alle Gesellschaften geprägt hat und die nun neben den erklärten Totalitarismen auch in den kapitalistischen Gesellschaften wirksam ist. Damit aber zeigt sich die Gesellschaftstheorie der Kritischen Theorie durchgängig als Totalitarismustheorie, die nicht nur Nationalsozialismus und Stalinismus im Blick hat, sondern auch die demokratischen, mit dem Kapitalismustheorem gefaßten Gesellschaftssysteme meint. In diesen totalitären Systemen nun totalisiert sich auch das Scheitern der Aspirationen der Menschheit auf Freiheit, Subjektivität und Autonomie zumindest für den größten Teil der Gesellschaftsmitglieder. Durch die Spaltung in zwei Klassen nämlich ist zugleich die Subjektivierung mittels instrumenteller Vernunft auf die Herrschenden beschränkt, während sie den Beherrschten verunmöglicht wird. Der von der instrumentellen Vernunft determinierte, totalitäre Gesellschaftszusammenhang erscheint damit als Unrechtssystem, das die Gewinnung von Autonomie und Subjektivität für die meisten Gesellschaftsmitglieder wieder verhindert, und die Gesellschaftsform kann in Kontrastierung mit dem aufklärerischen Ziel dieser Gewinnung als Verfallsform definiert werden.

Mit diesem Reflexionsgang realisiert die Gesellschaftstheorie ebenso wie die Rationalitätstheorie, bzw. durch deren Übertragung in die Gesellschaftsanalyse, alle drei Prämissen, die aus ihrer geschichtsphilosophischen Fragestellung hervorgingen. Sie konstituiert sich unmittelbar als Verfallstheorie, die, ausgehend von der ,Urspaltung der menschlichen Gesellschaft, die Perpetuierung und Perfektionierung des ab initio gesetzten Unrechts einer Requirierung des Subjektstatus durch eine Gruppe und der damit konkomitanten strukturellen Verhinderung von Subjektivierung und Autonomie für die Meisten skizzieren will. Dieser Verfall ist erneut dialektisch angesetzt, wobei die Dialektik sich jedoch diesmal in zwei Klassen auseinanderlegt. So findet die gesellschaftliche Realisierung der instrumentellen Vernunft, durch die Subjektivität und Autonomie kollektiv erstrebt werden, ja nun offenbar nicht einfach nur in einer allgemein desubjektivierenden und heteronomisierenden Errichtung von Strukturen statt, sondern scheint im Zug dieser Errichtung es einer Gruppe zu gelingen, daraus Profit zu ziehen und den Gesellschaftsprozeß für ihre 
eigene Autonomisierung und Subjektivierung zu nutzen. Der Versuch einer Verwirklichung der emanzipativen Aspirationen scheint sich daher zwar dialektisch gegen eine große Zahl, jedoch nicht gegen alle Gesellschaftsmitglieder zu wenden, und die Dialektik von Aspirationen und Scheitern ist auf zwei kollektive Teilsubjekte verteilt. Freilich ließe sich, ähnlich wie in Marx Theorie die Nötigung des Kapitalisten zur Mehrung des Kapitals, in der Kritischen Theorie der Zwang zum Herrschaftserhalt als heteronomistisches Moment herausheben, das selbst die souveräne Subjektivität der Herrschenden untergräbt. Auch findet sich dieser Gedanke bei Adorno in einigen Texten. Doch hebt die Gesellschaftstheorie vordringlich auf die Nutznießung der Herrschenden $\mathrm{ab}$, so $\mathrm{da} \beta$ die auseinandergelegte Dialektik hier als primärer Strang der Theorie erscheint. Schließlich vollzieht die Gesellschaftstheorie durch die Übertragung der Rationalitätstheorie in ihren Bereich auch gemäß der dritten Prämisse den Rückgang hinter die ökonomistische Perspektive Marx', wenn sie nun die ökonomischen Bewegungsgesetze insbesondere des Kapitalismus als gewissermaßen bereichsspezifische Ausfaltungen der instrumentellen Vernunft begreift. Das Scheitern der proletarischen Revolution und das Überleben des Kapitalismus können dann daraus begründet werden. So bleibt unter der weltgeschichtlichen Vorherrschaft und Dominanz der instrumentellen Vernunft weder dieser Revolution, noch den dem kapitalistischen System Unterworfenen eine nicht-instrumentelle Option offen. Eben diese aber wäre die Voraussetzung für das Gelingen der Ersten und die Sprengung des Zweiten. Unter Fehlen einer solchen Voraussetzung kann dann zum einen die revolutionäre Gesellschaftsbildung nur nach ebenfalls instrumentellen Gesichtspunkten erfolgen und braucht zum anderen die Fähigkeit des Kapitalismus, sich durch eine Differenzierung seiner instrumentellen Selbsteinrichtung sowie durch instrumentelle Flexibilität über Krisensituationen hinweg retten zu können, nicht mehr zu verwundern. Mit ihrer Gesellschaftstheorie schließt die Kritische Theorie so ihren Bogen zurück zur geschichtsphilosophischen Problemstellung und realisiert sie zugleich die aus dieser hervorgegangenen Prämissen. In der instrumentellen Vernunft scheint das Strukturgesetz der Gesellschaftsbildung überhaupt gefunden, das den Verfall der Aspirationen der Moderne in den zeitgenössischen Totalitarismen dialektisch zu erklären scheint und gleichzeitig die ökonomistische Theoriedetermination überwindet.

Gleichwohl bietet die Gesellschaftstheorie Horkheimers und Adornos Probleme. So interpretiert sie, wie zu sehen war, in ihrem Bemühen, Faschismus, Stalinismus und Kapitalismus aus einer Wurzel heraus zu entfalten, und durch ihre Diagnose eines Scheiterns der aufklärerischen Ambitionen in allen drei Gesellschaftsformen auch den Kapitalismus als totalitäres System. Damit aber unterwirft sie die unter diesem Titel behandelten modernen demokratischen Gesellschaften dem Verdikt, Unrechtssysteme zu sein, die dem Großteil der Gesellschaftsmitglieder ihre Subjektivität und Autonomie, d.h. letztlich ihre Menschenwürde, rauben. Aus der in dieser Weise konkretisierten, exklusiv verfallstheoretischen Perspektive vermag die Kritische Theorie Realisierungsformen und -chancen des Projekts der Moderne in den demokratischen Gesellschaften nicht mehr in Blick zu bekommen, und entgehen ihr zwangsläufig auch die Potenzen der Subjekte, ihren Status selbst gegen Gefährdungsstrukturen durchzusetzen. Das, so denke ich, verweist auf eine Engführung der Kritischen Theorie in ihrer rekonstruktiven Theoriebildung, die es grundsätzlich fraglich 
macht, ob es unter ihren Prämissen überhaupt möglich ist, eine demokratische Gesellschaftsstruktur zu denken und einer differenzierten Analyse zu unterziehen, d.h. eine tragfähige Demokratietheorie zu entwickeln.

Ihren Ansatz hat diese Engführung zunächst in der bereits vermerkten problematischen Identifikation von objektivierend-instrumenteller Rationalisierung mit Herrschaft und Repression, wie sie die Rationalitätstheorie vollzieht. Mit ihr wird die grundsätzliche Bewertung aller Funktionalisierung als einer illegitimen Handlungsund Verhaltensweise eingeführt. So bedingt die genannte Identifikation, wie mehrfach zu sehen war, daß jede Form des sachhaften Gebrauchens als Überherrschung und Gewalttat, d.h. aber: stets als Mißbrauch des und der Betroffenen erscheint. Funktionalisierung und Instrumentalisierung, ja selbst schon bloße Objektivationen, sind derart prinzipiell diskriminiert und ihrer Legitimität entkleidet. Die mit Herrschaft und Repression identifizierte instrumentelle Rationalität impliziert in ihrem Begriff bereits per se, da $\beta$ sie mit dem kategorischen Imperativ, jeden Menschen nicht nur als Mittel, sondern zugleich als Zweck an sich selbst zu betrachten, in keiner Weise zusammengehen kann; eben das ,zugleich' nämlich gibt es nun nicht mehr. Jedes sachhafte Gebrauchen und Objektivieren schließt den gleichzeitigen Überschritt in die Achtung der Selbstzwecklichkeit des Anderen aus, da es Unterwerfung bedeutet. Unter dieser Prämisse kann dann eine legitime instrumentell-funktionale Einrichtung von Gesellschaft, d.h. etwa: eine demokratische Ausformung objektiver Strukturen (wie Institutionen) und Regeln (wie Gesetze), nicht mehr gedacht werden. Selbst lebensweltliche Prozesse von Institutionalisierung geraten, obschon möglicherweise gerade von den ,Beherrschten' veranlaßt, unter das Verdikt totalitärdesubjektivierenden Gemächtes. Für eine wahrhaft subjektive gesellschaftliche Existenz bleibt in diesem Theorieentwurf daher nur die Negation alles Strukturellen und Funktionalen. Damit aber löst sich Gesellschaft, auch als demokratische, auf und verfehlt die Gesellschaftstheorie ihren Gegenstand.

Diese Verfehlung wird in der vorliegenden Theorie noch dadurch befördert, daß vor allem Adorno eine exklusiv totalitarismustheoretische Perspektive auf Gesellschaft einnimmt und die funktionale Einrichtung von Gesellschaft als prinzipiell totalitär gehandhabt wird. Nicht nur mit der illegitimen Desubjektivierung, sondern mit dem Totalitarismus schlechthin scheint die strukturelle Umsetzung der instrumentellen Vernunft ja identisch zu sein. Der Grund für diese Identität nun liegt metatheoretisch in einer weiteren Engführung, die daraus hervorgeht, da $B$ die instrumentelle Vernunft die einzige Gestalt von Vernunft in der menschlichen Geschichte darstellen soll und entsprechend als exklusive Determinante der Gesellschaftsbildung erscheint. Diese Prämisse der rationalitätstheoretischen Rekonstruktion der Kritischen Theorie bedingt genau besehen einen totalitären Status der instrumentellen Vernunft in der Theoriebildung selbst, der jede konkretisierende Analyse daran hindert, in den gesellschaftlichen Formationen etwas anderes als Instrumentalität wahrzunehmen. Als einziger Rationalitätstyp determiniert die instrumentelle Vernunft der Theorie zufolge ja jede vernünftige Überlegung, Handlung und Lebensäußerung der Menschen schlechthin und erst recht deren strukturelle Fixierung. Alles Vernunftgemäße ist derart als instrumentelles Gemächte definiert. Realisiert in der instrumentellen Organisation der Gesellschaft und im instrumentellen Denken und Handeln der Menschen aber ist die instrumentelle Rationalität 
damit selbst die Gestalt des Totalen; es gibt keine Vernunft außer ihr, und was ihr nicht instrumentell kompatibel gemacht werden kann, wird reprimiert. Unter diesen Umständen freilich kann eine Abweichung von ihrer Totalität nicht mehr gedacht werden bzw. nur noch als unterworfener Bestand zu Gesicht kommen und fährt sich die Denkbewegung der Kritischen Theorie in einer totalitarismustheoretischen Perspektive fest. Selbst nicht-instrumentale Dysfunktionalitäten erscheinen dann noch als instrumentell-funktional umfangen, und der Reflexionsgang ist auf den Aufweis dieser Umfangenheit fixiert. Die Theoriebildung totalisiert sich derart selbst und kann nur eine, Totalität' rekonstruieren, die zudem durch die oben skizzierte begriffsidentifikative Diskriminierung alles Funktionalen als, schlechte' erscheinen muß.

In der Tat ist dies gerade bei Adorno der Fall. So gesteht er zwar zu, daß die ,kapitalistische Tauschgesellschaft" „ungezählte nicht-kapitalistische Enklaven“" enthalte, und scheint er derart gesellschaftliche Bereiche anzuerkennen, die vom totalen Umgriff freigesetzt sind. ${ }^{99}$ Doch betont er sogleich, da $B$ auch diese letztlich von der Totalität der instrumentell organisierten Gesellschaft eingefangen würden. So scheint die kapitalistische Gesellschaft „zur eigenen Perpetuierung“ eben ,solcher Enklaven" notwendig zu bedürfen und diese entsprechend zu nutzen, ja zu befördern. ${ }^{100}$ Unter der Voraussetzung der im Kapitalismus wirkmächtigen instrumentellen Vernunft scheinen derart selbst die Dissidenzen und Dissonanzen diesem System funktional einverleibt zu werden. Die Exklusivität des Status der instrumentellen Vernunft ist es damit, welche den totalitären Charakter der modernen Gesellschaft determiniert. Gleichzeitig aber ist es auch ihr exklusiver Status in der Theorie Adornos, der dieser die totalitarismustheoretische Interpretation der kapitalistischen Gesellschaft erlaubt und letztlich dieser Theorie selbst ein totalitäres, weil einliniges Gepräge verleiht. Auf diese Einlinigkeit macht etwa auch Honneth aufmerksam, wenn er darauf verweist, da $B$ gerade Adorno „unabhängig vom jeweiligen Ausma $B$ der politischen Freiheiten und dem je spezifischen Grad der sozialen Demokratisierung (...) den spätkapitalistischen Gesellschaften generell die Eigentümlichkeiten eines totalitären Herrschaftssystems" unterlegt. ${ }^{101}$ Ebensowenig wie die von Honneth genannte Demokratisierung kommen in der Theoriebildung Adornos noch Divergenzen in Blick, sondern es werden alle nicht-totalitären Eigenschaften der modernen Gesellschaft interpretativ geschluckt. Die aus der Rationalitätstheorie hergeleitete ,kritische Gesellschaftstheorie‘ vor allem Adornos aber läßt damit erkennen, daB sie die faktisch existenten demokratischen Gesellschaften verfehlt und mögliche gelungene Realisierungsformen des Projekts der Moderne nicht in den Blick zu bekommen vermag.

\subsection{Kultur und Medien im totalitär-instrumentellen System: Das Kulturindustrietheorem der Kritischen Theorie}

In der als totalitär-instrumentelle Struktur interpretierten Gesellschaft erhält schließlich auch die Kulturproduktion - und darin der Kultursachbereich der Me-

\footnotetext{
${ }^{99}$ Adorno, Positivismusstreit, 127

100 Adorno, Positivismusstreit, 127

101 Honneth, Kritik, 109
} 
dien - eine spezifische Verortung, Rolle und Funktion. Kulturproduktion und Medien nämlich werden zum einen als ein über die Ökonomie von der instrumentellen Vernunft an sich gezogener, jeder Autonomie entkleideter Bereich begriffen, der dann zum anderen unter dem Herrschaftsprinzip die Funktion erhält, als Kitt wie als Gleitmittel in der totalitären Gesellschaftsstruktur zu wirken und dieselbe dadurch (mit) aufrecht zu erhalten. In dieser Funktion gerät dieser Bereich zugleich zum Instrument der Herrschenden, das diese manipulativ einsetzen. Beide, Kulturproduktion generell wie auch der Kultursachbereich der Medien im besonderen, werden dabei von der Kritischen Theorie unter dem Begriff der ,Kulturindustrie ${ }^{`}$ zusammengefaßt und abgehandelt. Diesem Begriff eignet nicht zuletzt deshalb wieder eine gewisse, besonders für Adorno typische Unschärfe, die alle seine Begriffe dort aufweisen, wo sie von der philosophischen Spekulation zur konkreten Gesellschafts- oder Sozialanalyse übergehen und empirische bzw. kontingent-soziologische Tatbestände zu fassen beanspruchen. Doch läßt sich aus der Häufigkeit der zur Beschreibung und Illustration der Strukturlogik der Kulturindustrie herangezogenen Phänomene entnehmen, daB im Zentrum des Theorems die Medien stehen und darin wiederum besonders der Film eine herausragende Rolle zugemessen bekommt.

So reicht zwar die Bandbreite der kulturindustriellen Phänomene von der Baukunst über das Design von Gebrauchsgegenständen bis zur Gebrauchskultur und den Medien. Doch steigert sich in dieser Reihe die Häufigkeit der zum Zweck einer phänomenal-exemplarischen Begründung des Theorems herangezogenen Erscheinungsbereiche: Nur zu Beginn des Kulturindustriekapitels in der „Dialektik der Aufklärung" erscheint die Baukunst, und nur an wenigen Stellen der Texte zur Kulturindustrie wird das Design zur Exemplifizierung des Theorems herangezogen. Häufiger schon ist auf die Gebrauchskultur abgehoben, wie sie etwa in der modernen Musik (für Adorno besonders im Jazz) vorliegt, wobei hier dann bereits meist gleichzeitig die mediale Vermittlung dieser Kulturform mit im Blick steht. Zentraler Gegenstandsbereich des Kulturindustrietheorems scheint mir denn auch die letztgenannte, und mit ihr der Bereich der Medien selbst, zu sein. In ihm ist zugleich die Konzentration des Theorems auf Ästhetik durchbrochen und die mediale Information, ja die gesellschaftlich-diskursive Rolle der Kulturproduktion mit in die Reflexion einbezogen. Das Kulturindustrietheorem tritt daher in den meisten diesbezüglichen Äußerungen der Kritischen Theorie als Medientheorie auf. Unter den Medien wiederum stehen vordringlich Rundfunk, Comics, Film und (später) Fernsehen im Blick, unter denen der Film häufig eine paradigmatische Stellung eingeräumt bekommt. So fällt auf, daß gerade das Kulturindustriekapitel in der „Dialektik der Aufklärung“, wenn es Beispiele aus dem medialen Phänomenbereich bringen will, recht oft auf den Film rekurriert und die Zahl der filmbezogenen Beispiele die der aus den Bereichen der anderen Medien gewählten überwiegt. ${ }^{102}$ Auch findet sich bei Adorno in späteren Texten, trotz seiner musikalischen Neigungen und Prädilektionen (bzw. Antipathien), oftmals der Film bemüht, wenn der Charakter der Kulturindustrie phänomenal skizziert werden soll. ${ }^{103}$

102 Die Einleitung nennt deswegen auch „Film und Radio“ als die ,maßgeblichen Instanzen“ der Kulturindustrie, d.h. als jene Medien, welche Horkheimer und Adorno vordringlich im Blick hatten, als sie ihr Theorem entwarfen. (vgl. Horkheimer/Adorno, Dialektik, 5)

${ }^{103}$ vgl. etwa: Adorno, Ästhetik, 73, 322, 336, 440, 461 
Gestalt, Rolle und Funktion der Kulturindustrie nun werden aus zwei Determinanten hergeleitet, die den beiden, Theorieschienen' der Kritischen Theorie: der Rationalitäts- und der Gesellschaftstheorie, entsprechen und das Kulturindustrietheorem in deren Gesamtkontext eingliedern. So soll zunächst der Begriff der Kulturindustrie auf die ökonomische Determination der Kultur- und Medienproduktion verweisen und schließt er das Kulturindustrietheorem mittelbar an die Rationalitätstheorie an, die als Letztbezug und eigentliche Quelle der Ökonomie ja die instrumentelle Vernunft eingeführt hat. Als zweite Determinante der Kulturindustrie gilt dann der gesellschaftlich-totalitäre Herrschaftszusammenhang, wie er von der Gesellschaftstheorie entworfen worden ist. Beide Determinationen bestimmen die Kulturindustrie in ihrer Gestalt und ihrer Funktion: Zum einen nämlich scheint die Produktion der Kulturindustrie von Profitabilität und Konvertibilität, also den beiden Grundprinzipien der kapitalistischen Warenwirtschaft, geleitet zu sein. Sie ist damit eine gesellschaftliche Institution, in der sich die Herrschaft der instrumentellen Vernunft ökonomisch vermittelt realisiert und diese Vernunft alle Kulturprodukte der Zweckbestimmung durch die genannten Prinzipien instrumentell unterwirft. Kultur und Medien sind damit ihrer Autonomie entkleidet. In ihrer weiteren Auslegung bedingen die beiden Prinzipien für Adorno und Horkheimer eine Fixierung von Produktion und Publikum auf standardisierte Gehalte, die gleichermaßen eine Uniformierung des Rezeptionsangebots und der Rezipienten zum Ziel und zur Folge hat. Das kulturelle Bewußtsein wird dabei einer Nivellierung unterworfen, die es entleert.

Zum anderen gilt die kulturindustrielle Produktion als unter das Prinzip der Herrschaftswahrung gestellt, das sich primär über die Wahrung des Status quo auslegt und die Nivellierung des kulturellen durch eine repressive Zurichtung des gesellschaftlichen Bewußtseins ergänzt. Die Gruppe der Herrschenden scheint hierbei wieder an der Herrschaft der instrumentellen Vernunft teilnehmen zu können und sich die Kulturindustrie für ihre Zwecke zunutze zu machen. Dabei entwerfen die Herrschenden eine Reihe von Strategien, die dem Erhalt des Status quo und ihrer Stellung dienen sollen und durch welche die Produktion der Kulturindustrie die Funktion eines gesellschaftlich wirksamen Kitts und Gleitmittels erhält, das Friktionen verhindert, das Bestehende affirmiert und den totalitären Zusammenhang aufrecht erhält. Kulturindustrie gerät so zum bewußt von den Herrschenden eingesetzten Instrument der Manipulation, und das dichotomische Schema der Gesellschaftstheorie setzt sich medientheoretisch um. Verhindert und unterlaufen scheint durch die beiden Determinationen der Kulturindustrie jeweils wieder die Subjektivierung des Großteils der Gesellschaftsmitglieder zugunsten einer Gruppe und eines ökonomisch-instrumentellen Prozesses. Den Subjekten scheint gleichwohl kaum eine Potenz zur Subjektivierung zugestanden zu werden, sondern sie gelten als willfährige Objekte des kulturindustriell vorgenommenen Social engineering. Mit der Vorstellung einer standardisierenden und manipulativen Wirkung der Kulturindustrie sowie der Unterstellung einer ,Willfährigkeit' der Subjekte läßt das Theorem schließlich außerdem einen Bezug zur ,konservativen'Medienkritik erkennen.

\section{Konvertibilität und Profitabilität als Determinanten der Kulturindustrie}

Zunächst also gilt die Kulturindustrie in ihrer Wesensstruktur als ökonomisch determiniert. Schon Horkheimer formuliert dies, wenn er in seinem Aufsatz über Mas- 
senkultur deren Prägung durch die Gesetze ökonomischer Notwendigkeit, d.h. vor allem durch Tauschbarkeit und Profitabilität, beklagt. ${ }^{104}$ Damit sind zugleich die Prinzipien des später ausgearbeiteten Arguments angesetzt. Aus ihnen nämlich leitet sich dessen Grundfigur her: Der Zwang, Kulturprodukte unter dem Profitprinzip hervorzubringen, die sich auf dem Markt rasch umsetzen lassen, führt der Kritischen Theorie zufolge zu einer Standardisienung dieser Produkte und ihrer Abnehmer. Ziel dieser doppelten Standardisierung ist es, auf der Produktseite eine Minimierung des Aufwands zu ihrer Herstellung sowie eine Maximierung ihrer Rezipierbarkeit zu erreichen und auf der Rezeptionsseite eine stabile und kalkulable Nachfrage zu etablieren. Im Prozeß der Standardisierung bedingt zunächst die Nötigung, um des Profits willen eine möglichst breit gestreute, d.h. soziologisch gewendet: eine möglichst schichtunabhängige, Rezipierbarkeit zu garantieren, daß sich die Tauschabstraktion auf die Produkte ausdehnt und diese vordringlich unter dem Aspekt der Tauschbarkeit hergestellt werden. Es entstehen serialisierte und konvertible ,Kulturwaren', die dadurch weitgehend, entspezifiziert' (D. Prokop), d.h. ihrer Besonderheit entkleidet sind und die keine Neuheit, keine rahmensprengende Innovation und Veränderung zulassen. Damit scheint die Kultur in ihrem kreativen und innovativen Wesen zuinnerst getroffen und versehrt sowie ihrer Autonomie völlig beraubt zu werden. An die Stelle einer ,inneren Logik‘ von Kulturprodukten tritt die ökonomische Determination, die zugleich die Möglichkeit dieser inneren Logik zerstört. Als herausragender Repräsentant der kulturindustriellen Waren und ihrer korrumpierten Gestalt gilt der Film, an dem als Medium von Meinungen, Überzeugungen, Normen und Theorien sowie als Instanz einer inhaltlichen gesellschaftlichen Kommunikation gleichzeitig die Störung dieser Kommunikation durch Standardisierung auf der Produktseite deutlich werden soll. Auf der Rezipientenseite scheint die zunehmende Standardisierung der Kulturprodukte eine Nivellierung der Erwartungshaltung der Konsumenten zur Folge zu haben, die allmählich deren Steuerung ermöglicht und wodurch Produktplanung und Nachfrageorganisation fast identisch werden. Es ergibt sich derart ein Ineinander von ökonomischer Manipulation und ,freiwilliger ' Entsprechung, das bereits zur Desubjektivierung der Rezipienten führt.

Dieser Gedankengang, der ansatzhaft schon in Horkheimers Aufsatz spürbar ist, wird in der „Dialektik der Aufklärung“ und bei Adorno mit einer rationalitätstheoretischen Rückbindung ausgearbeitet; das Profit- wie Tauschprinzip gelten dabei wieder als Auslegungen der instrumentellen Vernunft. Eigentliches Bewegungsprinzip der strukturellen Einrichtung der Kulturindustrie ist daher diese Vernunft selbst, deren über die Ökonomie realisierter Eigendynamik sich der Zwang zur Standardisierung verdankt. Zunächst aber werden die ökonomischen Prinzipien und ihre determinative (bzw. korrumptive) Bedeutung eingeführt. So hebt Adorno darauf ab, daB „die Kulturwaren der Industrie“ sich „nach dem Prinzip ihrer Verwertung, nicht nach dem eigenen Gehalt und seiner stimmigen Gestaltung" richteten. ${ }^{105}$ Die Wesenszüge einer autonomen kulturellen Produktion sind derart a priori von der Kulturindustrie ausgeschlossen, und diese Produktion ist auf den ökonomischen Zweck hin instru-

${ }^{104}$ Horkheimer, Kunst, 28-46, 43. Der Aufsatz erschien unter dem Titel: „Art and Mass Culture“ zuerst 1941 (vgl. Horkheimer, Max, Art and Mass Culture, in: Zeitschrift für Sozialforschung 1941/9, 290-304).

105 Adorno, Kulturindustrie, $60-70,61$ 
mentell verplant. Statt einer ,Logik des Werks` zu gehorchen, überträgt die Kulturindustrie „das Profitmotiv blank auf die geistigen Gebilde“ und unterwirft sie ihre Produktion dem „Primat der ihrerseits in ihren typischsten Produkten genau durchgerechneten Wirkung“ ${ }^{106}$ Als Ziel der Kulturproduktion ist so die Erarbeitung eines finanziellen Gewinns dingfest gemacht, und Profitabilität zeigt sich als ihr erstes Prinzip. An dessen Seite tritt dann sogleich die Tauschbarkeit oder Konvertibilität, die um des Profits willen eine möglichst breit gestreute Rezipierbarkeit der Kulturprodukte fordert. Dies hat zur Folge, daß „die Details“ eines Produkts „fungibel“ für eine möglichst große Zielgruppe gemacht werden und das Produkt selbst zu einer auf den Durchschnitt hin nivellierten ,Kollektiverscheinung gerät. ${ }^{107}$ Unter beiden Prämissen wird dann „das Unerprobte als Risiko“ ausgeschieden und müht sich die Produktion um Herstellung einer „Immergleichheit“, d.h. um Fixierung des einmal erreichten ökonomischen Erfolgs durch Perpetuierung einer ,Produktformel ${ }^{108}$ Die Kulturindustrie scheint deshalb „Typen von Schlagern, Stars, Seifenopern" zu schaffen und diese „zyklisch als starre Invarianten“ ,durchzuhalten“ ${ }^{109}$ Auf der Produktseite führen die beiden ökonomischen Prinzipien so zu einer „Standardisierung der Sache selbst" und erweist sich das Wesen der Kulturproduktion als Nivellierung und Statifizierung. ${ }^{110}$ Sowohl Originalität und Authentizität als auch jede wirkliche Innovation und Entwicklung scheinen der Kulturindustrie fremd, ja geradezu konträr zu sein. Sie bringt unter der ökonomischen Determination anscheinend ausschließlich Produkte hervor, die sich durch Austauschbarkeit, Oberflächlichkeit und stumpfsinnige Wiederholung auszeichnen und derart die Kultur in ihrem Wesen korrumpieren.

Diese Korruption durch nivellistische Standardisierung gilt dann als am Film, dem „zentralen Sektor der Kulturindustrie“"111, besonders deutlich erkennbar. Der Film nämlich scheint sowohl Genres als ,Spartentypen' wie auch innerhalb dieser feste Handlungsschemata auszubilden und derart jeder kreativen Weiterentwicklung entgegengesetzt zu sein. In ihm scheint sich die Schablonisierung, wie sie „etwa die jedem Kinobesucher geläufige der Western" enthält, ${ }^{112}$ unübersehbar festzusetzen und für eine dumpfe, mechanistische Repetition identischer Sujets zu sorgen. Dabei treffen beim Film die Typisierung und ihre ,Oberflächlichkeit‘ neben der formalästhetischen Seite kultureller Produkte zugleich auch deren Gehalte, d.h. vor allem: kulturell vermittelte Welt- und Lebensinterpretationen. Identität und Nivellierung der standardisierten Filme scheinen sich so über die Zerstörung des formalästhetischen Niveaus der Kultur hinaus auch noch negativ auf die diskursive Bedeutung der Kulturproduktion auszuwirken. Die in den kulturellen Erzeugnissen gespeicherten gesellschaftlichen Interpretamente nämlich, in denen sich eine Kultur epochentypisch, aber auch tagesaktuell auszudrücken vermag, werden von der Standardisierung gewissermaßen einer ,Gleichschaltung unterworfen, und der in der Kulturproduktion geführte gesellschaftliche Diskurs ist unterbrochen. Es findet keine kulturproduktiv

106 Adorno, Kulturindustrie, 61

107 Adorno/Horkheimer, Dialektik, 112

108 Adorno/Horkheimer, Dialektik, 120

109 Adorno/Horkheimer, Dialektik, 112

110 Adorno, Kulturindustrie, 62

111 Adorno, Kulturindustrie, 63

112 Adorno, Kulturindustrie, 62 
vermittelte Auseinandersetzung mehr statt, sondern nur noch eine Wiederholung identischer Muster. Damit scheint die ökonomische Determination der Kulturindustrie neben der Zerstörung der Kultur schlechthin auch eine Verhinderung gesellschaftlichen Diskurses zur Folge zu haben.

Am Werk aber ist in dieser ökonomischen Determination die instrumentelle Vernunft, "die alles nach Bedeutung und Wirkung sich auszuweisen zwingt" und eine ihr konträre oder auch nur inkompatible Dysfunktionalität nicht duldet. ${ }^{13}$ Sie ist es, die für die genannte ,Durchrechnung der Wirkung unter dem Profitprinzip sorgt und eine nivellistische Instrumentalisierung der Kultur auf ihren ökonomischen Erfolg hin bedingt. Dabei zeigen sich die Aktivität der instrumentellen Vernunft und ihr Umgriff wieder als totalitär: So scheint das ökonomisch umgesetzte, instrumentelle Gemächte „das Sinnlose drunten so radikal verschwinden" zu lassen „wie oben den Sinn der Kunstwerke". ${ }^{114}$ Nicht nur die gefährliche Dysfunktionalität der emphatischen Kunst (vgl. dazu auch 5.6.) also wird von der instrumentell eingerichteten Kulturindustrie verdrängt, sondern auch das schlicht Unsinnige, das sich nicht instrumentell verwerten läßt. Unter dem Diktum der instrumentellen Vernunft scheint so nichts zu bleiben, was nicht instrumentell genutzt und vereinnahmt werden kann. Jedem kulturellen Bestand, der sich ihr nicht fügt - selbst wenn er dem Gesamtsystem nicht eigentlich schadet -, wird das Existenzrecht bestritten, und was sich fügsam vereinnahmen läßt, wird integriert. Die Kulturindustrie aber zeigt sich hierdurch auf der Produktseite als Realisierungsform der instrumentellen Vernunft im kulturellen Sektor, und die instrumentelle Vernunft erweist sich zunächst als die eigentlich bewegende Kraft dieser Industrie. Entsprechend treten die „Verfügenden“ derselben vorerst noch kaum als „Machthaber“, sondern als „Vollzugsorgane“ der eigendynamisch sich realisierenden instrumentellen Vernunft auf. ${ }^{115}$ Mit ihrem nichts Unverwertbares duldenden Umgriff läßt die Kulturindustrie außerdem einen totalitären Zug erkennen, oder genauer: es setzt sich die ,schlechte Totalität' der instrumentellen Vernunft auch in ihr um.

Auf der Rezipientenseite hat die standardisierte Kulturproduktion dann eine zunehmende Standardisierung auch der Rezipienten zur Folge, die mittels Marktforschung, Produktplanung und allmählicher ,Umerziehung der Produktion profitabel gefügig gemacht werden sollen. Diese Gefügigmachung scheint in einen anhaltenden Betrug der Rezipienten zu münden, der die kulturellen Bedürfnisse ständig durch Ablenkung und Scheinbefriedigungen unterläuft und in eine Auflösung von Kreativität und Spontaneität als primären Merkmalen von Subjektivität führt. Die Kulturindustrie hat so offenbar eine doppelte Desubjektivierung zur Konsequenz, indem sie die Subjekte einmal heteronomistisch der Manipulation unterwirft und ihnen ein andermal allmählich ihre Wesenseigenschaften raubt. - So scheint zunächst die Differenzierung verschiedener Standardprodukte voneinander wie „die von A- und BFilmen oder von Geschichten in Magazinen verschiedener Preislagen" primär der „Klassifikation, Organisation und Erfassung der Konsumenten" zu dienen und allmählich in deren aktive ,Zurichtung auf die Produktion hin zu münden. ${ }^{116}$ Sorgt

${ }_{113}^{113}$ Adorno/Horkheimer, Dialektik, 128

114 Adorno/Horkheimer, Dialektik, 128

115 Adorno, Kulturindustrie, 61

116 Adorno/Horkheimer, Dialektik, 110 
nämlich die zumindest empirisch noch an der "Basis‘ orientierte marktforschende Klassifikation dafür, daß „für alle (...) etwas vorgesehen" ist, so werden im weiteren Gang dieser ,Vorsehung ",die Unterschiede (...) eingeschliffen“ und wird die Rezipientenschaft schließlich auf die Entsprechung zur Produktion, getrimmt ${ }^{117}$ Die marginale Einflußnahme der Rezipienten und ihrer Interessen und Bedürfnisse scheint so sukzessive durch eine ,feininstrumentelle' wechselseitige Anpassung von Produktion und Rezeption zurückgedrängt zu werden, die schließlich auch die Wechselseitigkeit aufzukündigen vermag. Ausgehend von der Marktforschung nämlich scheint die Kulturindustrie die Bedürfnisse der Rezipienten weniger als normative Vorgabe für ihre Produktion zu begreifen, sondern mehr als Material, das sie durch ihre Produkte bearbeiten und der Produktion gemäß umformen will. Die erforschten kulturellen Bedürfnisse erhalten so den Status eines Rohstoffs, den die Industrie profitabel zu nützen weiß, und die Rezipientenschaft gilt dabei als zunehmend in den instrumentellen Umgriff gezwungen. Sie scheint zum Objekt der Manipulation der Kulturindustrie gemacht zu werden. Damit aber sind die Subjekte heteronomistisch verplant und in den totalitären Zusammenhang der instrumentellen Kulturorganisation eingegliedert; ihr Subjektstatus wird ihnen geraubt.

Flankiert und befördert scheint die manipulative Desubjektivierung außerdem durch Strategien zur Sicherung der doppelten Standardisierung. Um dieselbe aufrechterhalten zu können nämlich, scheint zum einen die Kulturindustrie den Rezipienten in eine hektische Betriebsamkeit zu verwickeln, die ihn nicht merken läßt, daß er mit immer gleichen Waren beliefert und um sein Bedürfnis nach Wechsel und Entwicklung betrogen wird. Zum anderen scheint jedoch der Rezipient selbst zunehmend dieses Bedürfnisses verlustig zu gehen und mit der seriellen Repetition zufrieden zu sein. So spricht die Kulturindustrie Horkheimer und Adorno zufolge in verschleiernder Absicht ständig „von idea, novelty und surprise“ und müht sie sich um eine Gestalt ihrer Standardprodukte, die ,zugleich allvertraut wäre und nie dagewesen“ ${ }^{118}$ Dieser Mischung aus breiter Rezipierbarkeit, Repetition und scheinbarer Neuheit dient eine Form der Standardisierung, die hinter „Tempo und Dynamik“ verborgen wird und derart scheinbar "nichts (...) beim alten bleiben“, sondern alles „unablässig laufen, in Bewegung sein" läßt. ${ }^{119}$ Die Bewegung und der Wandel freilich sind hierbei formal, bleiben an der Oberfläche und akzidentell. Darunter repetiert sich die ,Produktformel', und „das unablässig Neue“, das die Kulturindustrie „offeriert, bleibt die Umkleidung eines Immergleichen“ ${ }^{120}$ Allenthalben scheint so „die Abwechslung ein Skelett" zu ,verhüllen', ,,an dem so wenig sich änderte wie am Profitmotiv selber, seit es die Vorherrschaft über die Kultur gewann “. ${ }^{121}$ Jede Innovation in der Kulturindustrie gilt so als scheinbare, die sich lediglich auf der Ebene der ,Verpackung äußert und dazu dient, einen identischen Inhalt zu verdecken. Der Wechsel der Verpackungen aber und die Geschwindigkeit dieses Wechsels scheinen dazu zu dienen, das Publikum arglistig zu täuschen. Im Hintergrund wirksam ist nach wie vor das Profitprinzip, das anscheinend nicht auf wirklich neue Produkte zu set-

${ }_{117}^{117}$ Adorno/Horkheimer, Dialektik, 110

${ }_{118}$ Adorno/Horkheimer, Dialektik, 120

119 Adorno/Horkheimer, Dialektik, 120

${ }_{120}^{120}$ Adorno, Kulturindustrie, 62

${ }^{121}$ Adorno, Kulturindustrie, 62 
zen im Stande ist und daher die alte profitable Produktformel auf unmerkliche Weise zu wiederholen trachtet.

Das aber scheint dann zur Folge zu haben, daß der Rezipient sein Bedürfnis nach Wechsel verliert und sein kulturelles Verlangen sich in eines nach Repetition transformiert. Durch den nachhaltigen Einfluß immergleicher Kulturwaren, deren Gleichheit gut unter einer wechselhaften Oberfläche verborgen ist, scheint das Publikum gewissermaßen das Wünschen (nach Neuem) zu verlernen und sich schließlich mit der Repetition zufriedenzugeben bzw. diese Repetition gar zum Gegenstand ihrer dadurch als korrumpiert geltenden kulturellen Wunschproduktion zu machen. Der Wechsel der Verpackung darf nun durchschaut werden, da die Rezipientenschaft erfolgreich domestiziert ist. So ist zwar unter diesen Bedingungen etwa einem Film „durchweg (...) sogleich anzusehen, wie er ausgeht", doch ist der Rezipient damit einverstanden „und fühlt sich glücklich, wenn es wirklich so eintrifft" ${ }^{122}$ Dieses transformierte Bedürfnis nach Bekanntem und Bestätigung aber gilt Horkheimer und Adorno als äußerst verderblich. In ihm nämlich scheint sich „die Verkümmerung der Vorstellungskraft und Spontaneität des Kulturkonsumenten“ zu äußern und zusammen mit der innovativen Wunschproduktion auch der Verfall der Subjektivität selbst Gestalt gewonnen zu haben. ${ }^{123}$ Der Rezipient wird demnach nicht nur durch eine scheinbare, formal und oberflächlich bleibende Vielfalt und Innovation getäuscht und um eine, wirkliche', nämlich inhaltliche Entwicklung der Kulturprodukte betrogen, sondern zugleich in ein desubjektivierendes Gemächte verstrickt, das ihm Spontaneität und Imagination zunehmend raubt. Er gilt derart als doppelt desubjektiviertes Wesen, das einmal heteronomistisch in den Umgriff der Manipulation genommen und einem Zwang unterworfen ist sowie zum anderen von innen her in seinem Wesen aufgelöst wird.

Die Abhängigkeit der Struktur der Kulturindustrie von den beiden ökonomischen Prinzipien ist damit argumentativ eingeführt und demonstriert. Gleichzeitig findet damit eine mittelbare Rückbindung an die Rationalitätstheorie statt, die als Bewegungsprinzip der Ökonomie die instrumentelle Vernunft dingfest gemacht hat. Zunächst tritt hierbei die Kulturindustrie als eine strukturelle Einrichtung auf, die unter den beiden Prinzipien serialisierte und nivellistische Gehalte hervorbringt, von denen sie sich breite Rezipierbarkeit und geringen Herstellungsaufwand verspricht. Mit dem ökonomischen Umgriff scheint sie die Kulturproduktion jeder Autonomie zu berauben und einer Oberflächlichkeit und Einheitlichkeit zu unterwerfen, die zugleich die Kultur in ihrem Wesen zerstören. Als Wesenszüge der Kultur nämlich treten im Kulturindustrietheorem Innovation und Kreativität auf, die sich, ähnlich der analog bestimmten Kunst (vgl. 5.6.), von jeder Stillstellung, Statifizierung und Perpetuierung des Hergebrachten unterscheiden. Die Kulturindustrie jedoch hebt gerade auf eine solche repetitive Statifizierung einmal erfolgreicher ,Formeln' ab und untergräbt damit die Authentizität der Kultur. Gleichzeitig korrumpiert sie mit ihren serialisierten, ewig-gleichen Gehalten die diskursive, innergesellschaftliche Auseinandersetzung, wie sie in der Kulturproduktion ursprünglich anwesend zu sein scheint. Statt daß durch Produktion wechselnder kultureller Gehalte gesellschaftlich

${ }^{122}$ Adorno/Horkheimer, Dialektik, 112

${ }^{123}$ Adorno/Horkheimer, Dialektik, 123 
über Welt- und Lebensinterpretamente verhandelt werden könnte, scheinen diese Gehalte festgeschrieben und unter Einwirkung des Tauschprinzips zudem ,veroberflächlicht' zu sein. Weiter scheint die Kulturindustrie zum Zweck der Sicherung der Profitabilität der beiden letztgenannten ökonomischen Determinanten auf einen manipulativen Umgriff der Konsumenten abzustellen. Dieser Umgriff scheint einmal in Form eines von der Marktforschung eingeleiteten und in Nachfrageplanung überführten Prozesses zunehmenden Zwangs, von oben' gegenüber den Bedürfnissen der Rezipienten auf. Zum anderen gilt er als auch über allmähliche Gewöhnung und Verlust spontan-kreativer, kultureller Wunschbildungen ,von unten vermittelt. Beide, die manipulativen ,Zurichtungen“ und die defiziente Gewöhnung, scheinen sich dann verderblich zu entsprechen und eine Desubjektivierung der Rezipientenschaft zur Folge zu haben. Die Kulturindustrie korrumpiert so nicht nur die Kultur, sondern tritt auch als Feind jeder Subjektivierung und der darin beschlossenen Autonomie und Selbstbestimmung auf.

Über die beiden Prinzipien wird der gesamte Prozeß schließlich wieder auf die instrumentelle Vernunft rückbezogen, so daß die Kulturindustrie letztlich als Erscheinungsform dieser Vernunft gelten muß und sich ihr desubjektivierender Charakter der letztgenannten verdankt. Sowohl die Standardisierung der Kulturprodukte als auch jene der Rezipienten und ihrer Bedürfnisse nämlich leiten sich vorerst exklusiv aus den beiden Prinzipien und der in ihnen inkarnierten instrumentellen Vernunft, nicht jedoch aus einer verfügenden Entscheidung einer herrschenden Schicht etwa von ,Kapitalisten' her. Das Theorem führt damit die Kulturindustrie entsprechend dem rationalitätstheoretischen Rückgang hinter die marxistische Ökonomie als Ausformung und Folgeerscheinung der instrumentellen Einrichtung der Gesellschaft ein und bindet sich derart an die Figur eines eigendynamisch wirksamen Prozesses der Selbstrealisierung der instrumentellen Vernunft an, wie sie schon im Kapitalismustheorem deutlich war. Dem konveniert weiter, daß der Kulturindustrie in ihrer ökonomischen Instrumentalisierung von Kultur und Subjekten ein totalitärer Charakter zugesprochen wird. Mit dieser Figur der ökonomisch vermittelten, eigendynamischtotalitären Herrschaft der instrumentellen Vernunft in der kulturindustriellen Produktion ist das Kulturindustrietheorem so kohärent zum Kapitalismustheorem ausgelegt und mittelbar an die Rationalitätstheorie angeschlossen.

Die vorliegende Struktur der ökonomischen Einführung des Kulturindustrietheorems nun scheint mir einige Probleme mit sich zu führen. So setzt sie in ihrer argumentativen Logik neben einer schrankenlosen Manipulation sowohl eine entwicklungslose Ökonomie als auch eine statifizierte Gesellschaft und letztlich unkreative, ebenfalls entwicklungslose Subjekte voraus. Weder scheint es dem Theorem zufolge einen flexiblen, dynamischen Markt noch einen gesellschaftlichen Prozeß zu geben. Die Marktsituation gilt als definiert und innovationsfeindlich, die Gesellschaft als festgefügte Struktur, in der keine Veränderung erlaubt ist. Den Gesellschaftsmitgliedern wiederum scheint kein Antriebsüberschuß eigen zu sein oder er scheint ihnen zumindest nachhaltig ausgetrieben werden zu können. Nur unter den Prämissen dieser Präsuppositionen lassen sich die genannten Strukturmerkmale der Standardisierung, Nivellierung und desorientierenden hektischen Betriebsamkeit schlüssig aus den ökonomischen Prinzipien ableiten. Zunächst nämlich wäre unter der Annahme verbleibender Antriebsüberschüsse und kreativer Fähigkeiten der Subjekte zu ver- 
muten, daß einmal die Produzenten der Kulturindustrie selbst ein Interesse an Innovation hätten und versuchen würden, dies auch ökonomisch zu realisieren. Weiter wäre wahrscheinlich, daß die Rezipienten Innovation wünschen und sich nicht mit bloßer, formaler Betriebsamkeit zufriedengäben, sondern ,in the long run' von diesen Versuchen der Nachfragefixierung frustriert nach neuen Inhalten verlangen würden. Der Manipulationsversuch der Industrie fände hierbei doch seine Schranken, nämlich an den Subjekten und ihren Neuerungsbedürfnissen. Von diesen zeigte sich dann auch der Markt flexibilisiert, und die Innovationswünsche der Produzenten ließen sich durchaus mit dem Profitprinzip verbinden. Weder die Wünsche des Publikums, noch die kreativen Inputs der Produzenten müßten als bedrohlich oder systemunverträglich eingeschätzt werden. Sie verbänden sich vielmehr beide in einer wirklich innovativen Ökonomie mit Profitabilität und erfolgreicher Tauschbarkeit. Schließlich fände, vermittelt über die Kulturprodukte und ihre Gehalte, zugleich wieder ein gesellschaftlicher Diskurs statt, der von Rezipienten wie Produzenten bestimmt wäre. Eine solche Vorstellung aber scheidet für die Kritische Theorie aus; sie entspräche dem Paradigma einer demokratischen, nicht einer totalitären Gesellschaft, wie sie sie im Blick hat. Unter dem statisch-totalitären Paradigma erst nämlich erscheint jede wirkliche Innovation als Widerspruch zur Profitabilität oder als Gefährdung des auf diesem Prinzip ruhenden Systems. Lediglich die Grundannahmen einer allenthalben gleichbleibenden Statik sich repetierender und perpetuierender Verhältnisse sowie einspruchsloser, dociler Subjekte lassen es schlüssig erscheinen, daß Innovation nicht entstehen kann bzw. jede Veränderung allen als Bedrohung erscheint, die reprimiert oder manipulativ umgekehrt werden muß. Nur so kann auch die Deduktion plausibilisiert werden, daß die Marktforschung primär auf Umgestaltung der Publikumsbedürfnisse zugunsten von Produktpräformationen und nicht der Erhebung neuer Exploitationsmöglichkeiten dieser Bedürfnisse dienen soll.

Diese Konzeption aber scheint mir kaum die Realität zu treffen. So scheint mir schwer begründbar zu sein, wie die innovative Struktur der neuzeitlichen Ökonomie, die sich ja auch und gerade unter der Präsupposition des Profitprinzips um Neuheit mühen muß, sich ausschließlich mit einer Innovation der Oberfläche begnügen und die prekäre Strategie ständiger Verschleierung durch Betriebsamkeit akzeptieren kann, wenn sie die Möglichkeit hat, durch umfassende Produktinnovation neue Märkte zu erobern. Zwar kann eine ökonomische Neigung, erfolgreiche Konzepte zu repetieren, und damit eine statifizierende, schablonisierende Inklination nicht in Abrede gestellt werden (vgl. dazu auch 1.3.). Sie wird etwa durch die filmwirtschaftliche Begünstigung der Verlängerung eines Erfolgsfilms zur Serie sogar empirisch und besonders augenfällig belegt. Doch scheint es mir zu kurz gegriffen, darin das einzige Strukturgesetz selbst der populären Kulturproduktion zu sehen. Daneben nämlich gilt es, das genuin innovative Potential, das sich etwa filmgeschichtlich in einander ablösenden Epochen sowie in experimentellen Weiterführungen bestehender Genres und narrativer Typika äußert, zu reflektieren. In ihm zeigt sich eine Dynamik, die gerade nicht auf Festschreibung von Bekanntem zielt, sondern nach, neuen Ufern' sucht und die dies auch im populären Bereich tut. So scheinen mir etwa die Filme von John Carpenter, James Cameron, Kathryn Bigelow und Ridley Scott, die zweifelsohne ein breites Publikum suchen und sich in traditionellen Genres einrichten, nicht bloß formal, sondern auch inhaltlich neue Wege beschritten und veränderte 
Standards gesetzt zu haben. Ihre innovative Dynamik belegt weitaus mehr die Annahme einer offenen Ökonomie, in der sich die Kreativität der Kulturproduzierenden realisieren kann, als die einer geschlossenen, wie sie das Kulturindustrietheorem voraussetzt.

Wenig überzeugend scheint mir deshalb auch, da $\beta$ es möglich sein soll, gegenüber der Rezeptionsbasis die angenommene Statik durch Manipulation und betriebsame Camouflage auf Dauer zu sichern. Die Faktizität weist eher darauf hin, daß sich neben der Kreativität der Kulturproduzierenden auch die Spontaneität und Kreativität der Subjekte der Manipulation ,in the long run' widersetzen, die Betriebsamkeit einmal als leer durchschaut und eine inhaltliche Neuerung der Kulturprodukte gefordert wird. Tatsächlich sieht sich die Kulturindustrie mit eben doch aus der Basis aufsteigenden, kulturellen Forderungen konfrontiert, denen sie um ihres Selbsterhalts willen nachgeben muß. Gerade die Filmgeschichte zeigt, daß es einen solchen determinativen Einfluß der ,Basis', der zur Durchbrechung der Standardisierung nicht nur durch Bewegung und Scheininnovationen zwingt, stets gegeben hat. So war etwa in den 30er Jahren der Rückgang der Publikumszahlen eine Folge der schematisierten Produktion, die vom Publikum und seinen veränderten Bedürfnissen nicht mehr akzeptiert wurde. Dieser Tatbestand wurde von der Industrie in seinen Gründen auch entsprechend begriffen. Produktinnovationen, die über bloß neue Ausstattungen und Reizgebungen hinausgingen, taten not und erfolgten etwa durch die Einführung des Tonfilms, der veränderte Formen und Inhalte hervorbrachte, wie etwa die sozialkritische Schwarze Serie, die durch den Ton mehr ,theoretische', da sprachlich vermittelbare Reflexion ermöglichte (vgl. 1.3. und 1.5.). Gerade das Publikumsbedürfnis nach Auseinandersetzung mit der zeitgenössischen Situation Amerikas konnte von der Differenziertheit des Tonfilms gut aufgegriffen und auch inhaltlich beantwortet werden. Ein Vergleich der, stummen' Filme vor 1930 mit den ,tönenden danach vermag deshalb durchaus zu belegen, daß die Einführung des Tonfilms mehr war, als eine dem Kulturindustrietheorem entsprechende, rein formale Innovation. Die Konstruktion der mit Erfolg hektisch ihre Entwicklungslosigkeit verschleiernden, die Subjekte in eine anhaltende ,Beschäftigungstherapie' mit ablenkender Intention verwickelnden Gesellschaft und Kulturindustrie wirkt im Kontrast hierzu entsprechend abstrakt und wenig plausibel.

Das genannte Beispiel weist weiter darauf hin, daß auch die Annahme einer erfolgreichen Ausgrenzung des gesellschaftlichen Diskurses aus den Kulturprodukten, bzw. dessen Verhinderung durch eine normative Gleichschaltung dieser Produkte, recht gezwungen und empirisch wenig belegbar ist. Gerade die populäre Kultur nämlich zeigt sich faktisch als breit und nachhaltig von diesem Diskurs beeinflußt, ja sie stellt sich geradezu als ein Teil und Ort dieses Diskurses dar, der kaum Beschränkungen in der Aufnahme, Spiegelung und partiell der Fortführung gesellschaftlicher Interpretamente und Themen kennt. Eine aufmerksame Untersuchung populär-kultureller Erzeugnisse, die sich dann freilich stärker als die Kritische Theorie der Empirie zuwenden muß, vermag dies auch jenseits des genannten Beispiels gegen das Kulturindustrietheorem nachzuweisen. ${ }^{124}$ Auch diese Tatsache spricht

${ }^{124} \mathrm{Im}$ Bereich der kommerziellen Comics habe ich eine solche Untersuchung durchgeführt, auf die ich zum Beleg meiner Kritik am Kulturindustrietheorem verweise: Hausmanninger, Superman 
nochmals gegen die Annahme eines dauerhaften Erfolgs von Standardisierung und Nivellierung der Gehalte zugunsten einer breiten, schichtübergreifenden Rezipierbarkeit. Zwar ist es unleugbar, daß die kulturindustriellen Produkte, d.h. die Erzeugnisse der Populärkultur, eine unter anderem ökonomisch bedingte Tendenz haben, sich in den ,Mainstream ' des gesellschaftlichen Diskurses einzuklinken, um breites Interesse zu gewinnen, und daß derart etwa schichtspezifische Differenzen in der Haltung zu bestimmten Themen oder gruppenspezifische Ethosformen eingeebnet werden. Auch ist es unbestritten, daß es gerade in der Filmgeschichte wiederholt (meist allerdings nicht ökonomisch, sondern moralisch bedingte) Versuche gegeben hat, Kanons für die Produktion von Gehalten zu schaffen, die einen nivellierenden Effekt mit sich führten. ${ }^{125}$ Doch weder die Tendenz zum Trend-tie-inning, noch die Unterwerfung der Produktion unter Codes hat je jene Totalität der Nivellierung hervorgebracht, wie sie Horkheimer und Adorno vorschwebt. Im ersten Fall nämlich ist selbst der diskursive Mainstream noch zu uneinheitlich, um eine vollständige Kohärenz aller Produkte untereinander zu garantieren. Im Versuch, aus ihm eine breite Interessentenbasis zu gewinnen, legt die ökonomische Determination daher eher nahe, die Vielfalt dieses Mainstreams und seiner Randzonen auszuschöpfen, als seinen blanken und schmalen Querschnittbereich zu reproduzieren. Die Versuche mit den Codes wiederum, die zweifelsohne die starrste Form der Nivellierung vorstellen, zeigen weitaus mehr, daß die Nivellierung der Ökonomie widerspricht, als daß sie Erfolg habe. So vermochte kein Code allzulange zu überleben und wurde er meist von der Industrie nach einiger Zeit allmählich aufgelöst. ${ }^{126} \mathrm{Da}$ im Unterschied zur Supposition des Kulturindustrietheorems ein gesellschaftlicher Prozeß und eine Entwicklung des gesellschaftlichen Diskurses stattfinden, bleibt es gerade um des ökonomischen Erfolgs auf längere Sicht unmöglich, sich mit repetitiv-standardisierten, durchschnittlichen Produkten die Publikumsgunst zu erhalten. Aus diesem Grund durchbrechen im übrigen selbst die codegerechten Produktionen dessen Starrheit immer wieder; kein Publikum ist stets nur an Bestätigung und Repetition interessiert. Insgesamt scheint mir daher sowohl die Gleichschaltung der kulturellen Gehalte als auch die der Bedürfnisse der Subjekte in ihrer theoretischen Tragfähigkeit fragwürdig zu sein. Sie fügt sich allerdings theorieimmanent konsistent in die weitere Auslegung des Kulturindustrietheorems ein, die diese Industrie unter dem totalitarismustheoretischen Paradigma als Instrument der Herrschaftswahrung begreift und nun in der Tat jeden Versuch der ,Basis‘, Veränderungen einzuleiten, innovativ Bedürfnisse zu entfalten, oder Gesellschaft als prozessuale Einrichtung zu interpretieren, als prekär bewerten und schärfstens bekämpfen muß.

${ }^{125}$ Das von Horkheimer und Adorno auch zitierte Hays office, d.h. die Stelle, die die Einhaltung des Codes für die Filmproduktion überwachte, ist ein Beispiel hierfür. Seine Existenz, wie in einem anderen medialen Bereich: bei den Comics, die des Comics-Codes, verdankte sich jedoch weniger der Ökonomie, sondern den zeitgenössischen Moralvorstellungen, die durch Druck der Öffentlichkeit zu einer Fixierung in Kanons gelangten.

${ }^{126}$ Dies gilt sowohl für das Hays office, als auch für andere Code-Bestrebungen. Im Bereich der kommerziellen Comics, die gerade auf breite Rezipierbarkeit angewiesen sind, habe ich das in Auseinandersetzung mit dem Comics-Code gezeigt (vgl. Hausmanninger, Superman, $214-231$, bes. $226-227$ ). 


\section{Kulturindustrie als Herrschaftsinstrument}

Obschon in der Kulturindustrie sich zunächst vordringlich die instrumentelle Vernunft selbst realisiert und eine Eigendynamik entfaltet, scheint es in Analogie zur Gesellschaftstheorie dann den Herrschenden wieder zu gelingen, an der Herrschaft der instrumentellen Vernunft teilzunehmen bzw. deren strukturelle Umsetzung für sich und den Erhalt ihrer Stellung zu nutzen. Das Kulturindustrietheorem wird damit weitergeführt, und die Kulturproduktion wird als Instrument eines von den Herrschenden durchgeführten, Social engineering' skizziert. Die kulturelle Manipulation, die weiterhin als Grundmoment der Kulturindustrie gilt, findet sich jetzt nicht mehr um der Profitabilität (allein) willen eingerichtet, sondern zum Zweck dieser Steuerung. Aus diesem Ansatz ergeben sich weitere Strukturmerkmale, die der Kulturindustrie, ihrer Aufgabenstellung und ihrer Produktion zugeschrieben werden. So scheint die Kulturindustrie nun unter das schon in der Gesellschaftstheorie als tragend angesetzte Prinzip des Herrschaftserhalts gestellt zu sein und derart zum Instrument der Herrschenden zu geraten. In dieser Instrumentalisierung erhalten die kulturindustriellen Produkte und ihre (angenommene) serielle, statifizierende Struktur eine neue, zusätzliche Bedeutung. Sie dienen nun anscheinend neben der Fixierung des ökonomischen Erfolgs auch der Fixierung der gesellschaftlichen Organisation, d.h. primär der Festschreibung ihrer dichotomischen, klassenantagonistischen Gestalt. Um das zu erreichen, scheint die Kulturindustrie zunächst einmal diese Gestalt ständig zu bestätigen, indem sie sie reproduziert und euphemisiert. Neben Verdopplung und Beschönigung aber scheint es nötig zu sein, auch die mit der instrumentellen Gesellschaftsorganisation, ja mit der instrumentellen Einrichtung in der Welt schlechthin, dennoch einhergehenden Repressionen und Leidstrukturen zu kompensieren und gratifikativ zu dämpfen, um die Entstehung von Unzufriedenheit und protorevolutionären Regungen zu verhindern. Zusammen mit einer euphemistisch-affirmativen erhält die Kulturindustrie so auch eine gratifikativ-kompensative Funktion, die sie zu einer Gratwanderung zwischen Versagung und Erfüllung nötigt und die den Betrug der Rezipienten fortsetzt. Die Annahme eines Erfolgs der kulturindustriellen Strategie unter dem Ziel des Herrschaftserhalts bedingt schließlich in dieser Argumentation wieder eine axiomatische Unterschätzung der Subjekte, denen die Fähigkeit, dem manipulativen Umgriff sich zu widersetzen, per definitionem abgesprochen werden muß.

Zunächst also wird in der Durchführung der Argumentation als oberstes Prinzip der kulturindustriellen Aktivität der Herrschaftserhalt angesetzt, der sich dann in der jeweils konkreten Situation vordringlich als Erhalt des Status quo der Gesellschaftsorganisation auslegt und derart eine primäre Maxime formiert. Das Prinzip und seine Maxime nehmen damit zunächst die Kulturindustrie selbst in Pflicht und unterwerfen sie in all ihren Aktivitäten a priori ihrem Gebot. Wie immer die Kulturindustrie tätig wird, sie muß dem Erhalt des Status quo und der Stützung der Herrschenden dienen. Das wiederum bedeutet, daß ihre Produkte eine entsprechende Grundaussage transportieren müssen, durch die die Rezipienten zur Unterwerfung unter die gegebenen Verhältnisse veranlaßt werden. Die dem Prinzip und seiner Maxime konforme Grundausage, die alle kulturindustriellen Gehalte durchziehe und derart zu einer quasi-transzendentalen Formel gerate, formuliert Adorno als den „kategorische(n) Imperativ der Kulturindustrie“. ${ }^{127}$ Obschon als solcher Imperativ

${ }^{127}$ Adorno, Kulturindustrie, 67 
etikettiert, habe er jedoch „zum Unterschied vom Kantischen mit der Freiheit nichts mehr gemein“, ${ }^{128}$ sondern laute vielmehr: „Du sollst dich fügen, ohne Angabe worein; fügen in das, was ohnehin ist, und in das, was, als Reflex auf dessen Macht und Allgegenwart, alle ohnehin denken “. ${ }^{129}$ Die Kulturindustrie scheint so also ihre grundsätzliche Inpflichtnahme durch das Herrschaftsprinzip in eine prinzipielle Verpflichtung der Rezipienten zur Unterordnung, Anpassung und Einordnung zu transformieren. Die Bereitschaft zu dieser Einfügung gilt gewissermaßen als erste Bürgerpflicht; sie wird dem Publikum in allen Kulturprodukten nahegebracht und anempfohlen. Damit realisiert die Produktion der Kulturindustrie anscheinend nicht nur eine Perpetuierung profitabler Produktformeln, sondern auch eine Fortsetzung von Herrschaft, und sie scheint hierzu den Habitus des Gehorsams per se einzuüben.

Als transzendentale Bestimmung realisieren sich der Imperativ des Gehorsams und seine Einübung freilich nicht einfach nur in Form einer expliziten Anempfehlung der Unterwerfung und Einordnung, sondern sie vermitteln sich für die Kritische Theorie über eine Reihe von kulturindustriellen Strategien, mit denen sich gleichzeitig die Herrschenden diese Industrie als Instrument zu nutze machen. Der Status quo und die darin verortete Stellung der Herrschenden stellen ja eine spezifische Struktur vor, mit deren Errichtung und Gestalt ganz bestimmte Repressionen und Leidformen einhergehen. Auf ihrer Kehrseite machen Repression und Leid zugleich jene Bereiche benennbar, aus denen eine Gefährdung des Status quo und der Herrschaftsstellung kommen könnte und mit denen durch die blanke Empfehlung der Unterordnung noch nicht adäquat umgegangen ist. So findet sich die Herrschaft mittels der instrumentellen Vernunft und ihrer gesellschaftlichen Realisierung in Arbeitsorganisation, Institutionen und den ökonomischen Prinzipien errichtet, denen spezifische Versagungen korrespondieren. Soll der Status quo aufrechterhalten werden, so muß zunächst diese Strukturorganisation von der Kulturindustrie bestätigt und beworben und müssen ihre negativen Begleiterscheinungen verschleiert, gemildert oder kompensiert werden. Nur dann scheint die Realisierung des kategorischen Imperativs der Kulturindustrie durch ihr Publikum auch gewährleistet zu sein.

Dieser Aufgabenstellung nun versucht Horkheimer und Adorno zufolge die Kulturindustrie zunächst durch eine konformierende Affirmation der bestehenden Verhältnisse gerecht zu werden, die sie als faktizierende bzw. beschönigende Verdopplung der Welt vornimmt. Im ersten Fall erfolgt die Affirmation durch eine ,positivistische und im zweiten Fall durch eine euphemistisch-klischierende Reproduktion und Appräsentation des Status quo in den kulturindustriellen Produkten. Ergänzt werden diese beiden Strategien durch die ökonomisch eingeführte Standardisierung, die vor allem mit der zweiten Strategie zusammenklingen kann. Der Film scheint hierbei wieder eine zentrale Rolle zu erhalten. So heben Horkheimer und Adorno in der „Dialektik der Aufklärung“ hervor, daß unter dem Herrschaftsprinzip „die ganze Welt (...) durch das Filter der Kulturindustrie geleitet" werde und die Abbildung der ersten in der zweiten in einer Weise erfolge, welche die Realitätswahrnehmung herrschaftskonform verändere. ${ }^{130}$ Daher sei „die alte Erfahrung des Kinobesuchers, der

\footnotetext{
${ }_{128}^{128}$ Adorno, Kulturindustrie, 67

129 Adorno, Kulturindustrie, 67

130 Horkheimer/Adorno, Dialektik, 113
} 
die Straße draußen als Fortsetzung des gerade verlassenen Lichtspiels wahrnimmt " ${ }^{131}$ keineswegs ein Beweis für die Wirklichkeitsgerechtheit der in dieser Weise wirkenden Filme, sondern vielmehr ein Beweis für die konformierende und verschleiernde Wirkung des Films auf die Wahrnehmung des Publikums. In der Tat nämlich erhebe die von den Herrschenden gesteuerte Filmproduktion diese Erfahrung, die ,Kontinuierung' von Filminhalt und Realitätserleben, geradezu „zur Richtschnur der Produktion““ ${ }^{132}$ Nicht die bewußtseinsschaffende Spiegelung des Lebens im Film jedoch sei dabei das Ziel, denn diese könnte ja zur Auseinandersetzung mit der eigenen Lebenssituation führen und eventuell Unzufriedenheit und Widerspruch erzeugen, sondern die bewußtseinsverändernde (bzw. -verhindernde) Fortsetzung des Films im Leben, die zu einer konformen Interpretation der eigenen Befindlichkeiten führen soll. Das Leben soll sich daher „der Tendenz nach vom Tonfilm nicht mehr unterscheiden lassen "133, und die Kulturindustrie soll einen Verblendungszusammenhang etablieren, der einer Stabilisierung der Verhältnisse durch Konformierung dient. Sie wird damit als Instrument eines Social engineering unter dem Herrschaftsprinzip eingesetzt.

Der stabilisierende Verblendungszusammenhang scheint dann einmal durch die ,positivistische' Verdopplung des Bestehenden eingerichtet zu werden, die im Bewußtsein der Rezipienten einen ontologisierenden Effekt erzeugt. So scheint vor allem der Film „getreu die Erscheinung“ zu wiederholen und dann „durch deren Dichte die Einsicht" zu ,versperren'. ${ }^{134}$ Diese Wiederholung geschieht für Horkheimer und Adorno bereits durch die ,fotografische Realistik' des Films, d.h. durch seine abbildrealistischen Möglichkeiten, die eine Art ,fotologischen Beweis ${ }^{135}$ für die Wirklichkeit des Gezeigten vorstellen. Der Film scheint damit an sich schon eine Inklination zur ,positivistischen' Verdopplung zu haben bzw. ein ,positivistisches Medium' zu sein, und Horkheimers und Adornos Text läßt mit dieser Wendung eine prinzipielle Reserviertheit gegenüber diesem Medium erkennen. ${ }^{136}$ Die eigentlich perniziose Verdopplung aber wird dann nicht nur in der punktuellen Abbildung realer Objekte gesehen, sondern in der von den Herrschenden überwachten und gesteuerten systematischen Reproduktion der gesellschaftlichen Realität, d.h. in der bloßen, kommentarlosen Abbildung von strukturellen Zusammenhängen. Durch eine ständige Wiederholung der faktischen Verhältnisse soll jeder reflexive Abstand zu diesen oder eine kritische Distanz verunmöglicht werden. Mit der ihm unterstellten ständigen Repetition einer „Photographie des sturen Daseins“ scheint der Film diesem Dasein eine Unmittelbarkeit und Unausweichlichkeit zu verleihen, die jede Frage nach seinem Sinn ersticken und es mit dem Schein des zwangsläufig Sinnvollen, da anders nicht zu Denkenden, ausstatten. ${ }^{137}$ Die Kombination von Abbildrealismus und der einlinigen Darstellung gesellschaftlich-struktureller Faktizität im Film nämlich sehen Horkheimer und Adorno in einen „Kultus der Tatsache“ mün-

\footnotetext{
${ }^{131}$ Horkheimer/Adorno, Dialektik, 113

132 Horkheimer/Adorno, Dialektik, 113

133 Horkheimer/Adorno, Dialektik, 113

134 Horkheimer/Adorno, Dialektik, 132

135 vgl. Horkheimer/Adorno, Dialektik, 133

136 vgl. dazu auch: Adorno, Filmtransparente, $79-88,83$

${ }^{137}$ Horkheimer/Adorno, Dialektik, 133
} 
den, der sich darauf beschränke, ,das schlechte Dasein durch möglichst genaue Darstellung ins Reich der Tatsachen zu erheben ". ${ }^{138}$ Damit aber bringe er eine Geschlossenheit hervor, die "das Dasein selber zum Surrogat von Sinn und Recht" macht. ${ }^{139}$ Wo das Bestehende ständig treu reproduziert wird, erhält es eine fast ontologische Festigkeit, die jeden, der ,angesichts der Macht der Monotonie noch zweifelt", als ,Narren' erscheinen läßt. ${ }^{140}$ Die erste Form des Verblendungszusammenhangs entsteht damit also durch eine ,tendenzlose Verdopplung ${ }^{141}$ der gesellschaftlichen Wirklichkeit, die auf diese Weise einen ontologischen, zwangsläufigen Status erhält und umfassend affirmiert wird.

Wo die verdoppelnde Affirmation nicht ausreicht, scheint sie zum anderen durch eine zweite Form des Verblendungszusammenhangs ergänzt zu werden, die nun die ,bestehenden Verhältnisse‘ beschönigt, idealisiert und ideologisch überhöht. Während im ersten Fall die faktische Welt selbst zur ontologischen Struktur erklärt wird und gewissermaßen mit der Kontingenzstruktur zusammenfällt, findet sich im zweiten Fall die Ontologie von der Kontingenz wieder unterschieden. Sie wird der kontingenten Welt nun als ihr ,eigentliches' Wesen gegenübergestellt, angesichts dessen die Defizienzen der Kontingenz neglegibel erscheinen. Ist im ersten Fall die faktische Gesellschaft als die beste aller möglichen dargestellt, da neben ihr eine andere gar nicht in Blick kommt, so ist es nun ihr ,wahres Wesen', das in den Stand dieser ,Bestheit' erhoben wird. Dieses, wahre Wesen' tritt vorwiegend in Form von Wertstrukturen und habituellen Ausrichtungen auf, die als typisch für die Gesellschaft gelten, sich nur durch sie realisieren lassen und die Überlegenheit der Gesellschaftsstruktur über jede andere belegen sollen. Im Zentrum steht dabei für Horkheimer und Adorno der „Mythos des Erfolgs“, der besonders im amerikanischen Kapitalismus die ,Gutheit' des Systems inkarniere. ${ }^{142}$ Als Aussage dieses Mythos gilt, daß ein Jeder in der amerikanischen Gesellschaft die Chance habe, ,from rags to riches' aufzusteigen. In dieser ,Freiheit', als Selfmademan seinen eigenen Erfolg zu realisieren, scheint das ,wahre Wesen' der Gesellschaft zu bestehen, und in ihm scheint sich seine ,Bestmöglichkeit' trotz faktischer, kontingenter Defizienzen zu erweisen. Obschon offensichtlich sei, daB diese Chance gar nicht wirklich bestehe, werde ihr Fehlen von den betroffenen Subjekten lediglich als ,Pech im Einzelfall', als kontingente Abweichung von der dennoch geglaubten, ontologischen ,Realität' interpretiert, und diene der Mythos so als ideologisch-ontologisierende Legitimation, die für die Affirmation der ,kontingenten', faktischen Organisation der Besten aller möglichen Gesellschaften sorgt.

Ergänzt scheinen die beiden Strategien der Verdopplung, also die abbildrealistische Wiederholung der Faktizität und die Appräsentation der ideologischen Ontologie von der ,Gutheit' des Systems, durch die Klischierung, die der Film in seinen Genres, Typen und Handlungsschemata vornimmt. Die zunächst ökonomisch hergeleitete Standardisierung und Nivellierung erhält hierdurch eine weitere, über die Profitabilität hinausreichende Funktion und eine veränderte Bedeutung. Während

\footnotetext{
138 Horkheimer/Adorno, Dialektik, 133

139 Horkheimer/Adorno, Dialektik, 133

140 Horkheimer/Adorno, Dialektik, 133

141 vgl. Horkheimer/Adorno, Dialektik, 133

142 Horkheimer/Adorno, Dialektik, 120
} 
die Klischierung zur Reproduktion des Faktischen in einer vom Kulturindustrietheorem nicht aufgelösten Spannung steht, vermag sie mit der Ideologisierung gut zusammenzuklingen. Sie geht jedoch in dieser nicht auf, sondern stellt auch eine eigene Strategie dar. So wird dem Film zunächst attestiert, da $\beta$ er Standardsituationen und Persönlichkeitstypen schaffe, wie etwa „die vorübergehende Blamage des Helden, die er als good sport zu ertragen weiß, die zusätzlichen Prügel, die die Geliebte von der starken Hand des männlichen Stars empfängt, seine rüde Sprödheit gegen die verwöhnte Erbin" etc. ${ }^{143} \mathrm{Er}$ scheint damit ,fertige Klischees' zu liefern, die den Status einer in spezifischer Weise gültigen Symbolik erhalten. Bereits durch diese Symbolik, die ,filmspezifische' Typologie und Schematisierung, gilt die Realitätsauffassung des Publikums als konformativ verändert. Gerade weil die Schemata um breiter Rezipierbarkeit willen dem Durchschnitt sich anpassen, scheinen sie eine besondere Überzeugungskraft zu gewinnen, die dann das Publikum den Aussagen der Klischees normativ unterwirft. ${ }^{144}$ Die Klischierung eignet sich außerdem gut dazu, die ideologische Überhöhung des, wahren Wesens' der Gesellschaft in sich aufzunehmen und dieses Wesen ,idealtypisch' zu appräsentieren. An die Seite der bloßen Unterbrechung des gesellschaftlichen Diskurses durch schablonisierende Fixierung von Weltund Lebensinterpretamenten, die aus ökonomischen Gründen auf Massenrezipierbarkeit hin nivelliert sind und dem Profiterhalt dienen sollen, tritt damit die Hegemonialisierung des Diskurses durch die Herrschenden und die ,politpädagogische Vermittlung ideologischer Klischees. Der erzieherische Effekt der Standardisierung erhält so neben der Gleichschaltung der Nachfrage jetzt auch einen Aspekt der Gleichschaltung der Gesellschaftsinterpretation des Publikums zum Zweck des Herrschaftserhalts. Doch selbst dort, wo die Klischees nicht unmittelbar als realweltlich relevante Interpretamente rezipiert, sondern noch als fiktive, realitätsferne Schemata wahrgenommen werden, scheinen sie eine affirmativ-konformierende Wirkung entfalten zu können. So erzeugen Klischierung und Standardisierung Typen und Handlungskonstellationen, die ,völlig definiert (sind) durch den Zweck, der ihnen im Schema zufällt“" ${ }^{145}$ Die ständige Repetition des Schemas und die Geschlossenheit, die sich durch die friktionslose Funktion der Figuren in ihm ergibt, aber scheinen an sich schon den Imperativ der widerspruchslosen Ein- und Unterordnung zu transportieren und das Publikum zu veranlassen, sich gewissermaßen ähnlich reibungslos dem ,Lauf der Welt' zu ergeben wie die Figuren den fiktionalen Handlungsverläufen. Entsprechend richtet sich die Kritik des Kulturindustrietheorems an den Standardisierungen neben dem Angebot von Identifikationsfiguren und Handlungspräformationen besonders auf die Erzeugung eines in ihnen symbolisch annocierten Einverständnisses mit den ,Weltläuften:

Dabei scheint das Bedürfnis der Gesellschaftsmitglieder nach einem solchen Einverständnis, nach Bestätigung und nach Verankerung in gesicherten Verhältnissen der Affirmation in die Hände zu spielen. Wie nämlich „die Beherrschten die Moral, die ihnen von den Herrschenden kam, stets ernster nahmen als diese selbst“, scheinen „heute die betrogenen Massen“ nach Aufrechterhaltung des Betrugs zu verlan-

${ }^{143}$ Horkheimer/Adorno, Dialektik, 112

$144 \mathrm{vgl}$. Adorno, Filmtransparente, 85

145 Horkheimer/Adorno, Dialektik, 112 
gen und etwa "mehr noch als die Erfolgreichen dem Mythos des Erfolgs" der Schematisierung und der positivistischen Verdopplung zu verfallen. ${ }^{146} \mathrm{Da}$ sie ,ihre Wünsche" haben und sich offenbar diese Wünsche im Untertext auf Affirmation richten, scheinen sie „unbeirrbar (...) auf der Ideologie, durch die man sie versklavt“, zu bestehen und scheint „die böse Liebe des Volks zu dem, was man ihm antut, (...) der Klugheit der Instanzen noch voraus" zu eilen. ${ }^{147}$ Zwar in Wahrheit depraviert scheinen die Gesellschaftsmitglieder dennoch ständig die Versicherung zu fordern, daß alles gut sei und es neben den bestehenden Strukturen kaum bessere gebe. Die Realisierung des doppelten Verblendungszusammenhangs und seine Verstärkung durch die willig aufgenommene Standardisierung lassen damit erkennen, daß sich die Strategie der Affirmation der bestehenden Verhältnisse mit einem Bedürfnis nach solcher Affirmation ergänzt. Der Film und das Publikum kooperieren so zum Schaden der Zweiten, und die Subjekte scheinen erneut kaum eine Potenz zu besitzen, ihre Autonomie und Selbständigkeit zur Anwendung zu bringen. Sie gelten vielmehr als einordnungs- und unterwerfungsbereit und werden derart pessimistisch eingeschätzt. Das transzendentale Gebot scheint von ihnen beinahe begierig verwirklicht zu werden.

Trotz dieser pessimistischen Einschätzung, die unter dem Gesichtspunkt des Erhalts des gesellschaftlichen Status quo und des dadurch vermittelten Herrschaftserhalts eine ,günstige' Disposition der Gesellschaftsmitglieder bedeutet, reicht jedoch die Strategie der ontologisierenden und euphemisierend-ideologischen Weltverdopplung dem Kulturindustrietheorem zufolge offenbar noch nicht aus. Sollen die gesellschaftlichen Verhältnisse zuverlässig perpetuiert werden und soll die Stellung der Herrschenden wirklich garantiert sein, so tut es noch not, die schmerzhaften Folgen der instrumentellen Einrichtung der Gesellschaft überhaupt und der damit einhergehenden Repressionen zu mildern und zu kompensieren bzw. den Subjekten Möglichkeiten zu bieten, sich zumindest von diesen abzulenken und durch Gratifikationen die eigene Frustrationstoleranz zu erhöhen. An die Seite der konformierenden Affirmation tritt daher eine kompensativ-gratifikative Strategie, die möglicher Unzufriedenheit und einer daraus erwachsenden, protorevolutionären Bewußtheit entgegenzuwirken trachtet. Dabei kann die Kulturindustrie zum einen zwar wieder auf die ,Mitarbeit" der Gesellschaftsmitglieder rechnen. Zum anderen aber begibt sie sich, und in ihr der Film, auch auf eine Gratwanderung.

So gilt es zunächst als notwendig, nicht nur „Reklame (...) für die Welt" ${ }^{\text {“148 }}$ durch ihre Verdopplung und Idealisierung zu machen, sondern den in ihr tätigen, den gesellschaftlichen Zwängen unterworfenen Menschen auch Vergnügen zu verschaffen, das es ihnen erleichtert, die bestehenden Strukturen zu ertragen. Vergnügen nämlich stellt dem Kulturindustrietheorem zufolge einen wesentlichen Teil der „Apologie der Gesellschaft" dar, denn „Vergnügtsein heißt Einverstandensein“. ${ }^{149}$ Es gilt sowohl als entlastendes, temporäres Ausweichen vor den ,Drangsalen' der instrumentellen Gesellschaftsorganisation, als Eskapismus gegenüber den Nötigungen zur Repression der sinnlichen Antriebsstrukturen und zur Selbstinstrumentalisierung im Arbeitsprozeß, wie auch als endgültige Submission unter diese Nötigungen. Denn neben der

146 Horkheimer/Adorno, Dialektik, 120
${ }_{147}$ Horkheimer/Adorno, Dialektik, 120
148 Adorno, Kulturindustrie, 62
${ }^{149}$ Horkheimer/Adorno, Dialektik, 130 
„Flucht vor der schlechten Realität“ enthält der Eskapismus für Horkheimer und Adorno auch die „vor dem letzten Gedanken an Widerstand“. ${ }^{150}$ Statt ihre Unzufriedenheit ins Bewußtsein zu heben und sich mit der Herkunft derselben auseinanderzusetzen, scheinen die Subjekte wieder eine Bereitschaft zur Affirmation zu zeigen und jeder möglichen Reflexion über die gesellschaftlichen Bedingungen ihrer Existenz auszuweichen. Das Erlebnis der Unstimmigkeit von faktischem Leben und ursprünglichen Ansprüchen, das zum Widerspruch und Aufbegehren reizen könnte, gilt ihnen anscheinend als bedrohlicher als die Repression selbst. Beinahe freiwillig verabschieden sie sich daher mit Hilfe des Amüsements von den negativen Gefühlen und vom Reiz zum Widerspruch. So halten die Gesellschaftsmitglieder im Wechsel zwischen gesellschaftlicher Funktion und privatem Ausweichen ihre innerpsychische Ökonomie konform. Sie erhöhen bereitwillig durch diesen Wechsel ihre Frustrationstoleranz, nehmen die Repression und die Leidstrukturen hin und stützen sich durch temporäre Zufuhr jener Gratifikationen und Lusterlebnisse, die ihnen die Kulturindustrie liefert. Die „Befreiung, die das Amüsement verspricht“, ist Horkheimer und Adorno zufolge daher „die von Denken als Negation“, und die Kulturindustrie kann erneut auf die Kooperation der Unterdrückten rechnen. ${ }^{151}$

Allerdings scheint diese Kooperation nicht völlig gesichert und absolut verläßlich zu sein. In ihren Angeboten von Gratifikationen und Lusterlebnissen muß die Kulturindustrie daher darauf achten, die Repression und die Bereitschaft zur Unterwerfung nicht zu gefährden. Keinesfalls dürfen die kulturindustriellen Produkte am Horizont die Gestalt eines besseren Lebens, einer möglichen Erfüllung aufscheinen lassen oder die dennoch vorhandenen Sehnsüchte allzusehr aktivieren. Sie drohen sonst, die Bereitschaft der Rezipienten zur Verdrängung und Kooperation ins Wanken zu bringen. Das aber nötigt die Kulturindustrie zu einer Gratwanderung zwischen Versagung und Bereitstellung von Lust und Glück. Tatsächlich nämlich ist gerade die Kehrseite der Unterdrückung das, was den Eskapismus reizvoll macht, und gibt das freie Leben den Ort seines Fluchtziels an. Entsprechend sind es gerade auch die verdrängten Bestände, die das Amüsement erst zu einem solchen werden lassen und die den kulturindustriellen Gehalten das Interesse sichern. Die Kulturindustrie verwickelt sich derart in den dialektischen Widerspruch, ihre affirmative Funktion mit der kompensativ-gratifikativen Strategie nur dann erfüllen zu können, wenn sie dem Publikum das anbietet, was dieses sich ständig versagen soll. Anders gewendet bedeutet dies, daß ihre Aufgabe nun darin besteht, durch Lieferung des Versagten die Versagung zu bestätigen.

Konsequenz dieser fast aporetischen Aufgabe scheint es zunächst zu sein, daß „die offiziellen Modelle“ der Konformität in den Produkten der Kulturindustrie „von inoffiziellen",überlagert" werden und die letztgenannten „für die Attraktion sorgen“, obschon sie „von den offiziellen außer Kurs gesetzt werden“". ${ }^{152}$ Das hat zur Folge, $\mathrm{da} ß$, „um die Kunden zu fangen, ihnen Ersatzbefriedigungen zu beschaffen“, die ,inoffizielle, wenn man will: heterodoxe Ideologie vielfach breiter und saftiger ausgemalt" werden muß, , als dem fabula docet bekömmlich ist" ${ }^{153}{ }^{153}$ Damit die ,Fabel' dann

${ }^{150}$ Horkheimer/Adorno, Dialektik, 130

151 Horkheimer/Adorno, Dialektik, 130

152 Adorno, Filmtransparente, 82

${ }^{153}$ Adorno, Filmtransparente, 82-83 
dennoch wirksam bleibt, sieht sich die Kulturindustrie genötigt, um das Vergnügen, das sie verspricht, stets zu betrügen. Soll der Rezipient konform auf Verzicht und Unterwerfungsbereitschaft fixiert werden, so muß ihm die wirkliche Erfüllung vorenthalten werden und muß er, in the long run" gerade an diesem Vorenthalt sein neues Vergnügen finden. Dies versucht die Kulturindustrie zu erreichen, indem sie „den Wechsel auf die Lust, den Handlung und Aufmachung ausstellen, (...) endlos prolongiert: hämisch bedeutet das Versprechen, in dem die Schau eigentlich nur besteht, daß es zur Sache nicht kommt" ${ }^{154}$ Indem nun aber das kulturindustrielle Produkt „das Begehrte immer wieder exponiert, den Busen im Sweater und den nackten Oberkörper des sportlichen Helden“, ${ }^{155}$ ohne je zur Erfüllung des Begehrens zu schreiten, hält sie zum einen das Interesse wach und gewöhnt sie zum anderen an die Abwesenheit jeder Vollendung. Der Rezipient ,lernt' auf diese Weise, ,an der Lektüre der Menükarte sein Genügen (zu) finden “156, und sich mit der ,aufgestachelten Vorlust", „die durch Gewohnheit der Versagung längst zur masochistischen verstümmelt ist“, zu bescheiden. ${ }^{157}$ Damit aber gerät auch die kompensative Gratifikation zu einer weiteren Schule des Verzichts, und die Kulturindustrie zeigt sich erneut als Instanz der Einübung von Unterwerfungs- und Anpassungsbereitschaft. Die hierzu angewandte Strategie freilich bleibt eine Gratwanderung zwischen einem $\mathrm{Zu}$ viel an interesseweckenden Angeboten, das die Sehnsucht nach dem guten Leben allzusehr aktivieren und in protorevolutionäre Unzufriedenheit münden könnte, und einem Zuviel an Versagung, die zum Interesseverlust oder gar ebenfalls zur gefährlichen Unzufriedenheit führen könnte.

Mit diesem Argumentationsgang nun ist das Kulturindustrietheorem kohärent zur Gesellschaftstheorie durchgeführt. Während über die beiden ökonomischen Prinzipien ein unmittelbarer Anschluß an das Kapitalismustheorem sowie durch die in diesen Prinzipien wirksame instrumentelle Vernunft ein mittelbarer Anschluß an die Rationalitätstheorie erfolgt, wird nun auch das aus dem Basisparadigma der Gesellschaftstheorie hervorgehende primäre Interessenprinzip des Herrschaftserhalts als determinatives Prinzip der kulturindustriellen Produktion herangezogen und die Theorie der Kulturindustrie mit der gesellschaftstheoretischen Grundstellung verbunden. Nicht einfach nur die ökonomisch realisierte instrumentelle Vernunft allein zeichnet jetzt für die Organisation, Funktion und Wirkung der Kulturindustrie verantwortlich, sondern es gelingt offenbar den Herrschenden wieder, am Status dieser Vernunft zu partizipieren und deren Kraft für sich zu nutzen. Die Kulturindustrie zeigt sich daher als manipulatives Instrument der Herrschenden, d.h. als werkzeughafte Einrichtung, die nach instrumentellen Gesichtspunkten organisiert ist und einem Social engineering unter dem Prinzip des Herrschaftserhalts dienstbar gemacht wird. Die Form dieses Erhalts legt sich dabei über die Affirmation des Status quo der Gesellschaftseinrichtung aus. Entsprechend erscheint als Grundmaxime für die kulturindustrielle Produktion, daß sie dieser Affirmation zu dienen hat, und wird die von ihr zu vermittelnde Grundmaxime für die Rezipienten als quasi-transzendentales Gebot der Einfügung ins Gegebene und der Unterwerfung unter die damit ver-

${ }^{154}$ Horkheimer/Adorno, Dialektik, 125

155 Horkheimer/Adorno, Dialektik, 125

${ }_{157}^{156}$ Horkheimer/Adorno, Dialektik, 125

${ }^{157}$ Horkheimer/Adorno, Dialektik, 125 
bundenen ,Notwendigkeiten' spezifiziert. Die konkrete Realisierung der quasi-transzendentalen Maxime erfolgt dann auf der Seite der Kulturindustrie mit einer Reihe von Strategien, die auf eine, gebotskonforme' soziale Steuerung zielen. Diese Strategien lassen sich zu zwei Basisformen differenzieren, die jeweils weitere Differenzierungen unter sich befassen. So können zunächst eine euphemistisch-affirmative und eine gratifikativ-kompensative Strategie voneinander unterschieden werden. Die erste Strategie legt sich hierbei in eine positivistische und eine ideologische Bestätigung des Gegebenen auseinander. Die mit diesen beiden Differenzierungen vorgenommene Steuerung zielt auf eine Veränderung des Bewußtseins der Rezipienten und die Erzeugung von Einverständnis durch Manipulation der Wahrnehmung der gesellschaftlichen Wirklichkeit, die als ,beste aller möglichen' annonciert wird. Ergänzt gilt die Strategie durch eine ,an sich' konformierende, Anpassungsbereitschaft erzeugende Wirkung der Standardisierung, die dem Publikum reibungslose Einordnung in vorgegebene Zusammenhänge und Handlungsabläufe durch ihre schematisierte Geschlossenheit als formales Verhaltensideal andient und das quasi-transzendentale Gebot derart umsetzt.

Da jedoch die instrumentelle Gesellschaftsorganisation, von der die Herrschenden der Gesellschaftstheorie zufolge profitieren, spezifische Leidformen und Versagungen mit sich führt, scheint die Affirmation allein nicht auszureichen und wird deshalb mit der zweiten Basisform der Strategien für das Social engineering versucht, die Frustrationstoleranz der Beherrschten durch Ablenkungsmöglichkeiten und Ersatzgratifikationen zu erhöhen. Deren Notwendigkeit und die Reflexion auf Leidstrukturen innerhalb des Kulturindustrietheorems leiten sich dabei aus der rationalitäts- und gesellschaftstheoretischen Einführung der Repression als Kehrseite der Herrschaft her und ordnen das Theorem in diesen Gesamtkontext ein. So war zu sehen, daß bereits die Genese der instrumentellen Vernunft selbst eine Repression, nämlich die der inneren Natur des Menschen, bei sich führt und daß die gesellschaftliche Realisierung des Selbsterhalts in der instrumentellen Arbeit eine repressive, entfremdende Selbstinstrumentalisierung der arbeitenden Gesellschaftsmitglieder bedingt. Zusammen mit dem Unrechtscharakter der einseitigen Zuteilung der gesellschaftlichen Arbeit an die Beherrschten müssen diese beiden repressiven Momente gemildert und ertragbar gemacht werden, wenn eine systemgefährdende Unzufriedenheit und eine protorevolutionäre Bewußtheit der Beherrschten vermieden werden soll. Hierbei erhält nun das Vergnügen an den kulturindustriellen Produkten die Funktion, die Widersprüche zwischen der Gesellschaftsstruktur und den Aspirationen auf das ,gute Leben' zu verschleifen und zu verschleiern bzw. den Rezipienten eine spezifische Regeneration anzubieten, die es ihnen ermöglicht, danach die gegebenen Strukturen wieder einspruchslos zu ertragen. Um die Gratifikationen und Kompensationen jedoch wirklich zu solchen werden zu lassen und sich das Publikum zu erhalten, ist die Kulturindustrie zu einer Gratwanderung zwischen Erfüllung und Versagung genötigt. Eigentliches Interesse und Vergnügen nämlich erzeugen gerade jene Bestände, die von der instrumentellen Gesellschaftseinrichtung, ja der Herrschaft der instrumentellen Vernunft überhaupt, ausgegrenzt und verdrängt werden und deren Ausgrenzung verstärkt werden soll. So verwickelt sich die Kulturindustrie in eine dialektische Aporetik, die sie dadurch zu lösen versucht, daß sie den Rezipienten umerzieht und seine Wunsch- und Bedürfnisstruktur herrschafts- bzw. repres- 
sionskonform deformiert. Die Rezipienten freilich scheinen sowohl für die Affirmation des Bestehenden als auch zur Unterwerfung unter dessen Versagungsstruktur und zu einer entsprechenden Eigensteuerung ihrer psychischen Ökonomie bereit zu sein. Sie bringen offenbar ein Bedürfnis nach Bestätigung ihrer gesellschaftlichen Existenz und nach Sicherung ihrer noch so depravierten Stellung im gesellschaftlichen Gesamtsystem mit sich, das jede Veränderung und damit jedes Bewußtsein der eigenen, entfremdeten Befindlichkeit scheut. In einer perniziosen Weise kooperiert das Publikum so mit den Steuerungsabsichten der Herrschenden und arbeitet es der Manipulation durch die Kulturindustrie in die Hände.

Mit dieser Argumentation ordnet die Kritische Theorie das Kulturindustrietheorem konsistent in ihre pessimistisch-verfallstheoretische Grundstellung und ihr totalitarismustheoretisches Paradigma ein. Der verfallstheoretischen Perspektive und ihrem Pessimismus entspricht es zunächst, daß erneut eine Desubjektivierung des Großteils der Gesellschaftsmitglieder durch eine umfassende Manipulation und die Festschreibung des gesellschaftlichen Unrechts durchgezeichnet wird, ohne da $B$ den Kulturrezipienten die Kraft zur Selbstbestimmung, der Kulturindustrie eine kommunikative Gestalt oder der Gesellschaft eine Prozessualität zugestanden wird. So scheinen, wie schon in der ökonomischen Auslegung der Kulturindustrie, die Rezipienten sich keineswegs wie Subjekte zu verhalten, sondern beinahe freiwillig auf ihre Autonomie, ihre Fähigkeit zu einem vernunftbegründeten Selbstand und zur vernünftigen Selbstbestimmung zu verzichten. Sie scheinen mit einer geradezu autodestruktiven und masochistischen Sehnsucht nach Einrichtung in der bestehenden Struktur der Gesellschaft und nach der Versicherung, daß Besseres keinesfalls denkbar sei, ausgestattet zu sein. Die Kritische Theorie transportiert in ihrem Kulturindustrietheorem damit wieder einen Pessimismus gegenüber der Subjektivität, der gegen die Faktizität steht, jedoch durchaus konsistent aus dem umfassend verfallstheoretischen Ansatz Horkheimers und Adornos hervorgeht. Unter der rationalitätstheoretischen Prämisse, daß jede Chance auf Subjektivierung durch die Ausbildung der instrumentellen Vernunft in der Menscheitsgeschichte ohnehin unterlaufen ist, und durch die gesellschaftstheoretische Weiterführung dieser Annahme, in der zwar eine Gruppe sich der globalen Desubjektivierung durch gewissermaßen ein strukturell vermitteltes Bündnis mit der instrumentellen Vernunft entzieht, die Desubjektivierung aber gerade hierdurch für die meisten Gesellschaftsmitglieder institutionalisiert und strukturell fixiert wird, kann in der Tat eine Kraft zur Subjektivierung bei diesen meisten nicht mehr vermutet werden. Die der gesamten Geschichte supponierte statische Grundstellung einer permanenten Unterdrückung der meisten Subjekte läßt nur noch die Annahme zu, daß in diesem äonenlangen Verfall eine umfassende Gewöhnung an Repression entstanden ist und jede Fähigkeit zu eigenständigem und selbstbestimmtem Verhalten nachhaltig verlernt und durch ein Bedürfnis nach Leitung ersetzt wurde. Wo die Subjekte derart pessimistisch beurteilt werden, kann freilich auch eine gesellschaftliche Kommunikation und Prozessualität nicht mehr gedacht werden. An ihre Stelle tritt dann das statische Modell einer Einwegkommunikation in einer unveränderten und unveränderbaren Struktur, in der die Herrschenden den Beherrschten die gewünschte Leitung und die nötigen Gratifikationen geben. Ein derart axiomatischer Pessimismus den Subjekten gegenüber aber scheint mir kontrafaktisch und nicht angebracht zu sein. Bereits in der Auseinander- 
setzung mit der ökonomischen Determination der Kulturindustrie habe ich darauf verwiesen, daß sich durch eine stärker empirisch orientierte Analyse der kulturindustriellen Produkte und Gehalte eine rege, kontroverse und veränderliche Kommunikation der Gesellschaft mit sich selbst erkennen läßt, die über diese Produkte und Gehalte vermittelt wird. Die Produktion der Kulturindustrie ist faktisch sowohl abhängig vom gesellschaftlichen Diskurs wie auch Teil desselben, und dieser Diskurs verweist nachhaltig darauf, da $B$ es um die Fähigkeit der Subjekte zur selbstbestimmten Stellungnahme und Meinungsäußerung nicht so schlecht bestellt ist. Gerade die faktische Struktur der Kulturindustrie scheint mir daher dem Theorem von ihr, d.h. zunächst: dem Pessimismus gegenüber den Subjekten und der Annahme einer Manipulationsbereitschaft zu widersprechen.

Konsistent hingegen ordnet sich die Manipulationsthese selbst in das totalitarismustheoretische Paradigma der Kritischen Theorie ein. Jene ,von oben' dominierte, manipulativ-instrumentelle Verwendung der Medien zum Zweck eines Social engineering nämlich, das die letzten Reste noch vorhandenen Widerspruchspotentials beseitigen und mit einer Mischung aus Ablenkung, Ideologievermittlung und Vergnüglichkeit die Inklinationen des Publikums, sich mit dem Bestehenden einzurichten und eigenen Unstimmigkeitsgefühlen auszuweichen, verstärken will, ist exakt die medienpolitische Strategie totalitärer Systeme wie etwa des Nationalsozialismus. Dort ging es ja gerade um Verhinderung jeder Bewußtwerdung der Subjekte und um Zementierung des dichotomischen Systems von Führung und Geführtwerden bzw. von Führern und Geführten. Dort war in der Tat ein genuin instrumentell-rationaler Einsatz der Medien, insbesondere des Films, für ein entsprechendes sozial-gesellschaftliches Steuerungsunterfangen wahrzunehmen, dessen ,medienethischer' Utilitarismus durchaus vom Paradigma der instrumentellen Vernunft her interpretiert und offengelegt werden kann (vgl. 3.). Auch läßt sich die ,Klasse der Herrschenden dort eindeutig identifizieren und soziologisch-personenbezogen dingfest machen. Das Kulturindustrietheorem ,entbirgt' deshalb in seiner Modellvorstellung von einem instrumentellen Einsatz der Medien zum Zweck der Manipulation der Beherrschten durch die Herrschenden unmittelbar seine Herkunft aus einer Totalitarismusanalyse und seine kontextuelle Verknüpfung mit der geschichtsphilosophischen Fragestellung der Kritischen Theorie. Sie zeigt damit aber gleichzeitig (wieder), daß diese Fragestellung, auf die modernen demokratischen Systeme angewandt, diese verfehlen muß. Keinesfalls nämlich kann in diesen Gesellschaften noch von einer Manipulation unter der Dichotomie eines Klassenantagonismus gesprochen werden. Vielmehr finden sich dort vielfältige interaktionelle Bezüge zwischen Produzenten und Rezipienten sowie der Produzenten und Rezipienten untereinander, die es nicht mehr erlauben, von einem Social engineering durch eine sozial greifbare Schicht zu sprechen. An der Genese der diskursiven Inhalte und ihrer kulturindustriellen Umsetzung sind, wenn auch in unterschiedlicher Weise und in unterschiedlichem Grad, letztlich alle beteiligt. Wie die statische Vorstellung einer entwicklungslosen Gesellschaft der Realität nicht entspricht, verfehlt diese auch die einer rückkopplungslosen Kulturproduktion. Faktisch haben wir es hingegen mit einer prozessualen Gesellschaft zu tun, deren Proze $B$ von allen Gesellschaftsmitgliedern getragen ist und vorangetrieben wird und in der dieser Prozeß sich sowohl in den medialen Gehalten abbildet als auch von diesen Gehalten vermittelt wird. Daher kann es weder einem Produzenten 
gelingen, sich gegen die Bedürfnisse des Publikums auf Dauer durchzusetzen, noch kann angenommen werden, daß das Publikum nur auf Bestätigung des Gegebenen abstellt. $\mathrm{Zu}$ differenziert nämlich ist die Publikumsgruppe in sich und zu divergent sind die Diskursbeiträge der einzelnen Subgruppen und Subjekte, als daß aus diesen Beiträgen die blanke Affirmation abgelesen werden könnte. Durchaus ablesen läßt sich hingegen, da $B$ es im gesellschaftlichen Diskurs immer wieder zu Kontroversen und Meinungs-, Interessen- und Überzeugungskollisionen kommt, in denen sowohl der Streit darüber geführt wird, wie das ,Gegebene' auszusehen habe, als auch darüber, was es eigentlich sei. Die Struktur der demokratischen Gesellschaften und ihrer Kulturproduktion wird daher sowohl vom dichotomischen Basisparadigma als auch von der statischen Vorstellung der Manipulation faktisch verfehlt. Das Kulturindustrietheorem reicht zur Klärung der Interaktionsverhältnisse innerhalb und außerhalb des Kultursachbereichs der Medien nicht hin.

\section{Appendix: ,Kritische' und ,konservative' Medienkritik}

Im vorstehend rekonstruierten Kulturindustrietheorem fällt nun noch auf, da $B$ es mit seiner Kritik eine Verwandschaft zur ,konservativen' Medienkritik aufweist, wie sie bei Keilhacker und seinen Schülern vorliegt. Zwar kennt die Kritische Theorie keineswegs jene moralischen Vorwürfe, die dem Film eine Korrumpierung des Ethos, eine Verrohung und Brutalisierung oder Sexualisierung und Kriminalisierung anlasten. Im Unterschied zu den ,Konservativen' stellt sie ja nicht auf die Restitution einer vormodernen Moralität ab, unter deren Gesichtspunkten die neuzeitliche Dynamisierung und die autonome sittliche Kreativität der ,Basis' Probleme darstellten. Vielmehr entgeht ihr die Tatsache dieser Dynamisierung ebenso wie die kreative Autonomie und nimmt sie ein statisches Gefüge in Gesellschaft und (sittlicher) Lebenswelt an. Auch liegt es Horkheimer und Adorno ferne, gar eine soziale Destabilisierung vom Film verursacht zu sehen, dem sie ja gerade eine gesellschaftsbezogene Stabilisierung durch Affirmation vorwerfen. Sie sehen derart eher jenen Zustand realisiert, den Kinoreformer und Filmerzieher auf ihre Weise jeweils erst anstreben, und es ist diesen ein Skandalon, was jenen als hehres Ziel vor Augen steht. Trotz dieser antagonistischen Divergenz aber, die ihre Wurzel letztlich wieder in der konträren Grundstellung zum Projekt der Moderne hat (vgl. 5.3.), zeigt sich an einigen Stellen der Medienkritik auch eine überraschende Konvergenz. Sowohl die ,Konservativen', als auch Horkheimer und Adorno nämlich lasten dem Film Standardisierung und Manipulation an, durch die sie jeweils eine spezifische Form von Menschsein vernichtet sehen, und in beiden Fällen wird den Menschen hierbei eine verderbliche Schwäche und Kooperation attestiert.

So werfen sowohl die Filmerzieher als auch Horkheimer und Adorno dem Film vor, da $B$ er aus Gründen breiter Rezipierbarkeit und des finanziellen Gewinns eine Standardisierung und Serialisierung seiner Gehalte erkennen lasse, die zugleich deren ,Veroberflächlichung' bedingten. In beiden Fällen werden also die beiden ökonomischen Prinzipien der Tauschbarkeit und der Profitabilität für eine Nivellierung und Entleerung der transportierten Gehalte verantwortlich gemacht. In beiden Fällen scheint auch die Folge der Standardisierung der Filme eine Standardisierung der Rezipienten zu sein. Keilhacker spricht hierbei von ,Uniformierung und von der ,Herstellung des Massenmenschen' (vgl. 4.2.), während Horkheimer und Adorno 
zunächst auf die Bedürfnis- und Geschmacksgleichschaltung gegenüber Filmen zum Zweck der Produktplanung abheben. Doch auch sie implizieren dann die ,Vermassung und Angleichung der Rezipienten untereinander, wenn sie in ihrer Herrschaftskritik die Standardisierung unter anderem in eine Übernahme von Verhaltensschemata und habituellen Klischees münden sehen. Als Konsequenz erscheint hier eine ähnliche ,uniformierende' Gleichschaltung der Rezipienten wie bei Keilhacker. Ebenso findet sich das Keilhackersche Bild der extravertierten Individuen, die ständig von einer Reizquelle und Ablenkungsmöglichkeit zur nächsten hasten, in der Kritischen Theorie parallelisiert, wenn dort die Kulturindustrie durch ihre Scheininnovationen die Subjekte in eine hektische Betriebsamkeit verwickelt. Keilhacker und seine Schüler beklagen dabei als Kehrseite dieser Filmwirkungen den Verlust von ,Eigentlichkeit', die sich in eine personale, eine individuelle und eine erlebnisbezogene Komponente aufspaltet (vgl. 4.2. und 4.5.). Obschon gerade Adorno sich polemisch gegen einen derart ,heideggernden' „Jargon der Eigentlichkeit“158 wendet, lassen sich die ersten beiden Komponenten doch auch in seinem Vorwurf spüren, wenn er die ,Gleichschaltung der Rezipienten und damit den Verlust von Individualität beklagt oder wenn ihm die Spontaneität der Subjekte, ihre Kreativität und Vorstellungskraft durch Gewöhnung an Repetition präformierter Schemata korrumpiert scheinen. Freilich stellen Keilhacker und die Filmerzieher ihren Eigentlichkeitsbegriff in den Kontext der vita contemplativa und einer darin garantierten "Tiefe der Personalität, während die Kritische Theorie ihren Kontrastpunkt zur Standardisierung des Publikums und zur inhaltsleeren Beschäftigtheit aus der aufklärerisch bestimmten Subjektivität gewinnt. Die divergente Grundstellung zum neuzeitlichen Konzept des Subjekts bleibt derart auch hier zunächst nochmals betont. Abgesehen vom divergenten Begriffskontext aber wird in beiden Fällen mit der ,Uniformierung/ Gleichschaltung und dem formalen, hektischen Betrieb eine Art Selbstverlust in Blick genommen, der sowohl über den Eigentlichkeitsbegriff gefaßt werden, als aber auch durch entsprechende Adjektiva über den Subjektbegriff dingfest gemacht werden kann, ohne da $\beta$ der Gebrauch der beiden Begriffe hierbei, im vorliegenden Vorwurf, noch sehr verschieden erscheint. Was bei Keilhacker mit der ,Tiefe' der Personalität und dem Schöpfen aus dem Innenbezug gedacht ist, scheint mir durchaus vergleichbar mit dem Gedanken der (selbstursprünglichen) Spontaneität und Kreativität des Subjekts bei Adorno und Horkheimer zu sein. In der konkreten Kritik nähern sich die Begriffe so einander an und tritt der Antagonismus der Grundstellung daher erneut etwas hinter den in der Phänomenkritik erkennbaren Verwandtschaften zurück.

Ähnlich verhält es sich auch mit dem zweiten Vorwurf, dem der Manipulation. Zwar geben Horkheimer und Adorno dieser Manipulation einen totalitär-politischen Kontext, der den Filmerziehern und ihrem Lehrer völlig fremd ist. Auch stellen sie, kohärent zur betonten Grundoption, jetzt nicht auf das spontane, innenbezogenkreative, sondern auf das autonome Subjekt ab, das durch die Manipulation in seinem Wesen getroffen, ja dieses Wesens entkleidet scheint, während Keilhacker und seine Schüler die Subjektautonomie gerade ablehnen und lediglich eine begrenzte

158 vgl. Adorno, Theodor, Jargon der Eigentlichkeit, in: ders., Gesammelte Schriften 6, Frankfurt 1973, 413-526 
Form von Selbstbestimmung zulassen. Doch gilt beiden Positionen in ihrem Vorwurf die Fremdbestimmung des Menschen als Skandalon. Auch Keilhacker, der Autonomie nicht wiederherstellen will, wendet sich polemisch gegen Heteronomisierung und lastet diese den Medien an. In beiden Fällen steht im Zentrum der Klage so die entfremdende und vergewaltigende Wirkung, die den Medien unterstellt wird und offenbar der Würde des Menschen widerspricht. Die Skandalisierung dieser Heteronomie und ihrer Wirkung legt sich dann freilich etwas unterschiedlich aus. Als Konsequenzen der Manipulation nämlich erscheinen in der Filmerziehung, etwa bei Kerstiens, eine durch das ,Starwesen' und mimetische Suggestionen erzeugte ,Hörigkeit und Reizverfallenheit. Im Blick sind zunächst vordringlich manipulative ,Überfremdungen' durch modische, vom Starwesen vermittelte Verhaltensschemata. Horkheimer und Adorno hingegen monieren die anscheinend distanzlose Überwältigung der Rezipienten durch filmvermittelte Ideologien und die Auflösung des gesellschaftsbezogenen Urteilsvermögens. Bei ihnen geht es um die Überflutung der Subjekte durch heteronome Interpretamente und eine Störung ihrer politischen Weltauslegung. Damit weist der filmerzieherische Manipulationsvorwurf wieder eine Nähe zur Eigentlichkeitskritik auf, für die das ,Modische' eine ,Veroberflächlichung' und ,Uniformierung' bedeutet, während der Vorwurf der Kritischen Theorie sich auf ihre totalitarismustheoretische Gesellschaftskonzeption bezieht. Trotz dieses Unterschieds ergeben sich aber auch wieder Berührungen. Obschon nämlich verschiedene Lebensbereiche in den Blick genommen sind, geht es letztlich in beiden Fällen um den Verlust der eigenständigen Urteilsbildung bzw. der Fähigkeit zu dieser. Wenn auch in unterschiedlichen Kontexten zielen beide Positionen auf die Kompetenz der Subjekte bzw. Personen zu einer selbstbestimmten Meinungsfindung, die sie von der manipulativen Kraft der Medien bedroht sehen. Daneben wird außerdem in der Filmerziehung eine Korrumpierung des Realitätsbezugs und ein Verfall an eine Existenz in sekundären Welten beklagt. Zwar ist die Realität, die hierbei als verloren gilt, nicht eindeutig definiert, doch läßt die Figur des Arguments ebenfalls wieder einen Bezug zur Kritischen Theorie erkennen. Dort hat die verlorene Realität im Unterschied zum Vorwurf der Filmerziehung freilich eine eindeutige Gestalt: es ist die gesellschaftliche Wirklichkeit, die von der Manipulation als verdeckt gilt. Die Verdeckung aber scheint dabei in derselben Weise zu geschehen, wie sie in der Filmerziehung diskriminiert wird, nämlich durch die Etablierung einer Scheinrealität im Film, die in den Alltag hinübergenommen wird und dessen Wahrnehmung präformiert. Mit der Überformung der realweltlichen Wirklichkeit durch die Filmrealität beginnen die Subjekte ebenfalls in ,abgeleiteten' Realitäten zu existieren. Auf der Basis unterschiedlicher theoretischer Kontexte lassen die Manipulationsvorwürfe der beiden Positionen so wieder Berührungen und Verwandschaften erkennen. In beiden Fällen scheint die Potenz des Films, eine ,zweite Wirklichkeit‘ zu erzeugen, äußerst prekär zu sein und wird hieraus ein Verfall abgeleitet.

Schließlich aber, und darin sehe ich die entscheidende Verwandtschaft der beiden Konzepte, nehmen sowohl die Filmerziehung als auch die Kritische Theorie wieder eine pessimistische Einschätzung der Rezipienten vor, die anscheinend kaum eine Potenz für die Ausübung ihrer Autonomie und zur Erlangung eines Selbstands mitzubringen scheinen. Verortet sind die Gründe für die pessimistische Einschätzung, wie schon im Vergleich der Modernitätskritiken zu sehen war, in beiden Konzepten 
divergent. Sie werden von der Keilhackerschule primär anthropologisch erarbeitet, während die Kritische Theorie sie rationalitätstheoretisch herleitet. Doch scheint mir der rationalitätstheoretische Pessimismus dem anthropologischen durchaus adäquat und in der Wirkung ebenbürtig zu sein. Beidemale nämlich wird den Subjekten keine rechte Fähigkeit zur Herstellung und Erhaltung ihres Status zugetraut, und beidemale gelten sie als den Verfallsphänomenen schranken- und hilflos ausgeliefert. Im vorliegenden Fall findet dies bei Keilhacker seinen terminologischen Ausdruck in der ,Außengeleitetheit', die er als zeitgenössisches Phänomen den Studien Rießmanns diagnostisch entlehnt. Das ,typische‘ Individuum des 20. Jahrhunderts, ja der modernen Welt schlechthin scheint der ich-schwache, von Vorgaben abhängige und leitungsbedürftige Mensch zu sein. In der Konsequenz dieser Diagnose scheint es dann nur folgerichtig, den modernen Defizienzen durch die Forderung entsprechend verläßlicher normativer Direktiven für diesen führungsbedürftigen Menschen begegnen zu wollen, wie es Keilhacker mit der 'Wertewelt' versucht. Obschon nun die Kritische Theorie diese Konsequenz nicht zieht und keinesfalls ziehen will, findet sich auch bei ihr als Folge ihres - rationalitätstheoretisch grundgelegten - Pessimismus die Konstatierung einer Ich-Schwäche als Zeitsymptom, von dem alle Menschen des 20. Jahrhunderts gezeichnet und geschlagen scheinen. ${ }^{159}$ Unter den Bedingungen der instrumentell eingerichteten Gesellschaft und ihrer sozialen Strukturen sowie der äonenalten Festschreibung von Herrschaft und Unterwerfung gilt die Ichidentität als angegriffen und tendenziell aufgelöst, so daß kaum noch den Einflüssen von außen Widerstand entgegengesetzt werden und eine Selbstwahrung gelingen kann. Kehrseite dieser ,Entgrenzung' und ,Auflösung der Subjektivität und Ichhaftigkeit scheint dann ein Bedürfnis nach autoritativen Vorgaben, nach Leitung und Führung zu sein. Das derart bestimmte Individuum gerät in der Konsequenz nicht anders als bei Keilhacker zum Kollaborateur der Manipulation und scheint nach dieser geradezu zu verlangen. Die terminologische Fixierung der These vom derart fremdbestimmungsfreundlichen Subjekt findet entsprechend eine Gestalt, die der Keilhackerschen gleichklingt: Was in der ,konservativen' Theorie die ,außengeleitete' Persönlichkeit hieß, ist nun als ,authoritarian personality benannt. ${ }^{160}$ Die ,konservative' und die ,kritische 'Medienkritik lassen damit beide, analog zu den Modernitätskritiken, Verwandtschaften erkennen, die in der pessimistischen Bewertung der Subjekte und ihrer Potenzen beinahe zur Identität führen, zumindest aber in ihrem AusmaB durchaus vergleichbar sind.

\subsection{Ethik der Negation: Die Untauglichkeit der Medien für eine Lösung und die Aufbewahrung des Humanum in der Kunst}

Theodor W. Adorno konnte seine Absicht, eine Ethik zu schreiben, nicht mehr realisieren. Gleichwohl enthält der vorliegende Entwurf der Kritischen Theorie und ihrer Medienreflexion bereits Bausteine, die die Rekonstruktion in der Theorie enthaltener ethischer Intentionen und Imperative zulassen. Ähnlich wie bei den ,konservativen' Theoretikern können hierbei zunächst zwei Ebenen unterschieden werden, die

${ }^{159}$ vgl. hierzu auch: Honneth, Kritik, $96-100$

160 vgl. Adorno, Theodor, Studien zum autoritären Charakter, Frankfurt 1973 
den beiden Ebenen einer grundsätzlichen Auseinandersetzung mit der Moderne und ihren Gesellschaften sowie einer Reflexion der Rolle und Funktion der Medien darin entsprechen: Aus diesen Auseinandersetzungen ergeben sich die Ebene einer generellen Ethik, auf der die Restitution der Aspirationen des Projekts der Moderne angezielt wird, und die einer Medienethik, auf der die Formierung und Aufgabenstellung dieses Kultursachbereichs unter dem generellen ethischen Ziel normiert werden soll. Gleichwohl zeigt sich im zweiten Fall, daB die kulturindustrielle Organisation der Medien ihrer Aufgabe entgegenarbeitet und unter ihren Bedingungen das ethische Ziel gar nicht erreicht werden kann. Stattdessen erhält dann die Kunst den Status einer Platzhalterin des Humanum und zeigt sie sich als jener Kultursachbereich, in dem die Möglichkeit einer Realisierung des ethisch Gebotenen selbst unter den gegenwärtigen Bedingungen am Horizont aufscheint. Aber auch die derart vielversprechende Kunst scheint mit der Kulturindustrie wieder einen Widersacher zu erhalten, durch den die Hoffnung auf eine Lösung korrumpiert wird. Damit setzt sich die verfallstheoretische Perspektive der Kritischen Theorie auch in den Ansätzen zu einer ethischen Lösungsreflexion wieder durch.

\section{Die Negationsethik der Kritischen Theorie}

Zunächst nun können auf der Ebene einer generellen Ethik aus der ferventen Parteinahme der Kritischen Theorie für die Ziele und Intentionen der Aufklärung ein grundsätzliches ethisches Ziel und eine grundsätzliche Maxime abgeleitet werden. Diese Ableitung legitimiert sich daraus, da $B$ die Kritische Theorie die aufklärerischen Aspirationen zum Angelpunkt ihrer verfallstheoretischen Kritik macht und gerade die Verfehlung dieser Aspirationen skandalisiert. Gemäß der rationalitätstheoretischen Rekonstruktion und ihrer gesellschaftstheoretischen Konkretion besteht das eigentliche Ärgernis der Verfallsgeschichte ja in der Verhinderung und Verweigerung der vom Projekt der Moderne angezielten Subjektivität, Autonomie und Freiheit sowie einer vernünftigen Gesellschaftsorganisation, durch die das Angezielte realisiert und gesichert werden kann, und richtet sich die Kritik der Kritischen Theorie auf den Verrat dieser von Aufklärung und Moderne versprochenen Bestände. Die Empörung aber, mit der diese Kritik geübt wird, kann unschwer als moralische dekodiert werden: Sie setzt die genannten Versprechungen normativ als Zielmargen an und insistiert auf ihrer Realisierung als einer ethisch gebotenen. Das grundsätzliche ethische Ziel besteht daher offensichtlich in der Herstellung von Subjektivität, Autonomie und Freiheit sowie der vernünftigen Gesellschaftsorganisation, und die grundsätzliche, im Hintergrund der Kritik anwesende ethische Maxime ist das Gebot der Verwirklichung dieses Ziels. Obschon die Kritische Theorie hierzu kein explizit ethisches Prinzip bemüht, kann dabei die Subjektivität des autonomen Subjekts als ein solches, der Personwürde analog gebrauchtes Prinzip betrachtet werden. Aus dem Blickwinkel einer ethischen Rekonstruktion ergibt sich so zunächst ein prinzipienethischer Ansatz in der Kritischen Theorie, der ausgehend von der ,Würde des Subjekts' die Realisierung von Autonomie und Freiheit in einer entsprechenden Gesellschaftsstruktur fordert. Hieraus erhält die Kritische Theorie auch erst ihren Impetus und die kriteriologische Folie für ihre Kritik.

In der Bestimmung der konkreten Bedingungen für die Herstellung von Subjektivität, Autonomie und Freiheit sowie einer diesen dienlichen Gesellschaftsstruktur aber 
sieht sich die implizite Ethik der Kritischen Theorie gezwungen, die Angabe positiver Zielstrukturen und gebotener Strategien weitgehend wieder zu verlassen und sich auf weite Strecken in eine Ethik der Negation zu transformieren. Unter der Determination der Verfallsgeschichte nämlich gehen sowohl die Subjektivität als auch alle strukturellen Maßnahmen zu ihrer Herstellung im Gemächte der instrumentellen Vernunft unter. Wie zu sehen war, zeigt sich das Subjekt der instrumentellen Vernunft entweder als depraviertes Scheinsubjekt, das seiner menschlichen Natur entfremdet und einer Oligarchie unterworfen ist, oder als illegitimer Usurpator, der seinen Status durch Beherrschung und Desubjektivierung der anderen Subjekte erreicht. Die instrumentell-rationale Subjektivierung und ihre strukturelle Organisation kann stets nur Defizienz hervorbringen und ist ethisch verwerflich. Unter der Präsupposition der umfassenden Herrschaft der instrumentellen Vernunft aber lassen sich dann die Vorbedingungen für eine ethisch gerechtfertigte und konkret gelingende Subjektivität kaum noch positiv angeben. Jede Strukturbedingung wäre in Gefahr, sich wieder als ein Produkt des instrumentellen Gemächtes und somit als Verfallserscheinung zu erweisen. Daher ist eine positiv-normative Kriteriologie für die Einrichtung des Subjekts in der Welt und die Organisation der Gesellschaft, eine Festsetzung von ,zielhaften' Strukturbedingungen für die Herstellung von Subjektivität nicht eigentlich mehr möglich und bleiben die ,positiven` Zielaussagen der Kritischen Theorie spärlich und diffus. ${ }^{161}$

Die primäre normative Aussage zur Herstellung des ethischen Ziels führt entsprechend zunächst nur die Gebotenheit der Negation alles instrumentell-funktionalen und seiner strukturellen Fixierung, d.h. die Negation des Bestehenden schlechthin ein. Unter der Voraussetzung der von der Kritischen Theorie durchgezeichneten Verfallsgeschichte nämlich erscheint nicht nur das ,Ganze als das Unwahre (Adorno), sondern es entbirgt sich dieses Ganze ethisch betrachtet auch als das ,Ungute'. Wie Wahrheit entsprechend einzig noch im Modus ,bestimmter Negation' ausgesagt werden kann, kann das ethische Ziel vorerst nur durch ,praktische Negation' in den Blick genommen und realisiert werden. $\mathrm{Zu}$ fordern und zu fördern ist aus ethischen Blickwinkel entsprechend Widerspruch gegen die bestehenden

${ }^{161}$ Diese verfallstheoretische Denkfigur und die Totalität, mit der die objektivierend-instrumentelle Vernunft darin als Agent des Verfalls gehandhabt wird, zieht es zugleich nach sich, daB eine ethische Verwerfung dieser Vernunft auch auf die ethische Theoriebildung selbst zurückschlägt. Ebenso, wie sich die Subjektivierung aus ethischen Gründen praktisch nicht mehr systematisch-objektivierend vollziehen kann, kann sich auch die Ethik theoretisch nicht mehr auf diese Weise entwerfen und muß sie von einer zusammenhängenden, rationalen Konstruktion Abschied nehmen. Sie zeigt sich derart auch auf einer metatheoretischen Ebene als Negationsethik, nämlich als aus ethischen Gründen erfolgende Negation einer ethischen Theoriebildung mit objektivierenden Mitteln. Eine analoge Konsequenz hat Adorno in der Tat zunächst für die philosophische Reflexion gezogen, wenn er in der „Negativen Dialektik“ ihre Denkbewegung als die eines, Antisystems' angibt und versucht, ,anstelle des Einheitsprinzips und der Allherrschaft des übergeordneten Begriffs die Idee dessen zu rücken, was außerhalb des Banns solcher Einheit wäre" (Adorno, Dialektik, 10). Für die Ethik ist dieser Schritt nicht mehr explizit erfolgt, da sie nicht mehr verfaßt wurde. Gleichwohl läge in der Konsequenz des rationalitätstheoretischen Ansatzes und der verfallstheoretischen Grundstellung die Aufkündigung des systematisch-rationalen Anspruchs auch der Ethik zugunsten etwa einer ,Modellethik', die sich nur noch in praxi und von Fall zu Fall konstituiert. Faktisch freilich finden sich bei Adorno noch systematisch-objektive Aussagen, wie etwa die systematische Forderung der Negation alles Bestehenden (vgl. Text). 
Struktureinrichtungen und Kritik an denselben sowie die Dynamisierung und Veränderung statisch fixierter Verhältnisse. Wie jedoch diese Formen der ,praktischen Negation' konkret aussehen sollen, und wie sich in ihnen das Ziel realisieren läßt, bleibt etwas unklar. So scheint zwar zunächst aus der Negationsethik der Kritischen Theorie auf der generellen Ebene in letzter Konsequenz die Forderung der Revolutionierung der bestehenden Strukturen und Einrichtungen hervorzugehen, d.h. es scheinen Widerspruch und Dynamisierung in diesem Sinn zu interpretieren zu sein. Gemäß dem Marxschen Imperativ wären dann ,alle Verhältnisse umzuwerfen, in denen der Mensch ein erniedrigtes, ein geknechtetes, ein verlassenes, ein verächtliches Wesen ist ${ }^{\text {“162 }}$. Nur durch diese Form der Verneinung des desubjektivierenden Zustands, die die faktischen Struktureinrichtungen der totalitären Gesellschaft aufbricht, scheint den Subjekten die Chance auf eine dennoch gelingende Subjektivierung eröffnet. Der Marxsche Imperativ scheint daher durchaus die ethische Konsequenz des totalitarismustheoretischen Ansatzes der Kritischen Theorie zu benennen: Als totalitäre ist Gesellschaft schlechthin ethisch intolerabel und muß sie umgestürzt werden.

Doch ist bekannt, daß Adorno sich gegen eine solche Interpretation seiner Theorie etwa durch die Studentenbewegung von 1968 gewandt hat. Auch dies liegt in der Konsequenz seines Ansatzes: Unter den Bedingungen der totalen Herrschaft der instrumentellen Vernunft scheint ein Entkommen selbst revolutionär kaum möglich, sondern vielmehr die Revolution wieder instrumentell gefährdet zu sein. Der revolutionäre Impetus nämlich dürfte nicht aus einer rational-objektivierenden Reflexion hervorgehen und müßte sich zudem gegen jeden neuen Versuch einer Fixierung struktureller Ergebnisse wenden, soll die erneute Herrschaft instrumenteller Vernunft verhindert werden. Sonst droht eben jene Gefahr, an der auch die kommunistische Revolution gescheitert ist, d.h. die Gefahr einer instrumentellen Organisation und Fixierung der revolutionär entstandenen Verhältnisse, und damit eines neuerlichen Verfalls. Die von der Negationsethik geforderte Verneinung des Bestehenden bleibt daher ein letztlich nur heuristisches Prinzip, dessen Befolgung zwar die Möglichkeit des Guten, insbesondere des ,guten Lebens', als Kontrastmöglichkeit zur ,schlechten Realität' ex negativo in Blick treten läßt, aber weder seine Herstellung im Sinn einer revolutionären Strategie, noch seine Gestalt material-inhaltlich beschreibt, und die Negationsethik der Kritischen Theorie selbst fährt sich weitgehend in einem unbestimmten Gestus der Verneinung fest.

Ergänzt findet sie sich allerdings noch durch die implizite Forderung der Verfallsgeschichte, die ausgegrenzten und verdrängten Bestände, d.h. die Sinnlichkeit, Spontaneität, Kreativität und Irrationalität sowie alles Dysfunktionale, ,Systemunverträgliche' wieder zu reaktivieren. Hierdurch werden nun ,positive' Zielstrukturen ansatzhaft in Blick genommen, jedoch zunächst einmal wieder vordringlich als Folie und Impetus der Negation genutzt: Primär nämlich wird erneut das Bestehende, das gerade auf Ausgrenzung und Verdrängung zielt, durch die Reaktivierung negiert und skandalisiert. So deutet sich mit dem Verdrängten zwar ein ,positiv' benennbarer Bestand an, der jetzt in die Rolle eines Wegbereiters von Zielstrukturen gerät und einen Vorblick auf eine mögliche, ,nicht-repressive‘ Gesellschaft bietet. In diesem

162 Marx, Karl, Zur Kritik der Hegelschen Rechtsphilosophie, in: ders., Die Frühschriften, Stuttgart 1971, 207-225, 216 
Sinn spielt später auch die Kunst ihre Rolle als Aufbewahrungsort dieser Bestände (vgl. unten). Aber es lassen sich aus der Reaktivierung der genannten Bestände selbst kaum strukturell-gesellschaftliche Organisationsformen herleiten. Mit ihnen ist vielmehr die treibende Kraft der Verneinung, das Potential gefunden, aus dem die nötige Negation hervorgehen kann, nicht schon die endgültige materiale Bestimmung des zu erreichenden Zustands und der Zielstrukturen. Allenfalls kann gesagt werden, da $B$ die Zielstrukturen der Realisation des Verdrängten und Ausgegrenzten Raum bieten müssen. Im Blick ist so mittelbar die etwas diffuse Vorstellung einer ,nicht-repressiven' Gesellschaft, die ihren Mitgliedern unter anderem die Möglichkeit bietet, frei ihren Antrieben nachzugehen und ihre Sinnlichkeit zu leben sowie spontan und kreativ tätig sein zu können. Gleichwohl wird dieses Zielbild nicht sehr deutlich, sondern bleibt es wenig konkret. Unter den gegenwärtigen Bedingungen ist daher die Negationsethik der Kritischen Theorie auch dort, wo sie sich in dieser Weise auf das ausgegrenzte Potential bezieht, hauptsächlich am Widerspruch an sich interessiert und dient das diffuse Zielbild primär als kritische Folie für die ebenfalls diffuse und unbestimmte Verneinung des Bestehenden.

Dieser Ansatz schlägt sich dann auf der Ebene der Medienethik analog um. So bedeutet die prinzipienethische Einführung von Subjektivität, Freiheit und Autonomie als ethisch gebotenen Realisierungszielen, da $\beta$ auch die Medien dieser Realisierung zu dienen haben. Dabei sind auch sie zuallererst als Instanz des Widerspruchs, der Negation des Bestehenden gefordert. Adorno verweist daher darauf, daß nur dort, wo die ,inoffiziellen Modelle', die Kritik an den bestehenden Verhältnissen und die Appräsentation des Ausgegrenzten zum medialen Inhalt geraten, die kulturindustrielle Produktion Legitimität erlangen könnte. ${ }^{163}$ Vordringlich als Statthalter des Unbotmäßigen, als Instanz der Verneinung könnten die Medien demnach ihrer moralischen Pflicht genügen, und die Medienethik zeigt sich - als Ethik für die Medien vorerst einmal ebenfalls als Negationsethik. Aus der Umkehrung ihrer detaillierten Kritik an bestimmten kulturindustriellen Typika und Strategien lassen sich dann freilich zusätzlich auch ,positive' medienethische Kriterien angeben, die die gebotene Funktion und Rolle der Medien näher auslegen. Obschon die Kritik detailliert ist, bleiben jedoch die daraus ableitbaren, positiven' Zielstrukturen und -gebote für die Medienwelt wieder etwas diffus.

So gälte es für die Medien, die Subjektivität der Gesellschaftsmitglieder dadurch zu fördern, daß sie Kreativität und Spontaneität ermöglichen und einer autonomen Kulturschöpfung Vorschub leisten. Statt der Verstärkung der totalitären Struktur durch Serialisierung und Standardisierung sowie durch Manipulation ,von oben' in die Hände zu arbeiten, wäre es ihre ethisch gebotene Aufgabe, individuelle und stets neue, besondere Gehalte zu produzieren, die primär von der ,Basis' selbst gestellt werden. Neben der kritisch-negierenden (und wohl enthüllenden) Funktion tritt damit unter ethisch-rekonstruktivem Blickwinkel eine kommunikative und kulturschöpferische Rolle der Medien zutage, die der innergesellschaftlichen Verständigung und der kulturellen Innovation dient. Als Modelle für die Medienwelt stehen dabei der künstlerische Akt, der spontan, kreativ und autonom ist, und die face-to-face-Kommunikation bzw. eine ,Basiskommunikation' im Hintergrund. Um dieser Vorstellung

${ }^{163}$ vgl. Adorno, Filmtransparente, 82-83 
gerecht werden zu können freilich, müßten die Medien, entkommerzialisiert' werden und stände an erster Stelle die kreative Produktion, nicht aber die Rezeption. Gleichzeitig müßte entweder ihre massenhafte Verbreitung eingeschränkt oder jeder Rezipient mit einer Fülle von möglichst kontroversen medialen Gehalten beliefert werden, um auch die Gefahr einer Manipulation der ,Basis' durch sich selbst zu verhindern. Genau besehen bedeutet das, daß die Medien sich der Kunst annähern und die Rezipienten in den Stand von Künstlern erhoben werden sollen.

Das aber gilt als unter den gegebenen Bedingungen schlicht unmöglich. Die faktische Einrichtung der Kulturindustrie scheint gerade diese Erfüllung der medienethisch gesetzten Pflicht und die Etablierung der (wiederum diffusen) Zielgestalt der Medienwelt zu verhindern. So gilt die Kulturindustrie ja als Realisierung und Verstärkung der Herrschaft der instrumentellen Vernunft sowie als Büttel der Herrschenden, d.h. als Agentin der Aufrechterhaltung der bestehenden Defizienzstruktur. Damit aber zeigt sie sich als selbst ethisch zu negierende und als abzuschaffende Institution. Auf diese Weise setzt sich die Ethik der Negation letztlich wieder durch und läßt die Verneinung der Medien selbst als medienethisch geboten deutlich werden. Ähnlich, wie auf die Zielgestalt der Gesellschaft vordringlich durch Kritik, Widerspruch und Negation hingearbeitet werden soll, kann vorerst auch auf die der Medien nur ex negativo abgestellt werden und ist von ihnen in ihrer kulturindustriellen Gestalt keine Lösung zu erwarten.

\section{Ästhetische Erlösung: Kunst als Hort ,wahrer Humanität'}

Anstelle der Medien erhält dann die Kunst in der Kritischen Theorie die Funktion einer kritischen, auf die ethisch gebotene Zielgestalt hindeutenden Kraft sowie einer Statthalterin des Verdrängten. Obschon nämlich die rationalitätstheoretische Fundierung der Kritischen Theotie in der "Dialektik der Aufklärung" letztlich die gesamte europäische Vernunfttradition verwirft und obschon durch die gesellschaftstheoretische Wendung dieses Verwerfens dann der Verfall selbst den Charakter einer ,negativen Totalität' gewinnt, so daß kaum noch ein Ausweg aus der Defizienz möglich scheint, setzt gerade Adorno auch vorsichtig zu einer Lösungsoption an, in der er die Kunst als zwar versehrten, jedoch nicht völlig korrumpierten Kultursachbereich wählt, aus dem eine spezifische Heilung der fehlgegangenen Subjektivierung des Menschen hervorgehen und dessen Wirkung auf die Gesamtgesellschaft die ,negative Totalität ${ }^{\prime}$ aufsprengen soll. Durch die Kunst scheint so das ethisch-rekonstruktiv im Vorstehenden erarbeitete gebotene Ziel einer Herstellung von Subjektivität, Autonomie und Freiheit in Blick zu treten und diese Herstellung ansatzhaft vorbereitet werden zu können. Vor allem bei Adorno gerät daher die Ästhetik zu einer der zentralen Disziplinen, deren reflexive Ausarbeitung einen möglichen Überschritt auf eine Versöhnung des Projekts der Moderne mit sich selbst und einen ,Vorgriff' auf eine ,positive Totalität" verspricht. ${ }^{164}$ Präformiert freilich ist diese theoretische Ver-

164 Zur Stellung der ästhetischen Theorie im Gesamtkonzept Adornos gibt es eine anhaltende Auseinandersetzung, die zwei divergente Positionen erkennen läßt: Einmal wird die These vertreten, daß die ästhetische Theorie die Sinnspitze der Philosophie Adornos vorstelle und sich das philosophische Denken letztlich in ästhetische Interpretation auflöse. Die ästhetische Theorie erscheint dann als beinahe eine Art ,Neuer Kritischer Theorie', die die Rationalitäts- und Gesellschaftstheorie nicht nur übersteigt, sondern zugleich umfaBt. (vgl. hierzu etwa: Baumei- 
ortung der Kunst bereits bei Horkheimer, erst bei Adorno aber erfährt sie ihre systematische Ausarbeitung.

Der genannte Vorgriff scheint dann jedoch wieder von den perniziosen Veranstaltungen der Kulturindustrie, die in diesem Kontext nun auch als instrumentell-ökonomisch korrumpierte Form des Kultursachbereichs Kunst auftritt, konteragiert zu werden. Die Kulturindustrie nämlich scheint zu versuchen, Kunst entweder zu verdrängen oder sich integrativ einzuverleiben. Wo Kunst also noch bestehen bleibt, droht sie ihrer Autonomie verlustig zu gehen und den normativen Bedingungen der Kulturindustrie unterstellt zu werden, in denen sich, wie zu sehen war, der Zusammenhang der ,negativen Totalität' der instrumentellen Vernunft und der von dieser getragenen und bewegten kapitalistischen Gesellschaft fortzuzeugen scheint. Durch die Integration der Kunst in die Kulturindustrie wird so die Lösungshoffnung gefährdet und erneut die Realisierung des ethisch gebotenen Ziels in Frage gestellt. Damit bleibt die Theorie Adornos zugleich erneut ihrer verfallstheoretischen Perspektive treu und formuliert sie für den gegenwärtigen Zustand zwar eine mögliche Auflösung des Verderbens, doch konstatiert sie zugleich die Existenz einer ,verfallskonformen Gegenmacht', die der kaum angedachten Lösung schon wieder entgegenwirkt.

Die grundlegenden Bausteine einer ästhetischen Theorie nun sind bereits in der frühen Phase der Kritischen Theorie bei Horkheimer vorgedacht, wenn auch noch mit etwas anderen Begriffen und ohne die rationalitätstheoretische Verankerung. Schon dort erhält zunächst die Kunst die Rolle jenes Kultursachbereichs, in dem die vom dehumanisierenden Zusammenhang der kapitalistischen Gesellschaft ausgegrenzten Bestände aufbewahrt bleiben und aus dem - obschon er zum Schaden der Gesamtheit elitisiert ist - der befreiende Umsturz aller desubjektivierenden Verhältnisse hervorgehen könnte. So sieht Horkheimer der Kunst, die „es verschmäht, sich gemein zu machen“, ein „Element von Widerstand“ innewohnen, ${ }^{165}$ das sich vordringlich gegen die repressive Uniformierung und Egalisierung richte, wie sie das kapitalistische Wirtschaftssystem vollziehe. ${ }^{166}$ Dieses Wirtschaftssystem nämlich gilt als vollständig durchorganisierte Struktur, die jedem Individuum seinen Platz und seine Funktion zuweise, es jedoch hierdurch als Person auflöse. Personen seien in seinem System „nur noch scheinbar Personen“, und „,Eliten“ wie Massen gehorchen

ster, Thomas, Kulenkampff, Jens, Geschichtsphilosophie und philosophische Ästhetik, in: Neue Hefte für Philosophie 1973/5; Bubner, Rüdiger, Über einige Bedingungen gegenwärtiger Ästhetik, in: Neue Hefte für Philosophie 1973/5) - Eine zweite These hingegen faßt Adornos Ästhetik als Versuch auf, in einem Kultursachbereich zunächst eine Lösungsoption zu versuchen, dem weitere reflexive Optionen folgen sollen. Die ästhetische Theorie gerät dann zu einer Disziplin philosophischer Reflexion, welche diese Reflexion keineswegs aufkündigt oder zu ersetzen sucht, sondern vielmehr - ähnlich Heidegger - einen neuen, gleichwohl genuin philosophischen Reflexionstyp entwerfen und hierbei die Kunsttheorie wieder an die Philosophie als eine ihrer Teildisziplinen anschließen will. (vgl. hierzu vor allem: Müller, Erkenntniskritik, 185-216) Die zweite Position scheint mir hierbei die Intention Adornos besser zu treffen als die erste. Für sie spricht zudem nicht zuletzt die eingangs erwähnte Tatsache, daß Adorno als Nachfolgewerk der ästhetischen Theorie bereits ein moralphilosophisches Buch geplant hatte und offenbar der Intention der „Negativen Dialektik“ treu bleiben wollte, mit den Mitteln des philosophisch-begrifflichen Denkens selbst über dieses hinauszugelangen (vgl. Adorno, Dialektik, 27).

165 Horkheimer, Kunst 29
Horkheimer, Kunst, 28 
einer Apparatur, die in jeder Situation nur eine einzige Reaktion für sie offenläßt“. ${ }^{167}$ Spontaneität, Freiheit und die Kreativität des ,Entwurfs‘ gelten derart als verdrängt und zerstört. In dieser Situation scheint nun Kunst die „Widerstandskraft der geistigen Fähigkeiten“ und ein ,Bild der Möglichkeit" wahrer menschlicher Existenz, von dem die Menschen ,insgeheim durchdrungen“ seien, aufzubewahren oder zumindest in Form einer Klage über die Abwesenheit dieser Möglichkeit zum Ausdruck zu bringen. ${ }^{168}$ Die Kunst gilt noch als Hort individuellen, kreativen Schaffens, in dem sich der Künstler als Person verwirklicht, und dessen Produkte entweder einen Durchblick auf eine humane, personale Existenz ermöglichen, oder wenigstens die Abwesenheit dieser Möglichkeit zu Bewußtsein bringen und ,skandalisieren'. Daher erhält die Kunst bei Horkheimer sowohl die Rolle einer Art Statthalter der möglichen wahren Menschlichkeit als auch einer protorevolutionären Kraft, die „den geschändeten Menschen ein schockierendes Bewußtsein ihrer verzweifelten Situation gibt" und ex negativo auf Freiheit verweist. ${ }^{169}$

Die Grundlinien der Kunstkonzeption der Kritischen Theorie sind derart bereits bei Horkheimer festgelegt. Als Leitbegriffe erscheinen die Personalität, welche vordringlich über die Individualität, Spontaneität und Kreativität ausgelegt wird, und die Nivellierung bzw. Uniformierung, welche aus einer Verplanung hervorzugehen scheint. Im Hintergrund wirksam ist eine ökonomistische Konzeption, die die moderne Gesellschaft unter das Kapitalismustheorem nimmt und letztlich schon als instrumentellen Zusammenhang begreift. In diesem Zusammenhang droht sich der Theorie zufolge die individuelle Personalität zusammen mit Spontaneität und Kreativität aufzulösen. An ihre Stelle scheint die Eingliederung der Personen in das Kollektiv einer durch ökonomische Gesetze restlos fixierten Gesellschaft zu treten, die Anpassung, Einfügung und repetitive Schematisierung verlangt. Hierbei gilt die Kunst als letzter Hort der Verwirklichung kreativer, spontaner und individueller Personalität. In ihr drücken sich sowohl diese Personalität als auch deren strukturelle Verhinderung aus. Sie erhält deshalb gleichzeitig die Funktion einer auf die wahre Existenz verweisenden wie einer dadurch Unzufriedenheit und revolutionäres Sprengpotential schaffenden Kraft.

In der „Dialektik der Aufklärung“" sowie vor allem bei Adorno werden diese Grundlinien dann weitergezogen und unmittelbar mit der rationalitätstheoretischen Wende verbunden. Die Begriffe wandeln sich dabei. Statt von Person ist nun vom Subjekt die Rede, dessen Selbstkonstitution als autonomes unterlaufen scheint. Der ökonomische Zusammenhang wird jetzt, wie in der Gesellschaftstheorie zu sehen war, auf den rationalitätstheoretischen zurückgeführt und die kapitalistische Verplanung als Funktionalisierung durch die instrumentelle Vernunft ausgelegt. Außerdem läßt sich nun eine ,ideale‘ Kunst, die mit dem Begriff des Emphatischen belegt wird, von einer ,realen' unterscheiden, die vom gesellschaftlichen Zusammenhang und seiner Defizienz bereits angetastet ist. Noch immer aber erhält die Kunst den Status einer Platzhalterin der abwesenden wahren Humanität und einer protorevolutionären Kraft. - So gilt Kunst in ihrem Idealbegriff bei Adorno zunächst als Wegberei-

${ }^{167}$ Horkheimer, Kunst, 33

168 Horkheimer, Kunst, 28

${ }^{169}$ Horkheimer, Kunst, 35 
terin des ,Nichtidentischen ${ }^{170}$, das dem ,Konformitätsdruck ${ }^{`}$ der instrumentell organisierten Gesellschaft, ja der instrumentellen Vernunft selbst, entgegengesetzt ist. Der Konformitätsdruck kann dabei als Inbegriff aller ,Konsistenzanforderungen' verstanden werden, wie sie die instrumentell eingerichtete Gesellschaft beständig ihren Mitgliedern abfordert: der konsistenten Unterdrückung der Triebsphäre im Arbeitsproze B, der konsistenten Einpassung in die Anforderungen von gesellschaftlichen Institutionen, des konsistenten Selbstentwurfs der eigenen Person, wie sie von einer gleichförmigen Funktionalität in einer gesellschaftlichen Position erwartet wird, etc. ${ }^{171}$ Eine solche instrumentelle Konformierung scheint durch die Kunst durchbrochen zu werden. Sie nämlich scheint gerade auf das Individuelle, das Besondere einer Sache abzuheben, die diese von allem anderen unterscheidet, und sie scheint die Brüche, Dysfunktionalitäten und Inkonsistenzen in Gesellschaft, Mensch und Welt hervorzuheben. Außerdem scheint sie durch ihre einzig der immanenten Verpflichtung einer ,Logik des Werks' gehorchenden Selbstzwecklichkeit der Instrumentalisierung an sich per definitionem entgegengesetzt. Nicht Tauschbarkeit und nicht Brauchbarkeit für etwas anderes macht das Wesen des Idealbegriffs von Kunst aus und determiniert deren Produktion, sondern einzig die Authentizität einer subjektiven (bzw. subjektvermittelten) Expression. Aus diesen Gründen gilt sie als jene Ausdrucksform, die der von der instrumentellen Organisation der Menschheit reprimierten ,Wahrheit' über Mensch und Welt ${ }^{172}$ sowie dem Ziel des Projekts der Moderne näher ist als jede objektivierende Vernunftanstrengung und instrumentelle Gesellschaftseinrichtung. In der Kunst scheinen sich sowohl die aller Instrumentalisierung und objektivierenden Vereinheitlichung bzw. Beherrschbarkeit entgegenstellenden Wesenszüge des Menschen zu realisieren als auch alle Versuche einer funktionalen Reduzierung und Verzweckung seiner Expressivität und Produktivität aufzuheben. Kunst erhält daher den Status jener Kulturform, in der einmal das ,Nichtidentische', d.h. hier: die von der instrumentell-funktionalen Einrichtung des Menschen in der Welt ausgegrenzten Bestände, wie Sinnlichkeit und Spontaneität, wieder reaktiviert werden, und die zum anderen einen freien, einzig von subjektiver Zwecksetzung determinierten, d.h. aber: autonomen Produktionsprozeß ermöglicht. Sie erscheint damit gleichzeitig als Gegenkraft zur repressiven Herrschaft der instrumentellen Organisation, als "Statthalter“ einer gesellschaftlichen Realisierung, wahrer" Humanität sowie als mögliche Wegbereiterin für eine endlich doch noch gelingende Subjektivierung des Menschen. ${ }^{173}$ Mit dem Idealbegriff der Kunst scheint derart die Chance einer Vollendung des Projekts der Moderne, ja der Menschheitsgeschichte als ganzer, in Blick zu treten und damit auch die implizierte Ethik der Kritischen Theorie realisiert zu werden.

${ }^{170}$ Der Begriff wird von ihm vordringlich in der "Negativen Dialektik“ entfaltet. Auch er zeichnet sich jedoch durch eine gewisse Unschärfe aus, die ihn als Gegenbegriff sowohl zur logischen Identität $(A=A)$ als auch zur psychologischen Identität (Ich bin Ich) und zu gesellschaftlichen Identifikations- bzw. Rollenforderungen erscheinen läßt. vgl. zur Begriffsunschärfe und ihrer differenzierten Auseinanderlegung auch: Müller, Erkenntniskritik, 170-185, 203-216; und: Dubiel, Identität, 51 - 76

171 vgl. hierzu: Müller, Erkenntniskritik, 204

172 vgl. hierzu: Adorno, Artist, 124-125: „Die Kunst (...) meint Treue zum möglichen Bilde vom Menschen. (...) sie verkörpert die Resistenz gegen den unsäglichen Druck, den das bloß Seiende übers Menschliche ausübt."

173 vgl. Adorno, Artist, 125 
In ihrem Realbegriff gleichwohl zeigt sich die so bestimmte Kunst als historisch in zwei Formen zerfallen, eine ,hohe' (oder, ernste') und eine ,niedere' (oder ,leichte') Kunst. In Form der Hochkunst bewahrt sich zwar die ursprüngliche Emphase auf und scheint das Nichtidentische dennoch durch, doch schlägt zugleich die gesellschaftliche Unrechtssituation auf sie über, welche die ,Privilegierten' von der ,Basis' scheidet. Dabei wird dann die Hochkunst sowohl in abgrenzender Bezugnahme auf den Praxiszusammenhang der Gesellschaft definiert und zur ,reinen', ,geistigen' und aller Kontingenz enthobenen Tätigkeit erklärt als auch gruppenbezogen vereinnahmt. Die emphatische Selbstzwecklichkeit der Kunst gerinnt zur Abstinenz von material-praktischen Bezügen und formuliert sich ontologisierend, wodurch zugleich ihre subjektivierende Kraft auf einen Teil der Gesellschaftsmitglieder, nämlich jene, die sich eine solche Abstinenz leisten können, eingeschränkt wird. So sehen Adorno und Horkheimer beide in der „bürgerlichen Kunst, die sich als Reich der Freiheit im Gegensatz zur materiellen Praxis hypostasierte“, die ,Reinheit" der Kunst „mit dem Ausschluß der Unterklasse erkauft“" ${ }^{174}$ Kunst scheint sich derart (bis zu einem gewissen Grad) von der Rückbindung an den gesellschaftlichen Lebenszusammenhang zu lösen, und ihr dabei ,idealisiertes‘ Programm scheint sich nur für eine gesellschaftliche Teilgruppe und unter Beschränkung der Zugangschancen der anderen realisieren zu lassen. Die Spaltung der Gesellschaft, wie sie das Basisparadigma der Gesellschaftstheorie konstatiert, reproduziert sich im theoretischen Kunstkonzept so zunächst als Requirierung der Kunst durch die Klasse der Herrschenden, und wie sich die Subjektivierung gesellschaftlich nur auf Seiten dieser Klasse vollzieht, bleibt auch der sie befördernde Kunstgenuß zunächst derselben vorbehalten. Gleichzeitig freilich bewahrt die Hochkunst in ihrer idealisierten Form immer noch die ursprüngliche Emphase auf, wenn auch transformiert in ,bürgerlichen Idealismus'.

Ihr gegenüber bildet sich dann außerdem eine ,niedere' Kunst heraus, die der reprimierten ,Unterklasse' als Ort der Kompensation ihrer Situation dient. Mit dieser ,Basiskunst', die an die Seite der Hochkunst tritt, ist im Bereich der Kunst die gesellschaftliche Spaltung analog abgebildet. Gleichwohl gilt die ,niedere' Kunst Horkheimer und Adorno keineswegs als Verfallsform, sondern als „das gesellschaftlich schlechte Gewissen" der ,ernsten' Kunst. ${ }^{175}$ Auch in ihr tradiert sich ein Stück der urspünglichen Emphase, die sich nun als „das ungebärdig Widerstehende" robuster, burschikoser und derb-grotesker Formen und Gehalte äußert. ${ }^{176}$ Während also der emphatische Vorgriff der Kunst auf eine geglückte Existenz, transformiert in eine ,rein geistige' Idealität, in der Hochkunst noch spürbar ist, erhält sich derart ihre Wesenseigenschaft, gesellschaftliche Konsistenzforderungen $\mathrm{zu}$ durchbrechen, auf der Seite der , niederen' Kunst durch Transformation in eine gesellschaftsbezogene Renitenz. Obschon Kunst in ihrer Realgestalt durch ,Dekontingentierung ihres Programms in der Hochkunst und durch Trivialisierung ihrer ästhetischen Gehalte in der ,niederen' Kunst selbst von der bestehenden Verfallssituation angegriffen ist, findet sich so dennoch in beiden Fällen ihre ursprüngliche Bedeutung auch erhalten, und weist zudem ihre Spaltung, welche die gesellschaftliche Spaltung reproduziert,

${ }^{174}$ Horkheimer/Adorno, Dialektik, 121

175 Horkheimer/Adorno, Dialektik, 121

176 Adorno, Kulturindustrie, 60 
auf den bestehenden Unrechtszustand hin. Die Kunst scheint deshalb selbst in ihrem Realbegriff dazu geeignet, als Platzhalterin der korrumpierten Humanität und als Förderungsinstanz für protorevolutionären Widerspruch zu dienen.

Damit ist die Kunst in ihrer idealen wie in ihrer realen Gestalt als Hort des Widerspruchs gegen den instrumentellen Gesellschaftszusammenhang eingeführt. In dieser Charakteristik werden die Vorgaben Horkheimers gemäß der rationalitätstheoretischen Wende der Kritischen Theorie umgesetzt und weitergeführt. So erscheint Gesellschaft nun als von der instrumentellen Vernunft determinierter Zusammenhang, der sich in den ökonomischen Gesetzmäßigkeiten lediglich auslegt, und wird die von Horkheimer beklagte Nivellierung als umfassende ,Konsistenzforderung formuliert, die den Subjekten eine bis in die Persönlichkeitsorganisation reichende Unterwerfung unter die Forderungen der instrumentellen Gesamtorganisation des gesellschaftlichen Kollektivs abverlangt. Auf diese Weise wird zugleich das Paradigma einer totalitären Gesellschaftsstruktur wieder bemüht: Die Forderung der konsistenten Entsprechung gegenüber den instrumentellen Einrichtungen und Organisationsformen der Gesellschaft bedeutet letztlich wieder die Unterwerfung unter die totale Herrschaft der strukturell umgesetzten instrumentellen Vernunft. Statt von einer Zerstörung der Person (wie bei Horkheimer) wird dann von einer Korrumpierung der Subjekte gesprochen und der Personbegriff kohärent zur Aufklärungskritik durch den Subjektbegriff ersetzt. Diesem korrumptiven Defizienzzustand scheint die Kunst emphatisch entgegengesetzt zu sein: Durch ihre ideale Selbstzwecklichkeit entzieht sie sich jeder funktional-instrumentellen Verplanung, die ihre Produktion etwa dem Tausch- und Profitprinzip unterwerfen könnte, und durch ihre Subjektvermitteltheit bahnt sie dem Wiederaufgriff der instrumentell verdrängten ,Anthropologika' einen Weg. Sie erscheint derart als ,Unterbrechung' (R. Bubner) des totalitär-instrumentellen Zusammenhangs und reißt in ihm gewissermaßen eine Lücke auf bzw. eröffnet eine Nische, in der ein subjekthaftes Seinkönnen in den Blick kommt. Mit ihren beiden Wesenszügen stellt sie außerdem der instrumentellen Gesellschaft einen negativen Spiegel vor Augen, in dem sich deren Defizienz wahrnehmen läßt und zu Bewußtsein kommt. Auf diese Weise realisiert die Kunst das rekonstruktiv herauskristallisierte Gebot der Negationsethik, durch Verneinung und Einspruch das ,schlechte Ganze' zu denunzieren und aufzubrechen. Mit der Reaktivierung des Verdrängten deutet sie zugleich auf die diffuse Zielgestalt von Gesellschaft hin. Sie übt derart eine eminent kritische und ,bewußtseinsschaffende' Wirkung aus und läßt die Hoffnung erwachsen, da $B$ durch ihren Einflu $B$ sich die Chance einer Korrektur des fehlgegangenen Projekts der Moderne und einer Vollendung desselben eröffnet. Dieser ihr idealer Charakter scheint sich selbst noch in ihrer gespaltenen und versehrten Realgestalt zu erhalten, die einmal als Hochkunst die Emphase glückender Subjektivität weiterträgt und ein andermal als niedere Kunst die unmittelbare Renitenz gegen den desubjektivierenden Gesellschaftszusammenhang formiert. Sie gilt derart letztlich als eine zwar vom allgemeinen Verfall nicht unberührte, jedoch anscheinend nur schwer vollständig zu korrumpierende Instanz, von der realiter eine Lösung erhofft werden kann.

An diesem Punkt aber scheint nun erneut die Kulturindustrie als korrumptive Gegenkraft wirksam zu werden, welche die ästhetische Erlösung wieder gefährdet. Dies ist schon bei Horkheimer der Fall, der in seinen kunsttheoretischen Grundli- 
nien bereits die ,Massenkultur‘ als Widersacher der Kunst und ihrer befreienden Kraft zeichnet. Auch der Kulturindustriebegriff taucht dort schon sporadisch auf. Systematisch durchgeführt ist der Gedanke jedoch dann erst in der „Dialektik der Aufklärung“, welche nun die korrumptive Wirkung der Kulturindustrie kohärent zur Gesellschaftstheorie und rationalitätstheoretischen Wende festlegt. So sehen Horkheimer und Adorno in der Kulturindustrie „die jahrtausendelang getrennten Bereiche hoher und niederer Kunst zusammen"'177 ,gezwungen' und gewissermaßen für eine stellvertretende ,zwangsweise Versöhnung des gesellschaftlichen Klassenantagonismus gesorgt. ${ }^{178}$ Dabei scheint die ,hohe ${ }^{6}$,durch die Spekulation auf den Effekt um ihren Ernst gebracht" und die ,niedere" ihrer Widerständigkeit entkleidet ${ }^{179}$ sowie schließlich der gesellschaftliche Antagonismus verschleiert zu werden. Insbesondere mit Bezug auf die Widerständigkeit der ,Basiskunst' formulieren daher Horkheimer und Adorno den Begriff der ,Massenkultur' (endgültig) in den der Kulturindustrie um. Während der erstgenannte Begriff nämlich noch eine Nähe zur ,niederen' Kunst und ihrer Funktion suggeriere, schalte der zweitgenannte ,von vorneherein die Deutung“ aus, „daß es sich um etwas wie spontan aus den Massen selbst aufsteigende Kultur handle". ${ }^{180}$ Vielmehr gilt die Kulturindustrie, wie zu sehen war, als eine „willentliche Integration ihrer Abnehmer von oben “181, deren Produkte exklusiv ,nach dem Prinzip ihrer Verwertung, nicht nach dem eigenen Gehalt und seiner stimmigen Gestaltung" gefertigt werden. ${ }^{182}$ Kulturindustrie produziert so eine Kultur für die Massen, in der die nicht-konformen Momente beider historischen Konkretionen der Kunst aufgehoben werden und eine konforme Integration der Gesellschaftsmitglieder unter dem Herrschafts- und Profitprinzip angezielt ist. Diese Integration schlägt sich der Kunsttheorie zufolge auch im Versuch einer Konformierung der Kunst durch ihre Eingliederung in den Zusammenhang der Kulturindustrie nieder.

Die Kulturindustrie gilt so wieder als die Kraft, von der die ethisch gebotene Realisierung von Subjektivität, Autonomie und Freiheit - bzw. der exemplarische Vorgriff auf diese - konteragiert und verunmöglicht wird. Die verfallstheoretische Grundstellung greift damit auch die Lösungsansätze der Kritischen Theorie an. So scheinen durch die Kulturindustrie die Spaltung der Kunst nivellistisch aufgehoben und hohe und niedere Kunst miteinander vermittelt zu werden. Diese Vermittlung soll quasi stellvertretend für eine gesellschaftliche stattfinden. Dabei scheinen jedoch die kontrakonformen Momente, die aus dem idealen, emphatischen Kunstbegriff noch in dessen Realgestalten eingezogen waren, ausgegliedert und die gesellschaftliche Spannung der antagonistischen Klassen kontrafaktisch verhüllt zu werden. Nicht um eine stellvertretende, wirkliche Versöhnung der Klassen geht es also, sondern um eine verschleiernde Beschönigung der realen Unrechtsverhältnisse und um Beseitigung von deren künstlerischer Spiegelung. Die Kulturindustrie tritt derart als Feind der Kunst auf, und die Hoffnung auf eine ästhetisch vermittelte Erlösung von den perniziosen Verhältnissen der instrumentellen Welteinrichtung des Menschen

\footnotetext{
177 Adorno, Kulturindustrie, 60

178 vgl. Horkheimer/Adorno, Dialektik, 121-122

179 Adorno, Kulturindustrie, 60

${ }^{180}$ Adorno, Kulturindustrie, 60

181 Adorno, Kulturindustrie, 60

182 Adorno, Kulturindustrie, 61
} 
scheint wieder korrumpiert, zumindest aber ernsthaft bedroht zu werden. Die Negativität des geschichtsphilosophisch erarbeiteten Prozesses der Menschheitsgeschichte setzt sich tendenziell wieder durch und scheint eine Freisetzung positiver Potenzen nicht einfach zu gestatten. Selbst die Kunst ist wieder von einem instrumentellen Umgriff und einer Integration in dessen Gemächte gefährdet, und die verfallstheoretische Grundstellung der Kritischen Theorie wird hierin erneut wirksam. Damit aber bleibt zugleich die Ethik der Negation wiederum in der bloßen, undeutlichen Verneinung stecken. Jede Instanz nämlich, die eine ,positive' Gestalt des ethisch gebotenen Realisierungsziels vor Augen stellen könnte, scheint von der ,schlechten Totalität' des Bestehenden sogleich angegriffen und zerstört zu werden. Außer dem ,reinen' Gestus des Widerspruchs eröffnet sich den Subjekten keine Chance mehr auf ihre Subjektivierung. 


\section{BAUSTEINE FÜR EINE MODERNITÄTSGERECHTE MEDIENETHIK IN BEZUG AUF DEN FILM}

Die Rekonstruktion der bislang zu einem Abschluß gebrachten, zentralen Epochen des medienethischen Diskurses über den Film in Deutschland im 20. Jahrhundert fördert, wie zu sehen war, ein problematisches, um nicht zu sagen: desolates Bild zu Tage. Zu einem Zeitpunkt, da einige Vertreter einer ,avancierten' kulturphilosophischen Reflexion der Moderne und ihres Projekts in bezug auf Kunst, Architektur und Lebenswelt bereits von deren ,post' sprechen wollen, eröffnet sich dem rekonstruktiv gewissenhaften Blick die Tatsache, daß die medienethische Diskussion zumindest in ihren vier großen Hauptepochen die Moderne noch gar nicht erreicht hat und das zugehörige Projekt dort noch 200 Jahre nach seiner Ankündigung vergeblich der Verwirklichung harrt. Zwar sind Neuzeit und Moderne mit den kühnsten und vielversprechendsten Aspirationen auf eine humane Gestaltung der Welt und eine vernünftige Gesellschaftseinrichtung angetreten, in denen der Mensch als autonomes Subjekt den Stand seines Menschseins erreichen sollte, und haben sie eine ideengeschichtliche Dynamik entfaltet, die in ihren reflexiven Konsequenzen und Aufgabenstellungen keineswegs schon vollständig ausgeschöpft ist. Auch hat die (freilich zögerliche) Demokratisierung der deutschen Gesellschaft allmählich trotz der ,Unterbrechung' durch den Nationalsozialismus den Prozessen der Verbreiterung der Öffentlichkeit und der zunehmenden Einforderung von Mitsprache- und Mitgestaltungsansprüchen Raum und Geltung verschafft und derart jenen ,kontingenten Strukturprozessen politisch Rechnung getragen, in denen sich das Subjektivierungsprogramm der Moderne sozialstrukturell zu aktualisieren sucht. Mit dem Grundgesetz der Bundesrepublik Deutschland sind die grundlegenden Ideen des Projekts der Moderne - die Bestimmung des Menschen als autonomes Subjekt mit einer unantastbaren Würde und dem Recht auf Selbstrealisation, sowie die demokratisch-rationale Organisation der Gesellschaft als strukturelle Konsequenzkomponente dieser anthropologischen Bestimmung - zur Basis der gesellschaftlichen und staatlichen Ordnung geworden, und ist eine Wertentscheidung getroffen, die die grundlegenden ethischen Maximen der Gesellschaft - Schutz der Personwürde, Meinungsfreiheit, Mitspracherechte aller etc. - in Kohärenz zu diesem Projekt erstellt. Wie zu sehen sein wird, setzt sich diese Grundstellung auch im Bereich der Gesetzgebung um. Doch scheint im Gegensatz dazu den medienbezogenen ethischen Theorieoptionen dieses Jahrhunderts vordringlich die Problematisierung, Restriktion, Apotropie und Destruktion der Projektierung der Intentionen des Projekts der Moderne am Herzen gelegen zu haben. Statt sich reflexiv der Herausforderung durch die neuzeitliche Entwicklung zu stellen und nach Kriterien für eine ethische Einholung derselben im Bereich der Medien zu suchen, rekurrieren die epochalen Paradigmen entweder, wie bei den Reformern und Filmerziehern, auf vorneuzeitliche Moralbestände und $\mathrm{Re}$ flexionsformen oder transformieren sie sich, wie bei den Nationalsozialisten, in einen 
zynisch-totalitären, utilitaristischen Pragmatismus, bis einer kritisch-humanitären Option, wie der der Kritischen Theorie, nur noch die Haltung der Negation zu bleiben scheint. In keinem der bislang abgeschlossenen, paradigmatischen Theoriebildungen läßt sich deshalb die Bereitschaft erkennen, unter den Präsuppositionen des humanitären Gehalts des Projekts der Moderne nach fortschrittsfähigen, evolutiven Einlösungsformen dieses Gehalts zu suchen und diese Formen ethisch-reflexiv auf den Medienbereich hin zu denken. Neben der Verfassung und den Gesetzen der Bundesrepublik sowie der zugehörigen juristischen Reflexion sind einzig im Bereich der Medienpädagogik - und dort erst in neuerer Zeit - Reflexionsbemühungen erkennbar, die mehr oder weniger deutlich auf der Basis des Projekts der Moderne ansetzen. So treffen etwa einige Vertreter einer neueren, kommunikationstheoretisch orientierten Medienpädagogik mit der Rezeption der - noch in ihren Anfängen begriffenen - Diskurstheorie bzw. der Theorie des kommunikativen Handelns von Habermas eine dezidiert modernitätsgerechte Option. ${ }^{1}$ Andere legen bei ihren empirischen Untersuchungen nun bereits den Subjektstatus der Rezipienten - und damit die spezifischen Kompetenzen und Nutzungsformen auch schon von Jugendlichen - zugrunde und versuchen so eine Medienerziehung zu fundieren, die mit den Fähigkeiten und der Autonomie ihrer Edukanden kooperiert. ${ }^{2}$ Ein guter Teil der Medienpädagogen orientiert sich zudem heute auf eine Erziehung zur Mündigkeit hin, die nicht mehr, wie noch bei den Filmerziehern, von bewahrpädagogischen Inklinationen und negativen Anthropologika durchsetzt ist. Doch ist mit all diesen im übrigen recht jungen - pädagogischen Bemühungen noch keine ethische Systematik entworfen; in der Tat fällt dies ja auch nicht in den genuinen Aufgabenbereich der Pädagogik. Durchaus auf einem ethisch-systematischen Background tätig hingegen ist trotz der Fortentwicklung der Medienpädagogik noch immer ein Teil des Personals der Filmerziehung, das auch in dieser Disziplin für eine partielle Erhaltung der kontramodernen Optionen der ,Tradition' sorgt und mitunter große öffentliche Aufmerksamkeit und Wirkung erzielt (vgl. 4.7.). Neben der legislativ-juristischen Sphäre und den recht jungen Versuchen eines ,Paradigmenwechsels' in der Pädagogik auf der einen sowie der noch anhaltenden partiellen Fortwirkung kontramoderner Optionen auf der anderen Seite steht eine genuin medienethische, ihrem Gegenstand adäquate Theorie so noch weitgehend am Anfang. Vorschläge, Optionen, wegweisende Skizzen sind deshalb erwünscht, ja sie sind umso dringlicher, als sowohl die Pädagogik als auch das institutionelle Handeln im Bereich des Jugendschutzes auf einen entsprechenden ethischen Reflexionsbestand angewiesen sind, wenn die dortigen Anstrengungen um eine modernitätsgerechte Selbstausrichtung nicht nur fachspezifisch pädagogisch bzw. juristisch, sondern auch ethisch zu fundieren sein sollen. Freilich kann eine umfassende medienethische Systematik unter den gegenwärtigen Bedingungen anfanghafter Reflexion erst in der Zukunft zufriedenstellend geleistet werden. Dies entbindet jedoch nicht von der Bemühung um erste Schritte in diese Zukunft. Auf dem Weg zur Erfüllung des Desiderats einer modernitätsgerechten Medienethik nun kann meines Erachtens die christliche Ethik, näherhin die So-

\footnotetext{
${ }^{1}$ vgl. etwa: Baacke, D., Kommunikation und Kompetenz, München ${ }^{3} 1980$

2 Methodologisch herausragend ist hierbei gegenwärtig die schon erwähnte Studie: Theunert, Helga, Pescher, Renate, Best, Petra, Schorb, Bernd, Zwischen Vergnügen und Angst Fernsehen im Alltag von Kindern, Berlin 1992
} 
zialethik, einen fruchtbaren Beitrag leisten. Wie ein solcher Beitrag aussehen kann, will ich im folgenden in Form einiger Bausteine für eine modernitätsgerechte Medienethik in bezug auf den Film zeigen. Dabei soll zugleich der Versuch unternommen werden, die Konstruktion dieser Bausteine mit den entsprechenden modernitätsgerechten Optionen im rechtlichen Bereich zu verbinden, um ihr eine entsprechende Praxisrelevanz zu verleihen.

\subsection{Generelle Grundlinien einer modernitätsgerechten Ethik im theologischen Kontext}

Medienethik entsteht als bereichsspezifische Ethik nicht ,aus dem Stand". Wie die Wirtschafts- oder die politische Ethik bedarf sie eines grundsätzlichen Fundaments, in dem die zentralen Prinzipien fixiert und die generellen Optionen getroffen werden. Nicht von ungefähr ließ sich daher auch in der Rekonstruktion der systematischeren unter den epochalen Entwürfen medienethischer Optionen in diesem Jahrhundert zumeist die Ebene einer generellen Ethik von der einer Medienethik unterscheiden. Dabei zeigte sich, daß neben einer anthropologischen Reflexion auch Grundprinzipien fixiert wurden, aus denen dann die paradigmatischen normativen Aussagen abgeleitet werden konnten. In der Tat bedarf es auch für die theologischethische Konstruktion einer modernitätsgerechten Medienethik einer Grundlagenaxiomatik, die zentrale Prinzipien und anthropologische Grundoptionen fixiert. Dabei muß sich diese allgemeine ethische Grundlagenkonstitution durchaus nicht ex nihilo als eine ,neue Ethik' erst selbst schaffen. Im Bereich der theologischen Ethik vielmehr liegen modernitätsgerechte Entwürfe bereits vor, die in ihren Basisaxiomen zudem übereinstimmen und ein konsistentes rationales Ethikkonzept vorstellen. ${ }^{3}$ Statt eines unter dieser Voraussetzung letztlich arbiträr anmutenden Versuchs der Konstruktion ,neuer' ethischer Paradigmen greife ich daher im folgenden auf das bereits existente Konzept einer modernitätsadäquaten christlichen Ethik zurück und entnehme ich daraus die für meinen Versuch, medienethische Bausteine vorzustellen, notwendigen Bestimmungsstücke.

Hierzu ist es zunächst notwendig, die Gestalt des Menschen anthropologisch und ethisch zu bestimmen. Erst wenn prinzipiell festgelegt ist, wie der Mensch zu verstehen ist, kann auch eine ihm adäquate Ethik argumentativ begründet werden. Theologische Ethik setzt dabei den Menschen als Person an und gewinnt daraus zugleich ihr oberstes Sollensprinzip. Gleichwohl bedarf die in diesem Prinzip angesetzte menschliche Person einer anthropologischen Näherbestimmung, um ein ihr gerecht werdendes ethisches Paradigma skizzieren und insbesondere Herkunft und Reichweite der in den rekonstruierten Konzepten von Reformern und Filmerziehung problematisierten Entwurfsautonomie umschreiben zu können. Hierbei wiederum sind vor allem Definition und Verhältnis von Natur und Kultur bedeutsam, wie nicht zuletzt die diesbezüglichen Deduktionen der genannten Konzepte zeigen. Aus dieser Definition und diesem Verhältnis nämlich ergibt sich, ob dem naturalen Sein des

${ }^{3}$ Als Vertreter dieses Konzepts seien etwa genannt: Alfons Auer, Franz Böckle, Johannes Gründel, Gerfried Hunold und Wilhelm Korff. Freilich gibt es auch im Feld theologischer Ethik kontramoderne Beharrungsversuche, die sich meist deontologisch auslegen; als neuerer Vertreter einer solchen Position kann etwa Martin Ronheimer aufgeführt werden. 
Menschen gestalterisches Vertrauen entgegengebracht werden kann oder ob es repressiv domestiziert werden muß bzw. ob aus dem Sein ein Sollen zu deduzieren, dem Sein das Sollen entgegenzusetzen oder eine dritte diesbezügliche Option zu treffen ist. Weiter läßt sich daraus das Verhältnis von kreativem Ausgreifen des Menschen und seiner wiederholt betonten Verwiesenheit auf stabile und verläßliche Orientierungslinien fassen. Auf diesem anthropologischen Hintergrund erst können dann unterhalb des Personprinzips eine dem Menschen gemäße Ethik paradigmatisch umrissen und einige Linien zu deren gesellschaftlich-strukturellen Einlösungsbedingungen ausgezogen werden.

Der Mensch als Person und Bild Gottes: Die theologisch-anthropologische Verankerung des autonomen Subjekts und seiner Würde

Theologische Anthropologie nun versteht zum einen, wie angedeutet, den Menschen als Person sowie zum anderen als Geschöpf Gottes, das als dessen Bild an dessen Schöpfervernunft teilhat. Mit beiden Bestimmungen stellt sie sich letztlich auf die Seite des Projekts der Moderne und dessen Verständnis des Menschen als Subjekt. In gewisser Weise läßt sich sogar sagen, daß der Subjektbegriff der Neuzeit eine Folge des christlichen Personbegriffs ist und derart auf christliche Wurzeln des Subjektivierungsprogramms der Moderne verweist. Seine Herkunft hat der Personbegriff in der christlichen Dogmatik, näherhin in der Auseinandersetzung der ersten Jahrhunderte um die Trinitätstheologie und die Menschlichkeit Christi. Als einer der frühesten Autoren verwendet hierbei Tertullian den Begriff ,persona', um die Dreieinigkeit Gottes reflexiv zu klären. Zentrum seines durch den Personbegriff erreichten Reflexionsgewinns gegenüber vorausgehenden Versuchen ist die Verbindung von Selbstand und Relationalität in einem Wesensbegriff, durch die nun sowohl - in neuzeitlichen Termini - Autarkie als auch kommunikative Vernetzung und Bezogensein gleichermaßen als Konstitutiva von Personalität fixiert sind. ${ }^{4}$ Durch Athanasius, Basilius und Gregor von Nyssa wird diesen Bestimmungen bereits ein Moment der Unverfügbarkeit beigegeben, das sich trinitätstheologisch in Form von ,Eigentümlichkeiten' faßt, welche gerade durch den Akt der Kommunikation das Inkommunikable (hier vordringlich und im besonderen das Ursprungsein des Vaters, das Gezeugtsein des Sohns und das Hervorgehen des Geistes) zu Tage treten lassen. ${ }^{5}$ Die kommunikative Verbindung der drei göttlichen Personen, die ihr ,Ungetrennt' veranschaulicht, stellt so zugleich ihre Selbständigkeit und Verschiedenheit, ihr ,Unvermischt" und letztlich ,Unvermischbar' vor Augen. Gleichzeitig deutet die Inkommunikabilität auf jene Unverfügbarkeit und Unaussagbarkeit hin, die dem Personkern nicht nur der göttlichen Personen, sondern jedes personalen Seins eignet. Mit der bis auf den heutigen Tag definitorisch wirksamen Bestimmung des Personbegriffs durch Boethius werden schließlich die Eigenständigkeit und das Spezifikum der Person über die Individualität und Vernunftbegabtheit präzisiert. Person ist nun ,naturae rationalis individua substantia' (PL 64, 1343), ein aufgrund seiner Vernunftnatur unteilbar in sich Stehendes. Thomas von Aquin modifiziert diese Bestimmung, um ihr die mögliche

4 vgl. dazu auch die Untersuchung von Hilberath, B. J., Der Personbegriff der Trinitätstheologie in Rückfrage von Karl Rahner zu Tertullians „Adversus Praxean“, Innsbruck 1986, bes. $161-294$

5 vgl. Vorgrimler, Gotteslehre, $99-100$ 
Mißverständlichkeit einer überzogenen Autarkie, also eine gewissermaßen autistische Inklination, zu nehmen und korrigiert die Formel zu, subsistens in natura rationali‘ (STh I 29,3). Person ist für ihn ein in vernünftiger Natur gründendes Für-sichseiendes.

Unabhängig von der dogmatischen Bedeutsamkeit der letztgenannten, thomanischen Korrektur aber sind mit den Überlegungen der genannten Autoren nun die zentralen Bestimmungsstücke des Personbegriffs versammelt. Personalität faßt sich als individuelle Subsistenz und Unverfügbarkeit eines vernunftbegabten Wesens, das zugleich auf Verbindung mit anderen und auf Kommunikation angelegt ist. Die theologische Reflexion bringt mit dieser begrifflichen Konstruktion dabei nicht nur einen dogmatischen Gewinn, sondern zugleich durch projektive Spiegelung einen anthropologischen: In der Auseinandersetzung um die Beschaffenheit und das Verhältnis der göttlichen Personen wird auch die Auseinandersetzung um das Wesen des Menschen auf eine neue Stufe gehoben. Zunächst nämlich überschreitet die christliche Reflexion der Personalität in anthropologischer Hinsicht die griechische Philosophie und greift sie deren Reflexionsbestand zugleich integrativ auf. Dort wurde der

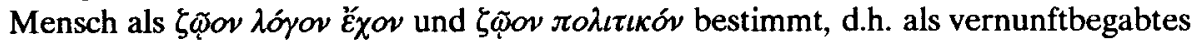
Wesen, das den Stand seines Menschseins erst in der Gemeinschaft der ,Freien' in

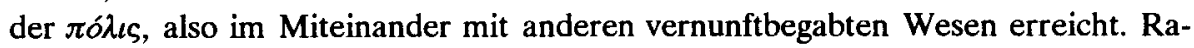
tionalität und kommunikative Sozialität stellten die zentralen Wesenseigenschaften des Menschen dort vor. Beide Bestimmungsmomente bleiben im christlichen Personbegriff letztlich erhalten. Gleichwohl zielte die griechische Bestimmung vordringlich auf das Allgemeine, jene Wesenseigenschaften, die den einzelnen Menschen mit allen anderen verbinden. Demgegenüber eröffnet der christliche Personbegriff in anthropologischer Rückwendung nun auch den Blick auf die Selbständigkeit und Unterschiedenheit, eben die Individualität des Menschen, die diesem zugleich jeweilige Einzigartigkeit attestiert. Mit der Bestimmung der Unverfügbarkeit dieses je einzigartigen Wesens tritt darüber hinaus wurzelhaft schon das Bewußtsein einer spezifischen, unantastbaren Würde des Menschen in den Bereich der Reflexion und wird ein Überschritt von der Anthropologie in die Ethik ermöglicht, die dann jedem Menschen aufgrund seines Personseins diese unantastbare Würde zuspricht. Die zunächst vordringlich prädikationslogische, aus der Unmitteilbarkeit und Unaussagbarkeit das individuelle Wesen ist ,ineffabile، - hergeleitete Unverfügbarkeit der Person gerät hierbei zur sittlich-normativen und zum ethischen Prinzip.

Dieser Überschritt von der Anthropologie in die Ethik wird in seiner Ganzheit freilich erst neuzeitlich vollzogen. Gleichwohl findet er schon im Neuen Testament eine Art Vorbereitung durch den Gedanken der Gleichheit aller Menschen vor Gott und der Einheit in Christus, der einmal einen weiteren Schritt über die griechische Philosophie hinaus bedeutet und zum anderen in Kombination mit dem Personbegriff später die neuzeitliche Reflexion ,sponsort'. Die paulinische Theologie nämlich, die ,nicht mehr Mann noch Frau, nicht Sklaven noch Freie‘ kennt und für die ,alle eins in Christus' sind (vgl. Gal 3,28), überwindet tendenziell bereits die aristotelische

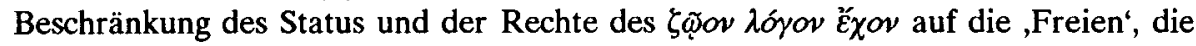
Mitglieder der $\pi \delta_{\imath} \iota \varsigma$. Unter dem theologalen Bezug gibt es keine Scheidung der Menschen in ,Freie' und Unterworfene, in solche, die mit dem Status der Menschenwürde ausgestattet sind, und solche, deren menschlicher Rang in Zweifel gezo- 
gen werden kann, so da $B$ sie als ,beseelte Werkzeuge' (Aristoteles) versklavt werden dürfen. Alle vielmehr haben vor Gott denselben Status und sind in Christus zusammengeschlossen, d.h. aber, sie besitzen auch im Vergleich miteinander dieselbe Würde. Daraus folgt eine Verpflichtung zu wechselseitiger Achtung und mutualem ,Dienst'. Obschon das Christentum die Sklaverei zunächst noch nicht aufhebt, birgt es derart den Kern einer theologischen Anthropologie in sich, die einer Generalisierung der Menschenwürde dienlich ist. Auf diese universalisierende ,Entelechie‘ des Christentums und ihr geschichtlich Neues gegenüber den Griechen weist auch etwa Hegel hin: So sieht er bei den Griechen zwar das Bewußtsein einer (auf der Vernunftbegabtheit basierenden) Freiheit des Menschen und einer damit verbundenen Gleichheit ihres Status anheben, das jedoch zugleich noch unvollständig bleibt und es daher zuläßt, daß der Status auf die wenigen zur $\pi o ́ \lambda \iota s$ Gehörigen eingeschränkt wird. ${ }^{6}$ Demgegenüber leitet erst das Christentum jene Ausweitung des mit der Freiheit konnotierten Status von ,Einigen' auf ,Alle' und damit die generelle Durchsetzung der Würde des Menschen ein.?

Gleichzeitig verhilft das Christentum mit seiner näheren Charakterisierung des theologalen Bezugs des Menschen sowie des Bezugs von Gott und Welt der theologisch-anthropologischen Einsicht der Menschenwürde zur motivational-identitätsbezogenen Verwurzelung und schafft es derart neben der ideengeschichtlichen auch die existenzielle Basis für die Durchsetzung dieser Einsicht. So bestimmt sich zum einen der Bezug Gottes zu Welt und Mensch christlich als ein Bezug der Liebe. Diese äußert sich nach christlichem Verständnis paradigmatisch in der Kenosis Christi und dem darin gesprochenen, unbedingten Ja Gottes zu seiner Schöpfung. Zum anderen zeichnet dieser Liebesbezug dem Menschen sein Verhältnis zu Mensch und Welt vor. Der Liebe Gottes zur Welt entsprechend nämlich sollen auch die Menschen ihren Weltumgang und darin wiederum besonders ihren Umgang miteinander einrichten. Wie der ,Vater im Himmel' seine ,Kinder' liebt, so sollen diese einander lieben, und dieses Liebesverhältnis soll geradezu das Spezifikum der Christen darstellen, das Charakteristikum, an dem sie zu erkennen sind. Die Liebe aber ist es, die „als Richtmaß und Ziel alles Sittlichen den Menschen als Person“ entdeckt. ${ }^{8}$ Sie läßt dem konkreten sittlichen Verhalten den Anderen erst als jenes unverfügbare, im letzten unfaßbare Wesen vor Augen treten, das dieser in seinem Personkern ist und das darin zu schützen und zu achten ist. Damit richtet der so ausgelegte theologale Bezug die Identität des Christen und seine habituelle Selbstdefinition in einer Weise ein, die die Wahrung und Generalisierung der Menschenwürde zum unverzichtbaren Bestandteil dieser Identität macht. Die ,Idee' dieser Würde wird auf diese Weise existenziell, nämlich in der Glaubensausrichtung des Christen, eingewurzelt und erhält daraus ihren motivationalen Impetus, so daß sich sagen läßt, daß das Christentum eigentlich erst jene Dynamik ins Werk setzt, die der theologisch-anthropologischen Errungenschaft des Gedankens der Menschenwürde geschichtlich-motivationell zur Durchsetzung verhilft. Gleichzeitig zeigt sich in der letztlich vom Glauben getragenen liebenden Hinwendung zum Anderen immer neu jenes zentrale Spezifikum des

${ }_{7}^{6}$ vgl. Hegel, Vorlesungen, 60; Korff, Ethik, 106

7 vgl. Hegel, Vorlesungen, 60; Korff, Ethik, 106

${ }^{8}$ Korff, Glaube, 280 
Christentums, das eine christliche Ethik auch in ihrer Spezifität zu begründen vermag. Für den Christen nämlich empfängt „,der ethische Anspruch (...) seine Geltung und Dynamik aus der Universalität der schöpferischen Liebe Gottes selbst“" ${ }^{\text {" Seine }}$ Moralität leitet sich so nicht nur aus vernunftbegründeter Einsicht und Theorie her, sondern erhält im Glauben an den liebenden Gott ihr unhintergehbares existenzielles Fundament. $^{10}$

Kombiniert man nun auf diesem Hintergrund den von der dogmatischen in die anthropologische Reflexion übertragenen Personbegriff und sein Moment der Unverfügbarkeit mit der Entelechie der neutestamentlichen Anthropologie, so erweist sich diese Kombination - wiederum ideengeschichtlich betrachtet - letztlich als normativ identisch mit dem obersten ethischen Prinzip von Neuzeit und Moderne, wie es von Kant im kategorischen Imperativ fixiert wird. Die Herleitung erfolgt jetzt dort freilich nicht mehr unmittelbar in theologalem Bezug, sondern aus der anthropologischen Konstitution des Menschen als Vernunft- und Freiheitswesen. Doch rekurriert sie mit dieser Anthropologie letztlich auf den christlichen Personbegriff und greift sie das ethische Anliegen des Neuen Testaments auf. Gleichzeitig läßt sie dieses Anliegen nun auch jenseits des christlichen Kontexts kommunikabel werden und dient sie derart seiner weiteren Generalisierung. So erscheint bei Kant zunächst Person als „ein mit praktischem Vernunftvermögen und Bewußtsein der Freiheit seiner Willkür ausgestattetes Wesen“, in dem sich „,der intelligibele Charakter der Menschheit überhaupt" realisiert. ${ }^{11}$ Als ein so bestimmtes Wesen stellt diese Person in ihrem Begriff den transzendentalen Einheitspunkt der Bestimmung des Menschseins überhaupt dar, und als Vernunft- und Freiheitswesen ist sie in ihrer Würde generell und unbedingt zu wahren. Entsprechend formuliert Kant den kategorischen Imperativ: „Handle so, daß du die Menschheit, sowohl in deiner Person, als auch in der Person eines jeden andern, jederzeit zugleich als Zweck, niemals bloB als Mittel brauchest. “12 Die Bestimmung der Person als Vernunftwesen koinzidiert dabei mit der des christlichen Personbegriffs, und die neutestamentlich initiierte Allgemeinheit des theologisch-anthropologischen Status des Menschen findet ihre Fassung nun transzendental als unbedingt geltende ethische Maxime für alle Menschen und Zeiten. Was für den Christen aus seinem Glaubensbezug heraus evident und prägewirksam wird, ist durch Kant in einen rein rationalen Begründungszusammenhang übertragen. Damit aber kann einmal die neuzeitliche ethisch-prinzipielle Fixierung der Personwürde als zumindest intentional identisch mit ihrer christlichen Präformation gesehen werden. Zum anderen findet die christliche, glaubensvermittelte Erkenntnis

${ }^{9}$ Korff, Glaube, 280

${ }^{10}$ Damit bleibt freilich unbestritten, daß sich diese Moralität bei konkreter Umsetzung in normatives Verhalten und Normsetzung rational einsichtig machen und begründen lassen muß. Sobald Moral aus der glaubensvermittelten Verhaltens- und Handlungsmotivation entsteht und Geltung beansprucht, muß dieser Anspruch sich über vernünftige, diskursive Argumentation einlösen lassen. Zwar liegt für den Christen im Glauben der Grund für seine moralische Intuition, doch bedarf diese Intuition - wie auch jede aus anderen existenziell-motivationellen Quellen fließende - einer Begründungsreflexion, die kommunikabel und transparent ist. Kommunikabilität und Transparenz aber stellen sich über Vernünftigkeit und diskursive Argumentation her.

${ }_{11}^{11}$ Kant, Anthropologie, 677

12 Kant, Grundlegung, 61 
der Personwürde über die kantische Reflexion ihre allgemeine, da rationale Kommunikabilität, die eine argumentative Generalisierung dieser Würde auch in glaubensexternen Kontexten erlaubt. Damit wird zugleich die grundsätzliche Forderung neuzeitlicher Ethik überhaupt erfüllt, die eine diskursive, rationale Einlösung jeder normkonstitutiven moralischen Intuition eines Subjekts verlangt. Über eine geistesgeschichtliche Vermittlung erhält so der christlich inaugurierte Gedanke der Personwürde seine rational universalisierbare Fundierung in Gestalt einer Maxime, deren Geltungsanspruch diskursiv einlösbar ist.

Mit dem Personbegriff und der daraus abgeleiteten kantischen Maxime sind nun die Grundgestalt des Menschen und das oberste ethische Prinzip festgelegt. Der Mensch ist als personales Wesen zu begreifen, das diese seine Personalität in seiner Vernunftbegabtheit, seinem Selbstand, seiner Individualität und Unverfügbarkeit gewinnt. Damit aber ist der Mensch zugleich als autonomes und freies Wesen anzusetzen, wie es die kantische Bestimmung mit der Freiheit des Willens letztlich schon tut. Ihren eigentlichen, transzendentalen Grund freilich finden die Autonomie und Freiheit des Menschen als Person nicht im Willen, sondern in seiner Vernunftbegabtheit. Durch diese nämlich unterscheidet er sich von, aller übrigen Natur' und ist er fähig, , sich selbst einen Zweck zu setzen.$^{13}$ Auch diese kantische Konsequenz liegt schon in der grundsätzlichen Definition der Personalität als vernünftiger und selbständiger vorbereitet, wie sie die skizzierte Begriffsgeschichte von früher Zeit an mit sich führt. Gleichzeitig ist damit nun die Konnotation mit dem Subjektbegriff gegeben. Das Subjekt nämlich, das neuzeitlich als auf der Basis der Vernunftbegabtheit zur Autonomie fähiges Wesen skizziert wird, koinzidiert weitgehend mit dem oben hergeleiteten Personbegriff und unterscheidet sich von diesem letztlich nur durch die fehlende explizite Bestimmung der Individualität. Der Subjektbegriff kann daher als gewissermaßen die allgemeine philosophische Fassung des darüber hinaus noch die Besonderheit und Unverfügbarkeit betonenden Personbegriffs verstanden werden. Dort, wo vom Projekt der Moderne gesprochen und auf die Subjektivierung des Menschen abgezielt wird, aber verwischt selbst dieser Unterschied und meint der Subjektbegriff letztlich die menschliche Person in ihrer Ganzheit. In den vorgängigen Rekonstruktionen ist dies nicht zuletzt im ethischen Grundduktus der Kritischen Theorie deutlich geworden, die ihren moralischen Impetus über den Subjektbegriff gewinnt und hierbei eine spezifische ,Würde des Subjekts' ansetzt, die unschwer als Personwürde dekodiert werden kann. In der Frühphase tritt, etwa bei Horkheimer, der Personbegriff deshalb auch noch auf und wird er erst später von der rationalitätstheoretischen Wende durch den Subjektbegriff ersetzt (vgl. 5.6.). Der vorgängig eingeführte Personbegriff aber läßt sich auf diesem Hintergrund bereits als spezifisch anthropologisch-ethischer Begriff verstehen, der mit dem Subjektbegriff koinzidiert und diesen mit umfaßt.

Aus theologisch-ethischer Perspektive lassen sich darüber hinaus noch zwei Momente ergänzen. So kann einmal die Bestimmung der menschlichen Person als freier und autonomer aus theologischer Perspektive noch über den imago-Dei-Gedanken gestützt werden, der den Personbegriff zugleich um ein weiteres Moment ergänzt. Zum anderen entdeckt sich der christlichen Reflexion ein Glaubensbezug auch der

13 vgl. Kant, Grundlegung, 71 
Wahrung von Autonomie und Freiheit des Subjekts, der dieser eine spezifische personale Tiefe und Fülle verleiht. - Zunächst läßt sich die Bestimmung der menschlichen Person als autonomer theologisch durch die Bestimmung des Menschen als imago Dei unterstreichen. Dabei wird zugleich ein weiterer, letzter Wesenszug der menschlichen Person deutlich. So ist der Mensch nach Gen 1,26 als Bild Gottes geschaffen. Damit aber hat er, theologisch gesprochen, zugleich an der Schöpfervernunft Gottes teil und vermag er selbst schöpferisch in der Welt tätig zu werden. Eben durch seine Vernunft und Freiheit entspricht theologischer Anthropologie zufolge der Mensch ,seinem Urbild, also Gott selbst“, und eben dadurch, daß er „Ursprungsprinzip seiner eigenen Werke ist", zeigt er sich als als das wahre Geschöpf seines Schöpfers. ${ }^{14}$ Gerade aus theologischer Perspektive ist so der Mensch als autonomes und freies Wesen zu begreifen. In theologischer Sicht widersprechen sich daher Theonomie - die Gesetzgebung des Schöpfergottes - und Autonomie - die Selbstgesetzgebung seines Geschöpfs - in keiner Weise, sondern ist der Mensch aus schöpfungstheologischen Gründen als autonomes Wesen anzusprechen. ${ }^{15}$ Dabei bilden seine Rationalität und Freiheit, kohärent zur Bestimmung des neuzeitlichen Subjekts (bzw. der Person), den Angelpunkt für diese Autonomie. Außerdem weist die theologische Bestimmung noch auf einen weiteren Wesenszug der Personalität und Subjektivität hin, nämlich die Kreativität. Als vernunftbegabtes autonomes Wesen ist der Mensch zugleich kreativ und auf Gestaltung seiner Welt hin angelegt. Damit aber umfaßt der Personbegriff, wie er in moderner Theologie gefaßt wird, alle Bestimmungsmomente, wie sie dem neuzeitlichen Subjekt zugesprochen werden. Nicht nur Rationalität und darauf fundierte Autonomie machen kohärent zum Subjektgedanken die menschliche Person aus, sondern es eignet ihr hierdurch auch die Kreativität des Entwerfens und ein dynamisches Moment. Der Personbegriff theologischer Anthropologie und des Prinzips christlicher Ethik bestätigt und umgreift derart den Subjektgedanken des Projekts der Moderne.

Weiter zeigt sich aus dem Vorangehenden, daß auch der neuzeitliche Gedanke der Autonomie und Freiheit der Person aus christlicher Sicht einen Glaubensaspekt hat und vom Glauben umfangen ist. So entdeckt sich durch die schöpfungstheologische Verankerung auch dem Glaubenden der Mensch als freies und autonomes Wesen und erhält diese Entdeckung im Glauben ihre Verankerung und Festigkeit. Wo Kant insbesondere die Freiheit als ,Idee‘, als ,regulatives Prinzip axiomatisch ansetzen muß und derart der rationalen Reflexion als unhintergehbares, d.h. letztlich ebenfalls ,zu glaubendes' Moment vorgibt, findet der Christ in der glaubensvermittelten Interpretation des Menschen, in seiner als schöpfungsmäßig gegründete Verfaßtheit und ,Gemeintheit' verstandenen Konstitution als personales Wesen die entsprechende Evidenz und Sicherheit. Er betrachtet den Menschen, wenn auch nicht in jedem Fall systematisch aus der Perspektive neuzeitlich-theologischer Anthropologie, so doch auf der Basis der neutestamentlichen Wurzeln dieser Anthropologie und vermag darin Freiheit und Autonomie als Wesensbestimmungen der Kinder Gottes, d.h. aber: letztlich aller Menschen zu erkennen. In der glaubensvermittelten Liebe zu

${ }^{14}$ Korff, Moraltheologie, 21

15 vgl. Korff, Moraltheologie, 21-22; Das genaue Verhältnis von Theonomie und Autonomie hier zu entfalten, würde zu weit führen. vgl. hierzu die präzise Ausarbeitung bei: Korff, Norm, $42-61$ 
diesen Menschen wird dann die derart gegründete Erkenntnis handlungswirksam. Dies hat - in Kohärenz zur Bedeutung des Glaubens und der Liebe für die Personwürde - vor allem für die Achtung der Autonomie und Freiheit des Menschen seine Bedeutung und dient hierdurch auch deren praktischer Realisienung. Wie sich die Personwürde des Menschen nämlich nicht nur über dessen Vernunftbegabtheit entdeckt, sondern letztlich erst in der vom Glauben vermittelten Liebe existenziell begreifbar wird, so findet auch erst diese Liebe zur existenziellen Erkenntnis und Respektierung der Freiheit und Autonomie des je Anderen. Der Glaube, der den Anderen als von Gott frei geschaffenes Wesen begreift, vermag dabei der Achtung dieser Freiheit ein praxiswirksames Fundament zu geben, das von einem rein rationalen Begründungsdenken allein nicht vermittelt werden kann. Der Gedanke allein hat nie jene handlungsrealisierende Kraft, die ihm durch seine Verbindung mit einer Glaubensüberzeugung und eine dadurch vermittelte entsprechende habituell-emotive Einwurzelung zuteil wird. In dieser Weise ist es daher der Glaube, der die Freiheit des Anderen erst (mit) ermöglicht. Dies zeigt sich vor allem dort, wo der Andere in seiner Selbstrealisierung AnstoB erregt oder eigenen Interessen empfindlich im Weg steht. Hier schaffen Glaube und Liebe die existenzielle Basis, auf der der Andere in seiner von Gott gemeinten Freiheit und Autonomie respektiert und geschätzt werden kann, ja im hiervon geprägten Miteinander erst die Chance seiner Realisierung als so gemeintes Wesen findet. Nicht einzig nur die abstrakt-rationale Ethikbegründung dient also der Bejahung und Ermöglichung der Autonomie und Freiheit, sondern die liebende Zuwendung, die sich gerade bei härterer ,Prüfung' erst über den Glauben als tragfähig erweist. Damit aber hängen Autonomie und Freiheit nicht im Leeren, sondern zeigen sie sich von Glaube und Liebe vermittelt und umfangen. Dies erst verleiht den Interaktionen der autonomen Subjekte eine spezifische, durch blanke Reflexion weder zu erzeugende noch zu ersetzende Tiefe und Fülle. Gleichzeitig konnotiert sich der christliche Zugang zur Realität, der derart wieder den abstrakt-prinzipiellen Gedanken erfahrbar macht und für seine existenzielle Verwurzelung sorgt, auch auf diese Weise mit den Intentionen des Projekts der Moderne.

\section{Das ,nichtfestgestellte Wesen: Die anthropologische Bestimmung der Autonomie im} Kontext des Natur-Kultur-Verhältnisses

Diese theologisch-anthropologische Fundierung kann nun noch ,säkular'-anthropologisch gestützt und untermauert werden. Dabei läßt sich zugleich das Natur-KulturVerhältnis klären und in einer modernitätsgerechten, der Autonomie des Subjekts adäquaten Weise fassen. So erlaubt die empirisch geleitete Anthropologie Arnold Gehlens zunächst die Bestimmung des Menschen als ein ,nicht festgestelltes Wesen', das durch seine ,Instinktunsicherheit' und (mit Heidegger gesprochen) ,Geworfenheit' in der Welt zu einer spezifischen Leistung, nämlich der Entwicklung von Vernunft und kreativ-instrumenteller Kompetenz genötigt ist, um sein Überleben betreiben zu können. ${ }^{16}$ Gegenüber dem durch Instinkte sowohl fixierten als auch mit einer eigentümlichen Kompetenz zur Bewältigung seiner Umwelt und (elementaren) Lebensvollzüge ausgestatteten Tier nämlich erscheint der Mensch als ,mangelhaft" ausgerüstetes Lebewesen, das sein Weltverhältnis durch Schaffung von Welt- und Le-

16 vgl. hierzu: Gehlen, Mensch, 10 
bensinterpretationen erst etablieren muß. Als ,extremer Nesthocker' (Portmann, Mitscherlich) ist der Mensch zudem auf kognitive Vermittlung der zur Lebensbewältigung notwendigen Wissensbestände und Techniken, d.h. auf Lernen angewiesen. Phylogenetisch ermöglicht sind die Hervorbringung der Wissens- und Interpretationsbestände sowie das Lernen durch die ihnen zugrundeliegende „geistig-rationale Potenz ${ }^{\text {"17 }}$, die in der allmählichen Ausbildung des Großhirns ihr naturales Fundament besitzt. Neben der Lernbedürftigkeit weist das ,biologische Mängelwesen Mensch jedoch auch eine defiziente - und im Prozeß seiner Kulturation zunehmend defizienter werdende - Ausstattung mit Organen der Umweltbewältigung, d.h. mit Klauen, Zähnen und Sinnesvermögen auf, so daß es außerdem auf die Schaffung von ,künstlichen', schützenden Umwelten und von Technik zu deren Erzeugung angewiesen ist. Gehlen nennt auf dem Hintergrund mangelnder Umweltzugepaßtheit der organischen Ausrüstung des Menschen dessen technisch-instrumentelle Erfindungen und Machinationen ,Organersatz, Organentlastung und Organüberbietung (vgl. auch 1.2.), da sie Kompensations- und ,Überstiegsleistungen' ermöglichen sollen. ${ }^{18}$ Mit diesen Bestimmungen aber, der Verwiesenheit auf Schaffung von Welt- und Lebensinterpretationen bzw. von rationalem Wissen sowie auf das Lernen und die technische Weltgestaltung, erweist sich der Mensch zugleich als ein Wesen, das von seiner naturalen Konstitution her auf Kultur angelegt ist. Kultur kann entsprechend vorerst als eine technisch erzeugte, ,künstliche' Umwelt sowie als Etablierung spezifischer Wissens- und Interpretationsreservoirs begriffen werden. Ohne diese ist das Überleben des Menschen in der Welt anthropologisch nicht denkbar. Damit ist bereits auch ein spezifisches Natur-Kultur-Verhältnis anthropologisch fixiert, das als Verschränkung (E. Morin) beschrieben werden kann: Aufgrund seiner Instinktunsicherheit und seiner Verwiesenheit auf die Schaffung technisch-instrumenteller Möglichkeiten und lebensnotwendiger Wissensbestände ist der Mensch ,von Natur aus ein Kulturwesen" ${ }^{19}$ Kultur erscheint so zunächst im Menschen selbst nicht als das Gegenüber der Natur, sondern als prinzipiell mit der naturalen Konstitution des Menschen verwobene Größe, als natural grundgelegte notwendige Bedingung seiner Existenz.

Im Kontext dieser Verschränkung kann nun die Autonomieproblematik (nochmals) näher betrachtet werden. Zum einen nämlich stützt die oben ausgeführte anthropologische Figur die kantische Herleitung der Autonomie des Menschen aus dessen Vernunft und Freiheit auch unabhängig von ihrer transzendentalen Fundierung. Zum anderen erweist eine genauere Ausführung der moralrelevanten naturalen Strebungen des Menschen ein anthropologisches Dispositionsfeld, das sowohl ein Moment der Unbeliebigkeit in den Autonomiegedanken einbringt als auch ein gewisses Vertrauen auf die menschliche Natur legitimiert. - Zunächst nun unterstreicht die mit Gehlen umrissene Grundbefindlichkeit des Menschen formal-anthropologisch, d.h. unter Ausblendung der inhaltlichen Bestimmtheit der menschlichen Natur und in Konzentration auf ihre Formalstruktur, die vernunft- und freiheitsbegründete Autonomie des letztgenannten. Als einem nicht-festgestellten Wesen, das seinen Bestand in der Welt erst selbst kreativ herstellen muß und hierzu kaum auf

${ }^{17}$ Korff, Institutionstheorie, 171

18 vgl. Gehlen, Technik, 93-94

19 Morin, E., Das Rätsel des Humanen, München 1974, 105; vgl. auch: Korff, Unbeliebigkeit, 150 und: Mertens, Ethik, 84-86 
instinktmäßige Präformationen, wohl aber auf seine vom Großhirn ermöglichte ,geistig-rationale Potenz' zurückgreifen kann, nämlich eignet dem Menschen sowohl Freiheit als auch die nötige Fähigkeit zur Selbstbestimmung. So setzt, wie angedeutet, seine instinktbezogene ,Aspezifität' den Menschen von präformativen Verhaltensmodi frei und eröffnet ihm im Unterschied zum Tier, das unter instinktmäßiger Determination lediglich eine mit dieser Determination interagierende Umwelt besitzt, eine offene Welt. Nicht auf ,Schlüssel-‘ und ,Auslösereize', deren Zugepaßtheit zur Instinktprägung ihm das ,adäquate ${ }^{\prime}$ Verhalten vorzeichnete, trifft das,mangelhaft' ausgerüstete Menschenwesen, sondern auf eine ,unspezifische Reizfülle', die erst der Interpretation und Einordnung bedarf. ${ }^{20}$ Bei dieser Einordnung und Interpretation, d.h. bei seiner Weltauslegung, aber ist der Mensch mit seiner der offenen Welt entsprechenden offenen Vernunft zum Entwurf freigesetzt. Anstelle der Instinktfixierung ermöglicht ihm diese Vernunft die Weltauslegung als Weltentwurf und hält sie das Entwerfen zugleich dynamisch und veränderbar. Mit ihr ist dem Menschen zugleich die Potenz zu seiner Selbstbestimmung, d.h. die formal-vermögenshafte Basis für seine Autonomie gegeben. Gleichzeitig freilich nötigt, wie oben schon angedeutet, die von der Nichtfestgestelltheit bedingte Freiheit des Menschen zu solchem vernünftigen Entwerfen, so daß - mit Sartre gesprochen - der Mensch als ,zur Freiheit verdammt' bzw. mit weniger Dramatik: als einem Kreativitäts- und Rationalisierungszwang unterworfenes Wesen bestimmt werden kann, dem Autonomie nicht nur gegeben, sondern auch aufgegeben ist. Darauf verweist wiederum Gehlen, der betont, da $\beta$ der Mensch ,aus eigenen Mitteln und eigentätig (...) die Mängelbedingungen seiner Existenz (...) in Chancen seiner Lebensfristung umarbeiten" $m u \beta .{ }^{21}$ Im ganzen zeigt sich so, da $\beta$ der Mensch in einer von seiner Nichtfestgelegtheit erzwungenen Leistungssituation zum Gebrauch seiner Freiheit genötigt ist und auf der Basis seines Vernunftvermögens zugleich seine Chance zum autonomen Weltentwurf findet. Freiheit und Autonomie des Menschen können derart auch ,unterhalb' der transzententalen Herleitung formal-anthropologisch gestützt werden, und der Mensch zeigt sich in seiner interpretativen Haltung gegenüber der Welt als prinzipiell ,stellungnehmendes Wesen ${ }^{22}$

Diese Autonomie und Stellungnahme nun übt der Mensch nicht allein gegenüber der äußeren, ihn umgebenden Welt aus, sondern auch gegenüber seiner inneren Welt, bzw. genauer: gegenüber seiner naturalen Basis, die im Kontext einer Auseinandersetzung mit der von den Kinoreformern und Filmerziehern vorgenommenen Bewertung dieser Basis besonders interessiert. Formal-anthropologisch zeigt sich hierbei zunächst, da $B$ sich der Mensch auch in bezug auf naturale Strukturen und Strebungen innerhalb seiner selbst interpretativ und kulturativ verhält. Als empirischer Hinweis darauf kann etwa das Experiment Schachters gewertet werden, der Versuchspersonen in unterschiedlichen Kontexten Adrenalin injizierte, um die qualitative Determinativität dieses Stoffs als eines naturalen Substrats auszutesten. Ergebnis des Versuchs war, daß die Qualität des Erregungszustands von einer interpretativen Leistung des affizierten Subjekts abhing. Je nach situativer Befindlichkeit und

${ }^{20}$ vgl. dazu: Gehlen, Mensch, 38

21 Gehlen, Mensch, 38; im Original partiell gesperrt.

22 vgl. Gehlen, Mensch, 10 
individueller Gestimmtheit ,erfuhren' die Versuchspersonen den Erregungszustand anders, d.h. sie erfuhren ihn unter den Prämissen ihrer subjektiv-interpretativen Vorleistung und ,gaben' ihm erst im Rahmen ihrer Subjektivität die ,eigentliche Qualität‘. ${ }^{23}$ Das naturale Substrat kann deshalb nicht als umfassend determinativer Wirkfaktor aufgefaßt werden, sondern erweist sich als einer ,, lenkenden Rücksteuerung' des Geistes" unterworfen, die gemäß der Natur-Kultur-Verschränkung zwar nicht völlig, jedoch relativ unabhängig von der naturalen Basis dieser eine spezifisch ,human-besondere' Gestalt aufprägt. ${ }^{24}$ Jenseits dieser experimentell nachgewiesenen situationellen Subjektivität kann zudem kulturgeschichtlich eine generelle Neigung des Menschen konstatiert werden, seine naturalen Strukturen einer interpretativen Formung zu unterziehen. So zeigt die Geschichte etwa der Sitten um das Essen, daß die Nahrungsaufnahme, die zweifellos von einem naturalen Grundantrieb ,determiniert' ist, gleichwohl über ihre bloße Notwendigkeit hinaus keineswegs determinativ fixiert, sondern menschlicher Gestaltung, also seiner Subjektivität und Autonomie unterworfen ist. Zwar kann der Mensch nicht umhin, sich zu ernähren, doch wie er das tut, ob in Form zelebrierten Speisens oder rascher ,Fast-food-Aufnahme', nach speziellen Rezepten oder in ,natürlich'-roher Form, bleibt seiner Entwurfsleistung überlassen. Analoges gilt für die Sexualität, die ebenfalls einer Fülle von kreativen Gestaltungsmöglichkeiten offen steht. Beide Grundantriebe können zudem (zumindest temporal) umgeleitet oder postponiert werden. Gehlen verweist daher darauf, daß ,,selbst die organisch repräsentierten Minimaltriebe - Hunger und Sexualität (...) an die Gesetze des höheren Interessenlebens" ,anschließen' und ,hemmbar, vertagbar, in gewissen Grenzen ablenkbar, sogar aus anderen Interessen heraus unter Umständen ganz zu überwinden (Askese, Hungerstreik, usw.) “ sind. ${ }^{25}$ Die naturale Konstitution des Menschen, seine Grundantriebe und Bedürfnisse, zeigen sich formal-anthropologisch so also als interpretable, gestaltbare und derart in gewissen Grenzen der subjektiven Autonomie unterworfen. Das instinktmäßig nicht festgelegte Menschenwesen erweist sich hierbei als auch in seiner naturalen Basis nicht (unausweichlich) fixiertes Wesen, sondern zeigt sich als gegenüber dieser Basis sowohl mit einer gewissen Distanzierungsfähigkeit, als auch mit einer Gestaltungspotenz ausgestattet. Gegenüber der filmerzieherischen oder reformerischen Position, die schon aus der formalen ,Übermacht' der naturalen Antriebsstrukturen eine Notwendigkeit entsprechend starker kultureller Barrieren deduzierte, kann somit vorerst in Anschlag gebracht werden, daß es eine übermächtige, determinative Teleologie dieser Antriebe gar nicht in dieser Weise gibt, sondern dem Menschen die Potenz eignet, sich zu denselben ins Verhältnis zu setzen und ihr Telos zumindest mitzuschaffen oder jedenfalls entscheidend qualitativ auszulegen. Weiter zeigt sich, daß der Mensch gemäß der Natur-Kultur-Verschränkung auf eine solche entscheidende ,Mitbestimmung' und -gestaltung, d.h. auf Kulturation seiner Naturalität und ihres Telos angelegt ist. Entgegen einer Position, die Kulturation als gewissermaßen brachiale Umkehrung der Naturzwänge und als einen repressiven Umgriff um diese Natur versteht, kann die Kulturation nun als ,kongeniale' Gestaltung der naturalen Strukturen

${ }^{23}$ vgl. dazu: Schmidtchen, G., Manipulation - Freiheit negativ, Neuwied - Berlin 1970, 35, und: Korff, Unbeliebigkeit, 151

24 Korff, Unbeliebigkeit, 151
${ }^{25}$ Gehlen, Mensch, 63 
begriffen werden. Der Natur-Kultur-Gegensatz der beiden genannten Positionen ist derart anthropologisch aufgelöst. Zugleich ist hierdurch eine modernitätsgerechte Position grundgelegt, die der Autonomie des Subjekts Rechnung trägt und sie anthropologisch detailliert zu begründen vermag.

Gleichwohl liefert die naturale Basis erneut einen Zwang zur Interpretation und Gestaltung: es $m u \beta$ mit ihr umgegangen werden, sowie eine Vorgabe für die Gestaltungsaufgabe: ihre (der naturalen Basis) Spezifität ist es, die subjektiv zu formen ist. Damit aber kann die Autonomie des Menschen nicht als schrankenlose, vollständig arbiträre gedacht werden, sondern ist sie selbst nochmals in den Rahmen der NaturKultur-Verschränkung gestellt. Diese Verschränkung nämlich bedeutet nicht einfach $\mathrm{bloB}, \mathrm{da} B$ der Mensch aus Mangel an naturaler Fixierung und Ausrüstung auf Kultur hin angelegt ist und hierbei eine Vernunft entfaltet, die auf die Natur interpretativ und formend einwirkt. Vielmehr stellt sich diese Vernunft selbst nochmals als Funktion der menschlichen Natur dar, die ihr gewisse material-,thematische Vorgaben liefert und sich darin als dispositiv erweist. Die Vernunft bewegt sich in bestimmten Grenzen, und „die Interessen, die sie leiten, die Funktionszusammenhänge, die sich als je vernünftig ausweisen, sind nicht allein durch sie selbst gesetzt, sondern in allem durch eine ihr je vorgegebene Natur mitbestimmt " ${ }^{26}$ Entsprechend ist auch die vernunftbegründete Autonomie des Menschen nicht bloße, willkürlich entwerfende Kulturpotenz, sondern unterliegt sie einer gewissen ,Unbeliebigkeit' (W. Korff), die jetzt in ihrer Materialität noch näher zu betrachten ist. Von Relevanz ist diese Betrachtung nicht zuletzt, da auch die Filmerzieher und Reformer eine ,unbeliebige' naturale Basis im Menschen annahmen, deren Materialität sie einer Bewertung, näherhin einer Verwerfung, unterzogen und aus der sie eine grundsätzliche Gefährdetheit des Menschen ableiteten. Dieser Gefährdung schien entsprechend nicht nur aus dem formalen Grund einer Übermacht naturaler Strebungen, sondern auch aus dem materialen einer prinzipiellen Verderbtheit nachhaltig entgegenzutreten zu sein. So zeigte sich bei Reformern und Filmerziehung eine Auseinandersetzung mit moralrelevanten Strebungen der menschlichen Natur, die als mit einem antimoralischen Impetus, einer unmoralischen Inklination ausgestattet gezeichnet wurden. Dabei wiederum ließ vor allem die Filmerziehung erkennen, daß dieser antimoralische Impetus vordringlich in der Aggression gesehen wurde: ${ }^{27}$ Die Rede war vom ,Tier im Menschen', der ,Bestie in uns', von ,sadistischen Neigungen' und einer destruktiven, raubtierähnlichen Konstitution (vgl. 4.4.). Ausgemalt wurde das Bild einer archaischen Brachialität und Brutalität des Menschen, die lediglich unter der ,dünnen Decke‘ zivilisatorischer Hege verborgen lauere und als gewissermaßen phylogenetisch ,eigentliches

${ }^{26}$ Korff, Unbeliebigkeit, 152

${ }^{27}$ Das Problem der Sexualität, die als Triebkraft im besonderen thematisiert wurde, zeigte sich im Unterschied hierzu sowohl bei den Reformern als auch bei den Filmerziehern weniger als ein anthropologisches, sondern mehr als ein sozialethisches Thema: Ärgernis bot nicht so sehr ihre Naturalität bzw. ihre naturale ,Entelechie', sondern der im Umgang mit ihr zutage tretende Ethoswandel. Wo es um die naturale Basis eines generellen Moralverfalls - also die der ,moralischen Primitivierung' - ging und eine ,in sich' negative Naturalität diskutiert wurde, stand hingegen vordringlich die Aggression im Zentrum. Entsprechend verzichte ich auf eine (nochmalige) Thematisierung der Sexualität in diesem Kontext; daß ich sie anthropologisch als Triebkraft auffasse, die der menschlichen Gestaltung offensteht und keineswegs ,aus sich heraus' eine fixiert-überwältigende, Entelechie‘ besitzt, ist bereits deutlich geworden. 
Wesen stets hervorzubrechen drohe. Der Mensch erschien als in seiner materialen naturalen Disposition zur Moralität unfähiges Wesen, und etabliert wurde auch aus diesem Grund ein Sein-Sollens-Antagonismus. Selbst wenn man also, wie ich es im vorgängigen getan habe, die Annahme einer Übermächtigkeit naturaler Strebungen des Menschen formal-anthropologisch zurückweist, bleibt daher noch die Frage, ob die derart unterstrichene menschliche Autonomie nicht aus material-anthropologischem Grund dazu genutzt werden müßte, im Sinn dieses Antagonismus der verderbten Natur des Menschen ein Moralität erst herstellendes Sollen entgegenzusetzen, und ob die ,kongeniale' Kulturation nicht letztlich doch als prekär zu beurteilen ist. Der naturale Unbeliebigkeitsrahmen der menschlichen Autonomie wäre hierbei als Hindernis, nicht aber als Vertrauen erweckendes ,Dispositiv (M. Foucault) zu bewerten. - Im Zusammenhang der Betrachtung des naturalen Unbeliebigkeitsrahmens läßt sich zugleich ein Blick auf die zwar nicht anthropologisch fixierte, jedoch bei ihrer prekären Einschätzung menschlichen Verhaltens ebenfalls auf das Aggressionsphänomen zielende Theorie von Selg werfen (vgl. 4.7.). Zwar stand dort nicht eine a priori gegebene negative Latenz des Menschen im Blick, doch schien a posteriori eine solche durch Lernen erzeugt zu werden und wurde diese in einer als Destruktivität gezeichneten Aggression gesehen. Die nachfolgende Aufschlüsselung des materialen naturalen Dispositivs des Menschen, die sich mit dem aggressiven Strukturmoment darin befaßt, legt daher eine Konfrontation auch mit dem materialen Aggressionsverständnis Selgs nahe.

Zunächst aber erweist sich aus einer material-anthropologischen Perspektive die negative Anthropologie der Reformer und Filmerzieher als falsch. Sie ruht genau besehen nämlich auf einer unvollständigen und einseitigen Skizze der menschlichen Naturalkonstitution auf. Weder kann diese Konstitution in ihren moralrelevanten Grundzügen als auf Aggression eingeschränkt gesehen werden, noch eignet der Aggression selbst ein ,in sich böser', einzig destruktiver Charakter. So verweist zunächst etwa Wilhelm Korff mit Freud darauf, daß Aggression ,nicht nur als ein durch mögliche Versagungserlebnisse ausgelöstes reaktiv-destruktives Antriebsverhalten, sondern, in ihrem jeweiligen Wirkungszusammenhang mit libidinösen Impulsen, zugleich auch als unverzichtbare, aktiv-konstruktive Komponente im Dienst des ,Lebenstriebs““ aufzufassen ist. ${ }^{28}$ Gegen die Verkürzungen der Frustrations-Aggressions-Hypothese der Yale-Schule verdeutlicht Korff so, daß die endogen entstehende, aggressive Energetik des Menschen nicht aus sich heraus schon auf mögliche Zerstörung gerichtet ist, sondern ebenso seine kreative, initiative und derart schöpferisch-aufbauende Aktivität ,sponsort', die sonst ohne Kraft bleiben würde. ${ }^{29}$ Aggression ist damit mehr im Sinn eines zunächst ,leeren', ,reinen' Antriebsimpulses zu verstehen, der sich an andere Strebungen und Triebkräfte (die wiederum, wie zu sehen war, einer Gestaltung durch die Vernunft geöffnet sind) bindet und erst in dieser Kombination sein ,Telos“ und seinen definitiven Inhalt gewinnt. An sich genommen, ,isoliert' auftretend, wäre ein Aggressionsimpuls zwar durchaus ,notwendig rein destruktiv“'30, doch läßt er sich in dieser Reinheit kaum auffinden. Vielmehr „baut sich“ in der Regel „eine je eigen-

${ }^{28}$ Korff, Norm, 82

29 vgl. Korff, Norm, 84-85

${ }^{30}$ Korff, Norm, 85 
tümliche ,Mischung und ,Legierung' von Antriebskonfigurationen auf" ${ }^{31}$ in der die aggressive Komponente eine ,Assistenzfunktion' zur Durchsetzung der sonst kraftlos bleibenden Strebungen ausübt. Von diesen ,Mischungen' und den in ihnen entstehenden, intentionalen Zielen hängt es letztlich ab, ob das vom Aggressionsimpuls gestützte Handeln eine destruktive oder konstruktive Bedeutung aufweist. Damit aber muß dort, wo über Destruktivität und Konstruktivität diskutiert wird, von vorneherein ein umfänglicheres Antriebsfeld in Blick genommen werden und reicht die Fixierung auf die Aggression allein zur anthropologischen Klärung nicht aus.

Das wiederum bedeutet, daß selbst im sadistisch-destruktiven Verhalten, das die Filmerzieher und Reformer im Blick haben, eine spezifische Bindung des aggressiven Impulses an andere Triebkonfigurationen und -versehrungen angenommen und reflektiert werden muß. Nicht aus der Destruktion allein, sondern durch sie hindurch und vermittels ihrer wird hierbei eine Gratifikation erwartet. Gerade im Sadismus, der zudem entgegen filmerzieherischer Einschätzung keine naturale Gegebenheit, sondern eine pathologische Deformation ist, tritt deshalb zutage, da $B$ der aggressive Impuls als eine Art Hilfsfunktion von in ihrem Ursprung und ihrer Motivation anderswo zu suchenden Verhaltensweisen auftritt. Aus diesem Grund aber verbietet es sich, aus der Aggressivität allein eine naturale Negativität des Menschen mit einer unaufhaltsamen, bösen ,Entelechie‘ zu konstruieren. $\mathrm{Zu}$ fragen ist vielmehr, worin die jeweils spezifisch destruktiven Verhaltensweisen von Menschen ihren kombinatorischen Ursprung haben und welche Strebungen (und Rationalisierungen) aus welchen Gründen zu diesem Verhalten zusammenschießen. Die mit dem Sadismus schon genannte Problematik der Pathologien und Versehrungen wird dabei das zentrale Thema bilden, und das ,Böse' wird sich zumeist als eine deficientia boni erweisen, kaum aber als eine ,positiv'böse Erscheinung. Weiter verweist die Möglichkeit der konstruktiven Wirkung des aggressiven Impulses darauf, daß eine ,Lösung des ,Negativitätsproblems' kaum in einer Hemmung oder gar Beseitigung der aggressiven Naturalität des Menschen bestehen kann und darf. Mit der aggressiven Energie wäre sonst auch die ,positive‘ Kraft der Durchsetzungsfähigkeit und des kreativen Vorwärtsdrängens beseitigt. Soll also die schöpferisch-konstruktive Aktivität des Menschen erhalten bleiben, so muß auch seiner natural grundgelegten aggressiven Strukturkomponente Rechnung getragen und Raum gegeben werden.

Nicht allein die reformerisch-filmerzieherische Anthropologie, sondern auch der materiale Aggressionsbegriff von Selg aber ist auf diesem Hintergrund nun abzulehnen. Wie zu sehen war, begreift Selg in pointierter Absetzung von einer psychoanalytischen Reflexion Aggression als erlerntes Destruktionsverhalten. Dieser Ansatz erscheint jetzt aus der hier skizzierten anthropologischen Perspektive heraus als recht undifferenziert: Bei Selg wird der Mensch als tabula rasa gezeichnet, dem dann jede Verhaltensform durch schlichte Appräsentation von entsprechenden Modellen aufgesetzt werden kann. Dabei scheint der Mensch von sich aus nur die leere Formbarkeit mitzubringen, jedoch keine eigene Antriebskonfiguration zu besitzen, die durch entsprechende Einflüsse weiter strukturiert werden könnte. Daher steht der blanken externen Formung des Verhaltensrepertoires des Menschen bei Selg auch nichts entgegen. Es gibt kein naturales Substrat, das in irgendeiner Weise mit Formeinflüs-

\footnotetext{
${ }^{31}$ Korff, Norm, 85
} 
sen interagieren würde. Entsprechend gilt die Formung von außen als unmittelbare und vollständige Determination und kann ihr Ergebnis aus den formenden Inhalten selbst deduziert werden. Die Frage nach Legierungen von inhaltlichen menschlichen Strebungen, nach der Verknüpfung des Durchsetzungsimpulses des Menschen mit entsprechenden motivationellen - auch destruktiven - Zielen sowie nach der jeweils spezifischen Herkunft dieser Ziele und der in ihnen gesuchten Gratifikation muß nicht mehr gestellt werden. Die Destruktion scheint von außen übergestülpt und eine durch ihren Vollzug erlangte Gratifikation scheint für diesen Vollzug völlig unwichtig zu sein. Einzig das Gelingen der Destruktion bildet bei Selg noch ein rudimentäres Kriterium für die Motivation zur Ausübung destruktiver Handlungen. Der Mensch, der eine mit ,Erfolg' ausgeführte zerstörerische Handlung wahrnimmt, scheint also schon deswegen, weil er diese Handlung gesehen hat, sich in begieriger Nachahmung zu ergehen. Im Unterschied zu diesem Konzept bietet der vorliegende Ansatz nun die Möglichkeit, differenzierter zuzusehen und der Komplexität menschlichen Verhaltens und seiner Genese Rechnung zu tragen. So kann unter der Voraussetzung eines formalen Aggressionsbegriffs, der Aggression als Impuls versteht, nun nach den Bedingungen gefragt werden, unter denen sich dieser Impuls der Durchsetzung bestimmter - möglicherweise auch destruktiver - Verhaltensweisen dienstbar machen läßt. Wie bei den Pathologien kann insbesondere gefragt werden, wodurch und unter welchen Bedingungen Handlungsziele generiert werden können, die mit bestimmten Gratifikationen verbunden sind und die unter Nutzung des Aggressionsimpulses erreicht werden sollen. Betrachtet werden können damit auch die spezifischen Legierungen von menschlichen Strebungen, die dem Aggressionsimpuls erst seine inhaltliche Richtung geben. Wo die je und je besonderen Gratifikationen, die Triebziele und Wunschgenerierungen in Blick genommen werden können, läßt sich dann auch begründeter und präziser sagen, ob und unter welchen Bedingungen der Aggressionsimpuls des Menschen in Destruktivität umgeleitet werden kann und wie sich im Unterschied dazu die konstruktive Auslegung der Aggression fördern und wahren läßt.

Gleichwohl ist mit dem Verweis auf die ,Kombinatorik“ von Aggression und ihrer konstruktiven Funktionsmöglichkeit die Frage nach materialen moralrelevanten Naturalstrukturen im Menschen noch nicht ausreichend geklärt und das genannte Feld zu berücksichtigender Antriebsformen keineswegs vollständig in Blick genommen. Selbst wenn Aggression nicht an sich als böse Kraft dingfest gemacht werden kann, bedeutet das noch nicht, daß schon Vertrauen in die materiale Natur des Menschen gesetzt werden darf und der Sein-Sollens-Antagonismus verabschiedet werden kann. Auch bliebe nach wie vor denkbar, daß sich ein negatives Zusammenspiel bestimmter Verhaltensappräsentationen in der Außenwelt mit bestimmten basalen menschlichen Strebungen ergeben könnte, das dann unter Nutzung des aggressiven Energieimpulses wieder notwendig zu zerstörerischem Verhalten führt. Zwar wäre nicht die Aggression selbst der anthropologische Wurzelgrund, aus dem die Destruktion hervorzugehen droht, doch ließe sich immer noch ein anderes Strukturmoment der menschlichen Grundkonstitution denken, dessen Legierung mit dem Aggressionsimpuls unter entsprechender äußerer Motivation unausweichlich die Zerstörung aus sich hervortreibt. Damit ließe sich dann zwar eine differenziertere Theorie des Lernens ansetzen, als sie bei Selg vorliegt, doch wäre letztlich dasselbe Ergebnis dedu- 
ziert und eine entsprechende Forderung nach ,Abschirmung des Menschen von verderblichen Stimulantien wie bei den Reformern zu stellen. Ohne eine genauere Reflexion der menschlichen Strebungen ist daher mit dem differenzierteren formalen Aggressionsbegriff allein noch nicht alles geklärt. Erst die Kenntnis aller Komponenten der basalen Antriebsstruktur des Menschen, des gesamten Felds grundlegender Legierungen und Mischungen seiner natural gegebenen Strebungen, also der prinzipiellen Konfiguration basaler Antriebe, gibt den nötigen AufschluB, der dann auch eine zureichende Einschätzung der Aggression und ihrer möglichen Kombinatorik erlaubt. $\mathrm{Zu}$ fragen ist daher, ob es noch weitere natural verankerte Basisstrukturen im Menschen gibt, die ein differenzierteres Bild ermöglichen.

Hier nun macht wiederum Korff in bezug auf das Sozialverhalten des Menschen ein ,naturales Strukturgesetz aus, in das die Aggression als eine seiner Komponenten eingebunden ist und das dem genannten Verhalten einen materialen Dispositionsrahmen setzt, der das gesuchte Vertrauen in die menschliche Natur stützt. Dieses Strukturgesetz, das er als, soziale Perichorese terminologisch fixiert, stellt eine „Spannungseinheit von sachhaft-bedürfnisgerichtetem, konkurrierendem und selbstlos-für-

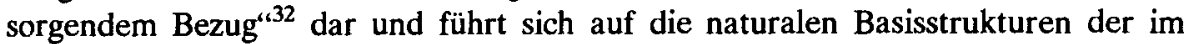
Fluchttrieb anschaulich wirksam werdenden, sozialisierenden Angst', der intraspezifischen Aggression und des Brutpflegetriebs zurück. Zunächst zeigt sich in diesem Strukturgesetz nochmals, wie die Aggression zu verstehen ist: Sie stellt sich als Antriebsimpuls dar, der auf Durchsetzung, Selbstbehauptung und darin auf ,Konkurrenz' gerichtet ist, ohne da $\beta$ damit schon benannt wäre, was durchgesetzt, welches Selbst gewahrt und worüber konkurrenziert werden soll. Unter sozial-handlungstheoretischem Aspekt erscheint dieser Impuls so als ,rein' dissoziierende, abgrenzungsorientierte Kraft. Über den Fluchttrieb, der den ,Artgenossen zum Fluchtziel' macht und in dessen Nähe Geborgenheit und ,Heimvalenz' suchen läßt, ${ }^{33}$ tritt dann ein spezifisch sozialer „Bindungs- und Vergesellungswille“34 vor Augen. Mit diesem vermittelt ist das, sachhaft-gebrauchende' Verhalten des Menschen, das den Anderen unter dem Aspekt eigener Bedürfnisse zu deren Erfüllung nutzt. Nicht nur in der Angstsituation aber und im Bedürfnis nach nötiger Geborgenheit aktualisiert sich dieses Gebrauchen, sondern in letztlich jeder Bedürftigkeitssituation, so da $B$ unter dem Aspekt der Bedürfniserfüllung stets ein Interaktionsverhältnis des sachhaften Gebrauchens entsteht. Der Vermittlung mit dem Bindungsaspekt entsprechend ist dieses sachhafte Gebrauchen von seiner Grundform her jedoch noch keineswegs als Überherrschen und $M i \beta$ brauchen zu denken, sondern stellt es nüchtern jene Verwiesenheit aufeinander vor Augen, in die der Mensch von seinen (zwischenmenschlichen) Bedürfnissen her gestellt ist, und die ihn zu einer kooperativen Vernetzung mit anderen nötigt. Als Bedürfniswesen ist der Mensch auf den Anderen angewiesen und findet er sich notwendig in einem natural gegründeten Miteinander. Die Vernetzung erhält dann mit dem vom Brutpflegetrieb natural disponierten Verhalten außerdem eine fürsorgende Komponente, in der altruistische Zuwendung, ja ,Selbstlosigkeit dispositiv grundgelegt sind. Von der Naturalstruktur dieses Triebs sieht Korff daher

\footnotetext{
${ }^{32}$ Korff, Norm, 92

33 vgl. Eibl-Eibesfeldt, Liebe und Haß, München 1970, 148

${ }^{34}$ Korff, Norm, 88
} 
in das ,Sozialverhältnis' des Menschen, seine ,Sozialnatur‘, eine „mitteilende (...) Zuwendungshaltung" eingebracht, „die von den Momenten des Gebens und Aufnehmens, des Sich-Gebrauchenlassens, des Schenkens und Sorgens erfüllt ist" “ ${ }^{35} \mathrm{Ne}$ ben dem dissoziativ-durchsetzungsbereiten Antriebsimpuls stehen so auch eine sozialisierend wirkende Bedürfnisverstrickung und eine spontan sich zuwendende, altruistische Haltung des Menschen, deren Impetus ebenso stark einzuschätzen sind wie jener der aggressiven Strukturkomponente.

Das aber bedeutet für diese Komponente, daß sie sich stets mit zwei Korrektiven konfrontiert findet, die neben der genannten Verbindung ihres Impulses mit anderen Trieben und Zielen einer ,reinen', material einseitigen Ausformung ihrer selbst auch etwa durch mimetisches Lernen - entgegenstehen. Gleichzeitig macht das naturale Strukturgesetz deutlich, daß die naturale Basis im Menschen unter dem Blickwinkel seiner Sozialität nicht eindimensional ausgelegt werden darf, sondern daß unter den moralrelevanten naturalen Strebungen mindestens drei in Spannung zueinander stehende angenommen werden müssen, die ein materiales Dispositiv darstellen. Auf diesem Hintergrund verbietet es sich von vorneherein, den Menschen in seiner materialen Naturalität als ,urzeitlichen Schlächter' und als ,Bestie' zu zeichnen. Nicht nur ,Aggressor', sondern auch vergesellungswilliges ,Bedürfniswesen' und zuwendungsbereiter ,Fürsorger' ist der Mensch dem Menschen von Natur aus. ${ }^{36} \mathrm{Da}$ her kann auch ein gewisses Vertrauen in seine materiale Naturalkonstitution und in seine Autonomie als legitim gelten. Die letztgenannte muß nun nicht dazu genutzt werden, der prekären, ja verderbten Materialität der menschlichen Natur entgegenzutreten, sondern kann in Kongenialität zu derselben, also in Verbindung mit den basalen materialen Strebungen des Menschen und ihren ,Mischungen' ihre Entwurfsleistungen vollziehen. Sie findet sich in einen ,Unbeliebigkeitsrahmen' gestellt, der sie zwar keineswegs vollständig determiniert, jedoch die Dispositionen des autonomen und spontanen Sozialverhaltens des Menschen umschreibt und blanker Asozialität gegentendiert. Auch eine unvermittelte, mimetische Anverwandlung destruktiver Verhaltensformen und gar die Generierung eines destruktiven Lebensstils wird durch die Strukturkomponenten der Fürsorgebereitschaft und Vergesellungswilligkeit zumindest gehemmt, und ein entsprechendes Lernen muß sich gegen diese Komponenten erst durchsetzen. In all seinem Handeln nämlich bleibt der Mensch auf die drei Basalstrukturen zurückbezogen, die korrektiv aufeinander einwirken und in Mischungen untereinander sowie mit anderen, ,höher' im Aufbau der Person gelegenen Antrieben sein Verhalten tragen. Jede ,Negativierung des Menschen durch eine destruktionsorientierte Kooperation mit der aggressiven Komponente oder gar deren ,Erziehung' zu ausschließlich destruktiven Aktualisierungsformen muß daher erst die beiden anderen Komponenten überspringen und lähmen, wenn sie gelingen soll. Unter Voraussetzung des skizzierten Dispositivs kann deshalb zum einen ein weiteres Mal die Konstruktion eines Sein-Sollens-Antagonismus zurückgewiesen werden. Auf dem Hintergrund der beschriebenen materialen Basalstrukturen der menschlichen Natur erscheint es nicht notwendig und legitim, dieser Natur ein Sollen brachial-normativ entgegenzusetzen. Auch scheint es zum anderen nicht unmittelbar

\footnotetext{
${ }^{35}$ Korff, Norm, 91

36 vgl. Korff, Norm, 91
} 
nötig, alle Appräsentationen destruktiver Verhaltensweisen vom Menschen fernzuhalten, weil dieser keine Grundlage für eine Distanzierung gegenüber diesen Verhaltensformen habe und mithin nicht Stellung zu diesen zu beziehen vermöchte. Die beiden ,sozialfreundlichen' Komponenten leiten ihn ja vielmehr dazu an, solche Appräsentationen differenziert zu verarbeiten und bieten ihm die Basis sogar für eine alternative Disposition seiner selbst.

Umgekehrt geht aus der Basalstruktur allerdings ebensowenig eine Sein-SollensIdentität hervor. Zwar setzt sie der menschlichen Autonomie einen Unbeliebigkeitsrahmen, doch wirkt dieser Rahmen nicht determinativ für menschliche Handlungsvollzüge und darf eine solche Determination auch nicht festgeschrieben werden. Pluralität und Reichtum menschlicher Strebungen auf der skizzierten Basis müssen erhalten bleiben. Angegeben ist mit dem naturalen Bedingungsfeld lediglich ein Feld, dem Korff daher den Status einer ,Metanorm' zuordnet, die dem menschlichen Verhalten Tendenzbedingungen vorgibt. ${ }^{37}$ An der konkreten Konstitution des Sollens hingegen bleiben beide beteiligt: die naturale Disposition und die mit der Fähigkeit, sich dieser gegenüberzusetzen, ausgestattete menschliche Vernunft. Daher schützt das Dispositionsfeld auch nicht unausweichlich davor, auf ihm einseitige und derart prekäre Dispositionen vorzunehmen. Obschon „die Vernunft des Menschen nicht nur seiner Natur ordnend und gestaltend gegenübersteht, sondern immer (...) auch Funktion dieser Natur bleibt“ “ ${ }^{38}$ bleibt ihr zugleich aufgegeben, im naturalen Bedingungsrahmen ihre Dezisionen richtig zu positionieren. Die Autonomie des menschlichen Subjekts hebt sich durch ihren Unbeliebigkeitskontext ebensowenig auf wie seine Verantwortung. Obschon der Antagonismus von Sein und Sollen sich als nicht haltbar erweist und die Materialität der menschlichen Natur ein gewisses Vertrauen erlaubt, stellt sich Moralität nicht , automatisch' her, sondern bleibt sie eine genuine Entwurfsleistung des autonomen, zu dieser Leistung gleichwohl gerüsteten menschlichen Subjekts.

Hier ist es dann durchaus legitim und geboten, Umfeldfaktoren voneinander zu sondern, die einer autonomen Konstitution von Moralität und einer Ausbalancierung der drei Strukturkomponenten dienlich, und solche, die dieser Konstitution und Balance hinderlich sind. Die Frage nach den äußeren - insbesondere den psychosozialen - Strukturbedingungen für eine zunehmende Gestaltung der auf dem skizzierten Dispositiv aufbauenden subjektiven Strebungen und handlungsbezogenen Zielfindungsprozesse muß in jedem Fall gestellt werden. Dies gilt vor allem für Kinder und Jugendliche, die noch auf dem Weg zu ihrer Mündigkeit sind und in ihrer psychosozialen Selbstorganisation durchaus der Förderung und Hilfestellung bedürfen. Eine genaue, an den konkreten empirischen Gegebenheiten orientierte Reflexion etwa der jeweils besonderen Sozialisationsbedingungen, der Entwicklungsphasen und je spezifischen Kompetenzen kann von der anthropologischen Reflexion der allgemeinmenschlichen Dispositionsstruktur nicht ersetzt werden. Sie kann jedoch auf den anthropologischen Erkenntnissen aufbauen und - nicht zuletzt für die moralpädagogische Programmatik - entsprechende Direktiven daraus gewinnen. Eine primäre Direktive ist auf dem vorgängig erarbeiteten Hintergrund etwa die

\footnotetext{
${ }^{37}$ Korff, Norm, 97

38 Korff, Norm, 97
} 
ethische Forderung an die Pädagogik, in ihrem formenden Bemühen den Menschen zu Selbstbestimmung und Selbststeuerung zu führen und hierbei vor allem auf die Ausbalancierung der drei Strukturkomponenten der fürsorgenden Zuwendung, der sachhaft-kooperativen Vergemeinschaftung und der abgrenzungsorientierten, konkurrierenden Durchsetzung Sorge zu tragen. Sowohl eine einzig fürsorgende Haltung als auch eine nur sachhaft-gebrauchende oder blank konkurrierend-dissoziierende Grundorientierung bliebe in ihrer Einseitigkeit defizitär und verhinderte eine human-ganzheitliche Selbstauslegung des Menschen. Die Fürsorge nämlich hätte ein matronenhaftes Ersticken der Eigenregungen aller ,Befürsorgten' zur Folge, das nur instrumentelle Verhalten ließe jede Beziehung mechanistisch zusammenschrumpfen, und die reine Konkurrenz hätte mindestens die Kälte völliger Vereinzelung und Vereinsamung, wenn nicht gar die Pathologie eines ,Kriegs aller gegen alle' zur Konsequenz. In der gegenseitigen Abgewogenheit und in wechselseitiger ,Abfederung und Korrektur erst kann hingegen das Humanum entstehen und findet auch jede Komponente zu einer adäquaten, ihrem Stellenwert im Gesamtgefüge der menschlichen Konstitution gemäßen Realisierung ihrer selbst. Das Zueinander der drei Komponenten, ihr jeweiliges Zusammenspiel, läßt auch erst die Vielfalt menschlicher Beziehungen entstehen und setzt den Reichtum darin frei. Die entelechiale Neigung des Menschen zur Etablierung jeweiliger Balancen zwischen den Komponenten zu fördern sowie durch entsprechende sozialisationstheoretische Forschung mögliche Störungen und Hindernisse dieser Balance ausfindig zu machen und zu beseitigen, kann daher die anthropologisch-ethische Rahmendirektive für die Selbsteinrichtung der Pädagogik sein. Gleichzeitig kann die anthropologische Fundierung dem Mißtrauen in die menschliche Natur steuern und zu einer ,kongenialen' Formung derselben, zu einer kooperativen Erziehung ermutigen. Vor allem dem Gebot einer erzieherischen Ausrottung der Aggression kann mit dieser Direktive differenziert entgegengetreten werden - nicht um Beseitigung des Durchsetzungsverhaltens, sondern um seine sachgerechte, humane Ausbalancierung und ,Legierung mit den anderen Strukturkomponenten geht es. In diesem Sinn scheint mir daher mit dem Dispositiv der ,sozialen Perichorese' jene Basalstruktur gefunden, die es zum einen erlaubt, die Nötigung einer solchen Erziehung zu ausschließlich barriereerrichtenden und -verstärkenden Maßnahmen begründet aufzukündigen, und mit der zum anderen eine entsprechende pädagogische Reflexion und Gestaltung des psychosozialen Umfelds und eine Erziehung zur Mündigkeit kooperieren kann.

\section{Dynamik und Konsistenz: Der Mensch im Spannungsfeld von Entwurf und Entlastung}

Bevor nun das Paradigma einer Ethik, die dem vorgängig anthropologisch reflektierten Menschen gerecht wird, skizziert werden kann, stellt sich nun noch die Frage, ob dieser Mensch - etwa im Sinn einer ,positiven' Wendung der Kritischen Theorie einzig als Wesen des Entwurfs und der Veränderung zu interpretieren ist, dem jede institutionell-objektive Struktur und jede Fixierung seiner kreativen Entwurfsleistungen feindlich ist, oder ob es anthropologische Daten gibt, die solche Strukturen und Fixierungen legitim erscheinen lassen. Zu fragen ist also, ob der Mensch nur ein Wesen des Entwurfs, oder auch eines der Entlastung ist, und wie gegebenenfalls das Verhältnis dieser beiden ,Existenzialien' zu bestimmen ist. - Mit Arnold Gehlen läßt sich hierzu zunächst der Entwurf als eine existenziale Disposition des Menschen an- 
thropologisch verankern. Nicht nur nämlich eignet dem Menschen in seiner Vernunftnatur die Fähigkeit, die Potenz zu kreativen Entwurfsleistungen und nicht nur nötigt ihn seine Mangelbefindlichkeit in der Welt dazu, entwerfend tätig zu werden, sondern es gibt in ihm auch eine spezifische, endogene Kraft, die ihn vorwärtsdrängen und aus sich heraus aktiv werden läßt. Diese Kraft nennt Gehlen einen,Antriebsüberschuß ${ }^{39}$ Er führt ihn zunächst noch mit Bezug auf die Entwurfsnötigung durch die mangelnde naturale Ausrüstung des Menschen ein und sieht in ihm ,die Innenseite eines nicht spezialisierten, eines Wesens von organischer Mittellosigkeit, das einem chronischen Druck innerer und äußerer Aufgaben ausgesetzt ist" ".0 ${ }^{40}$ Der aus der Instinktreduktion des Menschen hervorgehenden Aspezifität der Umwelt und dem Zwang zu ständigen Entwurfs- und Interpretationsleistungen korrespondiert nach Gehlen eine „Antriebsenergie“, die „von vorneherein zugeschnitten“ scheint auf „die nicht voraussehbaren, unter Umständen außerordentlichen Leistungen, welche widrige Sachumstände dem Menschen stellen". ${ }^{41}$ Aus dieser Perspektive stellt der Antriebsüberschuß so vorerst einmal eine plastische, ,offene' Kraft dar, die in Situationen, welche mangels Instinkt schwer einzuordnen sind und welchen mangels organischer ,Gerüstetheit' schwer zu begegnen ist, kreative Reaktionen motiviert und vorantreibt. Er ist damit jene Wirkmacht, die dem aus der Not geborenen schöpferischen Entwerfen des Menschen dient und den nötigen Impetus verschafft.

Darüber hinaus aber entsteht er auch aus der „fundamentalen Eigenschaft“, daß die Antriebe des Menschen ,selbst nicht-periodisch, d.h. chronisch sind" und entsprechend eine Dauersituation energetischen Drängens vorstellen. ${ }^{42}$ Hierbei nun zeigt sich der Antriebsüberschuß als „,Reflex der unbegrenzten Thematik einer chronischen Bedürftigkeit", die ,in bloßen Handlungen der Befriedigung der animalischen Minimalbedürfnisse, wie Hunger und Geschlechtstrieb, gar nicht unterzubringen ist“, ja die „über jede augenblickliche Erfüllungssituation“ ,hinaustreibt ${ }^{43}{ }^{43}$ Die ,Instinktreduktion“ bedeutet in dieser Perspektive „keineswegs eine dynamische Schwächung (...), sondern eine Umweltablösung der Antriebsquanten, ihre Konzentration aus der organischen Festlegung heraus “44, die keine fixiert vorgegebenen Triebziele und entsprechende ,Befriedungen' bei ihrer Erreichung mehr kennt, sondern über jedes Triebziel hinaus eine anhaltende, unspezifische ,Appetenz' und Aktivität konstituiert. Abgekoppelt von fixierten Triebzielen stellt der Antriebsüberschuß daher auch jene energetische Basis und motivationale Kraft dar, die den Menschen kulturschöpferisch im weitesten Sinn tätig werden läßt und möglicherweise sogar seine Transzendenzverwiesenheit konstitutionell stützt. Damit aber ist der mit einem Antriebsüberschuß ausgestattete Mensch als ein endogen kreatives, auf ständiges Übersteigen des Erreichten angelegtes Wesen bestimmt, das stets nach Neuem sucht und Neues schaffen will. Nicht allein die Nötigung zur Reaktion auf von der Umwelt gestellte Situationen konstituiert also die Entwurfsorientierung des Menschen, sondern ebenso seine ,endogen-entelechiale' Verfaßtheit, die mit dem Antriebsüber-

${ }^{39}$ vgl. Gehlen, Mensch, 60-65, 385-399

${ }^{40}$ Gehlen, Mensch, 60

${ }^{41}$ Gehlen, Mensch, 61

42 Gehlen, Mensch, 61

${ }^{43}$ Gehlen, Mensch, 60, 62

${ }^{44}$ Gehlen, Mensch, 63 
schuß zur Entwurfspotenz der Vernunft einen Entwurfsimpetus und -wunsch selbst dort gesellt, wo ,von außen' eine entwerfende Aktivität gar nicht verlangt ist. Entgegen jeder pessimistischen Anthropologie, die sich in der Rede vom, von Natur aus faulen Menschen' niederschlägt, erscheint der Mensch damit als das Wesen, das aus sich heraus kreativ tätig wird und werden möchte und mit dem errungenen Status quo selten zufrieden ist.

Gleichwohl ist damit die Konstitution des Menschen noch nicht vollständig gefaßt. Eben auf der Basis der Instinktreduktion eignet dem Menschen auch ein spezifisches Entlastungsbedürfnis. Nicht nur Wesen kreativ-entwerfenden Ausgreifens und ständiger Aktion ist er, sondern auch ein Wesen des Bedürfnisses nach Bekanntem, Vorgaben, Freisetzung von ständigem Kreativitätszwang und nach Stabilisierung seiner Befindlichkeit. Setzt man erneut bei der Instinktreduktion und einer idealtypisierten Basissituation eines individuellen, in die Welt ,geworfenen' Mängelwesens an, so zeigt sich dort zunächst die Notwendigkeit für dieses Wesen, spezifische Selektionen, Typisierungen und Schematisierungen seiner Wahrnehmung einzurichten, um überhaupt in der unspezifisch andrängenden Reizfülle etwas erkennen zu können. Diese Selektionen und Standardisierungen aber sind zugleich Entlastungsleistungen, die den Druck der Außenwelt mindern und erträglich machen. Die situationell bedingte Entlastungsleistung kann dann zudem fixiert werden und erlaubt als Schematismus in analogen Fällen einen raschen, dadurch erneut entlastenden Rückgriff auf eine erprobte und bekannte, Weltauffassungsform‘. Bereits in der Entwicklung von Wahrnehmungsweisen gegenüber der Außenwelt greift so das ,Entlastungsgesetz ${ }^{45}$. Ebenso aber findet gegenüber der eigenen physischen Verfaßtheit eine typisierendschematisierende Ordnung statt, die zunächst spezifische Bewegungsformen und Handlungskompetenzen ausbildet und derart ein Instrumentarium zur Beherrschung und Nutzung des eigenen Körpers schafft. ${ }^{46}$ Auch dies entlastet, indem es eine Vertrautheit mit den eigenen Möglichkeiten und ihren Grenzen erzeugt. Die wahrnehmungsbezogene und physisch-selbstbezügliche Schematisierung findet dann ihre Parallele in der entlastenden Schematisierung der Innenwelt, die durch ,Formierung ${ }^{47}$ der psychophysischen Antriebe und der Ausbildung von Interpretamenten der Selbsterfahrung zu einer relativ-unbeliebigen und stabilen Identität führt. In allen drei Bereichen zeigt sich jeweils die Neigung, ,Bestände‘ der Selektionen, Typisierungen und Schematisierungen festzuschreiben, die es erlauben, „die Beziehungen zur Welt (und zu sich selbst, T.H.) von der bloßen Gegenwart zu entbinden“48, und die es ermöglichen, auf ,Verläßliches‘, ,Erprobtes‘ und ,Bewährtes‘ zurückzugreifen. Darüber hinaus findet eine ,Sozialisierung' der Entlastungsschemata statt, sowie eine Fixierung von Schemata sozialer Interaktionen, von Welt- und Lebensinterpretamenten, rationalem Wissen etc. Diese bilden einen Fundus, der durch Traditionsbildung weitergegeben werden kann und es dem Einzelnen erspart, alles jeweils neu entdecken, ordnen und fixieren zu müssen. Es entsteht hierbei eine Welt jeweils temporal feststehender Lernvorgaben, Verhaltensmuster, Normen und Institutionen, die

\footnotetext{
${ }^{45}$ Gehlen, Mensch, 65

${ }_{47}^{46}$ vgl. dazu Geblen, Mensch, 65-77

47 vgl. Gehlen, Mensch, 63

48 Gehlen, Mensch, 66
} 
dem Entwerfen als Vorgaben entgegentreten und einer menschlichen Beharrungstendenz neben dem Antriebsüberschuß entsprechen.

Zugleich jedoch zeigt sich bei näherem Zusehen auch eine Interferenz von Entlastung und Entwurf, die eine wiederum dynamisierende Wirkung haben kann. So machen sowohl Gehlen als auch Korff auf ein freisetzendes Moment der Entlastung durch Fixierung und Tradierung bestimmter Vorgaben und Bestände aufmerksam. Wo nämlich etwa durch „Gewohnheitsbildung“ ein Verhaltensschema fixiert wird, wird zugleich „ein Reizverhaltensniveau“ festgelegt, ,von dem aus nun weitere, neue Inhalte erlebbar werden und in den Umkreis der Verwertung (durch das Subjekt, T.H.) rücken “499. Gehlen sieht daher von den Entlastungskreationen des Menschen geradezu dessen evolutive Produktivität und zivilisatorischen Fortschritt ermöglicht. Er verweist darauf, da $B$ „,alle höheren Funktionen des Menschen auf jedem Gebiete des intellektuellen und moralischen Lebens, aber auch der Bewegungs- und Handlungsverfeinerung“ dadurch entwickelt worden seien, „da $\mathrm{B}$ die Ausbildung fundierender, stabiler Basisgewohnheiten die ursprünglich dort verwendete Motivations-, Versuchs- und Kontrollenergie entlastet und ,nach oben abgibt' ".${ }^{50}$ In ähnlicher Weise interpretiert Korff in seiner Institutionstheorie die entlastende Bedeutung von Institutionen, denen er einen hierdurch ,dynamisierenden Effekt" zuschreibt. ${ }^{51}$ Eben dadurch nämlich, daß sie „entlastete Handlungsfelder schaffen, machen sie die Aktualisierung bislang ruhender Motivlagen möglich, setzen sie den Handelnden für neue Initiativen frei, werden überhaupt erst weitergehende und weitergreifende Sinnstrebungen lebenswirksam “ ${ }^{52}$ Dies freilich kann auch die Institution selbst treffen und ihren Wandel oder gar ihre Auflösung bedingen. Jedes „sich neu artikulierende Bedürfnis und Interesse, jeder Zuwachs an Einsichten" nämlich wirkt seinerseits wieder ,auf bereits gegebene institutionelle Lösungsbestände“ zurück und fordert möglicherweise die Ablösung jener, durch deren entlastende Funktion das Neue gerade gewachsen ist. ${ }^{53}$ Die Entlastung durch Fixierung von ,Beständen' kann damit zugleich flexibilisierend und dynamisierend wirken und führt unter Umständen dadurch zur Ablösung fixierter Bestände selbst.

Insgesamt zeigt sich damit ein Doppeltes: Zum einen erscheint der Mensch nun als ein Wesen, das sich im Spannungsfeld von Entwurf und Entlastung bewegt und das beider Pole seiner Existenz bedarf, um sich in einer Weise zu verwirklichen, die seiner grundsätzlichen anthropologischen Verfaßtheit gerecht wird. Weder kann der Mensch nur als ein Wesen des ständigen, ruhelosen Ausgriffs auf noch nicht Existentes und Neues gedacht werden, noch ist er einzig als ein Wesen der Verwiesenheit auf schematisierte Vorgaben, fixierte Strukturen und Vorschriften zu betrachten. Stattdessen erscheint er als wiederum ein Wesen der Verschränkung: In ihm interferieren Ausgriff und Beharrung, Nie-Dagewesenes und Vorgabe, Kreation und Rekreation. Zum anderen aber zeigt sich auch, daß Entlastung und Entwurf sich wechselseitig bedingen. Einmal nämlich muß die Entlastung selbst erst entworfen werden, um dann in fixierter Gestalt und durch Tradierung wirksam werden zu können. An-

${ }^{49}$ Gehlen, Mensch, 70

${ }_{51}^{5}$ Gehlen, Mensch, 70; im Original partiell gesperrt.

51 Korff, Institutionstheorie, 171; in Original partiell kursiv.

52 Korff, Institutionstheorie, 171

${ }^{53}$ Korff, Institutionstheorie, 171- 172 
dererseits wiederum ermöglicht die Entlastung im einen Bereich bzw. auf einer Stufe den Überschritt auf bislang Unerfundenes im anderen Bereich bzw. auf die nächste Stufe. Dieser Überschritt freilich kann auch den Entlastungsbestand selbst treffen: Unter Umständen macht der durch ihn ermöglichte Entwurf seine vorhandene Gestalt obsolet und setzt er Neues an seine Stelle. Entlastung und Entwurf sind einander derart dynamisch zugeordnet und erweisen eine spezifisch anthropologisch gegründete Strukturlogik, die auf Evolution drängt und hierbei stabile Stufen und Plateaus prinzipiell weder unauflöslich zementiert noch von vorneherein illegitim erscheinen läßt.

\section{Das ethische Basisparadigma: Autonome Moral im Kontext eines universalisierbaren und konsensfähigen Rahmenethos}

Auf dem Hintergrund der bislang entfalteten theologisch-anthropologischen Strukturen können nun Linien einer modernitätsgerechten Ethik ausgezogen werden. Für die Strukturlogik einer solchen Ethik zeigen sich drei Momente als konstitutiv: Zum einen bestätigt sich aus der Anthropologie der neuzeitliche Ansatz des Menschen als autonomes Subjekt, dem von seiner Verfaßtheit her auch die Fähigkeit und Kompetenz zum sittlich autonomen Entwurf zugesprochen werden kann. Zum anderen weist diese Verfaßtheit zugleich auf die Notwendigkeit von Lernvorgaben und die entlastende Wirkung von Traditionalität hin, wodurch sowohl ein Bestand an Normen, als auch Moralerziehung legitimiert erscheinen. Die anthropologische Interferenz von Entwurf und Entlastung greift dabei in analoger Weise auch ethisch und läßt eine Korrekturoffenheit und Wandelbarkeit des normativen Bestands ebenso wie eine vordringlich mäeutische Moralpädagogik fordern. Zum dritten schließlich verweist der Gedanke einer evolutiven Entwicklung menschlicher Entwurfsleistungen auf die Möglichkeit epochaler sittlicher Fortschritte, die in ihrer humanen Vernunft Unhintergehbares jedermann einsichtig kristallisieren und derart ein universalisierbares, konsensfähiges Rahmenethos konstituieren, das sich in übergreifenden Prinzipien und Maximen fixieren läßt.

Zunächst also belegen die vorgängig entfalteten anthropologischen Überlegungen die Realitätsgerechtheit und humane Angemessenheit des neuzeitlich-modernen Autonomisierungsprogramms, das jedem menschlichen Subjekt, oder in der eingangs eingeführten Begrifflichkeit: jeder menschlichen Person, die Fähigkeit und Kompetenz zum selbstgesetzten Entwurf zubilligt. $\mathrm{Zu}$ sehen war dabei einmal, daß der Mensch als instinktunsicheres, weltoffenes Wesen notwendig diesen Entwurf leisten muß, sowie zum anderen, da $B$ er aufgrund seiner Vernunftbegabtheit dazu auch in der Lage ist. Übertragen in die ethische Problematik bedeutet das, daß der auf Schaffung von Welt- und Lebensinterpretamenten angewiesene Mensch, der dieser Interpretamente bedarf, um sich in der für ihn unspezifischen Welt ,deutend, ordnend und gestaltend' (W. Korff) überhaupt verstehen, einrichten und verhalten zu können, hierbei zugleich normative Größen entwirft. Neben der metaphysisch-ontologischen Deutung, der ästhetisch-expressiven Selbst- und Weltauslegung und der wissenschaftlich-rationalen Durchdringung entstehen im Interpretationsprozeß auch Ethosformen und moralisch-praktische Verhaltensregeln. Mit ihnen erst entdeckt, erprobt und erfindet der Mensch die Möglichkeiten gelingenden Zusammenlebens mit anderen, der Herstellung eines ,stimmigen‘ Selbstverhältnisses und einer verant- 
worteten Weltgestaltung. Dabei zeigt er sich durch seine Vernunft für diese Aufgabe sittlich-normativen Entwerfens auch gerüstet. So weist Kant darauf hin, da $B$ der Mensch einzig seiner Vernunft bedarf, um sittliche Entscheidungen zu fällen. Nicht ein ,besonderer Sinn' für das sittlich Gute und Böse scheint ihm nötig, sondern die „praktische reine Vernunft (und ihr Gesetz)“ sind als Vermögen ausreichend, um die Moralität des Menschen zu garantieren und zu konstituieren..$^{54}$ Korff wiederum führt dies unter Rekurs auf das Kontradiktionsprinzip näher aus: Aus dem ,allgemeinsten Kriterium' der menschlichen Vernunft, der formallogischen Gesetzlichkeit, einen Sachverhalt nicht gleichzeitig als gut und schlecht begreifen zu können, leitet er die prinzipielle Fähigkeit des Menschen zu einer normativ-stellungnehmenden Welt- und Lebensauslegung her. ${ }^{55}$ Während das Begriffpaar gut - schlecht dabei den funktionalen Entscheidungsantagonismus für den „Bereich der Mittel“ setzt, führt das Begriffspaar gut - böse in den Bereich der "Wertigkeit von Vernunftentscheidungen und Handlungsabläufen im Hinblick auf den Menschen als Menschen“. ${ }^{56}$ Damit aber stellt die Vernunft des Menschen ein Vermögen einer argumentativ einlösbaren Unbedingtheitskonstitution auch für letzte ethische Zwecke dar. Unter der genannten Differenz nämlich müssen diese sich argumentativ einführen und legitimieren; die Vernunft aber ist in der Lage, hierbei Stimmigkeit (Nichtwidersprüchlichkeit) zu erkennen und entsprechend vernünftige Zwecke diskursiv-logisch zu entwerfen. In der menschlichen Natur als Vernunftnatur liegt deshalb ,wesenhaft der Grund aller menschlich-ethischen Autonomie“. ${ }^{57}$

Gemäß der vorgängigen anthropologischen Reflexion muß dabei diese Autonomie und ihre argumentativ-diskursive Konstitution von Zwecken und Normen nicht contra naturam gesetzt werden, sondern kann die autonome Normschöpfung als materialiter durchaus der naturalen Konstitution des Menschen ,kongeniale' Entwurfsleistung verstanden werden, welcher aufgrund dieser Konstitution auch Vertrauen entgegengebracht werden darf. Weder die menschliche Natur noch die auf ihr aufruhende Autonomie muß - anthropologisch betrachtet - als prekär und per se sittlichkeitsgefährdend bzw. gar als antimoralisch eingeschätzt werden. Vielmehr zeigt sich diese Natur als ,sittlichkeitsbegünstigende', zumindest aber sittlichkeitsfähige, die der Autonomie zudem ein materiales Dispositiv setzt und so eine spezifisch ,naturale Vernünftigkeit‘ des sittlichen Entwurfs ermöglicht. Moralität zeigt sich entsprechend nicht einfach nur als ,abstrakt-kognitive‘ Entwurfsleistung des Menschen, sondern als ,lebensnahe', ,physiophile ' Normschöpfung und Verhaltenseinrichtung, die dem Menschenwesen in seiner ,Ganzheit' gerecht zu werden vermag. Daher muß von der ethischen Theoriebildung sowohl ein Sein-Sollens-Antagonismus, wie auch eine Sein-Sollens-Identität als nicht realitätsgerecht zurückgewiesen und als ethisch untragbar beurteilt werden. An die Stelle beider ist vielmehr eine Sein-SollensInteraktion zu setzen, in der ebenso der vernunftbegründeten Autonomie wie der naturalen Disposition des Menschen Rechnung getragen wird. Sittliche Normativität aber läßt sich damit bislang als autonome Entwurfsleistung des Menschen begreifen,

54 vgl. Kant, I., Die Metaphysik der Sitten, Frankfurt 1978, 531 (= Immanuel Kant Werkausgabe, hrsg. v. W. Weischedel VIII)

55 vgl. Korff, Ethik, 19-22

56 Korff, Ethik, 21

${ }^{57}$ Korff, Ethik, 21 
deren Möglichkeit in seiner Vernunftnatur grundgelegt ist und der aufgrund der Tatsache, da $\mathrm{B}$ das naturale Dispositiv des Menschen keineswegs als sittlichkeitsfeindlich und verderbt zu bestimmen ist, auch Vertrauen entgegengebracht werden kann.

Diese Bestimmung von Moralität als autonomer Entwurf nun läßt sich noch durch zwei weitere Strukturmomente ergänzen. Zum einen nämlich macht die anthropologische Reflexion darauf aufmerksam, daß das menschliche Entwerfen kein Entwerfen ,ein für allemal' ist. Wie die Welt- und Lebensinterpretamente, die Wissensbestände und technisch-instrumentellen Leistungen und die künstlerisch-expressiven Hervorbringungen sind auch die sittlichen ,Bestände` entwicklungs- und fortschrittsfähig. Auf der Basis seines Antriebsüberschusses und seiner lediglich dispositional unbeliebigen, jedoch in diesem Rahmen weltoffenen Kreativität drängt der Mensch in allen Bereichen seines Lebens auf Überstiege und Überbietung des bisher Erfundenen und Erlangten. Daher darf nicht nur im kognitiv-wahrheitsbezogenen, im instrumentellen und im ästhetisch-expressiven Bereich kultureller Entwürfe mit Dynamik und Veränderung gerechnet werden, sondern muß gerade auch im moralischpraktischen Bereich Weiterentwicklungen und Wandel Recht und Raum zugestanden werden. Pointiert gegen ein ethisches Paradigma, wie etwa das von Keilhacker, das zwar ,modernitätsfreundlich' den wissenschaftlichen sowie den technisch-industriellen Prozessen - und in Grenzen auch der Kunst - eine Evolution zubilligt, jedoch im Bereich der Moralität auf überzeitliche Normfixierungen abhebt, muß daher eine nicht nur modernitäts-, sondern realitäts gerechte Ethik die Möglichkeit sittlichen Fortschritts und moralischen Wandels in ihre Reflexion einbeziehen und beidem Legitimität zusprechen. Moralität als Entwurf ist zugleich eine geschichtliche Größe, die ihr Fundament in der Konstitution des Menschen selbst besitzt und aus dieser Konstitution sowohl ihr Wesen als auch ihr Recht bezieht. Geschichtlichkeit aber bedeutet Veränderung und schließt die Möglichkeit von Fortschritt ein. Zum einen kann daher gegen die Paradigmen der Filmerzieher und Reformer ein Ethoswandel, der veränderten Lebensbedingungen mit veränderten Normen gerecht zu werden sucht, als legitim betrachtet werden. Zum anderen läßt sich dieser Wandel in Teilen auch als Ausdruck und Gestalt der sittlichen Entwicklung des Menschengeschlechts zu höheren Niveaus, d.h. einer sittlichen Evolution, verstehen.

Für diese sittliche Evolution vermag dabei wieder der christliche Glaube eine spezifische Funktion zu entfalten. Die Rückbindung an Gott weist der gegebenen Welt einen spezifischen ,Platz' im Weltverhältnis des Christen zu, und die in dieser Bindung stets neu gemachten Erfahrungen werfen auch immer wieder ein neues Licht auf die jeweiligen Verhältnisse. So erhält das, was ist, aus dem Transzendenzbezug heraus für den Menschen einen veränderten Stellenwert und findet sich insbesondere die ,Festigkeit', die ,Positivität' der Welt relativiert. Gerade in christlicher Perspektive stellt ja die Welt, obschon sie der Affirmation durch Gott gewiß sein kann, nur ein Vorläufiges dar, eine Entität und Befindlichkeitsstruktur, die über ihre immanente Geschichtlichkeit hinaus auch aus einer übergeordneten, nämlich heilsgeschichtlichen Warte veränderlich und vergänglich ist. Für den Christen ergibt sich aus dieser Perspektive ein sowohl gelassenes als auch ein das Bestehende immer wieder überbietendes, innovatorisches Weltverhältnis. Dadurch aber setzt der christliche Glaube zugleich frei von unhintergehbaren Verhaftungen an das Gegebene und von Verstrickungen in ,bestehende Verhältnisse'. Er konstituiert von der Ebene der 
Transzendenzverwiesenheit her eine Dynamik, die sich mit dem Antriebsüberschuß verbinden kann und zusätzlich Kreativität freisetzt. In dieser Kreativität vermag der Christ aus dem Glauben und den in ihm gemachten Erfahrungen heraus jene sittliche Stellungnahme zu entwickeln, die theologische Ethik als ,prophetisch-kritische bezeichnet und die auf eine Optimierung menschlichen Seins in der Welt gerichtet ist. Diese Optimierung kann auch das Ethos, die Moralität selbst betreffen und einen Ethoswandel ins Werk setzen. Der christliche Glaube entfaltet derart auch für die sittliche Evolution, den sittlichen Entwurf des Menschen eine kritisierende und ,stimulierende' (A. Auer) Kraft.

Schließlich verweist der Entwurfscharakter der Moralität noch darauf, daß die sittliche Konstitution des Subjekts zugleich etwas mit dessen Selbstkonstitution zu tun hat, näherhin, daß der Selbstentwurf des Menschen seinen sittlichen Selbstentwurf einschließt. Dies wiederum bedeutet, daß der Mensch zusammen mit seinem Selbst- und Weltverständnis auch sein moralisches Verständnis entwirft und seine sittliche Identität gewinnt. Die sittliche Identität eines Menschen aber nennt man sein Ethos. In ihm erst wird Ethik konkret handlungswirksam und setzen sich Normen habituell und überzeugungsbildend um. Als Identitätsform eignet dem sittlichen Selbstentwurf zugleich eine individuelle Besonderheit, die sich über den Personbegriff plausibel fassen läßt. Im Unterschied zum Subjektbegriff enthält der Personbegriff ja das Moment der Individualität und der aus Besonderheit hervorgehenden, d.h. differenten Unverfügbarkeit. Unter Heranziehung des Personbegriffs kann daher das personale Ethos als spezifischer, zumindest partiell von anderen differierender sittlicher Selbstentwurf definiert werden. Freilich entstehen hierbei keineswegs lauter vollständig voneinander verschiedene Ethosformen, sondern eher individuell gefilterte ,Ausgaben' der ethischen Grundsatzpostulate und der moralischen Normen einer Gruppe, Gesellschaft und Zeit. Doch muß das Ethos einer Person als das ihre und für sie spezifische verstanden werden, selbst wenn Abweichungen von Ethosformen anderer Menschen gering sind. Die Bindung an die je besondere und unverwechselbare Identität ist es, die das Besondere des personalen Ethos ausmacht. Sie ist es auch, die mit einem recht verstandenen Eigentlichkeitsbegriff, der dann Autonomie gerade einschließt, nicht aber diese zu ersetzen oder zu unterlaufen sucht (vgl. 4.2., 4.5. und 4.6.), gemeint sein kann. Der personal begründete, individuelle Identitätsbezug des Ethos als Entwurf nun läßt - im Rahmen von konsensuell gesicherten Grundüberzeugungen eines Rahmenethos (vgl. unten) - eine Pluralität von normativen Beständen legitim erscheinen. Erst in seinem speziellen, eigenen sittlichen Entwurf findet der Mensch zu sich als sittliche Person, und nur er selbst vermag diese seine Sittlichkeit herzustellen. Daher muß mit der Differenz der Selbstentwürfe auch eine gewisse Differenz der Ethoi von der ethischen Theorie akzeptiert werden. Diese Differenz kann sich dabei zusätzlich gruppenspezifisch fixieren und neue partiale Einheiten schaffen. Sie führt dann zu jenen teilkollektiven sittlichen Identitätsformen, die W. Korff als Binnenmoralen bezeichnet, und dehnt die personale Differenz und Besonderheit auf größere Agglomerate von Personen aus. Gleichwohl ist auch hier noch Pluralität der Gruppen untereinander erhalten und der Identitätsbezug deutlich. Insgesamt ergibt sich damit für die ethische Theorie aus dem Personalitätsgedanken und aus der Identitätsvermitteltheit von Moralität heraus eine spezifische Legitimität pluraler Ethosformen und pluraler Normkanones. 
Die Anthropologie freilich hat nun nicht nur gezeigt, daß der Mensch ein Wesen der Entwurfs ist, sondern auch, daß er der Entlastung durch Vorgaben, Verankerungen und Institutionalisierungen bedarf. Als in die Welt ,geworfenes' Wesen ist er zudem auf Lernen angewiesen, d.h. er benötigt zu seiner Entwicklung von Identität, Welt- und Lebenskompetenz auch als autonomes Wesen Vorgaben. Diese entlasten ihn davon, seine Welt- und Lebensinterpretamente, das zur Weltbewältigung nötige Wissen und Instrumentarium jeweils erst von neuem erfinden und gewissermaßen stets am phylogenetischen Punkt Null anfangen zu müssen. Wie zu sehen war, schränkt diese Rekurrenz auf Vorgaben die Entwurfspotenz des Menschen dabei keineswegs mit Notwendigkeit ein, sondern setzt sie ihn gerade zu neuen Überstiegen frei. Sie ist daher nicht per se ein Impediment, eine Obstruktion für die Autonomie des Subjekts, sondern eine Basis, zu der sich einmal diese Autonomie nochmals verhalten kann und die ihr zum anderen auch wieder Raum für Neues eröffnet. Freilich bedeutet die Entlastung durch Vorgaben aus dem Blickwinkel der Autonomisierung auch, daß einem Umkippen der Entlastung in Fixierung und Hegemonie stets gewehrt werden muß. Wo etwa wissenschaftliche Erkenntnisse und Wissensbestände ideologisch fixiert werden, tritt Stagnation und auf lange Sicht Rückschritt ein. Ebenso unterläuft die Fixierung von Lebens- und Weltinterpretamenten deren förderliche Funktion und läßt sie die Entlastung zum Gefängnis werden. Entlastung durch Vorgaben und Dynamisierung durch Überschritte bleiben, wie schon zu sehen war, daher aufeinander bezogen und müssen dies auch bleiben.

Für die ethische Theorie bedeutet dies nun zunächst, daß sowohl moralische Traditionalität und eine hierdurch geschehende Schaffung von normativen Beständen als auch eine darauf fußende vermittlungsorientierte Moralpädagogik durchaus legitim und nötig erscheinen. Auch in Sachen Sittlichkeit ist der Mensch auf Entlastung angewiesen und vermag er rascher zu sittlicher Kompetenz zu kommen, wenn er auf Vorgaben zurückgreifen und seine sittliche Autonomie sowie seinen sittlichen Entwurf auf der Basis von bereits vorhandenen Normangeboten und normativen Übungsfeldern entwickeln kann. Diese Angebote schaffen zudem ein ,günstiges Klima' für die Entwicklung der eigenen Moralität, einen hilfreichen Umraum, der zugleich davor schützen kann, bei der autonomen Moralitätskonstitution Fehldispositionen vorzunehmen. Gleichwohl dürfen diese Vorgaben ebenfalls nicht zu geschlossenen, unhinterfragbaren und unüberholbaren Entitäten erklärt werden, die jeder Veränderung und Kontingenz entgegenstehen. Zwar bedarf der Mensch normativer Präformationen, um seine Sittlichkeit in Auseinandersetzung damit zu schaffen, und zwar wird er hierbei sein Ethos relativ unbeliebig einrichten, um sittliche Identität und eine entlastende Stabilität seiner Verhaltens- und Handlungskriteriologie zu gewinnen, doch dürfen diese Präformationen nicht unüberschreitbar und unwandelbar sein, sollen sie dem autonomen Entwurf und der Fortschrittsfähigkeit des Menschen gerecht werden. Die Moralpädagogik wird bei ihrer Vermittlung daher nicht einzig auf Internalisierung des Vorgegebenen, sondern auf argumentative und damit hinterfragbare - Einsichtigkeit normativer Bestände, auf deren diskursive Transparenz abheben. Ihr primäres Ziel wird die Erzeugung sittlicher Kompetenz, d.h. der eigenverantwortlichen Entfaltung der autonomen Entwurfsfähigkeit des Menschen im Bereich der Sittlichkeit sein, und die vordringliche Methode wird an die Stelle der autoritativen Belehrung den mäeutischen Diskurs setzen. Dies schließt 
die Übernahme vorhandener Normbestände keineswegs aus, doch muß es der Moralpädagogik darum gehen, daß diese Übernahme aus Gründen der Evidenz, nicht der Präskription, erfolgt. Dabei wird neben der mäeutisch-diskursiven Vermittlung von Normangeboten auch die Verhinderung von Resistenzen gegen selbstgesteuertes Weiterlernen, die gewissermaßen durch einen Überschuß an Entlastungsbedürftigkeit entstehen können und die Überschreitung von einmal angenommenen Normbeständen hindern, zu den primären Zielen zu rechnen sein.

Die Legitimität traditionaler Bildung von Normbeständen ist schließlich - und dies gerade aus dem Blickwinkel des Entwurfs und der Wandelbarkeit von Normen - noch um den Gedanken der Herausbildung eines konsensfähigen, universalisierbaren Rahmenethos zu ergänzen. ${ }^{58}$ Hierbei allerdings geht es weniger um die Entlastung des Menschen, sondern vordringlich um die Fixierung und Erhaltung erreichten sittlichen Fortschritts sowie die Wahrung eines moralisch-praktischen Entwurfsrahmens, der diesem Entwerfen den Rückbezug auf ethische Einheit und eine Verständigungsbasis mit anderen Entwürfen garantiert. Die Fortschrittsfähigkeit menschlichen Entwerfens im Bereich der Moralität und die Legitimität von moralischer Pluralität habe ich bereits betont. Gleichwohl schließt einmal die Geschichtlichkeit dieses bereichsspezifischen Entwerfens auch die Möglichkeit von Rückschritten und historischen ,Unfällen' nicht aus. Der Mensch kann auch hinter Erreichtes wieder zurückfallen. Zum anderen droht einer Pluralität, die sich keiner prinzipiellen Einheitsbasis mehr versichert, ein Chaos, das jede Verständigung verunmöglicht, und unterläuft die ,reine‘ Differenz einer solchen Pluralität die Tatsache, daß Ethik in ihren letzten Fundamenten so unteilbar ist, wie der Mensch, der sie entwirft. Um beiden Verfallsmöglichkeiten zu wehren und zugleich realitätsgerecht zu optieren, setzt die ethische Theorie ihre Pluralität und Wandelbarkeit von Normen und Ethosformen im Rahmen konsensfähiger, unversalisierbarer ethischer Prinzipien und Maximen an. Diese Prinzipien und Maximen sind dabei so zu denken, da $B$ in ihnen ein Unhintergehbares und jedermann Evidentes zum Vorschein kommt, dessen Wahrung auch bei im Einzelnen und Konkreten differierenden Optionen grundsätzlich bejaht und unterstrichen werden kann. Universalisierbarkeit und Konsensfähigkeit machen dabei aus diesen Prinzipien und Maximen noch keine überzeitlichen, dem Diskurs entzogenen Entitäten. Vielmehr sind diese Prinzipien und Maximen als bislang noch nicht überbotene ethische Errungenschaften zu bestimmen, die, gerade weil sie sich als universell einsichtig und nicht überbotener Fortschritt erweisen, von jedermann gewahrt werden wollen. Ihre Unhintergehbarkeit ist daher eine Frucht ihrer Evidenz und ihrer argumentativ erweisbaren Nichtüberbotenheit. Nur so kann sie ethisch zureichend gedacht werden, wenn neuerlicher Ideologisierung und Ontologisierung von Normen gewehrt werden soll. Als konkretes Prinzip des Rahmenethos ist hierbei das Personprinzip anzusetzen, das zugleich die Maxime der unbedingten Wahrung der Personwürde impliziert. Aus dieser Maxime gehen dann weitere Maximen hervor, die im Schutzkatalog der Grundrechte und -werte bzw. der Menschenrechte ihren Ausdruck finden. Mit dem Personprinzip und den daraus ab-

58 vgl. zum Terminus des Rahmenethos: Kluxen, W., Ethik und Ethos, in: Hertz, A. u. a. (Hrsg.), Handbuch der christlichen Ethik 2, Freiburg - Basel - Wien 1978, 518-532; Kluxen, W., Ethik des Ethos, Freiburg 1974; Kluxen nimmt hierbei vordringlich das Problem der Internationalisierung in Blick. 
geleiteten Menschenrechten ist so ein - weiter entfaltbares - Rahmenethos grundgelegt, das sich sowohl argumentativ einsichtig machen läßt, als auch einen Grundkonsens der Neuzeit und Moderne fixiert, ja deren eigentliche ethische Errungenschaft darstellt. Insgesamt aber sind auf diese Weise das Anliegen ethischer Einheit und die Notwendigkeit einer Verständigungsbasis mit sittlicher Pluralität vermittelt und kann der autonome Entwurf des sittlichen Subjekts mit epochalen Fortschritten und ihrer Wahrung zusammengedacht werden.

\section{Strukturelle Konkretion: Repräsentativ-demokratische Gesellschaft und Trennung der Kultursachbereiche}

Das vorgängig entworfene anthropologisch-ethische Programm nun bedarf zu seiner Realisierung entsprechender struktureller Bedingungen, die ihm Raum geben, es stützen und fördern. Hierbei erweist sich zum einen die demokratische Staats- und Gesellschaftsorganisation als geeigneter Strukturrahmen und zeigt sich zum anderen der historische Prozeß der Trennung der Kultursachbereiche als wesentliches Element, das einer antiautonomistischen Totalisierung entgegenwirkt. Beide Strukturmomente will ich noch in ihren Grundzügen umreißen, bevor ich eine bereichsspezifische Anwendung auf den Film durchführe und einige medienethische Bausteine herstelle. - Bereits in der Skizze der Genese des Projekts der Moderne sowie in Auseinandersetzung mit der kontramodernen Position der Kinoreformer habe ich darauf hingewiesen, daß die vom Projekt der Moderne eingeleitete Autonomisierung und Subjektivierung auf der strukturellen Ebene wesenhaft mit einem Demokratisierungsproze $\beta$ verbunden ist (vgl. 1.1. und 2.5.). So ist historisch zweifelsohne im Subjektivierungsprogramm der Moderne die ideengeschichtliche Wurzel dieses strukturellen Prozesses zu suchen. Doch auch systematisch bedingen sich der Gedanke der vernunftbegründeten Autonomie von Subjekten, die sich ,ihres Verstandes ohne Leitung eines anderen bedienen' (Kant) und ihre Welt- und Lebensinterpretamente sowie ihre Moralität selbst entwerfen, und eine auf Mitbestimmung angelegte Staatsund Gesellschaftsorganisation, wie sie die Demokratie bereitstellt, wechselseitig. Erst in der Demokratie nämlich finden sich die Mitsprache- und Mitgestaltungsrechte aller Gesellschaftsmitglieder organisatorisch garantiert und gesichert, d.h. aber, erst durch sie findet die Autonomie der Subjekte den ihr zugehörigen Entfaltungsraum. Gleichzeitig zeigt sich die demokratische Strukturorganisation auch der mit der Autonomie verbundenen Entwurfspotenz der Subjekte zugepaßt. Sie eröffnet sowohl in der prinzipiellen Trennung von Staat und Gesellschaft als auch besonders in der mittelbaren Verbindung beider durch gewählte Repräsentativität die Möglichkeit für gesellschaftliche Prozesse, ohne daß diese mit der Strukturorganisation - wie noch im Ständestaat - notwendig kollidieren und deren Stabilität und Bestand gefährden müssen. Zum einen nämlich können diese Prozesse sich durch die genannte Trennung unterhalb der strukturellen Organisation und unabhängig von ihr vollziehen. Anders als im Ständestaat, der die genannte Möglichkeit (zunächst widerwillig, wie noch Kants Verbeugung vor dem Fürsten und seine Beschränkung der Vernunftautonomie auf nicht-politische Bereiche bezeugt,) $)^{59}$ ebenfalls bot, aber richtet die Demokratie zugleich noch die Chance ein, daß sich diese Prozesse durch Repräsen-

${ }^{59}$ vgl. Kant, Aufklärung, 55 
tativität auch in die Strukturorganisation umsetzen können. Eine demokratische Gesellschaft erweist sich daher als prozessuale Gestalt, die sich dem Wandel weder verweigert noch ihn regional einzuhegen sucht, sondern ihn gerade in sich aufzunehmen vermag und damit dem Entwurfscharakter des Menschen zugepaßt ist. Das Prinzip der Repräsentativität sichert darüber hinaus vor basisdemokratischer Überforderung und dysfunktionalen, kontraproduktiven Einflüssen mangelnder Sachkompetenz in Einzelfragen. Nicht jedermann muß in der demokratischen Gesellschaft seine Autonomie zusätzlich durch vollständige Information über alle zur Entscheidung anstehenden Sachfragen verantwortbar einrichten, sondern er kann die hierfür nötige Kompetenz über Wahl an Repräsentanten und von diesen bestellte Experten auf Zeit delegieren sowie seine Delegation bei Nichtzufriedenheit später wieder korrigieren. Über das Prinzip der Repräsentativität wird so gewissermaßen der Entlastungsbedürftigkeit des Menschen korrelativ zur Entwurfspotenz Rechnung getragen und dennoch beides strukturell umgesetzt und gesichert.

Schließlich garantiert die Demokratie durch eine Verfassung noch die Wahrung und konsensuelle Fixierung von Rahmenkriterien und Grundüberzeugungen. So fixiert etwa das Grundgesetz der Bundesrepublik Deutschland eine Wertentscheidung, die den Schutz der Menschenwürde für alle verpflichtend macht und bestimmte Grundrechte - darunter die für eine Medienethik besonders bedeutsame Meinungsfreiheit - prinzipiell garantiert. Mit dem Widerstandsrecht bei einer Bedrohung der Verfassung selbst wird zudem das gesellschaftliche Rahmenethos vor seiner Zerstörung geschützt und ist jedes Gesellschaftsmitglied zu diesem Schutz aufgerufen. Mit der Verfassung überträgt die Demokratie also das Rahmenethos der Gesellschaft in eine kodifizierte Form, auf die sich jedes Gesellschaftsmitglied zurückbeziehen kann und muß. Die Wahrung des ethischen Fortschritts und der Schutz erreichter normativer Einsichtsbestände ist hierdurch gesichert. Gleichzeitig aber schafft die Demokratie mit der Verfassung einen ,Unbeliebigkeitsrahmen', innerhalb dessen wiederum Pluralität sowie eine Koexistenz pluraler Entwürfe auf einer gemeinsamen Verständigungsbasis möglich sind. Zwar muß das Rahmenethos der Gesellschaft von allen geteilt werden, doch ist ,unterhalb' desselben wieder eine Vielzahl von Ethoi und Binnenmoralen möglich, die zwar zum Rahmenethos nicht in Widerspruch stehen dürfen, jedoch jene individuellen und gruppenspezifischen Besonderungen erlauben, deren der Mensch schon um seiner Identitätsgewinnung willen stets bedarf. Sowohl den Erfordernissen einer Fixierung erreichter ethischer Fortschritte und der Schaffung einer konsensuellen normativen Basis für Verständigung und gedeihliches Zusammenleben der einzelnen Gesellschaftsmitglieder und Gruppen als auch der menschlichen Entwurfspotenz und Individualität ist auf diese Weise Rechnung getragen. Die Demokratie kann daher insgesamt als die dem Projekt der Moderne und seinem Autonomisierungs- und Subjektivierungsprogramm adäquate, anthropologisch und ethisch zu rechtfertigende Strukturgestalt der Selbstorganisation des Menschen in der Welt betrachtet werden.

Neben einer grundsätzlichen Option für Demokratie aber zeigt sich noch ein weiteres, damit konnotiertes Moment bedeutsam für eine strukturelle Einlösung des entfalteten anthropologisch-ethischen Programms. So hat die Auseinandersetzung mit den kontramodernen Entwürfen wiederholt erbracht, daß diese sich nicht nur gegen die modernen Subjektivierungs-, Autonomisierungs- und Demokratisierungs- 
prozesse richten, sondern auch gegen eine damit verbundene Diversifizierung der Kultursachbereiche. Aufgegipfelt hat sich diese kontramoderne Stellungnahme in der Totalität des Nationalsozialismus, der versuchte, mit Führer- und Gemeinschaftsprinzip gerade auch der Ausdifferenzierung dieser Bereiche entgegenzutreten. Im Gegenzug dazu lassen sich die Diversifizierung der Kultursachbereiche und die hierbei geschehende Regionalisierung von Zuständigkeiten und Kompetenzen sowie eine relative Autonomisierung der Bereiche als kontratotalitäre Entwicklung erweisen, die Subjektivierung, Autonomisierung und Demokratisierung flankiert und stützt. - Der Prozeß der genannten Diversifizierung kann zunächst historisch mit Korff wie folgt beschrieben werden: Er findet seinen Beginn mit der „Kompetenzabgrenzung der religiösen Sphäre gegenüber der staatlich-politischen“ zur Zeit des Investiturstreits. ${ }^{60}$ Mit dieser Abgrenzung definieren sich ,der politische und der religiöse, der staatliche und der kirchliche Ordnungsbereich (...) als eigenständige, nicht aufeinander rückführbare Kultursachbereiche" und gewinnen sie jeweils eine spezifische Freiheit und Autonomie. ${ }^{61}$ Im 12. Jahrhundert ,erringt die geistige Welt der Wissenschaften in der Universität ihre institutionelle Eigenständigkeit" und erarbeitet sie sich einen „vor weltlichen und geistlichen Arrogationen geschützte(n) Raum" ${ }^{62}$ Verpflichtet nur noch auf methodologisch und diskursiv einlösbare Geltungsansprüche innerhalb der Scientific community erhält auch die Wissenschaft so eine spezifische Autonomie und vermag sie sich hierdurch erst produktiv zu entfalten. In der Spätrenaissance differenzieren sich dann Kunst und Technik voneinander und findet im ersten Fall eine zunehmende Freisetzung von Gebrauchsansprüchen statt, während im zweiten Fall die instrumentelle Vernunft die Chance ihrer ,reinen* und damit effizienteren Verwirklichung erhält. Korff verweist darauf, daß hierbei im Bereich der Kunst zunehmend ihre Subjektvermitteltheit ins Zentrum ihrer Strukturlogik tritt, während die Technik sich durch ihre Objektvermitteltheit auszeichnet. ${ }^{63}$ Die Letzte geht dabei mit der Wissenschaft eine neue, spezifische Verbindung und Interaktion ein (vgl. dazu auch 1.2.). Neben die genannten Kultursachbereiche treten schließlich noch die Wirtschaft als ebenfalls relativ autonomer Bereich sowie vordringlich ab dem 19. Jahrhundert die Medien.

Damit sind nun sieben voneinander abgegrenzte Handlungsfelder entstanden, die sich durch eine spezifische Selbständigkeit und nicht ineinander überführbare Kompetenzen und Zuständigkeiten auszeichnen. Dies aber bedeutet, daß mit der Trennung auch eine Gewaltenteilung stattfindet, die zunächst einmal einer Überherrschung eines Bereichs durch Direktiven eines anderen, wie dies im Nationalsozialismus etwa durch die politische Vereinnahmung von Kunst und Medien augenfällig war (vgl. 3.4. und 3.5.), gehindert wird. Die Regionalisierung von Zuständigkeit und Kompetenz wirkt derart einer Totalisierung entgegen und erlaubt jedem Bereich die autonome Entfaltung seiner eigenen Strukturgesetze. Zusammen damit wird auch die Verantwortung regionalisiert und erfolgt eine relative Freisetzung von kultursachbereichsexternen Aufgaben. Auch dies tendiert einer Totalisierung entgegen; wo nicht in einem Bereich immer gleichzeitig alles gelöst und bearbeitet werden muß,

\footnotetext{
${ }^{60}$ Korff, Wirtschaft, 174

${ }^{61}$ Korff, Wirtschaft, 174

${ }^{62}$ Korff, Wirtschaft, 174-175

63 vgl. Korff, Wirtschaft, 175
} 
bleibt die Inklination zu terrible simplifications und Ideologisierung gering gehalten. Stattdessen kann sich die Entwurfspotenz des Menschen, von übergreifenden Aufgaben weitgehend entlastet, bereichsspezifisch differenziert und sachgerecht entfalten. Freilich ist neben der Trennung dann auch wieder eine wechselseitige Verwiesenheit der Kultursachbereiche aufeinander beobachtbar. So zeigt schon die zunehmende Zusammenarbeit von Wissenschaft und Technik, in der die erste ,zur unverzichtbaren Voraussetzung“ der Entwicklung der zweiten und umgekehrt die zweite ,zum Instrument " der Erkenntnisgewinnung innerhalb der ersten gerät, ${ }^{64} \mathrm{da} B$ die Trennung der Bereiche ihre Konnotation nicht verunmöglicht. Auch läßt das Beispiel erkennen, da $B$ eine solche Konnotation durchaus produktiv sein kann. Vorsicht freilich ist geboten: Wo immer die Kooperation und hierbei erfolgende wechselseitige Verschränkung von Kultursachbereichen zu einseitigen Dominanzen führt und eine neuerliche Aufhebung der Diversifizierung droht, muß dies als neototalitäre Tendenz beurteilt und solchen Bestrebungen entgegengetreten werden. Gerade die Kombinatorik der Wirtschaft mit anderen Kultursachbereichen, die dort oft erst ,soziale Produktivität‘ (W. Korff) ermöglicht und die Produkte beispielweise von Kunst, Wissenschaft und Technik realisierbar sowie gesellschaftlich vermittelbar macht, hat dabei besondere Empfindlichkeit für Überherrschungstendenzen geweckt (vgl. etwa die Ökonomiekritik der Kritischen Theorie in 5.5.). Doch wird man die genannte Gefahr auch nicht überwertig sehen dürfen. So ist eine Zusammenarbeit noch keine Identität und bleibt in einer kooperativen Konnotation in der Regel die Diversifizierung erhalten. Diese Regel wird zudem von der skizzierten Struktur der Diversifizierung durch eine spezifische ,Entelechie‘ unterstüzt, die jede neuerliche ,Gleichschaltung erschwert und rasch als kontraproduktive Gewalttat entlarvt. Die Nötigung zur Zusammenarbeit nämlich nötigt gerade um der Produktivität willen auch zur Anerkennung der je sach- und bereichsspezifischen Kompetenzen innerhalb des anderen Bereichs. Soll die bereichsspezifische Produktivität kombinatorisch fruchtbar gemacht werden, muß um der Fruchtbarkeit willen die Spezifität des Bereichs gewahrt werden und kann sie nicht durch totalisierende Überschritte ersetzt werden. Das aber bedeutet, da $B$ bei der Nutzung der Potenzen eines Bereichs durch einen anderen zugleich dessen Autonomie genutzt wird und derart gewahrt werden muß. Die Verschränkung der prinzipiellen Diversifizierung der Bereiche mit ihrer effizienzsteigernden kooperativen Vernetzung hebt so die relativen Autonomien gerade nicht auf, sondern impliziert um der Effizienzsteigerung willen ihre Respektierung und enthüllt jede dennoch stattfindende Überherrschung als letztlich effizienzhindernde Gewalttat. Damit zeigt sich insgesamt die Diversifizierung als ein zentrales, strukturelles Moment der Hinderung von Totalitarismen, das zugleich durch Schaffung und Wahrung relativer regionaler Autonomien dem modernen Subjektivierungs- und Autonomisierungsprogramm zugepaßt ist.

\subsection{Bausteine einer modernitätsgerechten Medienethik}

Auf dem Hintergrund der generellen anthropologisch-ethischen Optionen können nun einige medienethische Bausteine zusammengesetzt werden. Hierbei will ich so

${ }^{64}$ Korff, Wirtschaft, 175 
vorgehen, drei größere ethische Bausteine herzustellen, deren einer zunächst Grundlinien der ethisch gebotenen Struktur des Medienbereichs überhaupt enthält, deren zweiter darin den spezifischen Bereich der Unterhaltung, der im Film eine große Breite einnimmt, begrifflich und legitimativ zu verorten sucht, und deren dritter dann einige Grundlinien zur Inhaltsethik, welche die ,Tradition' der medienethischen Reflexion ja hauptsächlich beschäftigt hat und bis auf den heutigen Tag in Auseinandersetzung um den Jugendmedienschutz bewegt, in bezug auf den Film vorstellt. Es ergeben sich so einmal ein grundsätzlich strukturethischer Baustein, der von einem unterhaltungsethischen und inhaltsethischen flankiert wird. Während im ersten Fall Fragen um das Subjekt des Medienbereichs, um Zugangschancen und deren Verteilung an Erwachsene und Jugendliche sowie um die gesellschaftliche Rolle der Medien im Blick steht, kann im zweiten Fall der Frage nach dem Verhältnis von Information, Kommunikation (bzw. Selbstverständigung) und dem Spezifkum entlastet-unterhaltsamer Aktivität im Kontrast zur Kunstrezeption nachgegangen sowie im dritten Fall nochmals auf die Vorwürfe gegen den Film und die darin sich aussprechenden, durchaus nicht einfach illegitimen Anliegen der Schaffung von inhaltsbezogenen ethischen Kriterien eingegangen werden. Insbesondere für ein praktikables institutionelles Handeln im Bereich gesellschaftlicher Kommunikationskontrolle erscheint eine solche inhaltsethische Kriteriologie sogar unverzichtbar. In einem vierten Baustein werde ich schließlich auf der Basis der größeren Bausteine noch etwas zu diesem praktischen Handeln, näherhin zur institutionellen Umsetzung der nicht zuletzt vom Jugendschutz geforderten gesellschaftlichen Kommunikationskontrolle sagen. Dabei beschränke ich mich auf die beiden bereits existenten Institutionen der Freiwilligen Selbstkontrolle der Filmwirtschaft (FSK) und der Bundesprüfstelle für jugendgefährdende Schriften (BPS).

\section{Strukturethischer Baustein: Aufgabenstellung der Medien, grundsätzliche Gebotenheit einer offenen Kommunikationsstruktur und der Trennung der Kultursachbereiche}

Die grundsätzliche Konstruktion einer Medienethik für die Moderne findet nun gemäß dem vorgängig erarbeiteten generellen Hintergrund jeder Ethikkonstruktion ihren Ansatz ebenfalls beim Verständnis des Menschen als Person bzw. in den Termini des Projekts der Moderne: beim autonomen Subjekt. Aus diesem Verständnis des Menschen und den im Zusammenhang damit hergeleiteten Grundlinien einerseits einer christlichen Ethik wie andererseits einer dem Subjektstatus des Menschen entsprechenden Gesellschaftseinrichtung lassen sich auch Grundlinien einer bereichsspezifischen Ethik, also in diesem Fall der Medienethik deduzieren. Dabei macht der Ansatz beim in Kohärenz zum Subjektgedanken eingeführten Personbegriff von vorneherein deutlich, daß es sich bei dieser Deduktion und bereichsspezifischen Detaillierung um eine spezifisch moderne Ethik handelt, die auf der Basis der ethischen Errungenschaften und Axiomatik dieser Epoche entworfen wird und zu ihr eine affirmative Stellung einnimmt. Eine so angesetzte Medienethik ist daher weder eine standpunktslose Ethik noch eine Theorie mit ontologischem Status. Sie begreift sich vielmehr als eine Ethik im geschichtlichen Prozeß, die um ihre spezifisch historische Situierung und Situationalität weiß, diese aber auch bejaht. Ihr so geartetes Selbstverständnis impliziert, daß sie sich ebenso zu einem reflexiven und argumentativen Eintreten für die Errungenschaften der europäischen Kultur- und Geistesge- 
schichte, für die dort entstandenen ethischen Fortschritte und das erreichte Reflexionsniveau verpflichtet fühlt, wie sie andererseits ihre Argumente selbst zur Diskussion stellt und sich weiteren Überstiegen und ethischen Fortschritten nicht verwehrt. In diesem Sinn stellt diese Medienethik daher eine modernitätsgerechte, diskursiv einlösbare und von besseren Argumenten überholbare Theoriekonstruktion dar, die der Axiomatik des Projekts der Moderne ebenso verpflichtet ist wie einem modernen evolutiven Wissenschaftsverständnis.

Mit dem Ansatz der modernen christlichen Ethik beim Personbegriff und Subjektstatus des Menschen sowie bei den daraus deduzierten Forderungen an die Struktureinrichtung der Gesellschaft sind nun bereits bestimmte Grundlinien der Medienethik präformiert und disponiert. So ist zunächst als oberstes Prinzip der Medienethik anzusetzen, daß als Subjekt des Medienbereichs die menschliche Person in ihrer Autonomie, individuellen Unverfügbarkeit und Kreativität anzusprechen ist und sein muß. Auf den Menschen als Person hin hat jede Struktureinrichtung der Gesellschaft und die Gesellschaft als Ganze orientiert zu sein. Daher schreibt gemäß diesem obersten Prinzip der christlichen Ethik auch das Konzilsdokument Gaudium et spes Art. 25, Abs. 1 für alle sozialen Institutionen fest: „Wurzelgrund nämlich, Träger und Ziel aller gesellschaftlichen Institutionen ist und muß auch sein die menschliche Person“. Als eine solche gesellschaftliche Einrichtung ist im weiteren Sinn auch der Kultursachbereich der Medien zu betrachten, so daß die institutionsethische Vorschrift sich auf diesen übertragen läßt. Der Medienbereich ist damit prinzipiell als Bereich zu fassen, der von menschlichen Personen geschaffen und realisiert wird und sich hierbei auf menschliche Personen bezieht, für sie da ist und ihnen in ihren Eigenheiten dienlich zu sein hat. Aus diesen Eigenheiten, also aus der vorgängig genauer skizzierten Verfaßtheit der menschlichen Personen, lassen sich erste grundsätzliche Aufgabenstellungen der Medien skizzieren und für die Art und Weise der Realisierung und der ,Dienlichkeit' bereits einige Rahmenpräskriptionen herleiten. So ergibt sich zunächst aus dem Moment der Kommunikativität und der damit verbundenen sozialen Verwiesenheit der Person, daß die primäre Aufgabe der Medien in eben der kommunikativen Vernetzung der Personen und der Erstellung einer kommunikativen Struktur besteht. Nicht nur ein Wesen individueller Eigenheit und Unverfügbarkeit ist ja der Mensch als Person, sondern auch ein Wesen des Sozialbezugs, der Angewiesenheit auf Andere und des Kontakts mit diesen. Er ist damit zugleich ein gesellschaftliches Wesen, das seine personale Existenz in der Welt nicht nur in individueller Einsamkeit, sondern auch gesellschaftlich betreibt und zu verwirklichen sucht. Hierbei nun stellen sich die Medien gemäß ihrem Begriff als ,Mittler‘, als Instanzen gesellschaftlicher Kontaktnahme und der Erfüllung kommunikativ vermittelbarer menschlicher Bedürfnisse dar.

Diese Bedürfnisse lassen sich näher als solche nach Information (im Doppelsinn der Bereitstellung, d.h. der Mitteilung, sowie des Erhaltens, d.h. der Rezeption), nach Selbstverständigung und nach Unterhaltung spezifizieren und auf die mediale Aufgabenstellung hin auslegen: Jede menschliche Person nämlich drängt einmal nach Ausdruck ihrer selbst und will sich, ihre Ideen und Vorstellungen mitteilen. Über die personal-intime Expression hinaus aber drängt sie auch danach, andere an ihrem Wissen und ihren Erkenntnissen teilhaben zu lassen. Die Bereitstellung von Information, der informationelle Austausch mit Anderen, gehört so zur näheren Spezifika- 
tion ihres kommunikativen Wesens und kann zumindest im Bereich der Wissensund Erkenntnisvermittlung auch medial realisiert werden. Weiter bedarf die Person, wie in der anthropologischen Reflexion zu sehen war, bereitgestellter Information, die sie neben zwischenmenschlicher, partiell unmittelbarer (face-to-face-communication) und partiell institutionalisierter (Schule, Bildungseinrichtungen) Kommunikation auch über die Medien erhält. Eine erste Aufgabe der Medien liegt also darin, einen Informationsaustausch zu ermöglichen und das diesbezügliche personale $\mathrm{Be}$ dürfnis zu erfüllen. Gleichwohl ist die Person nicht nur auf Verständigung mit anderen, sondern auch mit sich angewiesen, d.h. sie verhält sich auch kommunikativ zu sich selbst. Hier liegt ebenfalls eine Aufgabe der Medien. So können ihre Gehalte eine Art Spiegelfunktion erhalten oder Übungsmaterial bieten und derart die Selbstverständigung befördern. Am Fremden erst, am Nicht-ich faßt sich ja das Ich in seiner Besonderheit, und kommt die Person reflexiv zu sich selbst. Die mediale Gehalteproduktion kann derart die Identitätsgewinnung und den ,intrapersonalen Diskurs stützen. Schließlich sucht der Mensch noch nach Unterhaltung, deren Besonderheit jedoch eine eigene Reflexion erfordert (vgl. unten). Gesagt werden aber kann aus dem Skizzierten vorerst, daß die kommunikative Verfaßtheit der Person die grundsätzliche Aufgabe der Herstellung einer Kommunikationsstruktur und darin bereits drei spezifische Aufgaben an den Bereich der Medien stellt, nämlich den individuellpersonalen Bedürfnissen nach Information, Selbstverständigung und Unterhaltung zu entsprechen.

Die Herstellung einer Kommunikationsstruktur erscheint hierbei gemäß der Bestimmung des Menschen als gesellschaftliches Wesen jedoch auch noch als eine gesellschaftliche Aufgabe, die die Kommunikation über kleine Zirkel hinaus auf die Gesamtgesellschaft ausweitet und zur öffentlichen, sozialen Kommunikation werden läßt. Dies kann zunächst als sachliches Erfordernis gezeichnet werden, das insbesondere in der konkret-historischen Situation der Moderne und ihrer Gesellschaftsform sich stellt. Nicht nur das individuelle Informations- und Selbstverständigungsbedürfnis muß ja gedeckt werden, sondern die gesellschaftliche Selbstorganisation des Menschen in der Welt verlangt danach, eine größere Gruppe in innerem Kontakt zu halten. In der konkreten historischen Situation der Moderne hat dieses Erfordernis dabei zusätzlich eine neue Dimension erhalten: Die politische Realisierung der ideellen Axiomatik des Projekts der Moderne - also des Verständnisses des Menschen als Subjekt, das auf der Basis seiner Vernunft Autonomie gewinnt und beanspruchen darf - hat zunehmend zur Demokratisierung der Gesellschaft und zum Umbau der sozialen Strukturen auf Flexibilität, Wandelbarkeit und Dynamik hin geführt. In der Demokratie erst, die gesellschaftlichen Prozessen und der menschlichen Entwurfspotenz Raum gibt, hat der Subjektgedanke seine politische Form, seine strukturellen Realisationsbedingungen gefunden. Gleichzeitig hat sich im Zuge der Demokratisierung der rationale Diskurs als vorrangiges innergesellschaftliches ,Verkehrsmittel etabliert und sind rationale Organisationsstrukturen und Legitimationsformen der gesellschaftlichen Selbsteinrichtung des Menschen entstanden. An ihrer Rationabilität müssen sich daher alle Strukturen und gesellschaftlichen Prozesse letztlich ausweisen können, und die diskursive Einlösbarkeit von jeweiligen Ansprüchen auf Legitimität und Geltung gewinnt vordringliche Relevanz für das Funktionieren dieser modernen Gesellschaftsform. Mit der Ausweitung der modernen Rationalisierung 
durch ihre technisch-wissenschaftlichen Errungenschaften auf alle Teile der Erde erhält die rational-diskursive Verkehrsform der Menschen dabei zusätzlich internationale Bedeutung. Im Ganzen entsteht so die Aufgabe einer, anonymen', d.h. über die Face-to-face-Kommunikation hinausgreifenden Vermittlung von kommunikativer Kontaktnahme einer Vielzahl von Subjekten, die vor allem innergesellschaftlich nur noch durch eine technisch-mediale Konstitution von Öffentlichkeit zu lösen ist. Auch zwischengesellschaftlich aber können die Medien den nötigen Kontakt jenseits der politisch-föderalen Interaktionen fördern und durch Kenntnis auch Verständnis für fremde Gesellschaften schaffen sowie der zunehmenden Etablierung einer internationalen Rahmenkultur flankierend zur Seite stehen.

So geht es schon aus diesen sachspezifischen Erfordernissen heraus darum, eine öfentliche kommunikative Struktur zu errichten, die den gesellschaftlichen Austausch, die Kontaktnahme der Personen als Gesellschaftsmitglieder (und der Gesellschaften untereinander) ermöglicht. Es gilt insbesondere, innergesellschaftlich einen Raum zu schaffen, in dem die einzelnen Subjekte ihre je besonderen Vorstellungen zur Form ihrer kollektiven Existenz, zur Lösung gesellschaftlicher Probleme sowie zur Weiterformung der Gesellschaft selbst diskursiv zu vermitteln vermögen. Eben dies aber ermöglichen und fördern die Medien, wenn sie den aus der Konstitution der Person vorgängig eingeführten Aufgaben nachkommen. Die gesellschaftliche Kontaktnahme geschieht daher nicht extern zur Erfüllung der oben genannten Aufgaben, sondern gerade in dieser: Indem die Medien der Information und Selbstverständigung der Personen dienen, dienen sie zugleich einer gesellschaftlichen Informationsvermittlung und einer gesellschaftlichen Selbstverständigung. Die einzelnen Personen sind es ja, die mit ihren Vorstellungen, Einsprüchen und Expressionen gesellschaftliche Dynamik hervorrufen und den GesellschaftsprozeB konstituieren. Die auf die Bedürfnisse der Personen bezogenen Medien stellen deshalb in ihrer kommunikativen Struktur den offentlichen Raum her, in dem zum einen aus privaten Belangen einzelner Personen öffentliche werden, und zum anderen auch öffentliche Belange, die sich nicht nur aus der Privatexistenz allein ergeben, verhandelt werden können. In der Vermittlung individuell-personaler wie gesellschaftlicher Bedürfnisse begleiten, spiegeln und fördern die Medien so zugleich den Gesellschaftsprozeß. Sie erhalten derart zusätzlich zu privater Bedürfniserfüllung eine sozial-diskursive Aufgabe.

Dabei ist diese Aufgabe nicht nur eine von der Sache her gestellte, sondern auch ein aus der Axiomatik der Moderne hervorgehendes ethisches Desiderat. Der ProzeB einer zunehmenden Demokratisierung nämlich, der von der ideellen Axiomatik des Projekts der Moderne getragen und angestoßen worden ist, ist nicht einfach nur als historischer Prozeß der strukturellen Umsetzung beliebiger Ideen, sondern auch als der eines ethischen Fortschritts und seiner strukturell-gesellschaftlichen Einlösung zu lesen. Im Grundlegungsteil hat sich daher nicht nur gezeigt, wie der christlich inaugurierte Personbegriff - vermittelt durch philosophisch-theologische Reflexion und Geistesgeschichte - allmählich zur Durchsetzung als ethisches Prinzip gelangt, sondern auch, daß dieser Begriff dem Menschen in besonderer Weise gerecht wird, sein anthropologisch eruierbares ,Wesen' trifft und systematisch ,auf den Punkt bringt'. Aus seiner grundsätzlichen Struktur heraus war dort der Mensch als vernünftiges Wesen zu erkennen, das dadurch auch zu Autonomie und selbstbestimmter Realisation in der Welt befähigt ist. Die Bestimmung des Menschen als Person, als 
autonomes Subjekt, schien daher die menschliche Realität zu treffen und auch das zugehörige ethische Desiderat zu stützen, diesem so bestimmten Menschen Raum für seine selbstbestimmte Verwirklichung zu geben. Als adäquate strukturell-gesellschaftliche Realisation dieses Raums aber erschien dann weiter die Demokratie, die sowohl der Entwurfspotenz des menschlichen Subjekts, als auch der menschlichen Entlastungsbedürftigkeit entgegenkommt und mit dem Zueinander kollektiver Rahmenstrukturen und individueller oder gruppenspezifischer Besonderheiten in sich Einheit und Pluralität zu vereinen mag. Die Demokratie stellt daher dem Menschen als Person die entsprechende gesellschaftlich-politische Strukturgestalt für seine Selbstorganisation und -realisation zur Verfügung. Eine demokratische Gesellschaft aber ist nun weiter auf die Einrichtung einer kommunikativen Struktur angewiesen, die alle Gesellschaftsmitglieder miteinander in Kontakt zu bringen vermag und den gesellschaftlichen Diskurs vermittelt. Von den Medien wird eben diese Struktur mit ermöglicht. Die von der Demokratie geleistete politische und die von den Medien mitkonstituierte kommunikative Organisation der Gesellschaft stehen so in einem wesenhaften, systematischen Zusammenhang. Damit aber kann gesagt werden, da $B$ unter Voraussetzung eines anthropologisch gestützten Ansatzes der Ethik beim Menschen als Person und Subjekt sowohl die demokratische Organisation der Gesellschaft, als auch die Schaffung einer medial vermittelten Öffentlichkeit sich notwendig ergebende ethische Desiderate sind. Sie können mithin nicht einfach nur als historische Prozeßergebnisse beliebiger Ideenrealisation gelesen werden, sondern sind als Einlösungsformen von aus dem ethischen Ansatz der Moderne hervorgehenden ethischen Forderungen zu sehen.

Damit ist die ethische Gebotenheit der Einrichtung einer medialen kommunikativen Sphäre in der modernen demokratischen Gesellschaft nun eingeführt und argumentativ verankert. Auf der Basis des Verständnisses des Menschen als Person im Sinn des Subjektgedankens der Moderne und der daraus hergeleiteten Notwendigkeit der demokratischen Organisation der Gesellschaft erscheint auch die Errichtung einer kommunikativen Struktur durch die Medien als prinzipiell ethisch geboten. Die spezifischen Struktureigentümlichkeiten der menschlichen Person ergeben weiter bereits grundsätzliche Aufgabenzuschreibungen für die Medien: So haben diese den individuell-personalen Bedürfnissen der Information, Selbstverständigung und Unterhaltung zu entsprechen. Gleichzeitig aber fordert die demokratische Gesellschaft auch eine in der Erfüllung dieser Bedürfnisse erreichbare Etablierung eines gesellschaftlichen Diskurses, in dem die Gesellschaftsmitglieder Kontakt miteinander aufzunehmen vermögen und jenseits der individuell bedeutsamen Themen auch die öffentlich relevanten Themen vermittelt und bearbeitet werden können. Nach dieser grundsätzlichen Statuierung von Legitimität und Notwendigkeit des Medienbereichs kann jetzt genauer nach dessen erforderlicher Strukturierung und den an die medial kommunizierenden Subjekte selbst zu stellenden Forderungen gefragt werden.

Dabei zeigt sich zuächst, daß der Medienbereich grundsätzlich als offene Kommunikationsstruktur einzurichten ist und die Teilnahmemöglichkeiten aller Gesellschaftsmitglieder prinzipiell gesichert sein müssen. So läßt sich aus der sozial-diskursiven Aufgabe sowie aus den personkonstitutiven Momenten der Autonomie und der Kreativität deduzieren, da $\beta$ in der bereitzustellenden Kommunikationsstruktur der schöpferischen Kraft der Produzenten ebenso Raum gegeben werden muß, wie die 
Zugänge der Rezipienten zum medialen Geschehen gewährleistet sein müssen. Die Notwendigkeit und Gebotenheit des gesellschaftlichen Austauschs, die prinzipiell zu wahrende Selbstbestimmtheit und die kreative Kompetenz der Personen fordern eine prinzipielle Chance für alle zur Teilnahme am medialen Prozeß. Wo der Mensch als vernünftige Person, als autonomes Subjekt bestimmt wird und wo dessen gesellschaftliche Selbstorganisation demokratisch eingerichtet sein soll, müssen die Medien der gesellschaftlichen Kontaktnahme, des diskursiven Austauschs und des Meinungsbildungsprozesses allen gleichermaßen zur Verfügung stehen und für alle zu kommunizierenden Inhalte zumindest prinzipiell offen sein. Das wiederum bedeutet zunächst, da $B$ die grundsätzliche Verfaßtheit des Medienbereichs sich als in jeder Hinsicht offene Kommunikationsstruktur darzustellen hat, in der jeder seine eigenen Prädilektionen treffen, seine Interessen realisieren und seine Ansichten einbringen kann. Soll durch die Medien der gesellschaftliche Diskurs autonomer Subjekte vermittelt werden, so müssen also einmal alle Subjekte Zugang zu den Medien haben und darf andererseits aus der medialen Vermittlung keiner der von den Subjekten als relevant erachteten Gegenstände und Inhalte einfachhin ausgeschlossen werden.

Dieser Forderung entspricht auch die demokratische Gesellschaft der Bundesrepublik Deutschland in ihrer Verfassung. Sie schreibt in Art. 5 I GG die Freiheit der Meinung und ihrer Verbreitung, die Freiheit zur Information sowie im besonderen die Freiheit der Berichterstattung durch Presse, Rundfunk und Film als selbständige Grundrechte fest. Damit wird die ethisch geforderte offene Kommunikationsstruktur rechtlich umschrieben und fixiert. Die medienethische Grundforderung erhält auf diese Weise die nötige Basis für ihre Durchsetzbarkeit und findet sich strukturell garantiert und abgesichert. Dabei klingen eine modernitätsgerechte medienethische Konstruktion, die ihren Ausgang von den Grundideen des Projekts der Moderne nimmt, und die juridische Argumentation der Rechtsprechung der demokratischen Gesellschaft der Bundesrepublik zusammen: Wie die Medienethik unter Rekurs auf das Personprinzip/den Subjektgedanken und die Demokratisierung eine offene Kommunikationsstruktur fordert, tut dies auch die Argumentation der höchstrichterlichen Rechtsprechung. Neben die subjektive Freiheitsgarantie des Art. 5 I GG nämlich tritt die objektive Bezugnahme auf das demokratische Prinzip (Art. 20 I GG), dessen Funktionieren nach Urteil des Bundesverfassungsgerichts (BVerG) eine möglichst gut informierte und frei gebildete öffentliche Meinung voraussetzt. ${ }^{65}$ Das Recht der freien Meinungsäußerung, die Presse-, Rundfunk- und Filmfreiheit und die Freiheit der Information sind nach Auffassung des BVerG für eine freiheitlich-demokratische Staatsordnung "schlechthin konstituierend“ ${ }^{66}$ Die medienethische Forderung der offenen Kommunikationsstruktur und ihre Herleitung entdecken sich also in Verfassung und Rechtsprechung der Bundesrepublik wieder.

Gleichwohl ist es mit der medienethischen Einführung dieser Forderung noch nicht getan. Vielmehr stellen sich der Medienethik im Anschluß an die prinzipielle Einführung einer Gebotenheit offener Kommunikationsverhältnisse sogleich vier Probleme: Zum einen muß über das Phänomen der Zensur nachgedacht werden. Dies gilt es nicht nur zu tun, weil dieses Phänomen in der Geschichte der menschli-

65 vgl. BVerGE 27, 81; auch: Seifert/Hömig, GG, Art. 5 GG Rdn. 2

66 BVerGE 20, 97 
chen Gesellschaften bis in die Gegenwart hinein eine Rolle spielt, sondern auch, weil die Möglichkeit illegitimer medialer Gehalte auch unter den Prinzipien einer modernitätsgerechten Ethik nicht a priori ausgeschlossen werden kann. Dabei soll hier nun zunächst lediglich grundsätzlich auf die Frage zensuraler Maßnahmen eingegangen und die speziellere Frage nach bestimmten legitimen und illegitimen Inhalten später im Kontext der inhaltsethischen Überlegungen genauer geklärt werden. Zum zweiten gilt es dann hier bereits, die Problematik der Zugangschancen zur Produktion der Medien anzugehen. Insbesondere die Frage nach dem Verhältnis faktischer Unmöglichkeit der Beteiligung aller Gesellschaftsmitglieder zu einer entsprechenden ethisch reflektierten Strukturierung der Produktion ist dabei zu stellen. Zum dritten ist aber auch zu klären, wer in welchem Umfang an der Rezeption von Mediengehalten beteiligt werden soll und ob es nicht geboten sein kann, bestimmten gesellschaftlichen Gruppen - wie etwa Kindern und Jugendlichen - nur begrenzten, pädagogisch geregelten Zugang zu Medienprodukten zu gewähren. In diesem Kontext ist sowohl auf die grundsätzliche ethische Begründung und Verortung des Jugendschutzes als auch auf die Notwendigkeit eines Rezipientenethos zu blicken. Zum vierten schließlich muß noch die Frage nach der Interaktion und Verschränkung der Kultursachbereiche in den Blick genommen werden. Wie nicht zuletzt die Kritik Horkheimers und Adornos an der ökonomischen Organisation der Medien gezeigt hat, ist auch nicht a priori auszuschließen, daß die Offenheit des medialen Diskurses durch Direktiven eines anderen Kultursachbereichs - hier der Ökonomie - gefährdet wird. Auch dies ist ethisch grundsätzlich zu reflektieren.

Für die Zensurproblematik muB nun zunächst ein Begriff von Zensur geschaffen werden. Gemeinhin wird hierbei juristisch die Vorzensur von der Nachzensur unterschieden: Unter Vorzensur wird jede Verhinderung schon der Herstellung eines Medienprodukts verstanden, während die Nachzensur die nachträgliche Einziehung bereits entstandener Produkte meint. Ein Zensurverbot, das vordringlich die Vorzensur ausschließen will, bezieht sich unter diesen Umständen dann primär auf die Freiheit der Produktion, nicht aber unmittelbar auf die Freiheit der Verbreitung von Medienprodukten. Ohne nun schon auf die speziellere juristische Problematik eingehen zu wollen, kann aus dem vorgehend entwickelten ethischen Ansatz heraus ein Zensurverbot im Sinn zunächst des Verbots der Vorzensur grundsätzlich gestützt werden. Es ist medienethisch gesehen sogar noch zu erweitern um ein grundsätzliches Verbot jedes Versuchs eines medial vermittelten Social engineering durch Steuerung der Medienproduktion mittels zensierender Maßnahmen oder eines ,konstruktiven' Dirigismus. Beide Verbote ergeben sich aus der oben eingeführten Struktur des Medienbereichs als einer offenen kommunikativen Sphäre, die der Kontaktnahme autonomer Subjekte und der Vermittlung des gesellschaftlichen Diskurses dienen soll. Wenn nämlich die Medienproduktion als Institution der Vermittlung des gesellschaftlichen Diskurses zu begreifen ist, in dem sich der von autonomen Subjekten getragene Gesellschaftsprozeß spiegelt und vorantreibt, ist ein vorgängig zensierender Eingriff in diese Produktion als Verfälschung des Diskurses und als ethisch illegitime Behinderung der diskursiven Aufgabe der Medien zu bewerten. Ebenso kann es nicht angehen, daß dieser diskursive Prozeß, der ja von den Gesellschaftsmitgliedern selbst ,produziert' werden soll, in eine hegemoniale Steuerung der Kommunikation dieser Gesellschaftsmitglieder umgebogen und zu einer dirigisti- 
schen, heteronomen Lenkung der sozialen Prozesse mißbraucht wird. Dies gilt schon für Versuche eines Social engineering durch ,negative', ausschließende Maßnahmen, wenn diese sich nicht auf den Schutz der demokratischen Gesellschaft und ihrer vitalen Strukturen richten, sondern den Diskurs im Ganzen zu formen versuchen. Prinzipiell nicht statthaft ist hier insbesondere ein genereller Ausschluß bestimmter diskursiver Gehalte aus dem Diskurs durch eine kodifizierende Instanz, die damit versucht, dem gesellschaftlichen Diskurs insgesamt ein bestimmtes ,Gesicht' aufzuprägen oder eine ,Linie vorzuschreiben. Nicht ganz unproblematisch sind daher auch schon Moralkodices, wie etwa der Code Hollywoods in den 30er, 40er und 50er Jahren oder der Comics-Code von 1954, selbst wenn sie sich als Frucht des gesellschaftlichen Diskurses erweisen und auf Druck der Öffentlichkeit entstehen. In diesem Fall gälte es eher, diese Öffentlichkeit auf ihre eigene Mündigkeit und ihre Verantwortung gegenüber der Subjektautonomie aufmerksam zu machen, als ihr kodifikativ zu entsprechen. Erst recht aber ist ein vollständiger Steuerungsumgriff um die mediale Kommunikation zu verwerfen, der damit auf eine Steuerung des Gesellschaftsprozesses selbst abzielt. Jedes solche Unterfangen trifft die ethisch gebotene Aufgabe der Medien, ihre sozialethische Verortung in der Gesellschaft ins Herz: Sie, die gerade den Diskurs vermitteln und ermöglichen sollen, die die Selbststeuerung des Gesellschaftsprozesses zu fördern haben, wären dann zu Agenten der Diskursverhinderung und der Heteronomisierung gesellschaftlicher Prozessualität pervertiert. Beide, Vorzensur wie mediales Social engineering, stellen daher jeweils ein Unterfangen dar, dem medienethisch prinzipiell entgegenzutreten ist. Umgekehrt ist positiv zu fordern, daß zumindest alle erwachsenen Gesellschaftsmitglieder grundsätzlich Zugang zu Medien haben. Dies ergibt sich aus der prinzipiellen Bestimmung des Menschen als autonomes Subjekt und seiner demokratischen ,Vergesellschaftung - sollen diese gewahrt und im Medienbereich realisiert werden, kann als Grundnorm die grundsätzliche Zugänglichkeit von Medienprodukten aufgestellt werden. Nur auf diese Weise ist der gesellschaftliche Diskurs gewährleistet und wird dem Recht der Person auf selbstbestimmte Verwirklichung seiner - auch medienbezogenen - Neigungen und Strebungen entsprochen. Nur so wird auch der demokratischen Gesellschaftseinrichtung entsprochen, die ja auf dem Prinzip der Personwürde und der Subjektautonomie sowie der daraus herleitbaren Mitsprache- und Mitgestaltungsrechte der Gesellschaftsmitglieder aufbaut.

Gleichwohl bedeutet das noch nicht, $\mathrm{da} B$ alle medialen Gehalte legitim sind und ein Anrecht auf Verbreitung besitzen. Die grundsätzlich gebotene Zugänglichkeit von Medienprodukten im allgemeinen impliziert keineswegs, $\mathrm{da} B \mathrm{im}$ besonderen stets alle Produkte legitim sind und nicht im Einzelfall eventuell doch die Zugänglichkeit unterbunden werden muß. Auch aus dem Blickwinkel des medienethischen Ansatzes beim Subjektgedanken und der Demokratisierung nämlich entdecken sich noch ethisch illegitime Gehalte, deren Verbreitung selbst in einer offenen Kommunikationsstruktur schwerlich geduldet werden kann. So steht außer Frage, daß etwa nicht mit Hilfe der Medien zum Bruch der Verfassung der demokratischen Gesellschaft aufgefordert, in solcher Absicht Geschichtsfälschung betrieben, der Nationalsozialismus und seine Rassenlehre propagiert oder zu Straftaten aufgerufen werden darf (dazu auch mehr unten). Der von der Demokratie auf der Basis des Personprinzips um der personalen Entfaltungschancen und demokratischen Mitwirkungsrechte wil- 
len eröffnete Freiheitsraum nämlich darf nicht dazu mißbraucht werden, gegen die Demokratie und ihre Prinzipien vorzugehen oder die Entfaltungschancen der Gesellschaftsmitglieder und die diese gewährenden gesellschaftlichen Lebensstrukturen zu zerstören. Die ethische Axiomatik wäre hierdurch pervers beansprucht, d.h. gegen sich selbst gewendet. Dies aber ist nicht nur ein Widerspruch gegen die ethische Logik, sondern ein prinzipiell illegitimes und verwerfliches Verhalten. Entsprechend ist es, wo die Medienproduktion die offene Kommunikationsstruktur in dieser Weise mißbraucht, ethisch nicht nur legitim, sondern sogar geboten, daß derartige Medienprodukte aus der Öffentlichkeit entfernt werden. Die Verfassung der demokratischen Gesellschaft und die Würde der menschlichen Person sind prinzipiell schutzwürdig und ihr Bestand darf nicht durch ethisch verwerfliche Aktionen gefährdet werden. Angriffe auf die um der Funktionsfähigkeit des Gemeinwesens und der Ermöglichung der Selbstrealisation der Subjekte willen rechtlich gesicherten Strukturen und Güter sind in jedem Fall zu verhindern. Daher ist es auch medien ethisch geboten, für die Funktionsfähigkeit der demokratischen Gesellschaft, ein gedeihliches Zusammenleben der Gesellschaftsmitglieder und den Schutz der Grundwerte und Grundrechte sowie der von den Einzelgesetzen geschützten Strukturen und Güter Sorge zu tragen. Wie nicht mit anderen Mitteln das Recht der demokratischen Gesellschaft gebrochen und ein Verbrechen begangen werden darf, darf dies auch nicht mit Hilfe der Medien geschehen. Die Spezifität der ethischen Illegitimität entsprechender Gehalte und der erforderlichen strukturellen Maßnahmen verweist dabei darauf, daß sich hierfür zunächst einmal die Gesetzgebung, d.h. nicht zuletzt das Strafgesetz, als zuständig erweist. Von der Gesetzgebung sind jene Fälle erfaßt, die ob der Schwere ihrer Bedrohung für den Einzelnen und die Gesellschaft zu drastischen Maßnahmen nötigen, d.h. im Medienbereich: die Beseitigung der entsprechenden Produkte erforderlich machen. Die ethisch gebotene und rechtlich organisierte Beseitigung entsprechender Medienprodukte ist dabei durchaus mit einer Nachzensur vergleichbar. Zwar ist aus ethischem Gesichtswinkel bereits die Produktion verwerflicher Gehalte selbst verwerflich, ja muß schon der Vorsatz hierzu moralisch als negativ eingeschätzt werden. Doch vermag das Gesetz in der Regel erst zuzugreifen, wenn sich der Vorsatz in der entsprechenden Tat (seltener der Tatankündigung) aktualisiert hat. Daher ist kaum jemals das Produktionsvorhaben, sondern zumeist das Produkt Gegenstand eines entsprechenden Verfahrens und kann die Beseitigung eines solchen Produkts als nachzensuraler Effekt eingestuft werden. Wo nun ein solches rechtlich gestütztes exekutives Handeln gegen Medienprodukte nötig wird, weil von diesem Produkt eine entsprechend schwere und daher juridisch eingefangene Bedrohung ausgeht, muß der nachzensurale Effekt als medienethisch nicht nur legitim, sondern geradezu erforderlich bezeichnet werden. Entsprechend zensurales Handeln ist dann geboten. Gleichwohl bedeutet das nicht, daß die Nachzensur generell und uneingeschränkt legitim wäre. Sie findet vielmehr ihre Schranken an der von der Gebotenheit der offenen Kommunikationsstruktur mitbedingten Informationsfreiheit, die nur durch jene Regelungen beschnitten werden darf, die sich auf den unmittelbaren Schutz des Einzelnen sowie der demokratischen Gesellschaft und ihrer vitalen Strukturen richten. Eine Ausdehnung der Nachzensur über diesen meist rechtlich umschriebenen und geregelten Bereich hinaus muß vielmehr als ähnlich bedenklich beurteilt werden wie die Vorzensur. Die Öffentlichkeit hat, da sie aus 
autonomen Subjekten besteht, nach wie vor ein Recht auf Zugang zu den Medien, und nur die Gefährdung der Grundlagen und vitalen Strukturen der Gesellschaft sowie der Subjekte und ihrer garantierten Rechte selbst legitimiert ein Handeln mit zensuralem Effekt.

Auf dieser Linie bewegen sich auch die Optionen der Verfassung der Bundesrepublik und die zugehörige Rechtsetzung, sowie Rechtsprechung. So bestimmt zwar Art. 5 II GG, daß die Meinungs-, Informations-, Presse, Funk- und Filmfreiheit ,ihre Schranken in den Vorschriften der allgemeinen Gesetze, den gesetzlichen Bestimmungen zum Schutze der Jugend und in dem Recht der persönlichen Ehre" finden. Doch ordnet die Interpretation der Rechtssprechung diese Vorschrift selbst wieder in einen prinzipiell freiheitlichen Rahmen ein. So präzisiert zunächst das BVerG den Begriff der allgemeinen Gesetze und damit deren schrankengebende Form. Allgemeine Gesetze nämlich sind solche, „die sich nicht gegen die Äußerung einer Meinung als solche richten, die vielmehr dem Schutz eines schlechthin, ohne Rücksicht auf eine bestimmte Meinung, zu schützenden Rechtsgutes dienen" ${ }^{67}$ Diese Bestimmung, die zunächst vordringlich der formalen Definition des Terminus des ,allgemeinen Gesetzes' dient, verweist aus ethischer Perspektive zugleich auf das diesen Gesetzen innewohnende ,Telos': Das ,Telos' eines in einem Einzelfall möglicherweise beschränkend in den offenen Kommunikationsprozeß der demokratischen Gesellschaft eingreifenden Gesetzes nämlich ist stets der Schutz bestimmter unverzichtbarer Rechtsgüter der freiheitlich-demokratischen Gesellschaft - d.h. der Schutz der anderen Grundrechte und der rechtlich entfalteten Lebensstrukturen der Gesellschaft -, nicht aber der apriorische Ausschluß bestimmter (beispielsweise politisch mißliebiger) Kommunikationsinhalte. Nur wo die Grundrechte und vitale Rechtsgüter der demokratischen Gesellschaft bedroht sind und diese Bedrohung durch $\mathrm{Me}$ dien verursacht wird, vermag ein entsprechender Eingriff in die freiheitlich eingerichtete mediale Kommunikation zu erfolgen. Dies gilt auch für Gesetzesbestimmungen, die nicht mehr eindeutig dem Terminus der allgemeinen Gesetze zuzuordnen sind, weil sie einen bestimmten Kommunikationsinhalt illegitimisieren, wie dies etwa das gesetzliche Verbot der,Aufstachelung zum Rassenhaß ${ }^{*}$ in $\S 131$ I StGB tut. Zwar entsteht hier juristisch das formal-definitorische Problem, ob eine solche Vorschrift noch als Bestimmung eines allgemeinen Gesetzes zu beurteilen ist. ${ }^{68}$ Für die medienethische Reflexion der ,Entelechie' der juristischen Argumentation jedoch ist dieses formale Problem vernachlässigbar: Geschützt wird durch diese spezielle Bestimmung des Strafgesetzes letztlich wieder die Menschenwürde und damit das oberste Prinzip der demokratischen Verfassung. Das ethische Telos auch dieser ,besonderen' Vorschrift ist also der Schutz eines bestimmten Grundprinzips der demokratischen Gesellschaft, nicht aber die Behinderung der medial vermittelten sozialen Kommunikation. Der gesetzliche Zugriff ist daher von Vorzensur und Social engineering wohl zu unterscheiden: Kein Angriff auf die offene Kommunikation wird geführt, sondern Angriffe auf die Grundprinzipien und Rechtsgüter der demokratischen Gesellschaft werden abgewehrt. Es geht mithin also um den Schutz und die Wahrung der freiheitlichen Gesellschaftsordnung und der zugehörigen gesellschaftli-

${ }^{67}$ BVerGE 7, 198/209f; 62, 230/244; 71, 162/175

68 vgl. dazu: Jarass/Pieroth, GG, Art. 5 GG Rdn. 46, 53 
chen und persönlichen Lebensstrukturen. Die Bestimmung von Art. 5 II GG ist damit selbst in einem freiheitlichen Rahmen zu sehen, und sowohl im ethischen Gehalt des Rechts als auch in der Rechtsprechung entdeckt sich der oben skizzierte medienethische Argumentationsgang wieder.

Diese freiheitsorientierte Zielrichtung bestätigt sich insbesondere auch aus der für die Gesetzesanwendung normgebenden Auffassung des BVerG, daß die allgemeinen Gesetze ,in ihrer das Grundrecht beschränkenden Wirkung ihrerseits im Lichte der Bedeutung dieses Grundrechts gesehen und so interpretiert werden, da der besondere Wertgehalt dieses Rechts, der in der freiheitlichen Demokratie zu einer grundsätzlichen Vermutung für die Freiheit der Rede in allen Bereichen, namentlich aber im öffentlichen Leben, führen muß, auf jeden Fall gewahrt bleibt" ${ }^{69}$ Daraus ergibt sich eine "gegenseitige Beziehung zwischen Grundrecht und ,allgemeinem Gesetz““, die „nicht als einseitige Beschränkung der Geltungskraft des Grundrechts durch die ,allgemeinen Gesetze" aufzufassen" ist, sondern eine ,Wechselwirkung vorstellt, in der „die ,allgemeinen Gesetze` zwar dem Wortlaut nach dem Grundrecht Schranken setzen, ihrerseits aber aus der Erkenntnis der wertsetzenden Bedeutung dieses Grundrechts im freiheitlich-demokratischen Staat ausgelegt und so in ihrer das Grundrecht begrenzenden Wirkung selbst wiederum eingeschränkt werden" ${ }^{70}$ Notwendig ist auf diesem Hintergrund außerdem in jedem konkreten Fall eine „Güterabwägung, zwischen dem beeinträchtigten Kommunikationsgrundrecht und den Interessen, die mit den allgemeinen Gesetzen verfolgt werden" ".1 Des weiteren muß die Einschränkung der Kommunikationsfreiheit verhältnismäßig sein und dem Gebot der Vermeidung des Übermaßes gehorchen. ${ }^{72}$ Insbesondere strafrechtliche Vorschriften mit nachzensuralem Effekt sind außerdem stets restriktiv, d.h. zurückhaltend, auszulegen und zur Anwendung zu bringen. ${ }^{73}$ Damit aber findet eine weitere Stützung und interpretative Fixierung der freiheitlichen Grundorientierung von Art. 5 I GG statt und werden die von Art. 5 II GG ermöglichten Beschränkungsformen dezidiert auf die freiheitliche Grundoption rückverpflichtet. Im ganzen wird so durch die Verfassung und die zugehörige Rechtsprechung eine Normsetzung und -interpretation eingerichtet, die sich auf die Garantie und Wahrung der medienethisch gebotenen offenen Kommunikationsstruktur richtet und sowohl einem illegitimen, über den Schutz der Grundrechte und vitalen Rechtsgüter hinausgreifenden zensuralen Unterlaufen dieser Forderung als auch jedem Social engineering entgegenarbeitet. Für die möglicherweise nötige Beschränkung der Verbreitung bestimmter Medienprodukte sind äußerst zurückhaltende und vorsichtige Rahmenkriterien geschaffen, die in den Mittelpunkt die Grundoption für den demokratischen Prozeß und eine zugehörige offene Kommunikationsstruktur rücken.

${ }_{70}^{69}$ Lüth-Entscheidung vom 15. 1.1958 in: BVerGE 7, $198(208,209)$

${ }_{71}^{70}$ BVerGE 7, $198(208,209)$

71 Jarass/Pieroth, GG, Art. 5 GG Rdn. 47; vgl. auch: BVerGE 35, 202/224

72 Jarass/Pieroth, GG, Art. 5 GG Rdn. 47; vgl. auch: BVerGE 59, 231/265; 71, 162/181; 77 , $65 / 75$ - Das Verbot des Übermaßes bedingt es dabei, daß bei etwa einem inkriminierten Film nur die entsprechenden Teile entfernt werden dürfen, nicht hingegen das ganze Filmwerk eingezogen werden kann. Vgl. dazu: Hartlieb, Handbuch, Kap. 3 Rdn. 2

73 vgl. Hartlieb, Handbuch, Kap. 3 Rdn. 1 
Entsprechend ist daher auch eine Vorzensur explizit und vollständig ausgeschlossen. Art. 5 I GG bestimmt unmißverständlich, daß ,eine Zensur nicht stattfindet'. Die Interpretation dieser Bestimmung durch das BVerG verdeutlicht dabei einmal, daß mit Zensur hier in der Tat die Vorzensur gemeint ist sowie zum anderen, da $\beta$ das Zensurverbot „eine Schranke der Beschränkungsmöglichkeiten des Abs. 2“ bildet. $^{74}$ Das Verbot der Vorzensur kann auch durch beschränkende Gesetze nicht durchbrochen werden; es gilt absolut. Gleichwohl bleiben Beschränkungen im Bereich der Informationsfreiheit möglich, d.h. es können eben dort, wo bestimmte Grundrechte und vitale Rechtsgüter bedroht sind, durchaus durch Anwendung der allgemeinen Gesetze Schutzhandlungen vorgenommen werden. Die medienethisch in den Blick genommene nachzensurale Wirkung solcher Schutzhandlungen bleibt trotz des Zensurverbots möglich, ${ }^{75}$ und eingerichtet ist insgesamt eine Rechtsstruktur, die mit der medienethisch grundsätzlich umrissenen Argumentation verbunden erscheint.

Wie eingangs bemerkt, stellt sich jedoch in Bezug auf die grundsätzliche ethisch gebotene Strukturierung des Medienbereichs nicht nur die Frage nach der Zensur, sondern auch jenseits institutioneller und struktureller Regelungen nach den $\mathrm{Zu}$ gangschancen zu Produktion und Rezeption. Im Bereich der Produktion nun fällt dabei zum einen sofort ins Auge, daß eine Teilnahme aller Gesellschaftsmitglieder an der Produktion faktisch nicht möglich ist. Nicht jeder Einzelne kann selbst medial produktiv sein und seine eigenen Zeitungen, Filme und Fernsehsendungen machen. Zum anderen erstreben auch nicht alle Gesellschaftsmitglieder eine Teilnahme an der Produktion selbst und bringt nicht jeder die hierfür nötigen, spezifischen Kompetenzen mit. Die Meisten geben sich mit der Rezeption zufrieden und suchen derart eine entlastete Form der kommunikativen Teilnahme; sie informieren sich und bringen ihre Stellung, ihre Meinung nur durch ihr Rezeptionsverhalten zum Ausdruck, indem sie bestimmte Medienprodukte bevorzugen und andere neglegieren. Ihr Beitrag zum gesellschaftlichen Diskurs liegt medienbezogen derart vordringlich im ,Plebiszit am Kiosk', in Einschaltquoten und möglicherweise Leserbriefen. Von diesen Rezipienten zu fordern, sie sollten selbst Medienprodukte hervorbringen, bedeutete eine Überforderung. Doch weder aus dieser Tatsache, noch aus der organisatorischen Unmöglichkeit einer aktiv-produktiven Teilnahme aller am medialen Diskurs scheint mir die Schlußfolgerung - etwa im Sinn der Kritischen Theorie - zu ziehen zu sein, daß darin eine Defizienz der Medien liegt, die ethisch prekär zu beurteilen ist. Vielmehr sehe ich hier erneut die Dialektik von Entwurf und Entlastung am Werk, die neben dem individuellen auch das kollektiv-organisatorische Leben des Menschen prägt. So sucht die Mehrheit nicht nach Realisierung ihrer Entwurfspotenz durch Medienproduktion, sondern bringt sie diese vermittelter, indirekter in den Gesellschaftsdiskurs ein, während eine kleinere Gruppe sich als aktive Produzentenschaft in diesem Diskurs zu verwirklichen sucht. Ähnlich wie in der demokratischen Organisation der Gesellschaft müssen daher die über Zugangschancen ver-

${ }^{74}$ zur Interpretation der verbotenen Zensur als Vorzensur BVerGE 33, 52/71; zum Zitat: Jarass/Pieroth, GG, Art. 5 GG Rdn. 52

${ }^{75}$ vgl. Jarass/Pieroth, GG, Art. 5 GG Rdn. 52: „Die Nachzensur stellt (...) eine Beeinträchtigung des Abs. 1 dar, die über die Schranke des Abs. 2 gerechtfertigt werden kann." Auch: Seifert/Hömig, GG, Art. 5 GG Rdn. 20 
mittelten Mitsprache- und Entwurfsmöglichkeiten der einzelnen Gesellschaftsmitglieder differenziert eingerichtet werden.

Aus ethischem Blickwinkel scheint mir diese Einrichtung ebenfalls mit dem Prinzip der Repräsentativität zu reflektieren und zu legitimieren zu sein. Zu fordern ist aus medienethischer Perspektive ja, daß die mediale Gehalteproduktion die Gesellschaft als ganze miteinander in Kontakt bringt und den Austausch über gesellschaftlich relevante Themen ermöglicht sowie daB die inhaltliche Produktion reichhaltig ist und dem Publikum möglichst differenzierte Wahlmöglichkeiten gibt, durch die dieses sich und seine Bedürfnisse im Angebot repräsentiert finden kann. Die ethische Begründung für diese Forderung ergibt sich dabei wieder aus der Bestimmung des Menschen als Person und der zugehörigen Gesellschaftsform als demokratischer. Das demokratische Moment bedingt es, daß für die Gewährleistung eines von den gesellschaftlichen Subjekten selbst bestimmten und ins Werk gesetzten diskursiven Prozesses dieser Diskurs in adäquater Weise medial vermittelt und appräsentiert werden muß. Was gesellschaftlich verhandelt wird und in welcher spezifischen Weise es verhandelt wird, muß bei der Rezeption der medialen (Re-)Produktion des Verhandlungsprozesses erkennbar sein. Weiter tut es not, daß sich die Rezipienten auch mit ihren Wünschen und subjektiven Prädilektionen im medialen Angebot, beispielsweise im Bereich der Unterhaltung, wiederfinden können. Erst wo die Neigungen und Vorlieben der Subjekte Berücksichtigung finden und entsprechend in der Rezeption realisiert werden können, sind die Subjekte auch als solche mit ihren autonom generierten Bedürfnissen und Wünschen respektiert, und ist ihr Subjektstatus gewahrt. Die offene Kommunikationsstruktur der Medien muß daher also inhaltlich die Notionen, Interessen, Wünsche und Bedürfnisse des Publikums sowie die von ihm (mit-)generierten gesellschaftlichen Themen repräsentativ reproduzieren. Die Aufgabe dieser Reproduktion kann dabei an eine Gruppe von Produzenten delegiert werden, die dann als Repräsentanten des Publikums und des gesellschaftlichen Diskurses agieren. Sie sind gewissermaßen die zwar nicht unmittelbar gewählten, aber faktischen Vertreter der Interessen, Meinungen und Wünsche des Publikums, die diesen Interessen, Wünschen und Meinungen Rechnung zu tragen versuchen und damit den Diskurs medial vermitteln. Ihre Repräsentanz entbindet zugleich die übrigen Gesellschaftsmitglieder von der Überforderung, selbst auch noch medienproduzierend tätig zu sein. Das ethische Prinzip, das diesen Zusammenhang reflexiv auf den Punkt bringt, ist entsprechend das Repräsentativitätsprinzip. Es sorgt dafür, daß die Einrichtung der kommunikativen Struktur sowohl den gesamtgesellschaftlichen Diskurs in allen relevanten Äußerungsformen zur Darstellung und Realisation bringt als auch einer ,basisdemokratischen Überforderung' gewehrt ist. Auf diese Weise zeigt es sich zugleich als ein realitätsgerechtes und praktikables Prinzip.

Diese Repräsentativität nun stellt sich einmal als Gegebenheit und zum anderen als Aufgabe dar. Eine Gegebenheit ist sie zunächst dort, wo Produktion und Rezeption miteinander vermittelt sind. Gerade über das genannte ,Plebiszit am Kiosk', über Einschaltquoten und ähnliches findet eine Rückmeldung der Rezipienten an die Produzenten statt, die eine Art Analogat zur demokratischen Wahl im politischen Bereich darstellt. Diese Rückmeldung wird von den Produzenten partiell mit ermöglicht in Marktanalysen, Umfragen etc., durch welche Bedürfnislagen des Publikums erforscht werden. Beides bedingt es, daß die Produzentenschaft nicht unabhängig 
von ihrem Publikum ihre Produktion durchführen kann und wird. Die skizzierte mittelbare Kontaktnahme der Produzenten und Rezipienten miteinander bedingt damit bereits eine gewisse Repräsentativität der Produktion. Unmittelbarer gestützt werden kann die Repräsentativität dann über direktere Kontaktnahme der beiden Gruppen. Dies ist im Bereich des Films etwa durch Filmzeitschriften, Filmclubs und Filmmuseen möglich, die Foren für solche Kontaktnahmen darstellen. All das verweist darauf, daß die Medienproduktion selbst interaktiv zustande kommt und derart dem Prinzip der Repräsentativität strukturell zumindest zuneigt.

Freilich ist Repräsentativität auch eine Aufgabe. Sie beschreibt nicht nur die Funktion der Medienproduktion, sondern schreibt dieser zugleich eine entsprechende Mittlerschaft in der gesellschaftlichen Kommunikation vor. So bedingt das Prinzip der Repräsentativität, daß den Produzenten ein Ethos abverlangt ist, das deren Rolle als die ,ehrlicher Makler' festlegt. Der Produzent hat in seine Produktion nicht nur seine Kreativität einzubringen, sondern auch auf Wünsche und Bedürfnisse der Rezipienten zu achten, um statt der Fixierung einer ,Einwegkommunikation' gesellschaftlichen Diskurs zu ermöglichen. Gleichwohl bedeutet diese Forderung nicht, $\mathrm{da} B$ nun die individuelle Kreativität des Produzenten durch die Forderung der Repräsentativität geknebelt werden soll. Auch diese Kreativität ist ja ein Beitrag zu diesem Diskurs. Außerdem findet in der Vielfalt der Produktionen vieler Produzenten eine wechselseitige Ergänzung und Korrektur der kreativen Positionen statt. Schließlich haben die Produzenten auch die sachliche Funktion, Themen und Inhalte erst aufzufinden und dem Diskurs zur Verfügung zu stellen. Doch ist das Prinzip der Repräsentativität nicht nur deskriptiv, sondern auch normativ zu verstehen. Die Realisation des Prinzips kann entsprechend nicht einfach nur der Sachlogik der Medienproduktion, dem Spiel von Angebot und Nachfrage überlassen werden, sondern bedarf eines aktiven Einsatzes der Produzenten, die zu diesem Einsatz auch ein spezifisches Kommunikatorenethos mitbringen müssen. Dieses Ethos ist als Verpflichtung zur differenzierten Förderung des gesellschaftlichen Diskurses, zum Dienst an der sozialen Kommunikation im Sinn eines ,verständigungsorientierten Handelns (Habermas) zu begreifen. An die Stelle strategischer Durchsetzung der eigenen Meinung - auch wenn diese vom Produzenten als gutgemeinte Publikumspädagogik oder soziales Engagement gedeutet wird - muß eine Orientierung auf Transparenz der eigenen Argumentation und repräsentative Reproduktion auch der dieser entgegenstehenden, übrigen gesellschaftlichen Meinungsformen treten. Die Konstitution eines solchen Ethos kann dabei dem Kommunikator nicht durch institutionelle oder strukturelle Maßnahmen einfach abgenommen werden. Gerade das Erfordernis einer offenen, d.h. auch: dynamischen, veränderlichen und prozessualen Kommunikationsstruktur, die Raum eröffnet für die Kontroverse und den vielfältigen Austausch, verbietet es, diese Vielfalt und Differenziertheit durch externe normgebende und -durchsetzende Instanzen herstellen zu wollen. Der Weg einer Delegation der sittlichen Verpflichtetheit der Produktion gesellschaftlicher Kommunikation an eine Art ,Rahmenordnung', die von Institutionen repräsentiert ist, würde notwendig in eine Totalisierung des Umgriffs um die Medien führen. Schon um den feinen Bewegungen des Medienprozesses normativ folgen und ,Entgleisungen' verhindern zu können, bliebe einer Institution, die das Ethos der Produzenten ersetzen sollte, nichts anderes, als entsprechend feininstrumentell - und das heißt: totalitär - zuzu- 
greifen. Daher muß auch das Repräsentativitätsprinzip jenseits institutioneller Garantieversuche im Ethos der Kommunikatoren verwurzelt sein und sind Institutionen nur sparsam zur Anwendung zu bringen.

Gleichwohl bringt das Prinzip weiter mit sich, da $B$ in Medienbereichen, die eine monopolähnliche Stellung haben, wie dies lange der öfentlich-rechtliche Rundfunk und das Fernsehen in der Bundesrepublik hatten, die Repräsentativität nicht dem Ethos der (wenigen) Kommunikatoren oder der Marktsituation allein anvertraut werden kann, sondern hier dennoch zusätzlich strukturell fixiert werden muß. Der monopolistischen Durchsetzung auch eines mit einem Kommunikatorenethos ausgestatteten und an den Wünschen des Publikums orientierten Gremiums oder Stabs muß durch entsprechende Maßnahmen gewehrt werden. Wo immer ein Gremium oder Stab dominiert, bleibt die Gefahr einer gewissen Einseitigkeit, der dann nur strukturell, d.h. durch eine bestimmte Einrichtung des Stabs selbst begegnet werden kann. So sorgt beispielsweise der Rundfunkrat durch paritätische Besetzung mit Repräsentanten der ,gesellschaftlich relevanten Gruppen' für eine (weitgehende) Wahrung des Repräsentativitätsprinzips im Rundfunkbereich. ${ }^{76}$ Die Vielfalt der gesellschaftlichen Gruppierungen soll derart intern personell repräsentiert und umgesetzt werden. Freilich entbindet diese Struktur auch hier die einzelnen Mitglieder des Rats nicht von der Ausbildung eines spezifischen Kommunikatorenethos. - Insgesamt aber ist mit dem Repräsentativitätsprinzip eine mediale Struktur normativ verankert, in der sowohl einer basisdemokratischen Überforderung durch Teilnahme aller an der Produktion als auch einer einlinigen Hegemonialisierung der gesellschaftlichen Kommunikation konstruktiv entgegengetreten werden kann.

Neben dieser Reflexion der Zugangschancen zur Produktion tut jedoch auch noch eine Reflexion der Zugangschancen zur Rezeption not. Hier gilt zunächst gemäß dem Ansatz der Medienethik beim Subjektstatus der Gesellschaftsmitglieder, daß zumindest die Erwachsenen grundsätzlich Zugang zu allen Medienprodukten haben sollen und - vorbehaltlich der oben genannten unumgänglichen Schutzmaßnahmen der demokratischen Gesellschaft - kein genereller Ausschluß bestimmter Produkte aus der Rezeption oder die Fernhaltung bestimmter Rezipientengruppen von Medien stattfinden darf. ${ }^{77}$ Nicht zuletzt das Zweite käme einer Form der Nachzensur gleich, die sich einer funktionellen Vorzensur nähert und nicht statthaft ist. Einzig im Fall der Bedrohung anderer Grundrechte und vitaler Rechtsgüter der demokratischen Gesellschaft ist - wie zu sehen war - eine Unterbindung der Verbreitung entsprechender Medienprodukte - und damit eine Einschränkung der Zugangsmöglichkeiten zur Medienrezeption, also der Informationsfreiheit - zulässig. Im übrigen jedoch darf die Zugänglichkeit von Medien nicht strukturell verhindert werden. Der Ansatz

${ }^{76}$ Über den Terminus der ,Relevanz in der genannten Formel freilich kann mit Recht gestritten werden. Das Sonderproblem von Minderheitenrepräsentation und der Subgruppenartikulation ist hierdurch noch nicht gelöst.

77 Ausgenommen werden können hier freilich unter je und je zu begründenden Umständen jene Erwachsenen, die durch eine geistige Behinderung auch in anderen Kontexten nicht als mündig zu bewerten sind. Sie sind dann in Analogie zu Kindern und Jugendlichen zu behandeln. Allerdings wird sich diese Ausnahme auf die klinischen Fälle beschränken müssen, bei denen faktisch eine Vormundschaft ausgesprochen ist. Nicht statthaft ist es hingegen, etwa mit dem Verweis auf mangelnde Intelligenz oder Kompetenz mündige Erwachsene vom Mediengebrauch auszuschließen (vgl. dazu mehr im Text). 
beim Subjektstatus bedingt es dabei gleichwohl trotz des Auschlusses einer grundsätzlichen Verhinderung der Zugänglichkeit von Medienprodukten, daß den erwachsenen Subjekten eine Verantwortung bei ihrem Mediengebrauch zufält. Wie von den Kommunikatoren ein spezifisches Ethos verlangt werden muß, dürfen sich auch die Rezipienten eines Rezipientenethos nicht entschlagen. Hier ist zunächst zu fordern, da $B$ um der Funktionabilität des gesellschaftlichen Diskurses willen jedes Gesellschaftsmitglied im Rahmen seiner Möglichkeiten am Diskurs teilnimmt und sich zumindest in den wichtigen Gegenständen rudimentär informiert hält. Dabei ist der genannte Möglichkeitsrahmen ethisch durchaus bedeutsam: Nicht jedermann vermag dieselbe Menge medialer Information aufzunehmen und zu verstehen. Intelligenz- und Kompetenzniveaus müssen nicht nur berücksichtigt werden, sondern auch legitim bleiben. Über sein Vermögen hinaus kann auch medienethisch niemand gezwungen werden. Auch kann nicht jeder in jedem Bereich des gesellschaftlichen Diskurses gleichermaßen tätig sein. Schon die Interessen divergieren - nicht jeder rezipiert den Sportteil oder das Feuilleton der Tageszeitung; die spezielleren Diskurse des Kunstmarkts oder bestimmter Wissenschaftszweige mögen zwar in den Medien auch breiter Öffentlichkeit zugänglich sein, sind jedoch vordringlich für die betroffenen Subgruppen von Interesse. Weiter ist die Forderung der Selbstinformation auch nicht im Sinn eines ausnahmslosen Zwangs zur Information zu verstehen. Wie dem subjektiven Entwurf zuzugestehen ist, daß eine Person sich als unpolitische entwirft, muß ihr auch zugestanden werden, da $\beta$ sie sich aus bestimmten Gründen als uninformierte oder schlecht informierte konstituiert. Hier können unter Umständen etwa ,gegenkulturelle ${ }^{6}$ Motive eine Rolle spielen und Menschen aus kontemplativen Gründen auf den Mediengebrauch verzichten oder sogar durch ihre diesbezügliche Askese ein Zeichen setzen wollen. Distanz zur Dynamik der modernen Welt kann faktisch ebenso ein Motiv für eine solche Haltung sein wie die Favorisierung bestimmter Konzepte ,natürlichen' Lebens oder der Rückzug in die Face-to-faceKommunikation einer Wohngemeinschaft. Gleichwohl gilt hier wie bei jedem Selbstentwurf des Subjekts, daß er sich ethisch ausweisen und verantworten muß. Zwar kann der gesellschaftliche Diskurs durchaus auf eine gewisse Anzahl von Teilnehmern verzichten, ohne zu sehr zu vereinseitigen oder zum Subgruppendiskurs zu verkommen. Wie die Demokratie zum Wahlrecht nicht unbedingt die Wahlpflicht gesellen muß, um funktionsfähig zu bleiben, muß die mediale Selbsteinrichtung der gesellschaftlichen Kommunikation auch nicht eine Informationspflicht deontologisch einführen, um noch diskursiv zu bleiben. Doch ist von jedem Gesellschaftsmitglied, das sich aus dem gesellschaftlichen Diskurs grundsätzlich fernhält, zu fordern, daß es hierfür gute Gründe angeben kann und seine Wahl zu verantworten vermag.

Schließlich muß von den Rezipienten jedoch umgekehrt auch grundsätzlich gefordert werden, daß sie nicht nur den Verzicht auf die Rezeption bestimmter Mediengehalte zu legitimieren vermögen, sondern auch deren Gebrauch. Teil des Rezipientenethos muß ebenfalls sein, vor allem die Rezeption problematischer Gehalte vor sich selbst und vor dem eigenen Gewissen verantworten zu können. Zwar ist den erwachsenen Rezipienten das Recht auf selbstbestimmten Mediengebrauch unverstellt zuzusprechen, doch entbindet dies nicht von der generellen Verpflichtung des Menschen, wie mit anderen auch mit sich selbst verantwortlich umzugehen. So mag es grundsätzlich legitim sein, um eines bestimmten Selbstentwurfs wegen einseitige 
Dispositionen im eigenen Leben vorzunehmen, bestimmte Strebungen - z.B. das Verlangen nach kognitiver Durchdringung der Welt im Bereich der Wissenschaften - auf Kosten anderer besonders auszubilden oder bestimmte Fertigkeiten und Fähigkeiten - z.B. im Hochleistungssport - ,hypertroph' zu entwickeln und dergleichen mehr. Jede dieser Lebensformen muß hierbei aber als verantworteter Teil des Selbstentwurfs ausweisbar sein. Dies gilt prinzipiell auch für den Mediengebrauch. Bedeutsam ist in diesem Kontext aber, daB nur der Selbstausweis vor dem eigenen Gewissen gefordert werden kann, nicht hingegen etwa die Ersetzung dieses Ausweises durch eine strukturelle Maßnahme. Selbst wenn in concreto bei Einzelnen das Gelungensein der Subjektivierung und die Fähigkeit zur Verantwortung des eigenen Mediengebrauchs angezweifelt werden mögen, ist prinzipiell doch jedem der Subjektstatus zuzusprechen und entsprechende Eigenverantwortung zuzulasten. Eine Option wie etwa die reformerische, die alle Zugangschancen zum Film gerne am ,schwächsten Glied' der Gesellschaft (hier unter den Erwachsenen Frauen) bemessen sehen wollte, ist medienethisch keinesfalls legitim. Auf dem Hintergrund der erarbeiteten Grundlinien einer modernitätsgerechten Ethik darf sich niemand die Hoheit anmaßen, bestimmten erwachsenen Subjektgruppen in der Gesellschaft ihren Subjektstatus per Gruppe abzusprechen und daraus strukturelle Zugangsbeschränkungen zu Medien zu legitimieren. Erwachsene Subjekte sind für ihren ,Medienschutz' selbst verantwortlich. Der Versuch, ihnen diese Verantwortung abzunehmen, bedeutete einen Angriff auf den Subjektgedanken und damit die zentrale Errungenschaft der Neuzeit und Moderne. Ethisch gewendet kommt ein solcher Angriff einem Angriff auf die Gewissensfreiheit und damit auf die Personwürde gleich. An diesem Punkt endet daher auch das Wächteramt des Staates. Ein struktureller Umgriff um die Medienrezeption von Erwachsenen, der über die genannten Schutzerfordernisse gegenüber den Grundrechten und vitalen Rechtsgütern der Gesellschaft hinausreicht, ist medienethisch als illegitim zu bewerten, auch wenn er vorgeblich um des Schutzes von erwachsenen Personengruppen erfolgt, denen medienbezogen eine mangelnde Selbststeuerungskompetenz unterstellt wird. In anderen Kontexten als mündig erachtete Subjekte dürfen nicht im Kontext der Medienrezeption plötzlich als unmündig behandelt werden. Ein solches Vorgehen führt nur allzu leicht in ein illegitimes Social engineering zurück.

Anders freilich verhält es sich bei Kindern und Jugendlichen, bei denen es durchaus legitim erscheint, die Zugangschancen zu bestimmten Medien und Gehalten zu beschränken. Kinder und Jugendliche nämlich sind noch auf dem Weg zu ihrer Subjektivität und der damit gegebenen Autonomie und Kompetenz zur eigenverantwortlichen Lebenssteuerung. Sie bedürfen hierzu der Hilfestellung und auch des Schutzes vor Überforderung oder Obstruktionen. Zur Verdeutlichung dieses Tatbestands ist es nun an dieser Stelle hilfreich, zwischen der Würde der menschlichen Person oder dem Subjektstatus und der realisierten Vollgestalt realer Personalität bzw. Subjektivität zu unterscheiden. Die Personwürde nämlich ist schon Kindern und Jugendlichen zuzusprechen, die noch auf dem Weg zur faktischen Realisierung ihrer Personalität und der zugehörigen Kompetenzen sind. Aus dem Personstatus von Kindern und Jugendlichen leitet sich daher zunächst einmal prinzipiell ab, daß diese in ihrer personalen Eigenheit, ihrem Status als menschliche Wesen zu achten sind. Gleichwohl legt sich der Schutz der Personwürde von Kindern und Jugendlichen 
dann anders aus als der der Erwachsenen: Während diese bereits selbstbestimmte Subjekte - Personen mit der Fähigkeit zu rational-autonomer Selbstrealisation geworden sind, denen damit auch die Pflicht zu Selbststeuerung und verantwortetem Umgang mit sich und anderen zufällt, kann diese Selbststeuerung und Verantwortung Kindern und Jugendlichen noch nicht - bzw. genauer: nicht im selben Maß zugelastet werden. Aus ihrem Person- oder Subjektstatus leitet sich zwar ab, daß sie ein Recht darauf haben, zu einem selbstbestimmten Leben, zur Mündigkeit erzogen zu werden - und mithin diese Erziehung diesem Recht und Ziel nicht entgegenarbeiten darf -, doch bedeutet dies zugleich, daß sie vor Einflüssen, die das Erreichen personaler Selbstrealisation gefährden oder gar zerstören könnte, zu bewahren sind. Um ihrer Personwürde willen haben Kinder und Jugendliche ein Anrecht auf Eröffnung eines edukativen Raums, der ihnen die Ausbildung ihrer Personalität ermöglicht und aus dem entsprechend alles, was diese Ausbildung hindert, ferngehalten bleibt. In dieser prinzipiellen Argumentation gründen daher die ethische Legitimation und Gebotenheit des Jugendschutzes.

Der Ansatz bei der Personwürde von Kindern und Jugendlichen und bei der prinzipiellen, aus dem Subjektstatus fließenden Gebotenheit einer Erziehung zur Mündigkeit ergibt sich jedoch noch mehr als nur die blanke Legitimation des Schutzes von Kindern und Jugendlichen vor Obstruktionen ihres Entwicklungsprozesses. Die Forderung der Erziehung zur Mündigkeit nämlich impliziert weiter für eine entsprechend eingerichtete Pädagogik, daß diese Erziehung kooperativ mit den jeweils entstehenden und zunehmend sich entwickelnden Kompetenzen und Fähigkeiten der Kinder und Jugendlichen durchgeführt wird. Das bedeutet, daß zunächst diese Fähigkeiten und Kompetenzen eruiert und reflektiert werden. Hier ist die Entwicklungspsychologie gefragt, die etwa mit den Stufenkonzepten auch Kompetenzniveaus erarbeitet hat. Im Bereich der Mediennutzung von Kindern und Jugendlichen können diese Konzepte - wie etwa Piagets Rekonstruktion der Genese kognitiver Fähigkeiten und Wahrnehmungsweisen - fruchtbar zur Anwendung gebracht werden und ließe sich beispielsweise eine ,Medienleiter altersspezifischer Eignungen (oder Ungeeignetheiten) bestimmter Medienformen und -inhalte erstellen, die dann auch eine Bereitstellung je und je altersgerechter Medien für kindliche und jugendliche Rezipienten erlaubt. Weiter können freilich auch die situativ besonderen Fertigkeiten, die Kinder und Jugendliche durch Medienumgang bereits erworben haben, in empirischen Untersuchungen herausgearbeitet werden. Die Nutzung von Video in der ,Peer group' beispielsweise, die in bestimmten sozialen Gruppen je unterschiedlich ausfällt, kann zu je bestimmten Auffassungsformen und Fertigkeiten führen, mit denen eine auf Autonomisierung gerichtete Erziehung kooperieren kann. Freilich impliziert die Forderung einer Kooperation auch Steuerung und Einspruch. Zum rechten Mediengebrauch muß auch durch entsprechende Direktiven und Hilfestellungen erzogen werden. Allerdings kann hier eine Förderung oft mehr erzielen als ein bewahrender Umgriff. So wäre im Kontext einer autonomisierenden Medienpädagogik durchaus zu fordern, zu bestimmten Medien und ihrer spezifischen Struktur auch hinzuführen. Es kann etwa die ästhetische Konstruktion eines Films transparent gemacht und in altergerechter Form etwas Filmtheorie und Filmgeschichte vermittelt werden. Dabei läßt sich auch Qualitätsbewußtsein fördern, das dann unter Umständen sogar ohne bewahrende Maßnahmen die Rezeption problematischer 
Formen zurückdrängen kann. In diesem Zusammenhang erscheint es nun auch als dringliche medienethische Forderung, daß die audiovisuellen Medien - Film, Fernsehen und Video - Gegenstand des Schulunterrichts werden. Hier wiederum gälte es, sie nicht nur - etwa im Sinn der ideologiekritischen Entlarvungspädagogik der 70er Jahre - einer Dekonstruktion im Deutschunterricht zu unterziehen, sondern sie als ästhetische Gegenstände neben den ,etablierten' Kunstformen auch in den Kunstunterricht einzubeziehen. Wie Gemälde und Plastiken sinnlich und theoretisch erfahrbar gemacht werden, sollten dort auch die lebensweltlich ungleich bestimmenderen ästhetischen Formen vor allem des Films theoretisch und erfahrungsbezogen durchdrungen werden können. Nicht nur die Geschichte der etablierten Kunstäußerungen, sondern auch die des Films sollte längst umfassend Eingang in dieses Schulfach gefunden haben. Insgesamt muß es dabei in all diesen Bereichen entsprechend dem Ansatz bei der Personalität bzw. Subjektivität des Menschen um eine Kooperation mit den bereits vorhandenen Fertigkeiten und Fähigkeiten der Kinder und Jugendlichen sowie um die Förderung des Ausbaus und der Weiterbildung dieser Fähigkeiten und Kompetenzen gehen. Nur unter Nutzung bereits vorhandener Vorformen von Mündigkeit lassen sich Selbststeuerung und Selbstverantwortung des Menschen pädagogisch ,erzeugen'.

Diese Forderung hat nun zugleich Konsequenzen für den Jugendschutz. Auch dieser nämlich muB sich unter das Erfordernis einer Erziehung zur Mündigkeit stellen und kann zunächst nicht mehr sein als eine flankierende Maßnahme einer solchen Erziehung. Will der Jugendschutz nun diese Erziehung nicht durch falsche bewahrethische Maßnahmen obstruieren, so muß er sich ebenfalls auf der Basis einer genaueren Kenntnis der Kompetenzen und Lebensbedingungen der Kinder und Jugendlichen einrichten. Auch von den jugendschützerischen Maßnahmen ist zu fordern, da $B$ sie mit den Fähigkeiten und Möglichkeiten der Kinder und Jugendlichen kooperieren. Das aber bedeutet, daß für die Generierung schützender Maßnahmen die Erkenntnisse der Entwicklungspsychologie, der Sozialisationstheorie und der empirischen Untersuchungen zum Mediengebrauch ebenso wichtig sind wie für die Pädagogik. Nur auf diese Weise lassen sich differenzierte Maßnahmen entwerfen. Dabei bleibt der Jugendschutz freilich nicht nur Aufgabe einiger weniger Institutionen, sondern muß er auch Anliegen der Medienproduzenten und Teil des Kommunikatorenethos sein. Auch die Kommunikatoren müssen sich aufgerufen und motiviert fühlen, für den Schutz von Kindern und Jugendlichen vor Medienprodukten, die eine Erziehung zur Mündigkeit hindern und zu Versehrungen oder unzumutbaren Belastungen führen können, Sorge zu tragen. Gerade sie können diese Sorge zudem differenziert tragen; ihre Möglichkeiten sind ungleich reichhaltiger als die von Institutionen, und sie können sogar um konstruktive, über den bloßen Schutz hinausreichende Maßnahmen erweitert werden. Als Grundlage und Beispiel für einen möglichen Entwurf solcher Maßnahmen kann dabei etwa die bereits zitierte Studie des Instituts Jugend Film Fernsehen angeführt werden, die empirisch eine ,Tageszeittafel ${ }^{4}$ altersspezifischer Fernsehnutzung erarbeitet hat. ${ }^{78}$ Aus dieser Tafel läßt sich die tatsächliche Häufigkeitsverteilung der Rezeption des TV-Programms von Kindern entneh-

${ }^{78}$ vgl. Theunert, Helga u. a., Zwischen Vergnügen und Angst - Fernsehen im Alltag von Kindern, Berlin 1992, bes. 202-205 
men und mithin erkennen, wann welche Altersgruppe dieses Medium dominant nutzt. Daraus leitet die Studie Empfehlungen für die Programmstruktur ab. Mit einer solchen Arbeit nun ist medienethisch Entscheidendes gewonnen: Zum einen läßt sich durch entsprechende programmgestalterische Maßnahmen nun der realen Situation Rechnung tragen und können jugendungeeignete Sendungen anders plaziert werden. Statt einer vollständigen Entfernung solcher Sendungen greift eine schützende Kooperation mit den faktischen Rezipienten bestimmter Tageszeiten. Zum anderen können zu den entsprechenden Zeiten gezielt förderliche Sendungen angeboten werden, die der kindlichen Rezeptionskompetenz entgegenkommen und derart sogar ein Stück medienimmanenter Medienpädagogik ermöglichen. An die Seite der nur bewahrend-schützenden kann dadurch eine konstruktive Maßnahme treten und der Jugendschutz zur ,Jugendförderungs weitergebildet werden. Für eine solche Handlungsweise aber ist es nötig, daß die Programmanbieter, also die Kommunikatoren, ein entsprechendes Engagement auch für ihre jüngeren Zuschauer zeigen und mithin ein entsprechendes Ethos ausbilden. Unter dieser Voraussetzung ließe sich ein modernitätsgerechter Jugendschutz dann nicht nur konstruktiv, sondern auch effizient einrichten. Auf diese Weise wäre zudem der medienethischen Grundforderung einer prinzipiell offenen Kommunikationsstruktur entsprochen und diese Struktur im Bereich der Zugangschancen auch unter Berücksichtigung der Erfordernisse des Jugendschutzes entsprechend differenziert hergestellt. ${ }^{79}$

Die vorgängigen Reflexionen über die strukturelle Gestaltung des Medienbereichs, d.h. über den Ausschluß der Zensur bei gleichzeitiger Wahrung von selbstschützenden Eingriffsmöglichkeiten der demokratischen Gesellschaft in den medial vermittelten Diskursbereich, über die gebotene Organisation des Zugangs zu Produktion und Rezeption sowie über die im Rezeptionsbereich entstehenden Fragen des Jugendschutzes stellen damit nun bereits grundlegende und zentrale medienethische Strukturlinien vor Augen. Die Form der geforderten offenen Kommunikationsstruktur ist in diesen Linien deutlicher und detaillierter erkennbar geworden. Gleichwohl bleibt - wie eingangs erwähnt - noch ein weiteres Problem zu behandeln. Nicht nur die Wahrung der demokratischen Grundprinzipien und vitalen Lebensstrukturen der Gesellschaft sowie der Jugendschutz stellen sich als Erfordernisse dar, die bestimmte Beschränkungsformen der medialen Kommunikation bedingen

79 Auch hier sind bereits Rahmenvorschriften geschaffen, die der Durchsetzung dieser medienethischen Strukturforderung hilfreich sind. So bestimmt der Rundfunkstaatsvertrag vom 1./3. 4. 1987 (zuletzt geändert durch Staatsvertrag vom 15. 3. 1990) in Art. 10 II, daß Sendungen, also auch Filme, die ,geeignet sind, das körperliche, geistige oder seelische Wohl von Kindern und Jugendlichen zu beeinträchtigen“, sowie „Filme, die für Jugendliche unter 18 Jahren nicht freigegeben sind", nur zwischen 23:00 und 6:00 Uhr verbreitet werden dürfen. Weiter heißt es dort, daß „Filme, die nach dem Gesetz zum Schutz der Jugend in der Öffentlichkeit für Jugendliche unter 16 Jahren nicht freigegeben sind", nur zwischen 22:00 und 6:00 Uhr verbreitet werden dürfen. Die Vorschrift ist entsprechend in die Mediengesetze der Bundesländer eingegangen (vgl. etwa \$ 15 II BremLMG, \& 49 II LMedienG Ba-Wü etc). Auf diese Weise findet so eine gewisse Anpassung an die Zeitverteilung alterspezifischer Sehgewohnheiten statt. Über die Möglichkeiten gesetzlicher Regelungen hinaus, die zurückhaltend bleiben müssen und nicht etwa einfach eine empirisch erarbeitete Tageszeittafel zur Gänze programmregulativ reproduzieren können, wenn ein umfassender Dirigismus vermieden werden soll, bleibt freilich noch immer die medienethische Forderung einer Ausbildung eines entsprechenden Kommunikatorenethos bestehen. 
und nach dem Verhältnis dieser Beschränkungsformen zur gebotenen Offenheit der medialen Kommunkation fragen lassen, sondern auch die wechselseitige Verwiesenheit der grundsätzlich getrennten Kultursachbereiche muß unter der Rücksicht dieser prinzipiell gebotenen Offenheit reflektiert werden. So muß um der Offenheit der medialen Kommunikation willen nicht nur jede Beschränkungsmaßnahme differenziert und vorsichtig eingerichtet werden, sondern auch Überherrschungen des Medienbereichs durch andere Kultursachbereiche gewehrt und die relative Autonomie der Medien (auch diesbezüglich) gewahrt werden. Diese Wahrung ergibt sich dabei nicht ohne weiteres automatisch, sondern zeigt sich als ethisches, normativ zu stellendes Desiderat. Das will ich nun am Beispiel des Films nochmals kurz skizzieren.

Zunächst ist im Filmbereich sowohl der Eingriff des Kultursachbereichs Wirtschaft als auch jener der Kunst besonders deutlich erkennbar. Filmgeschichte hat sich entsprechend nicht nur als ästhetische (künstlerische) Geschichte gezeigt, sondern zugleich als Ökonomiegeschichte (vgl. 1.3.). Genau besehen überschneiden sich im Filmbereich sogar drei Kultursachbereiche, da neben den beiden genannten auch die Technik noch eine konstitutive Rolle spielt (vgl. 1.2.). Doch ist der technische Einfluß selten hinderlich - er hat die Evolution des Films auch in ästhetischer Hinsicht geradezu vorangetrieben. Weniger eindeutig hingegen sind der ökonomische und künstlerische Einfluß zu beurteilen. Zwar zeigt sich zunächst in beiden Fällen ein förderliches Moment. So liefert die Ökonomie durch Kombination und Kooperation mit dem Film diesem die finanzielle Produktionsbasis sowie ein zusätzliches Medium seiner gesellschaftlichen Vermittlung. Erst durch ökonomische Betreuung und Initiative wird der Film herstellbar, und über die ökonomische Kontaktnahme von Produktion und Rezeption erhält er ein zusätzliches, kommunikatives Moment, das unter dem Prinzip der Repräsentativität dem gesellschaftlichen Diskurs dienlich ist. Ebenso vermag die Kunst dem Film zu dienen, indem sie seine Ästhetik sponsort, ihn in den künstlerischen Diskursbereich hineinnimmt und mit dem Kunstfilm gar unmittelbar Kunstwerke schafft. Doch fließen aus der Kooperation auch obstruktive Gefahren. Besonders deutlich ist das zunächst wieder beim ökonomischen Eingriff, der unter dem Profitabilitätsprinzip unpopuläre und dennoch repräsentative (nämlich für Partialgruppen oder -niveaus in der Gesellschaft) Produkte zu beschränken droht. In der Skizze der ökonomischen Bestimmtheit des Films (vgl. 1.3.) und in Auseinandersetzung mit der Kritischen Theorie (vgl. 5.5.) war zu sehen, daß diese Gefahr, obschon sie nicht überzubewerten ist, zweifelsohne existiert. Auch die Kunst aber kann sich hinderlich auf die autonome Produktion von Filmen auswirken, wenn sie etwa, wie es die Kinoreformer wünschten, zur exklusiven Norm für das Filmschaffen gerät. Der mittlere Unterhaltungsbereich fällt dann aus der Filmproduktion heraus, und das Publikum wird nur noch mit der ästhetischen Anspannung der Kunst ,versorgt'. Die strukturelle Offenheit des Filmbereichs, die sich auch in der formalen und inhaltlichen Produktion manifestieren und eine Vielheit von Formen und Inhalten hervorbringen soll, wird durch kunstbezogene Engführung behindert und andersgeartete Bedürfnisse der Rezipientenschaft werden frustriert. Die Überschneidung der Kultursachbereiche kann also die prinzipielle medienethisch gebotene Offenheit des Kommunikationsbereichs Film obstruieren, und die in dieser Offenheit zu leistende repräsentative Erfüllung der Bedürfnisse des Publikums droht dann, unterlaufen zu werden. Aus diesen Gründen ist medienethisch wieder zu fordern, daß die 
relative Autonomie der Kultursachbereiche gewahrt bleibt und dabei auch dem Medienbereich seine eigene Entwicklungslogik zugestanden wird. Hierzu kann strukturell insbesondere eine personelle Trennung dienen, die dann wiederum zur kooperativen Zusammenarbeit, zur Absprache und darin zur Respektierung der sachspezifischen Kompetenzen und der Autonomie des jeweils Anderen nötigt. Für eine solche Trennung erweist sich die Struktur des Filmschaffens, die Produzent/Geldgeber, Regisseur, Drehbuchautor etc. voneinander zumeist unterschieden sein läßt, als recht günstig. Gleichwohl stellt sich die Wahrung der Autonomie des Kultursachbereichs der Medien (und darin des Films) wiederum keineswegs nur als Gegebenheit, sondern auch als Aufgabe dar, die von der Medienethik normativ gestellt wird. Nicht nur die Forderungen eines Ausschlusses von Zensur, der repräsentativen Einrichtung der Produktion und eines entspechenden Kommunikatorenethos, des prinzipiell möglichen Zugangs zu Medien für Erwachsene und einer Ausrichtung des Jugendschutzes auf eine Erziehung zur Mündigkeit also gehören zu den strukturbezogenen Grundlinien einer Medienethik, sondern auch die Freihaltung des Medienbereichs von Überherrschungsversuchen durch andere Kultursachbereiche. Mit dieser Forderung kann nun zugleich der Auszug der strukturbezogenen Grundlinien einer Medienethik und ihres prinzipiellen Gebots der Errichtung einer offenen Kommunikationsstruktur vorerst als abgeschlossen gelten.

\section{Unterhaltungsethischer Baustein: Struktur und Legitimität entlasteten Verhaltens im Kontrast zur Kunstrezeption}

An die Seite der grundsätzlichen ethischen Strukturlinien der Einrichtung des Medienbereichs sind nun jedoch auch genauere Überlegungen zur Frage nach der Funktion medialer Gehalte über ihre informativ-kommunikative Bedeutung hinaus zu stellen. So habe ich im Vorgängigen bereits drei Grundbedürfnisse entwickelt, die von den Medien befriedigt werden sollen und können und die ihnen derart spezifische Aufgaben zuweisen, nämlich das Bedürfnis nach Information/Expression, das nach individueller und gesellschaftlicher Selbstverständigung und das nach Unterhaltung. Dabei habe ich die Unterhaltung vorerst weitgehend ausgeklammert und Grundlinien für eine Medienethik unter vordringlich den beiden ersten Aufgabenstellungen entwickelt. Im Zentrum stand deshalb bislang wiederholt die Diskursivität des Medienbereichs. Eine Ethik der Unterhaltung hingegen geht über eine Ethik diskursiver Information und Selbstverständigung hinaus und soll deshalb im folgenden eigens umrissen werden. Zwar ist in den Überlegungen zur Notwendigkeit eines Rezipientenethos bereits einiges gesagt worden, das auch für eine Ethik der Unterhaltung relevant ist. Doch ist mit der Bestimmung, die Rezipienten mögen ihre Rezeption verantworten können, eine medienethische Forderung angesetzt, die die Legitimität der Unterhaltung schon voraussetzt. Eine Unterhaltungsethik hat im Unterschied hierzu jedoch zunächst auch diese Legitimität erst zu erweisen. Ungeachtet der Notwendigkeit eines Rezipientenethos auch im Unterhaltungsbereich ist daher eine grundsätzliche Reflexion dieses Bereichs durchaus erforderlich. Sie ist es nicht zuletzt auch deshalb, weil zum einen der Film für einen Großteil seiner Produkte diesen Titel in Anspruch nimmt, und zum anderen insbesondere bei den Reformern und der Kritischen Theorie zu sehen war, da $B$ gerade die Unterhaltung zugunsten der Kunst aus dem Kanon legitimer Medienprodukte ausgeschlossen werden soll. Im 
Gegenzug zu solcher Niveauanspannung will ich versuchen, die spezifische Struktur und Funktion des Unterhaltungsphänomens faßbar zu machen, um daraus dessen ethische Legitimität herzuleiten und das jeder konkreten Normierung unterhaltsamer Medienrezeption vorzuordnende ethische Prinzip anzugeben. Hierzu werde ich zunächst den Unterhaltungsbegriff klären und anthropologisch untermauern. Auf der Basis dieser Klärung und Untermauerung kann sodann die Legitimität selbst sogenannter, seichter' Unterhaltung betont werden und wird sich zeigen, daß Unterhaltung als Teil der menschlichen Selbstrealisation begriffen werden muß. Eben daraus ergibt sich ihre gesuchte ethische Legitimität, und die Selbstverwirklichung des Menschen stellt mithin das ethische Prinzip solcher Legitimation dar. Schließlich werde ich noch kurz auf die ethische Bedeutung der Kunstrezeption kontrastiv zu der der Unterhaltung eingehen, ohne allerdings hierbei schon eine Ethik der Kunst entwerfen zu wollen. Diese nämlich würde nicht nur einen eigenen Baustein, sondern ein eigenes Kapitel erfordern.

Der Unterhaltungsbegriff nun scheint mir zunächst, anthropologisch und phänomenologisch richtig verstanden, nicht ein Passivitätsbegriff zu sein, sondern ein aktives Verhalten zu benennen. Unterhaltung stellt sich nicht automatisch her, sondern ergibt sich aus einer spezifischen Form des Tätigseins. So verweist zum einen die Geschichte der unterhaltenden Formen schon darauf, da $B$ Menschen stets spezifische Handlungen vollzogen haben, wenn sie sich unterhalten wollten. Die Kultur des Spiels etwa, das zweifelsohne den umfangreichsten und zentralsten Unterhaltungsbestand der menschlichen Geschichte stellt, ist eine Kultur von bestimmten, meist implizit regelhaften Aktivitätsformen. Das Unterhaltsame wird dem Menschen nicht einfach nur von außen implantiert, sondern fordert ihn zum Handeln und Sichverhalten auf. Um Unterhaltung genießen zu können, muß der Mensch aktiv werden, muß er das Phänomen des Unterhaltsamen sich anverwandeln und den unterhaltenden Bewußtseinszustand erst erzeugen. Dies gilt nun auch für das ,Unterhaltungsangebot ${ }^{*}$ der Medien. Von sich aus ,bewirken' diese nämlich noch keine Unterhaltung. Erst, wo der Mensch sie aktiv in einer noch genauer zu betrachtenden Weise nutzt, wo er mit dem Medium zu interagieren und seine Angebote aufzufassen beginnt, kann das Phänomen des Unterhaltsamen entstehen. Damit aber eignet auch und gerade der Rezeption von Medien - insbesondere von Filmen - ein aktives Moment, das die eigentliche Unterhaltung dann hervorbringen kann. So muß zunächst schon das Dargebotene aufgenommen, dem Bewußtsein appräsentiert und verarbeitet werden. Entgegen der verbreiteten Meinung gibt es besonders beim Film und seiner komplexen pictorial-auditiven Montagestruktur kein ,Berieseln', selbst wenn die erworbene Kompetenz zur Filmrezeption den subjektiven Aufwand gering erscheinen lassen mag. Der Filmrezipient vollzieht selbst im gewohnheitsmäßigen Dauerkonsum durch das Fernsehen noch einen Akt der Wahrnehmung und Verarbeitung, der freilich weitgehend automatisiert ist und deshalb bereits ein entlastetes, jedoch immer noch ein Verhalten vorstellt. Filmvermittelte Unterhaltung bezeichnet deshalb vorerst eine spezifische menschliche Aktivität. Diese Aktivität ist dabei mit Lust verbunden und kann um dieser Lust willen angestrebt und vollzogen werden. Ich werde sie daher im Folgenden mit dem Begriff der delectatio, also des Genusses und des Vergnügen bezeichnen. 
Den Begriff der delectatio entnehme ich dabei den Überlegungen des Thomas von Aquin zu den ,lustschaffenden Tätigkeiten'. Thomas verweist bereits lange vor jeder Rezeptionsästhetik und -psychologie darauf, daß Vergnügen und Lust nur aus einem aktiven Verhalten, nicht aber aus einer passiven Affektation erwachsen. So betont er in STh I-II 31,1 gegen die Vorstellung, daß Lust aus einem ,Erleiden' entstehe, diese sei vielmehr Folge eines Handelns - „delectatio est operatio“ - und bestehe mithin nicht im ,Bewegtwerden - "delectatio non consistit in moveri“ -, sondern in einer Eigenaktivität des Menschen. Thomas gibt damit einen entscheidenden Hinweis auf die Natur der spezifisch delektativen Verhaltensformen und kennzeichnet sie als aktive Erlebnisformen. $\mathrm{Er}$ weiß außerdem bereits bis zu einem gewissen Grad darum, daß die spezifische Lust, die delectatio, dabei nicht unmittelbar an bewußtseinsexterne materiale Gehalte oder Gegenstände an sich gebunden ist, sondern durch deren Auffassung und die dabei vollzogene Bewußtseinsaktivität bzw. durch deren Aneignung und die damit verbundene physische Empfindung entsteht (vgl. STh I-II 32,1). Selbst die physische Empfindung ist ihm hierbei nicht bloße, an einen bestimmten Gegenstand gebundene Affektation, sondern eine mit Bewußtseinsaktivität verbundene Erlebnisform. So betont er etwa in STh I-II 31,5, daß aus den Tätigkeiten sowohl der sinnenhaften (für die physischen Empfindungen zuständigen) als auch der ,übersinnlichen' (für die geistigen Tätigkeiten verantwortlichen) Seele Lust entstehe, nicht bloß aus ihren Gegenständen. In STh I-II 32,1 wiederum weist er darauf hin, daß zur delectatio ein zweifaches gefordert sei, nämlich das Erreichen eines Gutes und das Erkennen des Erreichthabens. Ohne dieses Erkennen bleibt der Genuß unvollständig. Zumindest in der Tendenz steht so bei Thomas die Empfindungsund Bewußtseinsaktivität im Zentrum seiner Bestimmung der Lust, nicht hingegen eine nur gegenstandsbezogene Zuordnung von Gütern und Delektationen. Im delectatio-Begriff des Thomas von Aquin ist daher die populäre Notion, das unterhaltsame Vergnügen sei identisch mit einer passiven, blanken Hinnahme irgendwelcher Rezeptionsangebote, wie auch die Meinung, dieses Vergnügen sei wesenhaft mit bestimmten (meist in Entsprechung zur Passivitätsvorstellung als ,seicht' gedachten) Inhalten - und nur diesen - zusammengeschmiedet, schon im Ansatz zurückgewiesen. Sein Begriff scheint mir daher in besonderer Weise geeignet zu sein, das Unterhaltungsphänomen grundsätzlich zu erfassen. ${ }^{80}$

Wenn nun das Phänomen des Unterhaltsamen in dieser Weise als Delektation angesetzt wird, die aus einer spezifischen Aktivitätsform entspringt, so zeigt sich zugleich, daß die unterhaltsame Aktivität von den beiden unter dem Bedürfnisaspekt eingeführten Aktivitäten der Information und der Selbstverständigung nicht vollständig verschieden, sondern als ein Moment zu verstehen ist, das zu diesen als eine

${ }^{80}$ Dabei bleibt Thomas in der Argumentation freilich noch auf der Ebene einer bewußtseinsphilosophischen Spekulation, der die empirische Untermauerung durch moderne Anthropologie und Psychologie fehlt. Ich werde deshalb zwar den delectatio-Begriff verwenden und einige Überlegungen Thomas‘ aufgreifen, jedoch einen etwas anderen, eigenen Weg gehen, der sich um eine anthropologisch geleitete, transzendental-hermeneutische Klärung des Unterhaltungsphänomens bemüht. Es geht mir also nicht um die Entfaltung der in scholastischer Begrifflichkeit gefaßten delectatio-Lehre bei Thomas, die zudem über 50 verschiedene Delektationsformen mit begrifflichen Überschneidungen beinhaltet, sondern um eine Klärung der bei medialer Unterhaltung auftretenden Grundformen des Vergnügens, deren Denkfigur stärker einer anthropologisch rückgebundenen transzendentalen Hermeneutik verbunden ist. 
spezifische, akzidentelle Erlebnisaktivität hinzutritt. Ein spezifischer Genuß und ein bestimmtes Vergnügen nämlich lassen sich sowohl in der intellektuell-informationellen Tätigkeit als auch in der Selbstverständigung ausmachen. Der Erwerb und Besitz von Wissen, das Erlangen und Haben von Erkenntnissen, sind jeweils mit einer spezifischen Lust, einer Genugtuung und einem emotional positiven Zustand versehen. Freilich können die mit dem Erwerb oft verbundene Anstregung und der meist von außen oktroiierte Erfolgszwang dieses Lusterleben empfindlich stören. Doch bedeutet Wissen gewinnen, Erkenntnisse haben zugleich Bereicherung und erweist sich diese Bereicherung in der Regel bei Freisetzung von externen Zwängen als so lustbesetzt, daß sie es ermöglicht, die nötige Anstrengung überhaupt auf sich zu nehmen. Darauf verweist auch Thomas, wenn er in STh I-II 33,3 davon spricht, daß es eine Lust gebe, die man an der Tätigkeit der Vernunft selbst habe - „est ergo quaedam delectatio quae habetur de ipso actu rationis". Auf der Lust am Wissen beruht nach STh I-II 32,8 auch die Neigung des Menschen, die an sich mühevolle Tätigkeit des Forschens auf sich zu nehmen - in der Tat nämlich werde eine große Sehnsucht im Menschen durch die Erfahrung der Unwissenheit geweckt, die dieser sich dann durch Forschung zu erfüllen suche. Entsprechend habe der Mensch am meisten Lust an dem, was er neu finde oder hinzulerne - ,unde maximo homo delectatur in his quae de novo invenit aut addiscit" (ebd.). Thomas bestimmt so den Menschen ganz gegen die populäre Vorstellung von dessen, naturgegebener Faulheit' - als Wesen der Neugier und WiBbegier und verdeutlicht zugleich wieder die darin liegende Lust als ein Movens oder zumindest Begleitmoment der Wissen schaffenden intellektuellen Tätigkeit. Diese Tätigkeit aber zeigt sich nun als ebenfalls lustbesetzte, mithin als spezifische Delektation. Ähnlich verhält es sich mit dem Akt der Selbstverständigung durch projektive Spiegelung in zunächst bewußtseinsexternen Gehalten. Auf die Filmrezeption bezogen bedeutet eine solche Selbstverständigung die Nutzung fiktionaler Strukturen zur Spiegelung eigener und zur derart ,reflexiven', experimentellen Erprobung des eigenen Selbst, der eigenen Strebungen, Emotionen und ,Anschauungen'. Auch dies ist mit einer spezifischen delectatio konnotiert. Sowohl die informationelle als auch die selbstverständigende Tätigkeit des Menschen kann so also vorerst als eine mit Lust konnotierte Tätigkeit begriffen werden. Begrifflich fassen möchte ich die beiden bislang erarbeiteten Formen der delectatio mit einmal dem Begriff einer delectatio cognitionis ${ }^{81}$ (Lust aus Informationsgewinn und -besitz) und einmal mit dem Begriff der delectatio reflexiva (Lust aus geistig-emotionaler Selbstverständigung und -erprobung).

Nun kann in beiden Fällen - wie oben schon angedeutet - die akzidentelle Erlebnisaktivität des Sich-delektierens zum eigentlichen Gegenstand des Aktivitätsinteresses werden und derart die delectatio ins Zentrum der Tätigkeitsabsicht rük-

${ }^{81}$ Thomas spricht bei dieser Form von einer delectatio spiritualis et intelligibilis, also einer Lust an den geistigen Dingen und dem Intelligiblen. Der Begriff dieser delectatio, den Thomas dem der delectatio corporalis et sensibilis gegenüberstellt, ist dabei sehr weit gefaßt und umgreift neben der Lust, die das kognitive Erkennen, der Erwerb und Besitz von Wissen bei sich führen, auch die Lust an den ,geistlichen Dingen' (vgl. etwa STh Il-1l 52,4;180,7), an der Weisheit (vgl. etwa STh II-II 45,2) und an der Tugend (vgl. etwa STh II-II 123,8,9). Da es mir jedoch hier vordringlich um den kognitiv-rationalen Aspekt, um die Lust an der Verstandestätigkeit und der Kognition geht, spreche ich stattdessen von einer delectatio cognitionis. 
ken. Sie wird dabei vom Inhalt der Tätigkeit und dem mit diesem verbundenen Ziel weitgehend abgelöst und selbst zum Ziel, das lediglich über den Inhalt erreicht werden soll. In der Rezeption filmischer Gehalte geht es dann nicht mehr vordringlich um den Zugewinn von Wissen und Erkenntnissen oder eine identitätswichtige Selbsterfahrung, sondern um die mit den diesbezüglichen Aktivitätsformen verknüpfte Lust. Damit aber wird dem informationellen und selbstverständigenden Verhalten ein sonst mit ihm verbundener ,Ernst' genommen. Es besteht kein Zwang zum Erkenntnisgewinn oder zur Identitätsverständigung, und es ist nicht mehr vordringlich wichtig, ob die Information oder Verständigung gelingt und Erfolg bringt. Der Erfolg wird vielmehr anderswo, in der begleitenden Erlebnisaktivität der Lust und des Vergnügens gesehen und gesucht. Anders gewendet bedeutet das deshalb, $\mathrm{da} B$ der Inhalt der Tätigkeit im Relevanzgefüge eine sekundäre Position erhält und die Form der Tätigkeit als eigentlich Lust schaffende in die primäre Position rückt. Das informationelle und selbstverständigende Verhalten erhält auf diese Weise den Charakter eines entlasteten Verhaltens, wie es mit dem schon erwähnten Begriff des Spiels gefaßt ist. Der Rezipient spielt mit seinem Informationsbedürfnis und seiner Selbstverständigung, und er genießt dabei die damit verbundene delectatio in einer freigesetzten Form. Es ist also die jeweils spezifische Aktivität, die im unterhaltsamen Verhalten genossen wird, während der Inhalt und der damit verknüpfte Erfolg dilatorisch behandelt werden.

Diese Form des Verhaltens nun läßt sich unter Heranziehung einer Überlegung von Arnold Gehlen auch anthropologisch verankern. Daraus wiederum kann die zweite delectatio nochmals in sich spezifiziert und eine weitere delectatio abgeleitet werden, die den Unterhaltungsbegriff vervollständigt. Zunächst aber können die beiden in der skizzierten Weise hergeleiteten delectatio-Formen, von denen ich nun gesagt habe, daß ihr eigentlich lusthaftes Moment in der inhaltlich entlasteten Tätigkeit, im spezifischen aktiven Vollzug selbst liegt, über den Begriff der Funktionslust anthropologisch rückgebunden werden. So betont Gehlen, daß „die vitale Funktionslust (...) alle entlasteten Vollzüge des Menschen begleitet, von der Bewegungsfreude, dem Spiel, den hohen Automatismen gelernten Verhaltens an bis zur ästhetischen und denkenden freien Lebendigkeit ${ }^{\star 82}$. Angewandt auf meine Konstruktion der beiden delectatio-Formen bedeutet dies, da $B$ im Fall des informationellen Rezeptionsverhaltens, des Wissens- und Erkenntnisgewinns die spezifische, in einem entlasteten Vollzug dieses Verhaltens genossene Lust, also die delectatio cognitionis, in der Lust an der reinen Funktion, der Existenz und Nutzbarkeit des eigenen intellektuellen Vermögens ,an sich' zu finden ist. Im anderen Fall der Selbstverständigung wiederum kann die durch projektive, vom ,Ernst' der Identitätsgewinnung freigesetzte Spiegelung erzeugte Lust, die delectatio reflexiva, in der Lust an der Reflexivität, der Reflexionsfähigkeit des menschlichen Bewußtseins überhaupt gesehen werden. Das Funktionieren des Bewußtseins und der geistig-kognitiven Fähigkeiten ist es, das die jeweilige, darin durchaus spezifische und von anderen unterscheidbare delectatio ausmacht. ${ }^{83}$ Dieses Funktionieren ist freilich zugleich ein erworbenes, das

${ }^{82}$ Gehlen, Kategorien, 242-243

83 Aus heutiger Perspektive lassen sich auch einige der Überlegungen Thomas' in Konnex mit der anthropologischen Reflexion auf die Funktionslust bringen. Obschon, wie oben bemerkt, Thomas seiner Zeit entsprechend noch im Rahmen bewußtseinsphilosophischer Spekulation 
im Lauf der Ontogenese erst hergestellt und strukturell ausgeformt werden muß. Wie insbesondere Jean Piaget in seinen empirisch geleiteten Studien herausgearbeitet hat, müssen die geistig-kognitiven Fähigkeiten und die Kompetenzen reflektorischer Detaillierung und Präzisierung von Empfindungen, Eindrücken und Gefühlen - also die jede Bewußtheit und Wahrnehmung erst ermöglichende Kategorisierung potentieller Bewußtseinsinhalte - erst erarbeitet werden. ${ }^{84}$ Diese Erarbeitung und das mit ihrem Gelingen verbundene Erfolgserlebnis rufen eine auto-entelechiale Lust hervor, die in jeder Repetition und Nutzung der erarbeiteten Fähigkeiten reaktiviert werden kann und zu solcher repetitiver Nutzung anreizt. Die Übung und der Gebrauch erworbener Fähigkeiten sind demnach mit Funktionslust verbunden, die wiederum Primärziel von Übung und Gebrauch werden kann. Neben den rein organischen lustvollen Vollzügen eignet damit auch den erworbenen ein Lustaspekt, der als delectatio gefaßt und erstrebt werden kann.

Dabei legt es die anthropologische Fixierung nun nahe, die delectatio reflexiva noch genauer zu fassen und in zwei Formen zu unterscheiden. So hatte ich entsprechend der Herleitung aus den kommunikativen Bedürfnissen des Menschen hier den Aspekt der Selbstverständigung in den Mittelpunkt gestellt und die beiden Momente geistiger und emotionaler Selbstverständigung beieinander gelassen. Der Gedanke der Funktionslust macht nun darauf aufmerksam, daß neben dem Genuß der Reflexivität, der Möglichkeit, sich auf sich zurückzubeziehen, die vordringlich als geistige Potenz gefaßt werden kann, auch ein Genuß der Emotionalität, der Erzeugung und des Erlebens von Gefühlen angenommen werden muß. Nicht um selbstverständigende Erprobung der eigenen Gefühle muß es stets gehen, sondern es kann auch deren bloßes Vorhandensein lustvoll erlebt werden. Ich will deshalb der delectatio reflexiva nun noch eine delectatio emotionalis zur Seite stellen, in der die Funktion des emotionalen Apparats des Menschen Gegenstand des Genusses ist. Auch dies ist eine Delektationsform, die in der Filmrezeption ausgeübt werden kann, ja sie findet neben der emotionalen Selbstverständigung dort geradezu ein abundantes Angebotsfeld. Eben der fiktionale Film, der zu weiten Teilen auf ,Unterhaltung' abhebt, liefert mit seinen verschiedenen Genres von der aggressiv-angsthaften Spannung über die melodramatische Rührung bis zur Heiterkeit eine beinahe unausschöpfliche Palette an möglichen Gefühlsevokationen. Der GefühlsgenuB, die delectatio emotionalis, scheint mir deshalb eine vordringliche Rezeptionsmotivation und eine zentrale Form der Unterhaltung darzustellen.

Schließlich läßt sich aus Gehlens Überlegung auch noch eine vierte und (in Bezug auf die Unterhaltung) letzte delectatio herleiten, die auf die Lust am Funktionieren

agiert, scheint er mir doch eine den empirischen Ableitungen Gehlens entsprechende Intuition gehabt zu haben. So prägt er etwa den Begriff einer, delectatio animalis' (vgl. etwa: STh II-II, 168), zu denen sportliche und spielerische Aktivitäten sich rechnen. Damit setzt er eine Art Oberbegriff für diese stark organisch rückbezogenen Tätigkeitsformen an, der im Kerngehalt der Funktionslust nahe ist. In diesem Sinn faßt daher auch Schöllgen die delectatio animalis auf: Schöllgen, Werner, Soziologie und Ethik der Unterhaltung, in: ders., Aktuelle Moralprobleme, Düsseldorf 1955, 67-92, 86

${ }^{84}$ Vgl. zur Ontogenese der kognitiven Fähigkeiten etwa: Piaget, Jean, Biologie und Erkenntnis. Über die Beziehungen zwischen organischen Regulationen und kognitiven Prozessen, Frankfurt 1974; Piaget, Jean, Die Entwicklung des Erkennens I-III, Stuttgart 1975 (= Gesammelte Werke 8-10) 
der Sinnesorgane abhebt. Hier haben die bloße ,Schaulust', das ,ziellose Umherblikken', die Freude an Geräuschen, das nur am Spüren interessierte Tasten und das ,Schnuppern' ihren anthropologischen Ort. Diese letzte Form von unterhaltendem Genuß will ich daher als delectatio sensibilis bezeichnen. Von dieser Lustform spricht - unter demselben Begriff - auch Thomas, wenn er in STh I-II 31,4 mit Aristoteles darauf abhebt, daß es jedem Sinn entsprechend eine Lust gebe - „secundum omnem sensum est delectatio“. Diesen Delektationen schreibt er dabei den größten quantitativen Umkreis zu; ihnen nämlich folgten die ,Meisten', da die Sinnengüter besser und allgemeiner bekannt seien - "quia bona sensibilia sunt magis et pluribus nota" (STh I-II 31,5). Aus entwicklungspsychologischer Sicht läßt sich diese, allgemeine Bekanntheit heute ontogenetisch begründen: Die delectatio sensibilis nämlich benennt gleichzeitig den entwicklungspsychologisch betrachtet frühesten Formkreis der lustvollen Erlebnisaktivitäten, den sich jedes Menschenwesen erst erarbeiten und erschließen muß. In der Tat stellen ja die Entwicklung und Übung der Wahrnehmung und des Gebrauchs der sinnlichen Fähigkeiten sehr frühe Weisen der Selbstrealisation des Menschen dar, wenn schon im Kleinkindalter etwa Tastsinn und Greifmöglichkeiten oder Sehen und erkennendes Wahrnehmen allmählich von einer Potenz zur differenzierten Instrumentalität fortgebildet werden (müssen). Eben deshalb sind die Möglichkeiten des sensitiven Formkreises auch ,besser bekannt', während die spezifisch geistigen Möglichkeiten erst aufruhend auf den sensitiv-motorischen ausgebildet werden. Die Erarbeitung und Differenzierung der letztgenannten aber ist wieder empirisch nachweisbar mit höchsten Lusterlebnissen verbunden, die die spezifische Anstrengung ermöglichen und auch im späteren Lebensalter jederzeit reaktiviert werden können. Mit der delectatio sensibilis rekurriert der Mensch so sowohl auf seine ureigensten Möglichkeiten als auch auf seine frühesten Lustformen. Auch diese können dabei durch Medienrezeption aktiviert werden. In der Filmrezeption finden dabei besonders Auge und Ohr ihr lustvolles Feld, auf dem sie sich ihr Funktionieren differenziert bestätigen können.

Die vier Delektationsformen zeigen so nun insgesamt, $\mathrm{da} B$ Unterhaltung als eine Tätigkeit und ein Verhalten des Menschen verstanden werden kann, in denen dieser spezifische Formen von Lust aufsucht, die mit seiner anthropologischen Konstitution verbunden sind. Dabei bleibt der Vorgang lustvoller Unterhaltung noch immer ein aktiver Vorgang: Das kognitive Vermögen des Menschen muß betätigt werden, wenn seine Funktion genossen werden soll; die Reflexivität des Bewußtseins muß appräsentativ tätig werden, um den Genuß des Selbstbezugs zu ermöglichen; die Gefühle müssen ausgelöst und ins Bewußtsein gehoben werden, um sie erleben zu können; und die Sinneseindrücke müssen geistig verarbeitet werden können, um das Funktionieren der Organe ,genießbar' zu machen. Die Rezeption zeigt sich gerade, weil sie spezifische Funktionslüste erlebbar macht, als ein aktivitätsbezogener Vorgang, der Aktivität erfordert und auslöst. In all diesen lustvollen Vollzügen aber äußert sich damit die Lebendigkeit des Menschen, mit der er seine konstitutionell gegebenen und ontogenetisch ausgebildeten Möglichkeiten spielerisch übt, schärft, geschmeidig hält und realisiert. Der Begriff der Funktionslust läßt derart die vier Delektationen als spezifische, nämlich entlastete Weisen der Selbstverwirklichung des Menschen deutlich werden, und Unterhaltung zeigt sich als delectatio zugleich als menschliche Selbstrealisation. Aus dieser Perspektive kann zunächst der Unterhal- 
tung grundsätzlich Legitimität zugesprochen werden. Die Selbstverwirklichung, die Entfaltung der menschlichen Person in all ihren Kräften und Möglichkeiten nämlich muß ethisch als eines der zentralen Ziele jeder menschlichen Anstrengung angesetzt werden. Sie erhält dabei zugleich den Status eines metaethischen Prinzips, einer ,Metanorm' für die Versuche der Normierung dieser Anstrengungen, d.h. auch der normativen Verortung der Unterhaltung. Die letztgenannte erscheint nun als spezifische Weise der Selbstentfaltung menschlicher Kräfte und Möglichkeiten, und findet darin ihre prinzipielle Legitimität. Weiter aber kann jetzt selbst der ,seichten“ Unterhaltung eine gewisse Legitimität attestiert werden. Hierzu tut freilich eine weitere Differenzierung not. So läßt sich aus dem Vorgängigen zunächst ein Begriff, gehobener' Unterhaltung ableiten: Diese wäre in jenen Formen zu suchen, die neben der delectatio emotionalis und sensibilis auch noch die delectatio reflexiva und cognitionis ansprechen. Sie dienen hierdurch zugleich der Übung und Verwirklichung der mit den letztgenannten Delektationen verbundenen Fähigkeiten und stellen derart einen höheren, umfassenderen Anspruch an die sich unterhaltend betätigende menschliche Person. Gleichwohl scheint es mir auch legitim zu sein, zuweilen, oder möglicherweise vordringlich, nur der delectatio emotionalis und sensibilis anzuhängen. Reflexivität und Kognition bedeuten selbst in ihrer entlasteten Form noch eine spezifische Anstrengung. Hiervon mag man sich zuzeiten durch Beschränkung auf die anderen beiden delectationes erholen, die im übrigen ebenfalls zum Reichtum der Selbstentfaltung beitragen und ohne deren Beitrag diese Entfaltung durchaus einseitig und unvollständig bliebe. - Die Legitimität dieser zeitweiligen Rekurrenz ausschließlich auf diese Delektationen findet sich in ähnlicher Weise auch bereits bei Thomas insistiert. Dieser nennt neben den ,geistigen“ auch ,leiblich-sinnenhafte‘ Lüste - also neben delectationes spirituales et intelligibiles auch delectationes corporales et sensibiles - deren Recht er gegen alle Rigoristen ernsthaft verteidigt. So weist Thomas die Verwerfung aller leiblichen Delektationen als moralisch negativen Erscheinungsformen harsch zurück - diese Ansicht sei unrichtig, da niemand leben könne ohne jede sinnenhafte und leibliche Lust („Cum enim nullus possit vivere sine aliqua sensibili et corporali delectatione“, vgl. STh I-II 34,1). Im Blick steht ihm dabei neben einer rekreativen auch eine heilsame Funktion dieser ,körperlich-sinnlichen' Delektationen: Sie nämlich dienten als Heilmittel gegen vielfache Schmerzen und Betrübnisse und seien dem Menschen hierfür geradezu nötig (vgl. STh I-II 31,5). Mit seiner Verteidigung gegen die rigoristische Verwerfung jeden sinnlich-leibhaften Genusses ordnet Thomas dabei diese Delektationen in den Kontext eines ganzheitlichen Lebensvollzugs zumindest der Tendenz nach ein. Seine Argumentation berührt sich zudem im Punkt der delectatio sensibilis mit der von mir vorgenommen Differenzierung und läßt sich auch auf die delectatio emotionalis übertragen: Der zeitweilige Rekurs auf nicht nur die delectatio sensibilis, sondern auch auf die delectatio emotionalis dient durchaus der Heilung der ,vielfachen Schmerzen und Betrübnisse، bzw. der Linderung der Beanspruchung durch Widrigkeiten und Fährnisse des Lebens und erhält auch daraus seine Legitimität.

Damit aber kann nun gegen die Anspannungsnormativität der Reformer, Filmerzieher und selbst der Kritischen Theorie gesagt werden, daß eine exklusive Verzweckung des Films an Kunst und Bildung die anthropologische Bedeutung seiner Unterhaltungsfunktion verfehlt und daher einseitig bleibt. Sie bekommt die mensch- 
liche Ganzheit nicht in Blick, sondern verharrt in einer kognitiv-intellektuellen und ästhetischen Engführung, für welche entweder rationale Wissenbildung oder revolutionäre Reaktivierung des zivilisatorisch Verdrängten die einzige Zielnorm legitimer unterhaltender Tätigkeit abgibt. Damit sind die legitimen Unterhaltungsformen regionalisiert und ist außerdem der Aspekt des Delektierens beide Male marginalisiert und verzweckt. So wird einmal die Unterhaltung auf Bildung des Intellekts eingeschränkt und die delectatio allenfalls als motivationales Vehikel hierfür zugelassen. Im anderen Fall stehen nur bestimmte, nämlich ,aufrührerische` Lüste im Blick, die wiederum erst durch ihre ,systemsprengende', anti-affirmative Valenz Legitimität erhalten. Eine über Unterhaltung vermittelte Selbstverwirklichung geschieht demnach nur in bestimmten Bereichen des Menschseins und dort wiederum letztlich ,lustextern' unter funktionaler Umleitung bzw. Nutzung von Lüsten. Genau besehen kann auf diese Weise Unterhaltung als Delektationsform mit Selbstverwirklichung eigentlich gar nicht recht zusammengedacht werden, sondern muß sie im jeweiligen Reflexionssystem einen prekären Stellenwert widerwilliger Duldung erhalten. Im Gegenzug hierzu zeigt die vorgängige anthropologisch fundierte Überlegung zu einer Ethik der Unterhaltung, da $B$ es zur Ganzheit des Menschen gehört, seine Lebendigkeit in allen Bereichen seiner Existenz zu entfalten, und daß hierbei ein zweckfreies Lusterleben eine legitime und wichtige Rolle spielt. Die Betätigung aller menschlichen Kräfte und die darin lustvoll erlebte eigene Lebendigkeit erteilen der Unterhaltung ihre spezifische Bedeutung in der Selbstrealisation der menschlichen Person und verleihen ihr hierdurch auch ethische Legitimität.

Gleichwohl will der vorstehende Versuch einer primär legitimativen Unterhaltungsethik keineswegs die Legitimität und Gebotenheit von Kunstprodukten ausschließen, die auf ein ,Höheres' zielen und deren Rezeption ethisch wünschenswert ist. Auch in der anspannungsnormativen Motivation der Reformer und der Kritischen Theorie nämlich steckt ein legitimes und stützenswertes Anliegen, das sich durch den Film sehr wohl erfüllen läßt und das zudem über die bislang vorgenommene, alle Medien betreffende Bedürfnisdifferenzierung hinaus eine weitere Dimension menschlicher Bedürfnisse deutlich macht, die sich von jenen Medien vermitteln läßt, welche ,Kunstvalenz' besitzen. So geht es den Reformern - kaum anders als der Kritischen Theorie - neben der genannten Bildungsorientierung - bzw. der revolutionären Dynamik - in der Insistenz auf der Rolle der Kunst und in ihrem Versuch, den Film dieser Rolle und Funktion dienstbar zu machen, letztlich auch um eine spezifische Dimension menschlichen Seins, nämlich die des ,Nichtbegrifflichen', ,Nichtdiskursiven', oder in Adornos Sprache: des ,Nichtidentischen'. Gerade die Kunst vermittelt - über ihre zweifelsohne ebenfalls vorhandene gesellschaftlich-diskursive Bedeutung hinaus - dem Menschen ja auch ein Erlebnis, das ihn in den Gründen seiner Existenz zu berühren vermag, noch-nicht-Gedachtes in den Blick bringt und den herkömmlichen Lebenszusammenhang innovativ ,unterbricht'. Sie vermag derart jene existenzielle Dimension im Menschen anzusprechen, die in Konnotation zu seiner Transzendenzverwiesenheit steht, und kann - ähnlich dem Glauben - eine evolutiv-umstürzende, auf eine Neuwertung und neue Sicht des Gegebenen zielende Dynamik evozieren. Nicht umsonst scheint große Kunst oft den Appell ästhetisch zu vermitteln, da $B$ das bisherige Leben zu ändern sei und ganz andere, noch ungedachte Möglichkeiten menschlichen Seinkönnens in den Blick genommen werden müssen. 
Nicht zuletzt deshalb verwischt auch bei Künstlern wie etwa Joseph Beuys oder Franz-Erhard Walter die Grenze zwischen Kunst und Transzendenzbezug und haben Kunsthistoriker sich in neuerer Zeit wiederholt den Bezügen zwischen Kunst und Mystik zu nähern gesucht. Selbst die Tabubrüche der Mysterienspiele Nitschs sind in diesem Zusammenhang zu sehen.

Mit ihrer ,Unterbrechung' des Bestehenden und der Provokation des bislang Ungedachten aber kann Kunst derart auch das ethisch ,Höhere' in den Blick bringen, ja zu dessen Findung mit beitragen. Sie vermag so gerade dort, wo sie die ,Schau' eines anderen, größeren Seinkönnens evoziert, sittliche Kreativität hervorzurufen und zu stimulieren. Darüber hinaus kann sie - vorwiegend im narrativen Bereich - auch jenem ethisch ,Höheren' zur Anschauung zu verhelfen, das bereits existiert, ohne jedoch generell normativ vorschreibbar zu sein. Sie kann sittliche Überstiegsleistungen motivieren und derart ein ethisches, Surplus evozieren, wie es nur von Einzelnen als Hochethos hervorgebracht worden ist und nicht jedermann verordnet werden kann. Kunst vermag so auch bereits vorhandenen, jedoch vom „Stigma der Freiheit ${ }^{\text {“85 }}$ gezeichneten Haltungen, Tugenden und ,Werten' zur Erfahrung zu verhelfen und ein diesbezügliches existenzielles Erlebnis zu vermitteln, in dem die je spezifische sittliche Grundbedeutung des eigenen Lebens aufgeht und dessen besonderer Sinn anschaulich wird. An die Seite der ,unterbrechenden' tritt so auch eine ,affirmative، Dynamik, und Kunst vermag sowohl durch ,Kontrasterlebnisse‘ als auch durch ,Vorbilder' den sittlichen Überstieg zu motivieren. Auch der Film nun kann, wo er Kunst wird, diese Wirkungen haben, und seine diesbezügliche Funktion ist sowohl zu fördern, als auch zu fordern. In bezug auf den Film und andere Medien, die selbst Kunstformen hervorbringen können, läßt sich deshalb die Spezifizierung der medial erfüllbaren menschlichen Bedürfnisse um ein ,Kunstbedürfnis‘ oder ein spirituelles Bedürfnis im weiteren Sinn ergänzen, dem dann aus dem vorgängig Erarbeiteten eine weitere Delektationsform, nämlich eine delectatio spiritualis ${ }^{86}$ zur Seite zu stellen ist. Auch das Erleben des ,Höheren“, die Herausforderung zu Überstiegen ist ja nicht ohne Lust. So spricht wiederum Thomas davon, daß jedes ,Ruhen des Willens und jeden Strebens im Guten' - und das meint: auch im sittlich Guten und in der Tugend - Lust sei: „Quies autem voluntatis, et cuiuslibet appetitus, in bono, est delectatio“ (STh I-II 34,4). Ebenso kann die Verbindung des Willens und Strebens mit einem überragenden Guten als delectatio gedacht werden. Freilich ist diese delectatio nicht mehr als Unterhaltungsform zu begreifen und ist sie auch nicht über die Funktionslust anthropologisch zu fundieren. Sie suspendiert zudem nicht, wie die unterhaltungsethischen Überlegungen gezeigt haben, die Funktion und Legitimität ,rein' unterhaltender Gehalte und Produkte. Unterhaltung und Kunst können und

${ }^{85}$ Korff, Moraltheologie, 69

${ }^{86}$ Der Begriff wird, wie oben zu sehen war, auch von Thomas verwendet. Thomas läßt dabei das Moment der kognitiv-rationalen mit der spezifisch ,spirituellen' Geistigkeit beieinander. So ordnet er etwa die Lust, die ein erkennendes Beschauen des Göttlichen bei sich führt, also die Lust an der Kontemplation, ebenso der delectatio spiritualis zu (vgl. STh II-II 180,7), wie die Lust am Vollzug kognitiv-rationaler Akte, in denen die eigene Verstandestätigkeit genossen wird. Im Unterschied hierzu hebe ich im vorliegenden Kontext mit der delectatio spiritualis vordringlich auf die nicht-kognitiven Momente ab und benenne, wie zu sehen war, daher die Delektation an rationaler Kognition mit einem eigenen Begriff, der delectatio cognitionis. 
dürfen nicht gegeneinander ausgespielt werden, sondern haben beide ihre je spezifische ethische Bedeutung, Funktion und Dignität.

\section{Inhaltsethischer Baustein: Material-ethische Grundlinien zu Legitimität und Grenzen medialer Inhaltsformen}

Nachdem nun prinzipielle strukturethische Grundlinien für den Medienbereich ausgezogen und die Struktur und ethische Legitimität der Unterhaltung verdeutlicht sowie ein Blick auf die Kunstbedeutung des Films in ethischer Hinsicht geworfen ist, kann nun (nochmals) gefragt werden, ob und inwieweit sich aus dem vorgängigen Entwurf Kriterien einer Inhaltsethik gewinnen lassen. So war im strukturethischen Baustein bereits erkennbar, daB gerade auch die Forderung einer offenen Kommunikationsstruktur, die freien Zugang zu Produktion und Rezeption sowie den Ausschluß der (Vor-)Zensur verlangt, eine Reflexion auf mit dieser Struktur und ihren Prinzipien verträgliche Inhalte erfordert. Der Ansatz bei den Grundideen des Projekts der Moderne und der Entwurf eines vom Personbegriff ausgehenden ethischen Basisparadigmas erlauben durchaus nicht einen ,Wildwuchs der Kommunikation', sondern fordern mindestens die inhaltliche Treue zu diesen Ideen und Prinzipien ein. Dabei ist im strukturethischen Baustein sogar schon sichtbar geworden, daß diese Treue sich weiter detaillieren läßt und über die Grundvorschrift der Wahrung der Personwürde hinausreicht. Diese Detaillierung will ich nun im folgenden genauer ausziehen und fortführen. Hierbei werde ich zugleich nochmals einen Blick auf die im Verlauf des modernitätskritischen medienethischen Diskurses zum Film in diesem Jahrhundert vorgebrachten Vorwürfe werfen, jedoch jetzt, um das darin aufgehobene Anliegen einer ethischen Reflexion legitimer und illegitimer Inhaltsformen aus einer modernitätsgerechten Perspektive zu behandeln. Zweifelsohne nämlich kommt eine Medienethik für den Film ohne eine inhaltsethische Kriteriologie nicht völlig aus. Sie muß zumindest begründen können, wie weit eine freigesetzte Gehalteproduktion legitim ist, und sie muß sagen können, an welchen Stellen welche ethischen Kriterien zu wahren sind bzw. unzulässig verletzt werden. Hieraus erst vermag dann auch das wiederholt im Verlauf der Geschichte des medienethischen Diskurses geäußerte Desiderat einer gesellschaftlichen Kommunikationskontrolle richtig positioniert zu werden und kann Verzeichnungen dieses Desiderats konkret entgegengetreten werden.

Die Entwicklung inhaltsethischer Kriterien bedarf jedoch einer methodologischen Vorreflexion. Die Auffindung von Grenzlinien der medialen Gehalteproduktion hat zunächst einen Begriff von ,Inhalt' zu gewinnen. Hierbei nun ist vor allem eine grundsätzliche Differenzierung erforderlich, die über die Verwechslung von Inhaltsteilen mit dem Gesamtgehalt eines Medienprodukts hinausgelangt. $\mathrm{Zu}$ unterscheiden nämlich ist zwischen den einzelnen Szenen sowie Handlungssträngen etwa eines Films und der Aussage des Films insgesamt. In der ethischen Reflexion und Bewertung von Filminhalten kann es dabei nun einzig und allein um die Aussage eines Films gehen, wenn Mißverständnisse und Engführungen vermieden werden sollen. So kann durchaus z.B. eine der handelnden Figuren eines Films ein ethisch völlig intolerables Verhalten vor Augen stellen, ohne daß daher schon die gesamte Aussage des Films als ethisch untragbar zu bewerten wäre. Dies hängt vielmehr von der filmimmanenten Einordnung und Bewertung des genannten Verhaltens ab. Eine in- 
haltsethische Illegitimisierung von Inhaltsteilen hingegen würde die immanente Bewertung und damit die Aussage übergehen. Sie würde so aber auch etwa die problematisierende Behandlung ethisch prekärer Verhältnisse verunmöglichen. Das wiederum bedeutete nicht nur eine weitgehende Knebelung der thematischen Möglichkeiten des Mediums Film, sondern auch eine weitgehende Behinderung seiner sozial-kommunikativen Funktion. Diese aber muß unter Voraussetzung der im strukturethischen Baustein entworfenen gebotenen Kommunikationsstruktur unter allen Umständen erhalten bleiben. Wenn inhaltsethisch nach legitimen und illegitimen Mediengehalten gefragt wird, sind daher mit diesen Gehalten die Gesamtaussage und die Gesamttendenz eines Medienprodukts gemeint. Erst diese können einer inhaltsethischen Beurteilung unterworfen werden. Diese Überlegung schließt dabei ein, daß auch die Differenz von Fiktionalität und Realität zu berücksichtigen ist. Fiktionale Handlungszusammenhänge können und dürfen nicht unter den ethischen Gesichtspunkten realer Handlungszusammenhänge normiert werden, sondern sind ebenfalls in ihrer Gesamtheit als eine Aussage zu werten, die dann erst einer ethischen Kriteriologie unterstellt werden kann. Vor jedem inhaltsethischen Entwurf ist so eine Differenzierung von fiktionaler Inhaltsebene und realer Aussageebene zu vollziehen. Dies zu betonen ist vor allem deshalb nötig, da etwa die kinoreformerische Position (die mir in einigen zeitgenössischen normativen Bestrebungen zur Filmbeurteilung noch am Werk zu sein scheint) darauf abzielte, eine ethisch gerechtfertigte Aussage nur dort anzunehmen, wo ein ethisch zu rechtfertigendes Verhalten fiktional vor Augen gestellt wurde. In ähnlicher Weise verfuhren auch diverse Codes, die zum Zweck der ,moralischen Hebung des Films versuchten, ethisch legitime Aussagen zu fixieren, indem sie nur ein realweltlich als legitim akzeptiertes Verhalten fiktional zuließen. Die kritische Darstellung ethisch prekärer Verhältnisse (wie etwa der Drogenkriminalität, deren bloße Darstellung in den amerikanischen FilmCodes wie im Comics-Code als zu gefährlich beurteilt wurde) schied damit in der Tat von vorneherein aus dem Repertoire fiktionaler Narrativität aus. Eine Differenzierung von Aussageebene und Fiktionsebene hingegen erlaubt hier sachadäquatere Dispositionen und muß von jeder inhaltsethischen Reflexion vollzogen werden. Erst die Gesamtaussage kann inhaltsethisch gewertet werden. Der Verweis auf die Aussage eines Medienprodukts deutet dabei schließlich noch darauf, daß die inhaltsethische Konstruktion auf dem Hintergrund der Annahme eines reflexionsfähigen Publikums, das in der Lage ist, eine Aussage auch als solche zu erkennen, vorgenommmen wird. Damit unterscheidet sich der vorliegende Ansatz der inhaltsethischen Kriteriologie insbesondere von demjenigen Selgs, der dem Publikum offenbar die Fähigkeit der Differenzierung zwischen Fiktionalität und Realität sowie die bewußte Verarbeitung einer Aussage kaum zutraut und stattdessen unterstellt, daß die Rezipienten das fiktional Appräsentierte unmittelbar zum Rollenmuster eigenen Realverhaltens machen. Im Gegensatz hierzu nehme ich eine Verarbeitungskompetenz und stellungnehmende Fähigkeit des Publikums im Umgang mit Medienprodukten an, die dieses zumindest in die Lage versetzt, Gesamtaussagen von Teilinhalten zu unterscheiden und sich möglicherweise auch von der Gesamtaussage nochmals zu distanzieren.

Der Weg zu einer in dieser Weise zu entwerfenden inhaltsethischen Kriteriologie nun steht zunächst selbst unter einer medienethischen ,Metanorm', die sich aus dem 
strukturethischen Ansatz beim Subjektgedanken und der mit diesem verbundenen Demokratisierung im Bereich der Gesellschaftsorganisation ergibt. So war im strukturethischen Baustein zu sehen, daB die den Subjekten aufgrund ihrer vernunftgeleiteten Autonomie zugepaßte Gesellschaftseinrichtung die Demokratie ist, die wiederum auf eine offene Kommunkationsstruktur angewiesen ist. Die prinzipielle Gebotenheit einer offenen Kommunikation hat dabei sowohl das Verbot der (Vor-) Zensur, als auch eines Social engineering aus sich hervorgetrieben. Beide Handlungsformen nämlich würden die von der Offenheit der gesellschaftlichen, medial vermittelten Kommunikation zu leistende, autonome Konstitution der Themen und Inhalte dieser Kommunikation sowie die interaktive Dynamik von Bedürfnisproduktion und -erfüllung im Medienbereich zerstören. Nicht mehr das Publikum, die medial versammelten Gesellschaftsmitglieder, würden den medialen ProzeB inhaltlich bestimmen und vorantreiben, sondern zentrale Stellen würden diesem Prozeß ein inhaltliches ,Gesicht' aufzuprägen suchen. Diese Prägung aber erschien unter Voraussetzung der Ideen des Projekts der Moderne, der ethischen Axiomatik, die die Autonomisierung, Subjektivierung und Demokratisierung in ihren Mittelpunkt rückt, schlichtweg als illegitim. Das bedeutet nun freilich für die Inhaltsethik, daß auch diese nicht in Form eines Katalogs ethisch gebotener oder wünschenswerter Einzelinhalte erstellt werden kann. Um der Offenheit der medialen, von Produzenten und Rezipienten prozessual konstituierten Kommunikation willen darf im Bereich der Inhaltsethik die Frage nach den herzustellenden und zu verbreitenden Inhalten nicht konkret und bis ins Detail vorausentschieden werden. Hier bleiben lediglich - wie im strukturethischen Baustein zu sehen war - eine repräsentative Vielfalt der Inhalte und eine Komplementarität zu den Wünschen und Bedürfnissen des Publikums zu fordern. Eine konkretisierende Inhaltsethik hingegen muß unter Voraussetzung einer offenen Kommunikationsstruktur exklusiv, also ausschließend, verfahren. Ihre Aufgabe ist es entsprechend primär, ethische Grenzlinien zu ziehen, ein Feld abzustecken, innerhalb dessen sich der ProzeB der Gehalteproduktion dynamisch und kreativ vollziehen kann. Die Markierungen einer modernitätsgerechten Inhaltsethik sind daher hauptsächlich negativer Natur. Sie stellen Rahmenkriterien dar, die von der inhaltlichen Medienproduktion gewahrt werden müssen - oder besser: nicht verletzt werden dürfen -, und können mithin vordringlich besagen und begründen, was nicht geht, nur sehr bedingt und allgemein aber, welche Inhalte medial appräsentiert werden sollen.

Unter dieser Voraussetzung nun kann zunächst als generelle und übergreifende inhaltsethische Norm fixiert werden, daß keine gehalteproduktiv vollzogene Aussage in Medien gegen die obersten Prinzipien der Ethik, gegen das Rahmenethos und die vitalen, rechtlich gesicherten Lebensstrukturen der Gesellschaft sich wenden oder gar in zerstörerischer Absicht vorgehen darf. Diese allgemeine Vorschrift gilt dabei nicht einfach nur axiomatisch, sondern ist auch ein Gebot jeder ethischen Vernünftigkeit, die in sich konsistent bleiben will. Schon im strukturethischen Baustein hat sich angedeutet, da $B$ ein Vorgehen gegen die obersten Prinzipien, die ethische Axiomatik der Moderne, zugleich eine perverse Inanspruchnahme dieser Axiomatik bedeuten und sich so in einen ethisch-logischen Widerspruch begeben würde. Mit diesem Widerspruch würde sie jedoch auch ihre eigene Vernunft aufkündigen. So war zu sehen, daß sich aus den Grundprinzipien der Moderne, d.h. aus dem Subjekt- 
gedanken, der vernunftbegründeten Autonomie des Menschen und der diesen ,Prinzipienideen' zugepaßten demokratischen Gesellschaftsorganisation auch erst die Mitspracherechte der Gesellschaftsmitglieder und die offene Kommunikationsstruktur der Gesellschaft herleiten. Darüber hinaus begründen diese ,Ideen', wie sich im Grundlegungsteil gezeigt hat, auch das Rahmenethos der Gesellschaft und seine Fixierung in der Verfassung. Ein öffentlich in den Medien geführter Angriff auf die ethische Axiomatik der Moderne und das Rahmenethos würde damit nun gerade die Grundprinzipien, die damit angegriffen sind, wieder selbst beanspruchen. Erst sie sind es ja, die den Freiheitsraum eröffnen und begründet bereitstellen, in dem sich ein solcher Angriff realisieren kann. Unter diesen Bedingungen jedoch verwickelt sich jede Agitation gegen den Subjektstatus des Menschen, gegen seine Autonomie und Freiheit und gegen die strukturelle Einlösung dieser Freiheit in der Demokratie zumindest dort in einen unauflösbaren Widerspruch, wo sie sich selbst ethisch begründet sehen will. Wer gegen den Subjektstatus und die menschliche Selbstbestimmung kämpft nämlich, begreift sich implizit selbst als Subjekt, das zu solchem selbstbestimmtem Vorgehen erst fähig ist. Und wer öffentlich gegen die Mitsprache- und Mitwirkungsrechte der Demokratie zu Felde zieht, nimmt diese Rechte unwillkürlich in Anspruch. Aus der ethischen Axiomatik der Moderne, wie ich sie im Grundlegungsteil erarbeitet habe, ergibt sich mithin notwendig, da $B$ diese Axiomatik nur auf der Basis eines Selbstwiderspruchs angegriffen werden kann und dieser Angriff eine Perversion im wörtlichen Sinn darstellt. Dies gilt nun auch insbesondere für einen medial geführten Angriff und treibt die genannte Vorschrift aus sich hervor, da $B$ die Grundprinzipien der Ethik, die ethische Axiomatik der Moderne sowie das mit ihnen begründete Rahmenethos und die sich wiederum daraus herleitenden, die vitale gesellschaftliche Lebensstruktur fixierenden Rechtsgüter grundsätzlich zu schützen und zu wahren sind. Diese Vorschrift kann daher als die oberste inhaltsethische Maxime der Medienethik gelten. ${ }^{87}$

Von dieser Maxime her läßt sich die Inhaltsethik nun genauer detaillieren. So können zunächst nochmals die ethischen Grundprinzipien und die aus ihnen sich herleitenden grundlegenden Rechte aufgeführt werden, um daraus dann erste Schranken für die mediale Gehalteproduktion zu gewinnen. Im Zentrum der Inhaltsethik also stehen unter Ansatz beim Projekt der Moderne näherhin drei Prinzipien, aus denen spezifische Ansprüche und Rechte hervorgehen und die zusammen mit diesen Ansprüchen und Rechten in jedem Fall zu wahren sind: Es handelt sich hierbei einmal um das ethische Grundprinzip der Moderne schlechthin, das Personprinzip, das mit dem Subjektgedanken koinzidiert und den Anspruch auf Wahrung der Personwürde impliziert. Zum zweiten ist das Autonomieprinzip zu nennen, das mit dem Personprinzip verknüpft ist und Recht und Anspruch auf freie Persönlichkeitsentfaltung, auf einen selbstbestimmten existenziellen Entwurf und eine selbstbe-

${ }^{87}$ Dieser Maxime folgt auch die Verfassung der Bundesrepublik Deutschland, wenn sie in Art. 18 GG bestimmt, daß jeder, der ,die Freiheit der Meinungsäußerung, insbesondere die Pressefreiheit (...), zum Kampf gegen die freiheitlich-demokratische Grundordnung mißbraucht", dieses freiheitliche Grundrecht verwirkt. Der zitierte Artikel ist damit auch medienbezogen „Ausdruck der ,streitbaren Demokratie‘, die auf Selbstverteidigung angelegt ist“" (Jarass/ Pieroth, GG, Art. 18 Rdn. 1), und mithin ihre Selbstwahrung und ihren Selbstschutz durch entsprechende Vorschriften der Verfassung und der Gesetzgebung im einzelnen organisiert. 
stimmte Lebensgestaltung bei sich führt. Zum dritten geht es um das Demokratieprinzip, das den als autonome Subjekte aufzufassenden Personen eine entsprechende freiheitliche Gesellschaftsform bereitzustellen sucht, in der diese sich als Gesellschaftsmitglieder und soziale Wesen organisieren und zugleich als individuelle Personen entfalten können. Gemäß der eingeführten obersten Maxime muß jeder Angriff auf diese drei Prinzipien und die von ihnen begründeten Anspruchsrechte generell als illegitim und verwerflich gelten, und das Verbot eines solchen Angriffs stellt das oberste inhaltsethische Kriterium, die prinzipielle medienethische Schranke dar. Wie die genannten Prinzipien und aus ihnen abgeleiteten Rechte grundsätzlich nicht bedroht werden dürfen, dürfen sie es auch nicht mit Hilfe medialer Vermittlung. Konkret gewendet leiten sich aus dieser obersten Maxime dann drei spezifische gehaltenormative Schranken her. Zunächst ergibt sich aus dem ersten Prinzip die konkrete inhaltsethische Vorschrift, daB mit Hilfe der Medien weder die Personwürde noch die sich aus ihr begründenden Menschenrechte angegriffen oder verletzt werden dürfen und keinesfalls ihre Destruktion propagiert werden darf, sowie das weniger konkrete Gebot, da $B$ die Personwürde und die Menschenrechte zu achten sind. Da die Menschrechte aus den obersten Prinzipien, d.h. dem Personprinzip und dem mit diesem gegebenen Autonomieprinzip, fließen und Teil des stets zu wahrenden Rahmenethos sind, ist zusammen mit dem Angriff auf die obersten Prinzipien und das Rahmenethos auch der Angriff auf die Menschenrechte oder die Aufforderung zu deren Zerstörung ethisch prinzipiell verwerflich. Mit den Menschenrechten wären ja das Rahmenethos und die obersten Prinzipien selbst getroffen. Weiter leitet sich aus dem dritten Prinzip her, daß jeder Angriff auf den demokratischen Staat und seine Verfassung prinzipiell illegitim ist. Der demokratische Staat und seine Verfassung garantieren ja gerade die Einlösungsbedingungen für die genannten Prinzipien und die aus ihnen fließenden Anspruchsrechte auf der strukturellen Ebene. Wo die Prinzipien und die zugehörigen Rechte gewahrt werden sollen, müssen mithin auch Staat und Verfassung unantastbar bleiben. Schließlich bedingen alle drei Prinzipien, daß auch jeder $A$ ufruf $z u$ Straftaten verwerflich ist. In den Definitionen der strafwürdigen Handlungsweisen nämlich konkretisieren sich die ethisch eingeführten Grundstrukturen zu Lebensstrukturen und werden die Grundwerte in einzelne Rechtswerte bzw. die prinzipiellen Maximen in Einzelnormen ausgelegt.

Aus dem allgemeinen Gebot der Achtung der Personwürde und der Wahrung der Menschenrechte bzw. dem Verbot ihrer Verletzung ergibt sich nun zunächst die Notwendigkeit, die Verletzung von Personwürde und Menschenrechten durch eine mediale Darstellung inhaltsethisch zu reflektieren. Das Problem der Darstellung von Menschenrechtsverletzungen hingegen ist hiervon $\mathrm{zu}$ unterscheiden und gesondert zu behandeln (siehe weiter unten). Aus dem Verbot der Verletzung der Personwürde durch mediale Darstellungen ergeben sich nun vorerst einmal Konsequenzen für den Bereich der Ethik der Information bzw. im Filmbereich: für den Dokumentarfilm, filmische Reportagen (etwa auch im Bereich der Nachrichtensendungen des Fernsehens) oder semidokumentarische Filme, die real existierende lebende oder tote Personen und deren Lebensverhältnisse zum Gegenstand nehmen. So ist zunächst zum Personstatus zu rechnen, da $B$ jede (lebende) Person das Recht auf Verfügung über ihre Darstellung in Medien, über ihre öffentliche Präsentation hat. Dieses Recht ergibt sich aus der Verknüpfung des Personprinzips mit dem Autonomieprinzip: Jeder 
Person eignet das Recht auf Selbstbestimmung und damit auch auf Bestimmung des eigenen Erscheinungsbildes in der Öffentlichkeit. Das zeigt nun einmal, daß die Wahrung der Personwürde nicht von jener der Menschenrechte verschieden ist. In der Tat stellt das Recht auf Selbstbestimmung ja eines der zentralen Menschenrechte dar. Über die Achtung der Menschenrechte, die aus dem Personprinzip sich begründen, wird daher auch der Personwürde ihre Einlösung und Wahrung zuteil. Zum anderen aber leitet sich aus dem Selbstbestimmungsrecht medienbezogen her, da $\beta$ in praxi vor jeder medialen, Verarbeitungt von Personen die Frage, ob überhaupt eine öffentliche Darstellung der Person erfolgen darf, im Fall noch lebender Personen mit diesen selbst erörtert und im Fall Verstorbener zumindest reflektiert werden muß. Wo wiederum eine lebende Person in die Darstellung - sei es expressis verbis oder durch Wahl bestimmter Kontexte (wie etwa das Halten eines Vortrags vor öffentlichem Publikum) - einwilligt, sind dann drei spezifische Schranken zu beachten: Zum einen darf keine mediale Verfälschung der Selbstpräsentation im Sinn etwa einer verhetzenden oder verleumderischen Appräsentation der Person stattfinden. Zum zweiten ist eine böswillige, gezielte Bloßstellung zu vermeiden. In jedem Fall gilt es daher, mit dem erlangten informationellen und bildlichen Material achtsam umzugehen und bei filmischer Arbeit eine sorgfältige Montage des Materials vorzunehmen. Zum dritten ist schon bei der Materialbeschaffung die Privatsphäre zu achten und dürfen private Angelegenheiten der Person nicht ohne weiteres ans Licht gezerrt werden. Auch bei Verstorbenen sind diese Schranken in analoger Weise zu beachten. - Das Verbot einer Verleumdung ergibt sich dabei nicht nur aus der gebotenen Wahrung der Personwürde, sondern zugleich aus dem Wahrheitsgebot, das auch etwa für die journalistische Tätigkeit gilt und Teil des Kommunikatorenethos sein muß. Die Verbreitung falscher Tatsachen über eine Person ist grundsätzlich verwerflich und kann durch keinerlei übergeordneten Zweck legitimiert werden. Auch die Verhetzung aber etwa durch, schiefe Darstellung, durch sinnentstellende oder -verschiebende Montage in einer filmischen Reportage, ist grundsätzlich untersagt. Das Nämliche gilt für die Bloßstellung, die gleichwohl grundsätzlich auch dann zu unterlassen ist, wenn sie wahre Tatsachen über eine Person zum Gegenstand hat. Meist verbindet sich dabei das Verbot der Bloßstellung mit dem der Verletzung der Privatsphäre, die ebenfalls grundsätzlich zu wahren ist. Gerade über die Veröffentlichung privater Dinge, über den Zugang Anderer zu diesem Bereich, hat jede Person die vollständige Verfügungsgewalt - und muß sie haben.

In concreto nun bedeuten vor allem die beiden letztgenannten Schranken, daß etwa das journalistische ,Outing, das letzthin durch die Kampagnen Rosa von Praunheims selbst Gegenstand öffentlicher Auseinandersetzung geworden ist, grundsätzlich illegitim ist. Der instrumentelle Gebrauch der Bloßstellung von Personen, der Offenlegung ihrer Privat- und Intimsphäre zum Zweck der Erreichung auch eines an sich legitimen ethischen Ziels (in diesem Fall: der Beendigung der Diskriminierung Homosexueller) ist jedenfalls dort abzulehnen, wo die bloßgestellten Personen selbst weder gegen dieses ethische Ziel agiert haben, noch in irgendeinem Bezug zur Kampagne für die Erreichung dieses Ziels stehen. Ihre Wahl, mit ihrer Prägung in diesem Kontext nicht öffentlich in Erscheinung zu treten, muß um ihrer Würde als autonome Subjekte, als Personen mit Recht auf Selbstbestimmung willen in jedem Fall geachtet werden. Selbst wo es um Verbrechen von Privatpersonen geht, 
die durch die mit jedem Verbrechen gegebene Verletzung der generellen ethischen Prinzipien und der von diesen gewährleisteten Lebensstrukturen stets ein gewisses öfentliches Interesse mitbedingen oder hervorrufen, ist daher restriktiv zu handeln: Die Veröffentlichung von Namen oder gar Adressen beispielsweise ist aus ethischer Perspektive nicht statthaft. Auch gilt es hier auf die stets gebotene und anzustrebende Resozialisierung Rücksicht $\mathrm{zu}$ nehmen und beispielsweise eine anhaltende sensationslüsterne Berichterstattung nach einer verbüßten Freiheitsstrafe zu vermeiden. Ebenso ist bei Verstorbenen ein um bloßer Sensation willen erfolgendes Outing ihrer privaten Lebensumstände und Daten nicht zu legitimieren. Ein besonderes Problem bereitet hier die Veröffentlichung etwa von Tagebüchern und Briefen, die jeweils ein genaues und differenziertes Abwägen mit dem Recht der Öffentlichkeit auf Information erfordert.

Gleichwohl bedeuten die Verbote der Bloßstellung und des Offenlegens von privaten Dingen nicht, daß diese Grenzziehungen zugleich jede Form von Kritik oder der unter Umständen aus öffentlichem Interesse gebotenen Offenlegung bestimmter personal zurechenbarer Sachverhalte ausschließen. Vielmehr gilt es, jeweils im konkreten Fall entsprechende Einschätzungen der einzuhaltenden Grenzen und eine Güterabwägung zwischen dem Informationsrecht der Öffentlichkeit und dem Schutz der einzelnen Person vor unzumutbarer Preisgabe vorzunehmen. Die Grenze der Personwürde kann und darf nicht dazu genutzt werden, etwa ein Verbot jeglicher Kritik aufzustellen und derart den gesellschaftlichen Diskurs abzublenden. Auch wird es nötig sein, nach dem Bezug der betroffenen Personen zur Öffentlichkeit zu differenzieren: Politiker, bildende Künstler, Schriftsteller und Schauspieler etwa, die qua gewähltem Beruf ohnehin stets im Licht der Öffentlichkeit stehen und damit auch zu Personen öffentlichen Interesses werden, werden einen genaueren Blick der Medien hinnehmen und eine geringere Empfindlichkeit gegenüber Darstellungen an den Tag legen müssen. Sie haben ihre Stellung in der Öffentlichkeit ja selbst gewählt und sich damit bewußt in den Bereich öffentlichen Interesses begeben. Dies gilt neben den Personen der Zeitgeschichte auch für die der Historie, deren Wirken in entsprechend umfänglicher Weise Gegenstand medialer Erörterung sein können muB. In diesen Fällen wird daher der Raum der Privatsphäre dieser Personen weniger umfänglich einzuschätzen sein und die Veröffentlichung bestimmter Daten weniger restriktiv gehandhabt werden müssen. Bei bereits verstorbenen Personen kann zudem ein zum Abstand ihres Lebens von der Gegenwart proportionales Abnehmen der Schutzbedürftigkeit ihrer privaten Dinge angenommen werden. Doch bleibt insbesondere den noch lebenden und erst seit kürzerer Zeit verstorbenen Personen dieses Charakters noch immer eine Intimsphäre zuzurechnen, die medial keinesfalls durchbrochen werden darf, und muß in jedem Fall der Schutz der Personwürde im Blick behalten werden.

Mit dem Gebot der Achtung der Personwürde und dem Verbot ihrer Verletzung in der Produktion medialer Gehalte sind so erste Grenzlinien gezogen, innerhalb derer sich die autonome und eigendynamische Generierung medialer Inhalte vollziehen soll. Um der Durchsetzbarkeit willen ist dieser Rahmen jedoch nicht nur ethisch zu fordern, sondern zugleich rechtlich zu fixieren. ${ }^{88}$ Dies geschieht in der Bundesre-

88 Zur genaueren Vernetzung der hierfür relevanten Gesetze und ihrer Auslegung vgl. die präzise Zusammenfassung bei Hartlieb, Handbuch, Kap. 24-30 
publik dadurch, daß die Verfassung die Unantastbarkeit der Personwürde in Art. 1 I GG festschreibt und damit eine Wertordnung ansetzt, in der diese Würde den obersten Wert bildet. ${ }^{89}$ In der Konkretion der Wahrung dieses Werts geht dann die Rechtsstruktur der Bundesrepublik denselben Weg wie die Medienethik, d.h. sie kennt Vorschriften, die primär grenzziehenden Charakter im Sinn des Ausschlusses bestimmter illegitimer Verhaltensweisen haben. Von der Verfassung wird hierfür sogar explizit ein juridischer Grund gelegt, wenn in der bereits zitierten Formulierung des Art. 5 II GG u.a. bestimmt wird, daß die in Abs. 1 genannten Freiheitsrechte ihre Schranken ,in den Vorschriften der allgemeinen Gesetze“ und im „Recht der persönlichen Ehre" finden. Positiv formuliert werden mithin die Freiheitsrechte, während deren inhaltliche Ausübung und konkrete Konstitution von Realisierungsformen ganz im Sinn der ethischen Axiomatik der Moderne den einzelnen Gesellschaftsmitgliedern selbst anheim gestellt bleiben und nur die für die Wahrung der Axiomatik selbst nötigen Ausschlußlinien gezogen, bzw. Kollisionen von Grundrechten zum Ausgleich gebracht werden. Als eine erste solche Schranke erscheint dabei der Schutz der persönlichen Ehre, der in Verbindung mit Art. 1 I GG zu sehen ist. Hinzu tritt Art. 2 I GG, der die freie Entfaltung der Persönlichkeit garantiert. Er bedingt damit zugleich eine Begrenzung der ,Darstellung des Grundrechtsinhabers in der Öffentlichkeit““90, da dieser gemäß der Wertentscheidung der Verfassung ,selbst darüber befinden dürfen [soll], wie er sich gegenüber Dritten oder der Öffentlichkeit darstellen will, was seinen sozialen Geltungsanspruch ausmachen soll und ob und inwieweit Dritte über seine Persönlichkeit verfügen können, indem sie diese zum Gegenstand öffentlicher Erörterungen machen“91. Daraus folgen insbesondere das Recht am eigenen Bild und am eigenen Wort. Das Recht auf Verfügung der eigenen Darstellung in der Öffentlichkeit gilt ebenso für Politiker und andere Personen des öffentlichen Interesses. Es bedingt vor allem dort eine Einschränkung für den medialen ,Zugriff', wo es um deren aus diesem Interesse herausfallende Privatsphäre geht. ${ }^{92}$ Die medienethische Forderung wird so exakt in Verfassung und Rechtsprechung reproduziert. Weitere Grenzziehungen erfolgen dann neben einigen entsprechenden Vorschriften des Zivilrechts auch im Strafrecht. Dort finden sich spezifische Konkretionen der Wahrung der Personwürde, die mit der medienethischen Normierung zusammenklingen und diese konkret fixieren. So werden etwa Beleidigung, üble Nachrede und Verleumdung im Strafgesetzbuch gerade auch dann unter Strafe gestellt, wenn sie mit Hilfe der Medien erfolgen. Entsprechend bedroht $\S 185 \mathrm{StGB}$ die Beleidigung mit Strafe, wird in $\S 186$ StGB die nicht erweislich wahre Tatsachenbehauptung, die geeignet ist, einen Menschen ,verächtlich zu machen oder in der öffentlichen Meinung herabzuwürdigen“, illegitimisiert und bestimmt $\S 187$ StGB, daß auch die Behauptung einer unwahren Tatsache mit der genannten Eignung, wenn sie wider besseres Wissen erfolgt, strafwürdig ist. Auch das Andenken verstorbener Personen wird vom Strafgesetz geschützt, wenn $\S 189$ StGB verbietet, dieses Andenken zu verunglimpfen. In der Verfassung, den Gesetzen und der Rechtsprechung der Bundesrepublik werden die genannten, sich aus der Personwürde herleitenden

\footnotetext{
89 so auch BVerGE 27,6

90 Jarass/Pieroth, GG, Art. 2 GG Rdn. 28

91 BVerGE 63, 131/142; 35, 202/220; 54, 148/155

92 vgl. BGHE vom 19.12.1978 in: NJW 1979, 647ff
} 
medienethisch gezogenen Grenzlinien somit ebenfalls fixiert und wird auf diese Weise ein nicht nur ethisch, sondern auch rechtlich umschriebener Raum geschaffen, in dem sich die mediale Gehalteproduktion zu vollziehen hat. Die medienethischen Grundforderungen erhalten auf diese Weise zudem eine strukturelle Stütze, die sie konkret einklagbar und damit durchsetzbar machen.

Gleichwohl sind mit der Forderung der Wahrung der Personwürde noch nicht alle aus dem Person- und Autonomieprinzip hervorgehenden Grenzziehungen in Blick genommen. Zusammen mit dem Personstatus sind noch weitere dem Menschen als solchem zuzusprechende Rechte gegeben, die zum einen aus dem Personprinzip selbst hervorgehen, zum anderen das im Vorgängigen schon mit zur Anwendung gebrachte Recht auf grundsätzliche Selbstbestimmung weiter entfalten und zum dritten über dieses Recht auch hinausreichen. In Blick zu nehmen sind dabei näherhin das Recht auf Leben sowie auf körperliche und seelische Unversehrtheit und das Recht auf Gleichstellung mit allen anderen Menschen und entsprechende Gleichachtung. Das Recht auf Leben und Unversehrtheit ergibt dabei zwar eine zunächst recht enggeführt anmutende medienethische Vorschrift, doch hat auch sie sich nicht nur in den letzten Jahren als durchaus relevant und von zentraler Wichtigkeit erwiesen. So darf unter der generellen Vorschrift, daß nicht durch mediale Inhalte zur Destruktion der Menschenrechte oder ihrer Verletzung aufgerufen werden darf, selbstverständlich auch nicht zur Verletzung des Lebensrechts oder der Unversehrtheit anderer Menschen aufgerufen werden. In praxi bedeutet das, daß die mediale Propaganda der Tötung oder Verletzung von Menschen und Menschengruppen verwerflich und illegitim ist. Damit ist einmal die Propaganda eines Genozids, wie ihn die Nationalsozialisten zu ihrem Programm gemacht hatten, ausgeschlossen. Weiter sind auch Aufrufe wie jener zur Tötung Salman Rushdies medienethisch illegitim. Doch nicht nur diese eindeutigen Fälle sind dem aus dem Recht auf Leben hergeleiteten Verbot zu unterwerfen. Es ist vielmehr auch in der alltäglichen journalistischen Arbeit stets zu fragen, ob und wie durch bestimmte Formen von Berichterstattung der Überschritt in propagandistisches Verhalten droht, das eventuell die Lebensrechte von Menschengruppen zu bestreiten oder zu untergraben vermöchte. Insbesondere im Bereich der Kriegsthematik wird ein vorsichtiges Abwägen der hier jeweils aufeinanderstoßenden ethischen Maximen und gebotenen Ziele nötig sein und in jedem Fall propagandistisches Abgleiten, das personell zurechenbare Feindbilder - Bilder von Menschen(-gruppen), die als Menschen(-gruppen) an sich zu bekämpfen seien schafft, unbedingt vermieden werden müssen. Gerade die Gefahr einer Bestreitung des Lebens- und Unversehrtheitsrechts von Menschengruppen als solchen zeigt dabei, daß in diesem Kontext nun neben der Ethik der Information, in deren Bereich das Problem ebenfalls fällt, auch die Ethik fiktionaler Gehalteproduktion gefragt ist. Wie niemandem das Lebensrecht konkret bestritten werden darf, so darf dies auch nicht durch symbolisch-fiktionale Gehalte geschehen. Filmpropaganda, wie sie etwa in Hipplers „Der ewige Jude“ betrieben worden ist, ist daher in jeder Hinsicht absolut verwerflich. Auch das Menschenrecht auf Leben und Unversehrtheit aber erweist sich aus diesen Beispielen heraus als medienethisch höchst relevantes und wichtiges Recht.

Wie erwähnt, ist aus dem Personprinzip dann ebenfalls noch das Menschenrecht der Gleichstellung und Gleichachtung abzuleiten. Dies nun bedeutet, daß alle Perso- 
nen gleichberechtigt zu behandeln sind und mithin niemand etwa aufgrund seiner naturalen Bestimmtheit, d.h. seines Geschlechts, seiner Abstammung oder seiner ethnischen Zugehörigkeit benachteiligt, zurückgesetzt oder diskriminiert werden darf. Der Personstatus ist ja nicht nur für bestimmte Gruppen zu requirieren, sondern gilt für alle Menschen. Nicht nur die ideengeschichtliche Skizze im Grundlegungsteil, sondern auch seine Koinzidenz mit dem Subjektgedanken hat dies vor Augen gestellt: Die Zuschreibung des Subjektstatus gilt für den Menschen schlechthin, und sein universaler Geltungsumkreis inhäriert der begrifflichen Logik des Subjektbegriffs von Beginn an. Medienethisch bzw. genauer: inhaltsethisch gewendet aber bedeutet diese Zuschreibung, daß dann auch nicht vermittels medialer Gehalte eine Verketzerung oder Diskriminierung von Menschen aufgrund ihrer Geschlechtsspezifität oder ihrer Zugehörigkeit zu bestimmten Gruppen erfolgen darf. Auch darf keinesfalls zu einer Verfolgung bestimmter Individuen und Gruppen auf einer so gelegten Basis aufgerufen werden. Selbst wo diese Verfolgung nicht in Beeinträchtigung des Lebens- und Unversehrtheitsrechts, sondern etwa ,nur' in Vertreibung münden würde, wäre sie absolut verwerflich. Jede Propaganda gegen die natural fixierte $\mathrm{Zu}$ gehörigkeit $\mathrm{zu}$ bestimmten Gruppen bedeutet eine Verletzung des aus dem Personprinzip hervorgehenden Menschenrechts der Gleichheit und ist prinzipiell illegitim. Gleichwohl ist nicht nur die ,naturale' Zugehörgkeit in dieser Weise zu reflektieren. Auch die gewählte, aus einem bestimmten Persönlichkeitsentwurf hervorgehende Spezifität ist schutzwürdig und bedingt eine entsprechende inhaltsethische Grenzziehung. So ist zu den Menschenrechten zunächst unverzichtbar das Recht auf religiöse Selbstbestimmung zu rechnen. Ethisch läßt sich zu diesem Recht zudem das Recht gesellen, bestimmte, dem Rahmenethos zumindest nicht widersprechende Binnenmoralen und subkulturelle Eigenarten auszubilden. Das Person- und das Autonomieprinzip bedingen es ja, daß jeder Mensch sich selbst, sein Ethos und seine Lebensformen individuell entwerfen dürfen muß. Hierzu gehören freie Religionswahl und -ausübung sowie die Freiheit der Wahl auch bestimmter gruppenspezifischer Sondermoralen und Lebensformen. Auch die Betonung und Verwirklichung externer, aus anderen Teilen der Erde stammender kulturspezifischer Eigentümlichkeiten ist in diesen Zusammenhang zu stellen. An der je spezifischen Selbstauslegung und Selbstbindung sowie an der Realisierung seiner Transzendenzverwiesenheit darf nun der Mensch unter Voraussetzung der im Grundlegungsteil entfalteten ethischen Axiomatik nicht gehindert werden. Vor allem jede Verketzerung und Verfolgung von Menschen wegen spezifischer Selbstentwürfe oder der Aufruf zu einer solchen ist daher als illegitim zu beurteilen. Das aber bedingt es für die Inhaltsethik, daß diese Selbstentfaltungen des Menschen auch nicht durch entsprechende propagandistische Medieninhalte diskriminiert oder zur Verfolgung der jeweiligen Individuen und Gruppen aufgerufen werden darf. Freilich schließt diese Grenzziehung wiederum nicht Kritik aus. Auch über Religion, Binnenmoralen und Subkulturen muß diskursiv verhandelt werden können. Mithin muB eine kritische Bearbeitung in den Medien möglich bleiben. Illegitim sind daher lediglich die böswillige Diskriminierung und Verketzerung von Menschen und Gruppen aufgrund ihrer spezifischen religiösen, moralischen und kulturell-ethnischen Eigentümlichkeiten sowie der Aufruf zur Verfolgung dieser Menschen und Gruppen.

Diese Grenzziehungen nun finden sich ebenfalls wieder in Verfassung und Recht der Bundesrepublik mitvollzogen, wenn einmal in Art. 2 II GG jedem ,das Recht auf 
Leben und körperliche Unversehrtheit" zugesprochen wird und Art. 3 III GG bestimmt, da $B$ niemand ,wegen seines Geschlechts, seiner Abstammung, seiner Rasse, seiner Sprache, seiner Heimat und Herkunft, seines Glaubens, seiner religiösen (...) Anschauungen benachteiligt oder bevorzugt werden" darf. Damit werden Lebensrecht und prinzipielle Gleichheit der Menschen, die sich aus dem Personprinzip herleiten, grundsätzlich festgeschrieben. Der Gleichheitssatz hat dabei zunächst primär für die Gesetzgebung Bedeutung: Niemand darf durch die konkreten Rechtssetzungen als Person oder Angehöriger einer Gruppe aufgrund der genannten Eigenschaften gegenüber anderen benachteiligt oder bevorzugt werden. Doch entfaltet der Gleichheitssatz gerade auf diese Weise eine Wirkung, die ihn ins Konkrete transformiert. Durch seine Beachtung in der Konstruktion der Einzelgesetze nämlich werden dort Vorschriften entworfen, die der Realisation und Durchsetzung der Gleichberechtigung dienen. Damit wird die Gleichheit einer Konkretion zugeführt, die auch medienethisch relevant ist. So bedroht etwa $\$ 131$ I StGB u.a. die ,Aufstachelung zum Rassenhaß mit Strafe und kann er als konkretisierender Auszug des medienethischen Verbots der Propaganda gegen Menschen und Gruppen aufgrund ihrer naturalen Zugehörigkeit und Eigenart betrachtet werden. Die Glaubensfreiheit wiederum wird in Art. 4 I GG explizit als Grundrecht fixiert und um die Freiheit des weltanschaulichen - also eventuell auch nicht-religiösen - Bekenntnisses erweitert. Von § $166 \mathrm{StGB}$ findet sich dann dieses Freiheitsrecht in eine Schutzvorschrift transponiert, wenn jede Beschimpfung von Bekenntnissen, Religionsgesellschaften und Weltanschauungen, die ,geeignet ist, den öffentlichen Frieden zu stören“, unter Strafe gestellt wird. Schutzobjekte sind hierbei die Bekenntnisse von Weltanschauungsgemeinschaften und der öfentliche Friede, durch deren Schutz bzw. Wahrung die ungestörte Religionsausübung bzw. die Lebensausrichtung nach einer gemeinschaftlichen „Weltansicht für alle existenziellen Probleme“ ${ }^{\text {“93 }}$ gewährleistet werden sollen. Nicht ausgeschlossen hingegen ist die religiöse und weltanschauliche Auseinandersetzung, die ,als solche durchaus erwünscht ist, aber nicht in Form friedensstörender Beschimpfungen geführt werden darf ${ }^{\alpha}{ }^{94}$ Die Diskursivität der gesellschaftlichen Kommunikation bleibt so also erhalten, obschon der Wahrung der Grundrechte Durchsetzbarkeit verliehen wird. Im Ganzen zeigt sich damit wieder, daß in Verfassung und Recht der demokratischen Gesellschaft der Bundesrepublik die medienethischen Grenzziehungen wiederzufinden sind und diese so erneut strukturelle Durchsetzungskraft erhalten.

Gleichwohl ist noch eine weitere Überlegung anzustellen. Wie zu sehen war, bezogen sich die bisherigen Grenzziehungen alle auf Menschenrechtsverletzungen, die durch eine mediale Darstellung erfolgen. Die inhaltsethische Frage nach dem Verhältnis der Personwürde und der Menschenrechte zu bestimmten medialen Darstellungen kann jedoch nicht auf diesen Problembereich beschränkt werden. In der Tat ist ja nicht nur denkbar, daB eine mediale Darstellung extern zu dieser bestehende Menschenrechte verletzt, sondern es muß auch geprüft werden, wie es sich mit der ethischen Legitimität oder Illegitimität der Darstellung von Menschenrechtsverletzungen selbst verhält. Schon um der systematischen Vollständigkeit willen gilt es, die

\footnotetext{
${ }^{93}$ Hartlieb, Handbuch, Kap. 8 Rdn. 7

94 Dreher/Tröndle, StGB, § 166 Rdn. 1
} 
medienethische Frage darauf auszuweiten. Gerade das Beispiel des Menschenrechts auf Leben und körperliche Unversehrtheit verweist jedoch weiter darauf, $\mathrm{daB}$ diese Ausweitung auch aus ,quantitativen Gründen' notwendig ist: Nicht zuletzt im Film finden sich unzählige Darstellungen der massiven Beeinträchtigung dieses Rechts. Ganze Genres - etwa der Western, der Actionfilm und der Kriminalfilm - leben zu einem nicht unbeträchtlichen Teil von entsprechenden Darstellungen, die zwar nun nicht Realität zur Grundlage haben - die handelnden Schauspieler und Stuntmen werden nicht wirklich so behandelt -, die aber doch immerhin realistische Appräsentationen bezwecken. Weiter aber können auch die Verletzung der anderen, bereits aufgeführten Menschenrechte, also die Verletzung der Privatsphäre, die Zerstörung der Gleichberechtigung, die Diskriminierung von Personen und Gruppen und die Propaganda gegen Religionen und Weltanschauungen Gegenstand medialer Darstellung sein. So wird beispielsweise ein Film über die Agitation der Nationalsozialisten ohne entsprechende Darstellungen nicht hergestellt werden können. Ein Bericht über das illegitime journalistische Outing wird ebenfalls nicht ohne Beispiele aus der Realität durchführbar sein. Zusätzlich zur vorgängigen Reflexion von Verletzungen der Menschenrechte durch mediale Darstellungen muß also auch das Problem der Darstellung von Menschenrechtsverletzungen behandelt werden. Der Verweis auf die Problematik körperlicher Unversehrtheit bringt dabei sogar in Blick, daß dies quantitativ zweifelsohne ein umfänglicheres Feld der Inhaltsethik vorstellt als die bereits behandelten Fragen. Es gilt also grundsätzlich und nochmals darauf zu antworten, ob und wie die Darstellung von realen und fiktionalen Menschenrechtsverletzungen zu bewerten ist und wo diese Darstellung ihre Grenze findet. In diesem Zusammenhang kann dann auch nochmals auf die Gewaltproblematik eingegangen werden, die die ,Tradition' zu einem guten Teil beschäftigt hat und die auch gegenwärtig wieder diskutiert wird (vgl. etwa 4.7.).

Zunächst nun hat sich bereits oben aus der angesetzten ethischen Axiomatik hergeleitet, daß kein medialer Inhalt auf der Aussageebene die Personwürde und die Menschenrechte angreifen und verletzen, bzw. genauer: zum Angriff auf sie und zu ihrer Verletzung aufrufen darf. Ethisch illegitim sind mithin alle Inhalte, die eine solche Aussage machen und Menschenrechtsverletzungen propagieren. Doch gilt es bei dieser Grenzziehung gemäß der eingangs eingeführten Unterscheidung zwischen inhaltlicher Darstellung und inhaltlicher Aussage differenziert zuzusehen: Die illegitime Propagierung von Menschenrechtsverletzungen ist keineswegs und niemals identisch mit einer medialen Thematisierung von Menschenrechtsverletzungen, die etwa gerade gegen solche Verletzungen protestieren will oder auch nur in psychologisierender Absicht ,Abgründe‘ und Versehrungen der menschlichen Seele reflektiert. Ein Dokumentarfilm oder ein Filmbericht über die Folter ist wohl zu unterscheiden von einer Anleitung zur Folterung oder deren Verherrlichung. Auch ist die kritische Beleuchtung beispielsweise der Psychopathologie der, Ärzte', die in einem Konzentrationslager ihre menschenverachtenden Experimente unternommen haben, mit den Mitteln eines fiktionalen Spielfilms nicht gleichzusetzen mit einer GutheiBung der dargestellten Handlungen. Daher gilt es, die einzelne Darstellung selbst immer im Kontext der Gesamtaussage eines Medienprodukts zu sehen und einzig diese Aussage ethisch zu werten. Besonders die Filmerziehung hat, wie zu sehen war, eine große Empfindlichkeit gegen solche Darstellungen und auf der Basis ihrer nega- 
tiven Anthropologie hierbei eine Neigung zur Verwechslung der Ebenen bewiesen. Gegen solche fehlgehende Empfindlichkeiten und sachinadäquate Verwechslungen gilt es differenziert positiv-normativ in Anschlag zu bringen, daß zweifelsohne auf der Aussageebene die neuzeitlich-moderne Errungenschaft des Personprinzips und der Menschenrechte zu wahren ist und jedem Versuch, diese Errungenschaft wieder zu zerstören, entgegengetreten werden muß. Hier hat eine gesellschaftliche Kommunikationskontrolle ihren legitimen Ort und muß sie tätig werden. Wie Folterungen sind auch Aufrufe zur Folter illegitim, und wie die kollektive Mißachtung der Personwürde etwa in Bezug auf gesellschaftliche Teilgruppen ist auch der Aufruf zu einer solchen Mißachtung illegitim. Gleichwohl ist eine solche llegitimisierung nicht identisch mit einer Illegitimität der reflexiven oder kritischen Darstellung illegitimer Tatbestände und Verhaltensformen auf der Inhaltsebene. Wer in fiktionaler Form Stellung zu ethischen ,Negativa' beziehen will, muß sie auch ins Bild bringen können. Die Darstellung von Menschenrechtsverletzungen, soweit sie nicht in gutheißender oder gar propagandistischer Weise erfolgt, ist daher medienethisch durchaus als legitimer Teil der medialen Gehalteproduktion zu bezeichnen.

Gleichwohl ist diese Grundnorm noch genauer zu entfalten und zu ergänzen. So liegt der Fall zwar recht eindeutig, wo durch eine Darstellung von Menschenrechtsverletzungen auf der Aussageebene eine Glorifizierung dieser Verletzung erfolgt oder sie in propagandistischer Weise gutgeheißen bzw. zu ihr aufgerufen wird. Hier findet ein expliziter und deutlicher Angriff auf die Menschenrechte und ihre Wahrung statt. Damit aber sind die obersten ethischen Prinzipien verletzt und ist das unbedingt zu wahrende Rahmenethos gefährdet. Die prinzipielle Illegitimität derartiger Formen der ,Thematisierung' von Menschenrechtsverletzungen liegt deshalb auf der Hand. Doch bedeutet die Umwendung auf die Legitimität von Darstellungen, die diesem Kriterium nicht unterfallen, keineswegs, daß nun schon jede Darstellung, die nicht unmittelbar und in penetranter Offensichtlichkeit verherrlichend oder propagandistisch ist, legitim wäre. Vielmehr sind Grenzfälle denkbar, bei denen genau abgewogen werden muß, ob die Form der Darstellung noch tolerabel ist, oder ob sie bereits Grenzen überschreitet und tendenziell zur Affirmation von Menschenrechtsverletzungen überleitet. Hier ist zunächst auf die Möglichkeit einer Verharmlosung von Menschenrechtsverletzungen zu blicken. Darstellungen, die solche Verletzungen zum Inhalt haben und auf der Aussageebene die Verwerflichkeit des Gezeigten ,herunterspielen', gezeigte Menschenrechtsverletzungen in der Gesamtaussage ,verniedlichen'oder in einer, nihilistischen' Weise als alltäglich und tolerabel appräsentieren, geraten bedenklich in die Nähe einer Affirmation des dargestellten, ethisch illegitimen Verhaltens. Hierzu gehören etwa Reportagen oder Dokumentarfilme, die die Folter in totalitären Regimen als selbstverständlichen, lebensweltlichen Teil der dortigen Lebenszusammenhänge zeigen, oder auch gewalthaltige Filme aus dem Kriegsfilmgenre, die einen zynisch-beiläufigen Umgang mit Menschen als ,Material ${ }^{*}$ auf der Aussageebene als selbstverständlich erscheinen lassen. Auch die Verharmlosung von Menschenrechtsverletzungen ist so in das exklusive Kriterium illegitimer Darstellungen einzubeziehen.

Weiter ist insbesondere auch bei der Darstellung von Sadismen und sadistischen Verhaltensweisen genau zuzusehen. Dort, wo diese Darstellung in einer Weise erfolgt, die etwa zu starker Identifikation mit der sadistisch handelnden Figur in einem 
narrativ-fiktionalen oder dokumentarischen Kontext einlädt, ist die Grenze wohl überschritten. Auch kann eine Darstellung, die sich in selbstzweckhafter Form auf Ermöglichung einer sadistischen Kontemplation der dargestellten sadistischen Menschenrechtsverletzungen und der dabei vorgenommenen grausamen Handlungen richtet, die also einzig zum Zweck einer solchen Kontemplation hergestellt worden ist, kaum Legitimität für sich in Anspruch nehmen. Dort, wo sadistisches Vergnügen erzeugt werden soll, wo Sadismen um solchen Vergnügens willen zur Darstellung kommen, ist das Rahmenethos selbst gefährdet. Der Sadismus bleibt zudem eine heilungsbedürftige Pathologie, nicht aber ist er ein legitimes Bedürfnis, das medial erfüllt werden müßte. Er steht dem Rahmenethos und seinen Prinzipien empfindlich entgegen, und seine mediale Beförderung oder eine Einladung zur experimentellen Erprobung möglichen Genusses an dieser pathologischen Verhaltensform ist prinzipiell zu unterbinden. Gleichwohl ist in jeder konkreten Beurteilung auch Vorsicht geboten: Wo beispielsweise in der Absicht einer psychologischen Reflexion durch eine Darstellung Verständnis der psychopathologischen Beweggründe des Handelns einer sadistisch agierenden Figur geweckt werden soll - und mithin ebenfalls eine gewisse Einladung zu identifikativen Selbstverständigungsprozessen stattfindet -, kann nicht ohne weiteres eine sadismusaffirmative Valenz behauptet werden. Ebenso kann dort, wo die Verharmlosung von Menschenrechtsverletzungen oder der nihilistisch-zynische Umgang mit Menschen selbst Thema eines Films ist, der auf der Aussageebene gerade diese Phänomene skandalisieren will, nicht einfach Illegitimität behauptet werden. Selbst eine kommentarlose Darstellung, die eine produktive Verstörung des Publikums anzielt bzw. durch Provokation zur Stellungnahme herausfordern will, kann in entsprechenden Kontexten noch erlaubt sein. Sowohl die Aussageebene, als auch die durch eine bestimmte Situierung einer Darstellung in bestimmten kommunikativen Kontexten gegebene interaktive Bedeutung der Darstellung müssen also Berücksichtigung in der Beurteilung ihrer ethischen Zuträglichkeit oder Unzuträglichkeit finden. Obschon aus einer inhaltsethischen Legitimation der Darstellung von Menschenrechtsverletzungen somit nicht abzuleiten ist, daß es für diese Darstellungen keine oder zu weit angesetzte Schranken gäbe, gilt es bei jeder konkreten Beurteilung der Legitimität oder Illegitimität einer Darstellung genau und differenziert zuzusehen und möglichst präzise und auf den speziellen Fall hin argumentativ durchgeklärte Einschätzungen vorzunehmen. Als Grundnorm für diese Einschätzungen und entsprechende Inhalte kann nun wiederum formuliert werden, daß jede propagandistische, verherrlichende, verharmlosende und sadistische Darstellung von Menschenrechtsverletzungen sowie der Aufruf zu diesen medienethisch illegitim ist. $\mathrm{Zu}$ dieser Grundnorm gehört dabei jedoch die Verfahrensvorschrift, daß ein solcher illegitimer Charakter nicht einfach unterstellt werden darf, wo Menschenrechtsverletzungen überhaupt thematisiert werden, sondern daß jeweils unter differenzierter Analyse der Gesamtaussage und -intention eines Medienprodukts genau geprüft werden muß, ob dieser Charakter wirklich zu konstatieren ist.

Darüber hinaus ist jedoch aus medienethischem Blickwinkel zugleich wünschenswert, daß sich die mediale Gehalteproduktion nicht in diesem Themenbereich erschöpft. Das Spektrum der angebotenen Inhalte etwa im Bereich des Spielfilms soll möglichst umfassend und breit sein, damit aber auch eine möglichst vielseitige Themenstruktur zur Verfügung stellen. Die Verletzung von Menschenrechten kann zwar 
zu engagierten Stellungnahmen im Filmbereich führen und unter Umständen Phasen der Filmgeschichte stark mitprägen, doch würde eine einlinige Konzentration auf diese Thematik sowohl der Realität als auch der vom Repräsentativitätsprinzip gebotenen zureichenden Erfüllung der Publikumsbedürfnisse nicht gerecht. Daher soll sich die mediale Gehalteproduktion allen in einer Gesellschaft möglichen Themen widmen und ein möglichst differenziertes Angebot für die Rezeption bereitstellen. Daraus folgt dann auch etwa für die Verbreitung von Filmen über das Fernsehen eine entsprechende Anforderung an die Programmstruktur: In dieser ist dem Gebot der thematischen Vielfalt ebenfalls zu entsprechen. Weder eine fast ausnahmslose Füllung des Programms mit Kriminal-, Horror- und Actionfilmen, noch aber auch eine überwertige Appräsentation von im Gestus der Anklage erstellten Autorenfilmen zu den gegenwärtigen Zuständen in Südafrika oder den vergangenen in Deutschland, noch schließlich eine Überfrachtung des Programms mit Dokumentarfilmen zur Folter in totalitären Regimen und ähnlichem ist wünschenswert. Vielmehr geht es um eine gewisse Ausgewogenheit des inhaltlichen Rezeptionsangebots, das es den Rezipienten ermöglicht, sich in differenzierter Weise ihre Bedürfnisse zu erfüllen.

Schließlich ist in diesem Zusammenhang auch noch zu berücksichtigen, da $B$ nicht nur der Versto $\beta$ gegen die Menschenrechte und das Rahmenethos, in dem sie angesiedelt sind, einen Inhalt der medialen Vermittlung und Darstellung bilden kann, sondern das Rahmenethos selbst einen gewissen Anspruch auf seine positive Appräsentation in medialen Gehalten hat. Zur gesellschaftlichen Selbstverständigung, die sowohl in den dokumentarisch-informationellen als auch in fiktionalen Gehalten (mit) geschieht, gehört ebenso die Verständigung über die Geltung und Inhalte des Rahmenethos. Auch dieses also kann und soll Teil der medial erstellten Inhalte sein, ohne da $B$ diese Anforderung schon als Dirigismus oder Social engineering zu verstehen wäre. Nicht eine ständige lehrhafte Appräsentation des Rahmenethos oder gar seiner Konkretion in der gesellschaftlichen Normstruktur ist ja angezielt, sondern lediglich die Tatsache, daB auch die normativen Grundlagen der Gesellschaft Thema der inhaltlichen medialen Kommunikation sein können und sollen. Die inhaltliche Produktion sollte sich daher nicht nur in ,negativen' Themen der Verletzung von Menschenrechten und Rahmenethos erschöpfen, sondern auch konstruktiv die Grundstrukturen des gesellschaftlich verbindlichen Ethos zur Anschauung bringen. Gemäß der eingangs aufgestellten Metanorm, daß die Inhaltsethik um der Vermeidung eines Dirigismus und der Offenhaltung der Kommunikationsstruktur willen vordringlich exklusiv zu verfahren hat und positive' Vorschriften nur sehr allgemein und grundsätzlich erstellen kann, bleibt freilich auch diese Anforderung nur eine Rahmenvorschrift, die ihre konkrete Ausformung und Füllung der kommunikativen Praxis der Gesellschaft selbst überlassen muß.

Auf diesem Hintergrund kann nun nochmals auf zwei der Devianzvorwürfe der ,Tradition' eingegangen werden. Zunächst erscheint dabei der von der ,Tradition' vorgebrachte Vorwurf der moralischen Primitivienung in einem veränderten Licht. Aus dem Blickwinkel der vorgängig erarbeiteten inhaltsethischen Kriteriologie nämlich läßt sich moralische Primitivierung zunächst dort wahrnehmen, wo eben jene genannte illegitime, strafwürdige Propagierung von Menschenrechtsverletzungen betrieben wird. Die Primitivierung besteht hierbei jedoch nicht unmittelbar in einer ,Verrohung' des Publikums, sondern im Rückschritt hinter das ethische Niveau von 
Neuzeit und Moderne, hinter ihre ethischen Errungenschaften, wie sie das Personprinzip und die Fixierung von Menschenrechtskatalogen darstellen. Ein solcher Rückschritt bedeutet in der Tat eine Primitivierung, doch erweisen sich hierbei weniger die Rezipienten als primitiv, sondern mehr der jeweilige Produzent und sein Produkt. Ob das Publikum hingegen einen solchen Rückfall annimmt oder gar mitzuvollziehen bereit ist, ist an der Existenz eines derartigen Produkts noch nicht abzulesen. Keinesfalls nämlich ist, wie sich im Grundlegungsteil gezeigt hat, eine moralisch negative Naturalbasis im Menschen anzunehmen, die der Propagierung moralischer Rückschritte in die Hände arbeiten würde. Auch verweist die Nichtfestgestelltheit des Menschen darauf, daß dieser in der Welt nicht auf Auslösereize trifft, von denen ein vorgezeichnetes Verhalten unwiderstehlich hervorgerufen wird. Stattdessen hat sich gezeigt, daß der Mensch über eine durchaus auch moralitätsförderliche Basis verfügt, die ihn mit vermutlich größerer Wahrscheinlichkeit vor propagierten Negativa zurückschrecken läßt. Außerdem war deutlich, daß der Mensch durch seine Instinktunsicherheit zur Autonomie freigesetzt ist und sich zu appräsentierten Reizen verhalten kann. Selbst die illegitime Propaganda von Menschenrechtsverletzungen könnte so durchaus noch verstärkend für Akzeptanz und Erhalt dieser Rechte wirken. Die Deduktion einer notwendig stattfindenden moralischen Primitivierung des Publikums aber ist zunächst erneut zurückzuweisen, und der Primitivierungsvorwurf ist, so der Terminus noch einen Sinn behalten soll, auf das Moment der Regression, den Rückfall hinter das erreichte ethische Niveau der Moderne hin auszulegen. Moralische Primitivität findet sich dort, wo Menschenrechtsverletzungen propagiert, verherrlicht, verharmlost oder sadistisch appräsentiert werden und wo zu ihnen aufgerufen wird.

Weiter aber kann nun auch der Vorwurf gegen die Darstellung von Gewalt, der in der ,Tradition' im Kontext des Primitivierungsvorwurfs aufschien und gegenwärtig als eigenständiger Vorwurf vorgebracht wird, inhaltsethisch genauer betrachtet werden. In der Tat nämlich ist mit den vorstehenden Überlegungen zur Darstellung von Menschenrechtsverletzungen die Frage nach der inhaltsethischen Bewertung von Gewaltdarstellungen noch nicht vollständig gelöst. Zwar kann zunächst die bereits entworfene Kriteriologie auch auf die Gewaltproblematik übertragen werden. So ergibt sich aus dem Vorstehenden, daß jede Gewaltdarstellung aus dem Kanon der Legitimität fällt, wenn sie verherrlichenden, verharmlosenden oder propagandistischaufrufenden Charakter besitzt. Weder die Glorifizierung von Gewalt als begrüßenswerte und förderungswürdige Verhaltensform, noch ihre Verharmlosung zu einer alltäglichen, nicht weiter normativ zu reflektierenden Erscheinung, noch auch die Propaganda von Gewalttaten kann medienethisch toleriert werden. Gewalt stellt keine ethisch legitime Verhaltensform vor, daher kann mithin auch nicht ihre Glorifizierung, Verharmlosung oder Propaganda geduldet werden. Durch solche Appräsentationen wäre das Rahmenethos selbst angegriffen, das jedoch unter allen Umständen zu wahren ist. Weiter aber müssen auch alle sadistischen Gewaltdarstellungen, die sich auf die Ermöglichung einer sadistischen Kontemplation richten und ,selbstzweckhaften' Charakter tragen, als illegitim beurteilt werden. Genau besehen sind sadistische Gewaltdarstellungen ohnehin als mit der sadistischen Darstellung von Menschenrechtsverletzungen identisch anzusetzen und richten sie sich mithin ebenfalls gegen das Rahmenethos der Gesellschaft. Daher müssen auch sie aus dem 
,Katalog' legitimer Gehalte von vorneherein aus ethischen Gründen ausgeschlossen werden. Gewonnen ist auf diese Weise wieder eine inhaltsethische Grundnorm, die die bereits entworfene Kriteriologie auf die Frage der Darstellung und Thematisierung von Gewalt überträgt und dieser bestimmte Grenzen vorgibt. Darüber hinaus kann aus den vorgängig entfalteten inhaltsethischen Überlegungen noch abgeleitet werden, daB die Quantität der Gewaltdarstellungen sich im Gesamtkorpus der Medienproduktion und -verbreitung in verhältnismäßiger Weise, d.h. unter Rücksicht auf die Wahrung der Angebotsvielfalt ebenso wie unter Rücksicht auf die allgemeine Gebotenheit einer thematischen Appräsentation auch des Rahmenethos in Mediengehalten einzurichten hat. Auch die Verbreitung von gewalthaltigen Darstellungen unterliegt so einer Norm, die einen nun quantitativ ausgerichteten Rahmen absteckt.

Umgekehrt jedoch bedeutet die Übertragung der entworfenen Kriteriologie auf die Gewaltfrage dann, daß die Darstellung von Gewalt zumindest dort nicht völlig illegitim ist, wo sie die aufgeführten Kriterien nicht verletzt und beispielsweise um einer kritischen, entlarvenden oder psychologisch-reflexiven Absicht willen geschieht. Das läßt sich sogar noch dahin ausweiten, daB selbst eine nicht unmittelbar in kritischer oder psychologisch-reflexiver Absicht erfolgende Gewaltdarstellung dort noch Legitimität beanspruchen kann, wo zumindest nicht Gewalt verherrlicht, verharmlost, propagiert, sadistisch appräsentiert oder zu ihrer Ausübung aufgerufen wird. Innerhalb des abgesteckten Rahmens ist somit die Produktion gewalthaltiger Medienprodukte wie etwa von Action-, Kriminal- oder Horrorfilmen durchaus legitim. Damit aber stellt sich eine Reihe von Fragen. Gerade die auf diese Weise eingeführte Legitimität nämlich bedarf wieder einer genaueren Reflexion. Der durch Exklusion hergestellte Rahmen erlaubt immerhin auch eine ,neutrale; nicht sogleich auf eine bestimmte moralische Wertung - etwa im Sinne Selgs, der bei jeder Gewaltdarstellung die sofortige Bestrafung der gezeigten Gewalt fordert - und kommunikativ-informationelle Funktion - etwa im Sinn der Dokumentation skandalöser Verhältnisse in Militärdiktaturen - verpflichtete Gewaltappräsentation. Er liefert damit zugleich die grundsätzliche Möglichkeit, gewalthaltige Inhalte zum Zweck der Unterhaltung zu produzieren und zu verbreiten. An diesem Punkt entsteht das eigentliche Problem und wird insbesondere die Frage nach der Legitimität und legitimen Form einer Unterhaltung durch gewalthaltige Medienprodukte virulent. Zu fragen ist deshalb näherhin, ob die Rezeption solcher Produkte, die dem eingeführten Kriterium gehorchen, als ethisch verantwortbares Verhalten bewertet werden kann und ob mithin dieses Kriterium für die Beurteilung inhaltsethisch legitimer bzw. illegitimer Darstellungsformen ausreicht.

Zur Klärung dieser Frage kann nun die transzendental-hermeneutische Rekonstruktion des unterhaltenden Verhaltens aus dem unterhaltungsethischen Baustein herangezogen werden. Dort hat sich gezeigt, da $B$ das Unterhaltungsphänomen als eine besondere Aktivitätsform zu begreifen ist, die auch unter Nutzung je spezifischer medialer Gehalte ausgeübt werden kann und bestimmte Delektationen ermöglicht. Die entworfene Struktur sei nun auf Filme mit gewalthaltigen Darstellungen angewandt, um zu eruieren, welche Delektationen hierdurch möglich werden und ob diese ethisch zumindest tolerabel sind. Eingeschränkt wird diese Anwendung entsprechend der oben angesetzten Frage dabei auf Filme, die dem skizzierten Kriterium gehorchen. Um die von der Rezeption dieser Filme ermöglichten Delektatio- 
nen in Blick zu bekommen, wird es zunächst hilfreich sein, zumindest ein ausschnitthaftes Bild der unter Befolgung der inhaltsethischen Grundnorm noch denkbaren Rolle von Gewalt in ihnen zu gewinnen. So sind dort, wo Gewalt der Kriteriologie gemäß nicht selbstzweckhaft appräsentiert wird, die entsprechenden Darstellungen in einen narrativen Kontext eingebunden und entfalten sie in diesem eine spezifische, sehr vielfältig zu denkende Funktion. Sie können beispielsweise der Designation des Bösen dienen, die moralische Zwiespältigkeit eines Charakters veranschaulichen, strukturreflexiv als Konsequenz bestimmter lebensgeschichtlicher oder gesellschaftlich-subkultureller Gegebenheiten dargestellt werden oder aber auch der Provokation einer Eigenreflexion des Rezipienten dienen. So findet sich die erstgenannte Form etwa in den mit der Juxtaposition von individueller Selbstmächtigkeit und law and order befaßten Western der 50er Jahre, aber auch noch beispielsweise im Action-Science-fiction-Film der Gegenwart. Die moralisch zwiespältigen, gewalttätigen Figuren treten insbesondere ab den 70er Jahren in den Vordergrund und provozieren sogleich Diskussionen über ihre Legitimität, wie etwa Don Siegels ,Dirty Harry' (1971). Auch hier aber bleibt durchaus denkbar, daß diese Form der Gewaltappräsentation einer differenzierten Analyse dient, wie es etwa in Scorseses ,Taxi Driver' (1975) oder Hodges, Auf den Schwingen des Todes' (1987) der Fall ist. Eine Neigung zur Strukturreflexion wiederum läßt sich beispielsweise in den ,Halbstarkenfilme' der 60er Jahre erkennen; sie kennzeichnet aber auch Filme der Gegenwart, wie etwa Spottiswoodes ,Under Fire' (1982) oder ,New Jack City، (1991). Zur Provokation von Reflexion durch Verstörung des Publikums mittels Gewaltappräsentation neigen etwa John Carpenter in ,Assault on Precinct 13' (1976) oder Paul Verhoeven in ,Türkische Früchte' (1972). Etwas anders verhält es sich im Horrorfilm, wo die Gewaltdarstellung meist der Erzeugung von Schocks und der Designation von Bedrohung dient. Sie hat in diesem Genre mithin besonders deutlich eine dramaturgische Funktion. Auch dort aber kann sich die Appräsentation von Gewalt der Reflexion von gesellschaftlichen Strukturen, moralischen Problemen oder psychopathologischen Phänomenen dienstbar machen. Gerade der Horrorfilm nutzt Gewalt oft, um in Travestie moralische und realweltliche Probleme zu reflektieren - von Murnaus ,Nosferatu' (1922) bis zu Cronenbergs, Videodrome' (1982). In all diesen Funktionsformen kann die gezeigte Gewalt dabei durch entsprechende Einbindung in die narrativ-dramatische Struktur der Erzählung zugleich von sadistischer, propagandistischer, glorifizierender oder verharmlosender Valenz freibleiben. So wird, Propaganda, Glorifizierung oder Verharmlosung dort gerade nicht vermutet werden können, wo die Gewalt der Designation des Bösen dient. Auch die Veranschaulichung moralischer Zwiespältigkeit durch den gewalttätigen Charakter einer Figur vermag zumindest in jenen Filmen den eingeführten Kriterien zu gehorchen, in denen gerade eine reflexive Problematisierung dieser Zwiespältigkeit stattfindet. Ebenso verhält es sich mit strukturreflexiven und milieukritischen Filmen. Selbst die Provokation von Reflexion durch Verstörung des Publikums aber, so wirklich eine solche reflexionserzeugende Absicht erkennbar ist, muß nicht den illegitimen Formen zugerechnet werden. Gewalt kann damit in einer vielfältigen Weise auch unter Befolgung der eingeführten Grundnorm in Filmen eingesetzt werden und dort eine vielschichtige, je spezifische Funktion entfalten. Die aufgeführten Beispiele zeigen, da $\beta$ es solche, dieser Norm gehorchende Filme auch gibt und da $B$ diese zudem nicht einfach 
nur im Kunstfilmbereich zu finden sind. In ihnen stellt Gewalt ein dramaturgisches und narratives Mittel dar, das in einer großen Bandbreite von Themen genutzt werden kann und wird und das wiederum eine entsprechend vielschichtige Auffassung durch das Publikum erlaubt.

Diese Auffassung kann nun generell mit den Delektationsformen etwas gegliedert werden. Zunächst nämlich ermöglichen alle gewalthaltigen Filme durch ihre Konstruktion und die je spezifische Situierung gewalthaltiger Szenen an entsprechenden Stellen des Handlungsgangs Spannung und Aufregung. Sie geben dem Rezipienten damit die Möglichkeit psychophysischer Stimulanz. Diese Stimulanz ist dabei noch nicht inhaltlich, sondern formal zu verstehen: Fühlbar und erlebbar gemacht wird durch entsprechende Szenen die eigene Energie, die physiologisch nicht zuletzt durch die Erregung und den Adrenalinaussto $B$ bei der Rezeption entsprechender Erzählstrukturen freigesetzt wird. Der gewalthaltige Medieninhalt liefert mithin zunächst einmal die Basis für die Produktion eines Anspannungs- und Erregungszustandes, der den psychophysischen Haushalt dynamisiert und , in Bewegung bringt". Das wiederum erlaubt einen spezifischen Genuß, der seine Wurzel in der Funktionslust findet. Die Funktion des eigenen psychophysischen Apparats ist der erste und primäre Gegenstand jedes durch Rezeption gewalthaltiger Erzählungen erzeugten Genusses, der damit im weiteren Sinn der delectatio sensibilis zugeschlagen werden kann. Genossen wird also zunächst bei jeder Rezeption entsprechender Filme ,die Spannung' und ,das Aufregende', und Gegenstand des Genusses ist die Dynamisierung des psychophysischen Haushalts an sich. Zu dieser nun gesellen sich spezifische Gefühle, die je nach appräsentiertem Inhalt verschieden ausfallen können. Sie können vom Mitleiden mit der durch Gewalt affizierten Figur und Furcht über Abgestoßensein und Ekel bis zu Freude und Erleichterung über die endlich geschaffene Lösung des dramatisch geschürzten Knotens reichen. All diese auf die Narrativität insgesamt zu beziehenden Gefühlslagen und ihr Wechsel erlauben bei der Rezeption eine delectatio emotionalis. Das Haben von Gefühlen, das Durchleben mehr oder weniger starker Affektationen und die meist rasche Abwechslung dieser Gefühle sind es, die den spezifisch emotionalen Genuß ausmachen. Mit beidem, der psychophysischen Erregung und den inhaltsbezogenen Gefühlen, wird dabei die eigene Energie und Lebendigkeit einmal erlebbar gemacht und zum anderen Gegenstand der primär empfundenen Lust an der Rezeption von Gehalten, die die Konstitution dieser Befindlichkeit erlauben. Auch die gewalthaltigen Szenen tragen zu dieser Delektation bei.

Bereits hieraus ergibt sich nun ein Doppeltes: Zunächst wird erkennbar, daß auch von der Rezeptionsform her eine selbstzweckhafte oder verherrlichende Appräsentation von Gewalt nicht legitim ist. Sie nämlich ließe es nur zu, einen auf die Gewalt an sich fixierten Genuß zu entwickeln. Obschon damit noch nicht präjudiziert ist, daß es gelänge, das Publikum zu einer solchen Fixierung zu bewegen - immerhin stehen dem, wie im Grundlegungsteil zu sehen war, die empathisch-altruistischen Neigungen des Menschen entgegen -, bedeutete es doch eine starke Vereinseitigung der Delektationsmöglichkeiten, die zudem dazu nötigen würde, die einem affirmativen Gewaltgenuß entgegenstehenden menschlichen Strebungen zu überspringen. In dieser Einseitigkeit und Nötigung aber würde der Zwang, Lust an bloßer Gewalt zu finden, sich strukturell einem sadistischen Genuß zuneigen. Das wiederum bedeutete, 
$\mathrm{da} B$ gewalthaltige Filme einzig in einer pathologischen Haltung und Form rezipiert werden könnten. Eine solche Vereinseitigung aber ist sowohl aus Gründen der Gebotenheit möglichst vielseitiger und differenzierter medialer Angebote als auch wegen der strukturellen Inklination zum ethisch illegitimen Sadismus auszuschließen. Die Analyse des unterhaltenden Rezeptionsvorgangs, der menschlichen Unterhaltungsaktivität, bestätigt auf diese Weise das ethisch-prinzipiell statuierte Verbot sadistischer und glorifizierender Appräsentation von Gewalt. - Zum anderen aber kann der nicht-sadistischen Rezeption aus der vorgängigen Analyse heraus bereits eine erste Legitimität zugesprochen werden. Die Betätigung der eigenen Lebendigkeit, der Genuß der psychophysischen Funktionen und der Gefühlsformen, ist dort, wo diese Gefühlsformen nicht in sadistische Kontemplation münden, medienethisch durchaus legitim. Er ist Teil jener auch in der Unterhaltung vollzogenen Selbstrealisation des Menschen, der Verwirklichung, Übung und Differenzierung seiner emotionalen Möglichkeiten, die bereits im unterhaltungsethischen Baustein skizziert worden ist.

Gleichwohl ist damit erst ein erster Teil des Gesamtphänomens der Rezeption gewalthaltiger Filme in den Blick genommen. In der Tat stellen die delectatio sensibilis und emotionalis ja nur zwei der möglichen Delektationsformen dar und bliebe ihre alleinige Nutzung etwas unvollständig. Die Rezeption gewalthaltiger Filme, in denen diese Gewalt narrativ eingebunden ist, ermöglicht aber noch weitere Delektationen. So tritt einmal die Notwendigkeit der Auffassung des narrativen Gesamt hinzu, wenn die gesehenen Szenen nicht unverstandene, bloße bildlich-auditive Wahrnehmungen bleiben sollen. Die erzählte Geschichte muß kognitiv mitvollzogen und mitunter sogar aus den montierten Erzählpassagen rekonstruiert werden. Der Erkenntniseffekt beim allmählichen Verständnis der Handlung liefert dem Rezipienten so eine weitere Genußform, nämlich die delectatio cognitionis. Besonders beim Kriminalfilm, der in vielen Fällen auf die allmähliche Rekonstruktion der Motivstruktur des Täters oder sogar die Entlarvung des Täters durch den Rezipienten selbst abstellt, wird diese Delektation ein großes Gewicht besitzen. Gezeigte Gewalt wird dabei zusätzlich funktionsbezogen kognitiv eingeordnet: Sie detailliert beispielsweise die Handlungsmuster des Täters, hilft, seine Motivstruktur zu entdecken und seinen Charakter zu verstehen. Weiter werden auf dieser Delektationsebene die Problemstellungen der entsprechenden Filme begriffen und wird der reflexive Aussagegehalt etwa der Milieukritik oder des moralischen Zwiespalts aufgefaßt. Auch im Verständnis des kognitiven Anteils der Erzählung und ihres, informationellen Gehalts liegt dabei eine bestimmte Lust. In der kognitiven Auffassung werden bestimmte Erkenntnisse und Wissensbestände gewonnen, deren ,Erarbeitung die Betätigung des eigenen intellektuellen Vermögens erlaubt und so ein - wenn auch nicht unmittelbar immer auf einem hohen abstraktiven Niveau angesiedeltes - intellektuelles Vergnügen erlaubt. Der thematische Gehalt und die Aussagestruktur eines Films sind so ebenfalls Teil der filmisch bereitgestellten Delektationsmöglichkeiten. Die delectatio cognitionis kann jedoch noch auf einer Metaebene betätigt werden. Dort nämlich, wo beim Rezipienten bereits ein genrespezifisches Wissen entstanden ist, die Muster, Topoi und Formen eines Genres bekannt sind, kann durch reflexives Erkennen des Spiels des Autors/Regisseurs mit diesen Mustern ein zusätzliches, nun auch ästhetisch-reflexiv bezogenes Vergnügen entstehen. Dabei kann auch der 
genrespezifische Umgang mit Gewalt auf dieser Ebene rezipiert werden, wenn etwa John Carpenter in ,Halloween' (1978) an einer entscheidenden Stelle den psychopathischen Mörder zur übernatürlichen Gestalt fortbildet und so das Genre des Psychothrillers in den metaphysischen Horrorfilm überleitet. Die kognitive Auffassung und Verarbeitung der Verknüpfung zweier sonst getrennter Filmgattungen mit je spezifischen Regeln und der daraus fließenden Konsequenzen für die inhaltliche Konstruktion machen das spezifische Vergnügen aus. Gewalt gilt an dieser Stelle dann der Designation dieser Verknüpfung und erhält eine zusätzliche, über den Handlungsgang hinausreichende Zeichenfunktion. Der zitierte Film ,funktioniert' von diesem Moment an anders, nach den Regeln eines anderen Genres, und der $\mathrm{Zu}$ schauer erkennt, daß er bislang auf einer nun als falsch erscheinenden Fährte geführt wurde. Er erkennt jedoch zugleich, daß dieses dem souveränen Spiel mit Genretypika zu verdanken ist, und vermag sich an diesem Spiel zu erfreuen. Auch der nur kognitiv zu erfassende Umgang mit Genretypika also liefert dem kundigen Rezipienten ein Moment seiner Delektation. Zusammen mit der delectatio sensibilis und emotionalis findet sich in der Rezeption gewalthaltiger Filme somit auch die delectatio cognitionis in vielschichtiger Weise am Werk, die zudem auf die anderen beiden Delektationsformen zurückwirkt und mit diesen interagiert.

Schließlich aber tritt inhaltsbezogen noch das Moment einer Selbstverständigung über die mit der Gewaltdarstellung verbundene, immanent-referentielle Bewertung der dargestellten Handlung hinzu. Gerade in gewalthaltigen Filmen ist in der Regel auch immer die normative Ebene angesprochen und werden moralische Problemstellungen bearbeitet. Wo nun diese Bearbeitung, wenn sie sich der Darstellung von Gewalt bedient, nicht in Verherrlichung oder Verharmlosung, Propaganda oder Sadismus führt, erlaubt sie eine Vielzahl differenzierter narrativer Verständigungsformen über das menschliche Handeln, die menschlichen Bedürfnisse, Strebungen und Lebensvollzüge, die realiter auch mit Gewalt konnotiert sein können. Die filmische Konnotation mit Gewalt kann zudem einer Verdeutlichung durch besonders drastische Appräsentation dienstbar gemacht werden und dadurch die reflexive Selbstverständigung des Rezipienten über die normative Seite des thematisierten Problems provozieren, wie dies etwa einige Filme Verhoevens tun. Der Rezipient vollzieht dann zusammen mit der Auffassung des Aussagegehalts eines fiktional appräsentierten gewalttätigen Verhaltens eine mehr oder weniger bewußte und differenzierte eigene Stellungnahme zu dem Gesehenen. Sie ermöglicht es ihm dabei, das gezeigte Verhalten mit seinen eigenen Normstandards zu vergleichen und Position zu beziehen. Mit diesem Vergleich und diesem Positionsbezug aber vollzieht der Rezipient zugleich eine gewisse Selbstverständigung über seine eigenen Einstellungen, seine Strebungen und Neigungen. Er setzt sich zum normativen Gehalt eines Films in Beziehung und wertet seinerseits die gesehenen Handlungsformen, Motive und Handlungsbegründungen. Damit vermag sich der Rezipient im rezipierten Film zu spiegeln und in eine projektive Selbstverständigung einzutreten. Diese Selbstverständigung wiederum führt gerade dort, wo sie - wie bei der Filmrezeption - vom Druck realer Identitätsgewinnung oder -wiederherstellung entlastet ist, ein spezifisches Lustmoment bei sich. Insbesondere bei der Medienrezeption liegt dieses Moment zumeist in der Bestätigung der eigenen Haltung durch affirmatives Wiedererkennen derselben im medialen Gehalt, oder durch Abgrenzung gegen einen der 
eigenen Haltung widersprechenden Inhalt. Damit tritt nun zur primären Funktionslust in der delectatio sensibilis und ihrer Kombination mit der delectatio emotionalis und cognitionis auch noch die delectatio reflexiva, die Lust an projektiver Selbstverständigung.

All diese Formen der Delektation erscheinen dabei nun durchaus nicht negativ. Vielmehr kann in ihnen erneut eine vielschichtige Betätigung des Menschen gesehen werden, der in der unterhaltsamen Rezeption medialer Gehalte sowohl seine Lebendigkeit aktualisiert, seine Kräfte und Möglichkeiten betätigt, als auch seinen Geist übt und sich über sich verständigt. Unter der Voraussetzung wiederum des im unterhaltungsethischen Baustein entwickelten Kriteriums der menschlichen Selbstaktualisierung und -realisation kann daher der Rezeption auch gewalthaltiger Filme, die den entwickelten Kriterien der inhaltsethischen Grundnorm gehorchen, durchaus Legitimität zugesprochen werden. Gewalt als dramaturgisch und reflektiert eingesetztes Mittel erlaubt spezifische Formen der Selbststimulanz, der Gefühlsproduktion, der intellektuellen Auseinandersetzung und der normativen Selbstverständigung, die durchaus nicht abzulehnen und zu diskriminieren sind. Wo das aufgestellte Kriterium befolgt wird, können vielmehr all die skizzierten Delektationsformen, die unterhaltenden psychophysischen und kognitiven Aktivitäten in der Rezeption zur Bereicherung der menschlichen Existenz beitragen. Dabei gilt freilich auch hier wieder das unterhaltungsethische Kriterium, daß möglichst alle vier Delektationsformen betätigt werden können sollen. Zwar mag man sich zuzeiten auch in den Formen bloßer emotional-sensitiver Delektation erholen, doch ist im Ganzen durchaus wünschenswert, daß um einer, ganzheitlichen' Verwirklichung willen jene Form ,gehobener' Unterhaltung möglich bleibt, die sich nicht auf nur zwei der unterhaltenden Vermögen beschränkt. Daher kann die Kriteriologie um die Rahmendirektive ergänzt werden, daß auch in Filmen mit gewalthaltigen Szenen eine möglichst differenzierte und vielschichtige Erzählstruktur und ästhetische Konstruktion geboten werden sollte, um den Delektationen ein entsprechend differenziertes Feld für ihre Betätigung zu bieten.

Dieser Betätigung und den in ihr aktivierten Gefühlen und Reflexionen muß dann auch nicht a priori mißtraut werden, wie dies die ,Tradition' auf der Basis einer negativen Anthropologie tat und wie es in der Gegenwart noch immer auf dem Hintergrund eines materialen Aggressionsbegriffs geschieht. Von der anthropologisch eruierten Konstitution her ist durchaus nicht zu befürchten, daß der Rezipient gewalthaltiger Darstellungen eine verderblich ,positive', das gesehene gewalttätige Verhalten affirmativ auffassende Stellungnahme vollzieht. Vielmehr ist ja, wie zu sehen war, den beiden axiomatischen Grundlagen des Mißtrauens in die, gedeihliche Auffassung gewalthaltiger Darstellungen begründet entgegenzutreten. Weder ist der Mensch als ,urzeitlicher Schlächter' zu betrachten, dessen delektative Selbstverständigung in eine perniziose Rückerinnerung an die eigene destruktive Natur münden könnte, noch ist das Aggressionsphänomen mit dem materialen Aggressionsbegriff zureichend gefaßt, der zudem dazu tendiert, Aggression mit Pathologien wie dem Sadismus gleichzusetzen. So kann schwerlich der genannte, Schlächter" durch ,Schlüsselreize' aus einem Wesen hervorgelockt werden, das keine instinktfixierten ,Schlösser' mehr besitzt. Das materiale Aggressionsverständnis wiederum hat sich als zu kurzschlüssig erwiesen, um die mit dem Aggressionsbegriff gefaßte menschliche 
Eigenschaft wirklich in den Blick zu bekommen. Entsprechend eignen sich diese Paradigmen auch nicht zu einer Analyse der Bedeutung gewalthaltiger Medieninhalte. Wie im Grundlegungsteil zu sehen war, ist vielmehr der Mensch als Wesen zu begreifen, das mindestens drei zueinander in Beziehung stehende Grundstrebungen bzw. antriebsstrukturen besitzt, nämlich die aus dem Brutpflegetrieb abzuleitende altruistische Fürsorgeneigung, das aus dem Fluchtverhalten deduzierbare sachhaftgebrauchende und zugleich vergesellungswillige Verhalten und die als Durchsetzungsimpuls zu verstehende Aggression. Auf diesem Hintergrund kann dann dem Menschen prinzipiell und auch seiner Medienrezeption im besonderen Vertrauen entgegengebracht werden. Da weder die Aggression material als Destruktionstrieb zu verstehen ist, noch sie die einzige wirkmächtige Grunddisposition des Menschen darstellt, muß auch nicht befürchtet werden, daß der Mensch als Medienrezipient bei der Realisierung seiner Delektationen an gewalthaltigen Filmen in den ,urzeitlichen Schlächter' zurücktransformiert wird. Für eine distanzierende Einordnung und Bewertung der Gewalt in Filmen stehen ihm ja die beiden nicht-aggressiven Komponenten zur Verfügung, auf deren Basis und korrektiver Interaktion mit der aggressiven Komponente er im Verlauf seines Lebens zudem seine eigene Moralität, seine Normkanones und sittlichen Einstellungen entwickelt hat. Diese Moralität erhält durch das naturale Dispositiv des Menschen eine spezifische Rückbindung und $\mathrm{Fe}$ stigkeit, die sie daher als mehr denn nur eine ,zivilisatorische Tünche' erscheinen läßt und die entsprechend auch der Befürchtung einer Auflösung dieser Tünche durch gewalthaltige Filme entgegengestellt werden kann. Die naturale Grunddisposition des Menschen und seine auf deren Basis konstituierte Moralität läßt es daher durchaus begründet erscheinen, der Rezeption auch gewalthaltiger Filme nicht mit übergroßer Ängstlichkeit zu begegnen und den in der Rezeption realisierten Delektationen Vertrauen entgegenzubringen. Angesichts der anthropologisch erarbeiteten Konstitution des Menschen erscheint es daher ebenfalls legitim, da $B$ der so verfaßte Mensch als Medienrezipient seine Delektationsmöglichkeiten auch in der Rezeption gewalthaltiger Filme realisiert. Das unterhaltungsethisch eingeführte Kriterium der Selbstrealisation kann deshalb begründet und, ohne den Verdacht der ,Blauäugigkeit* erwecken zu müssen, auf die Unterhaltung durch diese Filme angewendet werden.

Umgekehrt aber verdeutlicht die anthropologisch geleitete Überlegung auch die Notwendigkeit der aufgestellten inhaltsethischen Grundnorm nochmals aus einer anderen Perspektive. So war schon in Auseinandersetzung mit der Bedeutung der menschlichen moralrelevanten Basalstrukturen, dem naturalen Dispositiv, deutlich, $\mathrm{daB}$ diese eben auch nur eine Disposition vorstellen. Keineswegs ist der Mensch durch die drei Strukturkomponenten unausweichlich in der Generierung seiner Verhaltensformen fixiert. Ich habe daher schon dort die Aufgabe für insbesondere die Pädagogik eingeführt, in ihrem erzieherischen Bemühen für eine gedeihliche Ausformung des Zueinanders der drei Komponenten und die Wahrung einer Balance zwischen ihnen Sorge zu tragen. Gerade bei der Entwicklung seiner Moralität ist diese Ausbalancierung von größter Wichtigkeit. Entsprechend ergibt sich daraus dann auch die Forderung, all jene Einflüsse und Momente aufzusuchen, die dieser Balance hinderlich sind und eine gedeihliche Einrichtung des Zueinanders der basalen menschlichen Strebungen obstruieren können. Zu solchen Einflüssen sind auch jene Formen der Gewaltdarstellung zu rechnen, die gegen die Grundnorm verstoßen. 
So hat die Rekonstruktion der Delektationsmöglichkeiten in diesem Zusammenhang bereits gezeigt, daß etwa die sadistische Appräsentation eine nur einseitige und sogar pathologische Rezeptionshaltung erlaubt, wenn eine Delektation überhaupt zustandekommen soll. Bei der Generierung einer solchen Delektation fände mithin gerade jene Legierung des an sich neutralen Aggressionsimpulses mit anderen Strebungen statt, die nicht wünschenswert ist. In der Tat kann der Aggressionsimpuls ja einer Vielzahl von Verhaltensformen dienstbar gemacht, also auch zur Durchsetzung eines negativen, destruktiven Verhaltens genutzt werden. Ähnlich verhält es sich dort, wo Gewalt verherrlicht oder propagiert wird. Hier bliebe eine Delektation insbesondere an der normativen Appräsentation und ihrer kognitiv-reflexiven Auffassung nur möglich, wenn die beiden nicht-aggressiven Komponenten übersprungen und gelähmt werden. Die Verharmlosung von Gewalt schließlich würde tendenziell in dieselbe Richtung führen - sie bedeutete letztlich ebenfalls eine Affirmation von Gewalt, die eine Übertölpelung der sozial-altruistischen Strebungen nötig machen würde, so sie noch delektativ aufgefaßt werden soll. Obschon sich aus der Appräsentation der illegitimen Gewaltdarstellungen nicht unmittelbar herleiten läßt, daß eine entsprechende Pathologisierung und Übertölpelung gelänge - unter Umständen fände das Publikum an solchen Darstellungen nur sein Mißvergnügen -, ist doch deutlich erkennbar, $\mathrm{daB}$ auch aus der Rekonstruktion der basalen moralrelevanten Antriebsstrukturen des Menschen die Illegitimität dieser Appräsentationsformen hervorgeht. Wo die Balance der drei Komponenten des Dispositivs die Rahmendirektive für alle Selbsteinrichung der menschlichen Handlungsstrukturen darstellt, können Formen, die, um überhaupt genießbar zu sein, zu einer Aufkündigung und Störung dieser Balance nötigen, nicht mehr als legitim betrachtet werden. Die inhaltsethisch aufgestellte Grundnorm leitet sich somit nicht nur aus der spezifisch ethischen Überlegung her, daß die von ihr illegitimisierten Darstellungsformen das Rahmenethos verletzen würden, sondern sie erhält durch die anthropologische Reflexion eine zusätzliche Plausibilität.

Damit aber kann nun insgesamt ein Doppeltes festgestellt werden: Zum einen erweist sich aus den anhand der Delektationsformen angestellten Überlegungen, da $\beta$ die Rezeption gewalthaltiger Filme, die der inhaltsethischen Norm entsprechen, zum Zweck der Unterhaltung durchaus Legitimität beanspruchen kann. Die in der unterhaltenden Aktivität stattfindenden Prozesse und die daraus hervorgehenden Delektationen sind ethisch keineswegs negativ zu beurteilen, sondern stellen ein legitimes ,vergnügliches' Verhalten des Menschen vor Augen. Zum zweiten aber erweist sich aus der hermeneutischen Überprüfung der Delektationen, die bei der Nutzung jener Filme möglich sind, die der inhaltsethischen Grundnorm gehorchen, sowie aus der anthropologischen Flankierung dieser Überprüfung, daB die Grundnorm sowohl plausibel als auch ausreichend ist. Gerade die Reflexion der Delektationsmöglichkeiten und die anthropologische Erarbeitung der menschlichen moralrelevanten Grunddispositionen nämlich hat gezeigt, daß eine Verletzung der inhaltsethischen Kriterien die Delektationen in eine pervertierte Form treiben würde. Umgekehrt aber ist ebenso deutlich erkennbar, da $\beta$ der anthropologisch eruierten Konstitution des Menschen prinzipiell Vertrauen entgegengebracht werden kann und die Grundnorm daher in suffizienter Weise alle wirklich prekären und ethisch intolerablen Appräsentationsformen von Gewalt umfaßt. Aus diesem Grund ist es nicht einsichtig, 
weshalb in der Frage der Legitimität von Gewaltdarstellung und -rezeption anders verfahren werden sollte als bei den übrigen inhaltsethischen Fragestellungen. Der Subjektcharakter des Menschen und seine damit supponierte Fähigkeit zu einer gedeihlichen Ausformung seiner Strebungen kann auch in Fragen der Gewaltrezeption zugrundegelegt werden, und es erscheint nicht nötig, der menschlichen Subjektivität gerade in diesem Bereich mit übergroßem Mißtrauen zu begegnen. Wenn die im Grundlegungsteil und im strukturethischen Baustein entfaltete ethische Axiomatik, die beim Menschen als Person und Subjekt mit der Fähigkeit zur autonomen Konstitution seiner selbst ansetzt und auf dieser Basis eine prinzipiell offene Kommunikationsstruktur fordert, gewahrt werden soll, so ist es sogar geboten, die Frage der Gewalthematisierung in Medien nicht restriktiver zu beantworten als die anderen, bereits geklärten inhaltsethischen Probleme. Soll dem (erwachsenen) Menschen in der offenen Kommunikationsstruktur der demokratischen Gesellschaft prinzipiell die Verantwortung für seinen Mediengebrauch unverstellt zugelastet werden und ihm Recht und Pflicht zur Ausbildung eines entsprechenden Rezipientenethos zugesprochen sein, dann gilt dies auch für die Rezeption gewalthaltiger Medienprodukte. Auf dem Hintergrund der unterhaltungsethischen und anthropologischen Reflexion erscheint es zudem auch möglich und legitim, dieses Zusprechen ohne Furcht vor einer Überforderung der moralischen Potenz des Menschen vorzunehmen. Daher bleibt auch in der Gewaltthematik lediglich ein Angriff auf das Rahmenethos der Gesellschaft, eine Verletzung der obersten Prinzipien und der Menschenrechte illegitim und ist als entsprechende Schranke nur das Verbot der propagandistischen, glorifizierenden, sadistischen oder verharmlosenden Appräsentation von Gewalt und des Aufrufs zur Gewaltanwendung aufzurichten. Außerhalb dieser illegitimen Formen aber muß die mediale Gehalteproduktion auch in ihrer kreativen Verarbeitung des Gewaltphänomens frei und offen bleiben.

Dieser inhaltsethischen, wiederum exklusiv vorgenommenen Normierung, die lediglich Grenzen gegen mit dem gesellschaftlichen Rahmenethos und der Wahrung der Menschenrechte nicht verträgliche Gewaltdarstellungen zieht, neigt nun weitgehend auch das Recht der Bundesrepublik zu. So bestimmt § 131 I StGB, daß die Herstellung, Verbreitung etc. von medialen Darstellungen, die „grausame oder sonst unmenschliche Gewalttätigkeit gegen Menschen in einer Art schildern, die eine Verherrlichung oder Verharmlosung solcher Gewalttätigkeiten ausdrückt", illegitim und strafwürdig ist. Weiter ist dort ausgeführt, daß auch die Herstellung, Verbreitung etc. von medialen Darstellungen illegitim ist, die „das Grausame oder Unmenschliche des Vorgangs in einer die Menschenwürde verletzenden Weise" appräsentiert. Damit konzentriert sich die Illegitimisierung des Strafrechts zunächst ebenfalls einmal auf die Glorifizierung von Gewalt, die ethisch aus den oben genannten Gründen verwerflich ist und juridisch dort gesehen wird, wo etwa Gewalttaten eine ,Berühmung als etwas Großartiges ${ }^{6}$ erfahren. ${ }^{95}$ Dem gesellt das Gesetz noch die Verharmlosung zu, welche dort gesehen wird, wo eine „Bagatellisierung“ von Gewalttaten ,als eine im menschlichen Leben übliche Form des Verhaltens oder mindestens als ,nicht verwerfliche Möglichkeit zur Lösung von Konflikten“" erfolgt. ${ }^{96}$

\footnotetext{
${ }_{95}^{9}$ vgl. Dreher/Tröndle, StGB, § 131 Rdn. $6 a$

${ }^{96}$ Dreher/Tröndle, StGB, § 131 Rdn. $6 \mathrm{~b}$
} 
Damit ist ein weiteres praktikables Kriterium geschaffen, das es erlaubt, etwa beiläufiger Gewaltappräsentation zu steuern, die die Gewalt als „belanglos, unbedeutend (...) oder gar als gleichsam selbstverständlich ${ }^{\star 97}$ erscheinen läßt. Medienethisch betrachtet käme eine solche Appräsentation einer Negierung des Rahmenethos durch Nihilisierung seiner Geltung gleich. Weiter enthält das Gesetz das Kriterium der Verletzung der Menschenwürde. Nach gängiger Auslegung wird dabei die Menschenwürde nicht als die einer konkreten Person, sondern als „abstrakter Rechtswert ${ }^{\text {“98 }}$ verstanden, der an sich schutzwürdig ist und nicht durch entsprechende Darstellungen verletzt, diskriminiert oder zerstört werden darf. Eine solche Verletzung liegt nach Ansicht des Schriftlichen Berichts des federführenden Ausschusses für Jugend, Familie und Gesundheit des Deutschen Bundestags insbesondere dann vor, wenn „das Thema Gewalttätigkeiten gegen Menschen in einer menschenunwürdigen bzw. -verachtenden Weise abgehandelt wird“" ${ }^{99}$ Hierunter sind „exzessive Schilderungen von Gewalttätigkeiten zu verstehen, die u.a. gegeben sind durch das Darstellen von Gewalttätigkeiten in allen Einzelheiten, z.B. das (nicht nur) genüßliche Verharren auf einem leidverzerrten Gesicht oder den aus einem aufgeschlitzten Bauch herausquellenden Gedärmen“. ${ }^{100}$ Das Kriterium der Verletzung der Menschenwürde will so dem Gesetz eine Handhabe geben, zynischen und exzessiven Gewaltdarstellungen zu steuern, auch wenn diese sich nicht ohne weiteres unter das Verherrlichungs- oder Verharmlosungskriterium fassen lassen. Aus medienethischer Perspektive kann dieser Impetus des Gesetzes als praktikable Konkretion einer durch bestimmte Gewaltdarstellungen geschehenden Mißachtung der Personwürde und der Menschenrechte aufgefaßt werden, wobei in dieser Mißachtung sogar eine tendenzielle Stellungnahme gegen diese Würde und Rechte liegen kann. Gerade die Exzessivität und die ausufernde, selbstzweckhafte Appräsentation enthält ja zweifelsohne eine Mißachtung der werthaften Ranghöhe der Personwürde und der Menschenrechte im System der ,Prinzipienideen' des gesellschaftlichen Rahmenethos. Eine solche Mißachtung, die der Wahrung der Bedeutung und Ranghöhe dieser Prinzipien entgegensteht, aber impliziert in der Tendenz eine Stellungnahme oder potentiell sogar eine Agitation gegen diese, die medienethisch nicht geduldet werden kann. Des weiteren kann die so erfolgende Gewaltappräsentation auch als sadistische Appräsentation verstanden werden, die durch ihre Exzessivität oder ihr ,genüßliches Verharren' zu einer sadistischen Kontemplation einlädt. So nennt der Kommentar als Beispiel für menschenrechtsverletzende Darstellungen auch solche, die „ein blutrünstiges Geschehen ausschließlich zur Erzeugung von Ekel und Nervenkitzel“ ausmalen. ${ }^{101}$ Auch die exemplarische Kriteriologie Hartliebs, der die Menschenwürde

${ }^{97}$ Hartlieb, Handbuch, Kap. 4 Rdn. 9 - Die Erläuterungen des Schriftlichen Berichts des federführenden Ausschusses für Jugend, Familie und Gesundheit des Deutschen Bundestages führen hierzu zudem aus, daß „bisher der Begriff der Verharmlosung zu restriktiv interpretiert wurde“. Gerade auch die Fälle einer ,beiläufigen" oder ,emotionsneutralen" Schilderung von Gewalt sollen fürderhin mit unter das Verharmlosungskriterium gerechnet werden, selbst wenn die Gewaltappräsentation ohne ein „Herunterspielen“ geschieht, „sofern derartige Schilderungen als ,selbstzweckhaft" einzuordnen sind". (Vgl. BT-Drs. 10/2546, 22)

98 Dreher/Tröndle, StGB, § 131 Rdn. $6 \mathrm{c}$

99 BT-Drs. 10/2546, 22

100 BT-Drs. 10/2546, 22

101 Dreher/Tröndle, StGB, $\$ 131$ Rdn. 6c 
durch Gewaltdarstellung verletzt sieht, wenn „diese Gewalttätigkeit in ihrer Grausamkeit direkt und detailliert ausgemalt oder genüßlich zelebriert, also wegen des sensationellen Effekts ausgespielt wird" ${ }^{102}$ kann medienethisch in dieser Weise interpretiert werden. Bei Gewaltdarstellungen dieser Art nämlich wäre in der Tat die delectatio emotionalis in eine schwerlich noch auch von einem Rezipientenethos vertretbare, sadistische Delektation hinein überschritten. Unter Voraussetzung der aufgeführten kommentatorischen Verstehensperspektive läßt sich daher dann das Kriterium der Menschenrechtsverletzung auch dort als anwendbar betrachten, wo die medienethisch illegitimisierte sadistische Appräsentation von Gewalt statthat. Im ganzen aber zeigt sich damit erneut, da $B$ die modernitätsgerechte medienethische Kriterienkonstruktion mit der Rechtskultur der Bundesrepublik zusammenklingt bzw. kompatibel ist und das Recht der Einlösung der medienethischen Forderungen flankierend zur Seite steht bzw. stehen kann.

Auf diesem Hintergrund rückt nun auch das Problem der Kriminalisierung in ein verändertes Licht und kann es differenziert inhaltsethisch behandelt werden. So läßt sich zunächst aus der oben entfalteten Prinzipienkonstruktion ableiten, da $B$ auf der Aussageebene von Medienprodukten wie zu Menschenrechtsverletzungen auch zu anderen Gewalttaten und Verbrechen nicht aufgerufen werden darf. Wie Gewalttaten und Verbrechen selbst illegitim sind, ist es auch der Aufruf zu ihnen oder ihre Propagierung. Propaganda und Aufforderung stellen mithin selbst eine Straftat dar, die in diesem Fall mit Hilfe medialer Vermittlung begangen wird. Der Appell an andere Personen, ein Verbrechen zu begehen, nämlich ist als Anstiftung zu bewerten, die nach $\$ 30$ I StGB selbst einen Straftatbestand darstellt. Eine solche Anstiftung kann nun zweifelsohne auch durch mediale Vermittlung geschehen, wenn etwa durch Schriften dazu aufgefordert wird, rechtswidrige Taten zu begehen. Daher ist nach \$ 111 I StGB jeder, der „öffentlich, in einer Versammlung oder durch Verbreiten von Schriften (...) zu einer rechtswidrigen Tat auffordert", wie ein Anstifter zu behandeln. Nach \$ 11 III StGB stehen dabei den ,Schriften“ „Ton und Bildträger, Abbildungen und andere Darstellungen in denjenigen Vorschriften gleich, die auf diesen Absatz verweisen", wie es $\$ 111$ I StGB auch tut. Seinen ethischen Grund nun findet das Verbot der Propagierung von und Aufforderung zu Straftaten darin, da $B$ durch Verbrechen und Gewalttaten die von den obersten ethischen Prinzipien sich herleitende Selbstentfaltung des Menschen und das gedeihliche Zusammenleben angegriffen und zerstört werden. Dies freilich ist keinesfalls legitim. Für eine Bestimmung illegitimer Handlungsformen - und damit auch illegitimer Propaganda derselben - ist dann medienethisch vordringlich das Strafgesetz - in geringerem Umfang die Zivilgesetzgebung - zu befragen. Dort finden sich im einzelnen jene Handlungsformen definiert, die als kriminell einzustufen und prinzipiell zu unterlassen sind und deren Evokation oder Propaganda ebenfalls illegitim ist. Die ethische Begründung für eine diesbezügliche Konsultation des Gesetzes ergibt sich dabei daraus, da $B$ das Gesetz eine Detaillierung und Konkretion der im Rahmenethos enthaltenen Prinzipien und Maximen auf Praxisregeln hin vornimmt, die die Selbstentfaltung des Einzelnen und das gesellschaftliche Zusammenleben ermöglichen und garantieren sollen. Das Strafgesetz nämlich formuliert im einzelnen jene Tatbestände, durch die ein

${ }^{102}$ Hartlieb, Handbuch, Kap. 4 Rdn. 11 
gedeihliches kollektives Miteinander und der individuelle Existenzvollzug gefährdet und bedroht sind. Es legt mithin die Grundwerte in konkrete einzelne Rechtswerte aus und formuliert Normen zu deren Schutz. Wie nun die Gefährdung des einzelnen Subjekts und des gedeihlichen gesellschaftlichen Lebens nicht durch Verbrechen generell erfolgen darf, darf sie auch nicht durch Verbrechen geschehen, die mit Hilfe medialer Vermittlung begangen oder eingeleitet werden. Daher ergeben sich die einzelnen Handlungsformen, die nicht evoziert oder propagiert werden dürfen, aus dem Gesetz selbst.

Doch kann sich die medienethische Reflexion wieder nicht darin erschöpfen, da $B$ der Aufruf zu Straftaten verboten ist. Sie muß sich vielmehr auch der Frage widmen, wie es um die Darstellung von Straftaten, mithin um die Verbrechensthematisierung in Medien bestellt ist. Gerade der Film erweist sich hier wiederum als Medium, der diese Reflexion erforderlich macht. So hat er mit dem Kriminalfilm ein Genre entwickelt - bzw. aus der Literatur übernommen -, das die Kriminalität geradezu zu ihrem hervorragenden und zentralen Gegenstand nimmt. Der Kriminalisierungsvorwurf der ,Tradition' hat dabei wiederholt gezeigt, $\mathrm{da} \beta$ dieses Genre gerade wegen der Darstellung von Verbrechen selbst als ethisch recht prekär beurteilt worden ist. Es gilt mithin, nun aus einer modernitätsgerechten Perspektive inhaltsethische Kriterien zu benennen, die diesem Problemkreis gerecht werden, ohne in die Pessimismen der ,Tradition' zurückzufallen. Hierbei nun sind die Überlegungen, die in Bezug auf die Gewaltthematik angestellt worden sind, wiederum hilfreich. Sie stellen in gewisser Weise Vorarbeiten auch für die Reflexion des Kriminalitätsproblems dar - mit dem sie sich zudem dort, wo Gewaltdarstellung und Verbrechensthematisierung gekoppelt sind, überschneiden - und sind analog zur Anwendung zu bringen. So ist zunächst wieder der Rezeption von Verbrechensdarstellungen durchaus Legitimität zuzusprechen. Wie bei der Gewaltrezeption findet darin eine Aktivierung der delectatio sensibilis, emotionalis, cognitionis und reflexiva statt. Da Verbrechen zudem einen größeren moralisch-reflexiven Anteil besitzen als Gewalt, wird in der Rezeption diesmal die delectatio reflexiva sogar einen breiteren Raum einnehmen. Wie schon erwähnt, geht es bei der Kriminalitätsdarstellung insbesondere im Kriminalfilm in der Regel ja auch und mitunter vordringlich um die narrative Erarbeitung der Motivstruktur des Täters, seiner Legitimationsstrategien, und um die Gesamtbewertung seines Handelns. Kriminalfilme haben daher meist explizit moralische Problemstellungen und fordern zu einer Reflexion ihrer normativen Implikationen geradezu heraus. Neben ,Spannung' und ,Aufregung' findet der Rezipient dort daher ein abundantes Feld für seine Selbstverständigung, für den spielerischen Vergleich der filmisch vorgetragenen Normen und Normkollisionen mit seinem eigenen Normkanon. Wie schon in der Diskussion der Gewaltproblematik festgestellt, muß dabei einer ,gedeihlichen' Auffassung des appräsentierten Materials nicht mißtrauisch begegnet werden. Der moralischen Kompetenz des Rezipienten und seiner Verarbeitungsfähigkeit kann durchaus getraut werden. Das Bild eines nach einem Kriminalfilm sich in begieriger Nachahmung ergehenden Rezipienten ist erneut und begründet zurückzuweisen. Auf dem Hintergrund des entfalteten Unterhaltungsbegriffs ist daher auch der Rezeption von Kriminalitätsdarstellungen Legitimität zu attestieren.

Daraus folgt freilich wiederum nicht, daß es für diese Darstellungen keine inhaltsethischen Kriterien gäbe. Vielmehr ist auch für die Darstellung kriminellen Verhal- 
tens, das ja realweltlich ein ethisch verwerfliches Verhalten ist, zu fordern, daß durch diese Darstellung keine Propaganda, Verherrlichung oder Verharmlosung dieses Verhaltens erfolgt. Nicht nur der oben bereits ausgeschlossene Aufruf zu Verbrechen stellt einen Angriff auf das Rahmenethos und die vitalen Lebensstrukturen der Gesellschaft dar und ist daher als illegitim zu beurteilen, sondern auch jede Darstellung, die den genannten Kriterien zuzuordnen ist. Wie die Verletzung des gesellschaftlichen, von allen zu teilenden Ethos illegitim ist, ist es auch jede Verherrlichung dieser Verletzung. Das Böse darf nicht gepriesen und gelobt werden. Es darf gleichwohl auch nicht verharmlost werden. Wer so tut, als seien Verbrechen tolerable und weiter nicht erhebliche Vorkommen in einer Gesellschaft, mißachtet die ethischen Prinzipien und Rahmenstrukturen. Zwar tut er das nicht in einer so drastischen Weise wie jemand, der zu ihrer Verletzung aufruft oder diese Verletzung glorifiziert. Doch begibt er sich durch die mit der Verharmlosung von Verbrechen vollzogene Geringschätzung dieser Prinzipien und Rahmenstrukturen zumindest in große Nähe zu einer solchen Mißachtung. Schließlich zeigt sich in Analogie zur sadistischen Appräsentation von Menschenrechtsverletzungen und Gewalttaten auch eine sadistische Darstellung von (anderen) Verbrechen als illegitim. Wo kriminelles Verhalten so dargestellt wird, daß das spezifisch Böse des Verhaltens genußfähig gemacht werden soll und keine übergeordnete korrektive Aussage oder reflexionsprovokative Absicht erkennbar ist, nähert sich die Darstellung einer prekären Affirmation und damit sogar einer Verherrlichung an. Als exklusive Grundnorm für die Verbrechensdarstellung zeigt sich mithin wiederum die bereits entwickelte Kriteriologie, die eine propagandistische, verherrlichende, verharmlosende und sadistisch-appräsentative Thematisierung ausschließt.

Gleichwohl ist diese Kriteriologie wiederum umsichtig und zurückhaltend zur Anwendung zu bringen. So ist nicht unbedingt zu fordern, daß jede Darstellung wertend sein müsse und stets die moralisierende Aussage der Verwerflichkeit von Gewalttat und Verbrechen vor sich her zu tragen habe, wie dies die Codes etwa der 50er Jahre taten. Wo nicht propagiert, verherrlicht und verharmlost wird, bleibt immer noch die Darstellung von Verstrickungen, Versehrungen und dergleichen legitim. Auch die reflektierte Appräsentation des spezifisch Bösen im kriminellen Verhalten, die eine Einsicht in die Motivstruktur und - für den Täter immer bestehende - negative ,Überzeugungskraft' kriminellen Handelns gewähren will, darf nicht einfach ausgeschlossen werden. Abgründe, Pathologien, psychodynamische Zusammenhänge und individuelle Erlebnisformen des kriminellen Agierens müssen dort Thema und Gegenstand medialer Darstellung bleiben können, wo die Darstellung reflektiert erfolgt. Selbst die Verführungskraft, die unter bestimmten psychischen, sozialen und situativen Voraussetzungen von Verbrechen ausgehen kann, kann unter dieser Voraussetzung reflektierter Appräsentation zum ,Kanon` legitimer medialer Themen gerechnet werden. In der Feststellung illegitimer medialer Gehalte nämlich ist zurückhaltend zu operieren. Die inhaltsethische Kriteriologie hat sich unter der Voraussetzung einer offenen Kommunikationsstruktur und einer Inhaltskonstitution durch den gesellschaftlichen Prozeß der Interaktion von Produzenten und Rezipienten selbst stets restringiert und vorsichtig zu verhalten, wenn ein Abgleiten in ein illegitimes Social engineering verhindert werden soll. Dieses Social engineering wäre auch als ,Moral engineering zumindest dort illegitim, wo es über die Wahrung des Rahmen- 
ethos hinausgreift. Einer solchen Ausweitung in der Anwendung der inhaltsethischen Kriteriologie aber ist nachdrücklich entgegenzutreten. Zur Anwendung gebracht werden darf diese Kriteriologie nur unter der strukturethischen Metanorm der Gebotenheit und mithin der gebotenen Wahrung der Offenheit der sozialen Kommunikation und ihrer medialen Organisation. Diese Metanorm muß daher bei jeder konkreten inhaltsethischen Prüfung von Medienprodukten berücksichtigt bleiben und zieht der Prüfung selbst wieder eine Grenze.

Die grundsätzliche Gebotenheit einer offenen Kommunikationsstruktur und die von dieser ermöglichte Konstitution der medialen Gehalte durch das Publikum und seine Interaktion mit den Produzenten ist auch in der Auseinandersetzung mit der inhaltsethischen Problematik des Umgangs mit der Sexualität bedeutsam. Dabei muß heute zwischen Thematisierung von Sexualität in Spielfilmen und Pornographie differenziert werden, die beide auch unterschiedlichen Zugangsräumen zugewiesen sind. Zunächst ist für den ersten Bereich zu sagen, daß die Thematisierung der menschlichen Sexualität selbstverständlich legitim ist. Sie stellt immerhin einen wesentlichen Lebensbereich und -bezug des Menschen dar und kann so weder einem gesellschaftlich vermittelten Diskurs noch der projektiv-spielerischen Selbstverständigung entzogen werden. Die gesellschaftliche Auseinandersetzung über Sexualität und die Freude an erotischen Szenen auch im Kino gehören beide mit zu den bereichernden Möglichkeiten fiktionaler Gehalteproduktion und -rezeption. Dabei ist wieder zu betonen, daß auf der Aussageebene Personwürde und Rahmenethos zu wahren sind. Konkretisiert bedeutet dies, daß der Aufruf zu sexuellen Gewalttaten, also etwa die Propagierung von Vergewaltigung, illegitim ist. Wo Gewalt im Spiel ist und mit Sexualität gekoppelt wird, greift zudem unmittelbar die für Gewaltdarstellung entworfene Kriteriologie. ${ }^{103}$ Jenseits der illegitimen Formen der Gewaltdarstellung hingegen muß einer reflektierten erotischen Darstellung Raum gegeben werden, die auch problematische Themen nicht ausschließt. Hierbei entscheidet vorwiegend die Zeitsituation selbst darüber, wie weit eine Darstellung von Erotik

${ }^{103}$ Hier kann durchaus legitim darüber diskutiert werden, ob diese Kriteriologie nicht im Bereich der erotischen Darstellungen sogar schärfer und restriktiver zur Anwendung zu bringen ist als bei nicht mit Sexualität konnotierter Gewaltdarstellung. So stellt jede Kombination von Sexualität mit Gewalt einmal eine Verletzung des der Sexualität inhärierenden Telos der $\mathrm{Zu}$ wendung dar. Nun kann zwar durchaus die Negation dieses Telos Thema einer Darstellung sein. Doch ist es unter Umständen geboten, die Frage, ob diese Darstellung in ausreichender Weise von jeder Verherrlichung, Verharmlosung und Propaganda abgegrenzt ist, strenger zu stellen als bei anderer Gewaltappräsentation. Gerade im sexuellen Bereich nämlich ist die Entstehung prekärer Legierungen von Antrieben und Strebungen zu befürchten, wenn die hochgradig lustbesetzte Erotik mit gewalttätigem Handeln kombiniert wird. Selbst wenn daraus nicht sogleich wieder ein Überschritt in mimetisches Handeln deduziert werden muß, ist doch die Gefahr der Versehrung und Pathologisierung nicht auszuschließen. Erotik spricht die menschlichen Strebungen ja weitaus unmittelbarer an, als dies bei der ,herkömmlichen' Gewaltdarstellung der Fall ist. Während es keinen,Gewalttrieb` gibt - das materiale Aggressionsverständnis wurde ja begründet zurückgewiesen - , ist im erotisch-sexuellen Bereich durchaus von einer Triebstruktur zu sprechen. Wo dann die erotische Stimulation mit Gewalt gekoppelt ist, kann eine Konfusion der Strebungen und eine Verletzung oder Versehrung des erotischen Empfindens drohen. Auch wenn daraus nicht sogleich die Generierung eines Heers von Vergewaltigern, Sadisten und in andere Pathologien verstrickten Menschen abgeleitet werden muß, bleibt die Gefahr einer Versehrung der sexuellen Strebungen unter Umständen Grund genug, hier eine strengere Anwendung der entwickelten Kriterien zumindest in Betracht zu ziehen. 
gehen kann und wo sie Grenzen zur Obszönität überschreitet. Im Unterschied zur Darstellung von Menschenrechtsverletzungen und Kriminalität können hier keine präzisen und weit ausgreifenden Kriterien im Sinn etwa der Festschreibung des ,Schicklichen' entworfen werden. Aus Gründen der mehrfach vor Augen getretenen Zeitverhaftetheit erotischer Konnotationen lassen sich ethisch keine ,Anständigkeitsschwellen' festlegen. Jene Schwellen entsprechen zusammen mit der sexuellen Affizierung durch bestimmte Signale und Bilder einzig der jeweiligen zeitgenössischen Fixierung von Erregungsniveaus auf diese Signale und Bilder. Selbst eine formale Aussage, die Darstellung habe sich auf das jeweilige, zeittypisch als legitim erachtete Stimulationsniveau zu beschränken, aber läßt sich nicht treffen. In der Überschreitung solcher Niveaus nämlich vermag sich ein durchaus legitimer Ethoswandel auszudrücken, der ethisch nicht von vorneherein ausgeschieden werden darf. Die konkrete Zulässigkeit von erotischen Darstellungen muß deshalb von der Medienethik dem gesellschaftlichen Diskurs zur Sexualethik überhaupt, dem Streit der Meinungen, den Experimenten der Produktion, der Interaktion von Produzenten und Rezipienten überantwortet werden. Zurückzuweisen ist dabei außerdem erneut die Schreckensvorstellung, da $B$ aus der Thematisierung menschlicher Sexualität eine Evokation etwa überhandnehmender Triebtäterschaft deduziert werden müsse oder könne, wie dies gegenwärtig zeitgenössische Feminismen in unfreiwilliger Konnotation zur Kinoreformbewegung tun. Freilich stimuliert die Betrachtung erotischer Szenen entsprechende Strebungen und Lüste, und sie tut dies in einem unmittelbareren Verhältnis zwischen fiktionalem Inhalt und Realität als etwa die Gewaltdarstellung. Doch nimmt dies den Subjekten nicht ihre Autonomie in der interpretativen Auffassung und Verarbeitung der gebotenen Reize. Eine Überschwemmung, der durch Barrieren gewehrt werden müßte, ist kaum anzunehmen.

Schwieriger liegt der Fall bei der Pornographie, die einer umfassenderen ethischen Reflexion bedürfte, als es hier möglich ist. In bezug auf Pornographie ist ja schon die Frage, ob sie ethisch überhaupt zulässig sei, äußerst strittig. Diese Frage ist das jedoch - ähnlich der nach der ethischen Verortung von Prostitution - schon seit sehr langer Zeit und hat selbst bei Negativantwort das Phänomen nicht auszurotten vermocht. Stattdessen führt eine Prohibition pornographischer Darstellungen zu denselben Phänomenen, wie es die des Alkohols in den USA tat, nämlich statt zur Beseitigung lediglich zur Kriminalisierung der Herstellung, Beschaffung und Verbreitung dieser Darstellungen. Unter dem Aspekt einer sozialethischen Güterabwägung kann es daher unter Umständen als das geringere Übel gewertet werden, die Pornographie in regionalisierten Bereichen zuzulassen, als sie zu verbieten. Wie in Spielfilmen mit erotischem Bezug darf dann freilich auch in pornographischen Produktionen nicht zu Gewalttaten und Menschenrechtsverletzungen aufgerufen werden und keine diesbezügliche Propagierung stattfinden. Die Kombination von Gewalt und Pornographie ist als noch weitaus bedenklicher einzustufen als die mit erotischen Darstellungen. Gewalthaltige Pornographie muß daher medienethisch als illegitime Form eingestuft werden. Entsprechendes gilt für die gegenwärtig auftretende, die Personwürde hochgradig verletzende Kinderpornographie und die Darstellung der diversen Pathologien. Das Verbot des Aufrufs zu Menschenrechtsverletzungen schließt außerdem ein, daß gemäß der bereits entwickelten Kriteriologie auf der Aussageebene auch keine propagandistische Verketzerung von Frauen und Männern 
in ihrer Geschlechtsspezifität stattfinden darf. Gleichwohl ist dieses Prinzip nicht identisch mit einer verbothaften ,Lösung' der heute vieldiskutierten Diskriminierungsproblematik, die solche Diskriminierung schon durch die inhaltlichen Darstellungen der Pornographie gegeben sieht und eine strafrechtliche Sanktionierung von Pornographie überhaupt fordert. Aussageebene und Inhaltsebene müssen unterschieden werden, wenngleich auch zuzugestehen ist, daß diese Scheidung beim pornographischen Film nur mit Schwierigkeiten zu vollziehen ist. Sie bleibt aber notwendig und ist in jedem einzelnen Fall, in dem eine Verletzung der Personwürde durch einen solchen Film angemahnt wird, differenziert und präzise vorzunehmen, soll einer ethischen und strafrechtlichen Pauschalisierung gewehrt werden. Auch in Sachen Pornographie nämlich darf der fiktionale Inhalt nicht mit der Realität verwechselt werden und ist das inhaltliche Angebot für projektive ,Selbstverständigung und Fantasietätigkeit mit einem Aufruf oder einer Propagierung nicht gleichzusetzen. Obschon in dieser Thematik noch vieles zu klären wäre, kann damit vorerst festgestellt werden, daß sich unter den angedeuteten Prämissen selbst die Pornographie zumindest unter sozialethischem Aspekt als tolerables Phänomen im Sinn der Domestizierung eines malum erwiese.

Diesen Weg geht auch das Strafgesetz. So bestimmt $\$ 184 \mathrm{III} \mathrm{StGB,} \mathrm{daß} \mathrm{u.a.} \mathrm{die}$ Verbreitung von Pornographie, die „Gewalttätigkeiten, den sexuellen Mißbrauch von Kindern oder sexuelle Handlungen von Menschen mit Tieren zum Gegenstand haben“, einen Straftatbestand darstellt. Ausgeschlossen und kriminalisiert werden mithin die Extremformen im pornographischen Bereich, während - im Sinn der Domestizierung eines malums - Pornographie nicht einfach zur Gänze verboten wird. Auch das Verbot in $\S 184$ I StGB, pornographische Gehalte an Kinder und Jugendliche gelangen zu lassen, kann - neben der jugendschützerischen Bedeutung als solches Domestizierungsunterfangen betrachtet werden. Auf dieser Linie liegt zudem die Regionalisierung des Angebots, wenn nach § 184 I StGB pornographisches Material nur in geschlossenen Räumen, die von außen nicht eingesehen werden können und Kindern und Jugendlichen nicht zugänglich sind, appräsentiert werden darf. Darüber hinaus enthält § 184 I StGB noch weitere Vorschriften, die den Zugang zu pornographischem Material zwar nicht zur Gänze verunmöglichen, jedoch strengen Beschränkungen unterwerfen. Pornographie wird auf diese Weise sowohl inhaltlich wenigstens in bezug auf ihre Extremformen restringiert als auch in ihren Verbreitungschancen örtlich und personengruppenbezogen regionalisiert. Damit beschreitet das Strafgesetz einen der medienethischen Überlegung ähnlichen, weder prohibitiven noch permissiven Weg.

Aus der medienethischen Prinzipienkonstruktion nun geht schließlich noch die Grenzziehung hervor, daß durch mediale Inhalte kein Angriff auf den Staat und seine Verfassung geführt werden darf. In der Verfassung kristallisiert sich ja das Rahmenethos der Gesellschaft, und wird es in politisch-strukturelle Maximen und Vorschriften übertragen, die die Einrichtung der demokratischen Gesellschaft organisieren. Der Staat wiederum stellt die übergeordnete Strukturorganisation dieser Gesellschaft dar und garantiert mit seinen Untergliederungen und institutionellen Einrichtungen den Bestand der demokratischen Gesellschaft. Da nun aus der ethischen Axiomatik gerade hergeleitet wurde, daß die Demokratie die zugepaßte politische Strukturorganisation der als autonome Subjekte begriffenen Personen ist, bedingt es 
diese Axiomatik auch, daß jeder Versuch, den demokratischen Staat zu zerstören und seine Verfassung außer Kraft zu setzen, als prinzipiell illegitim einzustufen ist. Weiter aber bedingt es die entwickelte ethische Axiomatik, die beim Personprinzip und Subjektgedanken ansetzt, daß auch die Subjekte in anderen Staaten, ihr Selbstbestimmungsrecht und ihr Recht, sich eine eigene politische Strukturorganisation zu geben, zu achten und zu wahren sind. Auch ein Angriff auf andere Staaten, der in der Absicht geführt wird, diesen zu zerstören, ist entsprechend medienethisch prinzipiell illegitim. Schließlich muß unter Voraussetzung der gebotenen gedeihlichen Einrichtung nicht nur des binnenräumlichen Zusammenlebens der Subjekte, das jedem seine Realisierungschancen und Mitspracherechte einräumt, sondern auch des internationalen Zusammenlebens zudem jeder Destruktionsversuch auf dieser Ebene als illegitim betrachtet werden.

In Blick treten mithin drei Handlungsfelder im medialen Bereich, auf denen bei der inhaltlichen Produktion bestimmte Grenzen zu wahren sind: Zum einen ist jeder Inhalt medienethisch abschlägig zu beurteilen, der gegen Verfassung und Staat agitiert und einen Umsturz herbeizuführen versucht. Der demokratische Staat und seine Verfassung sind unbedingt schutzwürdig, und im Fall eines Angriffs auf sie besitzt daher jeder Staatsbürger ein Recht auf Widerstand gegen die Auflösung der Demokratie selbst. Weiter ist in diesem Feld aber auch jeder medial vermittelte, von der Absicht der Zerstörung getragene Angriff auf die verfassungsmäßigen Organe und die institutionellen Einrichtungen des Staates illegitim. Durch sie wird ja der demokratische Staat selbst gegliedert und strukturell-konkret realisiert. Soll also der Staat funktionsfähig bleiben, kann auch die in destruktiver Absicht vollzogene Agitation gegen seine Organe, Institutionen und Strukturen nicht geduldet werden. Im konkreten bedeutet das, da $B$ etwa der Aufruf zu terroristischen Aktionen gegen staatliche Einrichtungen oder die Unterstützung solcher Aktionen durch Medien verwerflich ist. Auch die Bereitstellung von Informationen, die mit dem Ziel der Ermöglichung terroristischer Akte erfolgt, oder Anleitungen zur Durchführung solcher Akte - wie sie etwa in diversen ,Handbüchern' der RAF enthalten waren - sind grundsätzlich illegitim. Im ersten Feld geht es so also um die Sicherung und Wahrung der internen Grundlegung und Organisation des Staates und der Demokratie. Zum zweiten gilt es dann auch, das Verhältnis des Staates zu anderen Staaten nicht zu gefährden. Die politische Organisation eines gedeihlichen Zusammenlebens der Subjekte und ihrer Selbstrealisierungschancen ist nicht nur auf der Ebene eines Staatswesens selbst zu wahren, sondern muß auch auf der Makroebene des internationalen Miteinanders zureichend eingerichtet werden können. Eine solche Einrichtung aber wäre gefährdet, wo die Beziehungen der Staaten untereinander durch mediale Agitation destruktiv beeinflußt werden sollen. Dies kann zudem im Extremfall auf die Existenz des eigenen Staates zurückwirken, wenn durch medial geschürte Beziehungsstörungen etwa Kriege mitbedingt werden. Konkret bedeutet dies wiederum, daB etwa die Veröffentlichung von eigenen und fremden Staatsgeheimnissen untersagt ist, sofern der Titel des Staatsgeheimnisses nicht seinerseits illegitim, d.h. in einer mit der Verfassung und der Gesetzgebung nicht vereinbaren Weise, beansprucht wird. Auch die Vortäuschung von Sachverhalten, die die internationalen Beziehungen gefährden können, ist in diesem Zusammenhang zu sehen. Sie wird nicht nur durch das journalistische Wahrheitsgebot, sondern auch durch die inhaltsethische 
Maxime illegitimisiert. Ebenso ist jede kriegstreiberische Propaganda, die direkt zum Krieg aufhetzen will, grundsätzlich verwerflich. Zum dritten ergibt sich in diesem Zusammenhang auch das Gebot der Achtung des Selbstbestimmungsrechts der Staatsbürger in anderen Staaten und anderer Staaten selbst. Die medial betriebene Agitation gegen andere Staaten und ihre Mitglieder ist daher ebenfalls als illegitim zu beurteilen. Jede Verketzerung anderer Staatswesen und ihrer Staatsbürger bedeutete einen Angriff auf deren Selbstbestimmungsrecht und im letzten wieder einen Angriff auf den Personstatus der in diesem Staat lebenden und ihn tragenden Menschen. Insbesondere die Agitation für eine kriegerische Auseinandersetzung muß auch in diesem Kontext untersagt werden, die neben dem Selbstbestimmungsrecht auch das Recht auf Leben treffen und verletzen würde.

Mit diesen grundsätzlichen Überlegungen sind so bereits auch grundlegende Grenzlinien für die mediale Gehalteproduktion ausgezogen. Diese Grenzen finden sich um ihrer praktischen Durchsetzbarkeit und Einhaltung willen wieder rechtlich fixiert. So bestimmen etwa $\S 81 \mathrm{StGB}$, daß der Hochverrat gegen den Bund, und $\S 83$ $\mathrm{StGB}, \mathrm{da} ß$ auch die Vorbereitung eines Hochverrats gegen den Bund ebenso wie gegen ein Land strafwürdig sind. Dabei kann die illegitime Vorbereitung auch die „geistige oder seelische Beeinflussung der Bevölkerung des Staates sein, gegen den das Unternehmen geplant ist“", und mithin durch Medien erfolgen. ${ }^{104}$ Nach § 90b StGB ist jede, auch die durch mediale Vermittlung geschehende, Verunglimpfung von Verfassungsorganen strafwürdig, die das Ansehen des Staats gefährdet und mit der sich jemand "gegen den Bestand der Bundesrepublik Deutschland oder gegen Verfassungsgrundsätze einsetzt“. $\$ 90$ a StGB wiederum stellt unter Strafe, wenn jemand „öffentlich, in einer Versammlung oder durch Verbreiten von Schriften (...) 1. die Bundesrepublik Deutschland oder eines ihrer Länder oder ihre verfassungsmäßige Ordnung beschimpft oder böswillig verächtlich macht oder 2. die Farben, die Flagge, das Wappen oder die Hymne der Bundesrepublik Deutschland oder eines ihrer Länder verunglimpft“. Weiter sind nach Art. 9 II GG die Gründung und der Unterhalt von Organisationen illegitim, die sich gegen die verfassungsmäßige Ordnung richten. Diese Rahmenvorschrift wird medienbezogen konkretisiert, wenn etwa § $86 \mathrm{StGB}$ das Verbreiten von Propagandamitteln verfassungswidriger Organisationen und die Herstellung solcher Propagandamittel zu diesem Zweck untersagt. Entsprechendes gilt nach § 86a StGB für die Verwendung der Kennzeichen verfassungswidriger Organisationen. Auch die verfassungsfeindliche Einwirkung auf die Bundeswehr und öffentliche Sicherheitsorgane, die von $\S 89 \mathrm{StGB}$ unter Strafe gestellt wird, gehört in diesen Zusammenhang der Konkretisierung illegitimer verfassungswidriger Handlungsweisen, die mit Hilfe von Medien realisierbar wären. Mit all diesen Bestimmungen werden so präzise Handlungsformen benannt, die gegen den demokratischen Staat und seine Verfassung gerichtet sind und durch Medien erfolgen können. Das Strafgesetzbuch enthält damit eine Sammlung von bestimmten Einzelnormen, die alle auf den Schutz des demokratischen Staats gerichtet sind und den Grenzen, die im ersten inhaltsethischen Feld gezogen worden sind, Durchsetzbarkeit verschaffen.

Weiter werden jedoch auch die illegitimen Medienprodukte und durch sie realisierten Handlungsformen des zweiten und dritten Felds im Strafgesetzbuch aufge-

${ }^{104}$ Dreher/Tröndle, StGB, § 83 Rdn. 4 
griffen. Im Hintergrund steht dabei zunächst die Vorschrift von Art. 9 II GG, die jede Vereinigung verbietet, die sich ,gegen den Gedanken der Völkerverständigung“ richtet. Nicht nur solche Zusammenschlüsse jedoch sind untersagt, sondern auch deren Erhaltung und Förderung sowie mediale Propaganda für sie. So bestimmt $\S 86$ II $\mathrm{StGB}$, daß die Verbreitung von Propagandamitteln von Vereinigungen verboten ist, die sich "gegen den Gedanken der Völkerverständigung“ richten, und überträgt damit wortgleich die Bestimmung der Verfassung in eine konkrete medienbezogene Strafvorschrift. Weiter wird etwa in $\S 103$ StGB die Beleidigung von Organen und Vertretern ausländischer Staaten illegitimisiert. Die durch Medieninhalte vorgenommene Beleidigung wird dabei in Abs. 2 ausdrücklich genannt. Neben diesen Formen der Gefährdung der zwischenstaatlichen Beziehungen und des Friedens wird jedoch auch der Verrat von Staatsgeheimnissen strafrechtlich behandelt und der möglichen Rolle der Medien hierbei Rechnung getragen. So ist nach § $94 \mathrm{StGB}$ der Verrat von Staatsgeheimnissen auch etwa durch deren Veröffentlichung in Medien strafwürdig, wenn dabei „die Gefahr eines schweren Nachteils für die äußere Sicherheit der Bundesrepublik Deutschland" herbeigeführt wird. Ebenso ist nach $\S 100$ a I StGB die landesverräterische Fälschung strafbar, d.h. die Übermittlung oder Veröffentlichung "unwahre(r) Behauptungen tatsächlicher Art", durch die „die Gefahr eines schweren Nachteils für die äußere Sicherheit oder die Beziehungen der Bundesrepublik Deutschland zu einer fremden Macht" heraufbeschworen werden könnte. Des weiteren sind auch alle Formen der Vorbereitung und Begünstigung von Kriegen, an denen die Bundesrepublik beteiligt sein soll, rechtlich erfaßt. Im Hintergrund steht hier Art. 26 I GG, der ausdrücklich - nicht zuletzt aus der Erfahrung des Nationalsozialismus heraus - festlegt, da $B$ alle „Handlungen, die geeignet sind und in der Absicht vorgenommen werden, das friedliche Zusammenleben der Völker zu stören, insbesondere die Führung eines Angriffskrieges vorzubereiten, (...) verfassungswidrig“ sind. Gemäß der Vorschrift dieses Artikels, daß solche Handlungen „unter Strafe zu stellen“ sind, werden im Strafgesetz entsprechende Einzelmaximen geschaffen, die auch medienbezogen ausgelegt werden. So bedroht zunächst $\S 80$ StGB generell die Vorbereitung eines Angriffskriegs, an dem „die Bundesrepublik Deutschland beteiligt sein soll" und durch die "die Gefahr eines Krieges für die Bundesrepublik Deutschland" herbeigeführt wird, mit Strafe. Die medienethisch relevante Wendung dieser generellen Vorschrift findet sich dann in $\$ 80 \mathrm{a} \mathrm{StGB}$, der die ,Aufstachelung' zum Angriffskrieg, also die mediale Kriegstreiberei, unter Strafe stellt. Mit diesen und weiteren von der Verfassung getragenen und strafrechtlich konkretisierten Bestimmungen finden sich also auch die Grundnormen im zweiten und dritten Feld durch Gesetze realisiert und wird der medienethischen Normierung auch hier Durchsetzungskraft verliehen. Damit zeigt sich zugleich erneut, daß eine modernitätsgerechte Medienethik mit dem Recht der demokratischen Gesellschaft der Bundesrepublik zusammenklingt.

Die in dieser Weise aufgestellten Grundnormen bedeuten gleichwohl wiederum nicht, daß durch sie jede Form von Kritik ausgeschlossen wäre. Mit ihnen ist durchaus nicht im Sinn des Vorwurfs der sozialen Destabilisierung, wie ihn die ,Tradition vor allem der Kinoreformer vorgebracht hat, eine Restriktion des medial vermittelten Diskurses oder die Aufkündigung der offenen Kommunikationsstruktur angezielt, sondern gerade die Wahrung derselben. Nur in der demokratischen Gesell- 
schaft und durch deren Verankerung in der Verfassung und Organisation im demokratischen Staat ist diese offene Komunikationsstruktur ja wirklich garantiert. Der Schutz von Demokratie, Verfassung und Staat schützt damit diese Struktur und den Diskurs mit. Entsprechend bleibt unterhalb der aufgestellten Grundnormen und ihrer rechtlichen Fixierung dieser Diskurs in all seinen Möglichkeiten erhalten und muß er es auch bleiben. Das impliziert, daß auch Fragen der gesellschaftlichen Selbstorganisation des Menschen, aktuelle soziale Problemstellungen und politische Bezüge verarbeitet, reflektiert und kritisiert werden dürfen. Hierbei darf dem medial vermittelten Diskurs kein Stein in den Weg gelegt werden. Sowohl die Auseinandersetzung mit den internen Verhältnissen in Staat und Gesellschaft als auch mit den internationalen Beziehungen und den Verhältnissen in anderen Staaten bleiben unterhalb der Grundnormen durchaus offengehalten und möglich. Sie sind sogar medienethisch geboten. So wird gerade in einer demokratischen Gesellschaft deren kritische Auseinandersetzung mit sich selbst auch über die Medien vollzogen und bleibt der medialen Gehalteproduktion immer auch ein Stück weit eine Wächterfunktion gegenüber der Wahrung der demokratischen Verhältnisse zuzumessen. Wo der Staat und staatliche Organisationen sich gegen die Verfassung zu entwickeln beginnen, wo gesellschaftliche Strukturen sich in Richtung einer Totalisierung entwikkeln, dort ist dann auch gerade der mediale Diskurs zu Protest und Einspruch aufgerufen. Nicht nur haben nach der Verfassung ,alle Deutschen das Recht zum Widerstand" gegen jeden der es ,unternimmt, die verfassungsmäßige Ordnung zu beseitigen' (Art. 20 IV GG), sondern es sind ethisch auch alle gesellschaftlichen Kräfte, d.h. auch die Medien, zum Schutz der Demokratie und ihrer Ordnung aufgerufen. Das schließt Kritik an jeder zu den demokratischen Grundsätzen in Widerspruch stehenden Erscheinung ein und verpflichtet zu einer kritischen Begleitung des Gesellschaftsprozesses. Weiter sind auch die Beziehungen eines demokratischen Gemeinwesens zu anderen Staaten durchaus Angelegenheiten, die im öffentlichen Diskurs kritisch behandelt und vermittelt werden können und sollen. Die medienethische Bestimmung richtet sich hier keineswegs gegen eine kritische Auseinandersetzung oder die Initiierung einer Diskussion. Ausgeschlossen und illegitmisiert sind lediglich friedensgefährdende und darin gerade diskursfeindliche, destruktive und verhetzende Bestrebungen. Die Völkerverständigung darf nicht zerstört werden, sehr wohl aber darf sie als auch kritische Verständigung eingeleitet, unterstützt und befördert werden. Ebenso kann es unter Umständen geradezu geboten sein, aus der Perspektive der demokratischen Grundsätze heraus die Verhältnisse in anderen Staaten kritisch zu beleuchten und Bewußtsein für die dortige gesellschaftliche Situation zu befördern. Dies kann dann auch Demokratisierungsprozesse und Verbesserungen in der Wahrung der Menschenrechte in diesen Staaten mit befördern. Gerade die Umschichtungen in Südafrika und die Auflösung der Apartheid können als einer der Prozesse begriffen werden, an denen auch die nicht-afrikanischen Medien ihren Anteil hatten und haben. Die Grundnormen im Bereich der politischen Valenz der Medien bedingen so nicht eine Störung und Behinderung ihrer kritisch-diskursiven Kraft, sondern wollen sie gerade in diese hinein freisetzen. Sie schließen weder Kritik aus, noch intendieren sie das Gebot einer bloß affirmativen Beschäftigung mit dem Gegebenen, sondern sie richten sich einzig gegen umstürzlerische, friedensgefährdende und böswillige Agitation und Verhetzung. 
Auf dem Hintergrund der so entfalteten inhaltsethischen Überlegungen kann nun zuletzt auch noch knapp auf die Bedenken vor allem der Kritischen Theorie gegenüber ökonomisch vermittelten Standardisierungsphänomenen inhaltsethisch eingegangen werden. Diese Sorge kann als eine um die Pluralität und Spezifität der Gehalte gelesen werden. So schien einmal durch Standardisierung und ,Entspezifizierung' versucht zu werden, binnenmarktbezogen Erfolge zu repetieren bzw. schichtübergreifende Rezipierbarkeit zu erzeugen und das Publikum an ,genormte Ware' zu gewöhnen. Zum anderen schien die internationale Auswertung des Films eine Entspezifizierung der Inhalte zum Zweck nationen- und kulturenübergreifender Rezeptionsmöglichkeit Platz zu greifen. Während im ersten Fall die Pluralität der Inhalte bedroht und in Wiederholungen unterzugehen scheint, droht im zweiten Fall die Differenziertheit und Verschiedenheit der Kulturen einer Nivellierung anheim zu fallen. Weder die konkurrierende Vielfalt der Meinungen, Einstellungen und Überzeugungen einer Gesellschaft noch die Buntheit der Kulturen scheint zum Ausdruck zu kommen. Dazu läßt sich aus den anthropologischen und ethischen Überlegungen der Grundlegung folgendes sagen: Binnengesellschaftlich bezogen scheint mir dieselbe Dialektik von Entwurf und Entlastung festzustellen zu sein wie in bezug auf die individuelle menschliche Person. So, wie für das Individuum dauernde Entwurfsanspannung überfordernd wirkt, tut dies auch die gesellschaftliche Dynamik eines nur auf Veränderung und Widerstreit der Meinungen ausgelegten Diskurses. Nicht nur der Einzelne, auch das gesellschaftliche Kollektiv bedarf daher einer entlasteten Affirmation seiner Befindlichkeit, der Repetition von Bekanntem und der Bestätigung durch Vertrautes. Eben dies liefert der Film, wo er Erfolge zu wiederholen trachtet und erfolgreiche, d.h. publikumsbegünstigte Inhalte reproduziert. In der ökonomisch vermittelten, zeitweiligen Stabilisierung der Gehalteproduktion und -rezeption äußern sich mithin ein durchaus legitimes gesellschaftliches Bedürfnis und ein legitimer StrukturprozeB. Dieser muß noch keineswegs als Gefährdung von Pluralität und Wandel ausgelegt werden. In der Tat besteht ja das Publikum auch aus entwurfsorientierten, nach neuem und vorwärts drängenden Personen, so da - wie mehrfach an empirischem Material belegt - Standardisierungen sich auch nicht ungebührlich lange durchhalten lassen. Das Fortschreiten des Diskurses wird von den Stabilitätsbedürfnissen und -neigungen nicht dauerhaft gehindert. Auch die Entspezifizierung von Gehalten, die diese einem breiteren Publikum zugänglich halten will, scheint mir legitim. Binnengesellschaftlich äußert sich in ihr eine Art ,Minimalkonsens' der verschiedenen Gruppen und Schichten, der bei ethischer Standardisierung in Konnotation mit dem Rahmenethos gesehen werden kann. Auf internationaler Ebene wiederum kann ein solcher ,Minimalkonsens' als allmähliche Schaffung einer ,weltumspannenden Rahmenkultur' betrachtet werden, in der sowohl kulturübergreifende ,Universalien' zusammenfließen, als auch solche erst entstehen. In beiden, entspezifizierenden' Phänomenen tritt mithin eine spezifisch integrierende Kraft des Films zutage, die der schicht-, gruppen- und kulturübergreifenden Verständigung dient. Die binnengesellschaftliche wie die internationale Standardisierung und Affirmation wollen mir daher inhaltsethisch durchaus legitim erscheinen. 
Institutionsethischer Baustein: Überlegungen zu Aufgaben und Grenzen institutionalisierter Kommunikationskontrolle im Filmbereich am Beispiel von FSK und BPS

Obschon nun zu wünschen ist, daß die skizzierte Inhaltsethik mit ihren Rahmenvorschriften nicht nur ein Geschäft des Ethikers bleibt, sondern zugleich die Basis des Kommunikatorenethos der Produzenten darstellt, verweist schon die Tatsache, daß ein gut Teil der inhaltsethischen Kriterien in Gesetzen aufgefangen ist, darauf, daß es mit der Forderung eines der Inhaltsethik verpflichteten Kommunikatorenethos allein nicht getan ist. Dem grundsätzlichen material-ethischen Rahmen, der mit den inhaltsethischen Maximen und Kriterien vorgegeben ist und jene ethischen Essentials benennt, auf die durch ihre enge Verknüpfung mit den obersten ethischen Prinzipien und dem Rahmenethos keinesfalls verzichtet werden kann, muß ob seiner Essentialität auch eine entsprechende strukturelle Durchsetzungskraft gegeben werden. Dies nun geschieht nicht allein durch die Gesetzesvorschriften, sondern auch auf dem Weg der Institutionalisierung einer gesellschaftlichen Kommunikationskontrolle, die über die Einhaltung der medienethischen Grundsätze, und das heißt auch insbesondere der Inhaltsethik, wacht. Darüber hinaus ist im strukturethischen Baustein bereits deutlich geworden, $\mathrm{da} ß$ nicht nur die grundsätzliche Legitimität und Illegitimität von Medienprodukten in den Blick zu nehmen ist, sondern zusätzlich über eine Verteilung und Staffelung der Zugangschancen zur Rezeption von Mediengehalten nachgedacht werden muß. Wie die Lösung des Problems legitimer und illegitimer Inhalte nicht allein dem Kommunikatorenethos anvertraut werden kann, kann dabei auch die Frage der Einrichtung der Rezeptionsformen nicht nur dem Rezipientenethos zugelastet werden. Insbesondere dort, wo es sich um Rezipienten handelt, die noch auf dem Weg zu ihrer Mündigkeit sind, würde eine einseitige Lösung in diesem Sinn eine Überforderung des - noch in der Ausbildung befindlichen Ethos dieser Rezipienten bedeuten.

Im Filmbereich erwachsen damit zwei grundsätzliche Aufgaben, die unter Mitwirkung von Institutionen erfüllt werden können: Einmal gilt es zu fragen, ob und inwieweit der Film die offene Kommunikationsstruktur der Gesellschaft in der rechten Weise gebraucht bzw. inwieweit ein Mißbrauch derselben ausgeschlossen ist. Hier bedarf es näherhin insbesondere der Prüfung der bereits produzierten Filme auf ihr Verhältnis zu den inhaltsethischen Grundnormen, in denen die Grenzen ausgezogen worden sind, die gerade um der Wahrung der freiheitlichen Gesellschaft und ihrer grundlegenden ethischen Axiomatik willen einzuhalten sind. Zum anderen aber gilt es auch, den Erfordernissen des Jugendschutzes gerecht zu werden und spezifische Einlösungsformen hierfür zu finden. Gerade der Jugendschutz hat sich ja ebenfalls als von den obersten ethischen Prinzipien und dem freiheitlichen Ansatz her gebotene Unternehmung erwiesen. Obschon nun der Jugendschutz als Teil einer Erziehung zur Mündigkeit verstanden werden muB und so nicht mehr als flankierende Maßnahmen konstituieren kann, bleibt er in einer Gesellschaft unverzichtbar, die um der Ausübung der Mündigkeit willen ihre Medienproduktion weitgehendst autonom hält und nicht generell am ,schwächsten Glied' ausrichten will. Nicht alle Gehalte sind für alle Altersklassen gleichermaßen geeignet. Soll mithin die Produktion nicht einzig auf die niederste Klasse ausgerichtet sein, so tut eine entsprechende Einrichtung der Zugangschancen zur Rezeption not. Beide Aufgaben nun werden in der 
Bundesrepublik vor allem durch zwei Institutionen wahrgenommen, die für die Prüfung von Filmen unter je spezifischen Modi zuständig sind. Es handelt sich hierbei einmal um die Freiwillige Selbstkontrolle der Filmwirschaft (FSK) und zum anderen um die Bundesprüfstelle für jugendgefährdende Schriften (BPS). Der FSK kommt dabei die doppelte Aufgabe sowohl der allgemeinen Prüfung als auch der der altersspezifischen Eignung von Filmen zu. Die BPS hingegen prüft hauptsächlich im Videobereich-Filme daraufhin, ob ihre mögliche schädliche Valenz für Jugendliche eine zusätzliche, über die herkömmlichen Formen altersspezifischer Begrenzung der Zugänglichkeit hinausreichende Beschränkung der Verbreitungschancen erforderlich erscheinen läßt. Mit beiden Institutionen und ihrer spezifischen Zuordnung scheinen so bereits Strukturen geschaffen worden zu sein, die der Realisierung einer institutionell flankierten Durchsetzung von Inhaltsethik und jugendschützerischen Erfordernissen differenziert dienen können. Ich will im folgenden daher nun beide Institutionen näher betrachten, ihre Struktur, Aufgabenstellung und Funktionen beleuchten und dabei untersuchen, inwieweit und auf welche Weise sie als hilfreiche Realisierungsinstrumente der vorgelegten medienethischen Konstruktion begriffen werden können. Dazu gilt es zum einen, das Verhältnis der Institutionen zu den im strukturethischen Baustein aufgestellten Forderungen zu betrachten, und zum anderen, die Beziehungen der institutionell verwendeten Prüfkriterien zur Inhaltsethik sowie möglicherweise zur, Tradition' zu reflektieren.

Zunächst möchte ich mich hierzu der FSK widmen und ihre Organisationsstruktur und grundsätzliche Aufgabenstellung in Blick nehmen. - Die FSK stellt eine Form freiwilliger Selbstkontrolle im Filmbereich dar, die 1948 als Abteilung der Spitzenorganisation der deutschen Filmwirtschaft (SPIO) gegründet wurde, um eine staatliche Vorzensur des Films zu verhindern. Sie ist zugleich eine unabhängige deutsche Folgeorganisation der alliierten Filmprüfung, die diese ersetzt und die Prüfung in deutsche Hände zurückverlagert. Im Lauf der Jahre hat die FSK mehrere Wandlungen durchgemacht, die jedoch hier nicht im einzelnen aufgeführt und betrachtet werden sollen. In den Blick genommen werden sollen vielmehr ihre aktuelle Gestalt und Funktion, also der zeitgenössische Befund der 90er Jahre. Gegenwärtig hat die FSK, wie erwähnt, grundsätzlich die Aufgabe der Prüfung von Filmen und Bildträgern (Videos, Bildplatten etc.) nach bestimmten Kriterien, die sie gemäß $§ 6$ FSK-Grundsätze durch eine Grundsatzkommission selbst entwirft. Die Grundsatzkommission setzt sich aus Vertretern der Filmwirtschaft/Videowirtschaft, der öffentlichen Hand, dem ständigen Vertreter der Obersten Landesbehörden für Jugendfragen und dem Leiter der FSK zusammen. Für die Film/Videowirtschaft gehören der Kommission dabei der Vorsitzende des Vorstands und der Hauptgeschäftsführer der SPIO, je ein Vertreter des Verbandes deutscher Spielfilmproduzenten e.V., des Verbandes der Filmverleiher e.V. und des Hauptverbandes Deutscher Filmtheater e.V. sowie zwei Vertreter des Bundesverbandes Video e.V. an. Für die öffentliche Hand wiederum gehört der Kommission je ein Vertreter des Bundesministeriums des Inneren, des Bundesministeriums für Jugend, Frauen, Familie und Gesundheit, der Kultusministerkonferenz, der für den Filmjugendschutz zuständigen federführenden Stelle der Obersten Jugendbehörden der Länder, der evangelischen und der katholischen Kirche sowie des Bundesjugendrings an. Die von der so besetzten Kommission erlassenen Prüfbestimmungen bedürfen dann gemäß \& 6 FSK- 
Grundsätze, soweit es sich ,um materielle oder wesentlich verfahrensmäßige Bestimmungen handelt", der Zustimmung der Verbände der Film/Videowirtschaft und ihrer Partner.

Auf der Basis der erlassenen und gebilligten Bestimmungen wird die Prüfung der Filme - d.h. von Kinofilmen und Bildträgern (hauptsächlich Videos) - vorgenommen. Diese Prüfung erfolgt dabei auf Antrag. Hierfür sieht die FSK gemäß $§ 7$ FSKGrundsätze drei Prüfausschüsse vor, nämlich den Arbeitsausschuß, den HauptausschuB, der die erste Berufungsinstanz darstellt, und den RechtsausschuB, der eine weitere Berufungsinstanz ist. Die Ausschüsse werden - nach Maßgabe des Aufgabenbereichs des jeweiligen Ausschusses (s.u.) - von der Film- und Videowirtschaft und den verschiedenen fachlich beteiligten Gruppen der öffentlichen Hand bestellt. Hinzu kommen ein Jugendsachverständiger, der von den Landesjugendbehörden benannt wird, und ein ständiger Vertreter dieser Behörden, der von ihnen im Benehmen mit der Film/Videowirtschaft bestellt wird. Dabei sorgt die Auswahl der Prüfer aus den verschiedenen Gruppen und aus verschiedenen Berufen „für die Relevanz im Sinne der pluralistischen Gesellschaft, wobei die jeweils verlangte Fachkenntnis die Verbindung zum Sachverstand auf dem Filmgebiet herstellt" ${ }^{105}$ So sind in den Ausschüssen beispielsweise vertreten „Richter, Staatsanwälte, Jugendpsychologen und -pädagogen, Filmhistoriker, Filmsachverständige, Kirchenvertreter, Funktionäre des Bundesjugendrings, Kulturbeamte, Hausfrauen, Studierende, Lehrer, Journalisten" etc. ${ }^{106}$ In den Ausschüssen werden dann folgende Prüfaufgaben erfüllt: Zum einen nimmt die FSK die bereits erwähnte Prüfung von Filmen für Erwachsene vor, die im Fall der Freigabe zugleich eine Übereinstimmung mit den Grundsätzen der FSK bescheinigt. Im Bereich der Erwachsenenprüfung wirkt dabei die öffentliche Hand nicht mit, sondern ist diese Prüftätigkeit allein als Aufgabe einer Selbstkontrolle eingerichtet. Entsprechend werden die Prüfer hier ausschließlich von der Filmund Videowirtschaft benannt. Um zugleich kommerziell-parteiliche Interessen auszuschließen, dürfen diese Prüfer zudem nicht selbst in der Film/Videowirtschaft tätig sein. Sie sind außerdem weisungsfrei. Zum zweiten findet eine Jugendprüfung von Filmen statt, die sich in einer entsprechenden Etikettierung der Filme mit Alterslabels konkretisiert. Die Altersstaffelung setzt gemäß \& 28 I FSK-Grundsätze in Übereinstimmung mit dem Jugendschutzgesetz (JÖSchG), d.h. näherhin mit $\$ 6$ III JÖSchG, als Stufen sechs, zwölf, sechzehn und achtzehn Jahre an. Im Bereich der Jugendprüfung trug die FSK dabei bis zum Februar 1992 die Bezeichnung FSK/J bzw. FSK-Jugend. Hier wirkt nun auch die öffentliche Hand wieder mit, deren Delegierte „zur Wahrung des gesetzlichen Auftrags auf diesen Gebieten (...) die Majorität in den Ausschüssen besitzen““ ${ }^{107}$ Der gesetzliche Auftrag wird dabei von $\$ \S 6$ und 7 JÖSchG umschrieben, nach welchen die Obersten Landesjugendbehörden, d.h. die für Jugendfragen zuständigen Länderminister, auch zuständig für die Prüfung und Freigabe von Filmen und Bildträgern für Kinder und Jugendliche sind. Für ihre diesbezügliche Entscheidung bedienen sie sich dabei der FSK und ihrer Prüfung, doch sind sie an deren Vorgaben nicht gebunden. Obschon praktisch eine abweichende

${ }^{105}$ Hartlieb, Handbuch, Kap. 17 Rdn. 6

106 Hartlieb, Handbuch, Kap. 17 Rdn. 6

107 Hartlieb, Handbuch, Kap. 17 Rdn. 6 
Entscheidung der Obersten Landesjugendbehörden kaum vorkommt, hat die FSK in diesem Zusammenhang also vordringlich eine Gutachterstellung, in der sie den Landesjugendbehörden zuarbeitet. ${ }^{108}$ Sie wirkt damit als privatrechtlich organisierte Selbstkontrolle an der Realisation des gesetzlich vorgesehenen Jugendschutzes im Filmbereich maßgeblich mit. Sowohl bei der Erwachsenenprüfung als auch bei der Jugendprüfung hat die FSK neben einer Erteilung oder Verweigerung der Freigabe auch die Möglichkeit, Filme nur unter Erfüllung bestimmter Schnittauflagen freizugeben. Solche eventuell gemachten Auflagen haben dabei dem Grundsatz der Verhältnismäßigkeit und dem Verbot des Übermaßes zu gehorchen. ${ }^{109}$ Zum dritten prüft die FSK die Eignung von Filmen im Hinblick auf ihre Rezeption an stillen Feiertagen. Hierbei legt sie die jeweiligen Gesetze zur Feiertagsregelung zugrunde und prüft insbesondere, ob in einem Film der ,diesen Tagen entsprechende ernste Charakter gewahrt ist “110. Der ernste Charakter gilt dabei bereits dann als gewahrt, wenn ein Film „menschliche Bezüge aufweist, die zur Reflexion anregen". 111 An der Feiertagsprüfung ist die öffentliche Hand ebenfalls wieder maßgeblich beteiligt. Zum vierten schließlich ist die FSK auch für die Prüfung der Werbeunterlagen und Filmtitel zuständig.

Die Prüfung durch die FSK hat dabei nun eine spezifische Verpflichtungskraft, die gleichwohl zunächst einmal nur die eine Prüfung beantragenden Firmen bindet. Zur Vorlage von Filmen und Werbematerial verpflichtet haben sich nach $\$ 21$ FSKGrundsätze die Mitglieder der in der SPIO zusammengeschlossenen Verbände, die zudem nur die von der FSK geprüften und freigegebenen Filme in der freigegebenen Fassung und nach den Freigabekriterien (Altersstufung) der Öffentlichkeit zugänglich machen dürfen. Bei dieser Verpflichtung handelt es sich um einen freiwilligen Akt der Selbstbindung, die im Sinn eines privatrechtlichen Vertrags organisiert ist. Durch „Gewährung des rechtlichen Gehörs in schriftlicher und mündlicher Form sowie durch den Instanzenweg“, der Berufung bei Nichtzufriedenheit mit einer Entscheidung der FSK möglich macht, und schließlich durch ,ausgewogene Fristen“ werden außerdem im Prüfverfahren „die erforderlichen rechtsstaatlichen Garantien

108 Juristisch entsteht hierbei ein Streit zur Frage, ob die Zuweisung der Prüfaufgabe an die FSK und die üblicherweise erfolgende Übernahme des Prüfergebnisses so zu interpretieren seien, daß die FSK hier ein Mandat erhalten habe. So sieht Hartlieb hier „keine Anmaßung von Hoheitsrechten durch eine privatrechtliche Institution (...), da keine Delegation von Hoheitsrechten oder entsprechende Mandate gegeben worden sind, die einer gesetzlichen Ermächtigung bedurft hätten, sondern nur gutachtliche Äußerungen einer privatrechtlichen Institution vorliegen, welche die Länder für ihre Hoheitsentscheidungen übernehmen“ (Hartlieb, Handbuch, Kap. 17 Rdn. 9). Etwas anders hingegen Weides: „ob allerdings die FSK-Jugend lediglich in der Stellung eine Gutachters tätig wird, muß nach wie vor bezweifelt werden. Ungeachtet der rechtlichen Möglichkeiten der Obersten Landesbehörden, eine abweichende Entscheidung zu treffen, erfolgt die Kennzeichnung der Kinofilme nach \$ 6 III JÖSchG unmittelbar durch die FSK-Jugend; sie stellt eine Freigabebescheinigung aus, nach deren Inhalt die Filme als von der Obersten Jugendschutzbehörde freigegeben und gekennzeichnet gilt. Schon dies allein spricht eher dafür, daß die Obersten Landesbehörden der FSK-Jugend zulässigerweise ein Mandat übertragen haben." (Weides, Jugendmedienschutz, 227) Diesen fachjuristischen Streit zu entscheiden, ist jedoch hier nicht der Ort. Es muß daher mit dem Hinweis auf seine Existenz sein Bewenden haben.

${ }^{109}$ Vgl. dazu auch: Hartlieb, Handbuch, Kap. 18 Rdn. 4

110 Hartlieb, Handbuch, Kap. 19 Rdn. 10

111 Hartlieb, Handbuch, Kap. 19 Rdn. 10 
gegeben“. ${ }^{112}$ Davon unabhängig gibt die FSK gemäß § 26 FSK-Grundsätze noch die Möglichkeit einer Prüfung von Filmen durch die Juristenkommission (JK) der SPIO. Diese Prüfung erfolgt dann anstelle einer FSK-Prüfung und nicht nach den FSKGrundsätzen, sondern lediglich anhand der strafrechtlichen Bestimmungen. Sie stellt daher auch nicht eine Freigabe durch die FSK dar, sondern lediglich ein Gutachten darüber, ob ein Film gegen strafrechtliche Bestimmungen verstößt oder nicht. Für den Verleih, Kinobesitzer oder Videothekar etc. hat gleichwohl dieses Gutachten durchaus eine Bedeutung: Im Fall von Konflikten mit den Behörden kann dieser dann Gutglaubensschutz geltend machen. ${ }^{113}$

Über die bei einer Prüfung durch die FSK gegebene Selbstbindung und die Möglichkeit der JK-Prüfung hinaus ist jedoch noch ein weiteres zu berücksichtigen. Im Bereich der gestuften Freigabe oder Nichtfreigabe von Filmen und Bildträgern für Kinder und Jugendliche nämlich erhält die FSK-Prüfung eine noch weiterreichende Relevanz und Bedeutung. So die Obersten Landesjugendbehörden die FSK-Entscheidungen übernehmen, treten für diese die in den $\$ \S 6$ und 7 JÖSchG aufgeführten Wirkungen in Kraft. Die FSK-Entscheidungen erhalten dadurch bestimmte strukturelle Folgewirkungen und eine über die Selbstbindung der in der SPIO organisierten Firmen hinausreichende Verpflichtungskraft. So bestimmt $\& 6$ I JÖSchG, $\mathrm{da}$ Kindern und Jugendlichen die Anwesenheit bei Filmveranstaltungen nur zu gestatten ist, wenn die Filme von der Obersten Landesbehörde für sie freigegeben worden sind. Dies bedeutet in praxi, daß die Kinobesitzer auch kraft Gesetzes dafür Sorge zu tragen haben, daß die von der FSK vorgenommene und von den Obersten Landesbehörden übernommene Altersstufung eingehalten wird und eine entsprechende Kontrolle der Zugänglichkeit von Filmen stattfindet. ${ }^{114}$ Filme wiederum, die nicht zur Prüfung vorgelegt worden sind, sind nach § 6 I JÖSchG zu behandeln wie jene, die nicht unter 18 Jahren freigegeben worden sind. ${ }^{115}$ Damit erhält die FSK gleichzeitig für die Ermöglichung der Zugänglichkeit von Filmen für Kinder und Jugendliche eine Art Monopol, das nur von den Obersten Landesbehörden selbst durchbrochen werden kann. Des weiteren legt das Gesetz bestimmte Zeitgrenzen fest, innerhalb derer jeweils die Vorführung eines für eine Altersstufe freigegebenen Films beendet werden muß ( $\$ 6$ IV JÖSchG). Die Entscheidungen der FSK werden auf diese Weise also durch das Jugendschutzgesetz mit einer zusätzlichen Verpflichtungs- und Durchsetzungskraft versehen sowie durch die Fixierung von altersstufenbezogenen Tageszeitgrenzen ergänzt. Ziel des Gesetzes ist es dabei, einen umfassenden Jugendschutz zu gewährleisten und diesen zudem differenziert einzurichten, d.h. durch die gestufte Zugänglichkeit von Filmen die offene Kommunikationsstruktur auch im Kinder- und Jugendbereich zu wahren.

Auch im Bereich der Prüfung von Bildträgern aber setzt sich dieses Ziel um. Hier nun bestimmt $\$ 7$ I JÖSchG in entsprechender Weise, daß ,,bespielte Videokassetten, Bildplatten und vergleichbare Bildträger (...) Kindern und Jugendlichen in der Öffentlichkeit nur zugänglich gemacht werden [dürfen], wenn die Programme von der obersten Landesbehörde für ihre Altersstufe freigegeben und gekennzeichnet

${ }^{112}$ Hartlieb, Handbuch, Kap. 17 Rdn. 8

113 vgl. Hartlieb, Handbuch, Kap. 20 Rdn. 1

114 Zu den genaueren Modi vgl. Hartlieb, Handbuch, Kap. 10 Rdn. 11, Kap. 13

115 vgl. Scholz, Jugendschutz, 19 
worden sind". Auch diese Vorschrift versieht die von den Obersten Landesbehörden übernommene FSK-Entscheidung der Freigabe nur ab einer bestimmten Altersstufe mit einer über die Selbstbindung hinausreichenden Durchsetzungskraft. Dabei wird in bezug auf Bildträger außerdem in § 7 III JÖSchG festgelegt, daß Bildträger, die von der Obersten Landesbehörde mit, nicht freigegeben unter 18 Jahren' gekennzeichnet worden sind, Kindern und Jugendlichen „nicht angeboten, überlassen oder sonst zugänglich gemacht werden" dürfen. Weiter heißt es dort, daß solche Bildträger Kindern und Jugendlichen auch nicht ,im Einzelhandel außerhalb von Geschäftsräumen, in Kiosken oder anderen Verkaufsstellen, die der Kunde nicht zu betreten pflegt, oder im Versandhandel angeboten oder überlassen werden" dürfen. Ebenso wird von diesem Paragraphen in Abs. 4 festgelegt, daß ,in der Öffentlichkeit (...) bespielte Bildträger nicht in Automaten angeboten werden" dürfen. Die Vorschriften des Abs. 3 sind dabei den entsprechenden Bestimmungen des $\S 4$ I GjS nachgebildet und zielen auf eine Vernetzung der beiden Gesetze, um einen umfassenden Jugendschutz zu gewährleisten. Aus diesem Grund werden daher nicht gekennzeichnete Bildträger den erst ab 18 Jahren freigegebenen gleichgestellt und ebenfalls den skizzierten Vorschriften unterworfen. Diese Vorschriften wiederum kommen in dem Telos überein, Filme für Erwachsene von Kindern und Jugendlichen möglichst fernzuhalten. Daher werden in den Bestimmungen neben dem Verbot direkten Zugänglichmachens von Erwachsenenfilmen für Kinder und Jugendliche insbesondere jene Verbreitungsmöglichkeiten restringiert, die eine wirksame Kontrolle der Beschränkung der Zugänglichkeit entsprechender Filme auf Erwachsene nicht ausreichend ermöglichen oder gewährleisten - wie etwa der Versandhandel, der sich durch falsche Altersangaben täuschen ließe, oder der Automatenvertrieb, der überhaupt keine Kontrolle mehr ermöglicht. Mit der gesetzlichen Fixierung dieser Vorschriften aber wird zugleich den FSK-Entscheidungen, die einen Film, der durch Bildträger verbreitet werden soll, für unter 18-Jährige nicht freigeben, bei Übernahme der Entscheidung durch die Oberste Landesbehörde eine zusätzliche Durchsetzungskraft verliehen. Über die Selbstbindung der in der SPIO organisierten Firmen hinaus erhalten die Prüfentscheidungen der FSK damit aus Gründen des Jugendschutzes eine generelle Verpflichtungsmacht auch im Bildträgerbereich.

Aus der vorstehenden Skizze nun ist zunächst erkennbar, daB die FSK in ihrer grundsätzlichen Konstruktion eine durchaus demokratische Institution vorstellt, die zudem von einer Zensurstelle wohl zu unterscheiden ist. Ein Vergleich mit den im strukturethischen Baustein aufgestellten Grundforderungen läßt erkennen, da $B$ die Organisationsstruktur und die prinzipielle Aufgabenstellung der FSK mit diesen Forderungen durchaus kompatibel sind und sogar als konkretisierende Einlösung derselben gelesen werden können. So zeigt sich einmal, daß die Besetzung der verschiedenen Ausschüsse der FSK dem im strukturethischen Baustein eingeführten Repräsentativitätsprinzip entspricht. Die Beteiligung sowohl der Film/Videowirtschaft, d.h. der betroffenen Vertreter des Kultursachbereichs der Medien, als auch ,relevanter gesellschaftlicher Gruppen' und die Auswahl ehrenamtlicher Prüfer aus verschiedenen Berufen weisen - ähnlich der Organisation des Rundfunkrates (vgl. oben) - die geforderte Struktur einer Repräsentanz gesellschaftlicher Vielfalt in Verbindung mit kultursachbereichsspezifischer Kompetenz auf. Auch die Grundsatzkommission, die das oberste normative Gremium der FSK darstellt, aber ist re- 
präsentativ besetzt, so daß bei allen Gremien der FSK die Umsetzung der Repräsentativitätsforderung konstatiert werden kann. Dies nun scheint insbesondere deshalb wichtig, weil die FSK in den verschiedenen Prüfbereichen mit weit ausgreifenden Kompetenzen ausgestattet ist und so eine tendenziell umfassende, jedenfalls aber dominante Stellung einnimmt. Abgesehen von der JK gibt es neben ihr keine Instanz, die von Filmherstellern in Anspruch genommen werden kann, um die entsprechenden Freigabe- bzw. Unbedenklichkeitsbescheinigungen zu erhalten. Insbesondere für die Möglichkeit, einen Film Kindern und Jugendlichen zugänglich zu machen, hat die FSK eine annähernd monopolistische Position, die nur durch die Möglichkeit einer abweichenden Entscheidung der Landesjugendbehörden etwas aufgesprengt ist. Das JÖSchG verschafft den von diesen Behörden übernommenen FSK-Entscheidungen zudem eine generelle Durchsetzungsmacht. Für Gremien und Institutionen mit einer derartigen Stellung im Bereich medialer Kommunikation aber war im strukturethischen Baustein um der Wahrung der offenen Kommunikationsstruktur sowie der Verhinderung zensuraler Maßnahmen und eines Social engineering willen zu fordern, daß ihre personelle Besetzung in besonderem Maße dem Repräsentativitätsprinzip gehorcht. Dies nun ist bei der FSK der Fall. Mithin kann zunächst festgestellt werden, daß ihre Ausschüsse „fachkundig, sachverständig, unabhängig und gesellschaftlich repräsentativ"116 strukturiert sind und so der im strukturethischen Baustein für alle mit monopolistischen oder monopolähnlichen Befugnissen ausgestatteten Gremien im Medienbereich aufgestellten Forderung gerecht werden.

Des weiteren muß die FSK ungeachtet ihrer dominanten Position als von einer Zensurstelle durchaus verschiedene Institution begriffen werden. So stellt sie sich zunächst im Bereich der Erwachsenenprüfung strukturell als reine Selbstkontrollinstanz dar, die juristisch eine privatrechtliche Konstruktion ist und damit nur jene Einschränkungen in sich birgt, die ,mit fast allen privatrechtlichen Verträgen verbunden" sind. ${ }^{117}$ Ein solcher privatrechtlicher VertragsschluB, der die beteiligten Partner an bestimmte Grundregeln bindet, aber ist auch ethisch zumindest solange legitim, wie die Grundregeln nicht sich in eine heteronomistische Konformierung des gesellschaftlichen Diskurses transformieren, sondern auf die Durchsetzung und Wahrung der inhaltsethischen Rahmenvorschriften beschränken (dazu mehr unten) und die Möglichkeit gewahrt bleibt, dem Vertrag nicht beizutreten. Dies ist bei der FSK gegeben, obschon freilich die von ihr fixierten Prüfkriterien noch genauer auf ihre Verträglichkeit mit dem Verbot einer universellen Prägung des gesellschaftlichen Diskurses hin zu betrachten sein werden. In ihrer grundsätzlichen Organisationsstruktur aber kann die FSK keineswegs als Zensurinstanz bewertet werden, sondern ist sie lediglich eine Institutionalisierung freiwilliger Selbstbindung der in der SPIO organisierten und/oder die Prüfung beantragenden Firmen. Jener prekäre Prüfzwang, wie ihn etwa die vorzensuralen Maßnahmen des Reichslichtspielgesetzes insbesondere unter den Nationalsozialisten aufgestellt hatten, ist bei der FSK in keiner Weise vorhanden. So kann eine unabhängige Filmfirma sich auch gegen eine Vorlage ihres Films entscheiden und kann der Film, wenn er nicht strafrechtlich re-

${ }^{116}$ Hartlieb, Handbuch, Kap. 17 Rdn. 6

${ }^{117}$ Hartlieb, Handbuch, Kap. 17 Rdn. 14; auch; Urteil des OLG Frankfurt/M vom 12.11. 1962 (UFITA Bd. 38, 367) 
levant ist, der erwachsenen Öffentlichkeit durchaus zugänglich gemacht werden. Dies wird auch von den Bestimmungen des JÖSchG nicht verhindert, die sich einzig auf den Jugendschutz richten und die Vorführung nicht geprüfter Filme vor Erwachsenen in keiner Weise belasten. Darüber hinaus kann eine Firma sich auf lediglich eine Prüfung durch die Juristenkommission der SPIO zurückziehen und damit nur den rein strafrechtlichen Kriterien unterwerfen. Die Erwachsenenprüfung durch die FSK stellt also weder ein hoheitliches Oktroi dar - sie ist ja eine freiwillige Selbstbindung - noch ist sie eine Vorgabe, der sich keine der Filmproduktionen zu entziehen vermöchte. Soweit nun unter diesen Umständen negative oder beschränkende Prüfentscheidungen - sei es als Nichtfreigabe eines Films oder als Freigabe nur mit Schnittauflagen - getroffen werden, können diese nicht als illegitime Zensur verworfen werden. Zum einen kann es bei der Prüfung nur um die Wahrung der inhaltsethischen Essentials gehen, die wegen ihrer Verbindung zum Rahmenethos unverzichtbar sind. Zum anderen bleibt die Möglichkeit, Berufung einzulegen oder den Film der JK vorzulegen bzw. auf eine Prüfung zu verzichten.

In analoger Weise ist die Feiertagsfreigabe zu verstehen. Hier geht es vordringlich um die Einrichtung einer mit dem kollektiven Leben verträglichen medialen Angebotslage im Kinobereich zu bestimmten Zeiten. Darin liegt nun ebenfalls keine zensurale Beschneidung der sozialen Kommunikation - nach Verstreichen des Feiertags ist das gesamte Filmangebot ja wieder zugänglich. Auch von einem illegitimen Social engineering aber kann hier nicht die Rede sein. Zum einen ist die grundsätzliche Wahrung der Bedeutung von Feiertagen durch entsprechene Rahmenvorschriften sozialethisch durchaus legitim. Zum anderen sind die Kriterien dabei so weit angesetzt, da $B$ von einem heteronomistischen $Z$ wang der Gesellschaftsmitglieder unter das Joch einer bestimmten, eng umgrenzten Stimmungsproduktion ohnehin kaum gesprochen werden kann. Weder ein Social engineering noch auch ein ,Socio-emotional engineering' liegt hier vor, zumal ein Ausweichen auf ,feiertagsunverträgliche‘ Videos stets möglich bleibt. Daher wäre hier eher zu fragen, ob für die Realisation einer ethisch wünschenswerten Nutzung von Feiertagen, einer, besinnlichen' Reflexivität, die Feiertagsprüfung nicht ein allzu wirkungsloses, damit tendenziell obsoletes und durch ein geeigneteres zu ersetzendes Instrument darstellt.

Nicht nur im Bereich der Erwachsenen- und Feiertagsprüfung, sondern auch im Bereich der Jugendprüfung aber ist die Tätigkeit der FSK schwerlich als Zensur zu bewerten. So nimmt die FSK hier vordringlich eine Staffelung nach Altersklassen vor, die die Rezeptionsmöglichkeiten nach den Erfordernissen des Jugendschutzes einrichtet. Erwachsene sind hiervon nicht betroffen, so daß ein zensuraler genereller Ausschluß bestimmter Gehalte aus der Rezeption ohnehin nicht gegeben ist. Dies gilt auch für die Beschränkungen im Bildträgerbereich, die durch die Verbindung der Prüfentscheidung mit den Vorschriften des $\$ 7$ III JÖSchG als mittelbare Folgewirkung der Tätigkeit der FSK entstehen. Sie richten sich ja nicht auf eine Verhinderung der Zugänglichkeit von entsprechenden Bildträgern für Erwachsene, sondern lediglich auf Gewährleistung des Jugendschutzes durch eine möglichst weitgehende Verhinderung eines Unterlaufens der Rezeptionsbeschränkung auf Erwachsene. Die entsprechenden Verbote stellen dabei zwar eine gewisse Einschränkung der Zugänglichkeit dar - etwa, wenn der Automatenvertrieb generell untersagt wird -, doch bleibt die Zugänglichkeit noch in durchaus ausreichendem $\mathrm{Maß}$ erhalten. So ist es 
z.B. sogar möglich, Videos für Erwachsene in den Regalen einer Videothek auszustellen, wenn sie entsprechend gekennzeichnet sind und ,durch Aushang der geltenden jugendschutzrechtlichen Bestimmungen bzw. sonst in geeigneter Weise darauf aufmerksam [gemacht wird], daß sie Kindern und Jugendlichen" nicht überlassen werden. ${ }^{118}$ In diesem Fall ist es noch nicht einmal „erforderlich, die Bildträger in nach Kennzeichnung getrennten Regalen einzustellen" ${ }^{119}$ In den Bestimmungen des \& 7 III JÖSchG kann daher in keiner Weise eine zensurale Valenz wahrgenommen werden. Entsprechend kann auch nicht konstatiert werden, da $B$ durch die Gesetzesvorschriften dem Prüfhandeln der FSK eine zensurale Wirkung verliehen würde.

Auch gegenüber den Kindern und Jugendlichen aber handelt die FSK hier nicht zensural. Sie befolgt vielmehr das medienethische Grundgebot der Schaffung und Realisierung jugendschützerischer Maßnahmen, die dem aus dem Personprinzip hergeleiteten Anspruch von Kindern und Jugendlichen auf einen ihrer Reifung hilfreichen edukativen Umraum gerecht zu werden suchen. Die Staffelung erlaubt dabei sogar eine Verbindung dieser Maßnahmen mit einer Erziehung zur Mündigkeit: Sie ermöglicht es nämlich, auf altersspezifische Nutzungskompetenzen einzugehen und die Zugänglichkeit zu Filmen entsprechend differenziert einzurichten. Unter ihrer Vorgabe können daher auch etwa entwicklungspsychologische und sozialisationstheoretische Erkenntnisse sowie empirische Forschungen zur Mediennutzungskompetenz der Kinder und Jugendlichen berücksichtigt werden und kann die Vergabe der Alterslabels mit der oben geforderten pädagogischen Entwicklung einer altersspezifischen ,Medienleiter' verbunden werden. Ähnlich wie im Fall einer Orientierung der Programmgestaltung des Fernsehens an einer altersspezifischen Nutzungsverteilung (s.o.) läßt sich so auch hier eine Erziehung zur Mündigkeit fördern, da altersgeeignete Angebote gemacht werden können und ein schlichter Entzug aller Filme oder eine Orientierung nur an den untersten Altersstufen vermeidbar bleibt. $\mathrm{Zu}$ fragen wäre lediglich, ob die Stufung bereits ausreichend differenziert ist oder ob es nicht angebracht sein könnte, die zum Teil recht umfängliche Entwicklungsspannen umfassende Einteilung weiter zu unterteilen. Doch ist in jedem Fall festzustellen, daß die Filmprüfung mit ihrer Staffelung einer Zensur sogar im Kinder- und Jugendbereich entgegenzuwirken vermag: Anstelle nur beschneidender Maßnahmen tritt eine Stufung der Rezeptionsmöglichkeiten, die Filme nicht beseitigt, sondern je spezifischen Kompetenzniveaus zuteilen kann. Sie bietet so dem medienethisch konstatierten Erfordernis einer an der Realität der Kinder und Jugendlichen, an ihren altersspezifischen Kompetenzen und deren Veränderung durch veränderte Sozialisationsbedingungen orientierten Beurteilung der Zuträglichkeit bestimmer Filme und Gehalte eine gute Einlösungsbasis. Freilich bleibt auch hier wieder noch zu untersuchen, inwieweit die konkreten Prüfkriterien der FSK von dieser Möglichkeit Gebrauch machen bzw. sie offenhalten (dazu mehr unten). Die strukturelle Aufgabenbestimmung der FSK aber liefert hierfür zumindest eine Basis. Vom Zensurverdacht auszuschließen sind hierbei auch Schnittauflagen, die von der FSK unter Umständen für die Freigabe für eine bestimmte Altersstufe gemacht werden. Zum einen hat der Antragsteller die Möglichkeit, die Freigabe für ein höheres Alter zu beantragen, falls

${ }^{118}$ Scholz, Jugendschutz, 26

119 Scholz, Jugendschutz, 26 
er die Schnitte nicht durchführen will. Zum anderen kann als Kriterium für Schnitte wieder nur die Zuträglichkeit für ein bestimmtes Alter angewandt werden. Damit aber wird ebenso wie bei der Nichtfreigabe eines Films für dieses Alter nicht Zensur geübt, sondern dem Jugendschutz genüge getan. Eventuell durchgeführte Schnitte können hierbei sogar als kontrazensurale Maßnahmen im Kontext der Erziehung zur Mündigkeit und der Realisierung einer offenen Kommunikation begriffen werden, wenn durch sie ein Film einer Altersklasse zugänglich gemacht wird, der ansonsten unter Umständen nur wegen einer bestimmten Szene höher eingestuft werden hätte müssen. Freilich gilt für jedes Schnittvorhaben, daß es möglichst restriktiv und zurückhaltend auszuführen ist und der Grundsatz der Verhältnismäßigkeit wie auch das Verbot des Übermaßes zu wahren sind. - In eben dieser Weise sind schließlich auch die Erwachsenen- und Jugendprüfung des Werbematerials und der Filmtitel zu sehen. Sie dürfen ebenfalls nicht als zensurale und daher medienethisch illegitime Maßnahmen begriffen werden, sondern sind zunächst Maßnahmen der Selbstkontrolle und des Jugendschutzes, die denselben Kriterien unterliegen wie diese und die ebenfalls den medienethischen Grundforderungen unterstellt sind.

Im Ganzen zeigt sich damit die organisatorische und aufgabenstrukturelle Einrichtung der FSK als eine mit den medienethischen Grundforderungen kompatible und kohärente Strukturgestalt. Sie gehorcht dem Repräsentativitätsprinzip, das überall dort, wo eine monopolähnliche Institution Wirkung entfaltet, selbst strukturell zu realisieren ist; sie bleibt von einer Zensurstelle zunächst einmal prinzipiell verschieden und sie realisiert mit der auf eine Altersleiter gerichteten Jugendprüfung eine differenzierte Einrichtung der Zugangschancen, die mit einer Erziehung zur Mündigkeit kooperieren kann. Gleichwohl ist damit noch nicht alles geklärt. So reicht eine repräsentative Einrichtung einer mit weitreichenden, die mediale Kommunikation unter Umständen beschneidenden Kompetenzen ausgestatteten Institution noch nicht hin, um ihre zureichende Einordnung in die Wahrung der gebotenen offenen Kommunikationsstruktur wirklich zu gewährleisten und ein Hinübergleiten der von ihr geübten Kommunikationskontrolle in eine Nachzensur zu verhindern, die sich einer funktionellen Vorzensur annähert. Bereits in der Auseinandersetzung mit der organisatorischen Verfaßtheit der Erwachsenenprüfung habe ich deshalb angedeutet, da $B$ dieses Hinübergleiten nur dann nicht angenommen werden kann, wenn sich der Ausschluß bestimmter Filme von der Freigabe streng an der unverzichtbaren inhaltsethischen Rahmenkriteriologie orientiert und auf diese beschränkt. Nur so bleibt das Prüfhandeln auf die Essentials des gesellschaftlichen Rahmenethos und die obersten ethischen Prinzipien rückbezogen sowie auf deren gebotene Wahrung eingeschränkt, die das einzige Legitimationskriterium für beschneidende Eingriffe in die offene gesellschaftliche Kommunikation abgibt. Diese Beschränkung des Prüfhandelns aber muß selbst dann erfolgen, wenn die prüfende Institution kein vollständiges Monopol besitzt und ihr Zugriff sich zunächst vordringlich auf die sich freiwillig an sie bindenden Kommunikatoren bezieht. Gerade eine Institution wie die FSK nämlich hat dadurch immer noch einen Wirkkreis, der ihr Handeln gesellschaftlich relevant und einflußreich macht. Da dieser Einfluß nun gleichzeitig durch die Bestimmungen des JÖSchG und die Kooperation der Obersten Landesbehörden mit der FSK gestärkt wird, muß er sogar in besonderer Weise einem genauen medienethischen Blick unterworfen werden und gilt es, das Prüfhandeln kriteriologisch 
streng auf eine Orientierung ausschließlich am Rahmenethos zu verpflichten. Nicht statthaft wäre insbesondere eine an einem Sonderethos orientierte Filmprüfung, die den filmvermittelten gesellschaftlichen Diskurs ex negativo zu einem guten Teil auf eine Binnenmoral fixieren würde. In diesem Zusammenhang ist neben der Zensurproblematik auch nochmals die Vorschrift des strukturethischen Bausteins zu beachten, die zusammen mit der Zensur jeden Versuch illegitimisiert, durch einen ,konstruktiven` Dirigismus eine universelle Prägung der Medieninhalte zu erreichen und dem gesellschaftlichen Diskurs eine Linie vorzuschreiben, die in ein medial vollzogenes Social engineering mündet. Um der Wahrung der offenen Kommunikationsstruktur und der autonomen Produktion des Diskurses durch die Gesellschaftsmitglieder in ihren Rollen als interagierende Produzenten und Rezipienten willen kann auch eine unter Umständen gut gemeinte - vielleicht gar publikumspädagogische inhaltliche Normierung des medialen, auch über den Film vermittelten ,Zeitgesprächs der Gesellschaft‘ nicht geduldet werden, wenn diese Normierung über die Grenzen der inhaltsethischen Essentials hinausgeht. Daher gilt es nun, die von der FSK erlassenen und genutzten Prüfkriterien in Blick zu nehmen und vor dort her nochmals das Verhältnis dieser Institution und ihres Handelns zu der vorgelegten medienethischen Konstruktion zu beleuchten. Weiter aber muß auch ein Blick auf die im Bereich der Jugendprüfung zur Anwendung gebrachten Kriterien geworfen werden, um zu klären, ob und in welcher Weise diese Kriterien der von der Altersstufung prinzipiell ermöglichten Orientierung an den Kompetenzen von Kindern und Jugendlichen sowie der Verklammerung des Jugendschutzes mit einer Erziehung zur Mündigkeit dienen oder dienen können.

Zunächst nun führt die FSK im allgemeinen Teil ihrer Grundsätze einen prinzipiellen Prüfgrundsatz ein, den sie dann in drei Gruppen von Prüfkriterien aufspaltet. Dieser Grundsatz und die drei Gruppen haben dabei für die Prüfung aller Filme und ihres Werbematerials sowie der Filmtitel Relevanz, also neben der Erwachsenenprüfung auch für die Jugendprüfung. Als Grundsatz wird von $§ 2$ FSK-Grundsätze angesetzt, daß die FSK „die im Grundgesetz geschützen Werte, im besonderen die verfassungsmäßige Ordnung und das Sittengesetz (...) sowie die in Art. 5 GG eingeräumte Freiheit zu beachten" habe. Im Zusammenhang mit der Nennung des Sittengesetzes wird dabei auf Art. 2 I GG verwiesen, wo wiederum die freie Entfaltung der Persönlichkeit soweit garantiert wird, wie sie ,nicht die Rechte anderer verletzt und nicht gegen die verfassungsmäßige Ordnung oder das Sittengesetz verstößt". Der zitierte Grundsatz, der die oberste Norm der FSK darstellt, wird dann genauer auf die Filmprüfung hin entfaltet. Entworfen werden Kriteriengruppen, die sich einmal auf die Beziehungen der Staatsbürger untereinander, zum anderen auf gesellschaftliche Grundwerte und zum dritten auf Auslandsbeziehungen richten. ${ }^{120}$ So darf nach $\S 2$ FSK-Grundsätze ,in diesem Rahmen (...) kein Film oder Bildträger a) das sittliche und religiöse Empfinden oder die Würde des Menschen verletzen, entsittlichend oder verrohend wirken oder gegen den grundgesetzlich gewährleisteten Schutz von Ehe und Familie verstoßen“ sowie ,im besonderen brutale und sexuelle Vorgänge in übersteigerter, anreißerischer oder aufdringlich selbstzweckhafter Form schildern“. Weiter ist es untersagt, durch Filme/Bildträger „b) die freiheitlich-demokratische

${ }^{120}$ vgl. hierzu auch: Ronneberger, Selbstkontrolle, 294 
Grundordnung [zu] gefährden oder die Menschenrechte oder die Grundrechte [zu] mißachten, im besonderen durch totalitäre oder rassenhetzerische Tendenzen". Schließlich dürfen Filme/Bildträger nicht „c) das friedliche Zusammenleben der Völker stören und dadurch die Beziehungen der Bundesrepublik Deutschland zu anderen Staaten gefährden, imperialistische oder militaristische Tendenzen fördern oder das Kriegsgeschehen verherrlichen oder verharmlosen“.

Mit dem Grundsatz und seiner Auslegung in einzelne Prüfkriterien ist nun in der Tat eine Kriteriologie angesetzt, die mit der entworfenen Inhaltsethik weitgehend zusammenklingt, zumindest aber eine dieser entsprechende Interpretation zuläßt. Zunächst ist dabei erkennbar, daß ähnlich der Inhaltsethik die aufgestellten Normen gleichermaßen für Filme im Erwachsenen- wie im Jugendbereich gelten. Sie geben sich damit als generelle medienethische Kriterien zu erkennen, denen alle Filme bei der Prüfung zu unterwerfen sind und die daher vom Erwachsenenbereich auf den Jugendbereich übertragen werden müssen. Der Grundsatz führt dann mit dem Verweis auf Art. 5 GG die Vorschrift ein, daß jede konkrete Prüfung die Meinungsfreiheit zu berücksichtigen hat und entsprechend in einem freiheitlichen Rahmen zu vollziehen ist, der ihrem unter Umständen beschränkenden Handeln selbst wiederum eine Schranke setzt. Damit ordnet die FSK letztlich ihr Prüfhandeln prinzipiell dem medienethischen Gebot der offenen Kommunikationsstruktur unter und erweist sie ihren Ansatz als von vorneherein mit dem medienethischen Strukturrahmen kongenial. Wie dort für die Anwendung jedes inhaltsethischen Kriteriums eine Rückverpflichtung auf die gleichzeitige Wahrung der offenen Kommunikationsstruktur postuliert wurde, die für die Realisierung der Inhaltsethik eine metanormative Verfahrensvorschrift im Sinn restringierter Anwendung der Kriterien ergab, fixiert auch der Grundsatz der FSK eine solche Rückverpflichtung, die in eine entsprechende Verfahrensvorschrift münden kann. Mit der Bestimmung, die ,im Grundgesetz geschützten Werte zu beachten', verpflichtet sich die FSK dann weiter auf die Wahrung des Personprinzips, der damit verbundenen Freiheitsrechte und der Menschenrechte bzw. Grundrechte. Sie legt auf diese Weise die Basis für die Einführung entsprechender inhaltsethischer Einzelnormen, die den Schutz der Menschenrechte detaillieren und sich mit den oben entwickelten Einzelvorschriften verbinden lassen. So treten mit dem Verbot der Verletzung der Menschenwürde die Achtung der menschlichen Person und ihrer Ansprüche in Blick, die etwa auf das Verbot einer Bloßstellung oder Verleumdung und das Gebot der Wahrung der Privatsphäre hin konkretisiert werden können. Die llegitimisierung rassenhetzerischer Tendenzen und der Verletzung des religiösen Empfindens benennt sogar direkt inhaltsethische Konkreta, die systematisch aus dem Gleichheitsprinzip hervorgehen. Selbst die hier etwas diffus gehaltenen Bestimmungen bezüglich der Appräsentation von Sexualität und Gewalt aber lassen sich der Inhaltsethik zuordnen und weisen eine dieser kongeniale Entelechie auf. So ist mit einer , anreißerischen' und, aufdringlich selbstzweckhaften Form' der Darstellung von Sexualität zweifellos auf tendenziell pornographische Darstellungen abgehoben, die aus inhaltsethischem Blickwinkel im breitenwirksamen Publikumsfilm keinen Raum haben können. Die entsprechende Gewaltdarstellung wiederum kann im Sinn der sadistischen Appräsentation gedeutet werden, die Gewalt um der Gewalt willen zur Anschauung bringt und zu einer sadistischen Kontemplation einlädt. Wie zu sehen war, kann auch eine solche Appräsen- 
tation inhaltsethisch nicht geduldet werden. Etwas problematisch mutet freilich das Kriterium ,übersteigerter' Darstellung für den Bereich der Sexualität an, da es einen arg diffusen Ermessensspielraum eröffnet. Gemäß der inhaltsethischen Überlegungen lassen sich Anständigkeitsschwellen hier schwer festlegen und kann sich in deren Überschreiten gerade ein legitimer Ethoswandel ausdrücken. Das Kriterium wird daher besonders vorsichtig anzuwenden sein. Insgesamt aber sind damit im Bereich des Schutzes personaler Rechte bereits deutlich Verbindungen zur inhaltsethischen Kriteriologie der vorliegenden medienethischen Konstruktion erkennbar oder lassen sie sich zumindest herstellen.

Auch im Bereich der politischen Schutzvorschriften, in dem es inhaltsethisch vordringlich um den Schutz der demokratischen Gesellschaft, des sie rahmenstrukturell ermöglichenden demokratischen Staates und des internationalen Zusammenlebens ging, können kongeniale Vorschriften wahrgenommen werden. So ist mit dem Gebot des Schutzes der freiheitlich-demokratischen Grundordnung und der Beachtung der verfassungsmäßigen Ordnung die Wahrung der Verfassung der demokratischen Gesellschaft in Blick genommen. Im Verbot totalitärer Tendenzen wird dies dann beispielhaft konkretisiert. Neben diesen Schutzvorschriften, die sich nach innen auf die demokratische Gesellschaftsorganisation und den Staat selbst richten, sind jedoch auch die nach außen auf die internationalen Verhältnisse und Beziehungen gerichteten Normen in den FSK-Grundsätzen wiederzuentdecken. Explizit werden hierbei die Störung des friedlichen Zusammenlebens der Völker und die Beziehungen der Bundesrepublik zu anderen Staaten genannt. Mit dem Verbot der Kriegsverherrlichung oder -verharmlosung und der Beförderung militaristischer oder imperialistischer Tendenzen tritt weiter das inhaltsethische Verbot jeder Kriegstreiberei in Blick. Die so aufgestellten politischen Normen erweisen sich damit ebenfalls als mit der Inhaltsethik verbunden oder lassen sich im Sinn der Inhaltsethik weiter detaillieren und anwendungsbezogen konkretisieren. Auf diese Verbindung weist mittelbar auch der juristische Kommentar, der in den diesbezüglichen Vorschriften der FSK die $\$ \$ 80 \mathrm{a}$, 86, 86a, 90, 90a und 90b StGB aufgegriffen sieht und damit Paragraphen anführt, die sich bereits als mit der inhaltsethischen Kriteriologie verknüpft gezeigt haben. ${ }^{121}$

Interpretationsbedürftig sind hingegen die Bestimmungen der Beachtung des ,Sittengesetzes‘ und des Verbots der Verletzung des ,sittlichen Empfindens'. Im Zusammenhang mit dem Sittengesetz nennen die FSK-Grundsätze dabei den Art. 2 I GG, so daß in der Interpretation zunächst auf diesen zugegriffen werden kann. Hier bieten sich zwei gängige Auslegungen an: Einmal kann das Sittengesetz als Inbegriff der ,allgemein anerkannten Wertvorstellungen unserer Rechtsgemeinschaft" verstanden werden. ${ }^{122}$ Dabei ist dann zusätzlich angesichts des ,heutigen Grads der Durchnormierung aller Lebensbereiche ${ }^{6}$ zu fordern, „daß die Wertvorstellungen in einer Rechtsnorm ihren Niederschlag gefunden haben“ ${ }^{123}$ Folge ist dann, daß „das Sitten-

${ }^{121}$ Vgl. Hartlieb, Handbuch, Kap. 18 Rdn. 6 - Die Kriterienformulierungen der FSK sind dabei freilich weiter gefaßt als die entsprechenden Gesetze und greifen ähnlich der Inhaltsethik über den gesetzlichen Rahmen auch hinaus. Nicht zuletzt deshalb wurde in der Inhaltsethik ja stets nur auf die Parallelen in den Gesetzesvorschriften verwiesen, ohne daß diese als im Umfang völlig identisch oder deckungsgleich mit den inhaltsethischen Normen bezeichnet wurden.

I22 Jarass/Pieroth, GG, Art. 2 Rdn. 16; auch: BVerGE 6, 389/435

123 Jarass/Pieroth, GG, Art. 2 Rdn. 16 
gesetz (...) in der verfassungsmäBigen Ordnung aufgeht" ${ }^{124}$ Nach dieser Auslegung wäre das Sittengesetz weitgehend mit den Prinzipien und Grundnormen der Verfassung identisch. Ethisch gewendet ließe sich dies dann dahingehend interpretieren, $\mathrm{da} B$ mit dem Sittengesetz das gesellschaftliche Rahmenethos gemeint ist, das ja in der Verfassung seinen Niederschlag findet, wenn es sich auch nicht in den Bestimmungen derselben vollständig erschöpft. In diese Richtung weist auch die zweite Auslegung, die das Sittengesetz als ,Summe ethischer Verhaltensnormen' auffaßt, die "durch die gemeinsame Grundüberzeugung der Gesellschaft bestimmt" ist. ${ }^{125}$ Abgestellt wird hierbei insbesondere auf das ,Gemeinsame', während ,das persönliche sittliche Gefühl eines Richters oder die Auffassung einzelner Volksteile“ als „hierfür nicht maßgeblich" apostrophiert werden. ${ }^{26}$ Entsprechend der gesellschaftlichen Rückbindung dieses Begriffs des Sittengesetzes kann dieses zudem inhaltlich nicht als statische Größe betrachtet werden, sondern ist es „dem Wandel der gesellschaftlichen Grundanschauungen unterworfen " ${ }^{127}$ Um der juridischen Praktikabilität willen wird dann auch hier eine gesetzliche Rückbindung gefordert. ${ }^{128}$ Verbindet man diese beiden Auslegungen und legt man sie dem Verständnis der Sittengesetzes in den FSK-Grundsätzen zugrunde, so erweisen sich diese wieder als kompatibel mit der entworfenen Inhaltsethik. Das Sittengesetz nämlich erscheint dann in der Tat als das gesellschaftliche Rahmenethos, dessen zentrale und unverzichtbare, von allen Gesellschaftsmitgliedern zu teilenden Prinzipien, Grundmaximen und Grundideen in der Verfassung fixiert sind, das jedoch zugleich mit diesen Prinzipien, Maximen und Ideen konnotierte weitere Normvorstellungen kennt, die variabel sind, weil sie durch den Gesellschaftsprozeß entstehen und sich mit ihm verändern. Als Beispiel für das $\mathrm{Zu}$ einander von fixierten Grundprinzipien und variablen generalisierten Normen im Rahmenethos kann hier etwa die normative Auslegung der Ehe in bestimmte generalisierte Verhaltenserwartungen genannt werden, die sich bei unverändertem Fortbestand der Institution Ehe und der sie tragenden Leitidee bzw. Grundnormen durchaus verändert haben und zugleich von allen Gesellschaftsmitgliedern - selbst jenen, die die Ehe nicht wählen - als dieser Institution zugehörig geteilt werden. Sowohl die Leitidee und Grundnormen, als auch die von allen geteilte veränderliche normative Auslegung in generalisierte Verhaltenserwartungen sind hierbei als das Rahmenethos der Ehe zu begreifen, das diese Institution ethisch strukturiert. Mit einem so verfaßten Begriff des Sittengesetzes, der letztlich mit dem des Rahmenethos identisch ist, bewegt sich dann die FSK-Kriteriologie wieder auf der Linie der Inhaltsethik und zeigt sie sich erneut als mit dieser kohärent. Dabei erscheint eine derartige Kohärenz durchaus nicht als herbeigezwungen, da sie sich aus der skizzierten gängigen Interpretation des Art. 2 I GG nahelegt, auf den der FSK-Grundsatz ja verweist.

Problematisch hingegen wirken schließlich die Bestimmungen der ,Entsittlichung und der ,Verrohung'. Sie gemahnen in dieser terminologischen Fassung an die ,Tradition', näherhin an die Kinoreformbewegung. Der Konnex ist hier mit großer Wahrscheinlichkeit sogar historisch gegeben - wie zu sehen war, nahmen die Reformer

\footnotetext{
124 Jarass/Pieroth, GG, Art. 2 Rdn. 16

125 Seifert/Hömig, GG, Art. 2 Rdn. 7

${ }_{126}^{126}$ Seifert/Hömig, GG, Art. 2 Rdn. 7

127 Seifert/Hömig, GG, Art. 2 Rdn. 7

${ }^{128}$ Seifert/Hömig, GG, Art. 2 Rdn. 7
} 
nachhaltigen Einfluß auf die zeitgenössische Gesetzgebung, d.h. insbesondere auf das Reichslichtspielgesetz von 1920. Eine Orientierung an den Formeln dieses noch einer ,unverdächtigen' Zeit entstammenden Gesetzes kann nach 1945 durchaus vermutet werden. ${ }^{129}$ Ungeachtet des möglichen historischen Bezugs aber legt die Formel schon an sich eine Interpretation gemäß den Paradigmen der ,Tradition' nahe. Die ,Entsittlichung' wie auch die ,Verrohung ließen sich, so sie argumentativ plausibel als zu befürchtende Wirkung eines Films erwiesen werden sollen, zweifelsohne mit Rekurs auf die pessimistische Anthropologie der Reformer konkretisierend auslegen. Wie zu sehen war, ist der diesbezügliche Argumentationsgang ja durchaus in sich konsistent und zeigten sich lediglich seine Prämissen und axiomatischen Annahmen als problematisch. Die (unerwünschte) Möglichkeit, daß gerade eine um Konsistenz bemühte Wirkungsvermutung, die auf die beiden Termini abstellt, sich bei ihrer argumentativen Formulierung der Paradigmen der ,Tradition' mit mehr oder weniger Bewußtsein wieder bedient, ist daher nicht auszuschließen. Kontramoderne Optionen könnten auf diesem Weg (ungewollt) in das Prüfhandeln erneut einwandern. Soll hingegen eine anwendungsorientierte Interpretation der Termini erfolgen, die kohärent zur ethischen Axiomatik der Moderne und der entworfenen medienethischen Konstruktion ist, so gilt es, umsichtig vorzugehen. Die ,Entsittlichung ist dann streng auf eine Verletzung des Rahmenethos und der inhaltsethischen Kriteriologie hin zu interpretieren. Diese Interpretation kann moralpädagogisch vorsichtig um eine Beleuchtung der Wahrung der Balance innerhalb des moralrelevanten Dispositivs des Menschen, also des ausgeglichenen Zueinanders der drei Basalstrukturkomponenten der fürsorgend-altruistischen Zuwendung, des sachhaften Gebrauchens und des aggressionsspezifischen Konkurrierens und Durchsetzens, durch den Gesamtgehalt eines Films ergänzt werden. Doch wird in jedem Fall der Rücksturz in die Vorstellung eines ständig von brachial andrängenden unmoralischen Strebungen bedrängten und zur ,Entsittlichung geradezu willig geneigten Menschen vermieden werden müssen. Auch wird sorgfältig darauf zu achten sein, mit dem Entsittlichungsargument nicht jeden zunächst immer tendenziell verstörenden Ethoswandel und jede vom Durchschnitt auch nur leicht abweichende Binnenmoral anzugreifen oder gar aus dem Diskurs auszuschließen. Ebenso wird der Verrohungsterminus umsichtig zu reinterpretieren sein. Hier gilt es insbesondere, die Vorstellung des ,Tiers im Menschen' oder des ,urzeitlichen Schlächters' von jeder konkretisierenden Auslegung bei der Filmprüfung fernzuhalten. Die mit dem Terminus bezeichneten Phänomene, die ja in der Tat existieren, sind nach dem Standard der modernen Psychologie und Sozialisationstheorie keineswegs als Erscheinungen zu verstehen, die durch Zerstörung einer ,zivilisatorischen Tünche' oder von die Zivilisierung erst hervorbringenden ,Barrieren' entstehen. Vielmehr müssen die ,rohen", d.h. sadistischen, grausamen, gewalttätigen oder unmäßig irasziblen Verhaltensformen von Menschen als Ergebnisse einer Versehrung und Verletzung begriffen werden. Hier gilt es im Filmbereich daher auch nicht, nach ,barrierestürzenden' Darstellungen zu suchen, sondern insbesondere im Jugendbereich mögliche Entwick-

${ }^{129}$ Ronneberger unterstellt dies sogar, wenn er die „Versagungsgründe“ der FSK-Grundsätze „weitgehend den Verbotsgründen des Lichtspielgesetzes vom 12. Mai 1920 nachgebildet“ nennt. (Ronneberger, Selbstkontrolle, 294) 
lungsstörungen und Obstruktionen zu eruieren, die eventuell von bestimmten Filminhalten begünstigt oder provoziert werden könnten. Im Erwachsenenbereich hingegen hat der Verrohungsterminus keinen Ort. Jenseits der Verletzung der Inhaltsethik und des Rahmenethos sind Erwachsene für ihren ,Medienschutz' selbst zuständig und darf nicht durch eine kodifizierende Instanz der medial vermittelte Diskurs unter Berufung auf befürchtete ,Verrohungen' von ,Risikogruppen' u.ä. behindert werden. Hier ist daher nur auf die Wahrung der Inhaltsethik zu achten. Insgesamt wäre es daher um der Wahrung einer modernitätsgerechten Medienethik und der Vermeidung unwillkürlichen Rückfalls in die Paradigmen der ,Tradition' unter Umständen empfehlenswert, die beiden Termini aus den Prüfkriterien zu entfernen oder durch geeignetere zu ersetzen.

Die grundsätzliche Kriteriologie der FSK für die Prüfung von Filmen aber zeigt sich damit nun weitgehend als durchaus kohärent und kompatibel mit der Inhaltsethik und den diese mitbedingenden medienethischen Grundvorschriften. In einigen Formulierungen lassen sich sogar Identitäten feststellen; auf jeden Fall aber können fast alle Bestimmungen im Sinn der Inhaltsethik ausgelegt werden. Lediglich der Entsittlichungs- und Verrohungsterminus erscheinen problematisch und nötigen zu einer korrektiven statt kongenialen Interpretation. Davon abgesehen aber verweist die konstatierbare Kohärenz der FSK-Grundsätze mit der entworfenen modernitätsorientieren Medienethik nun nochmals darauf, daß die Institution der FSK keineswegs als zensurale Instanz zu verstehen ist und ihr Prüfhandeln auch eine Überleitung in ein illegitimes Social engineering vermeidet. Die Kriteriologie kann vielmehr der Wahrung und Durchsetzung der inhaltsethischen Vorschriften dienen und beschränkt sich dann gemäß der oben aufgestellten Forderung auf die Wahrung des Rahmenethos der Gesellschaft. Damit stellt sie nun weiter das Programm einer Selbstkontrolle vor Augen, die mit dieser Durchsetzung zugleich eine Anwendung der ebenfalls der Inhaltsethik dienlichen Gesetze unnötig zu machen sucht. So war weiter oben zu sehen, daß die inhaltsethischen Normen zu einem guten Teil auch in entsprechenden Bestimmungen vor allem des Strafgesetzes aufgefangen sind und damit Durchsetzungskraft erhalten. Durch die Selbstkontrolle der Filmwirtschaft in der FSK nun wird der Gesetzesanwendung ein Prüfverfahren vorgeschaltet, das den härteren und konsequenzenreicheren Zugriff des Gesetzes in vielen Fällen überflüssig machen und zudem ethisch präziser und feininstrumenteller zugreifen kann, als das Gesetz es vermag. Zwar ist die Zugriffsmöglichkeit des Gesetzes hierdurch nicht einfach ausgeschaltet; $\S 29$ a FSK-Grundsätze bestimmt sogar explizit, daß bei Verletzung der $\$ \S 131$ und 184 StGB die betreffenden Filme nicht gekennzeichnet werden und der Vorgang der "federführenden Obersten Landesbehörde zur Prüfung“ vorzulegen ist, die „gegebenenfalls die Mitteilung an die zuständige Strafverfolgungsbehörde veranlaßt“. Doch kann die FSK-Prüfung in weniger gravierenden Fällen, die gleichwohl doch ethisch relevant sind, eine juridische Auseinandersetzung verhindern. Die Wahrung der Inhaltsethik ist damit zum einen verstärkt einer gesellschaftlichen Kontrolle statt einer staatlich-polizeilichen oder gerichtlichen zugewiesen und zum anderen umfassender verwirklicht als es nur mit Mitteln des Rechts möglich wäre. Auf diese Weise realisiert sich sowohl das sozialethische Desiderat, dem gesellschaftlichen Handeln in der Demokratie gegenüber dem staatlichen den größeren Raum zu geben, als auch das medienethische Desiderat, den inhaltsethischen Normen strukturelle Durchsetzungskraft zu verleihen. 
Im Bereich der Jugendprüfung gesellen sich nun zu den allgemeinen Prüfbestimmungen noch weitere, stärker pädagogisch orientierte Kriterien, von denen vordringlich jene explizit aufgeführt sind, die eine Entscheidung gegen eine Jugendfreigabe angeraten sein lassen. So bestimmt $\$ 29$ I FSK-Grundsätze, daB Filme und Bildträger, die „geeignet sind, das körperliche, geistige und seelische Wohl von Kindern und Jugendlichen zu beeinträchtigen“, nicht zur „Vorführung vor ihnen oder zur Abgabe an sie freigegeben werden" dürfen. In $\$ 29$ II FSK-Grundsätze werden dann verschiedene Präzisierungen dieser allgemeinen Vorschrift vorgenommen. So wird der Begriff der Beeinträchtigung dahingehend präzisiert, daß darunter „Hemmungen, Schädigungen oder Störungen zu verstehen“ sind. Weiter heißt es dort, daß „das körperliche, seelische oder geistige Wohl von Kindern und Jugendlichen" insbesondere von Filmen beeinträchtigt werden könne, die „die Nerven überreizen, übermäßige Belastungen hervorrufen, die Fantasie über Gebühr erregen, die charakterliche, sittliche (einschließlich religiöse) oder geistige Erziehung hemmen, stören oder schädigen, zu falschen und abträglichen Lebenserwartungen verführen oder die Erziehung zu verantwortungsbewußten Menschen in der Gesellschaft hindern". Jenseits dieser eine Freigabe ausschließenden Kriterien wiederum bestimmt § 28 I FSK-Grundsätze im AnschluB an eine Auflistung der Altersstufen, daB die FSK Filme und Bildträger daraufhin prüfe, ,welcher Altersgruppe sie vorgeführt oder zugänglich gemacht werden dürfen“. Eine Freigabe darf dabei nur dann erfolgen, wenn „die Erziehung zur leiblichen, seelischen und gesellschaftlichen Tüchtigkeit keines Jahrgangs" der betroffenen Altersgruppe beeinträchtigt werden kann. ${ }^{130}$ Hierbei wiederum ist nach gängiger Auffassung eine Beeinträchtigung nur dann zu konstatieren, wenn „eine nachhaltige und nicht nur vorübergehende Wirkung auf Kinder bzw. Jugendliche stattfindet“. ${ }^{131}$ Weiter ist von „den durch die Umwelt und vor allem durch die anderen Massenmedien präformierten Kindern und Jugendlichen" auszugehen. ${ }^{132}$

Die so beschaffenen Bestimmungen und ihre Auslegungshinweise nun erweisen sich (weitgehend) als kompatibel mit einer Orientierung an den altersspezifischen Kompetenzen von Kindern und Jugendlichen und erlauben damit durchaus eine Verklammerung des durch sie zu gewährleistenden Jugendschutzes mit einer Erziehung zur Mündigkeit. So leitet der Ansatz der Kriteriologie bei einer Beeinträchtigung des körperlichen, seelischen oder geistigen Wohls der Betroffenen gerade dazu an, psychophysische Gesetzlichkeiten und Gegebenheiten bei bestimmten Altersstufen zu berücksichtigen und entwicklungspsychologische und sozialisationstheoretische Erkenntnisse in die konkrete Ausgestaltung des Prüfhandelns einzubeziehen. Die Konkretion des Beeinträchtigungsbegriffs als Hemmungen, Störungen und Schädigungen erlaubt dabei die Interpretation möglicher negativer Konsequenzen der Filmrezeption im Sinn von Versehrungen und Verletzungen, die auf der Basis von Entwicklungspsychologie und Sozialisationstheorie eruiert werden können. Damit aber ist zugleich bereits das reformerische Paradigma überwunden, das den Menschen als gefährdetes Latenzwesen ansetzte, dessen Erziehung durch Errichtung von Barrieren zu geschehen hatte. Stattdessen kann unter dem mit der zitierten

${ }^{130}$ Hartlieb, Handbuch, Kap. 18 Rdn. 8

131 Hartlieb, Handbuch, Kap. 18 Rdn. 8

${ }^{132}$ Hartlieb, Handbuch, Kap. 18 Rdn. 8 
Auslegung versehenen Beeinträchtigungsbegriff differenziert den autoentelechialen Strebungen und der Entwicklungsdynamik von Kindern und Jugendlichen nachgegangen und konstruktiv Raum gegeben sowie in Kooperation mit diesen agiert werden. Im Bereich der Filmprüfung muß es entsprechend nicht mehr um die Abwehr andrängender pernizioser menschlicher Strebungen gehen und durch Vorenthaltung möglicher gefährdender Filme einer ,Enthemmung gewehrt werden. Vielmehr kann nun auf mögliche Obstruktionen für die kindliche oder jugendliche Entwicklung geblickt und die Entwicklungsdynamik selbst statt als Gefährdungspotential nun als Schutzobjekt des Prüfhandelns betrachtet werden. Im Unterschied zu den Reformern wird damit unter dem Beeinträchtigungsbegriff eine konstruktive Wirkung des Prüfhandelns möglich und sichtbar, die den Menschen zu seiner Entwicklung freisetzt und deren Fortgang durch flankierende Maßnahmen gedeihlich zu halten sucht. Weiter aber gibt die Auslegung der Prüfkriterien zusätzlich auch Raum für einen Einbezug der medienspezifischen Kompetenzen von Kindern und Jugendlichen in die Prüfreflexion. Wenn nach gängiger Ansicht von durch Medien ,präformierten Kindern und Jugendlichen auszugehen ist, läßt dies in Blick treten, da $B$ diese ,präformierten' Individuen mit ihrer Formierung auch bereits spezifische Rezeptionstechniken, Wissensformen und Wahrnehmungsweisen entwickelt haben, die es ihnen ermöglichen, mit dem Medium und seinen Eigenarten differenziert und ,kundig umzugehen. Auch die Einordnung des Mediums in den kinder- und jugendspezifischen lebensweltlichen Kontext durch die Rezipienten ist im Zusammenhang mit der ,Präformation' zu sehen. Damit aber kann die Filmprüfung auf diese Nutzungskompetenzen und Einordnungen Bezug nehmen und etwa empirische Studien, in denen die ,Präformation' erarbeitet ist, praxisrelevant für ihr Handeln auswerten. Die Prüfung von Filmen wird auf diese Weise mit der lebensweltlichen Realität des Mediengebrauchs in Kontakt gehalten und kann entsprechend realitätsnah vollzogen werden. Auf diese Weise schließen sich die Kriteriologie der FSK und ihre Auslegung zumindest in ihren Möglichkeiten mit dem medienethischen Ansatz zusammen, der den Jugendschutz in den Kontext einer Erziehung zur Mündigkeit stellt und eine Kooperation mit den altersspezifischen und sozialisativ erzeugten Kompetenzen fordert.

Ein wenig problematisch mutet lediglich die beispielhafte Auflistung von Beeinträchtigungen an, die konkret durch Filme verursacht werden können. Diese Liste nämlich erinnert zunächst recht deutlich an diverse Devianzthesen der ,Tradition'. So hat die ,Nervenüberreizung zweifelsohne ebenso bei den Reformern ihren Ursprungsort wie die ,Übererregung der Fantasie‘. Die Nennung einer, Verführung zu falschen oder abträglichen Lebenserwartungen' wiederum gemahnt vor allem an die Befürchtungen der Filmerzieher, da $B$ der Film überspannte Hoffnungen wecken könnte. Doch auch die reformerische These von der filminduzierten ,Sucht nach Abenteuer und Aufregung' gegenüber der der Alltag recht ,blaß` anmute, könnte darin wiederentdeckt werden. Hier wird daher in der Anwendung bei einigen Kriterien eine Reinterpretation nötig sein. Ohne besondere Reinterpretation freilich wird man trotz des ,Traditionsbezugs' die Nervenüberreizung auslegen können; sie läßt sich zusammen mit der Ablehnung übermäßiger Belastungen als psychophysische Überforderung vor allem im Bereich der Kinderfreigabe von Filmen kriteriologisch applizieren. Die Fantasieübererregung hingegen ist bereits mit Vorsicht zu betrachten. Keinesfalls darf hier ein Rückfall in die skizzierten Befürchtungen der Refor- 
mer, die eine Zerstörung des logischen Denkvermögens oder gar Wahnsinn als Folge des Films ausmalten, statthaben. Besser ausgelegt erscheint der Terminus, wenn man ihn auf mögliche Neurotisierung oder durch überfordernde Konfrontationen mögliche Traumata hin konkretisiert. ${ }^{133}$ Dabei gilt es wiederum, die psychologische Forschung möglichst differenziert zu bemühen. Die Generierung falscher oder abträglicher Lebenserwartungen wiederum kann im Sinn einer Desinformation über die lebensweltlichen Gegebenheiten und gesellschaftlich-politischen Zusammenhänge reinterpretiert werden. Angesichts der Vielfalt der Lebenserscheinungen in der pluralistischen Gesellschaft und der Offenheit ihrer demokratischen Strukturen scheint mir jedoch dieses Kriterium selten anwendbar zu sein, wenn die Vorschreibung einer Linie für die Thematisierung gesellschaftlicher und lebensweltlicher Gegebenheiten und damit ein Abgleiten in ein Social engineering vermieden werden soll. Erst wenn sich die inhaltlichen Appräsentationen agitativ gegen die demokratische Gesellschaft richten, wird ein Grad erreicht sein, der nicht mehr vertretbar ist. Dann jedoch greifen die generellen inhaltsethischen Kriterien und wird eine zusätzliche Anwendung des Kriteriums der Erzeugung falscher Lebenserwartungen überflüssig. Gleichwohl ist im Ganzen zunächst erkennbar, daß auch die aufgeführten, noch an die ,Tradition' gemahnenden Kriterien zumindest im Sinn einer modernitätsgerechten $\mathrm{Me}$ dienethik reinterpretiert werden können. Freilich gilt es, auch hier wieder bei ihrer Anwendung Vorsicht walten zu lassen und wäre unter Umständen eine Reformulierung zu erwägen.

Unproblematisch hingegen sind die kriteriologischen Beispiele, die auf eine Hemmung, Störung oder Schädigung der charakterlichen, sittlichen, religiösen und geistigen Erziehung sowie einer Erziehung zu Verantwortungsbewußsein abheben. Sie sind im Kontext einer Erziehung zur Mündigkeit durchaus als Kriterien der Filmprüfung anwendbar. In der Tat war oben ja schon mehrfach zu sehen, da $ß$ diese Erziehung auch als moralpädagogisches Unterfangen zu verstehen ist und den Auftrag zu einer Flankierung durch entsprechende Schutzmaßnahmen in sich birgt. So ist im Bereich der charakterlichen und sittlichen Erziehung etwa auf die Ausbalancierung der moralrelevanten Strukturkomponenten zu achten und sind entsprechende Störfaktoren, zu denen auch Filme mit entsprechenden Inhalten gehören, auszuschalten. Weiter muß um einer gedeihlichen Moralitätskonstitution willen auch gerade bei Kindern und Jugendlichen, die diese Konstitution erst noch zu leisten haben, einer Desorientierung durch insbesondere Überforderung gewehrt werden. Überkomplexe normative Problemzusammenhänge in Filmen bergen, wo sie nicht zureichend verstanden und ausreichend reflexiv bewältigt werden können, die Gefahr in sich, in diese Desorientierung zu führen. Auch die kritisch-problematisierende Appräsentation verwerflicher Verhaltensformen kann nicht gleichermaßen von jeder Altersklasse begriffen und verarbeitet werden, so daß hier ebenfalls eine Vermeidung von desorientierenden Überforderungen anzuzielen ist. Zur Eruierung dieser und ähnlicher Störmöglichkeiten können wiederum einschlägige Untersuchungen zur Moralitätsentwicklung - wie etwa die recht differenzierte, empirisch geleitete Theoriekonstruktion von James W. Fowler ${ }^{134}$ - herangezogen werden. Die

${ }^{133}$ In diesem Sinn auch Hartlieb, Handbuch, Kap. 12 Rdn. 5

134 vgl. etwa: Fowler, James, Stages of Faith. The Psychology of Human Development and the Quest for Meaning, San Francisco 1981 
Stufung der Filme kann dann mit Blick auf die je altersspezifischen moralischen Kompetenzen vorgenommen und eventuell sogar auf eine Förderung der Weiterentwicklung dieser Kompetenzen hin orientiert werden. In den Kontext der Verhinderung einer Obstruktion der Moralitätsentwicklung scheint mir auch das Kriterium, $\mathrm{da} B$ eine Erziehung zu ,einem verantwortungsbewußten Menschen in der Gesellschaft' nicht gestört werden darf, zu stellen sein. Es repetiert diese Forderung mit einer nun stärker auf das Ethos gesellschaftlichen und gesellschaftsbezogenen Verhaltens orientierten Zielrichtung. Auch hier ist mithin Desorientierungen zu wehren, die nun vordringlich von Überforderungen durch eine überkomplexe oder schwer zu verarbeitende kritische Thematisierung gesellschaftlicher Sachverhalte evoziert sein können. In dieser Weise läßt sich auch das Kriterium auslegen, das Störungen der geistigen Erziehung abzuwehren gebietet. Es kann ebenfalls auf Überforderungen hin konkretisiert werden, die als eigentliche Ursache von Desorientierungen zu verstehen sind. ${ }^{135}$ In bezug auf gesellschaftliches Verantwortungsbewußtsein und gedeihliche geistige Erziehung werden daher ebenfalls die je spezifischen Kompetenzen einer Altersgruppe, ihre Möglichkeiten des Verstehens und der Verarbeitung von Formen und Inhalten, in den Blick zu nehmen sein, auf deren Basis eine entsprechene Zuordnung von Filmen geschehen kann. Das Verbot einer Störung der religiösen Erziehung schließlich läßt sich als Konkretion des allgemeinen Gebots der Achtung der Freiheit des religiösen oder weltanschaulichen Bekenntnisses im Kinder- und Jugendbereich auslegen. Wie es generell jeder Person zuzugestehen ist, ihre Transzendenzverwiesenheit denominativ zu realisieren, muß auch Kindern und Jugendlichen ein edukativer Umraum zugestanden werden, in dem sich diese denominative Realisierung allmählich entwickeln kann. Hier gewinnt daher das Verbot der Verketzerung religiöser oder weltanschaulicher Bekenntnisse eine zusätzliche, über die ,Wahrung des öffentlichen Friedens' hinausreichende pädagogische Bedeutung. Doch auch jenseits unmittelbarer verketzernder Agitation gilt es darauf zu achten, daß nachhaltige Obstruktionen der kindlichen und jugendlichen Entwicklung religiösen Bewußtseins möglichst vermieden werden. Auch eine zwar unter Umständen noch nicht verketzernde, jedoch die Verarbeitungsmöglichkeiten überschreitende Appräsentation religionsbezogener Themen muß deshalb differenziert geprüft wer-

135 Ethisch nicht tolerable Appräsentationen gesellschaftlicher Sachverhalte müssen an dieser Stelle nicht miterfaßt werden, wenn auch die Interpretation ,in geistiger Beziehung (...) eine Fehlleitung des gesellschaftlichen Bewußtseins durch fehlerhafte Darstellung gesellschaftlicher Vorgänge in Betracht zu ziehen" geneigt ist (so Hartlieb, Handbuch, Kap. 12 Rdn. 5). Eine ethisch intolerable ,Darstellung gesellschaftlicher Vorgänge‘ ist nur dort anzunehmen, wo gegen die demokratische Gesellschaft agitiert und deren Grundprinzipien angegriffen werden. Diese Darstellungsformen aber sind bereits generell inhaltsethisch erfaßt und nicht nur Jugendlichen vorzuenthalten, sondern überhaupt illegitim. Im Kontext der Jugendprüfung geht es daher nur noch um mögliche Überforderungen und daraus quellende ,Fehlleitungenc. - Der Terminus ,fehlerhafter Darstellung' erscheint im übrigen ohnehin problematisch - er gemahnt an die entsprechende Devianzthese der Reformer, die eine filminduzierte ,Verhetzung der Stände' und eine ,große Verworrenheit des Volkes in staatlichen Dingen“ ausmalten (vgl. 2.5.). Der Terminus ,Fehlerhaftigkeit' setzt zudem eine Instanz voraus, die bestimmt, was zutreffend und was fehlerhaft ist. Sie impliziert mithin eine Tendenz zu autoritativer Liniengebung und damit zu einer Gängelung des gesellschaftlichen Diskurses, die nicht legitimiert werden kann. Auch aus diesem Grund scheint es mir günstiger, sich auf eine Beurteilung von Thematisierungen gesellschaftlicher Belange zu beschränken, die sich ausschließlich an den inhaltsethischen Illegitimitäten orientiert, nicht aber ein Zusatzkriterium ,richtiger' und ,falscher' Darstellungen einführt. 
den. Dies wird freilich wiederum nicht die Konfrontation kindlicher und jugendlicher Rezipienten mit Kritik hindern, fordert aber eine Stufung der Zugänglichkeit von Filmen nach alterspezifischen Kompetenzniveaus. Zur empirisch geleiteten Rekonstruktion solcher Kompetenzniveaus hat dabei ebenfalls wieder Fowler grundlegende Beiträge geliefert, die sich entsprechend auswerten ließen.

Im Ganzen aber zeigt sich damit, daB die FSK sowohl im Bereich der in der Erwachsenenprüfung als auch in dem der bei der Jugendprüfung zur Anwendung gebrachten Kriteriologie durchaus Optionen triff, die der vorgelegten medienethischen Konstruktion entweder bereits gleichlaufen oder aber zumindest auf diese hin interpretiert bzw. von ihr interpretativ gestützt werden können. Damit bestätigt sich die eingangs skizzierte Struktur der FSK nochmals als zensurfremde und gegen ein Abgleiten in ein medial vermitteltes Social engineering gesicherte Organisation von Selbstkontrollmaßnahmen. Mit ihren generellen Prüfkriterien verhilft die FSK dabei dem Rahmenethos zur Durchsetzung und sichert sie die Wahrung der inhaltsethischen Essentials. Im Jugendbereich vermag sich das Prüfhandeln der FSK zudem mit der medienethisch aufgestellten Forderung des Einbezugs sozialisationstheoretischer und entwicklungspsychologischer sowie auf die lebensweltliche Realität der Mediennutzung bezogener Untersuchungen zusammenzuschließen. Es kann sich dabei auch auf eine Kooperation mit den spezifischen, bereits vorhandenen Kompetenzen der Kinder und Jugendlichen richten und erweist sich somit in jeder Hinsicht als Stützmaßnahme einer Erziehung zur Mündigkeit. Die FSK realisiert auf diese Weise sowohl die strukturelle Sicherung des Rahmenethos der Gesellschaft als auch das Gebot der differenzierten Einrichtung jugendschützerischer Maßnahmen. Sie erweist sich derart als eine Institution, die der Verwirklichung der medienethischen Forderungen, wie sie hier entwickelt worden sind, bereits umfassend dient bzw. dienen kann.

Ähnlich verhält es sich auch mit der Bundesprüfstelle für jugendgefährdende Schriften. Bei ihr handelt es sich um eine Bundesoberbehörde, d.h. eine Verwaltungsbehörde, die kollegial zusammengesetzt ist und kollegial entscheidet. ${ }^{136}$ Sie ist zuständig für die Durchführung der Aufgaben, die vom Gesetz über die Verbreitung jugendgefährdender Schriften (GjS) gestellt werden, d.h. insbesondere die Aufnahme jugendgefährdender Schriften in eine Liste (Indizierung), durch welche die indizierten Medienprodukte bestimmten Beschränkungen unterworfen werden. Durch den erweiterten Schriftenbegriff, der gemäß \& 1 III GjS auch „Ton- und Bildträger, Abbildungen und andere Darstellungen" zu den ,Schriften' zählt, erhält die BPS eine spezifische Zuständigkeit in bezug auf den Film. Die Realisierung dieser Zuständigkeit durch Prüfung und gegebenenfalls Indizierung von Filmen stellt dabei ein wesentliches Element der Durchführung des gesellschaftlichen Jugendschutzes dar, das die im JÖSchG und den Grundsätzen der FSK enthaltenen filmbezogenen jugendschützerischen Unternehmungen ergänzt. Die Struktur, die Aufgabenstellung und die Prüfkriterien der BPS lassen sich hierbei ebenfalls wieder in Konnex mit der hier vorgelegten medienethischen Konstruktion bringen und von dort her auslegen.

Die Zuständigkeit der BPS für den Filmbereich nun ist durch die Neufassung des JÖSchG so geregelt, da $B$ sich Überschneidungen bzw. Konkurrenzen und Widersprüche mit den Bestimmungen des GjS nicht (mehr) ergeben können. Während

136 vgl. dazu: Scholz, Jugendschutz, 68 
früher in einzelnen Fällen von der FSK ,namens der Obersten Landesbehörden für Jugendliche freigegebene Kinofilme als Bildträger wegen Jugendgefährdung indiziert" worden sind, gibt es jetzt präzise Kompetenzabgrenzungen. ${ }^{137}$ So bestimmen die $\$ \$ 6$ VII und 7 V JÖSchG, daß Kinofilme und Bildträger, die von den Obersten Landesbehörden für Kinder und Jugendliche freigegeben und entsprechend gekennzeichnet worden sind, nicht (mehr) der Indizierung und den damit verbundenen Beschränkungen des GjS unterliegen. ${ }^{138}$ Dies gilt auch für Kinofilme, die mit der Kennzeichnung "nicht freigegeben unter 18 Jahren" versehen worden sind. Eine unterschiedliche Beurteilung von Kinofilmen oder Bildträgern bei der Vorprüfung durch die FSK bzw. die Obersten Landesbehörden und der Nachprüfung durch die BPS wird auf diese Weise verhindert. Gleichwohl bleiben der BPS bestimmte Zuständigkeiten erhalten. So können von ihr zunächst all jene Kinofilme geprüft werden, „die nicht im Wege der Vorprüfung durch die Obersten Landesbehörden gekennzeichnet worden sind, sei es, daß sie nicht vorgelegt wurden, oder da $B$ die Obersten Landesbehörden die Kennzeichnung, also auch die Kennzeichnung ,nicht freigegeben unter 18 Jahren', nicht erteilt haben" ${ }^{139}$ Weiter bleibt die BPS zuständig für alle Bildträger, die nicht für Jugendliche freigegeben worden sind. Hier ist sie dann auch für jene Bildträger prüfberechtigt, die nicht unter $18 \mathrm{Jahren}$ freigegeben worden sind. ${ }^{140}$ Die letztgenannte Zuständigkeit, die eine unterschiedliche Behandlung von Filmen für Erwachsene im Kino- und Bildträgerbereich feststellen läßt, erklärt sich dabei aus der unterschiedlichen Verbreitungsart, die eine unterschiedliche Zugänglichkeit impliziert. Während sich im Kinobereich Kinder und Jugendliche nicht eines Erwachsenen bedienen können, um sich Zugang zu einem für sie nicht freigegebenen Film zu verschaffen - das Kinopersonal hätte die Pflicht, Kinder und Jugendliche auch in Begleitung Erwachsener abzuweisen -, besteht bei Bildträgern, etwa bei Videos, die Chance einer ,Ersatzbeschaffung durch Erwachsene. ${ }^{141}$ Dieser mißbräuchlichen Umgehung der Altersstufung und des mit ihr geregelten Jugendschutzes will die Andersbehandlung der Bildträger begegnen. Es handelt sich hierbei also um eine an der Praxis orientierte, aus jugendschützerischem Interesse vorgenommene Kompetenzzuteilung.

Übt die BPS diese ihre Kompetenz nun aus und indiziert sie Filme und Bildträger, so treten für diese bestimmte Beschränkungen in Kraft. So dürfen indizierte Medienprodukte gemäß § 3 I GjS Kindern und Jugendlichen u.a. nicht ,angeboten, überlassen oder zugänglich gemacht werden". Dies bedeutet weiter auch etwa, da $\beta$ kein indiziertes Medienprodukt an Orten ,ausgestellt, angeschlagen, vorgeführt oder sonst zugänglich gemacht" werden darf, die Kindern und Jugendlichen zugänglich sind oder von ihnen eingesehen werden können. Schließlich ist die gewerbliche Vermietung oder eine ,vergleichbare gewerbliche Gewährung des Gebrauchs' indizierter Medienprodukte ebenfalls unzulässig, es sei denn, sie erfolgt in Ladengeschäften, die von Kindern und Jugendlichen nicht eingesehen werden können und ihnen nicht zugänglich sind. Nach $\$ 4 \mathrm{GjS}$ sind dann auch die Verbreitung indizierter Medienpro-

${ }^{137}$ Hartlieb, Handbuch, Kap. 10 Rdn. 8

138 vgl. dazu auch: Hartlieb, Handbuch, Kap. 10 Rdn. 8

${ }_{139}$ Hartlieb, Handbuch, Kap. 11 Rdn. 2

140 vgl. Hartlieb, Handbuch, Kap. 11 Rdn. 2

141 vgl. dazu: Hartlieb, Handbuch, Kap. 10 Rdn. 9 
dukte im Einzelhandel außerhalb von Geschäftsräumen, in Kiosken etc., im Versandhandel, in gewerblichen Leihbüchereien etc., die Belieferung solcher Betriebe und die Einführung in den Geltungsbereich des GjS via Versandhandel untersagt. Mit diesen Vorschriften sind so zunächst einmal bestimmte Beschränkungen für die Verbreitung von indizierten Medienprodukten aufgestellt. Nach $\S 5 \mathrm{GjS}$ ist jedoch auch die Werbung für solche Medienprodukte eingeschränkt. So darf beispielweise nach § 5 II GjS ein indiziertes Medienprodukt ,nicht öffentlich oder durch Verbreiten von Schriften angeboten, angekündigt oder angepriesen werden". Eine Ausnahme allerdings statuiert Abs. 3 dieses Paragraphen für „den Geschäftsverkehr mit dem einschlägigen Handel sowie für Handlungen an Orten, die Kindern und Jugendlichen nicht zugänglich sind und von ihnen nicht eingesehen werden können“". Die Werbe- und Vertriebsbeschränkungen stellen so ganz auf den Schutz von Kindern und Jugendlichen $a b$ und versuchen die Modi unwillkommener Information über jugendgefährdende Medienprodukte und die Zugänglichkeit zu ihnen soweit zu restringieren, da $B$ Kinder und Jugendliche mit solchen Produkten möglichst nicht mehr in Berührung kommen können. Gleichzeitig sollen Information und Zugänglichkeit für Erwachsene möglichst weitgehend erhalten bleiben, wenn auch um der Effizienz des Jugendschutzes willen hier Einschränkungen stattfinden.

Mit der vorstehend skizzierten Kompetenzzuteilung und den Beschränkungsformen der Indizierung erhält die BPS eine wichtige Funktion im Bereich des Jugendschutzes, durch die sie die entsprechenden Unternehmungen der FSK und der Obersten Landesbehörden flankiert. Sie vermag zunächst einmal all jene Filme im Kinobereich zu erfassen, die der Jugendprüfung der FSK entgehen und die unter Umständen eine jugendgefährdende Relevanz besitzen. Weiter kann sie im Bildträgerbereich (d.i. hauptsächlich der Videobereich) jene Filme für Erwachsene prüfen, die zwar nicht gegen die Inhaltsethik verstoßen oder zumindest als noch tolerabel um der Wahrung der offenen Kommunikationsstruktur willen freigegeben worden sind, die jedoch keinesfalls in die Hände von Kindern und Jugendlichen gelangen sollten. Die spezifischen Beschränkungen im Werbe- und Vertriebsbereich suchen dann diese unerwünschte Möglichkeit weitgehend auszuschalten. ${ }^{142}$ Von besonderer Bedeutung sind dabei die Werbebeschränkungen, die spezifisch gegen die Möglichkeit einer Ersatzbeschaffung gerichtet sind. Durch sie nämlich soll erreicht werden, daß Kinder und Jugendliche über die Existenz von für sie unzuträglichen Medienprodukten möglichst nicht informiert sind und in der Folge deren Beschaffung auch nicht anstreben. Die Indizierung stellt somit eine flankierende Maßnahme des Jugendschutzes dar, durch die die entsprechenden Möglichkeiten der Altersprüfung sowohl bereichsbezogen bezüglich nicht gekennzeichneter Kinofilme und der Bildträger als auch in bezug auf die Umgehung der von dieser Prüfung bedingten Zugänglichkeitseinschränkung ergänzt werden. Die diesbezügliche Tätigkeit der BPS kann damit als

142 Dabei doppeln sich im Videobereich die Vertriebsbeschränkungen partiell mit der neugefaßten, dem GjS nachgebildeten Vorschrift von \$ 7 III JÖSchG, der für Bildträger, die unter 18 Jahren nicht freigegeben sind, der Verbreitung ähnliche Grenzen zieht. Die Vorschriften des GjS sind jedoch strenger und ziehen die Grenzen enger. Außerdem handelt es sich bei den Verstößen gegen die aufgeführten Vorschriften des GjS um Straftaten, während es bei den VerstöBen gegen die entsprechenden Bestimmungen des JÖSchG nur um Ordnungswidrigkeiten geht. (Vgl. dazu: Hartlieb, Handbuch, Kap. 13 Rdn. 5-8) 
Vervollständigung des gesellschaftlich notwendigen, institutionell organisierten Jugendschutzes begriffen werden.

Dabei ist diese Tätigkeit durchaus wieder von einer Zensur zu unterscheiden. Zwar sind die mit der Indizierung einhergehenden Beschränkungen durchaus nicht unerheblich, und treffen sie auch die Zugänglichkeit von Medienprodukten für Erwachsene. Doch wird diese Zugänglichkeit nicht schlechthin ausgeschaltet. Gerade im Filmbereich bleibt immerhin noch die Möglichkeit, in Videotheken, die nur Erwachsenen zugänglich sind und nicht von außen eingesehen werden können, indizierte Filme zu entleihen oder auch unter Umständen käuflich zu erwerben. Das GjS sieht diese Möglichkeiten sogar direkt vor, wenn es die zitierten Ausnahmen von den verbotshaften Regeln aufstellt, die etwa die Einrichtung von nicht einsehbaren, Kindern und Jugendlichen nicht zugänglichen Ladengeschäften ermöglichen, in denen dann auch indizierte Filme Erwachsenen angeboten werden können. Die indizierten Filme werden mithin der Öffentlichkeit nicht schlankweg entzogen. Vielmehr richtet sich das Handeln der BPS exklusiv auf den Schutz der Kinder und Jugendlichen, der möglichst praxisbezogen eingerichtet werden soll. Da dieser Schutz medienethisch durchaus geboten ist, entsteht hier lediglich das Problem einer Kollision dieses Gebots mit dem der Wahrung der offenen Kommunikationsstruktur, die eine möglichst ungehinderte Zugänglichkeit von Medienprodukten impliziert. Diese Kollision ist, wie alle anderen Konkurrenzen ebenfalls, nur durch Güterabwägung und eine entsprechende Kompromißbereitschaft zu lösen. Eine Beschränkung der Zugänglichkeit, die diese nicht völlig ausschaltet, kann dabei als durchaus legitimer Kompromiß bezeichnet werden. Gleichwohl sind die Beschränkungen - wie gesagt - nicht unerheblich und ist die mit der Indizierung verbundene Handlungsmacht nicht gering einzuschätzen. Es bedarf daher unter dem Gebot der Wahrung der offenen Kommunikationsstruktur und einer mit dieser kompatiblen Einlösung der Jugendschutzforderung auch einer entsprechend differenzierten und wohl abgewogenen Struktureinrichtung der Institution, die mit dieser Handlungsmacht ausgestattet ist, sowie eines Katalogs von Prüfkriterien, die sich auf die jugendschützerischen Erfordernisse beschränken und einem Überborden des indizierenden Handelns in einen ,Erwachsenenschutz' wehren. Ein genauer Blick nun zeigt, da $B$ dies bei der BPS (weitgehend) gewährleistet ist.

Zunächst zeigt sich, daß die Organisationsstruktur der BPS den im strukturethischen Baustein entwickelten Erfordernissen weitgehend gerecht wird. So stellt die BPS in ihrer strukturellen Zusammensetzung eine sachkundig und plural besetzte Institution dar, die - bis auf ein Moment - der für mit umfassenden Wirkmöglichkeiten ausgestattete Einrichtungen aufgestellten Repräsentativitätsforderung entspricht. GemäB § 9 I GjS besteht die BPS ,aus einem vom Bundesminister für Jugend, Familie und Gesundheit ernannten Vorsitzenden, je einem von der Landesregierung zu ernennenden Beisitzer und weiteren vom Bundesminister für Jugend, Familie und Gesundheit zu ernennenden Beisitzern". ${ }^{143}$ Die letztgenannten Beisitzer sind dabei nach Abs. 2 ,den Kreisen' der Kunst, der Literatur, des Buchhandels, der Verleger-

143 In der vorliegenden Fassung des Gesetzestexts vom 12. Juli 1985 (BGBl. III 2161-1) fehlt die Nennung der Frauen im Bundesministerium für Jugend, Familie, Frauen und Gesundheit noch. 
schaft, der Jugendverbände, der Jugendwohlfahrt, der Lehrerschaft, der Kirchen, der jüdischen Kultusgemeinden und ,anderen Religionsgemeinschaften, die Körperschaften des öffentlichen Rechts sind“', zu entnehmen. Die infrage stehenden ,Kreise“ haben dabei ein Vorschlagsrecht für ihre Vertreter. Ihre Entscheidungen fällt die BPS in einem Gremium von 12 Mitgliedern, das gemäß $\$ 9$ III GjS aus dem Vorsitzenden, drei Beisitzern der Länder und je einem Beisitzer der genannten Gruppen zusammengesetzt ist. In einigen genau umschriebenen Fällen - der vorläufigen Anordnung zur Listenaufnahme nach $\S 15 \mathrm{II}$ GjS und der Aufnahme im vereinfachten Verfahren gemäß $\$ 15 \mathrm{a}$ GjS - kann die Entscheidung in einem auf drei Mitglieder beschränkten Gremium gefällt werden. Im Dreiergremium muß dabei in jedem Fall ein Mitglied den aufgeführten gesellschaftlichen Gruppen angehören. Ist über ein Medienprodukt bereits eine rechtskräftige gerichtliche Entscheidung getroffen, daß dieses Produkt den Straftatbeständen der $\$ 1131$ und 184 StGB entspricht, oder ist ein Medienprodukt als mit einem indizierten ganz oder im wesentlichen inhaltsgleich, so wird nach $\$ 18$ I GjS bzw. §18a I GjS der Vorsitzende der BPS allein tätig. Indizierungsentscheidungen werden dabei von den Gremien in der Regel nur auf Antrag gefällt. Die BPS kann mithin nicht von sich aus Medienprodukte ihrem Prüfverfahren unterwerfen, sondern es bedarf hierfür einer Beantragung der Prüfung durch bestimmte Amtsträger und Stellen. Die Antragsberechtigung wird nach § 11 II GjS vom Bundesminister für Jugend, Familie und Gesundheit „durch Rechtsverordnung mit Zustimmung des Bundesrates" festgelegt. Gemäß § 2 DVO GjS sind antragsberechtigt die Obersten Jugendbehörden der Länder, die Landesjugendämter, die Jugendämter und der Bundesminister für Jugend, Familie und Gesundheit. Einzig in den Fällen der $\S \S 18 \mathrm{I}, 18 \mathrm{a}$ I GjS, sowie im Fall einer Dauerindizierung von Periodika gemäB \& $7 \mathrm{GjS}$, bei denen innerhalb von zwölf Monaten mehr als zwei ihrer Ausgaben indiziert wurden, entfällt das Antragsprinzip. Die BPS selbst macht darüber hinaus wiederholt darauf aufmerksam, daß jenseits der Antragsberechtigung ,jeder Bundesbürger und jede Bundesbürgerin (...) aufgerufen [ist], mitzuhelfen, damit unsere Jugend den Schutz erfährt, auf den sie ein Anrecht hat " ${ }^{144}$ Diese Mithilfe kann sich darin äußern, ,Indizierungsanträge an ein Jugendamt oder an ein antragsberechtigtes Ministerium heranzutragen“ bzw. ,an Arbeitskreisen mitzuwirken, deren Aufgabe es ist, die Jugendämter bei der Vorbereitung von Indizierungsanträgen zu unterstützen“. ${ }^{145}$

Eine medienethische Betrachtung dieser Organisationsstruktur läßt nun zunächst erkennen, daß die personelle Zusammensetzung der Prüfgremien der BPS in der Tat der Repräsentativitätsforderung weitgehend entspricht. Diese Gremien nämlich sind so ausgelegt, daß neben den Vertretern des betroffenen Kultursachbereichs der (Print-)Medien auch die relevanten gesellschaftlichen Gruppen darin vertreten sind und somit dem gesellschaftlichen Einfluß auf die Prüfung der entsprechende Raum gegeben wird. Auf diese Weise werden die aus jugendschützerischen Erwägungen unter Umständen nötigen Kommunikationsbeschränkungen prinzipiell in Kooperation mit den Vertretern der Produzenten und - vertreten durch die relevanten

144 BPS-Broschüre, 8 (Stand 8/1989) - Eine neue Broschüre ist in Vorbereitung, bislang jedoch noch nicht ausgeliefert.

${ }^{145}$ BPS-Broschüre, 8 
Gruppen - dem Medienpublikum beschlossen, d.h. aber: in Vernetzung mit dem gesellschaftlichen Diskurs herbeigeführt. Im Zwölfergremium erhalten die gesellschaftlichen Kräfte sogar maßgeblichen Einfluß auf die Entscheidungsfällung. Dort stehen ja vier Vertreter der betroffenen Sparten des Medienbereichs und vier Vertreter gesellschaftlicher Gruppen vier Vertretern von Ländern und Bund gegenüber. Nach $\S 13$ GjS ist für eine Entscheidung zur Indizierung eine 2/3-Mehrheit erforderlich, so da $B$ „der gesellschaftliche Einfluß zu Lasten des staatlichen Einflusses gestärkt wird“. ${ }^{146}$ Die Forderung, daß dort, wo beschränkende Maßnahmen im Kommunikationsbereich möglich werden, eine repräsentative Mitwirkung der betroffenen Produzenten und der gesellschaftlichen Kräfte gewährleistet sein muB, wird damit (zumindest für die Printmedien) erfültt. Das Übergewicht der gesellschaftlichen Kräfte wirkt hierbei zusätzlich jedem Abgleiten in ein vermittels Kommunikationsbeschränkung mögliches staatliches Social engineering entgegen und schaltet jeden diesbezüglichen Verdacht schon strukturell aus. Selbst im Dreiergremium aber ist der zur Wahrung der Repräsentativitätsforderung nötige gesellschaftliche EinfluB noch zumindest in Ansätzen gegeben. Das eingeschränkte Gremium soll zudem nur in eng umgrenzten Fällen tätig werden, stellt also eine Entscheidungsinstanz dar, die gewissermaßen nur in ,Ausnahmefällen' handelt. Dies ist gegeben, wenn von einem Medienprodukt große Gefahren für die Jugend ausgehen, seine Verbreitung kurzfristig in großem Umfang zu befürchten und eine Entscheidung des Zwölfergremiums zur Indizierung ohnehin zu erwarten ist sowie wenn die Jugendgefährdung ,offenbar gegeben ist. ${ }^{147}$ Die Fälle, in denen der Vorsitzende der BPS allein tätig wird, sind wiederum solche, in denen ein repräsentatives Gremium oder ein Gericht bereits gehandelt hat. So ist bei der Aufnahme inhaltsgleicher Schriften bereits ein Indizierungsverfahren durchgeführt worden und soll lediglich ein Unterlaufen der Indizierung verhindert werden. Bei Indizierung strafrechtlich sanktionierter Medienprodukte ist zudem deren Widerspruch zur Inhaltsethik und den Rechtsnormen bereits festgestellt, also eine entsprechende Prüfung schon vollzogen und stellt die Listenaufnahme mithin nur einen Nachvollzug geschehener legitimer Entscheidungsfällung dar. Die strukturelle Organisation der Entscheidungsfindung der BPS läßt damit erkennen, daß sie sowohl weitgehend dem Repräsentativitätsprinzip gehorcht, als auch im ,kleinen Gremium' und bei der fallweisen Entscheidung durch den Vorsitzenden den Strukturforderungen der Medienethik gerecht wird.

${ }_{146}^{146}$ Hartlieb, Handbuch, Kap. 11 Rdn. 4

${ }^{147}$ Vgl. zu dieser Umgrenzung der Tätigkeit des Dreiergremiums \$§ 15 I und 15a I GjS und Scholz, Jugendschutz, 76-77 - Gleichwohl entsteht hier ein Problem. So verweist Weides darauf, daß aus rein statistischen Erwägungen heraus anzunehmen sei, daß ein großer Teil der Entscheidungen zur Indizierung von Videos im Dreiergremium im vereinfachten Verfahren gefällt würden. Dies jedoch könne nicht angehen - das BVerG (BVerG, NJW 1980, 169 [170]) habe diese Entscheidungsfindung ,ausdrücklich als Ausnahme angesehen“. Die unbedingt zu fordernde pluralistische Zusammensetzung des Gremiums, gesellschaftliche Repräsentanz und vermutete Fachkenntnis nämlich ,treffen auf Entscheidungen der Dreiergremiums offensichtlich nur noch in sehr eingeschränktem Maße zu“. Für den normalen Gang der Entscheidungsfindung ist mithin in der Regel eine Entscheidung im Zwölfergremium zu fordern. Gerade dies sieht Weides im Bereich der Indizierung von Videos nicht in ausreichendem Maß gewährleistet. Daher moniert er die „Praxis der Bundesprüfstelle“, die „mit dem Anspruch der Betroffenen auf effektiven Rechtsschutz (Art. 19 IV GG) nicht zu vereinbaren" sei. (Vgl. Weides, Jugendmedienschutz, 229-230) 
Gleichwohl ist aus dem Blickwinkel der Zuständigkeit der BPS nicht nur für Schriften im Sinn von Druckwerken, sondern auch für Bildträger und damit für Filme noch ein Problem zu konstatieren. Zwar sind nämlich unter den Vertretern des Kultursachbereichs der Medien die Printmedien in hervorragender Weise vertreten, doch werden Repräsentanten aus dem Filmbereich, d.h. Vertreter der Film- und Videowirtschaft, im GjS nicht genannt. Dies nun bedeutet für die Prüfung in diesem Bereich einen Mangel, der mit den medienethischen Strukturforderungen schwer zu vereinbaren ist. Unter der Repräsentativitätsforderung sind vielmehr auch die betroffenen Vertreter dieses Bereichs in den Gang der Entscheidungsfindung miteinzubeziehen. Ihr Fehlen ist daher angesichts der Zuständigkeit der BPS für Filme und Bildträger - d.h. vordringlich Videos, aber in bestimmten Fällen auch Kinofilme als Defizienz zu bewerten, die nach Möglichkeit ausgeräumt werden muß. Doch nicht nur aus medienethischer, sondern auch aus juristischer Perspektive erscheint die geschilderte Tatsache als Mangel, den es zu beseitigen gilt. So moniert etwa Hartlieb die Abwesenheit von Filmproduzenten, Videoproduzenten, Filmverleihern, Videoprogrammanbietern und Filmtheaterbesitzern in der Aufzählung der Gruppen und sieht er hier „eine Korrektur geboten (...), um der BPS auf allen Gebieten die notwendige Repräsentanz im fachlichen Sinne, und damit auch im Sinne der pluralistischen Gesellschaftsordnung, zu verschaffen“. ${ }^{148}$ Weides, der diesen Tatbestand ebenfalls anmahnt, sieht durch die mangelnde Repräsentanz und den damit gegebenen Einfluß nur der Printmedienvertreter sogar „die Gefahr sachfremder Erwägungen (mißliebige Konkurrenz)“ gegeben. ${ }^{149}$ Er empfiehlt daher dem Gesetzgeber, „diesen Bedenken durch eine Änderung des $\$ 9$ II GjS Rechnung zu tragen“. ${ }^{150}$ Auch aus medienethischer Perspektive ist diese Empfehlung zu unterstützen. Abgesehen von diesem Problem, das wohl noch der Herkunft der Institution aus einer Zeit, in der Druckschriften den primären Prüfgegenstand darstellten und ,Bildträger‘ illustrierte Zeitschriften und Comics waren, zu verdanken ist, kann jedoch die BPS als eine demokratische Institution bezeichnet werden, die von ihrer Strukturierung her durchaus den medienethischen Erfordernissen gerecht wird.

Dies findet sich noch unterstützt durch die vorsichtige Einrichtung der Indizierung, die nur auf Antrag hin erfolgen kann und durch die damit die Option für eine offene Kommunikationsstruktur auch in der Organisation des Jugendschutzes prinzipiell gewahrt wird. Damit wird zunächst (erneut) der Verdacht ausgeräumt, daß es sich bei der BPS um eine staatliche Nachzensur oder zensurähnliche staatliche Zentralinstanz handeln könne, die, von oben her' eine monopolistische ,Wächterfunktion' über die gesellschaftliche Kommunikation ausübt. Statt einer ,auto-aktiven" Wächterfunktion erhält die BPS nur die Funktion, reaktiver Erfüllung von jugendschützerischen Erfordernissen, d.h. der Abwehr möglicher Jugendgefährdung, für deren Auffindung die Zuständigkeit zunächst andernorts liegt. Das beschränkende Handeln der BPS wird so selbst durch die Angewiesenheit auf Anträge eingeschränkt. Auch die ,Antragsmacht' aber wird in ihren Auswirkungen auf die gesellschaftliche Kommunikation bestimmten korrektiven Schranken unterworfen - der

\footnotetext{
${ }^{148}$ Hartlieb, Handbuch, Kap. 11 Rdn. 5

149 Weides, Jugendmedienschutz, 229

150 Weides, Jugendmedienschutz, 229
} 
Antrag muß ja von den pluralistisch zusammengesetzen Gremien der BPS auf seine Stichhaltigkeit hin geprüft werden und kann unter Umständen auch Ablehnung erfahren. Die Handlungsfreiheit der BPS bleibt derart an die Initiative der Antragsberechtigten gebunden, während deren Durchsetzungsmacht wiederum an die unter Umständen korrektive Prüfung durch die BPS gebunden ist. Mit dem Antragsprinzip wird so eine Art Gewaltenteilung geschaffen, die zu einer wechselseitigen Restriktion der mit der Indizierung verbundenen Einschränkung der gesellschaftlichen Kommunikation führt und so strukturell dem Beschränkungshandeln selbst nochmals Schranken setzt. Damit aber wird letztlich eine Struktur eingerichtet, die auf der Linie der Option für eine prinzipiell offene Kommunikation liegt und die auch die nötigen Beschränkungsmaßnahmen des Jugendschutzes unter Wahrung dieser Option einzurichten sucht.

Dies gilt in besonderem $\mathrm{Ma} B$ auch für die Möglichkeiten von Einzelpersonen und Gruppen, auf die Antragstellung Einfluß zu nehmen. Zunächst ist diese Möglichkeit als weitere Beteiligung gesellschaftlicher Kräfte - nämlich einzelner Gesellschaftsmitglieder oder von selbstorganisatorischen Zusammenschlüssen solcher - an der von der BPS durchgeführten jugendschützerischen Kommunikationskontrolle zu bewerten. Sie zielt damit auf eine Erhöhung des gesellschaftlichen Einflusses in Sachen Jugendschutz über die gesellschaftliche Repräsentanz in den Gremien hinaus und ist deshalb zunächst zu begrüßen. Gleichwohl richtet sich dieser Einfluß ja auf eine Teilnahme an Beschränkungsmaßnahmen gegenüber der gesellschaftlichen Kommunikation, so da $B$ diesbezügliche Aktivitäten der ,Basis' selbst wieder in ihrer Durchsetzungsmacht restriktiv organisatorisch eingebunden werden müssen. Würden sie dies nicht, so bestünde die Gefahr, daß - ähnlich wie mit den Film-Codes der 50er Jahre - ein Teil der Öffentlichkeit tendenziell die kommunikative Selbstknebelung der gesamten Öffentlichkeit besorgt. Auch die Durchsetzung von Sondermoralen und Subgruppenanschauungen wäre nicht vollständig auszuschließen. In der vorliegenden Struktur hingegen findet eine doppelte Korrektur der Basisaktivität statt, die einmal in einer Überprüfung durch die zuständigen antragsberechtigten Stellen und zum anderen durch die BPS selbst besteht. Damit aber bietet die Möglichkeit einer Basisinitiative durchaus die Chance gesellschaftlicher Einflußnahme und wird dennoch zugleich ,basisdemokratischer 'Überforderung und negativen Auswirkungen mangelnder Sachkompetenz gewehrt. Die Option für eine offene Kommunikation bleibt so hier ebenfalls tragend. Sie wird schlieBlich auch nicht durch die Ausnahmen vom Antragsprinzip durchbrochen. Sowohl für die Fälle des $\$ 18$ I GjS als auch für die des $\S 18 \mathrm{a}$ I GjS gilt das bereits Gesagte, aus dem hervorgeht, daß hier keineswegs eine autokratische Aktivität der BPS vorliegt und die gesellschaftliche Repräsentanz durchaus gewahrt ist. Im Fall der Dauerindizierung gemäß $\S 7 \mathrm{GjS}$ wiederum ist ebenfalls bereits ein Prüfhandeln der BPS auf Antrag vorausgegangen und stellt diese Maßnahme lediglich eine Folgewirkung bereits geschehener Antragstellung und Prüfentscheidung dar.

Kompatibel mit der vorgelegten medienethischen Konstruktion sind auch die Prüfkriterien der BPS. So bestimmt zunächst § 1 I GjS, daß „Schriften, die geeignet sind, Kinder und Jugendliche sittlich zu gefährden, (...) in eine Liste aufzunehmen“, mithin also zu indizieren sind. Die Eignung zu einer sittlichen Gefährdung wird dann durch Aufzählung von illegitimen Medienprodukten beispielhaft illustriert. Genannt 
werden in § 1 I GjS dabei ,unsittliche, verrohend wirkende, zu Gewalttätigkeit, Verbrechen oder RassenhaB anreizende sowie den Krieg verherrlichende Schriften“. In $\S 1$ II GjS werden den Indizierungsmöglichkeiten aufgrund der skizzierten Kriteriologie zugleich wieder Grenzen gezogen, wenn es dort heißt, daß die Aufnahme in eine Liste allein wegen des ,politischen, sozialen, religiösen oder weltanschaulichen Inhalts“ sowie bei Medienprodukten, die „der Kunst oder der Wissenschaft, der Forschung oder der Lehre" dienen, unzulässig ist. Auch ist die Indizierung gemäß diesem Paragraphen nicht zulässig, wenn ein Medienprodukt „,im öffentlichen Interesse liegt, es sei denn, daß die Art der Darstellung zu beanstanden ist“. Diese grundsätzlichen Bestimmungen für die Indizierung, die die generellen Prüfkriterien bzw. -maximen fixieren, werden dann noch ergänzt durch die Bestimmungen von $\S 6 \mathrm{GjS}$. Dort heißt es, daß in bestimmten Fällen die Folgen der Indizierung eintreten, ohne daß zuvor indiziert werden muß. Dies ist der Fall bei Medienprodukten, die die Tatbestände der $\$ \S 131$ und 184 StGB erfüllen, sowie bei solchen Medienprodukten, die "offensichtlich geeignet sind, Kinder oder Jugendliche sittlich schwer zu gefährden“. Mit diesen beiden Paragraphen führt das GjS zugleich einen begrifflichen Unterschied in der Fassung des Terminus der Jugendgefährdung ein. So werden von $\$ 1$ GjS die Tatbestände der ,einfachen sittlichen Jugendgefährdung' erfaßt, während $\$ 6$ GjS sich auf eine ,schwere‘ bzw. ,offensichtlich schwere Jugendgefährdung richtet. ${ }^{151}$ Der Begriff der Jugendgefährdung ist dabei „enger und strenger als der Begriff der Beeinträchtigung“, wie er in den FSK-Grundsätzen gebraucht ist, auszulegen, zumal es bei ihm keine Differenzierung nach Altersgruppen gibt, sondern von ihm alle Jugendlichen erfaßt werden. ${ }^{152}$ Abgestellt werden muß demnach bei seiner Anwendung auf einen Durchschnitt der Jugendlichen, nicht aber allein auf die unterste Altersgruppe, wenn eine ,Ausrichtung am schwächsten Glied' zuungunsten der übrigen Betroffenen vermieden werden soll. ${ }^{153}$ Außerdem ist der Begriff als auf eine „wesentlich stärkere Schädigung der Kinder und Jugendlichen“ gerichtet zu verstehen ,als die Jugendbeeinträchtigung“ ${ }^{154}$ Entsprechendes gilt dann für die ,schwere Jugendgefährdung, die gegeben ist, wenn „die Befürchtung besteht, daß die sittliche Entwicklung von Kindern oder Jugendlichen in besonders erheblichem Umfang“ gefährdet wird. ${ }^{155}$ Für sie sind also noch bedrohlichere Tatbestände zugrundezulegen als für die einfache Jugendgefährdung. Die ,Offensichtlichkeit‘ dieser schweren Bedrohung, die neben den Tatbeständen der $\$ \S 131$ und 184 StGB genannt wird, wiederum gilt dann als gegeben, wenn ,sie klar zutage tritt und jedermann ohne genaue Nachprüfung erkennbar ist" ${ }^{156}$

Mit diesen Kriterien und der Stufung des Gefährungsbegriffs nun schafft das GjS für das Prüfhandeln der BPS eine differenzierte Basis, die sich mit der vorgelegten medienethischen Konstruktion verbinden und von dort her weiter auslegen läßt. Zunächst ist mit den Vorschriften von $\$ 1$ II GjS den Freiheitsrechten des Grundgesetzes Rechnung getragen und damit eindeutig eine Option für die offene Kommu-

\footnotetext{
151 vgl. dazu: Brockhorst-Reetz, Maßnahmen, 11

152 Hartlieb, Handbuch, Kap. 12 Rdn. 10

153 vgl. Hartlieb, Handbuch, Kap. 12 Rdn. 10

154 Hartlieb, Handbuch, Kap. 12 Rdn. 10

155 Brockhorst-Reetz, Maßnahmen, 12

156 Brockhorst-Reetz, Maßnahmen, 12
} 
nikationsstruktur getroffen, deren Wahrung auch unter der Maxime des gebotenen Jugendschutzes gewährleistet sein soll. Das Wort, allein' versucht dabei zwischen dieser Option und dem Gebot des Jugendschutzes zu vermitteln: Nicht einzig wegen bestimmter religiöser, weltanschaulicher oder politischer Inhalte darf indiziert werden, sondern nur, wenn diese Inhalte durch die „Art ihrer Gestaltung“ eine Jugendgefährdung evozieren können. ${ }^{157}$ Entsprechendes gilt für Werke, die im öffentlichen Interesse liegen. Damit ist gegen die Möglichkeit eines Social engineering durch Behinderung der Zugänglichkeit bestimmter mißliebiger Gehalte via Indizierung eine Schranke errichtet, ohne daß das Anliegen des Jugendschutzes aufgegeben werden muß. Im Fall von Werken, die der Kunst, Wissenschaft, Forschung oder Lehre dienen, ist der Freiheitsraum sogar noch größer eingerichtet - hier kann auch die Art der Darstellung nicht beanstandet werden. ${ }^{158}$ Allerdings schließt dies Indizierung nicht einfach aus; es nötigt nur zu einer noch präziseren und vorsichtigeren Prüfung entsprechender Materialien daraufhin, ob diese dem Kriterium unterfallen und mithin die Schutzklausel des \$1 II GjS in Anspruch nehmen können. Zum Kunstvorbehalt hat die Rechtsprechung inzwischen Richtlinien geschaffen, die einer Güterabwägung im Einzelfall hilfreich sind. ${ }^{159}$ Mit den Schutzvorschriften des $\$ 1$ II GjS realisiert das Gesetz so auch im Kontext der Indizierungsmaßstäbe die freiheitliche Option der Verfassung und damit zugleich die medienethische Forderung der Wahrung der offenen Kommunikationsstruktur. Auf dieser Linie kann medienethisch auch die zurückhaltende, differenzierte Bestimmung des Jugendgefährdungsbegriffs verstanden werden, die zum einen diesen Begriff auf starke Schädigungen hin auslegt und ihn zum anderen nochmals in sich gestuft ansetzt. Bei der Feststellung des Vorliegens einer solchen Gefährdung ist die BPS durch die skizzierte Gestalt des Begriffs zu einer noch vorsichtigeren und restriktiveren Prüfung genötigt, als dies die FSK im Kontext der Feststellung möglicher Beeinträchtigungen ist. Seinen Grund findet das nicht zuletzt in der Betroffenheit aller Jugendlichen - und nicht nur bestimmter Altersgruppen - durch eine entsprechende Entscheidung zur Indizierung. Diese Entscheidung nämlich bedeutet einen generellen Einschnitt in die grundgesetzlich garantierten Freiheitsrechte, die auch Kindern und Jugendlichen in gewissem Maß zustehen, und kann daher nur angesichts besonderer Bedrohungen als verhältnismäßig erscheinen. Eben deshalb ist im Prüfhandeln auch nicht nur auf die unterste Altersgruppe abzustellen, sondern auf einen Durchschnitt. Gewahrt werden sollen auf diese Weise ,die berechtigten Informations- und Unterhaltungsinteressen der älteren Altersgruppen ${ }^{\star 160}$, die insbesondere bei jenen Medien durch eine nur auf die Jüngsten zielende Indizierung verletzt werden könnten, die nicht nur für Erwachsene reserviert sind. Unter Voraussetzung einer so eingerichteten, restriktiven Anwendung des Gefährdungsbegriffs aber ordnet sich dessen Bestimmung ebenfalls in den prinzipiell freiheitlichen Rahmen ein und erweist sie sich als kompatibel mit der vorgelegten medienethischen Konstruktion.

Mit dieser Einordnung sind jedoch durchaus nicht die Erfordernisse des auch ethisch gebotenen Jugendschutzes konterkariert. Das GjS verbindet vielmehr diese

${ }_{157}^{157}$ Hartlieb, Handbuch, Kap. 12 Rdn. 13

158 vgl. dazu: Hartlieb, Handbuch, Kap. 12 Rdn. 13

159 vgl. dazu: Scholz, Jugendschutz, 54

${ }^{160}$ Hartlieb, Handbuch, Kap. 12 Rdn. 10 
Erfordernisse mit der Option für eine offene Kommunikationstruktur und richtet den Jugendschutz damit kriteriologisch in einer modernitätsgerechten Weise ein. Zunächst wird hierbei der Begriff der einfachen Jugendgefährdung als sittliche Gefährdung verdeutlicht. Er richtet sich mithin auf den Schutz eines edukativen Umraums für eine gedeihliche Moralitätskonstitution, wie er im strukturethischen Baustein bereits gefordert worden ist. Der Terminus der sittlichen Gefährdung ist dabei so $\mathrm{zu}$ verstehen, daß durch die Medienrezeption eine ,wesentliche Abweichung des sittlichen Verhaltens des Kindes oder Jugendlichen von den Normen des,gesellschaftlich generell verbindlichen Erziehungsziels' zu befürchten ist. ${ }^{161}$ Dieses Erziehungsziel ist wiederum ,vor allem dem Grundgesetz, insbesondere der Menschenwürde und den Grundrechten, aber auch den mit dem GG übereinstimmenden pädagogischen Erkenntnissen und Wertmaßstäben, über die in der Gesellschaft Konsens besteht, zu entnehmen “. ${ }^{162}$ Mit dieser Bestimmung ist nun eine Erziehung zur Übernahme und Wahrung des Rahmenethos als Zielgröße angesetzt, die sich als der medienethischen Forderung gleichgerichtet erweist. Sittliche Gefährdung ist mithin dort zu besorgen, wo das Rahmenethos entweder direkt verletzt wird oder Inhalte appräsentiert werden, die Verständnis und Anerkenntnis des Rahmenethos infragestellen können, selbst wenn die Darstellung sich nicht unmittelbar gegen dieses richtet. Aus dieser Perspektive ist daher auch (wieder) auf mögliche Überforderungen von Kindern und Jugendlichen zu blicken, obschon dieses Kriterium im Kontext der Prüfung möglicher Jugendgefährdung restriktiver als bei der auf Beeinträchtigung gerichteten FSK-Prüfung zur Anwendung zu bringen sein wird. ${ }^{163}$ In diesem Sinn der Gefährdung einer am Rahmenethos orientierten Erziehung zur Moralität scheint mir auch der häufig bei Prüfungen verwendete Begriff der ,sozialethischen Begriffsverwirrung، oder ,sozialethischen Desorientierung zu verstehen zu sein. ,Sozialethisch' bezieht sich dabei nicht auf eine strukturethische Reflexion, sondern meint die Normierung des gesellschaftlichen bzw. des auf Sozialität gerichteten Verhaltens. ${ }^{164}$ Auch der Gefährdung der Konstitution dieses Verhaltens ist zu wehren, und dieses Wehren kann wieder als Schutzmaßnahme im Kontext der Ermöglichung einer gedeihlichen Moralerziehung und Moralitätskonstitution verstanden werden. Das Kriterium der sittlichen Gefährdung aber zeigt sich aus diesem Blickwinkel als an der Wahrung des Rahmenethos orientiert und konnotiert sich so mit der vorliegenden medienethischen Konstruktion. Freilich muß es dann auch im konkreten Prüfhandeln auf das Rahmenethos bezogen bleiben und darf nicht in praxi eine Einführung zusätzlicher moralischer Kriterien stattfinden. Dies bleibt der konkreten Moralerziehung selbst vorbehalten, die über das Rahmenethos hinausgreift und -greifen muß. Hier haben auch subjektive Ethosformen und gruppenspezifische Binnenmoralen ihren legitimen Ort. Der Zugriff der BPS hingegen muß sich als struktu-

$161 \mathrm{vgl}$. Schol, Jugendschutz, 48

162 Scholz, Jugendschutz, 48

163 Hartlieb nennt hier als Beispiel die kritiklose Appräsentation von Rassenhaß, der eine Beeinträchtigung und Gefährdung evozieren kann, während etwa die kritische Thematisierung von Rauschgiftkonsum zwar keine Gefährdung, wohl aber durch überfordernde Konfrontation noch eine Beeinträchtigung befürchten läßt. (Vgl. Hartlieb, Handbuch, Kap. 12 Rdn. 12) Analoge Beispiele lassen sich für die Thematisierung moralischer Probleme finden, die unmittelbar eine Auseinandersetzung mit dem oder Stellungnahme zum Rahmenethos implizieren.

164 vgl. dazu: Scholz, Jugendschutz, 48 
relles Handeln auf die Abwehr grundsätzlicher sittlicher Gefährdungen beschränken, die eben dort gegeben sind, wo das Rahmenethos infragegestellt oder seine Übernahme als Basis des eigenen Ethos gefährdet ist.

Auf diesem Hintergrund lassen sich dann für das Prüfhandeln im Einzelnen durchaus die Kriterien der Inhaltsethik zur Anwendung bringen. Hier nun nennt das Gesetz bereits selbst exemplarisch Mediengehaltsformen und befürchtete, durch diese evozierte Wirkungen, die mit der Inhaltsethik implizit bereits verbunden sind oder sich zumindest von dort her auslegen lassen. Zunächst tritt dabei der Begriff ,unsittlicher Schriften' in Blick. Gemäß dem Kommentar ist dieser Begriff ausschließlich auf Medienprodukte "mit sexuell-erotischem Inhalt" zu beziehen. ${ }^{165}$ Für die Bestimmung der Unsittlichkeit werden als „untere Schwelle“ Darstellungen mit ,z.B. Hervorhebung der Geschlechtsmerkmale" genannt, während die „obere Schwelle (...) unterhalb der Pornographie“ liegt, die ja bereits eine schwere offensichtliche Jugendgefährdung darstellt. ${ }^{166}$ Obschon nun für diese kriteriologische Einschätzung wieder gilt, daß sich im Bereich der Darstellung erotischer Sachverhalte schwer ,Anständigkeitsschwellen' festlegen lassen und das Kriterium mithin restriktiv zur Anwendung zu bringen ist, erweist es sich doch als kompatibel mit der Inhaltsethik. So konkretisiert der Kommentar das Moment des Unsittlichen beispielsweise auf Darstellungen, die „die Frau zum Konsumartikel (...) degradieren, (...) den Eindruck erwecken, das menschliche Leben sei auf Sexualgenuß zentriert, (...) die Prostitution oder Promiskuität verherrlichen oder verharmlosen“. ${ }^{167}$ Damit aber wird die Unsittlichkeit wieder - ganz im Sinn der Inhaltsethik - auf Verletzungen des Personstatus und der Menschenrechte fixiert. Die ,Zentrierung des Lebens auf Sexualgenu $\beta^{\prime}$ kann dabei auf eine Desorientierung hin interpretiert werden und ist durchaus kompatibel mit der Inhaltsethik und insbesondere ihren strukturethischen Voraussetzungen, die den Schutz einer ausgewogenen Moralitätsentwicklung fordern. - Dies gilt auch für die Kriterien des Anreizes zur Gewalttätigkeit, zu Verbrechen oder zum RassenhaB sowie für die Kriegsverherrlichung. Zwar wird in der Gewaltfrage vorsichtig zu operieren sein und - da das Gesetz auf den Anreiz abstellt eine differenzierte Wirkungstheorie bemüht werden müssen. ${ }^{168}$ Zur Feststellung per

${ }_{165}^{165}$ Scholz, Jugendschutz, 50

166 Scholz, Jugendschutz, 50

167 Scholz, Jugendschutz, 50; vgl. dazu auch: BPS-Broschüre, 3

168 Die BPS rekurriert hierbei nicht zuletzt auf die Theorie von Selg und macht diese mit zur Grundlage ihrer Entscheidungen. In der Schriftenreihe der BPS sowie in der BPS-Broschüre ist zudem programmatisch festgelegt, daß diese Theorie die axiomatische Basis der Indizierungsentscheide liefert. (vgl. etwa: Stefen, Rudolf (Hrsg.), Schriftenreihe der BPS 7: Massenmedien und Jugendschutz, Bonn-Beuel 1976, 100: „Die Bundesprüfstelle legt ihren Prüfungen die Lerntheorie (vgl. H. Selg in Heft 3 der Schriftenreihe der BPS) zugrunde"; auch: BPS-Broschüre, 2; zur Rezeption Selgs in Prüfentscheidungen etwa: BPS-Entscheidung Nr. 2814 (V) vom 3. März 1987, in: BPS-Report 3/1987, 13-18, 15; BPS-Entscheidung Nr. 3968 vom 11. 5. 1989, in: BPS-Report 5/1989, 39-44, 42) - Angesichts der skizzierten Probleme (vgl. 4.7. und 6.1.) erscheint jedoch diese Theorie als Wirkungstheorie nicht ganz zureichend. Eine Erweiterung der wirkungstheoretischen Basis der BPS wäre daher wünschenswert. - Die auf Wirkungsbefürchtungen gestützten Kriterien für prekäre Gewaltdarstellungen, wie sie die BPS-Broschüre aufführt, wären daher ebenfalls nochmals zu ventilieren. So darf beispielsweise die Frage gestellt werden, ob wirklich alle Darstellungen von „Gewalttaten, die im Namen des Gesetzes oder durch den Gesetzeshüter oder im Dienste einer guten Sache begangen werden“, als jugendgefährdend einzustufen sind (BPS-Broschüre, 2). Nach Selg sind sie es zweifelsohne, da 
se - also unabhängig von der Wirkungsfrage - prekärer Appräsentationsformen hingegen kann die entwickelte Inhaltsethik durchaus Hilfestellung und Stützen geben. In der Tat stehen diese Formen auch mit im Blick der Prüfperspektive, wenn im Kommentar als Beispiele für Inhaltsformen, bei denen eine perniziose Wirkung befürchtet wird, etwa ,gewaltverherrlichende' Medienprodukte oder die Darstellung von Gewalt „als etwas Normales und als legitimes und gängiges Konfliktlösungsmuster" genannt werden. ${ }^{169}$ Die BPS selbst sieht zudem bei Selbstjustizfilmen und Filmen, ,,in denen die dürftige Handlung den Rahmen für möglichst viele Mord- und Metzelhandlungen abgibt", gefährdende Appräsentationen von Gewalt gegeben. ${ }^{170}$ In all diesen Fällen nun werden letztlich ethische Kriterien zur Anwendung gebracht, die im Sinn der Inhaltsethik auf Wahrung des Rahmenethos und mit diesem kompatible Rezeptionsmöglichkeiten zielen. Sehr deutlich ist das bei der verherrlichenden Darstellung oder der Appräsentation von Gewalt als etwas Normalem und Legitimem, die letztlich mindestens Verharmlosung bedeutet. Selbstjustiz wiederum stellt jedenfalls dort einen illegitimen Gehalt vor, wo sie zustimmend und tendenziell agitativ dargestellt wird (nicht freilich dort, wo die Darstellung der Problematisierung dient). Wo schließlich die Handlung zum Alibi der Gewaltappräsentation gerät, legt sich der Verdacht einer selbstzweckhaften Darstellung nahe, die zu einer sadistischen Kontemplation einlädt. Auch eine solche Darstellung kann inhaltsethisch nicht gerechtfertigt werden. In diesen skizzierten Fällen ziehen die entworfene Inhaltsethik und die Prüfkriteriologie von GjS und BPS also gleich. Diese Kriteriologie kann daher auch unabhängig von der Wirkungsfrage medienethisch gestützt werden. - Nicht anders verhält es sich mit dem Kriterium des Anreizes zum Verbrechen. Aufruf und Anleitung zu Straftaten sind generell illegitim. Vorsicht ist freilich geboten in der Beurteilung der Kriminalitätsdarstellung in vor allem den entsprechenden Genres des Kriminalfilms und des Actionfilms. Hier kann die inhaltsethische Reflexion einer Differenzierung dienlich sein, die Anreiz und Thematisierung auseinanderzuhalten hilft. - Unmittelbar im Konnex mit der Inhaltsethik kann die Illegitimisierung des Anreizes zum Rassenhaß gesehen werden. Hier doppelt das Gesetz die Vorschrift gleichwohl mit $\S 6 \mathrm{GjS}$, wo die ,Aufstachelung' zum Rassenhaß gemäß $\S 131$ StGB als ,schwere Jugendgefährdung' aufgeführt ist. Der Anreiz wird daher als bei graduell weniger deutlichen und agitativen Appräsentationen gegeben konstatiert werden müssen, während die Aufstachelung eine deutliche und unmißverständlich zielgerichtete Agitation meint. Die Doppelung der Vorschrift und ihre gradualisierte

dieser - wie zu sehen war - eine überbordende Gewaltbereitschaft und unter Umständen sogar eine Flut von Nachahmungshandlungen aus der Rezeption hervorgehen sieht. Selg aber deduziert dies letztlich auf der Basis eines Reiz-Reaktions-Schemas, demzufolge bei positiver Gewaltappräsentation eine Mimesis erzeugt wird, gegen die kaum eine Gegenwehr möglich zu sein scheint. Hiernach wäre dann ein großer Teil der Kriminal-, Action- und Abenteuerfilme sogleich zu indizieren, um den drohenden Verfall Jugendlicher an mimetische Gewalthandlungen in der Realität aufzuhalten. Nimmt man aber eine Fähigkeit zu stellungnehmendem Verhalten auch beim jugendlichen Rezipienten an, so lassen sich dieser Verfall - und damit die Gefährdung durch Gewaltdarstellung - nicht mehr so ohne weiteres annehmen. Das Kriterium bedürfte mithin einer erneuten Reflexion. - Bezüglich der Legitimität oder Illegitimität positiver Gewaltdarstellung wiederum ist inhaltsethisch zu argumentieren. Dazu wurde bereits im inhaltsethischen Baustein einiges gesagt.

169 Scholz, Jugendschutz, 51

170 BPS-Broschüre, 2 
Auslegung lassen sich dann als Bemühen deuten, möglichst umfassend entsprechenden Gefährdungen steuern zu können. Dieses Bemühen wiederum ist ganz im Sinn der Inhaltsethik. - Die Kriegsverherrlichung wird als Appräsentation gedeutet, die den Krieg „als anziehend, reizvoll, als romantisches Abenteuer oder aber auch nur als auf keinem anderen Gebiet zu erreichende Bewährungsprobe für männliche Tugenden oder heldische Fähigkeiten " u.ä. darstellt. ${ }^{171}$ Damit richtet sich das Kriterium gegen die mögliche Erzeugung von Einstellungsmustern, die einer Kriegstreiberei in die Hände arbeiten könnten und konnotiert sich ebenfalls mit der Inhaltsethik. Die Auflistung der ,männlichen Tugenden' und der ,heldischen Fähigkeiten' stellt sich zudem der Doktrin der ,heroischen Lebensauffassung entgegen, wie sie in der Programmatik des Nationalsozialismus enthalten war. Auf diese Weise kann das Kriterium gleichzeitig als weitere Selbstschutzmaßnahme der demokratischen Gesellschaft begriffen werden, die dann auch mit dem diesbezüglichen inhaltsethischen Impetus verknüpft erscheint. Auf der Linie dieses Selbstschutzes liegt weiter das von der BPS in diesem Zusammenhang zusätzlich zur Kriegsverherrlichung eingeführte Kriterium der NS-Verherrlichung. ${ }^{172}$ Werbung für den Nationalsozialismus, Desinformation über das NS-Regime, seine Verbrechen und die Ursachen des Zweiten Weltkriegs werden hiervon erfaßt. ${ }^{173}$ Damit wird der diesbezügliche Selbstschutz der demokratischen Gesellschaft nochmals kriteriologisch im Prüfhandeln der BPS verankert. Problematisch ist allerdings schließlich wieder der Begriff der Verrohung, der unter Umständen eine Einwanderung der negativen Anthropologie der Reformer in die Jugendschutzbestrebungen der Gegenwart begünstigen könnte. Für ihn gilt daher das bereits oben im Kontext der Auseinandersetzung mit den FSK-Kriterien Gesagte. Im ganzen aber zeigt sich, daß die beispielhafte Auflistung von inhaltsbezogenen Anlässen für mögliche sittliche Jugendgefährdungen durchaus im Konnex mit der entworfenen medienethischen Konstruktion gesehen werden kann und mit dieser Konstruktion sogar verwandt ist. Sie richtet sich auf die Wahrung des Rahmenethos, wehrt dessen Verletzung - bzw. eine Gefährdung seiner Übernahme in das Ethos von Kindern und Jugendlichen - ab und legt so den Begriff der sittlichen Jugendgefährdung in Einzelkriterien aus, die mit der skizzierten Inhaltsethik weitgehend dekkungsgleich sind.

In entsprechender Weise lassen sich auch die Vorschriften bezüglich der ,schweren Jugendgefährdung der vorgelegten medienethischen Konstruktion zuordnen. Deren Tatbestände sind zum einen bereits durch Strafgesetze vorgegeben, wie der explizite Verweis des Gesetzes in $\S 6$ GjS auf die $\$ \$ 131$ und 184 StGB auch zeigt. Der Einbezug dieser Tatbestände in die Bestimmung schwerer Jugendgefährdung dient dabei einer Vernetzung des GjS mit dem StGB und trägt dem Willen des Gesetzgebers Rechnung, da $B$ die beiden Paragraphen des StGB die ,zentrale Grundlage des Schutzes von Kindern und Jugendlichen gegen gewaltverherrlichende, rassenhetzerische, pornographische und sonstige offensichtlich schwer jugendgefährdende Medien darstellen" sollen. ${ }^{174}$ Der Konnex der genannten Gesetze mit der Inhaltsethik nun ist bereits aufgewiesen worden, so daß hier eine entsprechende Ver-

171 Scholz, Jugendschutz, 51

172 vgl. BPS-Broschüre, 2

173 vgl. BPS-Broschüre, 2

174 BT-Drs. 7/514; auch: Scholz, Jugendschutz, 65 
bindung festgestellt werden kann. Zum anderen aber zeigt sich bei näherem Zusehen, da $B$ auch der in diesem Zusammenhang verwendete Begriff der ,offensichtlichen Jugendgefährdung mit der vorliegenden medienethischen Konstruktion kompatibel ist. Sie nämlich ist dort zu konstatieren, wo ohne Zweifel eine erhebliche Schädigung der Moralitätsentwicklung zu befürchten ist und mit beinahe penetranter Offensichtlichkeit Grundstrukturen der Inhaltsethik verletzt werden. Im Fall der $\S \S 131$ und 184 StGB liegt die Gefährdung auf der Hand und ist sie in der Tat ,offensichtlich'. Weiter aber nennt der Kommentar in diesem Sinn als schwere Gefährdung die nicht zu billigende, maßgebliche Beeinflussung ,grundlegende(r) Wert- und Lebensvorstellungen des Rezipienten", also letztlich die Verletzung des Rahmenethos. ${ }^{175}$ Das Merkmal der ,Offensichtlichkeit" gilt hierbei dann als gegeben, wenn diese Gefährdung jedermann ersichtlich ist, also wenn beispielsweise der Rauschmittelmißbrauch verherrlicht wird, Gebrauchsanweisungen zum Anbau und zur Verarbeitung von Drogen publiziert werden, zu schweren Straftaten oder anderen Verbrechen angeleitet wird und dergleichen mehr. ${ }^{176}$ Derartige Appräsentationen nun sind in der Tat ,offensichtlich' gegen das Rahmenethos gerichtet bzw. mit diesem nicht verträglich und für jedermann als untragbar zu erkennen. Freilich wird das Kriterium der offensichtlichen schweren Jugendgefährdung restriktiv und umsichtig zur Anwendung zu bringen sein. Immerhin treten die Indizierungsfolgen hier ohne Indizierungsverfahren ein, und sind mithin die Verbreiter von Medienprodukten - also die Zeitschriften- und Buchhändler, die Videothekare etc. - selbst angewiesen, die Prüfung vorzunehmen. Eine zu starke Einschränkung der offenen Kommunikation durch etwa überängstliche Vorprüfungen durch Medienhändler - die in Sachen Medienethik und Jugendschutz letztlich Laien sind - ist nicht wünschenswert. Auch die Realisierung von Sondermoralen unter dem Mantel einer Prüfung von Medienprodukten durch den ,gesunden Menschenverstand', die vom Kriterium der Offensichtlichkeit ja ermöglicht wird, kann nicht - zumindest nicht in größerem Umfang - als erwünscht bezeichnet werden. Daher gilt es hier auch für die BPS bei doch nach $\S 6$ GjS erfolgenden Indizierungen, die durchaus zulässig sind, ${ }^{17}$ ein entsprechendes kriteriologisches Beispiel zu geben. Im ganzen aber läßt sich wieder erkennen, daß auch die Bestimmung der Kriterien der schweren und offensichtlichen Jugendgefährdung - bei rechtem Verständnis der ,Offensichtlichkeit - durchaus mit den skizzierten medienethischen Grundlinien kompatibel ist.

Insgesamt nun zeigt sich damit, daB sowohl die FSK als auch die BPS zusammen mit den ihnen zugrunde liegenden Gesetzen und den von diesen Institutionen genutzten Prüfkriterien als Instrumente der Sicherung und Durchsetzung der inhaltsethischen Normen sowie in diesem Zusammenhang auch als Realisierungsinstrumente des ethisch gebotenen Jugendschutzes begriffen werden können. In ihren organisatorischen Strukturen lassen beide Institutionen erkennen, daß sie die für mit umfassenden Einflußnahmekompetenzen gegenüber der gesellschaftlichen Kommunikation ausgestatteten Instanzen aufgestellte Repräsentativitätsforderung (weitge-

${ }^{175}$ Scholz, Jugendschutz, 66

176 vgl. Scholz, Jugendschutz, 66; auch: BPS-Broschüre, 3 - Nach der Broschüre ist die Verherrlichung von Drogenkonsum den einfachen Jugendgefährdungen zuzurechnen, während Scholz hier anders optiert.

177 vgl. Scholz, Jugendschutz, 65 
hend) erfüllen. Mit ihren Prüfkriterien wiederum treffen sowohl die FSK als auch die BPS prinzipiell eine Option für die offene Kommunikationsstruktur, deren Erfordernisse sie dann mit denen der ethisch nötigen inhaltlichen Grenzziehungen und des Jugendschutzes zu vermitteln suchen. Dabei zeigen sich beide Institutionen als von einer Zensurinstanz grundsätzlich verschieden und richten sie ihre kriteriologische Basis entsprechend ein. Die ethisch nötigen Grenzziehungen wie auch die Prüfkriterien im Bereich des Jugendschutzes erweisen sich aus medienethischer Perspektive als mit der entworfenen Inhaltsethik kompatibel. Sie sind entweder bereits implizit mit dieser verbunden oder aber lassen sich auf sie hin interpretieren bzw. von der Inhaltsethik her auslegen. Damit kann festgestellt werden, da $B$ die beiden Institutionen zum einen in der Tat die im strukturethischen Baustein einer modernitätsgerechten Medienethik aufgestellten Forderungen - bis auf einen gewissen Mangel in der Besetzung der BPS-Gremien - erfüllen und zum anderen auch den im inhaltsethischen Baustein entworfenen Vorschriften nahestehen. Sie können so der Realisierung und Durchsetzung der skizzierten Medienethik dienen bzw. sich mit dieser zusammenschließen. Dabei können dann zugleich unter Umständen noch vorhandene oder wirksame Restbestände der ,Tradition' kontramoderner Entwürfe aufgespürt und entsprechend reinterpretiert oder verändert werden. Umgekehrt aber läßt sich in diesem Zusammenschluß dann auch die hier vorgelegte Konstruktion weiter auf ihre Tragfähigkeit prüfen, wo nötig korrigieren und in jedem Fall fortentwickeln. 



\section{BIBLIOGRAPHIE}

Die in den Anmerkungen verwendeten Kurztitel werden im folgenden durch kursive Schreibweise der Stichworte kenntlich gemacht.

Aaron, R., Die industrielle Gesellschaft und die drei Welten, Zürich 1961

Abel, W., Massenarmut und Hungerkrisen im vorindustriellen Deutschland, Göttingen 1972

Ackerknecht, E., Das Lichtspiel im Dienste der Bildungspflege, in: Die Bedeutung des

Films und Lichtbildes, München 1917 (Deutsche-Wacht-Flugschriften 6), 5-14

Adorno, T. u. a., Der Positivismusstreit in der deutschen Soziologie, Darmstadt 1972

Adorno, T., Ästhetische Theorie, Frankfurt 1973 [Ästhetik]

Adorno, T., Der Artist als Statthalter, in: Adorno, Schriften 11, 114- 134

Adorno, T., Drei Studien zu Hegel, Frankfurt 1974

Adorno, T., Einleitung, in: Adorno, Positivismusstreit, 7-81

Adorno, T., Filmtransparente, in: Adorno, Leitbild, 79-88

Adorno, T., Gesammelte Schriften 6, Frankfurt 1973

Adorno, T., Gesammelte Schriften 11, Frankfurt 1974

Adorno, T., Negative Dialektik, Frankfurt ${ }^{2} 1980$

Adorno, T., Ohne Leitbild. Parva Aesthetica, Frankfurt 1967

Adorno, T., Résumé über Kulturindustrie, in: Adorno, Leitbild, 60-70

Adorno, T., Studien zum autoritären Charakter, Frankfurt 1973

Adorno. T., Jargon der Eigentlichkeit, in: Adorno, Schriften 6, 413-526

Albersmeier, F. (Hrsg.), Texte zur Theorie des Films, Stuttgart 1979

Albrecht, G., Nationalsozialistische Filmpolitik, Stuttgart 1969

Altenloh, E., Zur Soziologie des Kino, Jena 1914 (Schriften zur Soziologie der Kultur 3)

Anders, G., Die Antiquiertheit des Menschen, München 1956

Arens, K.-P., Manipulation, Berlin 1971

Auer, A., Ist Unterhaltung vertane Zeit? Überlegungen zur Unterhaltung in den Massenmedien aus der Sicht einer theologischen Ethik, in: Stimmen der Zeit $198 / 1980,735-749$

Auer, A., Verantwortete Vermittlung. Bausteine einer Informationsethik des Rundfunks, in: Stimmen der Zeit 197/1979, 15-24

Auer, A., Verantwortete Vermittlung. Neue Überlegungen zu einer medialen Ethik, in: Stimmen der Zeit 199/1981, 147-160

Aufermann, J., Fernsehen und Hörfunk für die Demokratie, Opladen 1979

Avenarius, F., „Konto Lügenabwehr“, in: Kunstwart 1923/4, 178-179

Avenarius, F., An unsere Leser, in: Kunstwart 1923/5, 181-182 
Baacke, D., Kommunikation und Kompetenz, München ${ }^{3} 1980$

Bamberger, St., Christentum und Film, Aschaffenburg 1968

Bauer, M., Selg, H., Gewaltdarstellungen im Fernsehen - kennen wir die Folgen?, in: BPS-Report 5/1981, 6-15

Baumeister, T., Kulenkampff, J., Geschichtsphilosophie und philosophische Ästhetik, in: Neue Hefte für Philosophie 1973/5, 74-104

Becker, W., Film und Herrschaft, Berlin 1973 (Zur politischen Ökonomie des NSFilms 1)

Belling, C., Der Film in Staat und Partei, Berlin 1936

Bergner, H., Versuch einer Filmwirtschaftslehre, Berlin 1962

Beyfuss, E., Kossowsky, A., Das Kulturfilmbuch, Berlin 1924

Böckelmann, F., Theorie der Massenkommunikation, Frankfurt 1975

Bouhler, P. (Hrsg.), Der großdeutsche Freiheitskampf 1-2, München 1943

BPS-Broschüre „Jugendmedienschutz“ (Stand 8/1989)

BPS-Report 3/1987

BPS-Report 5/1989

Brandt, H.-J., NS-Filmtheorie und dokumentarische Praxis: Hippler, Noldan, Junghans, Tübingen 1987 (Medien in Forschung und Unterricht 23)

Brannen, B., Die Filmemacher, München - Gütersloh - Wien 1973

Brauneck, M. (Hrsg.), Film und Fernsehen, Bamberg 1980

Brauneck, M., Einige Anmerkungen zur Frühgeschichte des Films, in: Brauneck, Film, 7-20

Braunschweigisches Gesetz betreffend Sicherheitsvorschriften, Filmzensur, Dauer der Vorstellungen, Kinderbesuch, Schankbetrieb in Kinematographentheatern, Sonntagsheiligung vom 5. Dezember 1911, in: Hellwig, Rechtsquellen, 147-149

Bredow, W., Zureck, R. (Hrsg.), Film und Gesellschaft in Deutschland, Hamburg 1975

Brockhorst-Reetz, B., Repressive Maßnahmen zum Schutze der Jugend im Bereich der Medien Film, Video und Fernsehen, München 1989

Brunner, K., Der Kinematograph von heute - eine Volksgefahr, Berlin 1913

Brunner, O. u. a. (Hrsg.), Geschichtliche Grundbegriffe 4, Stuttgart 1978

Bubner, R., Über einige Bedingungen gegenwärtiger Ästhetik, in: Neue Hefte für Philosophie 1973/5, 38-73

Ceram, C.W., Eine Archäologie des Kinos, Reinbeck 1965

Clair, R., Vom Stummfilm zum Tonfilm, München 1952

Conradt, W., Kirche und Kinematograph, Berlin 1910

Der Dürerbund, in: Kunstwart und Kulturwart (Sammelband: Sechsunddreißigster Jahrgang, erste Hälfte Oktober 1922 bis März 1923), München 1923, o. Paginierung

Der homo cinematicus, in: Deutsches Volkstum, 13. Oktober 1919, 319-320

,Der Spiegel' 17/1991, 101-105

Dessauer, F., Streit um die Technik, Frankfurt 1956

Dickson, W., Dickson, A., History of the Kinetograph, New York 1895 (Reprint New York 1970)

Die Bedeutung des Films und Lichtbildes, München 1917 (Deutsche-Wacht-Flugschriften 6) 
Dieckmann, F., Das Kino. Sein Werden und die Möglichkeiten seiner Gestaltung, Wolfenbüttel 1921

Domarus, M., Hitler - Reden und Proklamationen 1, Würzburg 1963

Drange, E., Schuljugend und Kinematographen, in: Pädagogische Zeitung 1907/36, $737 \mathrm{ff}$.

Dreher, E., Tröndle, H., Strafgesetzbuch und Nebengesetze. Kommentar, München ${ }^{10} 1991$ [Dreher/Tröndle, StGB]

Dreyer, E. (Hrsg.), Deutsche Kultur im neuen Reich, Berlin 1934

Dröge, F., Wirkungen der Massenkommunikation, Münster 1969

Dröge, F., Wissen ohne Bewußtsein, Frankfurt 1973

Dubiel, H., Identität und Institution, Düsseldorf 1973

Dubiel, H., Wissenschaftsorganisation und politische Erfahrung, Frankfurt 1978

Dürerbund-Flugschrift 82/1911

Eder, J., Geschichte der Fotografie, Halle ${ }^{4} 1932$

Eger, L., Der Kampf um das neue Kino, München o. J. (Dürerbund-Flugschrift 189)

Eibl-Eibesfeldt, I., Liebe und $\mathrm{Ha}$, München 1970

Ellis, J., A History of Film, Englewood Cliffs, New Jersey 1979

Erlaß des preußischen Kultusministers vom 8. März 1912, in: Hellwig, Kind, 92-93

Erla $\beta$ des preußischen Ministers des Inneren betreffend Kinderbesuch und Plakate der Kinematographentheater vom 3. Mai 1912, in: Hellwig, Rechtsquellen, 46-49

Erlaß des Reichsministers für Volksaufklärung und Propaganda zur Steigerung der Leistungsfähigkeit des deutschen Filmschaffens vom 28. 2. 1942, in: Albrecht, Filmpolitik, 529-530

Ernst, G., Marschall, B., Film und Rundfunk. 2. Internationaler katholischer Filmkongreß, München 1929

Fischer, A., Die Entfremdung des Menschen in einer heilen Gesellschaft, München 1978

Fowler, J., Stages of Faith. The Psychology of Human Development and the Quest for Meaning, San Francisco 1981

Franke, K., Schnalle, K., Die Kinematographie im Dienste der Schule, Chemnitz 1913

Fuchs, E., Die Karikatur der europäischen Völker I-II, München I ${ }^{4}$ 1921, II 1921

Fulton, A., Motion Pictures, Oklahoma 1980

Furian, M. (Hrsg.), „Du tust mir weh ..." Aggressionen im Leben der Kinder und Jugendlichen, Fellbach - Oeffingen 1979

Gaupp, R., Der Kinematograph vom medizinischen und psychologischen Standpunkt, in: Gaupp, Lange, Kinematograph, 1-12

Gaupp, R., Lange, K., Der Kinematograph als Volksunterhaltungsmittel, München 1912 (Dürerbund-Flugschrift 100)

Gehlen, A., Anthropologische Forschung, Reinbek 1961

Gehlen, A., Der Mensch, Bonn ${ }^{5} 1955$

Gehlen, A., Die Seele im Technischen Zeitalter, Reinbek 1957

Gehlen, A., Die Technik in der Sichtweise der Anthropologie, in: Gehlen, Forschung, $93-103$

Gehlen, A., Studien zur Anthropologie und Soziologie, Neuwied - Berlin 1963 
Gehlen, A., Über einige Kategorien des entlasteten, zumal des ästhetischen Verhaltens, in: Henrich, Iser, Theorien, 237-251

Gesetz über die Errichtung einer vorläufigen Filmkammer, in: RGBl I, 1933, 483

Glaser, H., Das Dritte Reich, Freiburg 1961

Glogauer, W., Kriminalisierung von Kindern und Jugendlichen durch Medien, BadenBaden 1991

Glogauer, W., Video film-Konsum der Kinder und Jugendlichen. Erkenntnisstand und Wirkungen, Bad Heilbrunn 1989

Glogauer, W., Vorbilderleben und Leitbildwirkung im Film, München 1958

Glorius, F., Haller, M., Film, Jugend, Kirche, München 1960

Godard, J.-L., Montage, meine schöne Sorge, in: Kotulla, Film 2, 153 - 155

Goebbels, J., Der Film als Erzieher. Rede zur Eröffnung der Filmarbeit der $H J$, Berlin 12. Oktober 1941, in: Albrecht, Filmpolitik, 480-483

Goebbels, J., Rede anläßlich der Kriegstagung der Reichsfilmkammer am 15. 2. 1941 in Berlin, in: Albrecht, Filmpolitik, 465-479

Goebbels, J., Rede bei der ersten Jahrestagung der Reichsfilmkammer am 5. 3.1937 in der Krolloper, Berlin, in: Albrecht, Filmpolitik, 447-465

Goebbels, J., Rede im Kaiserhof, Berlin, am 28. 3. 1933, in: Albrecht, Filmpolitik, $439-442$

Goebbels, J., Rede in den Tennishallen, Berlin am 19. 5. 1933, in: Albrecht, Filmpolitik, 442- 447

Goebbels, J., Rede vor den Filmschaffenden am 28. 2. 1942 in Berlin, in: Albrecht, Filmpolitik, 484-500

Golias, E. (Hrsg.), Film und Schule, Berlin 1925

Gregor, J., Das Zeitalter des Films, Wien - Leipzig 1932

Gregor, U., Patalas, E., Geschichte des Films 1-2, Reinbek 1986

Gürtner, F., Freisler, R., Das neue Strafrecht, Berlin 1936

Habermas, J., Die Moderne - ein unvollendetes Projekt, in: Welsch, Wege, 177-192 Habermas, J., Strukturwandel der Öffentlichkeit, Darmstadt - Neuwied ${ }^{16} 1984$

Habermas, J., Theorie des kommunikativen Handelns 1 -2, Frankfurt 1981

Haes, K., Frage an die Künstler, in: Kunstwart 1922/1, 4-6

Haes, K., Gegenantwort, in: Kunstwart 1922/2, 77-78

Hagemann, W., Der Film, Heidelberg 1952

Handke, P., Ich bin ein Bewohner des Elfenbeinturms, Frankfurt 1981

Handke, P., Ich bin ein Bewohner des Elfenbeinturms, in: Handke, Bewohner, 19-28

Happel, H.-G., Der historische Spielfilm im Nationalsozialismus, Frankfurt 1984 [hist. Spielfilm]

Hartlieb, H. v., Handbuch des Film-, Fernseh- und Videorechts, München ${ }^{3} 1991$

Hausmanninger, T., Superman. Eine Comic-Serie und ihr Ethos, Frankfurt 1989

Häfker, H., Der Kino und die Gebildeten, Mönchengladbach 1915 (Lichtbühnenbibliothek 8)

Häfker, H., Kino und Kunst, Mönchengladbach 1913 (Lichtbühnenbibliothek 2) Hegel, G. W. F., Vorlesungen über die Philosophie der Geschichte, Stuttgart 1980 Heidegger, M., Sein und Zeit, Tübingen ${ }^{15} 1979$ 
Hellwig, A., Die Beziehungen zwischen Schundliteratur, Schundfilm und Verbrechen, in: Archiv für Kriminalanthropologie und Kriminalistik 1913/1, 1-32

Hellwig, A., Kind und Kino, Langensalza 1914

Hellwig, A., Rechtsquellen des öffentlichen Kinematographenrechts, Mönchengladbach 1913 (Lichtbühnenbibliothek 5)

Hellwig, A., Schundfilms, Halle 1911

Hennig, W., Über die Beurteilung von Aggression en in Filmen, in: Jugend, Film, Fernsehen 1960/2, 11-20

Henrich, D., Iser, W., Theorien der Kunst, Frankfurt 1982

Hertz, A. u. a. (Hrsg.), Handbuch der christlichen Ethik 1-3, Freiburg - Basel Wien 1978- 1982

Hilberath, B.J., Der Personbegriff der Trinitätstheologie in Rückfrage von Karl Rahner zu Tertullians „Adversus Praxean“, Innsbruck 1986

Hippler, F., Betrachtungen zum Filmschaffen, Berlin 1942

Hitler, A., Der deutschen Kunst Zukunftsaufgabe, in: Dreyer, Kultur, 9-19

Hitler, A., Große deutsche Kunstausstellung 1937, in: Domarus, Hitler-Reden 1, 705

Hitler, A., Mein Kampf, München ${ }^{11} 1933$

Hitler, A., Rede auf dem Kulturtag des Parteitages 1933, in: Domarus, Hitler-Reden, 298

Hitler, A., Rede zum Heldengedenktag vom 10. 3. 1940 in Berlin, in: Bouhler, Freiheitskampf 1, 181- 185

Hofer, W., Die Diktatur Hitlers, Wiesbaden 1965

Honneth, A., Kritik der Macht, Frankfurt 1989

Horkheimer, M. u. a., Recht und Staat im Nationalsozialismus, Frankfurt 1981

Horkheimer, M., Adorno, T., Dialektik der Aufklärung, Frankfurt 1971

Horkheimer, M., Art and Mass Culture, in: Zeitschrift für Sozialforschung 1941/9

Horkheimer, M., Neue Kunst und Massenkultur, in: Prokop, Kommunikationsforschung, 28-46

Horkheimer, M., Zur Kritik der instrumentellen Vernunft, Frankfurt 1985

Horn, M. (Ed.), The World Encyclopedia of Comics, New York 1976

Hölscher, L., Art. „Öffentlichkeit“", in: Brunner, Grundbegriffe, 413-463

Huber, E., Verfassungsrecht des Großdeutschen Reiches, Hamburg ${ }^{2} 1939$

Institut für Bild und Film in Wissenschaft und Unterricht (Hrsg.), Bilddokumente zur Geschichte des Films, München 1967

Jäger, G., Der Kampf gegen Schmutz und Schund, in: Archiv für Geschichte des Buchwesens 31/1988, 163-191

Jarass, H., Pieroth, B., Grundgesetz für die Bundesrepublik Deutschland. Kommentar, München 1992 [Jarass/Pieroth, GG]

Jossé, H., Die Entstehung des Tonfilm s, München 1984 (Alber Broschur Kommunikation)

Kant, I., Anthropologie in pragmatischer Hinsicht, in: Kant Werkausgabe XII, 397-690

Kant, I., Beantwortung der Frage: Was ist Aufklärung?, in: Kant Werkausgabe XI, $53-61$ 
Kant, I., Die Metaphysik der Sitten, Frankfurt 1978, 531 (Immanuel Kant Werkausgabe, hrsg. v. W. Weischedel VIII)

Kant, I., Grundlegung zur Metaphysik der Sitten, in: Kant Werkausgabe VII, 7-102

Kant, I., Idee zu einer allgemeinen Geschichte in weltbürgerlicher Absicht, in: Kant Werkausgabe XI, 31-50

Kant, I., Kritik der praktischen Vernunft. Grundlegung zur Metaphysik der Sitten, Frankfurt 1978 (Immanuel Kant Werkausgabe, hrsg. v. W. Weischedel, VII)

Kant, I., Schriften zur Anthropologie, Geschichtsphilosophie, Politik und Pädagogik 1, Frankfurt ${ }^{2} 1978$ (Immanuel Kant Werkausgabe, hrsg. v. W. Weischedel, XI)

Kant, I., Schriften zur Anthropologie, Geschichtsphilosophie, Politik und Pädagogik 2, Frankfurt 1978 (Immanuel Kant Werkausgabe, hrsg. v. W. Weischedel, XII)

Kauer, E., Der Film, Berlin 1943

Keilhacker, M., Erziehung und Bildung in der Industriegesellschaft, Stuttgart - Berlin - Köln - Mainz 1967

Keilhacker, M., Kino und Jugend, München 1960

Keilhacker, M., Pädagogische Grundprobleme der gegenwärtigen industriellen Gesellschaft, Stuttgart 1964

Keilhacker, M., Pädagogische Orientierung im Zeitalter der Technik, Stuttgart 1958

Kerstiens, L., Erziehungsziele - neu befragt, Bad Heilbronn 1978

Kerstiens, L., Filmerziehung, Münster ${ }^{3} 1968$

Kienzl, H., Theater und Kinematograph, in: Der Strom 1911/12/1, 219

Kliesch, H., Die Film- und Theaterkritik im NS-Staat, Berlin 1957 [Filmkritik]

Kluge, F., Etymologisches Wörterbuch der deutschen Sprache, Berlin - New York ${ }^{21} 1975$

Kluxen, W., Ethik des Ethos, Freiburg 1974

Kluxen, W., Ethik und Ethos, in: Hertz, Handbuch Ethik 2, 518-532

Knight, A., The Liveliest $A r t$, New York 1957

Kolb, R., Siekmeier, H., Rundfunk und Film im Dienste nationaler Kultur, Düsseldorf 1933

Kommer, H., Früher Film und späte Folgen, Berlin 1979

Korff, W., Aggression und gesellschaftliche Normen, in: Furian, M., „Du tust mir weh ..." Aggressionen im Leben der Kinder und Jugendlichen, Fellbach - Oeffingen $1979,52-67$

Korff, W., Christlicher Glaube als Quelle konkreter Moral, in: Herder Korrespondenz 1990/44, 279-287

Korff, W., Die Frage nach dem Glück als Frage nach einer humanen Ethik, in: Korff, Mensch glücken, 9-32

Korff, W., Die naturale und geschichtliche Unbeliebigkeit menschlicher Normativität, in: Hertz, Handbuch Ethik 1, 147-167

Korff, W., Institutionstheorie, in: Hertz, Handbuch Ethik 1, 168-176

Korff, W., Kernenergie und Moraltheologie, Frankfurt 1979

Korff, W., Leitideen verantworteter Technik, in: Münchener Theologische Zeitschrift $1987 / 2,134-142$

Korff, W., Norm und Sittlichkeit, Mainz 1973

Korff, W., Theologische Ethik, Freiburg - Basel - Wien 1975

Korff, W., Wie kann der Mensch glücken?, München 1985 
Korff, W., Wirtschaft vor der Herausforderung der Umweltkrise, in: Münchener theologische Zeitschrift 1990/2, 171-185

Kotulla, T. (Hrsg.), Der Film 2: 1945 bis heute, München 1964

Kracauer, S., Kult der Zerstreuung, in: Witte, Theorie, 230-235

Kracauer, S., Theorie des Films, Frankfurt 1985 (Erstausgabe: ders., Theory of Film, New York 1960)

Kracauer, S., Von Caligari zu Hitler, Frankfurt 1984

Kreimeier, K., Ideologieproduktion und Klassenwirklichkeit nach 1945, Kronberg 1973

Kroner, U., Film - Spiegel der Gesellschaft? Heidelberg 1973

Kuberzig, K., Vom Film für Fans, Düsseldorf 1962

Kübler, H.-D., Unterhaltung und Information im Fernsehen, Tübingen 1975

Kühn, G. u. a. (Hrsg.), Film und revolutionäre Arbeiterbewegung in Deutschland 1918-1932 I-II, Berlin 1975

Lange, K., Das Kino in Gegenwart und Zukunft, Stuttgart 1920

Lange, K., Das Wesen der Kunst I-II, Berlin 1901

Lange, K., Der Kinematograph vom ethischen und ästhetischen Standpunkt, in: Gaupp, Lange, Kinematograph, 12-50

Lange, K., Nationale Kinoreform, Mönchengladbach 1918

Lenk, H., Zur Sozialphilosophie der Technik, Frankfurt 1982

Lersch, P., Aufbau der Person, München ${ }^{4} 1951$

Lersch, P., Der Mensch in der Gegenwart, München - Basel 1947, ${ }^{2} 1955$

Lolling, J., Kino und Schule, Bielefeld 1913 (Pädagogische Abhandlungen XIII/8)

Lukacz, G., Geschichte und Klassenbewußtsein, in: Lukacz, Werke 2, 161-517

Lukacz, G., Werke 2, Neuwied - Berlin 1968

Lukesch, H. u. a. (Hrsg.), Jugendmedienstudie. Medienforschung 1, Regensburg 1989

Lukesch, H. u. a. (Hrsg.), Video im Alltag der Jugend. Medienforschung 2, Regensburg 1989

Lukesch, H. u. a. (Hrsg.), Wenn Gewalt zur Unterhaltung wird ... Medienforschung 3, Regensburg 1990

Maletzke, G., Medienwirkungsforschung, Tübingen 1971

Marx, K., Die Frühschriften, Stuttgart 1971

Marx, K., Zur Kritik der Hegelschen Rechtsphilosophie, in: Marx, Frühschriften, 207-225

Mertens, G., Ethik und Geschichte, Mainz 1982

Metken, G., Comics, Frankfurt - Hamburg 1970

Meyer, M., Theaterzensur in München. 1900 - 1918, München 1982

Meyer-Drawe, K., Illusionen von Autonomie, München 1990

Meyers Lexikon 4, Leipzig 1938

Monaco, J., Film verstehen, Reinbek 1980

Moreck, C., Sittengeschichte des Kinos, Dresden 1926

Morin, E., Das Rätsel des Humanen, München 1974

Mosse, H., Die Bedeutung der Massenmedia für die Entstehung kindlicher Neurosen, Köln-Klettenberg 1954

Muckermann, R., Film und Volk, Essen 1925 
Muth, H., Landjugend und Kino, in: Wollenweber, Lebenslage, 293-377

Müller, U., Erkenntniskritik und negative Metaphysik bei Adorno, Frankfurt 1988

Müller-Mehlis, R., Die Kunst im Dritten Reich, München 1977

Münchhausen, B. Freiherr von, Gegen die Volkshochschulen, in: Kunstwart 1920/33, $1-4$

Neuhäusler, A., Verrohung durch Filme, in: Jugend, Film, Fernsehen 1959/4, 11 - 18

Neumann, H.-J., Der deutsche Film heute, Frankfurt - Berlin 1986

Neupert, D., Filmfreiheit und ihre verfassungsmäßigen Schranken, Zürich 1976

Nickol, H., Kino und Jugendpflege, Langensalza 1919

Niessen, C., Der „Film“, eine unabhängige deutsche Erfindung, Emsdetten 1934

Osterland, M., Gesellschaftsbilder in Filmen. 1949-1964, Stuttgart 1970

Packard, V., Die große Verschwendung, Düsseldorf 1961

Panofsky, W., Die Geburt des Films, ein Stück Kulturgeschichte, Würzburg 1940

Pflaum, H.-G., Prinzler, H., Film in der Bundesrepublik Deutschland, Frankfurt 1982

Piaget, J., Biologie und Erkenntnis. Über die Beziehungen zwischen organischen Regulationen und kognitiven Prozessen, Frankfurt 1974

Piaget, J., Die Entwicklung des Erkennens I-III, Stuttgart 1975 (Gesammelte Werke $8-10$ )

Pichert, D., Kostenprobleme der Filmproduktion, Pullach 1975

Pick, A., Psychiatrie und Kolportageroman, in: Die Hochwacht. Monatsschrift zur

Bekämpfung des Schundes und Schmutzes in Wort und Bild 1910/1, 34-35

Plugge, W., Film und Gesetzgebung. Die kulturelle, politische und wirtschaftliche Bedeutung der deutschen Filmindustrie, Berlin 1926

Polizeiverordnung der Polizeidirektion zu Dresden betreffend Sicherheitsvorschriften, Dauer der Vorstellungen, Sonntagsheiligung, Filmzensur, Kinderbesuch, Plakate vom 8. Mai 1909, in: Hellwig, Rechtsquellen, 100-103

Postman, N., Das Verschwinden der Kindheit, Frankfurt 1987

Postman, N., Wir amüsieren uns zu Tode, Frankfurt 1989

Prokop, D. (Hrsg.), Kritische Kommunikationsforschung, München 1973

Prokop, D. (Hrsg.), Materialien zur Theorie des Kinos, München 1971

Prokop, D., Soziologie des Films, Frankfurt 1982

Pröstler, V., Die Ursprünge der nationalsozialistischen Kunsttheorie, München 1982

Pudowkin, W., Über die Montage, in: Albersmeier, Theorie, 77-99

Püschel, W., Der Niedergang des Rechts im Dritten Reich, Reutlingen 1947

Rahner, K., Vorgrimler, H. (Hrsg.), Kleines Konzilskompendium, Freiburg - Basel - Wien 1966

Ramsaye, T., A Million and one Nights, London ${ }^{3} 1964$

Reichslichtspielgesetz vom 12.5. 1920 in der Fassung vom 6. 10. 1931, in: Albrecht, Filmpolitik, 512

Reichslichtspielgesetz vom 12.5. 1920 in: Lange, Kino, 225-230

Reichslichtspielgesetz vom 16. 2. 1934, in: Albrecht, Filmpolitik, 515

Richter, (o. Vorn.), Der Kampf gegen Schund- und Schmutzschriften in Preußen auf Grund des Gesetzes zur Bewahrung der Jugend vor Schund- und Schmutzschrif- 
ten vom 18. Dezember 1926, Berlin ${ }^{2} 1931$ (Veröffentlichungen des Preußischen Ministeriums für Volkswohlfahrt 7)

Roloff, B., Seeßlen, G., Grundlagen des populären Films, München 1976

Ronneberger, Franz, Selbstkontrolle der Medien, in: Schiwy, P., Schütz, W. (Hrsg.), Medienrecht. Lexikon für Wissenschaft und Praxis, Neuwied - Frankfurt ${ }^{2} 1990$, 289-296

Rosenberg, A. (Hrsg.), Das Parteiprogramm, München 1941

Rosenberg, A., Der Mythus des 20. Jahrhunderts, München ${ }^{5} 1933$

Sadoul, G., Geschichte der Filmkunst, Frankfurt 1982

Sarris, A., Notes on the Auteur Theory in 1962, in: Film Culture 1962/3, 1-8

Sartre, J.-P., Drei Essays, Frankfurt - Berlin - Wien 1979

Sartre, J.-P., Ist der Existentialismus ein Humanismus?, in: Sartre, Essays, 7-51

Schelsky, H., Wandlungen der deutschen Familie in der Gegenwart, Stuttgart ${ }^{3} 1955$

Schmidtchen, G., Manipulation - Freiheit negativ, Neuwied - Berlin 1970

Schmucker, J., Adomo - Logik des Zerfalls, Stuttgart 1977

Schneider, H.-J., Kriminalitätsdarstellung im Fernsehen und kriminelle Wirklichkeit, Opladen 1977

Schnelle, F., Suspense Schock Horror. John Carpenter und seine Filme, Stuttgart 1991

Schöllgen, W., Soziologie und Ethik der Unterhaltung, in: ders., Aktuelle Moralprobleme, Düsseldorf 1955, 67-92

Schoenbaum, D., Die braune Revolution, Köln 1968

Schönhammer, R., Der, Walkman', München 1988

Scholz, R., Jugendschutz. Gesetz zum Schutze der Jugend in der Öffentlichkeit, Gesetz über die Verbreitung jugendgefährdender Schriften und andere Vorschriften mit Erläuterungen, München 1992

Scholz, R., Lebensfragen der bildenden Kunst, München 1937

Schorb, B., Swoboda, W. (Hrsg.), Medienpädagogen kommentieren populäre Thesen über die Wirkungen der Darstellungen von Gewalt und Sexualität im Fernsehen auf Kinder und Jugendliche. Dokumentation einer bundesweiten Expertenbefragung, München 1991

Schottky, J. (Hrsg.), Rasse und Krankheit, München 1937

Schreiben Ludendorffs an das Kgl. Kriegsministerium vom 4.7.1917, in: Bredow, Zurek, Film, 102-104

Schubert, K., Das Filmgespräch mit Jugendlichen, München - Basel 1957

Schultze, E., Der Kinematograph als Bildungsmittel, Halle 1911

Schultze, E., Die Gefahren der Schundliteratur und ihre Bekämpfung durch die Schule, Langensalza 1910 (Zur Volksschulpädagogik 13)

Schultze, E., Die Schundliteratur, Halle 1909

Schumann, W., Kunstwart einst und jetzt, in: Kunstwart 1923/7, 1-6

Schwab, H., Konzert. Öffentliche Musikdarbietung vom 17. bis zum 19. Jahrhundert, Leipzig 1971

Seidl, C., Der deutsche Film der fünfziger Jahre, München 1987

Seifert, K.-H., Hömig, D. (Hrsg.), Grundgesetz für die Bundesrepublik Deutschland. Taschenkommentar, Baden-Baden ${ }^{4} 1991$ [Seifert/Hömig, GG]

Selg, H., Irreführung en der Öffentlichkeit über Wirkungen von Gewaltdarstellungen in Medien, in: BPS-Report 4/1984, 9-11 
Selg, H., Über Auswirkungen der Brutalität in den elektronischen Medien auf Kinder und Jugendliche, in: BPS-Report 1/1987, 1-3

Selg, H., Über Gewalt darstellungen in Massenmedien, in: Stefen, R. (Hrsg.), Schriftenreihe der Bundesprüfstelle 3: Über massenmediale Gewaltdarstellungen, Bonn-Beuel 1972, 11-31

Sellmann, A., Der Kinematograph als Volkserzieher?, Langensalza 1912

Sellmann, A., Kino und Schule, Mönchengladbach 1914 (Lichtbühnenbibliothek 6)

Sieferle, R., Fortschrittsfeinde? Opposition gegen Technik und Industrie von der Romantik bis zur Gegenwart, München 1984

„Skizzenwirtschaft" oder mehr?, in: Kunstwart 1922/2, 74-77

Sohn-Rethel, A., Geistige und körperliche Arbeit, Frankfurt 1970

Sohn-Rethel, A., Warenform und Denkform, Frankfurt 1971

Sohnrey, (o. Vorn.), Das dunkle Kinematographentheater, in: Volksbildung 1912/3, 64

Spengler, O., Der Mensch und die Technil, München 1933

Spengler, O., Die Jahre der Entscheidung 1, München 1933

Spier, I., Die sexuellen Gefahren des Kinos, in: Neue Generation 1912, 192- 198

Spiker, J., Film und Kapital, Berlin 1975 (Zur politischen Ökonomie des NS-Films 2)

Stefen, R. (Hrsg.), Schriftenreihe der BPS 7: Massenmedien und Jugendschutz,

Bonn-Beuel 1976

Steranko, J., The Steranko History of Comics I, Reading, Pennsylvania 1970

Stolte, D., Das Fernsehen und sein Publikum, Mainz 1973

Storck, H., Der Unterhaltungsfilm für jugendliche Zuschauer, Wiesbaden - Bieberich 1954 (Film und Jugend II, Schriftenreihe des deutschen Instituts für Filmkunde)

Stork, H., Einführung in die Philosophie der Technik, Darmstadt 1977

Stückrath, F., Schottmayer, G., Psychologie des Filmerlebens in Kindheit und Jugend, Hamburg 1955 [Stückrath/Schottmayer, Psychologie]

Stümmer, E., Vogg, G. (Hrsg.), Leitfaden zur Film- und Fernseherziehung, München 1966

Taylor, R., Film Propaganda. Soviet Russia and Nazi Germany, London 1979

Theunert, H., Pescher, R., Best, P., Schorb, B., Zwischen Vergnügen und Angst Fernsehen im Alltag von Kindern, Berlin 1992

Thomas von Aquin, Summa Theologica, Hrsg. v. d. Albertus-Magnus-Akademie Walberberg, Heidelberg - Graz - Wien - Köln 1955 [STh]

Thomas, O., Die Propaganda-Maschinerie, Berlin 1978

Toeplitz, J., Geschichte des Films 1, München 1987

Traub, H., Als man anfing zu filmen, Berlin 1940 (Filmschaffen - Filmforschung.

Schriften der Ufa-Lehrschau 2)

Tröger, W., Der Film und die Antwort der Erziehung, München - Basel 1963

Truffaut, F., Die nouvelle vague - drei Jahre nach ihrem Beginn, in: Kotulla, Film 2, 165- 195

Truffaut, F., Eine gewisse Tendenz im französischen Film, in: Kotulla, Film 2, $116-131$

,tz‘ vom 28. Juni 1991 
Verordnung des Ministeriums des Innern von Sachsen-Weimar betreffend Sicherheitsvorschriften, Kinderbesuch, Filmzensur, Plakate vom 4. Januar 1913, in: Hellwig, Rechtsquellen, 137-143

Vogg, G., Die Bedeutung der Massenmedien, in: Stümmer, Vogg, Leitfaden, 11- 18

Vorgrimler, H., Theologische Gotteslehre, Düsseldorf 1985

Wasem, E., Jugend und Filmerleben, München - Basel 1957

Weides, P., Bundeskompetenz und Filmförderung, Berlin 1971

Weides, P., Der Jugendmedienschutz im Filmbereich, in: NJW 1987/5, 224-233

Weill, K., Tonfilm, Opernfilm, Filmoper, in: Witte, Theorie, 187-191

Weiß, W., Kritik der Kritik, in: Deutsche Presse 1935/51, 52

Welsch, W., Wege aus der Moderne, Weinheim 1988

Wendland, W., Nationalsozialistische Kulturpolitik, in: Deutsche Kulturwacht $1933 / 28,1-2$

Wendt, U., Die Technik als Kulturmacht, Berlin 1906

Wertham, F., Seduction of the Innocent, New York 1954

Wertheimer, J., Ästhetik der Gewalt, Frankfurt 1986

Witte, K. (Hrsg.), Theorie des Kinos, Frankfurt ${ }^{3} 1982$

Wollenweber, H. u. a. (Hrsg.), Die Lebenslage der westdeutschen Landjugend 1-2, München 1956

Wright, B., The Long View, London 1974

Württembergisches Lichtspielgesetz, in: Lange, Nationale, 63-66

Zeman, Z., Nazi Propaganda, London - New York 1964

Zglinicki, F. von, Der Weg des Films 1-2, Hildesheim - New York ${ }^{2} 1979$

Zglinicki, F. von, Die Wiege der Traumfabrik, Berlin 1986

Zielinski, J., „Kino und Jugend“, in: Jugend, Film, Fernsehen 1959/2, 21-28

Zimmermann, K., Die Filmzensur, Breslau - Neukirch 1934

Zöchbauer, F., Jugend und Film, Emsdetten 1960 